\title{
Evaluation of the Hydrologic Source Term from Underground Nuclear Tests on Pahute Mesa at the Nevada Test Site: The CHESHIRE Test
}
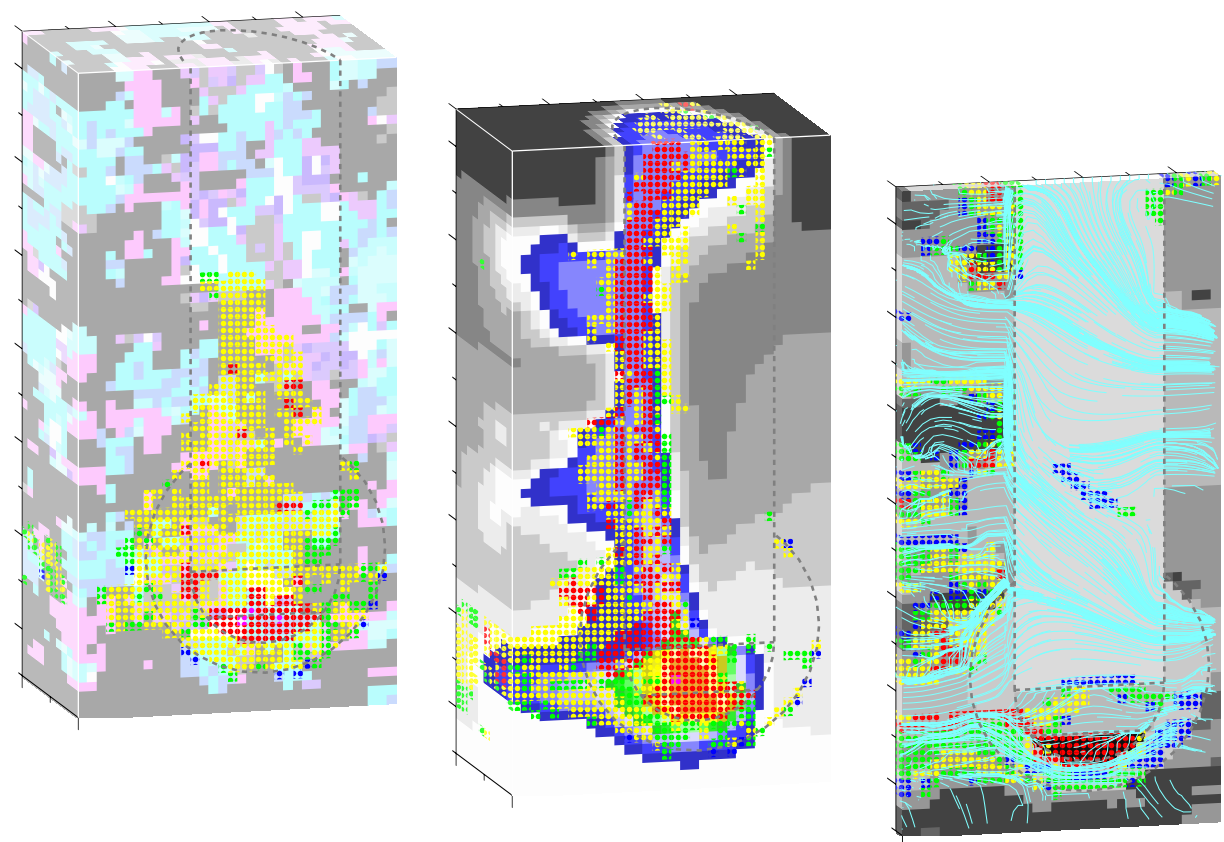

U.S. Department of Energy

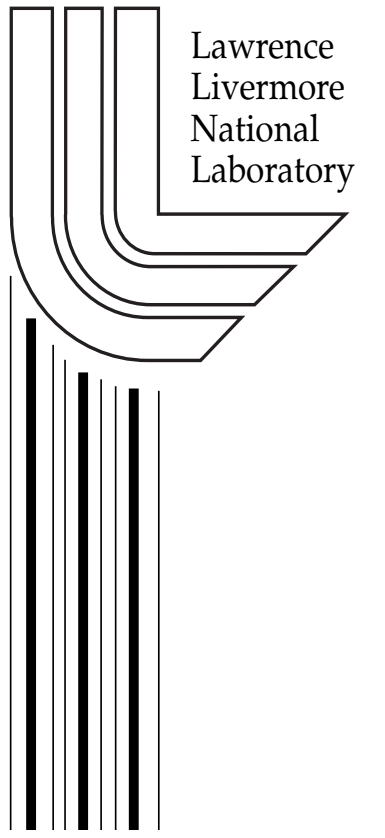

Gayle A. Pawloski,

Andrew F. B. Tompson, and

Steven F. Carle,

Editors

May 2001 


\section{DISCLAIMER}

This document was prepared as an account of work sponsored by an agency of the United States Government. Neither the United States Government nor the University of California nor any of their employees, makes any warranty, express or implied, or assumes any legal liability or responsibility for the accuracy, completeness, or usefulness of any information, apparatus, product, or process disclosed, or represents that its use would not infringe privately owned rights. Reference herein to any specific commercial product, process, or service by trade name, trademark, manufacturer, or otherwise, does not necessarily constitute or imply its endorsement, recommendation, or favoring by the United States Government or the University of California. The views and opinions of authors expressed herein do not necessarily state or reflect those of the United States Government or the University of California, and shall not be used for advertising or product endorsement purposes.

This work was performed under the auspices of the U. S. Department of Energy by the University of California, Lawrence Livermore National Laboratory under Contract No. W-7405-Eng-48.

This report has been reproduced directly from the best available copy.

Available electronically at http://www.doe.gov/bridge

Available for a processing fee to U.S. Department of Energy

and its contractors in paper from

U.S. Department of Energy

Office of Scientific and Technical Information

P.O. Box 62

Oak Ridge, TN 37831-0062

Telephone: (865) 576-8401

Facsimile: (865) 576-5728

E-mail: reports@adonis.osti.gov

Available for the sale to the public from

U.S. Department of Commerce

National Technical Information Service

5285 Port Royal Road

Springfield, VA 22161

Telephone: (800) 553-6847

Facsimile: (703) 605-6900

E-mail: orders@ntis.fedworld.gov

Online ordering: http://www.ntis.gov/ordering.htm

OR

Lawrence Livermore National Laboratory

Technical Information Department s Digital Library

http://www.llnl.gov/tid/Library.html 


\title{
Evaluation of the Hydrologic Source Term from Underground Nuclear Tests on Pahute Mesa at the Nevada Test Site: the CHESHIRE Test
}

\author{
Editors: \\ Gayle A. Pawloski \\ Andrew F. B. Tompson \\ Steven F. Carle \\ Contributors: \\ William L. Bourcier ${ }^{1}$ \\ Carol J. Bruton ${ }^{1}$ \\ Steven F. Carle ${ }^{1}$ \\ Jeffrey I. Daniels ${ }^{2}$ \\ Reed M. Maxwell ${ }^{1}$ \\ Gayle A. Pawloski ${ }^{1}$ \\ Dana E. Shumaker ${ }^{3}$ \\ David K. Smith ${ }^{4}$ \\ Andrew F. B. Tompson ${ }^{1}$ \\ Mavrik Zavarin ${ }^{1}$ \\ ${ }^{1}$ Geosciences and Environmental Technologies Division \\ ${ }^{2}$ Health and Ecological Assessment Division \\ ${ }^{3}$ Center for Applied Scientific Computing \\ ${ }^{4}$ Analytical and Nuclear Chemistry Division
}

May 2001

Lawrence Livermore National Laboratory

Livermore, California 94551 


\section{CONTENTS}

\section{EXECUTIVE SUMMARY}

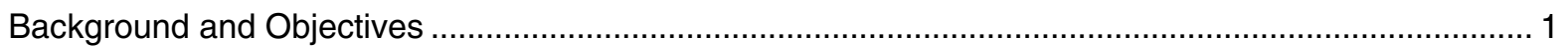

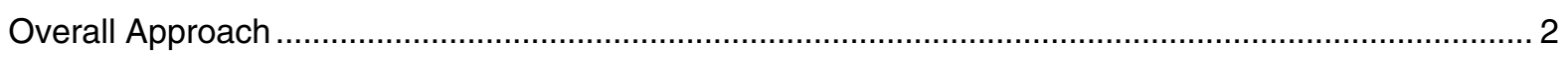

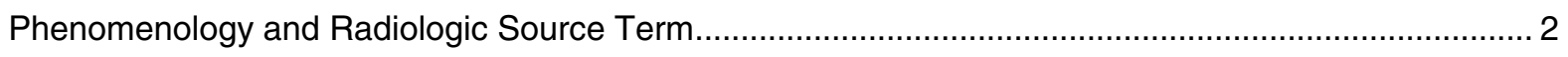

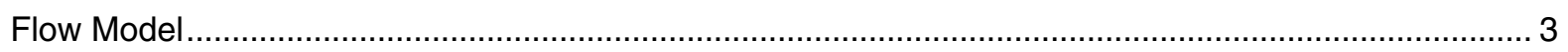

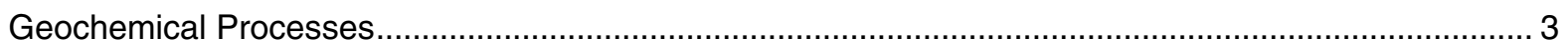

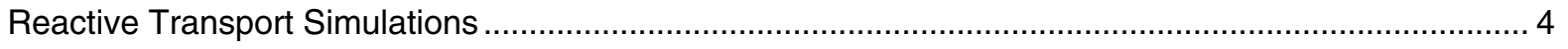

Larger Scale Transport Issues ................................................................................................... 5

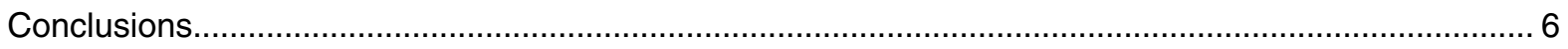

\section{CHAPTER 1}

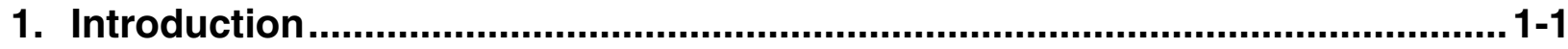

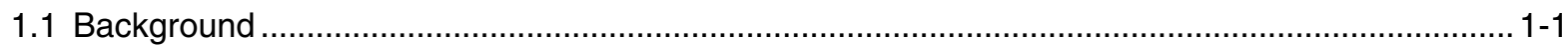

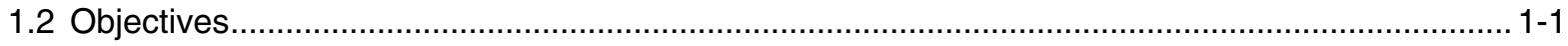

1.3 Additional Background on the Purpose of this Report ........................................................... 1-2

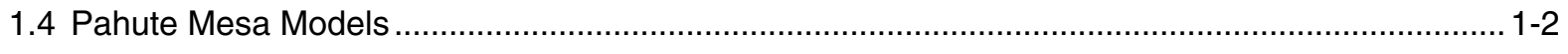

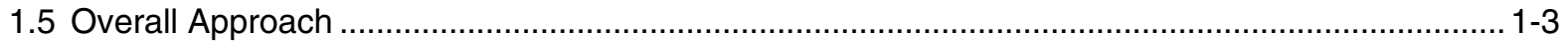

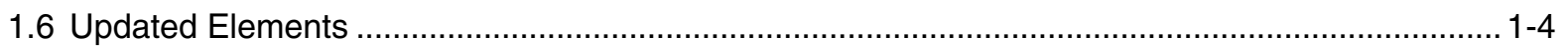

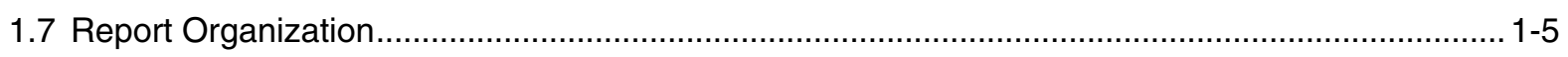

\section{CHAPTER 2}

2. Modeling Approach and Model Selection..................................................... 2-1

2.1 Initial Setting

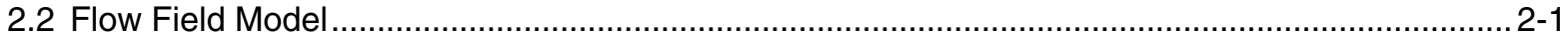

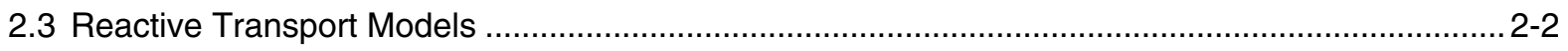

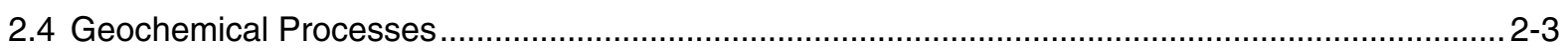

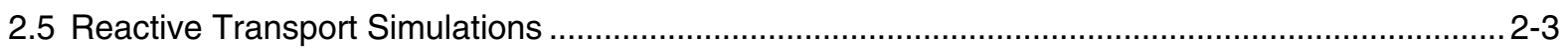

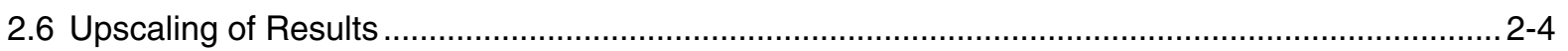




\section{CHAPTER 3}

3. CHESHIRE Test Overview and Model ............................................................. 3-1

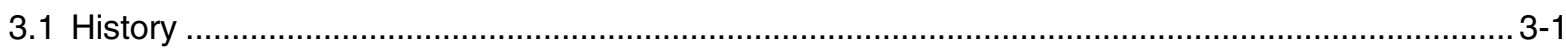

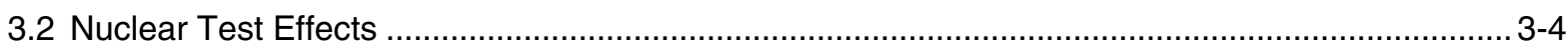

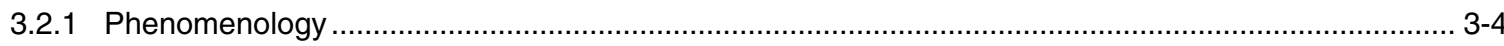

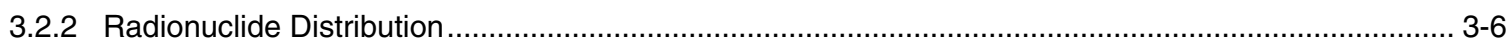

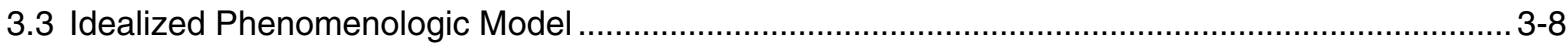

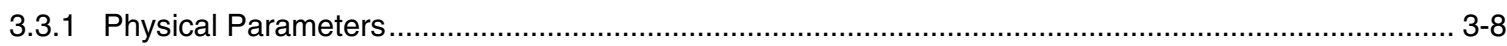

3.3.2 Initial Conditions for Model Analysis ……………............................................................... 3-9

\section{CHAPTER 4}

4. Radiological Source Term and Initial Distribution ............................................ 4-1

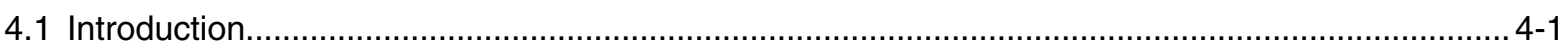

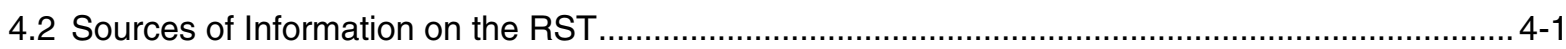

4.2.1 Radionuclide Inventory for Pahute Mesa ..................................................................................... 4-1

4.2.2 UGTA Source Term Subcommittee Recommendations...................................................................... 4-2

4.2.3 Radionuclide Measurements in Groundwater near CHESHIRE........................................................ 4-2

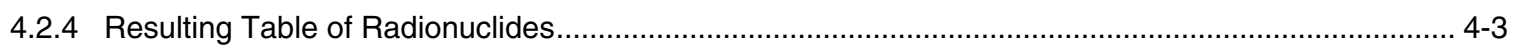

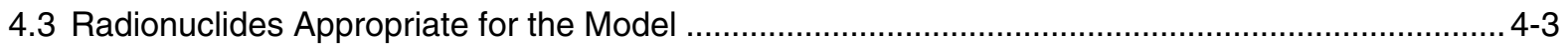

4.4 Radionuclides Included in the Model ...................................................................................... 4-3

4.5 Radioactive Decay Chains ................................................................................................. 4-6

4.6 Initial Distribution of Radionuclides in the Unclassified CHESHIRE Model .................................... 4-8

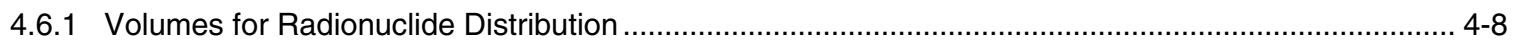

4.6.2 Distribution of Radionuclides in Volumes................................................................................ 4-10

\section{CHAPTER 5}

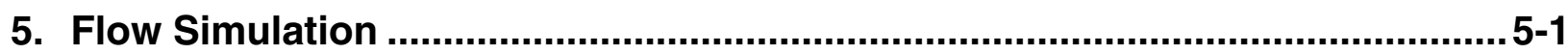

5.1 Introduction

5.2 Conceptual Hydrogeologic Model ..................................................................................... 5-2

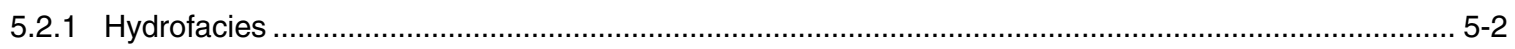

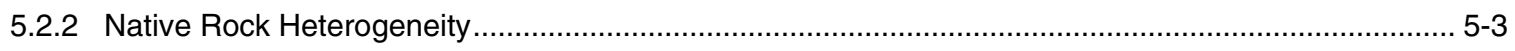

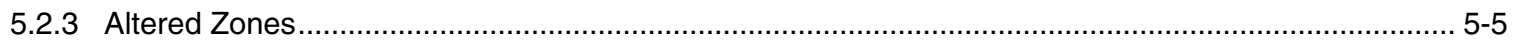

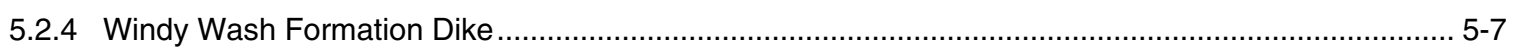

5.3 Model Coordinate System ....................................................................................................

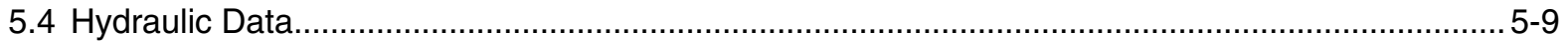

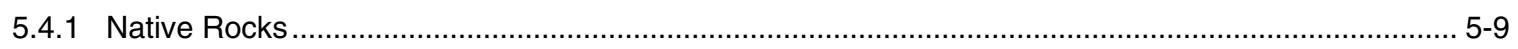

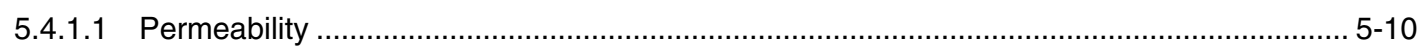

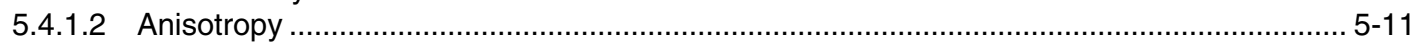

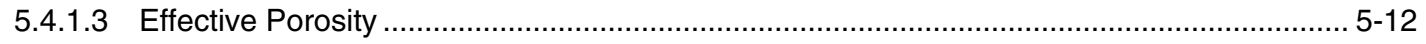




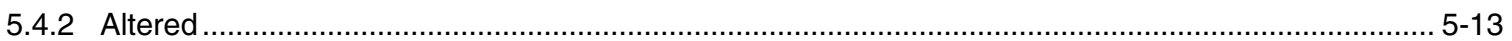

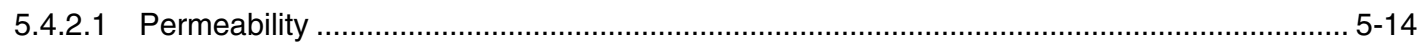

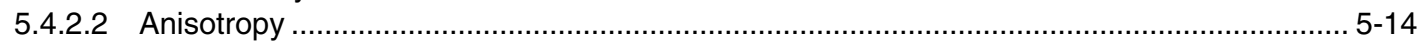

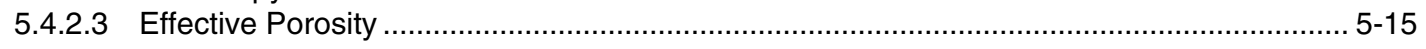

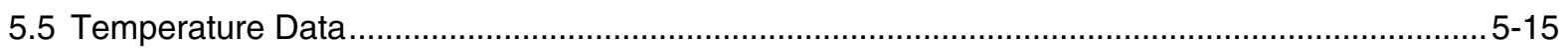

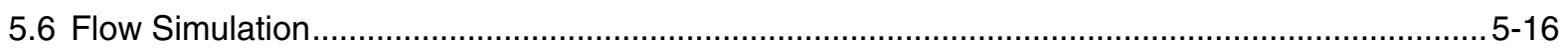

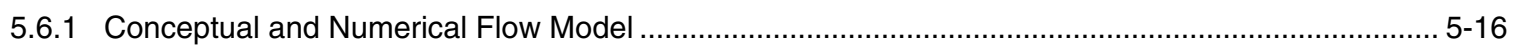

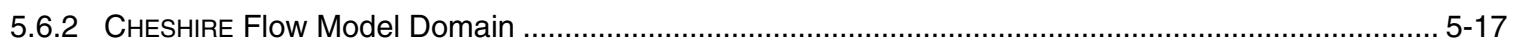

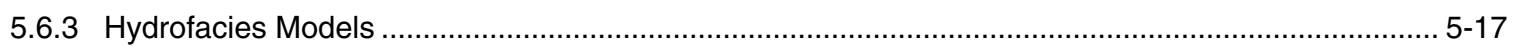

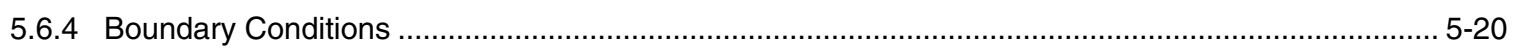

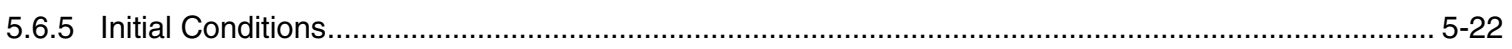

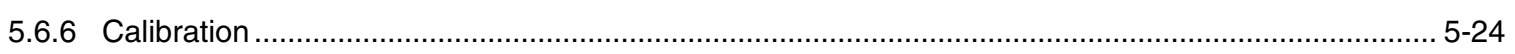

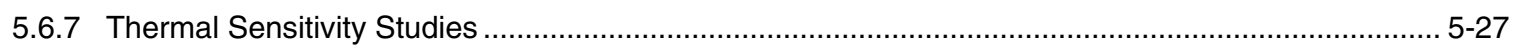

5.6.7.1 Data from Hole U-20n PS \#1DD-H ................................................................... 5-27

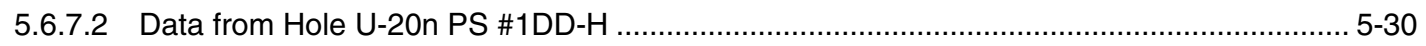

5.6.7.3 Conclusions on Thermal Sensitivity Studies ........................................................ 5-31

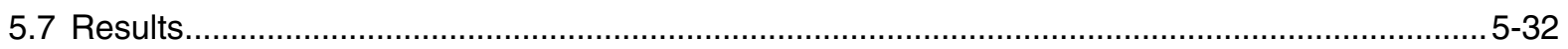

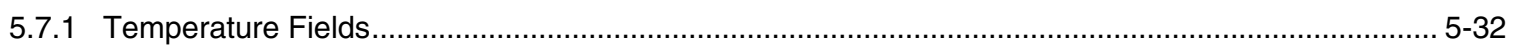

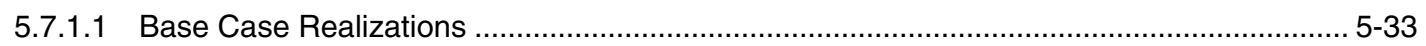

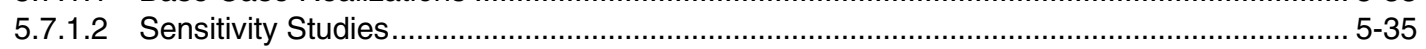

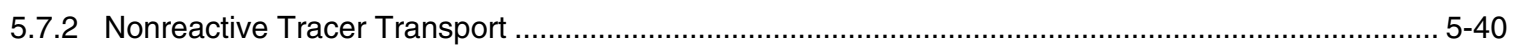

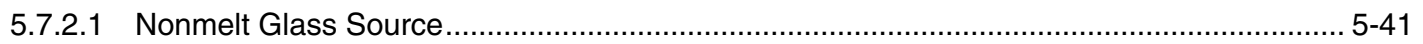

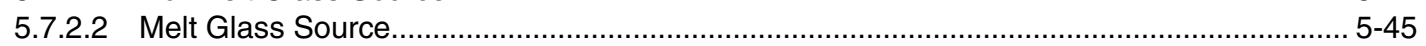

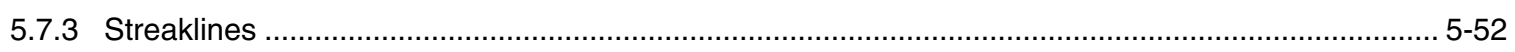

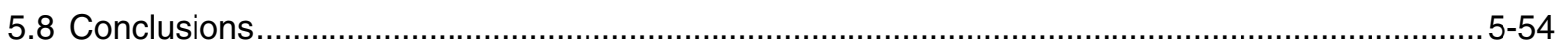

\section{CHAPTER 6}

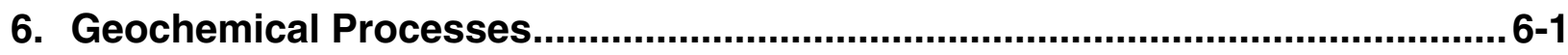

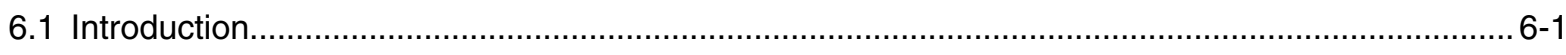

6.2 Petrology and Mineralogy Near CHESHIRE ......................................................................... 6-1

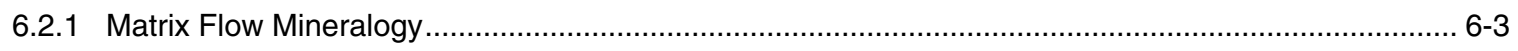

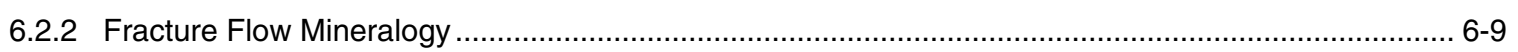

6.2.2.1 Fracture-Lining Mineral Distribution and Abundance — Pahute Mesa................................. 6-9

6.2.2.2 Fracture-Lining Mineral Distribution and Abundance - Yucca Mountain ......................... 6-11

6.2.2.3 Fracture Density and Morphology in the CHESHIRE Near Field ..................................... 6-21

6.2.2.4 Summary of Fracture Flow Mineralogy .................................................................. 6-26

6.2.3 Reactivity and Mineral Distribution in Zones Affected by the CHESHIRE Test ..................................6-27

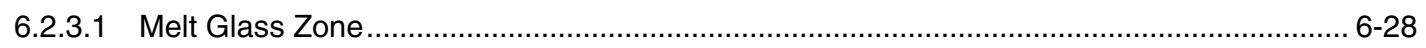

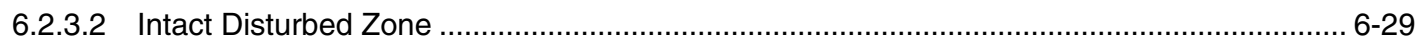

6.2.3.3 Cavity, Chimney, and Collapse Chimney Disturbed Zones .......................................... 6-29

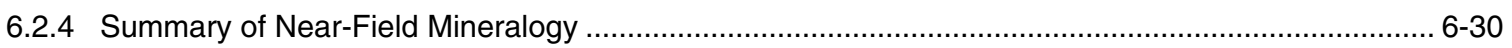

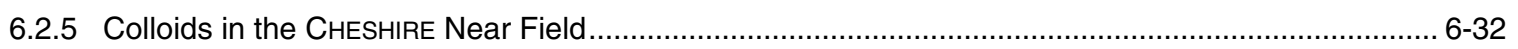

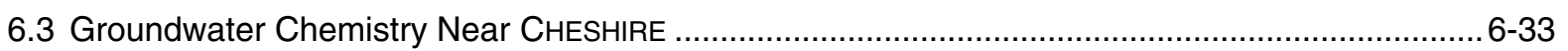

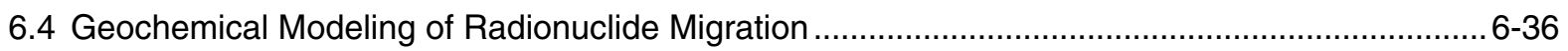

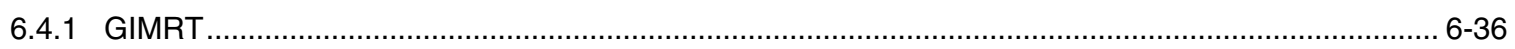

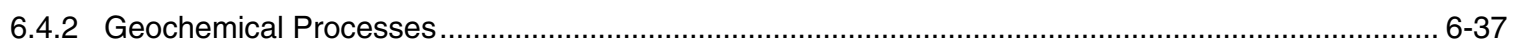


6.4.3 Aqueous Species and Minerals Considered in GIMRT ..................................................... 6-38

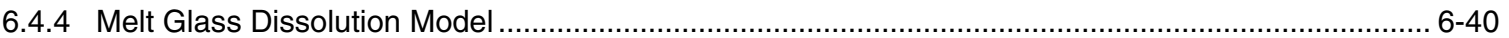

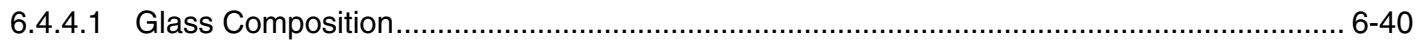

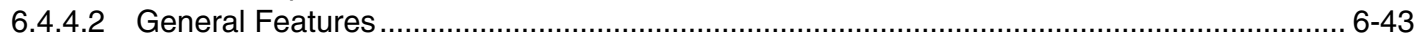

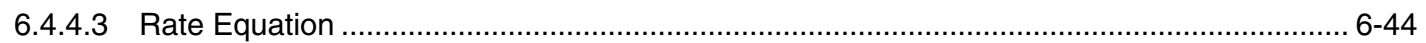

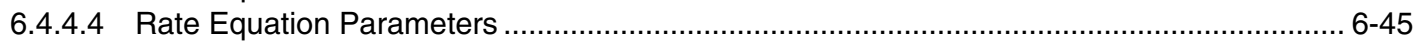

6.4.4.5 Comparison with Experimental Data.......................................................................... 6-50

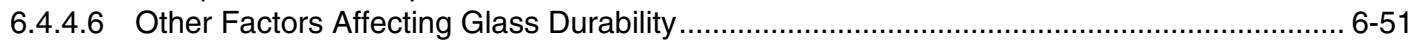

6.4.5 Implementation of Glass Dissolution Model................................................................... 6-51

6.4.5.1 Model Used in the Particle Code................................................................................ 6-51

6.4.5.2 Model Used in GIMRT Streamline Calculations ............................................................ 6-55

\section{CHAPTER 7}

7. Reactive Transport ….........................................................................................

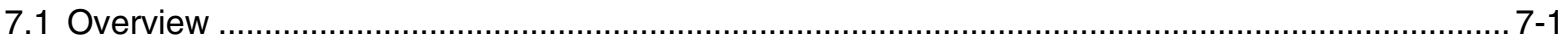

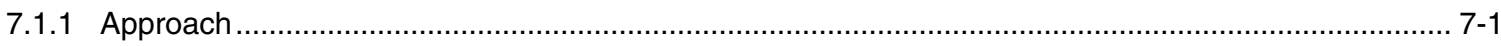

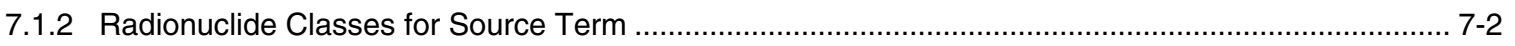

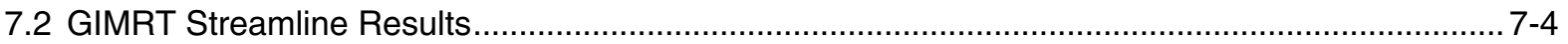

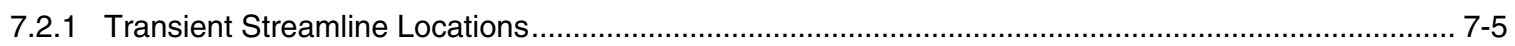

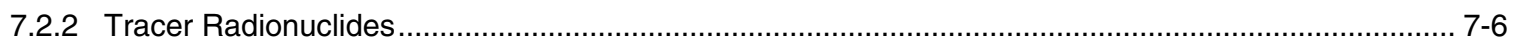

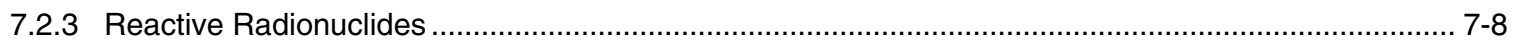

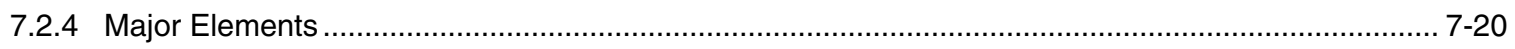

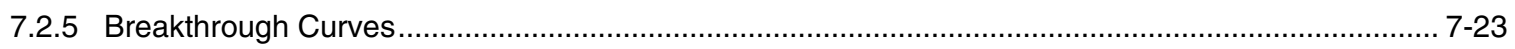

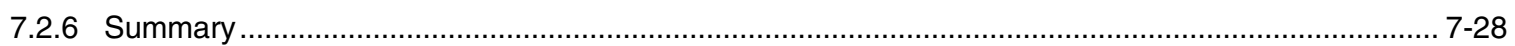

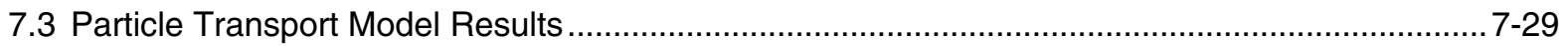

7.3.1 Transport in a Single Flow Field: Realization 9, Mineralization 1 ............................................... 7-30

7.3.2 Comparison of Breakthrough Curves for GIMRT Transient Streamline and Particle Models............ 7-37

7.3.3 Effect of Spatial Variability of Mineralization and Permeability ................................................... 7-40

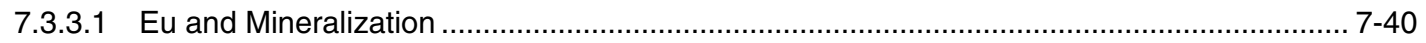

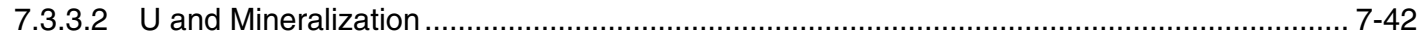

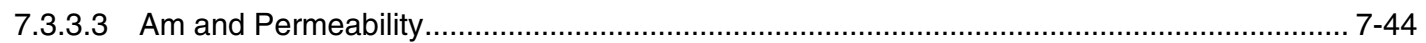

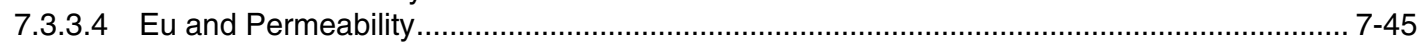

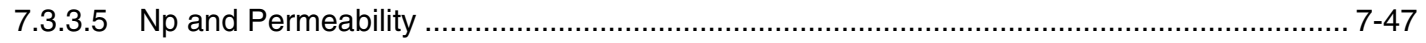

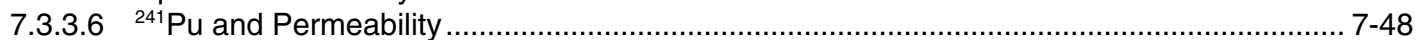

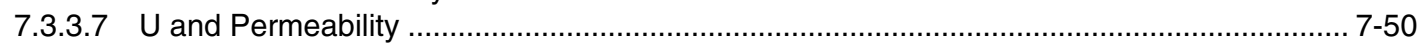

7.3.4 Breakthrough Curves_All Realizations, All Radionuclides ................................................... 7-51

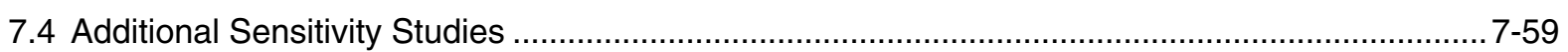

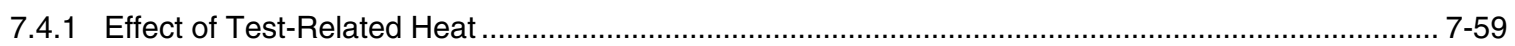

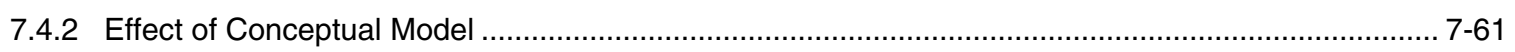

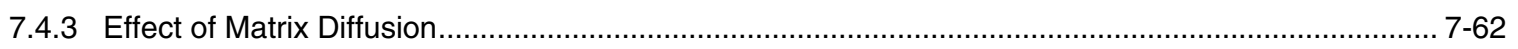

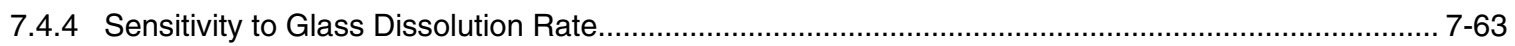

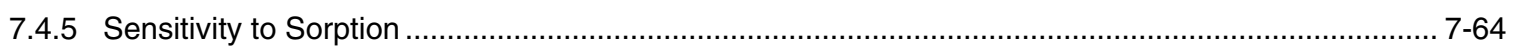

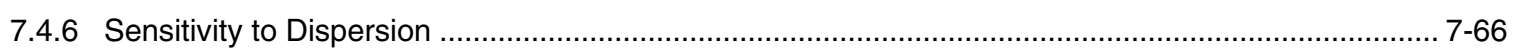

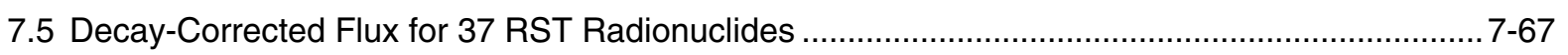

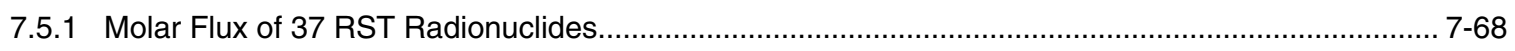

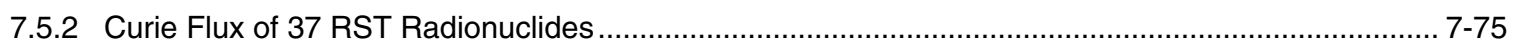




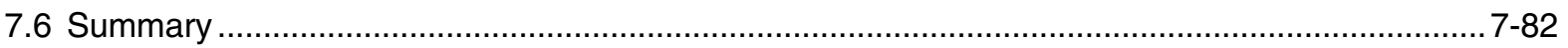

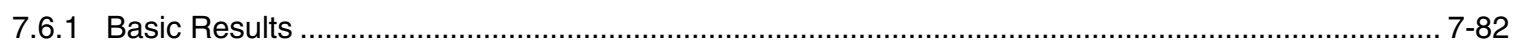

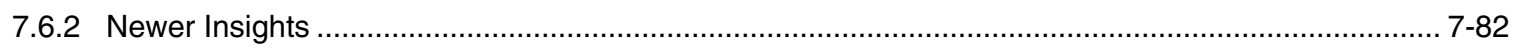

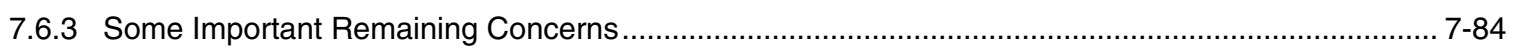

\section{CHAPTER 8}

8. Large-Scale Transport Issues....................................................................... 8-1

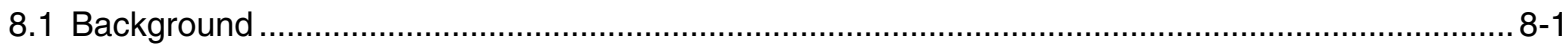

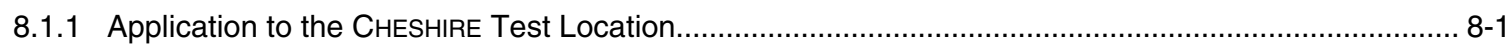

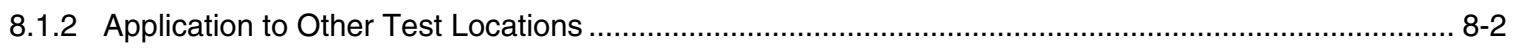

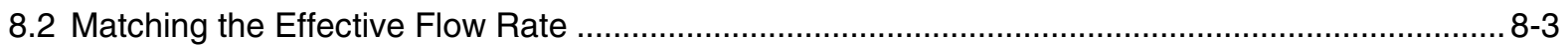

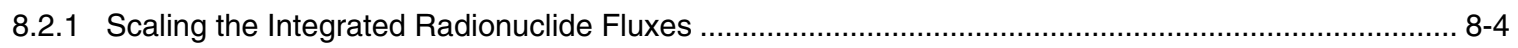

8.2.2 Matching the Effective Permeability and Hydraulic Gradient ............................................................ 8-4

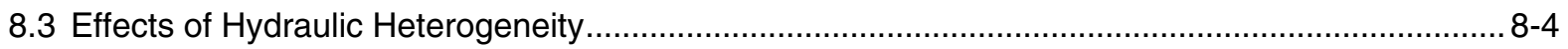

8.3.1 Effective Horizontal Hydraulic Conductivity ……..................................................................... 8-5

8.3.2 Effective Longitudinal Macrodispersivity .............................................................................. 8 8

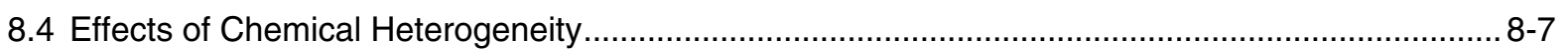

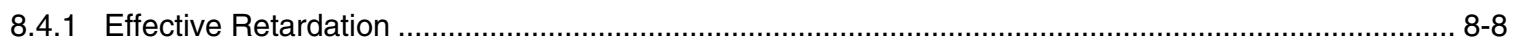

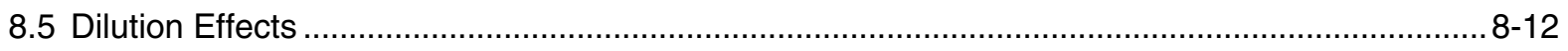

8.6 Other Metrics for Representing the Source Term Results ................................................... 8-13

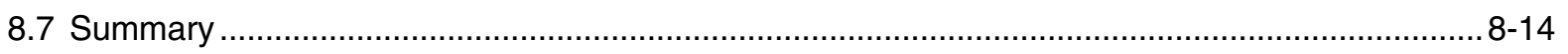

\section{CHAPTER 9}

9. Summary, Conclusions, and Recommendations............................................. 9-1

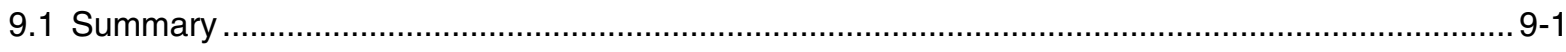

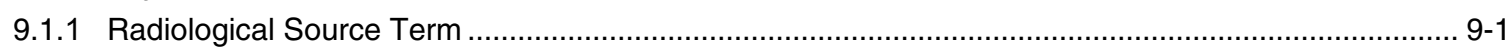

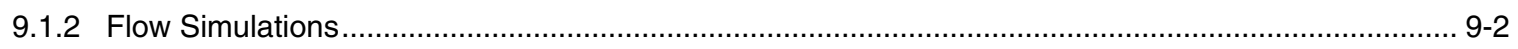

9.1.3 Mineral Distributions and Retardation ................................................................................ 9-3

9.1.4 Radionuclide Transport Simulations .................................................................................... 9-3

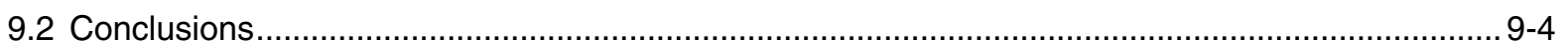

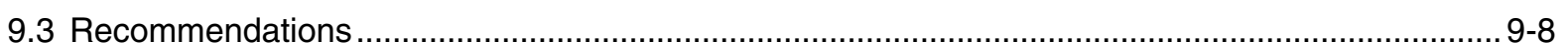

\section{CHAPTER 10}

10. References.............................................................................. 10 


\section{APPENDICES}

\section{A: Radiological Source Term}

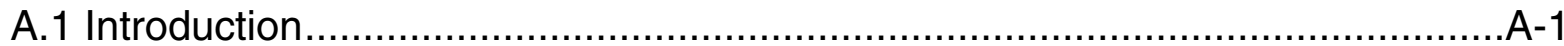

A.2 Unclassified Radiological Source Term ......................................................

A.2.1 Radionuclide Inventory for Pahute Mesa ....................................................................

A.2.2 UGTA Source Term Subcommittee Recommendations ..............................................A-3

A.2.3 Radionuclide Measurements in Groundwater near Cheshire .........................................

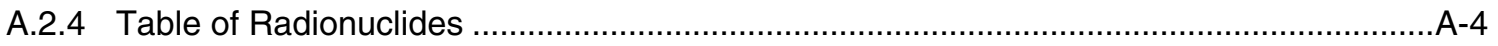

A.3 Radionuclides Appropriate for the Model....................................................

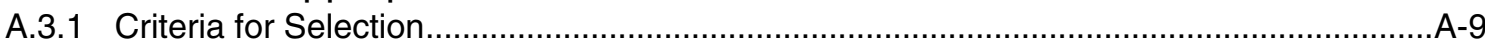

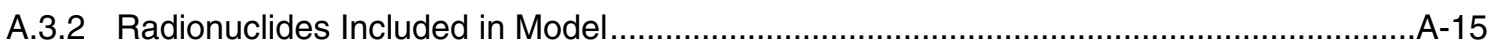

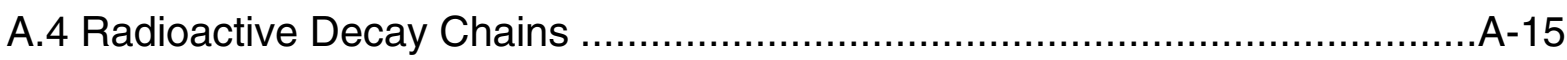

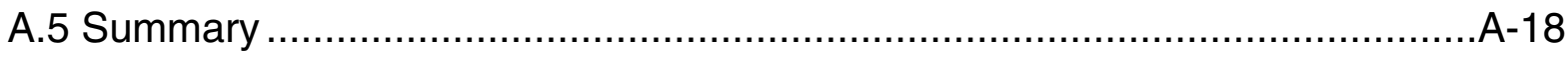

\section{B: Mathematical Models of Fluid Flow and Radionuclide Transport}

B.1 General Conceptualization and Approach ...................................................

B.2 Flow and Thermal Energy Balance Equations...........................................

B.3 Numerical Solution of Flow and Thermal Energy Equations............................3

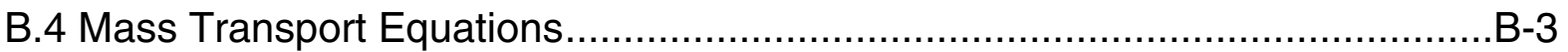

B.5 Alternative Forms of the Mass Transport Equations ..................................... 6

B.5.1 Dilute Concentrations ....................................................................................

B.5.2 One-Dimensional, Approximately Steady Flows …………………………………...

B.6 Numerical Solution of the Mass Transport Equations......................................8-8

\section{C: Streamline Transport Model}

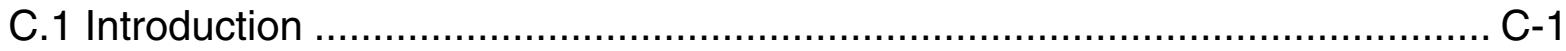

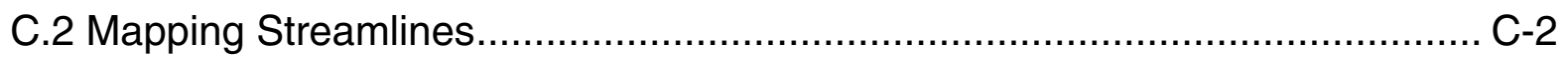

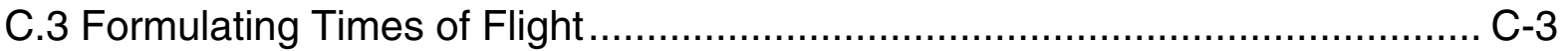

C.4 Relating Streamline and Grid-Block Quantities ......................................... C-4

C.5 Adding Dispersion, Diffusion, and Reaction Processes................................ C-5

C.6 Accounting for Radioactive Decay Processes .............................................. C-5

C.7 Addressing Matrix Diffusion Processes ……............................................ C-6

C.8 Treating Transport in Transient Flow Systems .......................................... C-8

C.9 Implementing the Incremental Streamline Approach................................... C-9

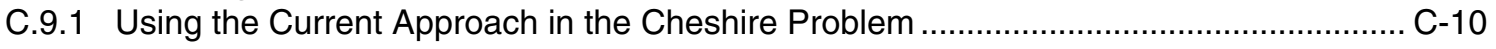

C.9.2 Determining Streamline Flux in the Cheshire Problem ............................................ C-11 


\section{D: Particle Transport Model}

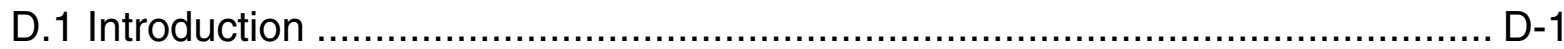

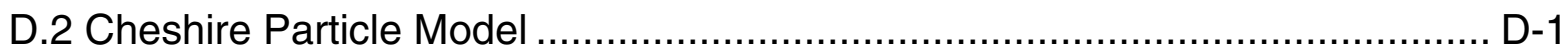

D.3 Advection, Dispersion, and Retardation Processes..................................... D-3

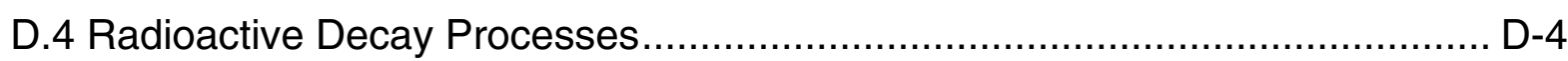

D.5 Matrix Diffusion Processes ................................................................... D-6

D.6 Radionuclide Release from the Melt Glass .............................................. D-9

\section{E: Comparisons of the GIMRT and Particle Transport Models}

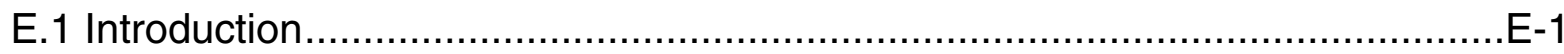

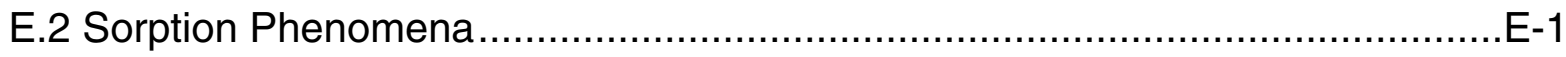

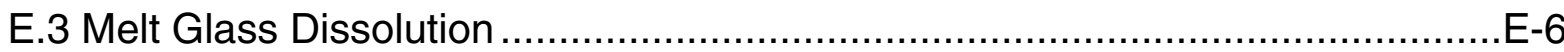

\section{F: Analysis of Hydraulic Data}

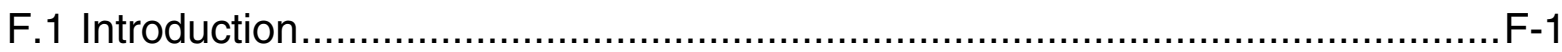

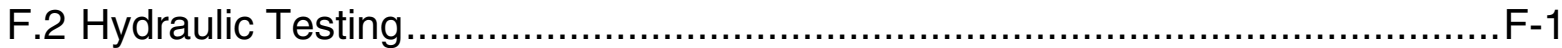

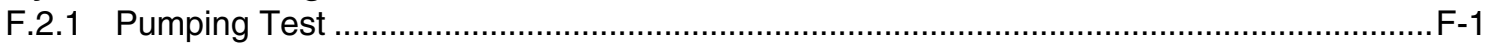

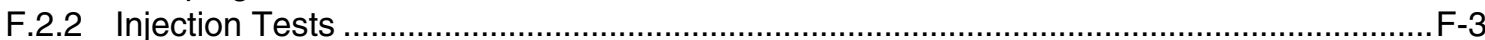

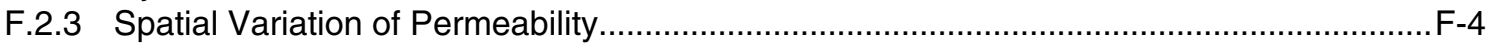

F.2.4 Interpretation of RSC Values with Respect to Permeability ............................................F-5

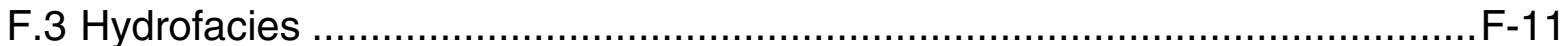

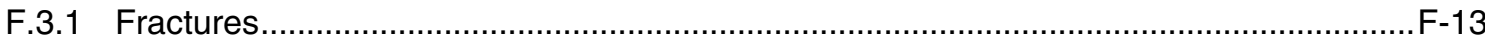

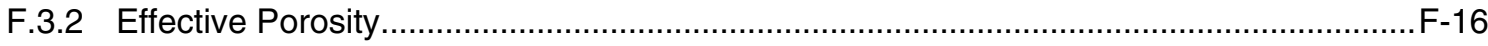

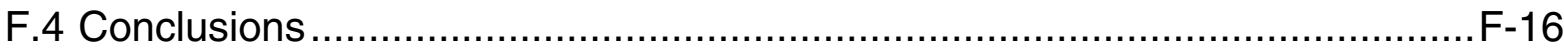

\section{G: Geostatistical Modeling}

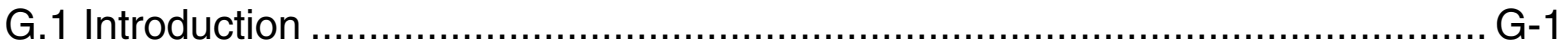

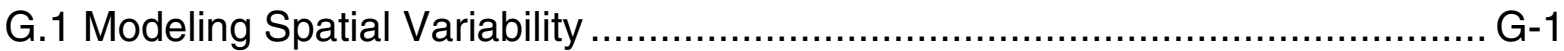

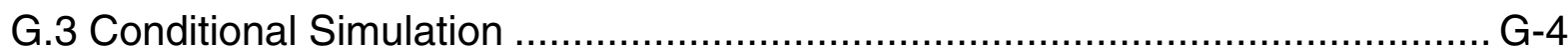

G.4 Conclusions and Recommendations ....................................................... G-6

\section{H: Spatial Variation of Mineralization}

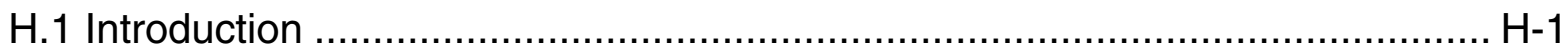

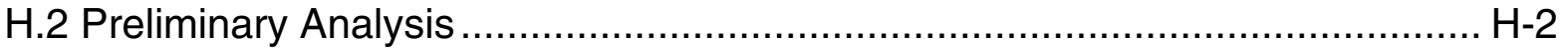

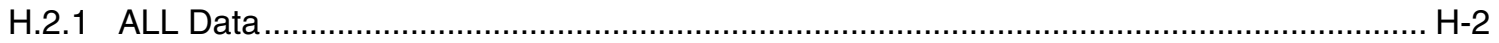

H.2.1.1 Lag Spacing of $1 \mathrm{~m} \ldots \ldots \ldots \ldots \ldots \ldots \ldots \ldots \ldots \ldots \ldots \ldots \ldots \ldots \ldots \ldots \ldots \ldots \ldots \ldots \ldots \ldots \ldots \ldots \ldots \ldots \ldots \ldots \ldots \ldots \ldots \ldots \ldots \ldots \ldots . . . \mathrm{H}-2$

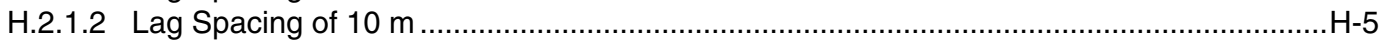




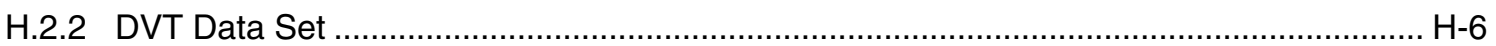

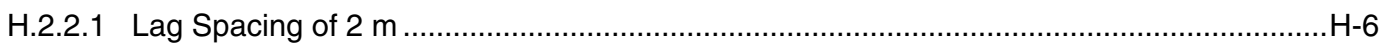

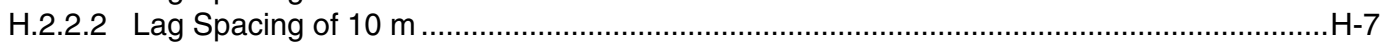

H.3 Analysis of High and Low Mineralization Zones .................................. H-7

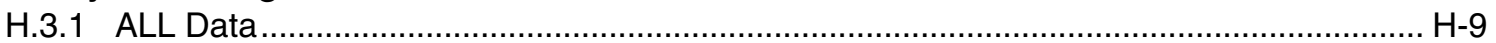

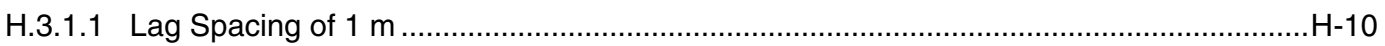

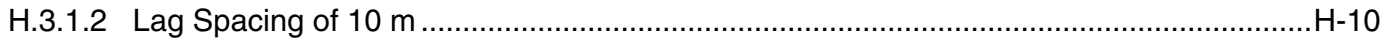

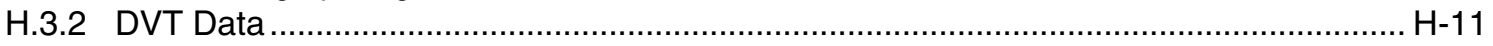

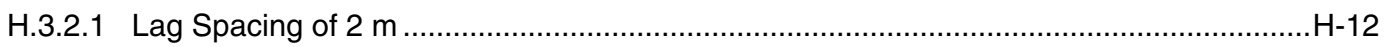

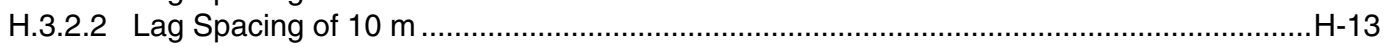

H.4 Spatial Variability Modeling ............................................................

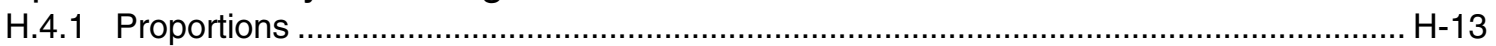

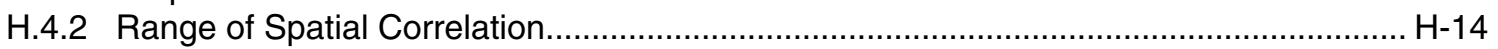

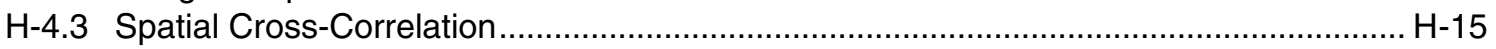

H.5 Realizations of Mineralization Zones................................................... H-15

H.6 Final Conceptual Model................................................................... H-16

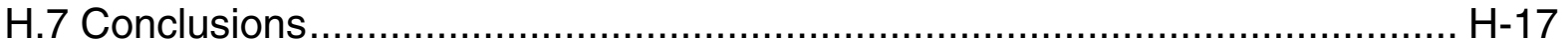

\section{I: Summary of Reactive Transport Simulations Using GIMRT Code}

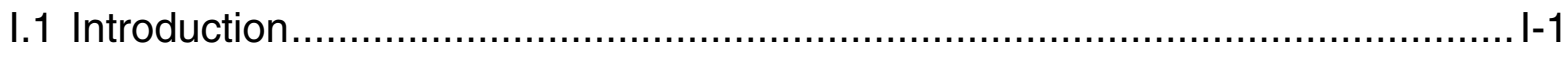

I.2 Radionuclide Decay and Ingrowth in the GIMRT Code .............................. I-1

I.3 Matrix Diffusion Effects on Radionuclide Retardation..................................... I-3

I.4 Mineral Heterogeneity Effects on Radionuclide Migration ............................... I-7

I.5 Effect of Colloids on Radionuclide Migration ............................................... I-11

I.6 Effect of Sorption Uncertainty on Radionuclide Migration............................... I-13

I.7 Glass Dissolution Model Effects ........................................................... I-15

I.7.1 Simple vs. Complex Glass Models ..........................................................................

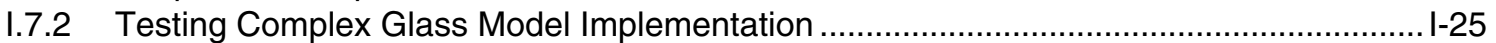

I.7.3 Reactive Surface Area of Melt Glass and Glass Durability ......................................... I-29

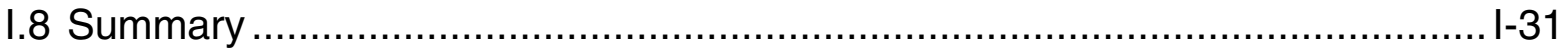

\section{J: Thermodynamic and Kinetic Data}

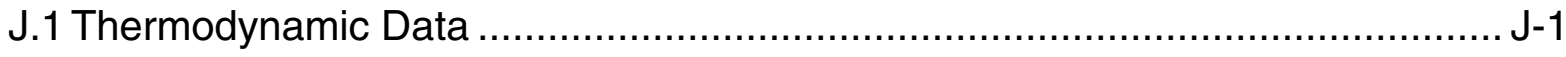

J.2 Kinetic Rate Equation and Parameters of Solids ........................................ J-6

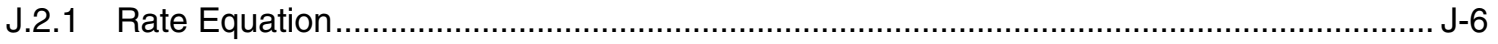

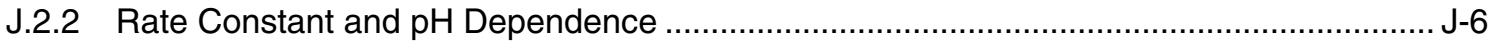

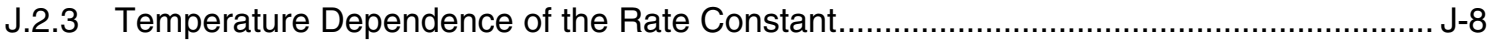

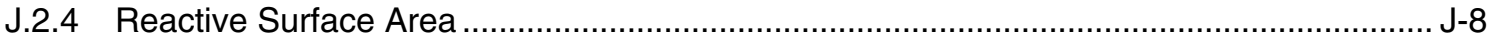




\section{K: Surface Complexation and lon Exchange}

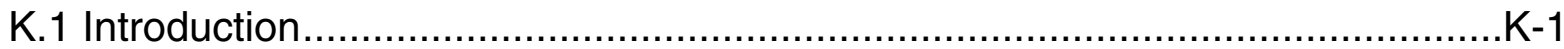

K.2 Reactions Included in the Near Field Simulations ......................................

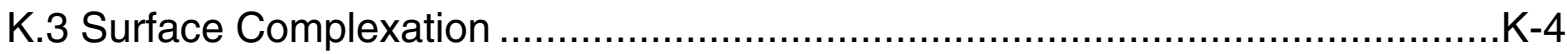

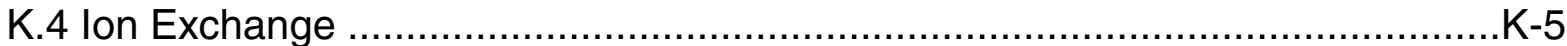

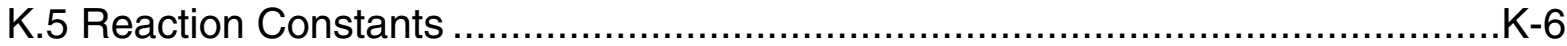

K.6 Comparison of Model to Sorption Experiments ........................................

K.7 Implementation in the GIMRT Transport Model.......................................

K.8 Implementation in the Particle Model.....................................................

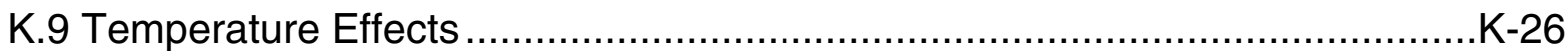

\section{L: Model Parameter Roadmap}

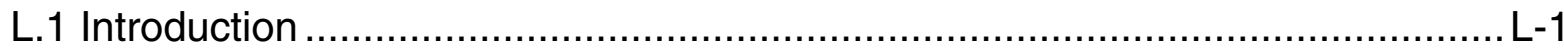

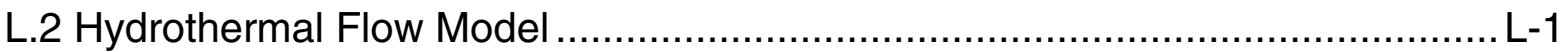

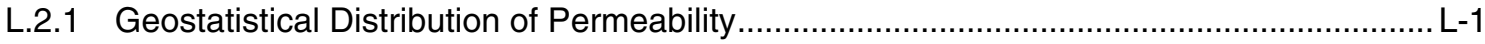

L.2.2 Alternative Hydrogeologic Models .........................................................................L-2

L.2.3 Flow Model Sensitivity Simulations ……………………………………………....-2

L.3 Reactive Transport Models .................................................................. L

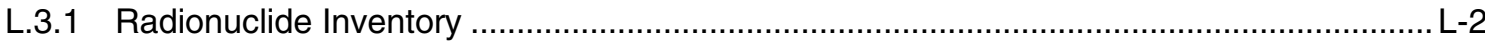

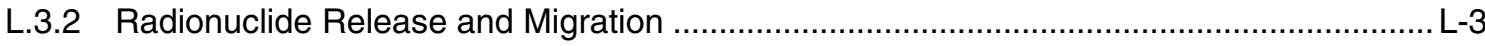

L.3.3 Geostatistical Distribution of Sorbing Minerals ……………………………………...... L-3

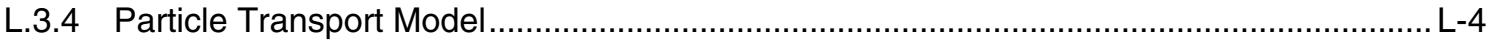

L.3.4.1 Particle Model Retardation Effects .......................................................................... L-4

L.3.4.2 Particle Model Sensitivity Simulations .................................................................... L-5

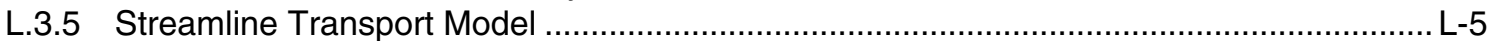

L.3.5.1 Geochemical Processes in the Streamline Model ........................................................ L-6 


\section{FIGURES}

\section{Executive Summary - no figures}

\section{Chapter 1 - no figures}

\section{Chapter 2 - no figures}

\section{Chapter 3}

Figure 3.1 The Nevada Test Site and locations of CHESHIRE, Area 20, and Pahute Mesa.

Figure 3.2 Cross-sectional view of the CHESHIRE site, oriented from northeast to southwest, parallel to the regional groundwater flow gradient. At hole U-20n, location of the CHESHIRE test, the working point is shown, along with the estimated cavity (inner circle) and exchange volume (outer circle), as well as the chimney zone and melt glass zone (black).

Figure 3.3 Plan view of the Cheshire area, oriented from the northeast to the southwest, paralleling the regional groundwater flow gradient. Included are the emplacement hole U-20n, posttest hole U-20n PS \#1DD-H, and characterization holes UE-20n \#1 and U-20a \#2 water well.

Figure 3.4 Conceptual view of the near-field CHESHIRE test environment showing the emplacement hole (U-20n), curvilinear posttest hole (U-20n PS \#1 DD-H) and the radionuclide migration study hole (UE-20n \#1).

Figure 3.5 Concept of phenomenology of an underground nuclear explosion showing accretion of melt glass puddle, redistribution of more volatile radionuclides, initially as gases, later as condensates, and collapse of the chimney.

Figure 3.6 Conceptualization of dynamic processes that occur after an underground nuclear test. The most logical starting point for examining radionuclide migration in groundwater will be in the days to months following detonation when groundwater returns to the cavity and chimney and most of the dynamic processes have ended.

Figure 3.7 In situ photograph of the melt glass from the reentry mining excavation at the RAINIER test (Wadman and Richards, 1961). Large blocks of host rock can be seen inside the melted glass. Vesicular zones (rich in bubbles) surround some of these inclusions. The photo is about $2 \mathrm{~m}$ across. The area is obviously heterogeneous in textural and hydrologic properties.

Figure 3.8 Idealized locations and sizes of the altered zones-melt glass, cavity, disturbed, and chimney - created by the CHESHIRE test using the maximum yield value of $500 \mathrm{kt}$.

\section{Chapter 4}

Figure 4.1 Comparison of terminology used in flow modeling and radionuclide

distribution for transport models and relationship to the phenomenologic model. 


\section{Chapter 5}

Figure 5.1 Cross-sectional view showing location of CHESHIRE test, holes U-20n and UE-

$20 \mathrm{n} \# 1$, and model domain. Altered zones are sized to the dimensions assumed in the

flow and transport simulations.

Figure 5.2 Plan view showing location of model domain and breakthrough plane with respect to holes U-20n, UE-20n \#1, and U-20n PS \#1DD-H and U-20a \#2 Water Well. 5-8

Figure 5.3 Cross section showing hydraulic conductivities of rhyolitic lava flows inferred from pumping and injection test data in U-20a \#2 Water Well. Based on these data, native rock permeabilities are categorized as high, moderate, low, and very low permeability hydrofacies for the flow simulations.

Figure 5.4 Perspective views of 10 geostatistical realizations used to assess the effect of heterogeneity in lava flows surrounding the CHESHIRE test.

Figure 5.5 Perspective views of the homogeneous and layer-cake conceptual models of subsurface permeability surrounding the CHESHIRE test.

Figure 5.6 Water level map in vicinity of Cheshire test. Water level contour interval is 50 $\mathrm{m}$. Purple label is measured water level elevation in meters. Large black-line grid size is $10,000 \mathrm{~m}$ (for scale).

Figure 5.7 Graphs showing temperature data (circles) and simulated thermal profiles from 10 realizations (dashed lines) for hole U-20n PS \#1DD-H at 154 and $201 \mathrm{~d}$ after the CHESHIRE test.

Figure 5.8 Graphs showing temperature data (circles) and simulated thermal profiles from 10 realizations (dashed lines) for hole U-20n PS \#1DD-H at $6.5 \mathrm{yr}$ after the CHESHIRE test and hole UE-20n \#1 at $11.3 \mathrm{yr}$ after the CHESHIRE test.

Figure 5.9 Sensitivity studies showing effect of changing hydrofacies permeabilities and thermal conceptual model through comparison of simulated temperatures with temperature log data from hole U-20n PS \#1DD-H at 154 and $201 \mathrm{~d}$ after the CHESHIRE test.

Figure 5.10 Sensitivity studies comparing effect of hydrogeologic and thermal conceptual models through comparison of simulated temperatures with temperature log data from hole U-20n PS \#1DD-H at 154 and $201 \mathrm{~d}$ after the CHESHIRE test.

Figure 5.11 Sensitivity studies for realization 9 showing effect of different hydrofacies permeabilities and thermal conceptual models through comparison of simulated temperatures with temperature log data from hole U-20n PS \#1DD-H at $6.5 \mathrm{yr}$ and UE20n \#1 at $11.3 \mathrm{yr}$ after the CHESHIRE test.

Figure 5.12 Sensitivity studies comparing effect of hydrogeologic and thermal conceptual models through comparison of simulated temperatures with temperature log data from holes U-20n PS \#1DD-H and UE-20n \#1.

Figure 5.13 Perspective views of temperature fields at different times from nonisothermal flow simulation for realization 9 .

Figure 5.14 Perspective views of temperature fields at different times from nonisothermal flow simulations for 10 realizations. Beneath each field, realization number and time are given. Each row is a different realization, and each column is a different time. 
Figure 5.15 Sensitivity studies comparing temperature behavior for realization 9 with base-case parameters, isotropic high permeability hydrofacies, increased melt glass permeability, decreased chimney permeability, increased lower cavity permeability, decreased disturbed zone permeability, no test-related heat, and isothermal conditions.

Figure 5.16 Sensitivity studies comparing temperature behavior for realization 9 with base-case parameters; a layer cake model with base-case parameters, isotropic high permeability hydrofacies, no test-related heat, and isothermal conditions; and a homogeneous model with base-case parameters, no test-related heat, and isothermal conditions.

Figure 5.17 Perspective views of tracer transport at different times for realization 3 with uniform initial concentration in cavity and disturbed zone (exchange volume). Yellow > $10^{-9}$ moles/liter; Green $>10^{-14}$ moles/liter..

Figure 5.18 Perspective views of tracer transport at different times for homogeneous native rock with uniform initial concentration in cavity and disturbed zone (exchange volume). Yellow $>10^{-9}$ moles $/$ liter; Green $>10^{-14}$ moles $/$ liter.

Figure 5.19 Perspective views of tracer transport at different times for layer-cake native rock permeability structure with uniform initial concentration in cavity and disturbed zone (exchange volume). Yellow $>10^{-9}$ moles/liter; Green $>10^{-14}$ moles $/$ liter.

Figure 5.20 Perspective views of tracer transport at different times for heterogeneous native rock with uniform initial concentration in cavity and disturbed zone (exchange volume). Yellow $>10^{-9}$ moles $/$ liter; Green $>10^{-14}$ moles $/$ liter.

Figure 5.21 Perspective views of tracer transport at different times for realization 3 with uniform initial concentration in cavity and disturbed zone (exchange volume). Yellow > $10^{-9}$ moles/liter; Green $>10^{-14}$ moles/liter

Figure 5.22 Perspective views of tracer transport at different times for realization 9 with melt glass source. Yellow $>10^{-9}$ moles /liter; Green $>10^{-14}$ moles $/$ liter.

Figure 5.23 Perspective views of tracer transport at different times for homogeneous conceptual model with melt glass source. Yellow $>10^{-9}$ moles/liter; Green $>10^{-14}$ moles/liter.

Figure 5.24 Perspective views of tracer transport at different times for layer-cake conceptual model with melt glass source. Yellow $>10^{-9}$ moles/liter; Green $>10^{-14}$ moles/liter.

Figure 5.25 Perspective views of tracer transport at different times for realization 9 with melt glass source and no test-related heat. Yellow $>10^{-9}$ moles/liter; Green $>10^{-14}$ moles/liter.

Figure 5.26 Perspective views of tracer transport at different times for 10 realizations with melt glass source. Beneath each image, realization number and time are given. Each row is a different realization, and each column is a different time. Yellow $>10^{-9}$ moles/liter; Green $>10^{-14}$ moles/liter. 5-51

Figure 5.27 Perspective views of streaklines originating from an instantaneous melt glass source for realization 3 .

Figure 5.28 Perspective views of streaklines originating from an instantaneous melt glass source for realization 9 . 


\section{Chapter 6}

Figure 6.1. Geologic units, rock types, and alteration observed in three cores near Cheshire (Warren et al., 2000). High permeability zones inferred by Blankennagel and

Weir (1973) and Erikson (1991) are overlaid on the Alteration plot.

Figure 6.2 Yucca Mountain and nearby drill holes from which core data were used to describe fracture-lining mineralogy (Carlos et al., 1995a).

Figure 6.3 Fracture-lining mineral distribution from well UE-25a\#1/UE-25b\#1 as a function of depth (below ground surface).

Figure 6.4 Fracture-lining mineral distribution from well USW G-1 as a function of depth (below ground surface).

Figure 6.5 Fracture-lining mineral distribution from well USW G-2 as a function of depth (below ground surface).

Figure 6.6 Fracture-lining mineral distribution from well USW G-3/USW GU-3 as a function of depth (below ground surface).

Figure 6.7 Fracture-lining mineral distribution from well USW G-4 as a function of depth (below ground surface).

Figure 6.8 Calico Hills Formation fracture-lining mineral distribution probabilities and concentrations. Total " + " probability indicates the percent of fractures examined that contained a mineral, average " + " concentrations indicates the average concentration of the mineral in fractures that contained that mineral, and average concentration indicates the absolute average concentration of the mineral in Calico Hills Formation fractures. Concentration is in relative percent.

Figure 6.9 Topopah Spring Tuff fracture-lining mineral distribution probabilities and concentrations. Total " + " probability indicates the percent of fractures examined that contained a mineral, average " + " concentrations indicates the average concentration of the mineral in fractures that contained that mineral, and average concentration indicates the absolute average concentration of the mineral in Topopah Spring Tuff fractures. Concentration is in relative percent.

Figure 6.10 Fracture-lining mineral distribution probabilities and concentrations for devitrified tuffs below the water table. Total " + " probability indicates the percent of fractures examined that contained a mineral, average " + " concentrations indicates the average concentration of the mineral in fractures that contained that mineral, and average concentration indicates the absolute average concentration of the mineral in devitrified tuff fractures below the water table. Concentration is in relative percent.

Figure 6.11 Fracture-lining minerals from UE-18t (top) and UE-20f (bottom) drill holes (IT Corporation, 1998b). C $=$ calcite, $\mathrm{q}=$ quartz, $\mathrm{Fe}=$ iron oxide.

Figure 6.12 A simplified diagram depicting the conceptual model used to define the nature of effective porosity and the interaction of radionuclides with fracture-lining minerals and matrix minerals. Some matrix flow was necessary to merge the flow and geochemical models. Rough fracture surfaces, microfracturing, or diffusion at the fracture-matrix boundary might also have been used to account for the difference between fracture porosity and effective porosity.

Figure 6.13 Photo of the RAINIER glass zone showing the heterogeneous distribution of melt glass and rubble. Tuff blocks are about $0.3 \mathrm{~m}$ in diameter. 
Figure 6.14 Radioactivity measured in drill-back holes into the RAINIER cavity. This radioactivity was located in both glass fragments and in the $<0.01 \mathrm{~mm}$ fraction of the tuff (Warner and Violet, 1959).

Figure 6.15 Schematic of the cavity and chimney zones dominated by $3 \mathrm{~m}$ lava blocks, $10 \%$ inter-block porosity, and sorbing mineralogy based on pretest fracture lining densities and additional matrix reactivity due to additional fracturing.

Figure 6.16 Range of concentrations and mean concentrations of major elements and $\mathrm{pH}$ in groundwater samples from Areas 19 and 20, Pahute Mesa (Table 6.9). Data from Smith et al. (1998), Smith et al. (1999), Rose et al. (1997), and IT.

Figure 6.17 Dissolution rates for synthetic volcanic glasses measured at $65^{\circ} \mathrm{C}$ by Mazer (1987). These rates are for test conditions far from saturation with respect to the glass.

Figure 6.18 Dissolution rates of rhyolitic glass at 25 and $65^{\circ} \mathrm{C}$. Data at $25^{\circ} \mathrm{C}$ are extrapolated from $65^{\circ} \mathrm{C}$ data in Mazer (1987). Curve through $25^{\circ} \mathrm{C}$ data is a least-squares fit based on linear three-term equation described in text. Plot shows both units of $\mathrm{g} / \mathrm{m}^{2} / \mathrm{d}$ and moles $/ \mathrm{m}^{2} / \mathrm{s}$, where one mole is defined to be $100 \mathrm{~g}$ of glass

Figure 6.19 Far-from-saturation, surface-area-normalized dissolution rates for CHESHIRE glass over the temperature range of glass-water interactions estimated for the CHESHIRE test.

Figure 6.20 Surface-area-normalized glass dissolution rate models for use in particle calculations. Data points represent estimates of saturation rates derived from data in Stout and Leider (1998) (see text).

Figure 6.21 Glass dissolution rate with time resulting from variations in the identity and rates of precipitation of secondary minerals. Rate in units of mole glass/(liter bulk volume medium per second).

\section{Chapter 7}

Figure 7.1 Perspective view of streamline locations along a one cell $(10 \mathrm{~m})$ wide $y$ - $z$ plane cross section for each time step of GIMRT reactive transport simulation. Streamlines weave in and out of this plane as a function of their 3-D path. Hydrofacies are shown as background.

Figure 7.2 Perspective cross-sectional views of tracer concentrations over time (100-1000 yr) from GIMRT streamline simulations for different radionuclide tracer classes: TracerGW, TracerMG, and TracerEV. Initial concentrations at $100 \mathrm{yr}$ are obtained from particle simulations.

Figure 7.3(a) Perspective cross-sectional views of GIMRT transient streamline simulations of total concentration over time (100-1000 $\mathrm{yr}$ ): $\mathrm{Am},{ }^{41} \mathrm{Ca}, \mathrm{Cs}, \mathrm{Eu}$, and $\mathrm{Np}$ radionuclide classes. Initial concentrations at $100 \mathrm{yr}$ are obtained from particle simulations

Figure 7.3(b) Perspective cross-sectional views of GIMRT transient streamline simulations of total concentration over time (100-1000 yr): $\mathrm{Pu},{ }^{241} \mathrm{Pu}, \mathrm{Sm}, \mathrm{Sr}$, and $\mathrm{U}$ radionuclide classes. Initial concentrations at $100 \mathrm{yr}$ are obtained from particle simulations. 
Figure 7.4(a) Perspective cross-sectional views of GIMRT transient streamline simulations of aqueous concentration over time (100-1000 yr): $\mathrm{Am},{ }^{41} \mathrm{Ca}, \mathrm{Cs}, \mathrm{Eu}$, and Np radionuclide classes. Initial concentrations at $100 \mathrm{yr}$ are obtained from particle simulations.

Figure 7.4(b) Perspective cross-sectional views of GIMRT transient streamline simulations of aqueous concentration over time (100-1000 yr): $\mathrm{Pu},{ }^{241} \mathrm{Pu}, \mathrm{Sm}, \mathrm{Sr}$, and $\mathrm{U}$ radionuclide classes. Initial concentrations at $100 \mathrm{yr}$ are obtained from particle simulations.

Figure 7.5 Perspective views of GIMRT transient streamline simulations of radionuclide aqueous concentrations near and down-gradient from melt glass.

Figure 7.6(a) Cross-sectional view at breakthrough plane showing GIMRT transient streamline simulations of aqueous concentration over time (100-1000 yr): Am, ${ }^{41} \mathrm{Ca}, \mathrm{Cs}$, $\mathrm{Eu}$, and $\mathrm{Np}$ radionuclide classes. Initial concentrations at $100 \mathrm{yr}$ are obtained from particle simulations.

Figure 7.6(b) Cross-sectional view at breakthrough plane showing GIMRT transient streamline simulations of aqueous concentration over time (100-1000 yr): $\mathrm{Pu},{ }^{241} \mathrm{Pu}, \mathrm{Sm}$, $\mathrm{Sr}$, and $\mathrm{U}$ radionuclide classes. Initial concentrations at $100 \mathrm{yr}$ are obtained from particle simulations.

Figure 7.7(a) Perspective cross-sectional views of GIMRT transient streamline simulations of $\mathrm{Al}, \mathrm{Ca}, \mathrm{Cl}, \mathrm{Fe}$, and $\mathrm{HCO}_{3}$ aqueous concentrations. Uncolored regions are not crossed by streamlines.

Figure 7.7(b) Perspective cross-sectional views of GIMRT transient streamline simulations of $\mathrm{K}, \mathrm{Mg}, \mathrm{Na}, \mathrm{SiO}_{2}$, and $\mathrm{SO}_{4}$ aqueous concentrations. Uncolored regions are not crossed by streamlines.

Figure 7.8(a) Radionuclide flux at the breakthrough plane as a function of time. GIMRT transient streamline results (-) are given on a yearly basis. Total (black - - - ), glass (red - - - ), and non-glass (blue - - - ) contributions to flux are averaged over one-half of a time step model. Particle model results are in gray.

Figure 7.8(b) Radionuclide flux at the breakthrough plane as a function of time. GIMRT transient streamline results (-) are given on a yearly basis. Total (black - - - ), glass (red - - - ), and non-glass (blue - - - ) contributions to flux are averaged over one-half of a time step model. Particle model results are in gray.

Figure 7.9 Cross-sectional perspective views of particle simulations of aqueous $\mathrm{Am},{ }^{41} \mathrm{Ca}$, $\mathrm{Cs}, \mathrm{Eu}$, and $\mathrm{Np}$ concentration at $201 \mathrm{~d}$ and at 2, 6.5, 11.3, 23.5, and $59 \mathrm{yr}$ after CHESHIRE test for realization 9 , mineralization 1 .

Figure 7.10 Cross-sectional perspective views of particle simulations of aqueous Am, ${ }^{41} \mathrm{Ca}$, Cs, Eu, and Np concentration at 100, 135, 208, 361, 689, and $1000 \mathrm{yr}$ after CHESHIRE test for realization 9 , mineralization 1 .

Figure 7.11 Cross-sectional perspective views of particle simulations of aqueous $\mathrm{Pu}$, ${ }^{241} \mathrm{Pu}, \mathrm{Sm}, \mathrm{Sr}$, and $\mathrm{U}$ concentration at $201 \mathrm{~d}$ and at 2, 6.5, 11.3, 23.5, and $59 \mathrm{yr}$ after CHESHIRE test for realization 9, mineralization 1 .

Figure 7.12 Cross-sectional perspective views of particle simulations of aqueous $\mathrm{Pu}$, ${ }^{241} \mathrm{Pu}, \mathrm{Sm}, \mathrm{Sr}$, and U concentration at 100, 135, 208, 361, 689, and $1000 \mathrm{yr}$ after CHESHIRE test for realization 9 , mineralization 1 . 
Figure 7.13(a) Comparison of GIMRT transient streamline (blue) and particle model (red) results for $\mathrm{Am},{ }^{41} \mathrm{Ca}, \mathrm{Cs}, \mathrm{Eu}, \mathrm{Np}, \mathrm{Pu},{ }^{241} \mathrm{Pu}$, and $\mathrm{Sm}$ flux at the breakthrough plane as a function of time. The $5^{\text {th }}$ and $95^{\text {th }}$ percentiles of the particle model results for 100 permeability and mineralization realizations are in gray.

Figure 7.13(b) Comparison of GIMRT transient streamline (blue) and particle model (red) results for Sr, U, TracerEV, TracerGW, and TracerMG flux at the breakthrough plane as a function of time. The $5^{\text {th }}$ and $95^{\text {th }}$ percentiles of particle results for $\mathrm{Sr}$ and $\mathrm{U}$, the $10^{\text {th }}$ and $90^{\text {th }}$ percentiles of particle results for tracers are in gray.

Figure 7.14 Cross-sectional perspective views of particle simulations of aqueous $\mathrm{Eu}$ concentration at $10 \mathrm{yr}$ after CHESHIRE test for permeability realization 9 with 10 different mineralization realizations

Figure 7.15 Cross-sectional perspective views of particle simulations of aqueous Eu concentration at $100 \mathrm{yr}$ after CHESHIRE test for permeability realization 9 with 10 different mineralization realizations

Figure 7.16 Cross-sectional perspective views of particle simulations of aqueous $U$ concentration at $10 \mathrm{yr}$ after CHESHIRE test for permeability realization 9 with 10 different mineralization realizations.

Figure 7.17 Cross-sectional perspective views of particle simulations of aqueous $U$ concentration at $100 \mathrm{yr}$ after CHESHIRE test for permeability realization 9 with 10 different mineralization realizations.

Figure 7.18 Cross-sectional perspective views of particle simulations of aqueous Am concentration at $10 \mathrm{yr}$ after CHESHIRE test for mineralization realization 1 with 10 different permeability realizations.

Figure 7.19 Cross-sectional perspective views of particle simulations of aqueous Am concentration at $100 \mathrm{yr}$ after CHESHIRE test for mineralization realization 1 with 10 different permeability realizations

Figure 7.20 Cross-sectional perspective views of particle simulations of aqueous Eu concentration at $10 \mathrm{yr}$ after CHESHIRE test for mineralization realization 1 with 10 different permeability realizations.

Figure 7.21 Cross-sectional perspective views of particle simulations of aqueous Eu concentration at $100 \mathrm{yr}$ after CHESHIRE test for mineralization realization 1 with 10 different permeability realizations.

Figure 7.22 Cross-sectional perspective views of particle simulations of aqueous $\mathrm{Np}$ concentration at $10 \mathrm{yr}$ after CHESHIRE test for mineralization realization 1 with 10 different permeability realizations.

Figure 7.23 Cross-sectional perspective views of particle simulations of aqueous $\mathrm{Np}$ concentration at $100 \mathrm{yr}$ after CHESHIRE test for mineralization realization 1 with 10 different permeability realizations

Figure 7.24 Cross-sectional perspective views of particle simulations of aqueous ${ }^{241} \mathrm{Pu}$ concentration at $10 \mathrm{yr}$ after CHESHIRE test for mineralization realization 1 with 10 different permeability realizations.

Figure 7.25 Cross-sectional perspective views of particle simulations of aqueous ${ }^{241} \mathrm{Pu}$ concentration at $100 \mathrm{yr}$ after CHESHIRE test for mineralization realization 1 with 10 different permeability realizations. 
Figure 7.26 Cross-sectional perspective views of particle simulations of aqueous $U$ concentration at $10 \mathrm{yr}$ after CHESHIRE test for mineralization realization 1 with 10 different permeability realizations.

Figure 7.27 Cross-sectional perspective views of particle simulations of aqueous $U$ concentration at $100 \mathrm{yr}$ after CHESHIRE test for mineralization realization 1 with 10 different permeability realizations.

Figure 7.28 Particle simulations of breakthrough flux in moles per year of $\mathrm{Am},{ }^{41} \mathrm{Ca}, \mathrm{Cs}$, $\mathrm{Eu}$, and $\mathrm{Np}, \mathrm{Pu},{ }^{241} \mathrm{Pu}, \mathrm{Sm}, \mathrm{Sr}$, and $\mathrm{U}$ showing mean (red line), median (green line), and $5^{\text {th }}$ and $95^{\text {th }}$ percentiles (blue lines) for all 100 realizations (gray lines). Breakthrough plane is located $300 \mathrm{~m}$ down-gradient of CHESHIRE test.

Figure 7.29 Particle simulations of breakthrough flux in moles per year of TracerGW, TracerEV, and TracerMG showing mean (red line), median (green line), and $10^{\text {th }}$ and $90^{\text {th }}$ percentiles (blue lines) for all 10 realizations (gray lines). Breakthrough plane is located $300 \mathrm{~m}$ down-gradient of CHESHIRE test.

Figure 7.30 Variation of particle simulation breakthrough behavior resulting from permeability realization 9 with 10 different mineralization realizations (gray lines) compared with mean (red line), median (green line) and $5^{\text {th }}$ and $95^{\text {th }}$ percentile (blue lines) for all 100 realizations.

Figure 7.31 Variation of particle simulation breakthrough behavior resulting from mineralization realization 1 with 10 different permeability realizations (gray lines) compared with mean (red line), median (green line) and $5^{\text {th }}$ and $95^{\text {th }}$ percentile (blue lines) for all 100 realizations.

Figure 7.32 Particle simulations of cumulative normalized mass flux of $\mathrm{Am},{ }^{41} \mathrm{Ca}, \mathrm{Cs}, \mathrm{Eu}$, and $\mathrm{Np}, \mathrm{Pu},{ }^{241} \mathrm{Pu}, \mathrm{Sm}, \mathrm{Sr}$, and $\mathrm{U}$ for all 100 realizations (gray lines), mean (red line), median (green line), and $5^{\text {th }}$ and $95^{\text {th }}$ percentiles (blue lines).

Figure 7.33 Particle simulations of breakthrough flux in moles per year of $\mathrm{Am},{ }^{241} \mathrm{Pu}$, and $\mathrm{Np}$ for permeability realization 9 , mineralization realization 1 .

Figure 7.34 Particle simulations of breakthrough flux comparing results with and without test-related heat for TracerEV, TracerMG, TracerGW, and radionuclides $\mathrm{Pu}$ and Sm.

Figure 7.35 Particle simulations of breakthrough flux comparing results for heterogenous, layer cake, and homogenous conceptual models for TracerEV, TracerMG, and TracerGW, and radionuclides Cs and Sm. Note that layer cake model was not run for TracerGW and the radionuclides $\mathrm{Cs}$ and $\mathrm{Sm}$.

Figure 7.36 Particle simulations of breakthrough flux comparing results for TracerGW and permeability realization 9 with (orange) and without (gray) matrix diffusion. Note log-log scale on left and linear scale on right.

Figure 7.37. Particle simulations of breakthrough flux comparing the results for the "long-term dissolution rate" case with the base-case simulation for $\mathrm{Cs}, \mathrm{Pu}, \mathrm{Sm}, \mathrm{U}$ and tracer-MG.

Figure 7.38. Particle simulations of breakthrough flux comparing the results for the low$\mathrm{kd}$ simulation with the base-case simulation for $\mathrm{Cs}, \mathrm{Pu}, \mathrm{Sm}, \mathrm{U}$. 
Figure 7.39. Particle simulations of breakthrough flux comparing the results for the base case simulation with local transverse and longitudinal dispersion for the tracer-EV radionuclide.

Figure 7.40(a) Decay-corrected radionuclide flux (moles per year) at the breakthrough plane for ${ }^{3} \mathrm{H},{ }^{14} \mathrm{C},{ }^{36} \mathrm{Cl},{ }^{39} \mathrm{Ar},{ }^{41} \mathrm{Ca},{ }^{59} \mathrm{Ni},{ }^{63} \mathrm{Ni}$, and ${ }^{85} \mathrm{Kr}$. Particle model results are in red with 5 and $95 \%$ confidence intervals in gray. GIMRT transient streamline results are in blue.

Figure 7.40(b) Decay-corrected radionuclide flux (moles per year) at the breakthrough plane for ${ }^{90} \mathrm{Sr},{ }^{93 \mathrm{~m}} \mathrm{Nb},{ }^{94} \mathrm{Nb},{ }^{93} \mathrm{Zr},{ }^{99} \mathrm{Tc},{ }^{107} \mathrm{Pd},{ }^{121 \mathrm{~m}} \mathrm{Sn}$, and ${ }^{126} \mathrm{Sn}$. Particle model results are in red with 5 and $95 \%$ confidence intervals in gray. GIMRT transient streamline results are in blue.

Figure 7.40(c) Decay-corrected radionuclide flux (moles per year) at the breakthrough plane for ${ }^{129} \mathrm{I},{ }^{135} \mathrm{Cs},{ }^{137} \mathrm{Cs},{ }^{150} \mathrm{Eu},{ }^{152} \mathrm{Eu},{ }^{154} \mathrm{Eu},{ }^{151} \mathrm{Sm}$, and ${ }^{166 m} \mathrm{Ho}$. Particle model results are in red with 5 and $95 \%$ confidence intervals in gray. GIMRT transient streamline results are in blue.

Figure 7.40(d) Decay-corrected radionuclide flux (moles per year) at the breakthrough plane for ${ }^{232} \mathrm{U},{ }^{233} \mathrm{U},{ }^{234} \mathrm{U},{ }^{235} \mathrm{U},{ }^{236} \mathrm{U},{ }^{238} \mathrm{U},{ }^{237} \mathrm{~Np}$, and ${ }^{238} \mathrm{Pu}$. Particle model results are in red with 5 and 95\% confidence intervals in gray. GIMRT transient streamline results are in blue.

Figure 7.40(e) Decay-corrected radionuclide flux (moles per year) at the breakthrough plane for ${ }^{239} \mathrm{Pu},{ }^{240} \mathrm{Pu},{ }^{241} \mathrm{Pu},{ }^{241} \mathrm{Am}$, and ${ }^{244} \mathrm{Cm}$. Particle model results are in red with 5 and 95\% confidence intervals in gray. GIMRT transient streamline results are in blue.

Figure 7.41(a) Decay-corrected radionuclide $\alpha$ flux (curies per year) at the breakthrough plane for ${ }^{232} \mathrm{U},{ }^{233} \mathrm{U},{ }^{234} \mathrm{U},{ }^{235} \mathrm{U},{ }^{236} \mathrm{U},{ }^{238} \mathrm{U},{ }^{237} \mathrm{~Np}$, and ${ }^{238} \mathrm{Pu}$ that contribute to $\alpha$ activity. Particle model results are in red with 5 and 95\% confidence intervals in gray. GIMRT transient streamline results are in blue.

Figure 7.41(b) Decay-corrected radionuclide $\alpha$ flux (curies per year) at the breakthrough plane for ${ }^{239} \mathrm{Pu},{ }^{240} \mathrm{Pu},{ }^{241} \mathrm{Am}$, and ${ }^{244} \mathrm{Cm}$ that contribute to $\alpha$ activity. Particle model results are in red with 5 and $95 \%$ confidence intervals in gray. GIMRT transient streamline results are in blue.

Figure 7.42(a) Decay-corrected radionuclide $\beta$ flux (curies per year) at the breakthrough plane for ${ }^{3} \mathrm{H},{ }^{14} \mathrm{C},{ }^{36} \mathrm{Cl},{ }^{39} \mathrm{Ar},{ }^{63} \mathrm{Ni},{ }^{85} \mathrm{Kr},{ }^{90} \mathrm{Sr}$, and ${ }^{93} \mathrm{Zr}$ that contribute to $\beta$ activity. Particle model results are in red with 5 and 95\% confidence intervals in gray. GIMRT transient streamline results are in blue.

Figure 7.42(b) Decay-corrected radionuclide $\beta$ flux (curies per year) at the breakthrough plane for ${ }^{94} \mathrm{Nb},{ }^{99} \mathrm{Tc},{ }^{107} \mathrm{Pd},{ }^{121 \mathrm{~m}} \mathrm{Sn},{ }^{126} \mathrm{Sn},{ }^{129} \mathrm{I},{ }^{135} \mathrm{Cs}$, and ${ }^{137} \mathrm{Cs}$ that contribute to $\beta$ activity. Particle model results are in red with 5 and 95\% confidence intervals in gray. GIMRT transient streamline results are in blue.

Figure 7.42(c) Decay-corrected radionuclide $\beta$ flux (curies per year) at the breakthrough plane for ${ }^{151} \mathrm{Sm},{ }^{152} \mathrm{Eu},{ }^{154} \mathrm{Eu},{ }^{166 \mathrm{~m}} \mathrm{Ho}$, and ${ }^{241} \mathrm{Pu}$ that contribute to $\beta$ activity. Particle model results are in red with 5 and $95 \%$ confidence intervals in gray. GIMRT transient streamline results are in blue. 
Figure 7.43 Decay-corrected radionuclide EC/IT flux (curies per year) at the breakthrough plane for ${ }^{151} \mathrm{Sm},{ }^{152} \mathrm{Eu},{ }^{154} \mathrm{Eu},{ }^{166 \mathrm{~m}} \mathrm{Ho}$, and ${ }^{241} \mathrm{Pu}$ that contribute to EC/IT activity. Total EC/IT activity shown at bottom. Particle model results are in red with 5 and $95 \%$ confidence intervals in gray. GIMRT transient streamline results are in blue..

\section{Chapter 8}

Figure 8.1 Simulated TracerEV flux past the UE-20n \#1 control plane in the realization 9 flow field based upon no test-related heat. Two analytical tracer flux profiles based upon a point source of $M$ moles located at the working point of the test and two different values of the macrodispersivity $A_{11}$ are superimposed.

Figure 8.2 Comparison of particle model median peak breakthrough for radionuclides with average retardation assuming statistically homogeneous mineralization. Thick black line represents ideal relationship assuming tracer breakthrough peak at $1 \mathrm{yr}$ with no testrelated heat. Thin gray lines bracket range of uncertainty of peak tracer breakthrough with no test-related heat. Dashed line represents ideal relationship assuming tracer breakthrough peak at $2 \mathrm{yr}$, as inferred from particle model median tracer breakthrough with test-related heat. Thin black line indicates ideal relationship assuming average flow velocity for high permeability hydrofacies.

Figure 8.3 Conceptual representation of the dilution effect created by mapping the integrated flux coming out of the finely discretized near-field model into a coarsely gridded CAU model. Although radionuclide mass is conserved, the highs and lows of the concentration variability visible along the near-field model exit face are lost. The small schematic at the top is used to suggest the possibility of preserving the small-scale variability in the near-field model by mapping the results into a particle-base transport simulator in the CAU model.

\section{Chapter 9 - no figures}

\section{Chapter 10 - no figures}

\section{APPENDICES}

\section{Appendix A}

Figure A.1 Ratio of alpha activities of individual radionuclides to the total alpha activity of all inventoried radionuclides, as a function of time, in groundwater on Pahute Mesa at the Nevada Test Site.

Figure A.2 Ratio of moles of individual alpha-emitting radionuclides to moles of all inventoried alpha radionuclides in groundwater, as a function of time, on Pahute Mesa at the Nevada Test Site.

Figure A.3(a) Ratio of beta activities of individual radionuclides to total beta activity of all inventoried radionuclides in groundwater, as a function of time, on Pahute Mesa at the Nevada Test Site $\left({ }^{3} \mathrm{H}\right.$ to $\left.{ }^{113} \mathrm{Cd}\right)$

Figure A.3(b) Ratio of beta activities of individual radionuclides to total beta activity of all inventoried radionuclides in groundwater, as a function of time, on Pahute Mesa at the Nevada Test Site $\left({ }^{121 \mathrm{~m}} \mathrm{Sn}\right.$ to $\left.{ }^{241} \mathrm{Pu}\right)$. Because ${ }^{121 \mathrm{~m}} \mathrm{Sn}$ and ${ }^{152} \mathrm{Eu}$ have two principal decay modes (Table A.1), only their respective inventory fractions partaking in a $\beta$-decay 
Figure A.4(a) Ratio of moles of individual beta emitting radionuclides to moles of all inventoried beta radionuclides in groundwater, as a function of time, on Pahute Mesa at the Nevada Test Site $\left({ }^{3} \mathrm{H}\right.$ to $\left.{ }^{113} \mathrm{Cd}\right)$

Figure A.4(b) Ratio of moles of individual beta emitting radionuclides to moles of all inventoried beta radionuclides in groundwater, as a function of time, on Pahute Mesa at the Nevada Test Site $\left({ }^{121 \mathrm{~m}} \mathrm{Sn}\right.$ to $\left.{ }^{241} \mathrm{Pu}\right)$. Because ${ }^{121 \mathrm{~m}} \mathrm{Sn}$ and ${ }^{152} \mathrm{Eu}$ have two principal decay modes (Table A.1), only their respective inventory fractions partaking in a $\beta$-decay process are included in these results.

Figure A.5 Ratio of EC and IT activities of individual radionuclides to the total electron capture and isomeric transition activity of radionuclides in groundwater, as a function of time, on Pahute Mesa at the Nevada Test Site. Because ${ }^{121 \mathrm{~m}} \mathrm{Sn}$ and ${ }^{152} \mathrm{Eu}$ have two principal decay modes (Table A.1), only their respective inventory fractions partaking in an EC/IT decay process are included in these results and those in Figure A.6.

Figure A.6 Ratio of moles of individual EC and IT radionuclides to moles of total electron capture and isomeric transition radionuclides in groundwater, as a function of time, on Pahute Mesa at the Nevada Test Site.

\section{Appendix B - no figures}

\section{Appendix C}

Figure C.1 Tritium breakthrough profile (square wave) from GIMRT in the absence of matrix diffusion in a 1-D test problem and the modified, postprocessed solution accounting for the effects of matrix diffusion (thin line), as obtained with the convolution result (C14). The 2-D (thick line) solution was obtained from a discrete simulation of the same problem using the GIMRT model.

\section{Appendix D}

Figure D.1 Normalized ingrowth of ${ }^{241} \mathrm{Am}$ and ${ }^{37} \mathrm{~Np}$ from the decay of an initial unit mass of ${ }^{241} \mathrm{Pu}$ over 1000 yr. Solid curves represent the Bateman solution; symbols represent a computed particle solution based on 100,000 particles and use of the transitional probability model (D10) with 1 yr steps.

Figure D.2 Particle breakthrough profile for tritium (thin line) reflecting the influence of matrix diffusion, as implemented with the transitional probability equations (D11) in a 1$\mathrm{D}$ test problem. The thicker line represents the solution provided by a 2-D, discrete fracture application of the GIMRT model to the same problem.

Figure D.3 Predicted mean temperature $\left({ }^{\circ} \mathrm{C}\right)$ in the melt glass zone and the approximate particle rate used to define glass dissolution $\left(\mathrm{mol} / \mathrm{m}^{3}-\mathrm{bulk} / \mathrm{yr}\right)$ in the particle simulations based upon a fixed $\mathrm{pH}$ of 8 and an initial melt glass surface area of $2000 \mathrm{~m}^{2} / \mathrm{m}^{3}(\sim 10$ $\left.\mathrm{cm}^{2} / \mathrm{g}\right)$.

\section{Appendix E}

Figure E.1 Predicted distribution of total ${ }^{241} \mathrm{Am}$ (mol/L-bulk) in the simple 1-D model after $100 \mathrm{yr}$ (left axis), as predicted by the GIMRT and particle models with no specified dispersion or diffusion. Retardation factors (right axis) as specified in the particle model input (solid curve) and as computed from the GIMRT model solution (open circles). 
Figure E.2 Predicted distribution of aqueous ${ }^{241} \mathrm{Am}$ (mol/L solution) in the simple 1-D model after $100 \mathrm{yr}$ (left axis), as predicted by the GIMRT and particle models with no specified dispersion or diffusion. Retardation factors (right axis) as specified in the particle model input (solid curve) and as computed from the GIMRT model solution (open circles).

Figure E.3 Predicted distribution of total ${ }^{241} \mathrm{Am}$ (mol/L-bulk) in the simple 1-D model after $100 \mathrm{yr}$ (left axis), as predicted by the GIMRT model with no specified dispersion or diffusion and by the particle model with a longitudinal dispersivity of $\alpha \mathrm{L}=10 \mathrm{~m}$.

Retardation factors (right axis) as specified in the particle model input (solid curve) and as computed from the GIMRT model solution (open circles).

Figure E.4 Predicted distribution of aqueous ${ }^{241} \mathrm{Am}$ (mol/L solution) in the simple 1-D model after $100 \mathrm{yr}$ (left axis), as predicted by the GIMRT model with no specified dispersion or diffusion and by the particle model with a longitudinal dispersivity of $\alpha \mathrm{L}=$ $10 \mathrm{~m}$. Retardation factors (right axis) as specified in the particle model input (solid curve) and as computed from the GIMRT model solution (open circles).

Figure E.5 Temperature $\left({ }^{\circ} \mathrm{C}\right)$ in the melt glass zone of the 1-D melt glass dissolution test problem and the glass dissolution rates $\left(\mathrm{mol} / \mathrm{m}^{3}-\mathrm{bulk} / \mathrm{yr}\right)$ computed in the corresponding particle and GIMRT simulations. The particle rate is predetermined as a function of temperature, and the simple GIMRT rate is fixed in the model to give essentially the same results. The complex rate is interrogated from the GIMRT simulation results at the end of the melt glass section, $100 \mathrm{~m}$ into the domain.

Figure E.6(a) Predicted distribution of total U (mol/L-bulk) released from melt glass in the simple 1-D model after $100 \mathrm{yr}$ (left axis), as predicted by the GIMRT and particle models with no specified dispersion or diffusion. Retardation factors (right axis) as specified in the particle model input (solid curve) and as computed from the GIMRT model solution (open circles)...

Figure E.6(b) Same as Figure E.6(a), but with concentrations shown on a log scale.

Figure E.7(a) Predicted distribution of aqueous U (mol/L) released from melt glass in the simple 1-D model after $100 \mathrm{yr}$ (left axis), as predicted by the GIMRT and particle models with no specified dispersion or diffusion. Retardation factors (right axis) as specified in the particle model input (solid curve) and as computed from the GIMRT model solution (open circles).

Figure E.7(b) Same as Figure E.7(a), but with concentrations shown on a log scale.

\section{Appendix F}

Figure F.1 Drawdown data from pumping test at U-20a \#2 Water Well. Straight-line fit

between 10-1000 min results in Cooper-Jacob transmissivity estimate of 18,000 gal/d/ft.

Figure F.2 Relationship between transmissivity and RSC, which was used to evaluate variations in permeability at Pahute Mesa (Blankennagel and Weir, 1973)...

Figure F.3 Permeability distribution inferred from injection tests in U-20a \#2 Water Well and well U-20n. The three clusters define the very low, low, and moderate permeability hydrofacies.

Figure F.4 Distribution of open fracture azimuths in mafic-poor Calico Hills Formation inferred from sonic (BHTV) log of well UE-20bh \#1 (modified from Drellack et al., 1997). 
Figure F.5 Distribution of open fracture azimuths in mafic-poor Calico Hills Formation inferred from microresistivity (FMS) log of well UE-20bh \#1 1 (modified from Drellack et al., 1997).

\section{Appendix G}

Figure G.1 Vertical transition probability measurements and Markov chain model. Data are based on hydrofacies interpretations of hydraulic data from U-20a \#2 Water Well.

Figure G.2 Realization \#9 out of 10 geostatistical realizations generated for flow and transport simulation at CHESHIRE.

\section{Appendix $\mathbf{H}$}

Figure H.1 Vertical transition probability matrix with $1 \mathrm{~m}$ lag spacing for mineralized and not-mineralized fractures for the ALL data set.

Figure H.2 Vertical transition probability matrix with $10 \mathrm{~m}$ lag spacing for mineralized and not-mineralized fractures for the ALL data set.

Figure H.3 Vertical transition probability matrix at $2 \mathrm{~m}$ lag for mineralized and notmineralized fracture categories of DVT data set.

Figure H.4 Vertical transition probability matrix at $10 \mathrm{~m}$ lag for mineralized and notmineralized fracture categories of DVT data set.

Figure H.5 Conceptualization of high and low mineralizations zones. In a high mineralization zone (at left), a high proportion of the fractures (black) are lined with a mineral (white). In a low mineralization zone (at right), a low proportion of the fractures are lined with a mineral.

Figure H.6 Vertical transition probability matrix at $1 \mathrm{~m}$ lag for high mineralization zones of ALL data set.

Figure H.7 Vertical transition probability matrix at $10 \mathrm{~m}$ lag for high mineralization zones of ALL data set.

Figure H.8 Vertical transition probability matrix at $2 \mathrm{~m}$ lag for high mineralization zones of DVT data set.

Figure H.9 Vertical transition probability matrix at $10 \mathrm{~m}$ lag for high mineralization zones of DVT data set.

Figure H.10 Transition probability measurements (circles) and Markov chain models (lines) for high mineralization zones for ALL data set (top row) and DVT data set (bottom row). Dashed lines indicate proportions of high mineralization zones in each data set.

Figure H.11 Realization of spatial distribution of high mineralization zones. The low clay category represents absence of high mineralization for all minerals.

\section{Appendix I}

Figure I.1 Relative ${ }^{241} \mathrm{Pu},{ }^{241} \mathrm{Am}$, and ${ }^{247} \mathrm{~Np}$ decay and ingrowth as modeled by the GIMRT code and as calculated by Bateman equations. 
Figure I.2 Breakthrough of $10^{-10} \mathrm{~mol} / \mathrm{L}$ tritium under conditions of no diffusion, diffusion with 1,5 , and 10 nodes in the matrix and $D_{e}=10^{-6} \mathrm{~cm}^{2} / \mathrm{s}$, and diffusion with 1 node in the matrix and $D_{e}=10^{-8} \mathrm{~cm}^{2} / \mathrm{s}$

Figure I.3 Breakthrough of $\mathrm{Eu}, \mathrm{Np}, \mathrm{Pu}$, and $\mathrm{U}$ with (thin line) and without (thick line) matrix diffusion. Note that background aqueous radionuclide concentrations vary between $10^{-20}$ to $10^{-23} \mathrm{~mol} / \mathrm{L}$, depending on the sorption strength of the various radionuclides.

Figure I.4 Breakthrough of Sr and Cs with (thin line) and without (thick line) matrix diffusion. Note that background aqueous radionuclide concentrations vary between $10^{-20}$ to $10^{-23} \mathrm{~mol} / \mathrm{L}$, depending on the sorption strength of the various radionuclides. $. \mathrm{I}-6$

Figure I.5 Breakthrough of Np under various model conditions.

Figure I.6 Schematic of 1D fracture flow simulations used to test the particle and GIMRT codes here and in Appendix E.

Figure I.7 Breakthrough of radionuclides for simple one-dimensional reactive transport simulations in which sorbing minerals are heterogeneously distributed using the method defined in Chapter 6. Colored curves represent 10 simulations with different mineral distributions; black line is the homogeneous mineralogy case for comparison.

Figure I.8 Radionuclide breakthrough in a heterogeneous fracture-lining mineralogy, 1$D$ reactive transport simulation in which colloids are present (thin line) and absent (thick line).

Figure I.9 Breakthrough of sorbing radionuclides in a heterogeneous fracture-lining mineralogy, 1-D reactive transport simulation. Thick line is the breakthrough when surface complexation constants are adjusted to two standard deviations from the average (thin line).

Figure I.10 Comparison of radionuclide breakthrough from the 1-D simple glass streamline (dashed lines) and complex glass streamline (solid lines). Radionuclides are not decay corrected except for $\mathrm{Am}, \mathrm{Np}$ and ${ }^{241} \mathrm{Pu}$.

Figure I.11 Comparison of retardation ratios of $\mathrm{U}$ and $\mathrm{Pu}$ as a function of time, labelled in years, in the 1D streamline model for the complex glass GIMRT model. Retardation ratio for $\mathrm{Pu}$ used in the particle model, assumed invariant with time, shown for reference.

Figure I.12 The $\mathrm{pH}$ along complex glass streamline as a function of distance and time, as labeled on the curves in years.

Figure I.13 Variations in $\mathrm{Na}$ and Ca concentration during dissolution of complex glass in GIMRT along an illustrative 1D streamline. The fluid composition at $0.001 \mathrm{yr}$ differs from the ambient fluid chemistry owing to re-equilibration of $35^{\circ} \mathrm{C}$ ambient fluid with $160^{\circ} \mathrm{C}$ conditions in glass melt during the initial time steps. Small amounts of alteration mineral precipitation caused the change in fluid chemistry.

Figure I.14 The pH along "simple glass" streamline as a function of distance and time, as labeled on the curves in years.

Figure I.15 Variations in $\mathrm{Na}$ and $\mathrm{Ca}$ concentrations during dissolution of simple glass in GIMRT along an illustrative 1-D streamline. 
Figure I.16 Precipitation of alteration minerals in the glass zone at a point $95 \mathrm{~m}$ along complex glass streamline in the glass zone. Trace quantities of kaolinite, $\mathrm{Na}$ - and Camontmorillonite precipitates are not shown owing to their small volumes (less than 0.4, 0.1 and $0.1 \mathrm{vol} \%$, respectively, at $1000 \mathrm{yr}$ ). Note that there was no feedback assumed in GIMRT between porosity and the flow field. Thus, although the volume of alteration minerals resulting was calculated along with the lost volume of glass, the porosity of the glass zone was fixed at $20 \%$

Figure I.17 The $\mathrm{pH}$ as a function of distance along streamline 1554 from135 to $1000 \mathrm{yr}$. Black blocks on top of $\mathrm{x}$ axis show position of glass zones.

Figure I.18 Ca and Na concentrations as a function of distance along streamline 1554

from 135 to $1000 \mathrm{yr}$. Black blocks on top of $\mathrm{x}$ axis show position of glass zones.

Figure I.19 Alteration minerals predicted by GIMRT to precipitate in glass zone along streamline 1554 from 135 to 1000 yr. Volume percent glass also shown. Note similarity to alteration minerals shown in Figure 7, although in smaller volumes because this simulation begins at $135 \mathrm{yr}$ when thermal pulse has dissipated.

Figure I.20 Breakthrough calculated by GIMRT for streamline 1554 from 135 to $1000 \mathrm{yr}$.

Figure I.21 Extent of glass dissolution predicted using the particle glass dissolution model as a function of time, temperature and reactive surface area given glass temperature-time relationship in Figure E.5.

\section{Appendix $\mathbf{J}$ - no figures}

\section{Appendix K}

Figure K.1 Correlation between measured and predicted sorption of $\mathrm{Am}, \mathrm{Cs}, \mathrm{Eu}, \mathrm{Np}, \mathrm{Pu}$, $\mathrm{Sr}$, and $\mathrm{U}$ to Yucca Mountain tuffs. $\mathrm{X}$-axis shows range of $\mathrm{Kd}$ values determined for each sample. $Y$-axis shows modeled $\mathrm{Kd}$ and uncertainty.

Figure K.2 Retardation ratios for surface complexation dominated radionuclide sorption in heterogeneously distributed mineral particle model.

Figure K.3 Retardation ratios for ion exchange dominated radionuclide sorption in heterogeneously distributed mineral particle model.

Figure K.4 Retardation ratios for radionuclide sorption in homogeneous mineral particle model.

\section{Appendix L - no figures}




\section{TABLES}

\section{Executive Summary — no tables}

\section{Chapter 1 - no tables}

Chapter 2 - no tables

\section{Chapter 3}

Table 3.1 Conceptual model parameters applied to the CHESHIRE test using the maximum yield value of $500 \mathrm{kt}$.....

\section{Chapter 4}

Table 4.1 Summary of average Pahute Mesa RST applied to the Cheshire test

Table 4.2 Assumed porosities and volumes used for the initial distribution of radionuclides.

Table 4.3 Initial radionuclide distributions.

Table 4.4 Initial concentration of radionuclides in the model.

Table 4.5 Simplified inventory used in reactive transport runs.

\section{Chapter 5}

Table 5.1 List of hydrofacies defined in flow models.

Table 5.2 Base-case values of effective lateral permeability ( $k x y)$, anisotropic permeability (kx: ky: kz) ratios with respect to kxy, and effective porosity assumed for native rock hydrofacies in simulations of flow and transport. Sources of data: $\mathrm{a}=$ pumping tests in U-20a \#2 Water Well; $b=$ injection tests in U-20a \#2 Water Well; $c=$ Bullion Forced Gradient Experiment; $d$ = fracture data; $\mathrm{e}=$ matrix porosity measurements. The last column summarizes the principal assumed mode of flow, as described in 5.4.1.3 and as regarded in the definition of retardation properties in Appendix K

Table 5.3 Base-case values of permeability and effective porosity assumed for altered rock hydrofacies in simulations of flow and transport. The last column summarizes the principal assumed mode of flow, as described in 5.4.2.3 and as regarded in the definition of retardation properties in Appendix K.

\section{Chapter 6}

Table 6.1 Average chemical analyses of mafic-poor Calico Hills Formation and intrusive Windy Wash Formation near CHESHIRE.

Table 6.2 Selected petrographic analyses of rocks in the vicinity of CHESHIREt. 
Table 6.3 Surface areas and XRD of devitrified tuffs of Yucca Mountaint and mafic-poor

Calico Hills Formation lava.

Table 6.4 CEC and XRD measurements of devitrified tuffs from Yucca Mountaint.

Table 6.5 Sorbing mineralogy of mafic-poor Calico Hills Formation used in near-field model.

Table 6.6 Fracture-lining mineral abundances as described by Drellack et al. (1997).

Table 6.7 Distribution of sorbing minerals in fracture flow zones in the CHESHIRE near field model.

Table 6.8 Mineral composition of the zones defined for the CHESHIRE near-field transport model

Table 6.9 Groundwater compositions from Areas 19 and 20, Pahute Mesa, Nevada Test

Site. Data from Smith et al. (1998), Smith et al. (1999), Rose et al. (1997), and IT (1999).... 6-35

Table 6.10 Ambient groundwater chemistry at $35^{\circ} \mathrm{C}$ used in the simulations.. $6-36$

Table 6.11 Aqueous species and gases used in GIMRT simulations.

Table 6.12 Minerals and solids used in GIMRT simulations. Column 1 (other than Melt glass) represents solids allowed to precipitate and dissolve in both melt glass zone and host lavas. Column 2 represents potential radionuclide-bearing precipitates, with some mass numbers omitted for convenience.

Table 6.13 Composition of average melt glass for CHESHIRE test at time $=0$ prior to onset of radionuclide decay.

Table 6.14 Dissolution reaction for melt glass. Isotopes of a given radionuclide are assumed to exhibit identical chemical behavior, so a given radionuclide represents the sum of all its isotopes. Isotope ${ }^{41} \mathrm{Ca}$ and ${ }^{241} \mathrm{Pu}$ are explicitly included so that their radioactive decay can be provided for by GIMRT. Note that one mole of glass is equivalent to about $100 \mathrm{~g}$ of glass. $6-42$

Table 6.15 Glass dissolution rate model parameters at $25^{\circ} \mathrm{C}$ $6-47$

Table 6.16 Results of GIMRT simulations of glass dissolution illustrating dependence of glass dissolution rate on secondary precipitates. Variability of secondary minerals was obtained by suppressing mineral precipitation in GIMRT. Note: $\alpha$ - and $\beta$-cristobalite were maintained in local equilibrium by using rate constant $\mathrm{k}=10^{-8} \mathrm{~mol} / \mathrm{m}^{2}$-s in runs 1,2 , 6,10 , and 11. Remainder of runs used kinetic rate law for cristobalite from Renders et al. (1995). Input for runs 1 and 2 used in the final GIMRT streamline simulations are not shown. Fluid compositions are not shown, although they were heavily factored into the choice of final set of precipitates. 6-61

\section{Chapter 7}

Table 7.1 Relationship between radionuclide class and RST radionuclide.

Table 7.2 Criteria for including radionuclides in the Cheshire near-field RST applied to decay-corrected downstream boundary flux values, both amount (moles) and activity (Bq)

\section{Chapter 8 - no tables}




\section{Chapter 9 - no tables}

\section{Chapter 10 - no tables}

\section{APPENDICES}

\section{Appendix A}

Table A.1 Radionuclides representing the RST for the CHESHIRE nuclear test conducted in Area 20 of Pahute Mesa, and identification of those considered appropriate for inclusion in the near-field simulation of radionuclide migration away from that test.

\section{Appendix B - no tables}

\section{Appendix C}

Table C.1 Streamline characteristics for the CHESHIRE problem C-10

\section{Appendix D - no tables}

\section{Appendix E - no tables}

\section{Appendix F}

Table F.1 Transmissivity and hydraulic conductivity estimates from interpretation of RSC data for U-20a \#2 Water Well.

Table F.2 Transmissivity and hydraulic conductivity estimates from interpretation of RSC data for U-20a \#2 Water Well, adjusted for overlapping intervals

Table F.3 Transmissivity and hydraulic conductivity estimates from interpretation of RSC data for well U-20n.

Table F.4 Hydrofacies defined by hydraulic conductivity ranges inferred from hydraulic testing data in U-20a \#2 Water Well and well U-20n.

Table F.5 Fracture data for core obtained from rhyolite lava flows of the mafic-poor Calico Hills Formation in U-20a \#2 Water Well, categorized by range of dip angle.

\section{Appendix $\mathbf{G}$ - no tables}

\section{Appendix $\mathbf{H}$}

Table H.1 Proportions of fractures in which hematite, calcite, zeolite, and clay fracturelining minerals are present in core samples from the ALL data set.

Table H.2 Proportions of fractures in which hematite, calcite, zeolite, and clay minerals are present in core samples from the DVT data set. 
Table H.3 Proportion of high and low mineralization zones and proportion of fractures that are mineralized within those zones for ALL data set.

Table H.4 Proportion of high and low mineralization zones and proportion of fractures that are mineralized within those zones for DVT data set.

\section{Appendix I - no tables}

\section{Appendix J}

Table J.1 Basis species used in GIMRT thermodynamic database.

Table J.2 Parameters in extended Debye-Hückel activity coefficient model as a function of temperature.

Table J.3 Logarithm of equilibrium constants (K) of aqueous reactions as a function of temperature $\left({ }^{\circ} \mathrm{C}\right)$ used in GIMRT thermodynamic database. When only one log K value is shown, $\log \mathrm{K}$ is assumed to be invariant with temperature. Data for Pu are not shown, pending Nuclear Energy Agency approval for publication.

Table J.4 Logarithm of equilibrium constants (K) of mineral solubility as a function of temperature $\left({ }^{\circ} \mathrm{C}\right)$ used in GIMRT thermodynamic data base. When only one log $\mathrm{K}$ value is shown, $\log \mathrm{K}$ is assumed invariant with temperature (see text).

Table J.5 Kinetic parameters for minerals and solids used in the GIMRT simulations consistent with rate equation (J1). Rate constant $\mathrm{k}$ in units of $\mathrm{mol} / \mathrm{m}^{2}$-sec.

Table J.6 Activation energy (Ea), in $\mathrm{kcal} / \mathrm{mol}$, for minerals and solids used in the GIMRT simulations

\section{Appendix K}

Table K.1 Radionuclide-mineral interactions described by nonelectrostatic surface complexation in the near-field model.

Table K.2 Radionuclide-mineral interactions described by Vanselow ion exchange in the near-field model.

Table K.3 Surface complexation reactions for iron oxides using the nonelectrostatic model

Table K.4 Surface complexation reactions for calcite using the nonelectrostatic model

Table K.5 Surface complexation reactions for aluminosilicates using the nonelectrostatic model.

Table K.6 Vanselow ion exchange reactions for smectite, illte/mica, and clinoptilolite. K-9

Table K.7 Parameters used to define reactions on mineral surfaces

Table K.8 Logarithm of the retardation ratios for the heterogeneous mineral distribution near-field model. Refer to Tables 5.2 and 5.3 to correlate flow condition with permeability and porosity values. 
Table K.9 Logarithm of the retardation ratios for homogeneous mineral distribution near-field model. Refer to Tables 5.2 and 5.3 to correlate flow condition with permeability and porosity values.

\section{Appendix $L-$ no tables}




\section{Executive Summary}

\section{Background and Objectives}

Increasing concern about radioactive contamination of groundwater from underground nuclear tests conducted at the Nevada Test Site (NTS) has reinforced the need for a basic understanding of how radionuclide inventories of such tests enter and migrate through groundwater. The objectives of this report are to develop, summarize, and interpret a series of detailed unclassified simulations that forecast the nature and extent of radionuclide release and near-field migration in groundwater away from the CHESHIRE test over 1,000 years. Collectively, these results are called the CHESHIRE "Hydrologic Source Term" (HST).

The CHESHIRE underground nuclear test was conducted on February 14, 1976 on Pahute Mesa (Area 20) at the NTS. Its working point was located in fractured volcanic rock, 1,167 m below the ground surface, and it had an announced yield of 200 to 500 kilotons $(\mathrm{kt})$. It is one of 76 underground nuclear tests that were fired below or within $100 \mathrm{~m}$ of the water table between 1965 and 1992 in Areas 19 and 20 of the NTS. These areas now comprise the Pahute Mesa Corrective Action Unit (CAU) for which a separate subregional groundwater flow and transport model is being developed by the U.S. Department of Energy's Underground Test Area (UGTA) Project to forecast the larger-scale migration of radionuclides from all underground tests on Pahute Mesa.

The current simulations are being developed, on one hand, to more fully understand the complex coupled processes involved in radionuclide release, with a specific focus on the CHESHIRE test. While remaining unclassified, they are as site specific as possible and involve a level of modeling detail that is commensurate with the most fundamental processes, conservative assumptions, and representative data sets available. However, the simulation results are also being developed so that they may be simplified and interpreted for use as a source term boundary condition at the CHESHIRE location in the Pahute Mesa CAU model. In addition, the processes of simplification and interpretation will provide generalized insight as to how this source term can be applied at other sites in the Pahute Mesa CAU.

The content and results of this report, as well as the overall approach to the problem documented in it, can be compared with an analogous analysis conducted by Los Alamos National Laboratory, focused on the TYBO/BENHAM tests on Pahute Mesa (Wolfsberg et al., 2001). In this work, a series of radionuclide release models at the BENHAM test, similar to, and partially supported by the CHESHIRE HST study, were used to examine specific questions related to plutonium migration between BENHAM and the ER-20-5 site, near TYBO, as well as between BENHAM and NTS boundaries. Although the main thrust of the analysis involved an intermediate scale model, many of its conclusions regarding the importance of test-related heat for moving radionuclides away from a test cavity environment are similar to those of the CHESHIRE simulations. 


\section{Overall Approach}

As in two previous reports (Tompson et al., 1999; Pawloski et al., 2000), the CHESHIRE HST simulations were developed around three fundamental tasks:

- Estimation of the abundance, spatial distribution, and chemical state of radionuclides just after the test;

- Determination of the mechanisms and rates controlling the release of radionuclides into the groundwater as a function of time; and

- Forecasting the rates of radionuclide movement away from the working point of the test for a 1,000-year timeframe, as affected by hydrothermal groundwater flow and chemical reactions.

\section{Phenomenology and Radiologic Source Term}

Because the yield and radiologic inventory of CHESHIRE are classified, several approximations were used to develop an initial setting for the simulations. First, the maximum value of the announced yield range was used to develop a conceptual model of the CHESHIRE cavity ( $80 \mathrm{~m}$ radius), melt glass mass $\left(3.5 \times 10^{5}\right.$ metric tons), and disturbed zone geometry (128 $\mathrm{m}$ radius). The collapse zone above the cavity (the chimney) is known to extend above the water table, located at a depth of $625 \mathrm{~m}$, but not completely to the ground surface. In addition, the unclassified radionuclide inventory reported for all 76 underground tests conducted below or within $100 \mathrm{~m}$ of the water table in Areas 19 and 20 (Smith, 2001) was averaged and applied as an unclassified residual inventory for the CHESHIRE test.

The averaged residual inventory includes information on 44 radionuclides associated with nuclear fuels, activation products, and fission products. Of those, 37 radionuclides were incorporated into the current transport model as its radiological source term (RST), with due recognition of their decay and ingrowth behavior. Inclusion or exclusion of radionuclides on this list was based upon their relative abundance over the 1,000-year lifetime of the analysis and additional considerations based upon their observation in the CHESHIRE cavity or chimney or in nearby monitoring wells.

Following IAEA (1998a) and our previous analyses (Tompson et al., 1999; Pawloski et al., 2000), the inventories of the 37 RST radionuclides were assumed to be partitioned into melt glass at the bottom of the cavity or distributed throughout an approximately spherical exchange volume surrounding the cavity and disturbed zone, and extending into portions of the chimney. The release of radionuclides to groundwater from this initial configuration and their subsequent migration is the subject of the remainder of the report. 


\section{Flow Model}

A transient hydrothermal model of groundwater flow through a $800 \times 300 \times$ $800 \mathrm{~m}$ prismatic volume of rock surrounding the CHESHIRE cavity, melt glass, and chimney system was developed as the basis for simulations of radionuclide transport away from the test.

A principal feature of the flow model was the inclusion of the effects of geothermal and test-related heat on groundwater flow. A 6-year record of test-related heat was available in a post-test drillback hole (U-20n PS \#1DD-H) passing through the undisturbed medium, chimney, cavity, and melt glass. Temperatures as high as $150{ }^{\circ} \mathrm{C}$ were measured in the melt glass 154 days after the test. In addition, small temperature perturbations were observed in the upper portions of a downgradient well (UE-20n \#1) 11.3 years after the test. When incorporated within the flow model, the temperature data allowed relative permeability differences between the undisturbed rock, cavity, chimney, and melt glass to be estimated. A buoyancy-driven recirculating flow system was shown to drive groundwater upward from the cavity and melt glass, through the chimney, and into the adjacent undisturbed formation. This effect was seen to last between 50 and 100 years following the test, after which a nearly steady flow field consistent with the background hydraulic gradient was reestablished. The existence of high temperatures also affected the rate of radionuclide release from the melt glass.

Another feature of the flow model was the recognition from borehole data and related hydraulic analyses that the fractured lava is markedly variable in terms of its degree of fracturing and permeability. Permeability contrasts spanning four orders of magnitude in various sections of the formation were evident. Furthermore, the spatial arrangement of zones of high and low permeability in the undisturbed rock adjacent to the test were not consistent with layer cake conceptualizations of the geologic system. An indicator-based geostatistical model was developed to represent the observed degree and spatial structure of four classes of fractured rock (hydrofacies) to which specific permeabilities were assigned in a calibration process. The geostatistical approach is a principal way to address the uncertainty in flow behavior arising from natural variability, and formed the basis for Monte Carlo flow simulations that were generated from ten permeability realizations. The calibration process was constrained by conditioning the permeability realizations on observed data and by requiring subsequent simulations to reproduce measured temperature profiles.

\section{Geochemical Processes}

In order to describe the geochemical interactions that control radionuclide release from the melt glass and exchange volume, as well as radionuclide-rock interactions along the flow path, mechanistic models were developed for kinetically controlled glass dissolution and radionuclide precipitation and equilibrium controlled aqueous speciation, surface complexation, and ion exchange.

The glass dissolution model was developed from a fundamental mechanistic model, and was then simplified for use in the particle code. Given the considerable uncertainty regarding the physical characteristics of the melt glass and coupled 
processes that affect glass dissolution, the glass dissolution model was implemented so that it generated a conservative dissolution rate (that is, one that will not underestimate release of radionuclides from the melt glass). This implementation of the model was chosen for the base case calculations in this report. A sensitivity study explored the implications of a lower glass dissolution rate on the downstream flux of radionuclides.

A non-electrostatic surface complexation model was used to model $\mathrm{pH}$ dependent sorption of radionuclides to iron oxide, calcite, and aluminosilicates. The Vanselow ion exchange formalism was used to describe ion exchange reactions among radionuclides and $\mathrm{Na}, \mathrm{Ca}, \mathrm{K}$, and $\mathrm{Mg}$ on smectite, illite/mica, and zeolite. Sorption to colloids was treated in a rudimentary fashion by modeling colloids as mobile sorbing minerals. The mechanistic sorption models were also simplified to a linear $\mathrm{K}_{\mathrm{d}}$ model for use in the particle code. A sensitivity calculation was employed to evaluate the uncertainty in surface complexation and ion exchange constants and its impact on the downstream flux of radionuclides.

An important feature of the transport model was the recognition that the spatial distribution of sorbing minerals in the fractured lava is markedly variable, and that this variability will influence radionuclide migration. Thus, analyses of the mineralogy at the CHESHIRE site and its near-field environment were used to develop indicator-based geostatistical models of the spatial distribution of four important sorbing minerals, with a fifth being assumed to be present everywhere. The geostatistical approach addresses the uncertainty in sorption arising from natural mineralogic variability. Ten separate mineralogic realizations were developed. When coupled with the ten flow simulations generated from the ten permeability realizations, this yielded a set of 100 reactive transport realizations.

\section{Reactive Transport Simulations}

The purpose of the reactive transport simulations was to forecast the release and migration of the RST within the transient, thermally driven hydrologic regime for a period of 1,000 years. Results were presented as mass flux profiles for individual radionuclides at a control plane crossing the downgradient UE-20n \#1 well.

Because of the computational complexity involved in coupling a transient, three-dimensional hydrothermal flow simulation to a three-dimensional reactive transport simulator based upon mechanistic geochemical models (no such suitable simulation code exists today), a two-pronged approach was used to adapt two existing reactive transport models to the CHESHIRE hydrothermal flow configuration. In the first, a simplified and efficient particle-based model was used to look at the full 1,000-year scenario, while in the second, a more intensive streamline-based model was used to look at behavior between 100 and 1,000 years.

The particle model was based upon three important approximations. First, only a simplified linear representation of sorption behavior could be addressed, which is equivalent to a retardation factor-based method of treating sorption. Second, the glass dissolution rate could only be considered a function of temperature and was otherwise constant and independent of local geochemistry. Third, because aqueous speciation, 
precipitation, and $\mathrm{pH}$-dependent reactions could not be handled in the model, the influence of changing geochemistry could not be accounted for. Because of its efficiency, the particle model was used for all 100 Monte Carlo-based transport simulations. Although particle models can address matrix diffusion, this effect was only examined in a sensitivity calculation outside of the Monte Carlo simulations.

The streamline model was based upon multiple one-dimensional reactive transport simulations using the GIMRT code (Steefel and Yabusaki, 1996), similar to the approach utilized in our previous work (Tompson, et al., 1999; Pawloski et al., 2000). Although this model is more capable of handling complex geochemical behavior, especially at earlier times when the interactions associated with high temperature are important, the viability of the streamline method is severely limited by transient nature of flow, which was quite significant during the first 100 years of the simulation, and it cannot address the effects of local transverse dispersion. Thus, this model could only be run after the first 100 years. Because of the higher computational complexity associated with this approach it was only run for one of the Monte Carlo simulations (a "base case"), did not include matrix diffusion, and was initialized with the particle model results obtained for that realization at 100 years. Beyond the first 100 years, reasonable comparisons between the results of both streamline and particle models were achieved, in part because the simpler geochemical models employed in the particle model were developed from simplifications to the GIMRT mechanistic sorption and glass dissolution models.

Outside of the 100 Monte Carlo simulations, several sensitivity simulations about the base case realization were conducted with the particle model. These were designed to examine the overall uncertainty produced by (1) use of alternate conceptual geologic models, (2) exclusion of test-related heat, (3) inclusion of matrix diffusion, (4) inclusion of local longitudinal and transverse dispersion, (5) use of a reduced glass dissolution rate, and (6) use of smaller sorption coefficients for the sorbing minerals.

\section{Larger Scale Transport Issues}

The current flow and transport modeling results were developed under detailed, site-specific conditions for the CHESHIRE test and have provided numerous insights into the nature of radionuclide release from the test. Nevertheless, it is important to consider how the results may be interpreted for use in large-scale CAU simulations, both (1) at the CHESHIRE location on Pahute Mesa, as well as (2) at other locations in the Pahute Mesa CAU.

In this report, several base assumptions and important factors were considered for the CHESHIRE location on Pahute Mesa. For example, the predicted radionuclide fluxes are matched to an effective flow rate through our near-field modeling domain. When applied to the CHESHIRE location in the CAU model, the CAU model flow rate may or not be similar, and some approximate scaling of the current results may be required.

Moreover, the predicted radionuclide fluxes exhibit macrodispersion and a mean retardation effect caused by the model of physical and chemical heterogeneity 
employed in our near-field simulations. These effects can be measured from the model results and applied in the CAU model at the CHESHIRE location.

The results of the current CHESHIRE HST model are presented as a series of integrated radionuclide flux profiles past a control plane. Because they are averaged quantities, they do not reflect specific, smaller-scale details in the near-field model, such as the spatial variation of concentration within the domain or spatial variation of flux at the exit plane. This dilution effect needs to be recognized and addressed, if possible, in the CAU transport model. In addition, by replicating these flux profiles in the largerscale model, radionuclide mass is conserved, but radionuclide concentrations are not. Other potential metrics for transferring results to a CAU model have been identified.

The current CHESHIRE near-field model was developed under site-specific conditions assuming an upper-bound announced yield, which affects the size of the cavity and the volume of melt glass, and a radiologic source term averaged for all tests on Pahute Mesa and applied at CHESHIRE. Classified simulations will be required to assess the impacts of these approximations.

\section{Conclusions}

Some of the more basic issues and findings from these simulations include:

- The release of radionuclides from the melt glass is generally slow and long lasting, regardless of their retardation characteristics in the geologic medium. The release rates can be higher, however, at higher temperatures, and this has the greatest impact on the migration of nonsorbing, glass-bound radionuclides such as ${ }^{36} \mathrm{Cl}$.

- The release of radionuclides from the exchange volume is generally quicker and more short-lived than release from the melt glass, although significant radionuclide retention in the near field occurs for more sorptive radionuclides.

- The flux of radionuclides past the UE-20n \#1 control plane is affected by heterogeneity in the physical and reactive properties of the geologic medium. The inclusion of the complex heterogeneous physical properties is necessary to reproduce parametric data and key observations of temperature and tritium concentration made in nearby drill holes.

- The fluxes of several short-lived radionuclides past the UE-20n \#1 control plane decrease to a relatively insignificant level within 400 years from the test date.

Other findings in this report include:

- An improved approach for identifying a comprehensive, yet unclassified RST was developed for application at the CHESHIRE site. To our knowledge this is the first time an objective and systematic approach has been 
advanced - beyond stand-alone criteria of half-life and dose equivalence to evaluate radionuclides of significance for transport calculations. It is a designed to be conservative, comprehensive, and transferable.

- Residual heat from the test, manifested as high initial temperatures in the melt glass, has numerous important effects on flow, transport, and reaction phenomena in the near-field system;

- Simple conceptualizations of the permeability distribution involving layered or uniform structures cannot be fully calibrated to available data and must be considered unrealistic;

- Geostatistical representations are needed to represent spatial variability in the permeability and mineralogy distributions. Monte Carlo simulations spanning a range of plausible and conditioned permeability and mineralogy realizations indicate a significant degree of variability - or uncertainty - with regard to the flux of radionuclides out of the near field;

- Melt glass dissolution rates are highly sensitive to variations in temperature, reactive surface area, silica concentration and $\mathrm{pH}$, and the secondary minerals that precipitate in the glass zone;

- The effects of coupled radionuclide decay and ingrowth can be important and are observable in the current simulations in the case of the ${ }^{241} \mathrm{Pu} \rightarrow$ ${ }^{241} \mathrm{Am} \rightarrow{ }^{237} \mathrm{~Np}$ decay chain.

- All 37 radiologic source term radionuclides but one contribute to at least $0.1 \%$ of the $\alpha, \beta$, or electron capture/isomeric transition mole and/or curie flux at the downstream boundary at some time over the 1000 year simulation time period.

- Proper use of the HST results in a large-scale (CAU) model will require compatibility of the effective (a) mean flow rates through the source locations, (b) dispersion rates as computed directly in the current model or specified in terms of marcodispersivities, and (c) retardation properties of the medium for each radionuclide. 


\section{Introduction}

\section{$1.1 \quad$ Background}

There is increasing concern about environmental risks posed by radionuclides produced by underground nuclear tests (USDOE, 1997a,b; IAEA, 1998a,b,c). These risks are dependent, in large part, on the physical and chemical mechanisms that control how radionuclides are introduced and transported in groundwater to various receptors in the biosphere. In Southern Nevada and other continental testing locations in the US, environmental concerns include the potential contamination of groundwater and its effect on domestic or agricultural uses, as well its ultimate discharge into surface water supplies where collateral ecological impacts may occur (USDOE, 1997a).

More than 800 nuclear tests were conducted underground at the Nevada Test Site (NTS), roughly a third of which were beneath the water table (USDOE, 1997b, 2000). The radionuclide inventory of below-water table tests alone currently includes over $10^{8}$ curies (Ci) of radioactivity (Wild et al., 1998). As most underground testing locations are hundreds of meters or more beneath the ground surface, they are difficult to access for characterization purposes, much less for removing radioactive contaminants or assessing their tendency to move toward public or private sources of water. As a result, the assessment of the potential for test-related radionuclides to enter and move through groundwater has tended to rely heavily on the use of computer simulations (USDOE, 1997a; IAEA, 1998b; Tompson et al., 1999; Pohll et al., 1999; Glascoe et al., 2000; Maxwell et al., 2000; Pawloski et al., 2000). At the NTS, the U. S. Department of Energy's Underground Test Area (UGTA) Project coordinates all such modeling efforts.

Although such models are designed to better understand the complex mechanisms involved in radionuclide release and migration, they serve equally well as tools to evaluate radionuclide migration and associated uncertainties, and are also useful for designing data acquisition strategies for future validation and characterization purposes.

\section{$1.2 \quad$ Objectives}

The objectives of this report are to develop, summarize, and interpret a series of detailed unclassified simulations that forecast the nature and extent of radionuclide release and near-field migration in groundwater away from the CHESHIRE underground nuclear test at Pahute Mesa at the NTS over 1000 yrs. Collectively, these results are called the CHESHIRE Hydrologic Source Term (HST).

The CHESHIRE underground nuclear test was one of 76 underground nuclear tests that were fired below or within $100 \mathrm{~m}$ of the water table between 1965 and 1992 in Areas 19 and 20 of the NTS. These areas now comprise the Pahute Mesa Corrective Action Unit (CAU) for which a separate subregional scale flow and transport model is being developed by the UGTA Project to forecast the larger-scale migration of radionuclides from underground tests on Pahute Mesa. 
The current simulations are being developed, on one hand, to more fully understand the complex coupled processes involved in radionuclide migration, with a specific focus on the CHESHIRE test. While remaining unclassified, they are as site specific as possible and involve a level of modeling detail that is commensurate with the most fundamental processes, conservative assumptions, and representative data sets available. However, the simulation results are also being developed so that they may be simplified and interpreted for use as a source term boundary condition at the CHESHIRE location in the Pahute Mesa CAU model. In addition, the processes of simplification and interpretation will provide generalized insight as to how the source term behavior at other tests may be considered or otherwise represented in the Pahute Mesa CAU model.

\subsection{Additional Background on the Purpose of this Report}

The CHESHIRE HST modeling application described in this report is unclassified and is consistent with the UGTA Project strategy, as identified in the Federal Facility Agreement and Consent Order (FFACO, 1996, 2000). In general, HST models will typically include both unclassified and classified components, each of which will be used as input to unclassified and classified subregional CAU models, respectively. As described in this report, a significant effort was made to construct an approach in which an unclassified HST could be developed at a site on Pahute Mesa using existing unclassified data. This work will be reviewed for technical merit and, upon finalization, will be made available to the public. Following the review and release of the unclassified application, a classified version of this HST will be developed using the same approach, but incorporating classified information to more closely describe the actual conditions related to the test. The classified HST will have a limited release due to controls on classified information. If additional data are developed or collected, the HST will be updated, incorporating new data as necessary.

\section{$1.4 \quad$ Pahute Mesa Models}

At the current time, there are three flow and transport models being developed under the UGTA Project to study radionuclide migration in groundwater on Pahute Mesa.

- The CHESHIRE HST near-field modeling application is the subject of this report. Its results provide source term input into the Pahute Mesa CAU subregional transport model.

- The Pahute Mesa CAU subregional flow and transport model is being developed by the International Technology (IT) Corporation to forecast radionuclide migration away from all underground tests on Pahute Mesa. It will be used to predict the location of the radionuclide contaminant boundary over 1000 years, as defined in the FFACO $(1999,2000)$. It is dependent on input from near-field HST models and is constrained, in part, by boundary conditions derived from the regional scale NTS groundwater flow model (DOE, 1997a). 
- The TYво/BENHAM intermediate-scale flow and transport model is being conducted by Los Alamos National Laboratory (Wolfsberg et al., 2001). In this work, a series of radionuclide release models at the BENHAM test, similar to, and partially supported by the CHESHIRE HST study, are being used to examine specific questions related to plutonium migration between BENHAM and the ER-20-5 site, near TYBO, as well as between BENHAM and NTS boundaries. Although the main thrust of the analysis involved an intermediate-scale model, many of its conclusions regarding the importance of melt glass dissolution and test-related heat for moving radionuclides away from a test cavity are similar to the CHESHIRE simulations.

\section{$1.5 \quad$ Overall Approach}

The CHESHIRE test was chosen for the current HST analysis because of its central location at Pahute Mesa and because additional data were collected during a field characterization and radionuclide migration study between 1976 and 1990 (Sawyer et al., 1999). HST modeling was based upon extensive data collected in a post-test hole into the chimney-cavity environment (U-20n PS \#1DD-H) and later construction of a downgradient monitoring well (UE-20n \#1) in which radionuclides were identified. The post-test hole was recompleted in 1998 and continues to provide sample information. Altogether, the site provides a unique opportunity to investigate radionuclide evolution and migration over time.

As in previous hydrologic source term studies (Tompson et al., 1999; Pawloski et al., 2000), a modicum of unclassified data pertinent to its hydrologic, geologic, and geochemical characteristics of the CHESHIRE test exists. The simulations in this report are supported by existing data, analyses, and interpretations that have been made throughout the NTS during underground nuclear testing program activities and previous and ongoing studies related to radionuclide migration in the subsurface (e.g., Borg et al., 1976; Hoffman et al., 1977; Bryant, 1992; Smith, 1995; Thompson, 1996; IAEA, 1998a; Sawyer et al., 1999; Kersting et al., 1999). However more complete data are still largely unavailable, and, as a result, the results of this study must still be used and interpreted accordingly. Most importantly, because the exact yield and radiological inventory of this test are classified, an averaged radionuclide inventory is applied for these unclassified simulations.

The CHESHIRE HST simulations were developed around three fundamental tasks:

- Estimation of the abundance, spatial distribution, and chemical state of radionuclides just after the test;

- Determination of the mechanisms and rates controlling the release of radionuclides into the groundwater as a function of time; and 
- Forecasting the rates of radionuclide movement away from the working point of the test for a 1,000-year timeframe, as affected by hydrothermal ground water flow and chemical reactions.

\section{$1.6 \quad$ Updated Elements}

In many respects, the modeling approach used for evaluating the HST for CHESHIRE is unchanged from previous simulations for Frenchman Flat. For example, the current work is focused only on processes that have occurred well after the nuclear test, as opposed to the more dynamic processes that take place within seconds to hours after detonation. The initial conceptualization of the post-test environment-the starting point for our simulations-is based upon an approximate, and possibly oversimplified, understanding of the phenomenology of underground nuclear tests. This understanding relates how underground nuclear explosions affect the surrounding geologic media and groundwater, and initially distribute radionuclides in the near field after detonation. Despite uncertainties, our approach to establishing the initial configuration of the post-test environment is largely unchanged from previous simulations.

In many other respects, however, the modeling framework builds upon previous Frenchman Flat simulations. Modifications have been incorporated to evaluate different geologic settings and additional data, and to develop our understanding of related flow and transport processes. Modifications are particularly evident in the following five aspects:

- The current simulations specifically address evaluating a hydrologic source term in a fractured volcanic rock, different from the alluvium considered at Frenchman Flat. Flow and transport processes in fractured rock are much more complex than in the porous alluvium. The current simulations have required consideration of flow and reaction processes in heterogeneous fractured rock, as well as the influence of diffusion and chemical reactions in the associated rock matrix.

- The list of radionuclides considered in the current simulations is more comprehensive than that addressed in the previous Frenchman Flat simulations. The criteria for selecting radionuclides for consideration in the model were reevaluated and modified to reflect concerns with daughter product ingrowth and a need for a more systematic and enumerated selection process than was previously used. A total of 37 distinct radionuclides are now considered. Because the inventory of CHESHIRE is classified, the current calculations use an unclassified mean inventory determined by dividing the total unclassified inventory for all tests detonated below or within $100 \mathrm{~m}$ of the water table in Areas 19 and 20 on Pahute Mesa at the NTS (Smith, 2001) by 76, the total number of such tests and apply this mean inventory to the CHESHIRE test.

- The geochemical speciation, ion exchange, and surface complexation models employed in the current simulations have been markedly 
improved, while the sensitivity and influence of the glass dissolution model on the overall release of radionuclides from the melt glass is now more seriously appreciated.

- The current simulations address more closely several physical and chemical effects associated with residual, test-related heat. One of the more significant improvements in this work involves the recognition and incorporation of the influence of test-related heat on the dynamics of groundwater flow and on the nature of glass dissolution. Temperature observations at two wells near CHESHIRE have been used to calibrate a hydrothermal groundwater flow model and demonstrate the importance of buoyancy-driven, upward flow away from the test for up to approximately $100 \mathrm{yr}$ after the explosion.

- Geostatistical methods are used to address uncertainty in flow and transport behavior arising from natural variability in the physical and chemical properties of the volcanic rock. Statistical realizations of rock permeability and mineralogic composition were generated in order to preserve, in a basic sense, observed levels of spatial variability. In turn, these led to a range of plausible flow and transport scenarios that are both consistent with observed rock characteristics and representative of uncertainty produced by spatial variability in these characteristics.

\section{$1.7 \quad$ Report Organization}

This report has two parts: the main body that highlights data, decisions and results related to the HST simulations, and appendices that describe in detail various decision and application processes that guided our progress. The following chapters and appendices describe:

- Modeling approach around which our simulations are constructed.

- Information on the CHESHIRE test.

- Radionuclide selection.

- Development of a posttest hydrothermal flow model.

- Discussion of the geochemical processes used in the reactive transport simulations.

- Description and interpretation of the reactive transport simulations at the CHESHIRE site, and application for CAU-scaled models.

- Discussion of large-scale transport issues.

- A summary of results, conclusions, and recommendations. 
- Numerous detailed appendices describing additional information on the radionuclide source term, equations used, streamline transport model, particle transport model, comparisons of GIMRT and particle transport models, development of hydraulic properties, geostatistical applications, variability in mineralogy, illustrative one-dimensional streamline simulations, thermodynamic and surface complexation data and a model parameter road map. 


\section{Modeling Approach and Model Selection}

The technical approach used in this project builds upon that used for unclassified and classified hydrologic source term calculations for the Frenchman Flat Corrective Action Unit (Tompson et al., 1999; Pawloski et al., 2000). It is based on several distinct characterization and modeling efforts that are ultimately linked together. Principal elements of these tasks are outlined below.

\section{$2.1 \quad$ Initial Setting}

Strictly speaking, the migration of test-related radionuclides begins at the time of detonation as gases are distributed and condensed inside the cavity and exchange volumes. However, the most logical starting point - or initial setting - for examining radionuclide migration in groundwater will be in the days to months following detonation when ground water returns to the cavity and chimney and the complex dynamics initiated by the detonation have ended. As described in Chapters 3 and 4, the initial physical and radiologic setting for the simulations is based on an analysis of nuclear test effects and explosion phenomenology and an approximation of the composition and distribution of the radiologic source term (RST). A protocol was developed to identify the radionuclides that comprise the RST applied at the CHESHIRE site using an unclassified average radionuclide inventory developed for Pahute Mesa. Additional other criteria related to the relative abundance of radionuclides over the $1000-y r$ lifetime of this study and consideration of their decay and ingrowth behavior were also used in this process. Inventory and chemical partitioning data were used to describe the distribution of radionuclide species in the melt glass and exchange zones surrounding the CHESHIRE working point. The existence of a 6-year record of residual test-related heat in a post-test hole motivated the need for a transient, hydrothermal flow and transport model as a means to investigate the impacts of heat on flow and chemical reaction processes.

\section{$2.2 \quad$ Flow Field Model}

The release of radionuclides from the initial setting will be influenced by groundwater flow and transport processes, variable temperature conditions, dissolution of melt glass, geochemical behavior associated with speciation, sorption or precipitation reactions, and colloidal-facilitated transport. The mathematical models that describe these processes are described in Appendix B. In the most ideal situation, we would incorporate these physical and chemical processes into a fully coupled, threedimensional hydrothermal flow and reactive transport simulator. However, since no such model was available at the time of this report, we decided to separate the hydrothermal flow simulations from the reactive transport simulations and consider the flow simulation as a separate, self-contained analysis. This can be done because the concentrations of radionuclides and other chemical species are not expected to influence the flow processes. 
As described in Chapter 5 and the preliminary work of Maxwell et al. (2000), the NUFT model (Appendix B; Nitao, 1998, 1999) was used to develop a threedimensional, transient groundwater flow model within the near-field environment surrounding the CHESHIRE test, incorporating zones affected by the underground nuclear explosion and the in situ fractured volcanic rock. A principal feature of this model was the inclusion of the effects of geothermal and residual test-related heat on groundwater flow and the use of pretest, posttest, and down-gradient temperature data to calibrate physical properties and determine the overall impacts of test-related heat over the 1000-yr simulation period. Hydraulic data from boreholes were used to determine the degree of fracturing and permeability in the fractured lava. The flow simulations reviewed in this report are an outgrowth of the preliminary work of Maxwell et al. (2000) in which simple conceptual models were used to gain initial perspectives on the role of nonisothermal flows. Additional structural detail in the fractured rock property distributions was represented in order to reproduce observed spatial variability. Specifically, an indicator-based geostatistical model was developed to represent four classes of fractured rock (hydrofacies) to which specific permeabilities were assigned in a calibration process.

\subsection{Reactive Transport Models}

For our HST simulations, the reactive transport model must utilize the transient flow results from the NUFT model and incorporate geochemical models of kinetically-controlled glass dissolution and radionuclide precipitation as well as equilibrium controlled aqueous speciation, surface complexation, and ion exchange in order to forecast radionuclide migration away from CHESHIRE. Because of computational complexities involved in including full mechanistic (and temperaturedependent) models of these processes (Chapter 6 and Appendix B) within the threedimensional setting of the problem, a two-pronged approach was used to adapt two existing reactive transport models to the CHESHIRE hydrothermal flow configuration. In the first, a simplified and efficient particle-based model was used to look at the full 1,000-year time frame, while in the second, a more intensive streamline-based model was used to look at behavior between 100 and 1,000 years.

The particle model (Appendix D) approach was based upon three important approximations that limited the complexity of processes that could be addressed. First, only a simplified linear representation of sorption behavior could be addressed, which is equivalent to a retardation factor-based method of treating sorption. Second, the glass dissolution rate could only be considered a function of temperature and was otherwise constant and independent of local geochemistry. Third, because aqueous speciation, precipitation, and $\mathrm{pH}$-dependent reactions could not be handled in the model, their influence on the results could not be accounted for.

The streamline model (Appendix C) approach was based upon multiple onedimensional reactive transport simulations using the GIMRT code (Steefel and Yabusaki, 1996), similar to the approach utilized in our previous work (Tompson, et al., 1999; and Pawloski et al., 2000). Although this model is capable of handling complex geochemical behavior, especially at earlier times when the interactions associated with high temperature are important, the viability of the streamline method is severely 
limited by transient nature of flow, which was quite significant during the first 100 years of the simulation. Thus, this model could only be run after the first 100 years of flow.

\subsection{Geochemical Processes}

In order to describe the geochemical interactions that control radionuclide release from the melt glass and exchange volume, as well as radionuclide-rock interactions along the flow path, mechanistic models were developed for kinetically controlled glass dissolution and radionuclide precipitation and equilibrium controlled aqueous speciation, surface complexation, and ion exchange (Chapter 6). These models were either incorporated into the GIMRT streamline model directly or simplified for use in the particle model.

The glass dissolution model predicts the rate at which glass-bound radionuclides are introduced into the groundwater. The kinetic rate law describing glass dissolution includes dependencies on temperature, reactive surface area (measured in recent laboratory experiments), $\mathrm{pH}$, and silica concentrations in solution. The glass dissolution model was developed from a fundamental mechanistic model and incorporated into the GIMRT streamline code. It was also simplified to a temperaturedependent constant (independent of local geochemistry) for which bounding values were chosen for use in the particle code.

A non-electrostatic surface complexation model was used to model $\mathrm{pH}$ dependent sorption of radionuclides to iron oxide, calcite, and aluminosilicates. Sorption to colloids was treated in a rudimentary fashion by modeling colloids as mobile sorbing minerals. Although the temperature dependence of glass dissolution and reactions among non-radionuclide-bearing aqueous species and minerals were accounted for, a temperature of $25^{\circ} \mathrm{C}$ was assumed for all reactions involving radionuclides owing to lack of data at elevated temperatures. The mechanistic sorption models were incorporated into the GIMRT streamline code and simplified to a linear $\mathrm{K}_{\mathrm{d}}$ model for use in the particle code.

The chemical reaction models built into the GIMRT streamline model were developed in a series of one-dimensional test problems. These test problems were the principal building blocks for the streamline model, and they were important for interpretive and diagnostic purposes before any three-dimensional simulations were conducted. The one-dimensional models were also used to develop a suite of illustrative comparison problems for both the GIMRT streamline and particle models (Appendix E). Comparisons allowed the viability and applicability of the simplified particle model to be demonstrated.

\subsection{Reactive Transport Simulations}

The purpose of the reactive transport simulations (Chapter 7) was to forecast the release and migration of radionuclides out of the near field within the transient, thermally-driven hydrologic regime for a period of 1,000 years. Results were presented 
as mass flux profiles for individual radionuclides at a control plane crossing the downgradient UE-20n \#1 well.

Because of its efficiency, the particle model was used for a series of 100 Monte Carlo-based reactive transport simulations that bounded the uncertainty of hydraulic and mineralogical heterogeneity on the transport results. Because of its higher computational complexity, the GIMRT streamline model was run for only a base case realization, did not include matrix diffusion, and was initialized with the particle model results obtained for that realization at 100 years.

In addition, several sensitivity simulations about the base case transport simulation were conducted with the particle model. These were designed to examine the overall uncertainty produced by (1) use of an alternate conceptual geologic models, (2) exclusion of test-related heat, (3) inclusion of matrix diffusion, (4) inclusion of local longitudinal and transverse dispersion, (5) use of a reduced glass dissolution rate, and (6) use of smaller sorption coefficients for the sorbing minerals.

\section{$2.6 \quad$ Upscaling of Results}

Although the current modeling results were developed under detailed, sitespecific conditions for the CHESHIRE test, it is important to consider how they may be interpreted for use in large-scale CAU simulations, both (1) at the CHESHIRE location on Pahute Mesa, as well as (2) at other locations within the Pahute Mesa CAU. In Chapter 8 , several base assumptions and important factors were considered, including:

- Matching the effective permeability and flow rate between the current model and the CAU model;

- Estimating the effective magnitudes of macrodispersion and retardation in the current model for use in the CAU model;

- Recognizing the effects of dilution in transferring the integrated flux profiles determined in the near-field model to the CAU model;

- Recognizing that some aspects of the results will be affected by the approximations required to keep the simulations unclassified. 


\section{ChESHIRE Test Overview and Model}

\subsection{History}

The CHESHIRE underground nuclear test was conducted on February 14, 1976, in fractured volcanic rocks of Area 20, Pahute Mesa, Nevada Test Site (Figure 3.1). The device was emplaced in drill hole U-20n at 1,167 m below the ground surface and $542 \mathrm{~m}$ below the static groundwater level (Figure 3.2). As described in USDOE (2000), CHESHIRE had an announced yield of 200 to $500 \mathrm{kt}$. Its official yield remains classified. No crater formed at the ground surface (Carlson and Wagoner, 1991), although geophone records indicate that cavity collapse probably occurred before posttest drilling operations began the day after detonation. Cable length information indicates the chimney formed by cavity collapse reached higher than the measured water table (Jorgensen, 1987). No release of radioactivity from the test occurred within the $24 \mathrm{hr}$ monitored for containment. The cross section in Figure 3.2 shows an estimated explosion cavity of radius $R_{c} \sim 80 \mathrm{~m}$, calculated from the upper level of the yield range, along with a chimney extending above the water table.

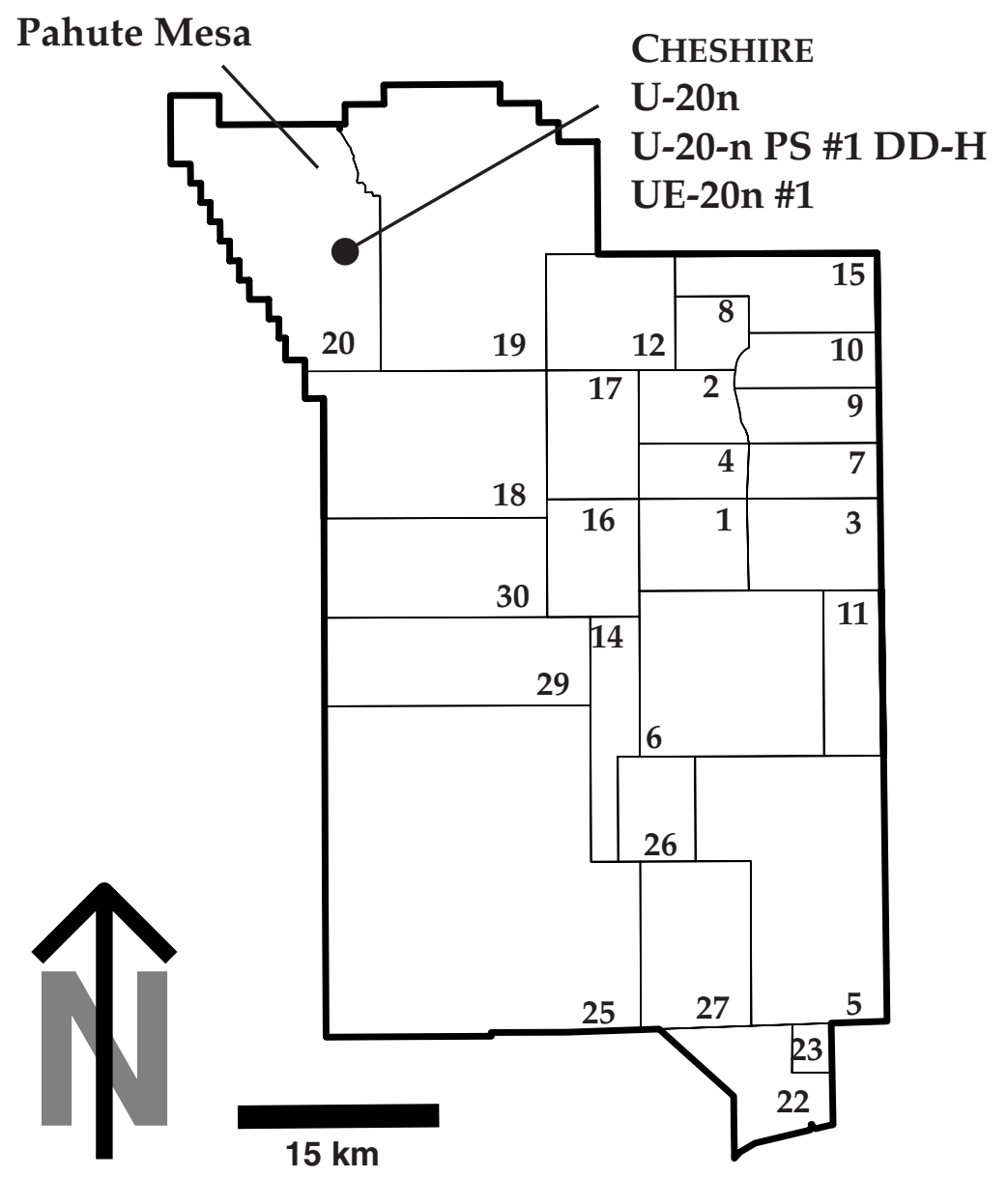

Figure 3.1 The Nevada Test Site and locations of CHESHIRE, Area 20, and Pahute Mesa. 


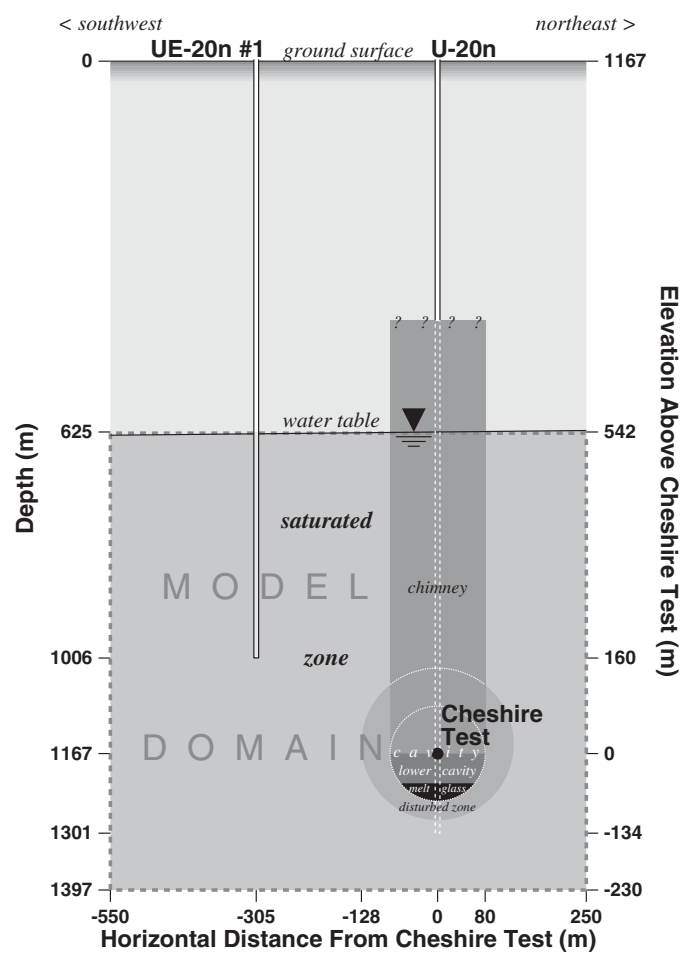

Figure 3.2 Cross-sectional view of the CHESHIRE site, oriented from northeast to southwest, parallel to the regional groundwater flow gradient. At hole U-20n, location of the CHESHIRE test, the working point is shown, along with the estimated cavity (inner circle) and exchange volume (outer circle), as well as the chimney zone and melt glass zone (black).

The emplacement hole penetrated tuffs and a succession of rhyolite lava flows common on Pahute Mesa. A bit unusual was the identification of an intrusive dike at the working point location. Chapter 5 discusses the lithology of the area.

Figures 3.3 and 3.4 show nearby holes U-20a \#2 water well, U-20n PS \#1 DD-H, and UE-20n \#1, which each contributed data to this study. Temperature logs acquired in U-20n before the CHESHIRE test, and in U-20n PS \#1 DD-H and UE-20n \#1 at various times after the test, provided data used to determine test-related temperature effects and calibration data for the flow model.

- Hole U-20a \#2 water well, 91 m west of U-20n, was originally drilled and tested in the 1960s to characterize the hydrologic conditions in this area when Pahute Mesa was initially explored as an underground testing area. Hydrologic test data were reinterpreted for this study and provided information on hydraulic conductivities at the CHESHIRE site.

- Hole U-20n PS \#1, collared 381 m southwest from U-20n, was drilled 1 day (d) after the CHESHIRE detonation to recover samples from the cavity area to determine device performance. Over time, four successive holes were sidetracked off U-20n PS \#1 to recover samples, and were plugged and abandoned. In June 1976, the successful sidetrack hole, U-20n PS \#1 
$\mathrm{DD}$, was converted to a radionuclide migration study hole and renamed U-20n PS \#1 DD-H (H signifying hydrologic hole). Seventeen solid samples were collected $128 \mathrm{~d}$ after the test. By this time, just four months after the test, water levels in the cavity/chimney region had returned, approximately, to their pre-test levels. Water samples were collected $212 \mathrm{~d}$ after the test from the lower cavity, and various hydrologic tests were conducted. Operational problems caused the pump and assorted tubular material to be abandoned in the hole. After remedial work, additional water samples were pumped from the hole near the working point in 1983 and 1984. Additional water was pumped from the chimney region higher in the hole during 1985. Hole U-20n PS \#1 DD-H was recompleted in 1998, and water samples were collected from near the cavity and chimney in 1998 and 1999. This hole is currently a long-term sampling site.

- In 1987, hole UE-20n \#1 was drilled 305 m southwest and down-gradient of U-20n as part of a dedicated radionuclide migration study of the CHESHIRE test (Sawyer et al., 1999; Erikson, 1991). Water samples were pumped from this hole in 1987 and 1988.

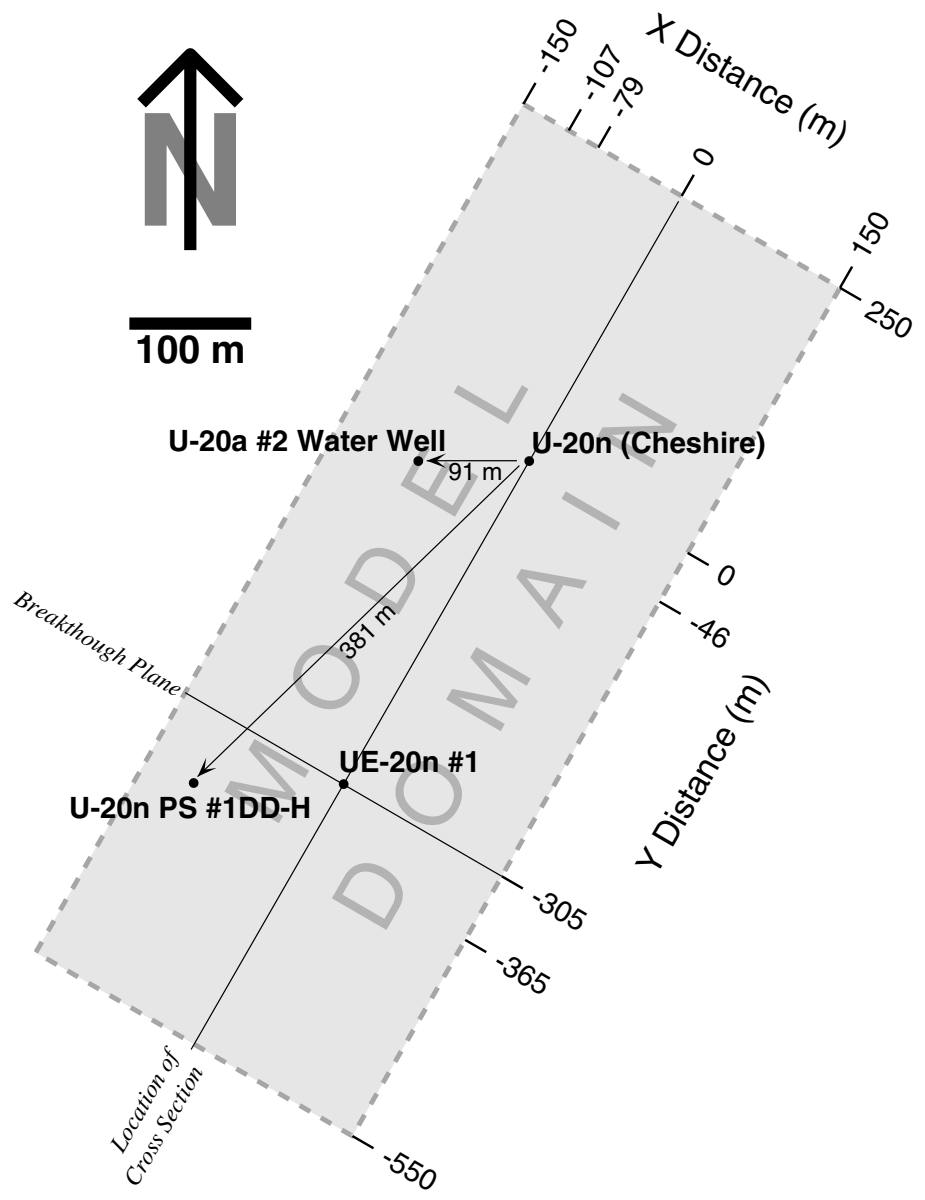

Figure 3.3 Plan view of the Cheshire area, oriented from the northeast to the southwest, paralleling the regional groundwater flow gradient. Included are the emplacement hole U20n, posttest hole U-20n PS \#1DD-H, and characterization holes UE-20n \#1 and U-20a \#2 water well. 


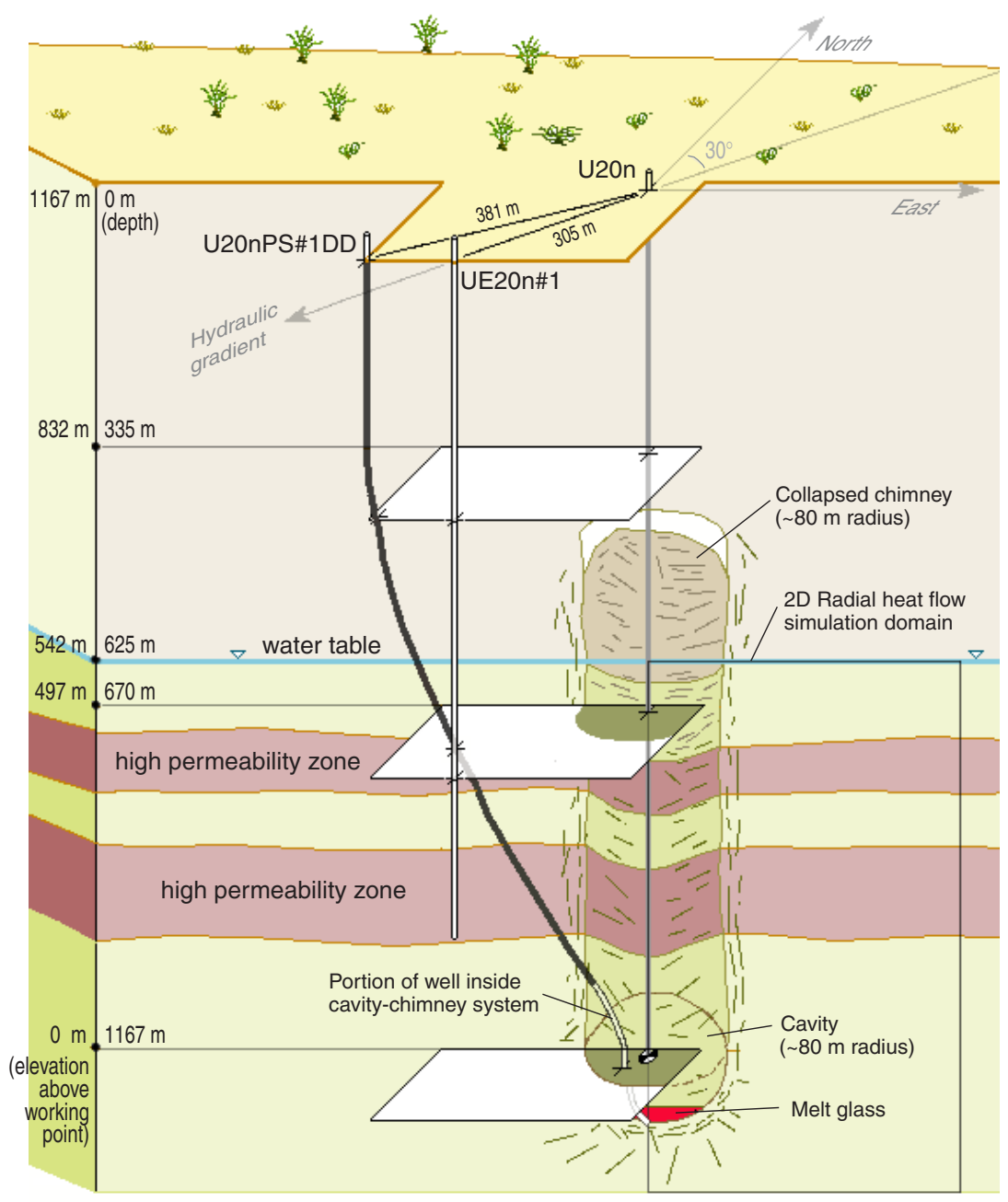

Figure 3.4 Conceptual view of the near-field CHESHIRE test environment showing the emplacement hole (U-20n), curvilinear posttest hole (U-20n PS \#1 DD-H) and the radionuclide migration study hole (UE-20n \#1).

\subsection{Nuclear Test Effects}

\subsubsection{Phenomenology}

The detonation of the nuclear device releases an immense amount of energy that vaporizes the device canister and rock in a local region surrounding the testing point (Germain and Kahn, 1968; Borg et al.,1976; Office of Technology Assessment 1989; and IAEA, 1998b). High temperatures and a compressive shock wave generated by the test produces a cavity and fracture or alter the formation beyond the cavity wall (Figure 3.5). Combined vaporization and compression of the original media creates a cavity void. Molten rock lines the cavity wall. An estimate of the cavity size is a function of the energy of the explosion, its depth of burial, and the strength of the geologic media. The cavity reaches maximum size about $500 \mathrm{~ms}$ after detonation. For tests conducted in the saturated zone, groundwater vaporizes in the immediate cavity region, and 
groundwater mounding can occur further away, which eventually relaxes over time (Knox et al., 1965; Borg et al., 1976; Burkhard and Rambo, 1991).

In the seconds and minutes following detonation, temperatures cool, gas pressures dissipate, and components of the cavity gas begin to condense in an order determined by their relative vapor pressures. First among these components are the rock and heavier radionuclide elements that, along with molten rock lining the cavity walls, tend to accumulate as a melt glass puddle at the bottom of the cavity. Within hours to days after the test, the overlying rock collapses into the cavity, creating a rubblized chimney column that may extend to the ground surface where a crater forms. Groundwater will begin to refill the cavity if the detonation point was initially below the water table. Temperature increases related to the nuclear explosion last for at least tens of years. Figure 3.6 conceptually relates the time history of dynamic processes associated with an underground nuclear test-nuclear explosion, vaporization, cavity growth, cavity collapse and chimney formation, return of groundwater, and reduction of test-related temperature effects.

HST simulations for CAMBRIC assumed an ambient environment (Tompson et al., 1999) and were initiated well after these dynamic processes occurred. The existence of posttest temperature data at the CHESHIRE site permitted incorporation of test-related heat. Thus, the initiation point for CHESHIRE simulations is earlier than that for CAMBRIC.

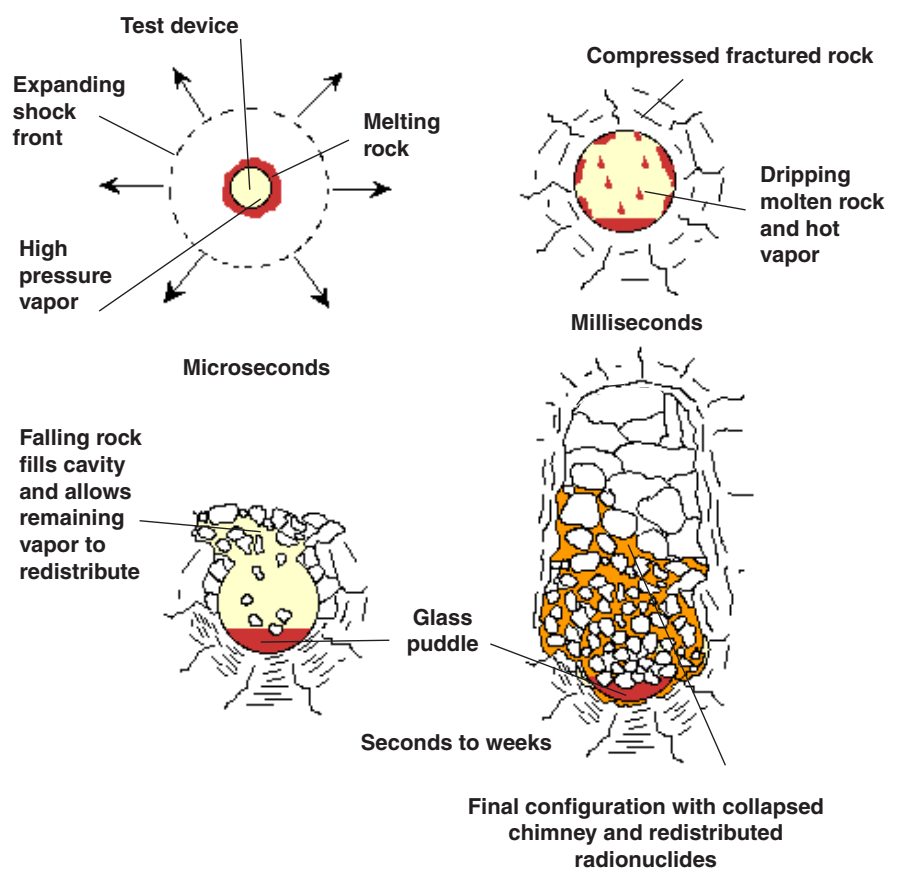

Figure 3.5 Concept of phenomenology of an underground nuclear explosion showing accretion of melt glass puddle, redistribution of more volatile radionuclides, initially as gases, later as condensates, and collapse of the chimney. 


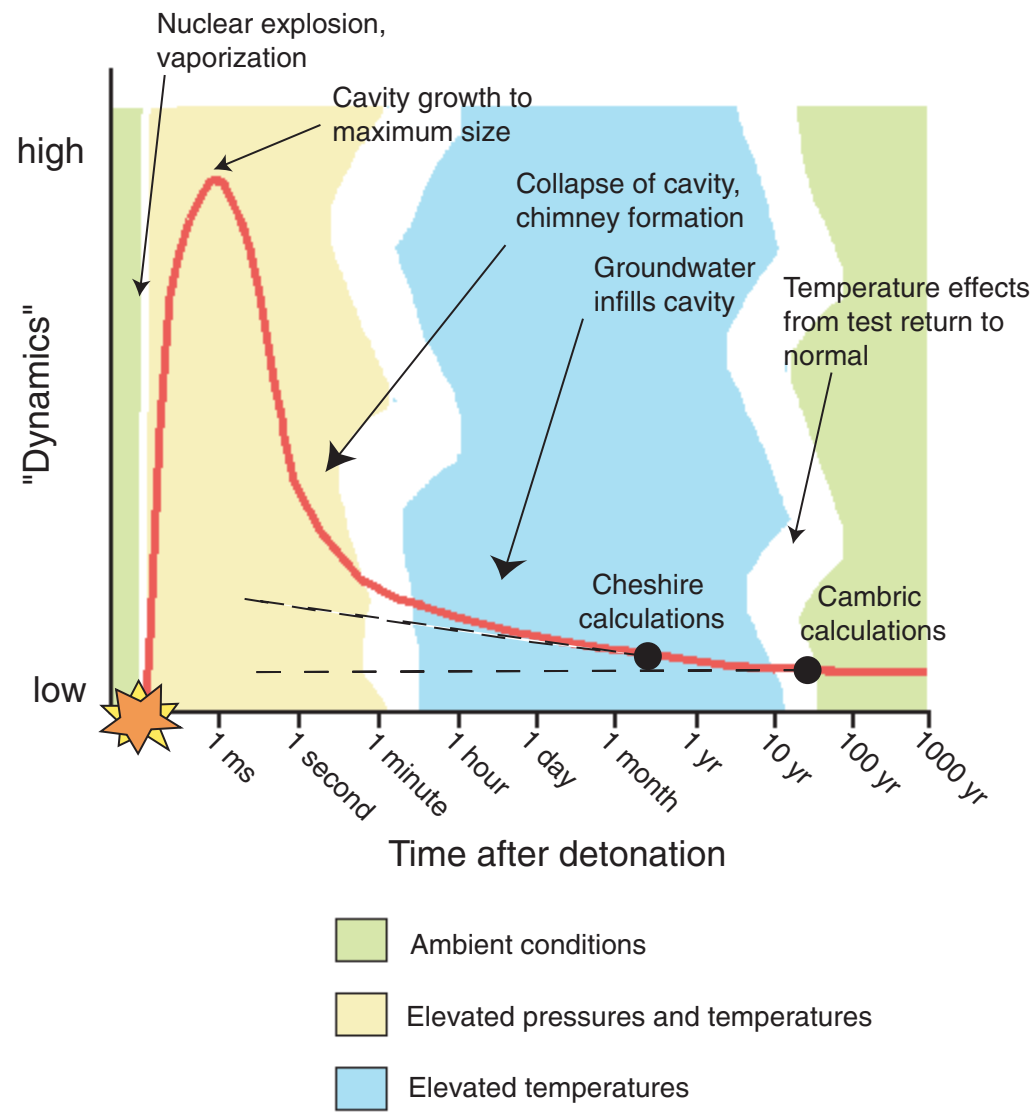

Figure 3.6 Conceptualization of dynamic processes that occur after an underground nuclear test. The most logical starting point for examining radionuclide migration in groundwater will be in the days to months following detonation when groundwater returns to the cavity and chimney and most of the dynamic processes have ended.

\subsubsection{Radionuclide Distribution}

Radionuclides associated with an underground nuclear explosion are derived from the original materials in the device, nuclear reactions driving the explosion, and activation products created through interaction with the device and geologic media. Complex dynamic processes, occurring milliseconds to hours after detonation, will control their initial chemical nature and spatial distribution. Most radionuclide gases are retained in the cavity region during cavity expansion. This is because the uniform state of compression in the surrounding medium, generated by the outgoing shock wave and subsequent rebound of the geologic medium toward the detonation point, tends to close or seal potential pressure-driven escape pathways. Some exceptions to this have been noted, however, that could result in the prompt injection of radionuclides away from the cavity region (Nimz and Thompson, 1992; Smith et al., 1996).

During the cooling and condensation process, heavier radionuclides with higher boiling points such as ${ }^{241} \mathrm{Am}$ and ${ }^{239} \mathrm{Pu}$ condense first and become incorporated in the coalescing melt glass (Borg et al., 1976; Smith, 1995). Radionuclides with lower boiling points, such as tritium $\left({ }^{3} \mathrm{H}\right),{ }^{36} \mathrm{Cl},{ }^{22} \mathrm{Na}$, and ${ }^{129} \mathrm{I}$, tend to condense later, usually 
along cavity wall and rubble surfaces within the cavity and in lower parts of the chimney, although some amounts can also be found in the melt phase (Borg et al., 1976). This zone of radioactivity is often conceptualized as a spherical volume centered near the testing point whose damaged zone (Townsend, 1994; Pawloski, 1999) or exchange volume radius (Hoffman et al., 1977), from one-and-a-half to two cavity radii, can be assessed from observations in drill-back holes and mine-back operations. Other radionuclides, such as ${ }^{85} \mathrm{Kr},{ }^{90} \mathrm{Kr}$, or ${ }^{137} \mathrm{Xe}$, will exist as noncondensable gases and may move beyond the exchange volume if conditions permit (Guell, 1997). In general, gas redistribution may be promoted by production and transport of incondensible gases or by gas phase displacement associated with cavity collapse, buoyancy forces, and molecular diffusion, and will occur to the extent that unsaturated pore space is available for gases to move into. Some radionuclides, such as ${ }^{90} \mathrm{Sr}$ and ${ }^{137} \mathrm{Cs}$, may be found outside the melt zones because they are daughter products of short-lived, gaseous precursors, such as ${ }^{90} \mathrm{Kr}$ and ${ }^{137} \mathrm{Xe}$, respectively (Smith, 1998).

The inventory of radionuclides produced by a test can be estimated from the test design and radiochemical diagnostic data, if available (e.g., Hoffman et al., 1977). The partitioning of this inventory among the melt glass, exchange volume, and noncondensable gas fractions has been estimated using diagnostic data from many tests and thermodynamic properties of the elements (IAEA, 1998a). Similar data can be used to estimate the total mass of melt glass produced in a test as a function of the test yield. Olsen (1993) suggested that approximately 700 metric tons ( $t$ ) of melt glass are produced per kiloton of test yield.

Little is known about how radionuclides are locally concentrated within the melt glass or exchange volume, nor of their chemical state in the rubble following condensation and groundwater return. The melt phase is known to be a heterogeneous brecciated mixture of vesicular and massive glass (Figure 3.7), often intermixed with collapsed rubble, all of which have different physiochemical properties and radionuclide contents (Wadman and Richards, 1961; Townsend, 1994; Smith, 1995). The glass retains the chemical composition of the host rock (Tompson et al., 1999). Within the rubble, condensed radionuclides may dissolve into returning pore water as steam condenses or when groundwater returns to the cavity. They will form aqueous species according to local geochemical conditions, and may also partition onto reactive mineral phases or form precipitates according to constraints on their solubility. Noncondensable radionuclides may also become incorporated into returning pore waters, or may, depending on the rate of groundwater return and proximity to the unsaturated zone, move away from the cavity and chimney area. 


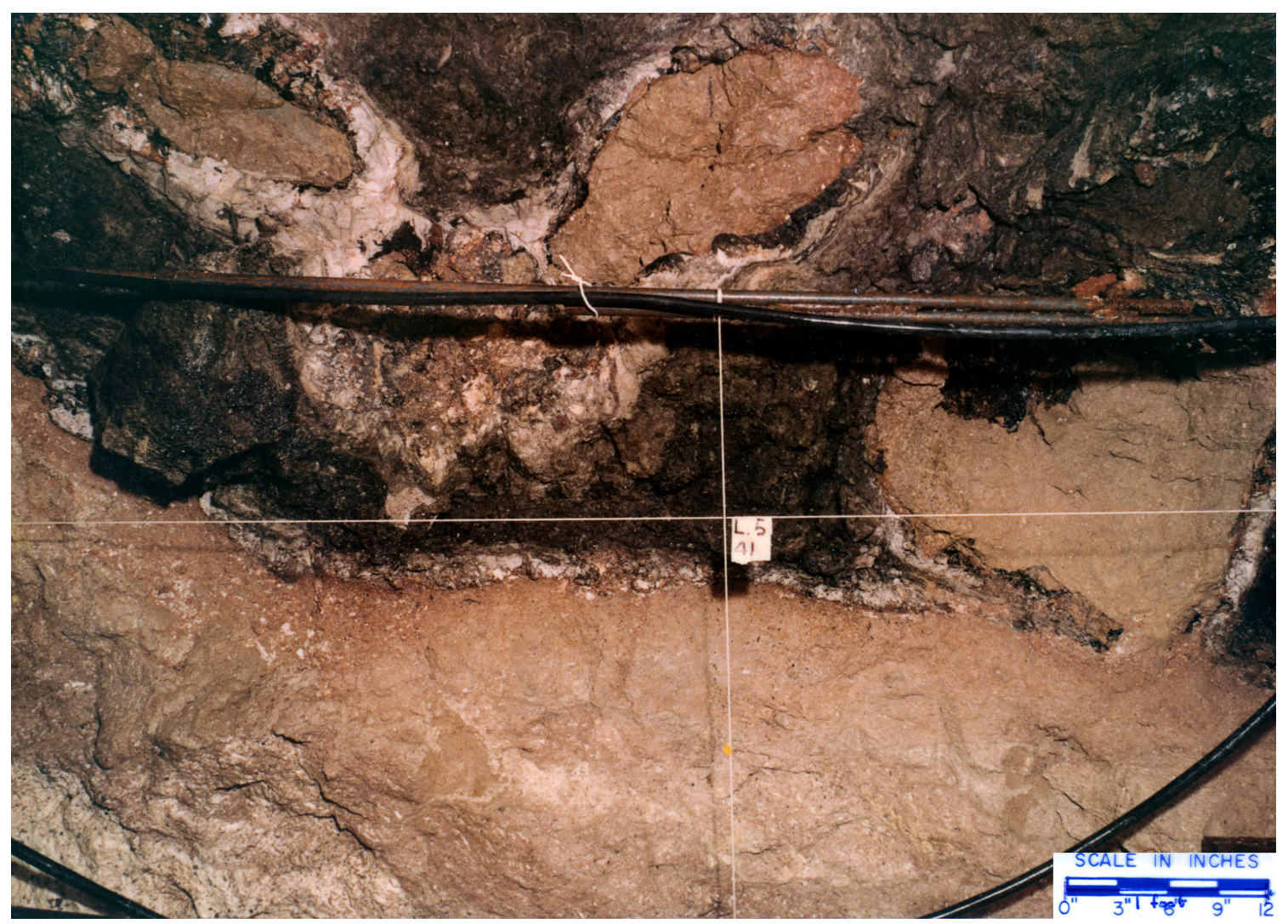

Figure 3.7 In situphotograph of the melt glass from the reentry mining excavation at the RAINIER test (Wadman and Richards, 1961). Large blocks of host rock can be seen inside the melted glass. Vesicular zones (rich in bubbles) surround some of these inclusions. The photo is about $2 \mathrm{~m}$ across. The area is obviously heterogeneous in textural and hydrologic properties.

\subsection{Idealized Phenomenologic Model}

\subsubsection{Physical Parameters}

The phenomenologic model developed for the CHESHIRE test uses the maximum value of the yield range to calculate the dimensions of the zones altered by the nuclear explosion. This conservatively creates the largest possible volumes in which to distribute the initial radionuclide inventory, and the largest cross-sectional areas through which groundwater will flow. Usage of smaller volumes would initially locate higher concentrations of radionuclides in these volumes, but the cross-sectional area available to groundwater flow for possible transport would be smaller. Table 3.1 summarizes values for the phenomenologic model, which are shown schematically in Figure 3.8. 
Table 3.1 Conceptual model parameters applied to the CHESHIRE test using the maximum yield value of $500 \mathrm{kt}$.

\begin{tabular}{|l|l|}
\hline Depth of burial: & $1,167 \mathrm{~m}$ below ground surface (measured) \\
\hline Static water level: & $625 \mathrm{~m}$ below ground surface (measured) \\
\hline Melt glass zone: & $350,000 \mathrm{t}$ (calculated) \\
\hline Cavity zone: & $79.1 \mathrm{~m}$ radius (calculated) \\
\hline Chimney zone: & $79.1 \mathrm{~m}$ radius (assumed equal to cavity radius) \\
\hline Disturbed zone & $118 \mathrm{~m}$ radius (assumed to be 1.5 times cavity radius) \\
\hline Chimney height: & $\begin{array}{l}\text { Extends at least to the static water level, the top of } \\
\text { the model domain (assumed from cable data) }\end{array}$ \\
\hline
\end{tabular}

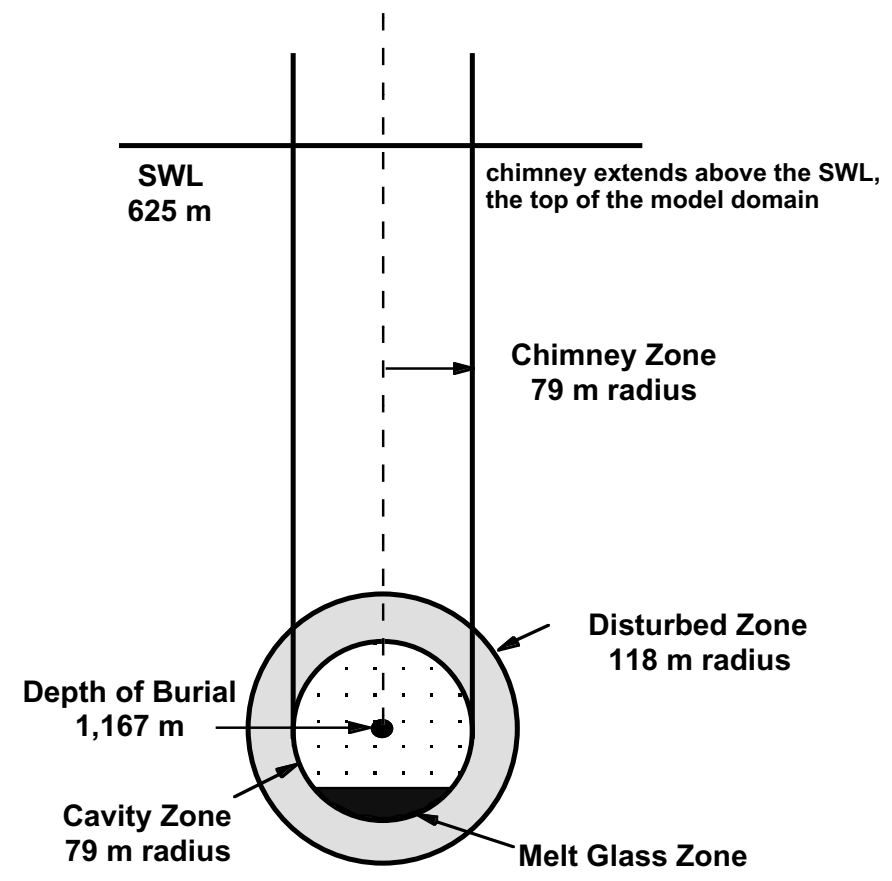

Figure 3.8 Idealized locations and sizes of the altered zones-melt glass, cavity, disturbed, and chimney — created by the CHESHIRE test using the maximum yield value of $500 \mathrm{kt}$.

\subsubsection{Initial Conditions for Model Analysis}

Strictly speaking, the migration of test-related radionuclides begins after detonation, as plasma begins to condense inside the cavity and exchange volumes. However, the most logical starting point for examining radionuclide migration in groundwater will be in the days to months following detonation when groundwater returns to the cavity and chimney. The radionuclide inventory distributed within the melt glass and throughout the exchange volume surrounding the cavity (as depicted in Chapter 4) will describe the initial conditions for model analysis. 


\section{Radiological Source Term and Initial Distribution}

\subsection{Introduction}

The total inventory of residual radioactivity resulting from an underground nuclear explosion is known as its radiological source term (RST). As described in Appendix A, a significant and systematic effort was undertaken to review as much unclassified information as possible to identify the radionuclides that comprise the CHESHIRE RST, to approximate their abundance using unclassified data, and to objectively determine their relative importance for inclusion in a model of their release into the hydrologic environment. To our knowledge this is the first time an objective approach has been advanced - beyond stand-alone criteria of half-life and dose equivalence - to evaluate radionuclides of significance for transport calculations. It is designed to be conservative, comprehensive, and transferable.

Altogether, a total of 52 candidate radionuclides were identified in this process. Of these, 37 have been chosen for inclusion in the model based upon the availability of unclassified data to estimate their inventories, their observation in CHESHIRE cavity waters or nearby monitoring wells, and an analysis of their decay and ingrowth properties. The latter aspect is important to identify whether additional derivative daughter radionuclides need to be addressed and to understand how their inventories and relative abundance vary over the 1000-year lifetime of this analysis.

\subsection{Sources of Information on the RST}

We reviewed three sources of radionulcide inventory information, including:

- Radionuclide measurements in groundwater near CHESHIRE.

- UGTA Source Term Subcommittee recommendations.

- Unclassified radionuclide inventory on Pahute Mesa at the NTS.

\subsubsection{Radionuclide Inventory for Pahute Mesa}

Smith (2001) summarizes the total activity (in Bq) and amount (in moles), decay corrected to 1 January 1994, of 48 radionuclides produced by the 76 individual underground nuclear tests detonated below or within $100 \mathrm{~m}$ of the water table in Areas 19 and 20 of the Pahute Mesa on the NTS. It is strongly emphasized that these data represent unclassified total values and do not pertain to any specific test on Pahute Mesa. Individual test inventories are classified. The total inventory data shown in Smith (2001) were averaged over the 76 tests, and the averaged values were applied as an unclassified RST at the CHESHIRE site. Again, these averaged values do not represent the specific inventory for CHESHIRE or any other test on Pahute Mesa.

The radionuclides that Smith (2001) itemizes are not an exhaustive list of all possible test-related radionuclides. These radionuclides were selected using a 
procedure similar to that described by Wild et al. (1998). Of the 48 radionuclide inventories listed in the Smith (2001) report, only 44 are distinct. Four radionuclides $\left({ }^{232} \mathrm{Th},{ }^{234} \mathrm{U},{ }^{235} \mathrm{U}\right.$, and $\left.{ }^{238} \mathrm{U}\right)$ have separately listed inventories attributable to the nuclear tests and to their natural abundance in the soil or rock. ${ }^{1}$ In addition,

- The inventory of ${ }^{40} \mathrm{~K}$ is wholly attributable to its natural abundance in the soil or rock and has no fraction derived from any test.

- The inventory of ${ }^{150} \mathrm{Gd}$ is listed (only) as a footnote in Smith (2001) but is, nevertheless, included because of its long half-life and decay by alpha emission.

- Only one $\left({ }^{154} \mathrm{Eu}\right)$ has a half-life shorter than $10 \mathrm{yr}$.

The Smith (2001) list of 44 radionuclides is more current than an earlier list of 30 (Tables V-VIII in Wild et al., 1998). The Smith (2001) list includes these 30, plus an additional 14 radionuclides.

\subsubsection{UGTA Source Term Subcommittee Recommendations}

The memorandum of Smith (1997) describes a list of 22 radionuclides identified to be potentially of concern for remedial investigations at the NTS by the Underground Test Area Source Term Subcommittee. The list was compiled by considering a list of 64 radionuclides (which included 56 natural and nuclear weaponrelated radionuclides with half lives greater than ten yrs. and an additional 8 with half lives less than ten yrs, but that have also been measured in explosion cavity fluids) and using a series of criteria to select the most important radionuclides of concern. These criteria considered

- Radionuclide abundance (based on production from an underground nuclear test).

- Relative radionuclide mobility in the aqueous phase (based on field observations).

- Health effects from radionuclides (based on whole body or organ dose).

Of the 22 radionuclides chosen, all but 5 (namely, ${ }^{60} \mathrm{Co},{ }^{106} \mathrm{Ru},{ }^{125} \mathrm{Sb},{ }^{134} \mathrm{Cs}$, and ${ }^{155} \mathrm{Eu}$ ) are already in the list of 44 from Smith (2001). These five all have half-lives shorter than $10 \mathrm{yr}$. Adding these 5 to the original 44 radionuclides considered above gives a total of 49 radionuclides were considered members of the RST.

\subsubsection{Radionuclide Measurements in Groundwater near CHESHIRE}

The reports of Finkel et al. (1992), Daniels et al. (1993), Smith et al. (1998), Smith et al. (1999), Smith et al. (2000), and Thompson et al. (2000) summarize

\footnotetext{
${ }^{1}$ Smith (2001) uses the term soil to refer to the host geologic medium containing the natural inventory; we use rock, as this term is more descriptive of the native medium at CHESHIRE.
} 
concentrations of several radonuclides measured in groundwater samples taken from the CHESHIRE cavity and chimney, or from drill holes on Pahute Mesa near the CHESHIRE test. These reports indicate that 26 different radionuclides were found in groundwater directly or potentially associated with the detonation of CHESHIRE, and not otherwise introduced as a consequence of natural geologic conditions (e.g., ${ }^{125} \mathrm{Sb}$ ). All but 3 of these radionuclides (namely, ${ }^{22} \mathrm{Na},{ }^{54} \mathrm{Mn}$, and ${ }^{144} \mathrm{Ce}$ ) are in the list of 49 addressed previously. Adding these 3 to the previous 49 yields a total of 52 radionuclides that may be considered members of the RST.

\subsubsection{Resulting Table of Radionuclides}

Table A.1 lists the 52 distinct radionuclides identified in the three grouped sources. The accompanying text in Appendix A provides specific information about how this table was developed.

\subsection{Radionuclides Appropriate for the Model}

The 37 radionuclides chosen for the CHESHIRE near-field hydrologic flow and transport model are a subset of the 52 radionuclides identified in Section 4.2.3 and Table A.1. The rationale for excluding particular radionuclides on this list involves compliance with the following standard: A radionuclide would be excluded from consideration (1) if there is no inventory, or (2) if there is an inventory, none of the following criteria related to their abundance were satisfied.

\begin{tabular}{|l|l|}
\hline $\begin{array}{l}\text { I } \\
\text { (required) }\end{array}$ & $\begin{array}{l}\text { The radionuclide must have a reported test-related inventory, as } \\
\text { defined by the data in Smith (2001), and this inventory must equal or } \\
\text { exceed any corresponding natural inventory in the rock. The mean } \\
\text { test-related inventory will be used as an approximation for the actual } \\
\text { inventory of CHESHIRE, which is classified. }\end{array}$ \\
\hline II, III, IV & $\begin{array}{l}\text { For an } \alpha, \beta, \text { or electron capture/isomeric transition decay } \\
\text { radionuclide, the ratio of its activity (in Bq) or amount (in mol) to the } \\
\text { total activity or amount }{ }^{2} \text { respectively, of all } \alpha, \beta \text {, or electron } \\
\text { capture/isomeric transition decay radionuclides exceeds a value of } \\
10^{-3}(0.1 \% \text { of the total) at some time over the next } 1000 \text { yr. }\end{array}$ \\
\hline V & $\begin{array}{l}\text { The radionuclide has a reported concentration in groundwater taken } \\
\text { from the CHESHIRE cavity, chimney, or near the CHESHIRE test. }\end{array}$ \\
\hline
\end{tabular}

For detailed information on these criteria, see Appendix A.

\subsection{Radionuclides Included in the Model}

Application of the above criteria to the list of 52 radionuclides in Table A.1 yields a total of 37 radionuclides (Table 4.1). One exception to these criteria was made in this process: ${ }^{238} \mathrm{U}$ was included in the model despite the fact that its natural inventory

\footnotetext{
${ }^{2}$ As computed from the radionuclides and inventories reported in Smith (2001).
} 
exceeds its corresponding test-related inventory. This exception was made specifically because its test-related molar inventory exceeds the combined test-related molar inventory of all other radionuclides reported in Smith (2001).

Table 4.1 List of the 37 radionuclides considered for the CHESHIRE source term model, their half lives, and their average Pahute Mesa (RST) inventory.

\begin{tabular}{|c|c|c|c|}
\hline \multirow{2}{*}{$\begin{array}{c}\text { Isotope } \\
\left(\begin{array}{l}\mathrm{A}=n+p \\
\mathrm{Z}=\boldsymbol{p}\end{array}\right)^{\mathrm{a}}\end{array}$} & \multirow{2}{*}{$\begin{array}{l}\text { Half-life } \\
\left(t_{1 / 2} ; y\right)^{b}\end{array}$} & \multicolumn{2}{|c|}{ Reported average inventory ${ }^{c}$} \\
\hline & & $\begin{array}{l}\text { Activity } \\
(\mathrm{Bq})^{\mathrm{d}}\end{array}$ & $\begin{array}{l}\text { Amount } \\
\text { (mole) }^{\mathrm{e}}\end{array}$ \\
\hline${ }_{1}^{3} \mathrm{H}$ [tritium $\left.(\mathrm{H}-3)\right]$ & $1.23 \times 10^{1}$ & $3.40 \times 10^{16}$ & $3.16 \times 10^{1}$ \\
\hline${ }_{6}^{14} \mathrm{C}$ (carbon-14) & $5.730 \times 10^{3}$ & $2.70 \times 10^{11}$ & $1.17 \times 10^{-1}$ \\
\hline${ }_{17}^{36} \mathrm{Cl}$ (chlorine-36) & $3.01 \times 10^{5}$ & $1.04 \times 10^{11}$ & 2.37 \\
\hline${ }_{18}^{39} \mathrm{Ar}$ (argon-39) & $2.69 \times 10^{2}$ & $8.99 \times 10^{11}$ & $1.83 \times 10^{-2}$ \\
\hline${ }_{20}^{41} \mathrm{Ca}$ (calcium-41) & $1.03 \times 10^{5}$ & $7.99 \times 10^{11}$ & 6.22 \\
\hline${ }_{28}^{59} \mathrm{Ni}$ (nickel-59) & $7.6 \times 10^{4}$ & $1.94 \times 10^{10}$ & $1.12 \times 10^{-1}$ \\
\hline${ }_{28}^{63} \mathrm{Ni}$ (nickel-63) & $1.00 \times 10^{2}$ & $2.05 \times 10^{12}$ & $1.55 \times 10^{-2}$ \\
\hline${ }_{36}^{85} \mathrm{Kr}$ (krypton-85) & $1.073 \times 10^{1}$ & $4.66 \times 10^{13}$ & $3.78 \times 10^{-2}$ \\
\hline${ }_{38}^{90} \mathrm{Sr}$ (strontium-90) & $2.91 \times 10^{1}$ & $5.81 \times 10^{14}$ & 1.28 \\
\hline${ }_{40}^{93} \mathrm{Zr}$ (zirconium-93) & $1.5 \times 10^{6}$ & $2.03 \times 10^{10}$ & 2.30 \\
\hline $\begin{array}{l}93 \mathrm{~m} \\
41\end{array} \mathrm{Nb}$ (niobium-93m) & $1.61 \times 10^{1}$ & $3.70 \times 10^{12}$ & $4.50 \times 10^{-3}$ \\
\hline${ }_{41}^{94} \mathrm{Nb}$ (niobium-94) & $2.0 \times 10^{4}$ & $8.44 \times 10^{10}$ & $1.27 \times 10^{-1}$ \\
\hline${ }_{43}^{99} \mathrm{Tc}$ (technecium-99) & $2.13 \times 10^{5}$ & $1.49 \times 10^{11}$ & 2.41 \\
\hline${ }_{46}^{107} \mathrm{Pd}$ (palladium-107) & $6.5 \times 10^{6}$ & $7.66 \times 10^{8}$ & $3.76 \times 10^{-1}$ \\
\hline${ }_{50}^{121 \mathrm{~m}} \mathrm{Sn}(\mathrm{tin}-121 \mathrm{~m})$ & $\approx 5.5 \times 10^{1}$ & $2.10 \times 10^{12}$ & $8.72 \times 10^{-3}$ \\
\hline${ }_{50}^{126} \mathrm{Sn}(\mathrm{tin}-126)$ & $\approx 1 \times 10^{5}$ & $2.39 \times 10^{10}$ & $1.81 \times 10^{-1}$ \\
\hline${ }_{53}^{129}$ I (iodine-129) & $1.57 \times 10^{7}$ & $4.59 \times 10^{8}$ & $5.44 \times 10^{-1}$ \\
\hline${ }_{55}^{135}$ Cs (cesium-135) & $2.3 \times 10^{6}$ & $1.54 \times 10^{10}$ & 2.68 \\
\hline${ }_{55}^{137} \mathrm{Cs}$ (cesium-137) & $3.017 \times 10^{1}$ & $7.36 \times 10^{14}$ & 1.68 \\
\hline
\end{tabular}

(continued on next page) 
Table 4.1 (Continued).

\begin{tabular}{|c|c|c|c|}
\hline \multirow{2}{*}{$\begin{array}{c}\text { Isotope } \\
\left(\begin{array}{l}\mathrm{A}=n+p \\
\mathrm{Z}=\boldsymbol{p}\end{array}\right)^{\mathrm{a}}\end{array}$} & \multirow{2}{*}{$\begin{array}{l}\text { Half-life } \\
\left(t_{1 / 2} ; y\right)^{\mathrm{b}}\end{array}$} & \multicolumn{2}{|c|}{ Reported average inventory ${ }^{c}$} \\
\hline & & $\begin{array}{l}\text { Activity } \\
(B q)^{d}\end{array}$ & $\begin{array}{l}\text { Amount } \\
(\text { mole })^{\mathrm{e}}\end{array}$ \\
\hline${ }_{41}^{93 \mathrm{~m}} \mathrm{Nb}$ (niobium-93m) & $1.61 \times 10^{1}$ & $3.70 \times 10^{12}$ & $4.50 \times 10^{-3}$ \\
\hline${ }_{41}^{94} \mathrm{Nb}$ (niobium-94) & $2.0 \times 10^{4}$ & $8.44 \times 10^{10}$ & $1.27 \times 10^{-1}$ \\
\hline${ }_{43}^{99} \mathrm{Tc}$ (technecium-99) & $2.13 \times 10^{5}$ & $1.49 \times 10^{11}$ & 2.41 \\
\hline${ }_{46}^{107} \mathrm{Pd}$ (palladium-107) & $6.5 \times 10^{6}$ & $7.66 \times 10^{8}$ & $3.76 \times 10^{-1}$ \\
\hline${ }_{50}^{121 \mathrm{~m}} \mathrm{Sn}(\mathrm{tin}-121 \mathrm{~m})$ & $\approx 5.5 \times 10^{1}$ & $2.10 \times 10^{12}$ & $8.72 \times 10^{-3}$ \\
\hline${ }_{50}^{126} \mathrm{Sn}(\mathrm{tin}-126)$ & $\approx 1 \times 10^{5}$ & $2.39 \times 10^{10}$ & $1.81 \times 10^{-1}$ \\
\hline${ }_{53}^{129}$ I (iodine-129) & $1.57 \times 10^{7}$ & $4.59 \times 10^{8}$ & $5.44 \times 10^{-1}$ \\
\hline${ }_{55}^{135} \mathrm{Cs}$ (cesium-135) & $2.3 \times 10^{6}$ & $1.54 \times 10^{10}$ & 2.68 \\
\hline${ }_{55}^{137}$ Cs (cesium-137) & $3.017 \times 10^{1}$ & $7.36 \times 10^{14}$ & 1.68 \\
\hline${ }_{62}^{151} \mathrm{Sm}$ (samarium-151) & $9.0 \times 10^{1}$ & $2.78 \times 10^{13}$ & $1.89 \mathrm{E} \times 10^{-1}$ \\
\hline${ }_{63}^{150}$ Eu (europium-150) & $3.6 \times 10^{1}$ & $5.40 \times 10^{11}$ & $1.47 \times 10^{-3}$ \\
\hline${ }_{63}^{152} \mathrm{Eu}$ (europium-152) & $1.348 \times 10^{1}$ & $1.60 \times 10^{13}$ & $1.63 \times 10^{-2}$ \\
\hline${ }_{63}^{154}$ Eu (europium-154) & 8.59 & $7.55 \times 10^{12}$ & $4.90 \times 10^{-3}$ \\
\hline $\begin{array}{l}166 \mathrm{~m} \\
67\end{array}$ & $1.2 \times 10^{3}$ & $2.18 \times 10^{10}$ & $1.98 \times 10^{-3}$ \\
\hline${ }_{92}^{232} \mathrm{U}$ (uranium-232) & $7.0 \times 10^{1}$ & $1.24 \times 10^{11}$ & $6.57 \times 10^{-4}$ \\
\hline${ }_{92}^{233} \mathrm{U}$ (uranium-233) & $1.592 \times 10^{5}$ & $8.33 \times 10^{10}$ & 1.00 \\
\hline${ }_{92}^{234} U_{\text {device }}$ (uranium-234) & $2.46 \times 10^{5}$ & $5.99 \times 10^{10}$ & 1.11 \\
\hline${ }_{92}^{235} \mathrm{U}_{\text {device }}$ (uranium-235) & $7.04 \times 10^{8}$ & $8.07 \times 10^{8}$ & $4.29 \times 10^{1}$ \\
\hline${ }_{92}^{236} \cup($ (uranium-236) & $2.342 \times 10^{7}$ & $2.30 \times 10^{9}$ & 4.07 \\
\hline${ }_{92}^{238} U_{\text {device }}$ (uranium-238) & $4.47 \times 10^{9}$ & $1.07 \times 10^{9}$ & $3.60 \times 10^{2}$ \\
\hline${ }_{93}^{237} \mathrm{~Np}$ (neptunium-237) & $2.14 \times 10^{6}$ & $1.78 \times 10^{10}$ & 2.87 \\
\hline${ }_{94}^{238} \mathrm{Pu}$ (plutonium-238) & $8.77 \times 10^{1}$ & $3.49 \times 10^{12}$ & $2.31 \times 10^{-2}$ \\
\hline${ }_{94}^{239} \mathrm{Pu}$ (plutonium-239) & $2.410 \times 10^{4}$ & $9.40 \times 10^{12}$ & $1.71 \times 10^{1}$ \\
\hline${ }_{94}^{240} \mathrm{Pu}$ (plutonium-240) & $6.56 \times 10^{3}$ & $3.02 \times 10^{12}$ & 1.50 \\
\hline
\end{tabular}

(continued on next page) 
Table 4.1 (Continued).

\begin{tabular}{|c|c|c|c|}
\hline \multirow{2}{*}{$\begin{array}{c}\text { Isotope } \\
\left.\left(\begin{array}{l}\mathrm{A}=n+p \\
\mathrm{Z}=\boldsymbol{p}\end{array}\right)\right)^{\mathrm{a}}\end{array}$} & \multirow{2}{*}{$\begin{array}{l}\text { Half-life } \\
\left(t_{1 / 2} ; y\right)^{b}\end{array}$} & \multicolumn{2}{|c|}{ Reported average inventory ${ }^{c}$} \\
\hline & & $\begin{array}{c}\text { Activity } \\
(B q)^{d}\end{array}$ & $\begin{array}{l}\text { Amount } \\
\text { (mole) }^{\mathrm{e}}\end{array}$ \\
\hline $\begin{array}{l}93 \mathrm{~m} \\
41\end{array} \mathrm{Nb}$ (niobium-93m) & $1.61 \times 10^{1}$ & $3.70 \times 10^{12}$ & $4.50 \times 10^{-3}$ \\
\hline${ }_{94}^{241} \mathrm{Pu}$ (plutonium-241) & $1.44 \times 10^{1}$ & $4.37 \times 10^{13}$ & $4.75 \times 10^{-2}$ \\
\hline${ }_{95}^{241} \mathrm{Am}$ (americium-241) & $4.327 \times 10^{2}$ & $2.27 \times 10^{12}$ & $7.43 \times 10^{-2}$ \\
\hline${ }_{96}^{244} \mathrm{Cm}$ (curium-244) & $1.81 \times 10^{1}$ & $1.45 \times 10^{12}$ & $1.98 \times 10^{-3}$ \\
\hline
\end{tabular}

a Isotopes are nuclides of an element with the same number of protons ( $p)$, but a different number of neutrons $(n)$ in the nucleus. Radioactive isotopes (i.e., radionuclides) representing the radiologic source term for CHESHIRE are ordered in this column by atomic number $(Z=p)$, and not by mass number $(\mathrm{A}=n+p)$.

b Walker et al. (1989).

c Mean unclassified radionuclide inventory (activity and amount) for 76 nuclear tests detonated below or within $100 \mathrm{~m}$ of the water table in Areas 19 and 20 reported by Smith (2001).

d To convert radioactivity units from Becquerel $(\mathrm{Bq})$ to Curie $(\mathrm{Ci})$, divide $\mathrm{Bq}$ by $3.7 \times 10^{10}$.

e The mass for any isotope ( $w=$ moles) can be computed from its activity $(A)$ by dividing that activity $(A=\mathrm{Bq})$ by the product of the decay (or transformation) constant $(\lambda)$ for that isotope and Avogadro's constant (i.e., $\mathrm{N}_{\mathrm{A}}=6.02 \times 10^{23}$ atoms $/ \mathrm{mole}$ ); where $\lambda=0.693 / t_{1 / 2}$, and $t_{1 / 2}$ is the isotope's half-life expressed in seconds [i.e., $\left.\left(t_{1 / 2} \mathrm{y}\right) \times\left(3.15 \times 10^{7} \mathrm{~s} / \mathrm{yr}\right)\right]$. Thus, for any isotope, $w=A /\left[\left(0.693 / t_{1 / 2}\right) \times\left(6.02 \times 10^{23}\right)\right]$.

Interestingly, these 37 radionuclides represent

- All but 5 of the 22 considered significant by the UGTA Source Term Subcommittee (Smith, 1997). The remaining 5 (i.e., ${ }^{60} \mathrm{Co},{ }^{106} \mathrm{Ru},{ }^{125} \mathrm{Sb},{ }^{134} \mathrm{Cs}$, and ${ }^{155} \mathrm{Eu}$ ) cannot otherwise be included because there is no reported testrelated inventory (i.e., no conformity with Criterion I above).

- All but 9 of the 26 radionuclides for which groundwater measurements have been reported. The remaining 9 (i.e., ${ }^{22} \mathrm{Na},{ }^{40} \mathrm{~K},{ }^{54} \mathrm{Mn},{ }^{60} \mathrm{Co},{ }^{106} \mathrm{Ru},{ }^{125} \mathrm{Sb}$, ${ }^{134} \mathrm{Cs}$, ${ }^{144} \mathrm{Ce}$, and ${ }^{155} \mathrm{Eu}$ ) cannot otherwise be included because there is no reported test-related inventory (i.e., no conformity with Criterion I earlier).

This unclassified RST represents a mean of 76 individual underground nuclear tests detonated below or within $100 \mathrm{~m}$ of the water table in Areas 19 and 20 of the Pahute Mesa on the NTS. This unclassified RST is applied for HST modeling at the CHESHIRE site, and does not represent the actual RST for the CHESHIRE test.

\subsection{Radioactive Decay Chains}

Radioactive decay and ingrowth processes associated with the RST radionuclides must be considered to 
- Determine whether coupled ingrowth and decay affect the relative abundance of any RST radionuclides.

- Identify whether any new derivative members of the RST need to be included or addressed.

- Decide whether ingrowth and decay affect the hydrologic mobility of any RST radionuclides (as specifically discussed in Chapter 6 and Appendices C and D).

By definition, all of the 37 radionuclides selected for inclusion in the model will undergo radioactive decay. The decay of each of these radionuclides has been discussed in Appendix A with regard to these considerations. It is particularly important to understand whether ingrowth is important, because it affects the way decay is incorporated into the model - either in a real time sense, or in a post-processing mode ${ }^{3}$.

Radionuclides with low to intermediate atomic numbers $(<80)$ will decay into stable, nonradioactive daughter products that are not included in the simulation, although their decay will lead to lower concentrations that may influence their sorptivity and hydrologic transport rates.

Some members of the RST, notably ${ }^{90} \mathrm{Sr},{ }^{126} \mathrm{Sn}$, and ${ }^{137} \mathrm{Cs}$, decay into short-lived radioactive daughter products (e.g., ${ }^{90} \mathrm{Y},{ }^{126} \mathrm{Sb}$, and ${ }^{137 \mathrm{~m}} \mathrm{Ba}$, respectively, with $t_{1 / 2}<1$ week; see Table A.1), which, in turn, decay into stable granddaughters. In general, all short-lived intermediaries will exist in secular equilibrium. Their abundance will be smaller than, and can be calculated as an instantaneous function of, their parent's abundance. Accordingly, their inclusion in the model as derivative members of the RST is not considered necessary.

Most of the heavier radionuclides in the RST are members of coupled decay chains that include two or more members of the RST. Of these (the eight decay chains associated with ${ }^{93} \mathrm{Zr},{ }^{152} \mathrm{Eu},{ }^{232} \mathrm{U},{ }^{241} \mathrm{Pu},{ }^{242} \mathrm{Pu},{ }^{238} \mathrm{Pu},{ }^{243} \mathrm{Am}$, and ${ }^{244} \mathrm{Cm}$ ), only three potentially need to be addressed in the $1000 \mathrm{yr}$ time frame of the model in a direct, real time sense to address ingrowth behavior:

- Equation (A4): ${ }^{241} \mathrm{Pu} \stackrel{14.4 y / \beta}{\longrightarrow}{ }^{241} \mathrm{Am} \stackrel{433 y / \alpha}{\longrightarrow}{ }^{237} \mathrm{~Np}$

- Equation (A6): ${ }^{238} \mathrm{Pu} \stackrel{87.7 y / \alpha}{\longrightarrow}{ }^{234} \mathrm{U}$

- Equation (A8): ${ }^{244} \mathrm{Cm} \stackrel{18.1 y / \alpha}{\longrightarrow}{ }^{240} \mathrm{Pu}$

\footnotetext{
${ }^{3}$ Decay and ingrowth may be handled in a real time sense, where concentration changes arising from these effects are calculated at each time step of the simulation. This is a natural way to approach the problem, but it can increase the computational time of a simulation. Conversely, decay may be treated in an ex-post-facto sense by post processing non-decayed results, but only if the daughter products are not relevant or important in the simulation, and only if the mobility of the parent is independent of its concentration (see Chapter 7, Appendices B, C, and D, and Tompson et al., 1999).
} 
Analysis of the inventory data in Table 4-1 indicates that the initial abundance of ${ }^{238} \mathrm{Pu}$ and ${ }^{244} \mathrm{Cm}$ are quite small relative to the initial abundance of their daughters, ${ }^{234} \mathrm{U}$ and ${ }^{240} \mathrm{Pu}$. Because of this, ingrowth of ${ }^{234} \mathrm{U}$ and ${ }^{240} \mathrm{Pu}$ will not be directly considered, and only ingrowth along the abridged ${ }^{241} \mathrm{Pu}$ chain above will be addressed in the models.

\subsection{Initial Distribution of Radionuclides in the Unclassified CheshiRe Model}

\subsubsection{Volumes for Radionuclide Distribution}

The chemical nature and physical distribution of the RST is heterogeneous and a function of device design, geological conditions, properties of the specific radionuclides, and the rate and character of cavity growth and collapse. In general, radionuclides are initially deposited in the melt glass, cavity, and disturbed zones (Figure 3.8 and Section 6.2.3). While some radionuclides are volumetrically incorporated in the melt glass, others condense on fracture surfaces in the cavity and disturbed zone. Table 4.2 summarizes initial radionculide locations, in terms of volumes over which they are distributed, and the porosities assigned to these volumes (See also Sections 5.4.1.3 and 5.4.2 for a discussion on porosity values). Volumes were calculated using the dimensions determined for the phenomenologic model (Table 3.1), porosities derived from hydraulic data (Appendix F), and sensitivities from flow modeling (Chapter 5).

Volumes identified for initial radionuclide distribution in transport simulations, based on phenomenologic model terminology, (Figure 3.8) include

- Melt glass zone-a volume at the bottom of the cavity zone where radionuclides are incorporated volumetrically.

- Cavity zone-a volume of collapsed rubble above the melt glass with $10 \%$ porosity. Radionuclides are condensed on fracture surfaces in this area.

- Disturbed zone-a volume of fractured and rubblized rock where radionuclides are condensed on fracture surfaces.

For initial radionuclide distribution, the disturbed zone volume is divided, based on differences porosities resulting from mechanical failure caused by chimney collapse:

- Intact-in place fractured lava with $1 \%$ porosity.

- Collapse chimney-rubble at the top of the cavity zone caused by chimney collapse, with $10 \%$ porosity.

The exchange volume (cavity and disturbed zones) describes a location where radionuclides are deposited on surfaces, as opposed to incorporated volumetrically (melt glass zone). Radionuclides in the exchange volume are subject to geochemical processes such as surface complexation, ion exchange, and precipitation. Radionuclides 
in the melt glass zone are subject to geochemical processes that begin with glass dissolution and can be followed by surface complexation, ion exchange, and precipitation.

In the flow model (Chapter 5), the cavity, disturbed, and chimney zones are defined slightly differently and are based on permeability differences instead of radionuclide distribution. In the flow model, the chimney extends downward to the depth of burial, incorporating the upper cavity zone and collapse chimney disturbed zones. The remaining sections of the exchange volume include the lower cavity zone and the intact disturbed zone (called simply the disturbed zone in Chapter 5). Figure 4.1 shows the relationships between the phenomenologic model, the initial radionuclide distribution, and the flow model near-field terminologies.
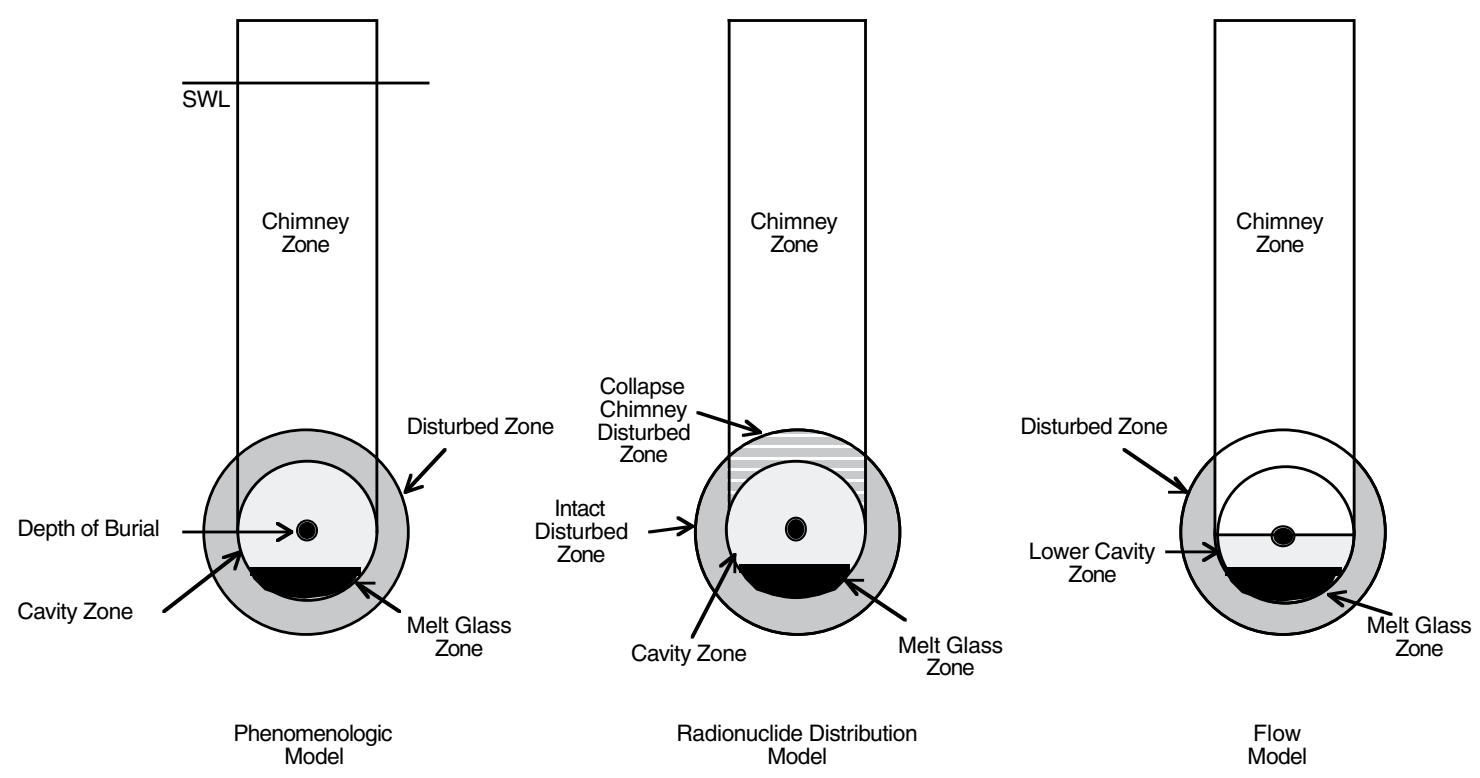

Figure 4.1 Comparison of terminology used in flow modeling and radionuclide distribution for transport models and relationship to the phenomenologic model. 
Table 4.2 Assumed porosities and volumes used for the initial distribution of radionuclides. See comment below table.

\begin{tabular}{|l|l|c|c|c|}
\hline \multicolumn{2}{|c|}{ Zones } & $\begin{array}{c}\text { Porosity, } \\
\%\end{array}$ & $\begin{array}{c}\text { Total volume } \\
\text { model, } \\
\mathbf{m}^{3}\end{array}$ & $\begin{array}{c}\text { Aqueous } \\
\text { volume model, } \\
\mathbf{m}^{3}\end{array}$ \\
\hline \multirow{3}{*}{ Disturbed } & intact & 1 & $5.01 \times 10^{6}$ & $5.11 \times 10^{4}$ \\
\cline { 2 - 6 } & $\begin{array}{l}\text { collapse } \\
\text { chimney }\end{array}$ & 10 & $1.62 \times 10^{6}$ & $1.64 \times 10^{5}$ \\
\hline Cavity & & 10 & $1.97 \times 10^{6}$ & $1.99 \times 10^{5}$ \\
\hline Melt glass & & 20 & $2.04 \times 10^{5}$ & $4.08 \times 10^{4}$ \\
\hline
\end{tabular}

The volumes used in the flow model differ slightly from idealized spherical calculated values for the following reasons, which are discussed further in Chapter 5:

- Volumes were translated to the $10 \mathrm{~m}$ grid blocks used in the model.

- Volumes were adjusted slightly to improve the fit to the thermal data.

- Volumes were adjusted slightly for consistency with descriptions of nearfield geometry.

\subsubsection{Distribution of Radionuclides in Volumes}

Table 4.3 shows how the 37 radionuclides included in the model are partitioned among the melt glass and cavity and chimney rubble as a function of the complicated cooling and condensation processes that immediately follow an underground nuclear explosion. The information in the table was derived (and extended in some cases) from IAEA (1998a) and takes into account the relative volatility of the radionuclides, their important radiologic precursors, as well as other phenomenologic effects. Table 4.3 lists the specific partitioning categories cited in the IAEA (1998a) report:

- Lava-radionuclides distributed in the melt glass (MG) zone.

- Rubble-radionuclides distributed in the aqueous fraction of the exchange volume (EV).

- Gas and water (GW)—radionuclides distributed in the aqueous fraction of the cavity and exchange volume, as well as the saturated pore space of the melt glass zone.

In Table 4.4, the partitioning data in Table 4.3 is combined with the volumetric data of Table 4.2 to yield specific initial concentrations of the 37 radionuclides in the melt glass, cavity and exchange volume water, and melt glass water of the CHESHIRE system (Figure 4.1). 
In Table 4.5, the list of radionuclides in Table 4.4 is simplified into a subset of radionuclide classes, where each class represents a number of radionuclides that are expected to have similar chemical reactivity, decay, and initial partitioning characteristics. Radionuclide classes were used to simplify the overall computational effort incurred by the transport models as well as the model input process. For example, isotopes of the same element will react in a similar manner and can, therefore, be grouped together. ${ }^{4}$ Certain elements could also be grouped together (e.g., the behavior of ${ }^{166 \mathrm{~m}} \mathrm{Ho}$ is expected to be analogous to that of $\mathrm{Eu}$ ). Some radionuclides were grouped as tracers (that move conservatively in groundwater like ${ }^{3} \mathrm{H},{ }^{36} \mathrm{Cl}$, etc.), even though they are likely to be retarded to some degree. Sorption data were not available to effectively characterize their transport and their reactivity was not expected to be analogous to other radionuclides of known reactivity. As a conservative measure, these radionuclides were allowed to migrate without any retardation.

\footnotetext{
${ }^{4}{ }^{241} \mathrm{Pu}$ is defined as a separate class because it is involved in a specific decay chain that must be incorporated separately in the model, as described in Section 4.5.
} 
Table 4.3 Initial distribution of the 37 radionuclides included in the model into the IAEA (1998a) partitioning categories. Molar inventory represents the average initial inventory shown in Table 4.1.

\begin{tabular}{|c|c|c|c|c|c|c|}
\hline \multirow[b]{2}{*}{ RN } & \multirow[b]{2}{*}{ Half-life* } & \multirow[b]{2}{*}{ Moles } & \multicolumn{4}{|c|}{ Distribution, \% } \\
\hline & & & Lava & Rubble & Gas & Water \\
\hline${ }^{3} \mathrm{H}$ & 12.3 & 31.6 & 0 & 0 & 2 & 98 \\
\hline${ }^{14} \mathrm{C}$ & $5.73 \times 10^{3}$ & 0.117 & 0 & 10 & 80 & 10 \\
\hline${ }^{36} \mathrm{Cl}$ & $3.01 \times 10^{5}$ & 2.37 & 50 & 40 & 0 & 10 \\
\hline${ }^{39} \mathrm{Ar} \dagger$ & 269 & 0.0183 & 0 & 10 & 80 & 10 \\
\hline${ }^{41} \mathrm{Ca}$ & $1.03 \times 10^{5}$ & 6.22 & 70 & 30 & 0 & 0 \\
\hline${ }^{59} \mathrm{Ni}$ & $7.6 \times 10^{4}$ & 0.112 & 95 & 5 & 0 & 0 \\
\hline${ }^{63} \mathrm{Ni}$ & 100 & 0.0155 & 95 & 5 & 0 & 0 \\
\hline${ }^{85} \mathrm{Kr}$ & 10.7 & 0.0378 & 0 & 10 & 80 & 10 \\
\hline${ }^{90} \mathrm{Sr}$ & 29.1 & 1.28 & 40 & 60 & 0 & 0 \\
\hline${ }^{93} \mathrm{Zr}$ & $1.50 \times 10^{6}$ & 2.30 & 95 & 5 & 0 & 0 \\
\hline${ }^{93 \mathrm{~m}} \mathrm{Nb}$ & 16.1 & 0.00450 & 95 & 5 & 0 & 0 \\
\hline${ }^{94} \mathrm{Nb} \ddagger$ & $2 \times 10^{4}$ & 0.127 & 95 & 5 & 0 & 0 \\
\hline${ }^{99} \mathrm{Tc}$ & $2.13 \times 10^{5}$ & 2.41 & 80 & 20 & 0 & 0 \\
\hline${ }^{107} \mathrm{Pd}$ & $6.5 \times 10^{6}$ & 0.376 & 70 & 30 & 0 & 0 \\
\hline${ }^{121 \mathrm{~m}} \mathrm{Sn}$ & 55 & 0.00872 & 60 & 40 & 0 & 0 \\
\hline${ }^{126} \mathrm{Sn}$ & $1 \times 10^{5}$ & 0.181 & 70 & 30 & 0 & 0 \\
\hline $129 \mid$ & $1.57 \times 10^{7}$ & 0.544 & 50 & 40 & 0 & 10 \\
\hline${ }^{135} \mathrm{Cs}$ & $2.3 \times 10^{6}$ & 2.68 & 20 & 80 & 0 & 0 \\
\hline${ }^{137} \mathrm{Cs} \S$ & 30.2 & 1.68 & 20 & 80 & 0 & 0 \\
\hline${ }^{151} \mathrm{Sm}$ & 90 & 0.189 & 95 & 5 & 0 & 0 \\
\hline${ }^{150}$ Euף & 36 & 0.00103 & 95 & 5 & 0 & 0 \\
\hline${ }^{152} \mathrm{Eu}$ & 13.5 & 0.0163 & 95 & 5 & 0 & 0 \\
\hline${ }^{154} \mathrm{Eu}$ & 8.59 & 0.00490 & 95 & 5 & 0 & 0 \\
\hline${ }^{166} \mathrm{Ho}$ & $1.2 \times 10^{3}$ & 0.00198 & 95 & 5 & 0 & 0 \\
\hline${ }^{232} U ¥$ & 70 & 0.000657 & 90 & 10 & 0 & 0 \\
\hline${ }^{233} \mathrm{U}$ & $1.59 \times 10^{5}$ & 1.00 & 90 & 10 & 0 & 0 \\
\hline${ }^{234} U ¥$ & $2.46 \times 10^{5}$ & 1.11 & 90 & 10 & 0 & 0 \\
\hline${ }^{235} U ¥$ & $7.04 \times 10^{8}$ & 42.9 & 90 & 10 & 0 & 0 \\
\hline${ }^{236} \mathrm{U}$ & $2.34 \times 10^{7}$ & 4.07 & 90 & 10 & 0 & 0 \\
\hline${ }^{238} U ¥$ & $4.47 \times 10^{9}$ & 360 & 90 & 10 & 0 & 0 \\
\hline${ }^{237} \mathrm{~Np}$ & $2.14 \times 10^{6}$ & 2.87 & 95 & 5 & 0 & 0 \\
\hline${ }^{238} \mathrm{Pu} \dagger$ & 87.7 & 0.0231 & 95 & 5 & 0 & 0 \\
\hline${ }^{239} \mathrm{Pu} \dagger$ & $2.41 \times 10^{4}$ & 17.1 & 95 & 5 & 0 & 0 \\
\hline
\end{tabular}


Table 4.3 (Continued).

\begin{tabular}{|c|c|c|c|c|c|c|}
\hline \multirow[b]{2}{*}{ RN } & \multirow[b]{2}{*}{ Half-life* } & \multirow[b]{2}{*}{ Moles } & \multicolumn{4}{|c|}{ Distribution, \% } \\
\hline & & & Lava & Rubble & Gas & Water \\
\hline${ }^{240} \mathrm{Pu}$ t† & $6.56 \times 10^{3}$ & 1.50 & 95 & 5 & 0 & 0 \\
\hline${ }^{241} \mathrm{Pu} \dagger$ & 14.4 & 0.0475 & 95 & 5 & 0 & 0 \\
\hline${ }^{241} \mathrm{Am} \dagger \dagger$ & 433 & 0.0743 & 95 & 5 & 0 & 0 \\
\hline${ }^{244} \mathrm{Cm} \neq \ddagger$ & 18.1 & 0.00198 & 95 & 5 & 0 & 0 \\
\hline
\end{tabular}

${ }^{*}$ Half-lives taken from Walker et al. (1989).

† Distribution for ${ }^{39} \mathrm{Ar}$ was not listed in IAEA (1998a) and was assumed equal to ${ }^{85} \mathrm{Kr}$.

‡ Distribution for ${ }^{94} \mathrm{Nb}$ was not listed in IAEA (1998a) and was assumed equal to ${ }^{93 \mathrm{~m}} \mathrm{Nb}$.

$\S$ Distribution for ${ }^{137} \mathrm{Cs}$ was set equivalent to ${ }^{135} \mathrm{Cs}$ to simplify model calculations; this will yield a more conservative result.

Tी Distribution for ${ }^{150} \mathrm{Eu}$ and ${ }^{166 \mathrm{~m}} \mathrm{Ho}$ was not listed in IAEA (1998a) and was assumed equal to ${ }^{152} \mathrm{Eu}$. $¥$ Distribution for these $U$ isotopes was not listed in IAEA (1998a) and was assumed equal to ${ }^{233} \mathrm{U}$ and ${ }^{236} \mathrm{U}$. †† Pu distribution was more conservatively estimated at $5 \%$ in rubble instead of $2 \%$.

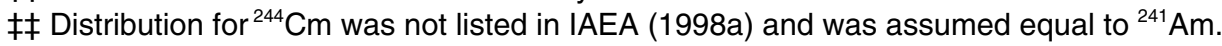


Table 4.4 Initial concentration of radionuclides in the model.

\begin{tabular}{|c|c|c|c|}
\hline \multirow[b]{2}{*}{ RN } & \multicolumn{3}{|c|}{ Initial distribution } \\
\hline & $\begin{array}{l}\text { Melt glass, } \\
\mathrm{mol} / \mathrm{g}\end{array}$ & $\begin{array}{l}\text { Cavity/exchange volume water, } \\
\mathrm{mol} / \mathrm{L}\end{array}$ & $\begin{array}{l}\text { Melt glass water, } \\
\mathrm{mol} / \mathrm{L}\end{array}$ \\
\hline${ }^{3} \mathrm{H}$ & 0 & $6.95 \times 10^{-8}$ & $6.95 \times 10^{-8}$ \\
\hline${ }^{14} \mathrm{C}$ & 0 & $2.60 \times 10^{-10}$ & $2.32 \times 10^{-10}$ \\
\hline${ }^{36} \mathrm{Cl}$ & $3.39 \times 10^{-12}$ & $2.81 \times 10^{-9}$ & $5.21 \times 10^{-10}$ \\
\hline${ }^{39} \mathrm{Ar}$ & 0 & $4.06 \times 10^{-11}$ & $3.62 \times 10^{-11}$ \\
\hline${ }^{41} \mathrm{Ca}$ & $1.24 \times 10^{-11}$ & $4.51 \times 10^{-9}$ & 0 \\
\hline${ }^{59} \mathrm{Ni}$ & $3.04 \times 10^{-13}$ & $1.35 \times 10^{-11}$ & 0 \\
\hline${ }^{63} \mathrm{Ni}$ & $4.21 \times 10^{-14}$ & $1.87 \times 10^{-12}$ & 0 \\
\hline${ }^{85} \mathrm{Kr}$ & 0 & $8.39 \times 10^{-11}$ & $7.48 \times 10^{-11}$ \\
\hline${ }^{90} \mathrm{Sr}$ & $1.46 \times 10^{-12}$ & $1.86 \times 10^{-9}$ & 0 \\
\hline${ }^{93} \mathrm{Zr}$ & $6.24 \times 10^{-12}$ & $2.78 \times 10^{-10}$ & 0 \\
\hline${ }^{93 \mathrm{~m}} \mathrm{Nb}$ & $1.22 \times 10^{-14}$ & $5.44 \times 10^{-13}$ & 0 \\
\hline${ }^{94} \mathrm{Nb}$ & $3.45 \times 10^{-13}$ & $1.53 \times 10^{-11}$ & 0 \\
\hline${ }^{99} \mathrm{Tc}$ & $5.51 \times 10^{-12}$ & $1.16 \times 10^{-9}$ & 0 \\
\hline${ }^{107} \mathrm{Pd}$ & $7.52 \times 10^{-13}$ & $2.73 \times 10^{-10}$ & 0 \\
\hline${ }^{121 \mathrm{~m}} \mathrm{Sn}$ & $1.49 \times 10^{-14}$ & $8.43 \times 10^{-12}$ & 0 \\
\hline${ }^{126} \mathrm{Sn}$ & $3.62 \times 10^{-13}$ & $1.31 \times 10^{-10}$ & 0 \\
\hline $129 \mid$ & $7.77 \times 10^{-13}$ & $6.45 \times 10^{-10}$ & $1.20 \times 10^{-10}$ \\
\hline${ }^{135} \mathrm{Cs}$ & $1.53 \times 10^{-12}$ & $5.18 \times 10^{-9}$ & 0 \\
\hline${ }^{137} \mathrm{Cs}$ & $9.60 \times 10^{-13}$ & $3.25 \times 10^{-9}$ & 0 \\
\hline${ }^{151} \mathrm{Sm}$ & $5.13 \times 10^{-13}$ & $2.28 \times 10^{-11}$ & 0 \\
\hline${ }^{150} \mathrm{Eu}$ & $2.79 \times 10^{-15}$ & $1.24 \times 10^{-13}$ & 0 \\
\hline${ }^{152} \mathrm{Eu}$ & $4.42 \times 10^{-14}$ & $1.97 \times 10^{-12}$ & 0 \\
\hline${ }^{154} \mathrm{Eu}$ & $1.33 \times 10^{-14}$ & $5.92 \times 10^{-13}$ & 0 \\
\hline${ }^{166} \mathrm{Ho}$ & $5.37 \times 10^{-15}$ & $2.39 \times 10^{-13}$ & 0 \\
\hline${ }^{232} \mathrm{U}$ & $1.69 \times 10^{-15}$ & $1.59 \times 10^{-13}$ & 0 \\
\hline${ }^{233} \mathrm{U}$ & $2.57 \times 10^{-12}$ & $2.42 \times 10^{-10}$ & 0 \\
\hline${ }^{234} U$ & $2.85 \times 10^{-12}$ & $2.68 \times 10^{-10}$ & 0 \\
\hline${ }^{235} \mathrm{U}$ & $1.10 \times 10^{-10}$ & $1.04 \times 10^{-8}$ & 0 \\
\hline${ }^{236} \mathrm{U}$ & $1.05 \times 10^{-11}$ & $9.83 \times 10^{-10}$ & 0 \\
\hline${ }^{238} \mathrm{U}$ & $9.26 \times 10^{-10}$ & $8.70 \times 10^{-8}$ & 0 \\
\hline${ }^{237} \mathrm{~Np}$ & $7.79 \times 10^{-12}$ & $3.47 \times 10^{-10}$ & 0 \\
\hline${ }^{238} \mathrm{Pu}$ & $6.27 \times 10^{-14}$ & $2.79 \times 10^{-12}$ & 0 \\
\hline${ }^{239} \mathrm{Pu}$ & $4.64 \times 10^{-11}$ & $2.07 \times 10^{-9}$ & 0 \\
\hline
\end{tabular}


Table 4.4 (Continued).

\begin{tabular}{|c|c|c|c|}
\hline \multirow[b]{2}{*}{ RN } & \multicolumn{3}{|c|}{ Initial distribution } \\
\hline & $\begin{array}{l}\text { Melt glass, } \\
\mathrm{mol} / \mathrm{g}\end{array}$ & $\begin{array}{l}\text { Cavity/exchange volume water, } \\
\mathrm{mol} / \mathrm{L}\end{array}$ & $\begin{array}{l}\text { Melt glass water, } \\
\mathrm{mol} / \mathrm{L}\end{array}$ \\
\hline${ }^{240} \mathrm{Pu}$ & $4.07 \times 10^{-12}$ & $1.81 \times 10^{-10}$ & 0 \\
\hline${ }^{241} \mathrm{Pu}$ & $1.29 \times 10^{-13}$ & $5.74 \times 10^{-12}$ & 0 \\
\hline${ }^{241} \mathrm{Am}$ & $2.02 \times 10^{-13}$ & $8.98 \times 10^{-12}$ & 0 \\
\hline${ }^{244} \mathrm{Cm}$ & $5.37 \times 10^{-15}$ & $2.39 \times 10^{-13}$ & 0 \\
\hline
\end{tabular}

Table 4.5 Simplified inventory classes used in reactive transport simulations.

\begin{tabular}{|c|c|c|c|c|}
\hline Classes & Radionuclide analogs & $\begin{array}{c}\text { Melt glass, } \\
\mathrm{mol} / \mathrm{g}\end{array}$ & $\begin{array}{c}\text { Melt glass } \\
\text { water, } \\
\text { mol/L }\end{array}$ & $\begin{array}{c}\text { Exchange } \\
\text { volume water, } \\
\mathrm{mol} / \mathrm{L}\end{array}$ \\
\hline Tracer $\mathrm{EV}^{*} \dagger$ & \multirow{3}{*}{$\begin{array}{l}{ }^{3} \mathrm{H},{ }^{14} \mathrm{C},{ }^{36} \mathrm{Cl},{ }^{39} \mathrm{Ar}, \\
{ }^{85} \mathrm{Kr},{ }^{99} \mathrm{Tc},{ }^{129} \mathrm{I},{ }^{59} \mathrm{Ni},{ }^{63} \mathrm{Ni},{ }^{93} \mathrm{Zr}, \\
{ }^{93 \mathrm{~m}} \mathrm{Nb},{ }^{94} \mathrm{Nb},{ }^{107} \mathrm{Pd},{ }^{121 \mathrm{~m}} \mathrm{Sn}, \\
{ }^{126} \mathrm{Sn} \ddagger\end{array}$} & 0 & 0 & $2.42 \times 10^{-9}$ \\
\hline Tracer GW* & & 0 & $2.20 \times 10^{-9}$ & $2.20 \times 10^{-9}$ \\
\hline Tracer $\mathrm{MG}^{*}$ & & $2.86 \times 10^{-12}$ & 0 & 0 \\
\hline${ }^{41} \mathrm{Ca}$ & & $1.24 \times 10^{-11}$ & 0 & $4.51 \times 10^{-9}$ \\
\hline${ }^{90} \mathrm{Sr}$ & & $1.46 \times 10^{-12}$ & 0 & $1.86 \times 10^{-9}$ \\
\hline${ }^{137,135} \mathrm{Cs}$ & & $2.49 \times 10^{-12}$ & 0 & $8.43 \times 10^{-9}$ \\
\hline${ }^{151} \mathrm{Sm}$ & & $5.13 \times 10^{-13}$ & 0 & $2.28 \times 10^{-11}$ \\
\hline${ }^{150,152,154} \mathrm{Eu}$ & ${ }^{166} \mathrm{Ho},{ }^{244} \mathrm{Cm} \S$ & $6.03 \times 10^{-14}$ & 0 & $2.69 \times 10^{-12}$ \\
\hline $232,233,234,235,236,238 \mathrm{U}$ & & $1.05 \times 10^{-9}$ & 0 & $9.88 \times 10^{-8}$ \\
\hline${ }^{237} \mathrm{~Np}$ & & $7.79 \times 10^{-12}$ & 0 & $3.47 \times 10^{-10}$ \\
\hline${ }^{238,239,240} \mathrm{Pu}$ & & $5.05 \times 10^{-11}$ & 0 & $2.25 \times 10^{-9}$ \\
\hline${ }^{241} \mathrm{Pu}$ & & $1.29 \times 10^{-13}$ & 0 & $5.74 \times 10^{-12}$ \\
\hline${ }^{241} \mathrm{Am}$ & & $2.02 \times 10^{-13}$ & 0 & $8.98 \times 10^{-12}$ \\
\hline
\end{tabular}

* Tracer EV is tracer in the exchange volume; Tracer GW is tracer in the gas and water; Tracer MG is tracer in the melt glass.

$\dagger$ The behavior of all nonsorbing radionuclides could be most easily described by defining three tracers of unit mol inventory distributed across the various volumes; the breakthrough of each radionuclide can be determined after transport simulations using linear combinations of the various tracers.

$\ddagger{ }^{3} \mathrm{H},{ }^{14} \mathrm{C},{ }^{36} \mathrm{Cl},{ }^{39} \mathrm{Ar},{ }^{85} \mathrm{Kr},{ }^{99} \mathrm{Tc}$, and ${ }^{129} \mathrm{I}$ are expected to behave largely as tracers while ${ }^{59} \mathrm{Ni},{ }^{63} \mathrm{Ni},{ }^{93} \mathrm{Zr},{ }^{93 \mathrm{~m}} \mathrm{Nb},{ }^{94} \mathrm{Nb},{ }^{107} \mathrm{Pd},{ }^{121 \mathrm{~m}} \mathrm{Sn},{ }^{a n d}$ ${ }^{126} \mathrm{Sn}$ are described as tracers because their reactive transport behavior has not been determined.

$\S{ }^{166 \mathrm{~m}} \mathrm{Ho}$ and ${ }^{244} \mathrm{Cm}$ breakthrough is assumed to be equivalent to that of Eu. 


\section{Flow Simulation}

\subsection{Introduction}

This chapter describes simulations of the three-dimensional nonisothermal flow (fully coupled and fluid flow) produced by the CHESHIRE underground nuclear test. These flow simulations generate the three-dimensional fluid velocity fields needed for applications of particle and transient streamline methods for simulation of reactive transport of radionuclides for CHESHIRE (Chapter 7). The porosity fields and hydrofacies distributions developed for the flow simulations are also used, in part, to map spatial distributions of geochemical properties. As a result, these nonisothermal flow simulations form a foundation for much of the physical and some of the geochemical behavior incorporated into the simulations of radionuclide transport.

Much of the work in this report is an outgrowth of the preliminary simulations of Maxwell et al. (2000), where simple conceptual models were used to gain initial perspectives on the role of nonisothermal flows in this problem. In this report, not surprisingly, heterogeneity of hydraulic properties now becomes an important and focal issue in the flow modeling process. For clarification, rocks that exist in their natural state, unaffected by the artificial influences of underground nuclear testing, are called native rocks. The native rocks in the model domain appear lithologically homogeneous as rhyolite flows of the mafic-poor Calico Hills Formation, except for an intrusive dike of the Windy Wash Formation. Hydraulic testing data indicate that permeability varies to several orders of magnitude within the rhyolite flows. Temperature log data also indicate heterogeneity in the permeability field. Given the presence of mixed fracture and matrix flow, heterogeneity undoubtedly occurs at multiple scales within the model domain, an issue to be carefully considered toward obtaining realistic predictions of radionuclide transport at any modeling scale. Additionally, explosion-induced subsurface heterogeneity caused by the CHESHIRE test must be considered.

The ability to address the issue of multiple scales of heterogeneity is constrained by the model resolution, which is $\sim 10 \mathrm{~m}$. Limited information exists on characterizing fine (sub $\sim 10 \mathrm{~m}$ ) scale heterogeneity in the rhyolite lava flows of the mafic-poor Calico Hills Formation. This is not to say that fine-scale heterogeneity will not significantly affect radionuclide transport. Inclusion of intermediate scale (greater than $\sim 10 \mathrm{~m}$ ) heterogeneity profoundly affects the flow behavior and, subsequently, the transport behavior. Inclusion of intermediate scale heterogeneity is essential to producing simulated thermal, flow, and transport behavior that is consistent with available hydraulic and thermal data.

Description of the development of the flow model must begin with the development of a conceptual model. Flow simulation results hinge on the choice of a conceptual model. Therefore, much prediction uncertainty can derive from uncertainty in the conceptual model. An exhaustive analysis of the conceptual model uncertainty, involving every conceivable hydrogeologic interpretation of the CHESHIRE site, would 
be excessive. Alternatively, three basic forms of a hydrogeologic conceptual model-homogeneous, heterogeneous, and layer cake-provide a perspective on the role of the conceptual model and delimit a plausible range of flow behavior.

Although the data available for characterizing the flow behavior surrounding the CHESHIRE test are abundant relative to other underground nuclear tests, considerable subjectivity and interpretation must be projected to arrive at the parameters used in these flow simulations. For example, some spatial continuity of permeability in the lateral directions must be assumed, for which no direct data exist despite this being a key variable for flow and transport behavior. Such limitations must be accepted; the cost to obtain direct permeability data for a rigorous, site-specific characterization of lateral permeability variations would be enormous. In this and future work, multiple angles of interpretation must be used, such as hydraulic testing data from sites with similar hydrogeologic conditions; geophysical logs; outcrop analogs; and geologic insight based on tectonic, lithologic, stratigraphic, and geomorphological knowledge.

Despite the model resolution and data limitations, one can confidently make important conclusions from the flow simulation work. Insights are gained on the issue of heterogeneity and its effect on producing accurate and realistic flow fields. Moreover, the flow simulation results help to evaluate the usefulness of various types of data. For example, temperature log data are useful for calibration of the flow simulations. Thus, one recommendation is to gather more temperature log data at multiple times and locations, if possible. The flow simulations demonstrate and provide a mechanism for analyzing and linking the sensitivities of certain parameters, such as melt glass permeability, to overall flow and transport behavior. Performing the flow simulations not only improves provides fluid velocity fields for streamlines and simulation of radionuclide transport, but also improves understanding of how to conceptualize the flow system and how to recognize key parameters. These insights will be useful for subsequent work at other sites.

\subsection{Conceptual Hydrogeologic Model}

The conceptualization of the hydrogeologic model begins with the geologic setting. The CHESHIRE test was situated within a succession of rhyolitic lava flows of the mafic-poor Calico Hills Formation, as indicated in lithologic logs from U-20a \#2 Water Well, U-20n, and UE-20n \#1 (Hoover et al., 1964; Jenkins, 1969; Erikson, 1991). Hole U20n and U-20a \#2 Water Well penetrated a rhyolitic dike of the Windy Wash Formation, which is discussed later in relation to the flow model.

\subsubsection{Hydrofacies}

Although the native rocks within the flow domain can be considered lithologically homogeneous-rhyolite flows of the mafic-poor Calico Hills Formation-they are not hydraulically homogeneous (Blankennagel and Weir, 1973). The CHESHIRE test added further complexity to the flow system by altering the subsurface through vaporization, melting, crushing, fragmenting, and fracturing of rock as a result of the nuclear explosion and subsequent chimney collapse. To address the 
issues of heterogeneity and alteration of the subsurface permeability structure, the physical domain of the flow model is conceptualized as an assemblage of hydrofacies - categories of rock with distinctive hydraulic properties (Appendix F, Section F.3). The hydrofacies in the flow model are defined according to rock categories based on permeability variations in both the native lava flows and the zones altered by the CHESHIRE test. Table 5.1 lists and describes the nine different hydrofacies defined in the flow models.

Table 5.1. List of hydrofacies defined in flow models.

\begin{tabular}{|l|l|}
\hline \multicolumn{1}{|c|}{ Hydrofacies } & \multicolumn{1}{c|}{ Description } \\
\hline \hline High Permeability & High-permeability native rhyolitic lavas \\
\hline Moderate Permeability & Moderate-permeability native rhyolitic lavas \\
\hline Low Permeability & Low-permeability native rhyolitic lavas \\
\hline Very Low Permeability & Very low permeability native rhyolitic lavas \\
\hline Homogeneous & $\begin{array}{l}\text { Rhyolitic lavas, assuming homogeneous } \\
\text { permeability structure }\end{array}$ \\
\hline Melt Glass & $\begin{array}{l}\text { Zone of rubble and melt puddled at bottom } \\
\text { of former test cavity }\end{array}$ \\
\hline Lower Cavity & $\begin{array}{l}\text { Zone rubble situated at base of chimney } \\
\text { above melt glass zone in lower half of } \\
\text { former test cavity }\end{array}$ \\
\hline Chimney & $\begin{array}{l}\text { Collapsed zone of rubble situated above } \\
\text { and within upper half of former test cavity }\end{array}$ \\
\hline Disturbed Zone & $\begin{array}{l}\text { Zone of native rock immediately outside of } \\
\text { former test cavity that was disturbed (but } \\
\text { not melted or vaporized) by test }\end{array}$ \\
\hline
\end{tabular}

\subsubsection{Native Rock Heterogeneity}

Lazniak et al. (1996) indicate that the discontinuous nature of volcanic aquifers complicates groundwater flow within lava flows at Pahute Mesa because the flow occurs primarily through interconnected fractures and is impeded by the crystalline parts of the lava flows. Prothro and Drellack (1997) indicate that internal structure of the lava flow aquifers beneath Pahute Mesa is geometrically complex:

"The viscous nature of rhyolite lavas results in the formation of bulbous domes, mesas, and elongated plateaus called coulees. All these features are relatively thick in relation to their areal extent and have steep, abrupt flanks."

"Rhyolite lavas at Pahute Mesa tend to coalesce and overlap, forming a complex three-dimensional network of lava flow lithologies."

Hydraulic data indicate that permeability of the native rhyolitic lava flows varies by several orders of magnitude (see Appendix F). However, the data are 
inadequate to determine the three-dimensional spatial variation of permeability within the model domain. To address the uncertainty of the permeability structure, three conceptual models were developed for the native rock, as follows:

- A heterogeneous (stochastic) model with spatial variations of permeability generated by geostatistical techniques.

- A layer cake-like model that assumes horizontally layered permeability variations.

- A homogeneous model with no spatial variation of permeability.

These three models are useful for defining a plausible range of flow and transport behavior. The layer cake and homogeneous models described in this report, and their associated parametric and geometric specifications, are more consistent with data used in the heterogeneous model than those discussed in the preliminary work of Maxwell et al. (2000).

By incorporating a stochastic algorithm to produce multiple realizations of permeability structure, the heterogeneous model addresses the issue of uncertainty and variation of flow behavior resulting from uncertainty in characterizing spatial variation of permeability within the native rock. Pohlmann et al. (2000) used a similar approach to provide uncertainty estimates for conservative radionuclide transport behavior resulting from the FAULTLESS test. In the referenced work, categorical (indicator) stochastic simulations of alluvium and low and high permeability rocks were generated. Gaussian random fields were superposed on the each rock type to produce the permeability field at a resolution of $50 \mathrm{~m}$. Our application differs in that the model domain is smaller and resides within one rock type. Our model resolution is also finer at $10 \mathrm{~m}$.

The choice was made to generate permeability heterogeneity within the native rock using a categorical or facies-based approach (see Appendix G). This approach was used because the permeability variations at the model scale can be attributed to zones with different fracture characteristics, which result in abrupt spatial transitions in permeability. A Gaussian random field assumption imparts continuous and smooth permeability variation. Hydraulic testing data indicate a modal (not Gaussian or log-normal) distribution of permeabilities spanning four orders of magnitude (see Appendix F, Table F.4 and Figure F.3). The categorical approach preserves connectivity within the extreme permeability values, particularly in the high permeability zones. Gaussian random field models tend to isolate extreme values and eliminate fast pathways (Deutsch and Journel, 1998), which are of concern in this modeling effort. The heterogeneous model, which includes high, moderate, low, and very low permeability hydrofacies within the rhyolitic lava flows, enables inclusion of interconnected high-permeability zones.

The layer-cake and homogeneous models are useful for illustrating lower and upper bounds on flow and transport behavior. Both of these models can be considered oversimplifications that will lead to drastically different and potentially unrealistic flow and transport behaviors. The homogeneous model assumes a single effective 
permeability for the native rocks. The flow and transport results from the homogeneous model will be useful for illustrating and contrasting the effect of not considering heterogeneity in the permeability structure.

The layer-cake model, on the other hand, does incorporate heterogeneity, in a one-dimensional sense, by assuming that high permeability zones are laterally extensive. Buddemeier et al. (1992a, 1992b) and Sawyer et al. (1999) used the layer-cake model to illustrate potential mechanisms for radionuclide transport at CHESHIRE. However, the layer-cake model assumption of perfect lateral continuity in high permeability zones, although a popular notion among groundwater modelers, typically leads to over-prediction of transverse and lateral migration and under-prediction of vertical migration and macrodispersion. For the layer-cake model, high and moderate permeability hydrofacies are included (the hydraulic data indicate that low and very low permeability hydrofacies are rare). As discussed in detail later, base-case permeability values are assigned to the hydrofacies, and those permeability values are varied in sensitivity studies.

\subsubsection{Altered Zones}

Spatial zones that have changed hydraulic and mineralogic properties as a result of the CHESHIRE underground nuclear test are referred to as altered zones. The working point for the CHESHIRE test was situated in U-20n at a depth of $1167 \mathrm{~m}$ below the surface and $542 \mathrm{~m}$ below the water table (Figure 5.1). Unclassified calculations based on the upper limit announced yield range of 200-500 kt (USDOE, 2000) are used to estimate a cavity radius (Rc) and a volume of melt glass. The volume estimate of melt glass is used to estimate a thickness of melt glass $(\mathrm{Hg})$ assuming spherical cavity geometry. Based on a $500 \mathrm{kt}$ yield, the assumption is that $R c=80 \mathrm{~m}$ and $H g=24.9 \mathrm{~m}$. To accommodate the numerical grid spacing of $10 \mathrm{~m}$, the melt glass height was modified to $30 \mathrm{~m}$ in the numerical simulations. Posttest data indicate that the collapsed chimney extends above the water table (Jorgensen, 1987) but not as far as the ground surface, since no crater was observed at surface ground zero (Carlson and Wagoner, 1991). 


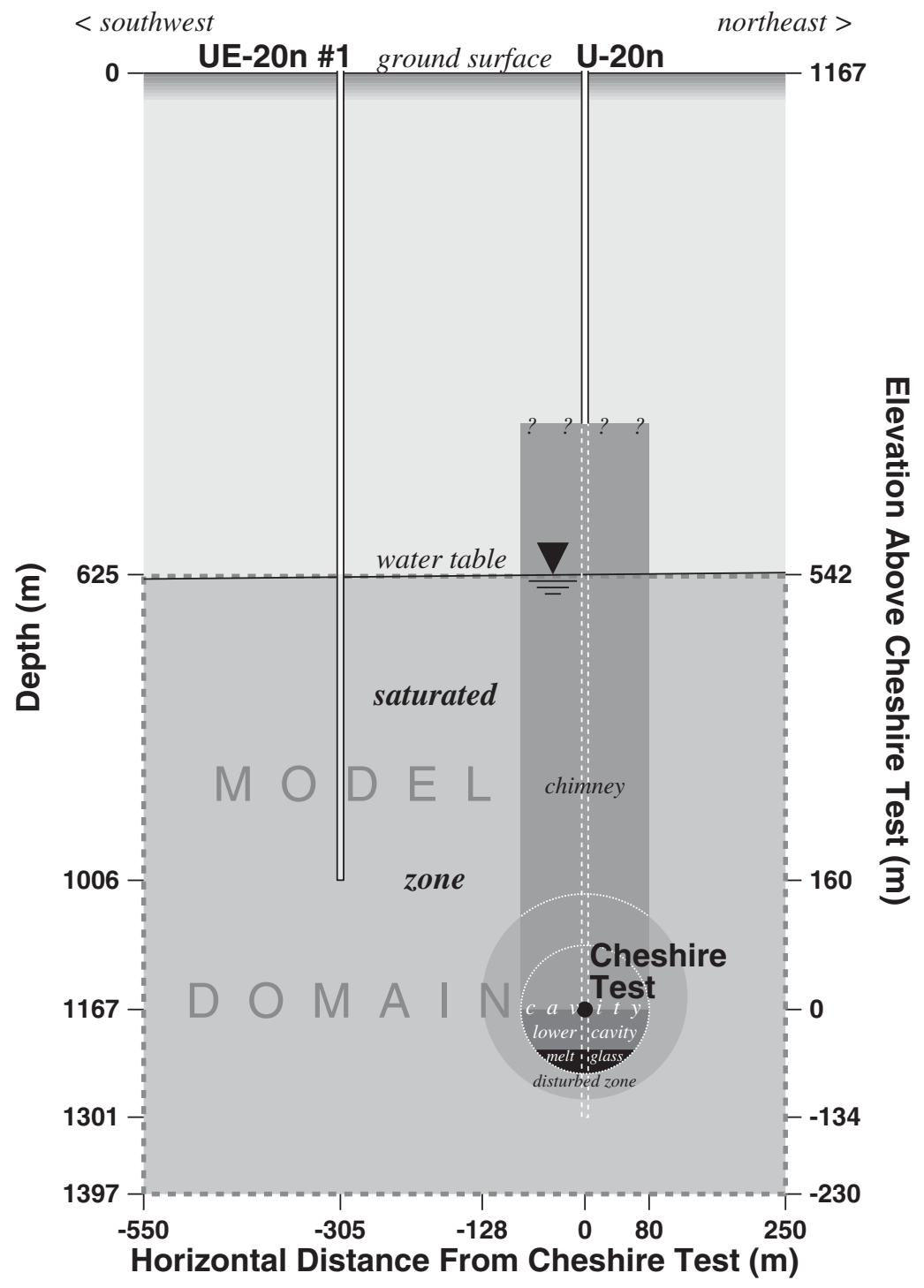

Figure 5.1 Cross-sectional view showing location of CHESHIRE test, holes U-20n and UE-20n \#1, and model domain. Altered zones are sized to the dimensions assumed in the flow and transport simulations.

Hydrofacies associated with altered zones associated with after-effects of the CHESHIRE test are the melt glass, lower cavity, chimney, and disturbed zone. These zones are included in all simulations. The melt glass is assumed to be puddled in the lower $30 \mathrm{~m}$ of an $80 \mathrm{~m}$ radius sphere (or cavity) centered at the working point. The lower cavity is above the melt glass in the lower half of the $80 \mathrm{~m}$ radius sphere centered at the working point. The chimney is within a cylinder of $540 \mathrm{~m}$ height and $80 \mathrm{~m}$ radius, with the bottom at the working point elevation and the top, in effect, at the water table elevation. The disturbed zone consists of a spherical shell zone with a radius of $128 \mathrm{~m}$ (1.6 cavity radii), centered $16 \mathrm{~m}$ above the working point. The slight upward off-center alignment with respect to the working point is meant to approximate an asymmetric fracture distribution as expected from crack formation models (Hazelton Nuclear Science Corporation, 1965) and field observations (Boardman et al., 1964). 
The cavity is a spherical zone of $80 \mathrm{~m}$ radius around the working point and above the melt glass. Although the cavity region is not used to define hydraulic parameters, it distinguishes the location of thermal, geochemical, and transport parameters.

\subsubsection{Windy Wash Formation Dike}

An intrusive rhyolitic dike of the Windy Wash Formation was identified near the CHESHIRE working point in hole U-20n and at the bottom of U-20a \#2 Water Well. ${ }^{1}$ Clark and McArthur (1986) also inferred a rhyolitic dike of the Windy Wash Formation to occur below U-20av about $1 \mathrm{~km}$ south of U-20n. Three point calculations indicate that the dike could be oriented at about $\mathrm{N} 20^{\circ} \mathrm{E}$, dipping $80^{\circ} \mathrm{W}$, with a thickness of about 10 $\mathrm{m}$. This orientation is realistic, considering the local structural grain and occurrences of Windy Wash Formation dike outcrops in the moat of the Claim Canyon caldera (Sawyer et al., 1999). The dike is assumed to present a relatively low permeability feature in the pre-CHESHIRE setting because the excavation chamber for CHESHIRE was preferentially sited within this dike, and results of injection tests in U-20n indicate low permeability (Jenkins, 1969). The CHESHIRE test, of course, completely obliterated the dike within the cavity, crumbled the dike in the chimney, and probably increased the dike permeability in the disturbed zone.

Flow simulations were run with and without a low permeability and laterally extensive dike in the native rock, and little difference was found in the flow behavior. In particular, the presence of a dike did not produce significant changes in flow velocities or convergent flow downgradient of the CHESHIRE test. As a low permeability sheet-like unit existing only in the undisturbed native rock, the dike has little effect on the nearfield behavior because flow is funneled through the cavity, chimney, and disturbed zone. Within the native rock, the dike is oriented nearly parallel to the flow direction, so it would primarily serve as a hindrance to lateral dispersion and a possible barrier to interconnectivity. The potential impact of the dike would depend on its lateral extent, which is unknown. Given the uncertainty of the geometry of the dike, the flow simulations do not consider it, which is a conservative measure considering that the dike would most likely cause a hindrance to radionuclide migration.

\subsection{Model Coordinate System}

The flow simulations were conducted with respect to a three-dimensional rectilinear coordinate system. The CHESHIRE test working point functions as the origin of the coordinate system. As Figure 5.2 shows, the $x$ coordinate is directed in the horizontal plane at $S 60^{\circ} \mathrm{E}$, and the $y$ coordinate is directed in the horizontal plane at $\mathrm{N}$ $30^{\circ} \mathrm{E}$. The $z$ coordinate is directed to vertical. The $x-y$ plane alignment is positioned such that the $y$ axis parallels the expected flow direction of $S 30^{\circ} \mathrm{W}$ (Erikson, 1991). This alignment is identical to the direction of a vector originating at well U-20n and heading to the location of well UE-20n \#1. The model domain extends from $-150 \mathrm{~m}$ to $+150 \mathrm{~m}$ in the $x$ direction, $-550 \mathrm{~m}$ to $+250 \mathrm{~m}$ in the $y$ direction, and $-230 \mathrm{~m}$ to $+570 \mathrm{~m}$ in the $z$ direction. As discussed in Section 5.6.4 on boundary conditions, the uppermost $30 \mathrm{~m}$ (a

\footnotetext{
${ }^{1}$ R. G. Warren, Los Alamos National Laboratory, oral communication, 1999.
} 
thickness of three grid blocks) functions as a buffer zone to accommodate both the thermal and hydrologic boundary conditions. Therefore, the top of the model domain is effectively placed at $+540 \mathrm{~m}$ in the $\mathrm{z}$ direction, which is very near the measured water table elevation of $+542 \mathrm{~m}$, as shown in Figure 5.3.

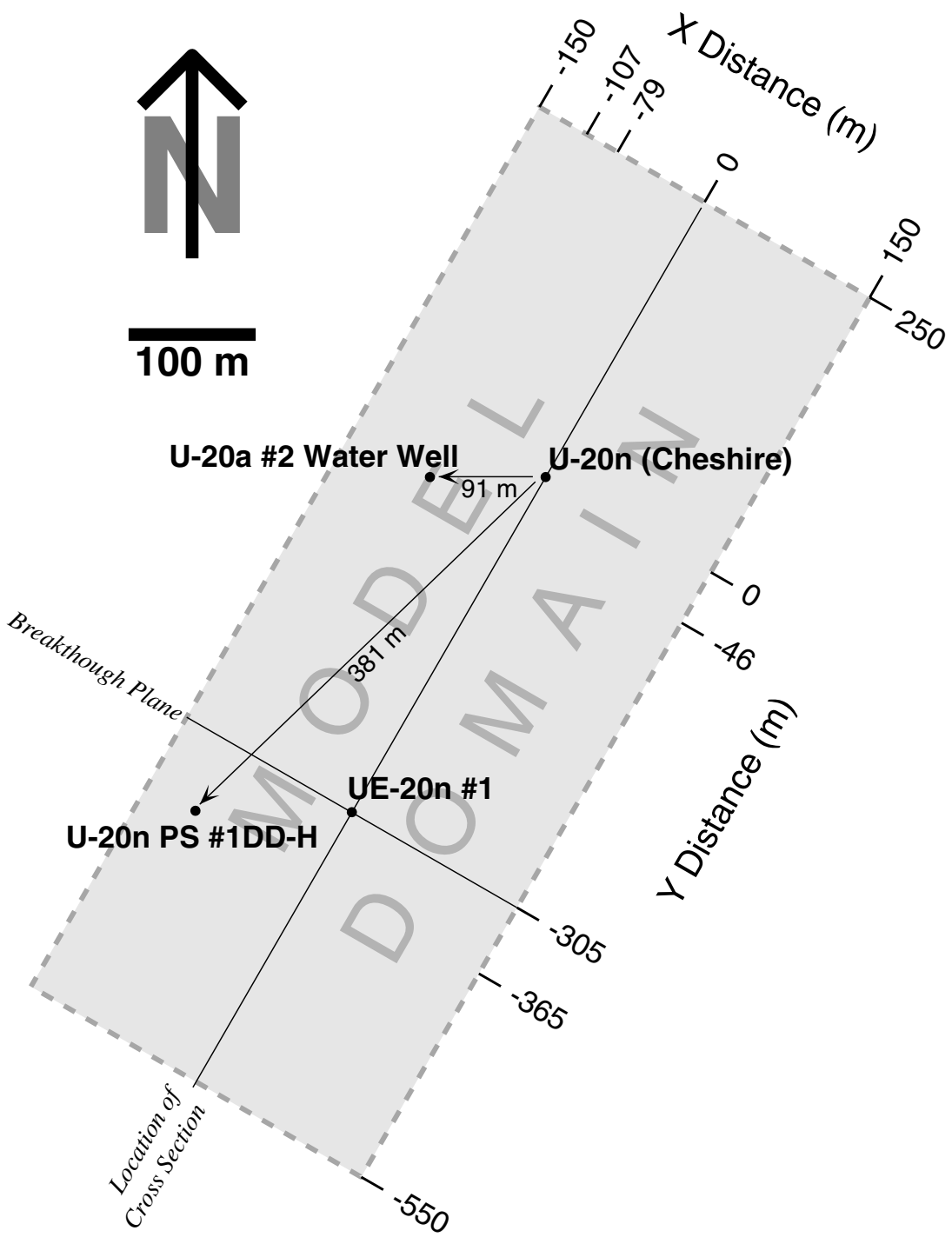

Figure 5.2 Plan view showing location of model domain and breakthrough plane with respect to holes U-20n, UE-20n \#1, and U-20n PS \#1DD-H and U-20a \#2 Water Well. 


\section{$5.4 \quad$ Hydraulic Data}

Various data-direct and indirect-were used to construct the flow model. Even data that might be considered direct, such as hydraulic testing data, required considerable effort to translate them into model parameters (Appendix F). In a strict sense, all hydraulic data incorporated into the model were indirect, because none pertain directly to the scaled effective hydraulic properties of grid blocks in the numerical model. As discussed earlier, the hydrofacies were divided into two categories:

- Native rock, signifying undisturbed mafic-poor Calico Hills Formation lava flows surrounding CHESHIRE.

- Altered rock, signifying rocks altered by the explosion from the CHESHIRE Test.

The following sections describe hydraulic data for each category.

\subsubsection{Native Rocks}

Table 5.2 shows the base-case permeability and effective porosity values for native rock hydrofacies in heterogeneous, layer-cake, and homogeneous conceptual models. The bases for selecting these values are given in the next sections.

Table 5.2 Base-case values of effective lateral permeability (kxy), anisotropic permeability ( $k x: k y: k z)$ ratios with respect to $k x y$, and effective porosity assumed for native rock hydrofacies in simulations of flow and transport. Sources of data: $a=$ pumping tests in $\mathrm{U}$ 20a \#2 Water Well; $b=$ injection tests in U-20a \#2 Water Well; c = Bullion Forced Gradient Experiment; $d=$ fracture data; $e=$ matrix porosity measurements. The last column summarizes the principal assumed mode of flow, as described in 5.4.1.3 and as regarded in the definition of retardation properties in Appendix K.

\begin{tabular}{|c|c|c|c|c|}
\hline Hydrofacies & $\begin{array}{c}\text { Effective } k_{x y} \\
\left(10^{-12} \mathrm{~m}^{2}\right)\end{array}$ & Anisotropy $k_{x}: k_{y}: k_{z}$ & $\begin{array}{l}\text { Effective } \\
\text { Porosity }\end{array}$ & Flow Regime \\
\hline $\begin{array}{l}\text { Heterogeneous- } \\
\text { high }\end{array}$ & $0.72^{a, b}$ & $0.32: 1.6: 1.6^{\mathrm{c}, \mathrm{d}}$ & $0.01^{\mathrm{c}}$ & Fracture flow \\
\hline $\begin{array}{l}\text { Heterogeneous- } \\
\text { moderate }\end{array}$ & $0.014^{\mathrm{b}}$ & (isotropic) & $0.01^{\mathrm{c}}$ & Fracture flow \\
\hline Heterogeneous-low & $0.0026^{b}$ & (isotropic) & $0.15^{e}$ & Matrix flow \\
\hline $\begin{array}{l}\text { Heterogeneous- } \\
\text { very low }\end{array}$ & $0.00025^{b}$ & (isotropic) & $0.15^{\mathrm{e}}$ & Matrix flow \\
\hline Layer cake_high & $0.72^{a, b}$ & $0.32: 1.6: 1.6^{c}$ & $0.01^{c}$ & Fracture flow \\
\hline $\begin{array}{l}\text { Layer cake- } \\
\text { moderate }\end{array}$ & $0.014^{b}$ & (isotropic) & $0.01^{\mathrm{c}}$ & Fracture flow \\
\hline Homogeneous & $0.24^{a}$ & (isotropic) & $0.01^{c}$ & Fracture flow \\
\hline
\end{tabular}




\subsubsection{Permeability}

Hydraulic testing was conducted in U-20a \#2 Water Well, located $91 \mathrm{~m}$ west of hole U-20n and the CHESHIRE test (Figures 5.1 and 5.2), providing the primary source of permeability data for rocks surrounding the CHESHIRE test. The U-20a \#2 Water Well was completed to a depth of $1372 \mathrm{~m}$ (4500 ft) on February 16, 1964. The depth of U-20a \#2 Water Well extends to within $25 \mathrm{~m}$ of the bottom of the flow model domain.

Permeability was estimated for the native rock hydrofacies by combining two types of testing:

- A pumping test conducted in U-20a \#2 Water Well (Blankennagel and Weir, 1965).

- Injection tests conducted on packed intervals in U-20a \#2 Water Well (Blankennagel et al., 1964).

The pumping test yielded an overall transmissivity of $224 \mathrm{~m}^{2} / \mathrm{d}$ in U-20a \#2 Water Well, which corresponds to an average permeability of $0.24 \times 10^{-12} \mathrm{~m}^{2}$. Injection tests were conducted over $98 \%$ of the saturated interval (Blankennagel et al., 1964). The injection tests were useful for estimating the permeability range of the relatively low permeability lava flows or lava flow aquitards. Although the injection test data do not directly yield permeability estimates, a conversion method was derived for obtaining permeability estimates for the lower permeability (aquitard) zones (Appendix F). Figure 5.3 shows the estimates of average hydraulic conductivity values over injection test intervals in U-20a \#2 Water Well. An average lateral permeability of $7.2 \times 10^{-13} \mathrm{~m}^{2}$ was estimated for high permeability lava flows or lava flow aquifers by subtracting the aquitard transmissivity from the overall transmissivity and dividing by the total length of the packed intervals that span high permeability zones.

Based on interpretations of the combined pumping test and injection test data, realistic effective permeabilities were estimated in the lateral direction, $k_{x y}$, for four native rock hydrofacies. Estimates for high, moderate, low, and very low permeability lava flows are $7.2 \times 10^{-13}, 1.4 \times 10^{-14}, 2.6 \times 10^{-15}$, and $2.5 \times 10^{-16} \mathrm{~m}^{2}$, respectively. These permeability estimates are used as the base-case values in the simulations; other values are used in sensitivity studies. The sensitivity studies considered two alternative cases of lava flow permeability:

- Homogeneous lava flows (all lava flows have permeability of $0.24 \times 10^{-13}$ ).

- Different anisotropy ratios for the high-permeability hydrofacies of 1:5:5 and 1:1:1 (isotropic).

From the injection test data, one can infer hydrofacies proportions of $37 \%$ high permeability lava flows or lava flow aquifers, $46 \%$ moderate permeability lava flows, and $17 \%$ low to very low permeability lava flows.

Given a 50:1 permeability contrast between the high and moderate permeability hydrofacies, fast pathways for radionuclide transport in native rocks will 
be dominated by the spatial distribution of the high permeability hydrofacies (lava flow aquifers). Transport behavior in the remaining hydrofacies will tend to exhibit largescale matrix diffusive effects evidenced by trapping of contaminants in low flow velocity regimes and tailing in breakthrough curves.

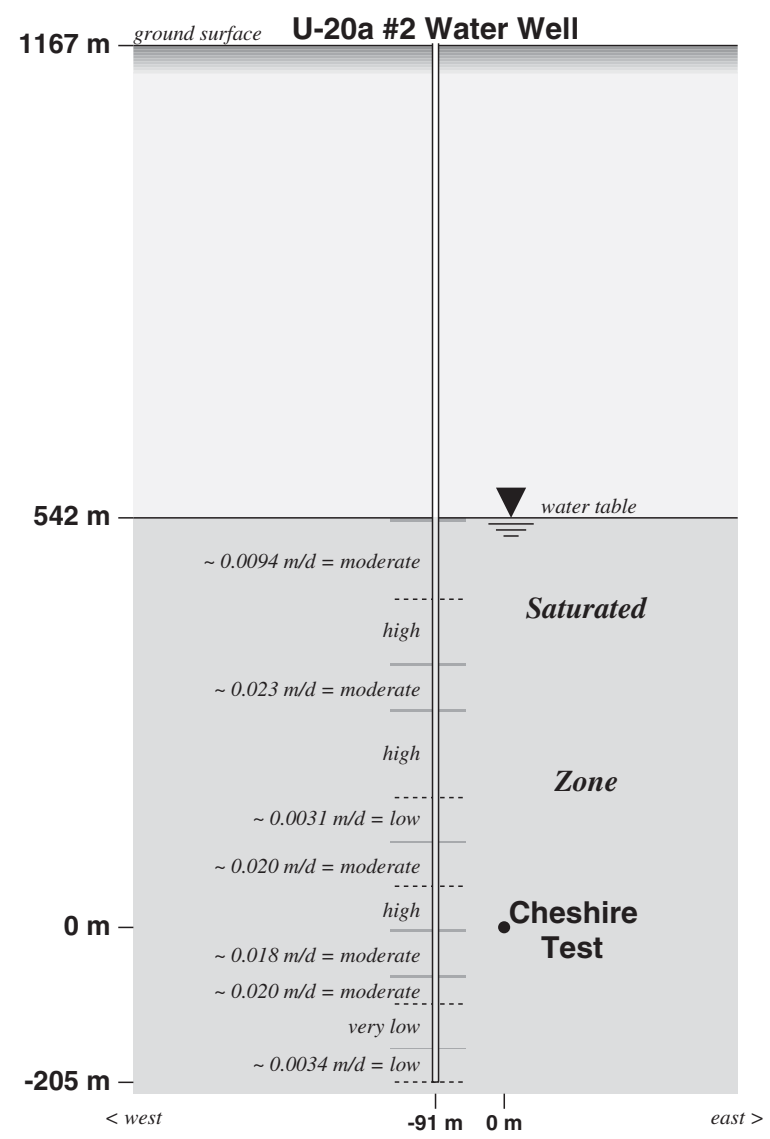

Figure 5.3 Cross section showing hydraulic conductivities of rhyolitic lava flows inferred from pumping and injection test data in U-20a \#2 Water Well. Based on these data, native rock permeabilities are categorized as high, moderate, low, and very low permeability hydrofacies for the flow simulations.

\subsubsection{Anisotropy}

Permeability anisotropy is expected to occur in the high permeability zones as a result of preferential orientation and spatial distribution of open fractures. In the basecase simulations, a permeability anisotropy ratio 1:5:5 is incorporated in the $x: y: z$ directions for lava flow aquifers to accommodate preferred fracture orientations in the NNE and vertical directions (Appendix F.3.1 and Drellack et. al, 1997). Anisotropic permeability was also necessary to calibrate the model with temperature log data. Our estimates of permeability magnitudes and anisotropy ratios for the high permeability hydrofacies are consistent with interpretations of multi-well pump test and tracer tests conducted for the BULLION Forced-Gradient Experiment at the ER-20-6 well cluster, which reported a 1:7 anisotropy ratio in $x: y$ directions. These flow and transport experiments were conducted in similar rhyolitic lava flow aquifers of the mafic-poor Calico Hills Formation, with a similar NNE alignment of the $y$-direction (IT 
Corporation, 1998a; Geldon ${ }^{2}$ ). Analysis of core and geophysical logs at Pahute Mesa indicate that fractures tend to preferentially align toward a NNE strike and steep dip (Drellack et al., 1997). In regard to hydrofacies spatial distribution (described in Appendix $\mathrm{G}$ ), isotropy was assumed in the $x: y$ direction because no preference in the lateral directional characteristics of rhyolitic lava flows at Pahute Mesa has been identified. Considering that rhyolitic lava flows tend to have limited lateral extent (Prothro and Drellack, 1997), lateral:vertical anisotropy ratios ranging from 4:1 to 5:1 were assumed for the geostatistical model of the native rock rhyolitic lava flow hydrofacies.

Fractures near CHESHIRE tend to be steeply dipping and oriented in the NNE direction (see Appendix F.3.1), which is aligned with the $y$-direction of the model coordinate system. Thus, one can expect that the high permeability zones will exhibit anisotropic permeability with increased permeability in the $y$ and $z$ model directions. This interpretation of anisotropic permeability is later supported by calibration of the nonisothermal flow simulations to temperature data. The $1^{\circ} \mathrm{C}$ temperature anomaly observed near the top of well UE-20n \#1 at 11.3 yr after the CHESHIRE test (Erikson, 1991) could be reproduced by assuming both anisotropy in the high permeability hydrofacies and the effective permeabilities indicated by hydraulic testing. Appendix $F$ gives a detailed description of an interpretation of the hydraulic and fracture data.

\subsubsection{Effective Porosity}

Measured total porosity of the lava flows ranges between $6.6 \%$ and $28.7 \%$ (Monk and Snyder, 1964) and averages $15.5 \%$ (Blankennagel and Weir, 1973). Measured total porosity may be significantly greater than effective porosity, which accounts for the fact that effective flow at the grid block scale may not, in reality, actively occur throughout all pore space of the rock. Groundwater flow in lava flows at Pahute Mesa is dominated by fractures, particularly in the high permeability zones (Blankennagel and Weir, 1973). Therefore, effective porosity will be significantly less than measured total porosity for the relatively high permeability native rocks surrounding CHESHIRE.

One must consider that at the $10 \mathrm{~m}$ scale of the grid blocks, simulated flow velocities represent volume averaged or effective flow velocities. Thus, porosity values used as parameters in the flow model represent effective porosity values used to obtain realistic effective flow velocities at the $10 \mathrm{~m}$ grid block scale. Effective porosity at the grid block scale in the flow model will be greater than fracture porosity. This difference arises because the effective fluid velocity is less than what would be obtained from an idealized parallel plate model, considering tortuosity, surface roughness, fracture interconnectivity, and flow occurring partially in the matrix. Knox et al. (1965) point out that in comparison to fracture porosity, effective porosity would need to be multiplied by a factor of 45 to convert observed (tracer determined) fracture flow velocities in dolomite at the GNOME test to the effective fluid velocities for a homogeneous porous medium model. For lava flow aquifers at Pahute Mesa, a fracture porosity of $0.02 \%$ is obtained from an average fracture density of $N=0.39 / \mathrm{m}$ and an average fracture aperture of $b=0.0005 \mathrm{~m}$ (Drellack et al., 1997). Effective porosity was estimated between

\footnotetext{
${ }^{2}$ A.L. Geldon, U.S.Geological Survey, written communication, 1999.
} 
0.008 and 0.023 for lava flow aquifers, based on interpretation of tracer breakthrough data from the BULLION Forced-Gradient Experiment (IT Corporation, 1998a).

Interestingly, multiplying a $0.02 \%$ fracture porosity by a factor of 45 yields an effective porosity of 0.009 , which falls within the range of estimated effective porosity from that experiment.

Base-case effective porosities of 0.01 were assumed for the high and moderate permeability hydrofacies and 0.15 for the low and very low permeability hydrofacies. These effective porosity assumptions impart conceptualizations of fracture-dominated flow in the high and moderate permeability hydrofacies and matrix-dominated flow in the low and very low permeability hydrofacies. Matrix-dominated flow in the low and very low permeability hydrofacies is expected, given the findings of Burkhard et al. (1989). These findings indicate that fractured volcanic NTS rocks have a matrix permeability range of $1 \mu \mathrm{D}$ to $10 \mathrm{mD}\left(1 \times 10^{-18}\right.$ to $\left.1 \times 10^{-14} \mathrm{~m}^{2}\right)$, which brackets the basecase permeability estimates for the low and very low permeability hydrofacies. Differences in permeability between high and moderate permeability hydrofacies are attributed to degree of interconnectivity of fractures, not necessarily the frequency and aperture distribution of fractures. Therefore, one can conceive of similar effective porosities for both the high and moderate permeability hydrofacies. The layer-cake and homogeneous conceptual models assume a constant effective porosity of 0.01 for natural rock hydrofacies because these models have no low permeability zones and, thus, assume fracture-dominated flow throughout. Clearly, effective porosity is an important transport simulation parameter that would benefit from further study. This point is emphasized by Pohlmann et al., (2000), who concluded that radionuclide transport results were particularly sensitive to effective porosity of their fractured welded tuff unit.

\subsubsection{Altered}

Direct measurements of hydraulic properties of the altered rock hydrofacies at CHESHIRE-melt glass, lower cavity, chimney, and disturbed zone-are unavailable. One must rely on scant data from other underground nuclear tests, insights gained from calibration of the flow and transport models, and understanding of the phenomenology of underground nuclear tests to develop a suite of representative hydraulic properties. Although heterogeneity in permeability and porosity undoubtedly exists within the altered rock hydrofacies, the combined lack of simulation resolution, data, and a fine-scale conceptual model has not warranted, for now, the added complexity of including permeability and porosity heterogeneity within altered rock hydrofacies. Clearly, further study is needed to examine the effect of smaller scale heterogeneities on flow and transport behavior in the altered (and undisturbed) zones. Our assumed base-case permeability and porosity values for altered rock hydrofacies are shown in Table 5.3. As for the native rocks, these permeabilities represent a set of base-case values - other permeability values were assumed for the altered rocks in sensitivity analyses. 
Table 5.3 Base-case values of permeability and effective porosity assumed for altered rock hydrofacies in simulations of flow and transport. The last column summarizes the principal assumed mode of flow, as described in 5.4.2.3 and as regarded in the definition of retardation properties in Appendix K.

\begin{tabular}{|l|c|c|l|}
\hline \multicolumn{1}{|c|}{ Hydrofacies } & $\begin{array}{c}\text { Permeability, } \\
\mathbf{1 0}^{-12} \mathbf{~ m}^{\mathbf{2}}\end{array}$ & $\begin{array}{c}\text { Effective } \\
\text { porosity }\end{array}$ & \multicolumn{1}{c|}{ Flow Regime } \\
\hline \hline Melt glass & 0.04 & 0.20 & Cavity chimney matrix flow \\
\hline Lower cavity & 1.0 & 0.10 & Cavity chimney matrix flow \\
\hline Chimney & 50.0 & 0.10 & Cavity chimney matrix flow \\
\hline Disturbed zone & 4.0 & 0.01 & Fracture flow \\
\hline
\end{tabular}

\subsubsection{Permeability}

The base case assumed a melt glass permeability of $4.0 \times 10^{-14} \mathrm{~m}^{2}$ and a lower cavity permeability of $1.0 \times 10^{-12} \mathrm{~m}^{2}$ based on the calibrations to temperature logs. A chimney permeability of $5.0 \times 10^{-11} \mathrm{~m}^{2}$ was assumed, based on three sources of information:

- Calibrations to temperature logs.

- A chimney permeability range of $1.2 \times 10^{-11}$ to $6.3 \times 10^{-11} \mathrm{~m}^{2}$ given by Rozsa et al. (1974).

- Consideration of plausible permeability values for a rubble material.

Other previous estimates of chimney permeability have ranged over 6 orders of magnitude. On the low side, Brikowski (1993) assumed a chimney permeability of $6 \times 10^{-13} \mathrm{~m}^{2}$ for analytical solutions of chimney conduit-aquifer systems formed by underground nuclear testing in fractured rhyolite. On the high side, Boardman and Meyer (1965) suggest that the permeability of the HARDHAT chimney in fractured and jointed granitic rock is very high-millions of darcies, or more than $1 \times 10^{-6} \mathrm{~m}^{2}(1 \mathrm{D}=$ $1 \times 10^{-12} \mathrm{~m}^{2}$ ), based on particle statistics of rubble (Rodean, 1964). The disturbed zone is assumed to consist of lava flows sheared or crushed by the radial compressive stress of the CHESHIRE test explosion. For the disturbed zone, a permeability of $4.0 \times 10^{-12} \mathrm{~m}^{2}$ was assumed. Boardman and Skrove (1966) reported permeability values of several darcies $\left(1 \mathrm{D}=1 \times 10^{-12} \mathrm{~m}^{2}\right)$ in the disturbed zone within about 2.5 cavity radii of the HARDHAT test conducted in granite at the Nevada Test Site.

\subsubsection{Anisotropy}

Isotropic permeability is assumed for all of the altered hydrofacies. Undoubtedly, permeability anisotropy exists in the altered zones, but insufficient information and model resolution exist to add such complexity in the models. 


\subsubsection{Effective Porosity}

A uniform effective porosity of 0.20 is assumed for the melt glass zone based on observations of abundant vesicules in core samples (Smith, 1995). Because the difference between total and effective porosity in a heterogeneous melt glass zone is not currently understood, the two are assumed to be the same in this analysis. An effective porosity of 0.10 is assumed for the chimney based on void space created in its collapse, which one expects to dominate chimney permeability. Rawson and Borg (1966) estimated a void space of 0.076 in the chimney volume for the GREELEY test, which was conducted beneath an overburden of lava flows and tuffs. An effective porosity of 0.10 is estimated for the lower cavity, assuming that it consists primarily of rubble, crushed rock, dust, and melt glass. Flow in all of these areas is assumed to occur, approximately, under coarse matrix-dominated conditions. An effective porosity of 0.01 is estimated for the disturbed zone, assuming fracture-dominated flow similar to the high permeability hydrofacies.

\section{$5.5 \quad$ Temperature Data}

Temperature logs were obtained in holes U-20a \#2 Water Well and U-20n before the CHESHIRE test, and in holes U-20n PS \#1DD-H and UE-20n \#1 after the CHESHIRE test.

The temperature logs obtained from U-20a \#2 Water Well and U-20n are useful for estimating a background geothermal gradient. Based on measured bottomhole and average top-hole temperatures in U-20a \#2 Water Well, Blankennagel and Weir (1973) estimated a geothermal gradient of $\left(20.7^{\circ} \mathrm{C} / \mathrm{km}\right)$. In interpreting the temperature log data, one must consider that many of the logs were obtained during or soon after well construction activities such as cementing, which can impart considerable thermal effects. Avoiding thermal logs showing well construction effects, one notices that in both U-20a \#2 Water Well and U-20n, the geothermal gradients appear higher in the unsaturated zone than the saturated zone. A temperature log obtained for U-20a \#2 Water Well on February 17, 1964, immediately after drilling, indicates a thermal gradient of about $9.6^{\circ} \mathrm{C} / \mathrm{km}$ in the saturated zone. For U-20n temperature logs obtained on August 25, 1968, and July 12, 1975, indicate geothermal gradients of about 7.1 and $8.3^{\circ} \mathrm{C} / \mathrm{km}$, respectively, in the saturated zone.

These gradients may appear anomalously low compared with the average geothermal gradient in the NTS area of $25.7^{\circ} \mathrm{C} / \mathrm{km}$ given by Sass and Lachenbruch (1982). However, other holes in Area 20 of NTS, namely U-20aa, U-20c, U-20d, U-20e, U-20i, U-20m, UE-20ad, and UE-20j, show similar geothermal gradients in the saturated zone (Pottorff et al., 1987). The anomalously low geothermal gradients could be attributed to groundwater circulation in the relatively high permeability lava flow aquifer system or relatively high thermal conductivity. Notably, lavas generally have higher thermal conductivity than tuffs, and rocks with higher silicic content, such as rhyolite, tend to have higher thermal conductivity.

Following the CHESHIRE test, a series of drill back holes were constructed to evaluate the effect of the CHESHIRE test. These drill back holes were later used for water sampling and temperature profile measurements. One drill back hole of interest, U-20n 
PS \#1DD-H, was located on the ground surface $381 \mathrm{~m}$ away from the main emplacement hole, U-20n, and slant-drilled toward the working point (Figure 5.2). Several thermal profiles were taken in this hole at different times after the test. Three of these (labeled runs two, three, and four) provide useful, continuous measurements of temperature at 154, 201, and $2356 \mathrm{~d}$ after the test.

Exploratory hole UE-20n \#1 was drilled $305 \mathrm{~m}$ (1000 ft) SSW of U-20n to a depth of $1005.8 \mathrm{~m}$ in May 1987 (Figures 5.1 and 5.2). Temperature data were also collected in UE-20n \#1 in June and July 1987 (11.3 yr after the CHESHIRE test). These data show a high temperature anomaly of approximately $1^{\circ} \mathrm{C}$ near the top of the saturated zone. This anomaly is most plausibly explained by migration of heated water through high permeability lava flows (lava flow aquifer) connected to the CHESHIRE chimney (Erikson, 1991).

Temperature data logged in drill back hole U-20n PS \#1DD-H and UE-20n \#1 at various times after the CHESHIRE Test have proven to be an invaluable calibration tool for the flow model. Thermal conductivity and specific heat vary slightly in rocks compared with permeability. For example, for Yucca Mountain model calculations set for volcanic rocks, wet-rock thermal conductivity and specific heat varies from 0.50 to $2.33 \mathrm{~W} / \mathrm{m}^{\circ} \mathrm{K}$ and 644 to $1330 \mathrm{~J} / \mathrm{kg}^{\circ} \mathrm{K}$, respectively, while permeability varies over eight orders of magnitude (Buscheck et al., 1998). For the CHESHIRE flow model, wet-rock thermal conductivities of 1.01 to $1.20 \mathrm{~W} / \mathrm{m}^{\circ} \mathrm{K}$ and a specific heat of $840 \mathrm{~J} / \mathrm{kg}^{\circ} \mathrm{K}$ are assumed for all hydrofacies. The migration of the thermal pulse caused by the CHESHIRE test is dominated by fluid convection. As a result, the thermal pulse acts like a tracer detected by the borehole temperature logs. The U-20n PS \#1DD-H data were useful for calibrating melt glass and lower cavity permeability, and the UE-20n \#1 temperature data were useful for calibrating permeabilities of the chimney and high permeability lava flows.

\subsection{Flow Simulation}

\subsubsection{Conceptual and Numerical Flow Model}

Within the CHESHIRE cavity/chimney system, the mobility of water is controlled by void space within the rubble of the collapsed zone. Within native rocks surrounding CHESHIRE, the mobility of water is primarily attributed to fracture flow. To address fracture flow, either discrete or continuum-based fracture modeling approaches can be utilized. We have chosen to employ a continuum-based approach for our conceptual flow model because:

- The scale of the CHESHIRE HST domain is very large. Thus, a discrete fracture model is prohibitive from a computational standpoint.

- Discrete fracture models require information on fracture size distribution and interconnectivity, which is not known at CHESHIRE.

- Discrete fracture fluid flow models have not included consideration for heat. 
- Flow within the cavity/chimney system occurs primarily through void space in rubble, for which a continuum-based flow modeling approach is appropriate.

In our continuum-based approach, the computer code NUFT (Nonisothermal Unsaturated-Saturated Flow and Transport model) is used to simulate flow of water and heat at CHESHIRE (NITAO, 1998, 1999). NUFT solves the continuum balance equations (Appendix B) for the conservation of mass, momentum, and thermal energy. In the continuum-based approach, the flow domain is discretized into "grid blocks" having effective property values. The balance equations are discretized in space using the integrated, finite-difference method (Edwards, 1972; Narisimhan and Witherspoon, 1978) and in time using the fully implicit backward Euler method. The resulting nonlinear system of equations is solved at each time step using the Newton-Raphson method.

\subsubsection{Cheshire Flow Model Domain}

The size and discretization of the flow domain strike a balance between capturing the detail of the flow processes, resolving the geometry of the hydrofacies, enforcing boundary conditions, and accommodating limitations on computing capabilities.

The vertical extent of the flow domain was limited to the top of the water table ( $\sim 542 \mathrm{~m}$ above the working point). All remaining boundaries, $-z$ (bottom), $-y$ (hydraulic down-gradient), $+y$ (hydraulic up-gradient), were arrived at by allowing a sufficient distance to capture major flow and transport features and minimize effects of boundary conditions. The model domain extends to distances of $-150 \mathrm{~m}$ to $+150 \mathrm{~m}$ in the $x$ direction, $-550 \mathrm{~m}$ to $+250 \mathrm{~m}$ in the $y$ direction, and $-230 \mathrm{~m}$ to $+570 \mathrm{~m}$ in the $z$ direction (Figures 5.1 and 5.2). Given a fixed cubic grid block size of $10 \mathrm{~m}$, the final numerical mesh contained 30,80 , and 80 cells in the $x, y$, and $z$ directions, respectively, for a total of 192,000 cells. This numerical mesh was found to yield a reasonable turnaround time for flow simulations, while maintaining sufficient resolution to capture known intermediate-scale variations in the permeability field and complex transient flow behavior such as convection cells. Numerous sensitivity studies were made at coarser and finer resolutions to examine the tradeoffs in accuracy and computation time.

For subsequent transport simulations, the $x-z$ plane bisecting well UE-20n \#1 at $305 \mathrm{~m}$ down-gradient $(y=-305 \mathrm{~m})$ from U-20n was used as the breakthrough plane for the source-term to be derived for the CAU-scale model. This breakthrough plane position was chosen because data from hole UE-20n \#1 offer some potential for verifying breakthrough behavior predicted by the flow and transport simulations.

\subsubsection{Hydrofacies Models}

Three different conceptual models were used to assign permeability fields based on native rock hydrofacies in the flow simulations: (1) heterogeneous, (2) 
homogeneous, and (3) layer cake. The heterogeneous permeability fields consist of high, moderate, low, and very low permeability hydrofacies (Figure 5.4). The heterogeneous permeability fields were generated using the transition probability/Markov geostatistical approach described by Carle (1996), Carle and Fogg (1996), Carle and Fogg, (1997), and Carle et al., (1998). Appendix G summarizes the approach. The homogeneous permeability field (Figure 5.5) assumes an effective permeability of $2.5 \times 10^{-13} \mathrm{~m}^{2}$ based on the transmissivity of $224 \mathrm{~m}^{2} / \mathrm{d}$ estimated from the pumping test in U-20a \#2 Water Well by Blankennagel and Weir (1973). The layer-cake conceptual model (Figure 5.5) is based on the assumption that high permeability zones inferred from the injection test data of Blankennagel and Weir (1973) are laterally extensive. The layer-cake permeability field contains three layers of high permeability $\left(7.2 \times 10^{-13} \mathrm{~m}^{2}\right)$ rock sandwiched between moderate permeability $\left(1.4 \times 10^{-14} \mathrm{~m}^{2}\right)$ rocks-a 50:1 contrast. The 5:1 $y: x$ anistropy ratio used for high permeability lava flows further increases the permeability contrast in the direction of ambient lateral flow. 

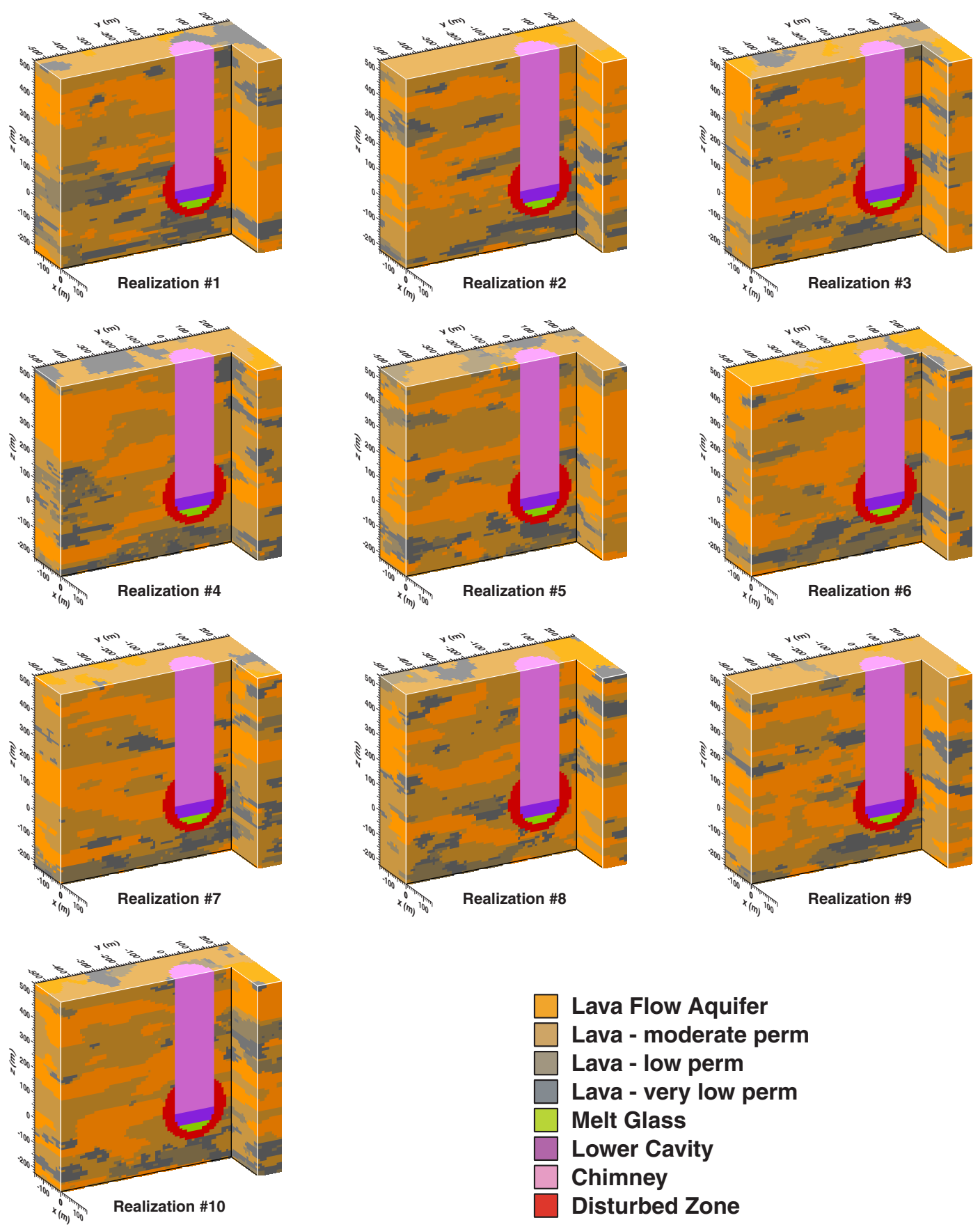

Figure 5.4 Perspective views of 10 geostatistical realizations used to assess the effect of heterogeneity in lava flows surrounding the CHESHIRE test. 

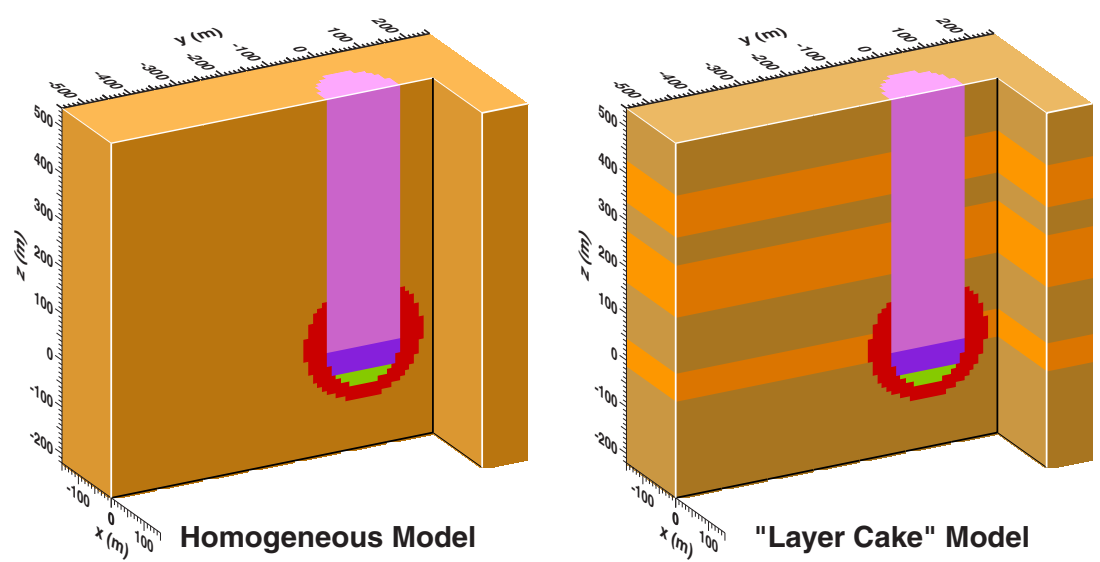

Figure 5.5 Perspective views of the homogeneous and layer-cake conceptual models of subsurface permeability surrounding the CHESHIRE test.

\subsubsection{Boundary Conditions}

Because the flow model simultaneously considers the flow of heat and fluid, both hydraulic and thermal boundary conditions need to be prescribed. The hydraulic boundary conditions are prescribed to maintain an ambient groundwater flow direction in the $-y$ direction (toward UE-20n \#1). This direction of $S 30^{\circ} \mathrm{W}$ is consistent with the hydraulic downgradient direction indicated on a contour map of water levels (see Figure 5.6) in the Pahute Mesa area near U-20a \#2 Water Well (Blankennagel and Weir, 1973) the alignment of faults and structural blocks and the preferential NNE alignment of fractures (Drellack et. al, 1997). Based on the water level contour map, the ambient hydraulic gradient at CHESHIRE is estimated between 0.005 and 0.015 . A base-case hydraulic gradient of 0.010 is assumed. The hydraulic gradient is prescribed by setting constant hydrostatic head pressures at the $-y$ and $+y$ boundaries of the flow domain. The $-x,+x,-z$, and $+z$ boundaries are set with no flow conditions. The no-flow conditions on the $-x,+x$ are set according to the assumed regional flow direction (the $-y$ direction), which is perpendicular to the $x$ axis. Downward flow (through the $-z$ plane) is not expected because of the buoyancy induced by the CHESHIRE test-related heat. Vertical hydraulic gradients may exist on Pahute Mesa by comparing static water level measurements at different elevations for packed-off intervals during injection testing (Blankennagel et al., 1964). In U-20a \#2 Water Well, static water levels were nearly uniform in the upper half of the saturated interval (including the two upper highpermeability zones. However, static water levels in the lower half were about 14 to 31 feet lower. This difference may indicate a potential for downward flow under ambient flow conditions. However, this information is not adequate to establish the presence of a vertical hydraulic gradient over the flow domain region. Moreover, the formation of the chimney at CHESHIRE provides a high-permeability vertical conduit that would tend to equalize differences in pressure with depth. Therefore, the CHESHIRE flow model assumes a regional vertical hydraulic gradient of zero. 


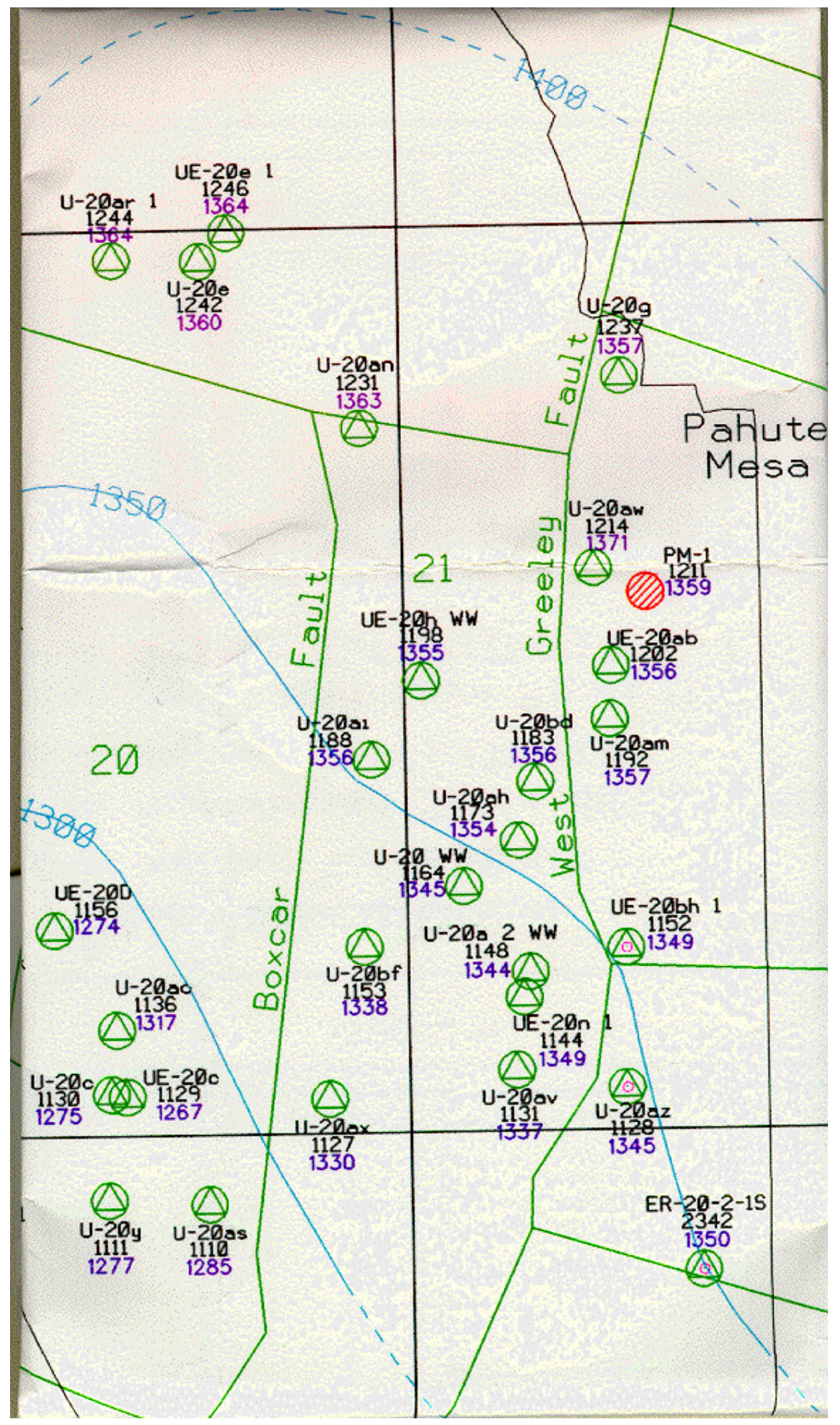

Figure 5.6 Water level map in vicinity of Cheshire test. Water level contour interval is $50 \mathrm{~m}$. Purple label is measured water level elevation in meters. Large black-line grid size is $10,000 \mathrm{~m}$ (for scale). 
The boundaries are set to full saturation on all sides, such that the flow domain is modeled under confined conditions. In reality, the fluid flow system surrounding CHESHIRE is an unconfined fluid flow system. Unfortunately, computational limits prevent simulation of the flow system under variably saturated conditions. Therefore, some transient phenomenological conditions related to the underground nuclear test, such as mounding and infilling of the cavity/chimney system with water, are not considered in the flow simulations.

The upper three layers of the domain are set as a homogeneous low permeability zone to allow flow of heat, prevent vertical flow of water (above the water table), and insulate the chimney from the $+z$ fixed-temperature boundary condition. The flow model must consider that the water table boundary prevents vertical flow of water, but allows heat to diffuse upward. The low-permeability zone (buffer) is added to the upper $(+z)$ boundary to mimic the water-table conditions from the perspective of the flow of heat. The $+z$ boundary buffer prevents vertical fluid flow but allows upward diffusion of heat (particularly test-related heat). Without the buffer, test-related heat rapidly flows out of the upper $(+z)$ boundary in an unrealistic manner.

The thermal boundary conditions are assumed to have an ambient geothermal vertical gradient of about $7.5^{\circ} \mathrm{C} / \mathrm{km}$. This gradient is generally consistent with pre-test temperature log data from holes U-20n and U-20a \#2 Water Well and posttest temperature log data from UE-20n \#1 and U-20n PS \#1DD-H (see Figures 5.7, $5.8,5.9,5.10,5.11$, and 5.12). In the base-case simulations, the ambient thermal gradient is set by fixing temperature at the $-z$ boundary to $40^{\circ} \mathrm{C}$ and fixing temperature at the $+z$ boundary to $34^{\circ} \mathrm{C}$. The $-\mathrm{x},+\mathrm{x},-\mathrm{y}$, and $+\mathrm{y}$ thermal boundary conditions are "no flow," preventing diffusive heat flow in the lateral directions. Convective heat flow is allowed in the lateral directions, such that fluid flow may carry heat across the $-\mathrm{y}$ or $+\mathrm{y}$ boundaries.

\subsubsection{Initial Conditions}

The initial hydraulic and thermal conditions are set to a time-zero state coinciding with initiation of the CHESHIRE test. By no means will initial conditions for the nonisothermal flow simulations capture the detailed phenomenology of an underground nuclear test. Rather, an attempt was made to set an initial condition that resides within the realm of liquid-phase flow of water and immobile solid rock. The complex phenomenology of the underground nuclear test (e.g., vaporization of rock and water, expansion of the cavity, pooling of melt glass, and collapse of the chimney) is assumed to occur in a relatively short time (within seconds to hours). The initial condition used for flow simulations assumes that this complex phenomenology is no longer occurring, such that rock deformation and fracturing has ceased, chimney collapse has completed, rock has solidified, and water vapor has condensed. Therefore, the initial conditions at time zero for the flow model are a simplified abstraction based on calibration to the data assuming fully-saturated and confined flow conditions and ignoring complex early-time phenomenology of the underground nuclear test. This concept is discussed in Section 3.2.1 and illustrated in Figure 3.6. With respect to clock time, the time zero of the model coincides with detonation of the CHESHIRE test.

However, the model initial conditions are effective values that do not coincide with true initial or early-time conditions. 
The initial hydraulic conditions assume hydrostatic pressure with singlephase flow of water. Granted, soon after initiation of the test, the hydraulic conditions near the altered zones were not hydrostatic and single phase. Significant disruption to the subsurface hydraulic pressure distribution would be caused by the heat and pressure shock from near-instantaneous vaporization of water and rock as a result of the underground nuclear explosion. A second cause would be subsequent creation of void space in the saturated zone as a result of cavity formation and chimney collapse. The creation of the cavity/chimney void space is analogous to a slug test, where a cylindrical volume in a well is instantaneously removed (or added) from a well below the water table.

Based on slug test type curves for an aquifer with low storativity, one would expect that the water table within the chimney would recover to about $95 \%$ of the chimney height in about 30 days. Water level data obtained from the drill back hole U20n PS \#1DD-H, which penetrated the CHESHIRE cavity within $154 \mathrm{~d}$ of the CHESHIRE test, indicated that water level recovery was rapid (Erikson, 1991; Sawyer et al., 1999). Nonetheless, one would recommend that future work examine effects of pressure transients and multi-phase, variably saturated flow associated with the phenomenology of the CHESHIRE test.

Outside of the cavity and melt glass, the initial conditions assume a linear ambient thermal gradient tied to the boundary conditions of fixed temperatures of $40^{\circ} \mathrm{C}$ at the $-z$ boundary and $34^{\circ} \mathrm{C}$ at the $+z$ boundary. The model assumes, in effect, that testrelated heat has not been released outside of the cavity and melt glass zone at "time zero." This assumption appears reasonable given the good model fits to temperature data at 154 and 201 days after the CHESHIRE test (see Figures 5.7 and 5.10). For initial conditions, the cavity temperature is assumed to be $50^{\circ} \mathrm{C}$, and the melt glass temperature is assumed to be $160^{\circ} \mathrm{C}$. These thermal initial conditions for cavity and melt glass result in good agreement between the nonisothermal flow simulations and temperature log data from drill back hole U-20n PS \#1DD-H at 154 and $201 \mathrm{~d}$ after the CHESHIRE test.

The initial thermal conditions by no means reflect the true conditions that existed at "time zero" or shortly after the CHESHIRE test. As discussed in Section 3.2 and illustrated in Figure 3.6, a large proportion of the dynamic behavior generated by the underground nuclear test is not considered in this modeling effort. Some of these dynamic behaviors are, for example, vaporization of water and rock, melting of rock, cavity expansion, release of explosion-induced pressure, chimney collapse, infilling of water into the cavity/chimney system, and water table recovery. Therefore, the "initial conditions" employed by the flow model are an abstraction used to maintain consistency with flow conditions occurring $\sim 5$ months or more after the CHESHIRE test (when calibration data are available). In particular, the initial melt glass temperature of $160^{\circ} \mathrm{C}$ is an extrapolation based on calibration of the flow model to temperature log data at 154 and 201 days (relatively soon) after the CHESHIRE test. This value was not chosen arbitrarily -the observed transient temperature data after 154 days could not be matched with higher initial temperatures."

Undoubtedly, boiling of water rapidly cools the melt glass zone soon after the underground nuclear test. Accordingly, a realistic initial (early time) melt glass 
temperature could be proposed as approximately $250^{\circ} \mathrm{C}$ based on the boiling point of water and the depth of the CHESHIRE test below the water table, assuming hydrostatic conditions. Although recovery of the water table was relatively fast at CHESHIRE (compared to the GREELEY or ALMENDRO tests), boiling of water in the melt glass zone could have ceased at a pressure far less than the hydrostatic pressure of the initial water table. Considering the dynamics of the fluid flow in underground nuclear test, the boiling point of water could conceivably depend on pressure conditions ranging between atmospheric and hydrostatic (e.g., between $\sim 100^{\circ} \mathrm{C}$ to $\sim 250^{\circ} \mathrm{C}$ for CHESHIRE). Therefore, the assumption of an initial melt glass zone temperature of $160^{\circ} \mathrm{C}$ is not unrealistic with respect to consideration of the boiling point of water.

\subsubsection{Calibration}

The objective of the flow model calibration was to find a plausible suite of hydraulic properties and geometric configurations of parameter distributions consistent with the available data. The most useful data for calibrating the flow model are the hydraulic testing data from U-20a \#2 Water Well and the temperature logs from holes U-20n PS \#1DD-H and UE-20n \#1.

Calibration to the hydraulic data is achieved by conditioning the permeability fields at the location of U-20a \#2 Water Well with permeability values that are consistent with permeabilities inferred from the pumping and injection tests (Figure 5.3). Specifically, hydrofacies (very low, low, moderate, or high-permeability) were assigned to locations along the saturated interval of U-20a \#2 Water Well according to the hydraulic testing data. The geometric configuration away from these conditioning data depend on the hydrogeologic conceptual model - heterogeneous, layer-cake, or homogeneous. In the case of the homogeneous model, the permeability was determined by the overall transmissivity. These hydraulic data also indirectly assist in calibrating the permeability fields for the heterogeneous hydrogeologic conceptual model by providing estimates of the hydrofacies proportions.

that:

Temperature logs were useful for estimating hydraulic properties considering

- Flow of test-related heat was primarily attributed to convection rather than thermal diffusion.

- Thermal conductivity of rocks varies little compared to permeability.

Calibration to temperature log data was achieved by adjusting permeability and porosity values to obtain general agreement between modeled and measured values. Specifically, the temperature log data assist in calibration of the flow model in three ways:

- To estimate permeabilities of the melt glass, lower cavity, and chimney.

- To estimate the anisotropy ratio of the high permeability hydrofacies.

- To identify high permeability zones penetrated by well UE-20n \#1. 
Figure 5.7 compares temperature log data from U-20n PS \#1DD-H at 154 and $201 \mathrm{~d}$ after the CHESHIRE test with temperatures from nonisothermal flow simulations for the 10 heterogeneous realizations with base-case parameters. Figure 5.8 compares temperature log data from U-20n PS \#1DD-H at $6.5 \mathrm{yr}$ and UE-20n \#1 at $11.3 \mathrm{yr}$ after the CHESHIRE test with simulated thermal profiles from the nonisothermal flow simulations for the 10 heterogeneous realizations with base-case parameters. Note that at $6.5 \mathrm{yr}$, a positive temperature anomaly is not evident in the upper portion of U-20n PS \#1DD-H. This interval is near the location of the upper portion of UE-20n \#1 that exhibits a positive temperature anomaly at $11.3 \mathrm{yr}$. This adds constraint to the timing of the appearance of the temperature anomaly in UE-20n \#1. In Figure 5.13, test-related heat has not extended far enough downgradient to reach the upper intervals of either U-20n PS \#1DD-H or UE-20n \#1. This progression of heat flow is consistently evident in all realizations except realization \#8 (see Figure 5.14).
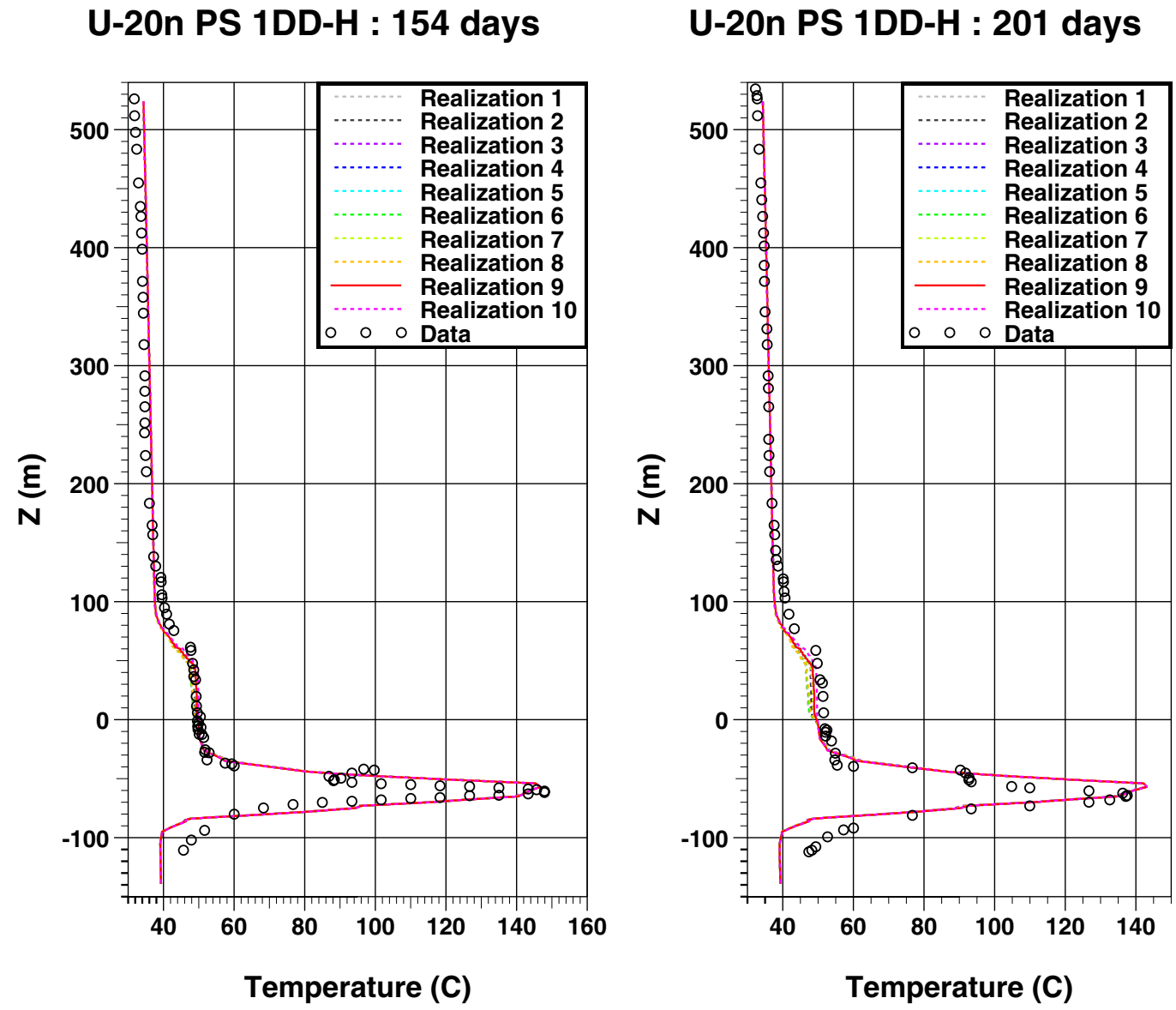

Figure 5.7 Graphs showing temperature data (circles) and simulated thermal profiles from 10 realizations (dashed lines) for hole U-20n PS \#1DD-H at 154 and $201 \mathrm{~d}$ after the CHESHIRE test. 
U20-n PS 1DD-H : 6.5 years

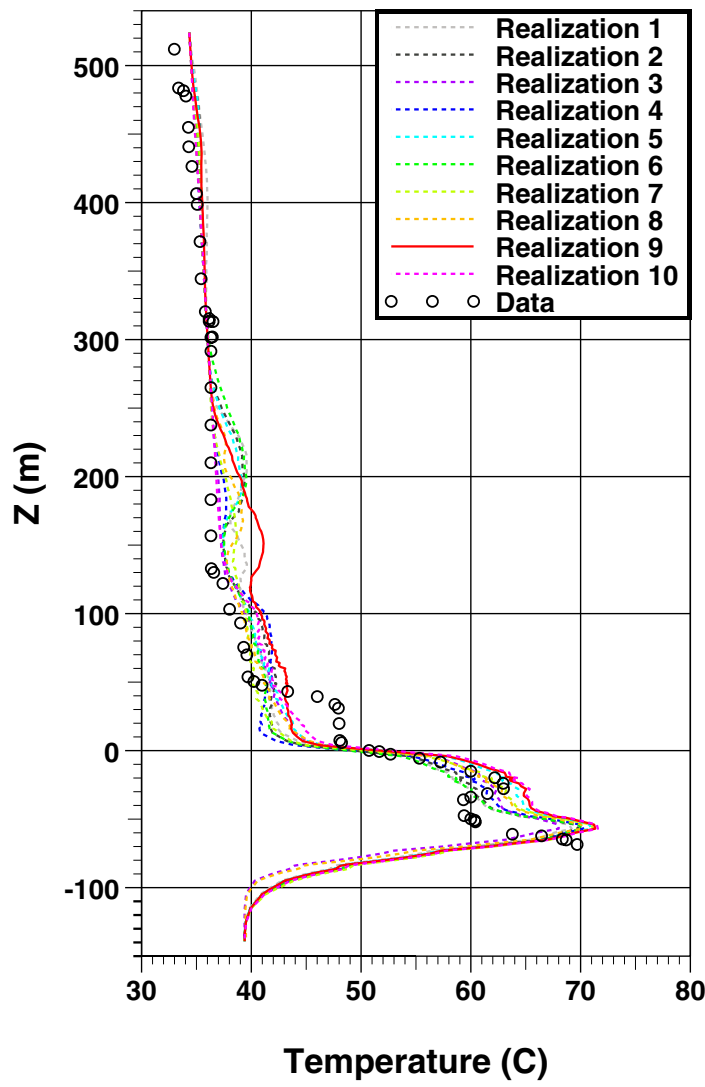

UE-20n \#1 : 11.3 years

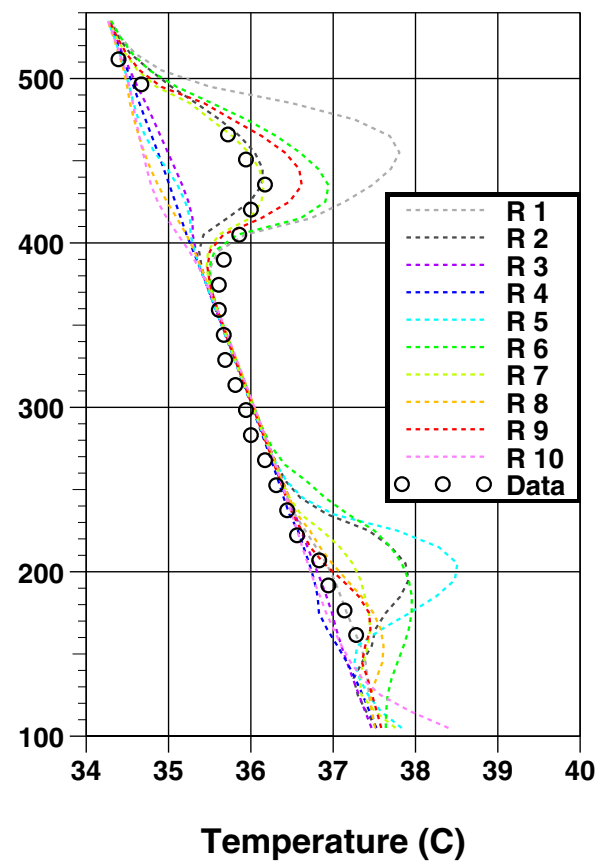

Figure 5.8 Graphs showing temperature data (circles) and simulated thermal profiles from 10 realizations (dashed lines) for hole U-20n PS \#1DD-H at $6.5 \mathrm{yr}$ after the CHESHIRE test and hole UE-20n \#1 at $11.3 \mathrm{yr}$ after the CHESHIRE test.

The thermal pulse initialized in the melt glass and cavity regions of the CHESHIRE test acts, in effect, as a tracer. The fate of the thermal pulse is sensitive to heterogeneity in permeability because, within the time range of these temperature log data, convection is dominant over diffusion in the thermal transport. For example, in sensitivity studies, the time history of melt glass temperature was found to be very sensitive to the melt glass permeability. Drillback hole U-20n PS \#1DD-H penetrates the melt glass. Temperature log data from U-20n PS \#1DD-H at $154 \mathrm{~d}, 201 \mathrm{~d}$, and $6.5 \mathrm{yr}$ enabled us to estimate the bulk permeability of the melt glass zone. This is evident in Figures 5.9 and 5.11 because a difference in melt glass permeability had a large impact on fitting the temperature logs. Figures 5.7, 5.8, and 5.10 show that different realizations and hydrogeologic conceptual models had little impact on the temperature profiles at early times. Similarly, the U-20n PS \#1DD-H temperature log data at 6.5 yr (Figure 5.11) was useful for estimating the permeability of the lower cavity. The temperature log data in UE-20n \#1 at $11.3 \mathrm{yr}$ (Figure 5.11) was primarily sensitive to the permeability of the chimney and high permeability lava flows.

The goal of calibration to the UE-20n \#1 temperature log was to bracket the temperature variations, with emphasis on producing a positive temperature anomaly in the zone of UE-20n \#1 at 380 to $500 \mathrm{~m}$ above the CHESHIRE working point. It can be seen in Figure 5.14 that 9 of 10 heterogeneous realizations (except for realization \#8), produce 
a positive temperature anomaly in this zone within 25 years after the CHESHIRE test. Granted the timing and magnitude are not exactly the same as the observation in UE$20 \mathrm{n} \# 1$ at 11.3 years. The point here is that the flow simulations consistently produce a mechanism for obtaining a zone of heated water at a location $300 \mathrm{~m}$ downgradient from the test. It was necessary to condition the realizations with high permeability hydrofacies in this zone to improve calibration. Experience gained in conducting the nonisothermal flow simulations suggested that a presence of high permeability hydrofacies in this zone was necessary to produce such a temperature anomaly. Temperature log data in UE-20n \#1 also suggested another positive temperature anomaly toward the bottom of the hole.

On the basis of experience from simulating the upper temperature anomaly, high permeability hydrofacies were placed at the base of UE-20n \#1, which is near the level of a high permeability zone identified in U-20a \#2 Water Well by Blankennagel and Weir (1973). Thus, the temperature log in UE-20n \#1 was used as indirect conditioning of the hydrofacies realizations. It was not expected, however, that the simulations would exactly match the temperature log data in UE-20n \#1. The combination of the permeability heterogeneity and transient flow behavior is too complex to raise the expectation that simulations should precisely match thermal observations after $11.3 \mathrm{yr}$ and hundreds of meters of transport have passed. Moreover, the geometry of the altered zones was fixed under the assumption of the upper $500 \mathrm{kt}$ yield range for the CHESHIRE test, which will also affect flow calibration, particularly with respect to the quantity of heated melt glass and the radius of the cavity and chimney. Our goal is to generate multiple realizations of realistic flow behavior that generally fit or bracket the observations.

\subsubsection{Thermal Sensitivity Studies}

Thermal sensitivity studies were useful for estimating permeabilities, particularly the altered hydrofacies for which little data are available. The key hydrofacies that were found to be sensitive to matching temperature log data are melt glass, lower cavity, chimney, and high permeability lava flows. This should not be too surprising because these hydrofacies contain the primary sources and conduits for transient heat flow. Importantly, these hydrofacies also contain the primary sources and conduits for radionuclide transport. This explains why emphasis is given to understanding the sensitivities of these hydrofacies permeabilities to the temperature $\log$ data. Furthermore, there is sensitivity to the conceptual model of the spatial distribution of the native hydrofacies - heterogeneous, layer cake, or homogeneous-that profoundly affects flow and transport behavior.

\subsubsection{Data from Hole U-20n PS \#1DD-H}

In Figure 5.4, realization 9 (R9) shows a good overall fit to the temperature log data for UE-20n \#1 at 11.3 yr. Realization 9 was selected as a base case for conducting sensitivity studies on the hydrofacies permeabilities. Figure 5.9 compares temperature log data in hole U-20n PS \#1DD-H at 154 and $201 \mathrm{~d}$ with simulated temperatures for cases where one hydrofacies permeability is changed from the basecase value. Cases for isothermal and thermal gradient (no heat from the CHESHIRE test) 
are also examined, because later evaluation was made of the effect of considering heat in predicting radionuclide transport.

Five permeability sensitivity cases are shown:

1. Isotropic high permeability — set high permeability lava flow permeability to isotropic $7.2 \times 10-13 \mathrm{~m} 2$.

2. $0.2 \mathrm{X}$ chimney permeability-reduce chimney permeability from $5.0 \times 10-11$ to $1.0 \times 10-11 \mathrm{~m} 2$.

3. Lower cavity = chimney-raise lower cavity permeability from $1.0 \times 10-12$ to $5.0 \times 10-11 \mathrm{~m} 2$.

4. 10X melt glass-raise melt glass permeability from $4.0 \times 10-14$ to $4.0 \times 10-13 \mathrm{~m} 2$.

5. 10X disturbed zone-raise disturbed zone permeability from $4.0 \times 10-12$ to $4.0 \times 10-11 \mathrm{~m} 2$.
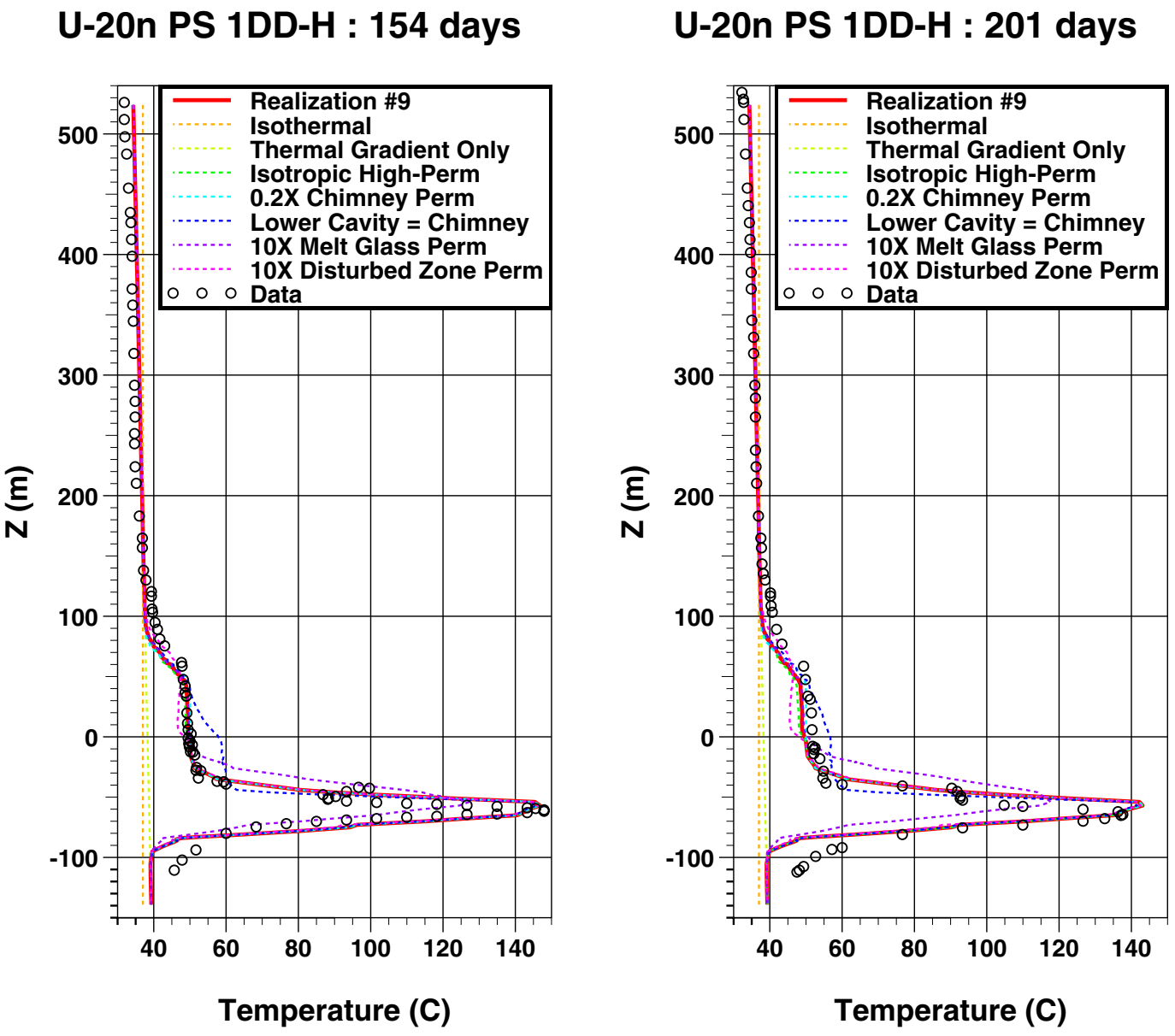

Figure 5.9 Sensitivity studies showing effect of changing hydrofacies permeabilities and thermal conceptual model through comparison of simulated temperatures with temperature log data from hole U-20n PS \#1DD-H at 154 and $201 \mathrm{~d}$ after the CHESHIRE test. 
Case 4 shows that the temperature profiles are very sensitive to the melt glass permeability, which illustrates how useful the temperature log data are for calibrating the melt glass permeability. Cases 3 and 5 show some temperature sensitivity to the lower cavity and disturbed zone permeabilities, with better fits to the temperature data obtained with the base-case permeabilities. Cases 1 and 2 illustrate that the temperature $\log$ data at 154 and $201 \mathrm{~d}$ are not very sensitive to the permeability of the high permeability lava flows and the chimney permeability.

Figure 5.10 introduces a sensitivity study to compare the effect of different hydrogeologic conceptual models. Temperature log data in U-20n PS \#1DD-H at 154 and $201 \mathrm{~d}$ is compared with simulated temperatures for cases with homogeneous and layer-cake models. Cases for homogeneous and layer-cake hydrogeology with isothermal and geothermal gradient (no heat from the CHESHIRE test) are examined because later evaluation was made of the effect of both the hydrogeologic model and heat in predicting radionuclide transport. These sensitivity studies show that only the temperature profile at $201 \mathrm{~d}$ is sensitive to the model for the homogeneous case. Therefore, the early time-temperature log data are not likely to be useful for evaluating permeability heterogeneity in the unaltered rocks.

U-20n PS 1DD-H : 154 days

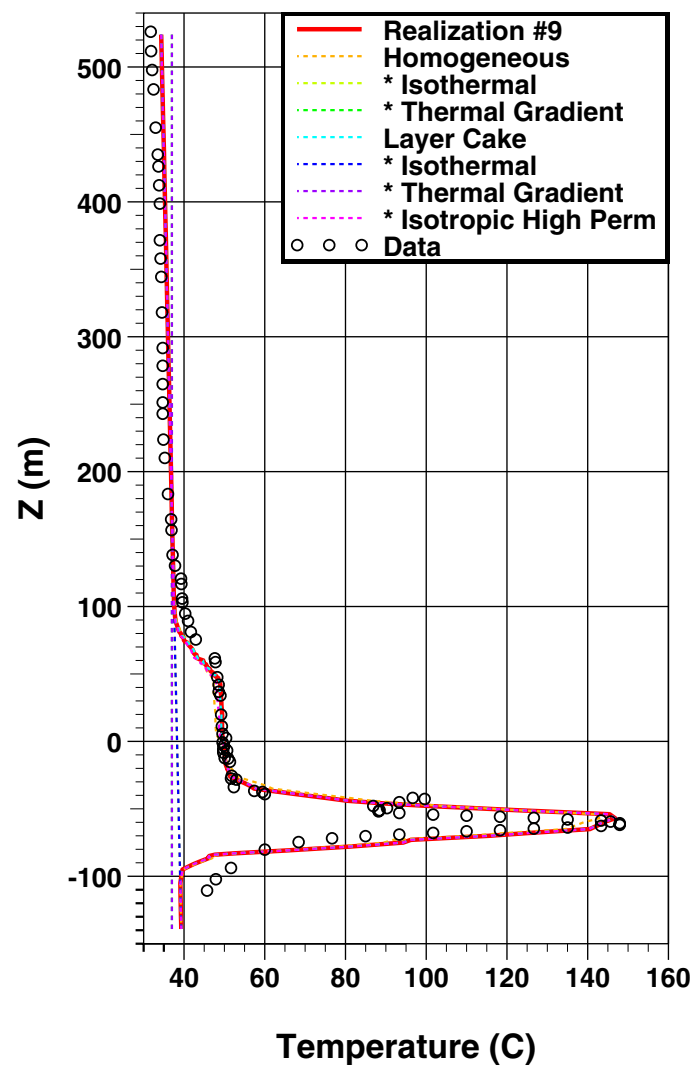

U-20n PS 1DD-H : 201 days

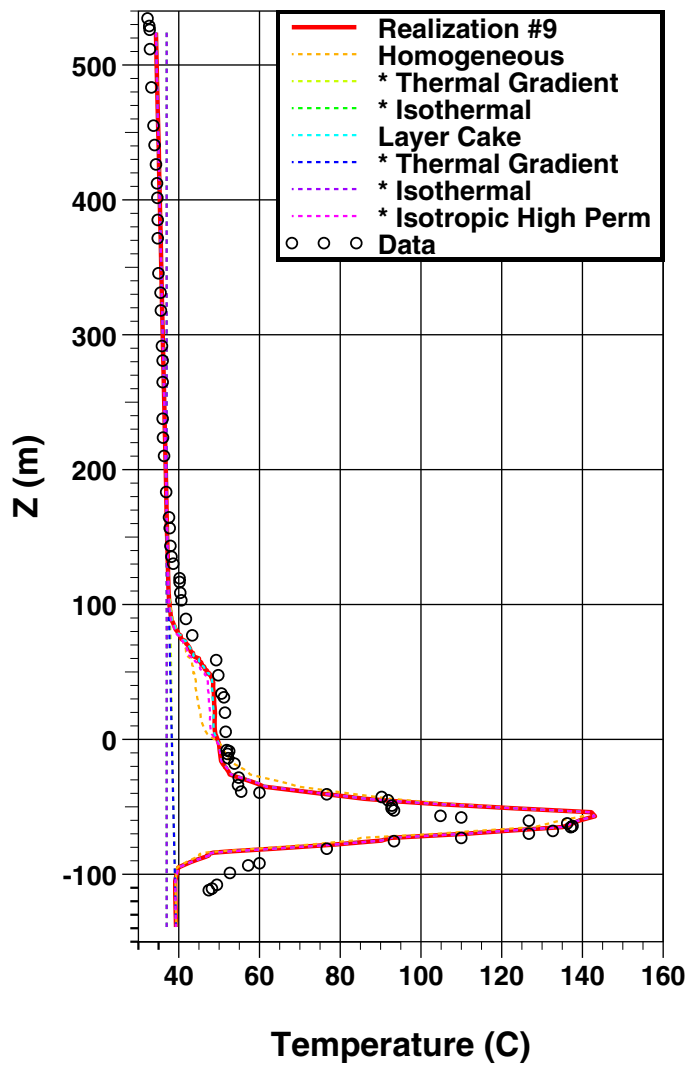

Figure 5.10 Sensitivity studies comparing effect of hydrogeologic and thermal conceptual models through comparison of simulated temperatures with temperature log data from hole U-20n PS \#1DD-H at 154 and $201 \mathrm{~d}$ after the CHESHIRE test. 


\subsubsection{Data from Hole U-20n PS \#1DD-H}

Figure 5.11 examines the sensitivities to hydrofacies permeabilities by comparing simulated temperatures with the temperature log data from hole U-20n PS \#1DD-H at $6.5 \mathrm{yr}$ and UE-20n \#1 at $11.3 \mathrm{yr}$ after the CHESHIRE test. These later time temperature data show sensitivities to all of the hydrofacies permeabilities examined. Permeability case 1 , isotropic high permeability lava flows (green line), shows a slight improvement in fit to the deeper temperature data for U-20n PS \#1DD-H at $6.5 \mathrm{yr}$. However, an assumption of isotropic high permeability lava flows greatly slows down the migration of the thermal pulse, such that the $1^{\circ} \mathrm{C}$ anomaly near the top of the saturated zone in UE-20n \#1 is not replicated. Permeability case 2, reduced chimney permeability, also slows down migration of the thermal pulse, such that the $1^{\circ} \mathrm{C}$ anomaly near the top of the saturated zone in UE-20n \#1 is not replicated. Permeability case 3 , raising the lower cavity permeability to the chimney permeability, causes misfit of the simulated temperatures to the temperature data for U-20n PS \#1DD-H at $6.5 \mathrm{yr}$ for levels between the 0 to $-50 \mathrm{~m}$ below the working point elevation. Permeability case 4 , increasing melt glass permeability by a factor of 10 , also causes misfit of the simulated temperatures to the temperature data for U-20n PS \#1DD-H at $6.5 \mathrm{yr}$ for levels below the working point. Permeability case 5, increasing disturbed zone permeability by a factor of 10, shows most effect on temperatures for U-20n PS \#1DD-H at $6.5 \mathrm{yr}$, particularly below the working point. This difference can be attributed to increased ability for the heat to diffuse into rock surrounding the cavity, or from another perspective, less of an insulating effect.

U-20n PS 1DD-H : 6.5 years

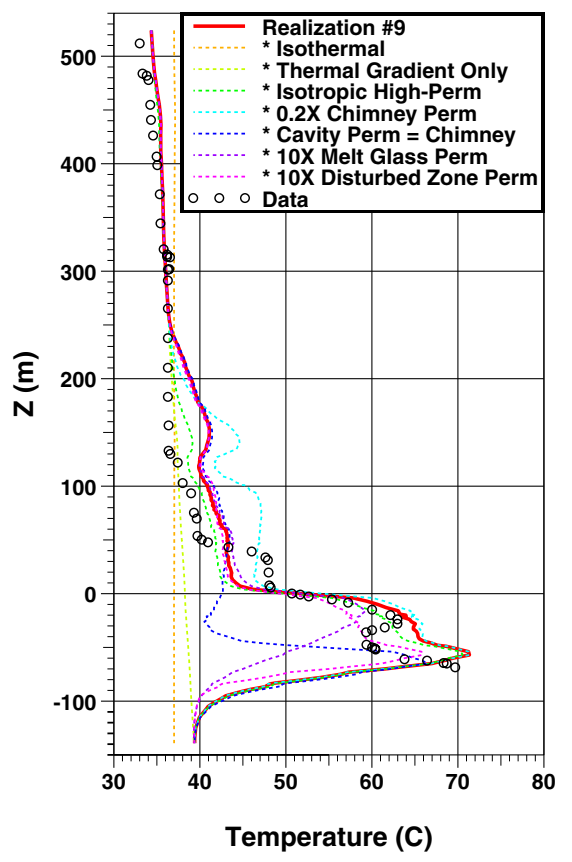

UE-20n \#1 : 11.3 years

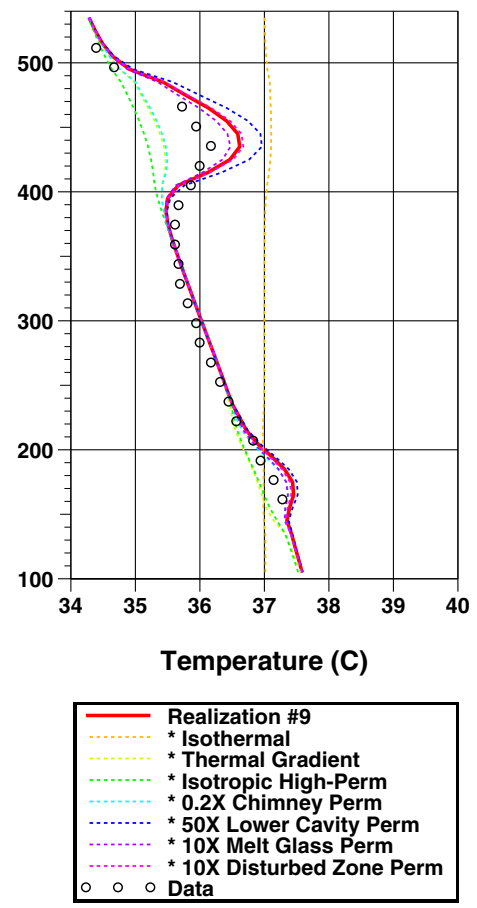

Figure 5.11 Sensitivity studies for realization 9 showing effect of different hydrofacies permeabilities and thermal conceptual models through comparison of simulated temperatures with temperature log data from hole U-20n PS \#1DD-H at $6.5 \mathrm{yr}$ and UE-20n \#1 at $11.3 \mathrm{yr}$ after the CHESHIRE test. 
Figure 5.12 compares the effect of assuming layer-cake and homogeneous conceptual models on temperature profiles in holes U-20n PS \#1DD-H and UE-20n \#1 at $6.5 \mathrm{yr}$ and $11.3 \mathrm{yr}$, respectively. These sensitivity studies show that the later time temperature data are very sensitive to the hydrogeologic conceptual model. The homogeneous model (yellow line) allows for more direct migration of heat into the rock surrounding the test, causing more rapid cooling in the cavity area. The homogeneous model cannot produce temperature anomalies similar to the $1^{\circ} \mathrm{C}$ anomaly near the top of the saturated zone in UE-20n \#1. The layer-cake model (aqua line) produces a temperature profile in U-20n PS \#1DD-H at $6.5 \mathrm{yr}$ similar to realization 9. Interestingly, the layer-cake model produces large temperature anomalies in UE-20n \#1 at 11.3 yr. However, if the high permeability lava flows are made isotropic (magenta line), those temperature anomalies do not appear.

U-20n PS 1DD-H : 6.5 years

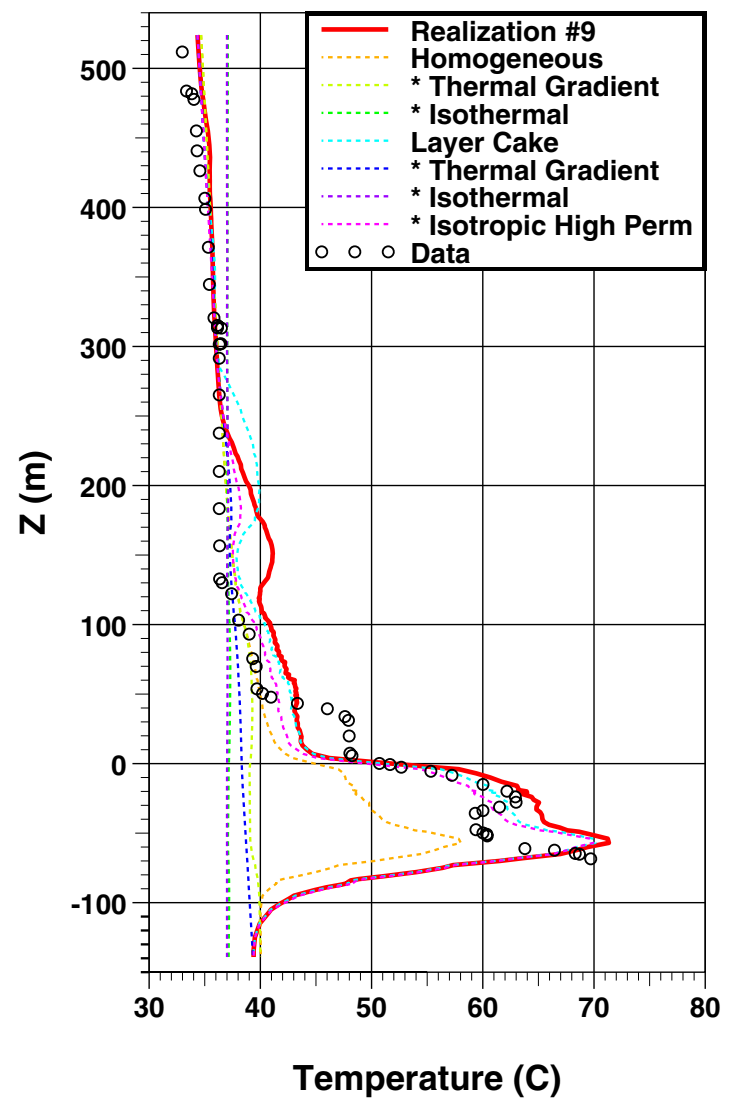

UE-20n \#1 : 11.3 years
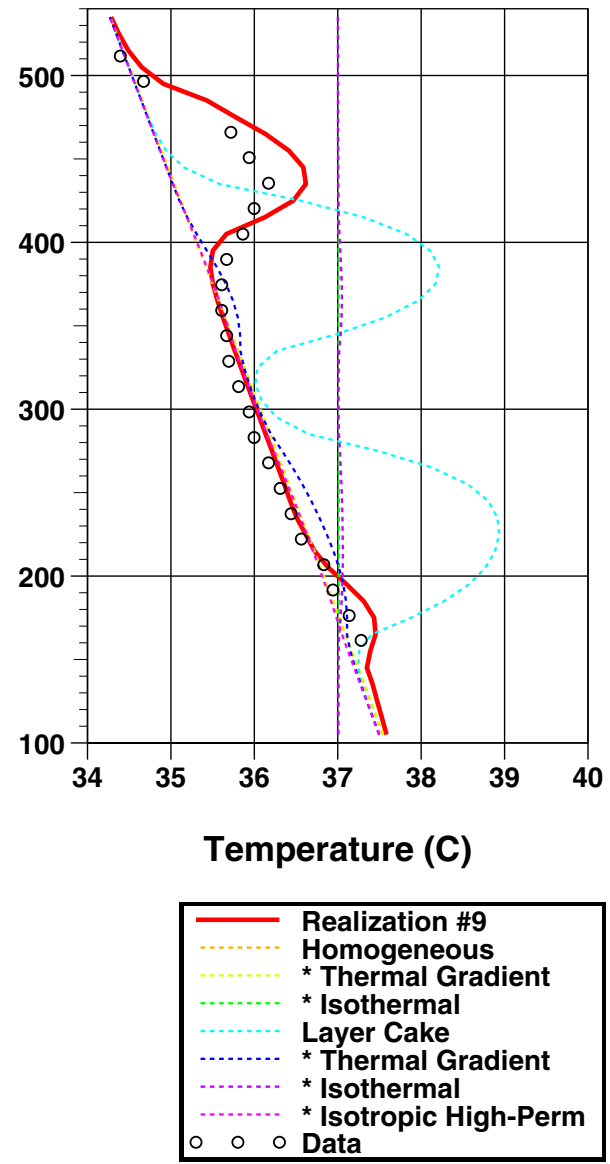

Figure 5.12 Sensitivity studies comparing effect of hydrogeologic and thermal conceptual models through comparison of simulated temperatures with temperature log data from holes U-20n PS \#1DD-H and UE20n \#1.

\subsubsection{Conclusions on Thermal Sensitivity Studies}

The temperature data obtained from holes U-20n PS \#1DD-H and UE-20n \#1 were extremely useful for estimating hydrofacies permeabilities and an anistropy ratio 
for the high permeability lava flows. Moreover, having temperature data at different locations and times was useful for testing conceptual models. The nonisothermal flow simulations demonstrate that high temperature anomalies in native rock, such as the one observed near the top of the saturated zone in UE-20n \#1 at $11.3 \mathrm{yr}$ after the CHESHIRE test, require presence of relatively high permeability rocks. On the basis of comparison of data and simulated temperatures for homogeneous, layer-cake, and heterogeneous conceptual models, one concludes that the heterogeneous conceptual model produces the most realistic results. Further work is needed to gain better understanding of the sensitivity to effective porosity and the hydraulic gradient.

\subsection{Results}

The three-dimensional simulations of nonisothermal flow behavior after the CHESHIRE test have revealed some important insights into flow behavior resulting from an underground nuclear test. Three approaches will be used to illustrate the nonisothermal flow behavior:

- Mapping of the simulated temperature field, including tracking of the thermal pulse caused by the CHESHIRE test.

- Mapping simulated concentrations of nonreactive tracers originating from the altered zones.

- Mapping transient streamlines or streaklines. These illustrations demonstrate the effect on flow behavior caused by heat and permeability and porosity variation in the altered zones and native rock.

\subsubsection{Temperature Fields}

The CHESHIRE test not only affected groundwater flow by altering the permeability and porosity of subsurface rocks, it also provided an enormous source of heat. Increased temperature affects groundwater flow by raising pressure through thermal expansion of water and reducing both viscosity and density of water. Thus, an instantaneous introduction of heat to the subsurface groundwater flow system will disrupt equilibrium by raising fluid pressure, increasing hydraulic conductivity, and introducing buoyancy forces. The nonisothermal flow simulations have been particularly useful for assessing the effect of heat on the groundwater flow behavior.

Anomalously heated groundwater (above hydrothermal equilibrium) will tend to rise. Our flow simulations indicate that during the first few decades after the CHESHIRE test, heat is predominately transported by convection of groundwater rather than thermal diffusion. The increased permeability of the chimney provides a convenient pathway for heated groundwater to rise. The upward motion of heated groundwater forces cooler upgradient recharge water downward. As a result, convection cells develop. As the heat pulse rises, it is pushed toward the down-gradient flow direction. The heat pulse eventually bleeds off the chimney into high permeability zones in the native rock. The heat pulse may continue rising to the top of the chimney and continue to recirculate within the chimney. By about $100 \mathrm{yr}$, CHESHIRE heat pulse is 
almost entirely dissipated. Without the CHESHIRE heat, the chimney still provides a preferential pathway for groundwater flow and, subsequently, a conduit for flow of geothermal heat. This interaction between groundwater flow and heat illustrates why temperature log data from borehole data has been so useful for characterizing the permeability of rocks surrounding the CHESHIRE test.

\subsubsection{Base Case Realizations}

Figure 5.13 shows perspective views of temperature fields obtained from the nonisothermal flow simulation for realization 9 with base-case parameters. The times of $154 \mathrm{~d}, 201 \mathrm{~d}$, and $6.5 \mathrm{yr}$ correspond with times that temperature log data are available from hole U-20n PS \#1DD-H. The time of $11.3 \mathrm{yr}$ corresponds with the time that temperature log data are available from hole UE-20n \#1. This three-dimensional nonisothermal flow simulation is calibrated to these temperature log data.

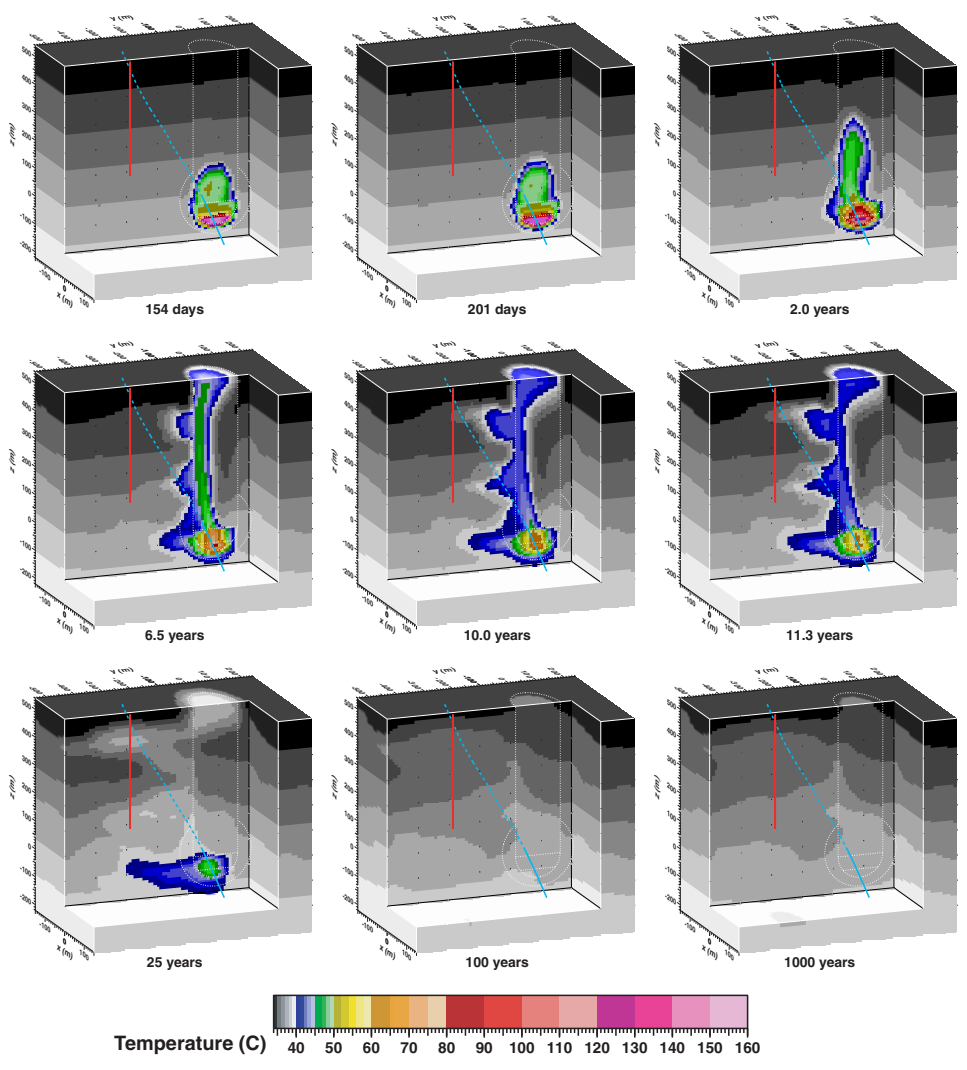

Figure 5.13 Perspective views of temperature fields at different times from nonisothermal flow simulation for realization 9.

The evolution of the temperature field in Figure 5.13 illustrates the phenomenology of long-term dissipation of heat from the CHESHIRE test. At time zero, the heat pulse is distributed at $50^{\circ} \mathrm{C}$ in the cavity and $160^{\circ} \mathrm{C}$ in the melt glass. After 154 to $201 \mathrm{~d}$, heat from the test is largely contained within the cavity and melt glass and has just begun to enter the chimney. At $2.0 \mathrm{yr}$, the heat pulse has advanced over halfway up the chimney to the water table, with a noticeable bent toward the down-gradient side of the chimney. At $6.5 \mathrm{yr}$, the heat pulse reaches the top of the chimney and collects, then begins to migrate toward the down-gradient direction in high permeability native rock. 
Between 10 and $11.3 \mathrm{yr}$, the heat pulse advances to the upper high permeability zone in hole UE-20n \#1. In this realization, heat migrates in the downgradient direction within three separate high permeability zones, clearly indicating that heterogeneity within the lava flows will play a major role in flow and transport. By $25 \mathrm{yr}$, residual heat from the CHESHIRE test is primarily advancing laterally and no longer rising up the chimney. Maximum temperatures have dropped below $50^{\circ} \mathrm{C}$. By $100 \mathrm{yr}$, heat from the CHESHIRE test is almost completely dissipated by observing that little temperature change occurs out to $1000 \mathrm{yr}$.

Of course, realization 9 represents only one possible scenario for the evolution of the nonisothermal flow field. Ten base-case nonisothermal flow simulations were generated from the 10 realizations of heterogeneous native rock permeability fields. These 10 realizations produce a range of flow behavior. Given that the hydrofacies permeabilities are held constant, this range in flow behavior is attributed to spatial variability of the geometry of the hydrofacies units, primarily the high permeability hydrofacies. Therefore, the 10 realizations provide means for assessing uncertainty in flow behavior resulting from uncertainty in three-dimensional characterization of the location of high permeability lava flows (i.e., lava flow aquifers).

Figure 5.14 shows an array of simulated temperature fields for all 10 realizations at the same nine times as shown in Figure 5.13. Each row represents a different realization, and each column represents a different time. Thus, comparison of the temperature fields along a single column demonstrates the variability in thermal flow behavior associated with spatial variability of permeability. Between 6.5 and $25 \mathrm{yr}$ (columns 4-7), a large variation is seen in the down-gradient migration of heat into the native rock. In some realizations (e.g., 3 and 10), heat tends to migrate more readily along a high permeability zone near the depth of the CHESHIRE test, accumulate near the top of the chimney, and then bleed off into an upper high permeability zone. In other realizations (e.g., 1, 6, and 8), heat tends to channel into the chimney and primarily enter directly into high permeability zones well above the CHESHIRE test. The remaining realizations $(2,4,5,7$, and 9$)$ show a combination of these two general behaviors. 


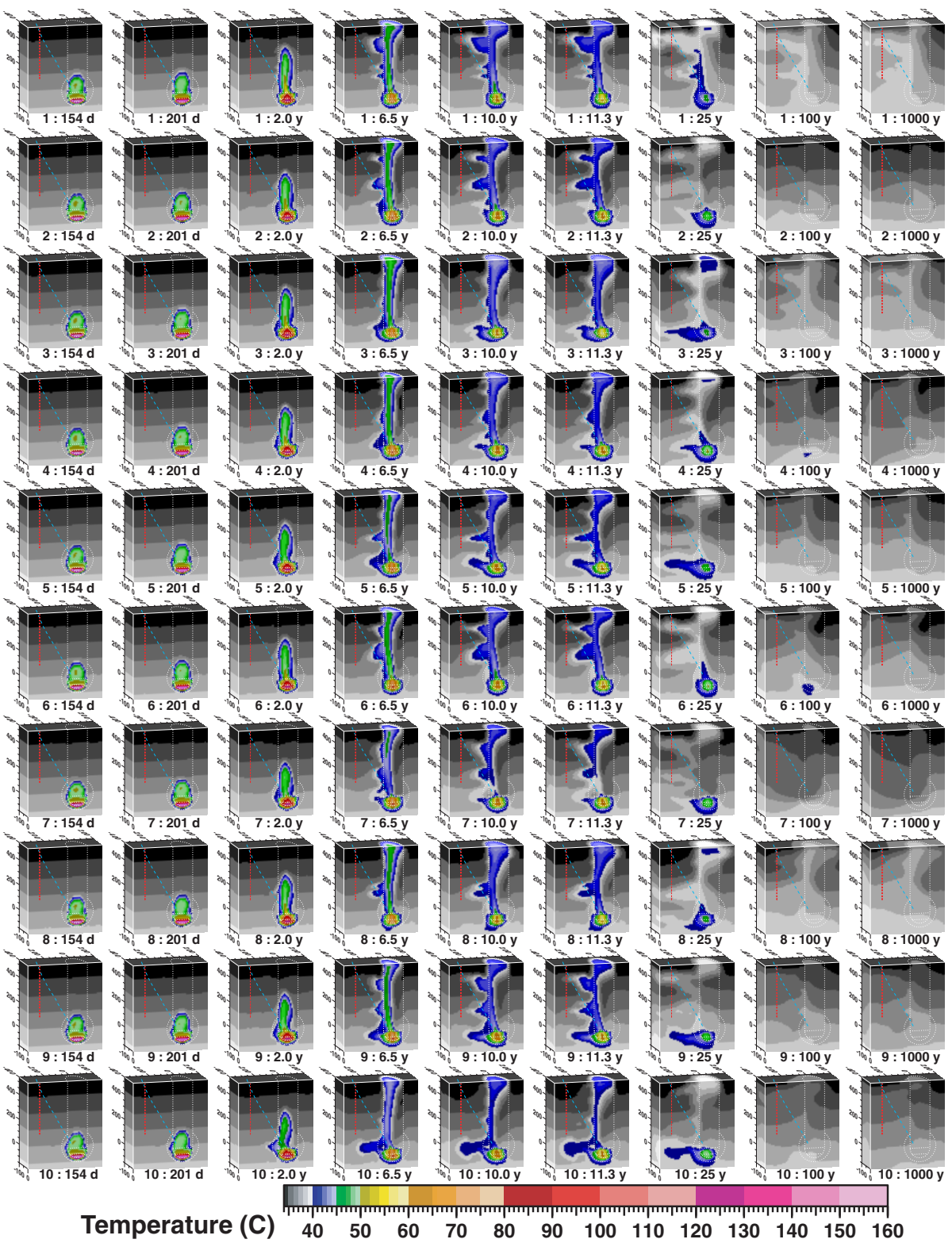

Figure 5.14 Perspective views of temperature fields at different times from nonisothermal flow simulations for 10 realizations. Beneath each field, realization number and time are given. Each row is a different realization, and each column is a different time.

\subsubsection{Sensitivity Studies}

The sensitivity of the nonisothermal flow simulations was examined in relation to hydrofacies permeabilities, CHESHIRE test-related heat, the geothermal gradient, and conceptual models. Figure 5.15 shows time sequences of temperature fields for realization 9 for sensitivity cases on hydrofacies permeability, CHESHIRE testrelated heat, and geothermal gradient. Figure 5.16 shows sensitivity cases that consider layer-cake and homogeneous conceptual models. 
In Figure 5.15, the time sequence for each sensitivity case is given along a row. The columns represent the times at 154 and $201 \mathrm{~d}$; and 2.0, 6.5, 10.0, 11.3, 25, and $100 \mathrm{yr}$. The top row represents the realization 9 with base-case parameters.

The second row examines sensitivity to anisotropy in the permeability of the high permeability hydrofacies. The base-case anisotropy is a 1:5:5 $x: y: z$ anisotropy ratio based on a geometric mean lateral permeability of $k_{x y}=7.2 \times 10^{-13} \mathrm{~m}^{2}$, so that $k_{x}=$ $3.2 \times 10^{-13} \mathrm{~m}^{2}$ and $k_{y}=k_{z}=1.6 \times 10^{-12} \mathrm{~m}^{2}$. This sensitivity case assumes isotropic permeability such that $k_{x}=k_{y}=k_{z}=7.2 \times 10^{-13} \mathrm{~m}^{2}$ for the high permeability hydrofacies. The main difference to notice between the base case is slowing of down-gradient migration of the CHESHIRE heat plume. With isotropic high permeability hydrofacies, the heat plume does not reach the upper permeability zone in hole UE-20n \#1 at $11.3 \mathrm{yr}$, when the temperature log data indicate an approximate $1^{\circ} \mathrm{C}$ anomaly.

The third row examines sensitivity to permeability of the melt glass by increasing melt glass permeability by a factor of 10 from the base-case value of $4.0 \times 10^{-14}$ to $4.0 \times 10^{-13} \mathrm{~m}^{2}$. The increase in melt glass permeability affects the temperature field primarily near the heat source. At $2.0 \mathrm{yr}$, the heat plume is longer and more intense in the chimney. The melt glass cools more rapidly. However, the temperature field far from the CHESHIRE test is not affected much.

The fourth row examines the sensitivity of decreasing the chimney permeability by a factor of 5 from the base-case value of $5.0 \times 10^{-11}$ to $1.0 \times 10^{-11} \mathrm{~m}^{2}$. Decreased chimney permeability diminishes migration of the CHESHIRE heat plume up the chimney. Compared with the base case, the heat plume does not affect the upper high permeability zone enough to produce an anomaly in UE-20n \#1 at $11.3 \mathrm{yr}$.

The fifth row examines increasing the lower cavity permeability to the permeability of the chimney, from $1.0 \times 10^{-12}$ to $5.0 \times 10^{-11} \mathrm{~m}^{2}$. The increase in lower cavity permeability hastens and intensifies the early time migration of the heat plume and causes slightly more rapid cooling of the melt glass. Similar to the effect of increased melt glass permeability, the increase in the lower cavity permeability does not affect the far field temperatures much. 


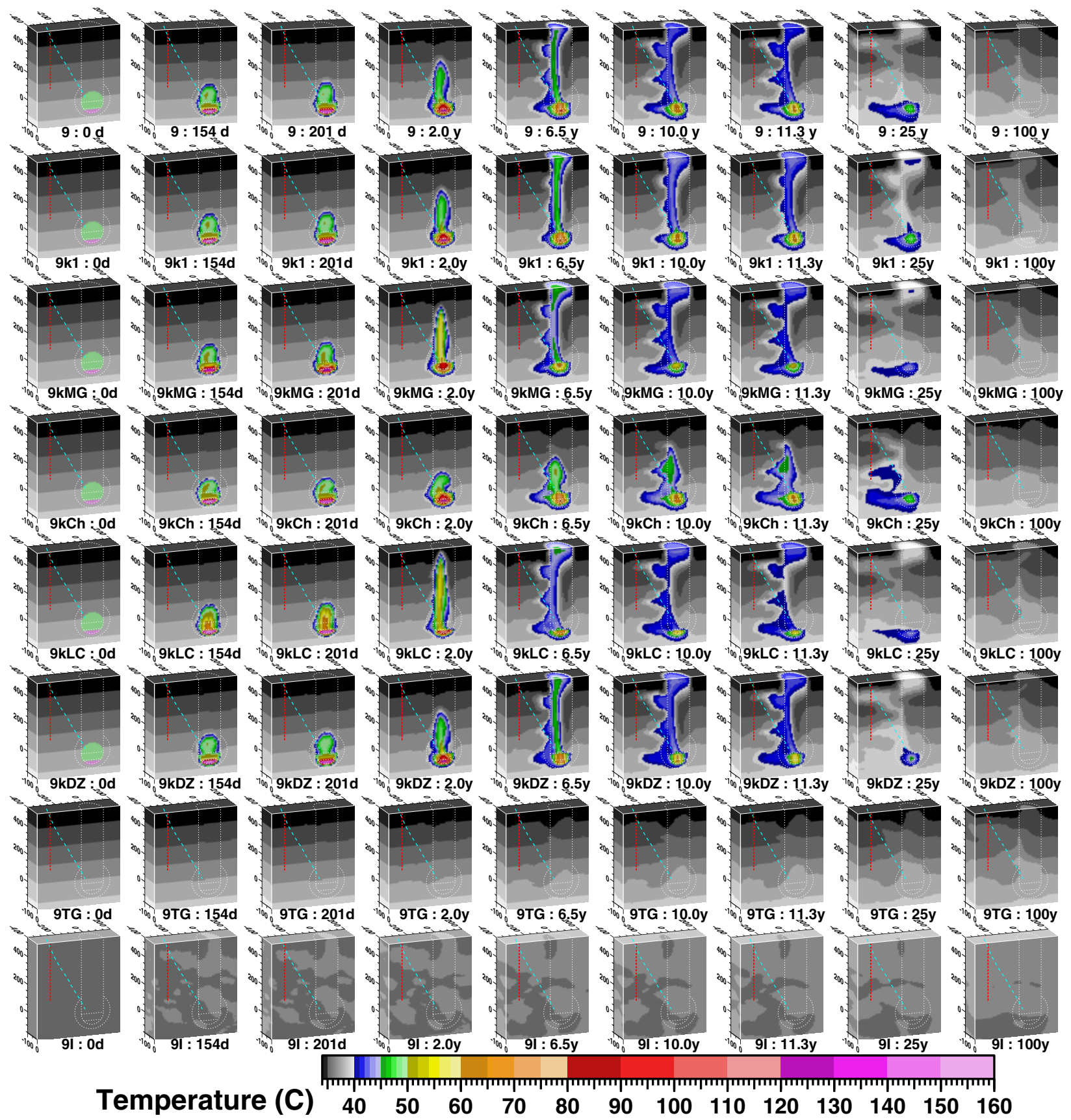

Figure 5.15 Sensitivity studies comparing temperature behavior for realization 9 with base-case parameters, isotropic high permeability hydrofacies, increased melt glass permeability, decreased chimney permeability, increased lower cavity permeability, decreased disturbed zone permeability, no test-related heat, and isothermal conditions.

The sixth row examines increasing disturbed zone permeability by a factor of 4 from $4.0 \times 10^{-12}$ to $1.6 \times 10^{-11} \mathrm{~m}^{2}$. This results in slightly more rapid cooling of the melt glass and lower cavity because heat can more readily disperse into surrounding rocks. Otherwise, the increased disturbed zone permeability does not have much effect on far field temperatures. 
The seventh and eighth rows examine cases where the CHESHIRE heat source is removed, with the seventh row showing a geothermal gradient only, and the eighth (bottom) showing no thermal gradients applied through the boundary conditions (isothermal case). The geothermal gradient case illustrates the effect of variations in permeability on the temperature field. The isothermal case shows a slight variations and drift in temperature over time, which is attributed to heterogeneity.

Figure 5.16 shows thermal sensitivity studies for the layer-cake and homogeneous conceptual models. The top row represents the realization 9 with basecase parameters.

The second row examines the layer-cake model, using base-case permeability values for the low and high permeability hydrofacies. The main difference with respect to the base case (row 1 ) is more rapid migration of the thermal plume along the middle and upper high permeability zones. In particular, thermal breakthough in hole UE-20n $\# 1$ at $11.3 \mathrm{yr}$ is much more significant in the middle high permeability zone. However, the thermal data do not indicate a large thermal anomaly in this depth range for hole UE-20n \#1 at $11.3 \mathrm{yr}$.

The third row examines the layer-cake model assuming isotropic permeability for the high permeability hydrofacies. In this case, the thermal plume migrates much more slowly along the high permeability zones, such that no thermal anomaly is produced in hole UE-20n \#1 at $11.3 \mathrm{yr}$. Considering these sensitivity studies and that an extensive high permeability zone was not observed in UE-20n \#1 at the depth range of the middle high permeability zone (Erikson, 1991), the layer-cake model is likely an oversimplified and inaccurate representation of the subsurface permeability structure.

The fourth row examines the layer-cake model assuming a geothermal gradient only (no test-related heat). This simulation indicates that alteration of the subsurface permeability structure by the CHESHIRE test would affect the local geothermal gradient. Interestingly, this simulation indicates that a measurable increase in temperature could be produced in the upper high permeability zone at hole UE-20n $\# 1$, although not as easily if test-related heat is included in the simulation.

The fifth row examines the layer-cake model assuming no test-related heat and no geothermal gradient (isothermal). This simulation indicates that the permeability structure causes some fluctuations in the simulated temperature field, but these are small compared with the temperature variations associated with the geothermal gradient and test-related heat as observed in the data.

The sixth row examines the homogeneous model with test-related heat. Testrelated heat rises up the chimney and appears to diffuse into the native rock. Hole UE$20 \mathrm{n} \# 1$ is not affected by the test-related heat until approximately $100 \mathrm{yr}$. 


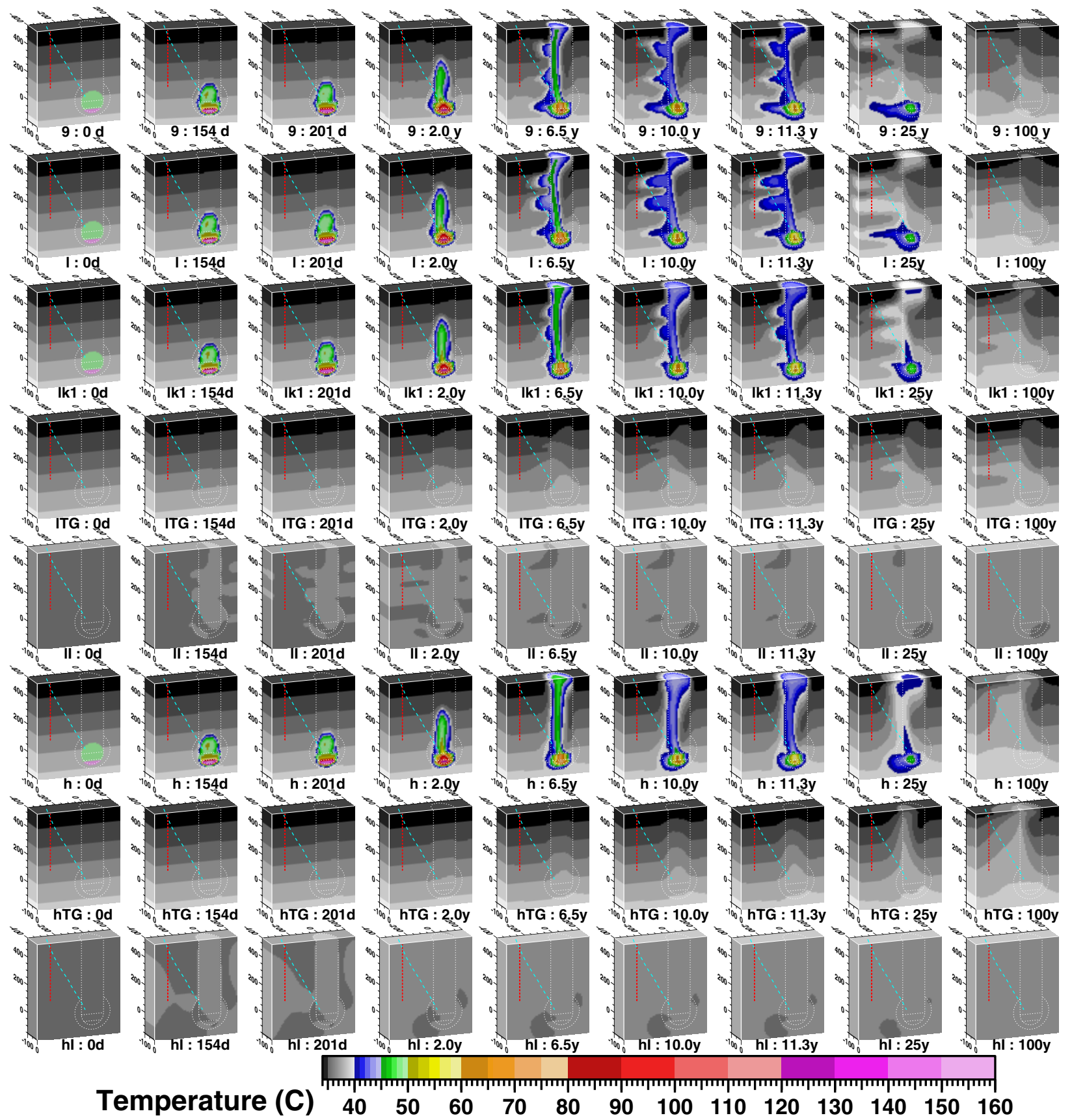

Figure 5.16 Sensitivity studies comparing temperature behavior for realization 9 with base-case parameters; a layer cake model with base-case parameters, isotropic high permeability hydrofacies, no test-related heat, and isothermal conditions; and a homogeneous model with base-case parameters, no test-related heat, and isothermal conditions.

The seventh row examines the homogeneous model with a geothermal gradient only (no test-related heat). Interestingly, this simulation produces a thermal anomaly in hole UE-20n \#1 at $100 \mathrm{yr}$, similar to the simulation with test-related heat. Combined with the layer-cake/no test-related heat simulation in the fourth row, one can conclude that, for an underground nuclear test below the water table, the increased 
permeability of the collapse chimney can certainly produce a long-term thermal anomaly in a nearby well, even without test-related heat.

The bottom row examines the homogeneous model with no thermal gradient and no test-related heat (isothermal). This simulation again illustrates that some fluctuations in the simulated temperature field are related to permeability variations in the model, but these are small relative to temperature variations observed in the data.

Overall, these sensitivity studies illustrate that the temperature log data are very useful for calibrating permeability of model units that otherwise have little or no permeability data. The temperature log data from the post-shot drillback hole, U-20n PS \#1 DD-H, are very useful for calibrating permeability of the melt glass zone and lower cavity. The temperature log data from the downgradient exploratory hole, UE20n \#1, are most useful for calibrating chimney and high-permeability lava flow permeability (and anisotropy, when coupled with other permeability data). The temperature log data, however, did not provide much insight to permeability of the disturbed zone.

\subsubsection{Nonreactive Tracer Transport}

The second approach to demonstrating flow behavior is to map the fate of a nonreactive tracer originating in fluids located in the altered hydrofacies-the melt glass, cavity, and disturbed zone. To accomplish this, concentrations of particles are assigned to the source regions, and the particles are allowed to advect according to flow velocity fields generated by the nonisothermal flow simulations. The locations of the particles are tracked, and, by averaging particle densities, maps of normalized concentration over time are obtained. To improve resolution of the flow behavior and transport pathways, one can divide the volume of altered hydrofacies into melt glass and nonmelt glass (cavity and disturbed zone) source regions. In the melt glass source region, the continuous tracer source concentration is time dependent according to a temperature-dependent dissolution rate for melt glass. In the nonmelt glass source region, the tracer originates as an initial concentration of constant value. These nonreactive tracer transport simulations are purely hypothetical simple transport cases that are used to gain insight on the complex flow processes involved with the CHESHIRE test.

The tracer simulations shown below illustrate several points that will help us analyze transport behavior with respect to flow behavior. First, the CHESHIRE testrelated heat source will produce complex convection cells in the chimney. The convection cells cause undulating, fingered, or spinning patterns of transport behavior, like clouds in a storm or eddies in a river. As a result, down-gradient migration of contaminants into high permeability zones may be initiated by pulses derived from circulating contaminant plumes in the chimney that occasionally contact the edges of the chimney. Second, heterogeneity in the permeability field, when combined with the transient flow behavior, will add considerably to the uncertainty in predicting downgradient migration of contaminants. In general, it appears that a tracer initially present in an unheated disturbed zone will tend to migrate down-gradient within the nearest high permeability zone. A tracer originally present in the heated cavity or melt glass tends to be pushed upward into the chimney, then bled off from the chimney into high 
permeability zones toward the down-gradient direction. Most of the tracer is flushed out the system within $25 \mathrm{yr}$. Transport into the relatively low permeability zones will disperse and retard transport, producing, in effect, a long-term, low level source region.

\subsubsection{Nonmelt Glass Source}

Figure 5.17 illustrates the evolution of tracer concentration from a nonmelt glass source for the nonisothermal flow simulation of realization 3 . Realization 3 is chosen as an example because it exhibits vigorous convection in the chimney, even more so than realization 9 . The initial concentration is a fluid concentration of $2.42 \times 10^{-9} \mathrm{moles} /$ liter. Two concentration cutoffs are shown: (1) yellow $>10^{-9}$ moles/liter, and (2) green $>10^{-14}$ moles/liter. The concentration plumes are superimposed over the hydrofacies (permeability) field. At time $=0 \mathrm{~d}$, the concentration is uniformly distributed over the nonmelt glass source region. At 154-201 d, the plume reflects initiation of a convection cell in the lower chimney and rapid migration of tracer from the disturbed zone into a high permeability zone toward the hydraulic downgradient. At $2.0 \mathrm{yr}$, the plume shows intricate folding caused by convection cells, continued migration into the lower high permeability zone, and initiation of migration into a middle high permeability zone. From 6.5 to $25 \mathrm{yr}$, part of the plume in the chimney continues to spin upward like a hurricane in slow motion, occasionally shedding particles into the surrounding native rock. The bulk of transport by advection through the high permeability zones has ceased. Many particles are stuck in the lower permeability zones, representing large-scale matrix diffusion. By $100 \mathrm{yr}$, most of the tracer has migrated out of the domain.

In contrast to the heterogeneous conceptual model, Figures 5.18 and 5.19 illustrate tracer transport originating from a nonmelt glass source for homogeneous and layer-cake conceptual models, respectively. In general, the tracer transport behavior for realization 3 (Figure 5.17) is similar to the transport behavior resulting from the layercake model, but not the homogeneous model. In the layer-cake model, the tracer is largely flushed through the system via high permeability zones before $6.5 \mathrm{yr}$, as is the case for realization 3 . After $6.5 \mathrm{yr}$, the remaining tracer occurs as a result of diffusion into the moderate permeability zones and a spinning convection cell at the top of the chimney. The homogeneous conceptual model, however, yields vastly different transport behavior. By $6.5 \mathrm{yr}$, no tracer has reached the breakthrough plane defined at the location of UE-20n \#1. Even at $25 \mathrm{yr}$, a large portion of tracer continues to pass through the breakthrough plane.

Interestingly, the homogeneous-case tracer transport simulations produce fingered plumes, characteristic of heterogeneous systems, resulting from the transient flow behavior. The flow simulation shows that convection cells cause tracer to sporadically bump into interfaces between the native rock and altered zones. Fingered tracer transport behavior in the homogeneous permeability field can be attributed temporal and spatial variation of source of contact between altered zones and the native rock. Overall, one expects vastly different breakthrough behavior between the homogeneous and nonhomogeneous conceptual models, illustrating the importance of considering spatial variations of permeability within the rhyolitic lavas of the maficpoor Calico Hills Formation. 
Figure 5.20 illustrates the array of tracer concentrations from a nonmelt glass source for all 10 heterogeneous realizations. This figure allows us to evaluate the variability of the tracer transport attributed to spatial variability of the native rock hydrofacies. In general, tracer originating in the disturbed zone tends to migrate rapidly down-gradient via the nearest high permeability zones, producing breakthrough at the UE-20n \#1 plane within a few years. Tracer originating from the heated cavity will tend to remain in convection cells occurring in the chimney. These convection cells enable the tracer to reach the entire length of the chimney, facilitating subsequent migration into multiple high permeability zones.
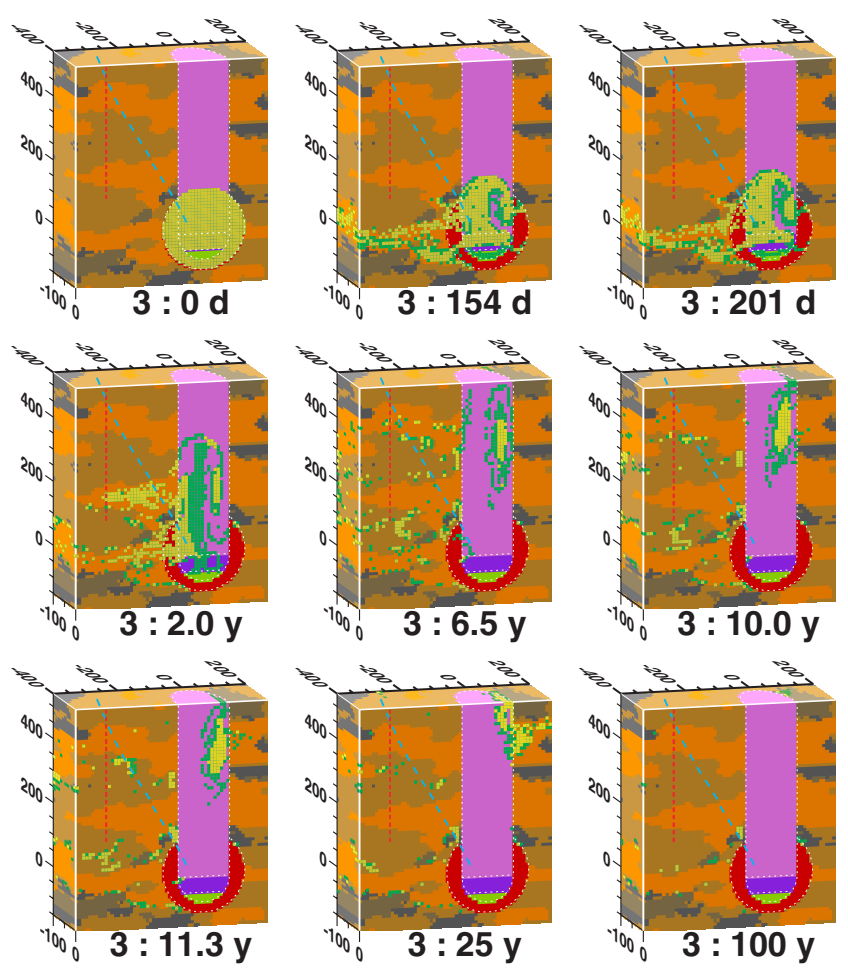

Figure 5.17 Perspective views of tracer transport at different times for realization 3 with uniform initial concentration in cavity and disturbed zone (exchange volume). Yellow $>10^{-9}$ moles/liter; Green $>10^{-14}$ moles/liter. 

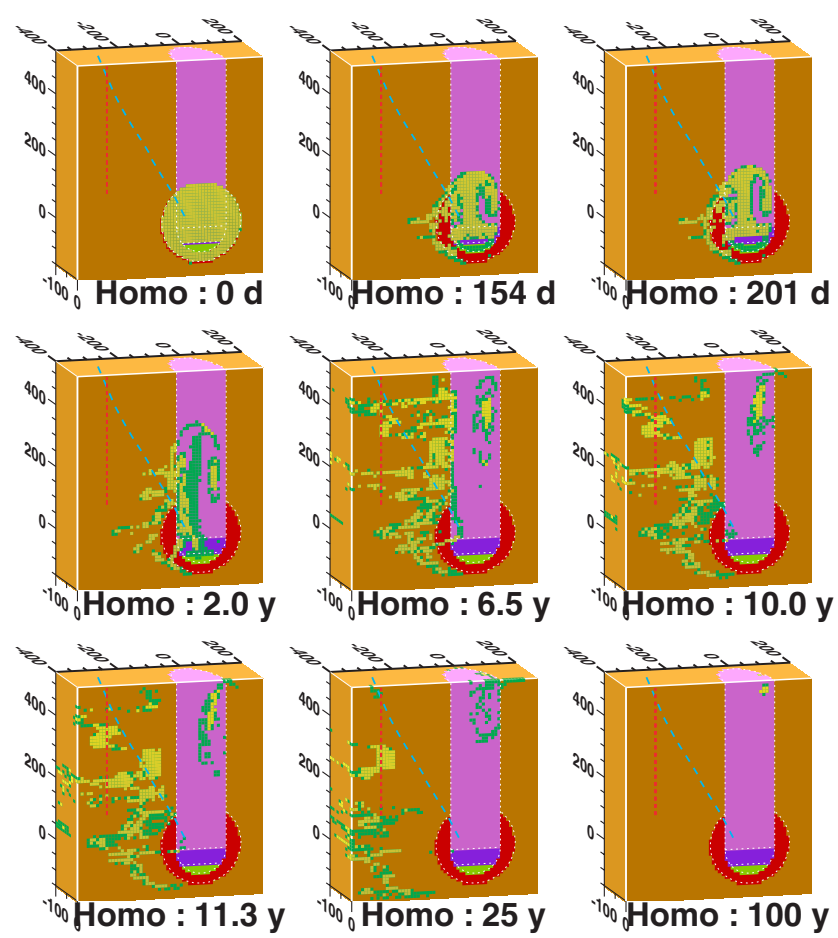

Figure 5.18 Perspective views of tracer transport at different times for homogeneous native rock with uniform initial concentration in cavity and disturbed zone (exchange volume). Yellow $>10^{-9}$ moles/liter; Green $>10^{-14}$ moles/liter.
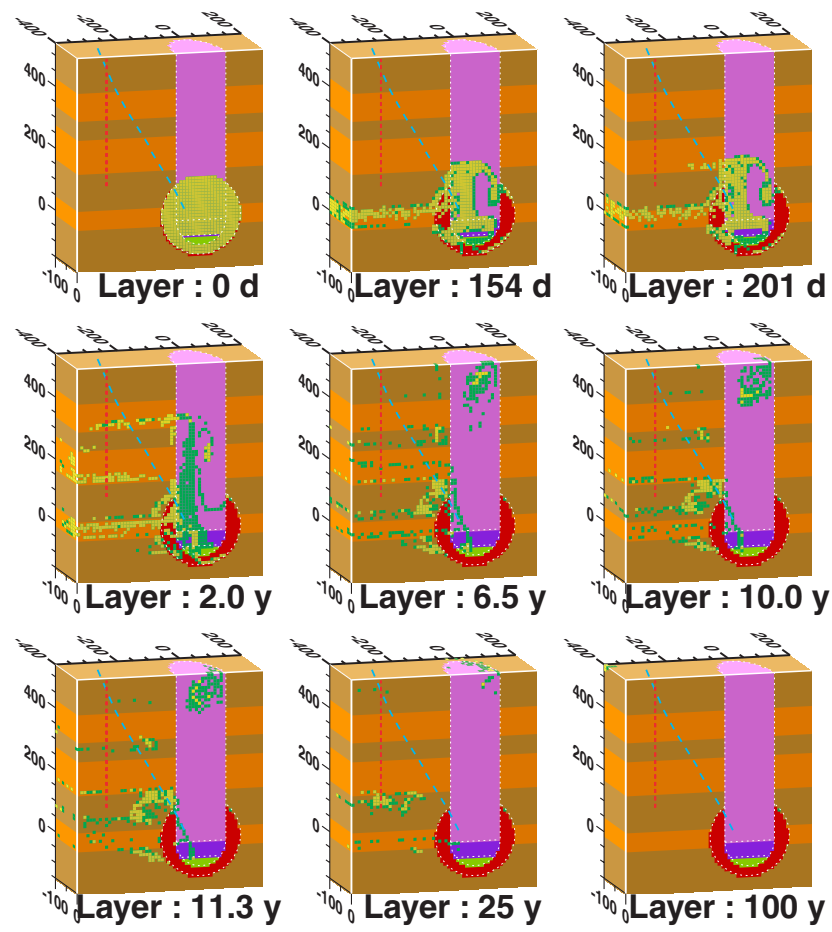

Figure 5.19 Perspective views of tracer transport at different times for layer-cake native rock permeability structure with uniform initial concentration in cavity and disturbed zone (exchange volume). Yellow $>10^{-9}$ moles/liter; Green $>10^{-14}$ moles/liter. 


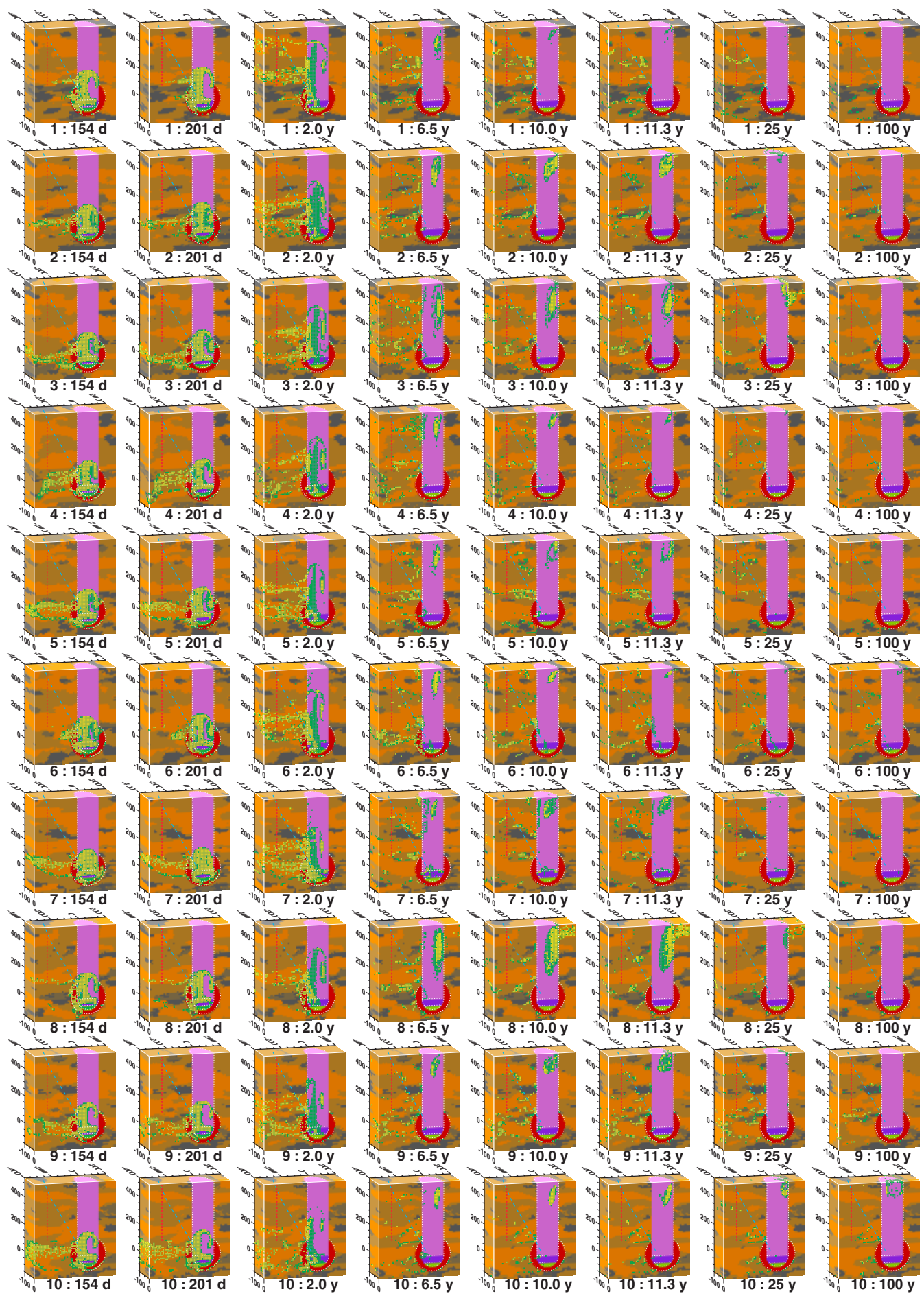

Figure 5.20 Perspective views of tracer transport at different times for heterogeneous native rock with uniform initial concentration in cavity and disturbed zone (exchange volume). Yellow $>10^{-9}$ moles/liter; Green $>10^{-14}$ moles/liter. 


\subsubsection{Melt Glass Source}

Similar to Figure 5.17, Figure 5.21 illustrates the evolution of tracer concentration for the nonisothermal flow simulation of realization 3 , but for a melt glass source. The melt glass source is conceived as a gradual release of tracer proportional to a melt glass dissolution rate. The dissolution rate in this simplified model depends on temperature and surface area, which evolve over time (Section 6.4.4, moderate rate in Figure 6.20). Although the glass dissolution model is not presented until the next chapter, showing nonreactive transport simulations with a melt glass source illustrates the sensitivity to different flow fields. These simulations yield insight into the combined effects of heterogeneity, test heat, and source location on tracer transport. Two concentration cutoffs are shown: (1) yellow $>10^{-9}$ moles/liter and (2) green $>10^{-14}$ moles $/ \mathrm{m}^{3}$.
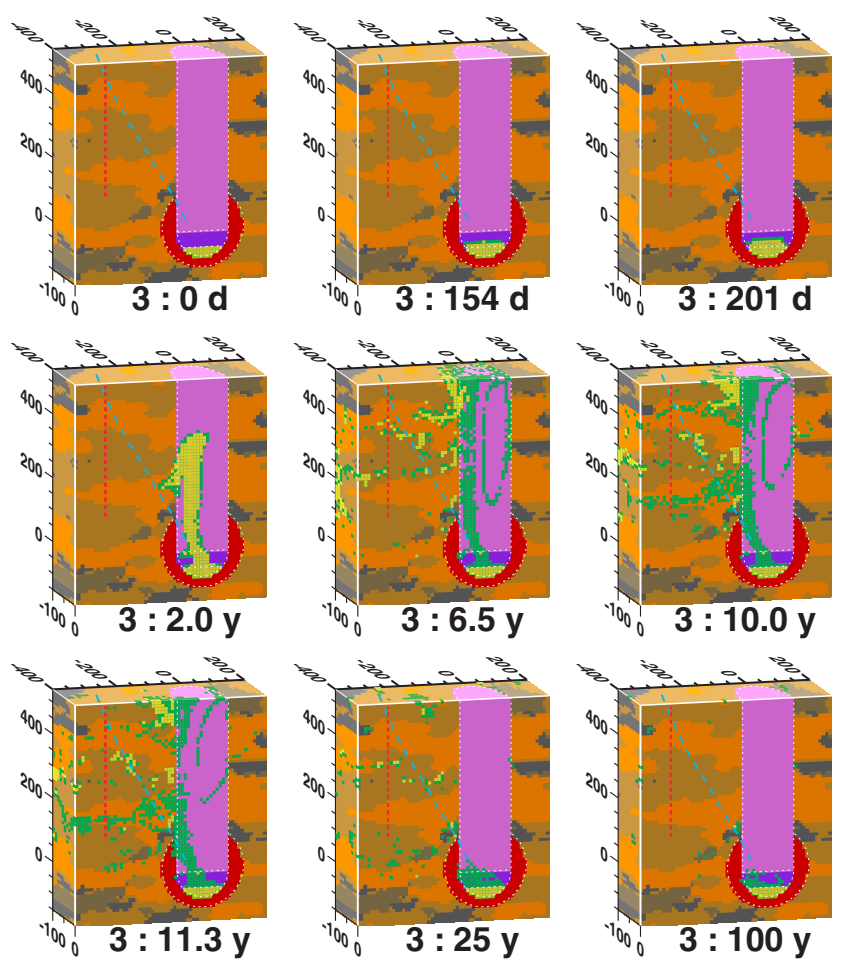

Figure 5.21 Perspective views of tracer transport at different times for realization 3 with uniform initial concentration in cavity and disturbed zone (exchange volume). Yellow $>10^{-9}$ moles/liter; Green $>10^{-14}$ moles/liter.

Because dissolution of the melt glass is required to release the tracer, the melt glass tracer plume takes longer than the nonmelt glass source plume to evolve. At 154-201 d, the concentration plume is only beginning to enter the lower cavity. At $2.0 \mathrm{yr}$, the concentration plume rapidly ascends the chimney and begins to spill into a high permeability zone. From 6.5 to $11.3 \mathrm{yr}$, the tracer plume shows intricate folding and circulation caused by convection cells and continued migration into the upper high permeability zones. At $25 \mathrm{yr}$, temperature and flow velocities have diminished such that the dissolution rate and heat-induced buoyancy forces have decreased substantially. The plume is now characterized by tracer caught in relatively low permeability zones, 
with slow bleed-off from the melt glass moving laterally. By $100 \mathrm{yr}$, the plume is largely contained to the melt glass and lower cavity.

Figure 5.22 shows the evolution of a tracer plume derived from a melt glass source with the same conditions as above, but for realization 9 . The differences in the tracer plume are a result of the differences in the heterogeneity of the native rocks for realizations 3 and 9 . Compared with realization 3 , the melt glass tracer plume shows less vigorous convection cell development in the chimney. More tracer enters the lowest high permeability zone, resulting in earlier initial breakthrough. This contrast in transport behavior illustrates the role of heterogeneity in assessing uncertainty of predicting radionuclide breakthrough out of the source term volume.

Figure 5.23 shows the evolution of a tracer plume derived from a melt glass source assuming a homogeneous conceptual model for the native rock permeability. Compared with the tracer simulations resulting from the heterogeneous conceptual model (Figures 5.21 and 5.22), the tracer transport appears different in three significant ways:

- Breakthrough is delayed.

- More vigorous convection cells occur in the chimney.

- More melt glass dissolution occurs.

Breakthrough is delayed as a result of the lack of fast pathways as discussed previously. More vigorous convection in the chimney occurs from relatively slower cooling of the melt glass as a result of reduced groundwater flow near the cavity and melt glass region (for lack of a high permeability zone near the depth of the working point). The slower cooling of the melt glass also results in greater melt glass dissolution according to the temperature-dependent dissolution rate (Chapter 6). 

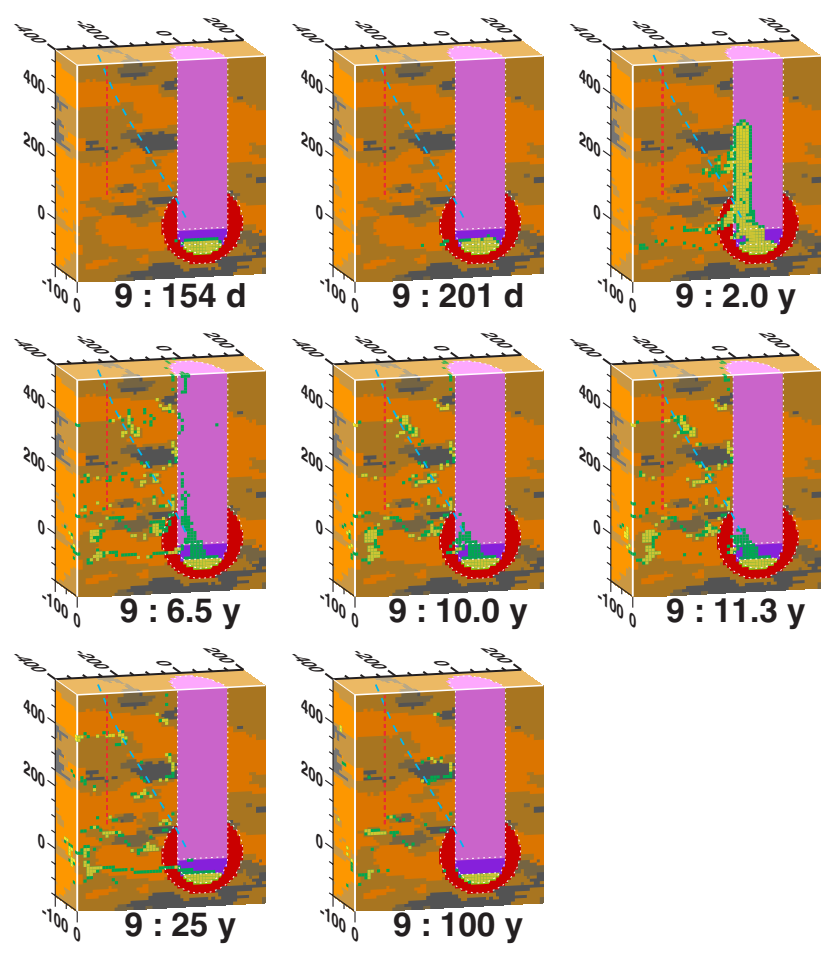

Figure 5.22 Perspective views of tracer transport at different times for realization 9 with melt glass source. Yellow $>10^{-9}$ moles/liter; Green $>10^{-14}$ moles/liter.
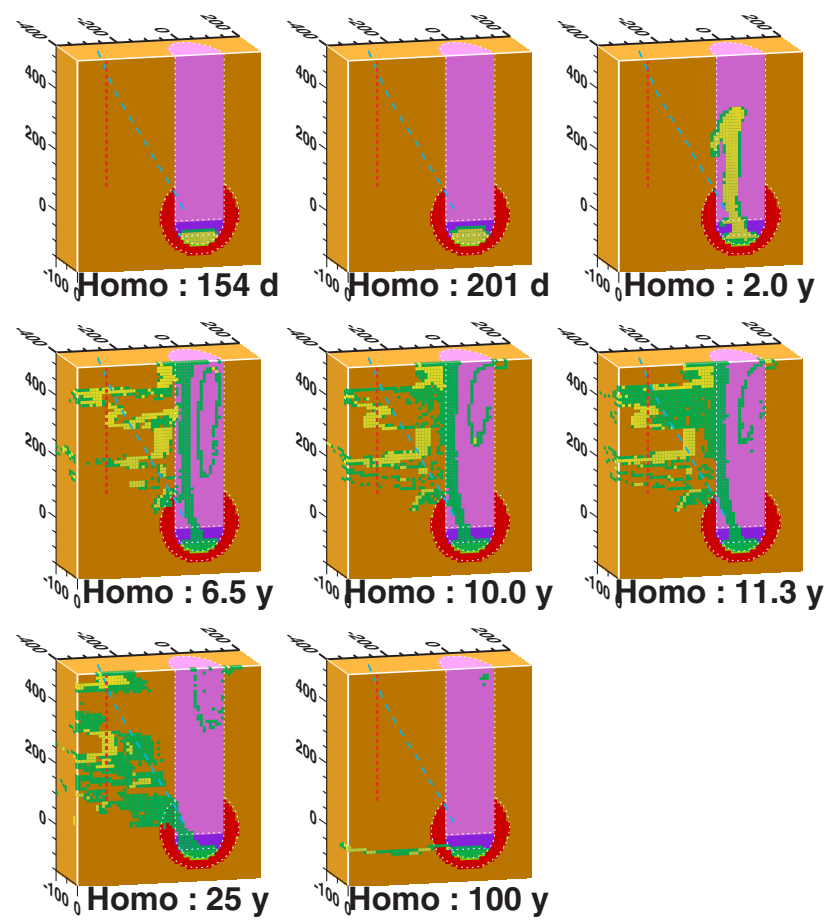

Figure 5.23 Perspective views of tracer transport at different times for homogeneous conceptual model with melt glass source. Yellow $>10^{-9}$ moles/liter; Green $>10^{-14}$ moles/liter. 
Figure 5.24 shows the evolution of a tracer plume derived from a melt glass source assuming a layer-cake conceptual model. Compared with the heterogeneous and homogeneous conceptual models (Figures 5.21, 5.22, and 5.23), the tracer transport resulting from the layer-cake conceptual model generally produces faster breakthrough. Interestingly, this layer-cake simulation clearly shows how the evolution of the convection cell in the chimney affects transport behavior into different high permeability zones. For example, at about $2 \mathrm{yr}$, the convection cell has contacted the middle high permeability zone, providing a path for early breakthrough, while the high permeability zone nearest the melt glass is just beginning to receive tracer. Between 2.0 and $6.5 \mathrm{yr}$, the uppermost high permeability zone provides a significant pathway for breakthrough. After $10.0 \mathrm{yr}$, the convection cells die down as the melt glass cools, and the tracer receives less upward push by the heat and eventually moves exclusively through the lowermost high permeability zone. Overall, the transport behavior of the layer-cake model is more similar to the heterogeneous model than the homogeneous model.
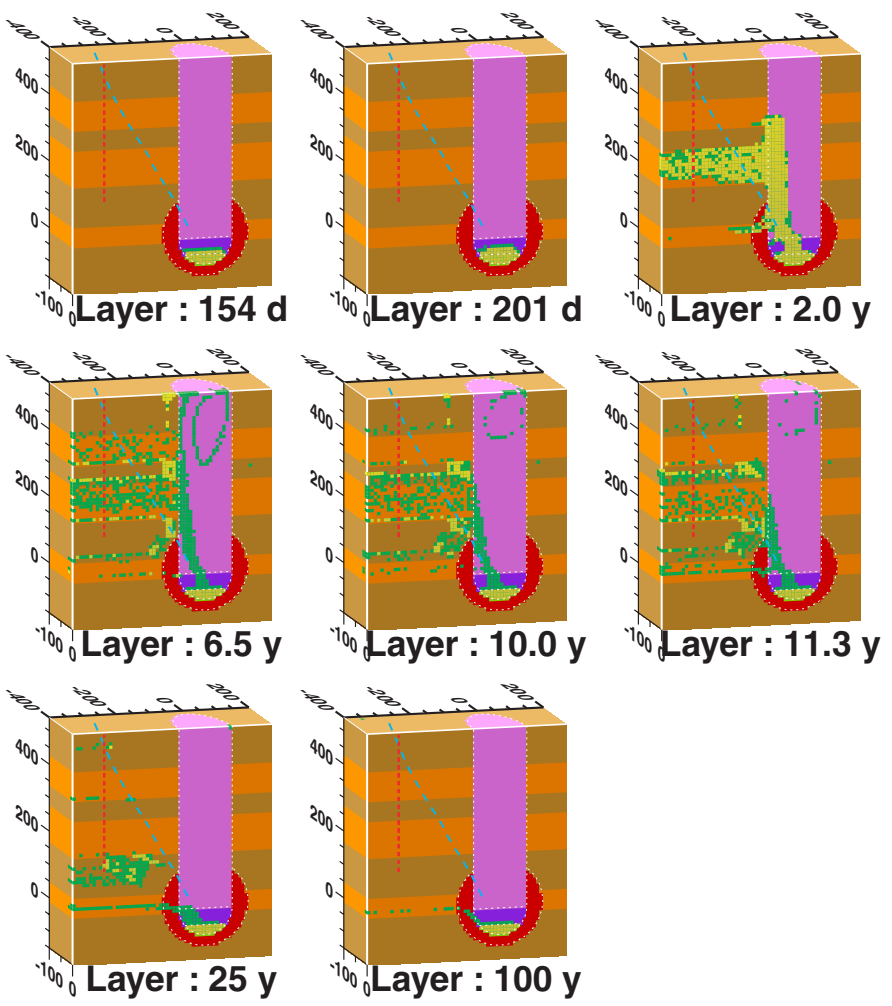

Figure 5.24 Perspective views of tracer transport at different times for layer-cake conceptual model with melt glass source. Yellow $>10^{-9}$ moles/liter; Green $>10^{-14}$ moles/liter.

Figure 5.25 shows the evolution of a tracer plume derived from a melt glass source assuming the heterogeneity of realization 9 and no test-related heat. The flow field assumes a steady state condition for realization 9 assuming the base-case boundary conditions of a 0.010 hydraulic gradient and $7.5^{\circ} \mathrm{C} / \mathrm{km}$ vertical geothermal gradient. In this case, with no test-related heat, the dispersal and total mass of tracer originating from the melt glass is greatly reduced for two reasons: 
- No thermally-induced convection cells are present.

- Melt glass dissolution rates are greatly reduced at ambient temperatures (Chapter 6).

As a result, this simulation indicates that tracer originating from the melt glass would be of low concentration and would tend to migrate toward the high permeability zone nearest the melt glass. Comparison of Figures 5.22 and 5.25 illustrates a dramatic difference in transport behavior that is directly attributed to consideration of residual heat from the CHESHIRE underground nuclear test.

Figure 5.26 illustrates the array of tracer concentrations from a melt glass source for all 10 realizations. This figure allows us to evaluate the variability of the tracer transport attributed to spatial variability of the native rock hydrofacies. Migration of tracer originating in the melt glass is initially delayed, but by 2 yr rapid migration via the chimney and high permeability zones is occurring. Breakthrough in hole UE-20n \#1 occurs in as little as 2 yr. Interestingly, the realizations produce wide variation in the depth of the first high permeability zone penetrated by the melt glass tracer. Between 6.5 and $11.3 \mathrm{yr}$, circulation is evident within the chimney that facilitates distribution of tracer throughout the upper section and into multiple high permeability zones. By 25 $\mathrm{yr}$, the dissolution rate has diminished considerably resulting from the strong temperature dependence on glass dissolution rate (Chapter 6). Much of the tracer that remains is in dead-end conduits or relatively low permeability zones. By $100 \mathrm{yr}$, the tracer primarily remains within the melt glass and lower cavity, and relatively small amounts are released from the cooled melt glass.

The tracer simulation results shown in Figures 5.17 through 5.26 illustrate several points that help us analyze transport behavior relating to flow behavior.

- The CHESHIRE test-related heat induces upward flow. In Figures 5.23 and 5.24, tracer originating from a melt glass source moves upward into the chimney at early times when the melt glass zone remains hot, and laterally at late times after the melt glass zone has cooled. In Figure 5.25, tracer originating from a melt glass source with no test-related heat migrates exclusively in the lateral direction. With test-related heat (Figure 5.25, row 9), tracer migrates upward into the chimney at early times for the same realization.

- The CHESHIRE test-related heat produces complex convection cells in the chimney. The convection cells may cause radionuclide transport having undulating, fingered, or spinning behavior in the chimney. The downgradient migration of radionuclides into high permeability zones may initiate as pulses, depending on the evolution of the convection cells in the chimney.

- Heterogeneity in the permeability field, when combined with the transient flow behavior, adds considerably to the uncertainty in predicting downgradient migration of radionuclides. In general, it appears that a tracer initially present in an unheated disturbed zone tends to migrate down- 
gradient within the nearest high permeability zone. A tracer originally present in the heated cavity tends to be pushed upward into the chimney, then bled off into high permeability zones in the down-gradient direction. Most tracer not bound in the heated melt glass is flushed out the system within 25 yr. Tracer released from the melt glass initially migrates upward through the chimney into middle and upper high permeability zones. Then, as the melt glass cools, the tracer migrates toward a high permeability zone situated nearest the working point. Large-scale matrix diffusion into relatively low permeability zones causes dispersion, retards transport, and provides a long-term, low level source of radionuclides.

- The CHESHIRE test-related heat can greatly increases the rate of melt glass dissolution at early time if processes do not counteract the tendency of glass to dissolve faster at elevated temperature (see Section 6.4.4). When combined with vigorous convection in the chimney, radionuclide migration may be facilitated from a melt glass source into permeable zones situated over the entire saturated zone near and above the working point. The potential for this transport mechanism is illustrated in Figures $5.21,5.22,5.23$, and 5.24 by the tracer transport simulations with a melt glass source.
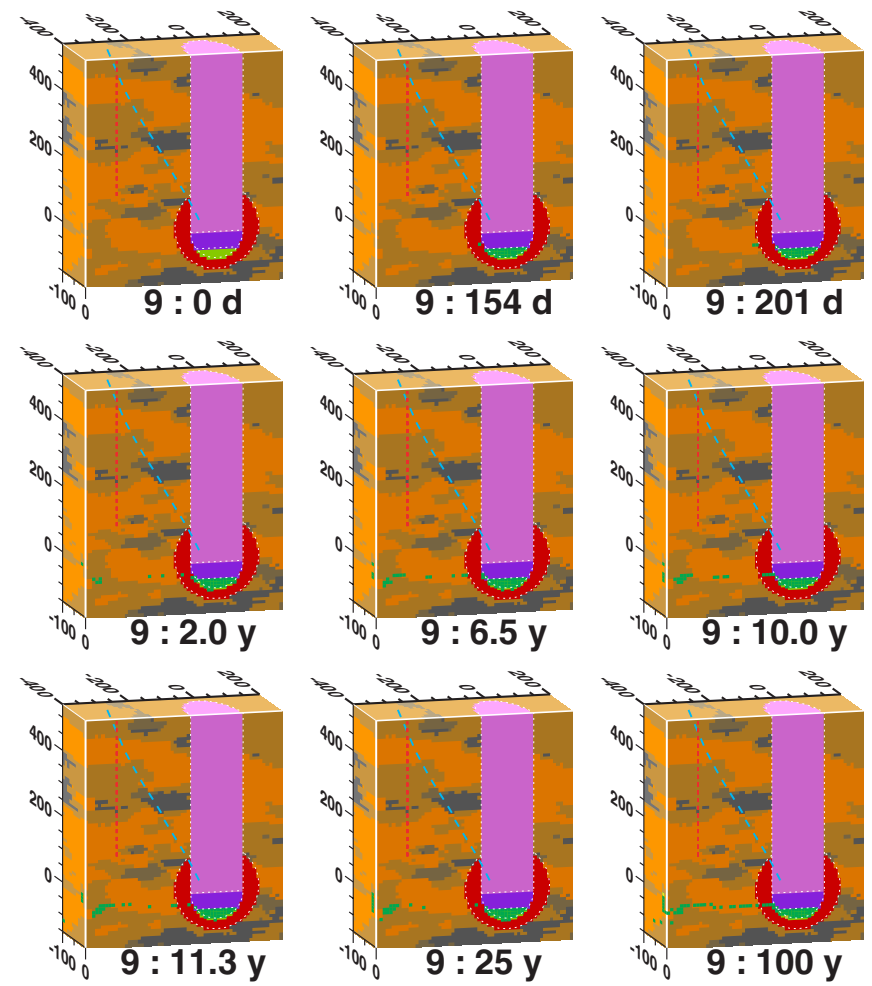

Figure 5.25 Perspective views of tracer transport at different times for realization 9 with melt glass source and no test-related heat. Yellow $>10^{-9}$ moles/liter; Green $>10^{-14}$ moles/liter. 


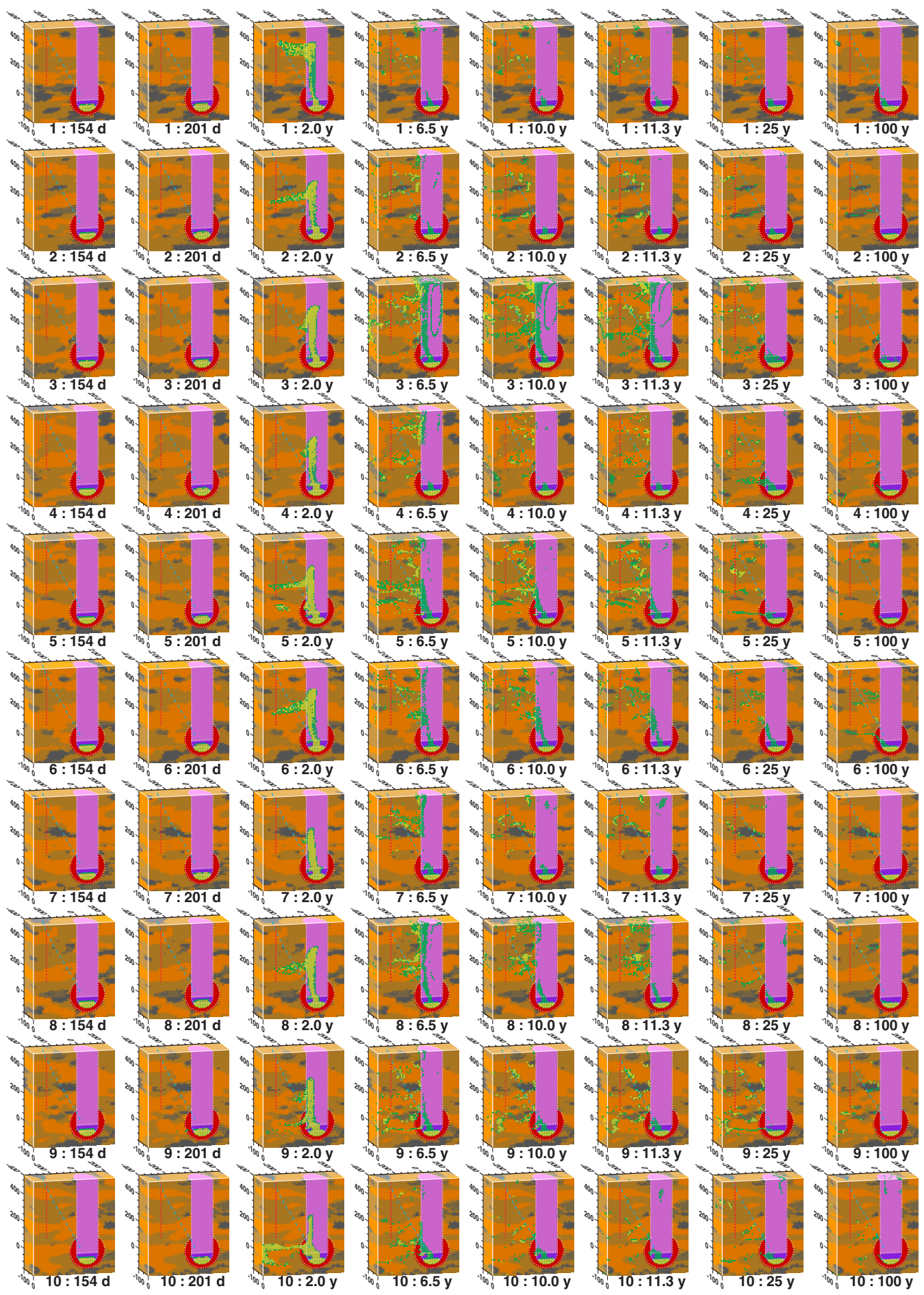

Figure 5.26 Perspective views of tracer transport at different times for 10 realizations with melt glass source. Beneath each image, realization number and time are given. Each row is a different realization, and each column is a different time. Yellow $>10^{-9}$ moles/liter; Green $>10^{-14}$ moles/liter. 


\subsubsection{Streaklines}

A streakline is a path tracing the location of a parcel of water in a transient flow field. Although one can view a streakline as a transient version of a streamline, a streakline considers the cumulative effect of a changing flow field on the particle path. Conversely, a streamline represents the static or steady state version of a streakline. Streaklines are useful for illustrating effects of a transient flow field on transport pathways, analogous to how an instantaneous injection of a nonreactive tracer can be used to study flow behavior in the field.

Figure 5.27 shows a perspective view of streaklines generated for an instantaneous melt glass source (at time zero of the simulation) for realization 3 . This instantaneous melt glass source can also be viewed as equivalent to a nonreactive tracer placed in the pore space of the melt glass source region, without any contribution from dissolution of the melt glass. One can view the streaklines as the transient flow paths (without dispersion) of nonreactive tracers originating from the melt glass at time zero. Each segment of the streakline is colored relative to age of origin of the parcel (or particle), which for this example is the time since the CHESHIRE test. The streakline plot illustrates that flow initially transports the melt glass tracer upward into the chimney. Within about $3 \mathrm{yr}$, some flowpaths bleed off into high permeability zones connected to the chimney. Most of the flow up the chimney initially remains in a large convection cell, such that the particles do not enter the high permeability zones within 5-10 yr of the CHESHIRE test. The thermal pulse provides enough energy to force flow upstream near the top of the chimney. If the streaklines enter moderate or low permeability zones, the flow velocities are significantly reduced, resulting in greater streakline ages.

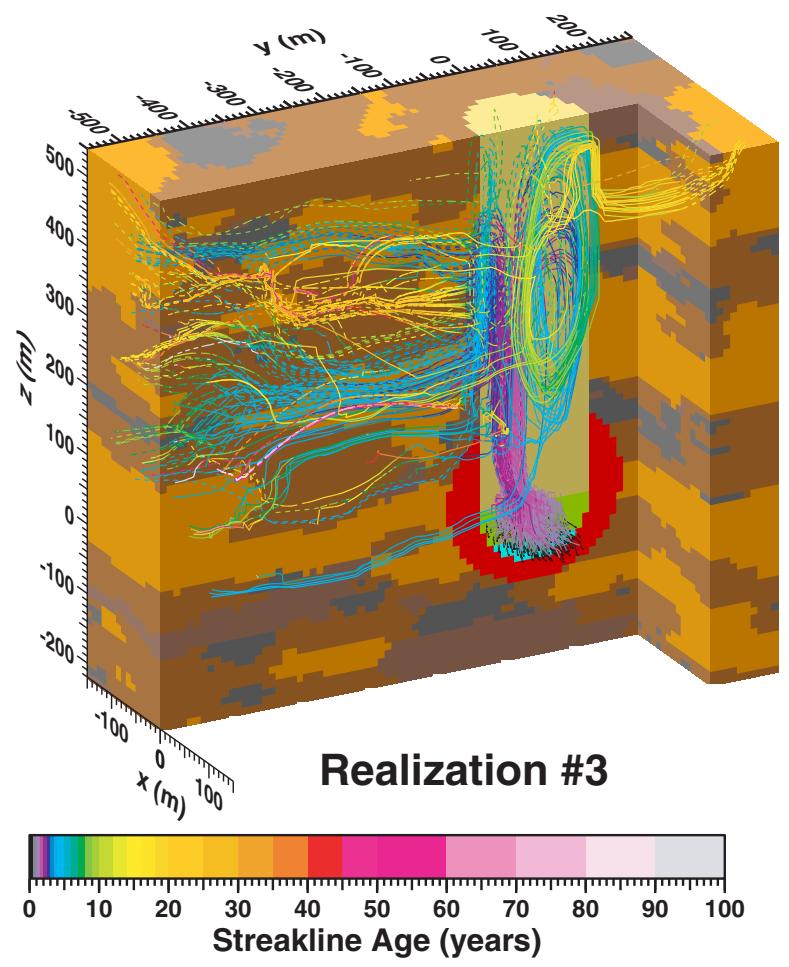

Figure 5.27 Perspective views of streaklines originating from an instantaneous melt glass source for realization 3. 
Figure 5.28 shows streaklines generated from an instantaneous melt glass source for realization 9. Interestingly, the streaklines for realization 9 appear significantly different than the streaklines for realization 3 (Figure 5.27). This comparison illustrates the effect of heterogeneity on the flow behavior. Depending on the permeability structure, one can expect significantly different transient flow behavior. The use of multiple realizations makes possible an examination of a range of transient flow behavior.

The streaklines for realization 9 appear to rise up the chimney and bleed directly into the high permeability zones with only one exceptional looping streakline. As a result, breakthrough for most of the tracer is rapid unless the flowpaths are forced through moderate or low permeability zones. Interestingly, the streaklines in the lowermost high permeability zone are almost entirely forced through a zone of moderate permeability. Although the streaklines take about 2 to $7 \mathrm{yr}$ to travel over $300 \mathrm{~m}$ to the beginning of this moderate permeability zone, they require about 15 to 50 yr to travel less than $50 \mathrm{~m}$ through the moderate permeability zone. This example shows how heterogeneity, particularly in regard to lateral continuity of high permeability zones, can greatly affect prediction of down-gradient transport of radionuclides.

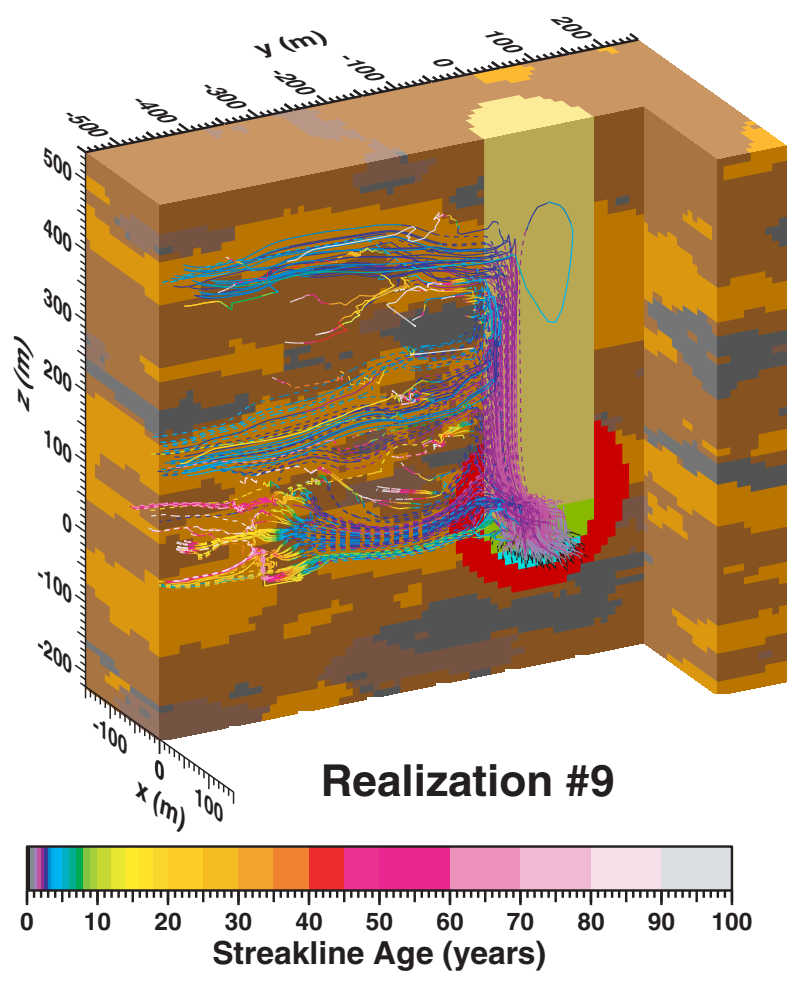

Figure 5.28 Perspective views of streaklines originating from an instantaneous melt glass source for realization 9. 


\subsection{Conclusions}

Before the beginning of this investigation, the joint effect of test-related heat and native rock heterogeneity on groundwater flow behavior was not understood for the CHESHIRE underground nuclear test. As a result of extensive flow simulation work, including multiple permeability realizations and parameter sensitivity studies, considerable insight has been gained into what should constitute a plausible near-field heat and ground water flow system for CHESHIRE. Moreover, considerable insight has been gained into what parameters and data are crucial to characterize the flow system. Another important point demonstrated is that the conceptual model of the native rock permeability structure is essential to predicting realistic flow behavior.

Heat generated by a large underground nuclear test such as CHESHIRE can have an immense effect on near-field groundwater flow behavior. Combined with the presence of a high permeability chimney, the test-related heat drives upward groundwater flow from the cavity and melt glass region, producing convection cells within the chimney. Within a few years after the test, flow funnels into high permeability zones of native rock adjacent to the cavity and chimney. Test-related heat can drive flowpaths from the cavity and melt glass regions that easily span the entire $540 \mathrm{~m}$ height of the chimney within the saturated zone. As a result, one expects that radionuclides can be transported via the chimney to high permeability zones well above the working point. This mechanism gives a plausible explanation for detection of radionuclides $11.3 \mathrm{yr}$ after the CHESHIRE test in the upper high permeability zone of UE20n \#1, about 305 m down-gradient from CHESHIRE, as suggested by Erikson (1991).

Through the use of multiple realizations of heterogeneous permeability in the native rocks surrounding CHESHIRE, a wide range of flow behavior was demonstrated to potentially exist given the state of knowledge of the flow system. As such, the fact that considerable uncertainty exists in the thermal and hydraulic properties of the flow model has been addressed. This uncertainty translates to considerable uncertainty in predictions of flow behavior, which must be accounted for in a radionuclide transport model. Any simulation approach that does not consider the complex, three-dimensional phenomenology of the combined thermal effects and hydraulic heterogeneity is simply not realistic at this near field scale. The true heterogeneity is now known to be more complex than what has been assumed, particularly because considerable sub-grid block-scale heterogeneity exists. Thus, the variability of flow behavior exhibited in the simulations should be considered a lower bound. More variability in flow behavior would be expected if smaller-scale heterogeneity were considered, such as flow in a discrete fracture network. The assumption of a more simplified conceptual model, such as a homogeneous or layer-cake permeability structure in the native rocks, results in unrealistic extreme-case scenarios without plausible means for addressing uncertainty related to permeability heterogeneity.

The exercise of conducting the coupled heat and fluid flow simulations has been invaluable for understanding sensitivity to the permeability of various hydrofacies. The injection test data from U-20a \#2 Water Well were useful for establishing permeabilities for the very low, low, and moderate permeability hydrofacies (lava flow aquitards), which is important to establishing the permeability 
contrast relative to the high permeability hydrofacies. This permeability contrast controls the degree of channelization of flow in the lava flow aquifers, which affects contaminant dispersion, "trapping" of contaminants in lower-permeability zones , and the impact of fast pathways. The injection test data should be useful at other sites, but careful interpretation is necessary, as described in Appendix F.

Interestingly, the temperature log data available from two holes at four separate times are very useful for estimating permeabilities, particularly the high permeability lava flows (lava flow aquifers) and the altered zones-melt glass, lower cavity, and chimney. In effect, heat is used as a tracer to assist in estimating hydrofacies permeabilities because the test-related heat induces heat flow that is initially dominated by fluid convection. Without the temperature logs, much more uncertainty in the flow behavior would exist. The temperature logs enabled estimation of permeability for the melt glass, lower cavity, and chimney, for which scant permeability data exists. The combination of the temperature logs and hydraulic testing data from U-20a \#2 Water Well was useful for estimating anisotropy factors in the permeability of the lava flow aquifers, which was consistent with fracture orientation data and interpretations of tracer tests from the BULLION Forced-Gradient Experiment (IT Corporation, 1998a).

Moreover, the temperature log data provided an excellent indication of the residual heat from the CHESHIRE test, which is expected to be a strong driver of groundwater flow for up to 25 yr or more. Without residual heat, the flow simulations could not produce direct, fast flowpaths to the upper portion of UE-20n \#1, where radionuclides have been detected. On the basis of flow simulation experience, temperature logs should be acquired in drill-back and exploratory holes, such as U-20n PS \#1DD-H and UE-20n \#1, at every opportunity. Most of these flow simulations indicate that, at $25 \mathrm{yr}$ after the test (year 2001), the thermal anomaly near the top of UE20n \#1 should be enhanced compared with 1987, and the melt glass should be cooled to between 45 and $50^{\circ} \mathrm{C}$. Temperature logs obtained today would be very useful for verification of the flow model. These simulations indicate that a highly dynamic, transient flow system can occur in the chimney, with vigorous convection cells supplying heated water to high permeability zones in the down-gradient direction. By about 25 yr, convection of heat up the chimney ceases. By about $100 \mathrm{yr}$, melt glass cools to background temperature, and near steady-state flow conditions resume.

Calibration of non-isothermal flow simulations to temperature logs in the post-shot drillback hole U-20n PS \#1 DD-H indicate that the temperature of the melt glass zone approached $160^{\circ} \mathrm{C}$ soon after the CHESHIRE test. This initial melt glass zone temperature may indicate a temperature at which rapid cooling of the melt glass zone with boiling of water ceased. A $160^{\circ} \mathrm{C}$ boiling point, which is lower than a $250^{\circ} \mathrm{C}$ boiling point under hydrostatic conditions, can be explained by the transient nature of infilling of water into void space created in the cavity and chimney by the CHESHIRE test.

Our preliminary simulations of transport using nonreactive transport indicate that source location and timing will have significant effects on migration pathways, largely as a result of the test-related heat. For example, tracer present as an instantaneous disturbed zone source (outside the cavity and melt glass) tends to migrate to the nearest high permeability zone. Tracer originating from an instantaneous melt glass source consistently advects up into the chimney where convection cells 
disperse the tracer throughout the chimney and toward the down-gradient direction in the saturated zone. However, as the melt glass cools, the convection cells die out, melt glass dissolution decreases, and the migration pathways from the melt glass tend toward the nearest high permeability zones. 


\section{Geochemical Processes}

\subsection{Introduction}

The geochemical processes that control radionuclide release from the melt glass and exchange volume and chemical retardation in the native rock are dependent on the mineralogy and fluid chemistry of the near field. Geochemical processes such as aqueous speciation, surface complexation and ion exchange dictate the level of radionuclide retardation, while dissolution kinetics control the release of radionuclides from the melt glass. Radionuclides can also precipitate from solution as solid phases and redissolve. Below, we discuss the relevant geochemical processes that control radionuclide release and transport in the near field.

This chapter covers a wide range of topics, beginning with an analysis of the petrology and mineralogy of the CHESHIRE site and its near-field environment. The minerals that control radionuclide retardation are identified and their spatial distribution in the three-dimensional near-field model domain is addressed. The geochemical conceptual model is also linked to the conceptual framework defined by the flow model (i.e. effective porosities and fracture/porous flow) (Chapter 5). The treatment of colloids, which can be thought of as mobile sorbing minerals, is also described. The remaining sections address the geochemical modeling tools, process models, and thermodynamic and kinetic data used to model the interactions of radionuclides with groundwater and sorbing minerals. Variations of these models are being used in both the particle and streamline simulations presented in this report. The final sections describe the melt glass dissolution model and the relationship between glass dissolution rates and the precipitation of alteration minerals.

\subsection{Petrology and Mineralogy Near CHESHIRE}

The mineralogic information used to develop the near-field model was derived to large extent from well data near CHESHIRE. Figure 6.1 shows geologic units of interest; these data are from three cores nearest the CHESHIRE site (U-20n, U-20a2ww, and UE-20n\#1). At CHESHIRE, the mafic-poor Calico Hills Formation is especially thick (>600 $\mathrm{m}$ ) and spans from at least $75 \mathrm{~m}$ below the CHESHIRE working point to near the water table. High permeability zones observed from pumping tests (Blankennagel and Weir (1973); Erikson (1991)), believed to be the primary conduits for radionuclide migration, are located within the devitrified lavas of the mafic-poor Calico Hills Formation (Figure 6.1). At the working point, the mafic-poor Calico Hills Formation is intersected by the intrusive Windy Wash Formation. The intrusive Windy Wash Formation mineralogy is comparable with the mafic-poor Calico Hills Formation, so its effect on retardation is expected to be similar. Thus, radionuclide retardation at CHESHIRE will be governed essentially by retardation properties of the mafic-poor Calico Hills Formation. Below, we discuss the properties of the mafic-poor Calico Hills Formation, the intrusive Windy Wash Formation, and the fracture-lining mineralogy of concern to our near-field modeling. 


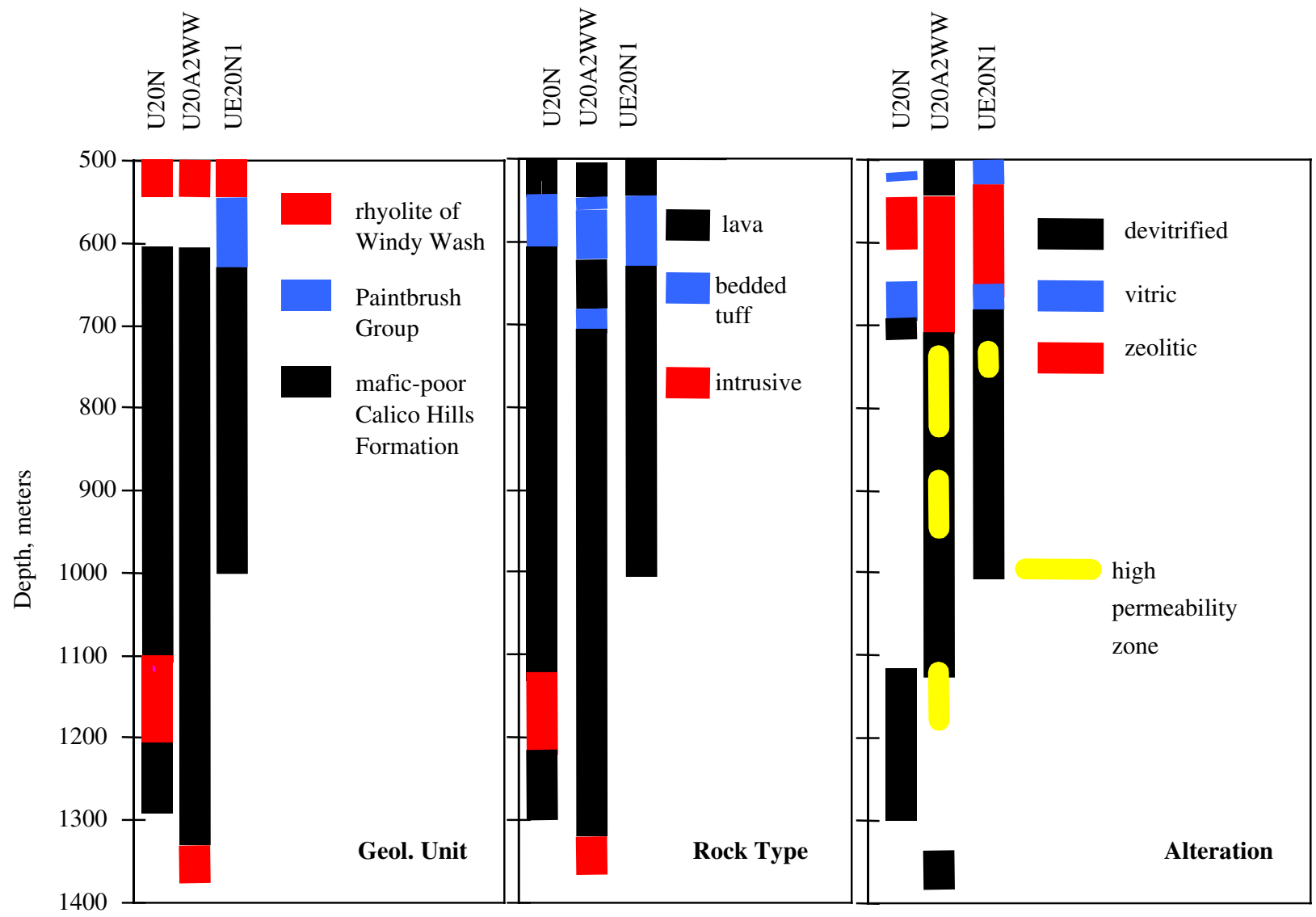

Figure 6.1. Geologic units, rock types, and alteration observed in three cores near Cheshire (Warren et al., 2000). High permeability zones inferred by Blankennagel and Weir (1973) and Erikson (1991) are overlaid on the Alteration plot. 


\subsubsection{Matrix Flow Mineralogy}

The average chemical composition of the mafic-poor Calico Hills Formation and intrusive Windy Wash Formation are compared with a typical rhyolite composition in Table 6.1. The minor and trace element chemistry of the two Pahute Mesa units is quite similar (e.g., total $\mathrm{Fe}$ for mafic-poor Calico Hills Formation and intrusive Windy Wash Formation are 0.6 and 0.8 mass percent, respectively) and consistent with published rhyolite compositions. The chemical composition of the mafic-poor Calico Hills Formation is used to define the melt glass composition in our model (see Section 6.4.4). However, the composition of the melt glass is simplified to include only the primary elements (i.e., $\mathrm{Na}, \mathrm{K}, \mathrm{Ca}, \mathrm{Mg}$, $\mathrm{Si}, \mathrm{Al}$, and $\mathrm{Fe}$ ) and $\mathrm{RST}$ radionuclides. The trace concentrations of naturally occurring $\mathrm{Eu}, \mathrm{Sm}, \mathrm{U}$, and other elements in the rhyolite were excluded from the melt glass to ensure that radionuclide concentrations in the near-field model would be based entirely on the RST-related radionuclide inventory. Of notable exception is $\mathrm{Ca}$, for which a stable background and a test-derived radioactive isotope were included in our model.

The sorbing mineral ${ }^{1}$ abundances in the mafic-poor Calico Hills Formation are difficult to ascertain due to the very limited mineralogic data. Petrographic point counting data from nearby well samples (Table 6.2) provide a wide range of mica and iron oxide concentrations. However, all samples indicate that mica and iron oxide concentrations are quite low. While the iron oxide and mica concentrations of the intrusive Windy Wash Formation are somewhat higher than those for the mafic-poor Calico Hills Formation, the more conservative values reported for the mafic-poor Calico Hills Formation are used in the reactive transport model (400 and 200 ppm for mica and iron oxide, respectively).

In Table 6.3, x-ray diffraction (XRD) analyses of several devitrified tuffs from Yucca Mountain are listed along with one sample of mafic-poor Calico Hills Formation from Pahute Mesa. The primary mineralogy of all samples consists of silica polymorphs and feldspars, while mica, hematite, and smectite are present in low to trace amounts. The smectite content of the mafic-poor Calico Hills Formation sample is $\pm 0.25 \%$ (at the detection limit). This sample was taken from UE-20c at the top of the mafic-poor Calico Hills Formation (a zone with partial zeolitization). Thus, the mineralogic composition of this sample is only a general indication of mineralogy of the mafic-poor Calico Hills Formation at CHESHIRE. The smectite content of the mafic-poor Calico Hills Formation sample is significantly lower than most devitrified tuffs at Yucca Mountain. This may be indicative of a real mineralogic difference between the devitrified tuffs or simply a result of the small number of samples available for comparison. For the near-field model, we estimate the smectite content in the mafic-poor Calico Hills Formation to be $0.25 \%$. The hematite (iron oxide) and mica values of the mafic-poor Calico Hills Formation listed in Table 6.3 are at the detection limit of the XRD analysis but are consistent with petrographic analyses. Because the mafic-poor Calico Hills Formation at CHESHIRE is largely devitrified (Figure 6.1), we conservatively estimate that no zeolite is

\footnotetext{
${ }^{1}$ Sorbing mineralogy is defined as the set of minerals that is believed to significantly contribute to radionuclide retardation. Sorbing minerals will typically include iron oxides, micas, clays, zeolites, carbonates, and manganese oxides.
} 
present within the lava of our model domain. However, zeolites are present in the fractures, as will be discussed below.

Table 6.4 lists some additional data on devitrified tuffs of Yucca Mountain. These cation exchange capacity (CEC) and XRD data are for devitrified tuff samples sieved to various particle size ranges. Quantitative XRD analyses suggest that the mineralogy of the samples is not dramatically affected by sieving. Thus, the mineralogy of these samples should be similar to the bulk rock. The XRD data also suggest that the devitrified tuffs are devoid of both zeolite and calcite, contain hematite (iron oxide) and mica at quantities at or near the detection limit $(\sim 0.5 \%)$, and contain about $5 \%$ smectite. The concentrations of ion exchangers calculated from XRD data and measured using wet chemical techniques are generally consistent. These data provide additional constraints to the sorbing mineral abundances used in the near-field transport model.

Based on the above information, Table 6.5 lists the mafic-poor Calico Hills Formation sorbing mineral abundances used in our near-field model. Because of the limited mineralogic information available for the mafic-poor Calico Hills Formation near CHESHIRE, an assumption is made that the mineralogy of this unit is homogeneous. While the mineralogy of the bulk rock is considered homogeneous, secondary mineral formation in fractures distributed throughout the unit are modeled as heterogeneous, as will be discussed in the following section. Included in Table 6.5 are the cation exchange capacities used for smectite and mica, and estimated surface areas of the various sorbing minerals. As mentioned earlier, the mineralogic composition of the intrusive Windy Wash Formation that intersects the CHESHIRE working point was assumed equivalent to the mafic-poor Calico Hills Formation. This is expected to result in a more conservative measure of radionuclide transport because XRD information suggests that the intrusive Windy Wash Formation contains somewhat higher concentrations of iron oxide and mica (two strong radionuclide sorbers). 
Table 6.1 Average chemical analyses of mafic-poor Calico Hills Formation and intrusive Windy Wash Formation near CHESHIRE.

\begin{tabular}{|c|c|c|c|c|}
\hline \multirow[b]{2}{*}{ Element } & \multirow{2}{*}{$\begin{array}{c}\text { Rhyolite† Range } \\
\text { (Average) }\end{array}$} & \multicolumn{2}{|c|}{ Average Concentrationๆ } & \multirow{2}{*}{$\begin{array}{l}\text { Mass } \\
\text { Units }\end{array}$} \\
\hline & & $\begin{array}{l}\text { Mafic-poor } \\
\text { Calico Hills } \\
\text { Formation }\end{array}$ & $\begin{array}{l}\text { Intrusive Windy } \\
\text { Wash Formation }\end{array}$ & \\
\hline $\mathrm{Al}_{2} \mathrm{O}_{3}$ & 11.6-16.2 (13.2) & 11.6 & - & $\%$ \\
\hline $\mathrm{CaO}$ & $0.27-1.9(0.88)$ & 0.5 & - & $\%$ \\
\hline total Fe & (1.3) & 0.6 & 0.8 & $\%$ \\
\hline $\mathrm{K}_{2} \mathrm{O}$ & $2.7-6.0(4.8)$ & 5.0 & 4.5 & $\%$ \\
\hline $\mathrm{MgO}$ & $0.01-0.70(0.25)$ & 0.1 & - & $\%$ \\
\hline $\mathrm{MnO}$ & $0-0.11(0.05)$ & 0.0 & - & $\%$ \\
\hline $\mathrm{Na}_{2} \mathrm{O}$ & $2.1-4.6(3.3)$ & 2.7 & 3.8 & $\%$ \\
\hline $\mathrm{P}_{2} \mathrm{O}_{5}$ & $0-0.46(0.05)$ & 0 & - & $\%$ \\
\hline $\mathrm{SiO}_{2}$ & 70-79 (74) & 77.7 & - & $\%$ \\
\hline $\mathrm{TiO}_{2}$ & $0.04-0.48(0.20)$ & 0.1 & - & $\%$ \\
\hline $\mathrm{As}_{2} \mathrm{O}_{3}$ & $-^{*}$ & 1.6 & 7.7 & ppm \\
\hline $\mathrm{B}_{2} \mathrm{O}_{3}$ & - & 64.4 & - & ppm \\
\hline $\mathrm{BaO}$ & - & 67.0 & 250 & ppm \\
\hline $\mathrm{BeO}$ & - & 11.1 & - & ppm \\
\hline $\mathrm{Ce}_{2} \mathrm{O}_{3}$ & - & 84.3 & 101 & ppm \\
\hline $\mathrm{Cr}_{2} \mathrm{O}_{3}$ & - & 7.3 & - & ppm \\
\hline $\mathrm{Cl}$ & - & 100 & - & ppm \\
\hline $\mathrm{CoO}$ & - & 0.3 & 0.6 & ppm \\
\hline $\mathrm{Cs}_{2} \mathrm{O}$ & - & 12.2 & 4.8 & ppm \\
\hline $\mathrm{CuO}$ & - & 13.8 & - & ppm \\
\hline $\mathrm{Eu}_{2} \mathrm{O}_{3}$ & - & 0.2 & 0.6 & ppm \\
\hline$F$ & - & 200 & - & ppm \\
\hline $\mathrm{Ga}_{2} \mathrm{O}_{3}$ & - & 26.9 & - & ppm \\
\hline $\mathrm{HfO}_{2}$ & - & 3.9 & 8.5 & ppm \\
\hline $\mathrm{La}_{2} \mathrm{O}_{3}$ & - & 41.8 & 54.0 & ppm \\
\hline $\mathrm{Lu}_{2} \mathrm{O}_{3}$ & - & 0.4 & 0.5 & $\mathrm{ppm}$ \\
\hline $\mathrm{MoO}_{3}$ & - & 3.4 & - & $\mathrm{ppm}$ \\
\hline $\mathrm{Nb}_{2} \mathrm{O}_{5}$ & - & 25.0 & - & $\mathrm{ppm}$ \\
\hline $\mathrm{Nd}_{2} \mathrm{O}_{3}$ & - & 26.8 & 32.7 & ppm \\
\hline $\mathrm{PbO}$ & - & 53.9 & - & ppm \\
\hline $\mathrm{Rb}_{2} \mathrm{O}$ & - & 203 & 186 & ppm \\
\hline $\mathrm{Sb}_{2} \mathrm{O}_{3}$ & - & 1.4 & 0.6 & $\mathrm{ppm}$ \\
\hline $\mathrm{Sc}_{2} \mathrm{O}_{3}$ & - & 4.2 & 2.9 & ppm \\
\hline $\mathrm{Sm}_{2} \mathrm{O}_{3}$ & - & 5.8 & 5.5 & ppm \\
\hline $\mathrm{SrO}$ & - & 29.6 & - & ppm \\
\hline $\mathrm{Ta}_{2} \mathrm{O}_{5}$ & - & 1.6 & 1.9 & ppm \\
\hline $\mathrm{Tb}_{2} \mathrm{O}_{3}$ & - & 0.7 & 0.7 & ppm \\
\hline $\mathrm{ThO}_{2}$ & - & 25.8 & 28.2 & ppm \\
\hline $\mathrm{UO}_{2}$ & - & 5.2 & 5.1 & ppm \\
\hline $\mathrm{WO}_{3}$ & - & 1.5 & - & ppm \\
\hline
\end{tabular}


Table 6.1 (continued) Average chemical analyses of mafic-poor Calico Hills Formation and intrusive Windy Wash Formation near CHESHIRE.

\begin{tabular}{lcccc}
\hline Element & $\begin{array}{c}\text { Rhyolite† Range } \\
\text { (Average) }\end{array}$ & \multicolumn{2}{c}{ Average Concentrationๆ } & Mass \\
\cline { 3 - 4 } & $\begin{array}{c}\text { Mafic-poor } \\
\text { Calico Hills } \\
\text { Formation }\end{array}$ & $\begin{array}{c}\text { Intrusive Windy } \\
\text { Wash Formation }\end{array}$ & \\
\hline \hline $\mathrm{Y}_{2} \mathrm{O}_{3}$ & - & 31.8 & - & $\mathrm{ppm}$ \\
\hline $\mathrm{Yb}_{2} \mathrm{O}_{3}$ & - & 3.2 & 3.2 & $\mathrm{ppm}$ \\
\hline $\mathrm{ZnO}^{\mathrm{nnyy}}$ & - & 64.7 & 72.2 & $\mathrm{ppm}$ \\
\hline $\mathrm{ZrO}_{2}$ & - & 149 & - & $\mathrm{ppm}$
\end{tabular}

I Data from Southwest Nevada Volcanic Field (SWNVF) database of Warren et al. (2000), U-20n and U-20a2ww.

† From Hyndman (1985).

* Data not available.

Table 6.2 Selected petrographic analyses of rocks in the vicinity of CHESHIRE†.

\begin{tabular}{|l|l|c|c|c|}
\hline \multicolumn{1}{|c|}{ Well } & \multicolumn{2}{c|}{ Unit } & $\begin{array}{c}\text { Biotite, } \\
\text { ppm }\end{array}$ & $\begin{array}{c}\text { Fe-Ti oxides, } \\
\text { ppm by vol. }\end{array}$ \\
\hline U-20n and U-20a2ww & mafic-poor Calico Hills Formation & average & 400 & 15 \\
\hline & & st. dev. & 300 & \\
\hline U-20n and U-20a2ww & intrusive Windy Wash Formation & average & 5000 & 2000 \\
\hline & & st. dev. & 3000 & 1000 \\
\hline U-20ww, U-20a, UE-20av & mafic-poor Calico Hills Formation & average & 400 & 200 \\
\hline & & st. dev. & 400 & 300 \\
\hline
\end{tabular}

† From SWNVF database of Warren et al. (2000). 
Table 6.3 Surface areas and XRD analysis of devitrified tuffs of Yucca Mountain $†$ and mafic-poor Calico Hills Formation lava§.

\begin{tabular}{|c|c|c|c|c|c|c|c|c|}
\hline & \multirow{2}{*}{$\begin{array}{c}\text { Surface } \\
\text { area, } \\
\mathrm{m}^{2} / \mathrm{g}\end{array}$} & \multicolumn{7}{|c|}{ Mineralogy, $\%$ by mass } \\
\hline & & smectite & quartz & feldspar & mica & hematite & tridymite & cristobalite \\
\hline & \multicolumn{8}{|c|}{ Devitrified Yucca Mountain tuffs } \\
\hline USW G1-732 & 2.1 & 5 & 8 & 52 & $0.5 \ddagger$ & 0 & 3 & 28 \\
\hline USW G1-1936 & 4.5 & 3 & 31 & 61 & 0.5 & 0 & 0 & 7 \\
\hline USW G4-270 & 2 & 0.5 & 0 & 66 & 0.5 & 1 & 25 & 3 \\
\hline USW G4-2570 & 2.8 & 1 & 37 & 58 & 0 & 1 & 0 & 0 \\
\hline USW GU3-747 & 2.2 & 3 & 0 & 57 & 0.5 & 0.5 & 4 & 33 \\
\hline USW GU3-2325 & 1.8 & 1 & 25 & 56 & 1 & 0.5 & 0 & 14 \\
\hline Average & 2.6 & 2.3 & 16.8 & 58.3 & 0.5 & 0.5 & 5.3 & 14.2 \\
\hline \multirow[t]{2}{*}{ Standard dev. } & 1.0 & 1.7 & 16.2 & 4.8 & 0.3 & 0.4 & 9.8 & 13.6 \\
\hline & \multicolumn{8}{|c|}{ Mafic-poor Calico Hills Formation lava } \\
\hline UE-20c lavaף & & 0.25 & 18 & 40 & 0.25 & 0.25 & 3 & 31 \\
\hline
\end{tabular}

† From Triay et al. (1996).

$\ddagger$ Values in italics assume trace detection is equivalent to $0.5 \%$.

$\S$ From SWNVF database of Warren et al. (2000); 0.25\% detection limit.

I) Partially zeolitized; $5 \%$ clinoptilolite. 
Table 6.4 CEC and XRD analysis of devitrified tuffs from Yucca Mountaint.

\begin{tabular}{|c|c|c|c|c|c|c|c|c|c|}
\hline \multirow{3}{*}{ Sample } & \multirow{3}{*}{$\begin{array}{c}\text { Particle } \\
\text { size, } \\
\text { micron }\end{array}$} & \multicolumn{2}{|c|}{ CEC measurement } & \multicolumn{6}{|c|}{ XRD analysis } \\
\hline & & $\begin{array}{c}\mathrm{CEC} \\
\left(\mathrm{NH}_{4} \mathrm{OAC}\right)\end{array}$ & $\begin{array}{c}\text { CEC } \\
\text { (cation } \\
\text { sum) }\end{array}$ & smectite & mica & zeolite & hematite & calcite & $\begin{array}{c}\text { CEC } \\
\text { from XRD }\end{array}$ \\
\hline & & \multicolumn{2}{|c|}{$\mathrm{meq} / 100 \mathrm{~g}$} & \multicolumn{5}{|c|}{$\%$ by mass } & $\mathrm{meq} / 100 \mathrm{~g}$ \\
\hline g1-1883 & $<106$ & 0.5 & 4.9 & 3 & $0.5 \S$ & 0 & 1 & 0 & 2.5 \\
\hline g1-2363 & $<500$ & 4.8 & 8 & 5 & 1 & 0 & 0.5 & 0 & 4.1 \\
\hline g1-2410 & $106-500$ & 0.4 & 4.9 & 3 & 1 & 0 & 0.5 & 0 & 2.5 \\
\hline g1-2476 & $75-500$ & 0.4 & 3.8 & 1 & 1 & 0 & 0.5 & 0 & 0.9 \\
\hline g1-2840 & $<38$ & 6.3 & 7.3 & 3 & 1 & 0 & 0.5 & 0 & 2.5 \\
\hline g1-2840 & $<106$ & 5.1 & 6.2 & 0.5 & 1 & 0 & 0.5 & 0 & 0.5 \\
\hline g1-2840 & $150-355$ & 3.9 & 4.8 & 1 & 1 & 0 & 0.5 & 0 & 0.9 \\
\hline g1-2840 & $355-500$ & 3.4 & 3.8 & 1 & 1 & 0 & 0.5 & 0 & 0.9 \\
\hline g1-2854 & $75-500$ & 0.9 & 3.8 & 0.5 & 2 & 0 & 0.5 & 0 & 0.7 \\
\hline gu3-0433 & $<500$ & 1.9 & 2.6 & 0.5 & 2 & 0 & 1 & 0 & 0.7 \\
\hline gu3-0916 & $75-500$ & 3.1 & 3.9 & 0.5 & 0.5 & 0 & 0 & 0 & 0.5 \\
\hline ym-22 & $75-500$ & 0.8 & 5.8 & 1 & 0.5 & 0 & 0.5 & 0 & 0.9 \\
\hline$y m-22$ & $<75$ & 1.4 & 4.4 & 2 & 0.5 & 0.5 & 0.5 & 0 & 2.8 \\
\hline ym-45 & $106-500$ & 5.5 & 9.5 & 7 & 0.5 & 0 & 0 & 0 & 5.7 \\
\hline ym-46 & $75-500$ & 3.8 & 8.9 & 1 & 0.5 & 0 & 0.5 & 0 & 0.9 \\
\hline & & & & & Avel & rage & & & \\
\hline & & 2.8 & 5.5 & 2.0 & 0.9 & 0.0 & 0.5 & 0.0 & 1.8 \\
\hline
\end{tabular}

† Data from Chipera and Bish (1989) and Thomas (1987).

‡ Calculated assuming $230 \mathrm{meq} / 100 \mathrm{~g}$ zeolite, $80 \mathrm{meq} / 100 \mathrm{~g}$ smectite, and $15 \mathrm{meq} / 100 \mathrm{~g}$ mica.

$\S$ Trace detection of mineral assumed to equal 0. 
Table 6.5 Sorbing mineralogy of mafic-poor Calico Hills Formation used in near-field model.

\begin{tabular}{|c|c|c|c|c|}
\hline Mineral & $\begin{array}{l}\text { Quantity, } \\
\text { volume \% }\end{array}$ & $\begin{array}{l}\text { Density, } \\
\mathrm{Mg} / \mathrm{m}^{3} \text { * }\end{array}$ & $\begin{array}{c}\text { Surface Area, } \\
\mathrm{m}^{2} / \mathrm{g}\end{array}$ & $\begin{array}{c}\text { CEC, } \\
\text { meq/100g }\end{array}$ \\
\hline $\begin{array}{l}\text { Iron oxide } \\
\text { (hematite) }\end{array}$ & 0.02 & 5.28 & $2.0 \dagger$ & -- \\
\hline Mica & 0.04 & 2.83 & -- & $200 \S$ \\
\hline Smectite & 0.25 & 2.83 & 30.0 & 850 \\
\hline Calcite & 0 & 2.71 & 2.2 & -- \\
\hline $\begin{array}{l}\text { Zeolite } \\
\text { (clinoptilolite) }\end{array}$ & 0 & 2.13 & -- & 2120 \\
\hline \multicolumn{5}{|c|}{$\begin{array}{l}\text { T Surface area listed only for those minerals that participate in surface complexation in our } \\
\text { model; CEC listed for ion exchanging minerals. } \\
\text { § Mica CEC is divided into three site types with differing exchange constants for the various } \\
\text { cations: } 0.5 \% \text { site I, } 3 \% \text { site II, and } 96.5 \% \text { site III (Viani and Bruton, 1992, 1996). } \\
\text { * A } 15 \% \text { porosity is assumed for the mafic-poor Calico Hills Formation. This value was } \\
\text { suggested by Blankennagel and Weir (1973) as an average porosity of lavas within the } \\
\text { rhyolites of Area 20, of which mafic-poor Calico Hills Formation lavas are a subset. }\end{array}$} \\
\hline
\end{tabular}

\subsubsection{Fracture Flow Mineralogy}

\subsubsection{Fracture-Lining Mineral Distribution and Abundance - Pahute Mesa}

Compared to the limited data on bulk mineralogy of the rhyolite lavas in the near-field model, significant evidence is available to suggest that the mineralogy of the fracture linings is heterogeneous at the near-field scale. Because the heterogeneous distribution of minerals will affect the migration of radionuclides from the near field (Tompson et al., 1999), the HST model must account for the abundance as well as the distribution of sorbing minerals. While some of the mineral distribution and abundance data can be taken directly from Pahute Mesa fracture lining investigations, data limitations require that information be culled from other sources such as Yucca Mountain fracture lining investigations. In this section, fracture-lining mineral distribution and abundance data from Pahute Mesa are reported; in the following section, we report on Yucca Mountain data relevant to the CHESHIRE near field. The combined data are used to model fracture-lining mineral distribution and abundance at CHESHIRE.

Drellack et al. (1997) published the most comprehensive set of information regarding the mineralogy of fracture linings at Pahute Mesa. These data are a semiquantitative determination of the prevalence of a variety of fracture-lining minerals that will likely influence radionuclide transport. Unfortunately, the regionally oriented scale of observation hampers the implementation of their data at the smaller near-field scale. For example, the hydrostratigraphic unit defined in Drellack et al. (1997) that encompasses the mafic-poor Calico Hills Formation (one of five stratigraphic units in the Volcanics of Area 20) comprises the entire Paintbrush, Volcanics of Area 20, and Crater Flat groups. Similarly, the hydrogeologic unit defined in Drellack et al. (1997) that includes the lava flow aquifers of the mafic-poor Calico Hills Formation at 
CHESHIRE also includes rhyolitic lava flows of variable transmissivity, fracture density, and zeolitization. The mineralogy of the CHESHIRE near field cannot be directly inferred from coarse scale (CAU scale) fracture lining observations. Nevertheless, the fracturelining mineralogies listed in Drellack et al. (1997) are a good basis from which to begin to develop a finer scale model for fracture-lining mineralogy.

Table 6.6 contains a summary of the fracture-lining mineralogies reported by Drellack et al. (1997) for the Tuff Cone hydrostratigraphic and Lava Flow Aquifer hydrogeologic units. These units include the mafic-poor Calico Hills Formation lavas at CHESHIRE. The fracture-lining mineralogy of the Tuff Cone hydrostratigraphic unit is similar to the mineralogy of the Lava Flow Aquifer hydrogeologic unit because the Tuff Cone unit is composed largely of lava flow aquifer units. In general, the data suggest that the fracture-lining mineralogy possesses greater sorption potential than the bulk mineralogy of the mafic-poor Calico Hills Formation (Table 6.5). However, this suggestion is tempered by the fact that the abundance of fracture-lining minerals on the bulk-rock scale is relatively small.

Table 6.6 Fracture-lining mineral observational probabilities as described by Drellack et al. (1997).

\begin{tabular}{|l|c|c|}
\hline \multicolumn{1}{|c|}{ Mineral } & $\begin{array}{c}\text { Tuff Cone } \\
\text { hydrostratigraphic } \\
\text { unit, } \\
\text { Mineral \% }\end{array}$ & $\begin{array}{c}\text { Lava Flow Aquifer } \\
\text { hydrogeologic } \\
\text { unit, } \\
\text { Mineral \% }\end{array}$ \\
\hline Chalcedony & 24 & 24 \\
\hline Quartz & 5 & 8 \\
\hline Calcite & 3 & 3 \\
\hline Zeolite & 30 & 35 \\
\hline Clay & 11 & 6 \\
\hline Fe/MnO & 20 & 17 \\
\hline Other & 7 & 7 \\
\hline
\end{tabular}

Some comments should be made regarding the data in Table 6.6. The values in Table 6.6 are observational probabilities rather than mass or volume fractions. The relative quantities of minerals determined by Drellack et al. (1997) were based on visual inspection of core, such that the percentages were determined by the number of times a mineral was observed. Thus, certain easily visible minerals such as iron and manganese oxides may have mass fractions significantly lower than the observational probabilities presented in Table 6.6. For example, in Appendix A of Drellack et al. (1997), visual observations are compared with spectroscopic (XRD) analyses. While iron/manganese oxides are visually observed in many samples, XRD analyses indicate that these minerals represent only a small mass fraction of the fracture-lining minerals. (However, iron/manganese oxides can be difficult to detect by XRD.) Data reported by Prothro et al. (1997) regarding the mafic-poor Calico Hills Formation fracture-lining mineralogy in ER-20-6 \#1 was also based on observational probabilities. Visual inspection of cores with fracture linings indicated that manganese oxides dominated all fracture linings. A similar statement regarding the abundance of manganese oxides was also made by 
Blankennagel and Weir (1973). However, care must be taken to distinguish between observational probability data and mass fraction data. Radionuclide retardation is dependent on mass fractions of minerals and not observational probabilities.

\subsubsection{Fracture-Lining Mineral Distribution and Abundance - Yucca Mountain}

A large number of quantitative fracture-lining mineral data are reported in Carlos et al. (1995a). Both visual observation and quantitative XRD were used to describe fracture-lining mineralogy in several cores at and near Yucca Mountain. Figure 6.2 shows the drill hole locations. Figures 6.3 to 6.7 show the fracture-lining mineralogy for the various drill holes. In these plots, fracture-lining minerals were grouped into six categories: clays (smectite), zeolites (clinoptilolite, mordenite, stellerite), carbonates (calcite), iron oxides (hematite), manganese oxides (ranceite, lithiophorite, cryptomelane, pyrolusite), and all other silicates (tridymite, cristobalite, etc.).

The XRD key defined in Carlos et al. (1995a) was simplified in the following ways (percent by mass):

- Major abundance $(\geq 20 \%) \Rightarrow 60 \%$.

- Minor abundance $(5-20 \%) \Rightarrow 12.5 \%$.

- Trace abundance $(\leq 5 \%) \Rightarrow 2.5 \%$.

- $\quad$ Not detected $\Rightarrow 0 \%$.

- Presence uncertain $\Rightarrow 0 \%$. 


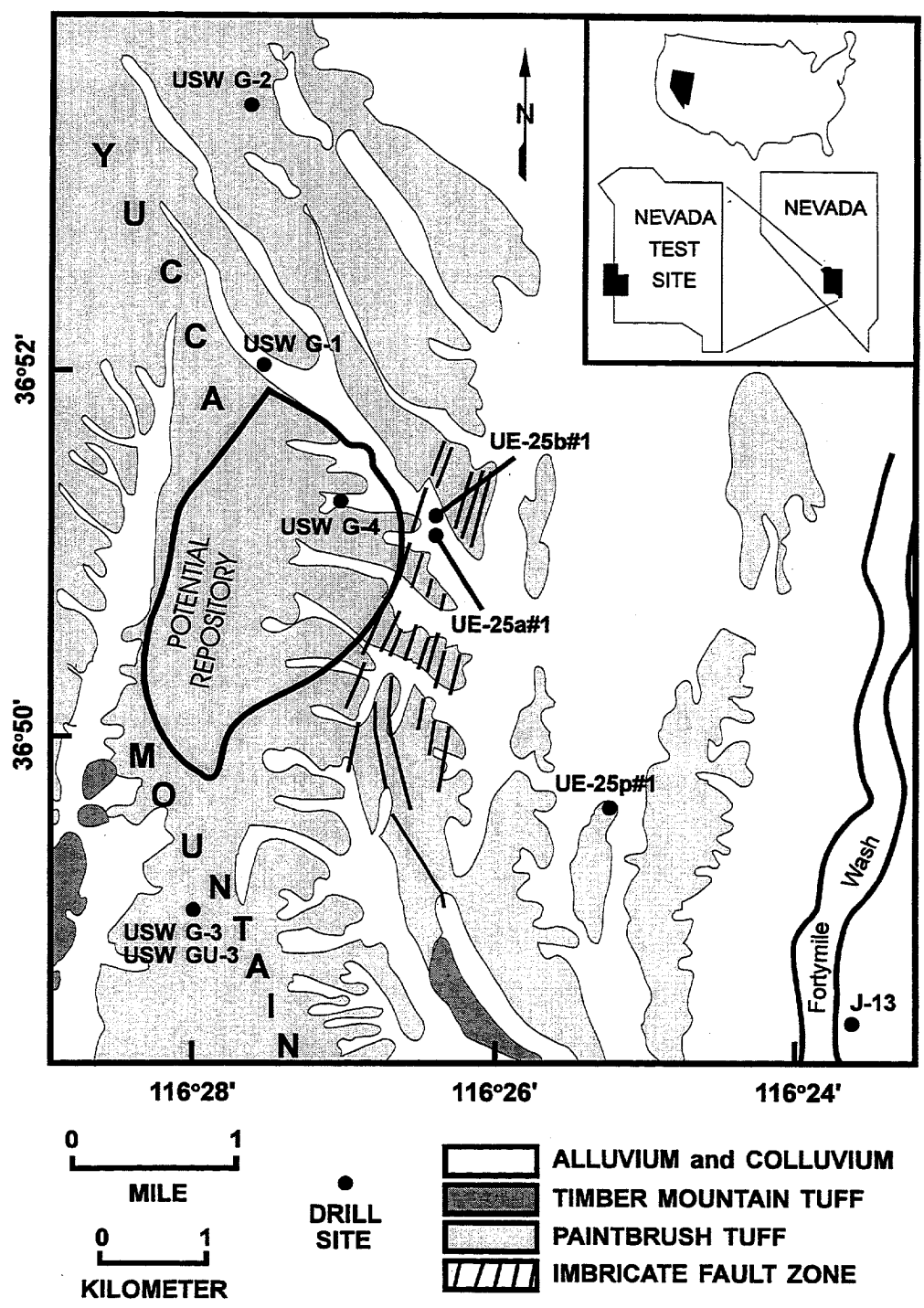

Figure 6.2 Yucca Mountain and nearby drill holes from which core data were used to describe fracture-lining mineralogy (Carlos et al., 1995a). 


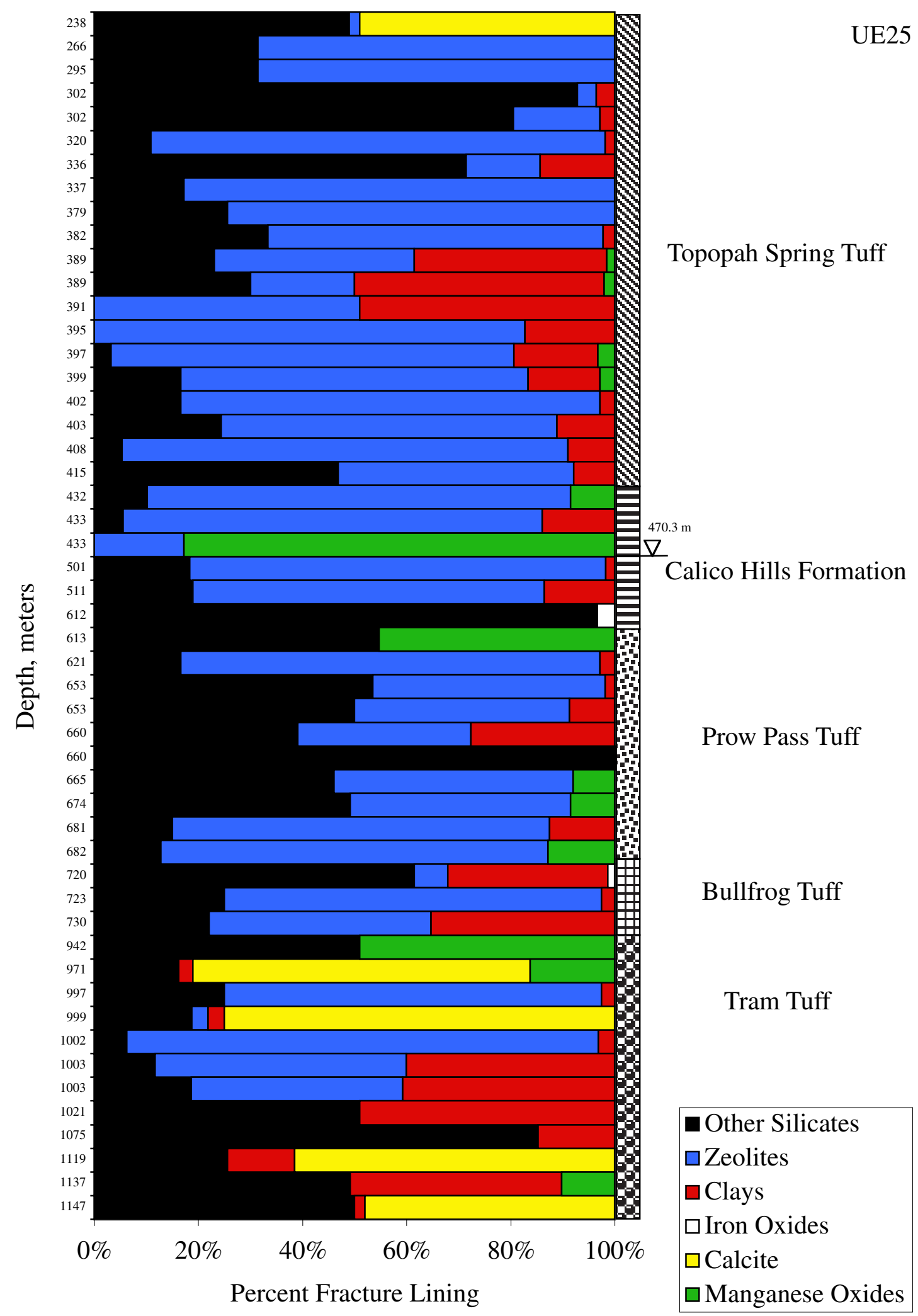

Figure 6.3 Fracture-lining mineral distribution from well UE-25a\#1/UE-25b\#1 as a function of depth (below ground surface). 


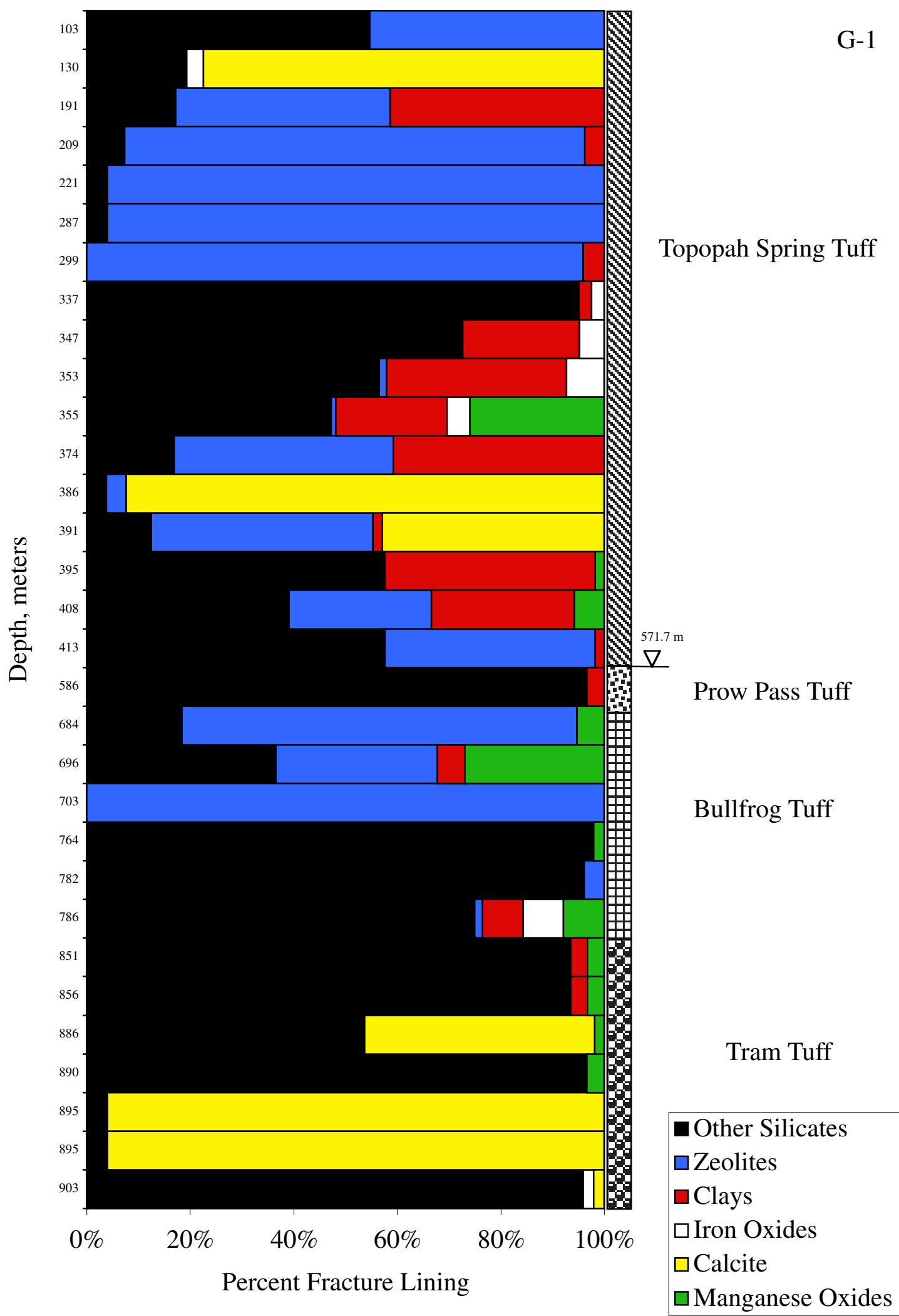

Figure 6.4 Fracture-lining mineral distribution from well USW G-1 as a function of depth (below ground surface). 


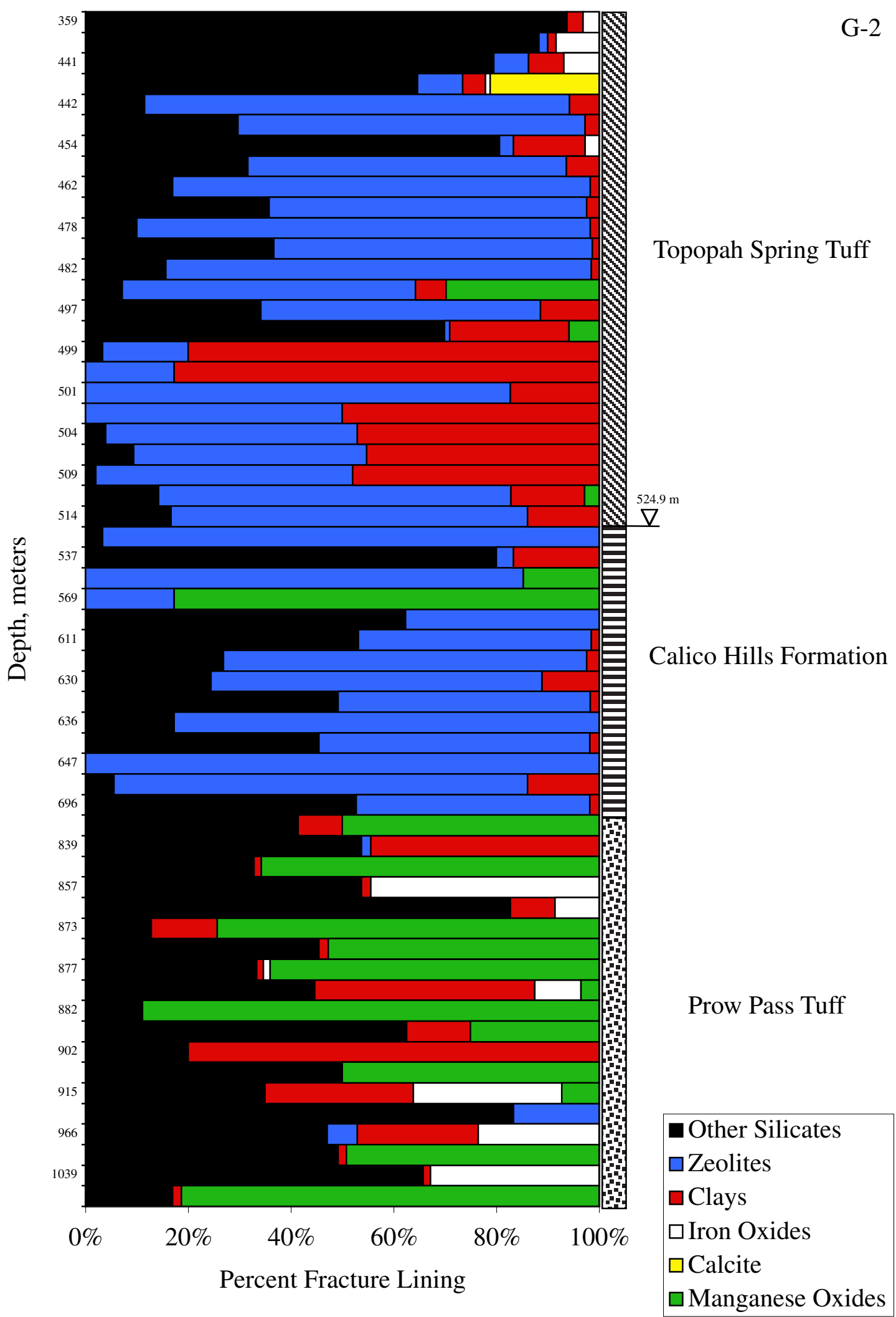

Figure 6.5 Fracture-lining mineral distribution from well USW G-2 as a function of depth (below ground surface). 


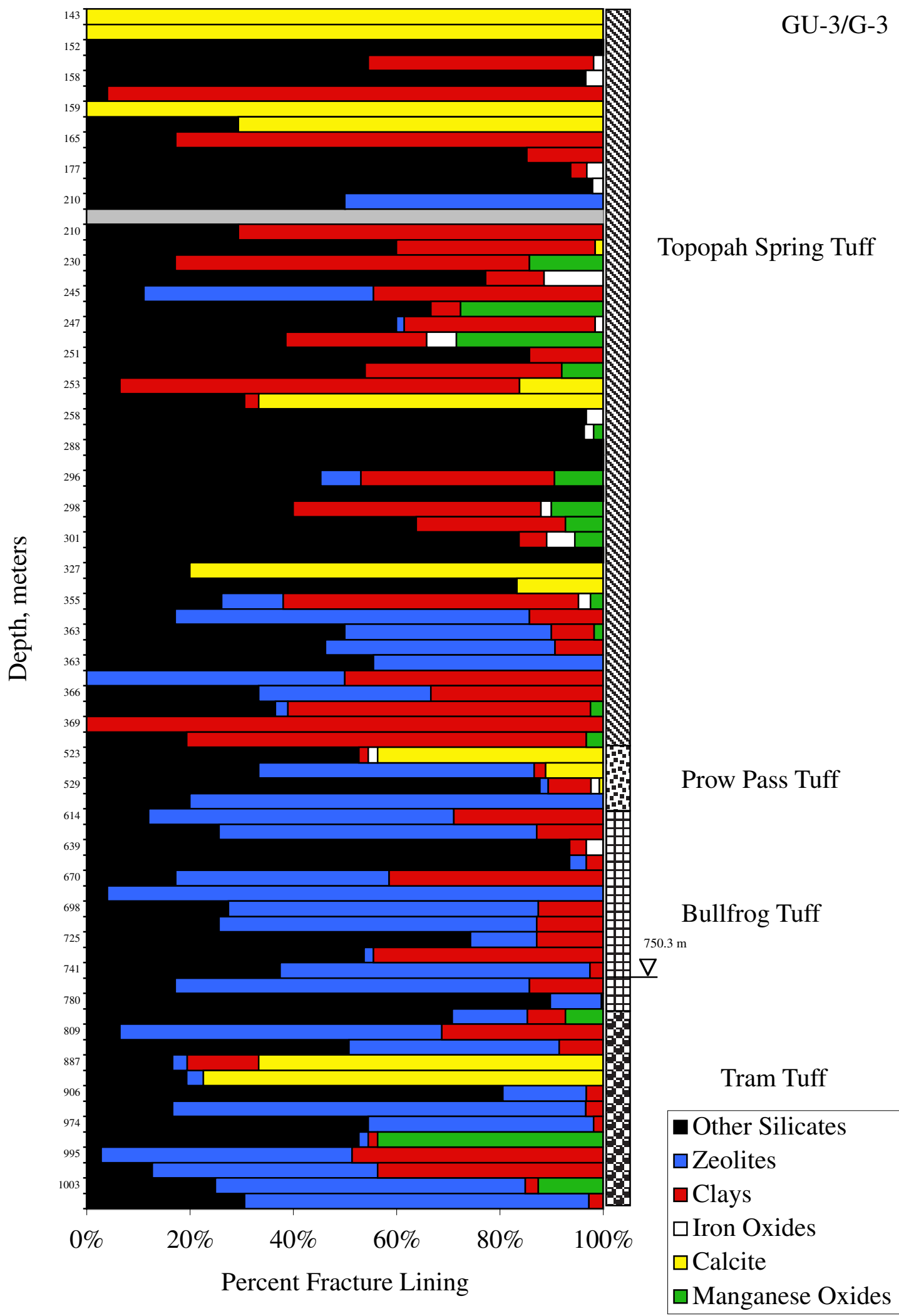

Figure 6.6 Fracture-lining mineral distribution from well USW G-3/USW GU-3 as a function of depth (below ground surface). 


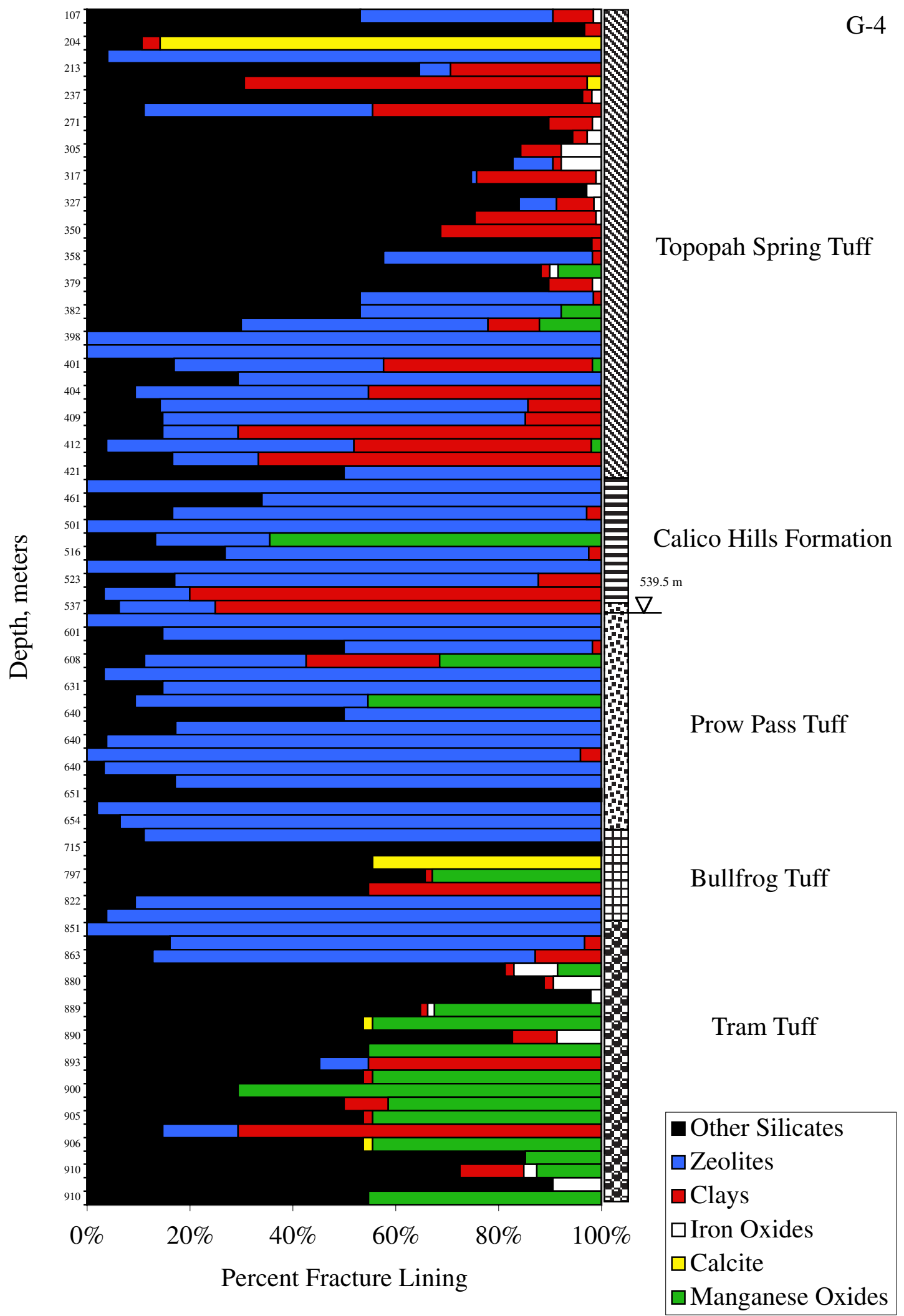

Figure 6.7 Fracture-lining mineral distribution from well USW G-4 as a function of depth (below ground surface). 
Figures 6.3 to 6.7 indicate that sorbing minerals (zeolites, clays, iron oxides, calcite, and manganese oxides) are distributed heterogeneously and that the distribution is different for each mineral. For example, zeolite distribution is heterogeneous but zeolitic zones are vertically continuous. This is significantly different from the distribution of calcite, which is rare and discontinuous. Smectite tends to appear in nearly all fractures while manganese oxides are rare, but when present, seem to occur in vertically continuous zones.

The fracture-lining mineralogy in Figures 6.3 to 6.7 is presented without reference to the geologic unit composition or its position with respect to the water table. The fracture-lining mineralogy ${ }^{2}$ encompasses devitrified, vitric, and zeolitic zones above and below the water table. However, it is important to note that the majority of the fracture-lining data presented in these figures fall within the single Tuff Cone hydrostratigraphic unit as defined in Drellack et al. (1997). Thus, this heterogeneous distribution of sorbing minerals is lost at the regional scale of observation of Drellack et al. (1997). The CHESHIRE near-field model requires finer scale fracture-lining mineral distribution information than is available from the regional scale data. The data from Yucca Mountain provide fracture-lining mineral distribution at a more appropriate scale.

Figures 6.8 to 6.10 present information on the abundance and observation frequency of sorbing minerals in three separate subsets of the Yucca Mountain fracturelining data: Topopah Spring Tuff, Calico Hills Formation, and devitrified tuffs below the water table. Data regarding position of the geologic units, their alteration, and the water table depth were taken from data contained in the SWNVF database (Warren et al., 2000). Additional mineralogic information was obtained from Bish and Chipera (1989). The Topopah Spring Tuff at Yucca Mountain is mainly devitrified and located above the water table. The Calico Hills Formation is largely zeolitized and located both above and below the water table, depending on location. The devitrified tuffs below the water table comprise samples from the Prow Pass, Bullfrog, and Tram tuffs.

Significant differences are evident among these three subsets. In the zeolitized Calico Hills Formation, zeolites are found ubiquitously on all fractures, calcite and hematite are largely absent, and smectite is found in $50 \%$ of samples but in relatively small quantities. Unlike fractures in the Calico Hills Formation, only $50 \%$ of fractures in the Topopah Spring Tuff contain zeolites but clays are significantly more abundant. In addition, calcite is present sporadically but at high concentrations. Iron oxides are present in the Topopah Spring Tuff, while manganese oxides are present at quantities significantly less than in the Calico Hills Formation. The devitrified tuffs below the water table contain the smallest quantity of zeolite but the largest quantity of manganese oxides, consistent with the discussions in Carlos et al. (1995a).

\footnotetext{
${ }^{2}$ No attempt is made here to define the paragenesis of the fracture-lining minerals. Thus, the extrapolation of fracture-lining distribution patterns from Yucca Mountain to the CHESHIRE site at Pahute Mesa provides a reasonable analog but not a verified representation of near-field fracture-lining mineralogy and mineral distribution. Differences in fluid temperatures, flow patterns, and chemistry could affect both the fracture-lining mineralogy and distribution patterns.
} 


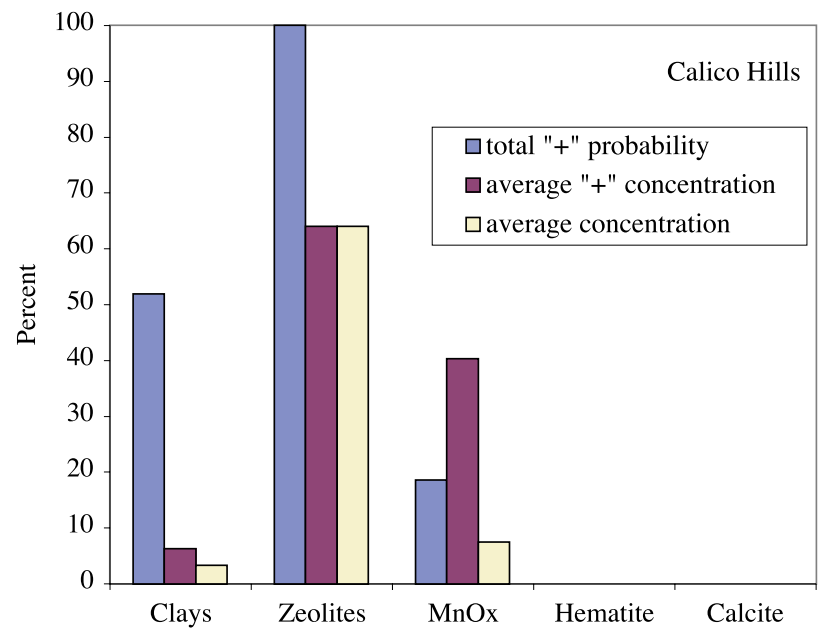

Figure 6.8 Calico Hills Formation fracture-lining mineral distribution probabilities and concentrations. Total " + " probability indicates the percent of fractures examined that contained a mineral, average " + " concentrations indicates the average concentration of the mineral in fractures that contained that mineral, and average concentration indicates the absolute average concentration of the mineral in Calico Hills Formation fractures. Concentration is in relative percent.

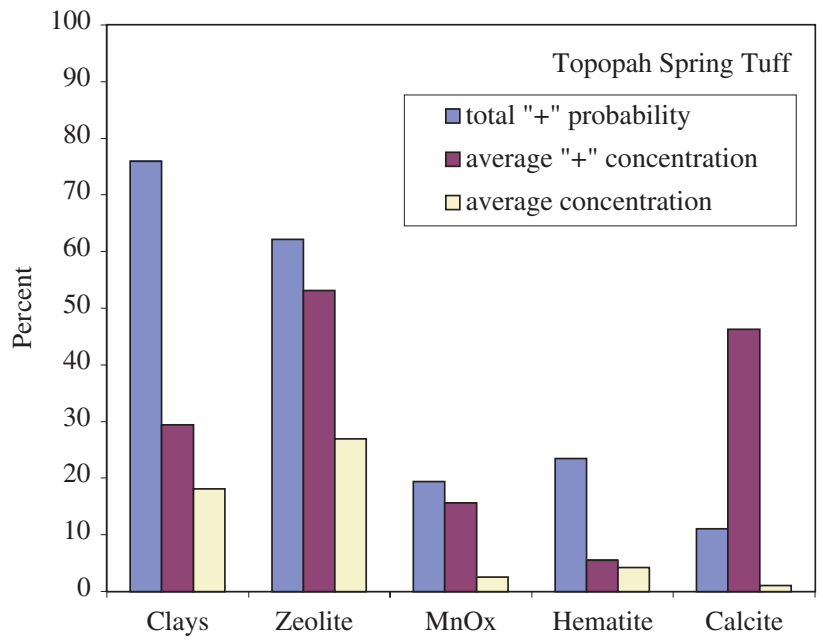

Figure 6.9 Topopah Spring Tuff fracture-lining mineral distribution probabilities and concentrations. Total "+" probability indicates the percent of fractures examined that contained a mineral, average "+" concentrations indicates the average concentration of the mineral in fractures that contained that mineral, and average concentration indicates the absolute average concentration of the mineral in Topopah Spring Tuff fractures. Concentration is in relative percent. 


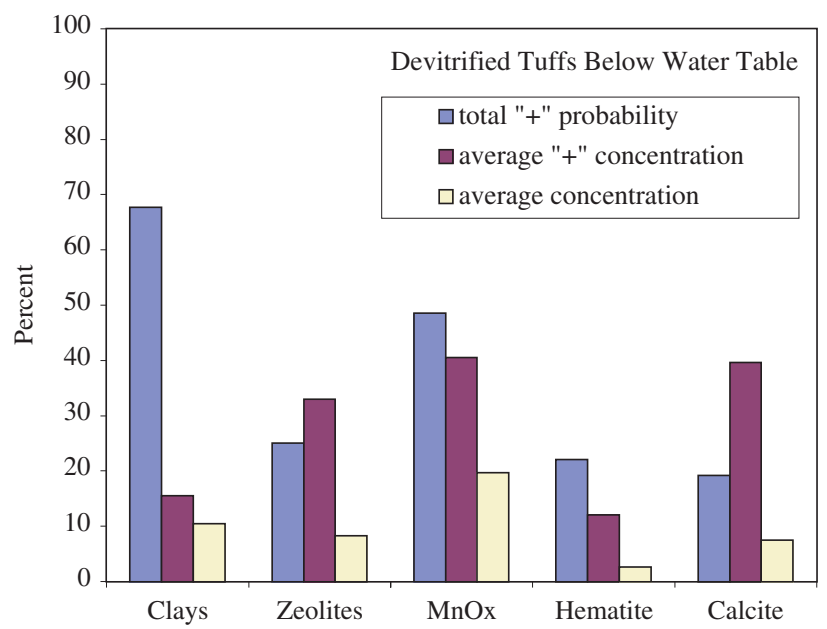

Figure 6.10 Fracture-lining mineral distribution probabilities and concentrations for devitrified tuffs below the water table. Total "+" probability indicates the percent of fractures examined that contained a mineral, average "+" concentrations indicates the average concentration of the mineral in fractures that contained that mineral, and average concentration indicates the absolute average concentration of the mineral in devitrified tuff fractures below the water table. Concentration is in relative percent.

Although the fracture-lining mineral distributions differ among the three subsets of data discussed above, the observed differences are relatively small. For all three subsets of fracture-lining minerals, the following statements can be made:

- Clay is present in $>50 \%$ of fractures.

- Zeolites and other silicates are present but to varying degrees.

- Manganese oxide minerals are present but to varying degrees.

- Iron oxides, if present, comprise a small fraction of the total fracture-lining mineralogy.

- Calcite, if present, is distributed heterogeneously and comprises a small fraction of the total fracture-lining mineralogy.

The observational probabilities of the various fracture-lining minerals presented by Drellack et al. (1997) regarding the Tuff Cone hydrostratigraphic and Lava Flow Aquifer hydrogeologic units have some similarity to the devitrified tuff subset of the Yucca Mountain data. The presence of the various minerals follows the order: zeolites $>$ iron/manganese oxides $>$ clays $>$ calcite for the Pahute Mesa data presented in Table 6.6. For the case of devitrified tuff below the water table at Yucca Mountain, mineral probabilities follow the order: manganese oxides plus iron oxides $>$ clays $>$ zeolites $>$ calcite. $^{3}$ The only difference in the order is for the case of zeolites. This is particularly important since the presence of zeolites will significantly retard many radionuclides. The information provided by Drellack et al. (1997) is of a regional scale,

\footnotetext{
${ }^{3}$ The order of average mineral abundance follows this same order.
} 
and the presence of zeolites as fracture linings is strongly dependent on the geologic unit and its thermal history (Figures 6.3 to 6.7).

The information available on the fracture-lining mineralogy near CHESHIRE (Blankennagel and Weir, 1973; Erikson, 1991) suggests that the more dominant mineralogy is manganese oxide, consistent with the fracture-lining mineral abundance and distribution data for devitrified tuffs below the water table at Yucca Mountain (Figure 6.10). The fracture-lining mineral data of Drellack et al. (1997) for the Tuff Cone unit may overestimate the importance of zeolites in the Cheshire near field which would lead to overpredicted retardation of certain radionuclides. Also, the data of Drellack et al. (1997) do not include fracture-lining mineral distribution data critical to the proper evaluation of radionuclide retardation. It is suggested, therefore, that the fracture-lining mineral abundances and distribution data for devitrified tuffs below the water table at Yucca Mountain provide a better estimate of sorbing mineral abundance and distribution in fractures in the CHESHIRE near-field.

Appendix $\mathrm{H}$ discusses the statistical representation of heterogeneous mineral distribution interpreted from the Yucca Mountain devitrified tuffs below the water table. The implementation of these mineral distributions in the geochemical modeling is discussed in the next section.

\subsubsection{Fracture Density and Morphology in the CHESHIRE Near Field}

Fracture densities, apertures, and fracture lining thicknesses were determined from both literature data and constraints based on the hydrologic model. A summary of information regarding fracture densities and morphologies and implementation in the geochemical model for fluid flow in fractures follows.

\subsection{Field data}

Fracture densities in UE-20n \#1, down-gradient from CHESHIRE, were reported by Erikson (1991). A zone of high permeability and high fracture density was intersected near the water table. Although this zone was not identical, in depth and thickness, to the high permeability zone described by Blankennagel and Weir (1973) (Figure 6.1), it was in approximate agreement. In this high permeability zone, fracture densities of 3.8 fractures per meter were reported. In a highly fractured zone farther down-hole, fracture densities of 2.2 fractures per meter were reported. The less fractured zones had densities of 0.3 fractures per meter. These fracture densities are consistent with the average fracture densities of 2.2 per meter reported by Drellack et al. (1997) for lava flow aquifers on Pahute Mesa. Drellack et al. (1997) also reported that $18 \%$ of fractures were open in the lava flow aquifers, with average apertures of $0.5 \mathrm{~mm}$. Prothro and Drellack (1997) suggested that the fracture densities within individual lava flows can vary considerably. They estimated that hydraulic conductivities within individual lava flows may vary between 0.001 and $20 \mathrm{~m} / \mathrm{d}$, which would correlate to some degree with fracture densities and connectivities.

Blankennagel and Weir (1973) described fracture densities in rhyolitic lava flows on Pahute Mesa ranging between 0 and 14.1 fractures per meter. No information regarding the size or openness of the fractures was reported. These fracture densities 
are somewhat higher than those of Erikson (1991) and others discussed above. However, they are consistent with observations reported for core from ER-20-6 \#1 (Prothro et al., 1997) located $2 \mathrm{~km}$ north of CHESHIRE. Here, fracture densities ranged from 0 to 20 fractures per meter, and averaged 8.5 fractures per meter in highly fractured zones. Fracture apertures were generally less than $5 \mathrm{~mm}$, and some evidence of possible flow in vesiculated zones (up to $2 \mathrm{~cm}$ vesicles) within the lava was also reported.

Using the maximum fracture density reported by Blankennagel and Weir (1973) of 14.1 fractures per meter, and assuming that $18 \%$ of those fractures are open (as reported in Drellack et al. (1997)), we arrive at a fracture density of 3 per meter. However, in the near-field geochemical model, a parallel plate fracture density of 8 per meter was used instead. This fracture density was chosen for several reasons. First, if the 3 fractures per meter are non-parallel and tortuous, the quantity of sorbing minerals associated with them will be significantly greater than that predicted using 3 parallel plate fractures. Second, the higher fracture density still falls within the total fracture density range for rhyolitic lava flows (such as the mafic-poor Calico Hills Formation) described by Blankennagel and Weir (1973) and Erikson (1991). Third, the higher fracture density helps to narrow the difference in effective porosity between the flow and geochemical models (discussed later in this section).

Little information is available on the thicknesses of fracture-lining minerals on fractures. Information presented by Drellack et al. (1997) suggests that Lava Flow Aquifer fractures have an average aperture of $0.5 \mathrm{~mm}$ and are $50-99 \%$ open. The range of openness is equivalent to fracture lining thicknesses of 125 to $2.5 \mu \mathrm{m}$. Electron microprobe images of fracture-lining minerals presented by IT Corporation (1998b) suggest that $100 \mu \mathrm{m}$ fracture lining thicknesses are common in various locations (Figure 6.11). This sparse evidence suggests that a $100 \mu \mathrm{m}$ thick fracture lining is a reasonable value for use in our near-field CHESHIRE model. A $0.5 \mathrm{~mm}$ fracture aperture was assumed throughout the CHESHIRE near-field modeling. 

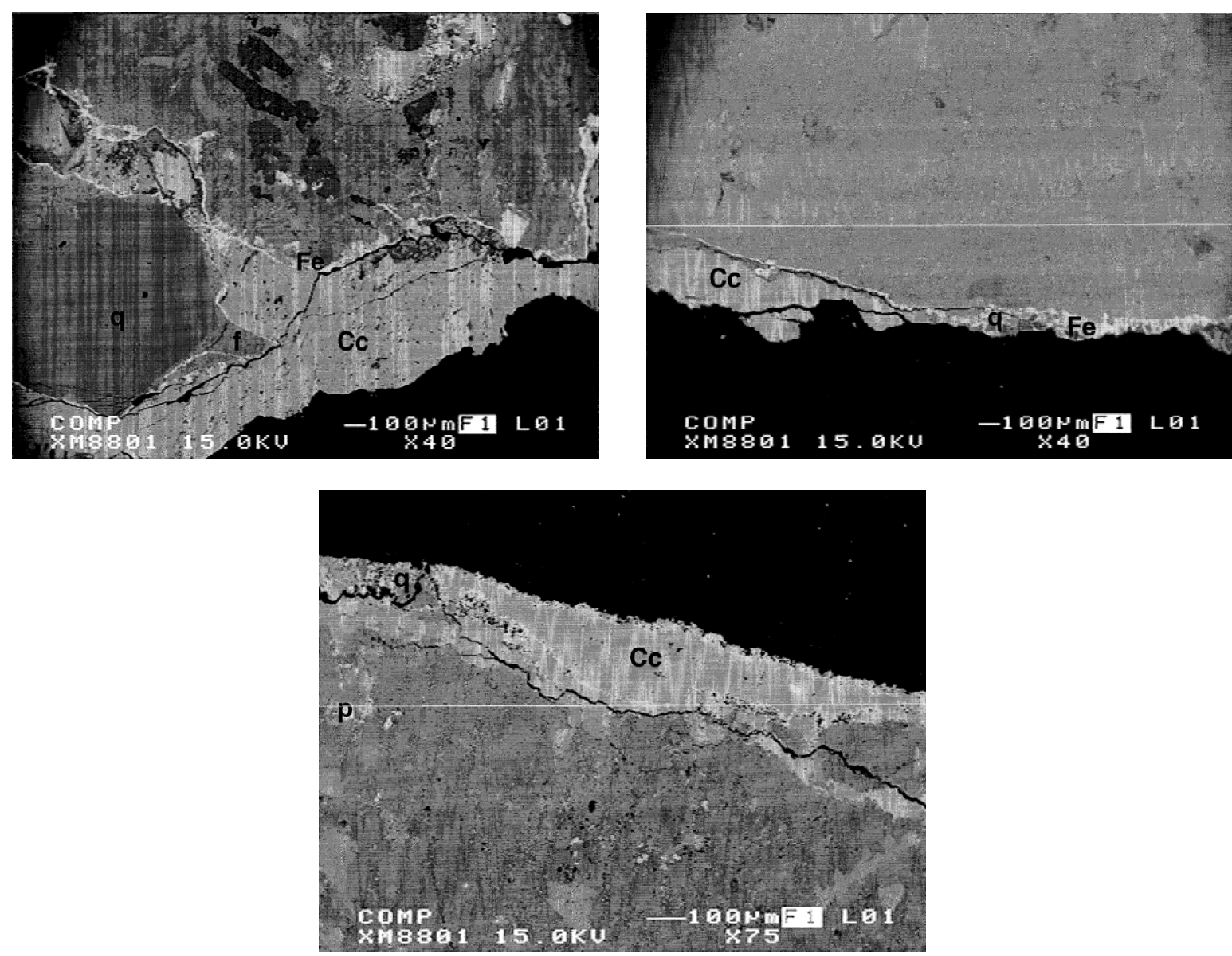

Figure 6.11 Fracture-lining minerals from UE-18t (top) and UE-20f (bottom) drill holes (IT Corporation, 1998b). $\mathrm{Cc}=$ calcite, $\mathrm{q}=$ quartz, $\mathrm{Fe}=$ iron oxide.

\subsection{Consistency between the flow model and the geochemical conceptual model}

While the above data provides information required to model reactive transport of radionuclides near CHESHIRE, our geochemical conceptual model must also be linked with the flow model (Chapter 4). The effective porosity links the flow and geochemical models. If the flow model is based on an effective porosity of $1 \%$ in fracture-flow dominated zones, the effective porosity in the geochemical model must also be based on an effective porosity of $1 \%$ for these zones. Flow model data, in this case, was used as an additional constraint to define the fracture densities and apertures required by the geochemical model.

The flow model data suggest that the highly fractured/permeable zones of the mafic-poor Calico Hills Formation lavas have an effective porosity near $1 \%$. This is considerably less than the average lava porosity and can be attributed to fracturedominated flow. The modeling approach we have taken is to assume that all flow is isolated to a single continuum (fracture flow or matrix flow at any point in space). In reality, flow may occur in the matrix and the fracture and would require the use of a dual continuum model. Nevertheless, the model constraints require that the $1 \%$ effective porosity in the highly fractured/permeable zones of the mafic-poor Calico Hills Formation be related entirely to fracture flow. If one assumed a high parallel plate 
fracture density of 10 per meter and a fracture aperture of $0.5 \mathrm{~mm}$, the effective porosity would equal $0.5 \%$. This value is still smaller than the effective porosity defined by the flow model $(1 \%)$. For the geochemical conceptual model to arrive at an effective porosity of $1 \%$, the following assumptions were made regarding fracture flow:

- All fractures have a fracture aperture of $0.5 \mathrm{~mm}(0.7 \mathrm{~mm}$ including fracture linings).

- All fractures have a fracture lining thickness of $0.1 \mathrm{~mm}$.

- The effective porosity of the fracture flow zones is $1 \%$.

- The effective porosity was accounted for by a combination of fracture density and interaction of fracture fluids with the matrix.

Note that our model of fracture flow is inherently flawed in that it is based on a single continuum. However, the strength of the near-field model is its geochemical basis for defining radionuclide-mineral interactions. Because radionuclide retardation is a function of aqueous speciation, sorbing mineral abundance, and effective porosities, the effective porosity (and associated sorbing mineral abundances) of the flow and geochemical models must be linked. What follows is a description of the method used to define the concentrations of sorbing minerals that is consistent with the effective porosities and flow velocities developed by the flow model.

Based on the assumptions enumerated above, the effective porosity based on a parallel plate fracture density of 8 per meter would be much less than $1 \%$. To increase the effective porosity of fracture flow zones, flow was assumed to occur in the matrix. Assuming a parallel plate fracture model, one needs to add a $2.5 \mathrm{~mm}$ flow zone within the matrix along each face of a fracture to result in a $1 \%$ effective porosity. Based on this conceptualization, sorbing minerals within this $2.5 \mathrm{~mm}$ matrix zone would also need to be included as part of the sorbing minerals of the fracture flow zones. Figure 6.12 presents the conceptual model of fracture flow. Note, however, that the need for flow within the matrix is a result of linking the geochemical and flow models-not from an independent conceptualization of physical flow.

The idea that flow will not be entirely restricted to a fracture is not entirely unreasonable. For example, tortuosity of fractures may lead to some flow directed into the matrix. Undoubtedly, flow in fractures is much more complicated than a "parallel plate" model would assume. It should, therefore, not be surprising that the effective porosity based entirely on fracture densities and apertures as parallel plates results in an underestimation of effective porosity. Nevertheless, the small amount of flow in the matrix was necessary primarily to link the hydrologic and geochemical models; it should, therefore, not be taken as a true conceptualization of flow in fractures. 


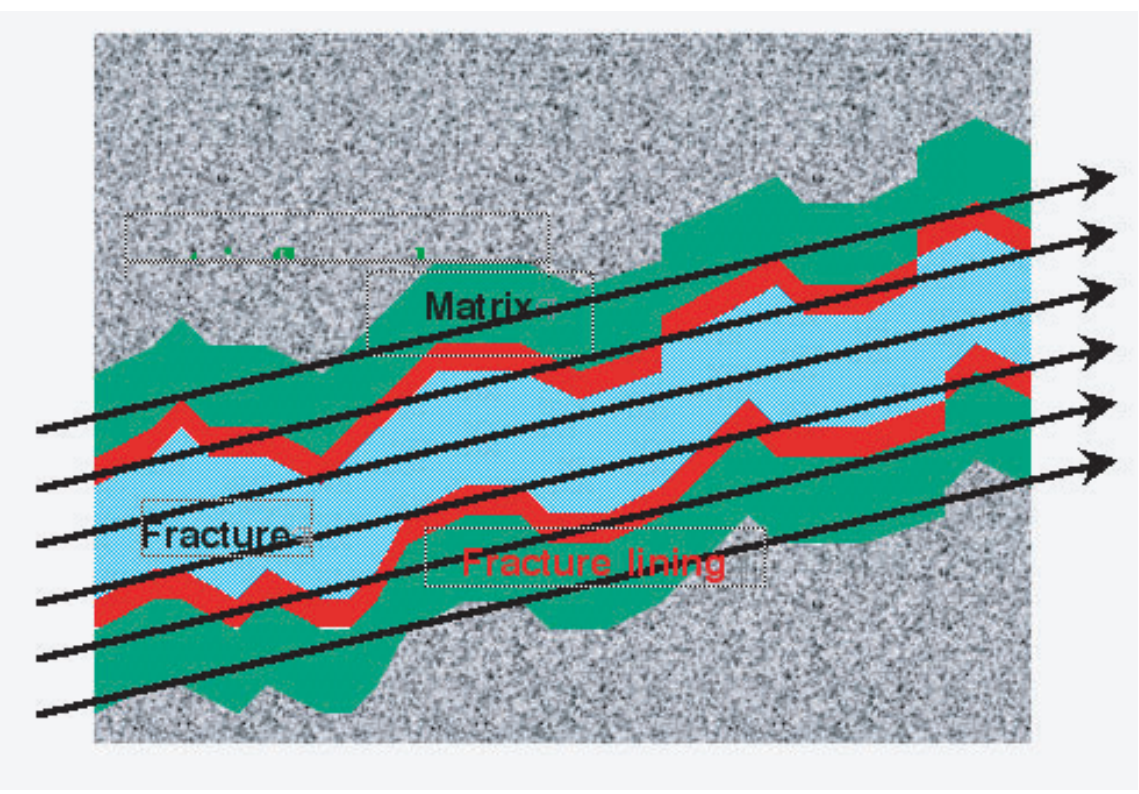

Figure 6.12 A simplified diagram depicting the conceptual model used to define the nature of effective porosity and the interaction of radionuclides with fracturelining minerals and matrix minerals. Some matrix flow was necessary to merge the flow and geochemical models. Rough fracture surfaces, microfracturing, or diffusion at the fracture-matrix boundary might also have been used to account for the difference between fracture porosity and effective porosity.

It is important to evaluate the implications of including a small amount of flow in the matrix on the resulting radionuclide transport. If flow were not allowed to occur in the $2.5 \mathrm{~mm}$ of matrix that parallels the fractures, the sorbing minerals in that matrix would, nevertheless, be accessible via diffusion. ${ }^{4}$ We can estimate the time it would take for the sorbing minerals in the $2.5 \mathrm{~mm}$ of matrix to be accessed by diffusion by calculating the time associated with a diffusive penetration thickness $(\eta)$ of $2.5 \mathrm{~mm}$ as defined in Neretnicks (1980):

$$
\bar{\eta}=\frac{2}{\pi^{1 / 2}}\left(D_{a} t\right)^{1 / 2}
$$

where $D_{a}$ is the apparent diffusion coefficient and $t$ is time. (The penetration thickness is only slightly larger than the $50 \%$ concentration point of an ideal diffusion profile.) A 2.5 $\mathrm{mm}$ thick matrix would be accessible to fluids in a fracture within approximately 24 hours. Thus, the quantity of matrix minerals allowed to react with the flowing fluid would likely be accessible to fracture fluid via diffusion even if flow were not allowed in the narrow matrix zone.

\footnotetext{
4 We do not explicitly include matrix diffusion in any of our simulation except for sensitivity runs described in Chapter 7. Diffusion is mentioned here only to evaluate whether sorbing minerals in the narrow flowing matrix zone would be accessible to fracture fluids regardless of whether flow was allowed or not in this narrow matrix zone.
} 


\subsubsection{Summary of Fracture Flow Mineralogy}

The geochemical model of fracture flow mineralogy was developed based on fracture information from Pahute Mesa and Yucca Mountain and the effective porosity information provided by the CHESHIRE flow model. A parallel plate fracture density of 8 per meter, with a $100 \mu \mathrm{m}$ fracture lining thickness, a $0.5 \mathrm{~mm}$ fracture aperture, and a $2.5 \mathrm{~mm}$ flowing matrix zone alongside each fracture results in an effective porosity of $1 \%$, consistent with the flow model. Flow is allowed within the narrow matrix zone, the fracture lining, and the fracture itself. This conceptualization of fracture flow was necessary to link the geochemical and flow models but should not be taken as a physical description of fracture flow. Nevertheless, the necessity to include some small amount of flow outside of the fracture can be justified to some degree (flow turbulence in fracture, tortuosity of fracture paths, etc.) and shown to, most likely, have little dramatic effect on transport.

Table 6.7 summarizes information regarding the mineral distribution used to model reactions of radionuclides migrating through fractured zones. Manganese oxide minerals were excluded from our model because little data are available to estimate their sorptive properties (Appendix K, Section K.2). Because flow is allowed in the fracture, the fracture lining, and a small fraction of the matrix, the mineralogy of each zone must be known. Based on the information in Table 6.7 and the fracture flow dimensions of the previous paragraph, an average fracture zone mineralogy can be determined. The volume fractions and distribution probabilities were based on data from devitrified tuffs below the water table at Yucca Mountain. ${ }^{5}$ The matrix composition is based on the matrix mineralogy defined in Section 6.2.1 and Table 6.5.

\footnotetext{
${ }^{5}$ The fracture-lining mineral probabilities shown here are slightly different from those shown in Figure 6.10; probability data in Table 6.7 were depth-integrated. The data were depth-integrated during statistical interrogation (Appendix $\mathrm{H}$ ) to arrive at a spatially meaningful distribution probability.
} 
Table 6.7 Distribution of sorbing minerals in fracture flow zones in the CHESHIRE near-field model.

\begin{tabular}{|c|c|c|c|c|c|}
\hline Mineral & Probability & $\begin{array}{c}\text { Volume, } \\
\% \S\end{array}$ & $\begin{array}{l}\text { Density, } \\
\mathrm{Mg} / \mathrm{m}^{3}\end{array}$ & $\begin{array}{c}\text { Surface area, } \\
\mathrm{m}^{2} / \mathrm{g}\end{array}$ & $\begin{array}{c}\text { CEC, } \\
\text { meq/100 g }\end{array}$ \\
\hline & \multicolumn{5}{|c|}{ Mineral concentrations in the fracture liningt } \\
\hline $\begin{array}{l}\text { Iron oxide } \\
\text { (hematite) }\end{array}$ & 0.43 & 4.94 & 5.28 & $2.0^{*}$ & -- \\
\hline Mica & 0.0 & - & 2.83 & -- & 200 \\
\hline Smectite & 0.52 & 20.7 & 2.83 & 30.0 & 850 \\
\hline Calcite & 0.28 & 25.8 & 2.71 & 2.2 & -- \\
\hline \multirow[t]{2}{*}{$\begin{array}{l}\text { Zeolite } \\
\text { (clinoptilolite) }\end{array}$} & 0.23 & 40.0 & 2.13 & -- & 2120 \\
\hline & \multicolumn{5}{|c|}{ Mineral concentrations in the matrix zonef } \\
\hline $\begin{array}{l}\text { Iron oxide } \\
\text { (hematite) }\end{array}$ & 1.0 & 0.02 & 5.28 & 2.0 & -- \\
\hline Mica & 1.0 & 0.04 & 2.83 & -- & 200 \\
\hline Smectite & 1.0 & 0.25 & 2.83 & 30.0 & 850 \\
\hline Calcite & & & 2.71 & 2.2 & -- \\
\hline $\begin{array}{l}\text { Zeolite } \\
\text { (clinoptilolite) }\end{array}$ & & & 2.13 & -- & 2120 \\
\hline \multicolumn{6}{|c|}{$\begin{array}{l}\text { * Surface area listed only for those minerals that participate in surface complexation in our model; CEC listed for ion } \\
\text { exchanging minerals. } \\
\S \text { Volume \% when minerals are present, as determined by the statistical distribution probabilities. } \\
\text { t Fracture lining is } 100 \mu \mathrm{m} \text { thick with } 15 \% \text { porosity. } \\
\text { † Matrix mineralogy is homogeneous and included as part of fracture flow as a } 2.5 \mathrm{~mm} \text { thick zone with } 15 \% \text { porosity along }\end{array}$} \\
\hline
\end{tabular}

\subsubsection{Reactivity and Mineral Distribution in Zones Affected by the CHESHIRE Test}

Changes in radionuclide retardation as a result of test-induced fracturing and rubblization occur in the cavity, chimney, disturbed and melt glass zones. However, little information is available to define test-induced changes in the physical environment and the initial distribution of radionuclides deposited by the CHESHIRE test. Some of the flow properties could be determined based on the calibrated flow model (Chapter 5) and temperature data. Additional information can also be gathered from the RAINIER test. Test-induced changes near the working point were described in several detailed post-test excavations of RAINIER (Johnson et al., 1958; Johnson and Violet, 1958; Kennedy and Higgins, 1958; Thompson and Misz, 1959; Wadman and Richards, 1961; Warner and Violet, 1959). The RAINIER test can, thus, be used to help define some near-field properties at CHESHIRE. However, the RAINIER test (1.7 kT) had a smaller yield than the CHESHIRE test (200-500 kT). As such, possible issues of scaling and other differences between the two tests should not be overlooked. 


\subsubsection{Melt Glass Zone}

The melt glass chemical composition is a combination of the vaporized rock surrounding the working point and the residual test radionuclides and activation products (see Section 6.4). An attempt was made to evaluate heterogeneity in the melt glass zone using information from the RAINIER test. As shown in Figure 6.13, the RAINIER melt glass zone contains both glass and large tuff blocks that collapsed into the melt. The RAINIER test at $1.7 \mathrm{kt}$ (USDOE, 2000) produced a calculated $1.19 \times 10^{9} \mathrm{~g}$ of melt glass. Assuming a glass density of $2.06 \mathrm{~g} / \mathrm{cm}^{3}$-medium and a cavity radius of $19.8 \mathrm{~m}$ (Wadman and Richards, 1961), a maximum glass thickness of $3.1 \mathrm{~m}$ would be expected at the bottom of the cavity. Wadman and Richards (1961) reported a maximum glass zone thickness of $6.1 \mathrm{~m}$. This difference in melt glass zone thickness suggests that the glass zone is composed of $27 \%$ glass and $73 \%$ unmelted rubble, and that the size of the melt glass zone may be much larger than the volume of glass produced by the test. ${ }^{6}$

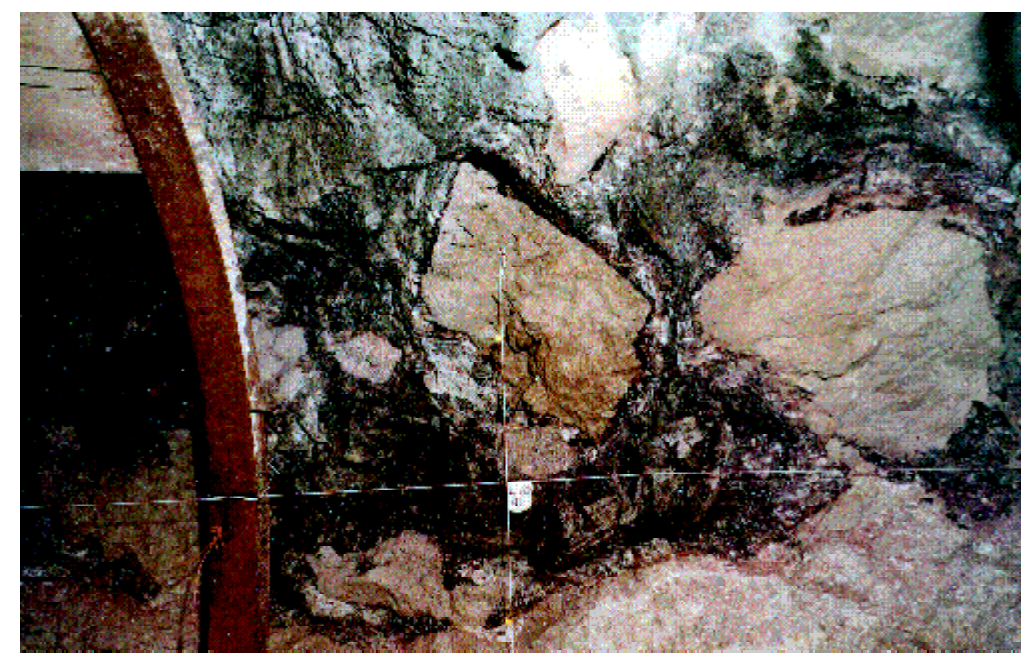

Figure 6.13 Photo of the RAINIER glass zone showing the heterogeneous distribution of melt glass and rubble. Tuff blocks are about $0.3 \mathrm{~m}$ in diameter.

Because we are using an approximate yield (500 kt) for CHESHIRE (the maximum of the announced 200-500 kt range), we decided not to account for the infallen rubble in the glass zone until classified HST simulations are undertaken and classified data can be used to help constrain our evaluation of heterogeneity. Therefore, a simplified melt glass zone composed entirely of melt glass and devoid of sorbing minerals is used in the unclassified CHESHIRE model. A porosity of $20 \%$ was assigned to the glass zone (see Section 5.4.2.3). As discussed in Section 5.2.3, some adjustment to the distribution of glass was made to accommodate the $10 \mathrm{~m}$ grid-block near-field resolution. This was accomplished in the geochemical model by augmenting the volume of the melt glass zone with a small quantity of fictitious nonreactive solid. The nonreactive solid accounts for only a small fraction of the melt glass zone volume.

\footnotetext{
${ }^{6}$ Evidence regarding the accesssibility of sorbing minerals in the infallen blocks to reaction with radionuclides is not available. Melting at the fringes of the infallen blocks may isolate the majority of the sorbing minerals from fluid flow. Additional study of the impact of heterogeneity in the glass zone on reactive transport would be required to better model flow and transport within this zone.
} 


\subsubsection{Intact Disturbed Zone}

The disturbed zone radius at RAINIER was estimated using the maximum distance from the working point that radionuclides were detected soon after the test. Figure 6.14 is a plot of the RAINIER cavity and the points at which radioactivity was detected in drill-back holes. The maximum distance of radionuclide detection was at $\sim 1.5$ cavity radii. This disturbed zone radius is used to define the exchange volume and distribute radionuclides at CHESHIRE (Chapter 4).

Fluid circulation during reentry drilling at the RAINIER test suggests that the permeability outside the cavity zone was relatively unchanged, but that drastic permeability changes occurred in the cavity and chimney zones. Hydrologic modeling at CHESHIRE and additional evidence (Chapter 5 ) suggest that the intact disturbed zone permeabilities are similar to or only slightly higher than pre-test permeabilities. Therefore, it is assumed that the quantities and distribution of sorbing minerals and porosities in the intact disturbed zone are equivalent to that in the native mafic-poor Calico Hills Formation fractured lava. For additional information regarding the permeability of the disturbed zone, see Chapter 5.

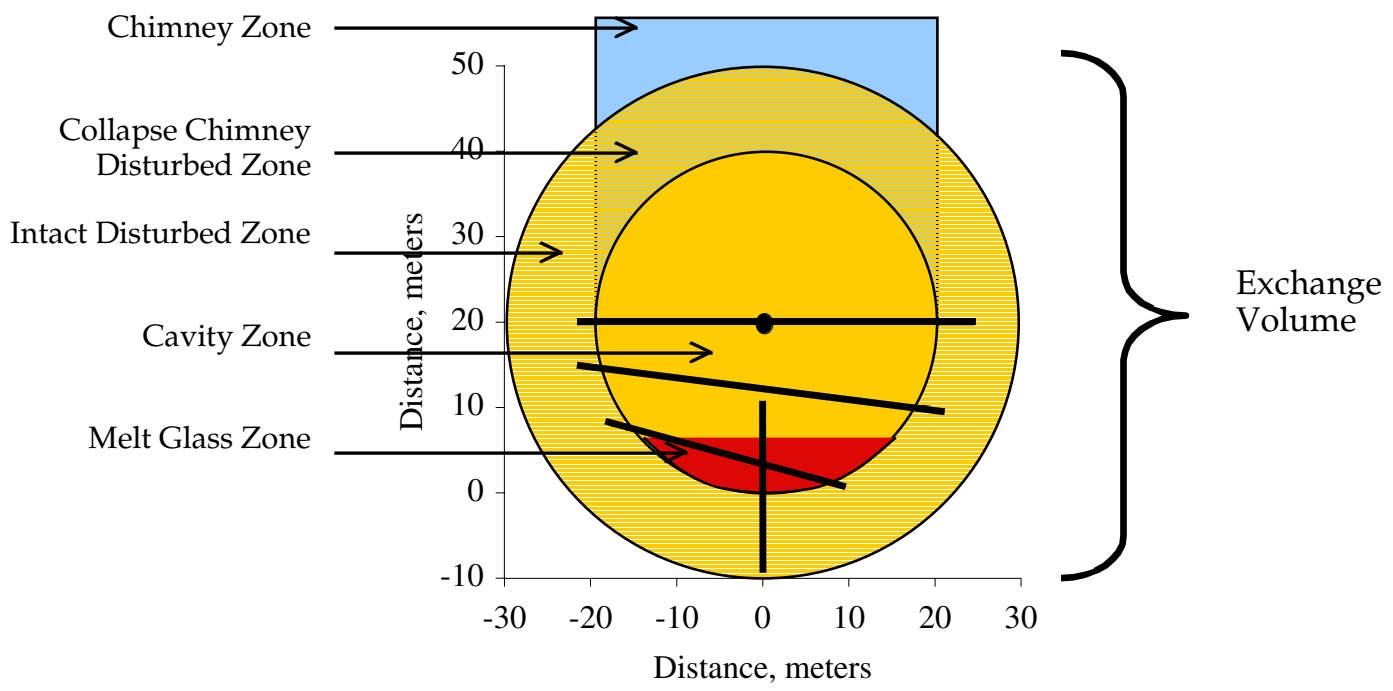

Figure 6.14 Radioactivity measured in drill-back holes into the RAINIER cavity. This radioactivity was located in both glass fragments and in the $<0.01 \mathrm{~mm}$ fraction of the tuff (Warner and Violet, 1959).

\subsubsection{Cavity, Chimney, and Collapse Chimney Disturbed Zones}

Evidence from RAINIER drill-backs suggests that the permeability of the cavity and chimney (as well as the collapse chimney disturbed zone, Figure 6.14) is far greater than the pre-test rock. Data in Wadman and Richards (1961) indicate that 0.15 to $0.6 \mathrm{~m}$ tuff blocks are found near the bottom of the glass zone, 0.9 to $1.8 \mathrm{~m}$ tuff blocks are found at the top of the glass zone, 0.3 to $0.9 \mathrm{~m}$ tuff blocks are found close to the cavity edge (within 0.9-1.5 m) and within the cavity, and block sizes increase toward the center of the cavity and up into the chimney. This morphology is consistent with the 
flow modeling (Chapter 5), which indicates that upper cavity and chimney permeabilities are very high. The morphology of the cavity and chimney zones (including the collapse chimney disturbed zone) is approximated by lava blocks with an average dimension of $3 \mathrm{~m}$ and 10\% inter-block porosity (Figure 6.15). The quantity of sorbing minerals is determined from the surface area of exposed lava (assuming blocks $3 \mathrm{~m}$ in width) and the pre-test fracture-lining mineralogy. For consistency, the quantity of sorbing minerals at the surface of the lava block is calculated in the same manner as described in the fracture lining reactivity discussed above. The role of matrix diffusion will be discussed separately.

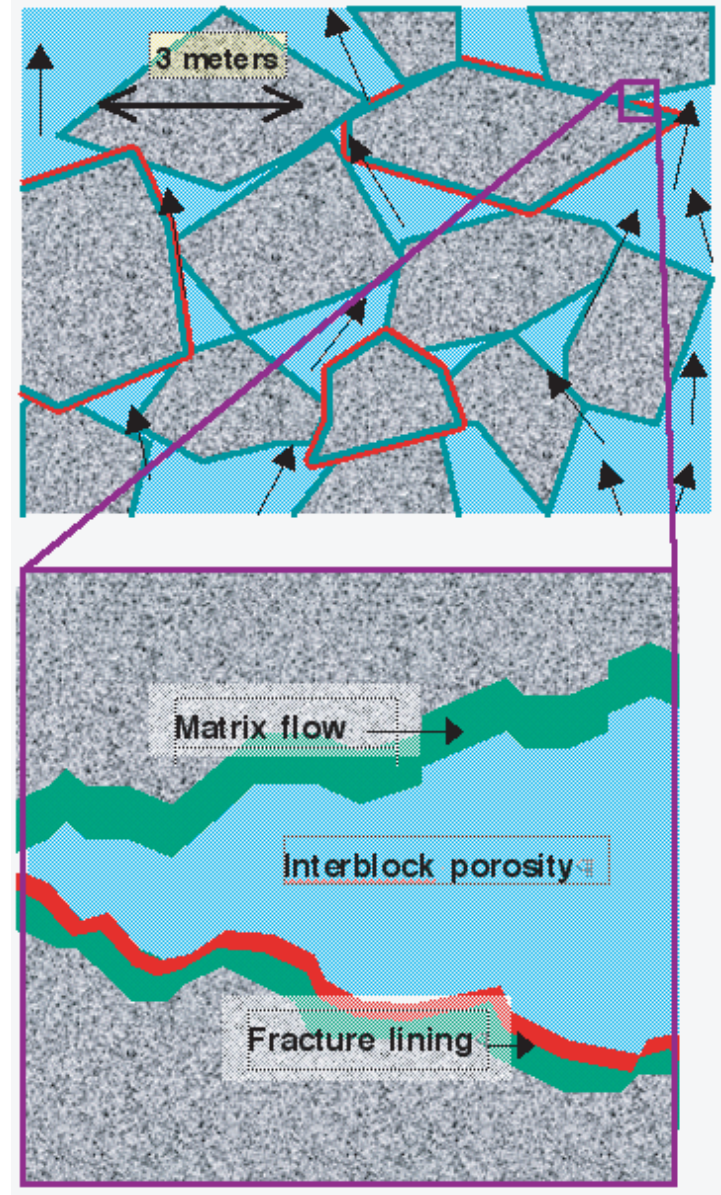

Figure 6.15 Schematic of the cavity and chimney zones dominated by $3 \mathrm{~m}$ lava blocks, 10\% inter-block porosity, and sorbing mineralogy based on pretest fracture lining densities and additional matrix reactivity due to additional fracturing.

\subsubsection{Summary of Near-Field Mineralogy}

Table 6.8 presents the mineralogic description of the flow zones defined in the near-field model. The fracture flow condition defines mineralogy and porosity for that fraction of the near field defined in the flow model as fracture flow dominated. This includes the intact disturbed zone located between 1 and 1.5 cavity radii away from the working point. The fracture flow condition is conceptualized as eight parallel fractures per meter with a $0.5 \mathrm{~mm}$ aperture, $0.1 \mathrm{~mm}$ fracture linings, a $2.5 \mathrm{~mm}$ matrix flow zone, 
and an effective porosity of $1 \%$. The cavity/chimney condition defines the mineralogy for the cavity, chimney, and collapse chimney disturbed zones. The cavity/chimney condition is conceptualized as $3 \mathrm{~m}$ cubic blocks with reactivities defined by the mineralogy of newly-formed fractures $(2.5 \mathrm{~mm}$ matrix flow zones but no fracture linings) and old fractures ( $2.5 \mathrm{~mm}$ matrix flow zones and $0.1 \mathrm{~mm}$ fracture linings). The effective porosity of the cavity/chimney condition is $10 \%$.

The sorbing minerals in the fracture flow and cavity/chimney conditions are heterogeneously distributed with each sorbing mineral having two possible abundances (on/off state, Table 6.8). Because glass and mica abundances are unchanged in the two possible states, 16 combinations of mineral abundances are possible for the fracture flow and cavity/chimney conditions.

The matrix flow condition includes that fraction of the near field defined in the flow model as matrix flow dominated. The mineralogy in this condition is homogeneous and the effective porosity is 15\%. Sorbing mineral abundances are based on values listed in Table 6.5.

The glass condition defines the glass zone of the near field. The glass zone is dominated by matrix flow with a porosity of $20 \%$. The fraction of glass in the glass zone is initially $68 \%$. The remaining $12 \%$ of non-sorbing mineral is included to accommodate the $10 \mathrm{~m}^{3}$ grid size of the model while retaining the appropriate total melt glass mass (Section 3.3). At the transition from the particle to the GIMRT transient streamline model at 100 years (Chapter 7), the volume fraction of glass has decreased to $52 \%$ owing to glass dissolution during the first 100 years. The transient streamline model was used to simulate transport between 100 and 1000 years after the CHESHIRE test. Thus, the glass zone initially contains $68 \%$ glass in the particle model at time zero but only $52 \%$ at the start of the streamline calculations at 100 years. Because the particle model cannot account for secondary mineral precipitation, the 100 year glass zone in the streamline model is assumed to have negligible quantities of sorbing minerals. Secondary minerals in the glass zone were not allowed to contribute to radionuclide sorption in either the particle or streamline models due to limited data regarding the identity of potential secondary minerals (see Section 6.4.5) and their sorptive properties at high temperature. The porosity of the glass zone is assumed to remain constant in all models. 
Table 6.8 Mineral composition of the zones defined for the CHESHIRE near-field transport model.

\begin{tabular}{|c|c|c|c|c|c|c|c|c|c|}
\hline \multirow[b]{2}{*}{ Condition } & \multirow[b]{2}{*}{$\begin{array}{l}\text { On/ } \\
\text { offt }\end{array}$} & \multirow[b]{2}{*}{ Porosity } & Glass & Calcite & Mica & Clino. & Smectite & Hematite & \multirow{2}{*}{$\begin{array}{c}\text { Non- } \\
\text { sorbing } \\
\text { mineralף }\end{array}$} \\
\hline & & & \multicolumn{6}{|c|}{$\mathrm{m}^{3} / \mathrm{m}^{3}$ (bulk volume fraction) } & \\
\hline \multirow[t]{2}{*}{ Fracture flow } & 1 & 0.01 & 0 & $4.1 \times 10^{-4}$ & $1.6 \times 10^{-5}$ & $6.4 \times 10^{-4}$ & $4.3 \times 10^{-4}$ & $8.7 \times 10^{-5}$ & П \\
\hline & 0 & 0.01 & 0 & $10^{-10}$ & $1.6 \times 10^{-5}$ & $10^{-10}$ & $1.0 \times 10^{-4}$ & $8.0 \times 10^{-6}$ & १ \\
\hline \multirow{2}{*}{$\begin{array}{l}\text { Cavity/ } \\
\text { chimney }\end{array}$} & 1 & 0.10 & 0 & $3.7 \times 10^{-4}$ & $1.8 \times 10^{-6}$ & $5.8 \times 10^{-4}$ & $3.1 \times 10^{-4}$ & $7.2 \times 10^{-5}$ & П \\
\hline & 0 & 0.10 & 0 & $10^{-10}$ & $1.8 \times 10^{-6}$ & $10^{-10}$ & $1.1 \times 10^{-5}$ & $9.0 \times 10^{-7}$ & П \\
\hline Matrix flow§ & & 0.15 & 0 & $10^{-10}$ & $4.0 \times 10^{-4}$ & $10^{-10}$ & $2.5 \times 10^{-3}$ & $2.0 \times 10^{-4}$ & १ \\
\hline $\begin{array}{l}\text { Glass at } 0 \\
\text { yrs }\end{array}$ & & 0.20 & 0.68 & $10^{-10}$ & $10^{-10}$ & $10^{-10}$ & $10^{-10}$ & $10^{-10}$ & १ \\
\hline $\begin{array}{l}\text { Glass at } 100 \\
\text { yrs } \neq\end{array}$ & & 0.20 & 0.52 & $10^{-10}$ & $10^{-10}$ & $10^{-10}$ & $10^{-10}$ & $10^{-10}$ & १ \\
\hline
\end{tabular}

† On/off category was used to define the heterogeneous distribution of fracture-lining minerals in the fracture zone, cavity, chimney, and exchange zones. Mineralogy at any particular location will be a combination of "on" and "off" parameters for mica, clinoptilolite, smectite, calcite, and hematite (i.e., a total of 16 combinations for each condition). CEC values are used to define ion exchange reactions; mineral volumes are used to define surface complexation reactions. Mica is homogeneously distributed in the fracture flow and cavity and chimney conditions. Mineral distribution patterns are described elsewhere.

$\S$ Mineralogy is assumed to be homogeneous in this condition.

$\ddagger$ The quantity of glass was determined from the output of the particle code at 100 yr. 0 years represents the start of the particle model simulations; 100 years represents the start of the transient streamline model simulations. Secondary mineral concentrations were set essentially at 0 because the particle model cannot account for secondary mineral precipitation.

If The non-sorbing mineral is used to adjust the geochemical conditions to the appropriate porosity. The non-sorbing mineral volume fraction in all cases is defined as 1-porosity-glass-calcite-mica-clinoptilolite-smectite-hematite.

\subsubsection{Colloids in the CHESHIRE Near Field}

Buddemeier and Hunt (1988) examined colloid concentrations and mineralogy in waters pumped in and near the CHESHIRE cavity. For the one sample that was examined, they found that the mineralogy of colloids ( 3 to $50 \mathrm{~nm}$ size) was dominated by quartz and feldspars, but that $10 \%$ could not be identified by XRD. Additional spectroscopic characterization suggested that this fraction might include clays (that are difficult to detect by XRD). Colloid concentrations varied from 4.3 to 63 $\mathrm{mg} / \mathrm{L}$ depending on the size range filtered and the location of the samples. The greatest colloid concentration was determined for a sample in which the largest colloid size range was selected $(0.006$ to $0.45 \mu \mathrm{m})$. Brachman and Kersting collected colloid samples from upper and lower aquifers at Cheshire and determined from XRD that colloids ( $>7$ $\mathrm{nm}$ size, $60 \mathrm{~nm}$ average size above cavity; $100 \mathrm{~nm}$ average size in cavity) predominantly consist of clays (illite, smectite) and zeolites (mordenite) (Smith et al., 2000). This was confirmed by SEM analysis as well. The difference in mineralogy reported by Buddemeier and Hunt (1988) and Brachman and Kersting (Smith et al., 2000) may have resulted from the difference in colloid size range examined. The more thorough characterization performed by Brachman and Kersting for the entire colloid size range collected provides a better representation of colloid mineralogy.

Kersting and Brachman (1998) and Kersting et al. (1999) characterized colloids from the ER-20-5 well cluster. Colloids were dominated by zeolites, clays (illite and smectite), and cristobalite. Samples from two nearby drill holes yielded colloid particle concentrations of $3.02 \times 10^{10}$ and $7.86 \times 10^{10}$ particles $/ \mathrm{mL}$ with average 
diameters of 91 and $81 \mathrm{~nm}$, respectively. Assuming a colloid density of $2.6 \mathrm{~g} / \mathrm{cm}^{3}$ and cubic particle shape, colloid concentrations are 60 to $100 \mathrm{mg} / \mathrm{L}$. These values are consistent with those reported by Buddemeier and Hunt (1988) but lie at the very high end of colloid concentrations reported in the literature. We modeled the interaction of radionuclides with colloids in the CHESHIRE near-fieldusing these conservative colloid concentrations (Appendix K).

The role of colloids in near-field transport of radionuclides in our CHESHIRE near-field model is being examined only at a rudimentary level. Our colloid model (1) excludes the possibility of real colloids, (2) assumes that pseudo-colloids are dominated by smectite mineralogy, (3) uses the maximum colloid concentrations reported by Kersting and Brachman (1998), and (4) assumes that the colloid concentrations in the near-field are steady state and constant across the entire domain. The role of colloids and our radionuclide-colloid interaction model is further defined in Appendix K; the role of colloids in radionuclide transport is compared to observations of Kersting et al. (1999) and Buddemeier and Hunt (1988) in Appendix I.

\subsection{Groundwater Chemistry Near CHESHIRE}

The chemistry of groundwater samples from Areas 19 and 20 on Pahute Mesa are listed in Table 6.9, and displayed in Figure 6.16. The measurements include 10 samples from well U-20n PS \#1 DD-H (Smith et al., 1998; Smith et al., 1999). One sample each was obtained from the upper interval (chimney) and lower interval (cavity) of U-20n PS \#1 DD-H. These samples are similar in composition to others in Areas 19 and 20.

Table 6.10 gives the ambient groundwater composition used in the geochemical calculations. Most concentrations are equal to the mean of the concentrations in Table 6.9, although the anion concentrations were weighted in favor of the analyses from U-20n PS \#1 DD-H. The groundwater as shown in Table 6.10 is not charge balanced. Charge balance can be achieved by increasing the $\mathrm{Cl}$ concentration without influencing chemical equilibria, owing to the low ionic strength of the water.

Reliable Al and Fe analyses were not available for the groundwater samples. The concentrations of $\mathrm{Al}$ and Fe were set by assuming equilibrium with respect to Camontmorillonite and hematite, respectively. The concentration of $\mathrm{Ca}$ was set according to equilibrium with calcite. The resulting Ca concentration $(10.4 \mathrm{mg} / \mathrm{kg})$ is close to the mean of the Ca concentrations $(7.6 \mathrm{mg} / \mathrm{kg})$ in Table 6.9. These equilibria were chosen so that the groundwater was initially close to equilibrium with sorptive minerals in the native rock in order to minimize mineral precipitation that was not related to glass dissolution.

The redox state of CHESHIRE groundwaters is unknown. The fugacity of $\mathrm{O}_{2}(\mathrm{~g})$ in the groundwater was fixed at $10^{-7}$ bars to ensure that $\mathrm{Pu}(\mathrm{V})$ is the dominant oxidation state of $\mathrm{Pu}$ in solution. $\mathrm{Pu}(\mathrm{VI})$ comprises about $10 \mathrm{~mol} \%$ of the aqueous $\mathrm{Pu}$ at this oxygen fugacity. Nitsche et al. (1993) identified mainly $\mathrm{Pu}(\mathrm{V})$ and $\mathrm{Pu}(\mathrm{VI})$ and minor $\mathrm{Pu}(\mathrm{IV})$ during solubility experiments in $\mathrm{J}-13$ water at $25^{\circ} \mathrm{C}$. At $25^{\circ} \mathrm{C}$, they measured the following distribution of $\mathrm{Pu}$ oxidation states: $44 \% \mathrm{Pu}(\mathrm{V})$ and $52 \% \mathrm{Pu}(\mathrm{VI})$ at $\mathrm{pH} 7 ; 58 \%$ 
$\mathrm{Pu}(\mathrm{V})$ and $24 \% \mathrm{Pu}(\mathrm{VI})$ at $\mathrm{pH}$ 8.5. Because the prevailing opinion is that $\mathrm{Pu}(\mathrm{V})$ will dominate in NTS waters, the redox state of the CHESHIRE groundwater was chosen to yield $\mathrm{Pu}(\mathrm{V})$ as the dominant oxidation state of $\mathrm{Pu}$.

Equilibrium thermodynamics predicts that $\mathrm{Pu}$ is in the (IV) oxidation state at fugacities of $\mathrm{O}_{2}(\mathrm{~g})$ less than about $10^{-15}$ bars (Eh values less than about $0.5 \mathrm{~V}$ at a $\mathrm{pH}$ of 8). The assumed $\mathrm{O}_{2}(\mathrm{~g})$ fugacity of $10^{-7}$ bars in the simulations ensured the existence of $\mathrm{Pu}(\mathrm{V})$ and $\mathrm{Pu}(\mathrm{VI})$ species in solution rather than $\mathrm{Pu}(\mathrm{IV})$. For the radionuclides considered in this study, only the oxidation state of Pu changes at $\mathrm{O}_{2}(\mathrm{~g})$ fugacities between $10^{-0.7}$ and about $10^{-40}$ bars (Eh values greater than about $0.2 \mathrm{~V}$ at a $\mathrm{pH}$ of 8 ). Further discussion regarding the effects of $\mathrm{O}_{2}(\mathrm{~g})$ fugacity on $\mathrm{Pu}$ sorption and reactive transport can be found in Zavarin and Bruton (2000a; 2000b).

Previous simulations of radionuclide migration away from the CAMBRIC test (Tompson et al. (1999) and Pawloski et al. (2000)) used a constant oxygen fugacity of $10^{-0.7}$ bars, which represents equilibrium with the atmosphere. $\mathrm{Pu}$ is dominantly in the $\mathrm{Pu}(\mathrm{VI})$ state at $10^{-0.7}$ bars $\mathrm{O}_{2}(\mathrm{~g})$ fugacity. Because Pu sorbs to iron oxide in the Pu(IV) and $\mathrm{Pu}(\mathrm{V})$ oxidation states, a groundwater $\mathrm{O}_{2}(\mathrm{~g})$ fugacity that favors $\mathrm{Pu}(\mathrm{VI})$ in solution minimizes $\mathrm{Pu}$ retardation and produces conservative estimates of $\mathrm{Pu}$ migration. This was the goal of the CAMBRIC calculations. Although conservative, this $\mathrm{O}_{2}(\mathrm{~g})$ fugacity is probably too high. Hence, it was reduced to $10^{-7}$ bars in the present CHESHIRE calculations.

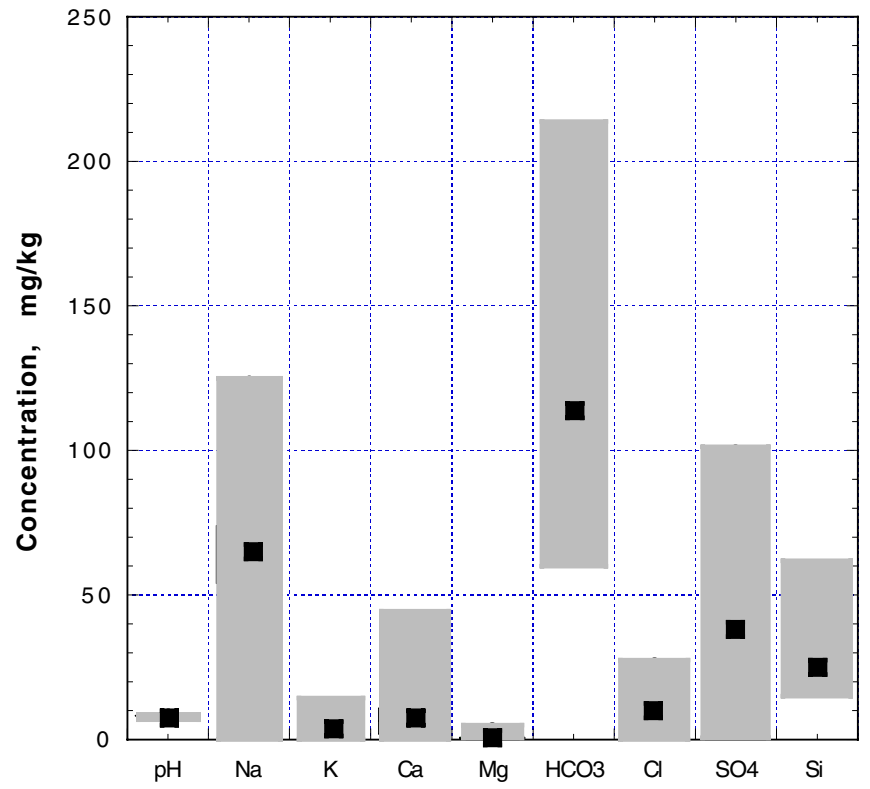

Figure 6.16 Range of concentrations and mean concentrations of major elements and $\mathrm{pH}$ in groundwater samples from Areas 19 and 20, Pahute Mesa (Table 6.9). Data from Smith et al. (1998), Smith et al. (1999), Rose et al. (1997), and $\mathrm{IT}^{7}$.

\footnotetext{
${ }^{7}$ IT Corporation, "Modeling of carbon-14 transport in the vicinity of Pahute Mesa and Oasis Valley, Nevada," Las Vegas, NV (unpublished report).
} 
Table 6.9 Groundwater compositions (in $\mathrm{mg} / \mathrm{kg}$, except for $\mathrm{pH}$ ) from Areas 19 and 20, Pahute Mesa, Nevada Test Site. Data from Smith et al. (1998), Smith et al. (1999), Rose et al. (1997), and IT (see footnote 7).

\begin{tabular}{|c|c|c|c|c|c|c|c|c|c|}
\hline Location & $\mathrm{pH}$ & $\mathrm{HCO}_{3}{ }^{\mathrm{a}}$ & $\mathrm{CI}$ & $\mathrm{SO}_{4}$ & $\mathrm{Na}$ & $\mathbf{K}$ & $\mathrm{Ca}$ & Mg & Si \\
\hline ER-20-5 \#3 & 8.8 & 109 & 17.8 & 35.1 & 73 & 3 & 3.1 & 0.1 & 27.6 \\
\hline ER-20-5 \#3 & 8.6 & 108 & 17 & 35 & 70 & 3.1 & 3.2 & 0.1 & 29 \\
\hline ER-20-5 \#1 & 8.4 & 187 & 26.4 & 40.6 & 113 & 4.2 & 6.1 & 0.2 & 28.7 \\
\hline ER-20-5 \#1 & 8.2 & 186 & 23 & 39 & 104 & 4.5 & 6.6 & 0.3 & 20 \\
\hline UE-20bh \#1 & 8.3 & 68 & 3.9 & & 38 & & 0.9 & & 21.8 \\
\hline U-20 water well & 8.2 & 92 & 12 & & 59 & 2.1 & 6.2 & 0.3 & 23 \\
\hline ER-20-6 \#3 & 8.4 & 109 & 13.6 & 31.8 & 56 & 3.6 & 10.1 & 0.8 & 23.3 \\
\hline ER-20-6 \#2 & 8.2 & 112 & 11.6 & 31.5 & 61.1 & 3.1 & 8.3 & 0.7 & 27.2 \\
\hline ER-20-6 \#1 & 8.1 & 103 & 12.3 & 32.3 & 60.6 & 2.2 & 7.1 & 0.6 & 26.1 \\
\hline UE-19c & 7.7 & 68 & 3.1 & & 35.8 & 0.5 & 1.4 & 0.01 & 19.7 \\
\hline UE-19h & 8.3 & 147 & 8.5 & & 63.8 & 4 & 14.9 & 1.5 & 25.5 \\
\hline U-20 water well & 8.16 & 110 & 12 & 32 & 59 & 2 & 7 & 0.3 & 22.76 \\
\hline UE-19h & 8.33 & & 8.5 & & 63.8 & 3.99 & 14.9 & 1.52 & 25.5 \\
\hline UE-19g S & 7.8 & 181 & 9.9 & 100 & 74 & 1 & 43 & 0.1 & 43 \\
\hline UE-19g S & 7.8 & & 8.9 & 75 & 68 & 0.8 & 35 & 0.2 & 60 \\
\hline \multicolumn{10}{|l|}{ UE-19g S } \\
\hline U-19ba \#1 & & 189 & & & 79 & 5.47 & 20.8 & 1.16 & 22.06 \\
\hline U-20a1 (Egmont) & 8.43 & 213 & & & 122 & 11.1 & 13.1 & 2.05 & 27.58 \\
\hline UE-19c wtr well & 8.51 & 67.1 & & & 30.2 & 0.79 & 1.42 & 0.22 & 20.66 \\
\hline UE-19c wtr well & 8.59 & 64.9 & & & 32.9 & 0.76 & 1.54 & 0.25 & 21.22 \\
\hline UE-19c wtr well & 7.71 & & 3.1 & & 35.8 & 0.46 & 1.35 & & 19.70 \\
\hline ER-20-6 \#3 & 8.35 & & 13.9 & 32.2 & 58.3 & 2.09 & 10.9 & 1.4 & 20.3 \\
\hline ER-20-6 \#3 & 8.42 & & 13.6 & 31.8 & 56 & 3.6 & 10.1 & 0.8 & 23.3 \\
\hline ER-20-6 \#3 & 8.29 & & & & 54 & 3.01 & 9.4 & 0.74 & \\
\hline ER-20-6 \#3 & & & & & 53 & 2.96 & 8.8 & 0.72 & \\
\hline UE-20bh \#1 & 8.18 & 214 & & & 87.7 & 8.72 & 3.14 & 0.59 & 21.8 \\
\hline UE-20bh \#1 & 8.26 & & 3.9 & & 38 & & 0.9 & & 44 \\
\hline U-20a \#2 wtr well & 7.9 & & 10 & 28 & 55 & 2.2 & 5.9 & 0.2 & \\
\hline U-20a \#2 wtr well & 8.3 & & & & 62 & 3.8 & 1.2 & 0.079 & 25.00 \\
\hline U-20a \#2 wtr well & 8.27 & 112 & & & 62.6 & 2.27 & 6.34 & 0.24 & 24.31 \\
\hline \multicolumn{10}{|l|}{ U-20a \#2 wtr well } \\
\hline Pahute Mesa \#3 & 8.38 & 158 & & & 124 & 12.3 & 18.9 & 4.03 & 15.05 \\
\hline U-20n PS\#1DD-H & 7.8 & 63 & & & & & & & \\
\hline U-20n PS\#1DD-H & 8.8 & 78 & & & & & & & \\
\hline U-20n PS\#1DD-H & 7.8 & 91 & & & & & & & \\
\hline U-20n PS\#1DD-H & & 103 & 11.9 & 26.5 & 57.3 & 7.5 & 16.7 & 0.45 & 25.6 \\
\hline U-20n PS\#1DD-H & 8.51 & & & & & & & & \\
\hline U-20n PS\#1DD-H & 8.35 & & & & & & & & \\
\hline U-20n PS\#1DD-H & 8.4 & 60 & 13.4 & & 74 & 2.4 & 1.9 & 0.2 & 29.7 \\
\hline U-20n PS\#1DD-H & 8.6 & 61 & 14 & & 77 & 3.1 & 1.7 & 0.1 & 33.1 \\
\hline U-20n PS\#1DD-H & 8.3 & 102 & 11.6 & 28.1 & 52 & 1.6 & 6.3 & 0.2 & 21 \\
\hline U-20n PS\#1DD-H & 8.55 & 109 & 11.3 & 28 & 61 & 1.7 & 2.9 & 0.1 & 23.3 \\
\hline
\end{tabular}


Table 6.10 Ambient groundwater chemistry at $35^{\circ} \mathrm{C}$ used in the simulations.

\begin{tabular}{|l|c|c|}
\hline \multicolumn{1}{|c|}{ Component } & $\begin{array}{c}\text { Concentration } \\
(\mathbf{m g} / \mathbf{k g})\end{array}$ & $\begin{array}{c}\text { Concentration } \\
(\mathbf{m})\end{array}$ \\
\hline \hline $\mathrm{SiO}_{2}$ & 56 & $9.40 \times 10^{-4}$ \\
\hline $\mathrm{Na}$ & 65 & $2.83 \times 10^{-3}$ \\
\hline $\mathrm{HCO}_{3}{ }^{1}$ & 107 & $1.78 \times 10^{-3}$ \\
\hline $\mathrm{Al}^{2}$ & $4.9 \times 10^{-5}$ & $1.80 \times 10^{-9}$ \\
\hline $\mathrm{Ca}^{3}$ & 10.4 & $2.60 \times 10^{-4}$ \\
\hline $\mathrm{K}$ & 3.4 & $8.70 \times 10^{-5}$ \\
\hline $\mathrm{Mg}$ & 0.5 & $2.06 \times 10^{-5}$ \\
\hline $\mathrm{Cl}$ & 12 & $3.39 \times 10^{-4}$ \\
\hline $\mathrm{Fe}^{4}$ & $1.6 \times 10^{-7}$ & $2.93 \times 10^{-12}$ \\
\hline $\mathrm{SO}_{4}$ & 35 & $3.64 \times 10^{-4}$ \\
\hline $\mathrm{O}_{2}(\mathrm{~g})$ & $10^{-7}$ bars & $10^{-7}$ bars \\
\hline \hline $\mathrm{pH}^{5}$ & 8.2 & 8.2 \\
\hline
\end{tabular}

${ }^{1}$ Total carbonate as $\mathrm{HCO}_{3}$.

2 Set by assuming equilibrium with $\mathrm{Ca}$-montmorillonite.

${ }^{3}$ Set by assuming equilibrium with calcite.

${ }^{4}$ Set by assuming equilibrium with hematite.

${ }^{5} \mathrm{~A} \mathrm{pH}$ of 8.2 at $35^{\circ} \mathrm{C}$ was calculated from the average $\mathrm{pH}$ of 8.3 at $25^{\circ} \mathrm{C}$ by assuming that the total carbonate concentration does not vary from 25 to $35^{\circ} \mathrm{C}$.

\subsection{Geochemical Modeling of Radionuclide Migration}

\subsubsection{GIMRT}

The 1D reactive transport streamline calculations were made with the GIMRT (Global Implicit Multi-component Reactive Transport) code (Steefel and Yabusaki, 1996). GIMRT was also used to calculate linear retardation factors used in the particle code (Appendix K). GIMRT can account for advective, diffusive, and dispersive mass transport processes, and can simulate multi-component mass transport in porous and/or fractured media under isothermal or nonisothermal conditions. Calculations can be made in one or two spatial dimensions. The user can specify a number of zones that vary in mineralogy and fluid chemistry.

GIMRT uses finite difference techniques to discretize the nonlinear mass balance equations associated with mass transport and reaction in porous media. The governing equations used in these models are reviewed briefly in Appendix 2 in Tompson et al. (1999). As its name implies, GIMRT is based on a one-step or global implicit solution approach. In this technique, the advection, diffusion, and reaction processes occurring over a single time step are treated in a coupled and implicit manner. 
Many recent improvements have been made to GIMRT by its author, Carl Steefel, to support the calculations in this report. The improvements listed below were added since the simulations reported in Tompson et al. (1999). Improvements include the following (Steefel, 2000):

- Cross-affinity option, which allows one mineral to substitute for another in the mineral saturation term of the kinetic rate law (see Bethke, 1996).

- Radionuclide decay/ingrowth option, which allows for radionuclide decay and ingrowth, both in aqueous and solid phases. ${ }^{8}$

- Vanselow, Gapon, and Gaines-Thomas ion exchange convention options.

- Electrostatic (diffuse layer) and non-electrostatic surface complexation options.

- Significant improvement in numerical efficiency.

GIMRT calculations were duplicated at times with the related OS3D 9 (Operator Splitting Three-Dimensional Reactive Transport) code (Steefel and Yabusaki, 1996). OS3D has many of the same capabilities as GIMRT except that OS3D is based upon an operator splitting approach in which processes are accounted for using individual numerical treatments that are performed in a sequential manner (Tompson et al., 1999). OS3D better minimizes numerical dispersion errors than GIMRT, which made it useful for code comparisons. However, the Courant number constraints in OS3D made it impractical for use in the streamline calculations (Tompson et al., 1999).

\subsubsection{Geochemical Processes}

Geochemical processes considered during the streamline calculations include aqueous complexation, surface complexation, ion exchange, mineral dissolution and precipitation, and radionuclide decay/ingrowth. Retardation factors computed for the particle code were based on aqueous complexation, surface complexation, and ion exchange reactions under ambient groundwater conditions, but were then distilled to linear Kd values.

Aqueous complexation is computed using thermodynamic data in Appendix J, Table J.3, assuming homogeneous equilibrium in the fluid phase. The nonelectrostatic surface complexation model is used to model $\mathrm{pH}$-dependent sorption of radionuclides to iron oxide, calcite, and aluminosilicates. The Vanselow ion exchange formalism is used to describe ion exchange reactions among radionuclides and $\mathrm{Na}, \mathrm{Ca}$, $\mathrm{K}$, and $\mathrm{Mg}$ on smectite, illite/mica, and zeolite. The surface complexation and ion exchange models and model parameters are discussed in detail in Appendix $\mathrm{K}$. The stability of minerals and the kinetics of mineral dissolution/precipitation are described using the thermodynamic data in Table J.4, and the kinetic rate law and parameters in

\footnotetext{
${ }^{8}$ At this time, changes in mineral solubility as a result of radionuclide decay are not accounted for.

${ }^{9}$ GIMRT and OS3D have recently been merged into the code CRUNCH.
} 
Appendix J. The modeling of the kinetics of glass dissolution is discussed in Section 6.4.4. The treatment of radionuclide decay and ingrowth is discussed in Appendix I.

\subsubsection{Aqueous Species and Minerals Considered in GIMRT}

Table 6.11 lists the aqueous species considered in the GIMRT simulations. The selection of relevant aqueous complexes was made by calculating aqueous speciation as described in Tompson et al. (1999), and by constructing a series of activity diagrams (e.g., Bowers, Jackson and Helgeson, 1984). The dominant aqueous complexes for each radionuclide were identified given potential changes in $\mathrm{pH}$, redox potential, and carbonate concentration. The aqueous species are relevant for values of $\mathrm{pH}$ greater than $6, \mathrm{O}_{2}(\mathrm{~g})$ fugacities greater than about $10^{-40}$ bars, and variations in carbonate concentration that vary from ambient by several orders of magnitude. Some aqueous complexes (e.g., $\mathrm{EuCO}_{3}{ }^{+}$) were included because the mass action expression relating the sorption of Eu onto calcite was written in terms of that species.

Table 6.11 Aqueous species and gases used in GIMRT simulations.

\begin{tabular}{|c|c|c|}
\hline$\overline{\mathrm{H}^{+}}$ & $\mathrm{SiO}_{2}(\mathrm{aq})$ & $\mathrm{Na}^{+}$ \\
\hline $\mathrm{HCO}_{3}^{-}$ & $\mathrm{Al}^{3+}$ & $\mathrm{Ca}^{2+}$ \\
\hline $\mathrm{K}^{+}$ & $\mathrm{Mg}^{2+}$ & $\mathrm{O}_{2}(\mathrm{aq})$ \\
\hline $\mathrm{Fe}^{2+}$ & $\mathrm{SO}_{4}^{2-}$ & $\mathrm{Cl}^{-}$ \\
\hline${ }^{41} \mathrm{Ca}^{2+}$ & $\mathrm{Cs}^{+}$ & $\mathrm{Sr}^{2+}$ \\
\hline $\mathrm{Am}^{3+}$ & $\mathrm{Eu}^{3+}$ & $\mathrm{Sm}^{3+}$ \\
\hline $\mathrm{Np}^{4+}$ & $\mathrm{Pu}^{4+}$ & ${ }^{241} \mathrm{Pu}^{4+}$ \\
\hline $\mathrm{UO}_{2}^{2+}$ & tracerEV & tracerGW \\
\hline tracerMG & $\mathrm{OH}^{-}$ & $\mathrm{CO}_{3}{ }^{2-}$ \\
\hline $\mathrm{AlO}_{2}^{-}$ & $\mathrm{HSiO}_{3}^{-}$ & $\mathrm{Fe}^{3+}$ \\
\hline $\mathrm{HFeO}_{2}(\mathrm{aq})$ & $\mathrm{FeO}_{2}^{-}$ & $\mathrm{PuO}_{2}^{+}$ \\
\hline $\mathrm{PuO}_{2}^{2+}$ & $\mathrm{PuO}_{2} \mathrm{OH}(\mathrm{aq})$ & $\mathrm{PuO}_{2} \mathrm{CO}_{3}^{-}$ \\
\hline $\mathrm{PuO}_{2}\left(\mathrm{CO}_{3}\right)_{2}^{2-}$ & $\mathrm{Pu}(\mathrm{OH})_{4}(\mathrm{aq})$ & $\mathrm{Pu}(\mathrm{OH})_{2}\left(\mathrm{CO}_{3}\right)_{2}^{2-}$ \\
\hline${ }^{241} \mathrm{PuO}_{2}^{+}$ & ${ }^{241} \mathrm{PuO}_{2}^{2+}$ & ${ }^{241} \mathrm{PuO}_{2} \mathrm{OH}(\mathrm{aq})$ \\
\hline${ }^{241} \mathrm{PuO}_{2} \mathrm{CO}_{3}^{-}$ & ${ }^{241} \mathrm{PuO}_{2}\left(\mathrm{CO}_{3}\right)_{2}{ }^{2-}$ & ${ }^{241} \mathrm{Pu}(\mathrm{OH})_{4}(\mathrm{aq})$ \\
\hline${ }^{241} \mathrm{Pu}(\mathrm{OH})_{2}\left(\mathrm{CO}_{3}\right)_{2}^{2-}$ & $\mathrm{AmCO}_{3}^{+}$ & $\mathrm{Am}\left(\mathrm{CO}_{3}\right)_{2}^{-}$ \\
\hline $\mathrm{Am}(\mathrm{OH})_{2}^{+}$ & $\mathrm{AmOH}^{2+}$ & $\mathrm{EuCO}_{3}{ }^{+}$ \\
\hline $\mathrm{Eu}\left(\mathrm{CO}_{3}\right)_{2}^{-}$ & $\mathrm{Eu}(\mathrm{OH})_{2}^{+}$ & $\mathrm{SmCO}_{3}^{+}$ \\
\hline $\mathrm{Sm}\left(\mathrm{CO}_{3}\right)_{2}^{-}$ & $\mathrm{NpO}_{2}^{+}$ & $\mathrm{NpO}_{2} \mathrm{OH}(\mathrm{aq})$ \\
\hline $\mathrm{NpO}_{2} \mathrm{CO}_{3}^{-}$ & $\mathrm{Np}(\mathrm{OH})_{4}(\mathrm{aq})$ & $\mathrm{UO}_{2}\left(\mathrm{CO}_{3}\right)_{2}^{2-}$ \\
\hline $\mathrm{UO}_{2}\left(\mathrm{CO}_{3}\right)_{3}{ }^{4-}$ & $\mathrm{UO}_{3}(\mathrm{aq})$ & $\mathrm{UO}_{2}(\mathrm{aq})$ \\
\hline $\mathrm{U}^{4+}$ & $\mathrm{O}_{2}(\mathrm{~g})$ & $\mathrm{H}_{2} \mathrm{O}$ \\
\hline
\end{tabular}

The tracerMG, tracerEV and tracerGW components were added to serve as proxy components for nonreactive radionuclides distributed among the melt glass (MG), exchange volume (EV) and gas/water (GW) as defined in IAEA (1998a) (Chapter 4).

Table 6.12 lists the solids chosen to set solubility limits on the concentrations of both radionuclides and rock-forming elements in solution. (Section 6.4.5 discusses the selection of the rock-forming minerals in detail.) These rock-forming minerals were 
allowed to dissolve and precipitate in both the melt glass zone and native rock. However, they were involved mainly in reactions within the melt glass zone.

As discussed in Tompson et al. (1999), $\mathrm{AmOHCO}_{3}$ and $\mathrm{EuOHCO}_{3}$ were chosen as the solubility limiting phases for $\mathrm{Am}$ and $\mathrm{Eu}$. (Note that mass numbers are omitted for convenience.) Because GIMRT does not track mixing of isotopes in precipitates, the solubility limit for the sum of isotopes ${ }^{238+239+240} \mathrm{Pu}$ was set by ${ }^{238+239+240} \mathrm{PuO}_{2}(\mathrm{OH})_{2} \bullet \mathrm{H}_{2} \mathrm{O}$, and that of ${ }^{241} \mathrm{Pu}$ was set by ${ }^{241} \mathrm{PuO}_{2}(\mathrm{OH})_{2} \bullet \mathrm{H}_{2} \mathrm{O}$. The need to distinguish between ${ }^{241} \mathrm{Pu}$ and all other $\mathrm{Pu}$ isotopes resulted from the need to track the decay of ${ }^{241} \mathrm{Pu}$ and ingrowth of ${ }^{241} \mathrm{Am}$ (Chapter 4). Both solid phases have the same thermodynamic properties. $\mathrm{Sm}(\mathrm{OH})_{3}(\mathrm{am})$, schoepite $\left(\mathrm{UO}_{3} \bullet 2 \mathrm{H}_{2} \mathrm{O}\right)$ and $\mathrm{NpO}_{2} \mathrm{OH}(\mathrm{am})$ were selected as the solubility limiting phases for $\mathrm{Sm}, \mathrm{U}$ and $\mathrm{Np}$, as discussed in Pawloski et al. (2000). Celestite $\left(\mathrm{SrSO}_{4}\right)$ was specified as the solubility limit for Sr. No solubility limits were considered for ${ }^{3} \mathrm{H},{ }^{14} \mathrm{C},{ }^{36} \mathrm{Cl},{ }^{39} \mathrm{Ar},{ }^{41} \mathrm{Ca},{ }^{59} \mathrm{Ni},{ }^{63} \mathrm{Ni},{ }^{85} \mathrm{Kr},{ }^{93} \mathrm{Zr},{ }^{94} \mathrm{Nb}$, ${ }^{99} \mathrm{Tc},{ }^{107} \mathrm{Pd},{ }^{121 \mathrm{~m}} \mathrm{Sn},{ }^{126} \mathrm{Sn},{ }^{129} \mathrm{I},{ }^{137} \mathrm{Cs},{ }^{166 \mathrm{~m}} \mathrm{Ho}$ and ${ }^{244} \mathrm{Cm}$, owing to lack of knowledge concerning their solubility constraints, and/or the unlikely chance that solubility limits will be exceeded given their initial distribution and concentrations, potential solubilitylimiting solids and solution chemistry.

The co-precipitation of a radionuclide with another cation to form a solid solution was not considered because GIMRT does not provide explicitly for solid solutions. Further discussion on the numerical problems associated with providing for solid solution models such as ideal site mixing can be found in Section 6.4.5.2.1.1.

Table 6.12 Minerals and solids used in GIMRT simulations.

Column 1 (other than Melt glass) represents solids allowed to precipitate and dissolve in both melt glass zone and host lavas. Column 2 represents potential radionuclide-bearing precipitates, with some mass numbers omitted for convenience.

\begin{tabular}{|l|l|}
\hline \hline Melt glass & $\mathrm{AmOHCO}_{3}$ \\
\hline $\mathrm{SiO}_{2}(\mathrm{am})$ & $\mathrm{EuOHCO}_{3}$ \\
\hline$\alpha$-cristobalite & $\mathrm{Sm}(\mathrm{OH})_{3}(\mathrm{am})$ \\
\hline K-feldspar & ${ }^{238+239+240} \mathrm{PuO}_{2}(\mathrm{OH})_{2} \cdot \mathrm{H}_{2} \mathrm{O}$ \\
\hline Kaolinite & ${ }^{241} \mathrm{PuO}_{2}(\mathrm{OH})_{2} \bullet \mathrm{H}_{2} \mathrm{O}$ \\
\hline Ca-clinoptilolite & Schoepite $\left(\mathrm{UO}_{3} \cdot 2 \mathrm{H}_{2} \mathrm{O}\right)$ \\
\hline Na-clinoptilolite & Celestite $\left(\mathrm{SrSO}_{4}\right)$ \\
\hline Ca-montmorillonite & $\mathrm{NpO}_{2} \mathrm{OH}(\mathrm{am})$ \\
\hline Na-montmorillonite & \\
\hline Ca-nontronite & \\
\hline Calcite & \\
\hline Goethite & \\
\hline
\end{tabular}




\subsubsection{Melt Glass Dissolution Model}

The melt glass contains a significant fraction of the radionuclide inventory associated with a nuclear test and therefore contributes to the source term for radionuclide transport. To predict the rates of release of radionuclides from the melt glass, the rate of glass reaction with typical groundwater must be known. How changes in parameters such as temperature, fluid $\mathrm{pH}$, and fluid composition affect that rate must also be known. This section describes the glass dissolution rate model that is used to model radionuclide release from the melt glass.

\subsubsection{Glass Composition}

Melt glass is expected to have a composition that is very close to that of the native rocks of the test, with the exception of added trace amounts of test-related radionuclides, some residual water, and test debris. All of these materials may be incorporated into the glass during its formation (Schwartz et al., 1984). An average of the analyzed compositions of four mafic-poor Calico Hills Formation tuffs and the Windy Wash Formation intrusive dike (Quinleven and Byers, 1977; Broxton et al., 1989) were used to derive the composition of the melt glass associated with the CHESHIRE test (Table 6.13). These are the lithologies that host the test. The concentrations of radionuclides in the glass generated in the test are also given in Table 6.13. Their absolute amounts are obtained from Chapter 4. Based on a yield of 500 kilotons and a factor of 700 metric tons glass per kiloton of yield, a melt glass mass of 350,000 metric tons is calculated for the CHESHIRE test. The amounts of radionuclides are based on an unclassified mean inventory of 76 nuclear tests carried out below or within $100 \mathrm{ft}$ of the water table (see Chapter 4 and Appendix A).

To model glass dissolution in reactive transport simulations, a data block for the glass reactant needs to be included in the thermodynamic data file. The glass composition in Table 6.13 was used to generate the reaction block shown in Table 6.14. This reaction block defines the stoichiometry of the glass dissolution reaction (in moles) for one mole (100 grams) of glass. Not included in the data block are the natural abundances of elements in the glass that have a corresponding radioactive isotope generated in the test (i.e., natural cesium is not included in the data block; only radioactive cesium is included). Their inclusion wouldgreatly increase the complexity of the modeling and the size of the basis set that must be used. Previous calculations (Tompson et al., 1999) have shown that their inclusion does not significantly affect retardation associated with sorption when there is a linear relationship between sorbed and aqueous concentrations. Their exclusion ensures that the source term includes only radionuclides generated by the test.

The fictitious element in the glass called "tracerMG" is used to generate release rates for nonreactive radionuclides such as ${ }^{36} \mathrm{Cl},{ }^{99} \mathrm{Tc}$ and ${ }^{129} \mathrm{I}$ that migrate as tracers (that is, do not participate in any chemical reactions) and radionuclides such as ${ }^{59} \mathrm{Ni},{ }^{63} \mathrm{Ni},{ }^{93} \mathrm{Zr},{ }^{93 \mathrm{~m}} \mathrm{Nb},{ }^{94} \mathrm{Nb},{ }^{10} \mathrm{Pd},{ }^{121 \mathrm{~m}} \mathrm{Sn}$ and ${ }^{126} \mathrm{Sn}$ that are treated as tracers because of a lack of data regarding their chemical interactions. As described in Chapter 4, one mole of tracerMG is distributed homogeneously in the glass, and the concentrations of the tracer radionuclides are calculated via postprocessing from the tracerMG concentration. 
Table 6.13 Composition of average melt glass for CHESHIRE test at time $=0$ prior to onset of radionuclide decay.

\begin{tabular}{|c|c|c|c|c|c|c|c|}
\hline Element & Oxide & $\begin{array}{c}\text { Oxide } \\
\text { wt } \%\end{array}$ & $\begin{array}{c}\text { Oxide } \\
\text { mole\% }\end{array}$ & $\begin{array}{c}\text { Oxide } \\
\text { mol/100g }\end{array}$ & $\begin{array}{c}\text { Element } \\
\text { wt } \%\end{array}$ & $\begin{array}{c}\text { Element } \\
\text { mole\% }\end{array}$ & $\begin{array}{l}\text { Element } \\
\mathrm{mol} / 100 \mathrm{~g}\end{array}$ \\
\hline $\mathrm{O}$ & $\mathrm{O}$ & & & & 49.5 & 63.7 & 3.09 \\
\hline $\mathrm{Si}$ & $\mathrm{SiO}_{2}$ & 78.6 & 84.7 & 1.31 & 36.7 & 26.9 & 1.31 \\
\hline $\mathrm{Al}$ & $\mathrm{Al}_{2} \mathrm{O}_{3}$ & 11.8 & 7.46 & 0.11 & 6.22 & 4.74 & 0.23 \\
\hline $\mathrm{Fe}$ & $\mathrm{Fe}_{2} \mathrm{O}_{3}$ & 0.76 & 0.31 & 0.005 & 0.53 & 0.20 & 0.009 \\
\hline $\mathrm{Na}$ & $\mathrm{Na}_{2} \mathrm{O}$ & 2.99 & 3.13 & 0.048 & 2.22 & 1.99 & 0.097 \\
\hline $\mathrm{K}$ & $\mathrm{K}_{2} \mathrm{O}$ & 4.89 & 3.36 & 0.052 & 4.06 & 2.14 & 0.104 \\
\hline $\mathrm{Ca}$ & $\mathrm{CaO}$ & 0.47 & 0.54 & 0.008 & 0.33 & 0.17 & 0.008 \\
\hline $\mathrm{Mg}$ & $\mathrm{MgO}$ & 0.061 & 0.097 & 0.0015 & 0.037 & 0.03 & 0.002 \\
\hline $\mathrm{Fe}$ & $\mathrm{FeO}$ & 0.41 & 0.37 & 0.0058 & 0.32 & 0.12 & 0.0058 \\
\hline${ }^{135+137} \mathrm{Cs}$ & ${ }^{135+137} \mathrm{Cs}_{2} \mathrm{O}$ & 3.5E-08 & 8.1E-09 & $1.2 \mathrm{E}-10$ & 3.3E-08 & 5.1E-09 & $2.5 \mathrm{E}-10$ \\
\hline${ }^{41} \mathrm{Ca}$ & ${ }^{41} \mathrm{CaO}$ & 7.0E-08 & 8.1E-08 & 1.2E-09 & 5.0E-08 & 2.6E-08 & 1.2E-09 \\
\hline${ }^{90} \mathrm{Sr}$ & ${ }^{90} \mathrm{SrO}$ & $1.5 \mathrm{E}-08$ & 9.5E-09 & $1.5 \mathrm{E}-10$ & 1.3E-08 & 3.0E-09 & $1.5 \mathrm{E}-10$ \\
\hline$U^{*}$ & $\mathrm{UO}_{2}{ }^{*}$ & 2.8E-05 & $6.8 \mathrm{E}-06$ & 1.0E-07 & $2.5 \mathrm{E}-05$ & 2.2E-06 & 1.1E-07 \\
\hline${ }^{237} \mathrm{~Np}$ & ${ }^{137} \mathrm{NpO}_{2}$ & 2.1E-07 & 5.0E-08 & $7.8 \mathrm{E}-10$ & $1.8 \mathrm{E}-07$ & 1.6E-08 & $7.8 \mathrm{E}-10$ \\
\hline $238+239+240 \mathrm{Pu}$ & ${ }^{238+239+240} \mathrm{PuO}_{2}$ & 1.4E-06 & 3.3E-07 & 5.0E-09 & $1.2 \mathrm{E}-06$ & 1.0E-07 & 5.1E-09 \\
\hline${ }^{241} \mathrm{Pu}$ & ${ }^{241} \mathrm{PuO}_{2}$ & 3.5E-09 & 8.3E-10 & $1.3 \mathrm{E}-11$ & 3.1E-09 & $2.6 \mathrm{E}-10$ & $1.3 \mathrm{E}-11$ \\
\hline${ }^{241} \mathrm{Am}$ & ${ }^{241} \mathrm{Am}_{2} \mathrm{O}_{3}$ & 5.4E-09 & $6.5 \mathrm{E}-10$ & $1.0 \mathrm{E}-11$ & 4.9E-09 & 4.2E-10 & $2.0 \mathrm{E}-11$ \\
\hline${ }^{151} \mathrm{Sm}$ & ${ }^{151} \mathrm{Sm}_{2} \mathrm{O}_{3}$ & 9.0E-09 & 1.7E-09 & $2.6 \mathrm{E}-11$ & 7.7E-09 & 1.1E-09 & $5.1 \mathrm{E}-11$ \\
\hline${ }^{150+152+154} \mathrm{Eu}$ & ${ }^{150+152+154} \mathrm{Eu}_{2} \mathrm{O}_{3}$ & 1.1E-09 & $2.0 \mathrm{E}-10$ & $3.0 \mathrm{E}-12$ & $9.2 \mathrm{E}-10$ & $1.2 \mathrm{E}-10$ & $6.0 \mathrm{E}-12$ \\
\hline tracerMG $\mathrm{MG}^{\star \star}$ & tracer(MG) & $2.9 \mathrm{E}-10$ & $1.9 \mathrm{E}-08$ & $2.9 \mathrm{E}-10$ & $2.9 \mathrm{E}-10$ & 5.9E-09 & $2.9 \mathrm{E}-10$ \\
\hline & Totals & 99.9 & 99.9 & na & 99.9 & 100.0 & na \\
\hline
\end{tabular}

${ }^{*} U$ is sum of isotopes: ${ }^{232} U,{ }^{233} U,{ }^{234} U,{ }^{235} U,{ }^{236} U,{ }^{238} \mathrm{U}$.

** See text for explanation of tracerMG.

na $=$ not applicable.

In generating the data block for melt glass, it is necessary to specify the oxidation states of multivalent elements. The oxidation states of these elements are important because they can affect the oxidation state of the groundwater into which they are released. However, there is no analytical data regarding the oxidation states of multivalent elements in actual melt glasses, and none for the oxidation state of groundwater in the CHESHIRE test vicinity. The $\mathrm{O}_{2}(\mathrm{~g})$ fugacity of CHESHIRE groundwater was ultimately fixed at $10^{-7}$ bars (see Section 6.3), which determines the oxidation state of all radionuclides released from glass. Therefore, the choice of oxidation states of elements in the melt glass reactant does not affect the results of the reactive transport calculation. There is the potential for chemical changes due to reaction of released radionuclides with $\mathrm{O}_{2}(\mathrm{aq})$ as the system comes to equilibrium at the $\mathrm{O}_{2}(\mathrm{~g})$ fugacity of $10^{-7}$ bars. However, the small concentrations of radionuclides involved and the oxidation state of groundwater minimizes this effect. 
Table 6.14 Dissolution reaction for melt glass. Isotopes of a given radionuclide are assumed to exhibit identical chemical behavior, so a given radionuclide represents the sum of all its isotopes. Isotopes ${ }^{41} \mathrm{Ca}$ and ${ }^{241} \mathrm{Pu}$ are explicitly included so that their radioactive decay can be provided for by GIMRT. Note that one mole of glass is equivalent to about $100 \mathrm{~g}$ of glass. The definition of a mole of glass is arbitrary owing to the amorphous nature of glass.

\begin{tabular}{|l|l|l|}
\hline Glass $+0.95748 \mathrm{H}+=$ & $4.7874 \mathrm{E}-01$ & $\mathrm{H}_{2} \mathrm{O}$ \\
\hline & $1.3077 \mathrm{E}+00$ & $\mathrm{SiO}_{2}(\mathrm{aq})$ \\
\hline & $2.3051 \mathrm{E}-01$ & $\mathrm{Al}^{3+}$ \\
\hline & $1.5271 \mathrm{E}-02$ & $\mathrm{Fe}^{3+}$ \\
\hline & $9.6598 \mathrm{E}-02$ & $\mathrm{Na}^{+}$ \\
\hline & $1.0393 \mathrm{E}-01$ & $\mathrm{~K}^{+}$ \\
\hline & $8.2956 \mathrm{E}-03$ & $\mathrm{Ca}^{2+}$ \\
\hline & $1.2443 \mathrm{E}-09$ & ${ }^{41} \mathrm{Ca}^{2+}$ \\
\hline & $1.5055 \mathrm{E}-03$ & $\mathrm{Mg}^{2+}$ \\
\hline & $1.0487 \mathrm{E}-07$ & $\mathrm{UO}^{2+}$ \\
\hline & $2.4905 \mathrm{E}-10$ & $\mathrm{Cs}^{+}$ \\
\hline & $1.4640 \mathrm{E}-10$ & $\mathrm{Sr}^{2+}$ \\
\hline & $5.1320 \mathrm{E}-11$ & $\mathrm{Sm}^{3+}$ \\
\hline & $6.0349 \mathrm{E}-12$ & $\mathrm{Eu}^{3+}$ \\
\hline & $7.7885 \mathrm{E}-10$ & $\mathrm{~Np}^{4+}$ \\
\hline & $5.0493 \mathrm{E}-09$ & $\mathrm{Pu}^{4+}$ \\
\hline & $1.2861 \mathrm{E}-11$ & ${ }^{24}{ }^{4+} \mathrm{Pu}^{4+}$ \\
\hline & $2.0189 \mathrm{E}-11$ & $\mathrm{Am}^{3+}$ \\
\hline & $2.8621 \mathrm{E}-10$ & $\mathrm{TracerMG}^{2+}$ \\
\hline & & \\
\hline
\end{tabular}

Molecular wt. $=99.955 \mathrm{~g} / \mathrm{mol}$

Molar volume $=39.98 \mathrm{~cm}^{3} / \mathrm{mol}$

For elements such as iron, the entire inventory in the melt glass is included in one oxidation state $\left(\mathrm{Fe}^{3+}\right)$ in order to minimize the number of basis species in the calculation and to better represent its probable dominant oxidation state in CHESHIRE groundwater. In other cases, the basis species oxidation state was chosen to comply with requirements of the radioactive decay algorithm in the GIMRT code (i.e., ${ }^{241} \mathrm{Pu}^{4+}$ and $\mathrm{Np}^{4+}$ ). Given the system under study and its conceptualization in GIMRT, none of these choices affects the results of the reactive transport calculations. 


\subsubsection{General Features}

Glasses are amorphous, thermodynamically unstable materials that tend to transform with time into more stable crystalline phases. The rate of this transformation provides an upper limit to the release rates of radioactive elements contained within the glass. Diffusion rates of ions through silicate glasses are too small to allow appreciable release of any radionuclide through diffusional processes (see Chapter 15 in Doremus, 1994). Water acts as a flux to allow the transformation from glass to crystalline material to proceed at a measurable rate.

When water first contacts an alkali aluminosilicate glass such as a rhyolitic melt glass, an ion exchange process takes place that quickly depletes alkalis from the outermost few nanometers of glass surface. With time, this outer alkali-depleted hydrous surface layer thickens. For high silica glasses such as rhyolites, the hydration layer can continue to thicken over time further slowing the release rates of species from the glass (Luo et al., 1998). This process also restricts further water contact along narrow fractures where the hydration swelling reduces fracture permeability (Timmons and Thompson, 1996).

Some of the elements released from the melt glass are incorporated into alteration phases, and some remain in solution and may be carried away in the fluid. For a silicate glass such as that generated at the CHESHIRE test, reaction with groundwater will cause the formation of mainly clay and zeolite minerals. Zeolite precipitation is generally restricted to temperatures above ambient. Alteration minerals can affect the release rates of radionuclides from the glass through ion exchange, sorption, and precipitation reactions involving both major elements and radionuclides. ${ }^{10}$ The partitioning of elements between the solution and the alteration phases is not considered a part of the glass dissolution model. It is accounted for in the reactive transport calculation as discussed in Appendix J.

Alkali aluminosilicate glasses, such as rhyolitic glass, typically show a Vshaped $\mathrm{pH}$ dependence to their dissolution rates that has a minimum at near-neutral pHs (Figure 6.17). The data in Figure 6.17 are for far-from-saturation conditions where the dissolution rates are not decreased by saturation effects (Mazer, 1987). These rates are therefore the maximum values at which the glass will dissolve at the given $\mathrm{pH}$ (excepting any catalytic effects such as might occur in the presence of strong complexing agents). The rate data show a progressive increase in durability (decrease in dissolution rate) as the silica content of the glass increases. For example, rhyolitic glass dissolves more slowly than basaltic glass.

\footnotetext{
${ }^{10}$ Note, however, that radionuclide sorption to alteration minerals in the melt glass zone was not accounted for owing to uncertainty regarding the alteration reactions (section 6.4.5) and the temperature dependence of sorption.
} 


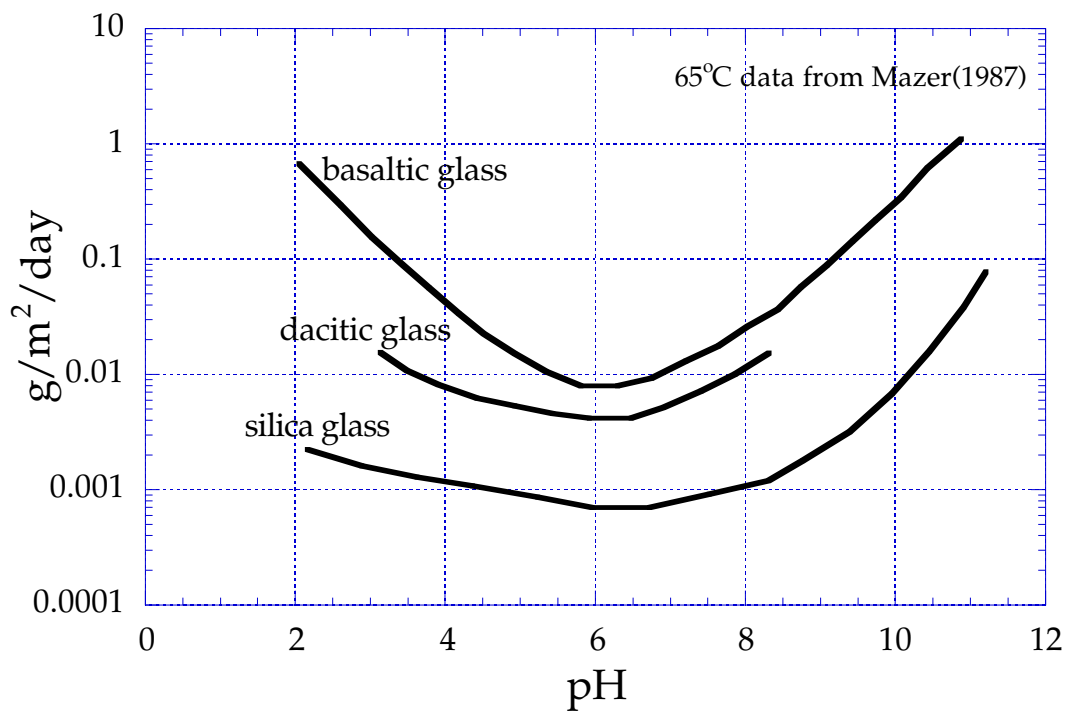

Figure 6.17 Dissolution rates for synthetic volcanic glasses measured at $65^{\circ} \mathrm{C}$ by Mazer (1987). These rates are for test conditions far from saturation with respect to the glass.

Glasses exhibit a saturation effect similar to that of crystalline solids. In closed system experiments, the dissolution rate slows as species build up in solution. The dissolution rate under near-saturation conditions can be several orders of magnitude slower than the rate measured far from saturation. For silicate glasses, the saturation effect is due mainly to dissolved silica (Grambow, 1987). Most other aqueous species have less effect, particularly in neutral to alkaline $\mathrm{pH}$ solutions. The saturation effect, which slows the reaction rate, is likely to be important for slowly flowing groundwater interacting with the melt glass for the CHESHIRE test. Slow groundwater flow rates relative to glass-water reaction rates favor a buildup of silica concentrations in solution. Also, the ambient groundwater flowing through the melt glass have relatively high silica concentrations owing to their reactions with volcanic rocks containing glass and cristobalite.

Although the saturation effect clearly needs to be considered in the modeling, there are no experimental data available for rhyolitic glasses that can be used to quantify it. Therefore, the effect was estimated based on data for borosilicate waste glasses as described in Section 6.4.5.1.1.

\subsubsection{Rate Equation}

The processes controlling the rate of glass dissolution described above are accounted for in a rate equation as follows:

$$
\frac{d n_{i}}{d t}=A v_{i} k \prod_{j} a_{j}^{p_{j}}\left(1-\frac{Q}{K}\right)+A r_{f}
$$

where $n_{i}$ is the number of moles of component $i$ released from the glass, $A$ is the reactive surface area of the glass $\left(\mathrm{m}^{2}\right), v_{i}$ is the stoichiometric coefficient for the element $i$ in the 
glass (moles of element $i$ per mole of glass), $k$ is the rate coefficient ( $\left.\mathrm{mol} / \mathrm{m}^{2} / \mathrm{s}\right), \Pi$ is the product function of catalytic or inhibitive species, and $Q$ and $K$ are the activity product and solubility product for the glass dissolution reaction (Aagaard and Helgeson, 1982). $r_{f}$ is a term sometimes used to account for the relatively slow rate of reaction of glasses close to saturation where the saturation term $(1-Q / K)$ alone is inadequate.

Alternatively, Equation (6.2) can be written as in Appendix B,

$$
\phi_{g} \frac{d c_{i}}{d t}=v_{i} r_{g}=v_{i} A_{s} k \prod_{j} a_{j}^{p_{j}}\left(1-\frac{Q}{K}\right)+A_{s} r_{f}
$$

where $c_{i}$ is the aqueous concentration of radionuclide $i$ (mol $/ \mathrm{m}^{3}$-fluid), $\phi_{g}$ is the melt glass porosity, and $A_{s}=A / V_{g b}$ is the specific reactive surface area of the glass per unit bulk volume, $V_{g b}\left(\mathrm{~m}^{2}\right.$-glass $/ \mathrm{m}^{3}$-bulk voume). The specific surface area can also be expressed as $A_{s}=A_{s}^{m} \rho_{g b}$ where $A_{s}^{m}$ is the specific reactive surface area of the glass per unit mass ( $\mathrm{m}^{2}$-glass/g-glass), and $\rho_{g b}$ is the bulk density of the glass.

For the case of melt glass dissolution, the product term $\Pi$ accounts for the effect of $\mathrm{pH}$ on the dissolution rate, where $a_{j}$ is the activity of $\mathrm{H}^{+}$and $p_{j}$ corresponds to the slope of log rate vs. $\mathrm{pH}$ curve (as in Figure 6.18). The term $(1-Q / K)$ is the saturation or affinity term and provides for the slow-down in rate due to saturation. Commonly, only the effect of dissolved silica is included in the saturation term in modeling silicate glass dissolution (Bourcier, 1994).

\subsubsection{Rate Equation Parameters}

To use the glass dissolution model in reactive transport calculations, rate law parameters that cover the anticipated range of underground conditions at the CHESHIRE test must be provided.

\subsection{Rate coefficient $k$}

Because the melt glass composition is similar to that for natural rhyolitic glasses, results of previous dissolution studies of natural silicate glasses can be used to estimate the dissolution rate of the radioactive melt glass. The effects of small amounts of contaminants, including radioactive ones with their associated radiation fields, have been shown to have negligible effects on glass dissolution rates (Bibler and Jantzen, 1987). 


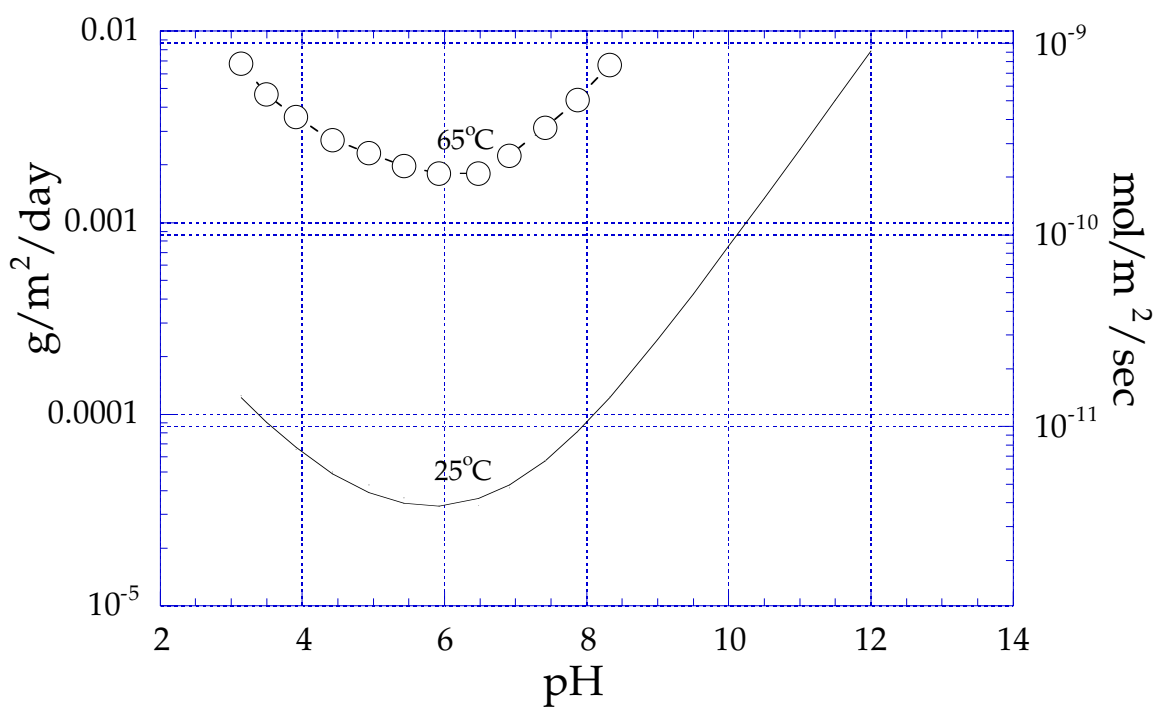

Figure 6.18 Dissolution rates of rhyolitic glass at 25 and $65^{\circ} \mathrm{C}$. Data at $25^{\circ} \mathrm{C}$ are extrapolated from $65^{\circ} \mathrm{C}$ data in Mazer (1987). Curve through $25^{\circ} \mathrm{C}$ data is a least-squares fit based on linear three-term equation described in text. Plot shows both units of $\mathrm{g} / \mathrm{m}^{2} / \mathrm{d}$ and moles $/ \mathrm{m}^{2} / \mathrm{s}$, where one mole is defined to be $100 \mathrm{~g}$ of glass.

For the CHESHIRE melt glass, the data in Figure 6.17 were used to regress the value of the rate coefficient as a function of glass silica content. ${ }^{11}$ First, the $65^{\circ} \mathrm{C}$ data for dacite glass are fit to a polynomial. Then it is assumed, based on the data shown in Figure 6.17, that the dissolution rate decreases by about $0.03 \log$ units for each $1 \%$ increase in $\mathrm{SiO}_{2}$ content. It is also assumed that the $\mathrm{pH}$ dependence of the glass dissolution rate parallels the measured data for dacite, but is offset to higher or lower rates depending on the glass silica concentration relative to dacite (Figure 6.18).

The product term in the rate Equation (6.2) accounts for the $\mathrm{pH}$ effect on dissolution rate where $a_{j}$ is the activity of $\mathrm{H}^{+}$and $p_{j}$ is the slope of the rate on a plot of $\log$ rate vs. $\mathrm{pH}$. Although this form of rate equation provides only a linear dependence between $\mathrm{pH}$ and $\log$ rate, experimental data show a V-shaped dependence on $\mathrm{pH}$, with a minimum at near-neutral $\mathrm{pH}$. This relationship was modeled by using a product term that is the sum of three linear parts: a negatively sloped dependence at low $\mathrm{pHs}$, a horizontal dependence at intermediate $\mathrm{pHs}$, and a positively sloped segment at high pHs. The sum of these three terms provides the fit to the curvature shown in Figure 6.18.

\footnotetext{
${ }^{11}$ The silica content is representative of the degree of differentiation of a volcanic rock from a less silicarich precursor. Volcanic rocks follow systematic differentiation trends for which the silica content is representative of position along that trend. Therefore the silica content alone can be correlated with volcanic glass durability, rather than using a more complex function of multiple components.
} 
Table 6.15 Glass dissolution rate model parameters at $25^{\circ} \mathrm{C}$.

\begin{tabular}{|c|c|c|}
\hline Species & Slope & $\begin{array}{c}\text { Intercept } \\
\left(\mathrm{mol} / \mathrm{m}^{2}-\mathrm{sec}\right)\end{array}$ \\
\hline $\mathrm{H}^{+}$ & 0.46 & $3.1 \times 10^{-10}$ \\
\hline $\mathrm{OH}^{-}$ & 0.52 & $9.8 \times 10^{-9}$ \\
\hline $\mathrm{pH}$ independent & 0 & $2.6 \times 10^{-12}$ \\
\hline
\end{tabular}

Table 6.15 contains the set of three rate constants and exponents used to provide the dissolution rate of the CHESHIRE melt glass at $25^{\circ} \mathrm{C}$ over a $\mathrm{pH}$ range of 2 to 12. The effect of temperature on glass dissolution is accounted for by assuming an activation energy for glass dissolution of $20 \mathrm{kcal} / \mathrm{mol}$. This value is typical for many measurements of temperature effects on glass dissolution rates (Bourcier, 1994). These numbers were used to generate the $25^{\circ} \mathrm{C}$ curve shown in Figure 6.18.

Figure 6.19 illustrates the effect of both $\mathrm{pH}$ and temperature on the far-fromsaturation dissolution rates of the CHESHIRE melt glass. The rates are calculated using an activation energy of $20 \mathrm{kcal} / \mathrm{mol}$. The product term $\mathrm{ka}_{\mathrm{H}+}{ }^{\mathrm{n}}$ shown in Figure 6.19 was used in the particle and GIMRT calculations described in this report.

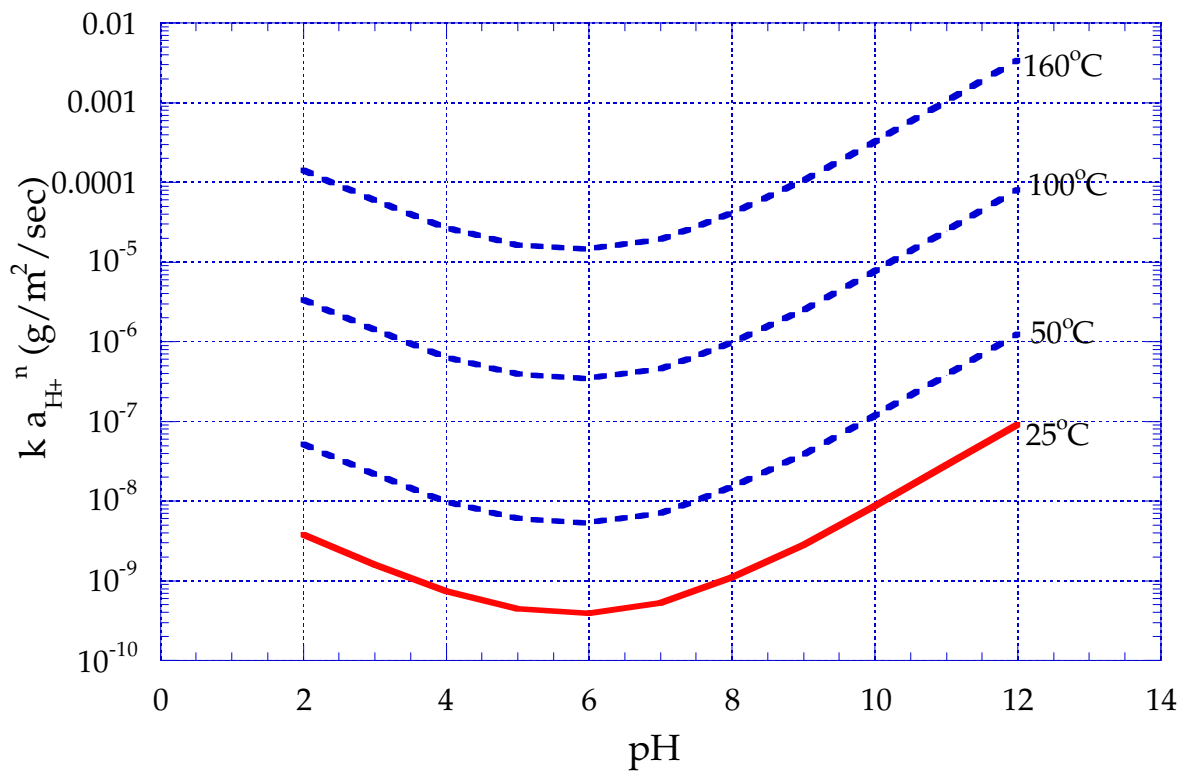

Figure 6.19 Far-from-saturation, surface-area-normalized dissolution rates for CHESHIRE glass over the temperature range of glass-water interactions estimated for the CHESHIRE test. 


\subsection{Saturation term (1-Q/K)}

As mentioned above, the rate of glass dissolution slows as glasses approach saturation with respect to the solution they are dissolving in. Previous studies have shown that the primary cause of the rate decrease is the increasing concentration of dissolved silica (Grambow, 1987). Although other species have some effect, our glass dissolution model is limited to the effect of silica because of the lack of more detailed information. This implies that for the saturation term $(1-Q / K)$ in the rate Equation (6.2), the value of $Q$ is simply the concentration of dissolved $\mathrm{SiO}_{2}(\mathrm{aq})$ and $K$ is the silica concentration in solution at glass "saturation" for a particular glass composition.

The saturation term for a mineral is normally expressed in terms of all the species participating in its dissolution reaction. For the melt glass, the dissolution reaction includes all the species present in the glass data block listed in Table 6.14. However, only dissolved silica is assumed to affect the saturation state of the glass. To correctly calculate rates that depend only on the concentration of aqueous silica, the "cross affinity" option of the GIMRT reactive transport code is used. The option allows only the activity of dissolved silica to define $Q$. GIMRT then calculates a glass dissolution saturation term that depends only on dissolved silica concentration.

The equilibrium constant $(K)$ for glasses is usually determined experimentally by measuring the silica concentration in solution under conditions when the dissolution rate of the glass slows to near zero in static (closed system) glass dissolution experiments. For silica-rich glasses such as rhyolites, values of $K$ usually lie between the values of $K$ for the silica polymorphs cristobalite and amorphous silica (Grambow, 1987). Because of the lack of available experimental data on saturation effects for melt glasses, the conservative assumption is made that $K$ is defined by amorphous silica. The larger the value of $K$, the larger the value of the saturation term and the higher the calculated dissolution rate.

\subsection{Glass surface area}

One of the most critical and poorly defined parameters necessary for predicting radionuclide release rates from melt glass is the reactive surface area of the melt glass. This term is important because the reaction rate of the glass is proportional to the reactive surface area in Equation (6.2). ${ }^{12}$

The problem of estimating a reactive surface area for the melt glass is complicated by the high degree of heterogeneity of the melt glass. An underground nuclear explosion results in the formation of a cavity followed by its collapse and in-fall of rubble. Photos taken of exploratory post-test drifts show that the melt glass zone is a breccia of rhyolite blocks, introduced during cavity collapse, incorporated into melt glass that is variably cracked and vesiculated (full of gas bubbles and having a texture

\footnotetext{
${ }^{12}$ Note that the reactive surface area of glass refers to the surface area of glass alone, and not the surface areas of secondary precipitates on the glass (e.g., clays). Surface areas of crushed glass measured using BET may include the contributions of these alteration minerals that have much higher surface areas than glass. Only the surface area of glass is included in the rate Equation (6.2). It is the dissolution of glass that releases radionuclides. Each alteration mineral is represented by its own rate equation and sorption characteristics, when appropriate.
} 
similar to pumice). The relative proportions of massive to fractured and vesicular glass are unknown, and their distributions in space are probably chaotic.

Glass is produced from the condensation of high temperature plasma created at the time of the explosion, from shock melting associated with the force of the explosion, and from thermal melting of wall rock along the edge of the cavity (Borg et al., 1976). Ground water and other volatiles present in the subsurface at the time of the test and incorporated in the melt will tend to exsolve as the melt solidifies. This will result in vesicular zones of high porosity and comparatively high effective surface areas. However, it is not known whether these vesicular zones also have high permeability and allow flowing groundwater to contact most of its surface area, which is a measure of reactive surface area.

In addition, when glasses cool from the outside, thermal gradients normal to the cooling surface produce differential thermal contraction that causes cracking. Even slowly cooled meter-sized glass masses end up as composites of fist-sized glass pieces along with finer material in a three-dimensional mosaic of cracks (Baxter, 1983). A similar cracking process probably affects massive melt glass as it cools.

In the long-term, reactions between the melt glass and water will give rise to hydrous alteration products. These reactions generally have a positive molar volume change and will therefore have a tendency to decrease the permeability in the zones that contain the hydrous phases. This effect has been observed in leaching studies of glasses from in situ vitrification sites (Timmons and Thompson, 1996). The above issues are difficult to address without detailed field examination and laboratory studies of actual melt glasses.

To provide a better estimate for reactive surface area, measurements of reactive surface areas of intact natural analog rhyolite glass cores were made. ${ }^{13}$ The glassy rhyolite samples were selected to match the textures observed in samples retrieved from cores drilled into melt glasses. Analog samples of pumice, breccias, massive glass, and mixtures of all three textures were collected. These samples were then cored and the cores used in flow-through dissolution tests. The reactive surface area was determined by measuring the amounts of species dissolved by the fluid during passage through and reaction with the glass. Because surface area-normalized glass dissolution rate constants are known from previous work under these conditions, the integrated reactive surface area for the sample can be computed from the amounts of dissolved glass constituents in the outlet fluid (i.e., known values of everything but $A$ in Equation (6.2)). The values for reactive surface area of these rhyolite samples ranged from about 0.001 to $0.01 \mathrm{~m}^{2} / \mathrm{g}$.

Based on observations of melt glass samples, it is believed that the natural analog samples tested had higher reactive surface areas in general than melt glasses. Melt glasses are heterogeneous and contain zones of massive glass in addition to the

\footnotetext{
${ }^{13}$ See "Determination of Reactive Surface Area of Melt Glass," proposed publication by Lawrence Livermore National Laboratory and Desert Research Institute. It describes recent surface area measurements of analog glass samples by flow-through tests on cores and BET measurements on smaller samples. Measured values from cores ranged from 0.001 to $0.01 \mathrm{~m}^{2} / \mathrm{g}$. We use $0.001 \mathrm{~m}^{2} / \mathrm{g}$ in our glass dissolution models for reasons described above.
} 
zones of brecciated and vesicular glass (Figure 6.13). The reactive surface area of massive glass could not be measured in the laboratory experiment because it is impermeable. Water will contact only fractured surfaces in massive glass. The reactive surface areas of fractured man-made glass cylinders reported by Baxter (1983) are on the order of $0.00005 \mathrm{~m}^{2} / \mathrm{g}$, which is much lower than our measured reactive surface areas for vesicular and brecciated natural glass samples. Baxter's measurements were made on glass logs $2 \mathrm{ft}$ wide and $10 \mathrm{ft}$ long. The logs fracture during cooling due to thermal gradients and dissolution along these fractures dominated the reactive surface area test.

A bulk value for reactive surface area of $0.001 \mathrm{~m}^{2} / \mathrm{g}$ for our particle and GIMRT simulations was chosen to account for the contribution of massive glass zones to reactive surface area, and to provide for the likelihood that hydrous phases will precipitate and reduce permeability. The $0.001 \mathrm{~m}^{2} / \mathrm{g}$ value lies on the low end of the range of reported data for the analog samples. However, given all the uncertainties involved in this choice, this value is considered a fairly conservative estimate of the reactive surface area of the melt glass (that is, it does not underestimate surface area). Additional discussion of the reactive surface area of melt glass and its implications regarding glass durability, especially with regard to natural systems, is included in Section I.7.3.

The surface area of $0.001 \mathrm{~m}^{2} / \mathrm{g}$ was used to initialize the total surface area of glass at the start of the particle simulations. The surface area of glass then decreases linearly with the amount of glass dissolution throughout the particle simulation. In contrast, after the transition from the particle code to GIMRT at $100 \mathrm{yr}$, the change in surface area $(A)$ during glass dissolution is controlled in GIMRT according to the following relation:

$$
A_{m}=A_{m}^{0}\left(\left(\frac{\phi}{\phi^{0}}\right)\left(\frac{\phi_{m}}{\phi_{m}^{0}}\right)\right)^{\frac{2}{3}}
$$

where the subscript $m$ stands for the glass (or mineral), $\phi^{\circ}$ denotes the initial porosity of the medium ${ }^{14}$ and $\phi_{m}{ }^{\circ}$ represents the initial volume fraction of glass. There is therefore a slight difference in the evolution in the surface area, and thus the dissolution rate, between the particle code and GIMRT. The difference is minimized because $80 \%$ of the total melt glass dissolution occurs before the GIMRT calculations begin at 100 years. Section I.7.3 contains a discussion of the merits of using the linear model for melt glasses versus Equation (6.4), which was developed for granular aggregates.

\subsubsection{Comparison with Experimental Data}

Some dissolution rate measurements of actual melt glass produced by tests hosted by tuff or tuffaceous alluvium at the Nevada Test Site (NTS) and natural glasses of similar bulk composition are available with which to compare and validate our glass dissolution model. Our choice of rate coefficient is within the range of data reported by

\footnotetext{
${ }^{14}$ Because the porosity of the glass zone is assumed constant at $20 \%$ in our model, $\phi / \phi^{\circ}=1$.
} 
Coles et al. (1978) and Failor et al. (1983) for flow-through dissolution tests of melt glasses collected from the CAMBRIC test (see discussion in Tompson et al., 1999).

In addition, White (1983) reports dissolution rates of silica-rich natural glasses measured in static tests. A dissolution rate of $0.87 \times 10^{-12} \mathrm{~mol} / \mathrm{cm}^{2} / \mathrm{s}$ (equivalent to $5.2 \times$ $10^{-10} \mathrm{~g} / \mathrm{m}^{2} / \mathrm{s}$ ) is reported for a $76 \mathrm{wt} \% \mathrm{SiO}_{2}$ obsidian dissolving in distilled water. For the same conditions ( $\mathrm{pH} 6.3,25^{\circ} \mathrm{C}, 0.03 \mathrm{mmol} \mathrm{Si}$ ), our model predicts a value of $3.9 \mathrm{x}$ $10^{-10} \mathrm{~g} / \mathrm{m}^{2} / \mathrm{s}$, which is in good agreement with the measured value.

\subsubsection{Other Factors Affecting Glass Durability}

The dissolution rate of a silicate glass depends fairly strongly on glass composition, but also depends on the annealing history of the glass. The faster a glass is quenched, the more strain energy remains that causes the glass to dissolve more quickly. The cooling rates of melt glass are expected to be fairly slow and comparable with the cooling rates of shallow intrusive rocks and the interiors of extrusive flows. Therefore, no attempt has been made to account for any dissolution rate differences that could arise from variable cooling histories.

As mentioned above, the radiation field associated with radionuclides incorporated into the glass is likely to have a minimal effect on glass dissolution rates. The most significant effect is likely to be due to alpha emission from decaying actinides such as ${ }^{239} \mathrm{Pu}$. However, at the low concentrations of plutonium in the melt glass, this effect will probably be negligible (Weber et al., 1997).

\subsubsection{Implementation of Glass Dissolution Model}

The glass dissolution model described in the previous section must be incorporated into both the particle and GIMRT codes. The particle code does not explicitly provide for the complex chemical interactions such as $\mathrm{pH}$ and secondary mineral precipitation that control glass dissolution rates. Thus, the effects of chemistry must be anticipated and hardwired into the glass model in the particle code. The transition from the particle code to GIMRT at 100 years requires that the rates in the particle model be consistent with the full chemistry-driven glass dissolution model in GIMRT. The implementations of the glass dissolution model for the particle code and GIMRT are discussed below.

\subsubsection{Model Used in the Particle Code}

A simplified temperature-dependent glass dissolution model is required for the particle code. The model must bound the expected limits of glass dissolution rates given potential variability in chemical and physical conditions. Based on the results of GIMRT simulations and published glass dissolution data, the rate of glass dissolution was bounded by a high rate and a long-term, near-saturation rate. A moderate rate was defined at $25^{\circ} \mathrm{C}$ that represents a conservative estimate of the glass dissolution rate under near-ambient chemical conditions. Figure 6.20 illustrates these bounding rates, normalized to surface area, as a function of temperature. To calculate the bulk rate of glass dissolution, the rates in Figure 6.20 should be multiplied by the reactive surface 
area. Sections 6.4.5.1.1, 6.4.5.1.2 and 6.4.5.1.3 below describe how these bounding rates were obtained.

Particle simulations can be run with each of these models to determine the sensitivity of radionuclide migration to the extremes of glass performance. The moderate rate, which produces a conservative estimate of radionuclide release resulting from glass dissolution (that is, does not under-estimate release), was selected as the base case value of the glass reaction rate. A conservative estimate was chosen chiefly because of our incomplete knowledge of the coupling among processes that control the melt glass dissolution rate. The long-term dissolution rate expression was used in a particle simulation evaluating the sensitivity of radionuclide migration to the glass dissolution rate.

It is important to realize that the rate of glass dissolution as the glass cools will probably not follow one or another of the curves in Figure 6.20 exclusively. Rather, the rate will vary among the curves. For example, in the first year during the thermal pulse, the rate may drop to the slow, long-term dissolution rate owing to the build-up of silica in solution. Then, as the temperature pulse passes, the rate may shift to the moderate rate as the fluid chemistry reverts to the ambient groundwater chemistry. Simple calculations using the rate data shown in Figure 6.20 (and presented later in Chapter 7) show that, using the moderate rate, about $25 \%$ of the glass dissolves from 0 to 100 years owing to the thermal pulse. In contrast, only about $5 \%$ of the glass dissolves from 100 to 1000 years when the temperature is near-ambient.

Based on the durability of natural glasses, it is clear that the moderate rate is a conservative choice because of the comparatively large amounts of glass dissolution that it predicts during the thermal pulse. However, we do not know enough about the controls of the glass dissolution rate during the thermal pulse in order to define the probable evolution of the glass rate with time. Thus we chose the moderate rate, based on well-defined ambient conditions, as our base case rate. In order to more accurately describe the glass dissolution rate as a function of time, temperature and fluid flow, we need to better define the interaction of processes that control the glass dissolution rate during the thermal pulse. For further discussion of these issues, see Section 6.4.5.2. 


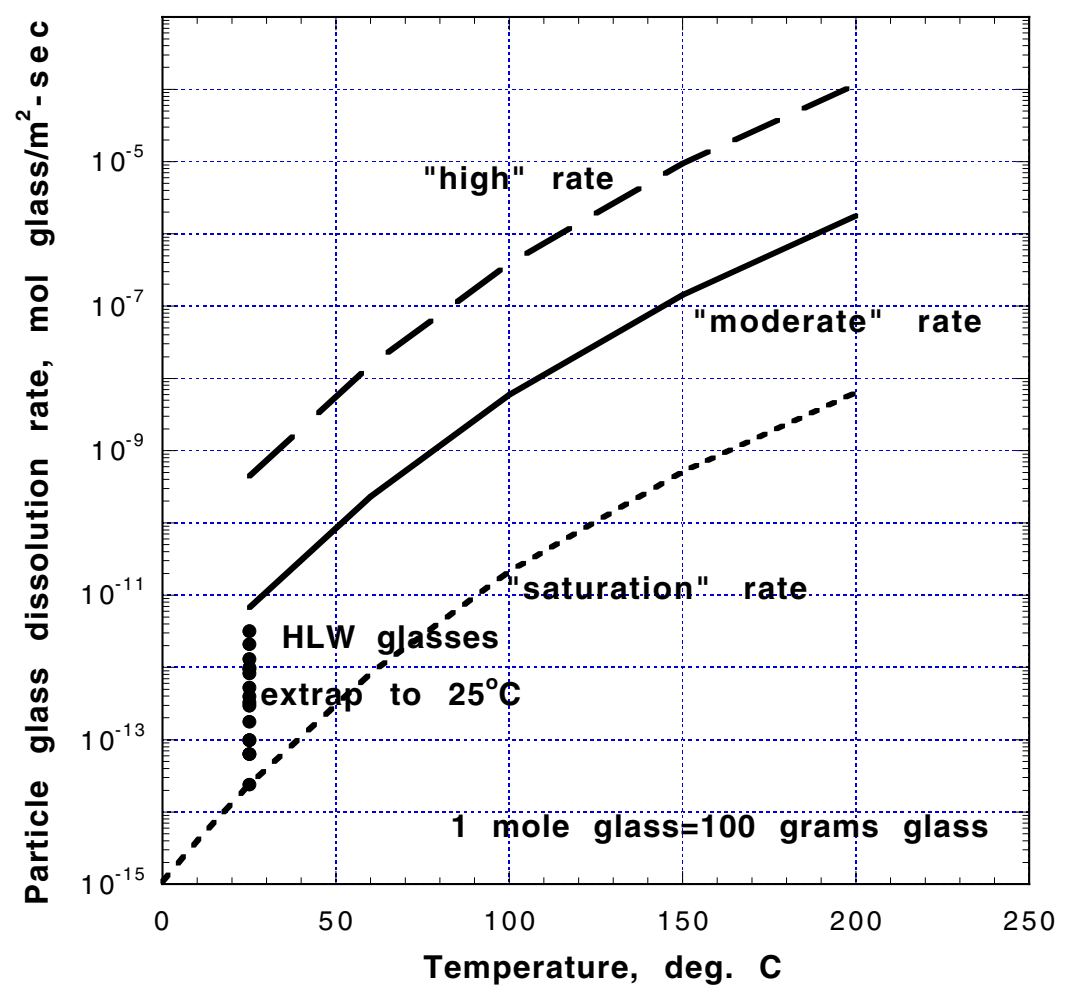

Figure 6.20 Surface-area-normalized glass dissolution rate models for use in particle calculations. Data points represent estimates of saturation rates derived from data in Stout and Leider (1998) (see text).

\subsection{Long-term dissolution rate}

With time in a closed system at neutral $\mathrm{pH}$, the dissolution rate of nuclear waste glass has been observed to slow until a long-term dissolution rate is achieved. This long-term rate has been attributed to silica-saturated conditions in which the decrease in the affinity term $(1-Q / K)$ reduces the dissolution rate. The rates are also minimized by the neutral $\mathrm{pH}$; acidic or alkaline $\mathrm{pH}$ values would increase the rates (Figure 6.19).

Long-term, surface-area-normalized dissolution rates have been obtained from published data for waste glasses with about $50 \mathrm{wt} \% \mathrm{SiO}_{2}$ (see summary in Stout and Leider, 1998, Table 3.5.1-5, p. 3-182. Note that rates in this table are for $90^{\circ} \mathrm{C}$, not $30^{\circ} \mathrm{C} .{ }^{15}$ ) However, long-term rates have not been measured for rhyolitic glasses with much higher silica contents. Therefore, the long-term dissolution rate of rhyolitic glass under silica-saturated conditions was derived from the data for waste glasses.

\footnotetext{
${ }^{15}$ Bourcier, personal communication, 2001.
} 
The lowest rate in Stout and Leider (1998) is $6 \times 10^{-4} \mathrm{~g} / \mathrm{m}^{2}-\mathrm{d}$ at $90^{\circ} \mathrm{C}(2.4 \mathrm{x}$ $10^{-14} \mathrm{~mol} / \mathrm{m}^{2}$-s) for R7T7/Volvic glass. Rates of glass dissolution decrease about $0.03 \mathrm{log}$ units per $1 \mathrm{wt} \%$ increase in $\mathrm{SiO}_{2}$ (Tompson et al., 1999). The long-term dissolution rate for the Cheshire rhyolitic glass with about $78 \mathrm{wt} \% \mathrm{SiO}_{2}$ is thus about a factor of $6.9\left(10^{0.84}\right)$ smaller than that of waste glasses. Correcting back to $25^{\circ} \mathrm{C}$ with an activation energy of $20 \mathrm{kcal} / \mathrm{mol}$ generates a long-term rhyolitic glass dissolution rate normalized to surface area at $25^{\circ} \mathrm{C}$ of $2.4 \times 10^{-14} \mathrm{~mol} / \mathrm{m}^{2}$-s. This rate (shown in Figure 6.20) anchored the long-term dissolution rate. Figure 6.20 also shows other rates derived from data in Stout and Leider (1998) in a similar manner.

\subsection{Moderate dissolution rate}

The moderate dissolution rate was calculated according to Equation (6.2) and Table 6.15 given the $\mathrm{pH}$ of ambient Cheshire groundwater at $25^{\circ} \mathrm{C}$ (Table 6.10) and aqueous $\mathrm{SiO}_{2}$ concentration corresponding to equilibrium with $\beta$-cristobalite. The rate constant at a $\mathrm{pH}$ of 8.3 and $25^{\circ} \mathrm{C}$ equals $1.4 \times 10^{-11} \mathrm{~mol} / \mathrm{m}^{2}-\mathrm{s}$. The saturation term $(1-$ $Q / K=0.48)$ was determined using a $\beta$-cristobalite saturated solution to set $Q$ and an amorphous silica $\left(\mathrm{SiO}_{2}(\mathrm{am})\right)$ saturated solution to set $K\left(\mathrm{at} 25^{\circ} \mathrm{C}\right) . \mathrm{SiO}_{2}(\mathrm{am})$ is used as a proxy for amorphous glass. A -cristobalite saturated solution was used to set the silica concentration because the aqueous $\mathrm{SiO}_{2}$ concentration in the ambient groundwater is close to saturation with $\beta$-cristobalite (for composition in Table 6.10: $Q / K=0.89$ at $25^{\circ} \mathrm{C}$; 0.68 at ambient temperature of $\left.35^{\circ} \mathrm{C}\right)$. The $(1-Q / K)$ term was assumed invariant with temperature. Given these assumptions, the term $\mathrm{ka}_{\mathrm{H}+}{ }^{\mathrm{n}}(1-\mathrm{Q} / \mathrm{K})$ in the rate equation equals $6.693 \times 10^{-12} \mathrm{~mol} / \mathrm{m}^{2}-\mathrm{s}$, which when multiplied by the reactive surface area yields the rate of glass dissolution. ${ }^{16}$

In this model, the glass dissolution rate is assumed to change only in accordance with the temperature dependence of the rate constant, and not by any changes in $\mathrm{pH}$ or saturation state. This is equivalent to assuming that glass dissolution either is sufficiently slow relative to fluid flow such that it does not significantly change ambient fluid chemistry, or that secondary mineral reactions buffer the fluid chemistry at near-ambient values. These assumptions are most applicable after the thermal effects of the test have passed, and most questionable during the thermal pulse when fluctuations in fluid chemistry are most likely to occur. If silica builds up in solution, the glass dissolution rate could approach the slow, long-term dissolution rate represented by the long-term dissolution rate described above. If glass dissolution and resultant secondary mineral precipitation causes the $\mathrm{pH}$ to increase or decrease, a higher dissolution rate could result. The definition of the high dissolution rate in the next section provides for this possibility.

\footnotetext{
${ }^{16}$ In the GIMRT streamline simulations, the aqueous $\mathrm{SiO}_{2}$ concentrations were controlled by $\alpha$-cristobalite instead of $\beta$-cristobalite because of implications regarding secondary mineral precipitation and fluid chemistry, as will be described in section 6.4.5.2.2. The switch caused the $(1-Q / K)$ term to increase from 0.5 to 0.8 . However, the difference was offset to some degree by a decrease in $\mathrm{pH}$. Thus the surface-areanormalized rate in the GIMRT streamline calculations was about a factor of 1.5 greater than the moderate particle glass rates. See Appendix I for further discussion.
} 


\subsection{High dissolution rate}

The highest rates of glass dissolution, normalized to reactive surface area, would be expected at alkaline or acid $\mathrm{pH}$ values (Figure 6.19). Acid $\mathrm{pH}$ values or $\mathrm{pH}$ values greater than 12 are not generally observed in glass dissolution tests, nor measured in groundwater emanating from glassy rocks. Glass dissolution rates at a $\mathrm{pH}$ of 12 were set as the upper bound to glass dissolution. The rate constant at a $\mathrm{pH}$ of 12 , $9.1 \times 10^{-10} \mathrm{~mol} / \mathrm{m}^{2}$-s, was determined directly from the data in Table 6.17 . Note that rate constants at acid $\mathrm{pH}$ are always less than this value, so the value is conservative for both acid and alkaline conditions.

The saturation term $(1-Q / K)$ was determined using $\beta$-cristobalite to set $Q$ and $\mathrm{SiO}_{2}(\mathrm{am})$ to set $K$, as described above for the moderate rate calculations. The resulting $(1-Q / K)$ term at $25^{\circ} \mathrm{C}$ of 0.48 was then assumed to be invariant with temperature. The product of the rate constant and $(1-\mathrm{Q} / \mathrm{K}), 4.4 \times 10^{-10} \mathrm{~mol} / \mathrm{m}^{2}-\mathrm{s}$, is shown in Figure 6.20.

The rates of glass dissolution generated by the high dissolution rate model would not be expected to be maintained over extended periods of time. The high rates of dissolution would produce amounts of glass dissolution that are not consistent with the durability of natural silica-rich volcanic glasses that were subjected to similar temperature histories.

\subsection{Temperature dependence of dissolution rate}

The glass dissolution rate constants for all three models vary with temperature according to the Arrhenius equation using an activation energy of $20 \mathrm{kcal} / \mathrm{mol}$ :

$$
\ln \left(\frac{k_{2}}{k_{1}}\right)=\frac{E_{a}}{R} \cdot \frac{T_{2}-T_{1}}{T_{2} T_{1}}
$$

\subsubsection{Model Used in GIMRT Streamline Calculations}

The rate of melt glass dissolution in GIMRT was calculated using Equation (6.2), with provisions to prevent the precipitation of glass. Equation (6.2) explicitly links the rate of glass dissolution to the chemistry, flow rate and residence time of in-flowing groundwater, the changes in chemistry imparted by dissolving glass, and the changes in chemistry caused by the precipitation of secondary minerals. The combined effects of these processes control solution $\mathrm{pH}$, redox state, and fluid chemistry that, in turn, greatly affect radionuclide solubility and sorption, and thus migration. For example, the retardation of radionuclides by surface complexation is a strong function of $\mathrm{pH}$. In addition, cations released from glass or consumed during precipitation of alteration minerals can influence the competition between cations and radionuclides for sorption sites.

The major differences between the glass model used in GIMRT and the glass model in the particle code are that 
- The $\mathrm{pH}$ and glass activity product $Q$ are allowed to vary in GIMRT.

- GIMRT allows alteration minerals to precipitate and sequester elements released from glass (see, for example, Figures I.16, I.19). The precipitation of alteration minerals changes the fluid chemistry, including $\mathrm{pH}$ and $Q$, the glass activity product, and therefore affects the glass dissolution rate. The alteration minerals were not assumed to decrease the reactive surface area of the glass or sorb radionuclides in the glass zone, however.

The manner in which the glass model is implemented in GIMRT can have a major impact on the glass dissolution rate. Because there is insufficient data available to implement the model with a high degree of confidence, care was taken to

- Ensure that the glass dissolution rates in the particle code and GIMRT are generally consistent.

- Avoid deviations in fluid chemistry that are not consistent with presentday chemistry and fluid-mineral equilibria of Cheshire groundwaters. The GIMRT streamline calculations were conducted from 100 to 1000 years in the post-thermal pulse period when rates of glass dissolution are expected to be sufficiently slow that they do not cause large deviations in fluid chemistry.

- Predict reasonable amounts of glass dissolution over the time span of the simulations, based on the stability of rhyolitic glasses in nature and in laboratory experiments.

- Ensure that our predictions of radionuclide release are conservative and thus do not under-predict release.

The key to achieving these goals was the judicious choice of potential secondary mineral precipitates. Potential secondary mineral precipitates were chosen based on observed glass alteration mineralogies to yield stable $\mathrm{pH}$ and fluid chemistry relative to ambient groundwater chemistry with stabilities insensitive to flow rate. The maintenance of fluid chemistry ensured that the retardation coefficients used in the particle model were generally consistent with sorption in GIMRT.

\subsection{Potential secondary mineral precipitates (nonradionuclide-bearing) in glass zone}

Potential secondary mineral precipitates were chosen based on their presence as alteration products of natural and human-made rhyolitic glasses (Kawano and Tomita, 1997; Levy, 1984, 1992; Moncure et al., 1981; Bish and Chipera, 1989; Section 6.2, this report) and the need to provide potential sinks for elements released from glass. The selected precipitates are as follows:

- Dioctahedral smectite (linear combination of homoionic Na- and Camontmorillonite and Ca-nontronite).

- Kaolinite $\left(\mathrm{Al}_{2} \mathrm{Si}_{2} \mathrm{O}_{5}(\mathrm{OH})_{4}\right)$. 
- Goethite (FeOOH).

- Calcite $\left(\mathrm{CaCO}_{3}\right)$.

- Clinoptilolite (linear combination of $\mathrm{Na}$ and $\mathrm{Ca}$ homoionic end-members).

- $\alpha$-cristobalite - $\mathrm{a} \mathrm{SiO}_{2}$ polymorph.

- K-feldspar $\left(\mathrm{KAlSi}_{3} \mathrm{O}_{8}\right)$.

\subsection{Smectite}

Smectites are commonly found as alteration products of natural and manmade glasses over a wide range of temperatures (Kawano, Tomita and Kamino, 1993; Yang and Kirkpatrick, 1990; Levy, 1984, 1992; Moncure et al., 1981). Smectites commonly ring glass fragments and line fractures. Eaton and Smith (2000) described alteration rinds believed to be clay minerals, on melt glass that was in contact with groundwater for ten years. Smectites were represented in the GIMRT calculations by the idealized end-members of dioctahedral smectite solid solutions: homoionic $\mathrm{Ca}$ - and Na-montmorillonite $\left(\mathrm{Ca}_{0.165} \mathrm{Mg}_{0.33} \mathrm{Al}_{1.67} \mathrm{Si}_{4} \mathrm{O}_{10}(\mathrm{OH})_{2}, \mathrm{Na}_{0.33} \mathrm{Mg}_{0.33} \mathrm{Al}_{1.67} \mathrm{Si}_{4} \mathrm{O}_{10}(\mathrm{OH})_{2}\right)$ and Canontronite $\left(\mathrm{Ca}_{0.165} \mathrm{Fe}_{2} \mathrm{Al}_{0.33} \mathrm{Si}_{3.67} \mathrm{O}_{10}(\mathrm{OH})_{2}\right)$. The solid solution model currently in use by LLNL for dioctahedral smectites contains $\mathrm{Na}, \mathrm{K}, \mathrm{Mg}$, and $\mathrm{Ca}$ end-members for montmorillonite, nontronite and beidellite (Bourcier, 1986). However, numerous simulations with React, X1t (Bethke, 1998) and GIMRT showed than only our selected end-members precipitated during any of the simulations, given the potential precipitates listed above. For simplicity's sake, just these end-members were included in our final calculations.

A variety of solid solution models are used to relate the free energies of endmembers to that of the solid solution. However, GIMRT does not provide for solid solutions, so each smectite end-member was considered a separate phase. The relative proportions of each can be summed to estimate the composition of the solid solution. Providing for solid solution would make the smectite solid solution more stable than the end-members and would slightly increase the total mass of smectite that precipitates. The relative masses of the end-member components, and the effect on solution composition, would not change significantly unless the solid solution was highly nonlinear.

Another option would have been to create a number of solid solution compositions with explicit consideration of the thermodynamics of mixing, and add all the phases to the database. The disadvantages of this are twofold. First, there would be a large number of phases owing to the wide range of compositional diversity on the exchange, tetrahedral and octahedral sites of clays. Secondly, GIMRT would have to keep dissolving and precipitating smectite as one phase equilibrated and another went out of equilibrium. This would place considerable computational strain on GIMRT, because smectites occur in small concentrations and GIMRT tries to accurately track the times at which phases appear and disappear. 
Although the current model is simplistic, it seems the only possible way to address solid solutions at the current time. When the ideal site mixing model was incorporated into models such as EQ3/6 (Wolery, 1992), run times increased dramatically for simulations that were not nearly as complicated and large as the streamline simulations described in this report. At worst, convergence was not achieved. More efficient numerical solution methods are required in reactive transport codes to address this issue.

\subsection{Kaolinite}

Kaolinite was chosen as a proxy for amorphous aluminosilicate precipitates that have been identified on altered rhyolitic glasses. Halloysite, a polymorph of kaolinite, and allophane (an amorphous aluminum silicate) have also been described in obsidian alteration tests (Kawano and Tomita, 1995, 1997; Kawano, Tomita, and Kamino, 1993; Fiore et al. 1999). The inclusion of kaolinite provides a sink for $\mathrm{Al}$ and $\mathrm{Si}$, both of which are in relatively high concentrations in the glass. Destabilizing crystalline kaolinite to better represent the higher free energy expected of an amorphous aluminosilicate was tested, but did not affect results, so it was not incorporated into the final data base. Aluminum oxides such as boehmite (AlOOH) have also been described in obsidian reactions (e.g., Kawano and Tomita, 1995) but were not included in the final calculations because they did not precipitate during preliminary modeling.

\subsection{Goethite}

Both goethite and nontronite were present in the simulations as potential sinks for iron. The addition of goethite permitted iron to precipitate without the need to compete for $\mathrm{Ca}, \mathrm{Al}$, and $\mathrm{Si}$ as is the case for nontronite. Iron released from glass immediately precipitated as a component of a secondary mineral in the GIMRT simulations because of the extremely low solubility of iron in low temperature NTStype waters.

\subsection{Calcite}

Calcite was added to serve as a Ca sink and a potential $\mathrm{pH}$ buffer. Calcite is close to saturation in NTS waters, and it has relatively fast precipitation and dissolution kinetics. It may therefore serve as a buffer for $\mathrm{pH}$ excursions caused by glass dissolution, although its precipitation is limited because of the limited availability of carbonate in groundwater. There is no carbonate in glass.

\subsubsection{1.5 Clinoptilolite}

Na- and Ca-clinoptilolite $\left(\mathrm{Na}_{3.467} \mathrm{Al}_{3.47} \mathrm{Si}_{14.533} \mathrm{O}_{36} \bullet 10.922 \mathrm{H}_{2} \mathrm{O}\right.$ and $\mathrm{Ca}_{1.7335} \mathrm{Al}_{3.47}$ $\mathrm{Si}_{14.533} \mathrm{O}_{36} \bullet 10.922 \mathrm{H}_{2} \mathrm{O}$ ), representing idealized end-members of a clinoptilolite solid solution, were added to the simulations because clinoptilolite is a common alteration product of silicic volcanic glasses at NTS and other locations and has been produced in laboratory glass dissolution tests at elevated temperature (Knauss, 1987; Knauss and Peifer, 1986; Levy, 1984, 1992; Moncure et al., 1981). Clinoptilolite precipitation served to buffer the alkaline $\mathrm{pH}$ values generated by smectite precipitation, as discussed 
further in Section 6.4.5.2.2. Clinoptilolite is considered a proxy for other high-silica zeolites such as heulandite and mordenite that are commonly found as alteration phases in silicic tuffs at Yucca Mountain and elsewhere.

\subsubsection{1.6 $\alpha$-cristobalite}

$\alpha$-cristobalite was allowed to precipitate from solution to sequester released Si. Cristobalite and feldspar are devitrification products of glass. Cristobalite has been identified as an alteration product on hydrothermally reacted silicic tuff (Knauss et al., 1984). Equilibrium with $\alpha$-cristobalite is generally consistent with silica concentrations in ambient NTS volcanic groundwater. Given the kinetic parameters discussed in the next section, $\alpha$-cristobalite controlled the silica concentration that defined the numerator $\mathrm{Q}$ in the affinity term of the glass rate equation.

It has been hypothesized ${ }^{17}$ that silica redistribution, resulting from dissolution of glass and re-precipitation at other locations, occludes permeability and causes some cavity systems to become hydrologically closed and chemically stagnant. The calculations in this report assume a constant permeability architecture, and thus silica precipitation in our model does not affect the flow field (see Section 6.4.5.2.4). This is, however, an important consideration for future studies, especially as it relates to the development of hydrologically closed systems.

\subsection{K-feldspar}

K-feldspar served as a sink for $\mathrm{K}$ in the simulations and acted to minimize the increases in $\mathrm{pH}$ caused by smectite precipitation. K-feldspar and cristobalite are common devitrification products of glass formed during cooling. The thermodynamic data that were used for K-feldspar are consistent with stable ordering of $\mathrm{Al}$ and $\mathrm{Si}$ between tetrahedral sites at any temperature (Helgeson et al., 1978).

\subsection{Dependence of the glass dissolution rate on the identity of secondary minerals: A sensitivity study}

K-feldspar, clinoptilolite, and cristobalite are common minerals in devitrified and altered silicic tuffs. However, their precipitation is usually associated with the high temperatures associated with cooling of volcanic rocks (e.g., the formation of feldspar and cristobalite during devitrification), or with burial diagenesis. Burial diagenesis refers to the alteration caused by burial, which in an active volcanic regime, subjects the rock to an elevated geothermal gradient. Zeolites such as clinoptilolite have been observed to form at low temperatures in response to highly alkaline conditions and/or high ionic strengths, such as associated with saline lakes. However, these conditions have not been described at NTS in its geologic past, and are not expected at the NTS, especially not at the future time represented by the transition from the particle code to GIMRT. Zeolites at NTS thus reflect a history marked by elevated temperature.

The selection of secondary minerals above therefore seems appropriate for high temperature alteration (greater than about $75-100^{\circ} \mathrm{C}$ ). However, the GIMRT runs

\footnotetext{
${ }^{17}$ Unpublished report by Rose, Pawloski, and Smith, 2001.
} 
described in this report were conducted largely at near-ambient temperatures. The need to include these higher temperature minerals was made clear by a series of preliminary simulations of glass dissolution using different sets of potential alteration minerals. The simulations illustrated the effects of competing forces. The identity and rate of precipitation of the silica polymorph controlled the aqueous silica concentration, and the identity of the alteration minerals, as well as the value of the saturation term in the glass rate equation. The precipitation of alteration minerals affected the $\mathrm{pH}$ and the glass dissolution rate.

The range in simulated glass dissolution rates caused by varying the set of potential alteration minerals and darcy flow velocity is illustrated in Figure 6.21 and Table 6.16. Eleven simulations are shown of CHESHIRE groundwater flowing through a $20 \%$ porosity melt glass zone at $35^{\circ} \mathrm{C}$ at darcy flow rates of 1 and $0.1 \mathrm{~m} / \mathrm{yr}$ (Table 6.16). The set of potential secondary minerals was changed through both suppression and alteration of the kinetic rate law parameters. Runs 1 and 2 represent the input for the GIMRT transient streamline calculations. Input conditions for the remaining runs are variations on runs 1 and 2 as noted in the caption to Table 6.16. These simulations are not intended to represent all possible combinations of flow rates and minerals, but are representative of the effects of a few illustrative combinations.

Simulations showed that when clay minerals dominated the secondary precipitates through the exclusion of feldspar, clinoptilolite, and similar framework silicates, the $\mathrm{pH}$ rose to unreasonable values of about 10 and above (runs 8, 9, and 10). Such high $\mathrm{pH}$ values are not representative of groundwater from silicic volcanic rocks at NTS and elsewhere. Precipitation of feldspar and clinoptilolite tended to decrease the $\mathrm{pH}$ (runs 4 to 7). Precipitation of feldspar and clinoptilolite together with clays tended to "buffer" the $\mathrm{pH}$ increase and maintain $\mathrm{pH}$ at near-ambient values (runs 1, 2).

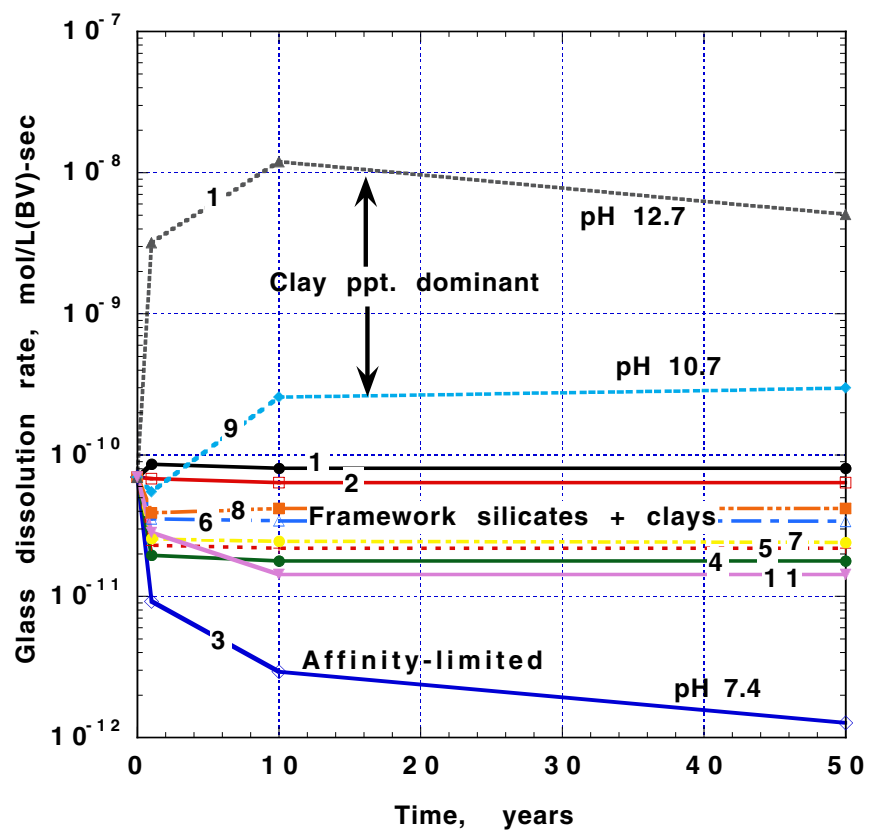

Figure 6.21 Glass dissolution rate with time resulting from variations in the identity and rates of precipitation of secondary minerals. Rate in units of mole glass/(liter bulk volume medium per second). 
Table 6.16 Results of GIMRT simulations of glass dissolution illustrating dependence of glass dissolution rate on secondary precipitates. Variability of secondary minerals was obtained by suppressing mineral precipitation in GIMRT. Note: $\alpha$ - and $\beta$-cristobalite were maintained in local equilibrium by using rate constant $\mathrm{k}=10^{-8} \mathrm{~mol} / \mathrm{m}^{2}-\mathrm{s}$ in runs $1,2,6,10$, and 11 . Remainder of runs used kinetic rate law for cristobalite from Renders et al. (1995). Input for runs 1 and 2 was used in the final GIMRT streamline simulations. Fluid compositions are not shown, although they were heavily factored into the choice of final set of precipitates.

\begin{tabular}{|l|c|c|c|c|c|c|c|c|c|c|c|}
\hline Run & $\begin{array}{c}\text { Vel. } \\
\mathrm{m} / \mathbf{y r}\end{array}$ & $\begin{array}{c}\mathrm{pH} \\
\mathrm{min} / \mathrm{max}\end{array}$ & $\begin{array}{c}\beta \text { or } \boldsymbol{\alpha} \\
\text { crist }\end{array}$ & $\begin{array}{c}\text { Cal- } \\
\text { cite }\end{array}$ & $\mathrm{Ksp} \neq$ & $\begin{array}{c}\text { Ca- } \\
\text { clino }\end{array}$ & $\begin{array}{c}\text { Na- } \\
\text { clino }\end{array}$ & $\begin{array}{c}\text { Ca- } \\
\mathrm{mont}\end{array}$ & $\begin{array}{c}\text { Na- } \\
\text { mont }\end{array}$ & $\begin{array}{c}\text { Ca- } \\
\text { non }\end{array}$ & $\begin{array}{c}\text { Kaol- } \\
\text { inite }\end{array}$ \\
\hline 1 & 1 & 8.1 & $\alpha$ & & $\mathrm{x}$ & $\mathrm{x}$ & $\mathrm{x}$ & $\mathrm{x}$ & $\mathrm{x}$ & $\mathrm{x}$ & \\
\hline 2 & 0.1 & 7.95 & $\alpha$ & & $\mathrm{x}$ & $\mathrm{x}$ & $\mathrm{x}$ & $\mathrm{x}$ & $\mathrm{x}$ & $\mathrm{x}$ & $\mathrm{x}$ \\
\hline 3 & 0.1 & 7.4 & $\beta$ & & $\mathrm{x}$ & $\mathrm{x}$ & $\mathrm{x}$ & & & $\mathrm{x}$ & \\
\hline 4 & 1 & 7.8 & $\beta$ & & $\mathrm{x}$ & $\mathrm{x}$ & & & & $\mathrm{x}$ & \\
\hline 5 & 1 & 7.8 & $\beta$ & & $\mathrm{x}$ & $\mathrm{x}$ & & & & $\mathrm{x}$ & \\
\hline 6 & 1 & 7.9 & $\beta$ & & $\mathrm{x}$ & $\mathrm{x}$ & & & & $\mathrm{x}$ & \\
\hline 7 & 1 & 7.8 & $\beta$ & & & $\mathrm{x}$ & $\mathrm{x}$ & & & $\mathrm{x}$ & \\
\hline 8 & 1 & 9 & $\beta$ & $\mathrm{x}$ & & & & $\mathrm{x}$ & $\mathrm{x}$ & $\mathrm{x}$ & \\
\hline 9 & 0.1 & 10.7 & $\beta$ & $\mathrm{x}$ & & & & $\mathrm{x}$ & $\mathrm{x}$ & $\mathrm{x}$ & $\mathrm{x}$ \\
\hline 10 & 0.1 & 12.7 & $\alpha$ & $\mathrm{x}$ & & & & $\mathrm{x}$ & $\mathrm{x}$ & $\mathrm{x}$ & $\mathrm{x}$ \\
\hline 11 & 0.1 & 6.7 & $\beta$ & & $\mathrm{x}$ & $\mathrm{x}$ & $\mathrm{x}$ & $\mathrm{x}$ & $\mathrm{x}$ & $\mathrm{x}$ & $\mathrm{x}$ \\
\hline
\end{tabular}

$\dagger$ Vel. = Darcy velocity (porosity 0.2 volume fraction).

‡ Mineral abbreviations: $\mathrm{Ksp}=\mathrm{K}$-feldspar, $\mathrm{Ca}$-clino $=\mathrm{Ca}$-clinoptilolite, $\mathrm{Na}$-clino $=\mathrm{Na}$-clinoptilolite, $\mathrm{Ca}-\mathrm{mont}=$ Ca-montmorillonite, $\mathrm{Na}-\mathrm{Mont}=\mathrm{Na}-$ montmorillonite, $\mathrm{Ca}-\mathrm{non}=\mathrm{Ca}-$ nontronite .

Differences in the flow rate can significantly impact the glass dissolution rate. Compare runs 3 and 4 whose starting conditions differed only in flow rate. The slower Darcy flow rate of $0.1 \mathrm{~m} / \mathrm{yr}$ is more representative of simulated flow rates in the postthermal glass environment. In the slow flow rate system, the buildup of silica in solution increases the value of the saturation term $1-Q / K$, which decreases the glass dissolution rate. In these runs, precipitation of $\beta$-cristobalite is controlled by a kinetic rate expression with parameters from Renders et al. (1995). $\beta$-cristobalite precipitation cannot keep pace with silica release from glass, which causes silica to build up in solution.

In contrast to runs 3 and 4, compare runs 1 and 2 whose starting conditions differ only in flow rate. The difference in flow rate does not significantly affect the glass dissolution rate in these runs because $\alpha$-cristobalite precipitates quickly, given a rate constant $=10^{-8} \mathrm{~mol} / \mathrm{m}^{2}$-s chosen specifically to represent rapid, near-equilibrium precipitation. Rapid $\alpha$-cristobalite precipitation not only maintains the glass rate by keeping silica in solution down, but also maintains the major element composition of the groundwater closer to ambient conditions. When $\beta$-cristobalite precipitates at $\mathrm{k}=$ $10^{-8} \mathrm{~mol} / \mathrm{m}^{2}$-s with only clay precipitation allowed (runs 8, 9; no clinoptilolite or feldspar precipitation), the $\mathrm{pH}$ increases significantly, even more so at slower flow rates (run 9). Substitution of $\alpha$-cristobalite for $\beta$-cristobalite (compare runs 9 and 10) results in an even greater, and probably unrealistic, increase in $\mathrm{pH}$ when only clay precipitation occurs. 
The above simulations suggest that feldspar and clinoptilolite precipitation in addition to clays is required to maintain near-ambient values of $\mathrm{pH}$. Rapid $\alpha$-cristobalite precipitation was required to maintain conservative estimates of glass dissolution rates that were not slowed significantly by the glass saturation term. Rapid $\alpha$-cristobalite precipitation also helped to maintain the ambient major element chemistry of the groundwater.

At the start of this study, it was thought that $\beta$-cristobalite would be a more appropriate choice than $\alpha$-cristobalite for controlling silica concentrations during glass dissolution at temperatures less than about $100^{\circ} \mathrm{C}$. Ambient groundwater near CHESHIRE is close to saturation with $\beta$-cristobalite. Silica concentrations are controlled at $\beta$-cristobalite or amorphous silica saturation in near-surface geothermal areas. It was also believed that a kinetic rate expression should be used to determine its precipitation rate. However, the above simulations indicated that rapid precipitation of $\alpha$-cristobalite was required to maintain ambient $\mathrm{pH}$ and groundwater composition, and to avoid unsubstantiated large decreases in glass dissolution rate (e.g., run 3) that would not result in conservative estimates of radionuclide release.

The use of $\alpha$-cristobalite to control silica concentration in the GIMRT simulations contrasts with the use of $\beta$-cristobalite to estimate the saturation term for the glass dissolution model used in the particle code. The particle calculations were begun before the GIMRT simulations when the implications of the choice of the silica polymorph in GIMRT were not yet clear. The inconsistency caused the GIMRT glass dissolution rates to be about 1.5 times greater than the particle code glass rates.

In summary, the set of potential secondary mineral precipitates listed above tended to maintain the $\mathrm{pH}$ and composition of ambient groundwater regardless of the flow velocity, in accordance with observations of the compositions of groundwater in contact with rhyolite glasses. Larger deviations in fluid chemistry and glass dissolution rate are expected under the influence of a thermal pulse. The present approach, which limits deviations in ambient fluid chemistry, is considered prudent, in light of how little data is available from natural analogues and laboratory experiments to guide our implementation of the glass model. It is considered best to avoid models that yield drastic changes in chemical conditions if one does not have adequate evidence to constrain the magnitude of these changes.

\subsection{Glass saturation $(1-Q / K)$ and $r_{f}$ terms}

As discussed previously in Section 6.4.4, $\mathrm{K}$ is defined in this study as the equilibrium constant for $\mathrm{SiO}_{2}(\mathrm{am})$ (amorphous silica), and $Q$ is defined as the activity of $\mathrm{SiO}_{2}(\mathrm{aq})$, the neutral aqueous complex of aqueous silica. The value of $\mathrm{SiO}_{2}(\mathrm{aq})$ depends on the rate at which silica is released from glass, the rate at which silica is incorporated into secondary minerals, and the rate of fluid flow. Given the choice of secondary minerals and their kinetic rate parameters listed in Tables 6.12 and J.6, the concentration of $\mathrm{SiO}_{2}(\mathrm{aq})$ was controlled by equilibrium with $\alpha$-cristobalite in the GIMRT streamline calculations.

Because a kinetic reaction controls the rate of precipitation of $\alpha$-cristobalite, it was considered prudent to provide for situations in which silica would be released from 
glass faster than it can be consumed by precipitation. Silica activity could then rise in solution and equilibrate with $\mathrm{SiO}_{2}(\mathrm{am})$, in which case glass would stop dissolving. However, it is observed that waste glasses continue to dissolve at a small rate even when the solution is at near saturation conditions. Bourcier (personal communication) estimated that the saturation rate is about 1000 times slower than the far-fromsaturation dissolution rate. This is the motivation behind adding an extra term $\left(r_{f}\right)$ to Equation (6.2) to represent the saturation rate.

Attainment of the saturation rate in GIMRT was represented by equilibrium with respect to the fictive mineral $\mathrm{SiO}_{2}$ (limit) with carefully chosen thermodynamic and kinetic parameters. The presence of $\mathrm{SiO}_{2}$ (limit) in the GIMRT model ensured that glass did not equilibrate if silica built up in solution, but instead dissolved at a saturation rate that is $1 / 1000$ of the far-from-equilibrium rate. By appropriately selecting its equilibrium constant relative to $\mathrm{SiO}_{2}(\mathrm{am})$, the fictitious mineral $\mathrm{SiO}_{2}$ (limit) will precipitate according to local equilibrium when the glass affinity reaches a value of $0.001(\mathrm{Q} / \mathrm{K}=0.999)$. This corresponds to a factor of 1000 decrease in the glass dissolution rate relative to far-from equilibrium conditions, and corresponds to the additional $\mathrm{r}_{\mathrm{f}}$ term in Equation (6.2).

The precipitation of $\mathrm{SiO}_{2}$ (limit) allows glass dissolution to continue, although at a slow rate. With the addition of the $r_{f}$ term, the term $k a_{H+}{ }^{n}$ in the glass rate Equation (6.2) defines the far-from-saturation rate, $k a_{H+}{ }^{n}(1-Q / K)$ defines the rate as silica builds up in solution (i.e., $1-Q / K$ varies from 1 to 0 ), and the saturation rate $\left(r_{f}\right)$ defines the rate when $1-Q / K$ is very close to 0 .

For comparison, the saturation rate used in the particle model was 278 times slower than the moderate rate. Although provided for in GIMRT, $\mathrm{SiO}_{2}$ (limit) never reached saturation in the simulations owing to the relatively fast precipitation of $\alpha$-cristobalite. However, the saturation term $r_{f}$ may become more important in future GIMRT simulations at elevated temperature.

\subsection{Relation between secondary mineral precipitation, porosity and permeability}

The precipitation of secondary minerals in the melt glass zone can reduce porosity and permeability. As noted in 6.4.4, the swelling of the outer hydration layer on glass reduces fracture permeability. The alteration products on glass surfaces (e.g., clays) often have larger volumes than the primary glass. Even small changes in porosity can change the permeability significantly. However, the porosity and permeability of the stratigraphic units and components of the cavity/chimney system were defined in the flow model. Thus, it was assumed in GIMRT that porosity was constant and unaffected by the precipitation and dissolution of minerals and glass. In addition, there was no feedback between porosity and permeability in our modeling.

These assumptions are considered reasonable for conditions in the native lava outside of the cavity because there was limited mineralogical change in the lava. The assumptions are most questionable in the melt glass zone where most of the mineralogic changes occur in response to glass dissolution. However, the relationship among alteration mineral precipitation, porosity, and permeability is not known in the melt glass zone. This would be especially difficult to specify given the chaotic, 
heterogeneous nature of the melt glass zone. The relationships are difficult to specify even for the cleanest, most regular of sandstones because permeability is dependent on the type and site of precipitation (e.g., pore throats vs. pore lining). 


\section{Reactive Transport}

\subsection{Overview}

This chapter exhibits, describes, and compares results obtained from the GIMRT streamline and particle modeling simulations of reactive transport at CHESHIRE. The reactive transport simulations were approached from two different perspectives. In the first, we used a streamline-based transport model using the GIMRT code, as in Tompson et al. (1999) and Pawloski et al. (2000). Because of the computational expense of the streamline model and because its applicability is limited in transient flow problems (Appendix C), we also applied a more efficient particle-based transport model (Appendix D). Both models of reactive transport of radionuclides away from the exchange volume and glass zones used the flow model developed in Chapter 5 . These results will be presented for a $1000 \mathrm{yr}$ period after detonation and will comprise the hydrologic source term (HST) for this test. The principal results predict radionuclide fluxes past a breakthrough plane as a function of time. Additional results involving various kinds of plume snapshots and major element (nonradionuclide) distributions are also provided for interpretational purposes. The theoretical backgrounds for the GIMRT streamline and particle transport approaches are given in Appendices C and D, respectively. Appendix E provides a comparison of GIMRT streamline and particle simulation results for simple one-dimensional test cases. Appendices I, J, and K, and Chapter 6 describe the geochemistry involved in the CHESHIRE near field and its implementation in both the GIMRT and particle codes.

The results of the GIMRT streamline model are presented in Section 7.2, represented as major classes of radionuclides. The definition and use of classes of radionuclides can be found in Section 7.1.2. The corresponding particle simulations are then presented and compared to the GIMRT streamline results in Section 7.3. Then the results of a Monte Carlo simulation, using the particle model and an ensemble of realizations of permeability and mineral distribution are presented. Following that, in Section 7.4, several additional sensitivity studies are presented using the particle model. In Section 7.5, the integrated mass flux of radionuclides out of the near-field environment is presented for the GIMRT and particle models. The radionuclides presented are those established in Chapter 4 and Appendix A as the radiological source term (RST). All radionuclides are decay-corrected and presented individually so that the importance of the various radionuclides can be assessed. In addition to the mass flux of radionuclides, the associated radiation flux (curies per year) is presented both for individual radionuclides and as a sum of alpha, beta, or electron capture/isomeric transition decay flux. The contribution of the various radionuclides to the total radiation flux is discussed as well.

\subsubsection{Approach}

The computational expense of the GIMRT streamline transport model limited its application to one comprehensive three-dimensional reactive transport simulation. This simulation used the flow results from permeability realization 9 (described in Chapter 5) and mineralization realization 1 (described in Chapter 6 and Appendix G). 
The computational expense results from a rigorous, mechanistic representation of the geochemical processes, incorporating glass dissolution, aqueous complexation, ion exchange, surface complexation, dissolution and precipitation. The geochemistry involved in the GIMRT model is discussed in Chapter 6 and Appendices I, J, and K. The NUFT simulations of the transient temperature and flow field, particularly at early times (before $100 \mathrm{yr}$ ), resulted in approximately 50 time steps (and 50 velocity fields) to a simulation time of 100 years, and on the order of five time steps from 100 to $1000 \mathrm{yr}$. For a steady-state flow field which has been used in past simulations of this type including the CAMBRIC test (Tompson et al., 1999) and Frenchman Flat HST (Pawloski et al., 2000), over the simulation time frame (1000 yr), only one velocity field and one set of streamlines was used to simulate three-dimensional reactive transport. After $100 \mathrm{yr}$, the flow-field in our CHESHIRE simulations is nearly steady because the test-related heat has largely dissipated. The GIMRT streamline simulations presented below were modeled as a transient flow system starting at $100 \mathrm{yr}$, using the radionuclide distribution at $100 \mathrm{yr}$ produced by the particle model as the initial condition. Due to the highly transient nature of the flow field between 0 and $100 \mathrm{yr}$, the streamline approach used here is not appropriate without further study of its efficacy. Although the streamline model is ostensibly more computationally efficient than a comparable, fully threedimensional grid-based model, it still requires a significant amount of computational time to run, and this fact prevents its use in a comprehensive Monte Carlo fashion. The geochemical behavior of the near field at early times was examined using onedimensional GIMRT simulations reported in Appendix K. Additional information regarding the incremental streamline approach used here is discussed in Appendix C. One-dimensional comparisons of radionuclide reactive transport at early times using the GIMRT and particle codes is discussed in Appendix E.

The particle transport model, as described in Appendix D, incorporates simplified geochemical assumptions (linear sorption interactions between radionuclide and reactive mineral) and a simplified glass dissolution model. However, the particle model is very efficient and can be implemented in transient or steady state flow fields with minimal extra computational overhead. The computational efficiency of the particle method also permits the simulation of multiple permeability and mineralogy realizations. Importantly, we can compare three-dimensional simulation results for both the GIMRT streamline and particle transport models over the same hydrogeological, thermal, and geochemical conditions used for realization 9 with mineralization 1 to examine whether the geochemical simplifications in the particle model result in significant changes in radionuclide reactive transport. The particle transport model was applied to 10 different heterogeneous permeability realizations with 10 different mineralization realizations, which enables a quantification of the uncertainty in radionuclide transport predictions resulting from uncertainty in the characterization of permeability and mineralogical variability. Moreover, the computational speed of the particle transport model enabled sensitivity studies to examine the effects of assumptions made in developing a conceptual hydrogeologic model, consideration of test heat, and consideration of matrix diffusion in fractured rock.

\subsubsection{Radionuclide Classes for Source Term}

In the following sections, the distribution of radionuclides in the near field and their breakthrough at the downstream boundary are presented. In Sections 7.2 to 
7.4, the 37 radionuclides defined to be the near-field RST have been aggregated to 13 classes of radionuclides with unique transport or release characteristics. These 13 classes of radionuclides do not represent any specific isotope but, in fact, represent the composite of a class of radionuclides whose geochemical behavior and initial distribution were equivalent in the model. For example, all isotopes of a single radionuclide were assumed to exhibit identical transport behavior and initial distribution in the near field. ${ }^{1}$ Thus ${ }^{233} \mathrm{U},{ }^{234} \mathrm{U},{ }^{235} \mathrm{U},{ }^{236} \mathrm{U}$, and ${ }^{238} \mathrm{U}$ were combined in our model and are labeled simply as U. Analysis of the reactive transport of these 13 classes of radionuclides allows for a more condensed discussion of processes controlling radionuclide transport. The 13 classes of radionuclides relate directly to the radionuclides used in our reactive transport model (see Chapter 4 and Appendix K). The following can be used as a key to the discussions on results of the GIMRT streamline model (this section) and the particle model (Sections 7.3 and 7.4):

- TracerEV, TracerGW, and TracerMG: These three classes of radionuclides migrate from the near field as tracers but their initial spatial distribution is different. These three classes of radionuclides can be recombined to model the behavior of ${ }^{3} \mathrm{H},{ }^{14} \mathrm{C},{ }^{36} \mathrm{Cl},{ }^{39} \mathrm{Ar},{ }^{85} \mathrm{Kr},{ }^{99} \mathrm{Tc},{ }^{129} \mathrm{I},{ }^{59} \mathrm{Ni},{ }^{63} \mathrm{Ni},{ }^{93} \mathrm{Zr},{ }^{93} \mathrm{Nb},{ }^{94} \mathrm{Nb}$, ${ }^{107} \mathrm{Pd},{ }^{121} \mathrm{Sn}$, and ${ }^{126} \mathrm{Sn} .{ }^{2}$

- ${ }^{41} \mathrm{Ca}$ : This radionuclide class includes ${ }^{41} \mathrm{Ca}$ only. It is distinguished from the label "Ca," which pertains to the stable form of calcium found in groundwater (Figure 7.7).

- Sr: This radionuclide class includes ${ }^{90} \mathrm{Sr}$ only.

- Cs: This radionuclide class includes ${ }^{135} \mathrm{Cs}$ and ${ }^{137} \mathrm{Cs}$.

- Sm: This radionuclide class includes ${ }^{151} \mathrm{Sm}$ only.

- Eu: This radionuclide class includes ${ }^{150} \mathrm{Eu},{ }^{152} \mathrm{Eu}$, and ${ }^{154} \mathrm{Eu}$. It is also used to model the reactive transport of ${ }^{166} \mathrm{Ho}$, and ${ }^{244} \mathrm{Cm} .{ }^{3}$

- $\mathrm{U}$ : This radionuclide class includes ${ }^{233} \mathrm{U},{ }^{234} \mathrm{U},{ }^{235} \mathrm{U},{ }^{236} \mathrm{U}$, and ${ }^{238} \mathrm{U}$.

- $\mathrm{Np}$ : This radionuclide class includes ${ }^{237} \mathrm{~Np}$ only.

- Pu: This radionuclide class includes ${ }^{238} \mathrm{Pu},{ }^{239} \mathrm{Pu}$, and ${ }^{240} \mathrm{Pu}$.

- ${ }^{241} \mathrm{Pu}$ : This radionuclide class includes ${ }^{241} \mathrm{Pu}$ only. It is distinguished from $\mathrm{Pu}$ because of its unique decay characteristics; ingrowth of ${ }^{241} \mathrm{Am}$ is modeled explicitly.

- Am: This radionuclide class includes ${ }^{241} \mathrm{Am}$ only.

$1{ }^{241} \mathrm{Pu}$ is an exception for reasons described in Chapter 4.

${ }^{2}{ }^{59} \mathrm{Ni},{ }^{63} \mathrm{Ni},{ }^{93} \mathrm{Zr},{ }^{93} \mathrm{Nb},{ }^{94} \mathrm{Nb},{ }^{107} \mathrm{Pd},{ }^{121 \mathrm{~m}} \mathrm{Sn}$, and ${ }^{126} \mathrm{Sn}$ should be retarded somewhat, but their retardation behavior was not examined before this simulation.

${ }^{3}$ Both ${ }^{166 \mathrm{~m}} \mathrm{Ho}$ and ${ }^{244} \mathrm{Cm}$ are trivalent cations and are expected to behave geochemically similar to the Eu radionuclides. 
In Sections 7.2 to 7.4, decay correction was implemented for only a small subset of radionuclide classes. In the GIMRT streamline simulations of Section 7.2, Sr, $\mathrm{Sm}, \mathrm{Am}$, and ${ }^{241} \mathrm{Pu}$ are decay-corrected. These radionuclide classes contain a single isotope and, therefore, could be decayed in real time by the GIMRT code. ${ }^{4}$ In the particle model simulations of Sections 7.3 and 7.4, only ${ }^{241} \mathrm{Pu}$ and Am were decay-corrected. Thus, significant differences between the GIMRT and particle models are expected for radionuclide classes of $\mathrm{Sr}$ and $\mathrm{Sm}$. For decay-corrected downstream boundary breakthrough plots of all radionuclides of the RST, see Section 7.5.

In Section 7.5, the 13 classes of radionuclides are used to calculate the breakthrough of all 37 RST radionuclides. Breakthrough is presented both in terms of molar flux and radiation (Ci) flux. Both fluxes are further segregated and summed to examine total $\alpha, \beta$, and electron capture/isomeric transition radiation.

\subsection{GIMRT Streamline Results}

The description of the streamline transport model in Appendix $C$ details the streamtube approach to integrating a transient, three-dimensional flow system with the reactive transport model GIMRT. The streamtube approach requires prior definition of streamline locations, fluxes, and porosities, which were derived from the NUFT simulations of the transient flow field for permeability realization 9, which is described in Chapter 5. The geochemical conditions along streamlines are described in Chapter 6 and Appendices I, J, and K. We refer to this streamtube approach using GIMRT, streamlines of constant flux, and transient flow conditions as a "GIMRT transient streamline" or simply a transient streamline approach.

To address the transient nature of the flow field, steady flow fields were assumed throughout each of a sequence of transient flow field time steps between 100 and $1000 \mathrm{yr}$ after the CHESHIRE test. Primarily as a result of test-related heat, the flow field is highly transient between 0 and $100 \mathrm{yr}$, requiring 50 time steps in the NUFT flow simulations. Therefore, the GIMRT transient streamline approach was not applied to that period. Between 100 and $1000 \mathrm{yr}$, the flow field is not as dynamic, typically requiring $\sim 5$ time steps, which is more practical to the application of the GIMRT transient streamline approach. Appendix $\mathrm{C}$ provides additional information about limitations of the GIMRT transient streamline approach.

To establish initial concentrations of radionuclides at $100 \mathrm{yr}$ after the CHESHIRE test, the particle model was applied to simulation of radionuclide transport from 0 to $100 \mathrm{yr}$ (and beyond to $1000 \mathrm{yr}$ ). The spatial distribution of radionuclides obtained at 100 years from the particle model was used to establish the initial concentrations of radionuclides at $100 \mathrm{yr}$ for the GIMRT transient streamline simulation. Additional description of the particle model and its results is given in Appendices D and $E$ and Section 7.3. Importantly, the particle model considers effects of transient flow between 0 and 100 yr. However, the particle model greatly simplifies representation of

\footnotetext{
4 At present, GIMRT cannot account for the decay of multiple isotopes unless those isotopes are input separately into the model. To reduce the complexity of the GIMRT simulation, all isotopes of the same element (excluding ${ }^{241} \mathrm{Pu}$ ) were grouped into a single class; this resulted in an inability to decay these radionuclides in real time.
} 
glass dissolution and geochemical reactivity (see Chapter 6 and Appendix K). Whereas the GIMRT streamline model explicitly models geochemical processes such as mineral precipitation/dissolution and aqueous speciation, the particle model uses retardation factors to approximate the sum effect of these processes on radionuclide transport.

\subsubsection{Transient Streamline Locations}

In applying the GIMRT transient streamline approach, permeability realization 9 was selected for the reactive transport simulation because it provided a good overall fit to hydraulic and temperature log data (Chapter 5). For permeability realization 9, a total of five flow field time steps occur between 100 and $1000 \mathrm{yr}$ at intervals of 100 to 135,135 to 208,208 to 361,361 to 689 , and 689 to $1000 \mathrm{yr}$. The streamlines used in the reactive transport simulation are prescribed according to the flow field and the spatial distribution of radionuclides prescribed at each of these time steps.

Figure 7.1 displays streamline locations for each time step along a longitudinal cross section through the simulation domain. Streamlines weave in and out of this longitudinal cross section as a function of their prescribed three-dimensional path. The streamlines change at each time step as a result of both changes in the flow field and changes in the spatial distribution of radionuclides. However, the transience in the flow field from 100 to 1000 yr seems to be rather slight, with streamlines following rather similar paths in each flow field. Flow over this time period is primarily lateral and thermally driven recirculation in the cavity and chimney does not occur. The effect of the slight transience between 100 and $1000 \mathrm{yr}$ on overall radionuclide has not been evaluated. It may, in fact, have little effect on large-scale radionuclide transport. Changes in the flow field were, however, dictated by the NUFT flow model and honored in the GIMRT simulations.

The initial distribution of radionuclides at 100 yr was defined by the particle model simulation, which assumed linear retardation of radionuclides and no matrix diffusion. ${ }^{5}$ Although the GIMRT streamline model considers nonlinear retardation by use of a more sophisticated geochemical model, matrix diffusion has not been incorporated because of computational limitations. ${ }^{6}$ For the 100-135 yr interval, streamlines were assigned such that at least one streamline intersected a block with a nonzero radionuclide concentration. In all later intervals, a total radionuclide concentration cutoff of $1 \times 10^{-16} \mathrm{~mol} / \mathrm{L}$ was used to reduce the number of streamlines necessary to represent the majority of radionuclide mass. The $1 \times 10^{-16} \mathrm{~mol} / \mathrm{L}$ includes both the sorbed and aqueous fractions of a single radionuclide (the associated aqueous concentration typically represents only a small fraction of that concentration). Thus, only those blocks that had a total radionuclide concentration $>10^{-16} \mathrm{~mol} / \mathrm{L}$ were considered in prescribing streamlines after $135 \mathrm{yr}$. The effect of this cutoff was examined with simple one-dimensional simulations and found to have little impact on radionuclide migration and mass balance.

\footnotetext{
5 For a discussion of matrix diffusion effects, see Appendices C and D and Section 7.4.

6 As described in Appendix C, the only viable way to include matrix diffusion in a transient (incremental) streamline simulation is to incorporate a computational intensive second dimension in each streamline calculation, along which diffusion occurs.
} 

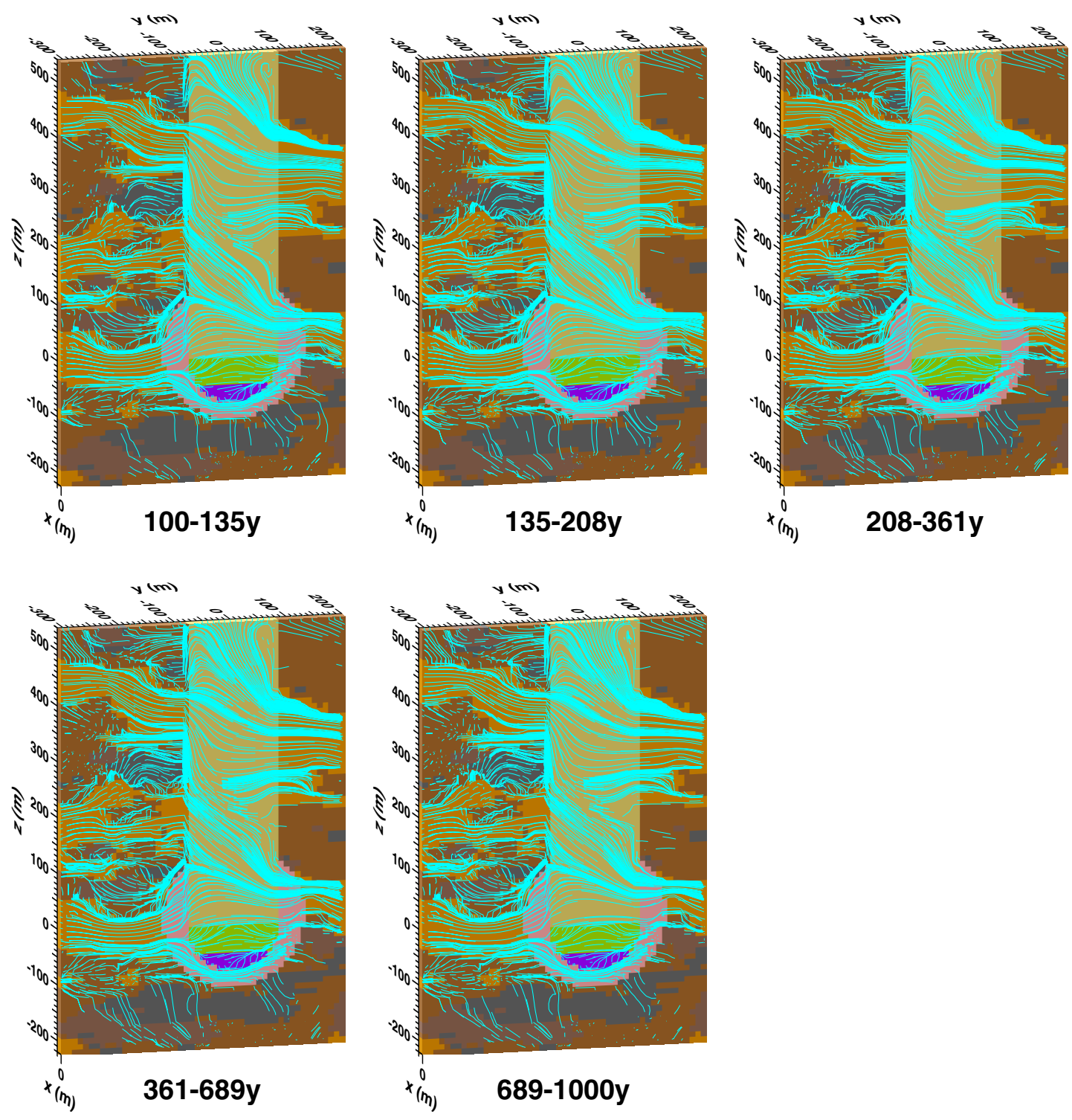

Figure 7.1 Perspective view of streamline locations along a one cell $(10 \mathrm{~m})$ wide $y$ - $z$ plane cross section for each time step of GIMRT reactive transport simulation. Streamlines weave in and out of this plane as a function of their 3-D path. Hydrofacies are shown as background.

\subsubsection{Tracer Radionuclides}

The streamline transport model was used to simulate transport of both tracers and chemically reactive radionuclide classes. Figure 7.2 shows cross-sectional views of simulated TracerGW, TracerMG, and TracerEV aqueous concentrations at 100, 135, 201, 361,689 , and $1000 \mathrm{yr}$ (times that bracket the flow field time steps). In Figure 7.2 and subsequent perspective cross-sectional views in Chapter 7 , distance units are meters relative to the working point, where $x, y$, and $z$ are the transverse, longitudinal, and vertical directions, respectively. The water table is situated at the top $(z=540 \mathrm{~m})$. The gray-shaded background represents different hydrofacies, with lighter shading 
representing higher permeability. The radionuclide distribution at $100 \mathrm{yr}$ represents the initial condition for the streamline transport model derived from particle simulations. The behavior of these tracer classes is not representative of any one radionuclide, but their fractional contributions can be used to model the reactive transport of a variety of radionuclides (see Chapter 4 and discussion above). The TracerMG represents tracer that is initially distributed solely in the melt glass; its release is governed entirely by melt glass dissolution. The TracerEV represents tracer that is initially distributed within the entire exchange volume pore space but is absent from the melt glass zone pore space; its migration is not affected by melt glass dissolution. The TracerGW represents tracer that is initially distributed within the entire exchange volume pore space including the pore space of the melt glass zone; its migration is not affected by melt glass dissolution.

TracerGW (Figure 7.2, top row) represents tracer class defined by IAEA (1998a) as initially incorporated into gas and water fractions. In these CHESHIRE simulations, this tracer class was distributed in the water fractions of the exchange and melt glass volumes. At $100 \mathrm{yr}$ (Figure 7.2, top left), the particle simulation indicates that significant concentrations of TracerGW would be found primarily in lower-permeability zones (very low, low, and moderate permeability hydrofacies are described in Chapter 5). Some TracerGW may also continue to circulate in the chimney. Between 135 and $1000 \mathrm{yr}$, the streamline transport model indicates that the highest concentrations of TracerGW remain in the lower-permeability zones. Comparison of the $100 \mathrm{yr}$ plots derived from the particle model with the later plots derived from streamline simulations clearly indicates that the streamline transport model achieves a much higher resolution of concentration. However, the dispersion of TracerGW (as well as the other tracer classes) results, in part, from numerical dispersion in the GIMRT code. The particle model does not suffer from numerical dispersion. ${ }^{1}$ The streamline transport model resolves the slow advective transport of all three tracer classes from the lowerpermeability zones out into the high-permeability zones. This is an important process to consider for prediction of a near-field source term over long periods. TracerEV (Figure 7.2 , bottom row) represents tracer originating from the pore space of the exchange volume excluding the glass zone. Because its distribution is nearly identical, the behavior of TracerEV is very similar to TracerGW.

TracerMG (Figure 7.2, middle row) represents tracer originating from dissolution of melt glass. The initial concentration at $100 \mathrm{yr}$ shows no concentration in the melt glass region because the particle model cannot resolve these low concentrations. However, at $135 \mathrm{yr}$, the streamline model resolves the $\sim 10^{-10} \mathrm{~mol} / \mathrm{L}$ plume that flows from the glass zone to the downstream boundary. The relatively constant TracerMG concentration from 135 to $1000 \mathrm{yr}$ indicates that glass dissolution has reached a relatively steady state. This is expected because the temperature in the glass zone (as well as the flow field) is nearly constant (ambient) over this period. Similar to TracerGW, the initial concentrations of TracerMG are highest in the lowerpermeability zones. Numerical dispersion along with slow advection from the lowerpermeability zones results in a broad plume that slowly migrates to the downstream boundary.

\footnotetext{
${ }^{1}$ Particle model simulations were run without a hydrodynamic dispersion term. The effect of hydrodynamic dispersion on the particle simulations is shown in Section 7.4.
} 

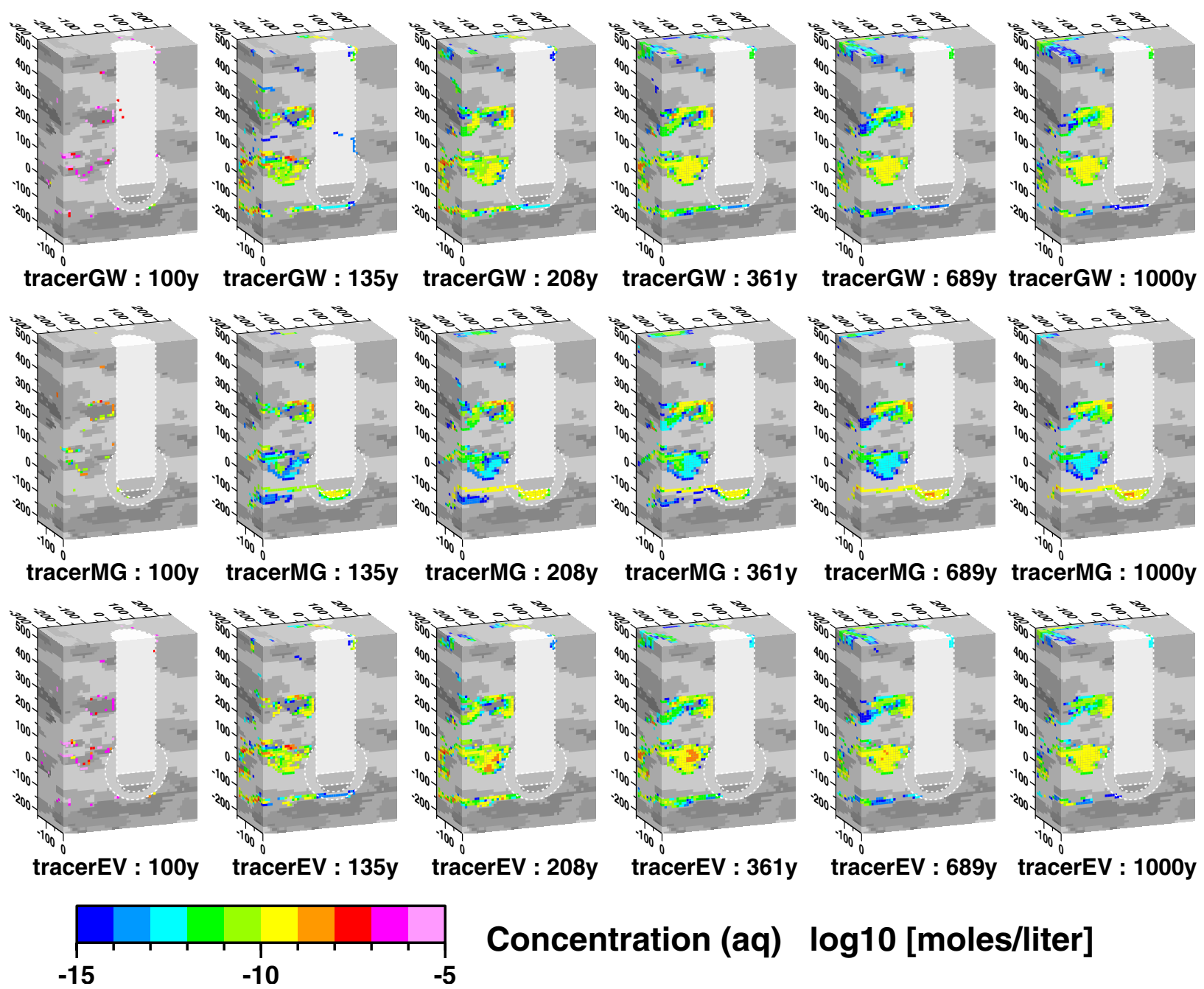

Concentration (aq) $\log 10$ [moles/liter]

Figure 7.2 Perspective cross-sectional views of tracer concentrations over time (100-1000 yr) from GIMRT streamline simulations for different radionuclide tracer classes: TracerGW, TracerMG, and TracerEV. Initial concentrations at $100 \mathrm{yr}$ are obtained from particle simulations.

\subsubsection{Reactive Radionuclides}

Both the GIMRT streamline and particle transport models can yield information on total and aqueous radionuclide concentrations. However, the GIMRT streamline model employs a mechanistic geochemical approach such that individual aqueous species concentrations, sorbed species concentrations, and other geochemical information can be examined. Here, we discuss only two sets of information: aqueous concentrations and total (aqueous+sorbed) concentrations. Aqueous concentrations are more directly relevant than total concentrations for prediction of the near-field source term because aqueous concentrations represent the mobile fraction of radionuclides. Nonetheless, knowledge of both the aqueous and total concentrations is useful to gain an understanding of the reactive transport processes. 
Figures 7.3(a) and 7.3(b) show cross-sectional views of total (aqueous + sorbed) concentrations of $\mathrm{Am},{ }^{41} \mathrm{Ca}, \mathrm{Cs}, \mathrm{Eu}, \mathrm{Np}, \mathrm{Pu},{ }^{241} \mathrm{Pu}, \mathrm{Sm}, \mathrm{Sr}$, and $\mathrm{U}$ radionuclide classes as simulated by the transient streamline transport model. The gray-shaded background represents different hydrofacies, with lighter shading representing higher permeability. As in the case of the three tracers discussed earlier, the $100 \mathrm{yr}$ concentrations represent initial concentrations obtained from particle simulations of radionuclide distribution at $100 \mathrm{yr}$.

Figures 7.4(a) and 7.4(b) show cross-sectional views of aqueous concentrations of $\mathrm{Am},{ }^{41} \mathrm{Ca}, \mathrm{Cs}, \mathrm{Eu}, \mathrm{Np}, \mathrm{Pu},{ }^{241} \mathrm{Pu}, \mathrm{Sm}, \mathrm{Sr}$, and $\mathrm{U}$ radionuclide classes as simulated by the transient streamline transport model. Note that aqueous concentrations in melt glass at $100 \mathrm{yr}$ are not accurate as shown in Figures 7.4(a) and 7.4(b). This is a result of practical differences between implementing melt glass dissolution in the particle and transient streamline transport models. For additional information regarding the implementation of melt glass dissolution in the particle model, see Appendix D.

Compared with tracers (Figure 7.2), the total concentrations of the reactive radionuclide classes are affected by their sorption to reactive minerals. As a result, the spatial distribution of reactive minerals significantly affects migration. Patches of radionuclides that persist in high-permeability zones are likely associated with patches of high concentrations of reactive minerals. The spatial distribution of reactive radionuclides at $100 \mathrm{yr}$ primarily results from

- Large-scale changes in permeabilities of hydrofacies.

- Retardation by chemically reactive mineralization zones (smectite, calcite, zeolite, and hematite zones).

- Dissolution of melt glass.

A small amount of radionuclides may appear to have delayed transport behavior as a result of recirculation in the chimney. A relatively small but obvious accumulation of all radionuclides shown in Figures 7.3(a) and 7.3(b) is present in the lower cavity at $100 \mathrm{yr}$, which subsequently provides a limited source for down-gradient transport in the streamline transport model. Concentrations in the melt glass are built up over time by the streamline transport model according to the melt glass dissolution model. 

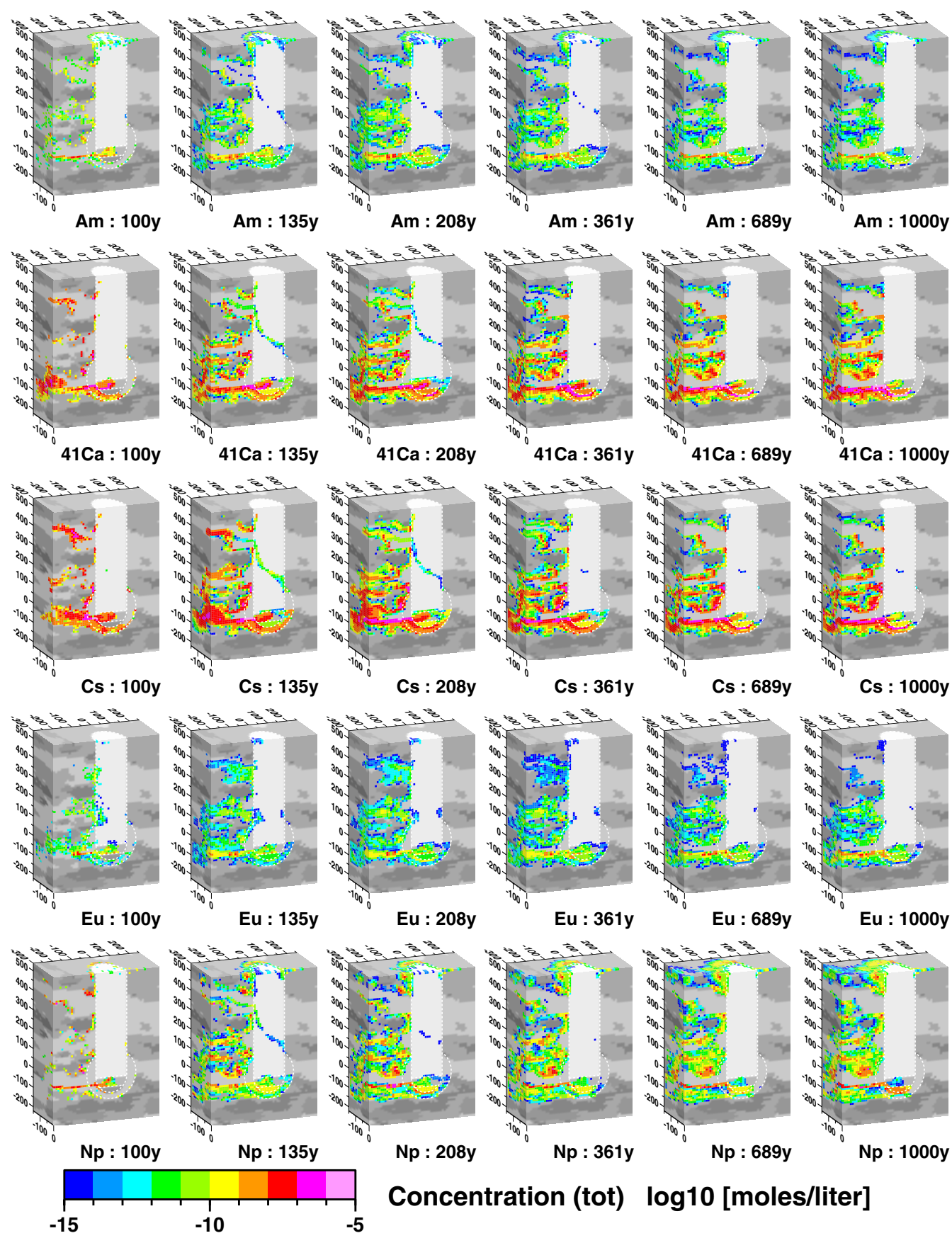

Concentration (tot) $\log 10$ [moles/liter]

Figure 7.3(a) Perspective cross-sectional views of GIMRT transient streamline simulations of total concentration over time (100-1000 yr): Am, ${ }^{41} \mathrm{Ca}, \mathrm{Cs}$, Eu, and $\mathrm{Np}$ radionuclide classes. Initial concentrations at $100 \mathrm{yr}$ are obtained from particle simulations. 

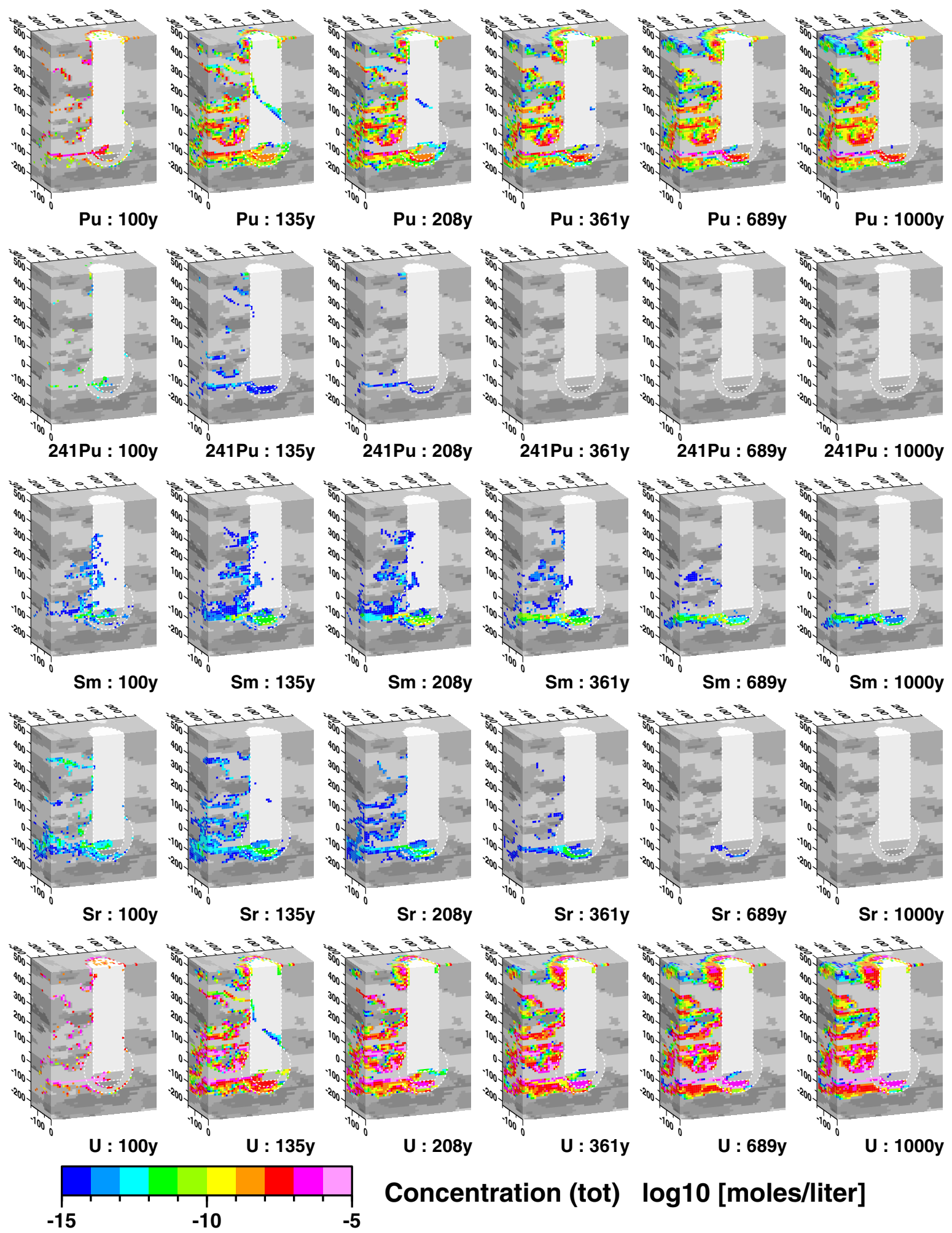

Concentration (tot) $\log 10$ [moles/liter]

Figure 7.3(b) Perspective cross-sectional views of GIMRT transient streamline simulations of total concentration over time $(100-1000 \mathrm{yr}): \mathrm{Pu},{ }^{241} \mathrm{Pu}, \mathrm{Sm}, \mathrm{Sr}$, and $\mathrm{U}$ radionuclide classes. Initial concentrations at $100 \mathrm{yr}$ are obtained from particle simulations. 

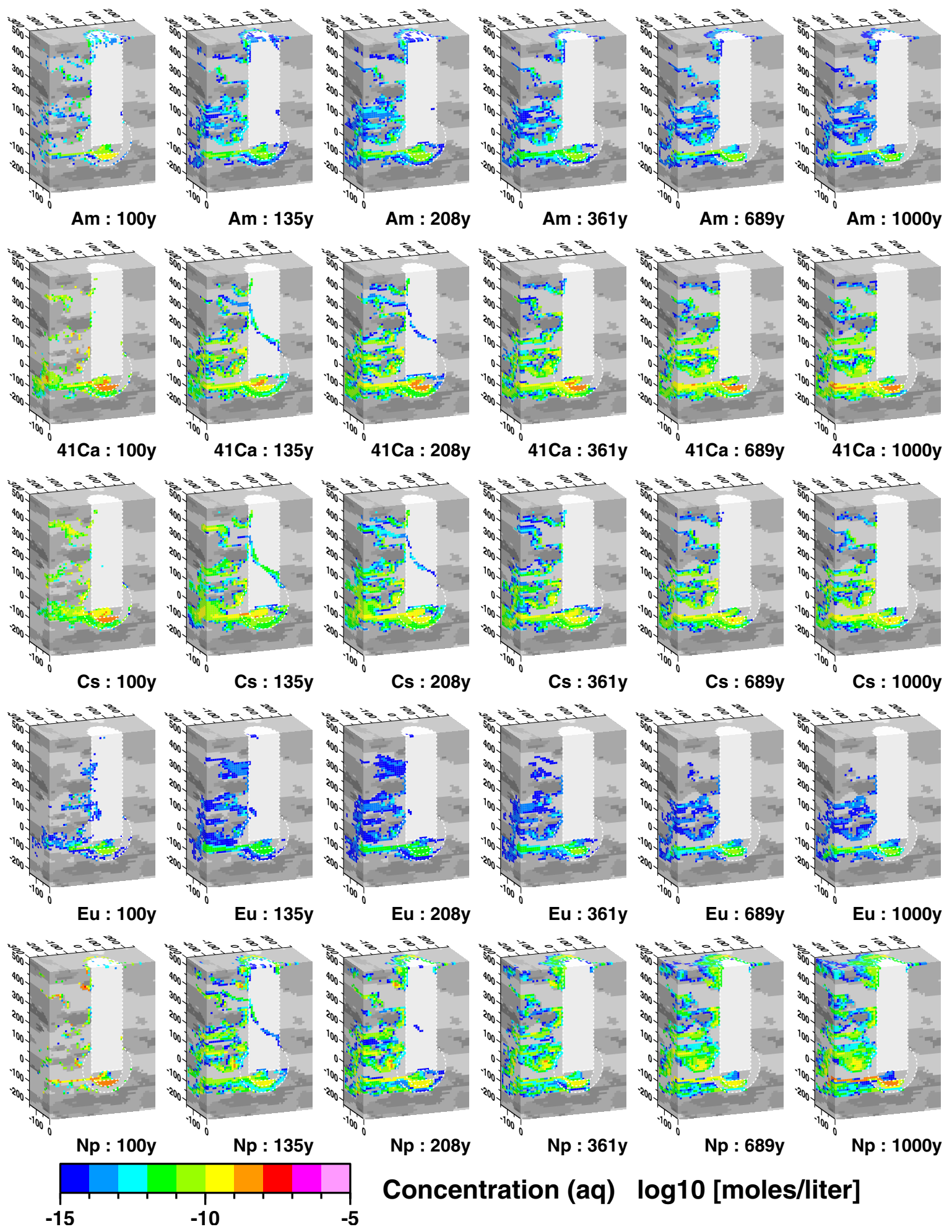

Concentration (aq) $\log 10$ [moles/liter]

Figure 7.4(a) Perspective cross-sectional views of GIMRT transient streamline simulations of aqueous concentration over time (100-1000 yr): Am, ${ }^{41} \mathrm{Ca}, \mathrm{Cs}$, Eu, and $\mathrm{Np}$ radionuclide classes. Initial concentrations at $100 \mathrm{yr}$ are obtained from particle simulations. 

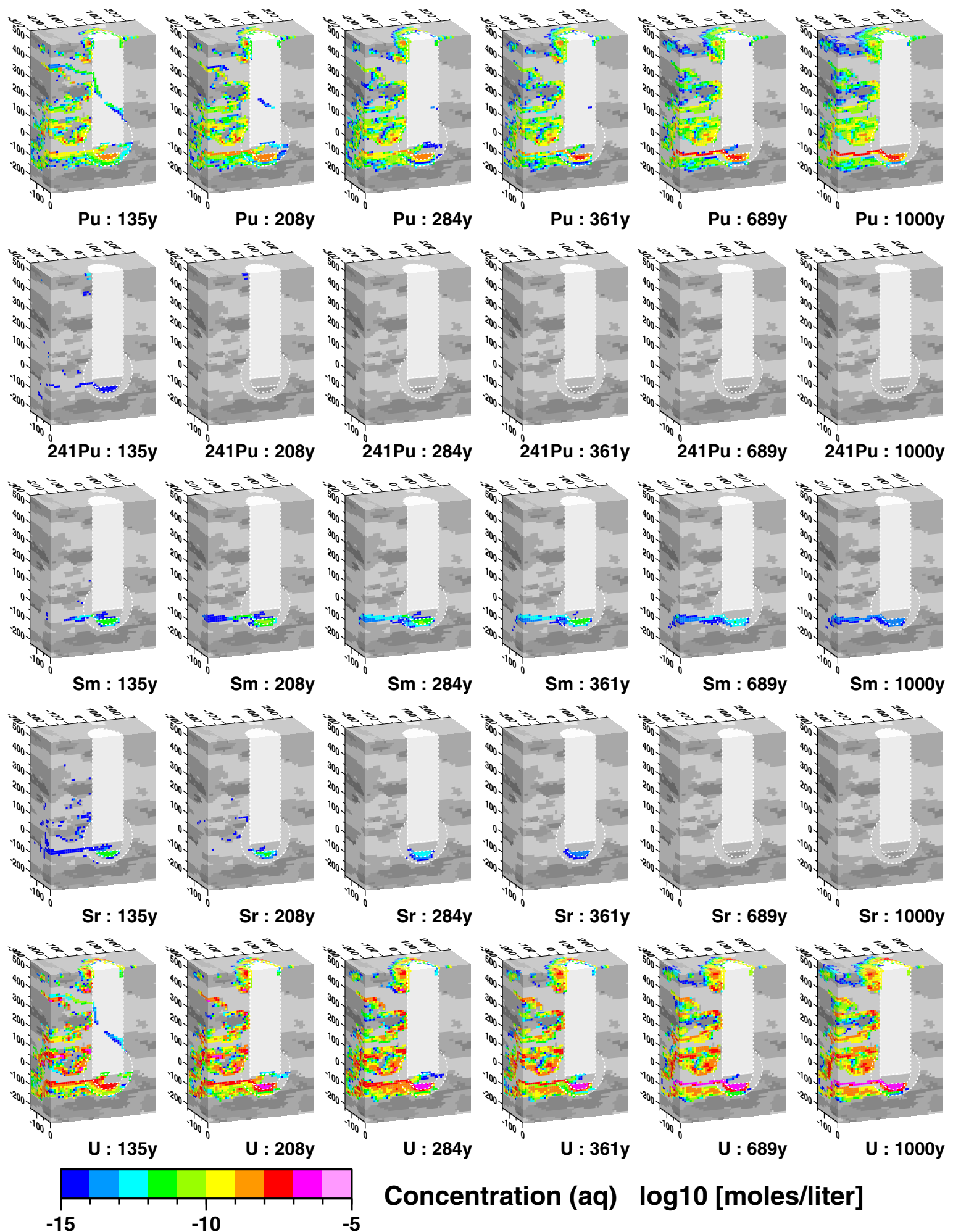

Concentration (aq) $\log 10$ [moles/liter]

Figure 7.4(b) Perspective cross-sectional views of GIMRT transient streamline simulations of aqueous concentration over time $(100-1000 \mathrm{yr}): \mathrm{Pu},{ }^{241} \mathrm{Pu}, \mathrm{Sm}, \mathrm{Sr}$, and $\mathrm{U}$ radionuclide classes. Initial concentrations at $100 \mathrm{yr}$ are obtained from particle simulations. 
It is instructive to examine the migration of the radionuclides classes by further grouping them by their expected behavior, while examining transport behavior exhibited in Figures 7.3(a) and 7.3(b):

- Am, Eu, and Sm are expected to behave similarly because they are classes of trivalent cations that sorb strongly to all minerals that participate in surface complexation in our geochemical model. However, Sm is decaycorrected in Figure 7.3(b), Am decays slowly and grows in as ${ }^{241} \mathrm{Pu}$ decays, and $\mathrm{Eu}$ is not decay-corrected in Figure 7.3(a).

- $\quad \mathrm{Np}, \mathrm{U}$, and Pu are expected to migrate relatively similarly and much faster than the trivalent cation classes. ${ }^{241} \mathrm{Pu}$ behaves as $\mathrm{Pu}$ but decays rather quickly.

- ${ }^{41} \mathrm{Ca}$ and $\mathrm{Sr}$ will behave similarly in that their ion exchange process is similar but $\mathrm{Sr}$ also sorbs by surface complexation to iron oxides. Sr is decay corrected in Figure 7.3(b).

- Cs is expected to migrate quite slowly and unlike other radionuclides. Its migration is controlled largely by mica, which is homogeneously distributed in matrix materials of the near-field model.

The distribution of Am and Eu in Figure 7.3(a) is quite similar. However, Am is flushed from the uppermost high-permeability zone somewhat more quickly than Eu (see 361 yr plots). From Table K.9, one finds that Eu sorbs more strongly in the chimney and high-permeability zones, while Am sorbs more strongly in the lower-permeability zones. This is consistent with Figure 7.3(a) in which Am resides largely in the lowerpermeability zones while small quantities of Eu remain in the chimney and highpermeability zones out to 1000 yr. While the distribution of Sm is consistent with that of Eu and Am at 100 yr, decay reduces its distribution to a plume originating solely from the melt glass zone at $1000 \mathrm{yr}$.

The behavior of $\mathrm{Np}, \mathrm{Pu}$, and $\mathrm{U}$ is difficult to distinguish at the coarse concentration scale presented in Figures 7.3(a) and 7.3(b). Average retardation factors listed in Table K.9 suggest that the retardation of these radionuclides should be quite similar. ${ }^{2}$ The topmost lower-permeability zone (the top face of the three-dimensional diagrams) clearly shows that the ability of $\mathrm{Np}, \mathrm{Pu}$, and $\mathrm{U}$ to migrate in the lowerpermeability zones is significantly greater than that of Am. This can also be observed in the aqueous concentration plots of Figures 7.4(a) and 7.4(b).

${ }^{241} \mathrm{Pu}$, with a half-life of $14 \mathrm{yr}$, decays very quickly. While some ${ }^{241} \mathrm{Pu}$ migrates out of the near field at early times, by $208 \mathrm{yr}$, the aqueous concentration of ${ }^{241} \mathrm{Pu}$ is essentially decayed to below $10^{-15} \mathrm{~mol} / \mathrm{L}$ in the near field. As such, its decay into ${ }^{241} \mathrm{Am}$ should be negligible beyond that time.

\footnotetext{
${ }^{2}$ Retardation in the GIMRT simulations is modeled by surface complexation and ion exchange. However, average retardation values presented in Table K.9 can be used as estimates of effective retardation factors.
} 
At $100 \mathrm{yr}$, the distribution of ${ }^{41} \mathrm{Ca}$ and $\mathrm{Sr}$ is relatively similar. However, the decay of $\mathrm{Sr}$ in the model quickly changes the distribution pattern of $\mathrm{Sr}$ compared with ${ }^{41} \mathrm{Ca}$. With a half-life of $29 \mathrm{yr}$, aqueous ${ }^{90} \mathrm{Sr}$ (the only isotope of the $\mathrm{Sr}$ radionuclide class) nearly drops below $10^{-15} \mathrm{~mol} / \mathrm{L}$ by $361 \mathrm{yr}$ (and certainly by $689 \mathrm{yr}$ ). Although the ${ }^{41} \mathrm{Ca}$ radionuclide class (containing only ${ }^{41} \mathrm{Ca}$ ) was not decay-corrected in these plots, its halflife is $\sim 10,000 \mathrm{yr}$; its distribution would be essentially unchanged with decay correction.

Figure 7.5 shows close-up, three-dimensional perspective views of aqueous radionuclide concentrations near and down-gradient of the melt glass at 135, 201, 284, 361,689 , and $1000 \mathrm{yr}$ (melt glass zone is at the right end of each figure, most easily seen in the "Sr:361y" plot). These concentration plumes allow a close examination of the evolution of the reactive transport simulation of radionuclides derived from dissolution of the melt glass. The evolution of the melt glass plume warrants close inspection because it may provide the largest long-term source of radionuclides. There is additional complexity in the spatial distribution of concentration in these plumes caused by the hydraulic and mineralogic heterogeneity in the model. Am and Cs radionuclide classes exhibit steady concentration behavior, while ${ }^{41} \mathrm{Ca}, \mathrm{Eu}, \mathrm{Np}, \mathrm{Pu}$, and $\mathrm{U}$ exhibit gradual increases in melt glass plume concentrations over time. ${ }^{241} \mathrm{Pu}, \mathrm{Sr}$, and, to a lesser extent, Sm display the effects of radioactive decay.

Figures 7.6(a) and 7.6(b) show cross-sectional views of $\mathrm{Am},{ }^{41} \mathrm{Ca}, \mathrm{Cs}, \mathrm{Eu}, \mathrm{Np}$, $\mathrm{Pu},{ }^{241} \mathrm{Pu}, \mathrm{Sm}, \mathrm{Sr}$, and $\mathrm{U}$ radionuclide class concentrations at the breakthrough plane (located $300 \mathrm{~m}$ down-gradient from the CHESHIRE test). These views are useful for understanding where breakthrough is actually occurring. In turn, this understanding can help identify the relative importance of various processes affecting radionuclide migration. These cross-sectional views emphasize the fact that the interaction of multiple geologic, hydraulic, thermal, and chemical processes produce a complex distribution of radionuclide flux at the breakthrough plane. The complex areal distributions of radionuclide flux at the breakthrough plane are integrated into predictions of the near-field source term in Section 7.5. 


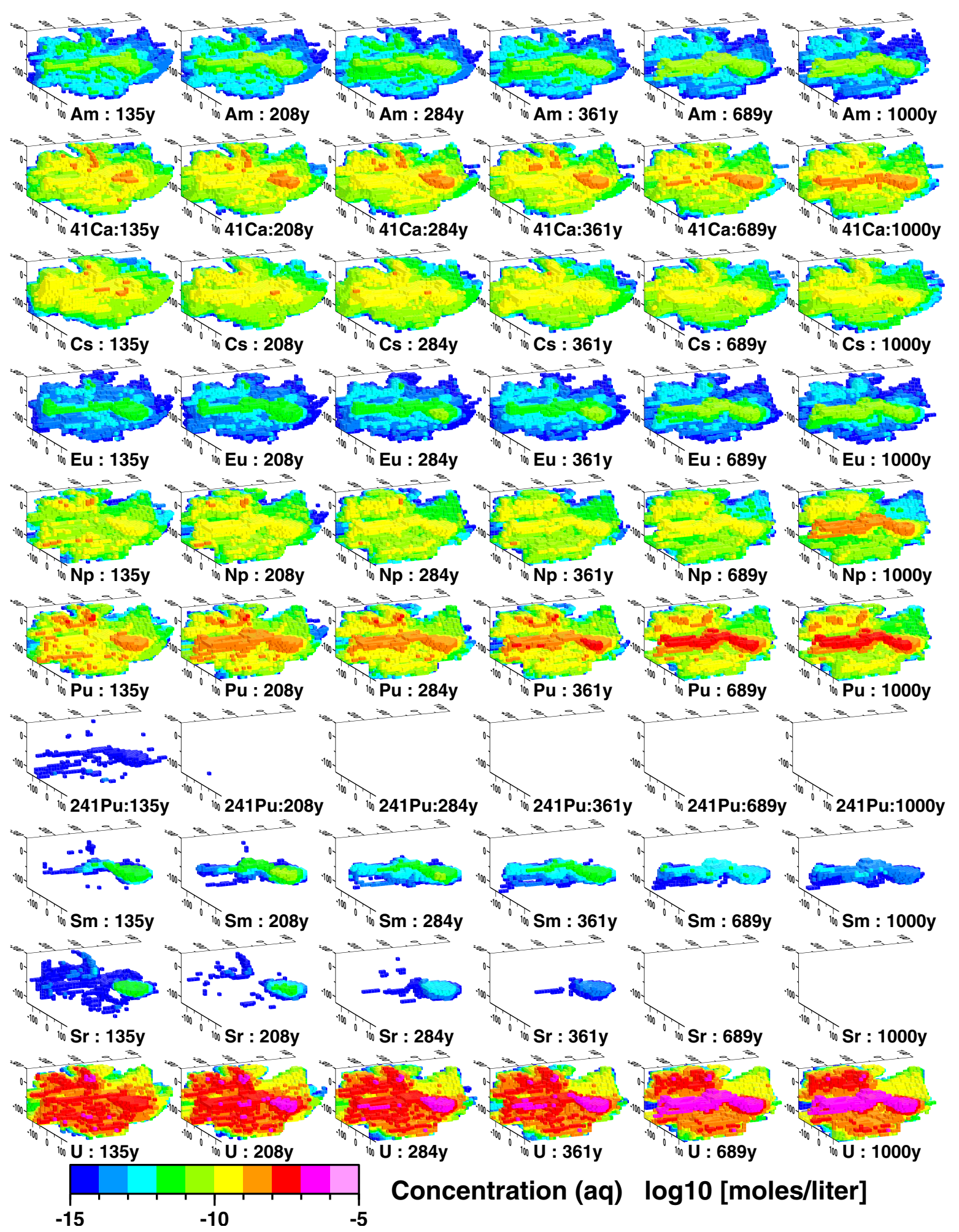

Figure 7.5 Perspective views of GIMRT transient streamline simulations of radionuclide aqueous concentrations near and down-gradient from melt glass. 


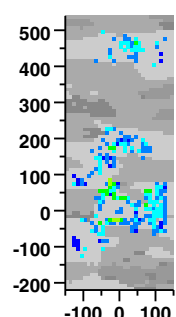

Am : 100y

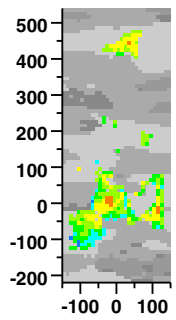

41Ca : 100y

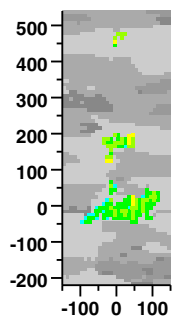

Cs : $100 y$

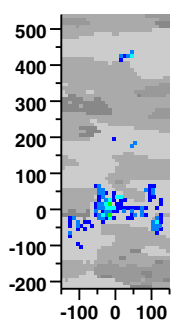

Eu : 100y

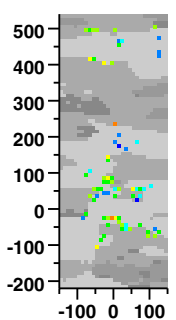

$\mathrm{Np}: \mathbf{1 0 0 y}$

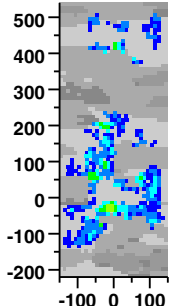

Am : 135y

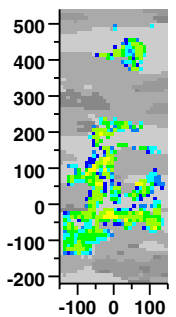

41Ca : 135y

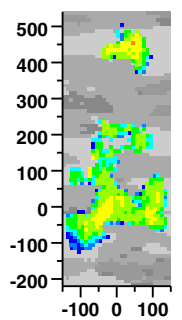

Cs : 135y

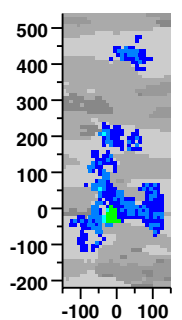

Eu : 135y

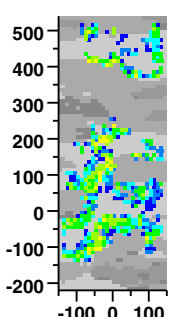

Np : $135 y$

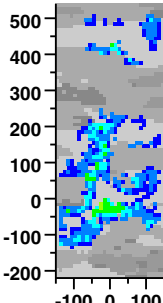

Am : 208y

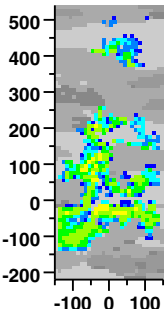

$41 \mathrm{Ca}: 208 \mathrm{y}$

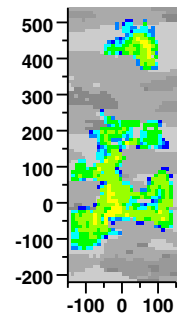

Cs : 208y

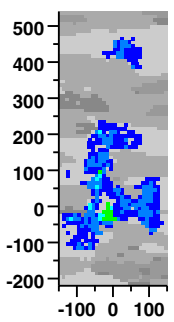

Eu : 208y

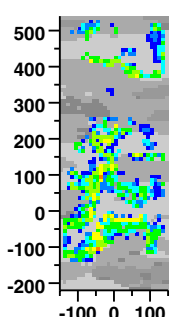

Np : 208y

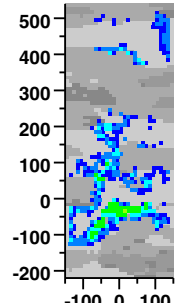

Am : 361y

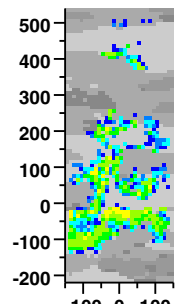

$41 \mathrm{Ca}: 361 \mathrm{y}$

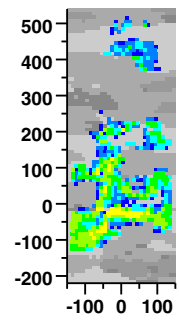

Cs : $361 y$

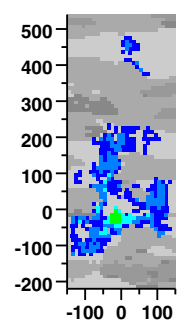

Eu : 361y

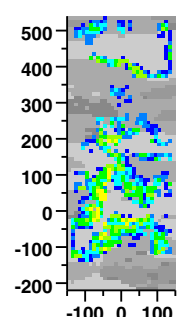

$\mathrm{Np}: 361 \mathrm{y}$
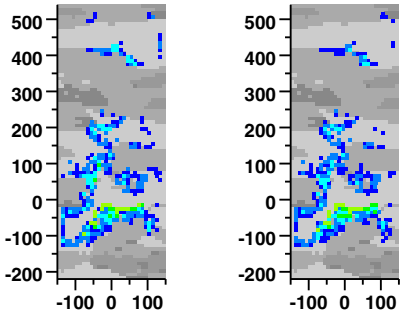

Am : 689y

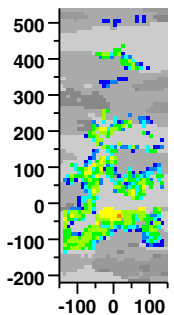

Am : 1000y

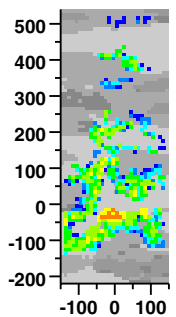

$41 \mathrm{Ca}: 689 \mathrm{y} \quad 41 \mathrm{Ca}: 1000 \mathrm{y}$
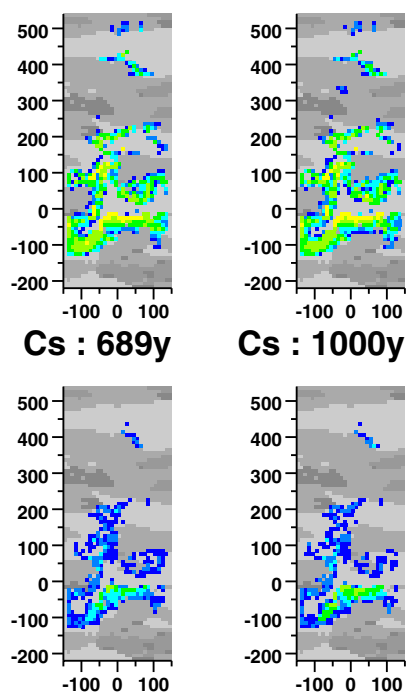

Eu : $689 y$

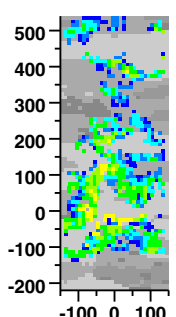

$\mathrm{Np}: 689 \mathrm{y}$

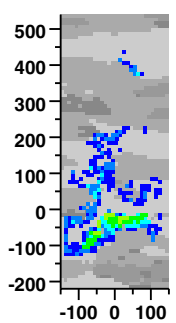

Eu : 1000y

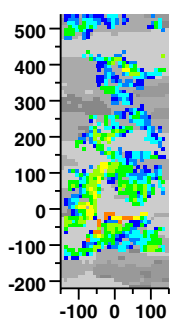

Np : 1000y

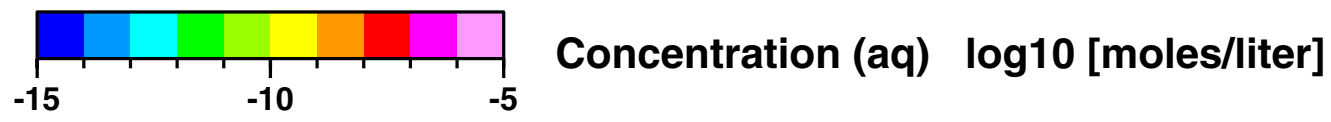

Figure 7.6(a) Cross-sectional view at breakthrough plane showing GIMRT transient streamline simulations of aqueous concentration over time (100-1000 yr): Am, ${ }^{41} \mathrm{Ca}, \mathrm{Cs}$, $\mathrm{Eu}$, and $\mathrm{Np}$ radionuclide classes. Initial concentrations at $100 \mathrm{yr}$ are obtained from particle simulations. 

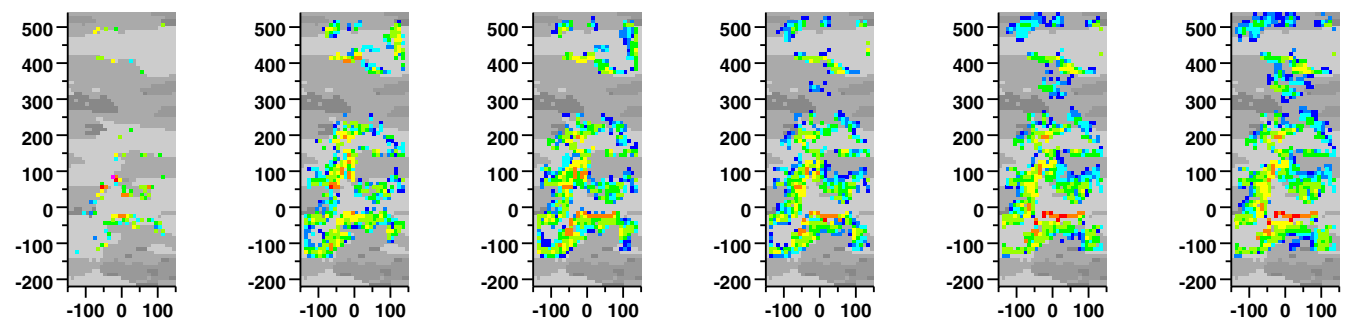

Pu : 100y

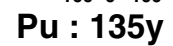

Pu : 208y

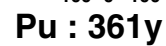

Pu : 689y

Pu : 1000y
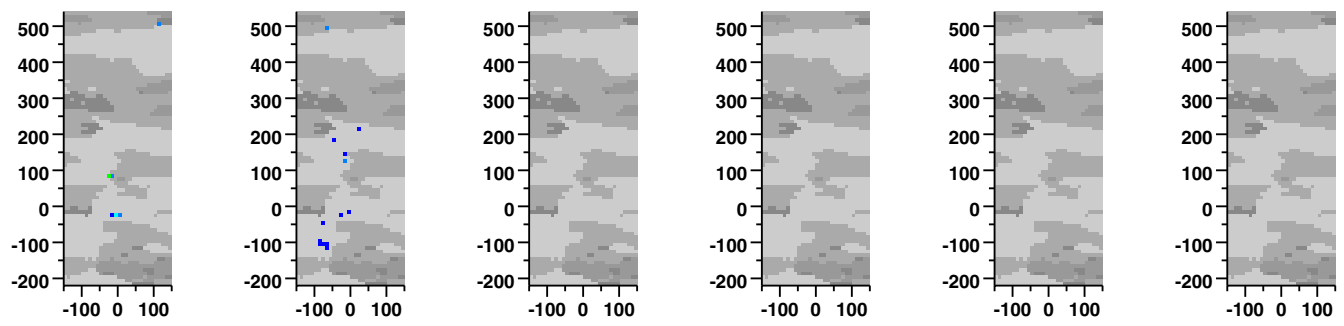

241Pu:100y

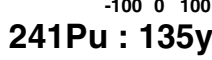

241Pu : 208y

241Pu : 361y
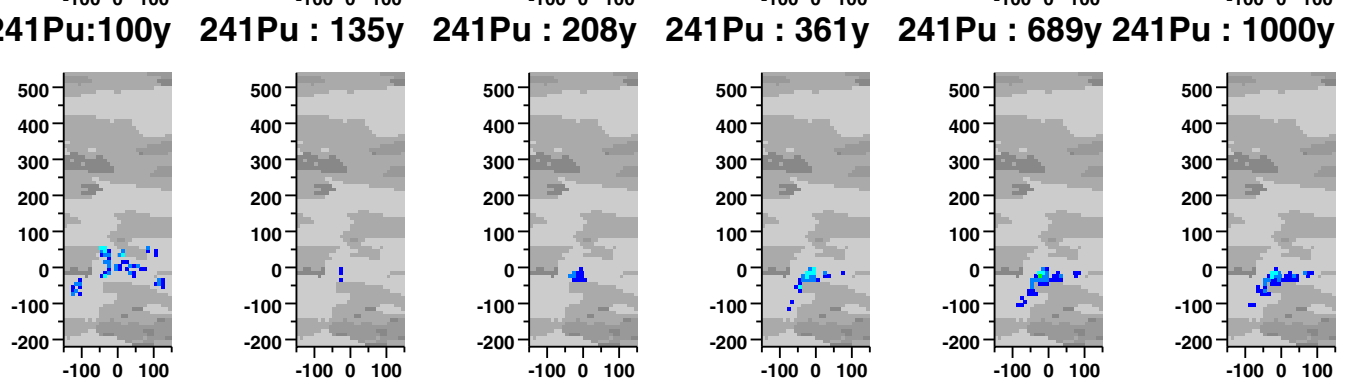

Sm : 100y

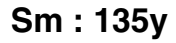

Sm : 208y

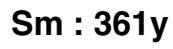

Sm : 689y
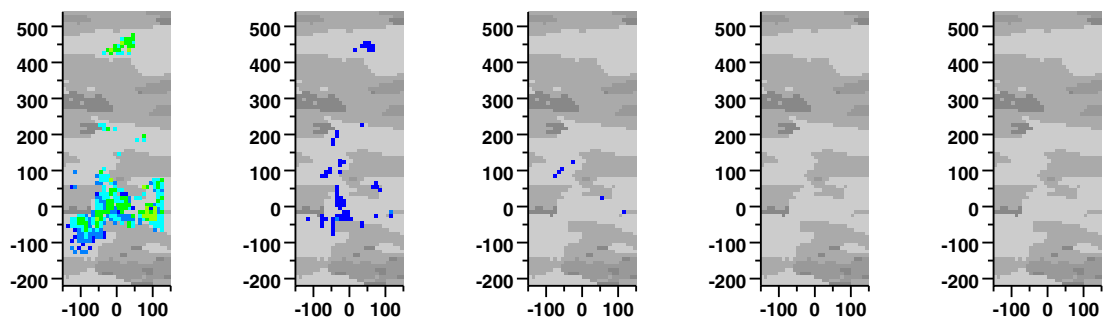

Sm : 1000y
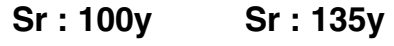

Sr : 208y
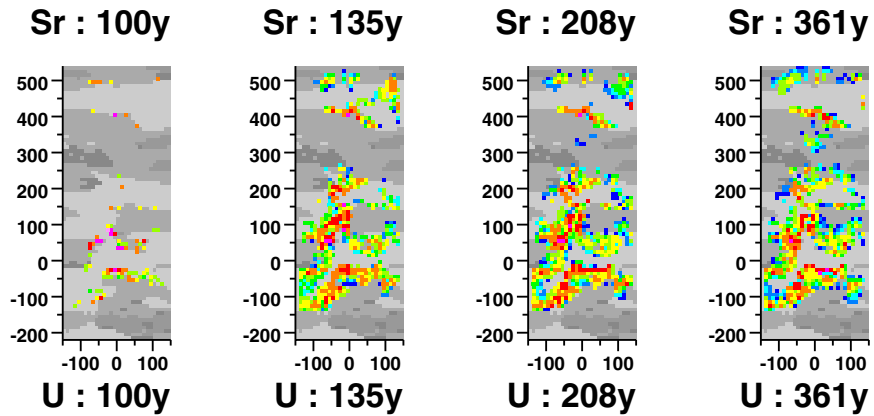

Sr: $689 y$
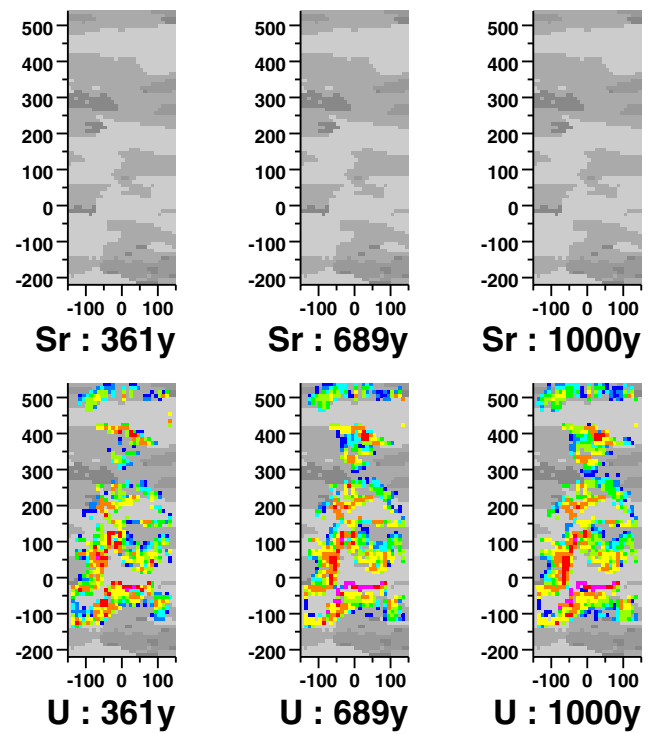

Sr: 1000y

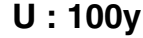

U : 135y

\section{Concentration (aq)}

$-15$

$-10$

$-5$

Figure 7.6(b) Cross-sectional view at breakthrough plane showing GIMRT transient streamline simulations of aqueous concentration over time (100-1000 yr): $\mathrm{Pu},{ }^{241} \mathrm{Pu}, \mathrm{Sm}, \mathrm{Sr}$, and $\mathrm{U}$ radionuclide classes. Initial concentrations at $100 \mathrm{yr}$ are obtained from particle simulations. 
The GIMRT transient streamline simulations show that nearly all radionuclide classes exhibit a contaminant plume moving laterally from the melt glass zone into the nearest high-permeability zone and toward the downstream boundary. This is evident by high concentrations of radionuclides tending to occur slightly below the elevation of the working point of the CHESHIRE test (at a $z$ coordinate of 0 , Figures 7.6(a) and 7.6(b)). ${ }^{241} \mathrm{Pu}$ and Sr breakthrough is negligible for most of the time because these radionuclides have a short half-life and were decay-corrected during the simulation. After $100 \mathrm{yr}$, very little vertical groundwater flow and, subsequently, vertical transport of radionuclides occurs. Groundwater tends to flow laterally. However, significant vertical groundwater flow as a result of test-related heat had occurred at earlier times, which transported radionuclides to the upper highpermeability zones. Because radionuclide mass in the uppermost high-permeability zone is not being replenished by vertical groundwater flow at later times, radionuclide concentrations decrease between 100 and 1000 yr. At 1000 yr, some U, Np, and Pu remains in the uppermost lower-permeability zones, but $\mathrm{Am},{ }^{41} \mathrm{Ca}, \mathrm{Cs}$, and Eu are largely absent. $\mathrm{U}, \mathrm{Np}$, and $\mathrm{Pu}$ are trapped within lower-permeability zones and are slowly being released.

The breakthrough plane cross-sectional views of aqueous radionuclide concentrations at 135, 208, 361, 689, and $1000 \mathrm{yr}$ as determined by the GIMRT transient streamline transport model offer better resolution of concentration than the particle transport model. The GIMRT transient streamline transport modeling results strongly reinforce an interpretation that long-term radionuclide transport out of the near field could occur as a result of the following processes:

- Down-gradient migration of plumes originating from dissolution of melt glass.

- Slow leaching of radionuclides out of the lower-permeability zones and back to the high-permeability zones.

- Chemical reactivity, causing retardation of transport behavior.

- Recirculation of transport pathways in the chimney as a result of testrelated heat.

The breakthrough plane cross-sectional views also provide a spatial reference for interpreting the processes that contribute to the estimation of radionuclide molar flux out of the near-field domain (Section 7.2.5). 


\subsubsection{Major Elements}

Figures 7.7(a) and 7.7.(b) show cross-sectional views of total aqueous concentrations of the following major and minor groundwater components- $\mathrm{Al}, \mathrm{Ca}, \mathrm{Cl}$, $\mathrm{Fe}, \mathrm{HCO}_{3}, \mathrm{~K}, \mathrm{Mg}, \mathrm{Na}, \mathrm{SiO}_{2}$, and $\mathrm{SO}_{4}$. The aqueous speciation of these components is not shown. Because the GIMRT transient streamline model considers mechanistic geochemical models of aqueous speciation, radionuclide sorption, and mineral dissolution/precipitation, one can examine the effects of glass dissolution and radionuclide reactions on the water chemistry of the near-field environment, and vice versa, as discussed in Appendix I.

In general, the groundwater composition does not vary greatly in the 100 to $1000 \mathrm{yr}$ span when the thermal pulse has dissipated. ${ }^{3}$ Therefore, changes in groundwater composition do not drastically alter the sorptive properties of the rhyolitic lavas. However, changes in $\mathrm{pH}$ caused by reactions in the glass zone do affect the sorptive properties of the medium. Between 100 and $1000 \mathrm{yr}$, the $\mathrm{pH}$ in the glass zone decreases to 8 , owing to secondary mineral precipitation, but the $\mathrm{pH}$ downstream of the glass increases to about 8.5, owing to dissolution of fracture-lining calcite. This change in $\mathrm{pH}$ alters the sorptive properties of the minerals along the flow path. The complex geochemistry along streamlines is discussed in Appendix I based on single streamline calculations.

The concentrations of $\mathrm{Na}, \mathrm{K}, \mathrm{Ca}, \mathrm{Mg}$, and Fe are affected by a combination of glass dissolution and mineral precipitation/dissolution both in the glass zone and in the rhyolitic lavas downstream of the glass. Ca concentration in the glass zone decreases as the result of clay and zeolite precipitation. The decrease in $\mathrm{Ca}$ is carried downstream, but is then buffered by ion exchanging minerals and the dissolution of fracture-lining calcite caused by the comparatively low $\mathrm{pH}$ of the water. The dissolution of calcite results in a slight increase in $\mathrm{HCO}_{3}$ concentration downstream of the glass zone. The $\mathrm{Mg}$ concentration decreases significantly in the glass zone because of montmorillonite precipitation. Montmorillonite is a Mg-rich end member of the 2:1 layered smectite clays. Based on natural analogs, we do not expect the $\mathrm{Mg}$ concentration to decrease to this extent; the discrepancy may result, in part, from our simplified treatment of compositional variability in clays. Fe concentrations increase in the glass zone because $\mathrm{Fe}$ is released by the dissolution of melt glass. Some of the Fe precipitates as Fe-rich nontronite, but nontronite precipitation does not keep pace with the rate of glass dissolution. $\mathrm{SiO}_{2}$ exhibits a small increase in concentration with depth, which is directly attributable to the temperature dependence of $\alpha$-cristobalite solubility. $\mathrm{Cl}$ and $\mathrm{SO}_{4}$ concentrations do not participate in reactions in the GIMRT model and are not included in our simulated melt glass. Thus, their concentrations are unchanged.

\footnotetext{
${ }^{3}$ Locations in Figures 7.7(a) and 7.7(b) that do not contain color, but remain shaded according to permeability, are regions where streamlines are not present.
} 

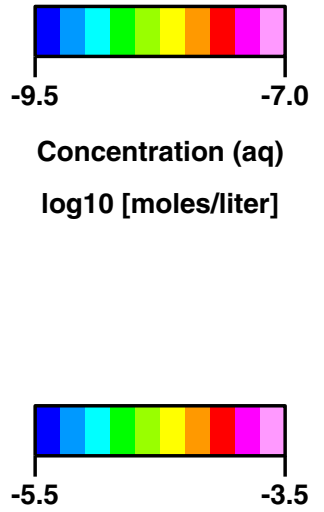

Concentration (aq) $\log 10$ [moles/liter]

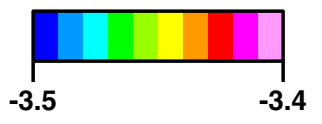

Concentration (aq) $\log 10$ [moles/liter]

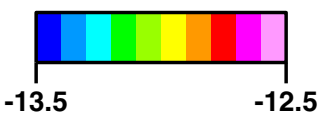

Concentration (aq) $\log 10$ [moles/liter]

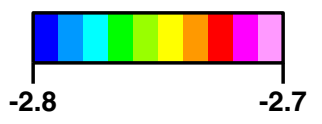

Concentration (aq) log10 [moles/liter]
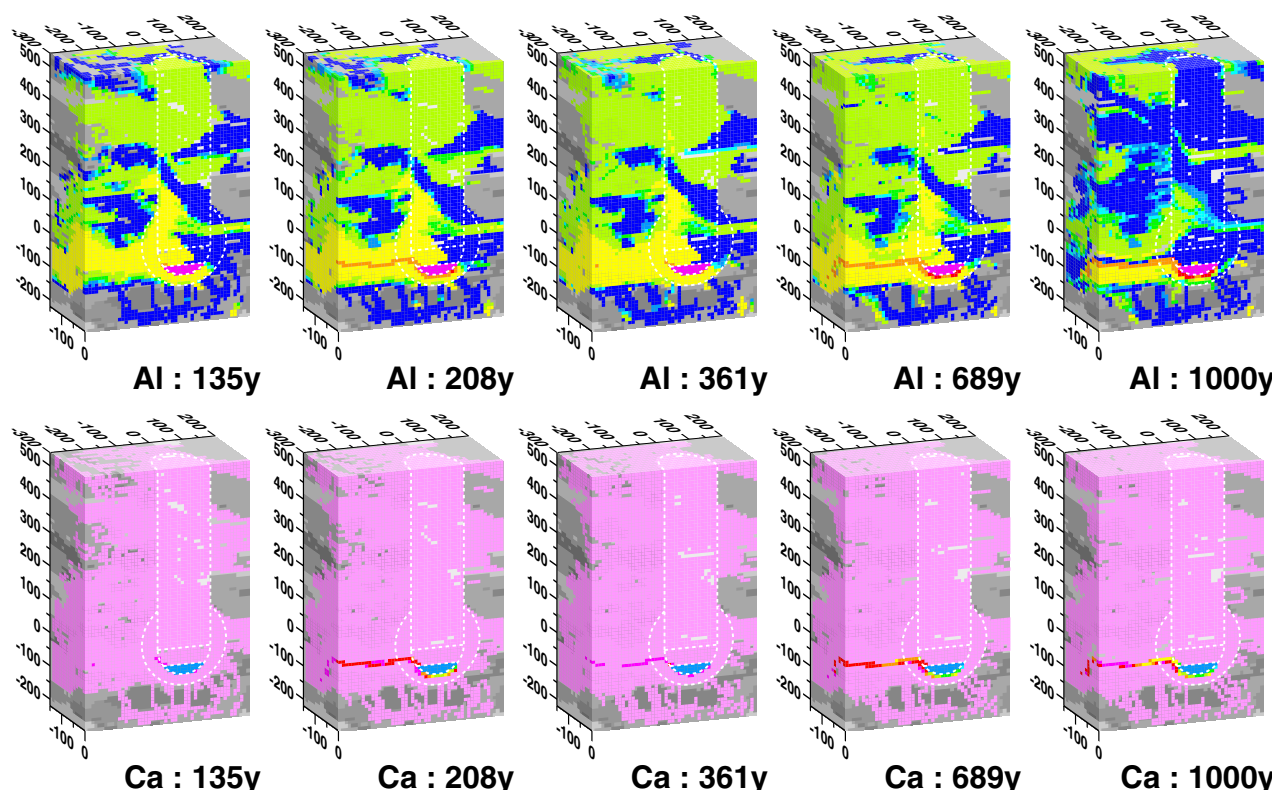

Ca : $135 y$
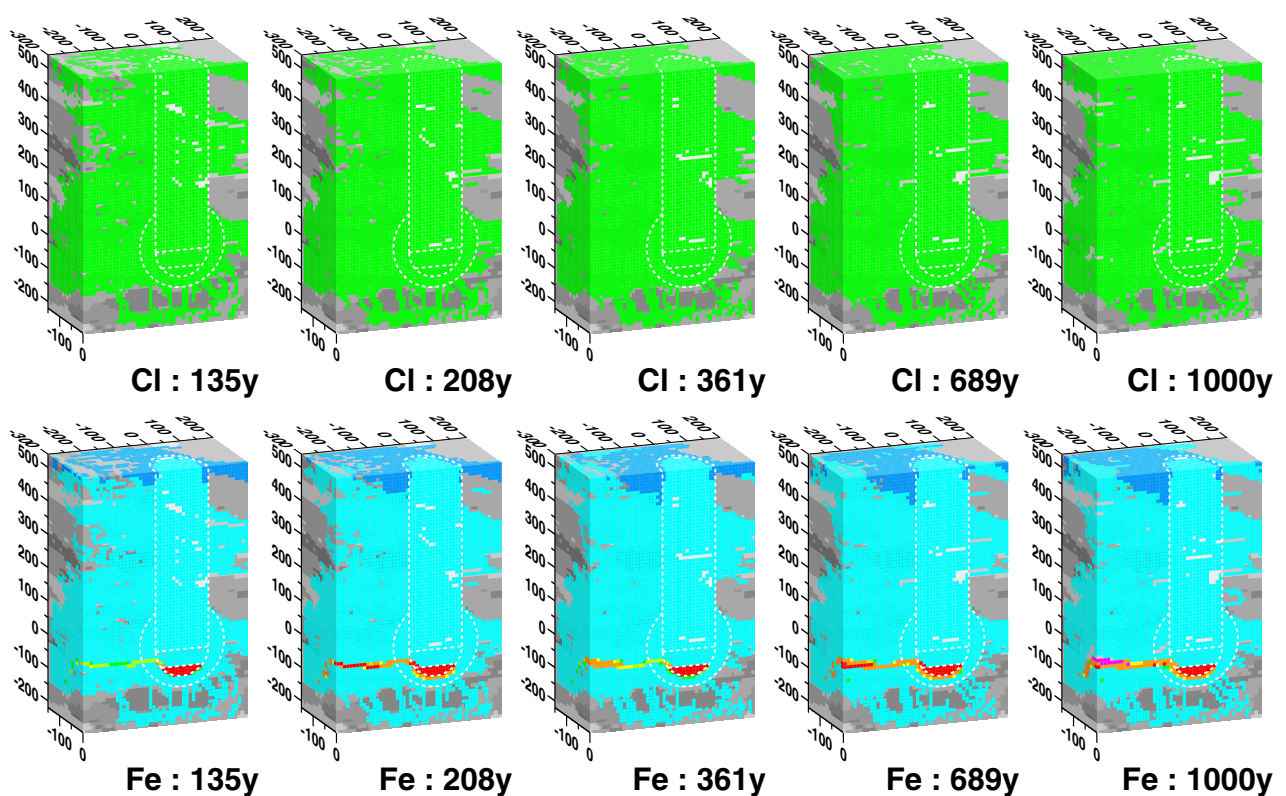

$\mathrm{Fe}: 135 \mathrm{y}$
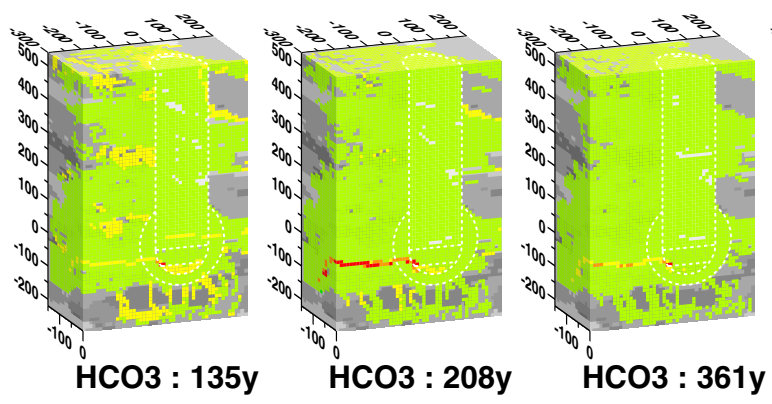

$\mathrm{Fe}: 689 \mathrm{y}$

Fe : 1000y
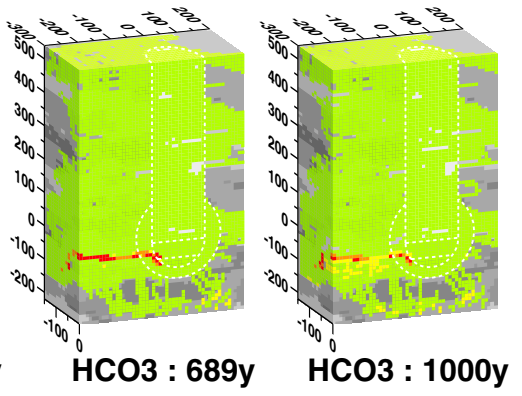

Figure 7.7(a) Perspective cross-sectional views of GIMRT transient streamline simulations of $\mathrm{Al}, \mathrm{Ca}$, $\mathrm{Cl}, \mathrm{Fe}$, and $\mathrm{HCO}_{3}$ aqueous concentrations. Uncolored regions are not crossed by streamlines. 


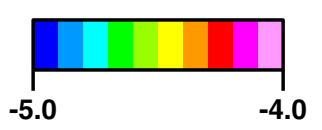

Concentration (aq) $\log 10$ [moles/liter]

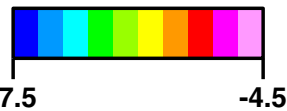

Concentration (aq) $\log 10$ [moles/liter]
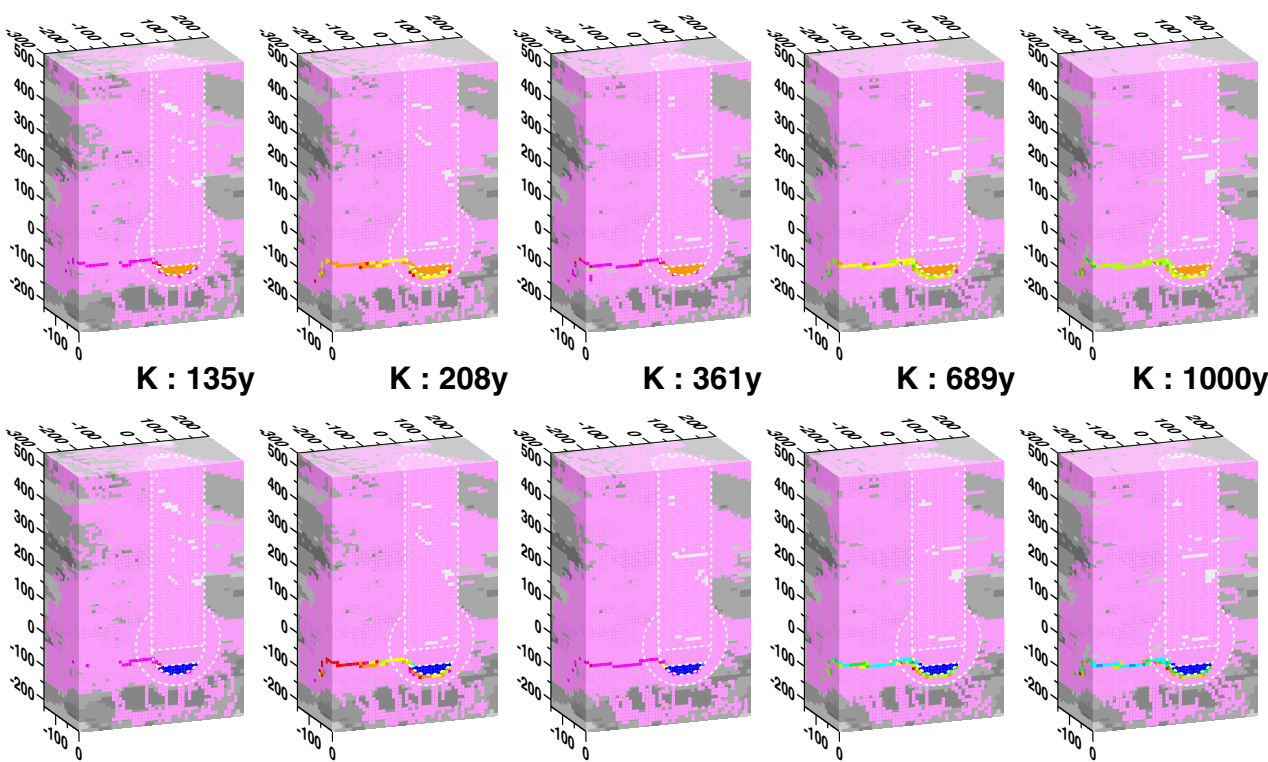

Mg : 135y

Mg : 208y
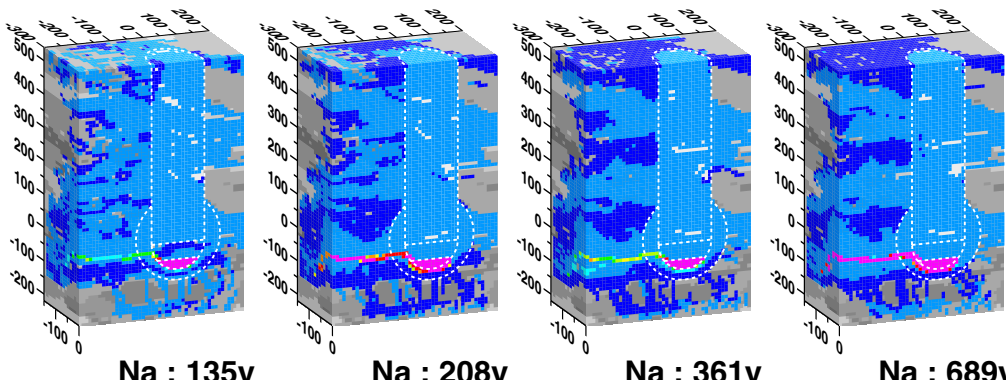

Mg : 1000y
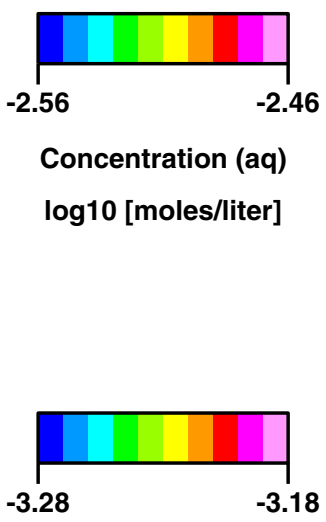

Concentration (aq) $\log 10[$ moles/liter]
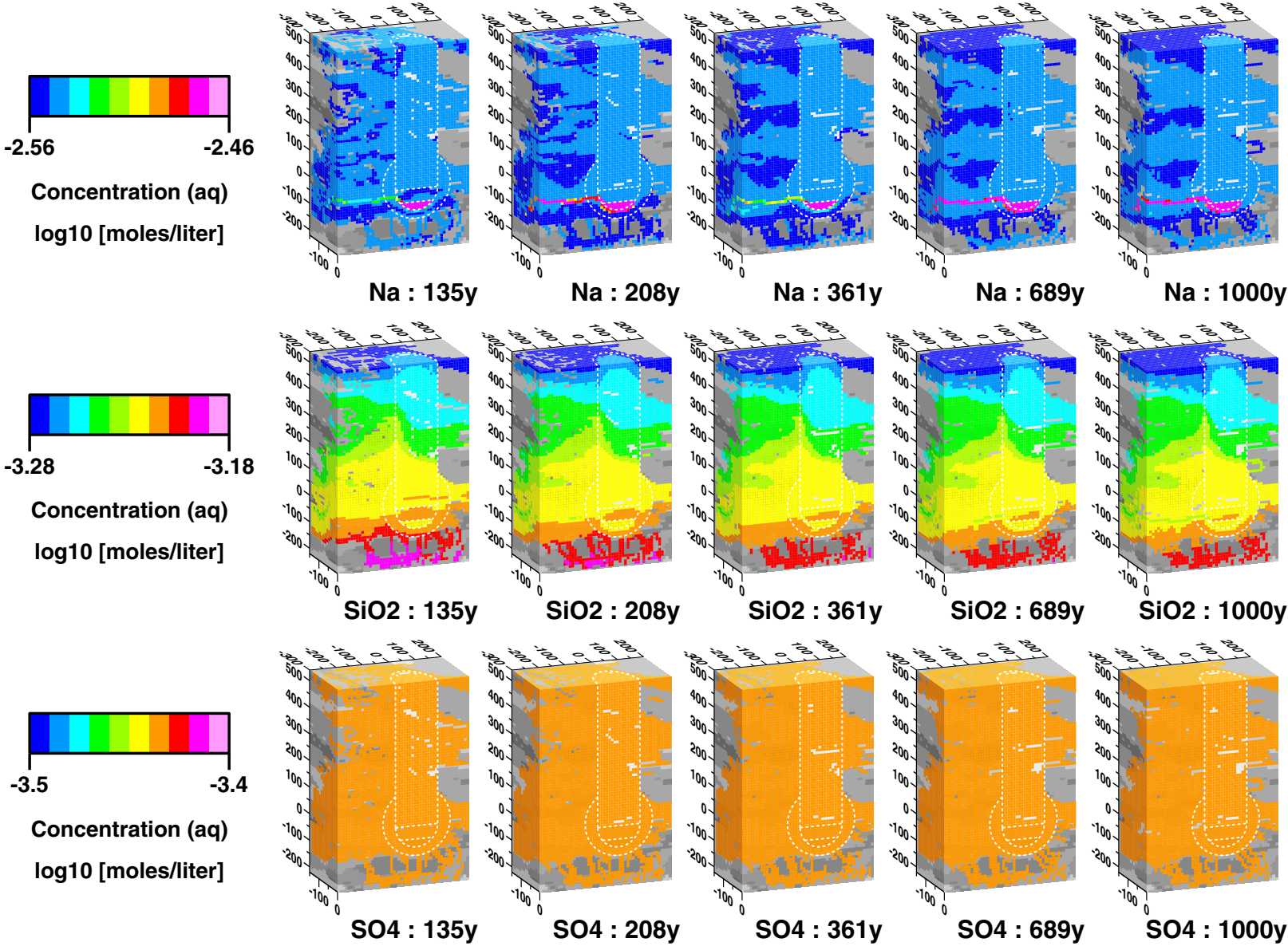

Figure 7.7(b) Perspective cross-sectional views of GIMRT transient streamline simulations of $\mathrm{K}, \mathrm{Mg}$, $\mathrm{Na}, \mathrm{SiO}_{2}$, and $\mathrm{SO}_{4}$ aqueous concentrations. Uncolored regions are not crossed by streamlines. 
The identity and rates of secondary mineral precipitates in the melt glass zone control, to a large extent, the water chemistry and mineral reactions in the melt glass zone and downstream of it. Large changes in the fluid chemistry near vitric zones at the NTS have not been observed. It is, therefore, not likely that large changes in the fluid chemistry (under ambient conditions) would occur in the melt glass zone or downstream of it. Nevertheless, mineral precipitates and their compositions can have a huge impact on water chemistry (see Section 6.4.5.2.1), particularly at higher temperatures.

Changes in the near-field chemistry and mineralogy as a result of high temperatures in the glass zone at early times were not captured by the particle model, nor could they be estimated to initialize the GIMRT streamline calculations from $100 \mathrm{yr}$ onward. At the start of the GIMRT simulations, conditions in the near field were assumed to equal those of the native, pre-test environment. This is not likely to be the case because high temperatures and the resulting fast glass dissolution rates and secondary mineral precipitates may significantly change the mineralogy and water chemistry of the near field, particularly near the melt glass zone. Simplified GIMRT simulations (Appendix I) have shown that early-time geochemical reactions can significantly affect water chemistry, reactive mineralogy, and radionuclide retardation. Significantly improved estimates of the HST would be achieved if these early-time (high temperature) geochemical reactions were explicitly accounted for in the particle or GIMRT simulations.

\subsubsection{Breakthrough Curves}

Figures 7.8(a) and 7.8(b) show the molar flux at the breakthrough plane (downstream boundary of the near-field modeling domain) of the 13 radionuclide classes. For reference, the breakthrough molar flux for permeability realization 9 , mineralization realization 1 of the particle model is also shown. Comparison between GIMRT transient streamline and particle model results is discussed in Section 7.3. The difference between the particle and transient streamline breakthrough fluxes for Sm and Sr radionuclide classes largely results from real-time decay implemented in GIMRT. A more appropriate comparison of the flux of Sm and $\mathrm{Sr}$ is made in Section 7.5 where breakthrough flux data for the 37 individual radionuclides that comprise the RST are presented in decay-corrected form. 

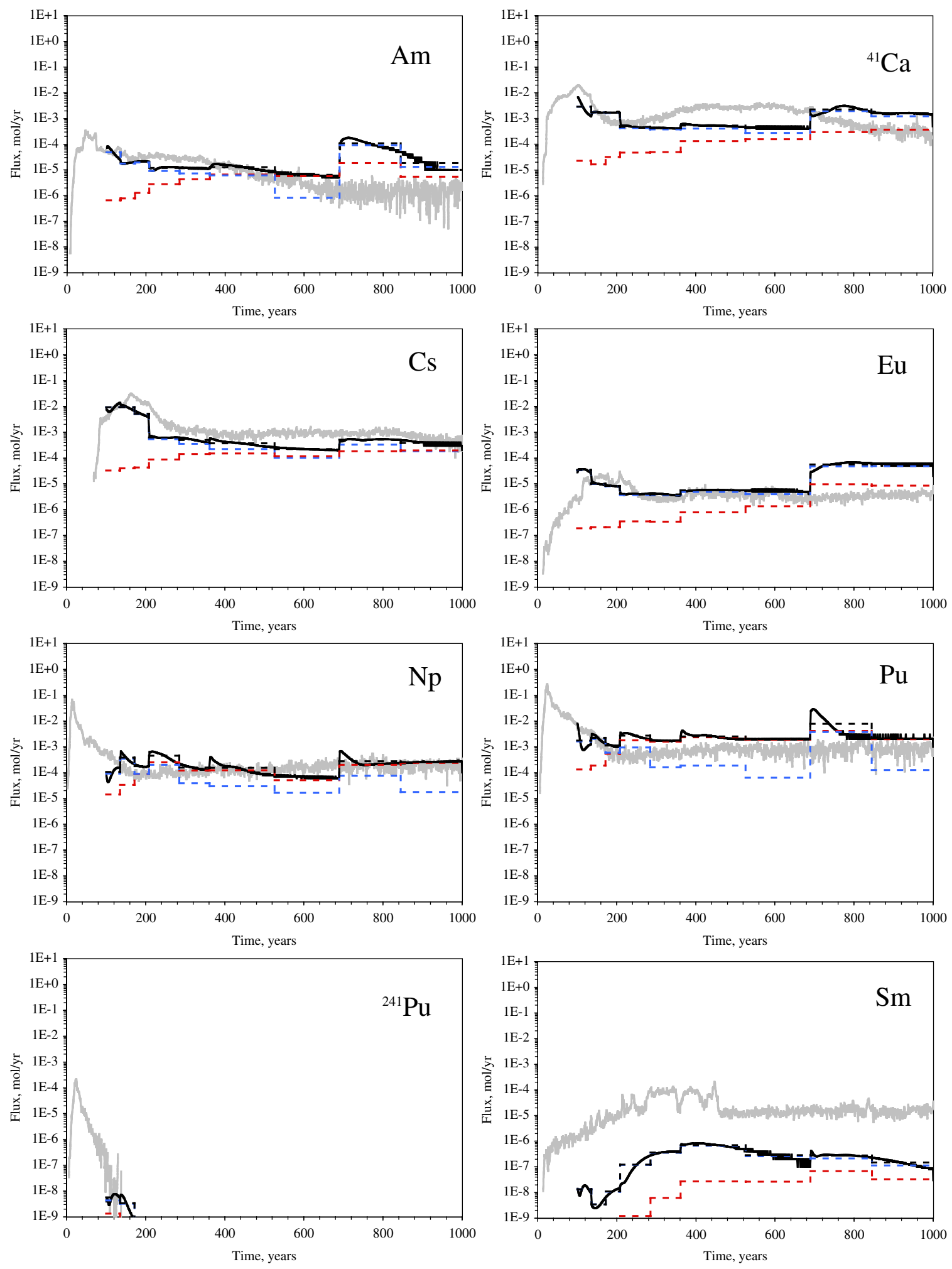

Figure 7.8(a) Radionuclide flux at the breakthrough plane as a function of time. GIMRT transient streamline results (-) are given on a yearly basis. Total (black - - -), glass (red - - -), and non-glass (blue - - - ) contributions to flux are averaged over one-half of a time step model. Particle model results are in gray. 

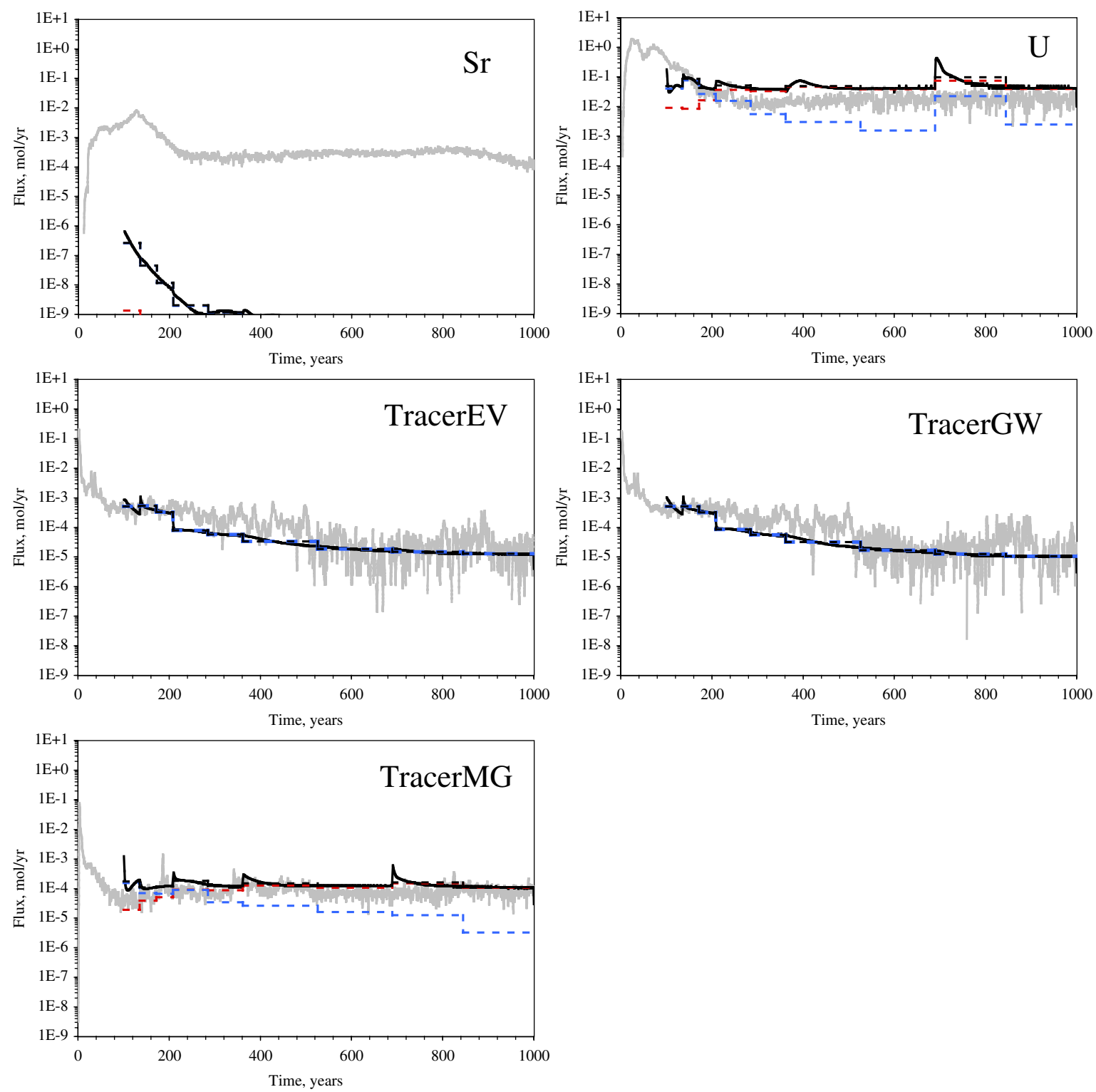

Figure 7.8(b) Radionuclide flux at the breakthrough plane as a function of time. GIMRT transient streamline results (-) are given on a yearly basis. Total (black - - -), glass (red - - -), and non-glass (blue - - - ) contributions to flux are averaged over one-half of a time step model. Particle model results are in gray. 
Several challenges to the implementation of the GIMRT transient streamline approach need to be addressed here. An apparent limitation of the transient streamline approach, as currently implemented, is a tendency for sharp transitions in flux of the radionuclide classes between time segments-at 135, 208, 361, and 689 yr (Figure 7.8). For some but not all radionuclide classes, the transition between time segments results in abrupt changes in the molar flux across the downstream boundary. The shape of these abrupt changes at the transition between time segments falls into two categories:

- A step increase or decrease in flux (e.g., see transition point at $689 \mathrm{yr}$ for $\mathrm{Eu}$.

- A temporary increase in flux that gradually decreases to a flux consistent with the previous time segment (e.g., sharp transition spikes in TracerMG and U plots).

The abrupt changes in flux result from uncertainty in the assignment of flux between streamlines at adjacent time segments. For example, consider a streamline that begins in a high-permeability zone and ends in a low-permeability zone. If the lowpermeability zone is highly sorbing, this low-permeability zone may become a radionuclide sink. Now consider that in the next time segment, there is some likelihood that the low-permeability zone becomes a source block for a streamline with relatively high flux (one that exits the near field through a high-permeability zone). This situation would result in a high pulse of radionuclide exiting the downstream boundary. If a larger number of streamlines were used, perhaps this effect would be minimized.

Another option for reducing the abrupt changes in flux in the transient streamline approach may be to provide additional constraints to the least squares fitting routine presently used to assign flux to streamlines. In the least squares approach, the assignment of flux to streamlines in the near field is made such that the net flux is made consistent with the volume occupied by those streamlines and the associated radionuclides. Between time segments, the path and flux of the set of streamlines changes. The new set of streamlines still occupies the same space in the threedimensional near field. ${ }^{4}$ Although the least squares fitting approach optimizes for the assignment of flux to streamlines, it has some limitations. For example, the total fluid flux in various time segments ranged from 82 to $554 \mathrm{~m}^{3} /$ day. ${ }^{5}$ The least squares fitting approach is also challenged by the spatially complex radionuclide plumes.

Because the transient streamline approach redefines streamlines at each time segment, the diffuse nature of the plume at later times requires a larger number of streamlines. In addition, the CHESHIRE near-field domain has the added complexity of large variations of permeability, flow velocity, and effective porosity. The complex nature of the plume, the complexity of the flow field, and the nature of the least squares

\footnotetext{
${ }^{4}$ The volume occupied by the streamline will change slightly as a result of the concentration cutoff placed on the streamline assignments and the changes in distribution of radionuclides in the threedimensional field.

${ }^{5}$ While some of this variability may result from the incorporation of a larger volume by the various sets of time segment streamlines, streamline plots in Figure 7.1 would tend to indicate that this effect is secondary.
} 
fitting routine used here to assign flux limits the accuracy of the approximations involved. In the future, the potential to improve accuracy of the transient streamline approach should be assessed by considering assignment of additional streamlines to better represent the near field, more tightly constraining assignment of streamline fluxes, and improving the least squares (or other) flux assignment fitting routines.

While there are significant limitations to the transient streamline approach presented here, the result are consistent with the particle model results. As shown in Figure 7.8(b), the TracerEV, TracerGW, and TracerMG are in excellent agreement with the particle model data and the abrupt changes discussed above are minimal. The results indicate that between 100 and $1000 \mathrm{yr}$, the flux of these radionuclide classes steadily decreases by two orders of magnitude. GIMRT simulations allow us to examine the contribution of the glass and nonglass streamlines on the downstream radionuclide fluxes. TracerEV and TracerGW fluxes are dominated by nonglass streamlines. Because these radionuclide tracer classes are excluded from the melt glass, this result would be expected. However, TracerMG is initially distributed entirely in the glass zone but $~ 10$ to $50 \%$ of its downstream boundary flux is carried by nonglass streamlines. At $100 \mathrm{yr}$, TracerMG is distributed through a large portion of the near field (Figure 7.2). At $100 \mathrm{yr}$, $\sim 50 \%$ of the TracerMG flux can be attributed nonglass streamlines. As the nonglass sources are depleted, the fraction of TracerMG that is associated with the glass lines grows to more than $90 \%$. $^{6}$

In general, radionuclide classes with relatively low retardation will have a long-term source that is dominated by flux from glass lines. For example, the flux of $U$, $\mathrm{Np}$, and Pu radionuclide classes is dominated by glass lines for all but the first 100 yr of the GIMRT simulation. Because glass dissolution is relatively slow under ambient temperatures (only 5\% of the original glass dissolves in the 100 to $1000 \mathrm{yr}$ time frame of the GIMRT simulation), the flux of these radionuclide classes is nearly constant between 100 and 1000 yrs. These radionuclide classes are also dominated by a sharp peak in flux at early times of each time segment that gradually relaxes to a flux consistent with the previous time segment. This seems to indicate that any inconsistencies in the assignment of streamline fluxes between time segments are quickly dampened, as those spurious radionuclide sources are depleted.

For the more strongly sorbing radionuclide classes, the source of radionuclides at the downstream boundary is less dominated by glass lines. However, in all cases, the relative importance of the glass lines increases with time. For ${ }^{41} \mathrm{Ca}$, the glass streamline component of downstream flux is $<1 \%$ at the start of the GIMRT simulation but is $>10 \%$ at the end. While the importance of the glass streamlines does change over the simulation period for these radionuclide classes, the flux at the downstream boundary does not change drastically. The exception to this is those radionuclide classes that are decay-corrected in the simulation and whose half-life is relatively short. For example, Sr flux decreases from $10^{-6}$ to $10^{-9} \mathrm{~mol} / \mathrm{yr}$ in the first $300 \mathrm{yr}$ of the simulation, ${ }^{241} \mathrm{Pu}$ flux dips below $10^{-9} \mathrm{~mol} / \mathrm{yr}$ in the first $75 \mathrm{yr}^{7}$

\footnotetext{
${ }^{6}$ Glass streamline paths are reassigned for each time segment. Glass streamline data will indicate the relative importance of the glass streamlines within one time segment, which should be considered when assessing the relative importance of the melt glass as a radionuclide source over the entire 100 to $1000 \mathrm{yr}$. ${ }^{7}{ }^{90} \mathrm{Sr}$ half-life is $29.1 \mathrm{yr}$ while that of ${ }^{241} \mathrm{Pu}$ is $14.4 \mathrm{yr}$.
} 


\subsubsection{Summary}

GIMRT streamline simulations indicate that for weakly sorbing radionuclide classes that have a significant component of their inventory in the melt glass, the flux at the downstream boundary is dominated by the lateral flow of these radionuclide from the glass zone to the downstream boundary (Figures 7.2 to 7.6 and 7.8 ). ${ }^{8}$ However, strongly sorbing radionuclide classes derive a significant fraction of their downstream flux from radionuclides situated in lower-permeability zones at $100 \mathrm{yr}$ after the CHESHIRE test. These fractions of radionuclides were transported into lowerpermeability zones by the particle model prior to the initial conditions for the GIMRT streamline simulations, at $100 \mathrm{yr}$ after the CHESHIRE test. This is particularly obvious in Figures 7.3(a) and 7.3(b), which show the extent of radionuclide distribution in the nearfield model. For all radionuclide classes for which decay was not an issue, the downstream boundary flux approaches a relatively steady state over the $900 \mathrm{yr}$ period examined by the GIMRT simulations. Radionuclide classes that were decay-corrected within GIMRT and those whose half-life was relatively short exhibited strong decreases in flux at the downstream boundary. For a complete analysis of decay-corrected radionuclide fluxes at the downstream boundary, see Section 7.5.

We have observed some limitations of the transient streamline approach as implemented to date. Simulation of radionuclide reactive transport between 0 and $100 \mathrm{yr}$ was not attempted because of the highly transient nature of the flow field and the practical limits of applying the transient streamline approach in its present form. ${ }^{9}$ In addition, limitations in the ability to consistently simulate radionuclide flux across time segments have been observed. Future attempts to use the transient streamline approach will require some improvement in the assignment of fluxes between streamlines of different time segments. Two possible avenues of investigation include using a higher density of streamlines and modification of the method of flux assignment. ${ }^{10}$

\footnotetext{
8 From 0 to $100 \mathrm{yr}$, this may not be the case; see Section 7.3 for a discussion of the early time radionuclide flux.

${ }^{9}$ Appendix I discusses the geochemical aspects of reactive transport at early time, while Section 7.3 discusses the reactive transport results of applying the more simplified geochemical approach used by the particle model at early times.

10 Some improvements in the least squares fitting routine have been obtained using other fitting conditions such as assigning a maximum allowable streamline flux.
} 


\subsection{Particle Transport Model Results}

This section describes results of reactive transport simulations of the CHESHIRE test using the particle transport model. Because of the computational efficiency of the particle model, many simulations were conducted to consider effects of

- Uncertainty in the spatial distribution of permeability.

- Uncertainty in the spatial distribution of reactive minerals.

In Section 7.4, we consider the effects of

- Test-related heat

- Different hydrogeological conceptual models

- Matrix diffusion in the fractured flow system

- Glass dissolution rate

- Retardation

- Dispersion

This suite of particle simulations has been useful for addressing uncertainties inherent to the complexity of modeling three-dimensional reactive transport under highly transient flow conditions given limited characterization information. To our knowledge, these uncertainties and sensitivities could not be practically and properly addressed by any other approach.

Granted, the particle transport model relies on simplifying assumptions and approximations in regard to simulation of reactive transport, compared with the GIMRT transient streamline model (as described in Appendices C, D, and E). The particle model approximates the effects of chemical reactivity using simple retardation factors and uses a simplified model for glass dissolution (as described in Chapter 6). To its credit the particle model fully incorporates transient flow behavior (like the GIMRT transient streamline transport model), considers radionuclide decay and daughter product ingrowth, conserves mass, considers molecular diffusion and local dispersion, matrix diffusion, and does not produce concentration artifacts related to numerical dispersion. Importantly, the particle transport model could be applied to the period of highly-transient flow within 100 yr after the CHESHIRE test. As discussed in the previous section, the particle transport model was used to define the initial spatial distribution of radionuclides at $100 \mathrm{yr}$ for the GIMRT streamline simulations of reactive transport for 100 to 1000 yr after the CHESHIRE test.

One limitation of a particle transport model is confined resolution of concentration. The ability of the particle model to resolve the concentration is limited by the number of particles used in a simulation and the lower limit of concentration. To 
improve resolution, particularly for low concentrations, the particle transport model uses a particle-splitting technique to increase the number of particles in regions of low concentration. In all of the simulations except for the matrix diffusion sensitivity studies, the particle transport model initially starts with 200,000 particles. The number of particles could grow to as many as 1 million with particle splitting. The matrix diffusion sensitivity studies did not implement particle splitting.

In the context of estimating breakthrough, defined as the spatially integrated molar or curie flux of radionuclides per unit time exiting the down-gradient plane of our near-field modeling domain, the spatial resolution of concentration is not as critical an issue. The particle transport model rigorously conserves mass, and its estimates of integrated molar flux crossing the breakthrough plane can be very accurate within the assumptions of the particle transport model. For very low molar flux, the breakthrough behavior can appear noisy, which indicates that few particles are crossing the breakthrough plane.

\subsubsection{Transport in a Single Flow Field: Realization 9, Mineralization 1}

The particle transport simulations consider a transient flow field and spatially variable chemical reactivity that is dependent on the radionuclide species. Therefore, the particle transport model produces much more complex transport behavior compared with a typical particle simulation that assumes steady state flow and constant retardation, such that initial particle location entirely prescribes the advective flow path. Because the particle transport model includes spatially variable and species-dependent retardation factors, the advective flow paths depend on species. As a result, some interesting characteristics in the radionuclide transport behavior can occur:

- Some radionuclides may show evidence of entrainment in recirculation cells in the cavity and chimney, as discussed in Chapter 5, others may not.

- Slightly higher retardation factors may actually result in earlier breakthrough, as the radionuclide takes a more direct path to the breakthrough plane, while more mobile radionucludes may be entrained in recirculation cells.

- Radionuclides that tend to sorb more strongly tend to cross the breakthrough plane at lower elevations because the resulting retardation dampens the degree of upward migration caused by the test-related heat.

Figures 7.9 and 7.10 show cross-sectional perspective views of particle transport model simulations of $\mathrm{Am}, \mathrm{Cs},{ }^{41} \mathrm{Ca}, \mathrm{Eu}$, and $\mathrm{Np}$ radionuclide concentrations for realization 9, mineralization 1 at $201 \mathrm{~d}$ and at 2.0, 6.5, 11.3, 23.5, 59, 100, 135, 208, 361, 689 , and 1000 yr. Figures 7.11 and 7.12 show results for ${ }^{241} \mathrm{Pu}, \mathrm{Pu}, \mathrm{Sm}, \mathrm{Sr}$, and $\mathrm{U}$ radionuclide concentrations. The gray-shaded background represents different hydrofacies, with lighter shading representing higher permeability. These figures provide insight into what could be plausible radionuclide transport behavior throughout the $1000 \mathrm{yr}$ following the CHESHIRE test. With respect to the GIMRT streamline transport simulations described in the previous section, the particle 
transport model provides insight into the dynamic transport behavior occurring in the first $100 \mathrm{yr}$ following the CHESHIRE test, when test-related heat had greater impact on the flow system. 

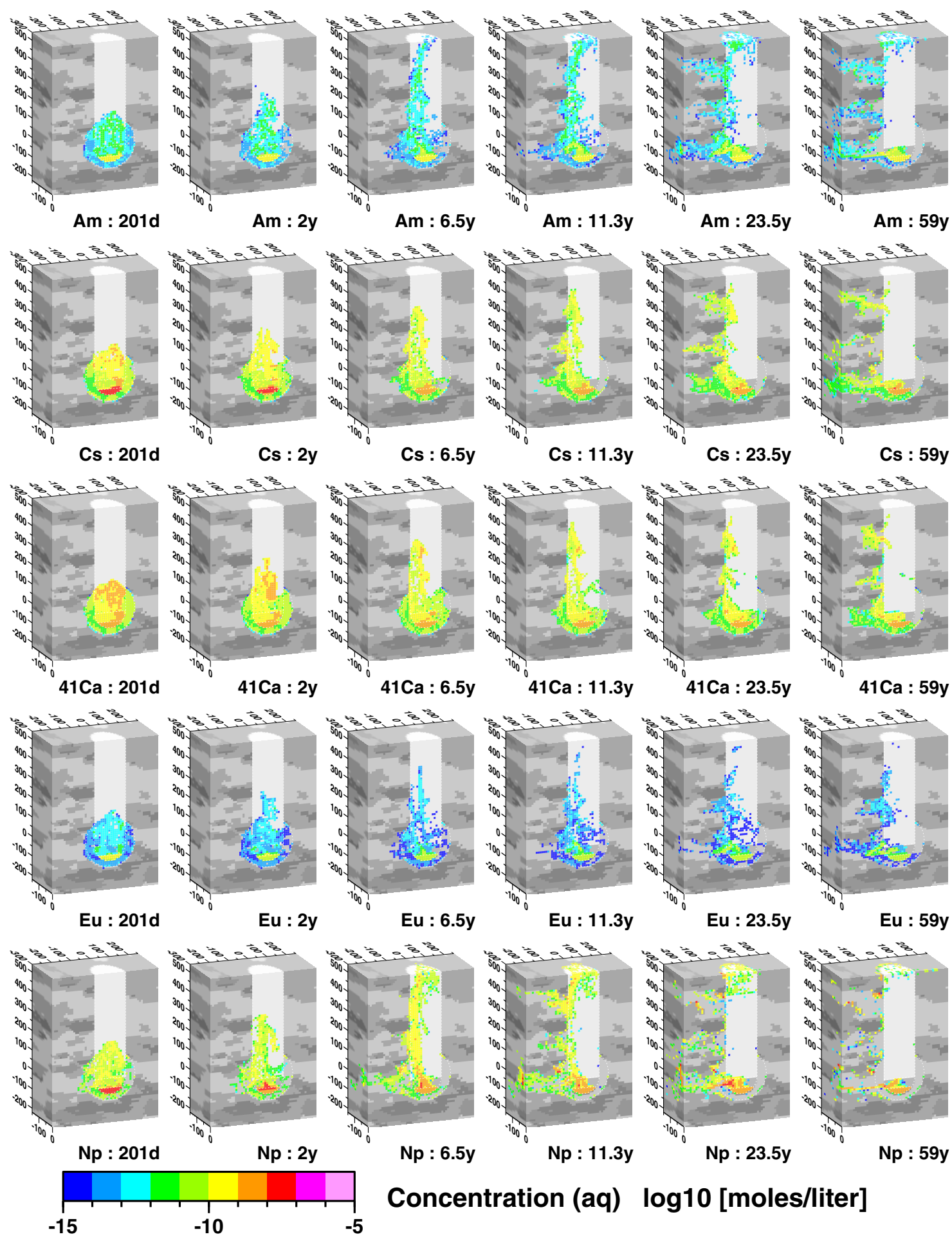

Concentration (aq) $\log 10$ [moles/liter]

Figure 7.9 Cross-sectional perspective views of particle simulations of aqueous $\mathrm{Am},{ }^{41} \mathrm{Ca}, \mathrm{Cs}$, Eu, and Np concentration at $201 \mathrm{~d}$ and at 2, 6.5, 11.3, 23.5, and $59 \mathrm{yr}$ after CHESHIRE test for realization 9, mineralization 1. 

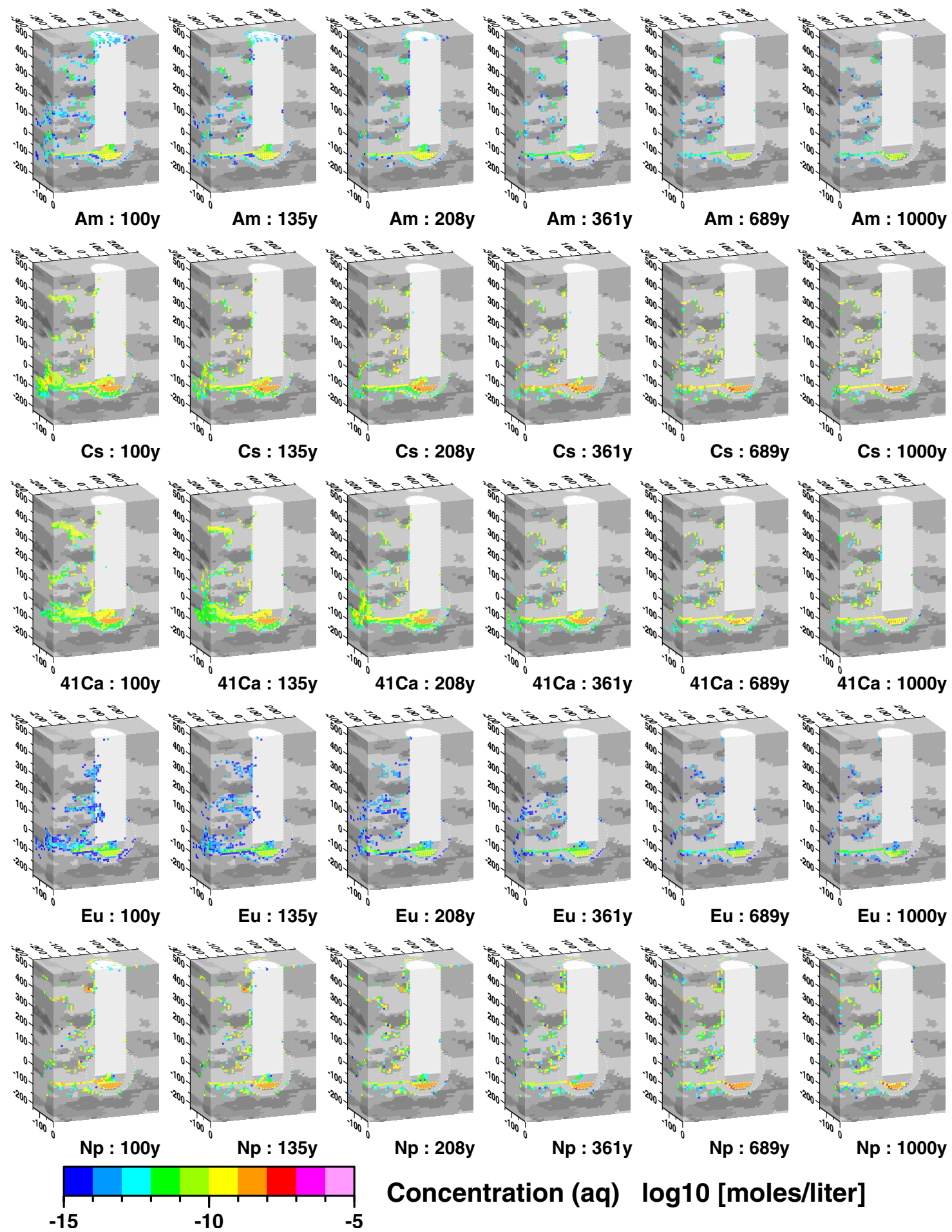

Concentration (aq) $\log 10$ [moles/liter]

Figure 7.10 Cross-sectional perspective views of particle simulations of aqueous $\mathrm{Am},{ }^{41} \mathrm{Ca}, \mathrm{Cs}$, Eu, and Np concentration at 100,135, 208, 361, 689, and $1000 \mathrm{yr}$ after CHESHIRE test for realization 9, mineralization 1. 

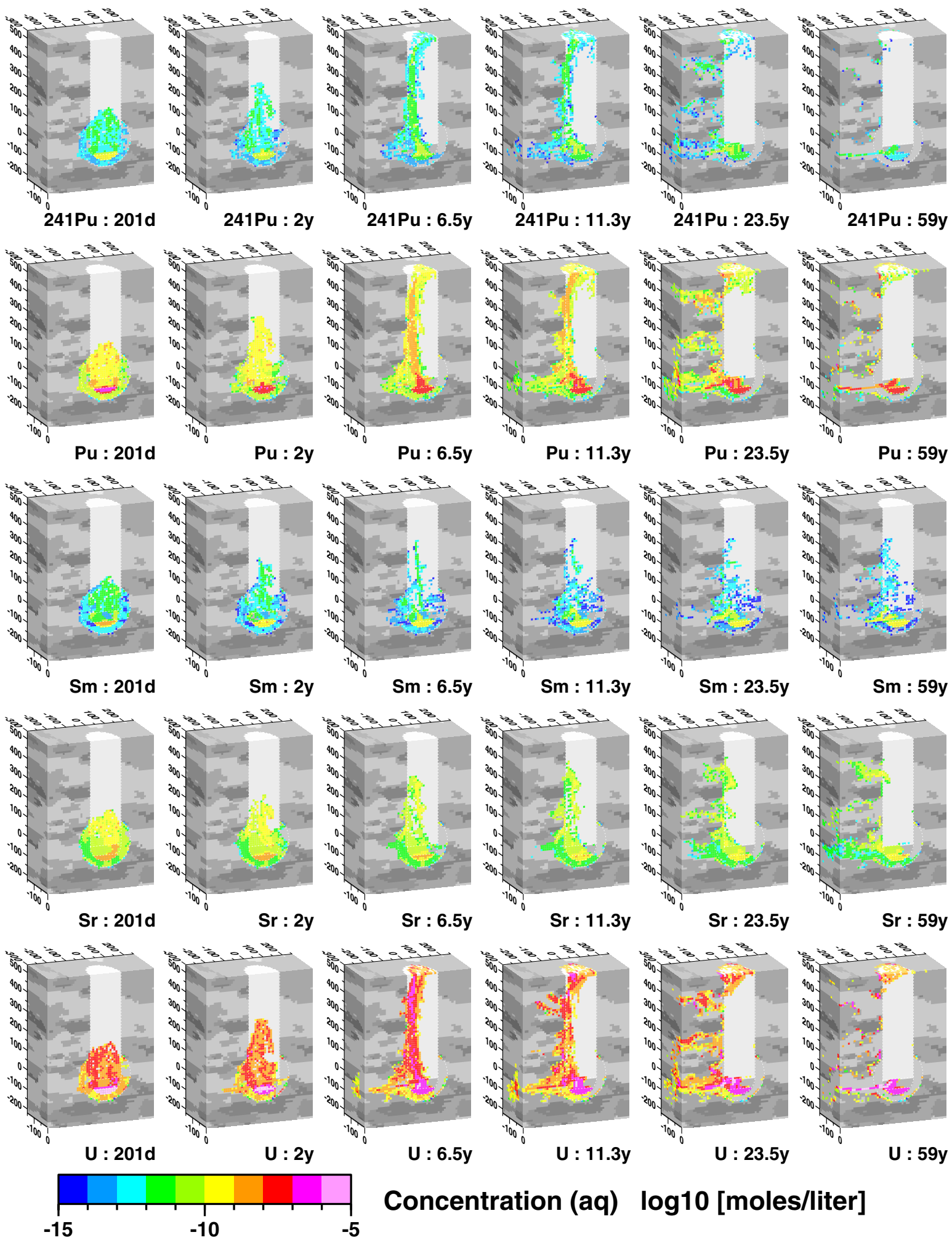

Concentration (aq) $\log 10$ [moles/liter]

Figure 7.11 Cross-sectional perspective views of particle simulations of aqueous $\mathrm{Pu},{ }^{241} \mathrm{Pu}, \mathrm{Sm}, \mathrm{Sr}$, and $U$ concentration at $201 \mathrm{~d}$ and at 2, 6.5, 11.3, 23.5, and $59 \mathrm{yr}$ after CHESHIRE test for realization 9, mineralization 1. 

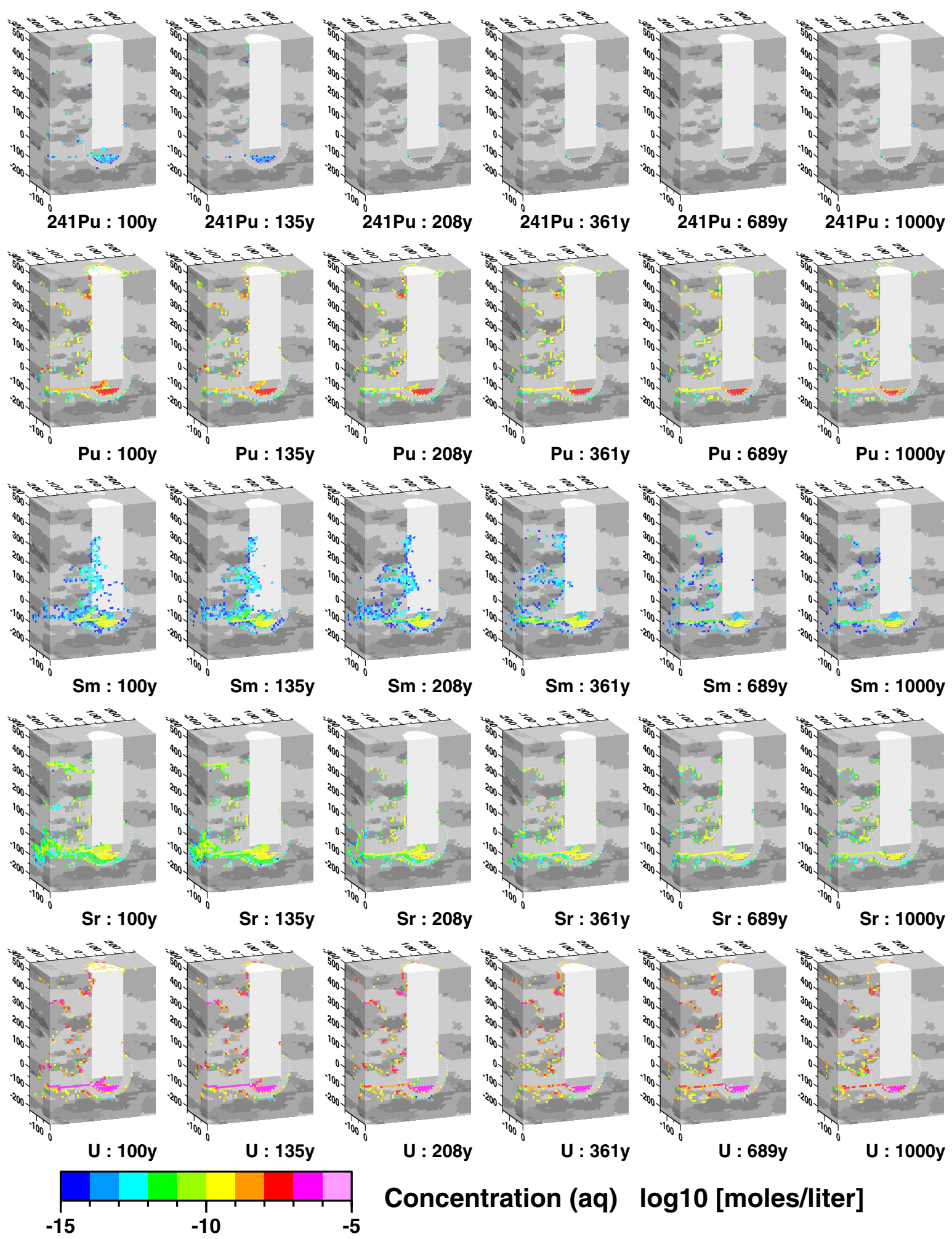

\section{Concentration (aq) $\log 10$ [moles/liter]}

Figure 7.12 Cross-sectional perspective views of particle simulations of aqueous $\mathrm{Pu},{ }^{241} \mathrm{Pu}, \mathrm{Sm}, \mathrm{Sr}$, and $U$ concentration at 100,135, 208, 361, 689, and $1000 \mathrm{yr}$ after CHESHIRE test for realization 9, mineralization 1. 
In the first $100 \mathrm{yr}$, the impact of test-related heat is clearly evident in the radionuclide transport behavior. For all 10 radionuclides, a strong tendency toward vertical migration through the chimney is seen within $6.5 \mathrm{yr}$ of the CHESHIRE test. Radionuclides originating from the melt glass and inner portions of the exchange volume tend to be buoyed by thermally induced upward flow, primarily as a result of the elevated temperatures of the melt glass. The evolution of the radionuclide concentration plumes before $2 \mathrm{yr}$ show the effects of recirculation cells in the lower chimney. Impacts of a recirculation cell in the upper chimney persist in $\mathrm{Np}, \mathrm{Pu}$, and $\mathrm{U}$ concentrations up to $11.3 \mathrm{yr}$. Some radionuclides originating from primarily from the down-gradient side of the exchange volume readily migrate down-gradient through the lower-elevation, high-permeability zone. For example, Np, which is relatively mobile, exhibits initial breakthrough via the lower-elevation, high-permeability zone within 6.5 yr. In contrast, ${ }^{41} \mathrm{Ca}$ exhibits much more retarded transport behavior and does not cross the breakthrough plane until at least $59 \mathrm{yr}$. To varying degrees, all of the radionuclides become distributed throughout the entire vertical extent of the chimney. Subsequently, the radionuclides may migrate into the entire saturated zone above and down-gradient of the working point. Initially, these down-gradient migration pathways are preferential toward the high-permeability zones situated down-gradient of the chimney or disturbed zone. While this initial thermally-driven pulse of radionuclides passes through the lava flow aquifer system, a portion of the radionuclides may become trapped in lower-permeability zones or very high-retardation zones, producing a largescale matrix diffusion-like effects. For example, at 59 yr much of the relatively mobile radionuclides, such as $\mathrm{Np}, \mathrm{Pu}$, and $\mathrm{U}$, are situated in lower-permeability zones near the edge of high-permeability zones.

Within the first $100 \mathrm{yr}$, the fate of aqueous concentrations of radionuclides derived from melt glass dissolution evolves with the cooling of the melt glass. Within $6.5 \mathrm{yr}$, plumes originating from the melt glass are directed upward toward the chimney. After $6.5 \mathrm{yr}$, the melt glass plumes generally begin to curl toward the down-gradient direction. After $23.5 \mathrm{yr}$, the melt glass plumes are directed exclusively toward the down-gradient direction, which becomes particularly pronounced after $100 \mathrm{yr}$ as also observed in the GIMRT streamline transport modeling results.

The aqueous concentrations of radionuclides obtained from the particle transport model at 100 to $1000 \mathrm{yr}$ shown in Figures 7.10 and 7.12 can be compared with the GIMRT streamline model aqueous concentrations shown in Figures 7.4(a) and 7.4(b). Note that the GIMRT streamline results for $\mathrm{Sr}$ and $\mathrm{Sm}$ include radioactive decay, while the particle models do not. Both models include decay and ingrowth for ${ }^{241} \mathrm{Pu}$, ${ }^{241} \mathrm{Am}$, and ${ }^{237} \mathrm{~Np}$. The GIMRT streamline model preserves the lower concentration values present in the simulation of the spatial distribution of concentration. Some of these lower concentration values may be attributed to numerical dispersion, and might not be physically realistic. Nonetheless, the particle transport model appears to capture the general transport behavior evident in the GIMRT streamline model and more accurately preserves peak values of concentrations. From a qualitative perspective, there appear to be no large errors in the particle model's approximation of the interactions between radionuclide and mineral as a simple linear sorption isotherm. 


\subsubsection{Comparison of Breakthrough Curves for GIMRT Transient Streamline and Particle Models}

Figures 7.13(a) and 7.13(b) show a comparison between GIMRT transient streamline and particle models for the breakthrough of the 13 radionuclide classes at the downstream boundary. GIMRT results are in blue while the particle model results are in red. The $5^{\text {th }}$ and $95^{\text {th }}$ percentile results for the 100 mineralogic and permeability realizations (Section 7.3.4) are shown in gray. In the GIMRT streamline simulations, $\mathrm{Sr}$, $\mathrm{Sm}, \mathrm{Am}$, and ${ }^{241} \mathrm{Pu}$ are decay-corrected. In the particle model simulations, only ${ }^{241} \mathrm{Pu}$ and Am were decay-corrected. Thus, in this comparison, significant differences between the GIMRT and particle models are expected for Sr and Sm.

According to the results of the particle model, peak breakthrough for all radionuclide classes except Sm and Sr occurs within 100 yr. Therefore, the interval of 100 to 1000 yr modeled by GIMRT transient streamline approach is after a large proportion of the source term mass has exited the near-field model domain. Generally, we expect that less reactive radionuclide classes such as $\mathrm{Np}, \mathrm{Pu}$, and $\mathrm{U}$ should exhibit early breakthrough. This is evident as steep curves at very early times in the particle model breakthrough curves. Breakthrough of Am is intertwined with both its own reactivity and its dependency as a daughter product of migrating ${ }^{241} \mathrm{Pu}$. Early time breakthrough of Am is significantly different from Eu for that reason. ${ }^{41} \mathrm{Ca}, \mathrm{Cs}, \mathrm{Eu}, \mathrm{Sm}$, and Sr show varying degrees of delay in breakthrough. Interestingly, Cs and Sm both show a delayed peak in breakthrough as a result of higher overall retardation, but Sm shows much earlier breakthrough than Cs. This result is attributed to the differences in the range of retardation of the two radionuclides; Sm has a wide range of retardations (retardation controlled in large part by heterogeneously distributed calcite in the high permeability fractures and cavity/chimney zones) that give it an ability to find lowretardation paths to the down-gradient boundary. Cs has a narrow range of retardations (retardation controlled in large part by homogeneously distributed mica in the devitrified lavas) and little ability to bypass high retardation zones. ${ }^{1}{ }^{241} \mathrm{Pu}$ exhibits early breakthrough, but also a steep decline in breakthrough as a result of decay. For the nondecaying radionuclide classes, the relatively constant breakthrough flux at times greater than 200 yr results from a combination of steady glass dissolution rates and the slow leaching from the lower-permeability to the high-permeability zones of the near field.

\footnotetext{
1 In the simplified colloid model used here, the sorption of Cs to colloids was not accounted for. Kersting et al. (1999) found a significant portion of aqueous Cs to be colloid associated. Inclusion of the Cs-colloid association in our model would also contribute to an earlier initial breakthrough of Cs in these simulations.
} 

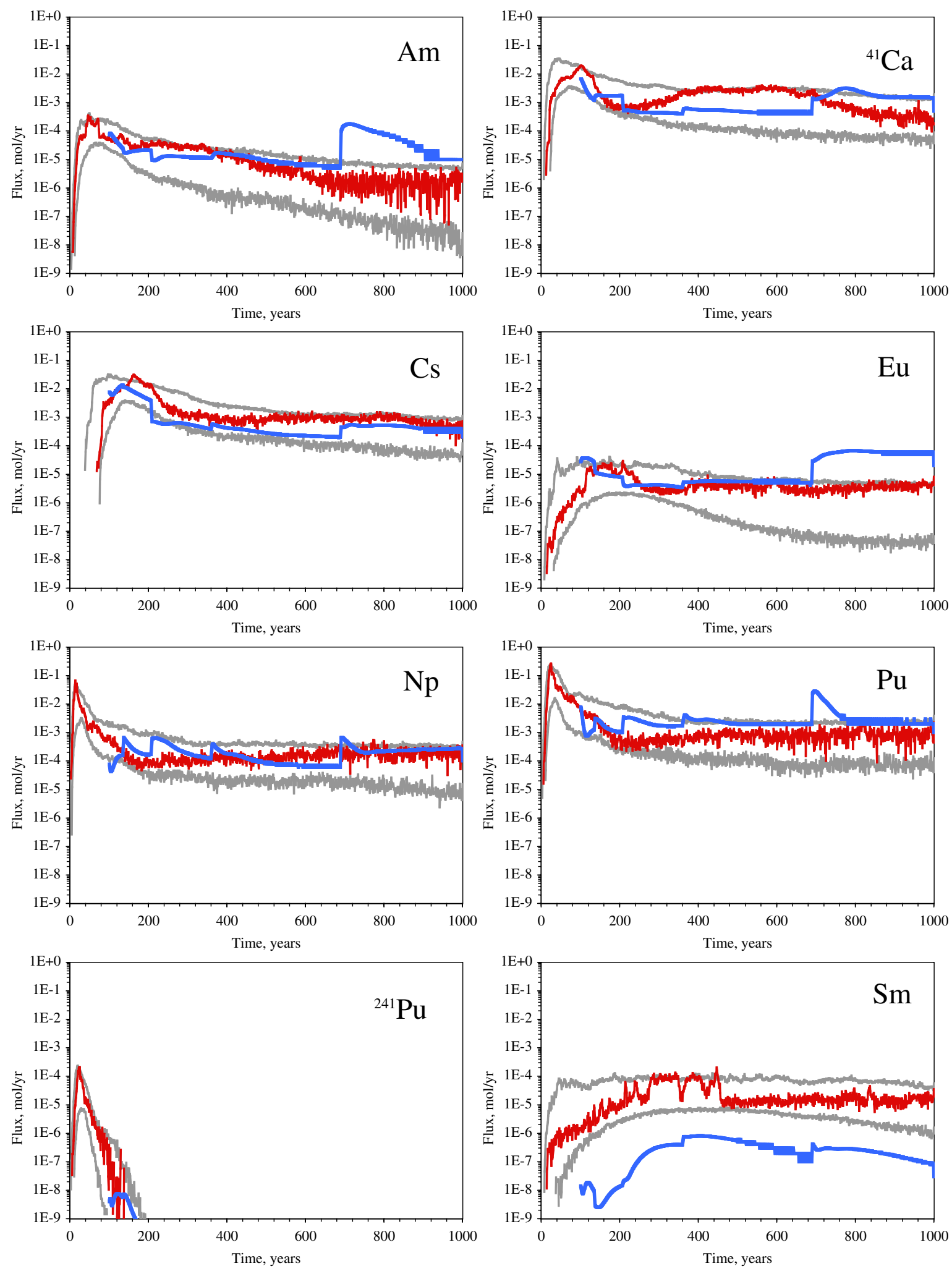

Figure 7.13(a) Comparison of GIMRT transient streamline (blue) and particle model (red) results for Am, ${ }^{41} \mathrm{Ca}, \mathrm{Cs}, \mathrm{Eu}, \mathrm{Np}, \mathrm{Pu},{ }^{241} \mathrm{Pu}$, and $\mathrm{Sm}$ flux at the breakthrough plane as a function of time. The $5^{\text {th }}$ and $95^{\text {th }}$ percentiles of the particle model results for 100 permeability and mineralization realizations are in gray. 

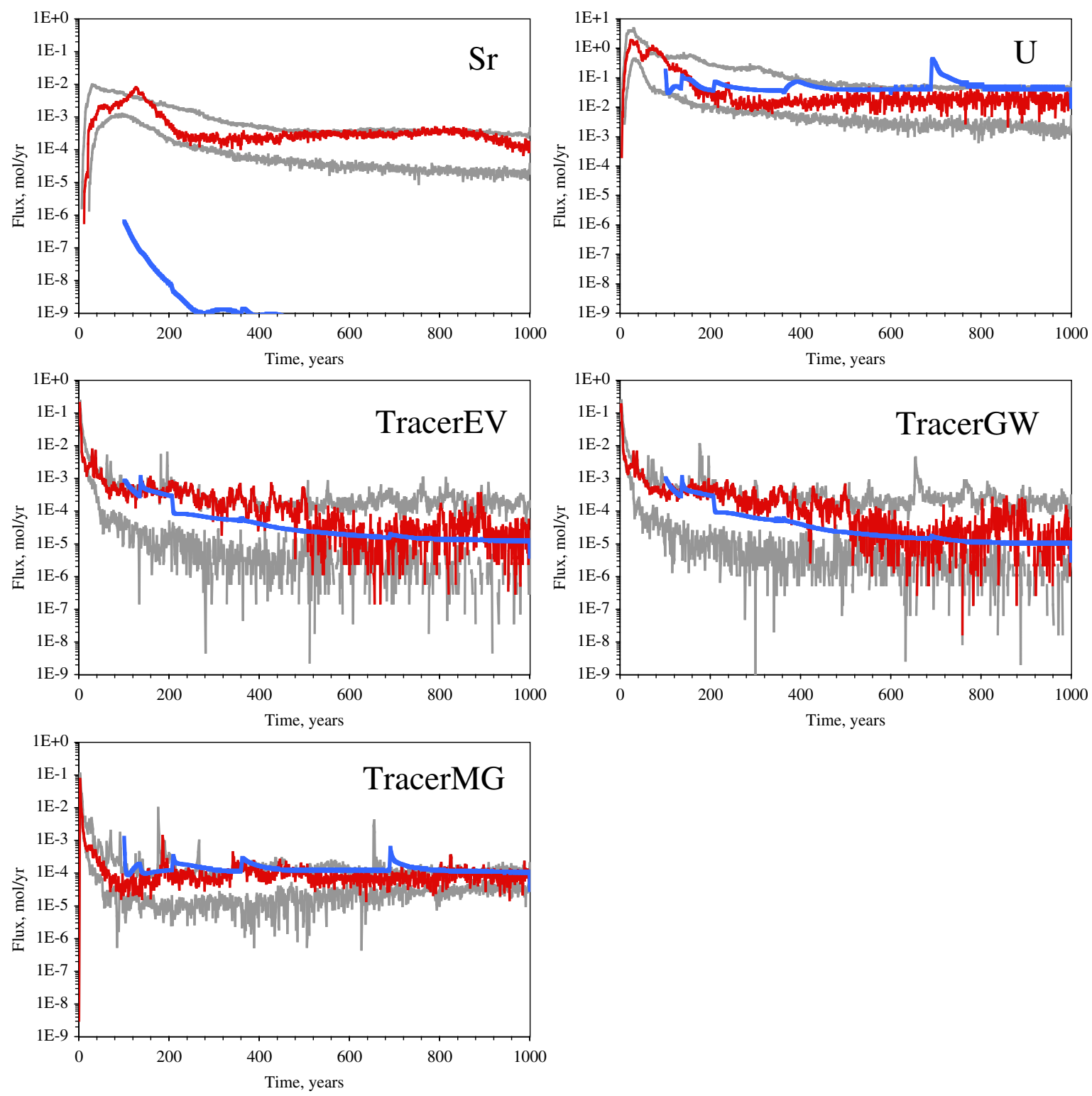

Figure 7.13(b) Comparison of GIMRT transient streamline (blue) and particle model (red) results for Sr, U, TracerEV, TracerGW, and TracerMG flux at the breakthrough plane as a function of time. The $5^{\text {th }}$ and $95^{\text {th }}$ percentiles of particle results for $\mathrm{Sr}$ and $\mathrm{U}$, the $10^{\text {th }}$ and $90^{\text {th }}$ percentiles of particle results for tracers are in gray. 


\subsubsection{Effect of Spatial Variability of Mineralization and Permeability}

Spatial variability of mineralization and permeability are two major sources of uncertainty for predicting transport of radionuclides in the near-field environment. Under the assumption that the particle model provides adequate accuracy and realism for simulation of three-dimensional radionuclide transport, its computational efficiency can be exploited to analyze sensitivities to model parameters and, thus, quantify the effects of these "categories" of uncertainty using a Monte Carlo approach.

This subsection shows cross-sectional views of radionuclide concentrations resulting from particle transport simulations made in a series of 100 of Monte Carlo runs that span two different categories of variability:

- Category 1: Ten different permeability realizations, to each of which corresponds a unique transient flow simulation;

- Category 2: Ten different mineralization realizations that can be used in each of the flow simulations to obtain a unique transport simulation.

Thus, for a given permeability realization, the transient flow field is the same for each mineralization realization; only the spatial distribution of the mineralized zones varies between the realizations. Development of the permeability and mineralization realizations is described in Appendices G and H. Differences in transport behavior can be attributed exclusively to each suite of Monte Carlo runs as follows: (1) spatial variability of the mineralized zones, and (2) spatial variability of permeability in native rocks. Variability of transport behavior in each suite of runs defines a reasonable degree of uncertainty associated with predicting transport behavior associated with uncertainty in characterizing the spatial variation of mineralization and permeability.

Of course, the accuracy of a Monte Carlo approach such as this is limited by the accuracy of the transport models and their parameters. Additionally, contributions from the uncertainty of the accuracy of the stochastic models representing permeability and mineralization heterogeneity are not considered and could affect model predictions. Here, the goal is simply to quantitatively assess the degree of uncertainty in predicting radionuclide transport assuming that the permeability and mineralization heterogeneity and transport models and their parameters are accurate. The degree of uncertainty is derived from the ranges of behavior exhibited in the suites of Monte Carlo runs. It is expected that these predicted ranges of transport behavior would be smaller than what would be obtained from a complete consideration of all model and parameter uncertainties.

\subsubsection{Eu and Mineralization}

Figure 7.14 shows cross-sectional perspective views of simulated aqueous Eu concentrations for permeability realization 9 with 10 different mineralization realizations at 10 years after the CHESHIRE test. The shaded background represents the magnitude of the retardation factor for Eu transport, with darker shades representing 
higher retardation factors. Lower retardation factors are present in the chimney as a result of differences in porosity and quantities of reactive surface minerals (Chapter 6). Overall the concentration distributions between realizations are not drastically different, except in the region directly down-gradient from the working point. For example, in mineralization 2, Eu has not significantly advanced beyond the disturbed zone; in mineralization 10, Eu has nearly reached the breakthrough plane. This difference can be attributed to variations in retardation at locations directly downgradient of flowpaths out of the disturbed zone. Of course, there is a three-dimensional character to the shape of the Eu plume.

Figure 7.15 shows Eu concentrations at $100 \mathrm{yr}$. At this time, more variation in the spatial distribution of concentrations of Eu is evident between the different mineralization realizations. Significant variation is present at the breakthrough plane (at the down-gradient exit face of the block shown), indicating that the spatial distribution of mineralization exerts significant control on preferential pathways.
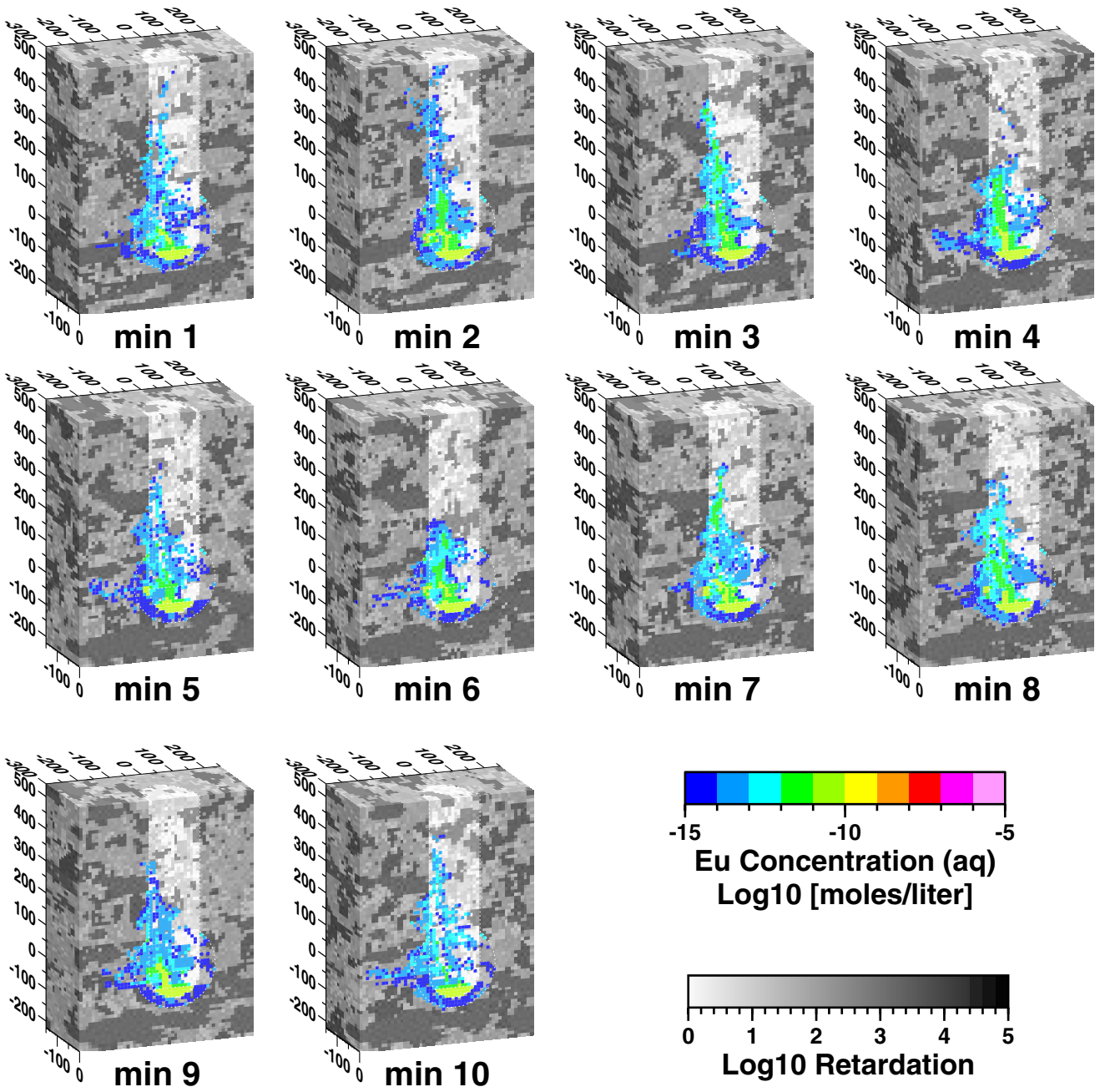

Figure 7.14 Cross-sectional perspective views of particle simulations of aqueous Eu concentration at $10 \mathrm{yr}$ after CHESHIRE test for permeability realization 9 with 10 different mineralization realizations. 

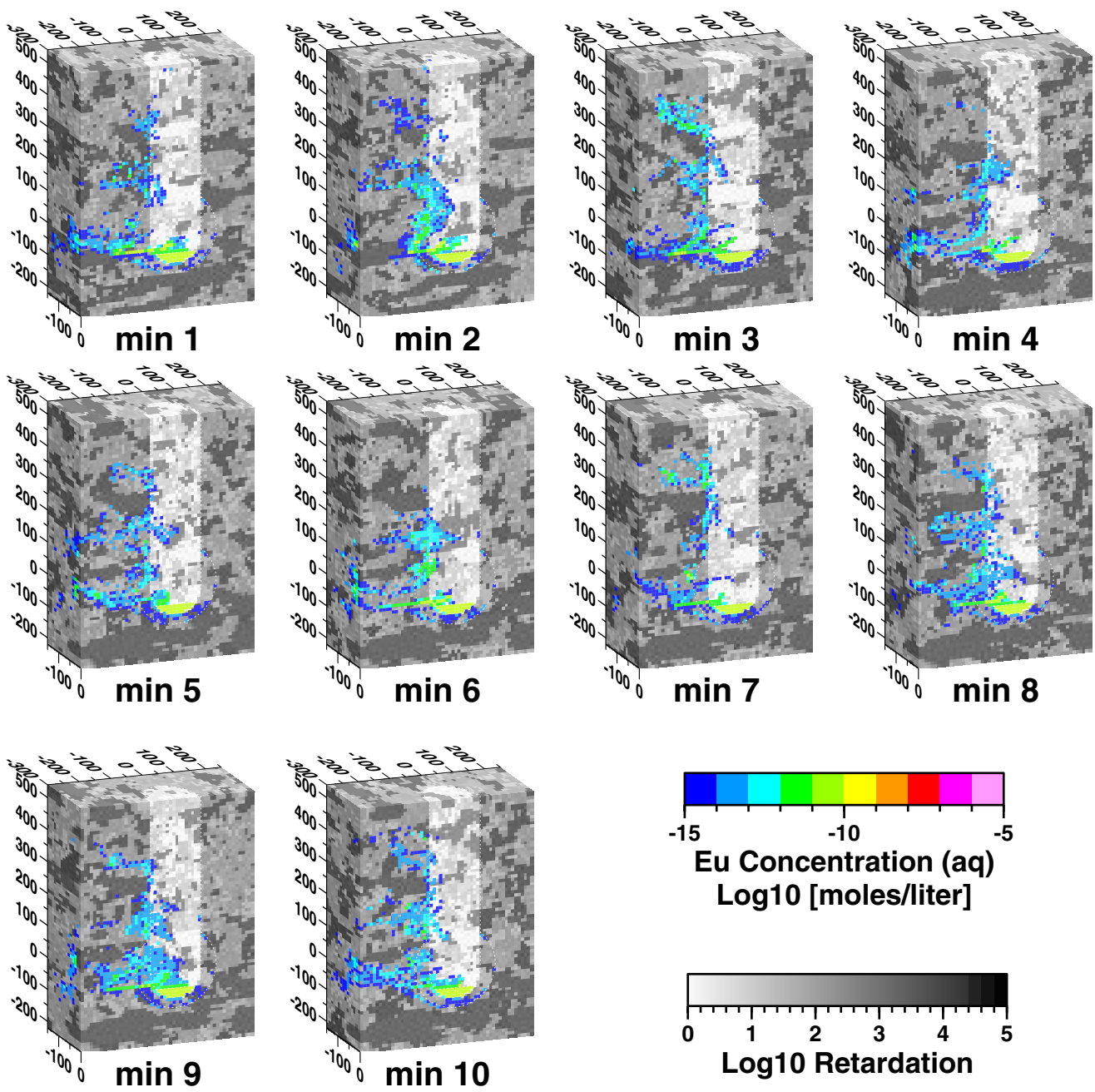

Figure 7.15 Cross-sectional perspective views of particle simulations of aqueous Eu concentration at $100 \mathrm{yr}$ after CHESHIRE test for permeability realization 9 with 10 different mineralization realizations.

\subsubsection{U and Mineralization}

Figure 7.16 shows cross-sectional perspective views of simulated aqueous $U$ concentrations for permeability realization 9 with 10 different mineralization realizations at $10 \mathrm{yr}$ after the CHESHIRE test. The shaded background represents the magnitude of the retardation factor for $U$ transport, with darker shades representing higher retardation factors. Comparing the spatial extent of $U$ migration with Eu migration in Figure 7.14, the greater retardation of Eu compared with $U$ is plainly evident. Although the particle model assumes lower retardation and lesser variation in retardation for $U$ than for $E u$, significant variation in the $U$ plume behavior can occur as a result of spatial variation in mineralization. This variation in plume behavior is prominent at the breakthrough plane.

Figure 7.17 shows U concentrations at 100 yr for the same realizations. Upon close examination, the spatial distribution of $U$ outside the melt glass plume exhibits very similar patterns, indicating that the $U$ that remains trapped is related to spatial variations in the permeability field. 

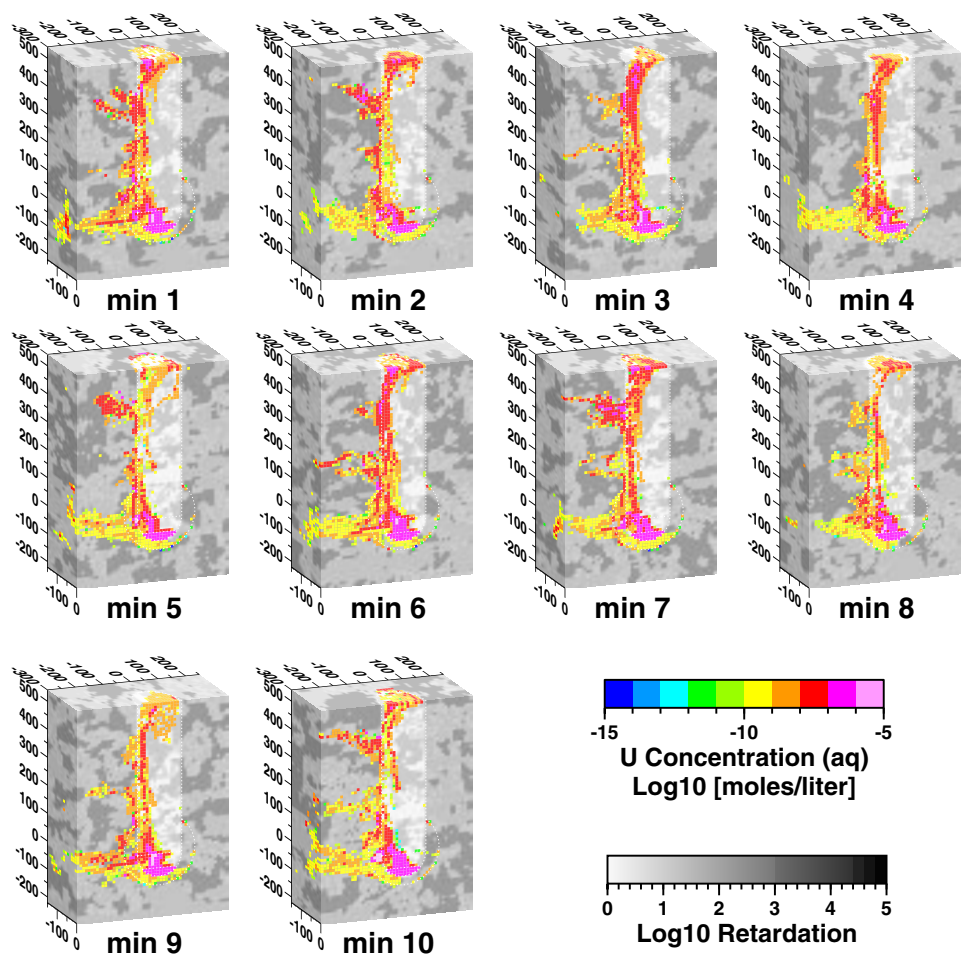

Figure 7.16 Cross-sectional perspective views of particle simulations of aqueous $U$ concentration at $10 \mathrm{yr}$ after CHESHIRE test for permeability realization 9 with 10 different mineralization realizations.
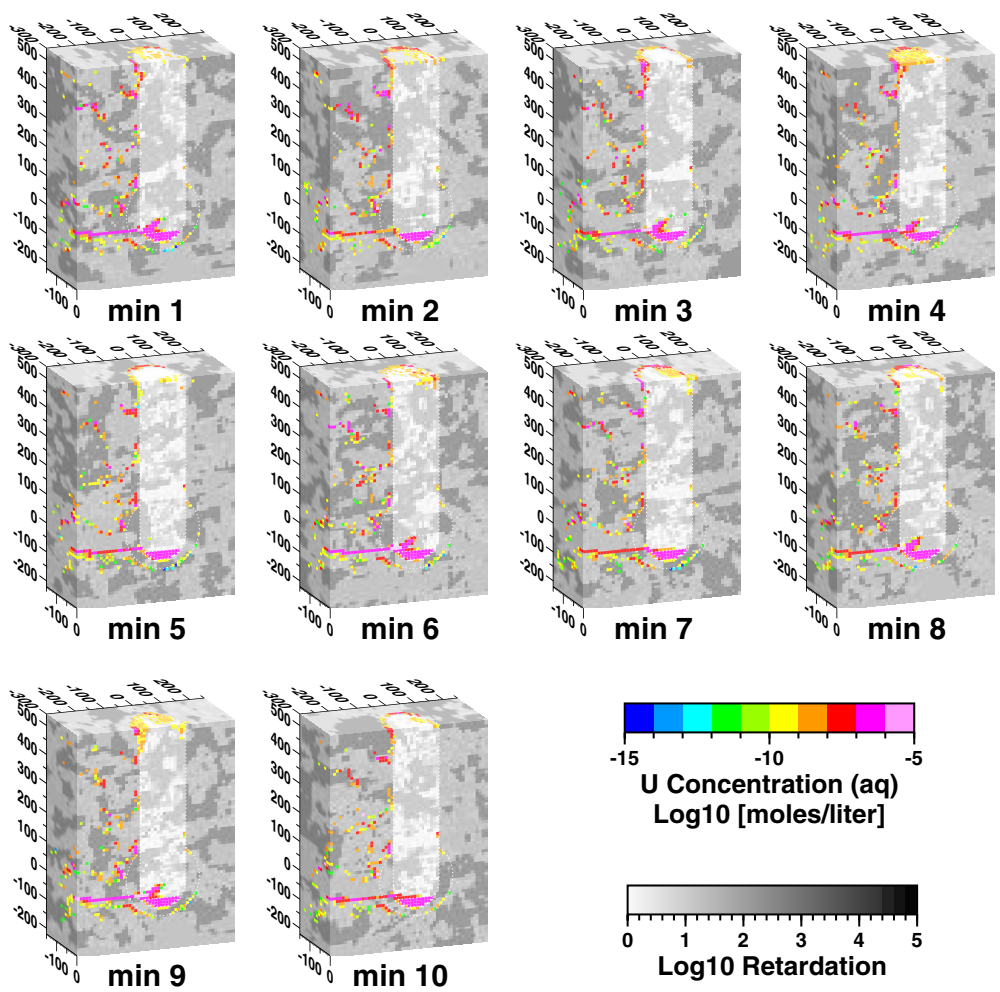

Figure 7.17 Cross-sectional perspective views of particle simulations of aqueous $U$ concentration at $100 \mathrm{yr}$ after CHESHIRE test for permeability realization 9 with 10 different mineralization realizations. 


\subsubsection{Am and Permeability}

Figure 7.18 shows cross-sectional perspective views of simulated aqueous Am concentrations for mineralization realization 1 with 10 different permeability realizations at $10 \mathrm{yr}$ after the CHESHIRE test. The gray-shaded background represents different hydrofacies, with lighter shading representing higher permeabilities. These simulations exhibit different degrees of upward migration via the chimney and downgradient migration toward transport pathways adjacent to the working point. Permeability realizations 3,5, and 8 exhibit strong vertical migration of Am derived from melt glass dissolution, whereas realization 7, 9, and 10 exhibit a tendency for migration toward a lower-elevation, high-permeability zone ${ }^{2}$. Clearly, the spatial distribution of the high-permeability zones will affect the degree to which radionuclides disperse into different high-permeability zones. Test-related heat provides enough energy to distribute the radionuclides throughout the chimney, from which the radionuclides enter different high-permeability zones.

Figure 7.19 shows the Am concentrations at $100 \mathrm{yr}$. Melt glass dissolution provides a continued source of Am, which tends to migrate in a plume directed toward the nearest high-permeability zone in the down-gradient direction. Elsewhere, Am is present in and near the edges of high-permeability zones.
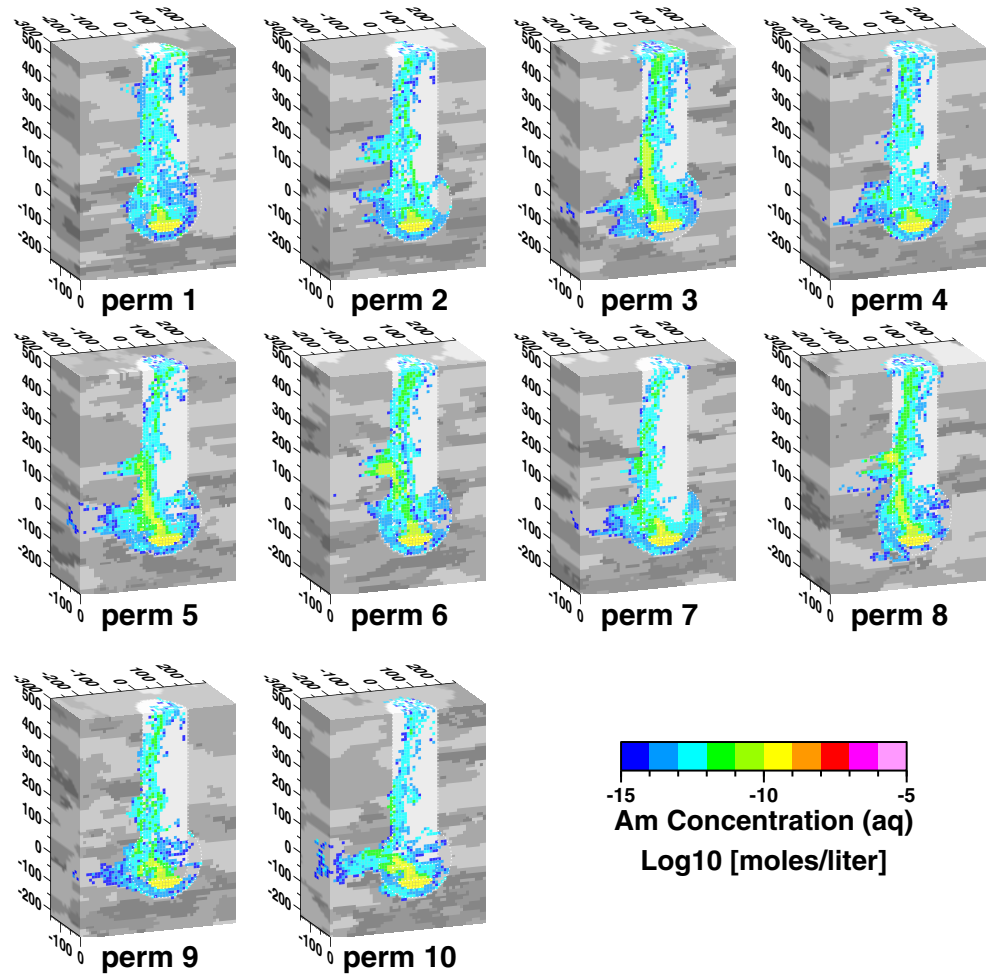

Figure 7.18 Cross-sectional perspective views of particle simulations of aqueous Am concentration at $10 \mathrm{yr}$ after CHESHIRE test for mineralization realization 1 with 10 different permeability realizations.

\footnotetext{
${ }^{2}$ Remember that the migration of Am results from a combination of Am present at the start of the simulation and the migration and decay of ${ }^{241} \mathrm{Pu}$. Because ${ }^{241} \mathrm{Pu}$ retardation is significantly lower than Am the leading edge of the Am plume will be largely the result of ${ }^{241} \mathrm{Pu}$ transport and decay. This is discussed in more detail in Section 7.3.4.
} 

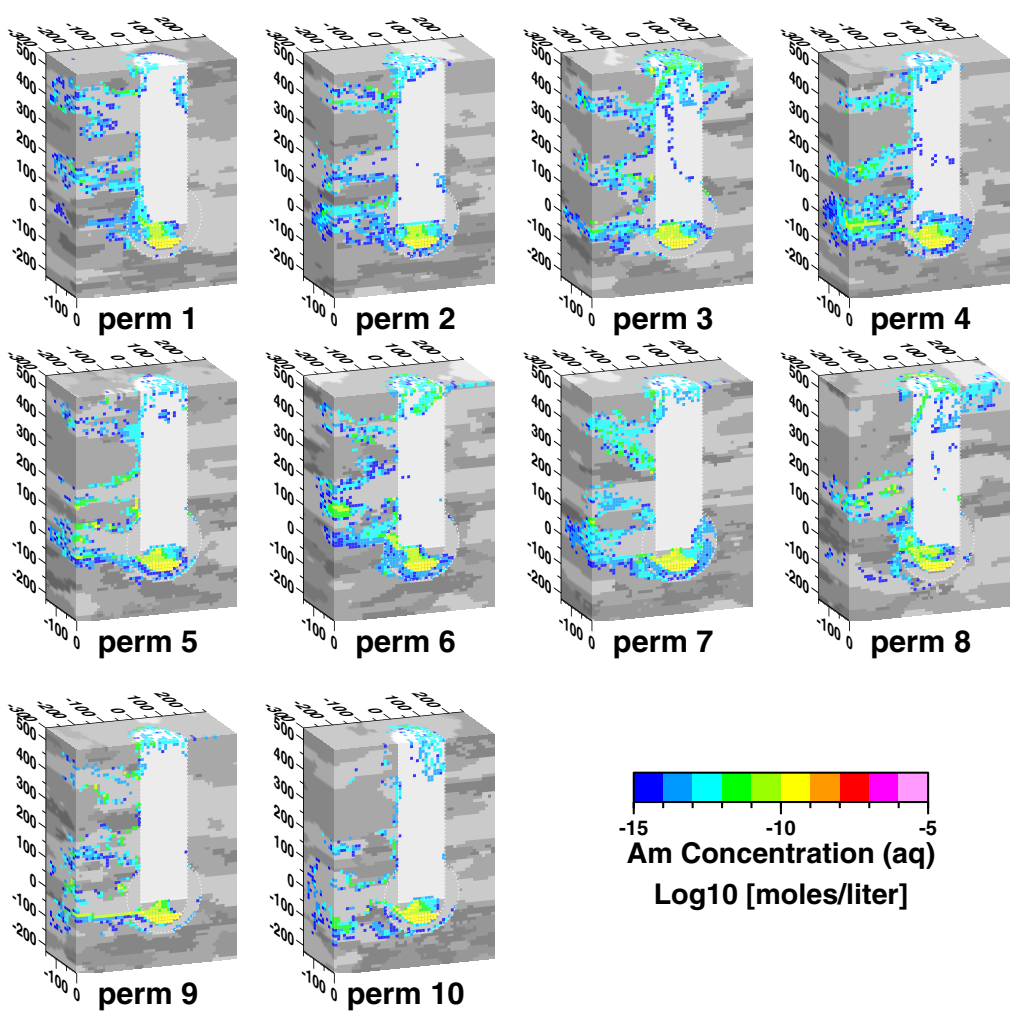

Figure 7.19 Cross-sectional perspective views of particle simulations of aqueous Am concentration at $100 \mathrm{yr}$ after CHESHIRE test for mineralization realization 1 with 10 different permeability realizations.

\subsubsection{Eu and Permeability}

Figure 7.20 shows cross-sectional perspective views of simulated aqueous Eu concentrations for mineralization realization 1 with 10 different permeability realizations at $10 \mathrm{yr}$ after the CHESHIRE test. The gray-shaded background represents different hydrofacies, with lighter shading representing higher permeabilities. Variations in the Eu concentrations do not appear as pronounced as for Am at $10 \mathrm{yr}$. In fact, the variation in Eu concentrations as a result of spatial variation in mineralization (Figure 7.14) appears greater, indicating that mineralization may have a relatively greater impact than permeability for Eu at $10 \mathrm{yr}$.

Figure 7.21 shows Eu concentrations at 100 yr. At this time, there appears to be as much or more variation in the spatial distribution in Eu as a result of permeability as compared with realizations with different mineralizations (Figure 7.15). Therefore, spatial variation of mineralization might have more impact Eu transport than permeability at earlier times, and the opposite may be true at later times. This observation lends credence to consideration and integration of both hydrogeologic and geochemical complexity into models of radionuclide transport. 

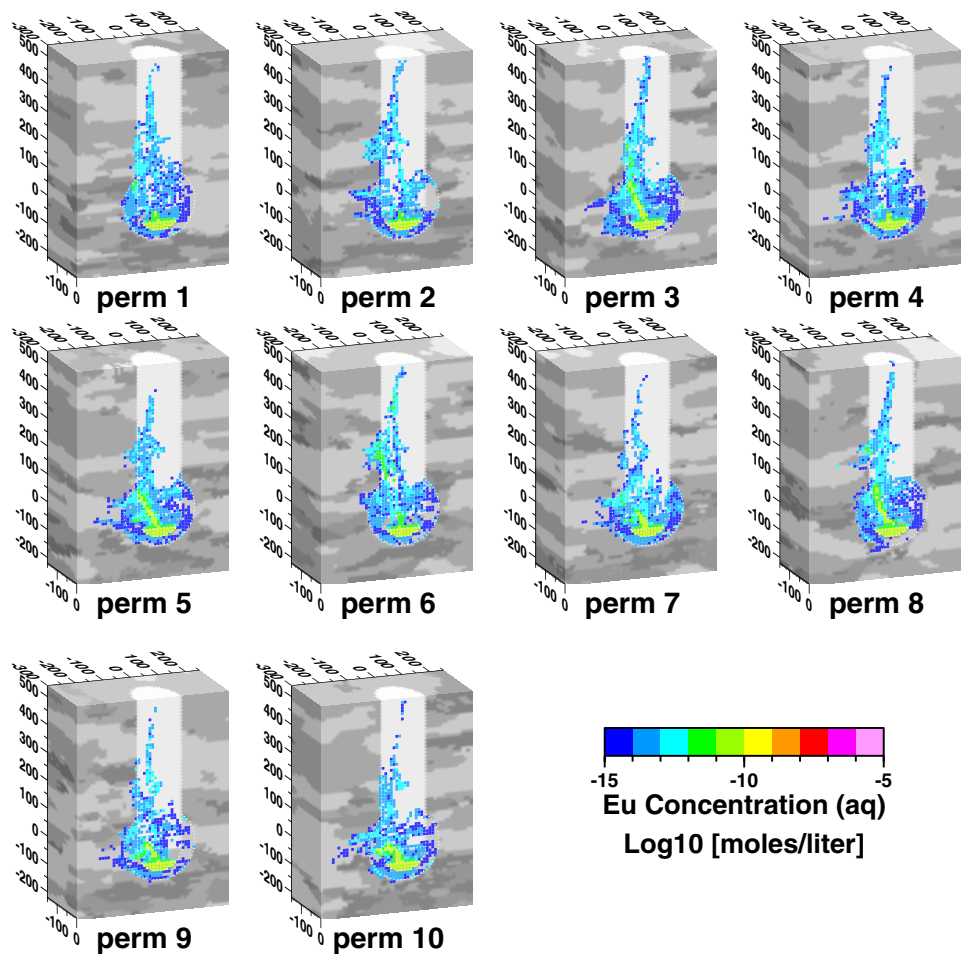

Figure 7.20 Cross-sectional perspective views of particle simulations of aqueous Eu concentration at $10 \mathrm{yr}$ after CHESHIRE test for mineralization realization 1 with 10 different permeability realizations.
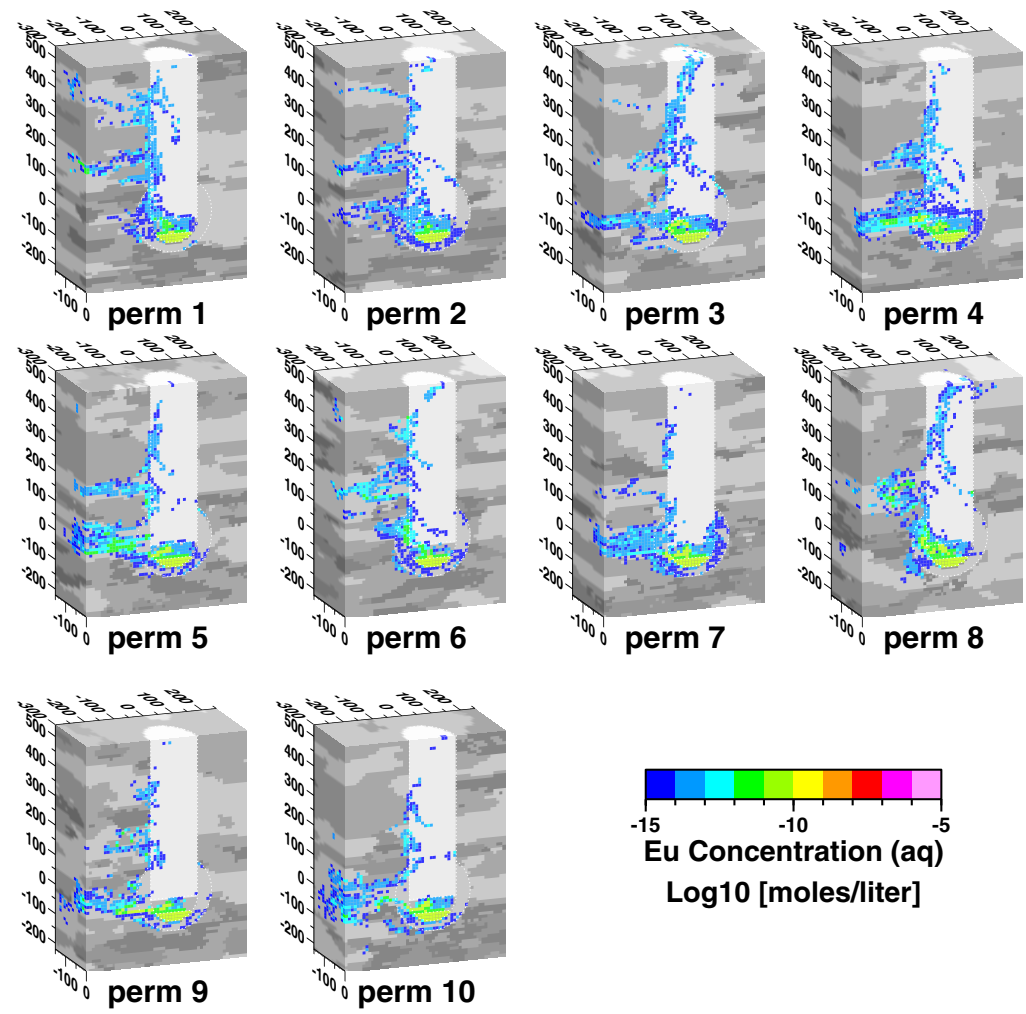

Figure 7.21 Cross-sectional perspective views of particle simulations of aqueous Eu concentration at $100 \mathrm{yr}$ after CHESHIRE test for mineralization realization 1 with 10 different permeability realizations. 


\subsubsection{Np and Permeability}

Figure 7.22 shows cross-sectional perspective views of simulated aqueous $\mathrm{Np}$ concentrations for mineralization realization 1 with 10 different permeability realizations at $10 \mathrm{yr}$ after the CHESHIRE test. The gray-shaded background represents different hydrofacies, with lighter shading representing higher permeabilities. Comparing this figure with Figures 7.18 and 7.20, Np is more mobile than Am or Eu. Given its mobility, Np is strongly influenced by the recirculation cells in the chimney and tends to reach all high-permeability zones adjacent to the chimney.

Figure 7.23 shows Np concentrations at $100 \mathrm{yr}$. By this time, high concentrations of $\mathrm{Np}$ are primarily derived from melt glass dissolution, as evident in permeability realizations 4,6 , and 10 . Some $\mathrm{Np}$ remains in the chimney as a result of recirculation cells, particularly for permeability realization 10 . Some $\mathrm{Np}$ remains trapped in lower permeability zones as a result of large-scale effects, similar in character to matrix diffusion, and decay from Am also trapped in the low-permeability zones. Comparing Figures 7.19 and 7.23, it appears that Np generated from Am in highpermeability zones migrates rapidly out of the near-field domain.
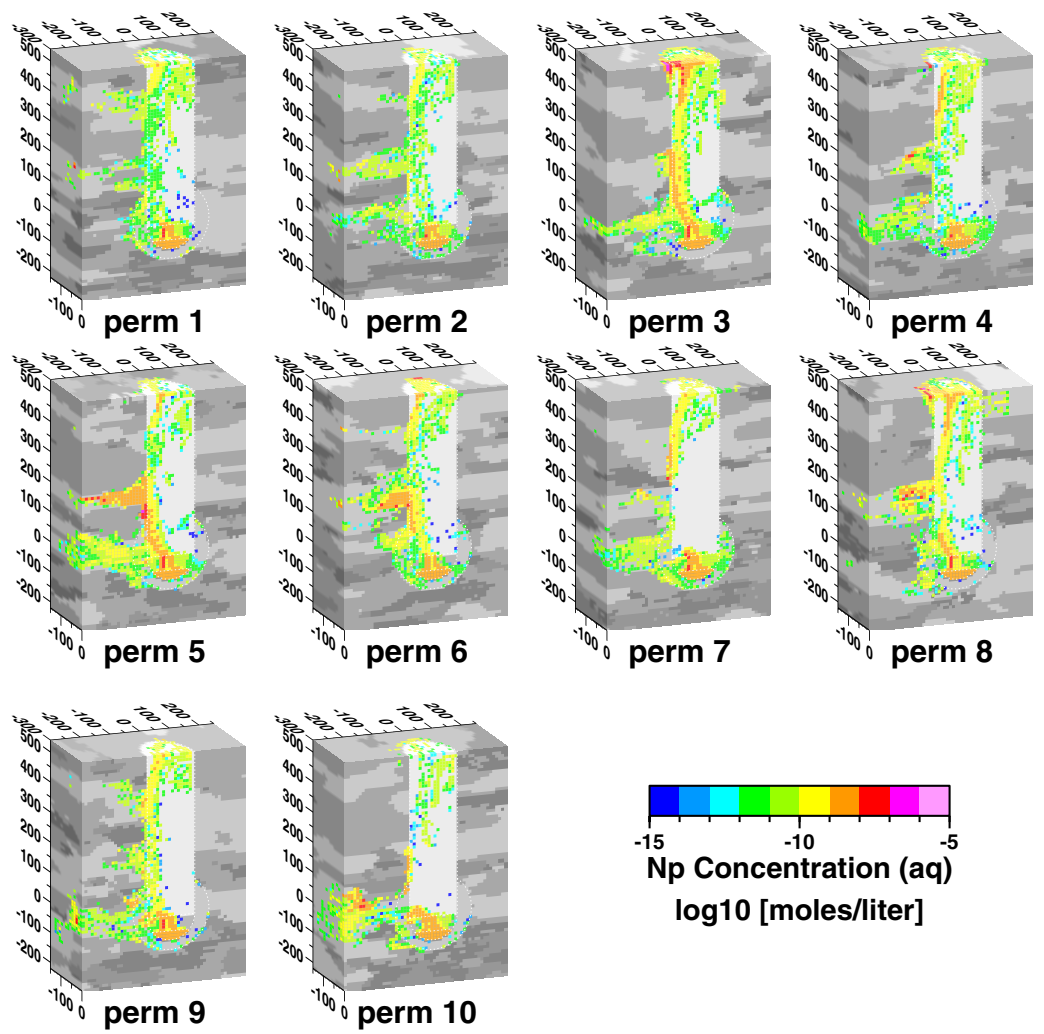

Figure 7.22 Cross-sectional perspective views of particle simulations of aqueous $\mathrm{Np}$ concentration at $10 \mathrm{yr}$ after CHESHIRE test for mineralization realization 1 with 10 different permeability realizations. 

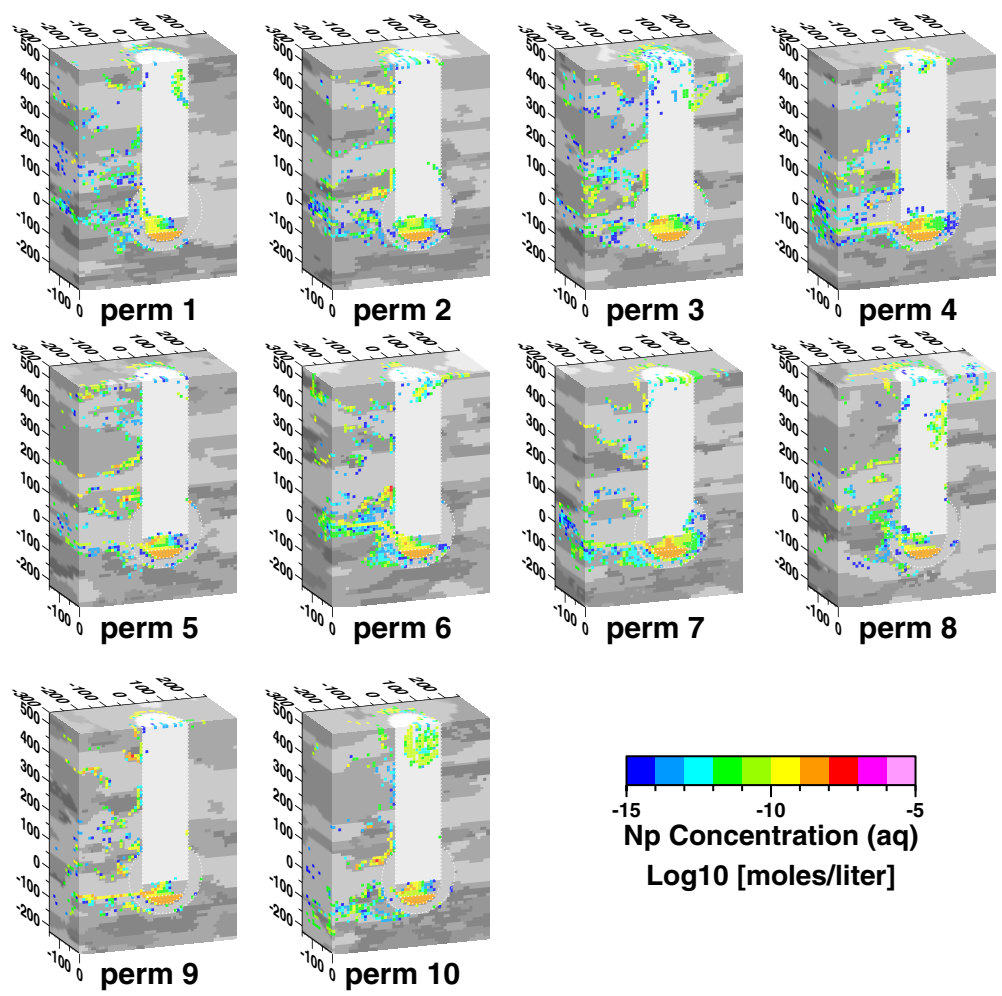

Figure 7.23 Cross-sectional perspective views of particle simulations of aqueous $\mathrm{Np}$ concentration at $100 \mathrm{yr}$ after CHESHIRE test for mineralization realization 1 with 10 different permeability realizations.

\subsubsection{6 $\quad{ }^{241} \mathrm{Pu}$ and Permeability}

Figure 7.24 shows cross-sectional perspective views of simulated aqueous ${ }^{241} \mathrm{Pu}$ concentrations for mineralization realization 1 with 10 different permeability realizations at $10 \mathrm{yr}$ after the CHESHIRE test. The gray-shaded background represents different hydrofacies, with lighter shading representing higher permeability. Comparison of the $\mathrm{Am}, \mathrm{Np}$, and ${ }^{241} \mathrm{Pu}$ concentrations in Figures 7.18, 7.22, and 7.24 is interesting because of their relationships to the ${ }^{241} \mathrm{Pu} \rightarrow \mathrm{Am} \rightarrow \mathrm{Np}$ decay chain. The spatial distributions of ${ }^{241} \mathrm{Pu}$ and Am are very similar in each realization, while $\mathrm{Np}$ displays significantly more mobility.

Figure 7.25 shows ${ }^{241} \mathrm{Pu}$ concentrations at 100 yr. Comparing Figures 7.19, 7.23, and 7.25, Am and Np display similar spatial distributions and concentration, while ${ }^{241} \mathrm{Pu}$ concentrations are dwindling as a result of decay.

The comparisons of $\mathrm{Am}, \mathrm{Np}$, and ${ }^{241} \mathrm{Pu}$ concentration distributions at 10 and $100 \mathrm{yr}$ indicate three important points:

- The presence of $\mathrm{Np}$ in the near-field environment is more exclusively tied to the presence of Am at later times than at earlier times.

- Spatial distributions of $\mathrm{Am}$ and ${ }^{241} \mathrm{Pu}$ concentrations are more closely associated with each other at earlier times than at later times.

- ${ }^{241} \mathrm{Pu}$ and $\mathrm{Np}$ concentrations may not necessarily be closely associated with each other because of the rapid decay of ${ }^{241} \mathrm{Pu}$. 

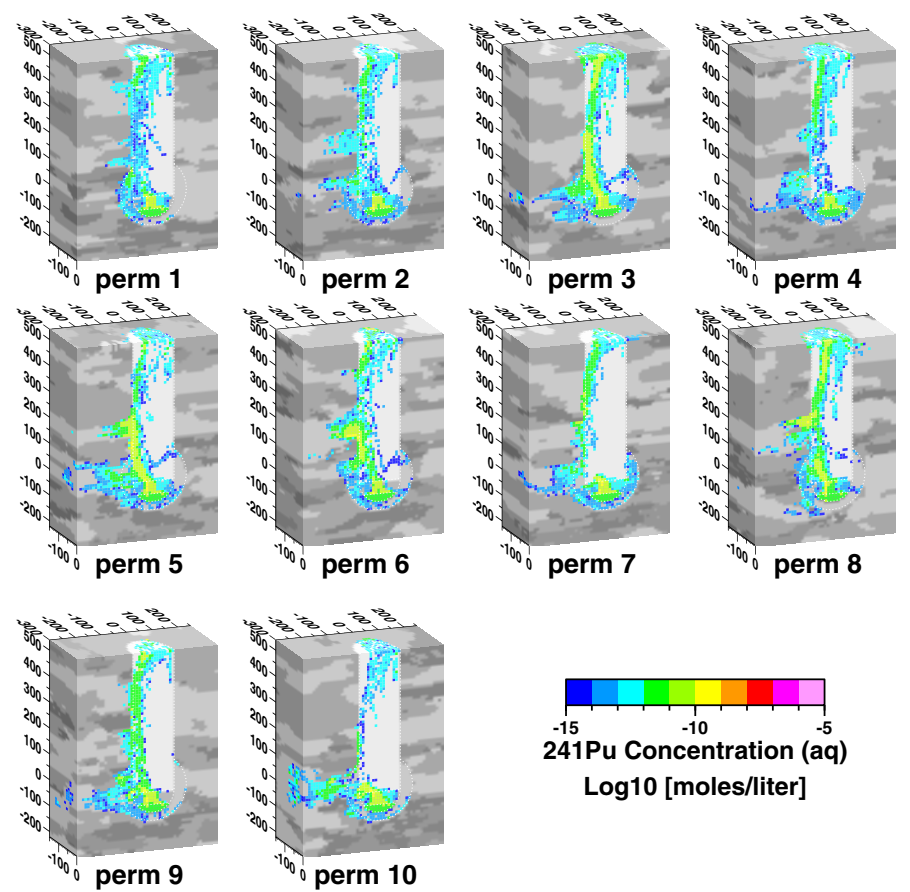

Figure 7.24 Cross-sectional perspective views of particle simulations of aqueous ${ }^{241} \mathrm{Pu}$ concentration at $10 \mathrm{yr}$ after CHESHIRE test for mineralization realization 1 with 10 different permeability realizations.
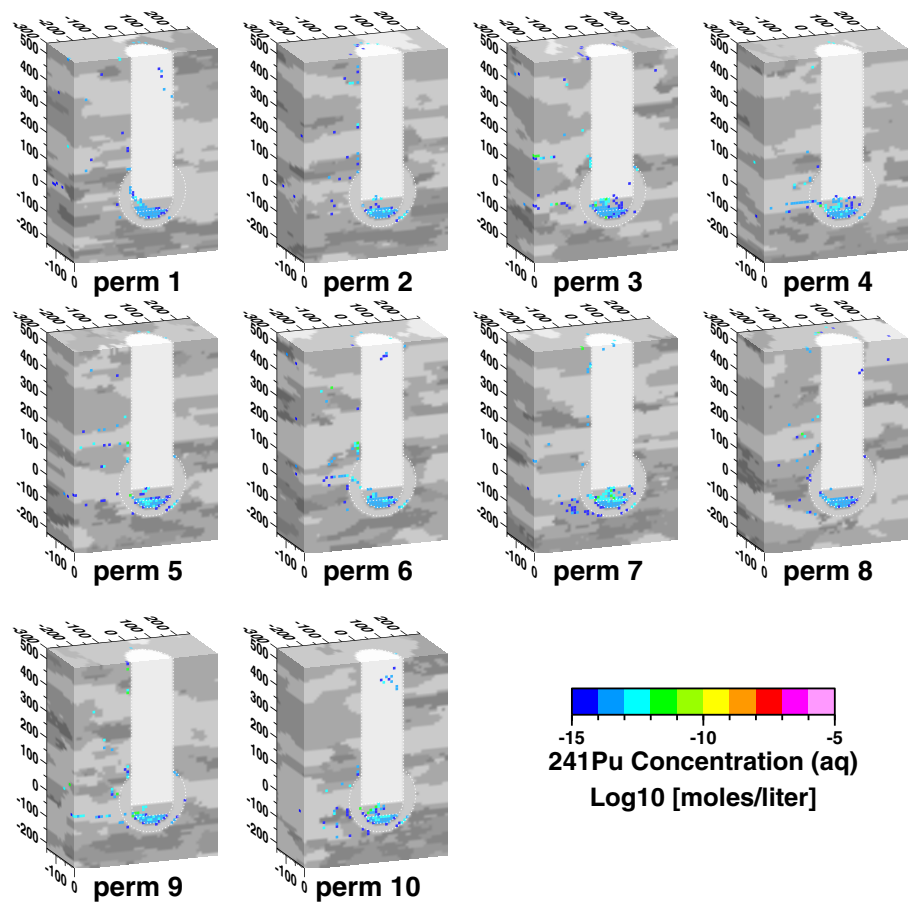

Figure 7.25 Cross-sectional perspective views of particle simulations of aqueous ${ }^{241} \mathrm{Pu}$ concentration at $100 \mathrm{yr}$ after CHESHIRE test for mineralization realization 1 with 10 different permeability realizations. 


\subsubsection{U and Permeability}

Figure 7.26 shows cross-sectional perspective views of simulated aqueous $U$ concentrations for mineralization realization 1 with 10 different permeability realizations at $10 \mathrm{yr}$ after the CHESHIRE test. The gray-shaded background represents different hydrofacies, with lighter shading representing higher permeability. All realizations show that $U$ migration is strongly influenced by recirculation in the chimney, and down-gradient migration can occur in any of the high-permeability zones adjoining the chimney. Compared with the $U$ concentrations resulting from different mineralization realizations (Figure 7.16), similar patterns of spatial variability are evident in Figures 7.26. Thus, the particle model simulations indicate that spatial variability of permeability and mineralization can have similar influences on $U$ migration at $10 \mathrm{yr}$.

Figure 7.27 shows $U$ concentrations at $100 \mathrm{yr}$. The spatial distribution of $U$ is associated with a narrow down-gradient plume derived from melt glass dissolution and additional $U$ trapped in lower-permeability zones. The melt glass plume is not necessarily seen in all of the cross-sectional views because of the three-dimensionality of the down-gradient flow paths. Comparing Figures 7.17 and 7.27, there is more spatial variability in the melt glass plume at 100 yr resulting from permeability variations compared with mineralization variations.
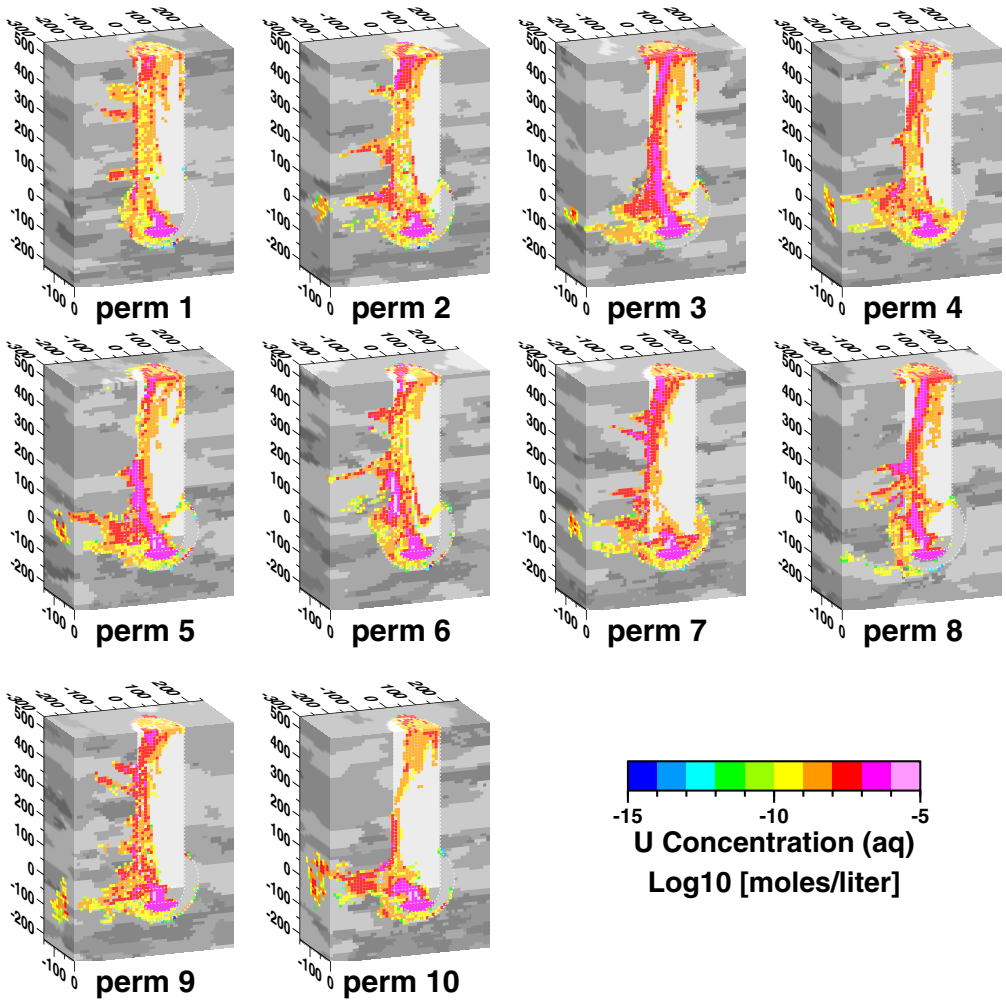

Figure 7.26 Cross-sectional perspective views of particle simulations of aqueous $\mathrm{U}$ concentration at $10 \mathrm{yr}$ after CHESHIRE test for mineralization realization 1 with 10 different permeability realizations. 

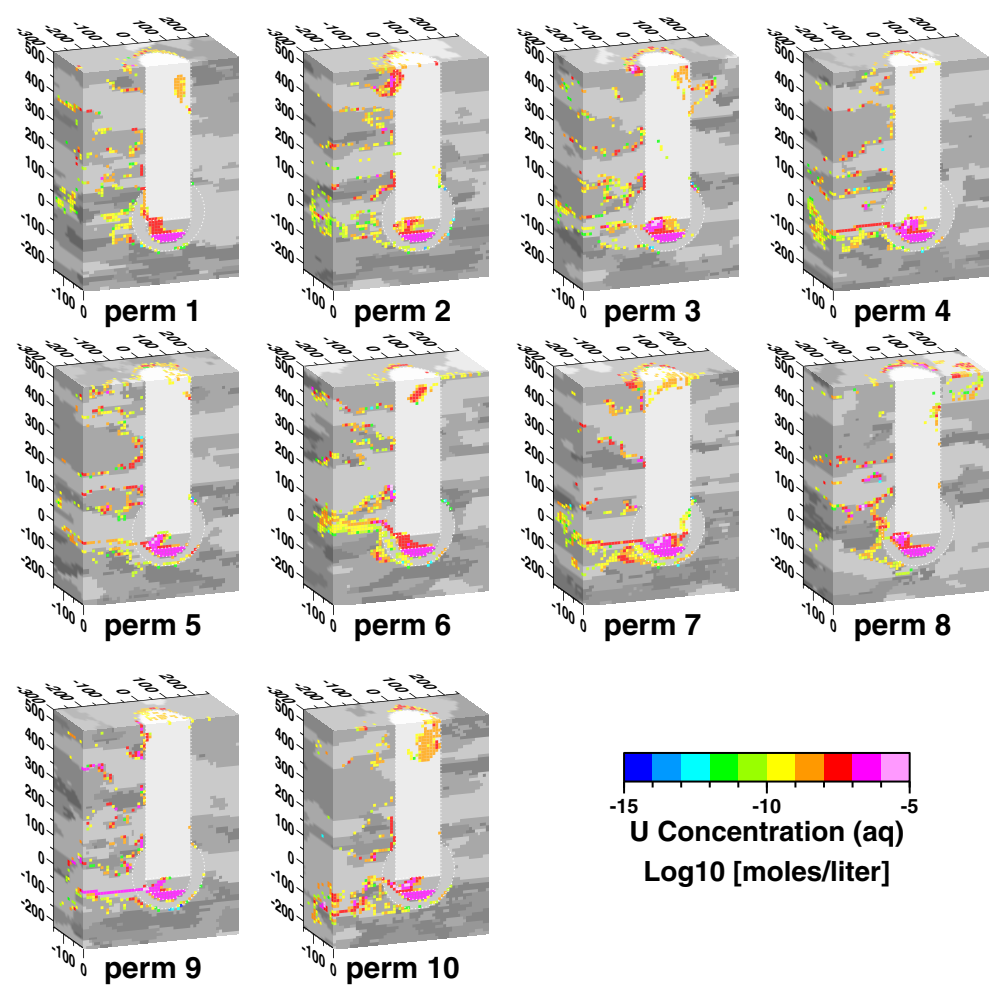

Figure 7.27 Cross-sectional perspective views of particle simulations of aqueous $U$ concentration at $100 \mathrm{yr}$ after CHESHIRE test for mineralization realization 1 with 10 different permeability realizations.

\subsubsection{Breakthrough Curves-All Realizations, All Radionuclides}

The particle transport model was applied to a total of 100 realizations using the base-case hydraulic and thermal properties described in Chapter 5 and the base-case geochemical properties described in Chapter 6. The 100 realizations consist of 10 different permeability realizations, each with 10 different mineralization realizations. Therefore, the 100 realizations are based on differences in the spatial distribution of mineralization zones and the spatial distribution of permeability zones associated with native rock hydrofacies. Uncertainties related to spatial variations of permeability and mineralization are expected to be some of the largest contributors to the uncertainty of predicting radionuclide mass flux from the near-field model domain. A less thorough analysis of model prediction sensitivity to other parameters is discussed in Section 7.5. The ability to perform Monte Carlo analyses of uncertainty, as presented in Figure 7.28, illustrates the capabilities of the computationally efficient particle transport model.

Figure 7.28 shows a composite of all 100 breakthrough curves for all realizations and all radionuclide classes- $\mathrm{Am},{ }^{41} \mathrm{Ca}, \mathrm{Cs}, \mathrm{Eu}, \mathrm{Np},{ }^{241} \mathrm{Pu}, \mathrm{Pu}, \mathrm{Sm}, \mathrm{Sr}$, and $\mathrm{U}$. The scales are log-log, with time on the $x$-axis in years and molar flux in moles per year on the $y$-axis. The same molar flux scale and range is used for all radionuclides. The range of molar flux spans 10 orders of magnitude, from $10^{-9}$ to $10 \mathrm{~mol} / \mathrm{yr}$. The mean and median of the molar flux breakthrough for the 100 realizations are shown by the red and green lines, respectively. The blue lines represent the lower and upper $5^{\text {th }}$ and $95^{\text {th }}$ percentiles of the suite of breakthrough curves for all 100 realizations. The gray lines are the breakthrough curves for each individual realization. 

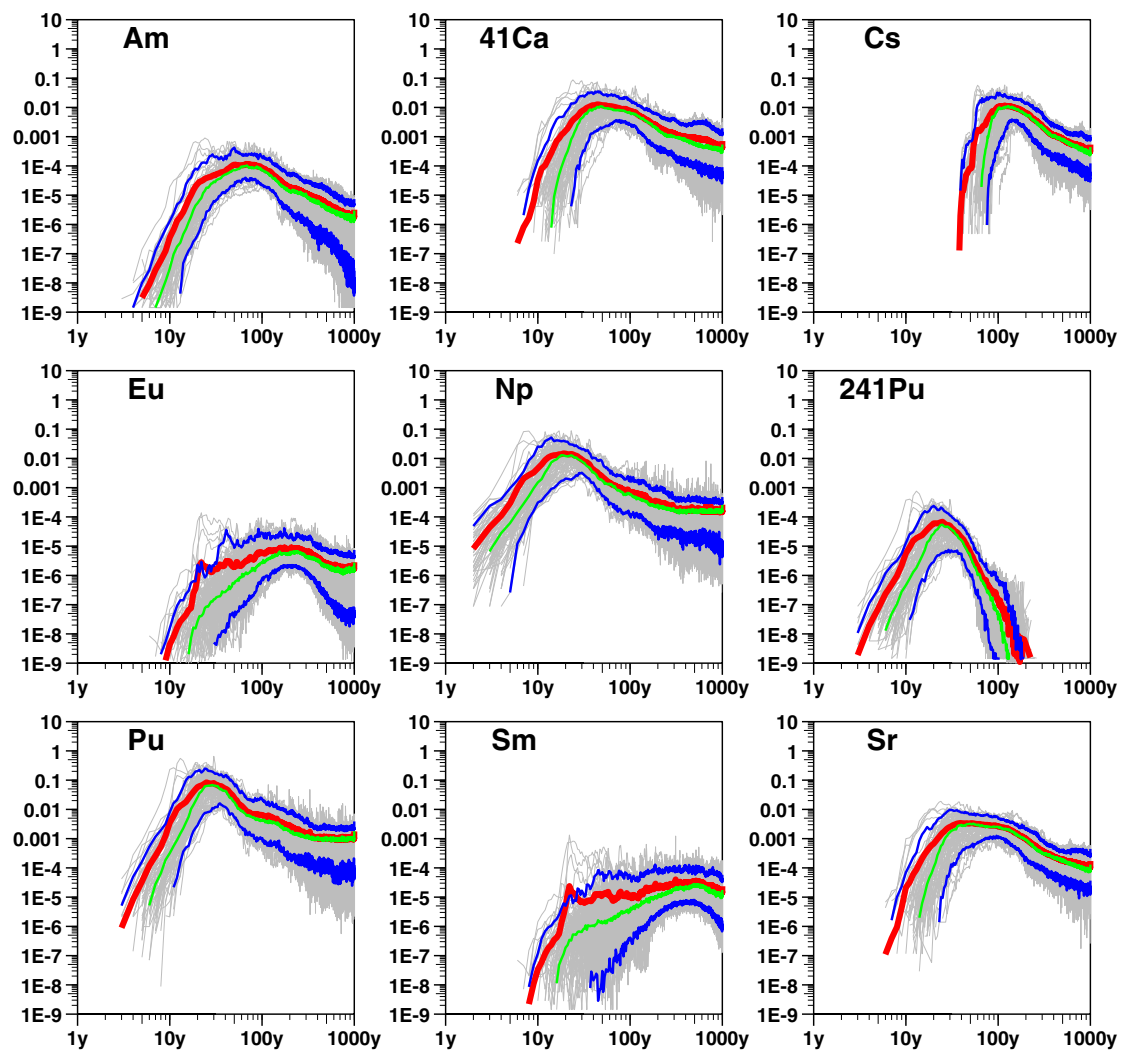

Flux at Breakthrough Plane [moles/year]
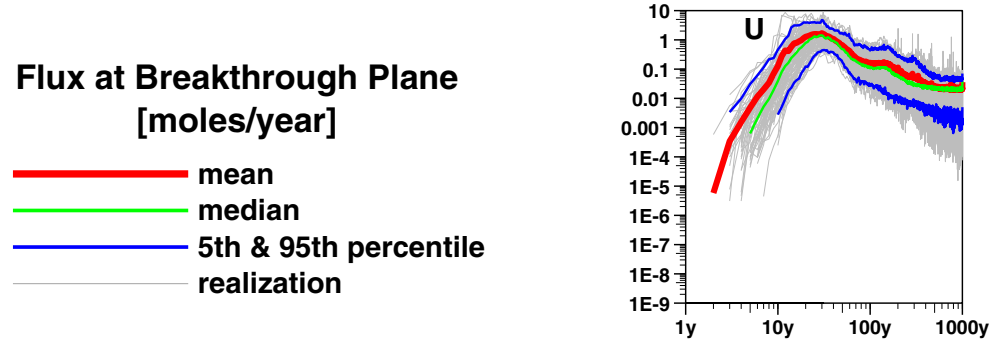

Figure 7.28 Particle simulations of breakthrough flux in moles per year of $\mathrm{Am},{ }^{41} \mathrm{Ca}, \mathrm{Cs}, \mathrm{Eu}$, and $\mathrm{Np}$, $\mathrm{Pu}$, ${ }^{241} \mathrm{Pu}, \mathrm{Sm}, \mathrm{Sr}$, and $U$ showing mean (red line), median (green line), and $5^{\text {th }}$ and $95^{\text {th }}$ percentiles (blue lines) for all 100 realizations (gray lines). Breakthrough plane is located $300 \mathrm{~m}$ down-gradient of CHESHIRE test.

In Figure 7.28, the shape of the breakthrough curve, time of first breakthrough, time of peak breakthrough, magnitude of breakthrough, and tailing of breakthrough are different for each radionuclide. These differences are attributed to the composite effect of various complexities built into the particle transport model including:

- Heterogeneous permeability structure.

- Test-related heat.

- Relative abundance of the radionuclide classes.

- Temperature-dependent melt glass dissolution. 
- Spatial variation of retardation.

- Variable retardation factors for different radionuclides.

- Radioactive decay.

Based on the mean values, initial breakthrough ranges from less than $2 \mathrm{yr}$ for $\mathrm{Np}$ and about 2-3 yr for $\mathrm{Pu}$ and $\mathrm{U}$ to $40 \mathrm{yr}$ for Cs. Time of peak breakthrough ranges from about $20 \mathrm{yr}$ for $\mathrm{Np}$ and $25 \mathrm{yr}$ for $\mathrm{Pu},{ }^{241} \mathrm{Pu}$, and $\mathrm{U}$ to $200 \mathrm{yr}$ for Eu. The relative retardation of the radionuclide classes is consistent with average retardation values listed in Table K.9. Magnitude of peak mass flux ranges from about $10^{-5} \mathrm{~mol} / \mathrm{yr}$ for $\mathrm{Eu}$ to $2 \mathrm{~mol} / \mathrm{yr}$ for $\mathrm{U}$.

Based on the $5^{\text {th }}$ and $95^{\text {th }}$ percentiles, a wide range of breakthrough behavior is possible. Initial breakthrough of $\mathrm{Np}$ could be as late as $5 \mathrm{yr}$, and for $\mathrm{Pu}$ and $\mathrm{U}$ it could be as late as $10 \mathrm{yr}$. Time of peak breakthrough for $\mathrm{Np}$ could be between about 13 and $30 \mathrm{yr}$, for $\mathrm{Pu},{ }^{241} \mathrm{Pu}$, and $\mathrm{U}$ it could be between 20 and $35 \mathrm{yr}$, for Eu it could be between 100 and $300 \mathrm{yr}$, for Sr it could be 25 and $100 \mathrm{yr}$. Magnitude of peak breakthrough for all radionuclide classes varies by about an order of magnitude or more.

Figure 7.29 plots mass breakthrough for all 10 permeability realizations for the three composite tracer cases, TracerGW, TracerEV, and TracerMG. There is much less uncertainty in the peak arrival time and the magnitude of the three tracers than was seen in the radionuclide classes. This reduced uncertainty in tracer breakthrough is largely because the variation in mineral distribution does not affect the migration of tracers. The three tracer cases all exhibit less than an order of magnitude spread in the prediction of the peak mass flux. There is significantly more uncertainty in the mass flux at later times. The tracer breakthrough curves are affected only by the differences in permeability distribution between realizations, impact of test-related heat, and impact of melt glass dissolution (in the case of TracerMG).

Again, this variation in breakthrough behavior shown in Figures 7.28 and 7.29 results only from our stochastic models of the spatial distribution of permeability and mineralization. Further uncertainty could be attributed to the important assumptions built into these particle model simulation results-that our conceptual hydrogeologic, flow, and transport models and their parameters are all correct.
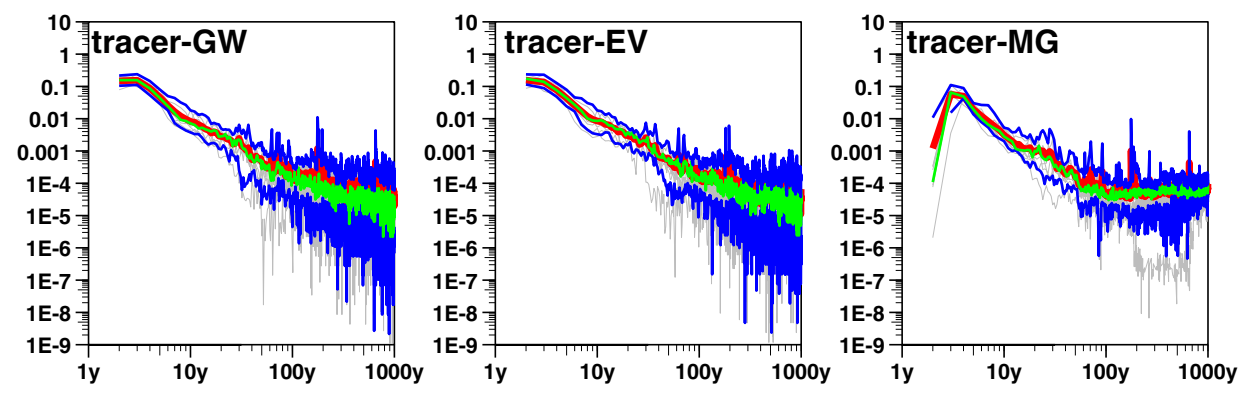

Figure 7.29 Particle simulations of breakthrough flux in moles per year of TracerGW, TracerEV, and TracerMG showing mean (red line), median (green line), and $10^{\text {th }}$ and $90^{\text {th }}$ percentiles (blue lines) for all 10 realizations (gray lines). Breakthrough plane is located $300 \mathrm{~m}$ down-gradient of CHESHIRE test. 
Because the distributions of breakthrough curves for radionuclide classes shown in Figures 7.28 and 7.29 include the composite effect of spatial variation of both permeability and mineralization, the specific effects of spatial variation of either permeability or mineralization by itself cannot be deduced from those figures. To assess the relative contributions of the spatial variation of permeability and mineralization, Figure 7.30 compares distributions of radionuclide breakthrough curves for 10 mineralization realizations having the same permeability distribution, and Figure 7.31 compares distributions of radionuclide breakthrough curves for 10 permeability realizations having the same mineralization distribution. Therefore, Figure 7.30 shows variation of breakthrough resulting from different mineralization realizations, and Figure 7.31 shows variation in breakthrough resulting from different permeability realizations. The mean, median, and $5^{\text {th }}$ and $95^{\text {th }}$ percentiles from the full suite of 100 realizations are shown for reference. In this comparison, similar degrees of variability are evident in the breakthrough curves, indicating that the spatial variability of permeability and spatial variability of mineralization have similar impacts on the variability of radionuclide breakthrough.

Figure 7.32 displays the ensemble of breakthrough behavior on linear scales with respect to cumulative normalized mass, which is referenced with respect to the mass of the RST radionuclide classes. These curves indicate the proportion of each radionuclide that has left the near-field domain over time; the mean cumulative breakthrough of ${ }^{241} \mathrm{Pu}$ levels off at about 0.09 within $100 \mathrm{yr}$, for example. According to the particle transport simulations, no ${ }^{241} \mathrm{Pu}$ is leaving the near-field domain after $100 \mathrm{yr}$, and, on average, about $9 \%$ of the ${ }^{241} \mathrm{Pu}$ that originated as a result of the CHESHIRE test leaves the near-field model domain. However, it is important to note that ${ }^{241} \mathrm{Pu}$ decay is accounted for in these data and the ${ }^{241} \mathrm{Pu}$ half-life is rather short (14.4 years). This decay effect may be observed by comparing the breakthrough of ${ }^{241} \mathrm{Pu}$ to $\mathrm{Pu}$ (which has not been decay-corrected). The difference between these sets of curves is the result of ${ }^{241} \mathrm{Pu}$ decay. The effect of Am ingrowth (from ${ }^{241} \mathrm{Pu}$ decay) may be seen by comparing Am and $\mathrm{Eu}$ breakthrough curves. The transport properties of $\mathrm{Am}$ and $\mathrm{Eu}$ are expected to be similar. Thus, any differences in the breakthrough curves, such as the greater cumulative breakthrough for Am at early times (0-300 yr), may be attributed to Am ingrowth. The $5^{\text {th }}$ and $95^{\text {th }}$ percentile values indicate that a wide range of cumulative breakthrough is possible for each radionuclide. For example, the particle model indicates that the cumulative mass of Sm leaving the near-field domain could range from about 9 to 55\% at 1000 yr. Interestingly, at $1000 \mathrm{yr}$ all radionuclides besides Eu, ${ }^{241} \mathrm{Pu}$, and $\mathrm{Sm}$, which are strongly decayed or retarded, exhibit similar mean cumulative mass breakthrough of about 0.6 . The shapes of the mean cumulative breakthrough curves are sufficiently smooth that they might be useful for extrapolating predictions of cumulative breakthrough to times beyond $1000 \mathrm{yr}$. 

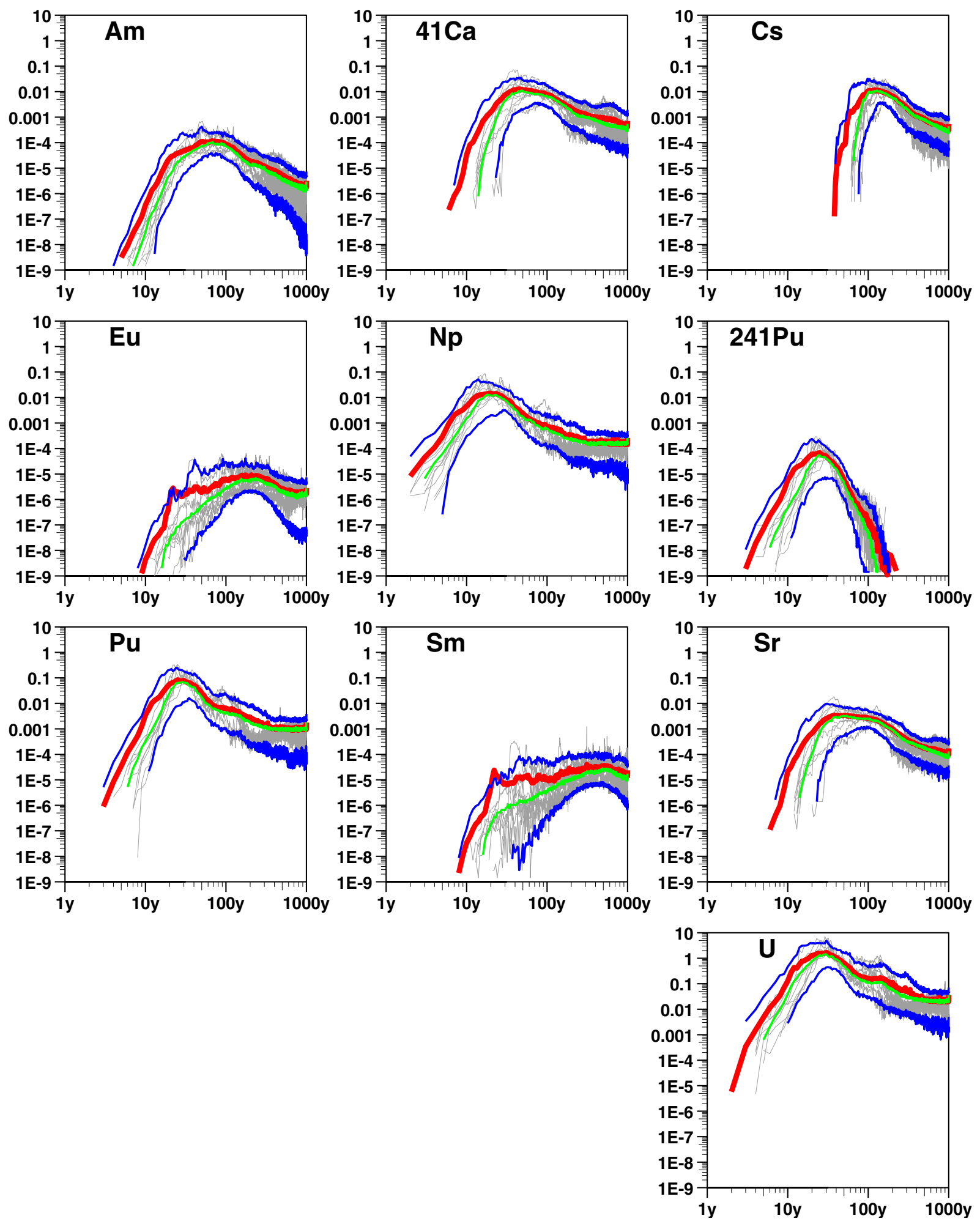

Figure 7.30 Variation of particle simulation breakthrough behavior resulting from permeability realization 9 with 10 different mineralization realizations (gray lines) compared with mean (red line), median (green line) and $5^{\text {th }}$ and $95^{\text {th }}$ percentile (blue lines) for all 100 realizations. 

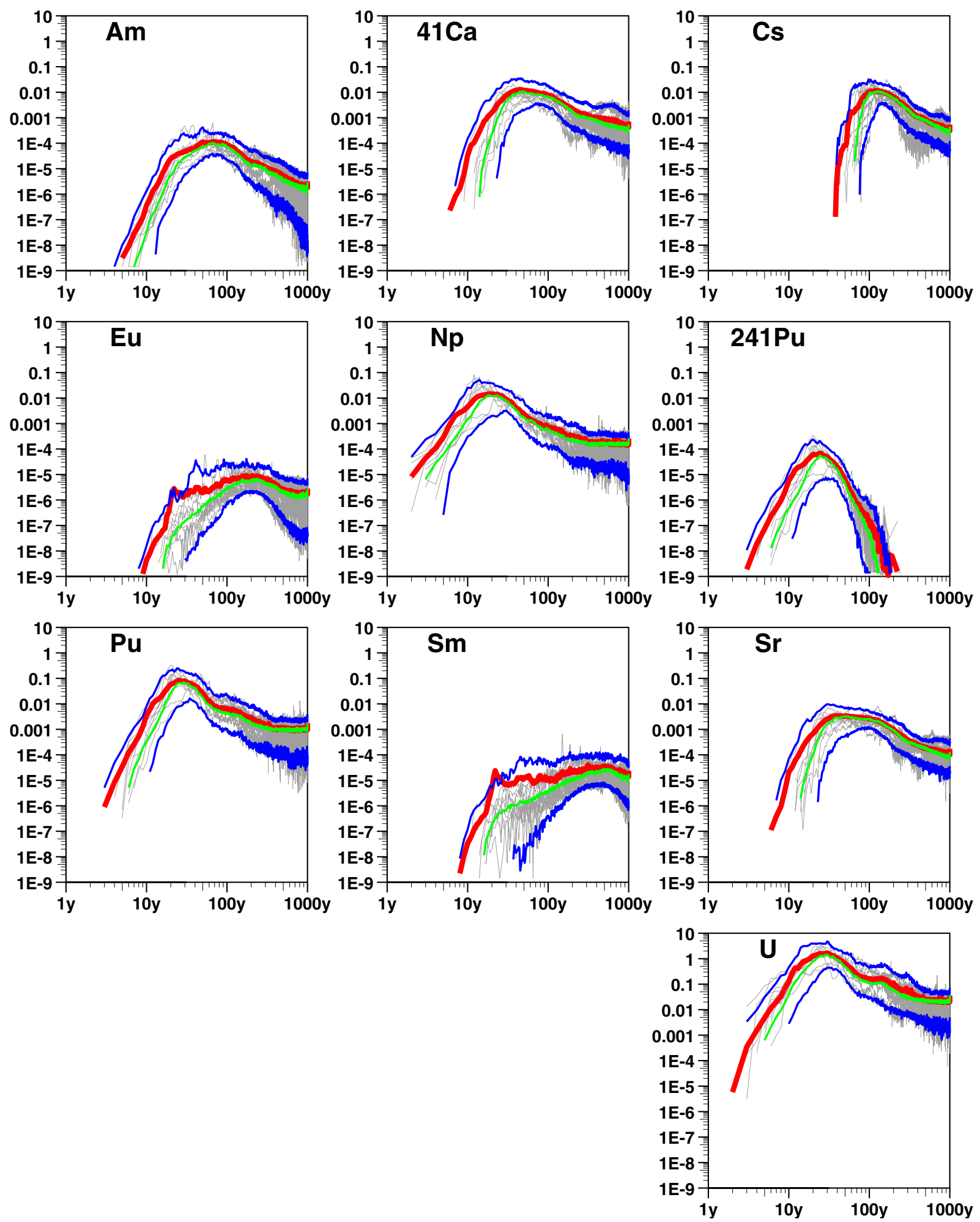

Figure 7.31 Variation of particle simulation breakthrough behavior resulting from mineralization realization 1 with 10 different permeability realizations (gray lines) compared with mean (red line), median (green line) and $5^{\text {th }}$ and $95^{\text {th }}$ percentile (blue lines) for all 100 realizations. 

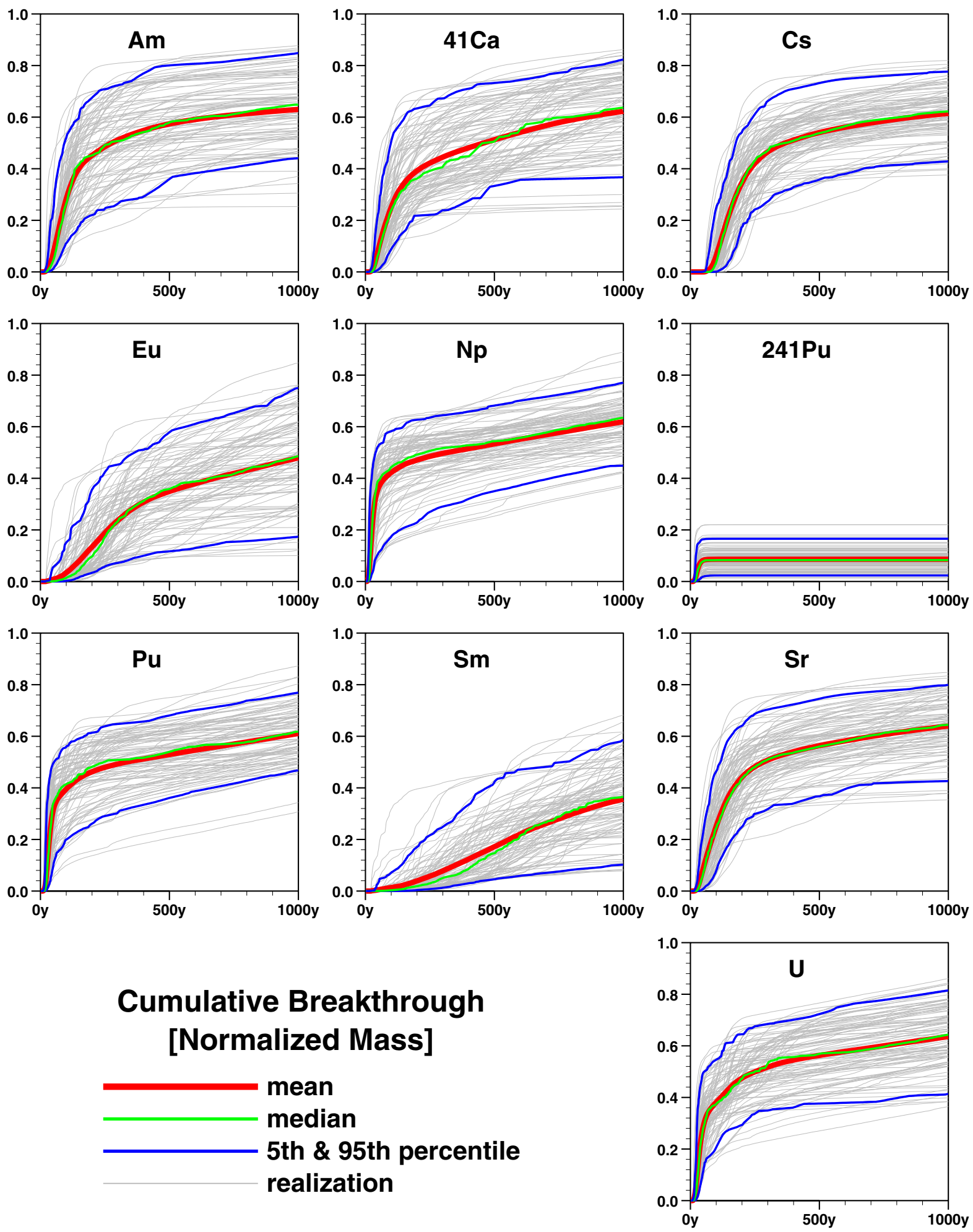

Figure 7.32 Particle simulations of cumulative normalized mass flux of $\mathrm{Am},{ }^{41} \mathrm{Ca}, \mathrm{Cs}$, Eu, and $\mathrm{Np}$, $\mathrm{Pu},{ }^{241} \mathrm{Pu}, \mathrm{Sm}, \mathrm{Sr}$, and $\mathrm{U}$ for all 100 realizations (gray lines), mean (red line), median (green line), and $5^{\text {th }}$ and $95^{\text {th }}$ percentiles (blue lines). 
Figure 7.33 plots the molar flux breakthrough for the decay chain ${ }^{241} \mathrm{Pu}, \mathrm{Am}$ and $\mathrm{Np}$ for permeability realization 9, mineralization realization 1 . All ${ }^{241} \mathrm{Pu}, \mathrm{Am}$ and $\mathrm{Np}$ in the RST and produced and removed by decay, ingrowth, or both, are included in this simulation. This figure demonstrates the effects of real-time decay of three radionuclides with different mobilities. $\mathrm{Np}$ is the most mobile of the three radionuclides, with a first arrival at the breakthrough plane occurring at $2 \mathrm{yr}$ and a peak molar flux at approximately $15 \mathrm{yr}$. Am is the least mobile of the three radionuclides and would normally have a peak molar flux at about 100 yr. Figure 7.33 clearly shows an initial breakthrough of Am starting between 10 and $11 \mathrm{yr}$, following the breakthrough of ${ }^{241} \mathrm{Pu}$ very closely. This first peak of Am at $\sim 50 \mathrm{yr}$ is due to continuous decay of ${ }^{241} \mathrm{Pu}$, which is modulated when the source of ${ }^{241} \mathrm{Pu}$ disappears before $100 \mathrm{yr}$. Am has a longer half-life than ${ }^{241} \mathrm{Pu}$, and undergoes significant change in total mass due to radioactive decay starting around $300 \mathrm{yr}$. The effect of this decay is seen in the breakthrough of $\mathrm{Np}$ after $400 \mathrm{yr}$, which increases, creating a second peak breakthrough of $\mathrm{Np}$ due to radioactive ingrowth.

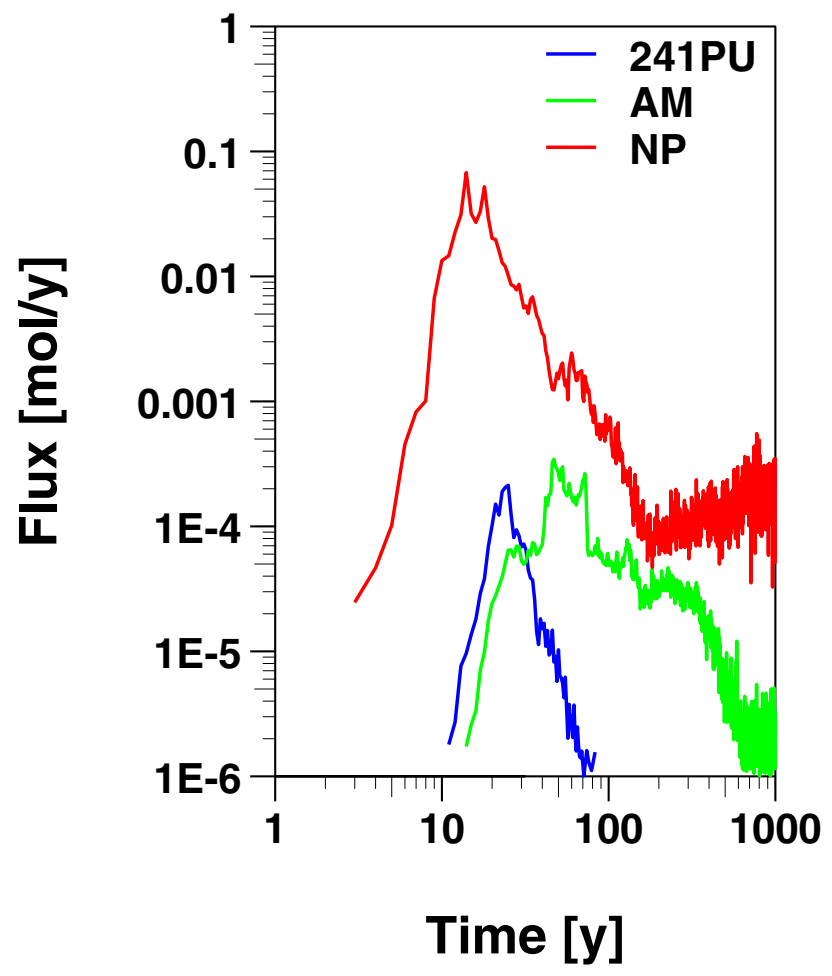

Figure 7.33 Particle simulations of breakthrough flux in moles per year of $\mathrm{Am},{ }^{241} \mathrm{Pu}$, and $\mathrm{Np}$ for permeability realization 9 , mineralization realization 1 . 


\subsection{Additional Sensitivity Studies}

The computational efficiency of the particle transport model is useful for conducting sensitivity studies on reactive transport behavior in the complex threedimensional, transient near-field flow system of the CHESHIRE test. Sensitivity studies were conducted to evaluate the effect of test-related heat, the conceptual model, and fracture-scale matrix diffusion.

\subsubsection{Effect of Test-Related Heat}

To evaluate the effect of test-related heat, particle transport simulations were conducted for permeability realization 9 without test-related heat assuming an ambient (steady-state) flow field. The flow field of the final time step from the permeability realization 9 was assumed as the ambient flow field. This flow field was considered very close to steady-state as prescribed by the base-case boundary conditions given in Chapter 5, observing that the temperature field changes very little between 100 and 1000 yr (Figure 5.13, row 9).

Figure 7.34 compares breakthrough curves for exchange volume (TracerEV), melt glass (TracerMG), and gas/water (TracerGW) tracers and the radionuclides Pu and Sm. Breakthrough curves for permeability realization 9 , mineralization realization 1 without test-related heat (orange lines) are compared to breakthrough curves with testrelated heat (gray lines) and the range of breakthrough defined by the $5^{\text {th }}$ and $95^{\text {th }}$ percentiles of all 100 realizations for the radionuclide classes and the $10^{\text {th }}$ and $90^{\text {th }}$ percentiles for the tracers with base-case parameters. For TracerEV and TracerGW, there is actually a greater breakthrough before 2 yr without test-related heat. The greater early-time breakthrough occurs because test-related heat tends to drive transport pathways from portions of the disturbed zone upward; without test-related heat, transport pathways are more directly routed down-gradient toward the breakthrough plane via the nearest high-permeability zones connected to the disturbed zone. In terms of overall breakthrough behavior, as indicated by the $5^{\text {th }}$ and $95^{\text {th }}$ percentiles, the TracerEV and TracerGW simulations without test-related heat are not significantly different from simulations with test-related heat.

For the melt glass tracer (TracerMG), however, the effect of test-related heat is pronounced. Without test-related heat, breakthrough is significantly delayed and dampened compared with simulation with test-related heat. This dampening results from a combination of the slower glass dissolution rate at lower temperature, the lower hydraulic conductivity of the melt glass at lower temperature, and differences in the flow field. Between 3 and 4 yr, when the transport simulation for permeability realization 9, mineralization 1 with test-related heat is achieving a peak breakthrough of over 0.5 moles per year, breakthrough from the simulation without test-related heat is slightly over $1 \times 10^{-7} \mathrm{~mol} / \mathrm{yr}$, over 6 orders of magnitude lower. Without test-related heat, breakthrough of TracerMG reaches a maximum flux of about $1 \times 10^{-4} \mathrm{~mol} / \mathrm{yr}$ at 1000 yr. Because this flux is also about the same flux as for the simulation with testrelated heat at $1000 \mathrm{yr}$, this late-time flux probably represents an amount that is largely determined by melt glass dissolution under ambient flow conditions. With test-related 
heat, the melt glass dissolution rate is higher, such that a much greater amount of TracerMG is available for transport. The integrated effect of test-related heat on breakthrough for TracerMG is represented by the area between the gray and orange curves. This difference is much more pronounced on a linear scale.

For $\mathrm{Pu}$, the effect of test-related heat is not significant until after about $15 \mathrm{yr}$. From 20 to $150 \mathrm{yr}$, molar flux of $\mathrm{Pu}$ is about an order of magnitude higher with testrelated heat than without test-related heat. This difference in Pu breakthrough between 20 to 150 yr is similar in magnitude to the variation in Pu breakthrough as a result of spatial variation of permeability and mineralization (blue lines). Therefore, the effect of test-related heat and heterogeneity are of comparable importance for evaluating migration of $\mathrm{Pu}$ out of the near-field environment.

For Sm, the breakthrough curves with and without test-related heat show a less distinctive difference compared with $\mathrm{Pu}$. In fact, breakthrough before about $150 \mathrm{yr}$ is greater without test-related heat than with test-related heat. After about $150 \mathrm{yr}$, breakthrough of Sm appears greater with test-related heat.

Based on analysis of particle transport simulations with and without testrelated heat, the following conclusions are made:

- Tracers that originate from melt glass will be more affected by test-related heat.

- For some radionuclides, test-related heat could enhance the magnitude of peak breakthrough by an order of magnitude.

- Radionuclides exhibiting highly retarded transport, such as Sm, will be less affected by test-related heat.

- Depending on the permeability distribution, test-related heat could actually delay initial breakthrough of some radionuclides by forcing initial transport upward through the chimney instead of laterally to the nearest high-permeability zones. 

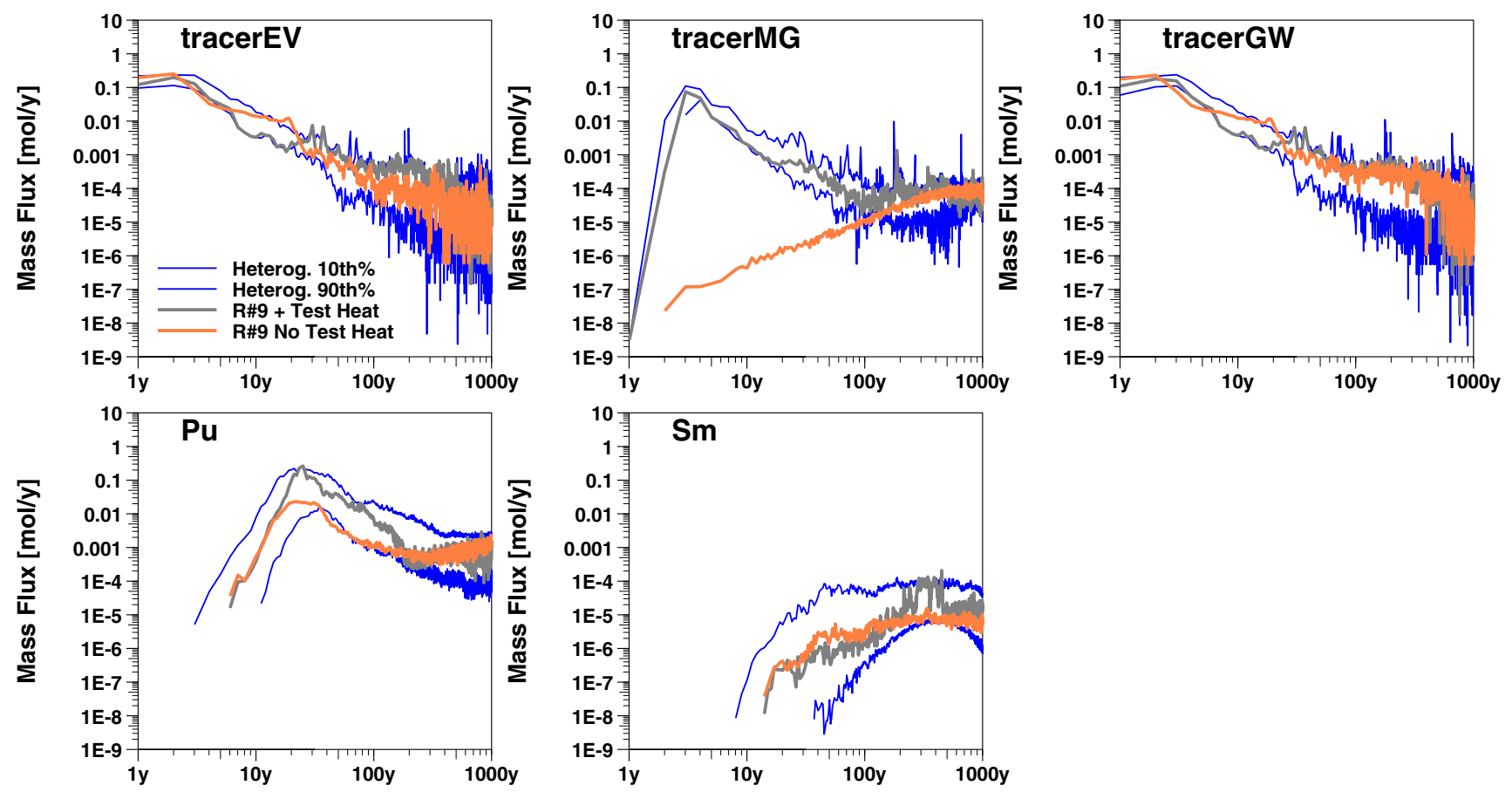

Figure 7.34 Particle simulations of breakthrough flux comparing results with and without test-related heat for TracerEV, TracerMG, TracerGW, and radionuclides Pu and Sm.

\subsubsection{Effect of Conceptual Model}

Differences in breakthrough behavior for the three conceptual modelsheterogeneous, layer cake, and homogeneous-illustrate the range of transport predictions that could result from different hydrogeological assumptions. In addition to simulations for heterogeneous realizations, the particle transport model was used to simulate TracerEV and TracerMG for the layer cake and homogeneous models. Particle transport simulations using the homogenous model were also applied to TracerGW and the radionuclides $\mathrm{Cs}$ and $\mathrm{Sm}$.

Figure 7.35 compares the resulting breakthrough curves for the layer cake and homogeneous cases with the $5^{\text {th }}$ and $95^{\text {th }}$ percentiles of the breakthrough curves for the 100 heterogeneous realizations for the radionuclide classes and the $10^{\text {th }}$ and $90^{\text {th }}$ percentiles for the tracers. Breakthrough of TracerEV and TracerMG for the layer cake model (light blue lines) largely falls within the $10^{\text {th }}$ and $90^{\text {th }}$ percentiles of the heterogeneous realizations. Breakthrough behavior for TracerEV and TracerMG and the homogeneous model, however, appears very different. For the heterogeneous and layer cake models, peak breakthrough of TracerEV and Tracer MG appears between 2 and $4 \mathrm{yr}$. For the homogeneous model, peak breakthrough appears at about $20 \mathrm{yr}$ for TracerEV and from about 5 to $30 \mathrm{yr}$ for TracerMG. The magnitude of peak breakthroughs for TracerEV and TracerMG is significantly lower for the homogeneous model. Assuming the heterogeneous conceptual model is most realistic, the layer cake model would be a much better conceptual model than the homogeneous model in terms of predicting near-field breakthrough behavior. 

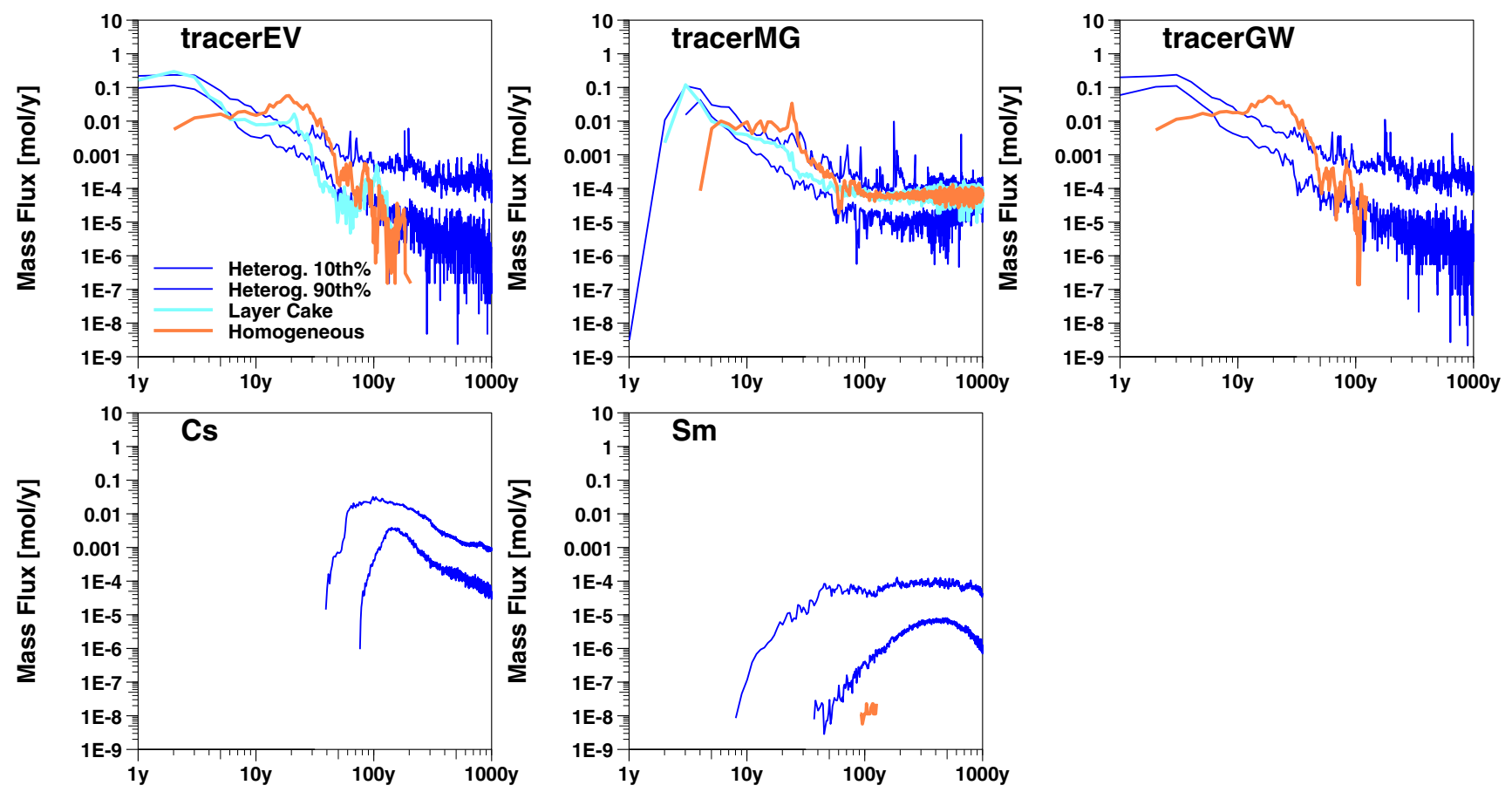

Figure 7.35 Particle simulations of breakthrough flux comparing results for heterogenous, layer cake, and homogenous conceptual models for TracerEV, TracerMG, and TracerGW, and radionuclides $\mathrm{Cs}$ and $\mathrm{Sm}$. Note that layer cake model was not run for TracerGW and the radionuclides $\mathrm{Cs}$ and $\mathrm{Sm}$.

For the homogenous conceptual model, the breakthrough behavior for TracerGW and TracerEV are very similar, as expected. The homogenous model exhibits no breakthrough of Cs and minimal breakthrough of Sm within $1000 \mathrm{yr}$. Thus, for some radionuclides, the choice of conceptual model could not only determine the character of breakthrough behavior, but also the fundamental presence or absence of radionuclide flux out of the near-field environment.

\subsubsection{Effect of Matrix Diffusion}

One simulation case examined the effects of matrix diffusion on mass breakthrough at the downstream plane for TracerGW. For this simulation, the approximate particle method of Liu et al., (2000) as detailed in Appendix D.4 was used. Matrix diffusion was simulated only in the high- and moderate-permeability zones and not in any other hydrofacies. Using Eqs. (D11a) and (D11b), with values of $B \sim 0.0619 \mathrm{~m}$, $b \sim 6.24 \times 10^{-4} \mathrm{~m}, \phi_{\mathrm{m}} \sim 0.15$ and $D_{f m} \sim 8.64 \times 10^{-6} \mathrm{~m}^{2} / \mathrm{d}$, the forward and reverse probabilities were found to be $P_{j, f m} / \Delta t=0.67$ and $P_{j, m f} / \Delta t=0.045$. The results of this simulation are shown in Figure 7.36. 

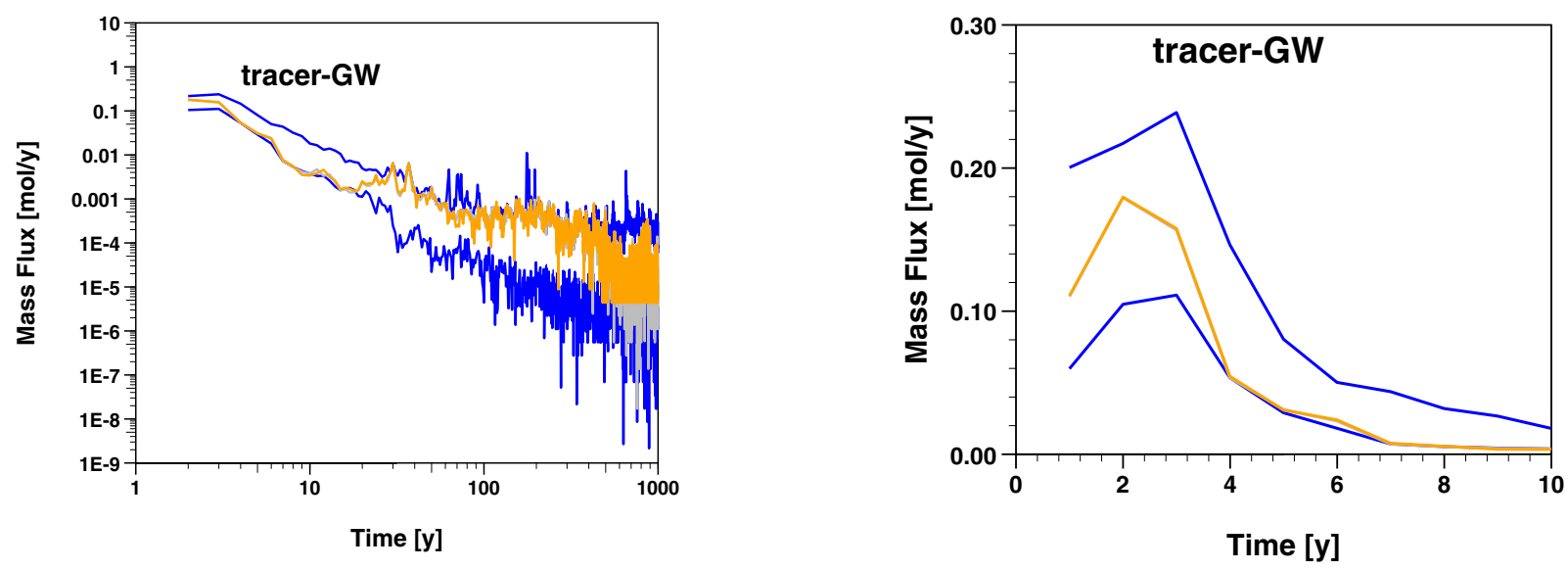

Figure 7.36 Particle simulations of breakthrough flux comparing results for TracerGW and permeability realization 9 with (orange) and without (gray) matrix diffusion. Note log-log scale on left and linear scale on right.

Due to the high density of fractures, matrix diffusion was found to have very little effect on breakthrough of TracerGW when compared to our base-case simulation. Notably, these numerical results are consistent with the field test results of Becker and Shapiro (2000), who found physical heterogeneity to have a more pronounced effect on breakthrough than matrix diffusion for conservative tracers. Nevertheless, for radionuclides that have significant retardation in the matrix, matrix diffusion could have a more significant impact on breakthrough. Moreover, because the recent laboratory-scale experiments of Reimus et al. (2002) do show observable impacts of matrix diffusion on the movement of tritium, ${ }^{14} \mathrm{C}$, and ${ }^{99} \mathrm{Tc}$ through fractured rock cores, additional sensitivity studies may be warranted.

\subsubsection{Sensitivity to Glass Dissolution Rate}

The sensitivity of radionuclide breakthrough flux at the downstream plane to a lower glass dissolution rate was investigated for five representative classes of radionuclides ( $\mathrm{Cs}, \mathrm{Pu}, \mathrm{Sm}, \mathrm{U}$ and TracerMG). Our base case permeability and mineralization realization (realizations 9 and 1, respectively) was used in this sensitivity analysis; the effects of test-related and geothermal heat were included.

This sensitivity simulation used the temperature-dependent "long-term dissolution rate" discussed in Section 6.4.5.1.1 and presented in Figure 6.20. The results of these simulations are shown in Figure 7.37. Under these conditions, $0.12 \%$ of the melt glass dissolved in $1000 \mathrm{yr}$ as compared to $30 \%$ in the base-case simulation. The low glass dissolution rate significantly changes the breakthrough of TracerMG, Pu and U (shown by the orange curve) when compared to our base-case simulation (shown by the gray curve). These three radionuclide classes all have a large fraction (or all in the case of TracerMG) of their initial mass distributed in the melt glass (see Table 4.3). Cs and Sm breakthroughs were much less sensitive to the glass dissolution rate. Cs has a relatively small fraction of its mass distributed in the melt glass; glass dissolution only 
affects breakthrough at later times. Sm sorbs very strongly to a number of minerals; though a large fraction of its mass is initially distributed in the melt glass, differences in breakthrough between the base-case and the long-term dissolution rate case appear only after 200 years. Most of the Sm breakthrough results from the mass initially distributed in the exchange volume.
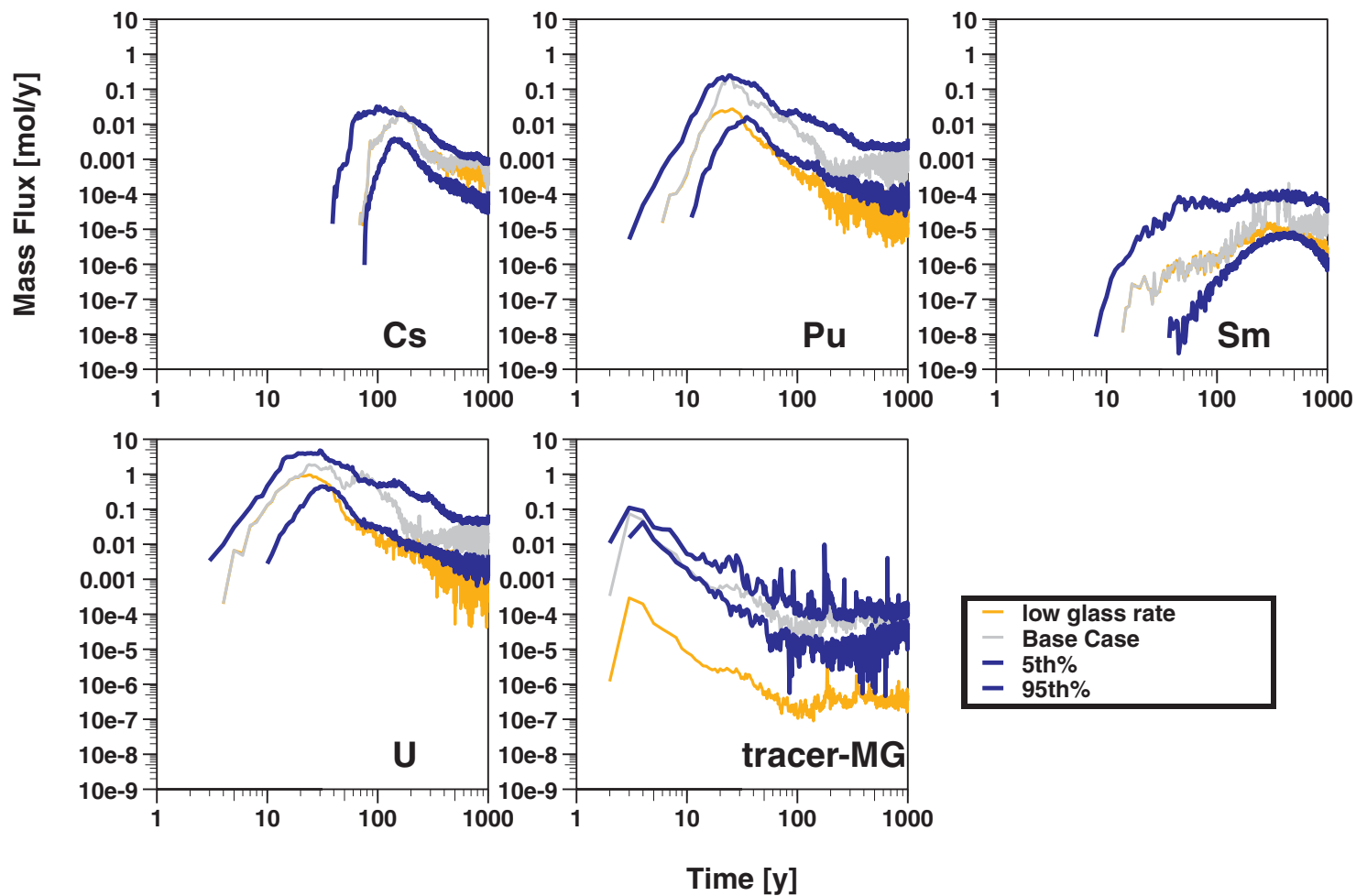

Figure 7.37. Particle simulations of breakthrough flux comparing the results for the "long-term dissolution rate" case with the base-case simulation for $\mathrm{Cs}, \mathrm{Pu}, \mathrm{Sm}, \mathrm{U}$ and tracer-MG.

\subsubsection{Sensitivity to Sorption}

The sensitivity of radionuclide breakthrough flux at the downstream plane to lower sorption coefficients was investigated for a particular suite of representative sorbing radionuclides ( $\mathrm{Cs}, \mathrm{Pu}, \mathrm{Sm}$, and $\mathrm{U})$. Our base case permeability and mineralization realization (realizations 9 and 1, respectively) was used in this sensitivity analysis; the effects of test-related and geothermal heat were included. Note that this sensitivity does not pertain to the geostatistical distribution of sorbing minerals, but, rather, to the uncertainty in sorption constants assigned to the various radionuclidemineral pairs (See Appendix K).

The sensitivity to sorption was investigated by lowering each of the mineral and radionuclide specific $\mathrm{K}_{\mathrm{d}} \mathrm{s}$. These $\mathrm{K}_{\mathrm{d}} \mathrm{s}$, given in Table K.8, were modified from the value used in all the base-case simulations to the "low" case. The "low" case was based on a two standard deviation uncertainty in surface complexation constants and an estimate of ion exchange constant uncertainty. The results of this sensitivity study are shown in Figure 7.38. Cs, Pu and $\mathrm{U}$ breakthrough is greatly affected by the uncertainty 
in sorption constants. These radionuclides had large changes in mineral-specific $\mathrm{K}_{d} \mathrm{~s}$ that result in large changes in transport behavior. Sm exhibited very little change in predicted molar flux, with the "low" sorption breakthrough still within the $5^{\text {th }}-95^{\text {th }}$ confidence intervals of the geostatistical permeability and mineral heterogeneity ensemble of realizations. A much smaller uncertainty in $\mathrm{Sm}$ retardation results from the balance between sorption to mobile colloids and sorption to immobile fracture lining minerals (see Appendix K). These results suggest that, depending on the mineral, uncertainty in surface complexation and ion exchange constants may affect radionuclide breakthrough at a scale similar to permeability and sorbing mineral heterogeneity. However, it is important to remember that the "low" sorption case presented here does not represent a rigorous evaluation of sorption uncertainty. A more statistically rigorous calculation of surface complexation and ion exchange uncertainty would need to be carried out to better evaluate its effect on radionuclide transport results.
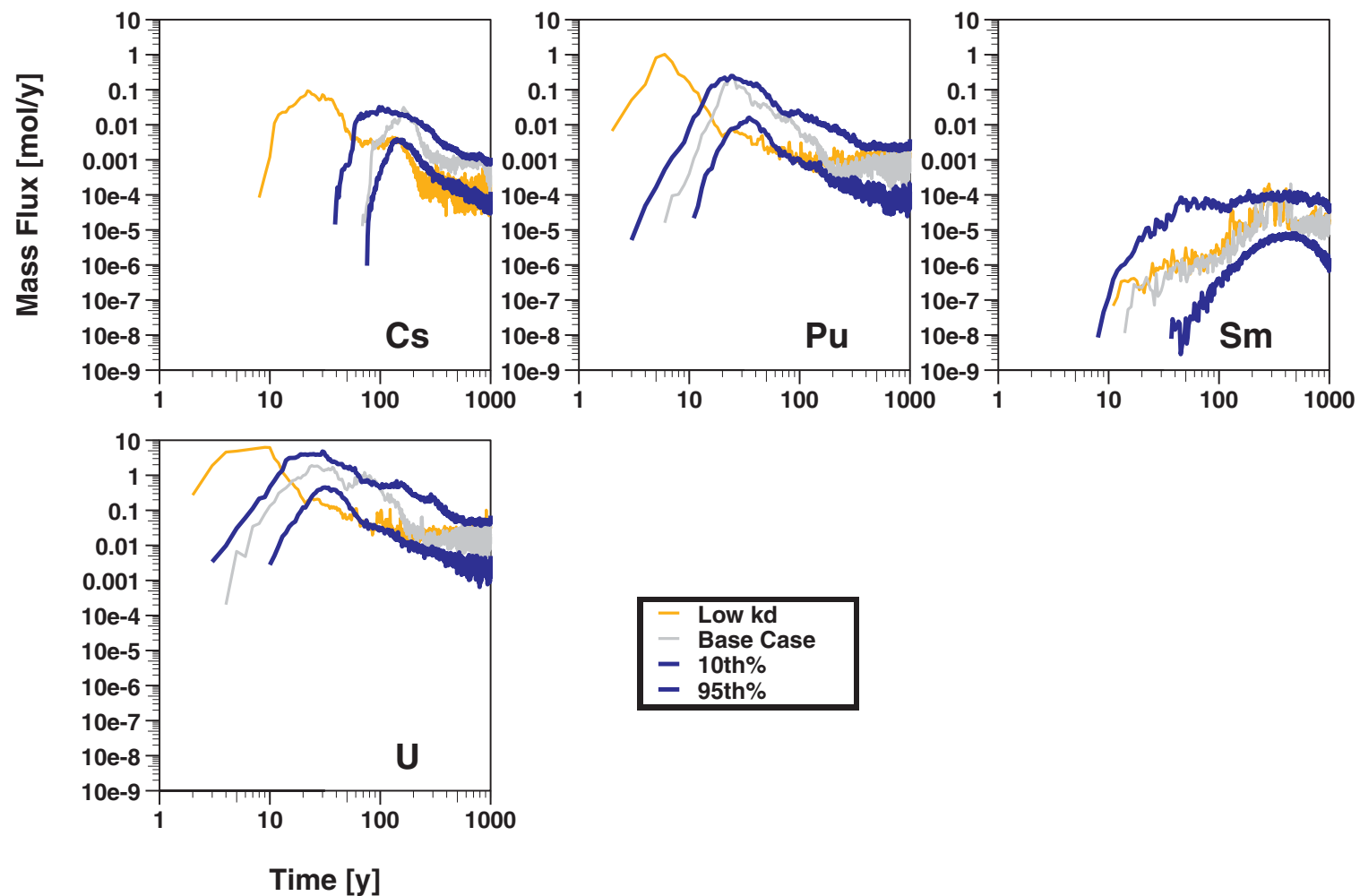

Figure 7.38. Particle simulations of breakthrough flux comparing the results for the low-kd simulation with the base-case simulation for $\mathrm{Cs}, \mathrm{Pu}, \mathrm{Sm}, \mathrm{U}$. 


\subsubsection{Sensitivity to Dispersion}

The sensitivity of longitudinal and transverse local dispersion was also investigated using the particle model, with a focus on the behavior of TracerEV. Results in a single base case permeability and mineralization realization (realizations 9 and 1, respectively) were used as the basis for comparison, and the effects of test-related and geothermal heat were included. Since local transverse dispersion may not be simulated using the streamline formulation in this study, the potential affects of it were of particular interest. The effects of local dispersion were not specifically included in any of the model simulations and should be distinguished from the macrodispersion produced by the heterogeneity effects incorporated in the model.

Inclusion of local dispersion was accomplished using a large range of longitudinal and transverse dispersivities in the particle tracking model. Two sets of simulations were run, once set with both longitudinal and transverse dispersivities and one set with transverse dispersivities only. These simulations were carried out for TracerEV and are shown in Figure 7.39. In this figure we see that only one case produced breakthrough at the downstream plane that was a noticeable departure from the base-case simulations. This case was for $\alpha_{L}=100 \mathrm{~m}$ and $\alpha_{T}=10 \mathrm{~m}$; a large choice of dispersivities for this simulation which has grid blocks of $10 \mathrm{~m}$, indicating that dispersivity values on the order of 10 grid blocks would not represent variations in material properties at the sub-grid scale. The cases with transverse dispersivity only resulted in very little departure from the base-case simulation, even when the values for dispersivity were varied over three orders of magnitude. This would indicate that transverse dispersivity is not important in the streamline simulations.
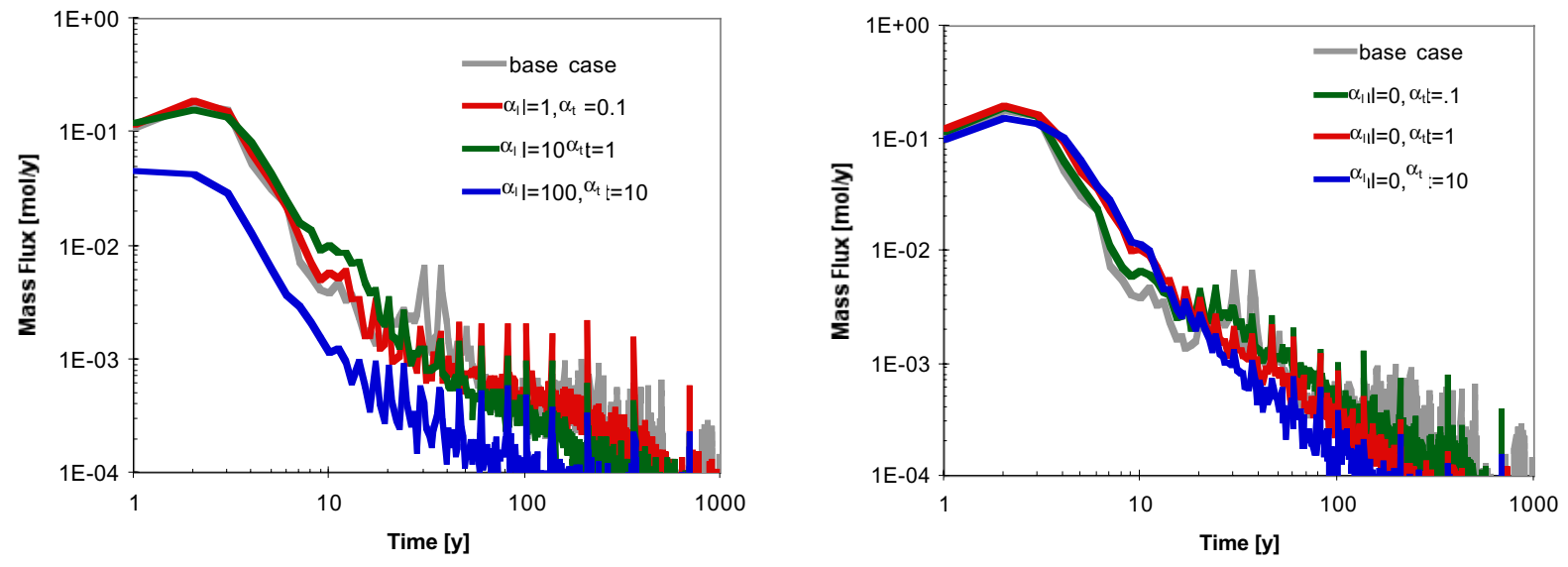

Figure 7.39. Particle simulations of breakthrough flux comparing the results for the base case simulation with local transverse and longitudinal dispersion for the tracer-EV radionuclide. 


\subsection{Decay-Corrected Flux for 37 RST Radionuclides}

In this section, the decay-corrected fluxes of 37 RST radionuclides across the downstream boundary of the CHESHIRE near field is presented. The half-lives of these radionuclides and their initial inventory and distribution are presented in Chapter 4. Reactive transport behavior of these radionuclides was based on the simulation of 13 radionuclides classes described in Section 7.1. Reactive transport simulations of the radionuclide classes using he particle and GIMRT transient streamline simulations can be found in Sections 7.2 to 7.4.

In Table 7.1, the relationship between the 13 radionuclide classes and the 37 radionuclides is shown. To convert molar breakthroughs of radionuclide classes to those of individual radionuclides, the following equations were used. For radionuclides that were modeled as tracers, flux was determined by:

$$
F_{i}=\left[\left(\frac{F_{E V} x_{i, E V}}{n_{E V}}\right)+\left(\frac{F_{G W} x_{i, G W}}{n_{G W}}\right)+\left(\frac{F_{M G} x_{i, M G}}{n_{M G}}\right)\right] n_{i} e^{-\lambda_{i} t}
$$

and

$$
\lambda=\frac{\ln 2}{T_{1 / 2}}
$$

where $F$ is the flux (moles per year); $n$ is the initial inventory; $x$ is the fractional distribution between TracerEV, TracerGW, and TracerMG as defined in Table 4.5; $\lambda$ is the decay rate in years for radionuclide $i ; T_{1 / 2}$ is the half-life; $t$ is time in years. For reactive radionuclides that were not decay-corrected in the transport model, flux was determined by:

$$
F_{i}=\frac{F_{j} n_{i} e^{-\lambda_{i} t}}{n_{j}}
$$

where $i$ is the radionuclide of interest and $j$ is the radionuclide class to which it belongs. Flux of reactive radionuclides that were decay-corrected in the transport model was determined explicitly by the model.

After the decay-corrected fluxes of all 37 radionuclides are established, the flux of radionuclide activity $f$ (in curies/year) for each radionuclide $i$ can be approximated by the following:

$$
f_{i}=\frac{F_{i} N_{A} \lambda_{i}}{\left[3.156 \times 10^{7}(\mathrm{sec} / \mathrm{yr})\right]\left[3.7 \times 10^{10}(\mathrm{~Bq} / \mathrm{Ci})\right]}
$$

where $N_{A}$ is Avogadro's number $\left(6.02 \times 10^{23}\right)$. 
Table 7.1 Relationship between radionuclide class and RST radionuclide.

\begin{tabular}{|c|c|c|c|}
\hline \multirow{2}{*}{$\begin{array}{l}\text { Radionuclide } \\
\text { class }\end{array}$} & \multirow[b]{2}{*}{ Radionuclides } & \multicolumn{2}{|c|}{$\begin{array}{c}\text { Decay correction in } \\
\text { model }\end{array}$} \\
\hline & & Particle & GIMRT \\
\hline TracerEV & ${ }^{3} \mathrm{H},{ }^{14} \mathrm{C},{ }^{36} \mathrm{Cl},{ }^{39} \mathrm{Ar}$, & no & no \\
\hline TracerGW & ${ }^{85} \mathrm{Kr},{ }^{99} \mathrm{Tc},{ }^{129} \mathrm{I},{ }^{59} \mathrm{Ni},{ }^{63} \mathrm{Ni},{ }^{93} \mathrm{Zr}$ & no & no \\
\hline TracerMG & ${ }^{93 \mathrm{~m}} \mathrm{Nb},{ }^{94} \mathrm{Nb},{ }^{107} \mathrm{Pd},{ }^{121 \mathrm{~m}} \mathrm{Sn},{ }^{126} \mathrm{Sn} \neq$ & no & no \\
\hline${ }^{41} \mathrm{Ca}$ & ${ }^{41} \mathrm{Ca}$ & no & no \\
\hline $\mathrm{Sr}$ & ${ }^{90} \mathrm{Sr}$ & no & yes \\
\hline Cs & ${ }^{137,135} \mathrm{Cs}$ & no & no \\
\hline $\mathrm{Sm}$ & ${ }^{151} \mathrm{Sm}$ & no & yes \\
\hline $\mathrm{Eu}$ & ${ }^{150,152,154} \mathrm{Eu},{ }^{166 \mathrm{~m}} \mathrm{Ho},{ }^{244} \mathrm{Cm} \S$ & no & no \\
\hline$U$ & $232,233,234,235,236,238 U$ & no & no \\
\hline $\mathrm{Np}$ & ${ }^{237} \mathrm{~Np}$ & yest & yest \\
\hline $\mathrm{Pu}$ & $238,239,240 \mathrm{Pu}$ & no & no \\
\hline${ }^{241} \mathrm{Pu}$ & ${ }^{241} \mathrm{Pu}$ & yes & yes \\
\hline Am & ${ }^{241} \mathrm{Am}$ & yes & yes \\
\hline
\end{tabular}

$\dagger$ Ingrowth of $\mathrm{Np}$ was accounted for but its decay was not; the half-life of ${ }^{237} \mathrm{~Np}$ is $2.14 \times 10^{6} \mathrm{yr}$.

${ }^{237} \mathrm{~Np}$ decay over $1000 \mathrm{yr}$ is negligible.

Table 7.1 also contains information regarding the decay correction of the various radionuclide classes. In the particle model, ${ }^{241} \mathrm{Pu}$ and ${ }^{241} \mathrm{Am}$ were decaycorrected and the ingrowth of ${ }^{237} \mathrm{~Np}$ was accounted for. In GIMRT transient streamline simulations, ${ }^{90} \mathrm{Sr}$ and ${ }^{151} \mathrm{Sm}$ were decay-corrected in the model. Because the GIMRT transient streamline simulations were initiated at $100 \mathrm{yr}$ using particle model data, the ${ }^{90} \mathrm{Sr}$ and ${ }^{151} \mathrm{Sm}$ concentrations from the particle model were adjusted to account for decay of these radionuclides. ${ }^{1}$

\subsubsection{Molar Flux of 37 RST Radionuclides}

Figures 7.40(a) through 7.40(e) present breakthrough flux (in moles/year) for all 37 RST radionuclides to 1000 yr. Note that the migration of radionuclides ${ }^{59} \mathrm{Ni}$, ${ }^{63} \mathrm{Ni}$, ${ }^{93} \mathrm{Zr},{ }^{93 \mathrm{~m}} \mathrm{Nb},{ }^{94} \mathrm{Nb},{ }^{107} \mathrm{Pd},{ }^{121 \mathrm{~m}} \mathrm{Sn},{ }^{126} \mathrm{Sn}$ was unretarded due to either a lack of published sorption information or insufficient opportunity to integrate their sorptive behavior into the reactive transport model. The migration of these radionuclides is conservative in that the transport models do not account for their sorption or ion exchange. However, we recognize that, in reality, their migration is most likely retarded.

\footnotetext{
${ }^{1}$ We recently discovered that the decay correction of ${ }^{90} \mathrm{Sr}$ and ${ }^{151} \mathrm{Sm}$ at the $100 \mathrm{yr}$ transition between the particle simulations and the GIMRT transient streamline simulations was incorrect. The $100 \mathrm{yr}$ concentrations of ${ }^{90} \mathrm{Sr}$ and ${ }^{151} \mathrm{Sm}$ were reduced by a factor of 1000 in error. Particle model simulations do not suffer from this error.
} 

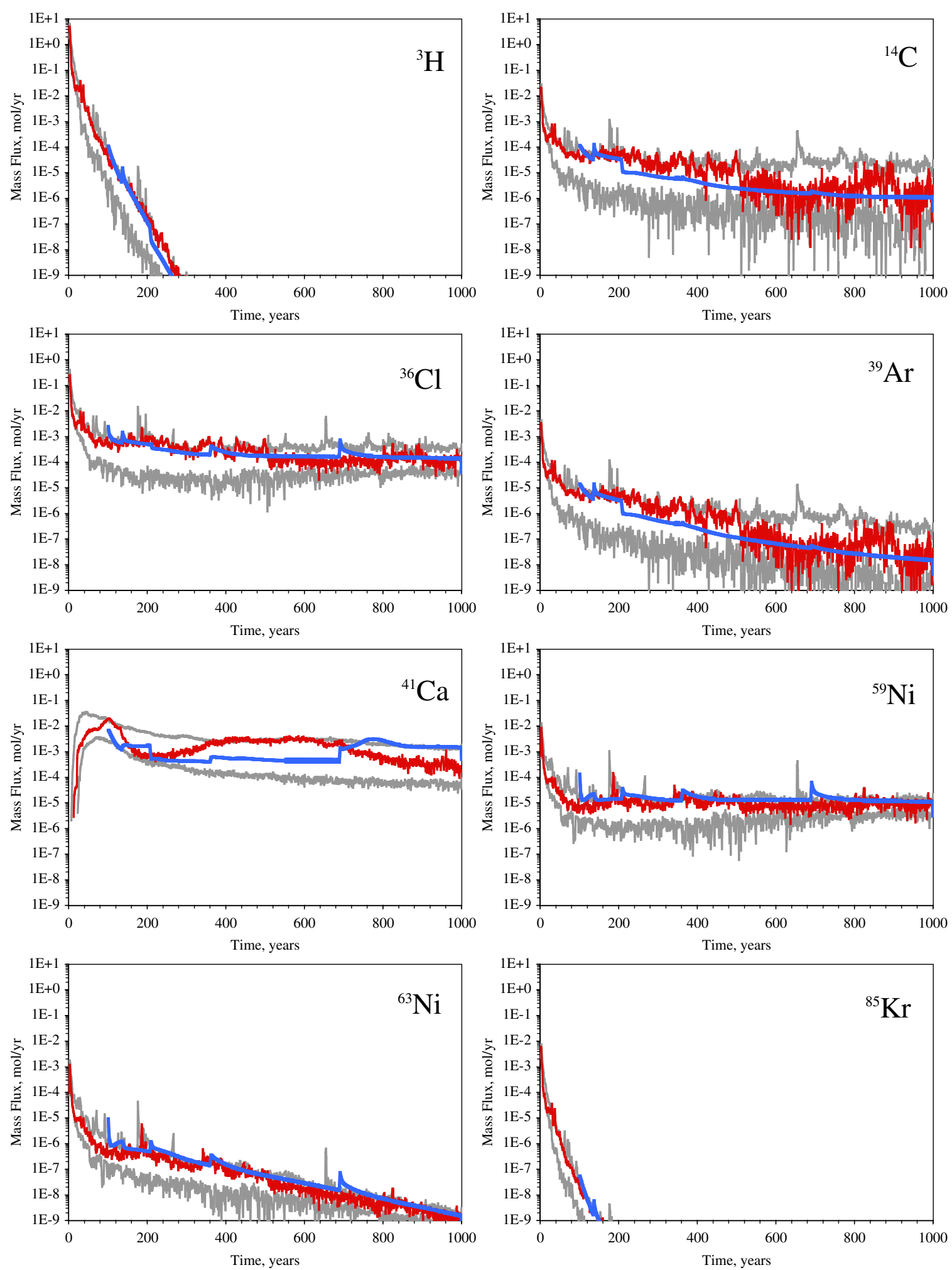

Figure 7.40(a) Decay-corrected radionuclide flux (moles per year) at the breakthrough plane for ${ }^{3} \mathrm{H},{ }^{14} \mathrm{C},{ }^{36} \mathrm{Cl},{ }^{39} \mathrm{Ar},{ }^{41} \mathrm{Ca},{ }^{59} \mathrm{Ni},{ }^{63} \mathrm{Ni}$, and ${ }^{85} \mathrm{Kr}$. Particle model results are in red with 5 and 95\% confidence intervals in gray. GIMRT transient streamline results are in blue. 

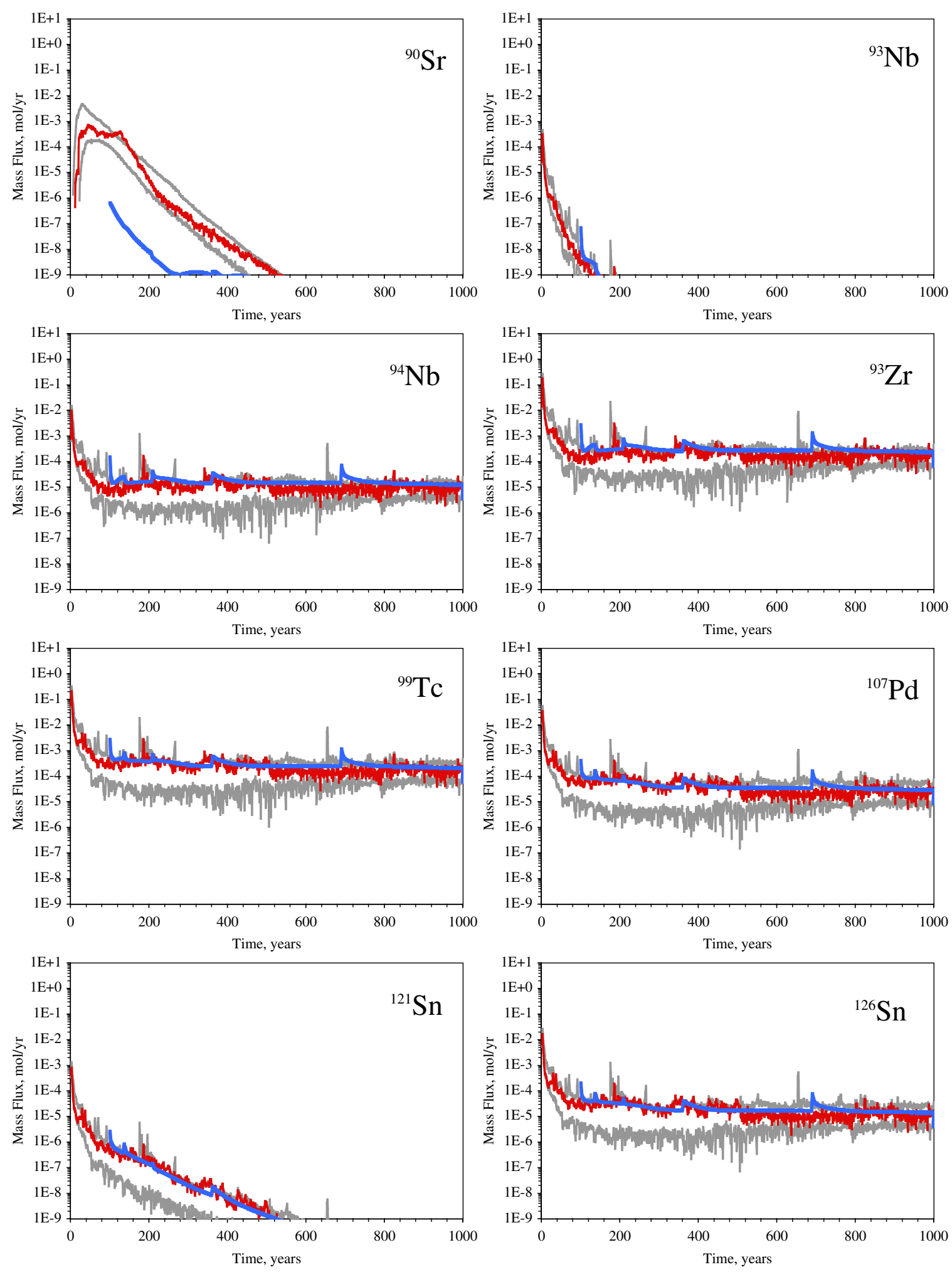

Figure 7.40(b) Decay-corrected radionuclide flux (moles per year) at the breakthrough plane for ${ }^{90} \mathrm{Sr},{ }^{93 \mathrm{~m}} \mathrm{Nb},{ }^{94} \mathrm{Nb},{ }^{93} \mathrm{Zr}$, ${ }^{99} \mathrm{Tc},{ }^{107} \mathrm{Pd},{ }^{121 \mathrm{~m}} \mathrm{Sn}$, and ${ }^{126} \mathrm{Sn}$. Particle model results are in red with 5 and $95 \%$ confidence intervals in gray. GIMRT transient streamline results are in blue. 

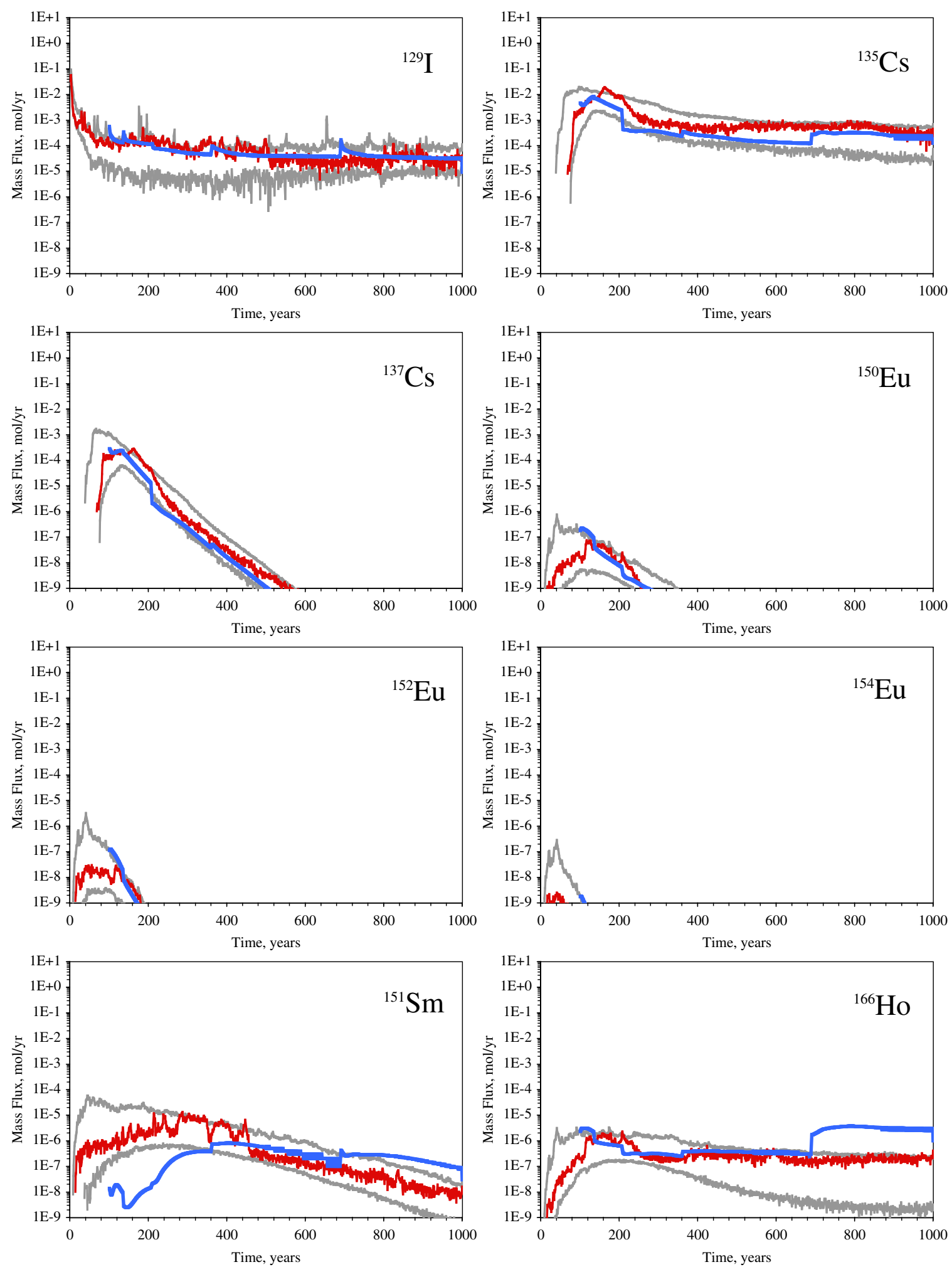

Figure 7.40(c) Decay-corrected radionuclide flux (moles per year) at the breakthrough plane for ${ }^{129} \mathrm{I},{ }^{135} \mathrm{Cs},{ }^{137} \mathrm{Cs},{ }^{150} \mathrm{Eu},{ }^{152} \mathrm{Eu},{ }^{154} \mathrm{Eu},{ }^{151} \mathrm{Sm}$, and ${ }^{166 \mathrm{~m}} \mathrm{Ho}$. Particle model results are in red with 5 and $95 \%$ confidence intervals in gray. GIMRT transient streamline results are in blue. 

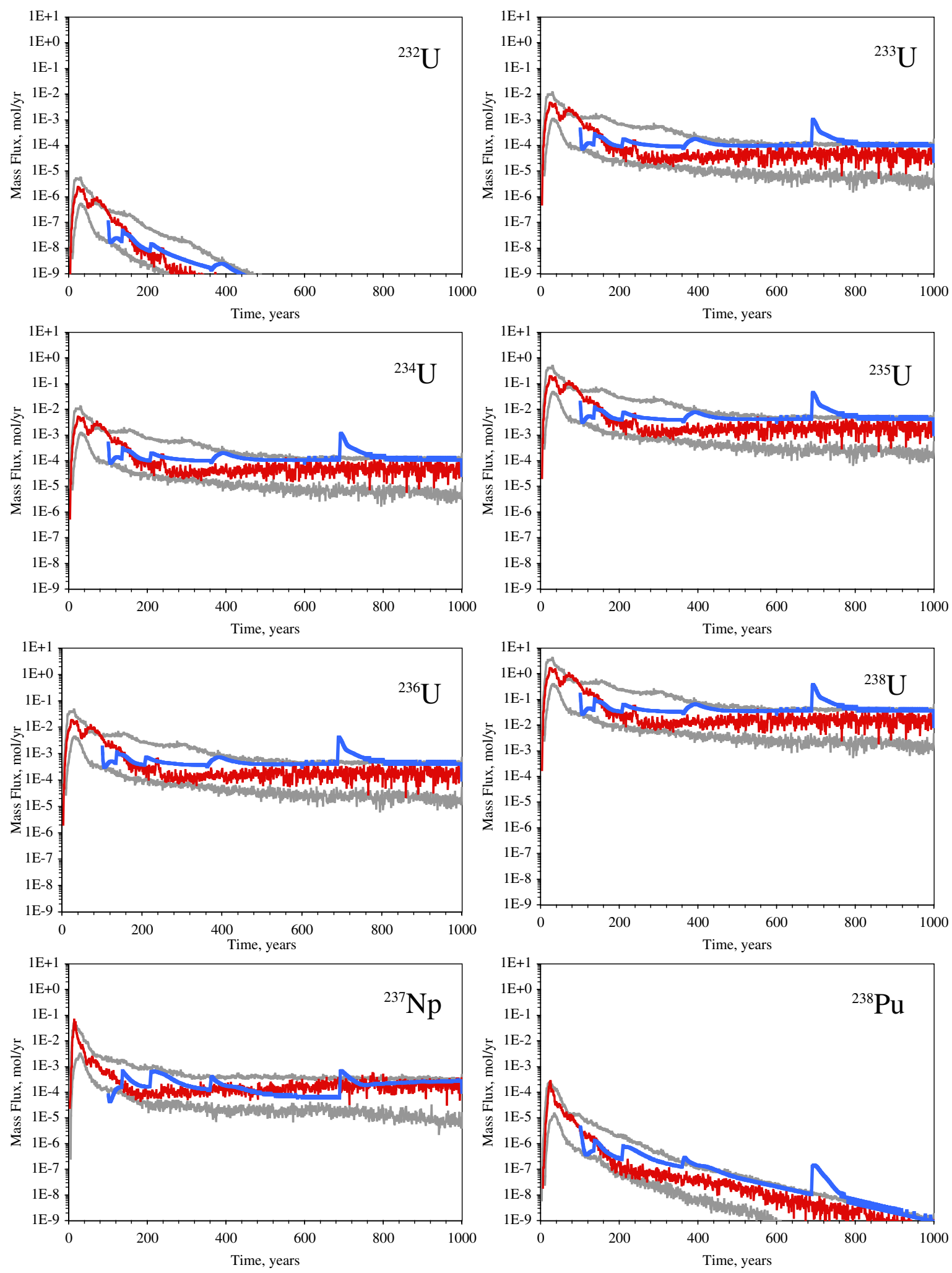

Figure 7.40(d) Decay-corrected radionuclide flux (moles per year) at the breakthrough plane for ${ }^{232} \mathrm{U},{ }^{233} \mathrm{U},{ }^{234} \mathrm{U},{ }^{235} \mathrm{U},{ }^{236} \mathrm{U},{ }^{238} \mathrm{U},{ }^{237} \mathrm{~Np}$, and ${ }^{238} \mathrm{Pu}$. Particle model results are in red with 5 and $95 \%$ confidence intervals in gray. GIMRT transient streamline results are in blue. 

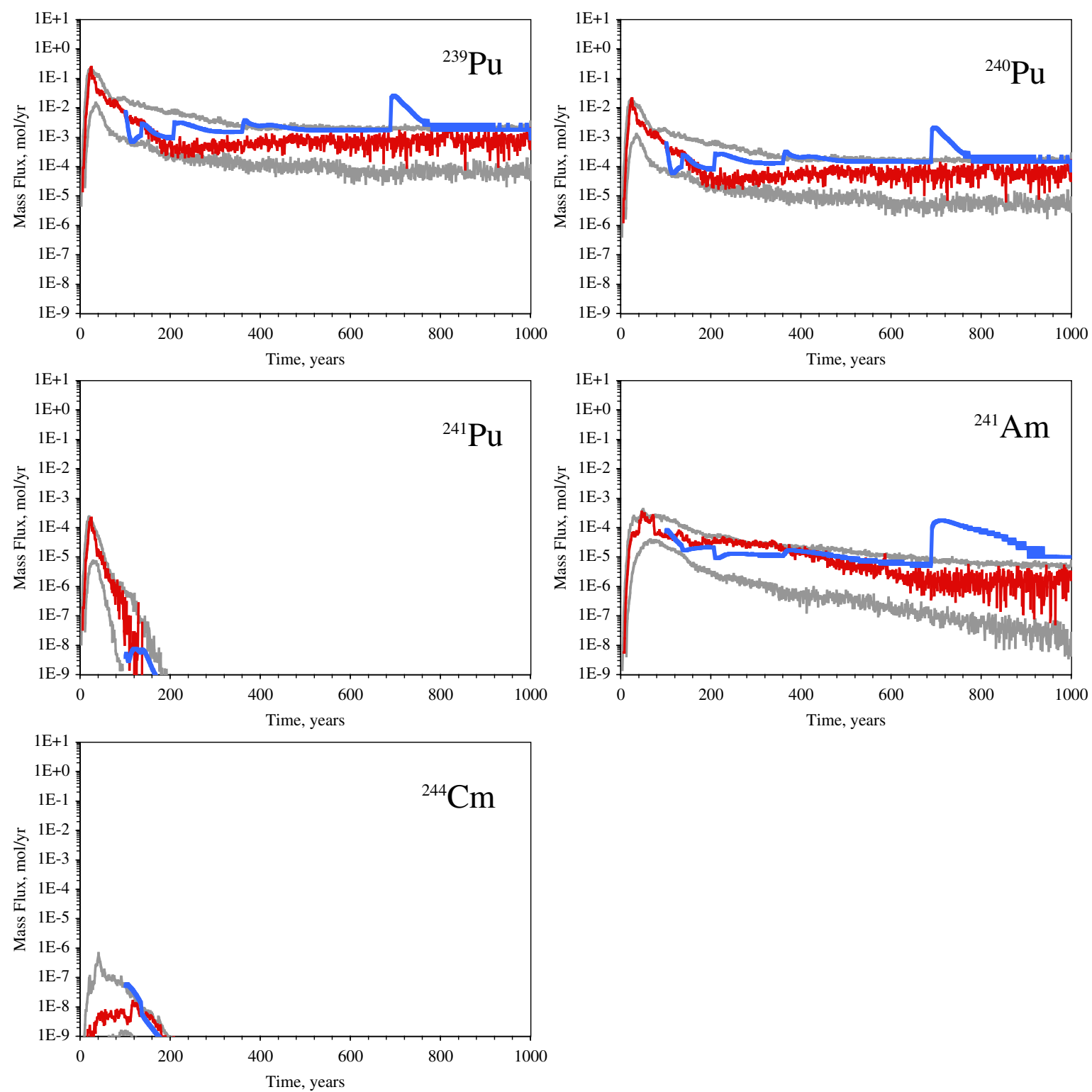

Figure 7.40(e) Decay-corrected radionuclide flux (moles per year) at the breakthrough plane for ${ }^{239} \mathrm{Pu},{ }^{240} \mathrm{Pu},{ }^{241} \mathrm{Pu},{ }^{241} \mathrm{Am}$, and ${ }^{244} \mathrm{Cm}$. Particle model results are in red with 5 and $95 \%$ confidence intervals in gray. GIMRT transient streamline results are in blue.

In Appendix A, a simple objective method for developing a comprehensive list of RST radionuclides was described. The choice of radionuclides to be included in the RST was accomplished by examining the amount (moles) and the activity (Bq) contribution of each radionuclide separated by three decay modes. Radionuclides are separated into $\alpha, \beta$, and EC/IT modes of decay. For each set of radionuclides belonging to a single mode of decay, if the molar contribution is $>0.1 \%$ of the total at any instant in time over $1000 \mathrm{yr}$, it is included in the RST. In Table 7.2, the criteria developed in Appendix A are applied to decay-corrected breakthrough flux data to examine whther the reactive transport behavior of radionuclides may make some RST radionuclides insignificant with respect to the HST. Of the 37 radionuclides included in the RST, 29 fall within the amount criterion as defined in Appendix A, and 35 fall within the 
activity criterion. The only two radionuclides that do not fall within this criterion are ${ }^{129} \mathrm{I}$ and ${ }^{154} \mathrm{Eu}$. However, ${ }^{129} \mathrm{I}$ falls within the molar criterion discussed in Section 7.5.1. Thus only ${ }^{154} \mathrm{Eu}$ does not fall within the molar or activity criteria established in Appendix A. In Appendix $\mathrm{A},{ }^{154} \mathrm{Eu}$ is included in the RST due to an additional criterion used (criterion V in Section A.3 of Appendix A): ${ }^{154} \mathrm{Eu}$ has been detected in groundwater.

Using the criteria developed in Appendix A and imposing them on the downstream boundary fluxes of the 37 radionuclides included in the RST, we find that all 37 radionuclides will contribute significantly to the near-field HST. Thus, if the same criteria developed in Appendix A are used to develop a list of radionuclides of interest to the CAU scale modeling effort, all 37 radionuclides will contribute to the radionuclide flux leaving the near-field modeling domain. The following section displays the flux of radionuclides presented as curies.

Table 7.2 Criteria for including radionuclides in the CHESHIRE near-field RST applied to decaycorrected downstream boundary flux values, both amount (moles) and activity (Bq).

\begin{tabular}{|c|c|c|c|c|c|c|c|c|}
\hline $\begin{array}{c}\alpha \text { decaying } \\
\text { radio- } \\
\text { nuclides }\end{array}$ & $\begin{array}{c}\alpha \\
\text { amount } \\
\text { (moles) } \\
>0.1 \%\end{array}$ & $\begin{array}{c}\alpha \\
\text { activity } \\
(\mathrm{Bq}) \\
>0.1 \% \\
\end{array}$ & $\begin{array}{c}\beta \text { decaying } \\
\text { radio-nuclides }\end{array}$ & $\begin{array}{c}\beta \\
\text { amount } \\
\text { (moles) } \\
>0.1 \%\end{array}$ & $\begin{array}{c}\beta \\
\text { activity } \\
(\mathrm{Bq}) \\
>0.1 \%\end{array}$ & $\begin{array}{c}\mathrm{EC} / \mathrm{IT} \\
\text { decaying } \\
\text { radio-nuclides }\end{array}$ & $\begin{array}{c}\text { EC/IT } \\
\text { amount } \\
\text { (moles) } \\
>0.1 \%\end{array}$ & $\begin{array}{c}\text { EC/IT } \\
\text { activity } \\
(\mathrm{Bq})>0.1 \%\end{array}$ \\
\hline${ }^{244} \mathrm{Cm}$ & No & Yes & $3 \mathrm{H}$ & Yes & Yes & ${ }^{41} \mathrm{Ca}$ & Yes & Yes \\
\hline${ }^{232} \mathrm{U}$ & No & Yes & ${ }^{14} \mathrm{C}$ & Yes & Yes & ${ }^{59} \mathrm{Ni}$ & Yes & Yes \\
\hline${ }^{233} \mathrm{U}$ & Yes & Yes & ${ }^{36} \mathrm{Cl}$ & Yes & Yes & ${ }^{93 \mathrm{~m}} \mathrm{Nb}$ & Yes & Yes \\
\hline${ }^{234} U$ & Yes & Yes & ${ }^{39} \mathrm{Ar}$ & Yes & Yes & ${ }^{121 \mathrm{~m}} \mathrm{Sn}^{\dagger}$ & Yes & Yes \\
\hline${ }^{235} \mathrm{U}$ & Yes & Yes & ${ }^{63} \mathrm{Ni}$ & No & Yes & ${ }^{150} \mathrm{Eu}$ & No & Yes \\
\hline${ }^{236} \mathrm{U}$ & Yes & Yes & ${ }^{85} \mathrm{Kr}$ & Yes & Yes & ${ }^{152} \mathrm{Eu}^{\dagger}$ & No & Yes \\
\hline${ }^{238} \mathrm{U}$ & Yes & Yes & ${ }^{90} \mathrm{Sr}$ & Yes & Yes & & & \\
\hline${ }^{237} \mathrm{~Np}$ & Yes & Yes & ${ }^{93} \mathrm{Zr}$ & Yes & Yes & & & \\
\hline${ }^{238} \mathrm{Pu}$ & No & Yes & ${ }^{94} \mathrm{Nb}$ & Yes & Yes & & & \\
\hline${ }^{239} \mathrm{Pu}$ & Yes & Yes & ${ }^{99} \mathrm{Tc}$ & Yes & Yes & & & \\
\hline${ }^{240} \mathrm{Pu}$ & Yes & Yes & ${ }^{107} \mathrm{Pd}$ & Yes & Yes & & & \\
\hline \multirow[t]{10}{*}{${ }^{241} \mathrm{Am}$} & Yes & Yes & ${ }^{121} \mathrm{mSn}^{\dagger}$ & No & Yes & & & \\
\hline & & & ${ }^{126} \mathrm{Sn}$ & Yes & Yes & & & \\
\hline & & & ${ }^{129} I$ & Yes & No & & & \\
\hline & & & ${ }^{135} \mathrm{Cs}$ & Yes & Yes & & & \\
\hline & & & ${ }^{137} \mathrm{Cs}$ & Yes & Yes & & & \\
\hline & & & ${ }^{151} \mathrm{Sm}$ & Yes & Yes & & & \\
\hline & & & ${ }^{152} \mathrm{Eu}^{\dagger}$ & No & No & & & \\
\hline & & & ${ }^{154} \mathrm{Eu}$ & No & No & & & \\
\hline & & & ${ }^{166 \mathrm{~m}} \mathrm{Ho}$ & No & Yes & & & \\
\hline & & & ${ }^{241} \mathrm{Pu}$ & Yes & Yes & & & \\
\hline
\end{tabular}

These radionuclides decay by both EC/IT and $\beta$ decay. 


\subsubsection{Curie Flux of 37 RST Radionuclides}

Figures 7.41 to 7.43 present the radionuclide flux in terms of curies per year. Figures 7.41(a) and 7.41(b) show radionuclides that contribute to $\alpha$ activity. The $\beta$ activity and EC/IT activity contributors are shown in Figures 7.42(a) through 7.42(c) and 7.43 , respectively. Included at the end of each figure is the total $\alpha, \beta$, and EC/IT flux at the breakthrough plane. Radionuclides ${ }^{152} \mathrm{Eu}$ and ${ }^{121 \mathrm{~m}} \mathrm{Sn}$ contribute to both $\beta$ and EC/IT activity; their fractional contribution to $\beta$ and EC/IT activity are presented in the appropriate figure.

For $\alpha$ activity at the downstream boundary, ${ }^{239} \mathrm{Pu}$ contributes the most to the flux of $\alpha$ activity over much of the $1000 \mathrm{yr}$ after the CHESHIRE test. However, between 150 and $400 \mathrm{yr},{ }^{241} \mathrm{Am}$ contributes significantly more. The prominence of ${ }^{241} \mathrm{Am}$ from 150 to $400 \mathrm{yr}$ is a direct result of its coupled transport with ${ }^{241} \mathrm{Pu}$. The transport of ${ }^{241} \mathrm{Pu}$ and decay to ${ }^{241} \mathrm{Am}$ contributes significantly to ${ }^{241} \mathrm{Am}$ flux at the breakthrough plane.

For $\beta$ activity at the breakthrough plane, various radionuclides contribute significantly to the total $\beta$ flux. It is dominated by ${ }^{3} \mathrm{H}$ in the first $100 \mathrm{yr},{ }^{90} \mathrm{Sr}$ between 100 and $150 \mathrm{yr},{ }^{137} \mathrm{Cs}$ between 150 and $275 \mathrm{yr}$, and ${ }^{151} \mathrm{Sm}$ between 275 and $700 \mathrm{yr}$. However, between 500 and $700 \mathrm{yr}$, significant contributions to the $\beta$ flux are made by several tracers including ${ }^{14} \mathrm{C},{ }^{36} \mathrm{Cl},{ }^{39} \mathrm{Ar}$, and ${ }^{99} \mathrm{Tc}$. Between 700 and $1000 \mathrm{yr}$, primary contributions to the $\beta$ flux are made by several tracers including ${ }^{14} \mathrm{C},{ }^{36} \mathrm{Cl}$, and ${ }^{99} \mathrm{Tc}$, while the contribution of ${ }^{151} \mathrm{Sm}$ is diminished.

For the EC/IT decay, ${ }^{41} \mathrm{Ca}$ dominates the flux at all times except the first $50 \mathrm{yr}$, when ${ }^{121 \mathrm{~m}} \mathrm{Sn}$ and ${ }^{93 \mathrm{~m}} \mathrm{Nb}$ dominate EC/IT flux. The ${ }^{121 \mathrm{~m}} \mathrm{Sn}$ and ${ }^{93 \mathrm{~m}} \mathrm{Nb}$ were modeled as tracers, a conservative assumption, even though they are expected to be retarded to some degree. Insufficient opportunity existed to develop a realistic sorption model for ${ }^{121 \mathrm{~m}} \mathrm{Sn}$ and ${ }^{93 \mathrm{~m}} \mathrm{Nb}$ based on published sorption data. Because the half-lives of ${ }^{121 \mathrm{~m}} \mathrm{Sn}$ and ${ }^{93 \mathrm{~m}} \mathrm{Nb}$ are relatively short, 55 and $15.1 \mathrm{yr}$, respectively, it is likely that they will decay significantly prior to reaching the breakthrough. Therefore, ${ }^{41} \mathrm{Ca}$ will dominate the breakthrough flux for EC/IT decay over the entire $1000 \mathrm{yr}$. 

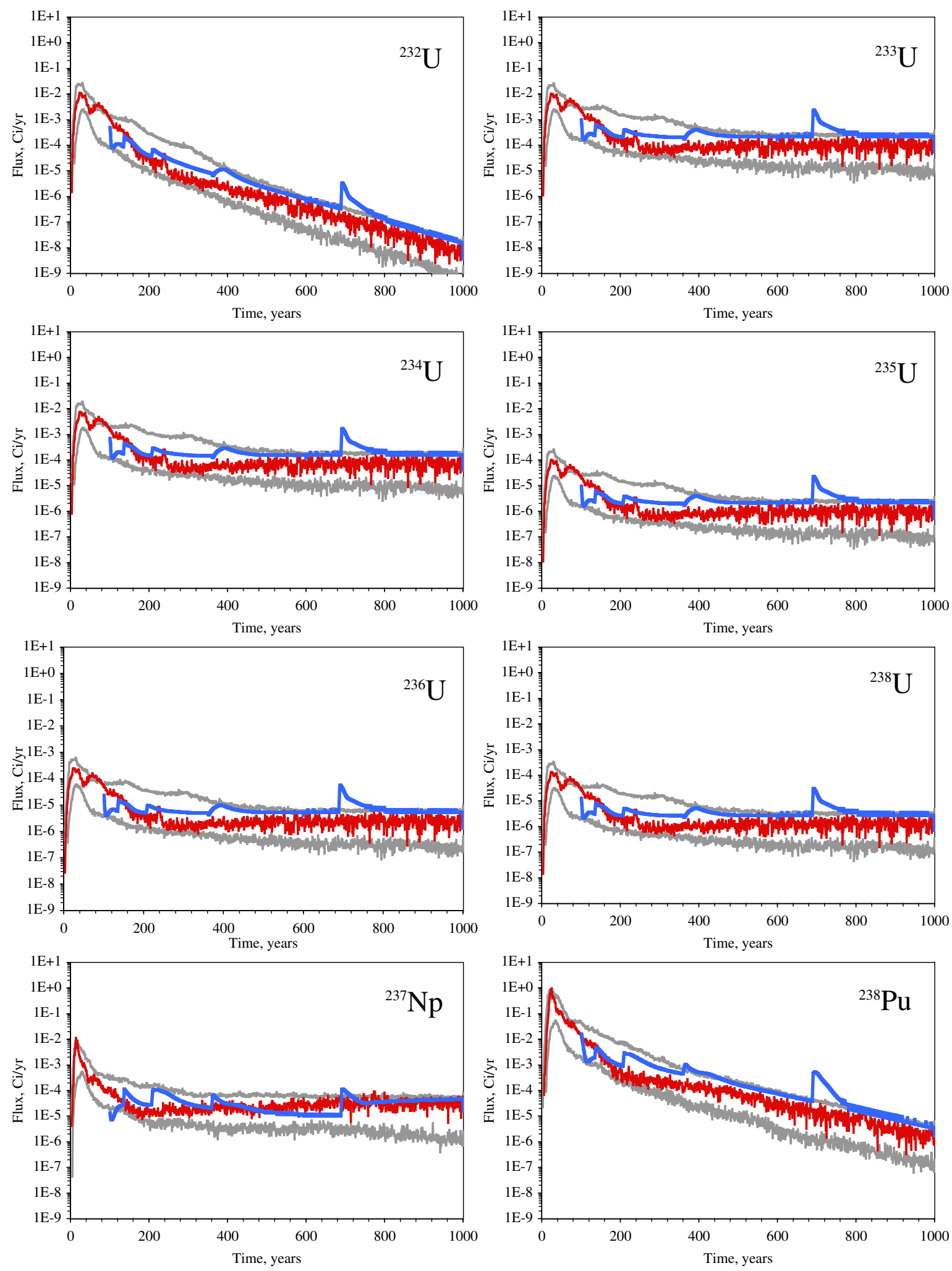

Figure 7.41(a) Decay-corrected radionuclide $\alpha$ flux (curies per year) at the breakthrough plane for ${ }^{232} \mathrm{U},{ }^{233} \mathrm{U},{ }^{234} \mathrm{U},{ }^{235} \mathrm{U},{ }^{236} \mathrm{U},{ }^{238} \mathrm{U},{ }^{237} \mathrm{~Np}$, and ${ }^{238} \mathrm{Pu}$ that contribute to $\alpha$ activity. Particle model results are in red with 5 and $95 \%$ confidence intervals in gray. GIMRT transient streamline results are in blue. 

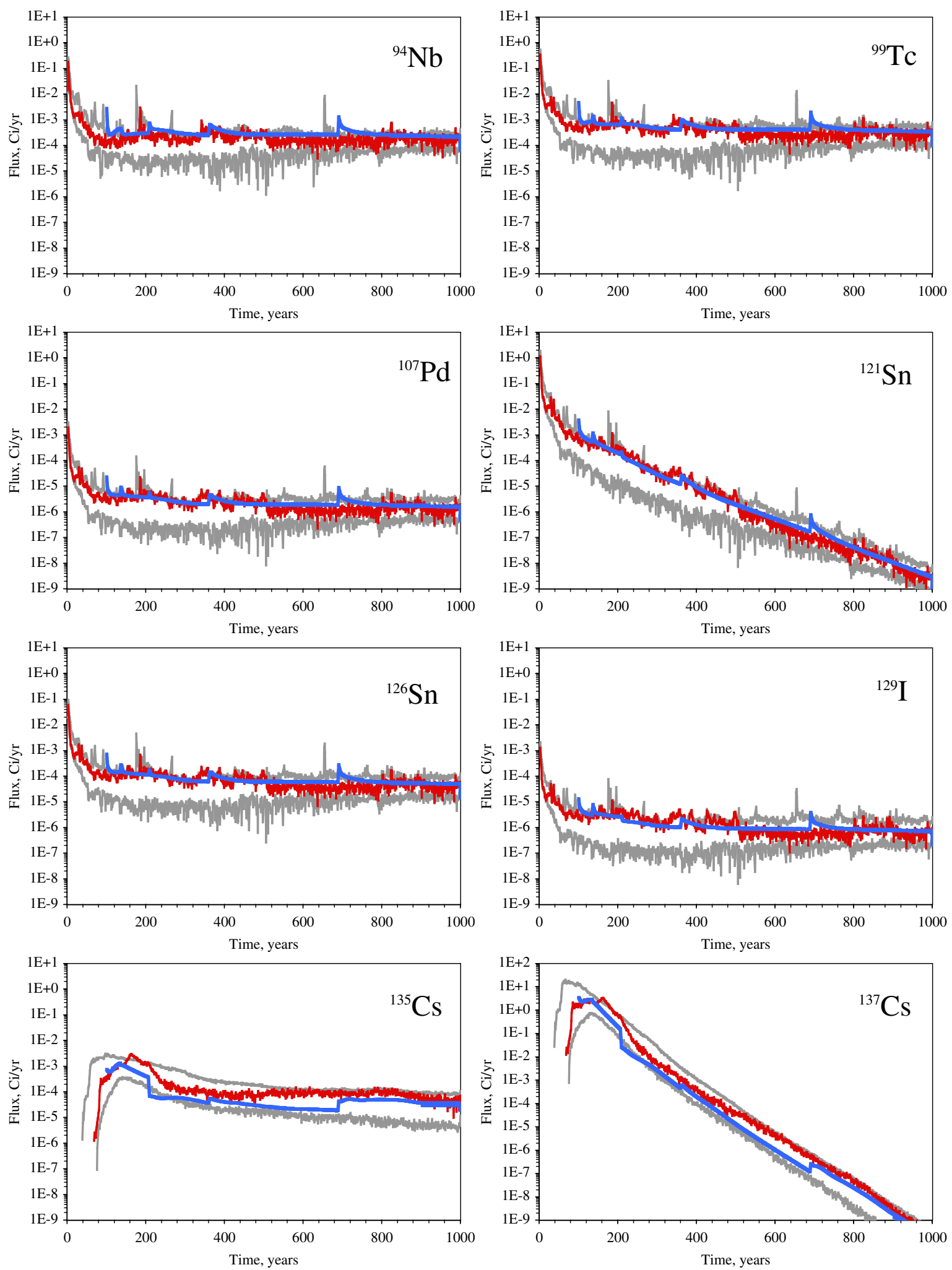

Figure 7.42(b) Decay-corrected radionuclide $\beta$ flux (curies per year) at the breakthrough plane for ${ }^{94} \mathrm{Nb},{ }^{99} \mathrm{Tc},{ }^{107} \mathrm{Pd},{ }^{121 \mathrm{~m}} \mathrm{Sn},{ }^{126} \mathrm{Sn},{ }^{129} \mathrm{I},{ }^{135} \mathrm{Cs}$, and ${ }^{137} \mathrm{Cs}$ that contribute to $\beta$ activity. Particle model results are in red with 5 and $95 \%$ confidence intervals in gray. GIMRT transient streamline results are in blue. 

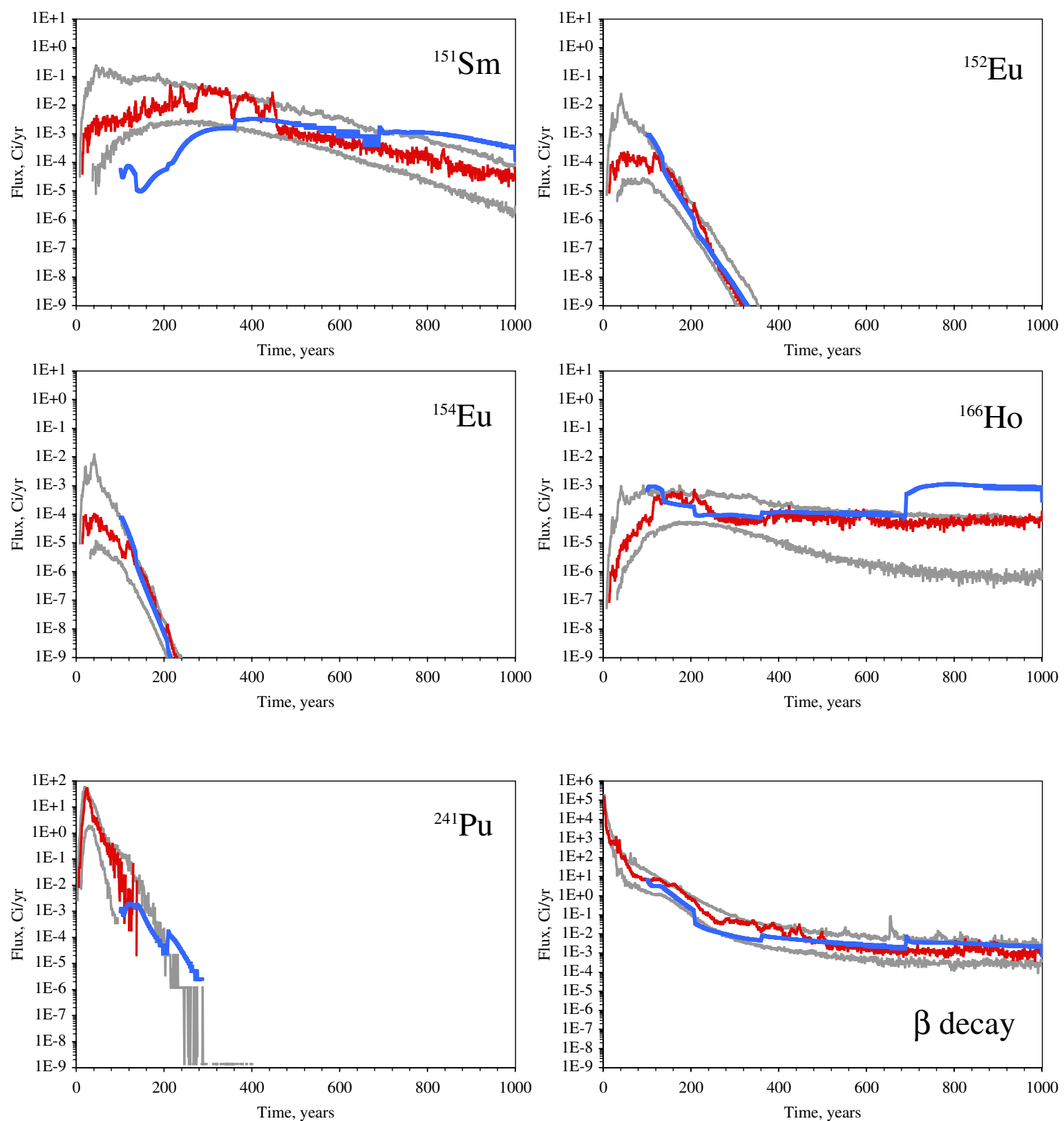

Figure 7.42(c) Decay-corrected radionuclide $\beta$ flux (curies per year) at the breakthrough plane for ${ }^{151} \mathrm{Sm},{ }^{152} \mathrm{Eu},{ }^{154} \mathrm{Eu},{ }^{166 \mathrm{~m}} \mathrm{Ho}$, and ${ }^{241} \mathrm{Pu}$ that contribute to $\beta$ activity. Particle model results are in red with 5 and $95 \%$ confidence intervals in gray. GIMRT transient streamline results are in blue. 

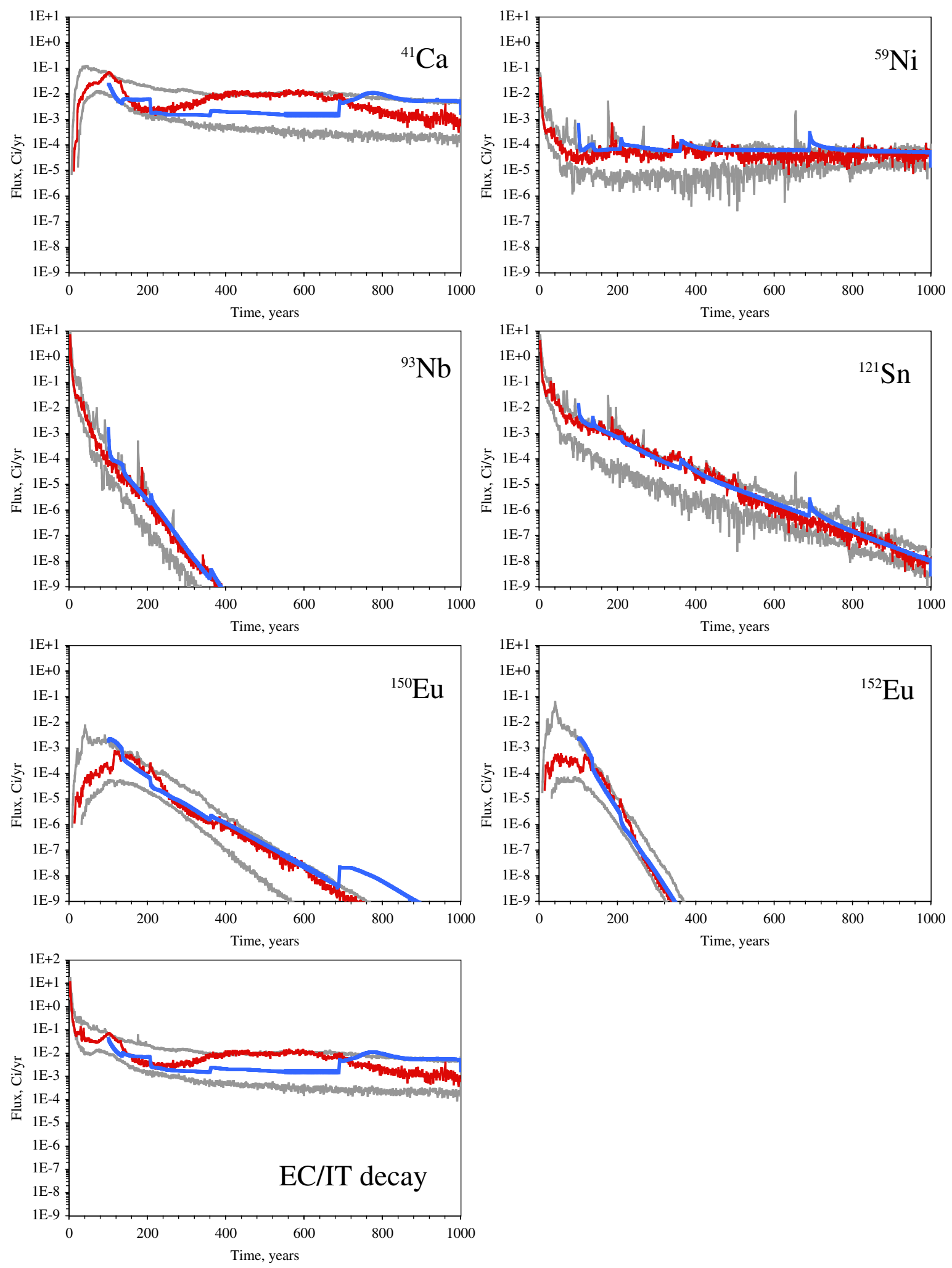

Figure 7.43 Decay-corrected radionuclide EC/IT flux (curies per year) at the breakthrough plane for ${ }^{151} \mathrm{Sm},{ }^{152} \mathrm{Eu},{ }^{154} \mathrm{Eu},{ }^{166 \mathrm{~m}} \mathrm{Ho}$, and ${ }^{241} \mathrm{Pu}$ that contribute to EC/IT activity. Total EC/IT activity shown at bottom. Particle model results are in red with 5 and $95 \%$ confidence intervals in gray. GIMRT transient streamline results are in blue. 


\subsection{Summary}

Some of the more pertinent observations and insights derived from the transport simulations will now be highlighted and summarized. These involve several basic results that are generally similar to findings made in the CAMBRIC and Frenchman Flat reports (Tompson et al., 1999; Pawloski et al., 1999). It also involves a number of newer insights related specifically to the inclusion of: (1) test-related heat, (2) experimentally derived constraints to the glass dissolution model, and (3) detailed information regarding the fractured rock geologic setting of this test.

\subsubsection{Basic Results}

- The release of radionuclides from the melt glass is generally slow and long lasting, regardless of their retardation characteristics in the geologic medium. The release rates can be higher, however, at higher temperatures, and this has the greatest impact on the migration of nonsorbing, glass-bound radionuclides such as ${ }^{36} \mathrm{Cl}$.

- The release of radionuclides from the exchange volume is generally quicker and more short-lived, although significant radionuclide retention in the near field occurs for the more sorptive radionuclides.

- The flux of radionuclides past the UE-20n \#1 control plane is affected by heterogeneity in the physical and reactive properties of the geologic medium. As pointed out in Chapter 5, the inclusion of these complex heterogeneous physical properties is necessary to reproduce parametric data and key observations of temperature and tritium concentration made in nearby drill holes.

- The fluxes of short-lived radionuclides past the UE-20n \#1 control plane decrease to relatively insignificant levels within $400 \mathrm{yr}$ from the test date. These radionuclides specifically include ${ }^{3} \mathrm{H},{ }^{85} \mathrm{Kr},{ }^{90} \mathrm{Sr},{ }^{93 \mathrm{~m}} \mathrm{Nb},{ }^{121 \mathrm{~m}} \mathrm{Sn},{ }^{137} \mathrm{Cs}$, ${ }^{150} \mathrm{Eu},{ }^{152} \mathrm{Eu},{ }^{154} \mathrm{Eu},{ }^{241} \mathrm{Pu}$, and ${ }^{244} \mathrm{Cm}$, whose half lives are each less than 50 years. Their flux past the control plane decreases to less than $10^{-9} \mathrm{~mol} / \mathrm{yr}$ within 400 yr of the test.

\subsubsection{Newer Insights}

- Residual heat from the test, manifested as high initial temperatures in the melt glass, has numerous important effects on flow, transport, and reaction phenomena in the near field system. As discussed in Chapter 5, test-related heat creates a circulatory and vertical flow away from the cavity chimney system for the first 50 to $100 \mathrm{yr}$ after the test. This allows for a fast, initial upward migration of the more mobile radionuclides, but has less of an impact on the more retarded or strongly sorbing radionuclides. 
- The dissipation of the higher temperatures in the melt glass is dominated by advective movement of thermal energy away from the glass. As such, the length of time at which temperatures remain elevated will become a barometer of flow rates through the high temperature region.

- Melt glass dissolution rates are highly sensitive to variations in temperature, surface area, silica concentration and $\mathrm{pH}$, and the secondary minerals that precipitate in the glass zone (Chapter 6). Based on the simplified glass model used in the particle transport code, higher temperatures in the melt glass significantly increase the rates of glass dissolution and associated radionuclide release. This most strongly affects the flux of weakly sorbing or nonsorbing glass bound radionuclides such as ${ }^{36} \mathrm{Cl}$ or ${ }^{99} \mathrm{Tc}$ out of the near field. In the current simulations, roughly $30 \%$ of the melt glass dissolved over the $1000 \mathrm{yr}$ simulation period, and over $70 \%$ of this loss occurred in the first $10 \mathrm{yr}$ when temperatures in the melt glass were at their highest. Conversely, in a sensitivity simulation run with a lower glass dissolution rate, only $0.12 \%$ of the melt glass dissolved in $1000 \mathrm{yr}$.

- Monte Carlo simulations spanning a range of plausible and conditioned permeability and mineralogy realizations indicate a significant degree of variability - or uncertainty - with regard to the flux of radionuclides past the UE-20n \#1 control plane. Control plane flux values (in moles per year) at any particular time can vary by 2 or more orders of magnitude for most radionuclides. Simulation results for multiple realizations indicate that permeability and mineralogic variability produce similar degrees of uncertainty in the prediction of radionuclide flux across the breakthrough plane.

- The effects of coupled radionuclide decay and ingrowth can influence the abundance and migration behavior of the source term radionuclides. Although all of the 37 radionuclides included in this model will undergo decay, only those in the chain ${ }^{241} \mathrm{Pu} \rightarrow{ }^{241} \mathrm{Am} \rightarrow{ }^{237} \mathrm{~Np}$ need to be considered from a coupled decay and ingrowth perspective.

- The effects of matrix diffusion, although incorporated in only a small subset of sensitivity runs of the particle model, appear to be insignificant when compared with the combined effects of heterogeneity. This is consistent with the field experiments of Becker and Shapiro (2000).

- For certain radionuclides, the downstream breakthrough is very sensitive to the choice of glass dissolution rate. While the initial breakthrough results from the radionuclide fraction initially distributed in the exchange volume, the long-term radionuclide flux is controlled by the glass dissolution rate. Those radionuclides that are least retarded are most sensitive to the glass dissolution rate. 
- For certain radionuclides the downstream breakthrough is very sensitive to sorption constant uncertainty. The sensitivity can be at the same scale as that derived from the Monte Carlo analysis of permeability and sorbing mineral heterogeneity. However, a more rigorous evaluation of surface complexation/ion exchange uncertainty is necessary to better evaluate its effect.

- The sensitivity of model results to the addition of local dispersion is small. Only when dispersion was set to very high values $\left(\alpha_{L}=100 \mathrm{~m}\right.$ and $\alpha_{T}$ $=10 \mathrm{~m}$ ) did breakthrough at the downstream plane noticeably depart from our base-case simulations. This indicates that dispersivity values on the order of 10 grid blocks ( $10 \mathrm{~m}$ grid blocks used in our model) would not represent variations in material properties at the sub-grid scale. With transverse dispersivity alone, no significant departure from the base-case simulation was observed. Transverse dispersivity is not, therefore, likely to be important in the streamline simulations.

- Although the three-dimensional streamline model could not be effectively used in strongly transient flow fields, such as those produced in the first $100 \mathrm{yr}$ of a typical CHESHIRE flow simulation, it still proved to be a viable tool in the later stages of the simulation, as well as a useful diagnostic technique for interpreting and simplifying the interplay of flow, reaction, and temperature phenomena in one-dimensional configurations.

- Although it is only based on an approximate parametric (retardation factor) representation of chemical sorption processes and an approximate (calibrated) model of melt glass dissolution, the three-dimensional particle model proved to be a viable tool to explore a multitude of threedimensional sensitivity and Monte Carlo replicate simulations of radionuclide migration for the entire simulation period.

- The use of both streamline and particle simulations proved to be a useful and successful marriage of two competing numerical techniques whose collective advantages could be mutually exploited in the analysis.

\subsubsection{Some Important Remaining Concerns}

- Uncertainties in matrix diffusion. Despite the apparent insignificance of matrix diffusion in our results, the recent laboratory-scale experiments of Reimus et al. (2002) do show observable impacts of matrix diffusion on the movement of tritium, ${ }^{14} \mathrm{C}$, and ${ }^{99} \mathrm{Tc}$ through fractured rock cores. This suggests additional sensitivity studies may be warranted.

- Uncertainties in the fracture system permeability and reactivity specifications. The ability of the geologic medium to retain or otherwise retard the motion of radionuclides is largely based on the existence and distribution of reactive minerals in the fractures. In addition, the ability of the geologic medium to allow for the advancement of radionuclides out of the near field will be affected by the existence and distribution of high permeability 
pathways between the cavity and breakthrough plane. The extent to which our current uncertain understanding of the physical and mineralogical specifications used in the model can be justified or subsequently improved will control our confidence in the radionuclide flux results.

- Effects of secondary precipitates in glass. The precipitation of secondary minerals in the glass zone as a result of glass dissolution has been predicted, but the effect of the precipitates on radionuclide retardation and glass zone permeability have not been considered. These effects could lead to significant changes in predicted flux. 


\section{Large-Scale Transport Issues}

\subsection{Background}

The current flow and transport modeling results were developed under detailed, site-specific conditions for the CHESHIRE test. This chapter considers how these or similarly detailed, site-specific (near-field) modeling results may be interpreted or generalized for use in large-scale simulations of radionuclide migration in the Pahute Mesa corrective action unit (CAU). The principal results of interest include the effective fluid flux moving through the near-field flow modeling domain (Chapter 5) and the integrated mass flux of radionuclides crossing the exit plane-the hydrologic source term (HST) (Chapter 7) — that would be used as an internal boundary condition applied to a small number of CAU model grid blocks (IT Corporation, 1998c).

There are two particular perspectives that that need to be recognized or distinguished in this process:

1. To what extent do the current near-field and HST modeling results need to be interpreted or scaled for use at the CHESHIRE location in the CAU model, and

2. To what extent can the current near-field and HST modeling results be scaled or otherwise generalized for use at any other test location in the CAU model?

\subsubsection{Application to the CHESHIRE Test Location}

In terms of perspective 1, several base assumptions and important factors need to be considered and carried forth into the CAU model. These include:

- The predicted radionuclide fluxes are matched to an effective flow rate through our near-field flow modeling domain. When applied to the CHESHIRE location in the CAU model, will the CAU model flow rate be similar, or must the current flux results be scaled in some sense to reflect the flow rate obtained in the CAU model? If a scaling process is used, to what extent can it represent the coupling between temperature and flow?

- The predicted radionuclide fluxes exhibit macrodispersion caused by the model of physical heterogeneity employed in our near-field flow simulations. How should a macrodispersive effect be measured and used in the CAU model at the CHESHIRE location?

- The predicted radionuclide fluxes exhibit a mean retardation effect created by the model of chemical heterogeneity employed in our nearfield simulations. As above, how should this retardation effect be measured and used in the CAU model at the CHESHIRE location? 
- The predicted radionuclide fluxes are averaged quantities that do not reflect specific, smaller-scale details in the near-field model, such as the spatial variation of concentration within the domain or spatial variation of flux at the exit plane. When incorporated into the CAU scale model, these details will be lost, even though they may still be relevant to the large-scale problem (Kapoor and Gelhar, 1994a,b).

- Are there better metrics for transferring results to a CAU model? The results of the current CHESHIRE HST model were presented as a series of integrated radionuclide flux profiles past a control plane. By replicating these flux profiles in the larger-scale model, radionuclide mass is naturally conserved, but radionuclide concentrations are not (see above).

Importantly, the current CHESHIRE near-filed model was developed under site-specific conditions assuming an upper-bound announced yield, which affects the size of the cavity and the volume of melt glass, and an averaged Pahute Mesa radiologic source term.

\subsubsection{Application to Other Test Locations}

In terms of perspective 2, the consideration of other test locations becomes more complicated in that:

- The current near-field modeling results may not be applicable to other tests because of basic differences in test conditions such as yield, depth of burial, and inventory. These factors control the estimated size of the cavity and exchange volumes, the mass of melt glass, and the initial concentrations of radionuclides, and, subsequently, influence the nature of radionuclide release. Although the current near-field model was sitespecific in terms of the physical and chemical conditions considered (see below), it was less specific in terms of the test-related conditions, as it utilized an averaged Pahute Mesa source term and was based upon an upper-bound announced yield which affected of cavity size and melt glass volume.

There may be other tests on Pahute Mesa where the aforementioned test conditions are similar to those at CHESHIRE (or could be assumed as such). In these cases, the following issues must also be considered:

- The current near-field modeling results were determined for a test located in saturated rhyolitic lavas. Some of the Pahute Mesa tests were conducted above the water table or in different lithologies, such as interbedded welded or nonwelded tuff units having various degrees of alteration, fracturing, and thickness. The use of these results in locations with different lithologic, hydrogeologic, and geochemical conditions may not be completely applicable or representative. Categorization of tests on Pahute Mesa - the understanding of the different types of tests and the interactions of the test with their structural, hydrologic, and mineralogic 
setting - has not yet been completed and was not incorporated in HST simulations.

- The current near-field flow model assumes a single value for the hydraulic gradient across the model domain. Different hydraulic gradients and hydraulic properties exist at different test locations. Besides temperature effects, these differences may lead to groundwater flow rates in the CAU model that are incompatible with those in the current model. These differences may also lead to mismatch in the solute flux inputs. Different effective porosities will cause similar effects by changing ground water flow velocity.

- The radionuclide flux results produced by the current near-field model are influenced by the initial temperature of the melt glass. Melt glass temperature affects dissolution rates and interaction with transient fluid flow through the near-field system. These effects may not be directly transferable to different testing locations in the CAU. However, the current near-field flow modeling results do emphasize the importance of groundwater flow in dissipating test-related heat.

- The current near-field flow modeling results were based on a plausible model of permeability heterogeneity in the rhyolitic lava flows. Although based on data from several nearby holes, this flow model is still uncertain in many respects, and its parametric representation could certainly vary from location to location. Unlike CHESHIRE, the near-field flow domain for a different test location may span more than one hydrostratigraphic unit in the CAU model.

- The current radionuclide retardation model was based on bulk mineralogy specific to the CHESHIRE site and fracture lining mineralogy of devitrified tuffs below the water table. Other test locations may vary significantly in mineralogy and, in turn, radionuclide retardation.

The remainder of this chapter focuses on application of the current near-field modeling results to the CHESHIRE location only (perspective 1). The viability of using or extrapolating the current near-field modeling results to other locations will be discussed in detail in a future report.

\subsection{Matching the Effective Flow Rate}

As mentioned above, the current simulations of integrated radionuclide fluxes depend on the effective flow rate computed in the near-field modeling domain. When imported into the CAU model at the CHESHIRE location, these fluxes must be similarly matched to the effective flow rate in the CAU model. Otherwise, the transfer of the HST from near-field to CAU scale models may produce an artificial build up or deficit of mass density in the CAU model. If the CAU model flow rate does not precisely equal the near-field model flow rate. there are two options: (1) scale radionuclide fluxes to be consistent with the flow rate obtained in the CAU model at the 
CHESHIRE location, or (2), force the flow rate in the CAU model to match that computed in the near- field model. Both of these options are discussed in more detail below.

\subsubsection{Scaling the Integrated Radionuclide Fluxes}

As discussed briefly by Tompson et al. (1999) and Pawloski et al. (2000) under simplified conditions, integrated flux profiles could be scaled to reflect an overall change in flow rate through the system. Such a change in flow rate in the CAU model, for example, might represent the use of a different effective permeability or hydraulic gradient at the CHESHIRE test location. The scaling approach involves separating the Exchange Volume and Melt Glass components of the integrated flux profile, applying simplified modifications to these profiles, and recombining the modified profiles into a "scaled result". The simplifications invoked in this process are dependent on the assumptions of isothermal conditions, a constant glass dissolution rate, and a linearized mathematical representation of the sorption reactions.

In the current near-field flow model representation, however, any change in flow rate through the system induced by a change in permeability or hydraulic gradient will affect the evolution of geothermal and test-related heat. The interaction between heat and fluid flow will have additional feedback into the rates of heat dissipation and changes in the glass dissolution rate. Thus, the scaling assumptions invoked above cannot be strictly used to forecast how existing flux profiles can be modified to reflect changes in permeability or hydraulic gradient. In general, the problem would have to be rerun specifically for the modified conditions, possibly as part of an additional Monte Carlo cycle. However, it may be possible to assume isothermal conditions as an approximation for scaling purposes, especially if the persistence of test-related heat in the system is confined to 50 to 100 years. Alternatively, additional sensitivity simulations of the near-field model may address these scaling issues further.

\subsubsection{Matching the Effective Permeability and Hydraulic Gradient}

Another approach to matching the effective flow rate in the CAU model with that obtained in the near-field model is to ensure compatibility between the effective parameters used in the near-field and CAU scale models. This applies not only to the concept of matching effective permeabilities and hydraulic gradients, but also, as mentioned above, to the effective rates of macrodispersion and retardation. These concepts will be discussed separately below in Sections 8.3 and 8.4 on the effects of hydraulic and chemical heterogeneity.

\subsection{Effects of Hydraulic Heterogeneity}

In the context of this work, hydraulic heterogeneity refers to spatially nonuniform distributions of hydraulic properties, such as permeability and porosity. The effects of hydraulic heterogeneity on transport at a larger scale are most easily described in terms of

- An effective permeability or hydraulic conductivity. 
- An effective longitudinal macrodispersion coefficient, to account for dispersion or spreading.

It is desirable to ensure compatibility between the parameters used in the near-field and CAU scale models. If the near-field or local models of heterogeneity are adequate, then the effective hydraulic properties may be estimated from numerical experiments or theoretical results based on the spatial statistics of the permeability distribution.

\subsubsection{Effective Horizontal Hydraulic Conductivity}

The effective (horizontal) hydraulic conductivity or permeability can be estimated for the near-field model. Such a parameter might be incorporated in the CAU model near the CHESHIRE test. Here, we consider the flow solution based upon the notest-related-heat configuration in permeability realization 9 . Only a slight transient effect produced by the background geothermal gradient is present, and the flow, $q_{y}$ solution settles quickly to a steady state configuration. Based upon this steady-state configuration, the mean horizontal (Darcy) groundwater flux in the direction $(y)$ of the imposed hydraulic gradient computed from the central core of the flow domain is

$$
\left\langle q_{y}\right\rangle=\left\langle\phi v_{y}\right\rangle=7.41 \times 10^{-8} \mathrm{~m} / \mathrm{s}=6.40 \times 10^{-3} \mathrm{~m} / \mathrm{d}
$$

where $v_{y}$ is the mean fluid flow velocity in the $y$ direction, and $\phi$ is the effective porosity.

Based on the mean or effective version of Darcy's law,

$$
\left\langle q_{y}\right\rangle=-K_{y}^{e f f} \nabla h
$$

an estimate of the effective horizontal hydraulic conductivity in the $y$ direction, $K_{y}^{\text {eff }}$, for a background hydraulic gradient of -0.01 is

$$
K_{y}^{e f f} \approx 7.41 \times 10^{-6} \mathrm{~m} / \mathrm{s}=0.640 \mathrm{~m} / \mathrm{d} .
$$

At a temperature of $37.5^{\circ} \mathrm{C}$, this corresponds to an effective horizontal permeability, $k_{y}^{\text {eff }}$, of

$$
k_{y}^{e f f} \approx 5.18 \times 10^{-13} \mathrm{~m}^{2} .
$$

These values are approximate because they reflect the influence of the cavity and chimney in (8.1).

\subsubsection{Effective Longitudinal Macrodispersivity}

The current near-field modeling results may enable estimation of the longitudinal macrodispersivity $\left(A_{11}\right)$ for a tracer moving through the hydrogeologic system. Again, such a parameter might be incorporated in the CAU model near the 
CHESHIRE test, but would be most meaningful in describing the form or leading edge of radionuclides moving away from the test. Here, attention is focused on the simulated flux of TracerEV past the UE-20n \#1 control plane, as shown in Figure 8.1. An estimate of $A_{11}$ cannot be made from any type of stochastic theory (e.g., Gelhar, 1993), because the underlying geostatistical description of permeability variation (Appendix $G$ ) is not the Gaussian random field assumption typically employed in most theoretical predictions.

Instead, a one-dimensional analytical solution based upon a point source of mass (or moles) $M$ placed at the working point of the test and moving unidirectionally toward the control plane can be used to estimate an order of magnitude of $A_{11}$ (as in Pawloski et al., 2000). The analytical solution for tracer flux $J_{\text {tracerEV }}(t)$ for time, $t$, at the control plane is,

$$
J_{\text {tracerE } V}(t) \approx V \cdot \frac{M}{2 \sqrt{\pi A_{11} V t}} \exp \left\{\frac{-\left(y_{e}-V t\right)^{2}}{4 A_{11} V t}\right\},
$$

where $y_{e}$ is the distance to the control plane.

The mean velocity $\left(V_{y}\right)$ can be specified from Equation $(8.1)$ as $7.41 \times 10^{-6} \mathrm{~m} / \mathrm{s}$ if a constant effective porosity of 0.01 is used. The control plane location $\left(y_{e}\right)$ is $305 \mathrm{~m}$ away from the working point of the test in the mean $(y)$ flow direction, and this particular simulation involved the release of $M=0.9911$ moles of TracerEV. Equation (8.1) is only approximate because it is based upon an assumption of constant porosity, and does not strictly account for the spatially distributed initial condition used to obtain the numerical solution in Figure 8.1. In addition, the solution will not reflect any nonlocal dispersion behavior evident in the numerical solution arising from the measurement plane being too close to the source location. 


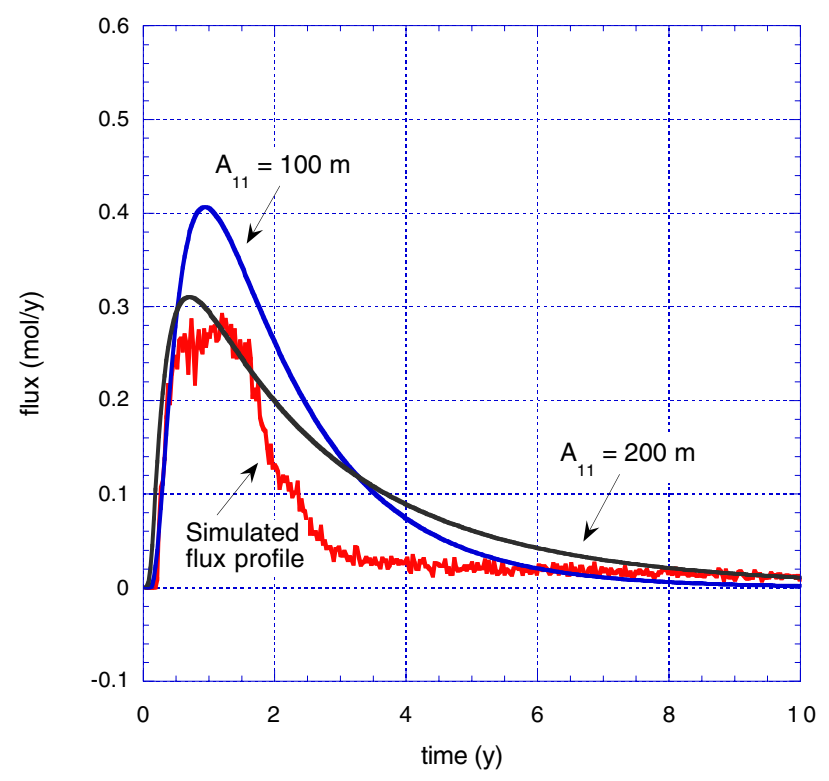

Figure 8.1 Simulated TracerEV flux past the UE-20n \#1 control plane in the realization 9 flow field based upon no test-related heat. Two analytical tracer flux profiles based upon a point source of $M$ moles located at the working point of the test and two different values of the macrodispersivity $A_{11}$ are superimposed.

Figure 8.1 shows analytical solutions for Equation (8.5) based upon values of $A_{11}=100$ and $200 \mathrm{~m}$. The fits are somewhat reasonable, but in no way exact. The sharp decline at the 2-year mark leading to a long, flat tail cannot be effectively reproduced by Equation (8.5). It would appear that values of $A_{11}$ bounded by 100 and $200 \mathrm{~m}$ may be the most reasonable estimates of macrodispersivity that can be made for this system, as based upon the current results. As noted in Garabedian et al. (1988), Gelhar (1993), and Pawloski et al (2000), different values of $A_{11}$ may be associated with different radionuclides, depending on their overall reactivity and the degree of heterogeneity associated with the distribution of sorptive minerals. Alternatively, a smaller value of $A_{11}$ combined with consideration of a spatially distributed source might provide a better model for the early-time ( $<3$ years) breakthrough. A dual-permeability model might capture the extended tailing behavior (Labolle et al., 1996).

\subsection{Effects of Chemical Heterogeneity}

In the context of this work, chemical heterogeneity refers to spatially nonuniform distributions of sorptive minerals in the rhyolitic lava flows of the maficpoor Calico Hills Formation. Chemical heterogeneity will affect the effective mobility, or apparent retardation, of contaminants moving out of the test region as well as the effective dispersion or spreading behavior associated with reactive contaminant plumes (in addition to effects induced by physical heterogeneity). As with hydraulic heterogeneity, it is desirable to ensure compatibility between the parameters used in the near-field and CAU models. 
More specifically, when viewed at a larger (CAU model) scale, the effects of chemical heterogeneity will result in ${ }^{1}$

- An overall reduction in the perceived retardation behavior, because some localized areas will have little or no sorptive minerals and little or no retardation.

- An increased level of spreading or dispersion of sorbing radionuclides relative to those produced for a nonsorbing tracer.

\subsubsection{Effective Retardation}

In a problem characterized by chemical heterogeneity, the effective mobility or retardation of a sorptive species at the larger scale will be some average of the retardation effects experienced by all parcels of that species in the system. If the local retardation effects for a particular radionuclide $i$ can be described by a simple medium constant, then Garabedian et al. (1988) and Gelhar (1993) suggest the appropriate effective retardation coefficient, $\left\langle R_{i}\right\rangle$, is merely an arithmetic average of the local point values. Such a mean value of $\left\langle R_{i}\right\rangle$ can be determined from an interrogation of the local retardation values across the model domain. Preliminary assessments made by Pawloski et al. (2000) appear to confirm the validity of the relationship.

Although the transport simulations described in Chapter 7 were not specifically designed to infer larger scale retardation coefficients, the effective retardation factor for a given radionuclide could be estimated by comparing the time of its peak breakthrough at the breakthrough plane with the time of peak breakthrough for a nonreactive tracer. As evident in the particle and streamline transport simulations for the CHESHIRE test, the migration of tracers and radionuclides is affected to varying degrees by several complicating factors:

- Transient flow.

- Variable rate of melt glass dissolution.

- Heterogeneity of permeability and mineralization.

- Spatial distribution of the RST.

- Alteration of permeability structure caused by the CHESHIRE test.

Test-related heat drives migration of radionuclides upward into the chimney to different degrees, largely depending on reactivity and time dependence of melt glass dissolution. At early times, the test-related heat and cavity/chimney permeability structure facilitates vertical migration and recirculation of radionuclides in the chimney and delays their lateral migration. Among all radionuclides, the migration of

\footnotetext{
${ }^{1}$ Garabedian et al. (1988), Gelhar (1993), Tompson (1993), Tompson et al. (1996), Tompson and Jackson
} (1996, and Pawloski et al. (2000). 
nonreactive tracers is most sensitive to test-related heat because their high mobility facilitates entrainment in highly transient flows. The timing of the peak breakthrough for a tracer (as estimated from the particle model) ranges between 0.5 and $1.5 \mathrm{yr}$ without test-related heat, and is about 2 yr with test-related heat (Figure 7.34). Test-related heat delays tracer breakthrough by causing more vertical migration and recirculation within the chimney at early times. The timing of peak breakthrough of sorbing radionuclides is not necessarily affected much by test-related heat (although the magnitude of peak breakthrough can be affected by test-related heat), as shown in Figure 7.34 for Pu and Sm.

Figure 8.2 compares the relationship between the timing of median peak breakthrough of radionuclides according to the particle model (Figure 7.28) with the value of the estimated average retardation for each radionuclide (Table K.9). The median peak breakthrough times obtained from the particle model include the impacts of test-related heat and heterogeneous permeability and mineralization. The average retardation values are based on the assumption of a homogeneous spatial distribution of sorptive minerals in fractures (Appendix K).

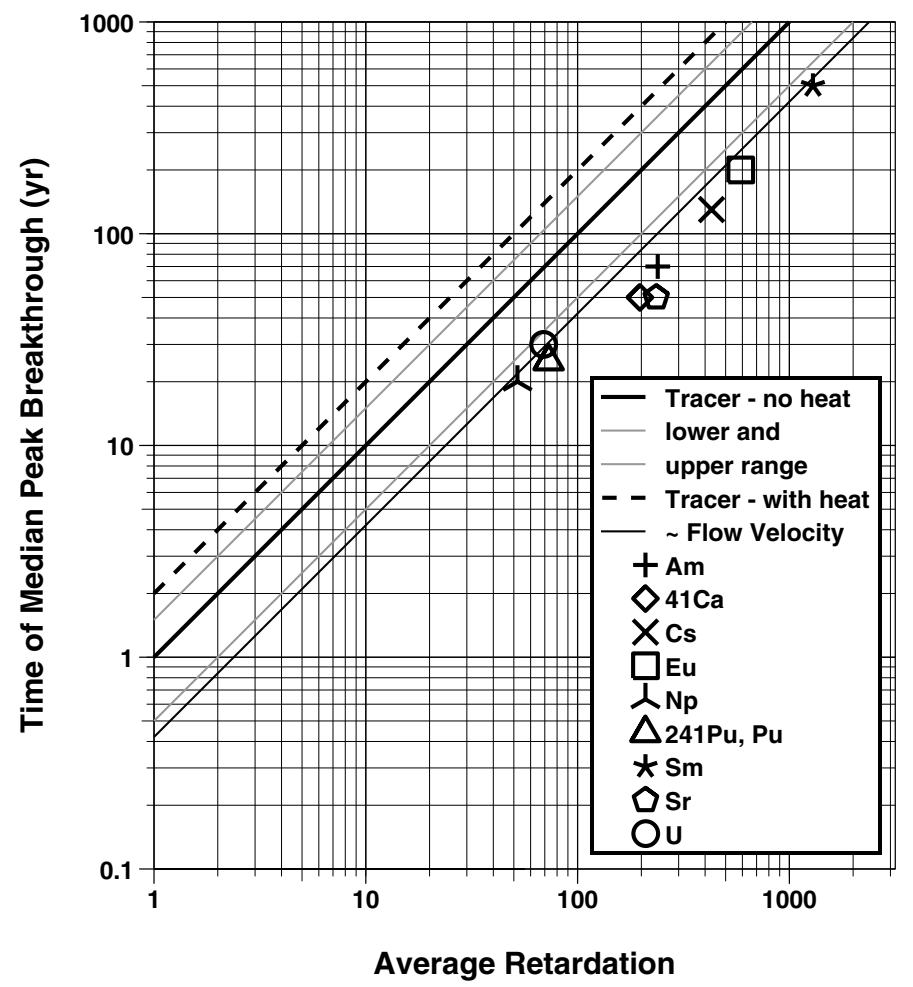

Figure 8.2 Comparison of particle model median peak breakthrough for radionuclides with average retardation assuming statistically homogeneous mineralization. Thick black line represents ideal relationship assuming tracer breakthrough peak at $1 \mathrm{yr}$ with no test-related heat. Thin gray lines bracket range of uncertainty of peak tracer breakthrough with no test-related heat. Dashed line represents ideal relationship assuming tracer breakthrough peak at $2 \mathrm{yr}$, as inferred from particle model median tracer breakthrough with test-related heat. Thin black line indicates ideal relationship assuming average flow velocity for high permeability hydrofacies.

The various 45-degree lines in Figure 8.2 represent idealized relationships of peak breakthrough of radionuclides for steady-state flow and transport conditions 
assuming linear retardation, homogeneous permeability and mineralization, constant temperature and flow velocity, and a point source. Based on this idealized model, time of peak breakthrough for a radionuclide $k, t_{b, k}$ is linearly related to the time of peak breakthrough of a nonreactive tracer, $t_{b, t}$, according to

$$
t_{b, k}=t_{b, t}\left\langle R_{k}\right\rangle
$$

where $\left\langle R_{k}\right\rangle$ is the average retardation of the radionuclide $k$. Converted to a base-10 logarithmic scale, Equation (8.6) becomes:

$$
\log _{10} t_{b, k}=\log _{10} t_{b, t}+\log _{10}\left\langle R_{k}\right\rangle
$$

Equation (8.7) yields a linear relationship on the log-log scale. The $y$-axis intercept for $\log _{10} t_{b, k}\left(\right.$ at $\left.\log _{10}\left\langle R_{k}\right\rangle=0\right)$ is $\log _{10} t_{b, t}$, which is the value of $\log _{10} t_{b, k}$ if the radionuclide is nonreactive (i.e., when $k=t$, a tracer) and $\left\langle R_{k}\right\rangle=R_{t}=1$. The slope of the line on the log-log scale is 1.0 (or 45 degrees) because

$$
\frac{\log _{10} t_{b, k}-\log _{10} t_{b, t}}{\log _{10}\left\langle R_{k}\right\rangle-\log _{10} R_{t}}=1.0
$$

by rearranging Equation (8.7) and considering that $\log _{10} R_{t}=0$.

Interestingly, the median peak breakthrough times for all 10 of the radionuclides do fall closely to a line with 45-degree slope. Ideally, a line fit through these data projected to a retardation of 1.0 would indicate the time of peak breakthrough for a tracer. However, as mentioned above, the simulations of tracer transport for the CHESHIRE test (Chapter 7) do not constitute idealized conditions of flow and transport.

The different lines shown in Figure 8.2 are based on different estimates of the time of peak tracer breakthrough:

- Thick black line-particle model without test-related heat.

- Thin gray lines-range of uncertainty for particle model without testrelated heat.

- Dashed line-particle model with test-related heat.

- Thin black line-idealized transport assuming average fluid velocity in high permeability zones.

The fluid velocity in the high-permeability zones is specifically considered here because most lateral tracer transport will be channeled through the highpermeability zones. An average fluid velocity in high-permeability zones is estimated at $1.96 \mathrm{~m} / \mathrm{d}$ based on base-case hydraulic properties described in Chapter 5: 
- Horizontal permeability, $k_{y}$ of $1.6 \times 10^{-12} \mathrm{~m}^{2}$ in the down-gradient $(y)$ direction.

- Hydraulic conductivity, $K_{y}$ of $1.96 \mathrm{~m} / \mathrm{d}$ assuming a temperature of $37.5^{\circ} \mathrm{C}$,

- Effective porosity of 0.01 .

- Hydraulic gradient of 0.01 .

The timing of peak breakthrough for the radionuclides falls at or below all of these idealized lines and, thus, implies various degrees of accelerated breakthrough relative to the average retardation values. Closer fits are obtained under the assumption of a tracer without test-related heat, probably because test-related heat affects the timing of peak breakthrough more for a tracer compared to the radionuclides. Accelerated breakthrough of radionuclides relative to average retardation values could occur for several causes:

- Test-related heat.

- Enhanced interconnectivity as a result of chimney and cavity formation.

- Heterogeneity in the spatial distribution of permeability and mineralization.

- Variable rate of melt glass dissolution.

- Spatial distribution of the RST.

The fact that the estimated times of peak breakthrough for the radionuclides fall close to a 45-degree line with respect to averaged retardation values is encouraging in several respects:

- The concept of a linear retardation coefficient may be scalable.

- Detailed near-field scale modeling may be useful for predicting effective radionuclide retardation coefficients for larger scale models.

- Given an ability to predict average retardation from mineralogical data, knowledge of mineral distributions may be used to predict large-scale effective retardation coefficients.

These modeling results also indicate, however, that large-scale retardation coefficients inferred from averaged mineral concentrations could lead to overestimation of effective retardation by a factor of between 2 and 8, depending on the assumptions made. For example, in Figure 8.1, the plot point for Sr (pentagon) falls the farthest below the 45 -degree lines. If the 45 -degree line determined by an average flow velocity in the high-permeability zones (thin black line) is assumed an appropriate model for 
predicting average retardation, then the median time of peak breakthrough for $\mathrm{Sr}$ occurs at about $50 \%$ of the time that the average retardation model would predict. The median breakthrough times for Am and ${ }^{41} \mathrm{Ca}$ occur at about $70 \%$ and $60 \%$, respectively, of the time that the average retardation model would predict. Nonetheless, the radionuclides $\mathrm{Eu},{ }^{241} \mathrm{Pu}, \mathrm{Pu}, \mathrm{Np}, \mathrm{Sm}$, and $\mathrm{U}$ show excellent agreement with the average retardation model assuming average flow velocity in the high-permeability zones. The other models shown in Figure 8.1, which are based on time of peak tracer breakthrough, would lead to greater overestimates of the time of peak breakthrough for sorptive radionuclides.

Clearly, predictions of large-scale retardation coefficients based on particle and GIMRT streamline modeling results in Chapter 7 are also uncertain because of various uncertainties and complexities involved with predicting near-field flow and transport. These reactive transport results are also predicated on the flow modeling results (Chapter 5) and the conceptualization of the abundance and spatial distribution of sorptive minerals (Chapter 6 and Appendices $\mathrm{H}$ and $\mathrm{K}$ ). The streamline and particle transport models could be applied in more direct ways to address the issue of predicting large-scale average retardation coefficients. Simulations could be developed for ambient flow conditions with no test-related heat and test-related permeability alterations, which would separate out the uncertainties associated with test-related effects. Clearly, modeling studies should be designed to directly address scaling issues that pervade any attempt to realistically estimate large-scale effective retardation coefficients.

\subsection{Dilution Effects}

As discussed above, the predicted radionuclide fluxes for the hydrologic source term are averaged quantities that do not reflect specific, smaller-scale details in the near-field model, such as the spatial variation of concentration within the model domain or spatial variation of flux at the exit plane. Although the radionuclide mass is conserved, Figure 8.3 shows conceptually how concentration variability can be lost in the process of scaling from near-field to CAU models. It is not clear whether dilution effects will be important or otherwise alter how the contaminant boundary is defined by the CAU model.

In the next section, an approach is suggested through which some or all of the "lost" information may be retained or recovered. This approach relies on the use of (1) more precise radionuclide flux results from the near-field model (e.g., non-integrated) and (2) a non-grid-based transport model in the CAU model. 


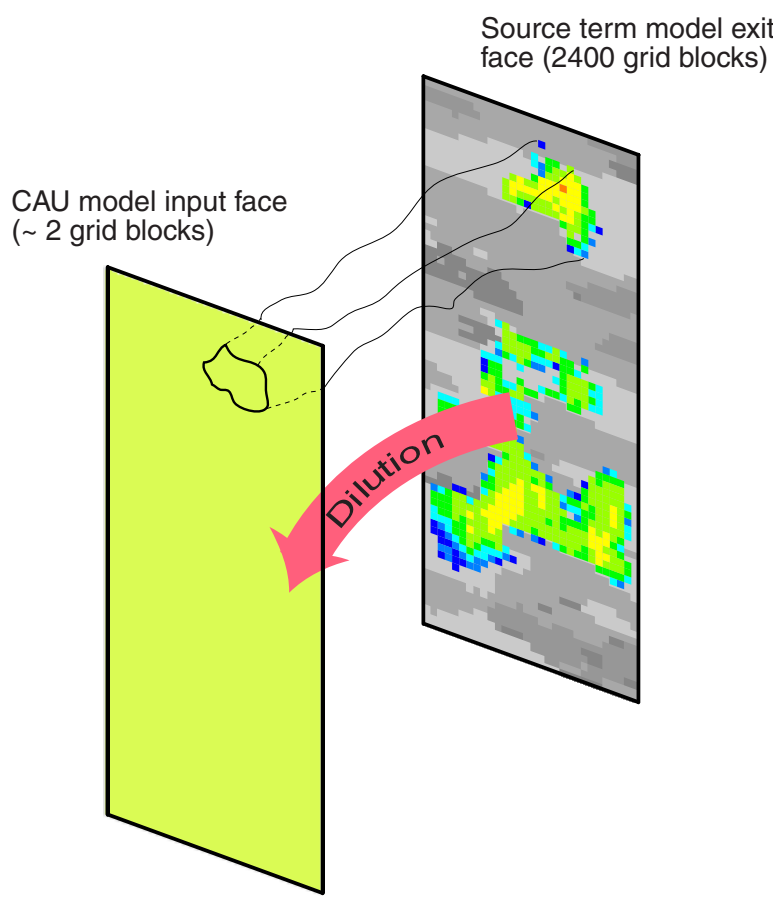

Figure 8.3 Conceptual representation of the dilution effect created by mapping the integrated flux coming out of the finely discretized near-field model into a coarsely gridded CAU model. Although radionuclide mass is conserved, the highs and lows of the concentration variability visible along the near-field model exit face are lost. The small schematic at the top is used to suggest the possibility of preserving the small-scale variability in the near-field model by mapping the results into a particle-base transport simulator in the CAU model.

\subsection{Other Metrics for Representing the Source Term Results}

The HST results were presented as a series of integrated radionuclide flux profiles crossing a control plane in the near-field model. The use of a flux profile effectively allows the mass of radionuclides emanating from the near-field model per unit time to be replicated or conserved in the transfer to the CAU model. The use of a flux-based quantity requires a reconciliation of the effective flow rates between the two models, or some additional scaling steps, given the risk of creating an artificial build up or deficit of mass density (e.g., concentration) in the CAU model. Such a build up or deficit should be distinguished from the dilution effects created by the use of integrated fluxes determined from cross-sectional averaging over the exit plane, as discussed in the previous section.

For reference, several other methods could be used to transfer the results of the near-field model to the CAU scale model. These include computation of:

- Flux-averaged concentrations at a control plane in the near-field model. In this approach, the cross-sectionally averaged flux value for a given radionuclide, say $J_{I}(t)$, is divided by an appropriate ground water flux $Q(t)$ crossing the same plane in the near-field model, yielding (once the units 
are made compatible) a cross-sectionally averaged concentration. The result of this operation may then be used as a concentration boundary condition within the CAU model. Although this approach does not necessarily require a synchronization of the flow rates between the two models, nor any analogous scaling procedure, it is not guaranteed to conserve mass moving between the models because the balance of the fluxes between the models is removed. Because the flux-averaged concentration is a cross-sectionally integrated quantity, it is also subject to the dilution effects discussed in the previous section. In addition, "appropriate" groundwater flux $(\mathrm{Q})$ is considered as the total flux moving through the contaminated portion of the exit plane as opposed to the entire flux moving through the near-field model domain (e.g., Pawloski et al., 2000). Although not recommended for use in transferring the HST to the CAU model, flux averaged concentrations may prove useful for model diagnostic purposes (as in Pawloski et al., 2000).

- Volume averaged concentrations in the near-field model domain. Analogous to the previous approach, the radionuclide mass within the near-field modeling volume can be divided by the contaminated pore volume to yield a composite concentration as a function of time. This quantity could also be used as an internal concentration condition in a CAU model, although its use will be subject to the same caveats and considerations listed above for flux-averaged concentrations.

- Smaller-scale fluxes over portions of the control plane in the near-field model. Here, the radionuclide flux results moving across the exit plane of the near-field model might be integrated over subareas of the exit plane in such a way to preserve some of the information lost to dilution. It might then be possible to employ a particle- or streamline-based transport scheme in the CAU model to propagate the spatially variable flux information across various portions of the CAU model input face, as illustrated in Figure 8.3. Such an approach might tend to limit the degree of dilution produced in transferring the HST from near-field model to the CAU model. Use of a particle-based scheme in the CAU model would also minimize the degree of artificial numerical dispersion produced in the CAU simulation. Use of a streamline scheme in the CAU model would produce no transverse dispersion (whose magnitude, relative to that of longitudinal dispersion, would not be expected to be large).

As above, a similar set of scaling approximations are needed to ensure continuity of the fluid flux crossing these same areas, so as to minimize any build up or deficit of mass density in the CAU model.

\subsection{Summary}

This chapter has considered how the current near-field model results at CHESHIRE may be interpreted or generalized for use in large-scale simulations of radionuclide migration in the Pahute Mesa corrective action unit (CAU). It is important 
to distinguish whether the source term results are being scaled (or otherwise interpreted) for use at the CHESHIRE location or being used to represent conditions at other locations in the CAU model.

With regard for using the current integrated radionuclide flux results at the CHESHIRE location, the following issues have been raised:

- The need for compatibility among the effective flow rates used in the nearfield and larger scale CAU models, as well as the need for compatibility among the effective permeability, macrodispersion, and retardation parameters in both models.

- The plausibility of scaling the integrated flux results for use in the CAU model if the effective flow rates in the two models differ, and the limitations associated with such an approach.

- The effect of hydraulic heterogeneity and its impact on predicting effective permeability and macrodispersivity.

- The effect of chemical heterogeneity on predicting effective retardation coefficients and enhancing macrodispersivity.

- The potential for predicting large-scale effective retardation coefficients based on average retardation values, as indicated by the reactive transport simulation results of Chapter 7 .

- The dilution effect that may occur as a result of the transfer of the HST from the near-field scale model to the large-scale CAU model. Care must be taken to evaluate this dilution effect and the potential impacts to conclusions and inferences that will be obtained from larger-scale modeling results.

- The pros and cons of using different metrics for representing the nearfield model results, such as through the use of flux-averaged or volume averaged concentrations. An important issue is whether mass or concentration should be preserved during transfer of the HST from the near-field model to the CAU model.

Interpreting or generalizing the current radionuclide flux results for use at other locations in the CAU model, different from CHESHIRE, is fraught with numerous complications and caveats. Although we have reviewed many of the critical issues, a detailed discussion on transfer of HST model results to other locations is beyond the scope of this report. 


\section{Summary, Conclusions, and Recommendations}

\section{$9.1 \quad$ Summary}

The objectives of this report were to develop and interpret a series of unclassified simulations of radionuclide release into groundwater and migration away from the near field at the CHESHIRE test on Pahute Mesa at the Nevada Test Site (NTS). These results comprise the hydrologic source term (HST) for the test. As in previous efforts (Tompson et al., 1999; Pawloski et al., 2000), the goal was to

- Estimate the abundance, spatial distribution, and chemical state of radionuclide contamination just after the test.

- Determine the mechanisms and rates of radionuclide release into the groundwater as a function of time.

- Forecast the rates of radionuclide movement away from the working point of the test for a 1000 yr period, as affected by groundwater flow and chemical reaction processes.

The simulations were complex and highly detailed. To provide the most basic understanding and evaluation of how radionuclide release and migration occur, a level of modeling detail commensurate with the most representative data sets, fundamental processes and conservative assumptions was used and incorporated within the simulations. Fine spatial resolution $(10 \mathrm{~m})$ was used to represent observed variabilities in hydraulic and mineralogic properties of the fractured rock medium. Such a complex representation was required to reproduce several pertinent observations of temperature and radionuclide transport in the system. Chemical reactions involving sorption, dissolution, and precipitation processes were modeled in terms of basic mechanistic approaches whose results could be subsequent used to justify parametric simplifications of the same processes.

Some noteworthy elements of the report are summarized in the following sections.

\subsubsection{Radiological Source Term}

The approach used for specifying the radiological source term (RST) - the initial inventory of radionuclides used in the modeling analysis-was guided by two principal issues. First, it was desired to include a more comprehensive suite of radionuclides in this modeling study, certainly a greater and more representative number than used in the previous reports (Tompson et al., 1999; Pawloski et al., 2000). Second, because this analysis was to remain completely unclassified, specific inventory data pertinent to the CHESHIRE test-as with all individual tests on Pahute Mesa-remains classified and could not be used. Instead, an alternative, and potentially 
more general, approach for identifying a representative unclassified inventory was developed for use at CHESHIRE.

In this approach, a candidate list of 52 radionuclides was first developed from

- The mean of the total radionuclide inventory for all 76 tests detonated below or within the water table in Areas 19 and 20 at Pahute Mesa, the total being unclassified (Smith, 2001);

- Radionuclides identified by the UGTA Source Term Subcommittee as generally significant for remedial investigation at the NTS based on abundance, mobility, and health effects; and

- Radionuclides measured in groundwater near the CHESHIRE test. Of these 52 radionuclides, 7 have no reported mean inventory and could not be considered further. Another 8 were removed as the result of a screening process designed to eliminate low abundance alpha-decaying, betadecaying, or electron capture/isometric transition-decaying radionuclides as viewed over the 1000 yr simulation period important to the UGTA Program. Any radionuclide measured in water that has a reported mean inventory was included in the model, regardless of this threshold. The remaining (final) 37 were scrutinized further with respect to daughter products that may arise in the same 1000 yr simulation period. This RST was then applied at the CHESHIRE site.

Within the cavity and chimney environment, the 37 radionuclides were initially distributed in the melt glass, the water of the melt glass, and the exchange volume surrounding the cavity using the IAEA (1998a) partitioning data. From a transport and mobility perspective, the original 37 radionuclides were segregated into 13 simplified classes of radionuclides that have similar partitioning and chemical reactivity characteristics. This step provided a significantly smaller set of elements for running the transport simulations. Some radionuclides were treated as tracers even though they are likely to be retarded, because sorption data were not available to characterize their mobility.

\subsubsection{Flow Simulations}

The flow simulations at CHESHIRE were based upon the NUFT (Nitao, 1998) model and can be regarded as a self-contained element of the source term analysis. The simulations are notable because they addressed the influence of test-related and geothermal heat and indicated a strong proclivity for rapid upward and dynamic movement of groundwater (and mobile radionuclides) away from the cavity area for a period lasting several decades.

Although three-basic conceptual models for the permeability structure of the native rock were considered - a simple homogeneous model, a layer cake model, and a geostatistically heterogeneous model-the latter proved to be the most robust in terms of its ability to reproduce all measured temperature profiles and observed tracer pathways. The model was calibrated to several temperature logs taken from U-20n PS 
\#1 DD-H and UE-20n \#1, in addition to hydraulic and tracer data taken from U-20a \#2 Water Well. Additional analyses of core and geophysical data and interpretations from the BULLION Forced Gradient experiment were also useful in this process. Within the cavity and chimney environment, the existence of the thermal logs in U-20n PS \#1 DD$\mathrm{H}$ allowed the relatively low permeability of the melt glass and higher permeabilities of the collapsed rock in the lower and upper chimney to be effectively determined and bounded.

Sensitivity studies were conducted related to the selected permeability values, test-related and geothermal heat, as well as the various conceptual models. The permeability of the melt glass, lower cavity, chimney, and higher-permeability hydrofacies in the undisturbed formation are sensitive to matching temperature data. Some early simulations of tracer transport were used to assess observations of tracer arrivals in UE-20n \#1.

Appendix L summarizes the important parameters used in the flow simulations and provides directions to where pertinent data used in the model are tabulated in the main body of the report.

\subsubsection{Mineral Distributions and Retardation}

Although not formally a part of the flow simulation, the existence and distribution of reactive minerals in the fractured rock were addressed as an extended part of the conceptual model development above. Because reactive minerals retard radionuclide transport (Tompson et al., 1999), it was mandatory that the existence and spatial distribution of reactive minerals be considered in our transport models. The mineralogy of the native rock and fracture linings was determined from limited sample data taken from Pahute Mesa and Yucca Mountain. Geostatistical procedures were used to assign variable distributions of minerals along fracture surfaces in the fractured tuff, and in the cavity and chimney.

\subsubsection{Radionuclide Transport Simulations}

Two approaches were used to develop reactive transport simulations of radionuclide migration away from the CHESHIRE cavity and melt glass region. Both of these incorporate the same NUFT flow simulations.

In the first approach, a reactive streamline model, similar to that used by Tompson et al. (1999) and Pawloski et al. (2000) was employed for both single onedimensional streamline and multiple three-dimensional streamline applications in which the complex processes associated with aqueous complexation, surface complexation, ion exchange, mineral dissolution and precipitation. Colloid-facilitated transport was incorporated in a rudimentary fashion. As discussed in Tompson et al. (1999) and Appendix C, the three-dimensional streamline approach, although computationally complex, appears much more tractable than a comparable threedimensional grid-based model.

In the second approach, a simpler and more efficient particle-based model was used to explore a multitude of three-dimensional sensitivity and Monte Carlo 
simulations of radionuclide migration. This model is based upon an approximate parametric (retardation factor) representation of chemical sorption processes and an approximate (calibrated) model of melt glass dissolution. The need for the two models was further established by the fact that the three-dimensional streamline model could not be effectively used in strongly transient flow fields, such as those produced in the first $100 \mathrm{yr}$ of a typical CHESHIRE flow simulation. Within this initial period, the particle models were solely used to obtain source term results.

As in previous efforts, one-dimensional streamline models were used to examine and diagnose many of the complex physical and chemical interactions occurring in the melt glass and disturbed zone of the near-field system. They were also used to bound or justify the validity of the simplified sorption and glass dissolution models used in the particle model.

In both the particle and streamline models, the effects of radioactive decay were generally incorporated as a postprocessing step, but some were handled in a realtime fashion as a means to properly account for daughter product ingrowth (as in the case of ${ }^{241} \mathrm{Pu}$ decay into ${ }^{241} \mathrm{Am}$ and ${ }^{237} \mathrm{~Np}$ in both models) or nonlinear sorption effects (as in the case of ${ }^{90} \mathrm{Sr}$ and ${ }^{151} \mathrm{Sm}$ in the streamline model). The effects of matrix diffusion were only incorporated in the particle model as a sensitivity study. Here, preliminary results seemed to indicate the effects of heterogeneity overshadowed the effects of matrix diffusion. The exclusion of real time matrix diffusion from the streamline calculations was motivated by concerns of computational complexity. Although some post processing approximations could be used to assess the effects of matrix diffusion in an approximate manner, they were not appropriate for the current application.

Appendix L summarizes the important parameters used in the transport simulations and provides directions to where pertinent data used in the model are tabulated in the main body of the report.

\section{$9.2 \quad$ Conclusions}

Basic conclusions from HST modeling at CHESHIRE include the following:

- The release of radionuclides from the melt glass is generally slow and long lasting, regardless of their retardation characteristics in the geologic medium. The release rates can be higher, however, at higher temperatures, and this has the greatest impact on the migration of non-sorbing, glass-bound radionuclides such as ${ }^{36} \mathrm{Cl}$.

- The release of radionuclides from the exchange volume is generally quicker and more short-lived, although significant radionuclide retention in the near field occurs for the more sorptive radionuclides.

- The flux of radionuclides past the UE-20n \#1 control plane is affected by heterogeneity in the physical and reactive properties of the geologic medium. The inclusion of the complex heterogeneous physical properties is necessary to 
reproduce parametric data and key observations of temperature and tritium concentration made in nearby drill holes.

- The fluxes of several short-lived radionuclides past the UE-20n \#1 control plane decrease to a relatively insignificant level within 400 years from the test date. These radionuclides specifically include ${ }^{3} \mathrm{H},{ }^{85} \mathrm{Kr},{ }^{90} \mathrm{Sr},{ }^{93 \mathrm{~m}} \mathrm{Nb},{ }^{121 \mathrm{~m}} \mathrm{Sn},{ }^{137} \mathrm{Cs}$, ${ }^{150} \mathrm{Eu},{ }^{152} \mathrm{Eu},{ }^{154} \mathrm{Eu},{ }^{241} \mathrm{Pu}$, and ${ }^{244} \mathrm{Cm}$, whose half lives are each less than 50 years. Their flux past the control plane decreases to less than $10^{-9} \mathrm{~mol} / \mathrm{yr}$ within $400 \mathrm{yr}$ of the test.

Newer insights are as follows:

- An improved approach for identifying a comprehensive, yet unclassified, RST was developed for application at the CHESHIRE site. To our knowledge this is the first time an objective and systematic approach has been advanced beyond stand-alone criteria of half-life and dose equivalence - to evaluate radionuclides of significance for transport calculations. It is a designed to be conservative, comprehensive, and transferable.

- Residual heat from the test, manifested as high initial temperatures in the melt glass, has numerous important effects on flow, transport, and reaction phenomena in the near-field system. Test-related heat creates a circulatory and vertical flow away from the cavity/chimney system for the first 50 to $100 \mathrm{yr}$ after the test. This allows for a fast, initial upward migration of the more mobile radionuclides radionuclides, but has less of an impact on the more retarded or strongly sorbing radionuclides.

- The dissipation of the higher temperatures in the melt glass is dominated by advective movement of thermal energy away from the glass. As such, the length of time at which temperatures remain elevated becomes a barometer of flow rates through the high temperature region.

- Melt glass dissolution rates are highly sensitive to variations in temperature, surface area, silica concentration and $\mathrm{pH}$, and the secondary minerals that precipitate in the glass zone (Chapter 6 ). Based on the simplified glass model used in the particle transport code, higher temperatures in the melt glass significantly increase the rates of glass dissolution and associated radionuclide release. This most strongly affects the flux of weakly sorbing or nonsorbing glass bound radionuclides such as ${ }^{36} \mathrm{Cl}$ or ${ }^{99} \mathrm{Tc}$ out of the near field. In the current simulations, roughly $30 \%$ of the melt glass dissolved over the $1000 \mathrm{yr}$ simulation period, and over $70 \%$ of this loss occurred in the first 10 yr when temperatures in the melt glass were at their highest. Conversely, in a sensitivity simulation run with a lower glass dissolution rate, only $0.12 \%$ of the melt glass dissolved in $1000 \mathrm{yr}$.

- Monte Carlo simulations spanning a range of plausible and conditioned permeability and mineralogy realizations indicate a significant degree of variability - or uncertainty - with regard to the flux of radionuclides past the 
UE-20n \#1 control plane. Control plane flux values (in moles per year) at any particular time can vary by 2 or more orders of magnitude for most radionuclides. In addition, the vertical distribution of flow pathways that connect the initially contaminated regions to the control plane can also be quite variable. This variability ultimately represent a balance of competing forces related to thermal buoyancy effects, horizontal hydraulic gradients, nonuniform permeability distributions, radionuclide-dependent reactivities and release times, and nonuniform reactive mineral distributions.

- Simple conceptualizations of the permeability distribution that involve layered or uniform structures cannot be fully calibrated to available data and must be considered unrealistic. Geostatistical variation in the permeability distribution, as guided by geophysical logs and other related observations, is necessary to develop a reasonable model that matches temperature and tracer data near the CHESHIRE cavity and chimney and at UE-20n \#1.

- Similar observations of the mineralogy of the native rock and fracture linings determined from limited sample data suggest that the distribution of minerals along fracture surfaces must also be considered spatially variable. However, the near-field transport simulations indicate that average retardation values based on mineral concentrations may be plausible at larger scales.

- The effects of matrix diffusion, although incorporated in only a small subset of sensitivity runs of the particle model, appear to be insignificant when compared with the combined effects of heterogeneity. This is consistent with the field experiments of Becker and Shapiro (2000). Nevertheless, because the recent laboratory-scale experiments of Reimus et al. (2002) do show observable impacts of matrix diffusion on the movement of tritium, ${ }^{14} \mathrm{C}$, and ${ }^{99} \mathrm{Tc}$ through fractured rock cores, additional sensitivity studies may be warranted.

- Colloids were incorporated in our models only in a rudimentary fashion. Onedimensional reactive transport simulations show that aluminosilicate colloids significantly affect the breakthrough of Am, Eu, and Sm, while other radionuclides in our model are affected only slightly. Our results do not explain the presence of colloid-associated Pu from the BENHAM test found at the ER-20-6 site, more than a kilometer away. Pu association with aluminosilicate colloids is highly dependent on redox state. If $\mathrm{Pu}$ reactive transport were modeled at a lower groundwater redox state, the influence of colloids on Pu transport would increase dramatically. Nevertheless, CHESHIRE simulations suggest that the initial breakthrough of free $\mathrm{Pu}$ at UE-20n \#1 occurs within a few years, which is consistent with the net Pu transport rates observed by Kersting et al. (1999).

- The effect of the uncertainty in surface complexation sorption constants derived from published and laboratory data varies between radionuclide. Decrease in initial breakthrough ranges from $25 \%$ for $\mathrm{Eu}$ and $98 \%$ for $\mathrm{Pu}$ when 
sorption constants are reduced by two standard deviations. Although decrease in breakthrough was not unexpected, the significance of the modifications due to uncertainty is related to limited published and laboratory sorption data and possible limitations of the simple nonelectrostatic sorption model. However, uncertainties in surface complexation are not inconsistent with the uncertainty in predicting the sorptive properties of natural minerals using ideal synthetic mineral laboratory sorption data.

- The effects of decay and ingrowth can influence the abundance and migration behavior of the source term radionuclides. Although all of the 37 radionuclides included in this model will undergo decay, only those in the chain ${ }^{241} \mathrm{Pu} \rightarrow{ }^{241} \mathrm{Am}$ $\rightarrow{ }^{237} \mathrm{~Np}$ need to be considered from a coupled decay and ingrowth perspective.

- All 37 RST radionuclides but one contribute to at least $0.1 \%$ of the alpha, beta, or electron capture/isomeric transition mol and/or curie flux at the downstream boundary over the 1000 yr simulation period.

- Proper use of the HST results in a large-scale (CAU) model will require compatibility of the effective (a) mean flow rates through the source locations, (b) dispersion rates as computed directly in the current model or specified in terms of marcodispersivities, and (c) retardation properties of the medium for each radionuclide. The effective properties of the fractured environment and the mean flow rates established in the HST model may vary over the largescale model. Scaling the HST results for different effective properties or flow rates may be difficult. Use of effective properties and flow rates at the large scale will eliminate finer details in concentration profiles observed in the HST model. Care must be taken for dilution effects when the HST is inserted in large-scale models and the impact to conclusions obtained from these models must be evaluated.

- Although the three-dimensional streamline model could not be effectively used in strongly transient flow fields, such as those produced in the first $100 \mathrm{yr}$ of a typical CHESHIRE flow simulation, it still proved to be viable tool in the later stages of the simulation, as well as a useful diagnostic technique for interpreting and simplifying the interplay of flow, reaction, and temperature phenomena in one-dimensional configurations.

- Although it is only based upon an approximate parametric (retardation factor) representation of chemical sorption processes and an approximate (calibrated) model of melt glass dissolution, the three-dimensional particle model proved to be a viable tool to explore a multitude of three-dimensional sensitivity and Monte Carlo replicate simulations of radionuclide migration for the entire simulation period.

- The sensitivity of model results to the addition of local dispersion is small. Only when dispersion was set to very high values $\left(\alpha_{\mathrm{L}}=100 \mathrm{~m}\right.$ and $\left.\alpha_{\mathrm{T}}=10 \mathrm{~m}\right) \mathrm{did}$ breakthrough at the downstream plane noticeably depart from our base- 
case simulations. This indicates that dispersivity values on the order of 10 grid blocks (10 m grid blocks used in our model) would not represent variations in material properties at the sub-grid scale. With transverse dispersivity alone, no significant departure from the base-case simulation was observed. Transverse dispersivity is not, therefore, likely to be important in the streamline simulations.

- The use of both streamline and particle simulations proved to be a useful and successful marriage of two competing numerical techniques whose collective advantages could be mutually exploited in the analysis

\subsection{Recommendations}

Several recommendations are made that will permit improved descriptions of the geologic and geochemical setting, more constrained parameter values to be measured, and a more complete specification of the geochemical reactions to be developed.

Acquisition of additional groundwater samples from U-20n PS \#1 DD-H and UE-20n \#1 can be used to validate assumptions and results associated with the current reaction and melt glass dissolution models. The CHESHIRE test on Pahute Mesa provides a unique opportunity to study the evolution of radionuclide migration over time. Data have been collected more frequently at CHESHIRE than any other test on Pahute Mesa. Recompletion of the post-test drill hole was a significant investment that should be maximized into the future by continued sampling. Samples from UE-20n \#1 are valuable because they demonstrate radionuclide migration down-gradient from the test. Because samples from UE-20n \#1 indicate the drill hole is now contaminated with iron and manganese oxides, this site should be evaluated to determine if remedial work and recompletion would provide an acceptable monitoring site, or recommend that a new hole be drilled to replace UE-20n \#1.

Better characterization of the spatial distribution of effective permeability and effective porosity in fractured rocks would be useful to improve the accuracy of flow velocity estimates. The effective porosity clearly affects the timing of breakthrough, and its relatively uncertain magnitude remains as a critical parameter to measure or bound the simulation results. The ability of the native formation to allow for the advancement of radionuclides out of the near field will be affected by the existence and distribution of high permeability pathways between the cavity and breakthrough plane. In addition, the ability of the native formation to retain or otherwise retard the motion of radionuclides is largely based upon the existence and distribution of reactive minerals in the fractures. Acquisition of effective permeability and effective porosity data from forced-gradient experiments, evaluation of geologic influences such as cooling fractures and tectonic motions, and examination of hydraulic data from other drill holes on Pahute Mesa, and acquisition of mineralogic composition and spatial distribution information from new and existing drill holes can be justified or subsequently improved will control our confidence in the radionuclide flux results. 
Acquisition of geochemical information for radionuclides at elevated temperatures would permit improved and more reliable description of their reactivity to be made under these conditions.

Laboratory measurements of glass dissolution at high temperatures over long times would provide data to refine the glass dissolution model.

Additional assessment of reactive transport behavior in the cavity and melt glass zones should be considered to confirm whether heterogeneity in the melt glass properties and composition affect radionuclide release. The Analytical and Chemical Division at Lawrence Livermore National Laboratory is compiling data to characterize the cavity and chimney environment. Modeling of this information will help determine if input on volumes, textures, permeabilities, and possibly radionuclide distributions increase or decrease radionuclide release from the glass dissolution model. This work should also include an attempt to understand the effects of secondary mineral precipitates on melt glass permeability and reactivity.

Acquisition of additional temperature logs in nearby holes would be useful to further calibrate and validate flow models.

Laboratory measurements of the sorptive properties of manganese oxides would permit inclusion of these reactive minerals in our sorption model. Manganese oxides are a dominant secondary mineral present on fracture linings, but were excluded from our simulations because of data limitations. Acquisition of such data would refine retardation effects in reactive transport models and provide a less conservative but more realistic near-field transport model for radionuclides retarded by manganese oxides.

Validation of the surface complexation /ion exchange models in fracture flow environments by performing controlled laboratory fracture-flow experiments would greatly improve the confidence in the retardation model used in these situations.

Improvement of the incremental streamline technique used to advance the streamline simulations across different velocity fields is needed to improve the continuity of results over time. 


\section{References}

Aagaard, P., and H. C. Helgeson (1982), Thermodynamic and kinetic constraints on reaction rates among minerals and aqueous solutions, I. Theoretical considerations. American Journal of Science 282, 237-285.

Aarts, E., and J. Korst (1989), Simulated Annealing and Boltzmann Machines, John Wiley \& Sons, New York, 272 p.

Abulaban, A., and J. L. Nieber (2000), Modeling the Effects of Nonlinear Equilibrium Sorption on the Transport of Solute Plumes in Saturated Heterogeneous Porous Media, Advances in Water Resources 23(8), 893-905.

Agterberg, F. P. (1974), Geomathematics, Elsevier Scientific Publishing Company, Amsterdam, New York, 596 p.

Ahlstrom, S., H. Foote, R. Arnett, C. Cole, and R. Serne (1977), Multicomponent Mass Transport Model: Theory and numerical implementation, Battelle Pacific Northwest Laboratories, Richland, WA, BNWL 2127.

Bagtzoglou, A., A. F. B. Tompson, and D. E. Dougherty (1992), Projection functions for particle grid methods, Numerical Methods for Partial Differential Equations 8, 325-340.

Batycky, R. (1997), A Three-Dimensional Two-Phase Field Scale Streamline Simulator, Ph.D thesis, Department of Petroleum Engineering, Stanford University, Stanford, CA.

Baxter, R. G. (1983), Description of Defense Waste Processing Facility Reference Form and Canister, Savannah River Plant, Savannah River, GA, Report no. DP-1606, rev. 1.

Bear, J., C-F. Tsang, and G. de Marsily, Eds. (1993), Flow and Contaminant Transport in Fractured Rock, Academic Press, San Diego, CA.

Becker M. W. and A. M. Shapiro (2000), Tracer transport in fractured crystalline rock: Evidence of nondiffusive breakthrough tailing, Water Resources Research, 36(7): $1677-1686$

Bethke, C. M. (1992), The Geochemist's Workbench: A users guide to Rxn, Act2, Tact, React, and Gtplot, U. Illinois Press.

Bethke, C. M. (1996), Geochemical Reaction Modeling, Oxford Univ. Press, New York, NY, 397 p. 
Bibler N. E. and C. M. Jantzen (1987), Materials interactions relating to long-term geologic disposal of nuclear waste glass, Materials Research Society Symposium Proceedings 84,47-66.

Bish, D.L. and S. J. Chipera (1989), Revised Mineralogic Summary of Yucca Mountain, Nevada, Los Alamos National Laboratory, Los Alamos, NM, LA-11497-MS.

Blankennagel, R. K. (1967), Hydraulic Testing Techniques of Deep Drill Holes at Pahute Mesa, Nevada Test Site, U.S. Geological Survey Interagency Report Special Studies I-1.

Blankennagel, R. K. (1968), Geophysical logging and hydraulic testing at Pahute Mesa, Nevada Test Site, Groundwater, 24-31.

Blankennagel, R. K., and J. E. Weir (1965), Water Production and Pumping Test Data for Exploratory Holes, Pahute Mesa, Nevada Test Site, U.S. Geological Survey Technical Letter Special Studies I-40.

Blankennagel, R. K., and J. E. Weir (1973), Geohydrology of the Eastern Part of Pahute Mesa, Nevada Test Site, Nye County, Nevada, U.S. Geological Survey Professional Paper 712-B, 93 p.

Blankennagel, R. K., R. A. Young, J. B. Cooper, and J. B. Whitcomb (1964), Summary of Ground Water Data Pertinent to Underground Construction and to Water-Supply Development, Pahute Mesa, Nevada Test Site, U.S. Geological Survey Technical Letter, Special Studies I-27.

Blum, A. E. and L. L. Stillings (1995), Feldspar dissolution kinetics, in White, A. F. and Brantley, S. L., Chemical Weathering Rates of Silicate Minerals, Rev. Min. v. 31, Mineralogical Society of America, Washington, DC.

Boardman, C. R., and G. L. Meyer (1965), Project HANDCAR: macro-deformation resulting from a contained nuclear explosion in dolomite, Lawrence Radiation Laboratory, Livermore, CA, PNE-802F.

Boardman, C. R., and J. Skrove (1966), Distribution in Fracture Permeability of a Granitic Rock Mass Following a Contained Nuclear Explosion, Lawrence Livermore National Laboratory Report, Livermore, CA, UCRL-14292, Rev. II.

Boardman, C. R., D. D. Rabb, and McArthur (1964), Contained Nuclear Detonations in Four Media - geological factors in cavity and chimney formation, Lawrence Livermore National Laboratory, Livermore, CA, UCRL-7711. 
Borg, I., R. Stone, H. B. Levy, and L. D. Ramspott (1976), Information Pertinent to the Migration of Radionuclides in Ground Water at the Nevada Test Site, Part 1: Review and analysis of existing information, Lawrence Livermore National Laboratory, Livermore, CA, UCRL-52078.

Bourcier, W. L. (1986), Improvements in the solid solution modeling capabilities of EQ3/6, Proc. Workshop on Geochemical Modeling, Sept. 14-17, 1986, Fallen Leaf Lake, CA, CONF-8609134, pp. 41-48.

Bourcier, W. L. (1994), Waste glass corrosion modeling: comparison with experimental results, Materials Research Society Symposium Proceedings 333, 69-82.

Bowers, T.S., K. J. Jackson, and H. C. Helgeson (1984), Equilibrium Activity Diagrams, Springer Verlag, New York, NY.

Bradbury, M. H. and B. Baeyens (1997), A mechanistic description of Ni and Zn sorption on Na- montmorillonite 2. Modelling, Journal of Contaminant Hydrology 27(3-4), 223-248.

Brady, P. V. (1992), Silica surface chemistry at elevated temperatures, Geochimica et Cosmochimica Acta 56, 2941-2946.

Brady, P. V. (1994), Alumina surface chemistry at 25, 40, and 60C, Geochimica et Cosmochimica Acta 56(3), 1213-1217.

Brikowski, T. (1993), Flow between aquifers through filled cylindrical conduits: analytical solution and application to underground nuclear testing sites, Journal of Hydrology 146, 115-130.

Browne, E., and R. B. Firestone (1986), Table of Radioactive Isotopes, V.S. Shirley Ed., Wiley-Interscience, John Wiley \& Sons, New York, NY.

Broxton, D. E., R. G. Warren, F. M. Byers, and R. B. Scott (1989), Chemical and mineralogic trends within the Timber Mountain-Oasis Valley caldera complex, Nevada: evidence for multiple cycles of chemical evolution in a long-lived silicic magma system, Journal of Geophysical. Research 94:B5, 5961-5985.

Bryant, E. A. (1992), The CAMBRIC migration experiment: A summary report, Los Alamos National Laboratory, Los Alamos, NM, LA-12335-MS.

Buddemeier, R. W., J. R. Hunt, K. V. Marsh, and J. H. Rego (1992a), Radionuclide migration at the CHESHIRE and CAMBRIC event sites, Hydrology and radionuclide migration program 1988 Progress Report, compiled by K. V. Marsh, Lawrence Livermore National Laboratory, Livermore, CA, UCRL-53799-88. 
Buddemeier, R. W., R. C. Finkel, K. V. Marsh, M. R. Ruggieri, J. H. Rego, and R. J. Silva (1992b), Radionuclide migration at the CHESHIRE and event site, Hydrology and radionuclide migration program 1989 Progress Report, compiled by K. V. Marsh, Lawrence Livermore National Laboratory report, Livermore, CA, UCRL-53779-89.

Buddemeier, R.W. and J. R. Hunt (1988), Transport of colloidal contaminants in groundwater: Radionuclide migration at the Nevada Test Site, Applied Geochemistry $3,535-548$.

Burkhard, N. R. and J. T. Rambo (1991), One Plausible Explanation for Groundwater Mounding, in Proc. Of the $6^{\text {th }}$ Containment of Underground Nuclear Explosions, Lawrence Livermore National Laboratory, Livermore, CA, CONF-9109114, Vol. 2.

Burkhard, N. R., J. R. Hearst, E. W. Peterson, R. H. Nilson, K. H. Lie (1989), Containment of Cavity Gas in Fractured or Rubblized Emplacement Media, Lawrence Livermore National Laboratory, Livermore, CA, UCRL-100953, 30 p.

Buscheck, T. A., J. Gansemer, T. H. De Lorenzo, J. J. Nitao, and R. Shaffer (1998), Multiscale Thermohydrologic Model Sensitivity Analysis, Lawrence Livermore National Laboratory, CA, UCRL-ID-131489.

Carle, S. F. (1996), A Transition Probability-based Approach to Geostatistical Simulation of Hydrostratigraphic Architecture, Ph.D. Dissertation, University of California, Davis, CA.

Carle, S. F. (1997), Implementation Schemes for Avoiding Artifact Discontinuities in Simulated Annealing, Mathematical Geology 29, 231-244.

Carle, S. F., and G. E. Fogg (1996), Transition Probability-based Indicator Geostatistics, Mathematical Geology 28, 453-476.

Carle, S. F., and G. E. Fogg (1997), Modeling Spatial Variability with One- and Multidimensional Continuous-Lag Markov Chains, Mathematical Geology 29, 891-918.

Carle, S. F., E. M. Labolle, G. S. Weissmann, D. V. Van Brocklin, and G. E. Fogg (1998), Conditional Simulation of Hydrofacies Architecture, a Transition Probability/Markov Approach, in Hydrogeologic Models of Sedimentary Aquifers, Concepts in Hydrogeology and Environmental Geology No. 1, Fraser, G. S., and Davis, J. M., SEPM Special Publication, pp. 147-170.

Carlos, B. A., S. J. Chipera, and D. L. Bish (1995a), Distribution and Chemistry of FractureLining Minerals at Yucca Mountain, Nevada, Los Alamos National Laboratory, LA12977-MS. 
Carlos, B. A., S. J. Chipera, and M. G. Snow (1995b), Multiple Episodes of Zeolite Deposition in Fractured Silicic Tuff, Los Alamos National Laboratory, Los Alamos, NM, LAUR-95-871.

Carlson, R. C., and J. L. Wagoner (1991), U20be Site Characteristics Report, Lawrence Livermore National Laboratory, Livermore, CA, UCRL-100953, 30 p.

Chipera, S. J., and D. L. Bish (1989), Quantitative X-ray Diffraction Analyses of Samples Used for Sorption Studies by the Isotope and Nuclear Chemistry Division, Los Alamos National Laboratory, Los Alamos, NM, LA-11669-MS.

Clark, S. R., and McArthur (1986), Site Characteristics Report U20av, Lawrence Livermore National Laboratory, Livermore, CA, CP 86-55, 56 p.

Coles, D. G., H. C. Weed, D. D. Jackson, and J. S. Schweiger (1978), Single-pass Leaching of Nuclear Melt Glass by Groundwater, Lawrence Livermore National Laboratory, Livermore, CA, UCRL-81617.

Cooper, H. H., and C. E. Jacob (1946), A Generalized Graphical Method for Evaluating Formation Constants and Summarizing Well Field History, Trans. Amer. Geophys. Union 27, 526-534.

Cooper, H. H., J. D. Bredehoeft, and I. S. Papadopulos (1967), Response of a FiniteDiameter Well to an Instantaneous Charge of Water, Water Resources Research 3(1), 263-269.

Cvetkovic, V., J. O. Selroos, and H. Cheng (1999), Transport of Reactive Tracers in Rock Fractures, Journal of Fluid Mechanics 378, 335-356.

Daniels, J. I., R. Andricevic, L. R. Anspaugh, and R.L. Jacobson (1993), Chapter 4. Risk Based Screening Analysis of Ground Water Contaminated by Radionuclides Introduced at the Nevada Test Site (NTS), in Pilot Study Risk Assessment for Selected Problems at the Nevada Test Site, J. I. Daniels, ed., Lawrence Livermore National Laboratory, Livermore, CA, UCRL-LR-113891.

Davis, J. A., J. A. Coston, D. B. Kent, and C. C. Fuller (1998), Application of the surface complexation concept to complex mineral assemblages, Environmental Science $\mathcal{E}$ Technology 32(19), 2820-2828.

Deutsch, C. V., and A. G. Journel (1998), Geostatistical Software Library and User's Guide, Second Edition, Oxford University Press, New York.

Deutsch, C. V., and P. W. Cockerham (1994), Practical Considerations in the Application of Simulated Annealing in Stochastic Simulation, Mathematical Geology 26, 67-82.

Dorhemus, R. H. (1994), Glass Science, John Wiley \& Sons, New York, NY, 339 p. 
Drellack, S. J., L. B. Prothro, K. E. Roberson, B. A. Schier, and E. H. Price (1997), Analysis of Fractures in Volcanic Cores from Pahute Mesa, Nevada Test Site, Bechtel Nevada $\mathrm{DOE} / \mathrm{NV} / 11718-160$.

Duff, M. C. et al. (1999), Mineral associations and average oxidation states of sorbed $\mathrm{Pu}$ on tuff, Environmental Science E Technology, 33(13): 2163-2169.

Duff, M. C., and C. Amrhein (1996), Uranium(VI) adsorption on goethite and soil in carbonate solutions, Soil Science Society of America Journal, 60(5), 1393-1400.

Dzombak, D. A., and F. M. M. Morel (1990), Surface Complexation Modeling: Hydrous Ferric Oxide, Wiley, New York, xvii, 393 p.

Eaton, G. F., and D.K. Smith (2000), Aged Nuclear Explosive Melt Glass: Radiography and Scanning Electron Microscope Analyses Documenting Radionuclide Distribution and Glass Alteration, Lawrence Livermore National Laboratory, Livermore, CA, UCRLJC-136658.

Edwards, A. L. (1972), TRUMP: A Computer Program for Transient and Steady-State Temperature Distributions in Multidimensional Systems, National Tech. Information Service, Springfield, VA.

Erikson, S. J. (1991), Report of Drilling and Radionuclide Migration Investigations at UE-20n \#1, Pahute Mesa, Nevada Test Site, 1987, Water Resources Center Publication \#45081, Desert Research Institute, University of Nevada.

Failor, R. A., D. G. Coles, and J. H. Rego (1983), A Leaching Study of Nuclear Melt Glass: Part 1, Lawrence Livermore National Laboratory, Livermore, CA, UCID-19729.

FFACO (Federal Facility Agreement and Consent Order) (1996), Agreed to by the U. S. Department of Energy, the U.S. Department of Defense, and the State of Nevada, Las Vegas, NV.

FFACO (Federal Facility Agreement and Consent Order) (2000), Appendix VI, December 7, 2000; Revision 1; Agreed to by the U. S. Department of Energy, the U.S. Department of Defense, and the State of Nevada, Las Vegas, NV.

Finkel, R. C., M. W. Caffee, K. V. Marsh, and J. H. Rego (1992), Accelerator Mass Spectrometry Measurements of 129I in CHESHIRE Site Groundwater, in Hydrology and Radionuclide Migration Program, 1988 Progress Report, K. V. Marsh, ed., Lawrence Livermore National Laboratory, Livermore, CA, UCRL-53779-88, pp. $11-12$. 
Fiore, S., F. J. Huertas, K. Tazaki, F. Huertas, and J. Linares (1999), A low temperature experimental alteration of a rhyolitic obsidian, European Journal of Mineralogy 11, $455-469$.

Friedlander, G., J. Kennedy, E. Macias, and J. Miller (1981), Nuclear and Radiochemistry, 3rd ed., John Wiley and Sons, New York, NY.

Garabedian, S. P., Gelhar, L. W., and Celia, M. A. (1988), Large-scale Dispersive Transport in Aquifers: Field Experiments and Reactive Transport Theory, Massachusetts Institute of Technology, Cambridge, MA, Parsons Laboratory Report 315.

Gelhar, L. W. (1993), Stochastic Subsurface Hydrology, Prentice Hall.

Germain, L. S. and J. S. Kahn (1968), Phenomenology and Containment of Underground Nuclear Explosions, Lawrence Livermore National Laboratory, Livermore, CA, UCRL-50482.

Glascoe, A. J. Olson, G. Lu, M. A. McGraw, P. C. Lichtner, and A. V. Wolfsberg (2000), Radionuclide transport from an underground nuclear test in the presence of residual heat and colloids, in Computational Methods in Water Resources XIII, Volume 1, L. Bentley, J. Sykes, C. Brebbia, W. Gray, and G. Pinder, Eds. (A. A. Balkema Publishers, Rotterdam, Netherlands), pp. 357-364.

Grambow, B. (1987), Nuclear Waste Glass Dissolution: Mechanism, model and application, JSS Project, Swedish Nuclear Fuel and Waste Management Co., Report Number 87-02, $114 \mathrm{p}$.

Guell, M. A. (1997), Subsurface Transport of Radionuclides at the Nevada Test Site, Ph.D thesis, Department of Civil and Environmental Engineering, University of California, Berkeley, CA.

Hassan, A., K. Pohlmann, and J. Chapman (1999), Modeling Groundwater Flow and Transport of Radionuclides at Amchitka Island's Underground Nuclear Tests: MILROW, CANNIKAN, and LONG SHOT (Draft), Desert Research Institute, Las Vegas, NV, publication 45172 (also U.S. Department of Energy, Nevada Operations Office publication DOE/NV/11508-51).

Hazelton, Nuclear Science Corporation (1965), Spatial Distribution of Radioactive Materials Around the Cavity of an Underground Nuclear Detonation, Report \#HNS-1229-47

(Supplement 1) submitted to Nevada Operations Office, U.S. Atomic Energy Commission, Las Vegas, Nevada, 25 p.

Helgeson, H. C. (1969), Thermodynamics of hydrothermal systems at elevated temperatures and pressures, American Journal of Science 267, 729-804. 
Helgeson, H. C., J. M. Delany, H. W. Nesbitt, and D. K. Bird (1978), Summary and critique of the thermodynamic properties of rock-forming minerals, American Journal of Science 278-A.

Hoffman, D. C., R. Stone, and W. W. Dudley, Jr. (1977), Radioactivity in the Underground Environment of the CAMBRIC Nuclear Explosion at the Nevada Test Site, Los Alamos National Laboratory, Los Alamos, NM, LA-6877-MS.

Hoover, D. L., J. W. Hasler, and R. P. Snyder (1964), Preliminary Lithologic Log of the U20a-2 Drill Hole, Pahute Mesa, Nevada Test Site, U.S. Geological Survey Technical Letter Special Studies I-16.

Hsi, C. D. and D. Langmuir (1985), Adsorption of uranyl onto ferric oxyhydroxides; application of the surface complexation site-binding model, Geochimica et Cosmochimica Acta 49(9), 1931-1941.

Hyndman, D.W. (1985), Petrology of Igneous and Metamorphic Rocks, International Series in the Earth and Planetary Sciences, McGraw-Hill, New York, 786 p.

IAEA (International Atomic Energy Agency) (1998a), The Radiological Situation at the Atolls of Mururoa and Fangataufa, Technical Report, Volume 3: Inventory of radionuclides underground at the atolls, Vienna, Austria, IAEA-MFTR-3.

IAEA (International Atomic Energy Agency) (1998b), The Radiological Situation at the Atolls of Mururoa and Fangataufa, Technical report, Volume 4: Releases to the biosphere of radionuclides from underground nuclear weapons tests at the atolls, Vienna, Austria, IAEA-MFTR-4.

IAEA (International Atomic Energy Agency) (1998c), The Radiological Situation at the Atolls of Mururoa and Fangataufa. Technical report, Volume 6: Doses due to radioactive materials present in the environment or released from the atolls, Vienna, Austria, IAEAMFTR-6.

IT Corporation (1998a), Report and Analysis of the BuLLION Forced-Gradient Experiment, International Technology Corporation, Las Vegas, , DOE/NV/13052-042.

IT Corporation (1998b), Summary of Micrographic Analysis of Fracture Coating Phases on Drill Cores from Pahute Mesa, Nevada Test Site, International Technology Corporation, Las Vegas, NV, DOE/NV/13052-050.

IT Corporation (1998c), Groundwater Flow and Contaminant Transport Model Development Package, unpublished report, Vol. III of Underground Test Area Project Correction Action Unit 98: Frenchman Flat Data Analysis Task, International Technology Corporation, North Las Vegas, NV. 
Jenkins, E. C., 1969, Summary Geologic Report on the U-20n Emplacement Hole, Area 20, Pahute Mesa, Nevada Test Site, U. S. Geological Survey Technical Letter Special Studies-16 Supplement 1.

Johnson, G. W., and C. E. Violet (1958), Phenomenology of Contained Nuclear Explosions, Lawrence Livermore National Laboratory, Livermore, CA, UCRL-5124 Rev.1.

Johnson, G. W., G. T. Pelsor, R. G. Preston, and C. E. Violet (1958), The Underground Nuclear Detonation of September 19, 1957, RAINIER, Operation Plumbbob, Lawrence Livermore National Laboratory, Livermore, CA, UCRL-5124.

Johnson, J W., and S. R. Lundeen (1997), GEMBOCHS thermodynamic data files for use with EQ3/6 modeling package, Lawrence Livermore National Laboratory, Livermore, CA, internal report.

Jorgensen, A. (1987), Indication of chimney heights, Lawrence Livermore National Laboratory internal document to J. Wagoner, January 23.

Kapoor V. and Gelhar, L. W. (1994a), Transport in three-dimensionally heterogeneous aquifers, 1. Dynamics of concentration fluctuations, Water Resources Research 30(6), $1775-1788$.

Kapoor, V. and Gelhar, L.W. (1994b), Transport in three-dimensionally heterogeneous aquifers, 2. Predications and observations of concentration fluctuations, Water Resources Research 30(6), 1789-1801.

Kawano, M., and K. Tomita (1995), Experimental study on the formation of zeolites from obsidian by interaction with $\mathrm{NaOH}$ and $\mathrm{KOH}$ solutions at 150 and $200^{\circ} \mathrm{C}$, Clays and Clay Minerals 45, 365-377.

Kawano, M., and K. Tomita (1997), Experimental study on the formation of clay minerals from obsidian by interaction with acid solution at $150^{\circ} \mathrm{C}$ and $200^{\circ} \mathrm{C}$, Clays and Clay Minerals 43, 212-222.

Kawano, M., K. Tomita, and Y. Kamino (1993), Formation of clay minerals during low temperature experimental alteration of obsidian, Clays and Clay Minerals 41, 431-441.

Keeney-Kennicutt, W. L., and J. W. Morse (1984), The interaction of Np(V)O2+ with common mineral surfaces in dilute aqueous solutions and seawater, Marine Chemistry 15, 133-150.

Keeney-Kennicutt, W. L., and J. W. Morse (1985), The redox chemistry of Pu(V)O2+ interaction with common mineral surfaces in dilute solutions and seawater, Geochimica et Cosmochimica Acta 49(12), 2577-2588. 
Kennedy, G. C., and G. H. Higgins (1958), Temperatures and Pressures Associated with the Cavity Produced by the RAINIER Event, Lawrence Livermore National Laboratory, Livermore, CA, UCRL-5281.

Kersting, A. B., and A. Brachman (1998), Progress Report FY98: Characterization of Groundwater Colloids from ER20-5 Well Cluster, UGTA Internal Report, Lawrence Livermore National Laboratory, Livermore, CA.

Kersting, A. B., D. W. Efurd, D. L. Finnegan, D. J. Rokop, D. K. Smith, and J. L. Thompson (1999), Migration of Plutonium in Groundwater at the Nevada Test Site, Nature 397, 56-59.

Kinzelbach, W. (1988), The Random Walk Method in Pollutant Transport Simulation, in Groundwater Flow and Quality Modeling, E. Custodio et al., Eds. (Kluwer Academic Publishers, Dordrecht, Holland), pp. 227-245.

Knauss, K. G. (1987), Zeolitization of glassy Topopah Spring tuff under hydrothermal conditions, Mat. Res. Soc. Symp. 84, 737-745.

Knauss, K. G., and D. W. Peifer, (1986), Reaction of Vitric Topopah Spring Tuff and J-13 Ground Water under Hydrothermal Conditions Using Dickson-type, Gold-Bag Rocking Autoclaves, Lawrence Livermore National Laboratory, Livermore, CA, UCRL53795.

Knauss, K. G., J. Delany, W. Beiriger, and D. W. Peifer (1984), Hydrothermal Interaction of Topopah Spring Tuff with J-13 Water as a Function of Temperature, Lawrence Livermore National Laboratory, Livermore, CA, UCRL-90853.

Knox, J. B., D. E. Rawson, and J. A. Korve (1965), Analysis of a groundwater anomaly created by an underground nuclear explosion, Journal of Geophysical Research 70(4), 823-835.

Koeppenkastrop, D., and E. H. Decarlo (1992), Sorption of Rare-Earth Elements From Seawater Onto Synthetic Mineral Particles-an Experimental Approach, Chemical Geology 95(3-4), 251-263.

Krishnaswami, S., W. C. Graustein, K. K. Turekian, and J. F. Dowd (1982), Radium, thorium, and radioactive lead isotopes in groundwaters: Application to the in situ determination of adsorption-desorption rate constants and retardation factors, Water Resources Research 18(6), 1663-1675.

Kurbatov, M. H., G. B. Wood, and J. D. Kurbatov (1951), Isothermal adsorption of cobalt from dilute solutions, Journal of Physical Chemistry 55, 1170-1182. 
LaBolle, E. M., G. E. Fogg, and A. F. B. Tompson (1996), Random-walk simulation in highly heterogeneous porous media: resolution of mass balance problem, Water Resources Research, 32(3), 583-593.

Laczniak, R. J., J. C. Cole, D. A. Sawyer, and D. A. Trudeau (1996), Summary of Hydrogeologic Controls on Ground-Water Flow at the Nevada Test Site, Nye County, Nevada, U. S. Geological Survey Water-Resources Investigations Report 96-4109.

Leckie, J. O., and W. Ela (1992), Annual Report: Studies of temperature effects on adsorption reactions in the mineral/solution interphase region, Lawrence Livermore National Laboratory, Livermore, CA, LLL B160441.

Levy, S. S. (1984), Studies of altered vitrophyre for the prediction of nuclear waste repository-induced thermal alteration at Yucca Mountain, Nevada, Proc. Mat. Res. Soc. Symp. 26, 959-966.

Lefeuvre, F., R. Turpening, C. Caravana, and A. Born (1993), Vertical open fractures and shear-wave velocities derived from VSPS, full waveform acoustic logs, and televiewer data, Geophysics, 58(6), 818-834.

Levy, S. S. (1992), Natural gels in the Yucca Mountain area, Nevada, USA, Applied Clay Science 7, 79-85.

Liu, H. H., G. S. Bovarsson, and L. Pan (2000), Determination of Particle Transfer in Random Walk Particle Methods for Fractured Porous Media, Water Resources Research 36(3), 707-713.

Luo J. S., T. A. Abrajano, and W. L. Ebert (1998), Natural Analogues of Nuclear Waste Glass Corrosion, Argonne National Laboratory, ANL-98/22, 177 p.

Maxwell, R. M. (1998), The Effects of Uncertainty and Variability in Groundwater-driven Health Risk Assessment, Ph.D. dissertation, University of California, Berkeley, 157 p.

Maxwell, R. M. and W. E. Kastenberg (1999), Stochastic Environmental Risk Analysis: An integrated methodology for predicting cancer risk from contaminated groundwater, Stochastic Environmental Research and Risk Assessment 13(1-2), 27-47.

Maxwell, R. M., A. F. B. Tompson, J. T. Rambo, S. F. Carle, and G. A. Pawloski (2000), Thermally induced ground water flow resulting from an underground nuclear test, in Computational Methods in Water Resources XIII, Volume 1, L. Bentley, J. Sykes, C. Brebbia, W. Gray, and G. Pinder, Eds. (A. A. Balkema Publishers, Rotterdam, Netherlands), pp. 45-50.

Mazer, J. J. (1987), Kinetics of Glass Dissolution as a Function of Temperature, Glass Composition, and Solution $p H s$, Ph.D. thesis, Northwestern University. 
McCarthy, J. F., and C. Degueldre (1993), Sampling and Characterization of Colloids and Paricles in Groundawater for Studying their Role in Contaminant Transport, in J. Buffle and H.P. van Leeuwen (Eds.), Environmental Particles, Lewis Publishers, Boca Raton, FL.

McKinley, J. P., J. M. Zachara, S. C. Smith, and G. D. Turner (1995), The influence of uranyl-hydrolysis and multiple site-binding reaction on adsorption of $\mathrm{U}(\mathrm{VI})$ to montmorillonite, Clays and Clay Minerals 45(5), 586-598.

Moncure, G. K., R. C. Surdam, and H. L. McKague (1981), Zeolite diagenesis below Pahute Mesa, Nevada Test Site, Clays and Clay Minerals 29, 385-396.

Monk, E. F., and R. P. Snyder (1964), Some Physical Properties Obtained from Cores Taken from Drill Hole U20a, between Depths of 2,273 Feet and 2,533 Feet, Pahute Mesa, Nevada Test Site, U. S. Geological Survey Technical Letter Special Studies I-14.

Moore, R. M., and K.A. Hunter (1985), Thorium adsorption in the ocean: Reversibility and distribution amongst particle sizes, Geochimica et Cosmochimica Acta 49, 2253-2257.

Moulin, V., and G. Ouzounian (1992), Role of colloids and humic substances in the transport of radio-elements through the geosphere, Applied Geochemistry, Supplemental Issue \#1, pp. 179-186.

Nagy, K. L. (1995), Dissolution and precipitation kinetics of sheet silicates: in Chemical Weathering Rates of Silicate Minerals, in A. F. White and S. L. Brantley, eds., Reviews in Mineralogy 31, Mineralogical Society of America, Washington, DC.

Narasimhan, T. N., and P. A. Witherspoon (1978), An integrated finite difference method for analyzing fluid flow in porous media, Water Resources Research, 14 255261.

Neretnicks, I. (1980), Diffusion in the rock matrix: An important factore in radionclide retardation? Journal of Geophysical Research 85(B8), 4379-4397.

Nimz, G. J. and J. L. Thompson (1992), Underground Radionuclide Migration at the Nevada Test Site, U. S. Department of Energy, Nevada Field Office, DOE/NV-246, UC-703.

Nitao, J. J. (1998), Reference manual for the NUFT flow and transport code, version 2.0, Lawrence Livermore National Laboratory, Livermore, CA, UCRL-MA-130651.

Nitao, J. J. (1999), User's Manual for the USNT Module of the NUFT Code, Version 2.0.1 (NP-phase, NC-component, thermal), Lawrence Livermore National Laboratory, Livermore, CA, UCRL-MA-130653-Rev-1. 
Nitsche, H., Gatti R. C., Standifer E. M., Lee S. C., Muller A., Prussin T., Deinhammer R. S., Maurer H., Becraft K., Leung S., and Carpenter S. A. (1993), Measured Solubilities and Speciations of Neptunium, Plutonium, and Americium in a Typical Groundwater (J13) from Yucca Mountain Region, Los Alamos National Laboratory, Los Alamos, NM, LA-12562-MS.

Nitsche, H., Roberts K., Prussin T., Muller A., Becraft K., Keeney D., Carpenter S. A., and Gatti R. C. (1994), Seasured Solubilities and Speciations from Oversaturated Experiments on Naptunium, Plutonium, and Americieum in UE-25p \#1 Well Water from the Yucca Mountain Region, Los Alamos National Laboratory, Los Alamos, NM, LA12563-MS.

Office of Technology Assessment (1989), The Containment of Underground Explosions, United States Congress, Office of Technology Assessment, OTA-ISC-414.

Olsen, C. W. (1993), Site Selection and Containment Evaluation for LLNL Nuclear Events in Proc. of the $7^{\text {th }}$ Symp. on Containment of Underground Nuclear Explosions, Lawrence Livermore National Laboratory, Livermore, CA, CONF-9309103 Vol. 1.

Paillet, F. L, and Goldberg, D. (1991), Acoustic televiewer log images of natural fractures and bedding planes in the TOA-BAJA borehole, Puerto Rico, Geophysical Research Letters, 18(3), 501-504.

Pawloski, G. A., A. F. B. Tompson, C. J. Bruton, and M. Zavarin, Eds. (2000), Evaluation of the Hydrologic Source Term from Underground Nuclear Tests in Frenchman Flat at the Nevada Test Site $(U)$, Lawrence Livermore National Laboratory, Livermore, CA, UCRL-ID-138007-DR.

Pawloski, G.A. (1999), Development of Phenomenological Models of Underground Nuclear Tests on Pahute Mesa, Nevada Test Site-BENHAM and TYBO, Lawrence Livermore National Laboratory, Livermore, CA, UCRL-ID-136003.

Pawloski, G. A., A. F..B. Tompson, C. J. Bruton, and M. Zavarin, Eds. (2000), Evaluation of the Hydrologic Source Term from Underground Nuclear Tests in Frenchman Flat at the Nevada Test Site $(U)$, Lawrence Livermore National Laboratory, Livermore, CA, UCRL-ID-138007-DR.

Pohll, G., A. Hassan, J. Chapman, C. Papelis, and R. Andricevic (1999), Modeling Ground Water Flow and Radioactive Transport in a Fractured Aquifer, Ground Water 37(5), 770-784.

Pohll, G., J. Chapman, A. Hassan, L. Papelis, R. Andricevic, and C. Shirley (1998), Evaluation of groundwater flow and transport at the SHOAL underground nuclear test: An interim report, Desert Research Institute, University of Nevada System, Reno, NV, Water Resources Center Publication 45162, DOE/NV/11508-35. 
Pohlmann, K. J., A. Hassan, and J. Chapman (2000), Description of hydrogeologic heterogeneity and evaluation of radionuclide transport at an underground nuclear test, Journal of Contaminant Hydrology 44, 353-386.

Pollock, D. W. (1988), Semianalytical Computation of Path Lines for Finite-Difference Models, Groundwater 26(6), 743-750.

Pottorff, E. J., S. J. Erikson, and M. E. Campana (1987), Hydrologic Utility of Borehole Temperatures in Areas 19 and 20, Pahute Mesa, Nevada Test Site, Desert Research Institute Publication, University of Nevada, 45060, 189 p.

Prothro, L. B., and S. L. Drellack (1997), Nature and Extent of Lava-Flow Aquifers Beneath Pahute Mesa, Nevada Test Site, Bechtel Nevada, Las Vegas, NV, DOE/NV/11718156.

Prothro, L. B., M. G. Townsend, S. L. Drellack, Jr., and J. L. Gonzales (1997), Processing and Geologic Analysis of Conventional Cores from Well ER-20-6\#1, Nevada Test Site, Bechtel Nevada, Las Vegas, NV, DOE/NV/11718-162.

Ragnorssdottir, K. V. (1993), Dissolution kinetics of heulandite at pH 2-12 and 25 C, Geochim. et Cosmochim. Acta 57, 2439-2449.

Rai, D., N. J. Hess, A. R. Felmy, D. A. Moore, M. Yui, and P. Vitorge (1999), A thermodynamic model for the solubility of $\mathrm{PuO}_{2}(\mathrm{am})$ in the aqueous $\mathrm{K}^{+}-\mathrm{HCO}_{3}^{-}$$\mathrm{CO}_{3}{ }^{2-}-\mathrm{OH}^{-}-\mathrm{H}_{2} \mathrm{O}$ system, Radiochimica Acta 86, 89-99.

Rambo, J. (1975), Preliminary Site Characteristics Summary U20N, Lawrence Livermore National Laboratory, Livermore, CA, UOPKB 75-114.

Rawson, D. E., and I. Y. Borg (1966), Results of the postshot exploration of the GREELEY event, Lawrence Livermore National Laboratory, Livermore, CA, UCRL-50979.

Reimus, P. W., and M. J. Haga (1999), Analysis of tracer responses in the BULLION forced-gradient experiment, Los Alamos National Laboratory, Los Alamos, NM, LA-13615-MS.

Reimus, P. W., Ware S. D., Humphrey A., Adams A., Wilson B., Gonzales D., Warren R. G., and Benedict F. C. (2002), Diffusive and Advective Transport of ${ }^{3} \mathrm{H},{ }^{14} \mathrm{C}$, and ${ }^{99} \mathrm{Tc}$ in Saturated, Fractured Volcanic Rocks from Pahute Mesa, Nevada, Los Alamos National Laboratory, Los Alamos, NM, LA-13891-MS.

Renders, P. J. N., C. H. Gammons, and H. L. Barnes (1995), Precipitation and dissolution rate constants for cristobalite from 150 to 300C, Geochim. et Cosmochim. Acta 59, $77-85$. 
Rodean, H. C. (1965), The Particle Statistics of Rubble Produced by Underground Nuclear Explosions, U.C. Lawrence Radiation Laboratory, Livermore, CA, UCRL-14292.

Rose, T. P., J. M. Kenneally, D. K. Smith, M. L. Davisson, G. B. Hudson and J. H. Rego (1997), Chemical and Isotopic Data for Groundwater in Southern Nevada, Lawrence Livermore National Laboratory, Livermore, CA, UCRL-ID-128000.

Rozsa, R. B., D. F. Snoeberger, and J. Baker (1974), Chimney Permeability Data Analysis, Lawrence Livermore National Laboratory, Livermore, CA, UCID-16440.

Sanchez, A. L., Schell, W. R. and Sibley, T. H. (1981), Distribution Coefficients for Plutonium and Americium on Particulates in Aquatic Environments, Environmental Migration of Long-Lived Radionuclides, International Atomic Energy Agency, Knoxville, KS.

Sass, J. H., and Lachenbruch, A. H. (1982), Preliminary Interpretation of Thermal Data from the Nevada Test Site, U.S. Geological Survey Open-File Report 82-973, 29 p.

Savage, D., Cave, M. R., Haigh, D., Milodowski, A. E. and Young, M. E. (1993), The reaction kinetics of laumontite under hydrothermal conditions, European Journal of Mineralogy 5, 523-535.

Sawyer, D. A., J. L. Thompson, and D. K. Smith (1999), The CHESHIRE Migration Experiment: A summary report, Los Alamos National Laboratory, Los Alamos, NM, LA-13555-MS.

Schafer-Perini, A. L., J. L. Wilson, and M. L. Perini (1991), Efficient and Accurate Front Tracking for Two Dimensional Groundwater Flow Models, Water Resources Research 27, 1471-1487.

Schoonen, M. A. A. (1994), Calculation of the point of zero charge of metal oxides between 0 and 350C, Geochimica et Cosmochimica Acta 58(13), 2845-4851.

Schwartz L., A. Piwinski , F. Ryerson, H. Tewes, and W. Beiringer (1984), Glass produced by underground nuclear explosions, in Natural Glasses (ed. L. D. Pye, J.

A. O'Keefe, and V. D. Frechette), North Holland, pp. 559-598.

Smith, D. K. (1995), Characterization of Nuclear Explosive Melt Debris, Radiochimica Acta 69, 157-167.

Smith, D. K. (1997), memo to Janet Wille (IT Corp.), Radionuclides Recommended by the Underground Test Area-Source and Transport (UGTA-S\&T) Subcommittee of Significance for Remedial Investigations at the Nevada Test Site, Lawrence Livermore National Laboratory, Livermore, CA, 2 April. 
Smith, D. K. (1998), A recent drilling program to investigate radionuclide migration at the Nevada Test Site, Jour. Radioanalytical and Nuclear Chemistry 235(1-2), 159-166.

Smith, D. K., A. B. Kersting, T. P. Rose, J. M. Keneally, G. B. Hudson, G. F. Eaton, and M. L. Davisson (1998), Hydrologic Resources Management Program and Underground Test Area Operable Unit, FY 1997 Progress Report, Lawrence Livermore National Laboratory, Livermore, CA, UCRL-ID-130792.

Smith, D. K., A. B. Kersting, T. P. Rose, J. M. Keneally, G. B. Hudson, G. F. Eaton, and M. L. Davisson, F. C. Benedict, Jr., and R. E. Criss (1999), Hydrologic Resources Management Program and Underground Test Area, FY 1998 Progress Report, Lawrence Livermore National Laboratory, Livermore, CA, UCRL-ID-135170.

Smith, D. K., A. B. Kersting, J. E. Moran, and T. P. Rose (2000), Radioisotope Tracers as Near-Field Diagnostics of Groundwater Flow at the Nevada Test Site, EOS Transactions American Geophysical Union 81(19), Supplement S241, American Geophysical Union, Washington, DC, May 9.

Smith, D. K., G. F. Eaton, T. P. Rose, J. E. Moran, A. Brachmann, J. E. McAninch, A. B. Kersting, V. V. Romanovski, R. E. Martinelli, R.E. and J. K. Werner, Jr. (2000), Hydrologic Resources Management Program and Underground Test Area FY 1999 Progress Report, Lawrence Livermore National Laboratory, Livermore, CA, UCRLID-139226.

Smith, D. K. (2001), Unclassified Radiologic Source Term for Nevada Test Site Areas 19 and 20, Lawrence Livermore National Laboratory, Livermore, CA, UCRL-ID-141706.

Steefel, C. I. and S. B. Yabusaki (1996), OS3D/GIMRT, Software for Modeling Multicomponent and Multidimensional Reactive Transport, User manual and programmer's guide, Version 1.0, Pacific Northwest National Laboratory, Richland, WA, PNL-11166.

Steefel, C.I. (2000), New directions in hydrogeochemical transport modeling: Incorporating multiple kinetic and equilibrium reaction pathways, in (L.R. Bentley, J.F. Sykes, C.A. Brebbia, W.G. Gray \& G.F. Pinder, eds.) Computational Methods in Water Resources XIII, A.A. Balkema, Rotterdam, 331-338.

Stout, R. B. and Leider, H. R, (1998), Waste Form Characteristics Report, CD-ROM version, Lawrence Livermore National Laboratory, Livermore, CA, UCRL-ID-132375, p. 3-182.

Sudicky, E. A. and E. O. Frind (1982), Contaminant Transport in Fractured Porous Media: Analytical solutions for a system of parallel fractures, Water Resources Research 18(6), 1634-1642. 
Thiele, M. R., R. P. Batycky, M. J. Blunt, and F. M. Orr (1996), Simulating Flow in Heterogeneous Systems Using Streamtubes and Streamlines, SPE Reservoir Engineering 11(1), 5-12.

Thomas, K.W. (1987), Summary of Sorption Measurements Performed with Yucca Mountain, Nevada, Tuff Samples and Water from Well J-13, Los Alamos National Laboratory, Los Alamos, NM, LA-10960-MS.

Thompson, J. L. (1996), Radionuclide Distribution in a Nuclear Test Cavity: The BASEBALL event, Radiochimica Acta 72, 157-162.

Thompson, J. L. (ed.), D. L. Finnegan, K. S. Kung, and B. A. Martinez (2000), Laboratory and Field Studies Related to Radionuclide Migration at the Nevada Test Site, October 1, 1998-September 30, 1999, Los Alamos National Laboratory, Los Alamos, NM, LA13701-PR.

Thompson, T. L., and J. B. Misz (1959), Geologic Studies of Underground Nuclear Explosions Rainier and Neptune Final Report, Lawrence Livermore National Laboratory, Livermore, CA, UCRL-5757.

Timmons, D. M., and L. E. Thompson (1996), Geochemical and petrographic studies and the relationships to durability and leach resistance of vitrified products from the in situ vitrification process, International Topical Meeting on Nuclear and Hazardous Waste Management.

Tompson, A. F. B. (1993), Numerical simulation of chemical migration in physically and chemically heterogeneous porous media, Water Resources Research 29(11), 3709-3726

Tompson, A. F. B., A. L. Schafer, and R. W. Smith (1996), Impacts of physical and chemical heterogeneity on co-contaminant transport in a sandy porous medium, Water Resources Research 32(4), 801-818.

Tompson, A. F. B., and D. E. Dougherty (1992), Particle-grid methods for reacting flows in porous media with application to Fisher's Equation, Applied Mathematical Modelling 16, 374-383.

Tompson, A. F. B., and K. J. Jackson (1996), Reactive transport in heterogeneous systems: An overview, Reviews in Mineralogy 34, Mineralogical Society of America, Washington, DC.

Tompson, A. F. B., and L. W. Gelhar (1990), Numerical Simulation of Solute Transport in Randomly Heterogeneous Porous Media, Water Resources Research 26, 2541-2562. 
Tompson, A. F. B., C. J. Bruton, and G. A. Pawloski, Eds. (1999), Evaluation of the hydrologic source term from the underground nuclear tests in Frenchman Flat and the Nevada Test Site: The CAMBRIC test, Lawrence Livermore National Laboratory, Livermore, CA, UCRL-ID-132300.

Tompson, A. F. B., E. Vomvoris, and L. W. Gelhar (1988), Numerical Simulation of Solute Transport in Randomly Heterogeneous Porous Media: Motivation, model development, and application, Technical Report 316, Ralph M. Parsons Laboratory, Department of Civil Engineering, Massachusetts Institiute of Technology, Cambridge, 114 pp. (also Lawrence Livermore National Laboratory, Livermore, CA, UCID 21287, 1987).

Townsend, D. R. (1994), RED HOT reentry, A report on the results of four phases of reentry mining and drilling conducted by the Defense Nuclear Agency between 1981 and 1985, Raytheon Services Nevada, NTS Operations, Geology/Hydrology section, TSP:DGP:066:95.

Triay, I. R., C. R. Cotter, M. H. Huddleston, D. E. Leonard, S. C. Weaver, S. J. Chipera, D. L. Bish, A. Meijer, and J. A. Canepa (1996), Batch Sorption Results for Neptunium Transport through Yucca Mountain Tuffs: Yucca Mountain Site Characterization Program Milestone 3349, Los Alamos National Laboratory, Los Alamos, NM, LA12961-MS.

Turner, G. D., J. M. Zachara, J. P. McKinley, and S. C. Smith (1996), Surface charge properties and UO22+ adsorption of a subsurface smectite, Geochimica et Cosmochimica Acta 60(18), 3399-3414.

Uffink, G. (1988), Modeling of solute transport with the random walk method, in Groundwater Flow and Quality Modeling, E. Custodio et al., Eds., Kluwer Academic Publishers, Dordrecht, 247-265.

USDOE (U.S. Department of Energy) (1997a), Regional groundwater flow and tritium transport modeling and risk assessment of the underground test area, Nevada Test Site, Nevada, USDOE, Nevada Operations Office, Environmental Restoration Division, Las Vegas, NV, DOE/NV-477.

USDOE (U.S. Department of Energy) (1997b), Shaft and tunnel nuclear detonations at the Nevada Test Site: Development of a primary database for the estimation of potential interactions with the regional groundwater system, U.S. Department of Energy, Nevada Operations Office, Las Vegas, NV, DOE/NV-464.

USDOE (U.S. Department of Energy) (2000), United States Nuclear Tests, July 1945 through September 1992, U.S. Department of Energy, Nevada Operations Office, Las Vegas, NV, DOE/NV-209, Rev 15. 
USEPA (U.S. Environmental Protection Agency) (1991), 40 CFR Parts 141 and 142, National Primary Drinking Water Regulations; Radionuclides; Notice of proposed rulemaking. Federal Register 56(138), 33050-33127, July 18.

USEPA (U.S. Environmental Protection Agency) (2000), 40 CFR Parts 9, 141 and 142, National Primary Drinking Water Regulations; Radionuclides; Final Rule. United States Environmental Protection Agency, Federal Register 65(236), 76708-76753, December 7.

Vaniman, D., A. Furlano, S. Chipera, J. Thompson, and I. Triay (1995), Microautoradiography in studies of $\mathrm{Pu}(\mathrm{V})$ sorption by trace and fracture minerals in tuff, in $\mathrm{W}$. M. Murphy and D. A. Knecht (Eds.), Scientific Basis for Nuclear Waste Management XIX, Material Research Society, Pittsburgh, pp. 639-646.

Viani, B. E., and C. J. Bruton (1992), Modeling Fluid-Rock Interaction at Yucca Mountain, Nevada: A progress report, Lawrence Livermore National Laboratory, Livermore, CA, UCRL-ID-109921.

Viani, B. E., and C. J. Bruton (1996), Assessing the Role of Cation Exchange in Controlling Groundwater Chemistry during Fluid Mixing in Fractured Granite at Aspo, Sweden, Lawrence Livermore National Laboratory, Livermore, CA, UCRL-JC-121527.

Wadman, R. E., and W. D. Richards (1961), Postshot Geologic Studies of Excavations below RAINIER Ground Zero, Lawrence Livermore National Laboratory, Livermore, CA, UCRL-6586.

Walker, F. W., J. R. Parrington, and F. Feiner (1989), Nuclides and Isotopes, Fourteenth Edition-Chart of the Nuclides, GE Nuclear Energy, General Electric Company, Nuclear Energy Operations, San Jose, CA.

Warner, S. E., and C. E. Violet (1959), Properties of the Environment of Underground Nuclear Detonations at the Nevada Test Site: RAINIER Event, Lawrence Livermore National Laboratory, Livermore, CA, UCRL-5542.

Warren, R. G., D. A. Sawyer, F. M. Byers, Jr., and G. L. Cole, (2000), A petrographic/ geochemical database and stratigraphic framework for the southwestern Nevada volcanic field, Los Alamos National Laboratory, Los Alamos, NM, LA-UR-00-3791.

Weber, W., R. Ewing, C. Angell, G. Arnold, A. Cormack, J. Delaye, D. Griscom, L. Hobbs, A. Navrotsky, D. Price, A. Stoneham, and M. Weinberg (1997), Radiation effects in glasses used for immobilization of high-level waste and plutonium disposition, Journal of Materials Research, 12(N8), 1946-1978.

White, A. F. (1983), Surface chemistry and dissolution kinetics of glassy rocks at $25^{\circ} \mathrm{C}$, Geochimica. Cosmochim. Acta 47, 805-815. 
Wild, J. F., W. Goishi, J. W. Meadows, M. N. Namboodiri, and D. K. Smith (1998), The LLNL Nevada Test Site Underground Radionuclide Source-Term Inventory, in Atmospheric Nuclear Tests-Environmental and Human Consequences, C. S. Shapiro, Ed. (Springer-Verlag, Berlin, Germany), NATO ASI Series, Partnership Sub-Series, 2. Environment-Volume 35, 69-77.

Wolery, T. J. (1992), EQ3/6, a software package for geochemical modeling of aqueous systems: Package overview and installation guide (Version 7.0), Lawrence Livermore National Laboratory, Livermore, CA, UCRL-MA-110662 PT 1.

Wolfsberg, A., L. Glascoe, G. Lu, A. Olson, P. Lichtner, M. McGraw, and T. Cherry (2001), TYBO/BENHAM Model Analysis of Groundwater Flow and Radionuclide Migration from an Underground Nuclear Test in Southwestern Pahute Mesa, NTS, Los Alamos National Laboratory, Los Alamos, NM, LA-UR-012924.

Wu, Y.-S. and K. Pruess (1988), A multiple-porosity method for simulation of naturally fractured petroleum reservoirs, SPE Reservoir Engineering 3, 327-336.

Yang, W. A., and R. J. Kirkpatrick (1990), Hydrothermal reaction of a rhyoliticcomposition glass: A solid-state NMR study, American Mineralogist 75, 1009-1019.

Zachara, J. M., C. E. Cowan, and C. T. Resch (1993), Metal cation/anion adsorption on calcite carbonate, in H.E. Allen, E.M. Perdue and D.S. Brown (Eds.), Metals in Groundwater, Lewis Publishers, Boca Raton, FL, pp. 37-71.

Zachara, J. M., C. T. Resch, and S. C. Smith (1994), Influence of humic substances on Co2+ sorption by a subsurface mineral separate and its mineralogic components, Geochimica et Cosmochimica Acta 58(2), 553-566.

Zavarin, M., and C. J. Bruton (2000a), A Non-Electrostatic Surface Complexation Approach to Modeling Radionuclide Migration at the Nevada Test Site: Aluminosilicates, Lawrence Livermore National Laboratory, Livermore, CA, UCRL-ID-141840 DR.

Zavarin, M., and C. J. Bruton (2000b), A Non-Electrostatic Surface Complexation Approach to Modeling Radionuclide Migration at the Nevada Test Site: Iron Oxides and Calcite, Lawrence Livermore National Laboratory, Livermore, CA, UCRL-ID-141841 DR.

Zhong, S. J., and A. Mucci (1995), Partitioning of rare earth elements (REEs) between calcite and seawater solutions at 25-degrees-C and $1 \mathrm{~atm}$, and high dissolved REE concentrations, Geochimica et Cosmochimica Acta 59(3), 443-453.

Zimmerman, P. W., and G. S. Bodvarsson (1994), Hydraulic Conductivity of Fractures, Lawrence Berkeley Laboratory, Berkeley, CA, LBL-35976 UC-800, 70 p. 


\section{APPENDIX A: \\ Radiological Source Term}




\section{A.1 Introduction}

Radionuclides introduced underground from an underground nuclear test are derived from the original fuel materials in the device, nuclear reactions driving the explosion, and activation products created in the geologic medium. Following detonation, and depending on the saturation conditions at the working point, they may be found in aqueous or gaseous states, precipitated or chemically sorbed states, or bound within melt glass produced by the test. Collectively, the list of these radionuclides and their residual abundance over these final states comprise the radionuclide inventory or radiological source term (RST) of the test.

Although the radionuclide inventory includes activation products created in the host geologic medium, it does not include pre-existing, naturally occurring radionuclides, although they may become redistributed or incorporated in melt glass as a result of the test. In addition, it does not include any nonradioactive materials introduced underground by the test, even though some of these might also be considered contaminants. This appendix describes the process developed and criteria established to select radionuclides for application in the near-field simulations at the CHESHIRE site.

\section{A.2 Unclassified Radiological Source Term}

Three sources of unclassified information provide quantitative data or information regarding the components of the RST at CHESHIRE, their actual abundance, and/or their relative importance for inclusion in models of release into the hydrologic environment. These are discussed separately below.

\section{A.2.1 Radionuclide Inventory for Pahute Mesa}

Smith (2001) summarizes the total activity (in Bq) and amount (in moles), decay corrected to 1 January 1994, of 48 radionuclides produced by the 76 individual underground nuclear tests detonated below or within $100 \mathrm{~m}$ of the water table in Areas 19 and 20 of the Pahute Mesa on the NTS. ${ }^{1}$ These data represent unclassified total values and do not pertain to any specific test on Pahute Mesa. Individual test inventories are classified.

The total inventory data shown in Smith (2001) were also averaged over the 76 tests Smith (2001). The averaged values will be used here to provide an unclassified RST in the hydrologic source term simulations at CHESHIRE. Again, these averaged values do not represent the specific inventory for CHESHIRE, or any other test on Pahute Mesa.

The particular radionuclide itemization by Smith (2001) is not considered an exhaustive list of all possible test-related radionuclides. They were selected according to

${ }^{1}$ CHESHIRE is in Area 20. 
a procedure similar to that described by Wild et al. (1998). Specifically, a radionuclide was included if its inventory in any of the 76 below-water-table tests, decay-corrected to $100 \mathrm{yr}$ in the future, was theoretically dissolved into a volume of water equal to the cavity volume for that test and found to have a concentration greater than one-tenth of the maximum contaminant level (MCL) for drinking water for that radionuclide, as proposed by the U. S. Environmental Protection Agency (USEPA, 1991). As Wild et al. (1998) states, ${ }^{2}$ "the ... [MCL] for a radionuclide is that concentration in drinking water that would impart a dose of $4 \mathrm{mrem} / \mathrm{yr}$ to a person ingesting an average of 2 liters per day. For nuclides with no ... [MCL] listed, we have conservatively assumed a $10^{-8}$ $\mu \mathrm{Ci} / \mathrm{mL}[0.37 \mathrm{~Bq} / \mathrm{L}]$ for the ... [MCL]."

Of the 48 radionuclide inventories listed in the Smith (2001) report,

- Only 44 are distinct, as four radionuclides $\left({ }^{232} \mathrm{Th},{ }^{234} \mathrm{U},{ }^{235} \mathrm{U}\right.$, and $\left.{ }^{238} \mathrm{U}\right)$ have separately-listed inventories attributable to the nuclear tests and to their natural abundance in the soil or rock. ${ }^{4}$

- The inventory of ${ }^{40} \mathrm{~K}$ is wholly attributable to its natural abundance in the soil or rock and has no fraction derived from any test.

- The inventory of ${ }^{150} \mathrm{Gd}$ is listed (only) as a footnote in Smith (2001) but is, nevertheless, included because of its long half-life and decay by alpha emission.

- Only one $\left({ }^{154} \mathrm{Eu}\right)$ has a half-life shorter than $10 \mathrm{yr}$.

The Smith (2001) list is considered more current than the recommended list in the Wild et al. (1998) report. The Smith list includes the final list of 30 radionuclides shown in Tables V-VIII of Wild et al. (1998) as well as an additional 14 distinct radionuclides.

\footnotetext{
${ }^{2}$ Wild (1998) uses the terminology "maximum permissible concentration (MPC)" in place of the "maximum contaminant level (MCL)" which is actually used in USEPA (1991).

${ }^{3}$ In truth, the MCLs applied by Wild et al. (1998) were based upon radionuclide activity data in Appendices B and C of USEPA (1991). The activity data in Appendix B are consistent with the proposed dose rate MCL and exposure model for contaminated drinking water that pertain to beta- and photonemitting radionuclides, assuming each radionuclide is present only by itself. When multiple radionuclides are present, the activity data in Appendix $B$ cannot be used to identify a total beta activity that is consistent with the proposed rule. The activity data in Appendix $\mathrm{C}$ do not pertain to the $15 \mathrm{pCi} / \mathrm{L}$ MCL proposed for gross alpha-emitting radionuclides. Rather, the activity data in Appendix $C$ represent activities in drinking water that individually produce estimated lifetime cancer mortality and incidence risks of $10^{-6}$ and $10^{-4}$, respectively, according to a 2-liter-per-day ingestion rate. Although not done, the proposed rule could actually have been applied to radionuclides not appearing in these appendices, instead of using the ad hoc $10^{-8} \mu \mathrm{Ci} / \mathrm{mL}$ MCL. It is possible that radionuclides excluded by Wild et al. (1998) might have been otherwise included if the proposed rule was followed more closely. The final rule has just been released (USEPA, 2000) and it differs from the 1991 proposed rule.

${ }^{4}$ Smith (2001) uses the term soil to refer to the host geologic medium containing the natural inventory; we use rock, as this term is more descriptive of the native medium at CHESHIRE.
} 


\section{A.2.2 UGTA Source Term Subcommittee Recommendations}

The memorandum of Smith (1997) describes a list of 22 radionuclides potentially of concern for remedial investigations at the NTS, as determined by the Underground Test Area Source Term Subcommittee. The list was compiled after considering 56 natural and nuclear weapon related candidate radionuclides with half lives greater than ten years and an additional 8 candidate radionuclides with half lives less than ten years that have been encountered in explosion cavity fluids.

These 22 radionuclides were selected from the original list of 64 using criteria that considered

1. Radionuclide abundance (based on production from an underground nuclear test).

2. Relative radionuclide mobility in the aqueous phase (based on field observations).

3. Health effects from radionuclides (based on whole body or organ dose).

Of the 22 radionuclides chosen in this process, all but 5 (namely, ${ }^{60} \mathrm{Co},{ }^{106} \mathrm{Ru}$, ${ }^{125} \mathrm{Sb},{ }^{134} \mathrm{Cs}$, and ${ }^{155} \mathrm{Eu}$ ) are already included in the list of 44 distinct radionuclides itemized by Smith (2001). These five all have half-lives less than $10 \mathrm{yr}$. Adding them to the original 44 radionuclides considered above gives a total of 49 radionuclides that may be considered members of the RST.

\section{A.2.3 Radionuclide Measurements in Groundwater near CHESHIRE}

The reports of Finkel et al. (1992), Daniels et al. (1993), Smith et al. (1998), Smith et al. (1999), Smith et al. (2000), and Thompson et al. (2000) summarize concentrations of several radionuclides measured in groundwater samples taken from the CHESHIRE cavity and chimney, or from drill holes on Pahute mesa near the CHESHIRE test. These reports indicate a total of 26 different radionuclides were found in groundwater that could be directly or potentially associated with the detonation of CHESHIRE, and not otherwise introduced as a consequence of geology (e.g., ${ }^{125} \mathrm{Sb}$ ). All but 3 of these radionuclides (namely, ${ }^{22} \mathrm{Na},{ }^{54} \mathrm{Mn}$, and ${ }^{144} \mathrm{Ce}$ ) are included in the list of 49 addressed previously. Adding these 3 to the previous 49 yields 52 radionuclides that may be considered members of the RST. 


\section{A.2.4 Table of Radionuclides}

Table A.1 lists the 52 distinct radionuclides identified in these three sources. As indicated in the first two columns, they are listed sequentially in order of increasing atomic mass. When the presence of a listed radionuclide is attributable to both a nuclear test and its natural abundance in the soil or rock, the radionuclide is itemized only once in the table. However, its numerical designation in column one is denoted either by an "a" or " $b$ " to differentiate its production from either the test ${ }^{5}$ (a) or natural abundance (b), and its corresponding symbol is annotated either by the word test or rock in parentheses. The remaining columns provide additional information bearing on radionuclide selection for the CHESHIRE RST, including their relevant mean inventories (as reported in Smith, 2001), their inclusion (or lack thereof) in the UGTA Subcommittee list (as reported in Smith, 1997), and whether they have been measured in groundwater from the cavity, chimney, or in drill holes near the CHESHIRE test. Additional aspects of this table are discussed later.

\footnotetext{
${ }^{5}$ The term device is used in Smith (2001) to refer to radionuclides produced or associated with the test.
} 


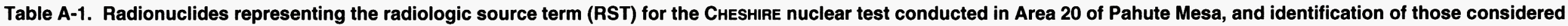
appropriate for inclusion in the near-field simulation of radionuclide migration away from that test.

Criteria for including radionuclide(s) in CHESHIRE near-field

hydrologic simulation: $I$. quantified inventory exceeding natural

abundance and conformity with at least one of the other

four remaining categories (i.e., II, III, IV, or V).

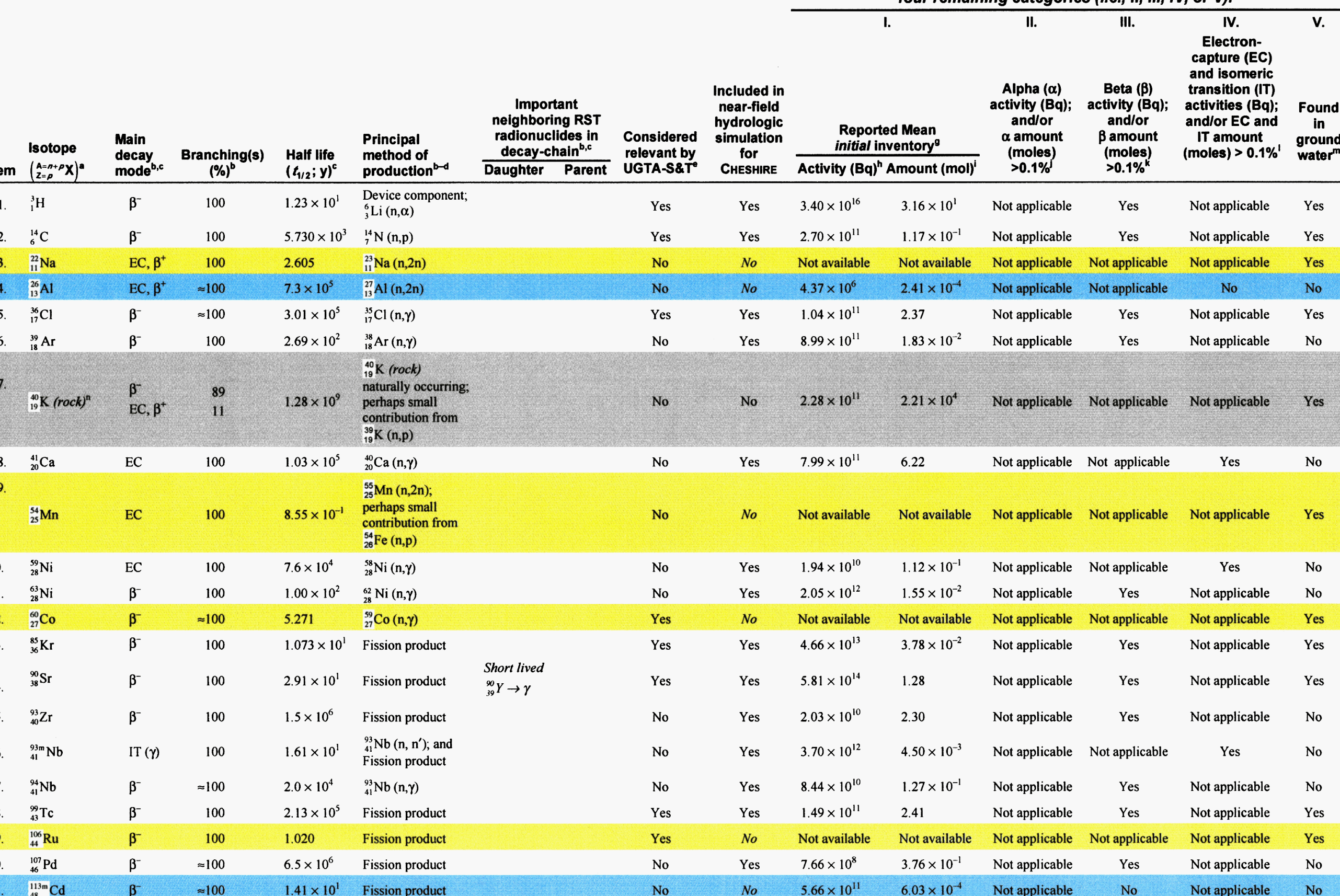


Criteria for including radionuclide(s) in CHESHIRE near-field

ydrologic simulation: I. quantified inventory exceeding natural

abundance and conformity with at least one of the other

four remaining categories (i. $I_{1}, I I, I V$, or $V$.

I. II.

IV.

v. Electronand isomeric

\begin{tabular}{|c|c|c|c|c|c|c|c|c|c|c|c|c|c|c|c|}
\hline \multirow[b]{2}{*}{ Item } & \multirow{2}{*}{$\begin{array}{l}\text { Isotope } \\
\left(\begin{array}{l}A=n+\rho \\
Z=\rho\end{array}\right)^{a}\end{array}$} & \multirow{2}{*}{$\begin{array}{l}\text { Main } \\
\text { decay } \\
\text { mode }\end{array}$} & \multirow{2}{*}{$\begin{array}{c}\text { Branching(s) } \\
(\%)^{b}\end{array}$} & \multirow{2}{*}{$\begin{array}{l}\text { Half life } \\
\left(t_{1 / 2} ; y\right)^{c}\end{array}$} & \multirow{2}{*}{$\begin{array}{l}\text { Principal } \\
\text { method of } \\
\text { production }^{b-d}\end{array}$} & \multicolumn{2}{|c|}{$\begin{array}{c}\text { Important } \\
\text { neighboring RST } \\
\text { radionuclides in } \\
\text { decay-chain }{ }^{b, c}\end{array}$} & \multirow{2}{*}{$\begin{array}{l}\text { Considered } \\
\text { relevant by } \\
\text { UGTA-S\&T }\end{array}$} & \multirow{2}{*}{$\begin{array}{c}\text { Included in } \\
\text { near-field } \\
\text { hydrologic } \\
\text { simulation } \\
\text { for } \\
\text { CHESHIRE }\end{array}$} & \multicolumn{2}{|c|}{$\begin{array}{c}\begin{array}{c}\text { Reported Mean } \\
\text { initial inventory }\end{array} \\
\end{array}$} & \multirow{2}{*}{$\begin{array}{c}\text { Alpha }(\alpha) \\
\text { activity }(\mathrm{Bq}) \text {; } \\
\text { and/or } \\
\alpha \text { amount } \\
\text { (moles) } \\
>0.1 \%)\end{array}$} & \multirow{2}{*}{$\begin{array}{c}\text { Beta }(\beta) \\
\text { activity }(\mathrm{Bq}) ; \\
\text { and/or } \\
\beta \text { amount } \\
\text { (moles) } \\
>0.1 \%^{k}\end{array}$} & \multirow[t]{2}{*}{$\begin{array}{c}\text { and isomeric } \\
\text { transition (IT) } \\
\text { activities (Bq); } \\
\text { and/or EC and } \\
\text { IT amount } \\
\text { (moles) }>0.1 \% \text { ' }\end{array}$} & \multirow[t]{2}{*}{$\begin{array}{l}\text { Found } \\
\text { in } \\
\text { ground } \\
\text { water }^{m}\end{array}$} \\
\hline & & & & & & Daughter & Parent & & & Activity (Bq) & Amount (mol) & & & & \\
\hline 22. & ${ }_{50}^{121 m} \mathrm{Sn}$ & $\begin{array}{l}\beta^{-} \\
\text {IT }(\gamma)\end{array}$ & $\begin{array}{l}22 \\
78\end{array}$ & $\approx 5.5 \times 10^{1}$ & Fission product & & & No & Yes & $2.10 \times 10^{12}$ & $8.72 \times 10^{-3}$ & Not applicable & Yes & Yes & No \\
\hline 23. & ${ }_{50}^{126} \mathrm{Sn}$ & $\beta^{-}$ & 100 & $\approx 1 \times 10^{5}$ & Fission product & $\begin{array}{l}\text { Short lived } \\
{ }_{51}^{126} \mathrm{~S} b \rightarrow \beta\end{array}$ & & No & Yes & $2.39 \times 10^{10}$ & $1.81 \times 10^{-1}$ & Not applicable & Yes & Not applicable & No \\
\hline 24. & ${ }_{51}^{125} \mathrm{Sb}$ & $\beta^{-}$ & 100 & 2.758 & Fission product & & & Yes & No & Not available & Not available & Not applicable & Not applicable & Not applicable & Yes \\
\hline 25. & ${ }_{33}^{129} \mathrm{I}$ & $\beta^{-}$ & 100 & $1.57 \times 10^{7}$ & Fission product & & & Yes & Yes & $4.59 \times 10^{8}$ & $5.44 \times 10^{-1}$ & Not applicable & Yes & Not applicable & Yes \\
\hline 26. & ${ }_{55}^{134} \mathrm{Cs}$ & $\beta$ & 100 & 2.065 & $\begin{array}{l}\text { Fission product, } \\
{ }_{55}^{13} \mathrm{Cs}(\mathrm{n}, \gamma)\end{array}$ & & & Yes & No & Not available & Not available & Not applicable & Not applicable & Not applicable & Yes \\
\hline 27. & ${ }_{55}^{135} \mathrm{Cs}$ & $\beta^{-}$ & 100 & $2.3 \times 10^{6}$ & Fission product & & & No & Yes & $1.54 \times 10^{10}$ & 2.68 & Not applicable & Yes & Not applicable & No \\
\hline 28. & ${ }_{35}^{137} \mathrm{Cs}$ & $\beta^{-}$ & 100 & $3.017 \times 10^{1}$ & Fission product & $\begin{array}{l}\text { Short lived } \\
{ }_{{ }^{136}}^{137 m} B a \rightarrow \gamma\end{array}$ & & Yes & Yes & $7.36 \times 10^{14}$ & 1.68 & Not applicable & Yes & Not applicable & Yes \\
\hline 29. & ${ }_{58}^{144} \mathrm{Ce}$ & $\beta^{-}$ & 100 & $7.80 \times 10^{-1}$ & Fission product & & & No & No & Not available & Not available & Not applicable & Not applicable & Not applicable & Yes \\
\hline 30. & ${ }_{62}^{151} \mathrm{Sm}$ & $\beta^{-}$ & 100 & $9.0 \times 10^{1}$ & Fission product & & & Yes & Yes & $2.78 \times 10^{13}$ & $1.89 \mathrm{E} \times 10^{-1}$ & Not applicable & Yes & Not applicable & No \\
\hline 31. & ${ }_{63}^{150} \mathrm{Eu}$ & EC & $\approx 100$ & $3.6 \times 10^{1}$ & ${ }_{63}^{151} \mathrm{Eu}(\mathrm{n}, 2 \mathrm{n})$ & & & No & Yes & $5.40 \times 10^{11}$ & $1.47 \times 10^{-3}$ & Not applicable & Not applicable & Yes & No \\
\hline 32. & ${ }_{63}^{152} \mathrm{Eu}$ & $\begin{array}{l}\beta^{-} \\
E C, \beta^{+}\end{array}$ & $\begin{array}{l}28 \\
72\end{array}$ & $1.348 \times 10^{1}$ & $\begin{array}{l}{ }_{63}^{151} \mathrm{Eu}(\mathrm{n}, \gamma) \\
{ }_{63}^{153} \mathrm{Eu}(\mathrm{n}, 2 \mathrm{n})\end{array}$ & & & Yes & Yes & $1.60 \times 10^{13}$ & $1.63 \times 10^{-2}$ & Not applicable & No & Yes & Yes \\
\hline 33. & ${ }_{63}^{154} \mathrm{Eu}$ & $\beta^{-}$ & $\approx 100$ & 8.59 & ${ }_{63}^{153} \mathrm{Eu}(\mathrm{n}, \gamma)$ & & & Yes & Yes & $7.55 \times 10^{12}$ & $4.90 \times 10^{-3}$ & Not applicable & No & Not applicable & Yes \\
\hline 34. & ${ }_{63}^{155} \mathrm{Eu}$ & $\beta^{-}$ & 100 & 4.71 & Fission product & & & Yes & No & Not available & Not available & Not applicable & Not applicable & Not applicable & Yes \\
\hline $35^{\circ}$. & ${ }_{64}^{150} \mathrm{Gd}$ & $\alpha$ & 100 & $1.8 \times 10^{6}$ & ${ }_{63}^{150 m}$ Eu decay & & & No & No & $1.85 \times 10^{2}$ & $2.52 \times 10^{-8}$ & No & Not applicable & Not applicable & No \\
\hline 36. & ${ }_{67}^{168 \mathrm{~m}} \mathrm{Ho}$ & $\beta$ & 100 & $1.2 \times 10^{3}$ & Fission product & & & No & Yes & $2.18 \times 10^{10}$ & $1.98 \times 10^{-3}$ & Not applicable & Yes & Not applicable & No \\
\hline $37 \mathrm{a}$. & $\begin{array}{l}{ }_{90}^{232} \mathrm{Th}(\text { test }) \\
\text { and } \\
{ }_{90}^{232} \mathrm{Th}(\text { rock })^{\mathrm{n}}\end{array}$ & $\alpha$ & 100 & $1.40 \times 10^{10}$ & $\begin{array}{l}{ }^{232} \mathrm{Th}(\text { device }) \text { is } \\
\text { about } 500 \text { times< } \\
{ }^{232} \mathrm{Th}(\text { rock) }\end{array}$ & & & No & $\begin{array}{c}\text { No } \\
\text { (refer to } \\
\text { production } \\
\text { method for } \\
\text { explanation) }\end{array}$ & $\begin{array}{l}2.84 \times 10^{7} \\
\text { and } \\
1.65 \times 10^{10}\end{array}$ & $\begin{array}{l}3.01 \times 10^{1} \\
\text { and } \\
1.74 \times 10^{4}\end{array}$ & No & Not applicable & Not applicable & No \\
\hline 38. & ${ }_{92}^{232} \mathrm{U}$ & $\alpha$ & 100 & $7.0 \times 10^{1}$ & Device component & See note ${ }^{\mathrm{p}}$ & & No & Yes & $1.24 \times 10^{11}$ & $6.57 \times 10^{-4}$ & Yes & Not applicable & Not applicable & No \\
\hline 39. & ${ }_{92}^{233} \mathrm{U}$ & $\alpha$ & 100 & $1.592 \times 10^{5}$ & Device component & & & No & Yes & $8.33 \times 10^{10}$ & 1.00 & Yes & Not applicable & Not applicable & No \\
\hline $40 \mathrm{~b}$. & $\begin{array}{l}{ }_{92}^{234} \mathrm{U}(\text { test }) \\
\text { and } \\
{ }_{92}^{234} \mathrm{U}(\text { rock })^{\mathrm{n}}\end{array}$ & $\alpha$ & 100 & $2.46 \times 10^{5}$ & $\begin{array}{l}{ }^{234} \mathrm{U}(\text { device }) \text { is } \\
\text { about } 10 \text { times > } \\
{ }^{234} \mathrm{U} \text { (rock) }\end{array}$ & & ${ }_{94}^{238} \mathrm{Pu}$ & Yes & $\begin{array}{l}\text { Yes } \\
\text { (refer to } \\
\text { production } \\
\text { method for } \\
\text { explanation) }\end{array}$ & $\begin{array}{l}5.99 \times 10^{10} \\
\text { and } \\
8.14 \times 10^{9}\end{array}$ & $\begin{array}{l}1.11 \\
\text { and } \\
1.51 \times 10^{-1}\end{array}$ & Yes & Not applicable & Not applicable & Yes \\
\hline
\end{tabular}


Criteria for including radionuclide(s) in CHESHIRE near-field

hydrologic simulation: I. quantified inventory exceeding natural

abundance and conformity with at least one of the other

four remaining categories (i.e., II, III, IV, or V).

I. III. IV.

V.

Electron-

capture (EC)

and isomeric

\begin{tabular}{|c|c|c|c|c|c|c|c|c|c|c|c|c|c|c|c|}
\hline \multirow[b]{2}{*}{ Item } & \multirow{2}{*}{$\begin{array}{l}\text { Isotope } \\
\left(\begin{array}{l}A=n+\rho \\
Z=p\end{array}\right)^{a}\end{array}$} & \multirow{2}{*}{$\begin{array}{l}\text { Main } \\
\text { decay } \\
\text { mode }^{b, c}\end{array}$} & \multirow{2}{*}{$\begin{array}{c}\text { Branching(s) } \\
(\%)^{b}\end{array}$} & \multirow{2}{*}{$\begin{array}{l}\text { Half life } \\
\left(t_{1 / 2} ; y\right)^{c}\end{array}$} & \multirow{2}{*}{$\begin{array}{l}\text { Principal } \\
\text { method of } \\
\text { production }^{b-d}\end{array}$} & \multicolumn{2}{|c|}{$\begin{array}{l}\text { Important } \\
\text { neighboring RST } \\
\text { radionuclides in } \\
\text { decay-chain }{ }^{b, c}\end{array}$} & \multirow{2}{*}{$\begin{array}{l}\text { Considered } \\
\text { relevant by } \\
\text { UGTA-S\&T }\end{array}$} & \multirow{2}{*}{$\begin{array}{c}\text { Included in } \\
\text { near-field } \\
\text { hydrologic } \\
\text { simulation } \\
\text { for } \\
\text { CHESHIRE }\end{array}$} & \multicolumn{2}{|c|}{$\begin{array}{c}\text { Reported Mean } \\
\text { initial inventory }\end{array}$} & \multirow{2}{*}{$\begin{array}{c}\text { Alpha }(\alpha) \\
\text { activity (Bq); } \\
\text { and/or } \\
\alpha \text { amount } \\
\text { (moles) } \\
>0.1 \%\end{array}$} & \multirow{2}{*}{$\begin{array}{c}\text { Beta }(\beta) \\
\text { activity }(\mathrm{Bq}) \text {; } \\
\text { and/or } \\
\beta \text { amount } \\
\text { (moles) } \\
>0.1 \%^{k}\end{array}$} & \multirow[t]{2}{*}{$\begin{array}{l}\text { and IsomerIC } \\
\text { transition (IT) } \\
\text { activities (Bq); } \\
\text { and/or EC and } \\
\text { IT amount } \\
\text { (moles) }>0.1 \% \text { ' }\end{array}$} & \multirow[t]{2}{*}{$\begin{array}{l}\text { Found } \\
\text { in } \\
\text { ground } \\
\text { water }^{m}\end{array}$} \\
\hline & & & & & & Daughter & Parent & & & Activity (Bq) & Amount (mol) & & & & \\
\hline $41 \mathrm{a}$. & $\begin{array}{l}{ }_{92}^{235} \mathrm{U}(\text { test }) \\
\text { and } \\
{ }_{92}^{235} \mathrm{U}(\text { rock })^{\mathrm{n}}\end{array}$ & $\alpha$ & 100 & $7.04 \times 10^{8}$ & $\begin{array}{l}{ }^{235} \mathrm{U} \text { (device) is > } \\
{ }^{235} \mathrm{U} \text { (rock) }\end{array}$ & & & No & $\begin{array}{c}\text { Yes } \\
\text { (refer to } \\
\text { production } \\
\text { method for } \\
\text { explanation) }\end{array}$ & $\begin{array}{l}8.07 \times 10^{8} \\
\text { and } \\
3.85 \times 10^{8}\end{array}$ & $\begin{array}{l}4.29 \times 10^{1} \\
\text { and } \\
2.05 \times 10^{1}\end{array}$ & Yes & Not applicable & Not applicable & Yes \\
\hline 42. & ${ }_{92}^{236} \mathrm{U}$ & $\alpha$ & 100 & $2.342 \times 10^{7}$ & Device component & & & No & Yes & $2.30 \times 10^{9}$ & 4.07 & Yes & Not applicable & Not applicable & No \\
\hline $43 b$. & $\begin{array}{l}{ }_{92}^{238} \mathrm{U}(\text { test }) \\
\text { and } \\
{ }_{92}^{238} \mathrm{U}(\text { rock })^{\mathrm{n}}\end{array}$ & $\alpha$ & 100 & $4.47 \times 10^{9}$ & $\begin{array}{l}{ }^{238} \mathrm{U}(\text { device }) \text { is } \\
\text { about } 10 \text { times }< \\
{ }^{238} \mathrm{U}(\text { rock })^{\mathrm{p}}\end{array}$ & & & Yes & $\begin{array}{c}\text { Yes }^{\mathrm{q}} \\
\text { (refer to } \\
\text { production } \\
\text { method for } \\
\text { explanation) }\end{array}$ & $\begin{array}{l}1.07 \times 10^{9} \\
\text { and } \\
8.14 \times 10^{9}\end{array}$ & $\begin{array}{l}3.60 \times 10^{2} \\
\text { and } \\
2.75 \times 10^{3}\end{array}$ & Yes & Not applicable & Not applicable & Yes \\
\hline 44. & ${ }_{93}^{237} \mathrm{~Np}$ & $\alpha$ & 100 & $2.14 \times 10^{6}$ & Device component & & ${ }_{95}^{241} \mathrm{Am}$ & Yes & Yes & $1.78 \times 10^{10}$ & 2.87 & Yes & Not applicable & Not applicable & No \\
\hline 45. & ${ }_{94}^{238} \mathrm{Pu}$ & $\alpha$ & 100 & $8.77 \times 10^{1}$ & Device component & ${ }_{92}^{234} \mathrm{U}$ & & No & Yes & $3.49 \times 10^{12}$ & $2.31 \times 10^{-2}$ & Yes & Not applicable & Not applicable & Yes \\
\hline 46. & ${ }_{94}^{239} \mathrm{Pu}$ & $\alpha$ & 100 & $2.410 \times 10^{4}$ & Device component & & & Yes & Yes & $9.40 \times 10^{12}$ & $1.71 \times 10^{1}$ & Yes & Not applicable & Not applicable & Yes \\
\hline 47. & ${ }_{94}^{240} \mathrm{Pu}$ & $\alpha$ & 100 & $6.56 \times 10^{3}$ & Device component & & ${ }_{96}^{244} \mathrm{Cm}$ & Yes & Yes & $3.02 \times 10^{12}$ & 1.50 & Yes & Not applicable & Not applicable & Yes \\
\hline 48. & ${ }_{94}^{241} \mathrm{Pu}$ & $\beta^{-}$ & 100 & $1.44 \times 10^{1}$ & Device component & ${ }_{95}^{241} \mathrm{Am}$ & & No & Yes & $4.37 \times 10^{13}$ & $4.75 \times 10^{-2}$ & Not applicable & Yes & Not applicable & No \\
\hline 49. & ${ }_{94}^{242} \mathrm{Pu}$ & $\alpha$ & 100 & $3.75 \times 10^{5}$ & Device component & & & No & No & $1.64 \times 10^{9}$ & $4.63 \times 10^{-2}$ & No & Not applicable & Not applicable & No \\
\hline 50. & ${ }_{95}^{241} \mathrm{Am}$ & $\begin{array}{l}\alpha \\
\text { (and } \gamma \text { ) }\end{array}$ & 100 & $4.327 \times 10^{2}$ & Device component & ${ }_{93}^{237} \mathrm{~Np}$ & ${ }_{94}^{241} \mathrm{Pu}$ & Yes & Yes & $2.27 \times 10^{12}$ & $7.43 \times 10^{-2}$ & Yes & Not applicable & Not applicable & Yes \\
\hline 51. & ${ }_{95}^{243} \mathrm{Am}$ & $\alpha$ & 100 & $7.37 \times 10^{3}$ & Device component & & & No & No & $8.73 \times 10^{7}$ & $4.86 \times 10^{-5}$ & No & Not applicable & Not applicable & No \\
\hline 52. & ${ }_{96}^{244} \mathrm{Cm}$ & $\alpha$ & 100 & $1.81 \times 10^{1}$ & Device component & ${ }_{94}^{240} \mathrm{Pu}$ & & No & Yes & $1.45 \times 10^{12}$ & $1.98 \times 10^{-3}$ & Yes & Not applicable & Not applicable & No \\
\hline
\end{tabular}

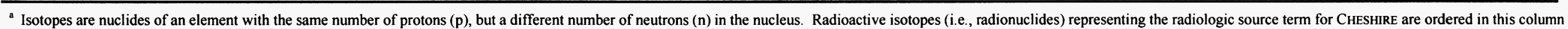
by atomic number $(\mathrm{Z}=p)$, and not by mass number $(\mathrm{A}=n+p)$.

${ }^{\mathrm{b}}$ Cited radionuclides are immediate parent or daughter radionuclides that are (i) members of the RST and (ii) important for ingrowth or decay processes within a 1,000 year time frame.

c Browne and Firestone (1986) and Walker et al. (1989).

${ }^{d}$ Wild et al. (1998).

' Smith (1997).

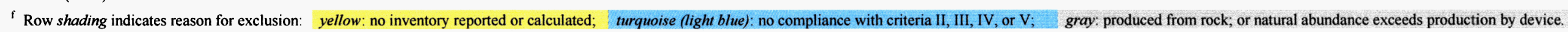

${ }^{8}$ Mean unclassified radionuclide inventory (activity and amount) for 76 nuclear tests detonated below or within $100 \mathrm{~m}$ of the water table in Areas 19 and 20 reported by Smith (2001), see Table II

${ }^{\mathrm{h}}$ To convert radioactivity units from Becquerel $(\mathrm{Bq})$ to Curie (Ci), divide Bq by $3.7 \times 10^{10}$.

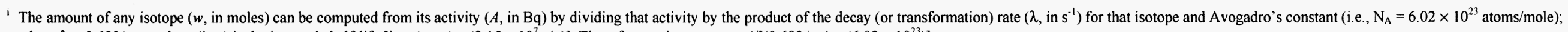
where $\lambda=0.693 / t_{1 / 2}$, and $t_{1 / 2}($ in s $)$ is the isotope's half-life [i.e., $\left.\left(t_{1 / 2} \mathrm{y}\right) \times\left(3.15 \times 10^{7} \mathrm{~s} / \mathrm{y}\right)\right]$. Thus, for any isotope, $w=A /\left[\left(0.693 / t_{1 / 2}\right) \times\left(6.02 \times 10^{23}\right)\right]$ 


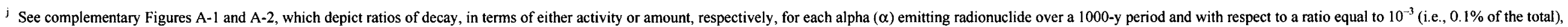

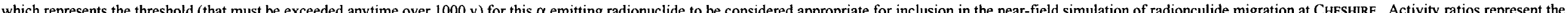

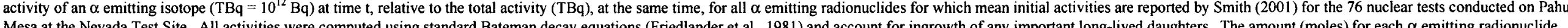

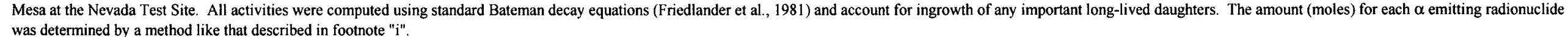

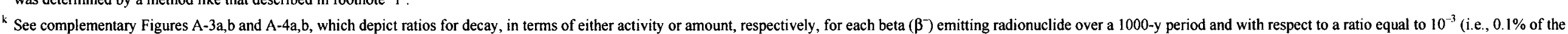

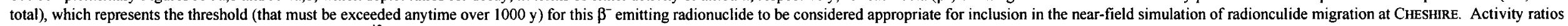

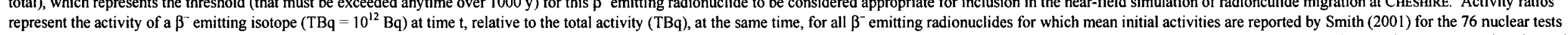

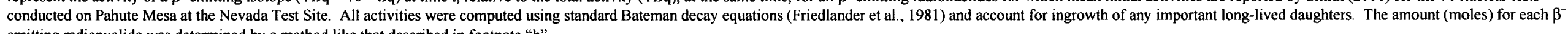
emitting radionuclide was determined by a method like that described in footnote " $\mathrm{h}$ ".

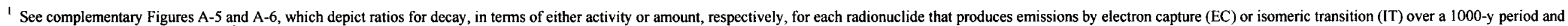

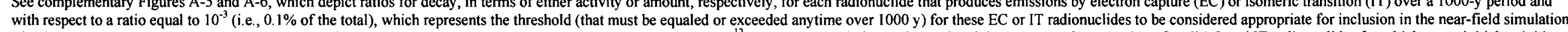

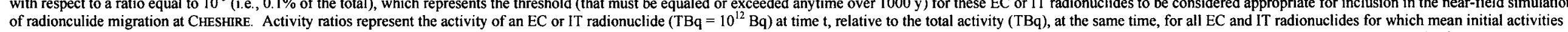

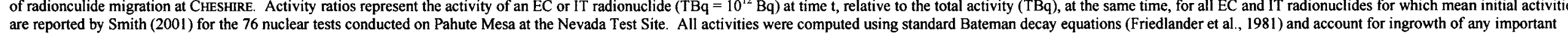
are reported by Smith (2001) for the 76 nuclear tests conducted on Pahute Mesa at the Nevada Test Site. All activities were compuled using standard Bateman decay equations
long-lived daughters. The amount (moles) for each radionuclide producing emissions by EC or IT processes was determined by a method like that described in footnote " $\mathrm{h}$.

${ }^{m}$ Concentration data for radionuclide(s) found in groundwater samples taken from the CHESHIRE cavity, chimney, or near the CHESHIRE test on Pahute Mesa of the Nevada Test Site are compiled in

Daniels et al. (1993); includes concentrations of radionuclides in groundwater related to CHESHIRE published in 1985 and 1988.

Smith et al. (1998); includes reported groundwater measurements of radionuclides related to CHESHIRE for 1997; and for 1977 to 1992

Smith et al. (1999); includes reported groundwater measurements of radionuclides related to CHESHIRE for 1998.

Smith et al. (2000) and Finkel et al. (1992); describe successful measurement of ${ }^{129} \mathrm{I}$ in groundwater near nuclear-test cavities at the Nevada Test Site, including CHESHIRE.

Thompson et al. (2000); includes reported groundwater measurement of ${ }^{154} \mathrm{Eu}$ related to CHESHIRE for 1984, 1998, and 1999.

"The isotopes of potassium (K), thorium (Th), and uranium (U) identified as being in "rock" are incorporated into melt glass as a consequence of the detonation.

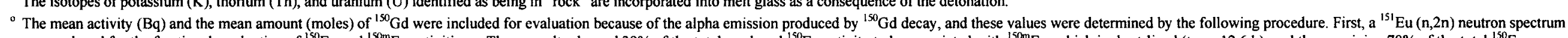

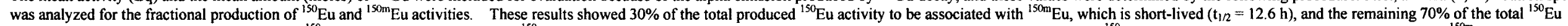

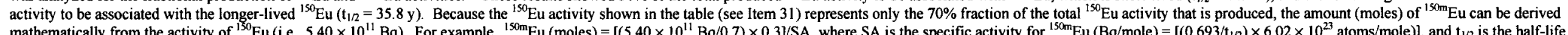

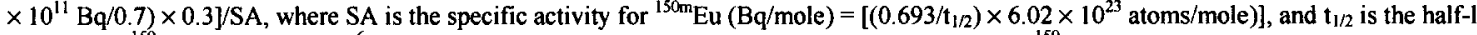

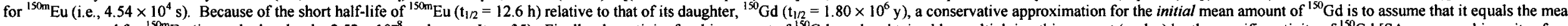

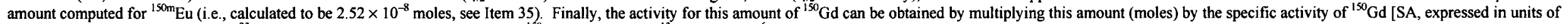
$\mathrm{Bq} / \mathrm{mole}=\left[\left(0.693 / \mathrm{t}_{1 / 2}\right) \times\left(6.02 \times 10^{23}\right.\right.$ atoms $/$ mole $\left.)\right]$, where $\mathrm{t}_{12}$ is the half life of ${ }^{150} \mathrm{Gd}\left(\right.$ i.e., $5.68 \times 10^{13} \mathrm{~s}$, or $\left.1.8 \times 10^{6} \mathrm{y}\right)$.

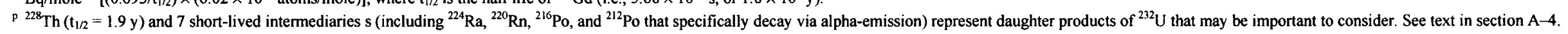

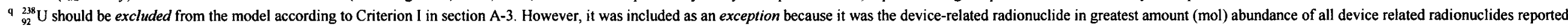
in the inventory by Smith (2001). Also, by including this uranium isotope we are complete in addressing all pertinent uranium isotopes. 


\section{A.3 Radionuclides Appropriate for the Model}

The radionuclides to be considered in the CHESHIRE near-field hydrologic flow and transport model were chosen as a subset of the list of 52 shown in Table A.1. The rationale for selecting these radionuclides involves compliance with the following standard: A radionuclide would be excluded from consideration (1) if there is no inventory (see criteria I), or (2) if there is an inventory, none of criteria II through V is satisfied.

\section{A.3.1 Criteria for Selection}

I. (Required) The radionuclide must have a reported test-related inventory, as defined by the data in Smith (2001), and this inventory must equal or exceed any corresponding natural inventory in soil or rock. The mean testrelated inventory will be used as an approximation of the actual inventory at CHESHIRE. ${ }^{6}$

II. For an $\alpha$-decay radionuclide, the ratio of its activity (in Bq) or amount (in moles) to the total activity or amount, ${ }^{7}$ respectively, of all $\alpha$-decay radionuclides exceeds a value of $10^{-3}(0.1 \%$ of the total) at some time over the next 1000 yr (see Figures A.1 and A.2, and Criterion-II column in Table A.1).

[Note: All figures in this appendix were computed using the Bateman decay equations (Friedlander et al., 1981) and the inventories and halflives listed in Table A.1. The $0.1 \%\left(10^{-3}\right)$ decision threshold is also indicated on each.]

III. For a $\beta$-decay radionuclide, the ratio of its activity (in Bq) or amount (in moles) to the total activity or amount (see footnote 4 ), respectively, of all $\beta$-decay radionuclides exceeds a value of $10^{-3}(0.1 \%$ of the total) at some time over the next $1000 \mathrm{yr}$ (see Figures A.3(a), A.3(b), A.4(a), and A.4(b); and Criterion-III column in Table A.1). For the particular cases of ${ }^{121 \mathrm{~m}} \mathrm{Sn}$ and ${ }^{152} \mathrm{Eu}$ that have two principal decay modes (Table A.1), only their respective inventory fractions partaking in a $\beta$-decay process are included in this calculation.

\footnotetext{
${ }^{6}$ As noted earlier, the individual Cheshire inventory, which was used in developing the data in Smith (2001), remains classified.

${ }^{7}$ As computed from the radionuclides and inventories reported in Smith (2001).
} 


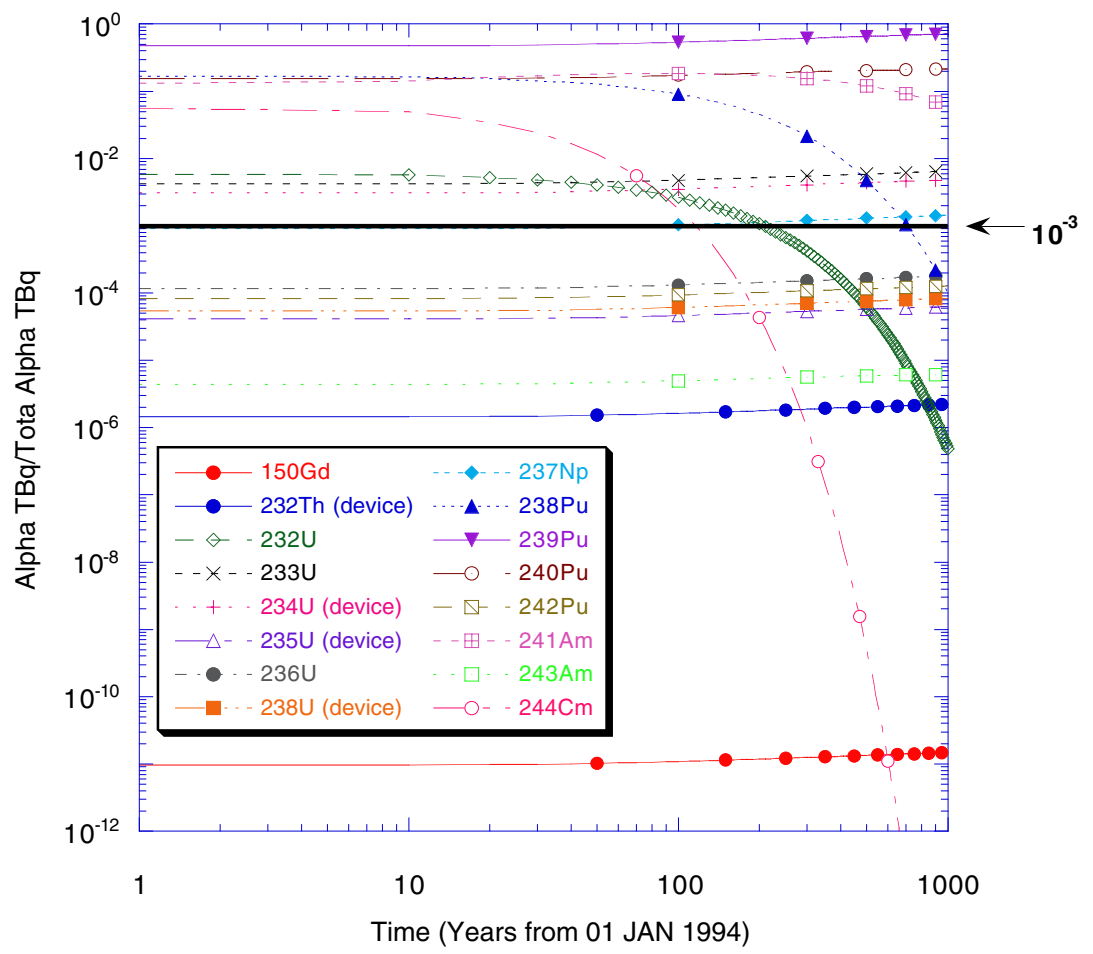

Figure A.1 Ratio of alpha activities of individual radionuclides to the total alpha activity of all inventoried radionuclides, as a function of time, in groundwater on Pahute Mesa at the Nevada Test Site.

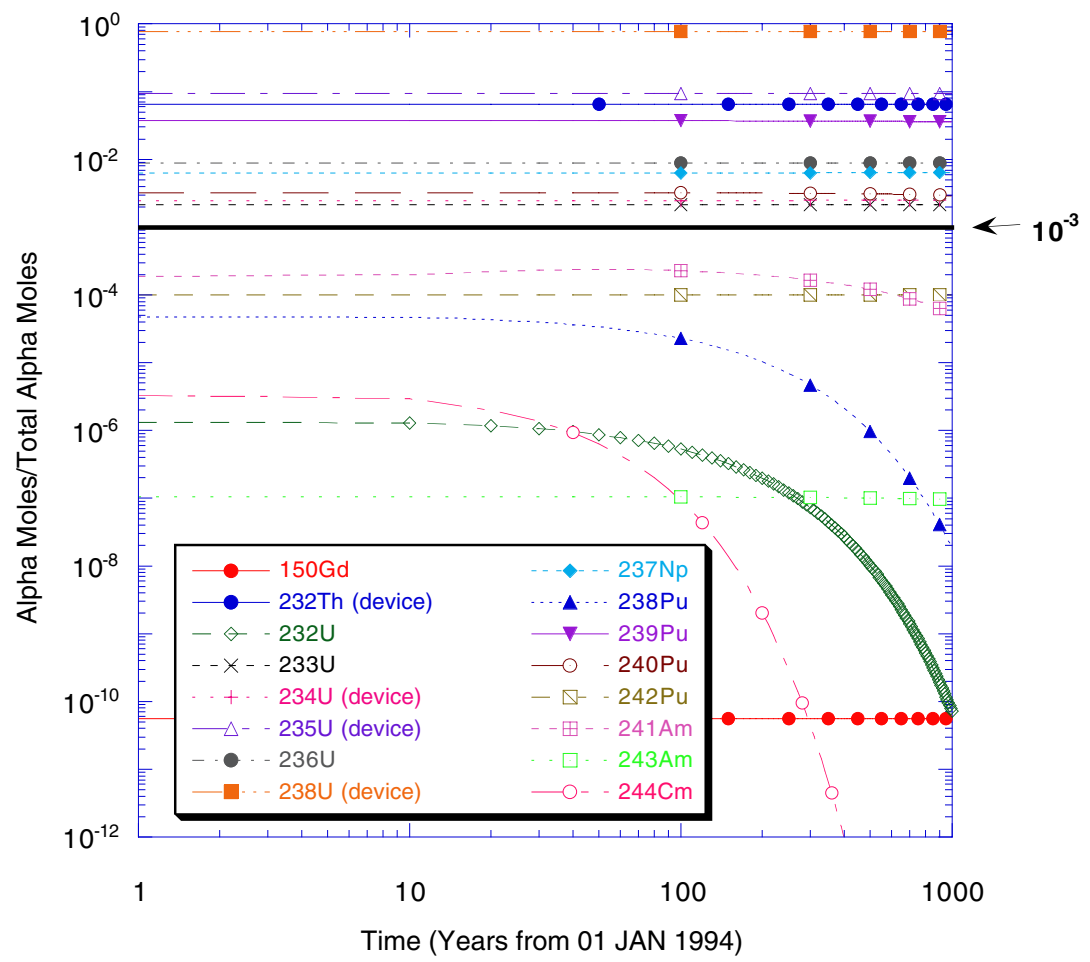

Figure A.2 Ratio of moles of individual alpha-emitting radionuclides to moles of all inventoried alpha radionuclides in groundwater, as a function of time, on Pahute Mesa at the Nevada Test Site. 
IV. For an electron capture/isomeric transition (EC/IT) decay radionuclide, the ratio of its activity (in $\mathrm{Bq}$ ) or amount (in moles) to the total activity or amount (see footnote 4 of this appendix), respectively, of all EC/IT decay radionuclides exceeds a value of $10^{-3}(0.1 \%$ of the total) at some time over the next $1000 \mathrm{yr}$ (see Figures A.5 and A.6; and the Criterion-IV column in Table A.1). For the particular cases of ${ }^{121 \mathrm{~m}} \mathrm{Sn}$ and ${ }^{152} \mathrm{Eu}$ that have two principal decay modes (Table A.1), only their respective inventory fractions partaking in an EC/IT decay process are included in this calculation.

V. The radionuclide has a reported concentration in groundwater taken from the CHESHIRE cavity, chimney, or near the CHESHIRE event (see Criterion-V column in Table A.1).

Criteria II through IV are meant to address the relative activity (and abundance) of a radionuclide over time as opposed to its absolute activity (and abundance), in the sense that what is considered low relative abundance today (for example, see ${ }^{14} \mathrm{C}$ or ${ }^{36} \mathrm{Cl}$ in Figure A.3a) may become high relative abundance later as a result of ingrowth and decay processes. Separate (albeit similar, in this case) criteria were developed for alpha, beta, and EC/IT decay radionuclides in order to be consistent with the Final Rule for Radionuclides in the National Primary Drinking Water Regulations (USEPA, 2000) in which MCL limits are placed on:

- Combined activity of ${ }^{226} \mathrm{Ra}$ and ${ }^{228} \mathrm{Ra}$.

- Beta and photon radioactivity.

- Gross alpha particle activity (excluding radon and uranium ${ }^{8}$ ).

- Uranium.

\footnotetext{
${ }^{8}$ We included uranium in the definition of Criterion-II, however, as a measure of convenience.
} 


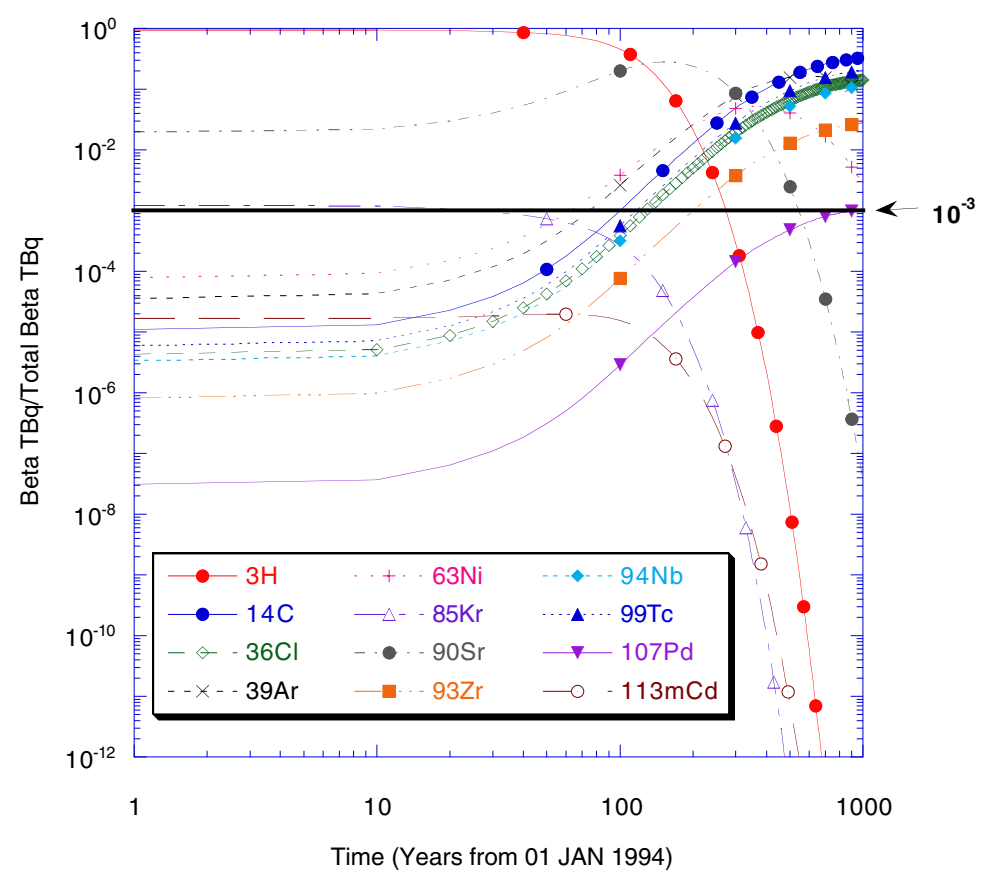

Figure A.3(a) Ratio of beta activities of individual radionuclides to total beta activity of all inventoried radionuclides in groundwater, as a function of time, on Pahute Mesa at the Nevada Test Site $\left({ }^{3} \mathrm{H}\right.$ to $\left.{ }^{113} \mathrm{Cd}\right)$.

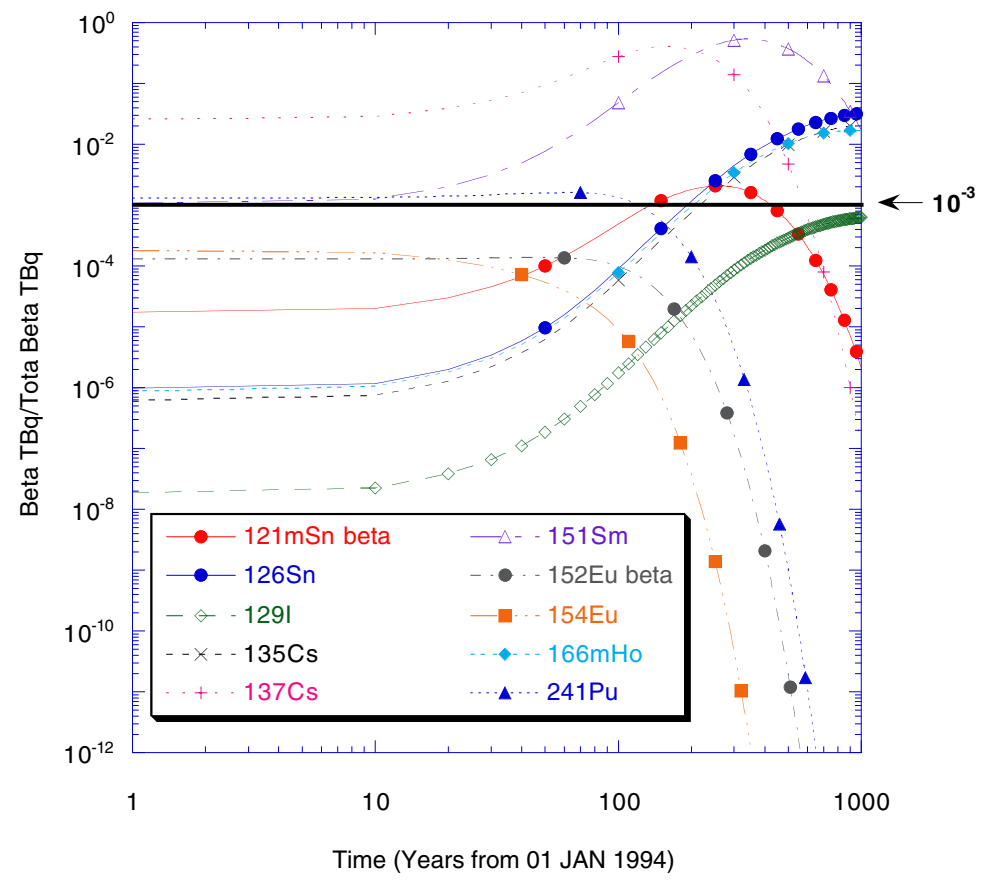

Figure A.3(b) Ratio of beta activities of individual radionuclides to total beta activity of all inventoried radionuclides in groundwater, as a function of time, on Pahute Mesa at the Nevada Test Site $\left({ }^{121 \mathrm{~m}} \mathrm{Sn}\right.$ to ${ }^{241} \mathrm{Pu}$ ). Because ${ }^{121 \mathrm{~m}} \mathrm{Sn}$ and ${ }^{152} \mathrm{Eu}$ have two principal decay modes (Table A.1), only their respective inventory fractions partaking in a $\beta$-decay process are included in these results. 


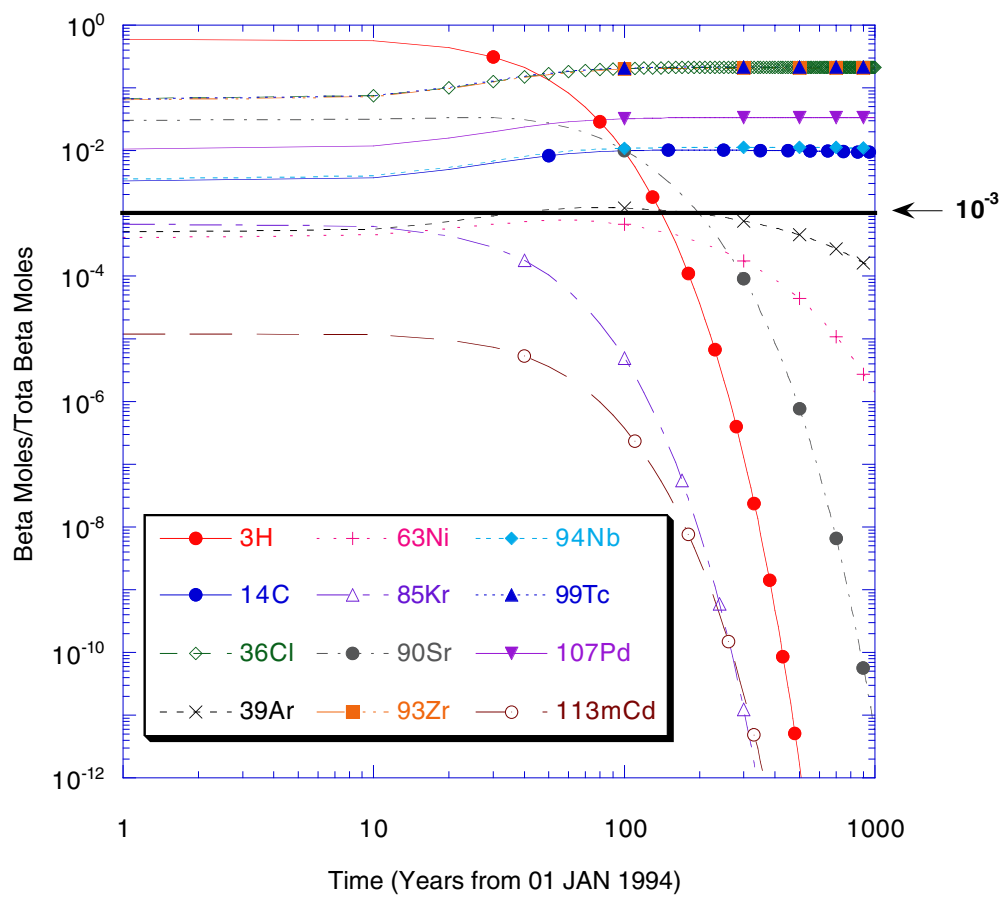

Figure A.4(a) Ratio of moles of individual beta emitting radionuclides to moles of all inventoried beta radionuclides in groundwater, as a function of time, on Pahute Mesa at the Nevada Test Site $\left({ }^{3} \mathrm{H}\right.$ to $\left.{ }^{113} \mathrm{Cd}\right)$.

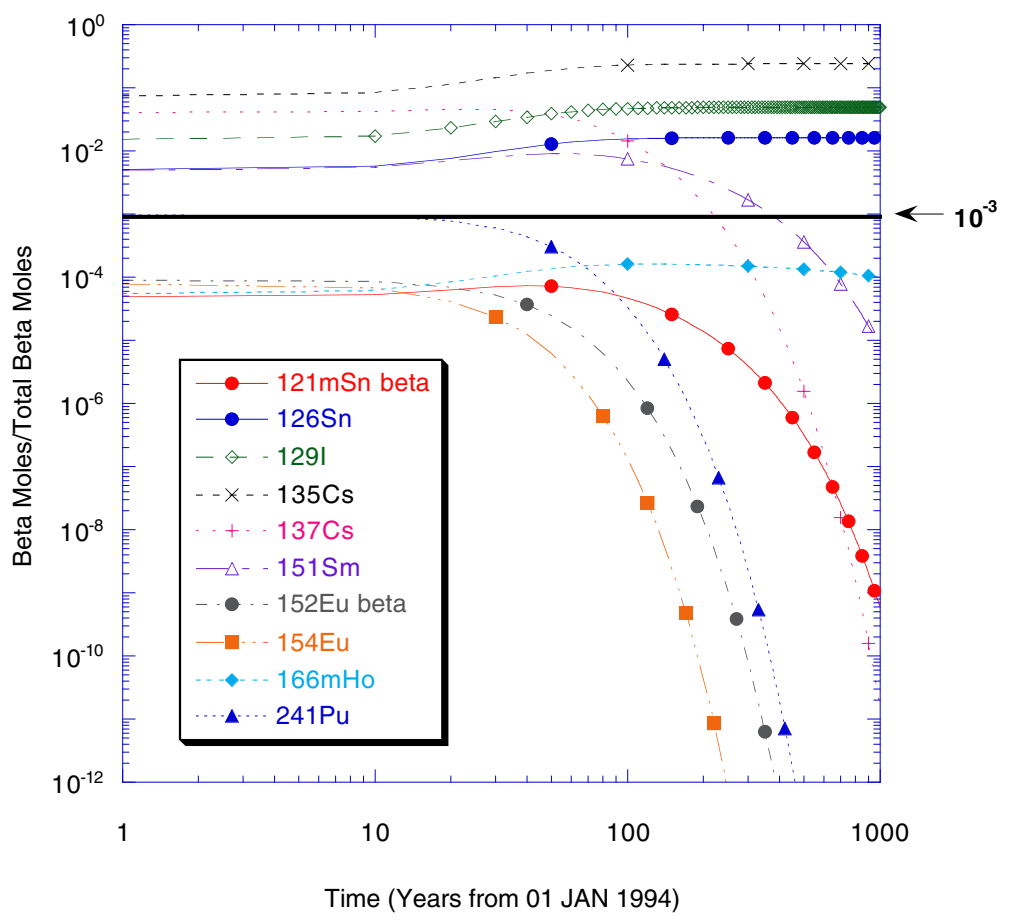

Figure A.4(b) Ratio of moles of individual beta emitting radionuclides to moles of all inventoried beta radionuclides in groundwater, as a function of time, on Pahute Mesa at the Nevada Test Site $\left({ }^{121 \mathrm{~m}} \mathrm{Sn}\right.$ to ${ }^{241} \mathrm{Pu}$ ). Because ${ }^{121 \mathrm{~m}} \mathrm{Sn}$ and ${ }^{152} \mathrm{Eu}$ have two principal decay modes (Table A.1), only their respective inventory fractions partaking in a $\beta$-decay process are included in these results. 


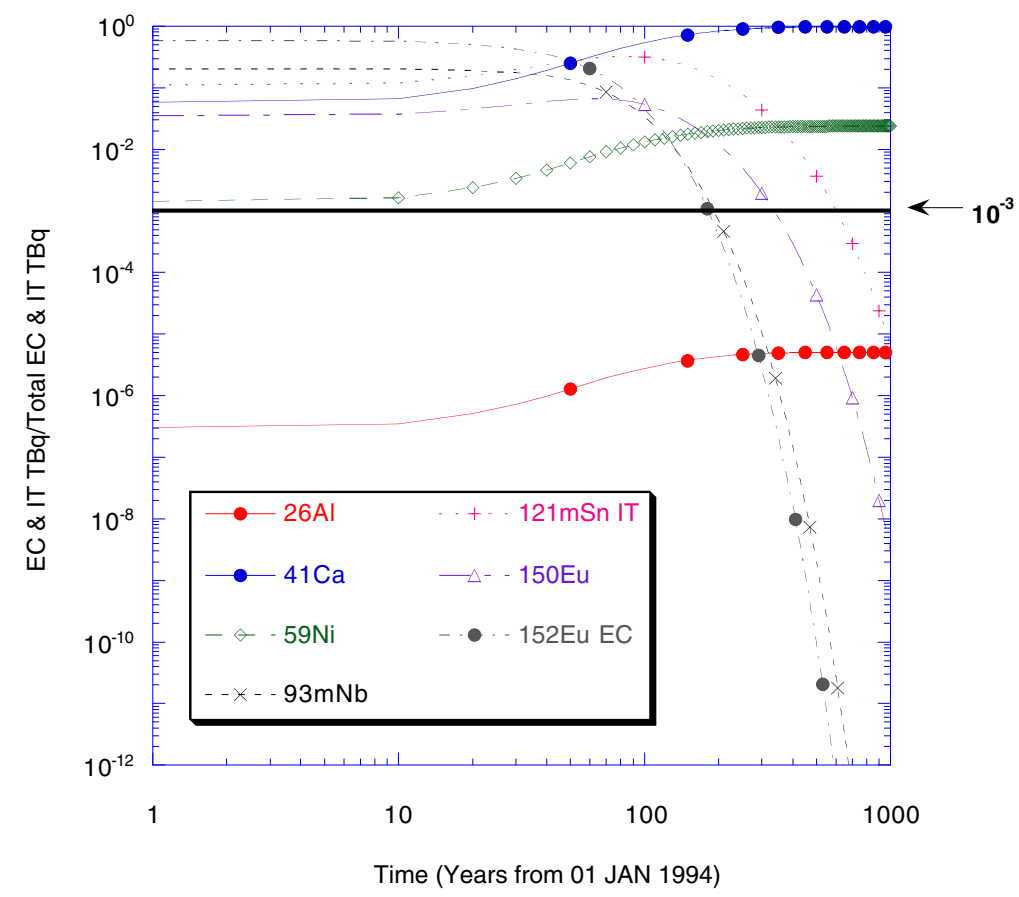

Figure A.5 Ratio of EC and IT activities of individual radionuclides to the total electron capture and isomeric transition activity of radionuclides in groundwater, as a function of time, on Pahute Mesa at the Nevada Test Site. Because ${ }^{121 \mathrm{~m}} \mathrm{Sn}$ and ${ }^{152} \mathrm{Eu}$ have two principal decay modes (Table A.1), only their respective inventory fractions partaking in an EC/IT decay process are included in these results and those in Figure A.6.

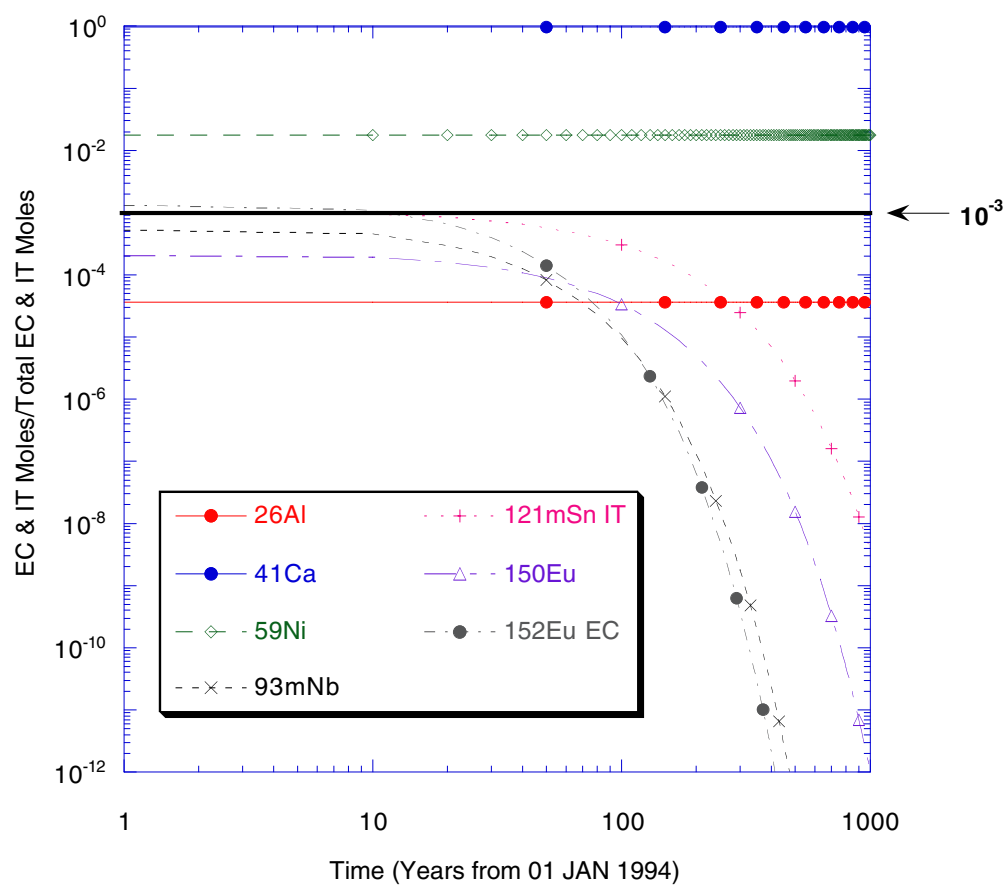

Figure A.6 Ratio of moles of individual EC and IT radionuclides to moles of total electron capture and isomeric transition radionuclides in groundwater, as a function of time, on Pahute Mesa at the Nevada Test Site. 


\section{A.3.2 Radionuclides Included in Model}

Application of these criteria to each of the 52 radionuclides in Table A.1 yields 37 that are to be included in the near-field hydrologic flow and transport model at CHESHIRE. There was one exception to these criteria: ${ }^{238} \mathrm{U}$ was included in the model, despite the fact that its natural inventory exceeds its corresponding test-related inventory. This exception was made specifically because its test-related molar inventory exceeds the individual, test-related molar inventory of all other radionuclides reported in Smith (2001). ${ }^{9}$ Interestingly, these 37 radionuclides represent:

- All but 5 of the 22 considered significant by the UGTA-ST Subcommittee (Smith, 1997). The remaining five (i.e., 60Co, 106Ru, 125Sb, 134Cs, and $155 \mathrm{Eu}$ ) cannot otherwise be included because there is no reported testrelated inventory (i.e., no conformity with Criterion I above).

- All but 9 of the 26 radionuclides for which groundwater measurements have been reported. The remaining nine (i.e., $22 \mathrm{Na}, 40 \mathrm{~K}, 54 \mathrm{Mn}, 60 \mathrm{Co}$, $106 \mathrm{Ru}, 125 \mathrm{Sb}, 134 \mathrm{Cs}, 144 \mathrm{Ce}$, and 155Eu) cannot otherwise be included because there is no reported test related inventory (i.e., no conformity with Criterion I above).

\section{A.4 Radioactive Decay Chains}

Radioactive decay and ingrowth processes associated with the RST radionuclides must be considered to

- Determine whether coupled ingrowth and decay affect the relative abundance of any RST radionuclide(s).

- Identify whether any new derivative members of the RST need to be included or addressed.

- Decide whether ingrowth and decay affect the hydrologic mobility of any RST radionuclides (as specifically discussed in Chapter 6 and Appendices C and D).

By definition, all of the 37 radionuclides selected for inclusion in the model will undergo radioactive decay: It is particularly important to understand whether ingrowth is important, because this affects the way decay is incorporated into the $\operatorname{model}^{10}$.

\footnotetext{
${ }^{9}$ It also allows the total uranium to be considered in relation to its specific MCL cited in USEPA (2000).

${ }^{10}$ Decay and ingrowth may be handled in a "real time" sense, where concentration changes arising from these effects are calculated at each time step of the simulation. This is a natural way to approach the problem, but it can increase the computational time of a simulation. Conversely, decay itself may be treated in an "ex-post-facto" sense by post processing non-decayed results, but only if the daughter products are not relevant or important in the simulation, and only if the mobility of the parent is independent of its concentration (see Tompson et al., 1999; Chapter 7, and Appendices B, C, and D.
} 
- Radionuclides with low to intermediate atomic numbers $(<80)$ will decay into stable, nonradioactive daughter products. They will not produce derivative members of the RST, but their decay will lead to lower concentrations which may influence their sorptivity and hydrologic transport rates.

- Some members of the RST, notably ${ }^{90} \mathrm{Sr},{ }^{126} \mathrm{Sn}$, and ${ }^{137} \mathrm{Cs}$, decay into shortlived radioactive daughter products (e.g., ${ }^{90} \mathrm{Y},{ }^{126} \mathrm{Sb}$, and ${ }^{137 \mathrm{~m}} \mathrm{Ba}$, respectively, with $t_{1 / 2}<1 \mathrm{wk}$; see Table A.1), which, in turn, decay into stable granddaughters. In general, all short-lived intermediaries will exist in secular equilibrium. Their abundance will be smaller than, and can be calculated as an instantaneous function of, their parent's abundance. . Accordingly, their "real time" inclusion in the model as derivative members of the RST is not considered necessary.

- Most of the heavier radionuclides in the RST are members of coupled decay chains that include two or more members of the RST. These need to be considered more carefully, as tabulated and discussed below.

Eight decay chains that involve 2 or more of the 37 modeled radionuclides have been identified. ${ }^{11}$ These chains are presented and discussed below in terms of the relevant members that need to be addressed over a $1000 \mathrm{yr}$ long simulation period.

$$
{ }^{93} \mathrm{Zr} \stackrel{\sim 10^{6} y / \beta}{\longrightarrow}{ }^{93 m} \mathrm{Nb} \stackrel{16.1 y / I T}{\longrightarrow}{ }^{93} \mathrm{Nb}^{\circ} \text { (stable) }
$$

In Equation (A1), both ${ }^{93} \mathrm{Zr}$ and ${ }^{93 \mathrm{~m}} \mathrm{Nb}$ are included in the model. Because of the long half-life of ${ }^{93} \mathrm{Zr}$, the ingrowth of ${ }^{93 \mathrm{~m}} \mathrm{Nb}$ from this reaction over $1000 \mathrm{yr}$ will not be significant, so both can be treated independently.

$$
{ }^{152} \mathrm{Eu} \stackrel{(28 \% \text { branch }) 13.5 y / \beta}{\longrightarrow}{ }^{152} \mathrm{Gd} \stackrel{\sim 10^{14} y / \alpha}{\longrightarrow} \cdots
$$

Decay chain (A2) indicates that $28 \%$ of the ${ }^{152}$ Eu decays via the beta emission branch into ${ }^{152} \mathrm{Gd}$, a radioactive element that is not included in the model. Because ${ }^{152} \mathrm{Gd}$ has such a long half-life, however, it can effectively be considered as a stable endmember of the chain. (The remaining $72 \%$ of the ${ }^{152} \mathrm{Eu}$ decays via electron capture to ${ }^{152} \mathrm{Sm}$, which is stable.)

$$
{ }^{232} \mathrm{U} \stackrel{70.0 y / \alpha}{\longrightarrow}{ }^{228} \mathrm{Th} \stackrel{1.9 y / \alpha}{\longrightarrow}\left(7^{\circ} \text { short - lived intermediaries }\right) \longrightarrow{ }^{208} \mathrm{~Pb}^{\circ} \text { (stable) }
$$

In Equation (A3), ${ }^{232} \mathrm{U}$ is shown to decay over a long, 10-member chain into ${ }^{208} \mathrm{~Pb}$, its stable end-member daughter. Although ${ }^{232} \mathrm{U}$ is included in the model, none of its radioactive daughter products is. The first, ${ }^{228} \mathrm{Th}$, has a half-life of $1.9 \mathrm{yr}$ and decays

\footnotetext{
${ }^{11}$ Three additional decay chains associated with non-modeled radionuclides in the RST (Table A.1) can also be identified. These specifically include chains associated with ${ }^{144} \mathrm{Ce},{ }^{150} \mathrm{Gd}$, and ${ }^{232} \mathrm{Th}$. Notably, decay of ${ }^{232} \mathrm{Th}$ leads to ingrowth of ${ }^{228} \mathrm{Ra}$, ${ }^{228} \mathrm{Ac}$, and ${ }^{228 \mathrm{Th}}$; and then follows chain (A-3). Also, observe that the chains associated with ${ }^{242} \mathrm{Pu}$ and ${ }^{243} \mathrm{Am}$ are discussed here because their daughter products are included in the model.
} 
via alpha-emission into several short-lived intermediaries whose half-lives range from microseconds to 3.6 days. Of these, four $\left({ }^{224} \mathrm{Ra},{ }^{220} \mathrm{Rn},{ }^{216} \mathrm{Po}\right.$, and $\left.{ }^{212} \mathrm{Po}\right)$ specifically decay via alpha-emission. However, because the half-lives of the ${ }^{232} U$ daughters are extremely short, or approximately so in the case of ${ }^{228} \mathrm{Th}$, we can assume they all exist in secular equilibrium with ${ }^{232} \mathrm{U}$.

${ }^{241} \mathrm{Pu} \stackrel{14.4 y / \beta}{\longrightarrow}{ }^{241} \mathrm{Am} \stackrel{433 y / \alpha}{\longrightarrow}{ }^{237} \mathrm{~Np} \stackrel{\sim 10^{6} y / \alpha}{\longrightarrow}\left({ }^{233} \mathrm{~Pa} \stackrel{\sim 27 d / \beta}{\longrightarrow}\right)^{233} \mathrm{U} \stackrel{\sim 10^{5} y / \alpha}{\longrightarrow} \cdots$

Four of the first five members of decay chain (A4) are included as primary members of the RST. The coupled decay and ingrowth between ${ }^{241} \mathrm{Pu},{ }^{241} \mathrm{Am}$, and ${ }^{237} \mathrm{~Np}$ must be treated explicitly in a transport model because of their relatively short halflives. However, since the half-lives of ${ }^{237} \mathrm{~Np}$ and ${ }^{233} \mathrm{U}$ are so long, the ingrowth of ${ }^{233} \mathrm{U}$ and subsequent daughters can be effectively ignored in our 1,000-year decay and transport calculations.

$$
{ }^{242} \mathrm{Pu} \stackrel{\sim 10^{5} y / \alpha}{\longrightarrow}{ }^{238} \mathrm{U} \stackrel{\sim 10^{9} y / \alpha}{\longrightarrow}{ }^{234} \mathrm{U} \stackrel{\sim 10^{5} y / \alpha}{\longrightarrow} \cdots
$$

In Equation (A5), the second and third members of this decay chain are included in the model. The first $\left({ }^{242} \mathrm{Pu}\right)$ was excluded because its inventory over $1000 \mathrm{yr}$ was predicted to be relatively small (Criterion II, Figures A.1, A.2). Because both ${ }^{238} U$ and ${ }^{234} U$ have relatively long half-lives, ingrowth of ${ }^{234} U$ and its further decay into additional daughters can be safely ignored in the model.

$$
{ }^{238} \mathrm{Pu} \stackrel{87.7 y / \alpha}{\longrightarrow}{ }^{234} \mathrm{U} \stackrel{\sim 10^{5} y / \alpha}{\longrightarrow} \cdots
$$

In Equation (A6), both ${ }^{238} \mathrm{Pu}$ and ${ }^{234} \mathrm{U}$ are included in the model; ${ }^{238} \mathrm{Pu}$ decays over a relatively short half-life into ${ }^{234} \mathrm{U}$ whose decay into further daughter products can be effectively ignored in the model because of its long half-life.

$$
{ }^{243} \mathrm{Am} \stackrel{7370 y / \alpha}{\longrightarrow}{ }^{239} \mathrm{Pu} \stackrel{\sim 10^{4} y / \alpha}{\longrightarrow}{ }^{235} \mathrm{U} \stackrel{\sim 10^{8} y / \alpha}{\longrightarrow} \cdots
$$

In Equation (A7), both the second and third members of the decay chain are included in the model, but the first $\left({ }^{243} \mathrm{Am}\right)$ was excluded because its inventory over 1000 yr was predicted to be relatively small (Criterion II, Figures A.1, A.2). Because both ${ }^{239} \mathrm{Pu}$ and ${ }^{235} \mathrm{U}$ have relatively long half-lives, ingrowth of ${ }^{235} \mathrm{U}$ and its further decay into additional daughters can be safely ignored in the model.

$$
{ }^{244} \mathrm{Cm} \stackrel{18.1 y / \alpha}{\longrightarrow}{ }^{240} \mathrm{Pu} \stackrel{6560 y / \alpha}{\longrightarrow}{ }^{236} \mathrm{U} \stackrel{\sim 10^{7} y / \alpha}{\longrightarrow}{ }^{232} \mathrm{Th} \stackrel{\sim 10^{10} y / \alpha}{\longrightarrow} \cdots
$$

The first three members of decay chain (A8) are included in the model. Although the ingrowth of ${ }^{240} \mathrm{Pu}$ from ${ }^{244} \mathrm{Cm}$ must be accounted for, the half-lives of ${ }^{240} \mathrm{Pu}$ and ${ }^{236} \mathrm{U}$ suggest the ingrowth of ${ }^{236} \mathrm{U},{ }^{232} \mathrm{Th}$, and subsequent daughters will not be significant over the 1000 yr time of the model. 


\section{A.5 Summary}

The 37 radionuclides to be included in the model appear as unshaded rows in Table A.1. They are considered to be consistent with an isotopically complex mixture of radionuclides that could have environmental, health, and safety consequences when exposed to potential down-gradient receptors sometime in the future. Except for a few coupled decay chains and some short-lived intermediary daughter products, all of these radionuclides decay to stable end-members or daughter products with long half-lives that do not appreciably decay over the $1000 \mathrm{yr}$ simulation period of the model. Important exceptions to this are noted below:

- The following decay chains involve coupled decay and ingrowth behavior and need to be considered in the 1000 yr long time frame of the model:

- Equation (A4): ${ }^{241} \mathrm{Pu} \stackrel{14.4 y / \beta}{\longrightarrow}{ }^{241} \mathrm{Am} \stackrel{433 y / \alpha}{\longrightarrow}{ }^{237} \mathrm{~Np}$

- Equation (A6): ${ }^{238} \mathrm{Pu} \stackrel{87.7 y / \alpha}{\longrightarrow}{ }^{234} \mathrm{U}$.

- Equation (A8): ${ }^{244} \mathrm{Cm} \stackrel{18.1 y / \alpha}{\longrightarrow}{ }^{240} \mathrm{Pu}$

- The short-lived radionuclides ${ }^{90} \mathrm{Y},{ }^{126} \mathrm{Sb}$, and ${ }^{137 \mathrm{~m}} \mathrm{Ba}$ will exist in secular equilibrium with their parents $\left({ }^{90} \mathrm{Sr},{ }^{126} \mathrm{Sn}\right.$, and ${ }^{137} \mathrm{Cs}$, respectively), and their abundance can be indirectly estimated from the abundance of their parents.

- Although not directly included in the model, some of the short-lived daughter products of ${ }^{232} \mathrm{U}$ (e.g., ${ }^{224} \mathrm{Ra},{ }^{220} \mathrm{Rn},{ }^{216} \mathrm{Po}$, and ${ }^{212} \mathrm{Po}$ ) could represent a potential internal-dose concern. Because they will all exist, approximately, in secular equilibrium with ${ }^{232} \mathrm{U}$, their abundance can be estimated from the model in terms of the simulated ${ }^{232} \mathrm{U}$ abundance.

A total of 15 radionuclides shown in Table A.1 (in the shaded rows) have been excluded from the model for one of the following reasons:

- There is no reported inventory for ${ }^{22} \mathrm{Na},{ }^{54} \mathrm{Mn},{ }^{60} \mathrm{Co},{ }^{106} \mathrm{Ru},{ }^{125} \mathrm{Sb},{ }^{134} \mathrm{Cs},{ }^{144} \mathrm{Ce}$, and ${ }^{155} \mathrm{Eu}$ (yellow shaded rows in Table A.1).

- Criteria II through $\mathrm{V}$ are not satisfied for ${ }^{26} \mathrm{Al},{ }^{113 \mathrm{~m}} \mathrm{Cd},{ }^{150} \mathrm{Gd},{ }^{242} \mathrm{Pu}$, and ${ }^{243} \mathrm{Am}$, despite the presence of a reported inventory (turquoise shaded rows in Table A.1).

- Natural abundance in soil or rock exceeds test-related inventories (e.g., ${ }^{232} \mathrm{Th}$ ) or has no corresponding test-related inventory (i.e., ${ }^{40} \mathrm{~K}$ ).

Although any of these 15 radionuclides might be considered in future simulations, ${ }^{22} \mathrm{Na},{ }^{54} \mathrm{Mn},{ }^{60} \mathrm{Co},{ }^{106} \mathrm{Ru},{ }^{125} \mathrm{Sb},{ }^{134} \mathrm{Cs},{ }^{144} \mathrm{Ce}$, and ${ }^{155} \mathrm{Eu}$ have relatively short halflives (5 yr or less) and no significant daughters or parents, and therefore, would not 
necessarily constitute a significant threat to public health and the environment in the distant future. In addition, ${ }^{26} \mathrm{Al},{ }^{113 \mathrm{~m}} \mathrm{Cd},{ }^{150} \mathrm{Gd},{ }^{242} \mathrm{Pu}$, and ${ }^{243} \mathrm{Am}$ have never been measured in groundwater near the CHESHIRE event. Furthermore, ${ }^{232}$ Th has a significant natural inventory that overwhelms its test-related inventory, while the entire inventory of ${ }^{40} \mathrm{~K}$ is natural and has no test-related counterpart. 


\section{APPENDIX B: \\ Mathematical Models of Fluid Flow and Radionuclide Transport}




\section{B.1 General Conceptualization and Approach}

Because the near field geologic environment surrounding the CHESHIRE test is largely composed of fractured volcanic rock, our mathematical models are based upon a dual porosity or dual continuum conceptualization. In this approach, flow and transport processes within the network of fractures and within the interstices of the rock blocks (or rock matrix) that separate them are treated separately (Bear et al., 1993) and associated, in general, with distinct flow and transport variables such as porosity, velocity, and concentration. This assumption applies to all parts of the domain, even though the size of the matrix blocks and the significance of flow through the rock matrix may be diminished in the cavity, chimney, and melt glass areas. In addition, all fracture and rock matrix variables are assumed to be defined over appropriate representative elementary volumes (REVs) of the medium, and balance equations written for mass, momentum, or energy quantities in each porous continuum will share appropriate terms for exchange of these quantities.

The models described in this report are based upon the observation that saturated conditions exist over the entire extent of the simulation period ${ }^{1}$ and the assumption that fluid flow occurs primarily within the fractured regime. Advective flow through the matrix pores is presumed to be negligible, leaving diffusive mass transport as the dominant means for moving fluids or dissolved radionuclide parcels in and out of the matrix pore system. As such, our simulations are focused primarily on the fracture porosity regime, and all variables and balance equations discussed below, with a few notable exceptions, pertain to the fracture porosity system alone. Although it is recognized a priori that the size of the fracture apertures and matrix blocks (or fracture densities) may vary throughout the domain, we assume for simplicity that a suitably common REV exists in all areas upon which the conceptual model can be based. We also appreciate the implications this assumption will have in relating model predictions with specific observations and measurements of temperature, concentration, or water levels in wells.

\footnotetext{
${ }^{1}$ Flow conditions at the CHESHIRE working point were saturated before detonation. Our overall approach assumes the starting point for examining radionuclide migration in groundwater after the test is in the days to weeks following zero time when groundwater returns to the cavity and chimney and most of the complex dynamics initiated by the detonation have ended. Measurements have confirmed that saturated conditions had returned to the CHESHIRE cavity area within 150 days after detonation. Simulations and observations have also indicated that existing high temperatures at the start of the modeling period were not sufficiently high to generate boiling (or two-phase flow) conditions in the system.
} 


\section{B.2 Flow and Thermal Energy Balance Equations}

The balance equation for fluid mass in the saturated fracture flow system is

$$
\frac{\partial(\phi \rho)}{\partial t}+\nabla \bullet(\phi \rho \mathbf{v})=0
$$

where $\phi$ is the fracture porosity ${ }^{2}, \rho$ is the fluid density (kg-solution/L-solution), and $\mathbf{v}$ is the average fracture seepage velocity $(\mathrm{m} / \mathrm{yr})$. This velocity may be computed from Darcy's law,

$$
\phi \mathbf{v}=-\frac{\mathbf{k}}{\mu} \bullet(\nabla p+\rho g \nabla z)
$$

where $\mathbf{k}$ is the fracture permeability tensor $\left(\mathrm{m}^{2}\right), p$ is the fluid pressure $\left(\mathrm{kg} / \mathrm{m}-\mathrm{s}^{2}\right), \mu$ is the fluid viscosity $(\mathrm{kg} / \mathrm{m}-\mathrm{s}), g$ is the gravitational constant $\left(\mathrm{m} / \mathrm{s}^{2}\right)$, and $z$ is an elevation (in meters) above some datum. In the current implementation, the principal axes of the permeability tensor are assumed to be aligned with the $x y z$ coordinate system so that $\mathbf{k}$ is diagonal $\left(k_{x}, k_{y}, k_{z}\right)$. Note that the density and viscosity will, in general, be temperature $(T)$ and pressure $(p)$ dependent.

Although these equations are fairly common, their solution may require the temperature dependence of fluid density and viscosity to be considered because of the impacts of geothermal and test-related heat near CHESHIRE. As such, a model equation for the balance of thermal energy in the composite (bulk) system will be required to complete the flow model. A typical form for this equation is

$$
\begin{aligned}
\frac{\partial}{\partial t}\left(\phi \rho E+\phi_{m} \rho E_{m}+\phi_{s} \rho_{s} E_{S}\right)+\nabla \bullet(\phi E \rho \mathbf{v}) & +\nabla \bullet(\phi p \mathbf{v})+ \\
& \nabla \bullet\left(\mathbf{q}+\mathbf{q}_{m}+\mathbf{q}_{s}\right)=0
\end{aligned}
$$

where $E, E_{m}$ and $E_{s}$ are, respectively, the internal energies of the fracture and matrix fluids and the solid (rock) phase; $\mathbf{q}, \mathbf{q}_{\mathrm{m}}$, and $\mathbf{q}_{\mathrm{s}}$ are the respective thermal energy fluxes due to heat conduction; $\phi_{m}$ is the matrix porosity; and $\rho_{s}$ is the solid phase density. This equation is solved by assuming the liquid and solid phases at a point in the medium are in thermal equilibrium, and thus at the same temperature $T$, and by relating the internal energy to temperature through the introduction of medium-specific heat capacities. The sum of the conductive energy fluxes is typically expressed as $-K_{H} \nabla T$, where $K_{H}$ is a bulk thermal conductivity. Importantly, the bulk heat capacity and thermal conductivity, do not significantly vary (under saturated conditions) between different types of rock (Nitao, 1999).

\footnotetext{
${ }^{2}$ This is to be distinguished from the matrix porosity, $\phi_{\mathrm{m}}$.
} 


\section{B.3 Numerical Solution of Flow and Thermal Energy Equations}

The coupled hydrothermal flow simulations in this report were performed with the NUFT (Nonisothermal Unsaturated-Saturated Flow and Transport) code (Nitao, 1998, 1999).

The following description of the NUFT model is adapted from NUFT user's manual (Nitao, 1999). NUFT solves the continuum balance equations (B1-B3) for the conservation of mass, momentum, and thermal energy. In the continuum-based approach, the flow domain is discretized into "grid blocks" having effective property values. The balance equations are discretized in space using the integrated, finitedifference method (Edwards, 1972; Narisimhan and Witherspoon, 1978) and in time using the fully implicit backward Euler method. The resulting nonlinear system of equations is solved at each time step using the Newton-Raphson method.

NUFT is capable of simulating flow and transport for multiple phases and components in variably saturated, non-isothermal conditions. However, for this CHESHIRE HST work, NUFT is used to simulate single-phase flow of liquid water under fully saturated and non-isothermal conditions; the variable saturation and transport capabilities (with multiple components and phases) of NUFT are not used.

Because the abundance and distribution of chemical mass addressed in this study will not affect the flow field, model simulations based upon these equations represent an independent and essentially self-contained portion of this analysis. Simulation of radionuclide transport for this CHESHIRE HST work is accomplished by combining either the GIMRT streamline or particle methods (see Appendices C and D) with the flow simulations generated by NUFT.

\section{B.4 Mass Transport Equations}

The balance equations for chemical mass and reactive transport in the fractured flow regime form the basis for our radionuclide release and transport model. These equations incorporate a number of relevant and specific geochemical process models that describe, for example, the kinetics of melt glass dissolution, radioactive decay, and aqueous complexation reactions, as well as several ion exchange and surface complexation reactions between dissolved radionuclides and reactive minerals in the fracture networks. Terms representing the diffusive exchange of mass between the fracture and matrix systems are not directly included. However, several approximate procedures based upon analytic idealizations of the matrix diffusion process can be used to adjust or postprocess results obtained for the fracture system to reflect the impacts of matrix diffusion. These approximations will be discussed further in Appendices $C$ and $D$. The nature of chemical migration is expected to have no influence on the flow dynamics in this problem such that the reactive transport problem can always be decoupled from the flow problem. 
The model equations are based upon an assumption that the chemical species in solution or sorbed or exchanged as surface complexes on the solid matrix are all in chemical equilibrium. ${ }^{3}$ In this sense, mass action expressions can then be defined and used to relate the concentrations of these species. In general, we consider a series of $N_{c}$ primary or basis species whose concentrations are denoted by $C_{j}$ (molal, or moles $j$ per $\mathrm{kg}-\mathrm{H}_{2} \mathrm{O}$ ), and a secondary set of $N_{x}$ species whose concentrations are denoted by $X_{i}$ (molal), where $N_{c}+N_{x}=N$ is the total number of species considered. The number of secondary species $N_{x}$ is equal to the number of mass action expressions that can be written from the known equilibria. These equilibria allow for the secondary concentrations $\left(X_{i}\right)$ to be determined from the primary concentrations $\left(C_{j}\right)$. The particular species chosen to be primary or secondary is arbitrary, in some sense, but is often guided by accuracy and numerical convergence issues that arise in the computer codes; it and can be modified during the course of a simulation (Steefel and Yabusaki, 1996).

The transport equations can be generally written in terms of the $N_{c}$ total primary species total concentrations given by

$$
U_{j}=C_{j}+\sum_{i=1}^{N_{x}} v_{i j} X_{i}
$$

and

$$
U_{i}^{i m}=C_{i}^{i m}+\sum_{i=1}^{N_{x}} v_{i j} X_{i}^{i m}
$$

In these expressions, $U_{i}^{i m}, C_{i}^{i m}$, and $X_{i}^{i m}$ represent the molal (moles $j$ per kilogram $-\mathrm{H}_{2} \mathrm{O}$ ) concentrations of the immobile surface complexes, where $j=1, \ldots N_{c}$ and the $v_{i j}$ are the stoichiometric coefficients that appear in the equilibrium relationships.

In the absence of any pumping well sources or sinks, the one-dimensional transport equation for the $j$-th total concentration may be written as

$$
\begin{gathered}
\frac{\partial}{\partial t}\left[\phi \rho M_{\mathrm{H}_{2} \mathrm{O}}\left(U_{j}+U_{j}^{i m}\right)\right]+\nabla \cdot\left(\phi \mathrm{v} \rho \mathrm{M}_{\mathrm{H}_{2} \mathrm{O}} U_{j}\right)-\nabla \cdot\left[\phi \mathbf{D} \cdot \nabla\left(\rho \mathrm{M}_{\mathrm{H}_{2} \mathrm{O}} U_{j}\right)\right]= \\
R_{j}^{\min }-\lambda \lambda_{j} \phi \rho M_{\mathrm{H}_{2} \mathrm{O}}\left(U_{j}+U_{j}^{i m}\right)+\lambda_{k} \phi \rho M_{\mathrm{H}_{2} \mathrm{O}}\left(U_{k}+U_{k}^{i m}\right)-s_{f m}
\end{gathered}
$$

where $M_{\mathrm{H}_{2} \mathrm{O}}$ is the mass fraction of water in the solution (kilograms-water/ kilograms-solution), $s_{f m}$ is a term representing loss or gain of mass to and from the matrix regime, and the various densities, porosities, and velocities are as defined above. If the exchange of radionuclide mass between the fracture and matrix regimes is ignored, then $s_{f m}=0$.

${ }^{3}$ This is not meant to imply that species involved in mineral precipitation or dissolution reactions are controlled by equilibrium; these will be considered separately. 
The hydrodynamic dispersion tensor is typically defined by

$$
\mathbf{D}(\mathbf{x})=\left(\alpha_{T} V+D_{e}\right) \mathbf{I}+\left(\alpha_{L}-\alpha_{T}\right) \frac{\mathbf{v v}}{V}
$$

where $\alpha_{\mathrm{L}}$ and $\alpha_{\mathrm{T}}$ are the longitudinal and transverse medium dispersivities $(\mathrm{m})$ and $D_{\mathrm{e}}$ is an effective molecular diffusivity $\left(\mathrm{m}^{2} / \mathrm{s}\right)$ for the fractured porous medium.

The rate of species production (moles- $j / \mathrm{m}^{3} / \mathrm{s}$ ) via dissolution or precipitation of mineral phase $\mathrm{m}$ is defined by

$$
R_{j}^{\min }=-\sum_{m=1}^{N_{m}} v_{j m} r_{m}
$$

where $v_{i m}$ is the number of moles of $j$ per mole of mineral $m, r_{m}$ is the rate of precipitation or dissolution of mineral $m$ per bulk volume of the medium (molmineral $/ \mathrm{m}^{3} / \mathrm{s}$ ), and $N_{m}$ is the number of separate mineral phases considered. If species $j$ is a member of a radionuclide decay chain, then $\lambda_{j}$ represents its decay rate ${ }^{4}$, while $\lambda_{k}$ represents its ingrowth rate from the decay of its parent nuclide $k$.

Within a numerical solution process, the $U_{j}$ and $U_{j}^{i m}$ are generally decomposed according to equations (B4) and (B5) such that the mass action phenomena in the aqueous speciation or surface complexation reactions can be explicitly incorporated. In this sense, the abundance of surface complexation sites on the minerals can be specified and used to control the overall partitioning of species between the aqueous and solid phases.

Precipitation and dissolution rates are generally described in terms of an expression of the form

$$
r_{m}=A_{s m} k_{m}(T) \cdot f_{m}\left(a_{i}\right) \cdot g_{m}\left(\Delta G_{r}\right)
$$

where $A_{s m}$ is the specific surface area of mineral $m$ in the medium $\left(\mathrm{m}^{2} / \mathrm{m}^{3}\right.$-medium), $k_{m}$ is a temperature-dependent rate coefficient associated with mineral $m\left(\mathrm{~mol} / \mathrm{m}^{2}\right.$ mineral/s), and $f_{m}$ and $g_{m}$ are, respectively, dimensionless factors that are dependent on the activities $\left(a_{i}\right)$ of up to $N$ catalytic or inhibitive aqueous species and the free energy $\left(\Delta G_{r}\right)$ of the dissolution or precipitation reaction.

Aagaard and Helgeson (1982) have formalized this rate law as

$$
r_{m}=S_{m} \cdot A_{s m} k_{m}(T) \cdot\left(\prod_{i=1}^{N} a_{i}^{p_{i}}\right) \cdot\left(\frac{Q_{m}}{K_{m}}\right)^{q}-\left.1\right|^{n}
$$

\footnotetext{
${ }^{4}$ Radionuclide decay rates $(\lambda)$ and half lives $\left(t_{1 / 2}\right)$ are related by $t_{1 / 2}=\ln 2 / \lambda$.
} 
where the $p_{i}$ are determined empirically, $Q_{m}$ and $K_{m}$ and are the activity product and equilibrium constant for the dissolution or precipitation reaction, respectively, $S_{m}$ is equal to the sign of $\log \left(Q_{m} / K_{m}\right)$, and $q$ and $n$ are additional (positive) experimental parameters. Application of this rate law to melt glass dissolution and other precipitation reactions is discussed in greater detail in Chapter 6. In general, both $q$ and $n$ have been set to 1.0 in the problems considered in this study. The effect of inhibiting or catalyzing species, as manifested in the product term, has only been considered and included in the puddle glass dissolution rate, specifically in terms of a direct dependence on $\mathrm{pH}$ (or $\left.a_{H^{+}}\right)$.

The radionuclide transport simulations in this study were approached from two different perspectives, both of which rely on the same flow results obtained from the NUFT simulations and one or more alternative versions of equation (B6) described below. In one approach (Appendix C), we implemented a streamline transport model using the GIMRT reactive transport code (Steefel and Yabusaki, 1996). The current technique is similar to that outlined in Tompson et al. (1999), yet tailored specifically for transient flow fields. The utility of this approach becomes increasingly limited when the transient nature of the flow dynamics is most significant, such as in the first $100 \mathrm{yr}$ of the typical CHESHIRE flow simulations. In a second approach (Appendix D), we applied a Lagrangian particle model, updated from that outlined by Tompson (1993) and Tompson et al. (1996). Although this approach was limited to a simpler set of geochemical processes, its validity was benchmarked against several representative GIMRT simulations, and it offers greater flexibility for exploring sensitivities to heterogeneity and other important, yet uncertain, variables of the problem.

\section{B.5 Alternative Forms of the Mass Transport Equations}

Several alternative or simplified forms of the mass transport equations will be of interest in this study in order to approach the simulation of reactive transport processes from two different computational perspectives.

\section{B.5.1 Dilute Concentrations}

If the abundance of radionuclides in solution is sufficiently small, as expected in the current application, then the fluid density will be unaffected by their concentrations and $M_{\mathrm{H}_{2} \mathrm{O}} \approx 1$. If the fluid density is also equal to $1 \mathrm{~kg} / \mathrm{L}$, or approximately $\mathrm{so}^{5}$, then the value of $U_{j}$ will be close or equal in magnitude to the molar concentration $u_{j}=\rho M_{H_{2}} O U_{j}$ (moles-j per liter solution) ${ }^{6}$, and (B6) may be written as

\footnotetext{
${ }^{5}$ Here, we acknowledge the influence of temperature will only make this approximate.

${ }^{6}$ Similarly, $U_{j}^{i m}$ will be close to the molar concentration of immobile species, $u_{j}^{\text {im }}$ (moles- $j$ per liter solution).
} 


$$
\frac{\partial}{\partial t}\left(\phi\left(u_{j}+u_{j}^{i m}\right)\right)+\nabla \bullet\left(\phi \mathbf{v} u_{j}\right)-\nabla \bullet\left(\phi \mathbf{D} \bullet \nabla u_{j}\right)=R_{j}^{\min }-\lambda_{j} \phi\left(u_{j}+u_{j}^{i m}\right)+\lambda_{k} \phi\left(u_{k}+u_{k}^{i m}\right)-s_{f m}
$$

With no loss of generality, (B11) may also be rewritten as

$$
\frac{\partial u_{j}^{T}}{\partial t}+\nabla \bullet\left(\frac{\mathbf{v} u_{j}^{T}}{R_{j}}\right)-\nabla \bullet\left(\phi \mathbf{D} \bullet \nabla \frac{u_{j}^{T}}{\phi R_{j}}\right)=R_{j}^{\min }-\lambda_{j} u_{j}^{T}+\lambda_{k} u_{k}^{T}-s_{f m},
$$

where $u_{j}^{T}=\phi\left(u_{j}+u_{j}^{i m}\right)$ represents the total (bulk) concentration (moles-j per liter bulk volume) of radionuclide $j$. This quantity represents the total number of moles of radionuclide $j$, aqueous or sorbed, within a liter of bulk volume of the medium. It should be distinguished from the sum $u_{j}+u_{j}^{i m}$, which denotes the total number of moles, aqueous or sorbed, per liter of solution or pore volume. In (B12), the quantity $R_{j}=1+u_{j}^{i m} / u_{j}=u_{j}^{T} / \phi u_{j}$ represents the instantaneous state of partitioning between the aqueous and immobile fractions of species $j$ at a point in space and time.

In general, $R_{j}$ may be a complicated function of $u_{j}$, the mineralogic characteristics of the porous medium, and the concentrations of aqueous species different from $j$ including other radionuclides, natural aqueous minerals, or the $\mathrm{pH}$ (Tompson, 1993; Tompson et al., 1996, Tompson and Jackson, 1996). However, under sufficiently dilute conditions, $R_{j}$ may become independent of one or all of the species concentrations or the $\mathrm{pH}$, such that, in the most convenient case, it reduces to a simple medium property. In this case, $R_{j}$ is often referred to as a retardation coefficient, and the partitioning among the mobile and immobile fractions of species $j$ can be described by a single medium-dependent constant.

The use of retardation coefficients to describe partitioning behavior in this way is an approximate, continuum scale concept that should ideally be based on or confirmed with fundamental, process-based descriptions of water rock interactions that occur at the pore or mineral surface scale. It is an approximation that may be viable in some scenarios and a totally inadequate one in others. As discussed in Appendices C and D, the GIMRT model employed in the streamline simulation approach addresses sorption behavior from a true, process-based perspective, while the alternative particlebased model uses a simplified retardation factor approach. Our particle model is, therefore, routinely tested through comparisons with the GIMRT model.

When the retardation factor approach is valid and mineralogic conditions are constant in space, the retardation effect will be constant in space such that the migration rate of the aqueous species is uniformly reduced by a factor $R_{j}$ relative to the groundwater velocity. If the mineralogic conditions are variable in space, then the retardation effect will be spatially variable and may lead to an enhanced dispersion 
effect (Gelhar, 1993), owing to the fact that the migration rates of different radionuclide parcels may be more widely distributed as a result.

\section{B.5.2 One-Dimensional, Approximately Steady Flows}

Consider, further, a one-dimensional problem where the flow is aligned with the x-axis such that $V=|\mathbf{v}|$, and $D_{L}$ is the longitudinal component of $\mathbf{D}$. Suppose, in addition, that the flow is approximately incompressible ( $\rho \sim$ constant), matrix diffusion is ignored ( $s_{f m}=0$ ), and that $\phi$ is unchanging over time such that $\phi V \sim$ constant (from B4). Under these conditions, the streamline model discussed in Appendix C assumes a one-dimensional version of (B11),

$$
\begin{aligned}
\phi \frac{\partial}{\partial t}\left(u_{j}+u_{j}^{i m}\right)+ & \phi V \frac{\partial u_{j}}{\partial x}-\frac{\partial}{\partial x}\left(\phi D_{L} \frac{\partial u_{j}}{\partial x}\right)= \\
& R_{j}^{\min }-\lambda_{j} \phi\left(u_{j}+u_{j}^{i m}\right)+\lambda_{k} \phi\left(u_{k}+u_{k}^{i m}\right)
\end{aligned}
$$

\section{B.6 Numerical Solution of the Mass Transport Equations}

Two alternative modeling approaches will be used for the CHESHIRE mass transport simulations. The first approach involves a modification of the streamline approach employed in the previous transport simulations at CAMBRIC (Tompson et al., 1999). As discussed in Appendix C, an incremental streamline approach must be considered in order to address the transient nature of the flow field. This approach involves a number of additional approximations that may limit its overall applicability in the early portions of the simulation. Because of this, and because a truly threedimensional, high resolution, nonisothermal reactive transport code based upon an equation such as (B4) remains unavailable, an alternative Lagrangian particle model will also be used. As discussed in Appendix D, the geochemical processes addressed in this approach must be simplified to some extent, although its ultimate flexibility and computational efficiency will nevertheless allow for numerous types of sensitivity and calibration studies to be performed. 


\section{APPENDIX C: Streamline Transport Model}




\section{C.1 Introduction}

Consider the transport of a dilute, conservative chemical species in a steady three-dimensional ground water flow field in the absence of dispersion, diffusion, or reaction processes. If we assume that the fluid density is approximately constant, then the concentration $c(\mathbf{x}, t)$ will satisfy

$$
\frac{\partial c}{\partial t}+\mathbf{v} \cdot \nabla c=0
$$

In a steady, incompressible flow field, the locus of points traced out by a particle passing through a point $\mathbf{x}$ defines a streamline whose length is described by the coordinate $s$. To each steady flow field, there exists a continuum of streamlines. This suggests that a generically three-dimensional transport problem of the form (C1) might be reduced, in a discrete sense, to a series of one-dimensional problems of the form

$$
\frac{\partial c}{\partial t}+V \frac{\partial c}{\partial s}=0
$$

along a finite number of streamlines extracted from the flow field. ${ }^{1}$ Clearly, the number of streamlines used will control how the problem is discretized and will ultimately affect the resolution and accuracy of the solution.

How will this work? At first, it is probably easier to conceptualize each streamline as the center of an associated streamtube that envelops a portion of the total flow moving through the domain. The boundaries of each streamtube are collinear with the flow so that fluid may only enter or leave through the ends of the streamtube. Each streamline or streamtube will occupy some volumetric fraction of the flow domain into which transport or other mass balance problems can be effectively parceled.

For example, the pore volume in a streamtube between an initial point located at $\zeta=0$ and an arbitrary intermediate point $s$ is

$$
\text { Volume }(s)=\int_{0}^{s} \phi(\zeta) A(\zeta) d \zeta
$$

where $\phi(\zeta)$ is the porosity and $A(\zeta)$ is the cross-sectional area of the streamtube at location $\zeta$. Although the cross-sectional area and velocity may fluctuate as a result of porosity variations or converging and diverging flows, the total flow remains fixed. For example,

\footnotetext{
${ }^{1}$ Note, also, that if the flow field is transient, then streamlines will migrate accordingly, and additional streakline and pathline concepts may be required in the solution of mass transport problems (Batycky, 1997). These will be discussed further later.
} 


$$
Q=\phi(s) V(s) A(s)
$$

where the streamline velocity is used to approximate a cross-sectional average velocity.

Importantly, the choice of $Q$ or $A(s)$ at some point on a streamline will ultimately define the size or volume of the associated streamtube. A larger flux or crosssectional area will correspond to a larger streamtube and a coarser representation of the flow behavior; a smaller flux or area will correspond to a finer representation. Thus, better resolution translates into a higher density of streamlines with smaller crosssectional areas.

It is not important to explicitly map out the geometrical boundaries of streamtubes. In fact, this very difficult and frustrating task is largely unnecessary. This will be made clearer in the following sections.

\section{C.2 Mapping Streamlines}

In traditional finite difference models of steady groundwater flow, streamlines may be easily mapped from initial points lying along an inflow boundary towards final points lying on an exit boundary (Pollock, 1988). Streamlines may also be mapped between injection and production wells (Thiele et al., 1996) or arbitrary internal surfaces or points. This procedure allows streamline coordinates, velocities, and travel times to be readily identified at arbitrary space or time intervals. Streamtube fluxes and cross-sectional areas may then be defined and assigned accordingly.

For example, consider a typical finite difference model of groundwater flow through a prismatic block domain of dimensions $L_{x}, L_{y}$, and in which the flow is constrained to enter and exit the negative and positive $x$-coordinate faces of the domain, respectively, with the other boundaries being impermeable. Consider, further, a particular finite difference block of dimensions $\Delta x, \Delta y$, and $\Delta z$ lying at the upstream boundary of the domain. Suppose the normal darcy flux crossing the upstream face of

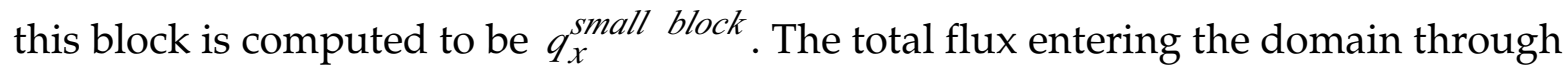
this block can then be approximated by $Q^{\text {smallblock }} \approx q_{x}^{\text {small block }} \cdot \Delta y \Delta z$.

Suppose further that a single streamline $i$ is launched from the center of the block inflow face and mapped downstream to the exit face of the domain. All other things being equal, we could assign the total flux entering the block to a streamtube about this streamline such that $Q_{i} \approx Q^{\text {small block }}$ and $A_{i}(0) \approx \Delta y \Delta z$. Thus, at any point $s$ along this streamline where the streamline velocity $V_{i}(s)$ can be estimated from the flow solution, the equivalent streamtube cross-sectional area could be inferred from (C4) as $Q_{i} / \phi_{i}(s) V_{i}(s)$.

Alternatively, suppose four streamlines $j=1,2,3,4$ are launched from equally or randomly parceled locations on the same block inflow face. In this case, the resolution is finer and each streamline can be associated with smaller diameter streamtubes with smaller fluxes. Because the entry flux cannot be resolved any finer 
than the scale of the finite difference block itself, the total flux $Q^{\text {small block }}$ might, as an approximation, be parceled out equally among the four streamtubes that correspond to

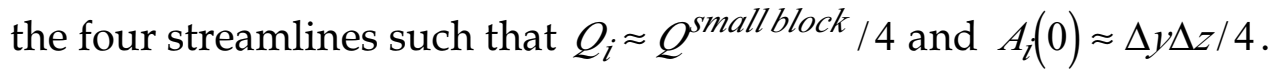

Thus, streamlines and their associated streamtubes can be launched from all (or some) of the entrance face blocks in a similar fashion to effectively parcel all (or a specified fraction) of the flow in the domain to the requisite streamtubes. Accordingly, the streamline density at the inflow face can be adjusted to control the resolution of this process. Alternatively, streamlines could also be launched from specific internal cross sections or subvolumes that intersect the chemical distribution in the flow field. An application of this type of approach in the context of the CHESHIRE problem will be discussed later.

Although streamtube boundaries cannot be explicitly recorded in this process, the variation of the streamtube cross-sectional area can be estimated as a function of the streamline coordinate. To complete the transport simulations within each streamtube, a discrete form of the one-dimensional transport equation (C2), expressed in terms of cross-sectional area and cross-sectionally averaged concentrations, must be obtained to account for fluctuations in the volume or area that accompany converging or diverging flows. Although this could readily be accomplished, we will now review a simpler, alternative formulation that eliminates the need for explicitly including area in the equation altogether.

\section{C.3 Formulating Times of Flight}

Consider the motion of an infinitesimal fluid or tracer parcel along a streamline extracted from a steady, three-dimensional flow field. The time of flight

$$
\tau=\int_{0}^{s} \frac{1}{V(\zeta)} d \zeta
$$

represents the parcel's travel time from an initial point located at $s=0$ to an arbitrary intermediate point located at $s$. Equation (C5) can be used to show

$$
\frac{\partial \tau}{\partial s}=\frac{1}{V}
$$

such that (C2) may be transformed into an equivalent time-of-flight form (Thiele et al. 1996; Batycky, 1997):

$$
\frac{\partial c}{\partial t}+\frac{\partial c}{\partial \tau}=0
$$

Because of its dependence on the time of flight, $\tau$, this equation automatically incorporates the volumetric information contained in a surrounding streamtube 
without explicit reference to cross-sectional area. This can be seen by associating a total flux $Q$ to a streamtube surrounding the streamline, using the methods discussed above, and then re-expressing the streamtube volume in (C3) as

$$
\operatorname{Volume}(s)=\int_{0}^{s} \phi(\zeta) A(\zeta) d \zeta=\int_{0}^{s} \frac{Q}{V(\zeta)} d \zeta=Q \tau(s)
$$

Thus, variations in time-of-flight will account directly for variations in streamtube volume.

Under this formulation, streamline transport simulations should be based upon (C7) instead of (C2). This approach is advantageous because streamline coordinate and travel time information is easily mapped from three-dimensional flow simulations, and such information provides a natural way to implement the transformation in (C6). The complicated area and volumetric information embodied in (C3) do not have to be calculated.

\section{C.4 Relating Streamline and Grid-Block Quantities}

Transferring streamline concentration information to an orthogonal background grid (consistent with the flow model, for example) may be required at specific times to graphically illustrate the spatial distribution of $c$ or to facilitate the solution of more complicated problems in unsteady flow fields. Conversely, grid information may have to be transferred back to the streamlines for similar purposes or to develop initial conditions for the streamline simulations.

This can generally be accomplished in a consistent manner using the approach of Batycky (1997, specifically Section 4.3). In brief, a grid block concentration $c_{g b}$ at some time $t$ may be calculated from a weighted sum of the average concentrations $c^{s l}$ along all streamlines that pass through that grid block. That is, for a series of streamlines $l$ passing through the block,

$$
c_{g b}=\sum_{l} \omega_{l} c_{l}^{s l}
$$

where the weighting factor is made proportional to the incremental time of flight and total flux via

$$
\omega_{l}=\frac{Q_{l} \Delta \tau_{l}}{\sum_{l} Q l \Delta \tau l}
$$

Referring to (C8), this ratio can also be interpreted as a streamtube volume fraction. 


\section{C.5 Adding Dispersion, Diffusion, and Reaction Processes}

The streamline approach can additionally treat longitudinal dispersion and diffusion behavior along a streamline, as well as many types of reaction processes. Unfortunately, cross-streamline mass transfer (as produced by transverse dispersion or diffusion processes) is not as easily incorporated into the method. Although this is a significant limitation, it is not expected to be pronounced in highly resolved problems where advection processes are dominant (Thiele et al., 1996). Most of our applications are expected to fall into this category.

Under conditions of constant fluid density and steady porosity, an equivalent version of (C2) that includes these processes and is pertinent to this work is described by equation (B13) of Appendix B,

$$
\phi \frac{\partial}{\partial t}\left(u_{j}+u_{j}^{i m}\right)+\phi V \frac{\partial u_{j}}{\partial s}-\phi V \frac{\partial}{\partial s}\left(\frac{D_{L}}{V} \frac{\partial u_{j}}{\partial s}\right)=R_{j}^{\min }-\lambda_{j} \phi\left(u_{j}+u_{j}^{i m}\right)+\lambda_{k} \phi\left(u_{k}+u_{k}^{i m}\right)
$$

where the streamline coordinate $s$ has been substituted for $x$, and an appropriate representation of the gradient operators in a curvilinear coordinate system has been used. Recall that the $u_{j}$ represent total (molar) concentrations of the principal mobile species, the $u_{j}^{i m}$ are the corresponding (molar) concentrations of the immobile species, and the $R_{j}^{\mathrm{min}}$ correspond to the rates of various precipitation and dissolution reactions.

An equivalent time-of-flight version of (C11) will be used to perform streamline reactive transport simulations in this report. Using (C6), this equation can be written as

$\phi \frac{\partial}{\partial t}\left(u_{j}+u_{j}^{i m}\right)+\phi \frac{\partial u_{j}}{\partial \tau}-\phi \frac{\partial}{\partial \tau}\left[\left(\frac{\alpha_{L}}{V}+\frac{D_{e}}{V^{2}}\right) \frac{\partial u_{j}}{\partial \tau}\right]=R_{j}^{\min }-\lambda_{j} \phi\left(u_{j}+u_{j}^{i m}\right)+\lambda_{k} \phi\left(u_{k}+u_{k}^{i m}\right)$

where the longitudinal component of the dispersion tensor, $D_{L} \sim \alpha_{L} V+D_{e}$, has been substituted from (B7) in Appendix B.

\section{C.6 Accounting for Radioactive Decay Processes}

The effects of radioactive decay may be accounted for in the streamline simulations in two ways. In the first, a simple postprocessing step may be employed to modify a calculated, yet undecayed concentration via

$$
u_{j}^{d}(\tau, t)=u_{j}(\tau, t) \cdot e^{-\lambda_{j} t}
$$


As written, this only accounts for the loss of the radionuclide and may be applied to results obtained at a breakthrough point (as a function of time) or to spatial or time-offlight profiles (as a function of $\tau$ ). This method will only yield valid results if specific details of daughter product accumulation are of no interest in the problem and if the loss of the radionuclide over the course of a simulation does not affect its mobility in the system. The previous CAMBRIC streamline simulations used this approach.

Alternatively, decay of a radionuclide may be incorporated in a real-time sense, as is the case with the current version of the GIMRT code. Here, decay is simply considered as an additional source or sink mechanism, as described by appropriate kinetic (decay) parameters. As implemented in GIMRT, both decay and ingrowth processes associated with a specified decay chains can now be addressed.

\section{C.7 Addressing Matrix Diffusion Processes}

The effects of matrix diffusion may be addressed in the streamline model in two principal ways. The first and most preferable option involves reinserting the exchange term $s_{f m}$ into the mass transport equation (e.g., equation (B13), (C11), or (C12)) and coupling this equation to an additional mass transport equation that addresses diffusion within the matrix continuum. Both equations would be subsequently solved explicitly in a real-time fashion. This is akin to adding a second spatial dimension to each streamline problem, analogous to the approach of $\mathrm{Wu}$ and Pruess (1988). Although feasible, running each streamline as a two-dimensional problem would likely lead to excessive computational times, especially when the complete ensemble of streamlines is considered.

As an alternative, the results of Cvetkovic et al. (1999) could be used to postprocess breakthrough profiles from simulations that have otherwise neglected matrix diffusion, much in the same way that the effects of simple radioactive decay may be postprocessed. Because of various assumptions and simplifications required in this approach (outlined below), it is a much less satisfying way to approach the problem, albeit more computationally efficient.

Consider a breakthrough profile $u_{j}(\tau, t)$ observed at an exit point on a streamline, where the point $\tau=0$ corresponds to the furthest extent (in $\tau$ ) of the radionuclide distribution at the initial time $t=0$. The corresponding modified breakthrough profile that would be produced if matrix diffusion were present is given by a convolution operation,

$$
u_{j}^{m d}(\tau, t)=\int_{0}^{\infty} \gamma\left(\tau, t-t^{\prime}\right) \cdot u_{j}\left(\tau, t^{\prime}+\tau\right) d t^{\prime},
$$

where 


$$
\gamma(\tau, t)=H(t-\tau) \frac{\kappa \tau}{2 \sqrt{\pi}\left(t-\tau R_{j, f}\right)^{3 / 2}} \exp \left(-\frac{\kappa^{2} \tau^{2}}{4\left(t-\tau R_{j, f}\right)}\right)
$$

$H(t-\tau)$ is the Heaviside step function, and $R_{j, f}$ and $R_{j, m}$ are approximate retardation factors in the fracture and matrix, respectively. The kernel function is given by

$$
\kappa=\frac{\phi_{m} \sqrt{D_{e, m} R_{j, m}}}{b}
$$

where $2 b$ is the typical fracture aperture and $D_{e, m}$ is an effective diffusivity in the matrix. This approach was used by Hassan et al. (1999) and is based upon additional simplifications that assume

- Spatially uniform fracture aperture (2b) and matrix block (2S) size distributions.

- Spatially uniform reactivity in the fracture and matrix regimes as expressed through the approximate retardation factors, $R_{j, f}$ and $R_{j, m}$.

- An infinitely large matrix block size $(S \rightarrow \infty)$ that prevents the matrix from becoming fully permeated by radionuclides.

- Steady state flow (to which corresponds a single set of fixed streamlines).

- No initial radionuclides in the matrix along the streamline path.

Figure C.1 shows results of a simple test of this algorithm. A one-dimensional problem involving flow and conservative tracer $\left(R_{j, f}=R_{j,}=1\right)$ migration through a $200 \mathrm{~m}$ fractured column was developed. Here, the seepage velocity $V$ was set to $100 \mathrm{~m} / \mathrm{yr}$ and a $10^{-10} \mathrm{~mol} / \mathrm{L}$ solution of tritium $\left(R_{\text {tritium }, m} \sim 1\right.$ ) was injected at the upstream boundary of the fractured regime for a period of $100 \mathrm{yr}$. The fracture properties are $b \sim 0.005 \mathrm{~m}$, $S \sim 0.495 \mathrm{~m}, \phi_{\mathrm{m}} \sim 0.15$, and $D_{e, m} \sim 3.15 \times 10^{-3} \mathrm{~m}^{2} / \mathrm{yr}\left(10^{-6} \mathrm{~cm}^{2} / \mathrm{s}\right)$.

Results in Figure C.1 show the one-dimensional GIMRT breakthrough profile in the absence of matrix diffusion (a square wave), the postprocessed version of this solution accounting for matrix diffusion from the convolution result (C14), and a twodimensional discrete simulation of the same problem using the GIMRT model. Although the postprocessed result agrees well with other analytical results for similarly posed problems (e.g., Sudicky and Frind, 1982), it differs from the discrete result, largely because the effects of a finite block size $S$ could not be taken into account in (C14). 


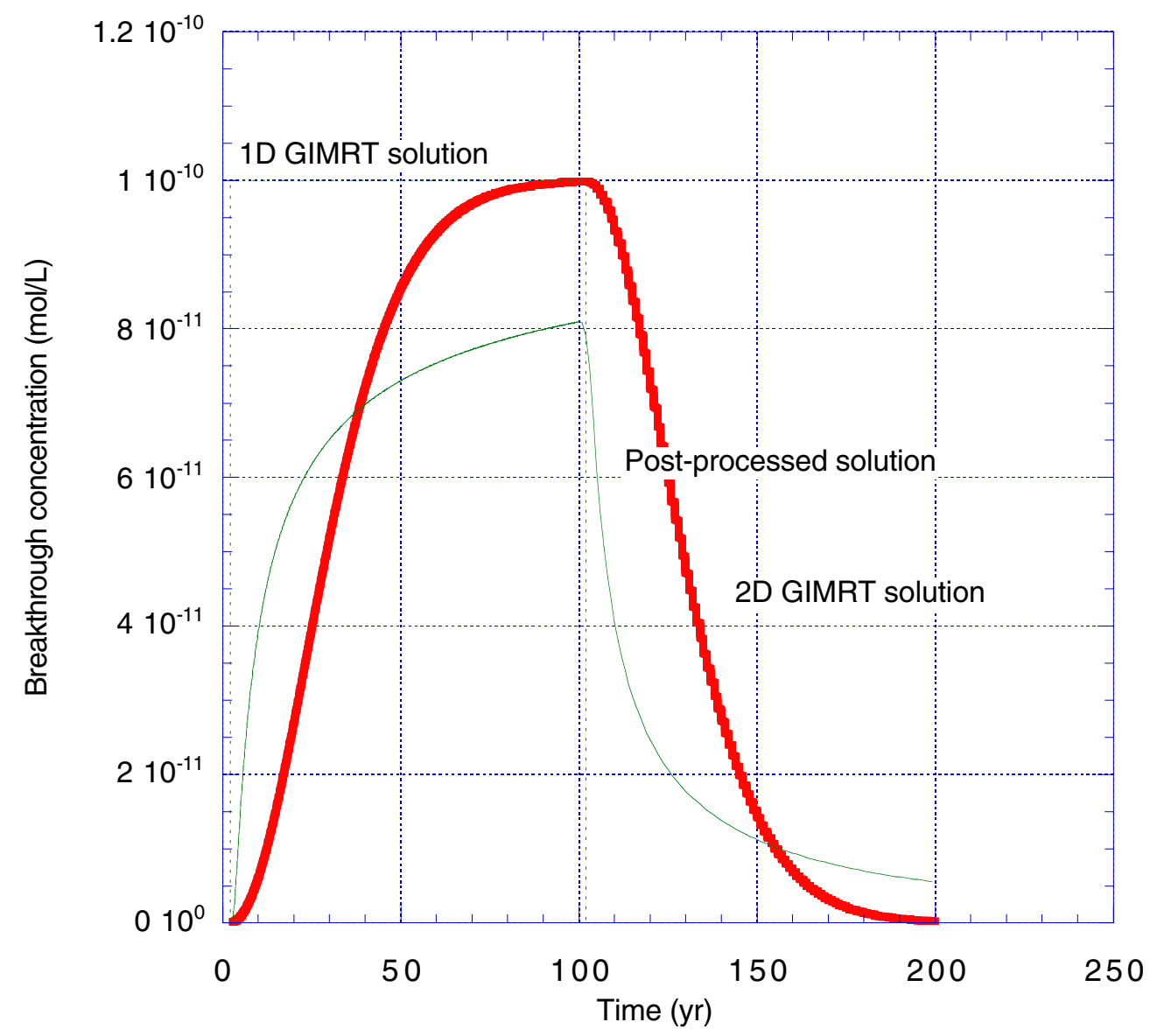

Figure C.1 Tritium breakthrough profile (square wave) from Gimrt in the absence of matrix diffusion in a 1-D test problem and the modified, postprocessed solution accounting for the effects of matrix diffusion (thin line), as obtained with the convolution result (C14). The 2-D (thick line) solution was obtained from a discrete simulation of the same problem using the Gimrt model.

\section{C.8 Treating Transport in Transient Flow Systems}

Although the streamline approach is not generally suited for solving transport problems in transient or unsteady flow fields, such as those that produced by geothermal and test-related heat in the CHESHIRE problem, it should be adaptable, as an approximation, to problems with slowly changing flow fields. One possible approach would be to produce a sequence of incremental streamline simulations that correspond to a sequence of flow field snapshots extracted from a transient flow field:

- Each flow field snapshot corresponds to a separate field of streamlines, chosen according to the above considerations and knowledge of the radionuclide distribution at the point in time corresponding to the snapshot. 
- Forward simulations along this set of streamlines proceed for a short period, corresponding to the snapshot interval, over which the flow field is considered approximately steady.

- Following this incremental transport step, the radionuclide distribution is distributed onto a background grid, saved, and used to initialize a new set of streamlines corresponding to the next flow field snapshot.

This idea is similar to a successful approach developed by Batycky (1997) for simulating density dependent miscible transport problems with streamlines.

An important limitation to the viability of this approach is the degree that the flow field shifts and changes over the time frame of interest, or, alternatively, the period over which significant changes occur. This degree is indicative of the extent that travel along a streamline differs from travel along a streakline over the same period. ${ }^{2}$

Consider, for example, the 1000-yr simulation time associated with the CHESHIRE study. Clearly, if the flow field is steady over the $1000 \mathrm{yr}$ period, then a single set of streamlines could be used to reliably address the transport problem, as demonstrated in previous applications (e.g., Tompson et al., 1999). However, now suppose the flow field corresponds to a typical dynamic result produced in the CHESHIRE study that corresponds to the dissipation of test-related heat. Here, judging from the number of NUFT time steps taken, the flow field is most rapidly changing in the earliest part of the simulation and more slowly changing in the latest part. While only five time steps may be taken in the latter $900 \mathrm{yr}$ of a typical simulation, as many as 50 may be taken in the first $100 \mathrm{yr}$. Thus, although the incremental streamline approach would seem to be less appropriate, or entirely inappropriate, in the early parts of this simulation, it may be more viable later, provided that a suitable distribution of radionuclide mass at the appropriate time could be determined.

Another limitation to the incremental streamline approach is that it can only address matrix diffusion by using "two-dimensional streamlines", as outlined above. Although this procedure would be computationally intensive, the simpler postprocessing technique, also outlined above, cannot be applied in a transient flow problem, regardless of its own intrinsic limitations.

\section{C.9 Implementing the Incremental Streamline Approach}

We will implement the incremental streamline approach as outlined earlier, but only between the $100 \mathrm{yr}$ point in the simulation to the $1000 \mathrm{yr}$ endpoint. The flow dynamics in the first $100 \mathrm{yr}$ of the simulation are just too strong for the streamline approach. The CHESHIRE simulations will be sequentially built using five flow fields

\footnotetext{
${ }^{2}$ In this sense, a streamline corresponds to the trajectory a fluid particle would take if released from a point in a frozen-time snapshot of a flow field, its path being everywhere tangential to the velocity field at that instant. A streakline corresponds to the locus of positions the particle would traverse over time as the flow field changes. In a truly steady flow field, the two curves are identical.
} 
derived from the NUFT flow model. These correspond to the five time intervals shown in Table C.1.

Importantly, each phase of streamline process will require a distinct initial radionuclide distribution. Instead of assuming that the zero-year initial condition is applicable, an approximate intermediate initial condition at the $100 \mathrm{yr}$ point will be generated using results from a particle transport model, as described in Appendix D. Important consideration must be given to updating the changing state of glass dissolution during each time interval of the simulation.

Notably, the post-processing approach to incorporate the effects of matrix diffusion through a modification of the breakthrough profile (see above) cannot be directly used here, because the requisite spatial information that describes the content of the matrix blocks along a streamline's length is never calculated and cannot be flashed to a grid to reinitialize the next set of streamlines.

Table C.1 Streamline characteristics for the CHESHIRE problem.

\begin{tabular}{|c|c|c|c|c|c|}
\hline $\begin{array}{l}\text { Time } \\
\text { interval }\end{array}$ & 100 to $135 \mathrm{yr}$ & 135 to $208 \mathrm{yr}$ & 208 to $361 \mathrm{yr}$ & 361 to $689 \mathrm{yr}$ & $\begin{array}{c}689 \text { to } 1000 \\
y r\end{array}$ \\
\hline $\begin{array}{l}\text { Number of } \\
\text { streamlines }\end{array}$ & 4,513 & 5,623 & 6,004 & 6,343 & 6,315 \\
\hline $\begin{array}{l}\text { Total number } \\
\text { of nodal } \\
\text { points in all } \\
\text { streamlines }\end{array}$ & 352,777 & 442,759 & 476,492 & 504,373 & 503,987 \\
\hline $\begin{array}{l}\text { Number of } \\
\text { source blocks }\end{array}$ & 21,585 & 37,427 & 40,923 & 42,427 & 39,837 \\
\hline $\begin{array}{l}\text { Total GIMRT } \\
\text { run time }{ }^{1} \\
\text { (days) }\end{array}$ & 30.2 & $256.2^{2}$ & 151.8 & 104.4 & 68.5 \\
\hline
\end{tabular}

\section{C.9.1 Using the Current Approach in the CHESHIRE Problem}

To initialize the streamline calculations, the distribution of each radionuclide provided by the particle model at the $100 \mathrm{yr}$ point is used as a basis for generating the first set of streamlines. The grid blocks occupied by radionuclides at this time are called source blocks. To represent-or translate-source block concentrations into the streamline model, at least one streamline is chosen to pass through each source block. The family of streamlines to be used in the first time interval is generated by sequentially looping through the list of source blocks and starting a streamline in the center of each block. Each streamline is mapped forward and backward in time until it is terminated at the domain boundaries or a specified exit plane. During this procedure, if a streamline passes through any other source block, this block is checked off the list of source blocks and skipped in the looping process. There is no need to start another streamline in any block that has been checked off. This procedure can be generalized, of course, to allow for any number of streamlines to pass through each source block. This 
would allow the resolution of the streamline model to be improved. In the CHESHIRE problem, however, the large size of the source region and finite computation resources precluded this type of increased resolution.

Following streamline selection, the streamline fluxes are determined and assigned, as outlined below. This allows the individual streamline calculations to begin in earnest. When all streamline simulations over a time interval are finished, the streamline concentrations are mapped back onto the grid, which defines a new sequence of source blocks for the next time interval. These blocks are used to generate the next sequence of streamlines that correspond to an updated flow field. Table C.1 shows the number of streamlines and source blocks chosen for each of the different time intervals.

\section{C.9.2 Determining Streamline Flux in the CHeshiRE Problem}

The best method we have found for determining the streamline flux, $Q_{l}$, is a least squares method. This approach strives to equate the fluid volume in each threedimensional source grid block $g b$,

$$
\mathbf{V}_{g b}=\phi_{g b} \Delta x \Delta y \Delta z,
$$

to the fluid volume associated with the streamlines passing through that grid block,

$$
\mathbf{V}_{g b}^{s l}=\sum_{l} Q_{l} \phi_{l} \Delta \tau_{l}
$$

where $l$ is the streamline index and the sum is over all streamline segments that pass through the specific block, $g b$. This leads to a large system of equations to solve one equation per source block. The system of equations minimizes the error,

$$
e=\sum_{g b}\left(\mathbf{V}_{g b}-\mathbf{V}_{g b}^{s l}\right)^{2}
$$

with respect to $Q_{l}$. This minimization must be constrained to give positive values of $Q_{l}$.

The streamline flux is used in two phases of our simulation. It is used in the interpolation of the streamline concentrations to the three-dimensional grid. The concentration of a chemical species $i$ in grid block $g b$ is collected from the streamlines passing through that block using equations (C9) and (C10). For example,

$$
c_{g b}^{i}=\frac{\sum_{l} c_{l}^{i, s l} Q_{l} \Delta \tau_{l}}{\sum_{l} Q_{l} \Delta \tau_{l}}
$$

where the sums loop over all streamline segments that intersect the block $g b$. At the beginning of the GIMRT run, the streamline concentrations are simply set to the three- 
dimensional grid concentrations. The flux is also used in the computation of the breakthrough for each of the chemical species. 


\section{APPENDIX D: \\ Particle Transport Model}




\section{D.1 Introduction}

Particle-based transport models have been widely applied to solve problems in fluid mechanics, plasma dynamics, astrophysics, and many other types of mass and energy transport applications. Recent investigations have shown that these techniques can be effectively and efficiently applied to solve equations describing conservative and reactive chemical transport in subsurface porous formations (Ahlstrom et al., 1977; Kinzelbach, 1988; Uffink, 1988, Tompson and Gelhar, 1990; Tompson and Dougherty, 1992; Tompson, 1993; Tompson, et al., 1996; Maxwell and Kastenberg, 1999; Abulaban and Nieber, 2000; Liu et al., 2000). They suffer little from negativity, numerical dispersion, or mass balance problems seen in many grid-oriented approaches at large grid-Peclet numbers. Particle-based models have been successfully applied to several underground radionuclide transport problems associated with nuclear testing (e.g., Hassan et al., 1999; Pohl et al., 1999; Glascoe et al., 2000).

The particle model employed in the CHESHIRE simulations is based upon a simplified version of the total mass balance equation (B12) in which the physical and geochemical processes are simplified to the extent that:

- Ion exchange and surface complexation reactions are described by simple retardation coefficients that can be considered functions or properties of the local mineralogy and ambient solution composition.

- Melt glass dissolution is represented by an approximate, temperaturedependent tabulated rate.

- Radionuclide precipitation and dissolution are not considered.

- Precipitation and dissolution of secondary minerals is ignored.

- The $\mathrm{pH}$ and groundwater composition are assumed constant.

- Matrix diffusion is accounted for in an approximate manner.

\section{D.2 CheshiRe Particle Model}

In the current particle approach, the spatial distribution of total radionuclide mass, as represented by the total concentration $u_{j}^{T}$, is approximated by a finite system of $N_{j}$ particles

$$
u_{j}^{T}(\mathbf{x}, t)=\phi\left(u_{j}+u_{j}^{i m}\right)=\phi R_{j} u_{j}=\sum_{p=1}^{N_{j}} m_{p} \delta\left(\mathbf{x}-\mathbf{X}_{p}(t)\right)
$$

where $\delta$ is a Dirac function and $R_{j}$ is the retardation factor associated with radionuclide $j$. The particles may carry, or be associated with, different radionuclide attributes such as 
mass $\left(m_{p}\right)$, position $\left(\mathbf{X}_{p}\right)$, type $(j)$, age $\left(t-t_{0}\right)$, or even its regime or phase of existence (e.g., fracture, matrix, melt glass).

Although the total concentration function is considered a spatially continuous function, its particle representation in (D1) is discontinuous and may be difficult to graphically portray. To aid in the visualization process, the masses and positions of particles associated with radionuclide $j$ may be used at any time to estimate $u_{j}^{T}$ at any point $\mathbf{x}$ via (D1) or a modified expression of the form

$$
u_{j}^{T}(\mathbf{x}, t)=\phi\left(u_{j}+u_{j}^{i m}\right)=\phi R_{j} u_{j}=\sum_{p=1}^{N_{j}} m_{p} \zeta\left(\mathbf{x}-\mathbf{X}_{p}(t)\right)
$$

In this representation, the function $\zeta$ is used to project the contributions of particles near $\mathbf{x}$ to the value of $u_{j}^{T}$ at $\mathbf{x}$ and provide a smoother solution (Bagtzoglou et al., 1992). For example, in the applications below, $\zeta\left(\mathbf{x}-\mathbf{X}_{p}\right)$ is defined to be $1 / \mathrm{V}_{\mathrm{b}}$ when $\mathbf{X}_{\mathrm{p}}$ lies within a grid block of volume $V_{b}$ surrounding the point $x$, and zero otherwise. Because the total concentration is the fundamental variable in this representation, the corresponding aqueous and sorbed fractions of $u_{j}^{T}$ at a point must be determined by decomposing a computed value of $u_{j}^{T}$ with known values of $\phi$ and $R_{j}$ at that point.

A simulation is initialized by mapping specified distributions of $u_{j}^{T}$ and other relevant attributes onto a field of particles in a manner consistent with (D1) or (D2). The number of particles used to represent a unit of total radionuclide mass is defined as the particle resolution, $N_{r}$, and may be controlled to improve the quality of the solution. The simulation proceeds over discrete time steps by changing the various particle attributes. This will involve, for example,

- Moving the particles according to a known background velocity field and other medium characteristics associated with dispersion and chemical retardation forces.

- Shifting the phase associated with each particle to reflect melt glass dissolution or movement into or out of the matrix.

- Changing the type of each particle to represent radioactive decay from one radionuclide $(j)$ into another $(k)$.

As posed here, the particle model is inherently mass conservative in the sense that

- The total mass between the aqueous and sorbed states is conserved.

- The total mass within a decay chain is conserved. 
- The total mass moving between the fracture and matrix or emanating from the melt glass is conserved.

These features comprise the most attractive attributes of the particle model.

\section{D.3 Advection, Dispersion, and Retardation Processes}

The movement of particles is based upon an explicit random walk algorithm (Kinzelbach, 1988; Uffink, 1988, Tompson and Gelhar, 1990; Tompson, 1993; Maxwell and Kastenberg, 1999; Abulaban and Nieber, 2000),

$$
\mathbf{X}_{p}(t+\Delta t)=\mathbf{X}_{p}(t)+\left(\frac{\mathbf{v}}{R_{j}}+\frac{\nabla \bullet \mathbf{D}}{R_{j}}+\frac{\mathbf{D} \bullet \nabla(\ln \phi)}{R_{j}}\right) \Delta t+\mathbf{B}_{j} \bullet \mathbf{Z} \sqrt{\Delta t}
$$

In this expression, the second term on the right accounts for particle displacement along flow streamlines and includes two factors to correct for nonuniform distributions of $\phi$ or $\mathbf{D}$. The porosity correction is usually a small quantity and is typically neglected. The third (random walk) term on the right accounts for the dispersive flux, where $\mathbf{B} \cdot \mathbf{B}^{\mathrm{T}}=2 \mathbf{D} / R_{j}$ and $\mathbf{Z}$ is a random vector whose independent components have zero mean and unit variance. Ultimately, the particle mass density evolved through repeated use of (D3) on all particles will satisfy a conservative (e.g., zero right-hand side) form of the simplified mass balance equation (B12) in the limit as $N_{p}$ or $N_{r} \rightarrow \infty$ (Tompson and Gelhar, 1990).

The time step, $\Delta \mathrm{t}$, used in this algorithm is chosen uniquely for each individual particle as a function of accuracy limits imposed by the velocity field, in conjunction with other limits associated with the dispersion, matrix diffusion, and radioactive decay steps discussed both here and later. ${ }^{1}$ Typically, provisional values are chosen with respect to the constraints associated with each process, with the lowest value ultimately being selected for use. For example, the provisional time step associated with the displacement equation (D3) is selected for each particle to advance it via advection along an interpolated streamline within each grid block, at most from one edge to the next (Pollock, 1988; Schafer-Perini and Wilson, 1991), but potentially over shorter distances if a change in the velocity field or constraints from other mechanisms dictate. The value will be modified to account for retardation if $R_{j}>1$.

The advective substep is followed by other substeps that address the correction and random portions of the displacement shown in equation (D3). Provisional time steps are chosen independently for these steps as well, each limited by the magnitude of the velocity gradient or the largest dispersion coefficient.

Because different time steps are used for different particles, periodic rendezvous times, $T$, may be identified to collect the position and state of all particles

\footnotetext{
${ }^{1}$ This differs from the use of a uniform time step that may be used to advance the position of all particles simultaneously (e.g., as in Tompson and Gelhar, 1990).
} 
for visualization and other interrogation purposes (Tompson et al., 1988; Maxwell, 1998; Maxwell and Kastenberg, 1999).

As defined in Appendix B, the retardation factor $R_{j}$ represents the instantaneous state of partitioning between the aqueous and immobile fractions of species $j$ at a point in space and time. In the current particle application, the magnitude of $R_{j}$ for each sorbing radionuclide ${ }^{2}(j)$ was evaluated as a function of the ambient CHESHIRE groundwater composition, which was assumed to be fixed throughout the domain, and the local mineralogy, which was assumed to be spatially variable (Appendix $\mathrm{H}$ ). For evaluation purposes the definition of $R_{j}$ (Equation D1) was decomposed into the following form

$$
R_{j}(\mathbf{x}, t)=1+\frac{u_{j}^{i m}}{u_{j}}=1+\sum_{i} \hat{R}_{j}^{i}(\mathbf{x}, t)
$$

where the sum represents the individual (and independent) contributions of different sorbing minerals (i) to the overall immobile mole fraction of radionuclide $j$ at location $\mathbf{x}$ and time $\mathrm{t}$.

In Appendix K, the magnitude of the various retardation ratios $\hat{R}_{j}^{i}$ appearing in (D4) have been evaluated and tabulated as a function of radionuclide (j), mineral (i), and "gross" location (e.g., fractured regime, matrix regime, or cavity/chimney). In Appendix E, the efficacy of the simplified retardation approach built into equation (B12) and the particle model is compared with a similar GIMRT solution for a simple, onedimensional test problem.

\section{D.4 Radioactive Decay Processes}

The effects of radioactive decay can be accounted for in two ways. Simple decay of a radionuclide into a daughter product may be accounted for at any time in a postprocessing step by modifying the calculated, undecayed concentration via

$$
u_{j}^{T d}(\mathbf{x}, t)=u_{j}^{T}(\mathbf{x}, t) \cdot e^{-\lambda_{j} t},
$$

where $\lambda_{j}$ is the decay rate for species $j$. This method will only yield valid results if accumulations of the daughter product are of no interest in the problem and if the loss of the radionuclide over the course of a simulation does not affect its mobility in the system. This approach was used in the previous CAMBRIC simulations, and will be used for most—but not all—of the radionuclides in this study.

Alternatively, real-time decay of a radionuclide may be implemented within a particle simulation by incrementally removing its mass and transferring it to the inventory of its daughter product. This approach must be pursued if daughter product

\footnotetext{
${ }^{2}$ More specifically, for each class of sorbing radionuclide, as described in Table 4.5.
} 
ingrowth is important over the course of the simulation, or if the loss of the radionuclide affects its mobility or retardation in the system.

For example, in the CHESHIRE problem, this issue will be of concern for three radionuclides that are members of the ${ }^{241} \mathrm{Pu}$ decay chain, e.g.,

$$
{ }^{241} \mathrm{Pu} \stackrel{\lambda_{241 \mathrm{Pu}}}{\longrightarrow}{ }^{241} \mathrm{Am} \stackrel{\lambda_{241 \mathrm{Am}}}{\longrightarrow}{ }^{237} \mathrm{~Np} \stackrel{\lambda_{23 \mathrm{~Np}}}{\longrightarrow} \ldots
$$

This issue arises because ${ }^{241} \mathrm{Pu},{ }^{241} \mathrm{Am}$, and ${ }^{237} \mathrm{~Np}$ are included in the radiological source term (Appendix A) and because the half-lives ${ }^{3}$ of ${ }^{241} \mathrm{Pu}$ and ${ }^{241} \mathrm{Am}$ are small enough - relative to the $1000 \mathrm{yr}$ focus of the simulation-to render the ingrowth of ${ }^{241} \mathrm{Am}$ and ${ }^{237} \mathrm{~Np}$ significant. Because the half-life of ${ }^{237} \mathrm{~Np}$ is large, its daughter products will not accrue appreciably over the $1000 \mathrm{yr}$ focus study, and so its decay will only be considered as part of a postprocessing step.

Suppose we have $N^{241} \mathrm{Pu}$ moles of ${ }^{241} \mathrm{Pu}$ at some location $\mathbf{x}$ and time $t$. Over an increment of time $\Delta t$, a portion of this mass will decay and produce some amount of ${ }^{241} \mathrm{Am},{ }^{237} \mathrm{~Np}$, and other daughter products of ${ }^{237} \mathrm{~Np}$. If we assume the decay rate of ${ }^{237} \mathrm{~Np}$ is approximately zero, then the loss of ${ }^{241} \mathrm{Pu}$ over this time is

$$
\Delta N_{241 \mathrm{Pu}}=-N_{241 \mathrm{Pu}}(\mathbf{x}, t) \cdot\left(1-e^{-\lambda_{241 \mathrm{Pu}} \Delta t}\right)
$$

and leads to the production of the following amounts of ${ }^{241} \mathrm{Am}$ and ${ }^{237} \mathrm{~Np}$,

$$
\Delta N_{241 \mathrm{Am}}=N_{241 \mathrm{Pu}}(\mathbf{x}, t) \cdot \frac{\lambda_{24 \mathrm{Pu}}}{\lambda_{241 \mathrm{Am}}-\lambda_{241 \mathrm{Pu}}}\left(e^{-\lambda_{241 \mathrm{Pu}} \Delta t}-e^{-\lambda_{241 \mathrm{Am}} \Delta t}\right)
$$

and

$$
\Delta N_{237 \mathrm{~Np}}=N_{241 \mathrm{Pu}}(\mathbf{x}, t) \cdot\left(1-\frac{\lambda_{241 \mathrm{Am}}}{\lambda_{241 \mathrm{Am}}-\lambda_{241 \mathrm{Pu}}} e^{-\lambda_{24 \mathrm{Pu}} \Delta t}-\frac{\lambda_{241 \mathrm{Pu}}}{\lambda_{241 \mathrm{Am}}-\lambda_{241 \mathrm{Pu}}} e^{-\lambda_{241 \mathrm{Am}} \Delta t}\right) .
$$

This suggests that a transition probability can be identified for simulating radionuclide decay in the particle model. Over an increment of time $\Delta t$, the probabilities that a particle of ${ }^{241} \mathrm{Pu}$ will decay into a particle of ${ }^{241} \mathrm{Am}$ or ${ }^{237} \mathrm{~Np}$ are just

$$
P_{P u \rightarrow A m}=\frac{\Delta N_{241 \mathrm{Am}}}{N_{241 \mathrm{Pu}}(\mathbf{x}, t)}=\frac{\lambda_{24 \mathrm{Pu}}}{\lambda_{241 \mathrm{Am}}-\lambda_{241 \mathrm{Pu}}}\left(e^{-\lambda_{241 \mathrm{Pu}} \Delta t}-e^{-\lambda_{241 \mathrm{Am}} \Delta t}\right)
$$

and

${ }^{3}$ Radionuclide decay rates $(\lambda)$ and half-lives $\left(t_{1 / 2}\right)$ are related by $t_{1 / 2}=\ln 2 / \lambda$. 


$$
P_{P u \rightarrow N p}=\frac{\Delta N_{237 \mathrm{~Np}}}{N_{241 \mathrm{Pu}}(\mathbf{x}, t)}=1-\frac{\lambda_{241 \mathrm{Am}}}{\lambda_{241 \mathrm{Am}}-\lambda_{241 \mathrm{Pu}}} e^{-\lambda_{241 \mathrm{Pu}} \Delta t}-\frac{\lambda_{241 \mathrm{Pu}}}{\lambda_{241 \mathrm{Am}}-\lambda_{241 \mathrm{Pu}}} e^{-\lambda_{241 \mathrm{Am}} \Delta t} .
$$

Similarly, suppose we independently consider $\mathrm{N}_{241} \mathrm{Am}$ moles of ${ }^{241} \mathrm{Am}$ at the same location $\mathbf{x}$ and time $t$, different from any produced by ${ }^{241} \mathrm{Pu}$ decay. Over the same increment of time, a portion of this mass will also decay and produce some amount of ${ }^{237} \mathrm{~Np}$, and other daughter products of ${ }^{237} \mathrm{~Np}$, independent from amounts associated with ${ }^{241} \mathrm{Pu}$ decay. Since the decay rate of ${ }^{237} \mathrm{~Np}$ is approximately zero, then the loss of the initial ${ }^{241} \mathrm{Am}$ over this time will produce

$$
\Delta N_{237 \mathrm{~Np}}=N_{241 \mathrm{Am}}(\mathbf{x}, t) \cdot\left(1-e^{-\lambda_{241 \mathrm{Am}} \Delta t}\right)
$$

such that the probability of an ${ }^{241} \mathrm{Am}$ particle decaying to ${ }^{237} \mathrm{~Np}$ over $\Delta t$ is

$$
P_{A m \rightarrow N p}=\frac{\Delta N_{237 \mathrm{~Np}}}{N_{241 \mathrm{Am}}(\mathbf{x}, t)}=1-e^{-\lambda_{241 \mathrm{Am}} \Delta t}
$$

If the time step is sufficiently small, these probabilities can be approximated by

$$
\begin{gathered}
P_{P u \rightarrow A m} \sim \lambda_{241 \mathrm{Pu}} \Delta t \\
P_{P u \rightarrow N p} \sim \frac{\lambda_{241 \mathrm{Pu}} \lambda_{241 \mathrm{Am}} \Delta t^{2}}{2},
\end{gathered}
$$

or

$$
P_{A m \rightarrow N p} \sim \lambda_{241 \mathrm{Am}} \Delta t
$$

As an example, the transitional probability decay results of equations (D8) and (D10) were applied to 100,000 particles of ${ }^{241} \mathrm{Pu}$ located within an elemental volume of a static, nonflowing system. In a series of 1000 one-year time steps, particles of ${ }^{241} \mathrm{Pu}$ were randomly transferred to ${ }^{241} \mathrm{Am}$ or ${ }^{37} \mathrm{~Np}$ particles according to equation (D8). As particles of ${ }^{241} \mathrm{Am}$ accrued in this process, they were also randomly transferred to ${ }^{237} \mathrm{~Np}$ particles according to equation (D10). As shown in Figure D.1, the net result is consistent with the ingrowth predicted from the Bateman equations.

\section{D.5 Matrix Diffusion Processes}

The effects of matrix diffusion can be implemented into the particle model using a similar transitional probability approach, as suggested by the approximate model of Liu et al. (2000). This approach is based upon a simplified conceptual model of the fractured system in which typical parallel fractures are of a width $2 b$ and are separated from one another by a typical distance $2 S$. During each time step, particles in the fractured regime may be transferred into stationary particles in the matrix regime, 
and vice versa, as a probabilistic function of the time step, various geometrical factors associated with the idealized fracture system model, and several physicochemical properties of the matrix blocks. In our case, we assume that these exchange processes occur only because of diffusion into and out of the matrix blocks. Particles located in the matrix are not advected or diffused according to a model like (D3); rather, their position remains fixed until they are probabilistically returned to the fracture regime. ${ }^{4}$

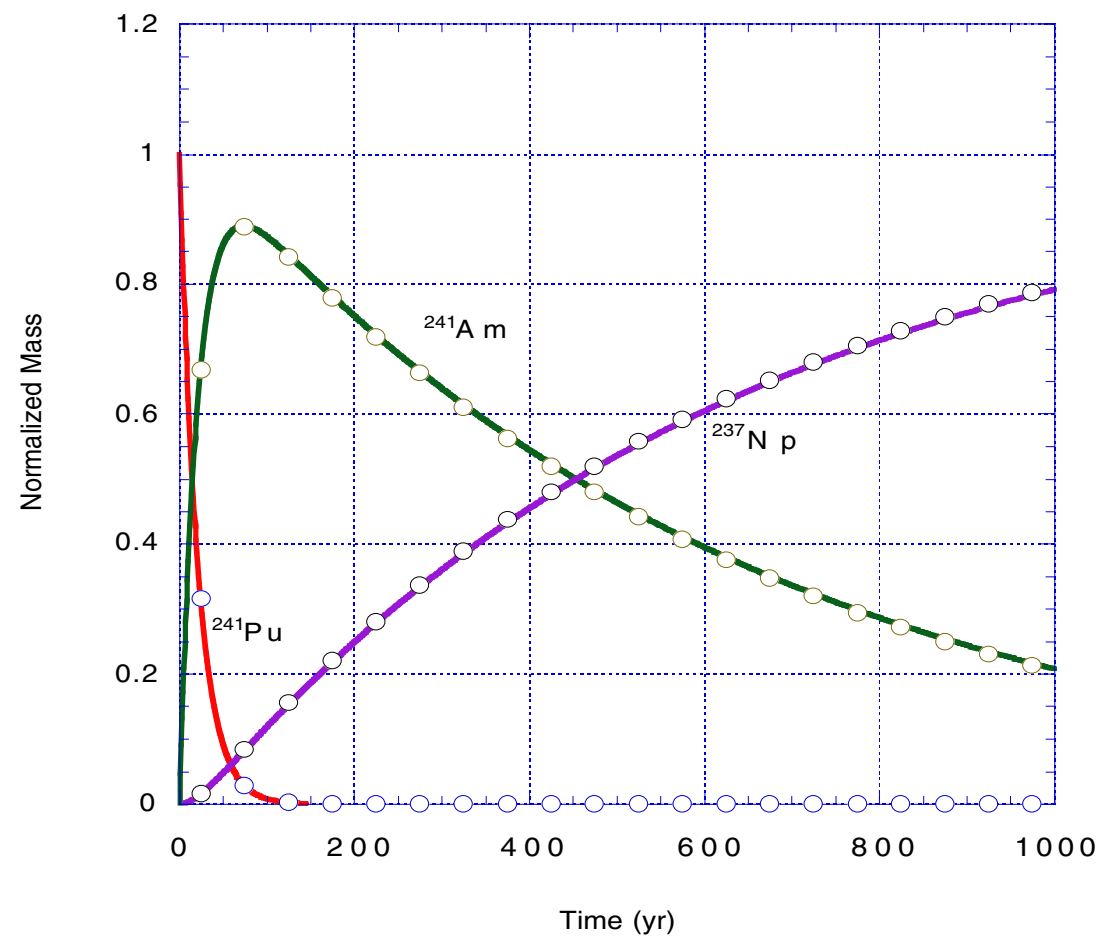

Figure D.1 Normalized ingrowth of ${ }^{241} \mathrm{Am}$ and ${ }^{37} \mathrm{~Np}$ from the decay of an initial unit mass of ${ }^{241} \mathrm{Pu}$ over $1000 \mathrm{yr}$. Solid curves represent the Bateman solution; symbols represent a computed particle solution based on 100,000 particles and use of the transitional probability model (D10) with $1 \mathrm{yr}$ steps.

For radionuclide $j$, the probability of moving from the fractures into the matrix is given by

$$
P_{j, f m} \sim \frac{3 D_{e, m}}{S b R_{j, m}} \Delta t
$$

where $D_{e, m}$ and $R_{j, m}$ are, respectively, the effective molecular diffusivity and retardation coefficient for radionuclide $j$ in the matrix. Conversely, the probability of moving from the matrix into the fractures is given by

$$
P_{j, m f} \sim \frac{3 D_{e, m}}{S^{2} R_{j, m}^{2} \phi_{m}} \Delta t
$$

\footnotetext{
${ }^{4}$ Nevertheless, the exchange probabilities do account for the diffusive processes that occur in the matrix, as they are functions of the block size, $S$.
} 
where $\phi_{\mathrm{m}}$ is the matrix porosity. Our experimental tests indicate that the provisional time step associated with these transitional terms should be chosen such that $P_{j, f m}$ and $P_{j, m f}$ are less than 0.02 .

Figure D.2 shows results of a simple test of this algorithm based upon the same one-dimensional test problem described in Section C.7. Here conservative tracer migration was induced in a $200 \mathrm{~m}$ fractured column with a seepage velocity $V$ of $100 \mathrm{~m} / \mathrm{yr}$. A $10^{-10} \mathrm{~mol} / \mathrm{L}$ solution of tritium $\left(R_{\text {tritium, } m} \sim 1\right)$ was injected at the upstream boundary of the fractured regime for a period of $100 \mathrm{yr}$. The injected pulse employed 25,000 particles. The fracture properties are $b \sim 0.005 \mathrm{~m}, S \sim 0.495 \mathrm{~m}, \phi_{\mathrm{m}} \sim 0.15$, and $D_{e, m} \sim 3.15 \times 10^{-3} \mathrm{~m}^{2} / \mathrm{yr}\left(10^{-6} \mathrm{~cm}^{2} / \mathrm{s}\right)$.

The results in Figure D.2 show the particle breakthrough as influenced by implementation of (D11), and as compared with a two-dimensional discrete fracture simulation of the same problem using the GIMRT model (here the second spatial coordinate axis points into the matrix block). The particle result is clearly much more accurate than the convolution technique discussed in section C.7 of Appendix C, and it would appear to offer greater flexibility and applicability as well.

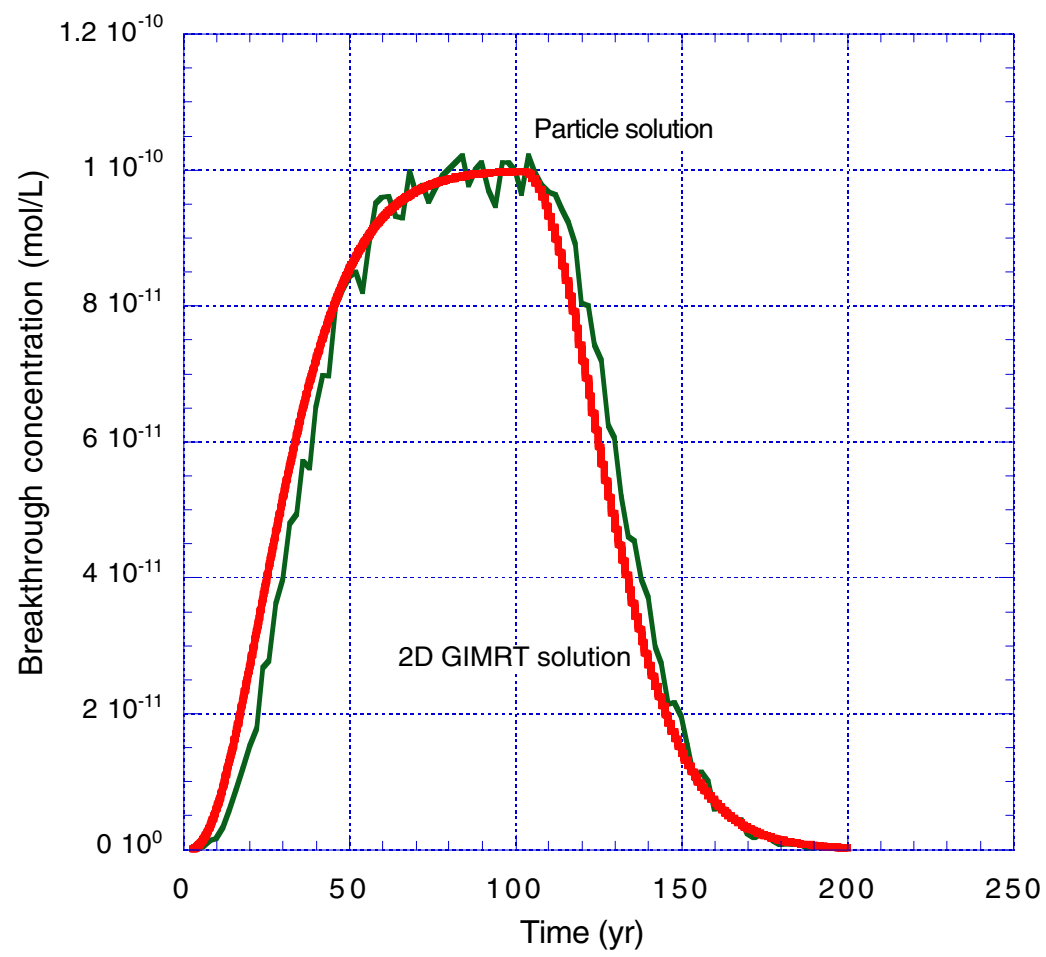

Figure D.2 Particle breakthrough profile for tritium (thin line) reflecting the influence of matrix diffusion, as implemented with the transitional probability equations (D11) in a 1-D test problem. The thicker line represents the solution provided by a 2-D, discrete fracture application of the GIMRT model to the same problem. 


\section{D.6 Radionuclide Release from the Melt Glass}

In the particle model, release of radionuclides from the melt glass will be achieved by periodically discharging particles that are initially associated with the melt glass into groundwater according to

$$
\Delta M_{j}=v_{\mathrm{j}} R_{\text {glass }} \bullet \Delta t
$$

as indicated in equation (B8). For the particle model, a simplified melt glass dissolution rate $\left(r_{\text {glass }}\right)$ was developed from the full glass dissolution rate equation (equation (B10) in Appendix B, or the equation in Chapter 6, section 6.4.4, "Melt Glass Dissolution Model"), using a number of assumptions described in Chapter 6, section 6.4.5, "Implementation of Glass Dissolution Model." The particle rate model assumes constant values of $\mathrm{pH}$ and saturation term to define a temperature-dependent rate parameter $k(T)$ whose temperature dependence is described by an Arrhenius relationship. The surface area of particle glass, expressed in units of square meters per gram of glass, decreases linearly with the mass of glass. Given the average thermal history of the melt glass predicted by the NUFT model, the particle glass dissolution rate with time can be calculated, as shown in Figure D.3.

The resulting rate shown in Figure D.3 shows a dramatic decrease that parallels the drop in melt glass temperature. The decline is also influenced by the predicted decrease in surface area. For every mole of glass dissolved, ${ }^{5}$ a stoichiometrically determined mass of radionuclide $j$, as determined by the parameter $v_{j}$, is released and allowed to migrate in the flow system. Because the particle release function can be predetermined as a function of the temperature, it could also be reevaluated under different $\mathrm{pH}$ conditions or with different surface area parameters in order to assess the overall sensitivity of the melt glass dissolution rate to the various dissolution rate parameters.

For comparison purposes, the same assumptions regarding the dissolution model were codified into the GIMRT model to yield a simple rate, which differs from the particle rate only in the way in which the surface area is adjusted in time. ${ }^{6,7}$ Both models should be distinguished from a more complex rate that may be implemented in GIMRT, in which the $\mathrm{pH}$ and saturation terms are not fixed but instead are allowed to vary over the course of the simulation. In Appendix E, the efficacy of the simplified particle release function will be compared with comparable GIMRT solutions using the simple rate and complex rate glass dissolution models in a simple, one-dimensional test problem.

\footnotetext{
${ }^{5} \mathrm{~A}$ mole of glass is defined here as $100 \mathrm{~g}$ of glass.

${ }^{6}$ Note that the simple rate model is similar to the rate model used in the previous CAMBRIC studies (Tompson et al., 1999).

${ }^{7}$ The change in glass surface area with time in GIMRT is described by equation (6.4) in Section 6.4.4.4.3 in Chapter 6, section named "Glass surface area."
} 


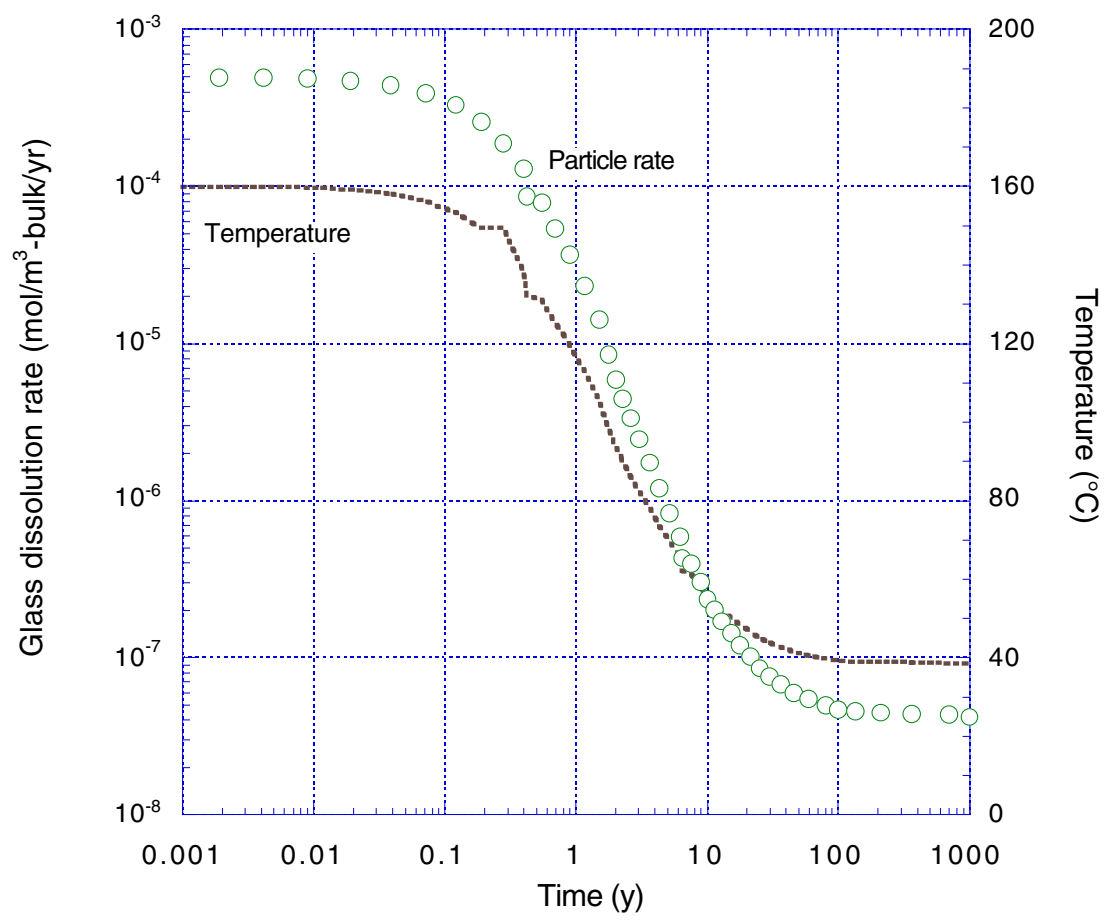

Figure D.3 Predicted mean temperature $\left({ }^{\circ} \mathrm{C}\right)$ in the melt glass zone and the approximate particle rate used to define glass dissolution $\left(\mathrm{mol} / \mathrm{m}^{3}-\mathrm{bulk} / \mathrm{yr}\right)$ in the particle simulations based upon a fixed $\mathrm{pH}$ of 8 and an initial melt glass surface area of $2000 \mathrm{~m}^{2} / \mathrm{m}^{3}(\sim 10$ $\mathrm{cm}^{2} / \mathrm{g}$ ). 


\section{APPENDIX E: \\ Comparisons of the GIMRT and Particle Transport Models}




\section{E.1 Introduction}

The particle model employed in the CHESHIRE simulations is based upon a simplified version of the total mass balance equation (B9) in which the physical and geochemical processes are simplified as described in Appendix D. It is of interest to understand how the simplified particle model simulations compare with GIMRT simulations for identically posed problems. The comparisons also illustrate the differences in the way each model achieves its solution. GIMRT seeks to advect and diffuse the aqueous species (e.g., $u_{A m}$ ) while simultaneously maintaining equilibria among the various aqueous species and between the aqueous and sorbed (e.g., $u_{A m}^{i m}$ ) fractions of the radionuclide. The total concentration is a derived quantity, determined by combining the aqueous and sorbed portions of the GIMRT solution according to

$$
u_{A m}^{T}=\phi\left(u_{A m}+u_{A m}^{i m}\right)
$$

The GIMRT retardation factor is also a derived quantity, and is computed from the ratio

$$
R_{A m}=1+u_{A m}^{i m} / u_{A m}
$$

The particle model, on the other hand, collectively advects and diffuses the total species mass $u_{A m}^{T}$ as a function of specified velocity and retardation parameter fields. In this case, the total concentration is the fundamental solution and the aqueous concentration is derived from it via

$$
u_{A m}=\frac{u_{A m}^{T}}{\phi R_{A m}}
$$

In this appendix, we compare a series of one-dimensional simulations computed with the particle and GIMRT models that incorporate sorption and melt glass dissolution. Appendices $\mathrm{C}$ and $\mathrm{D}$ separately discuss the ability of either model to treat matrix diffusion.

\section{E.2 Sorption Phenomena}

A simple one-dimensional model of radionuclide transport was developed to compare the solutions of the GIMRT and particle models for a problem characterized by spatially variable reactive minerals. The selected domain contains a $600 \mathrm{~m}$ long segment passing through the disturbed zone and the native fractured formation. The first $100 \mathrm{~m}$ is assumed to lie in disturbed zone with a porosity of $10 \%$, while the remaining $500 \mathrm{~m}$ extends into a native, fracture-flow dominated rock with an effective porosity of $1 \%$. For simplicity, matrix diffusion is not included in this simulation, and flow and chemical reactions occur under isothermal conditions. The cross-sectional area of the domain is assumed constant so that the specified darcy flux of $1 \mathrm{~m} / \mathrm{yr}$ is constant as well. This flux 
translates into seepage velocities of 10 and $100 \mathrm{~m} / \mathrm{yr}$, respectively, in the two portions of the domain.

We focus here on the transport of a pulse of ${ }^{241} \mathrm{Am}$, located initially in the cavity/exchange volume water region in which the total concentration $u_{A m}+u_{A m}^{i m}$ is equal to $8.98 \times 10^{-12} \mathrm{~mol} / \mathrm{L}$-solution. This is equivalent to the ${ }^{241} \mathrm{Am}$ concentration specified in the exchange volume of the three-dimensional model (Table 4.5). The transport of ${ }^{241} \mathrm{Am}$ is also influenced by its ingrowth from ${ }^{241} \mathrm{Pu}\left(5.74 \times 10^{-12} \mathrm{~mol} / \mathrm{L}\right.$ solution initially distributed in the exchange volume) and by ${ }^{241} \mathrm{Am}$ decay. We assume that the reactive minerals that line the fractures are unevenly distributed throughout the $600 \mathrm{~m}$ domain, but that the minerals, when present, occur in fixed volume percentages. Their volume fractions and surface areas are consistent with those used in the threedimensional model.

The GIMRT solution of this problem is actually based upon the inclusion of all source term radionuclides present in the exchange volume at the concentrations listed in Table 4.5. Accordingly, all reactive minerals involved with ion exchange or surface complexation of these radionuclides were included in the reactive mineral specification, not just those associated with surface complexation of Am. This allowed for competitive effects or other potential nonlinearities associated with the speciation, sorption, or decay reactions to occur if conditions so dictated. For detailed description of geochemical reactions controlling radionuclide transport, see Appendix K.

The particle solution of this problem is based only on the inclusion of ${ }^{241} \mathrm{Pu}$, ${ }^{241} \mathrm{Am}$, and ${ }^{237} \mathrm{~Np}$ as source term radionuclides, as they are linked by the decay and ingrowth processes discussed in Appendix D. Separate particle distributions consistent with their total initial abundance in the exchange volume (Table 4.5) were specified and allowed to advect and decay according to equations (D3) and (D10). In this example, 50,000 particles were used for each radionuclide. Retardation factors associated with surface complexation of $\mathrm{Pu}, \mathrm{Am}$, and $\mathrm{Np}$, approximately valid under low concentration conditions, were determined independently from appropriate combinations of surface complexation constants and reactive mineral abundances (Table K.8) and used as specified material properties to advance particle positions in the step equation (D3).

Figures E.1 and E.2 compare the distributions of total ${ }^{241} \mathrm{Am}$ and aqueous ${ }^{241} \mathrm{Am}$ after $100 \mathrm{yr}$ predicted by the GIMRT and particle models in the absence of any specified physical dispersion or diffusion. The total concentration profiles shown in Figure E.1 are in reasonable agreement. The GIMRT profile is slightly diffused and damped, apparently owing to numerical dispersion errors. The computed GIMRT retardation factor exactly matches the pre-computed retardation factor used in the particle model (as is the case in Figures E.1 through E.4). For ${ }^{241}$ Am, and for this problem in particular, the agreement would appear to indicate a lack of competitive or nonlinear sorption behavior and support the manner in which retardation coefficients were calculated for use in the particle model, at least under the ambient groundwater flow conditions used in this example.

The aqueous concentration profiles shown in Figure E.2 are dissimilar, owing to the fact that the numerical dispersion effects in GIMRT are most evident in the 
aqueous solution as opposed to the sum of the aqueous and immobile solutions. The immobile (sorbed) solution (not shown) retains a degree of sharpness that is controlled by the spatial variability of the reactive minerals. The spatial variability of the reactive minerals, of course, also controls the spatial variability of the retardation parameters used in the particle model. The method by which GIMRT advects radionuclides in the aqueous phase tends to produce a smoother concentration profile than that of the particle model, which advects the total mass.

Figures E.3 and E.4 show the same kinds of comparisons, albeit with a particle model based upon a local dispersivity of $10 \mathrm{~m}$. The purpose of these simulations was to see whether a genuine diffusive effect in the particle model, as specified by the dispersivity, mimics the numerical dispersion error in GIMRT. In Figure E.3, the total concentration profile of the GIMRT model is unchanged, while that of the particle model is clearly dispersed relative to the previous particle (Figure E.1) and GIMRT solutions.

In Figure E.4, the aqueous concentration profile associated with the particle model is markedly different than the GIMRT profile, and exhibits a noticeable degree of variability imparted by the spatial distribution of the reactive minerals. This occurs because the specified dispersion effect is manifested in the total concentration profile as opposed to the aqueous portion alone. Fluid flow seeks to move aqueous parcels from one zone to the next. That sharp gradients occur in the aqueous concentration profile along boundaries between the reactive and nonreactive zones is a consequence of the local equilibrium assumption used to describe the surface complexation and ion exchange reactions. Here, the infinitely fast rates of partitioning assumed by the particle model exceed the finite rates of flow and instantaneously redistribute sorbed and aqueous mass fractions across reactive zone boundaries. If this assumption were relaxed, sorption reactions would occur with finite rates and lead to more continuous aqueous concentration profiles across these boundaries, which would be more representative of natural systems.

Altogether, the particle model would appear to adequately represent the requisite physical processes set forth for this example, and potentially offer some improvements over the GIMRT model owing to its limited numerical dispersion. However, the sharpness of the aqueous concentration profile generated by the particle model does not represent profiles in natural systems, owing to the assumption of infinitely fast partitioning rates in the particle model. Importantly, the role of diffusive or dispersive mass transport, whether real or error-driven, would appear to manifest differently in the models' results, a fact to note when interpreting results from either model. 


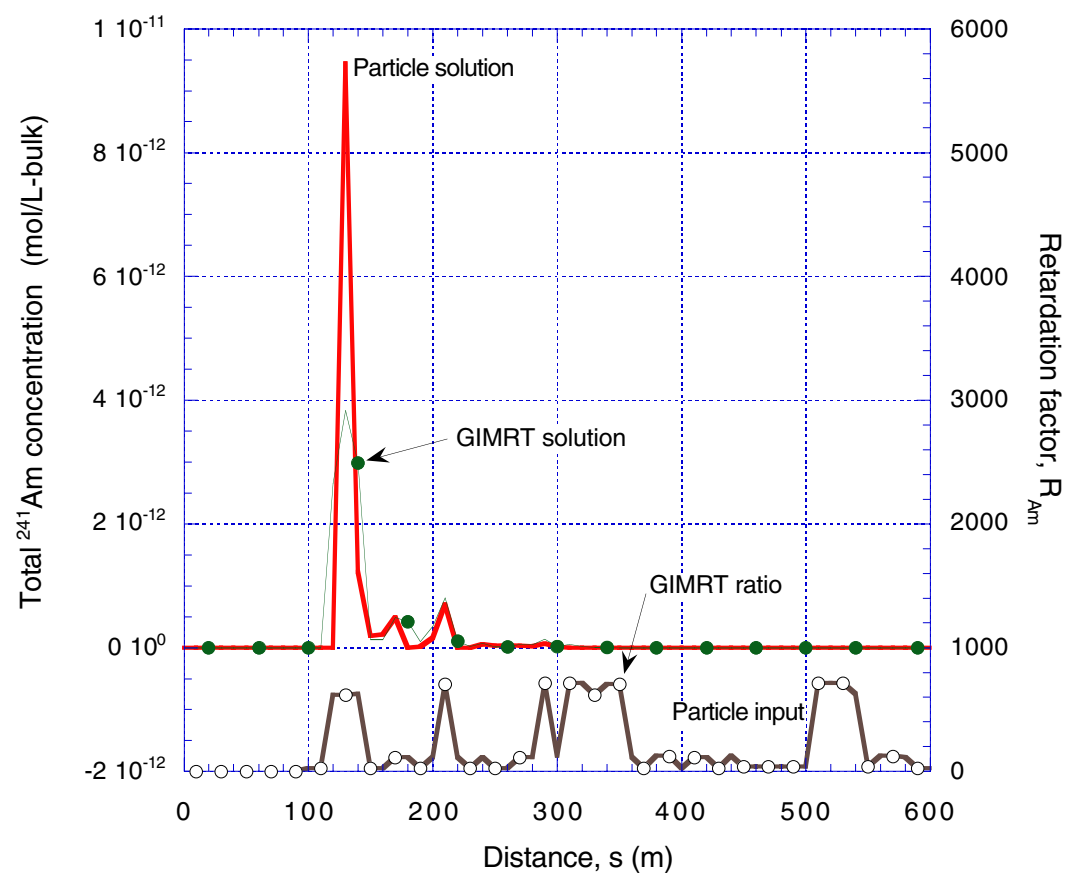

Figure E.1 Predicted distribution of total ${ }^{241} \mathrm{Am}$ (mol/L-bulk) in the simple 1-D model after $100 \mathrm{yr}$ (left axis), as predicted by the GIMRT and particle models with no specified dispersion or diffusion.

Retardation factors (right axis) as specified in the particle model input (solid curve) and as computed from the GIMRT model solution (open circles).

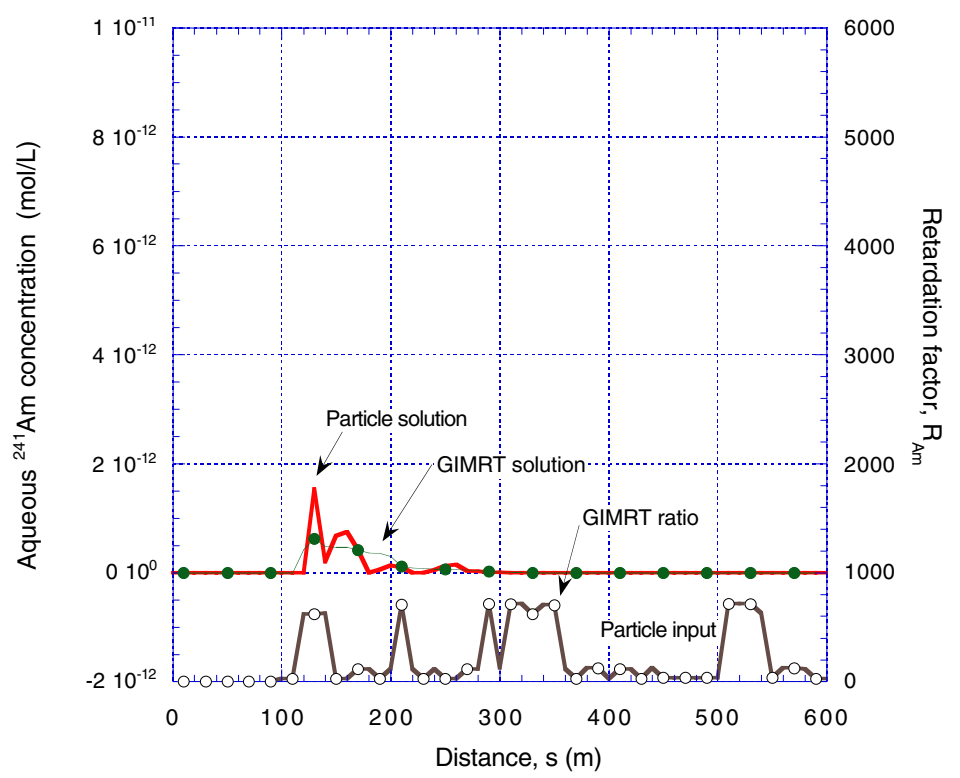

Figure E.2 Predicted distribution of aqueous ${ }^{241} \mathrm{Am}$ (mol/L solution) in the simple 1-D model after $100 \mathrm{yr}$ (left axis), as predicted by the GIMRT and particle models with no specified dispersion or diffusion.

Retardation factors (right axis) as specified in the particle model input (solid curve) and as computed from the GIMRT model solution (open circles). 


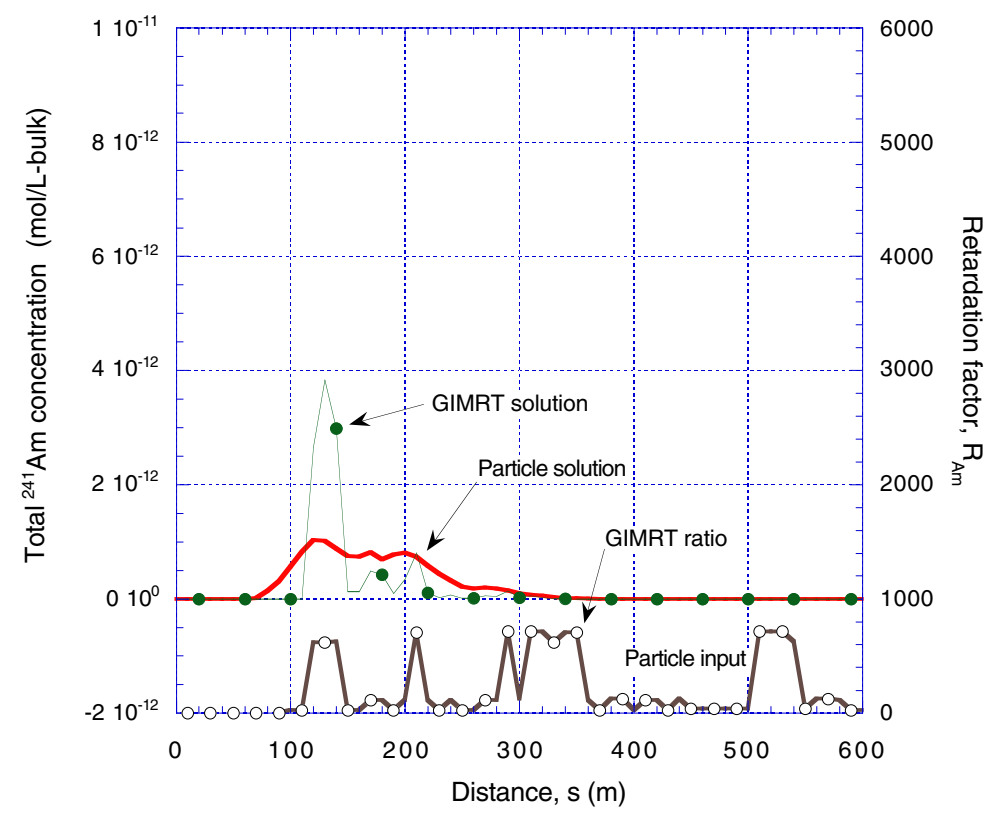

Figure E.3 Predicted distribution of total ${ }^{241} \mathrm{Am}$ (mol/L-bulk) in the simple 1-D model after $100 \mathrm{yr}$ (left axis), as predicted by the GIMRT model with no specified dispersion or diffusion and by the particle model with a longitudinal dispersivity of $\alpha \mathrm{L}=10 \mathrm{~m}$. Retardation factors (right axis) as specified in the particle model input (solid curve) and as computed from the GIMRT model solution (open circles).

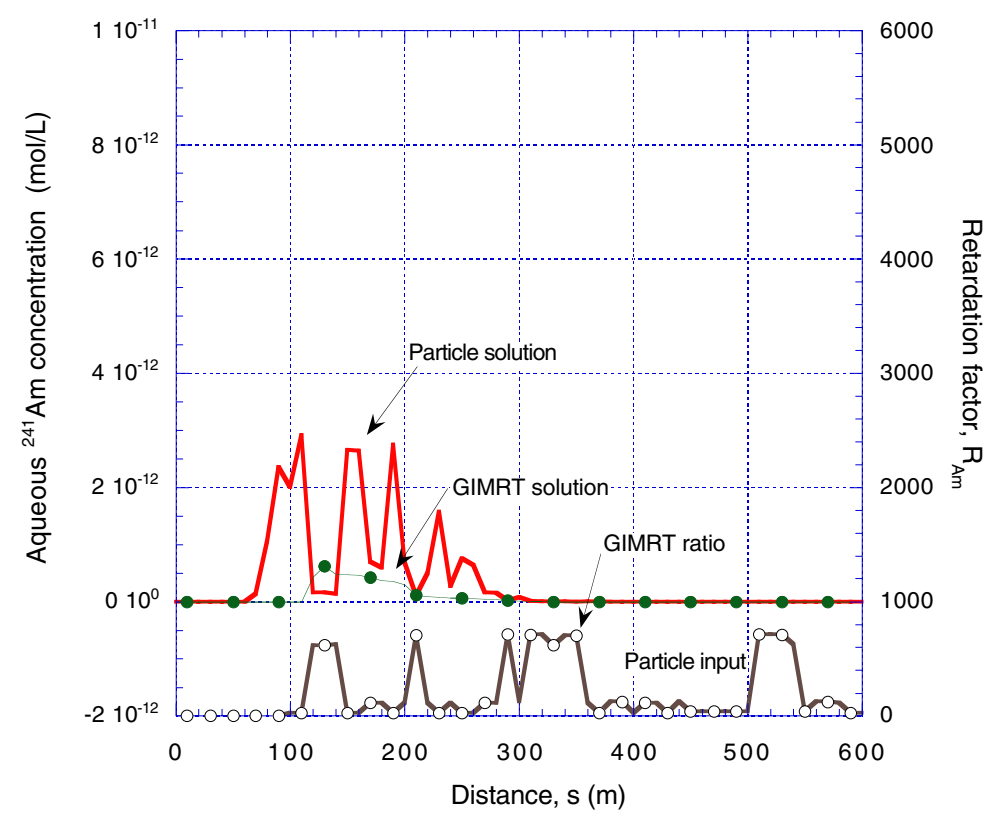

Figure E.4 Predicted distribution of aqueous ${ }^{241} \mathrm{Am}$ (mol/L solution) in the simple 1-D model after $100 \mathrm{yr}$ (left axis), as predicted by the GIMRT model with no specified dispersion or diffusion and by the particle model with a longitudinal dispersivity of $\alpha \mathrm{L}=10 \mathrm{~m}$. Retardation factors (right axis) as specified in the particle model input (solid curve) and as computed from the GIMRT model solution (open circles). 


\section{E.3 Melt Glass Dissolution}

A one-dimensional model of radionuclide transport through a glass zone was developed to compare the solutions of the particle and GIMRT models for a problem involving melt glass dissolution. The one-dimensional model is similar to that described above. The selected domain again contains a $600 \mathrm{~m}$ long segment that passes first through a $100 \mathrm{~m}$ long portion of melt glass and then through $500 \mathrm{~m}$ of the native, fractured rock. The porosity of the melt glass is assumed at $20 \%$, while that of the native fractured rock remains at $1 \%$. For simplicity, matrix diffusion is not included in these comparisons.

The melt glass temperature history taken from the three-dimensional NUFT model, reproduced (from Figure D.3) in Figure E.5, affected the glass dissolution rate but was not assumed to affect the flow field. Temperatures in the remainder of the domain were considered fixed at $35^{\circ} \mathrm{C}$ over the duration of the simulation. The crosssectional area of the domain is presumed to be constant so that the specified darcy flux of $q=1 \mathrm{~m} / \mathrm{yr}$ is constant as well. This flux translates into seepage velocities of 5 and $100 \mathrm{~m} / \mathrm{yr}$, respectively, in the two portions of the domain.

We focus here on the transport of uranium released from the melt glass, and note that "uranium" implies all of the six isotopes considered in this problem (i.e., ${ }^{232} \mathrm{U}$, ${ }^{233} \mathrm{U},{ }^{234} \mathrm{U},{ }^{235} \mathrm{U},{ }^{236} \mathrm{U}$, and ${ }^{238} \mathrm{U}$; see Appendix A). For a bulk cross-sectional area of $1 \mathrm{~m}^{2}$, the first $100 \mathrm{~m}$ of the domain will contain $80 \mathrm{~m}^{3}$, or approximately $1.6 \times 10^{8} \mathrm{~g}$ of glass, assuming a glass density of $2.5 \mathrm{~g} / \mathrm{cm}^{3}$ and a porosity of $20 \%$. Given $1.05 \times 10^{-9} \mathrm{~mol} \mathrm{U} / \mathrm{g}$ glass used in the three-dimensional model (Table 4.5), this yields $0.168 \mathrm{~mol}$ of $\mathrm{U}$ in the glass of this test problem. We also assume that the reactive minerals involved in the surface complexation of $U$ in the fractures are uniformly present, yet unevenly distributed throughout the 600-m domain. Their volume fractions, surface areas, and distribution patterns are consistent with those used in the three-dimensional model. Diffusion, dispersion, and decay were not included in these tests.

Two particular solutions of this problem were developed with GIMRT, both of which were based upon the inclusion of all source term radionuclides present in the melt glass at the concentrations listed in Table A.1. The first solution is based upon a simple rate law for glass dissolution in which the $\mathrm{pH}$ and saturation terms are fixed so that variations of the rate are only achieved through the variation of temperature (see Appendix D and Figure E.5; section "Glass dissolution model used in the particle tracking code"). This simple rate yields essentially the same glass dissolution rates used in the particle model. The approach to formulating the simple glass rate law is similar to that used in the previous CAMBRIC simulations (Tompson et al., 1999). Changes in fluid composition were allowed to affect sorption. However, the glass composition was simplified to a composition of silica and radionuclides such that fluid compositions stayed relatively constant; this ensured that the particle model and simple rate model were nearly equivalent.

The second solution is based upon a more complex rate law in which the $\mathrm{pH}$ and saturation terms are allowed to vary over the course of the solution. This complex rate law, described in Chapter 6, section 6.4.4, "Glass Dissolution Model," was used in 
the GIMRT streamline calculations. Allowing these terms to vary results in slightly faster dissolution rates (Figure E.5). In both solutions, all reactive minerals involved with ion exchange and surface complexation were included, not just those associated with surface complexation of $U$. This allowed for competitive effects or other potential nonlinearities associated with the speciation, sorption, or decay reactions to occur, if conditions so dictated.

The particle solution of this problem is based only on the inclusion of $U$ as a source term radionuclide. A single distribution of 53,000 particles was used to represent the $0.168 \mathrm{~mol}$ of $U$ in the melt glass and was released in time according to the simple particle rate model (Appendix D). Once released, particles would be subject to advection and decay processes according to equations (D3) and (D10) in the absence of dispersion. Retardation factors associated with surface complexation of $U$, valid given trace concentrations of radionuclides, were determined independently from appropriate combinations of surface complexation constants and reactive mineral abundances, and were used to advance particle positions in (D3).

Figures E.6(a), E.6(b), E.7(a), and E.7(b) compare the predicted distributions of total $U$ and aqueous $U$ after 100 yr predicted by the GIMRT and particle models in the absence of any specified physical dispersion or diffusion. Note that the differences in how the particle and GIMRT models achieve their solutions, as reviewed in section E.2, are relevant here.

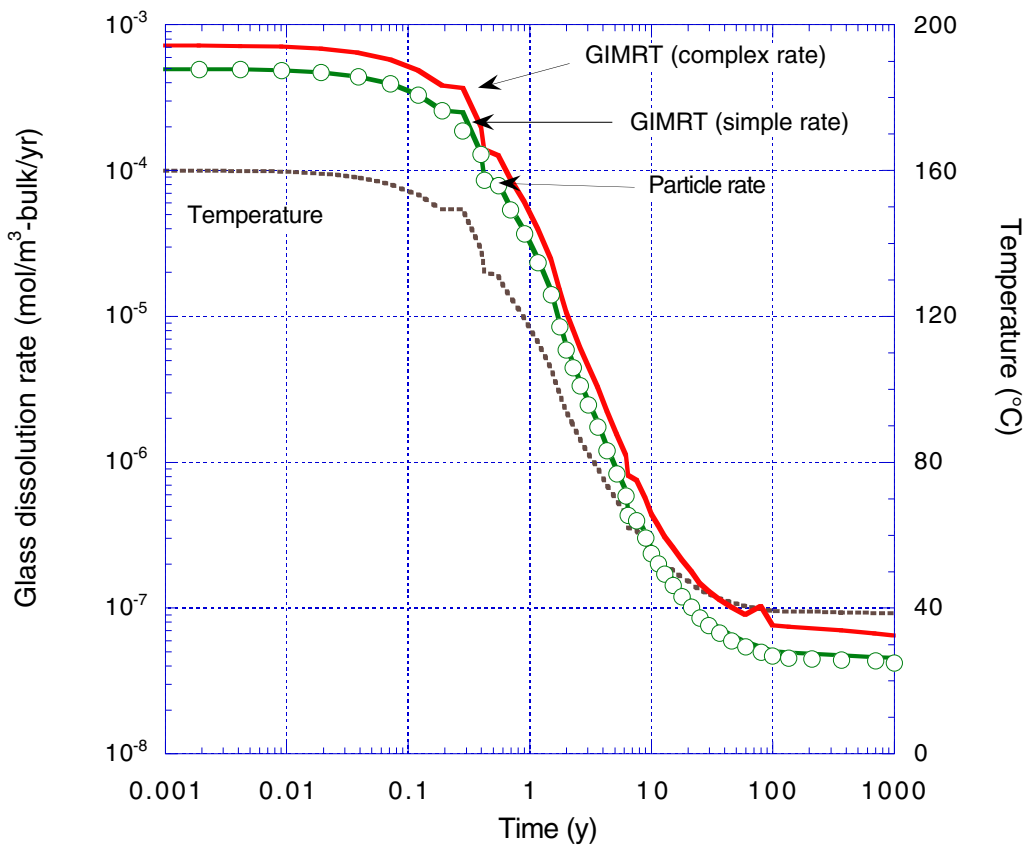

Figure E.5 Temperature $\left({ }^{\circ} \mathrm{C}\right)$ in the melt glass zone of the 1-D melt glass dissolution test problem and the glass dissolution rates ( $\mathrm{mol} / \mathrm{m}^{3}$-bulk/yr) computed in the corresponding particle and GIMRT simulations. The particle rate is predetermined as a function of temperature, and the simple GIMRT rate is fixed in the model to give essentially the same results. The complex rate is interrogated from the GIMRT simulation results at the end of the melt glass section, $100 \mathrm{~m}$ into the domain. 


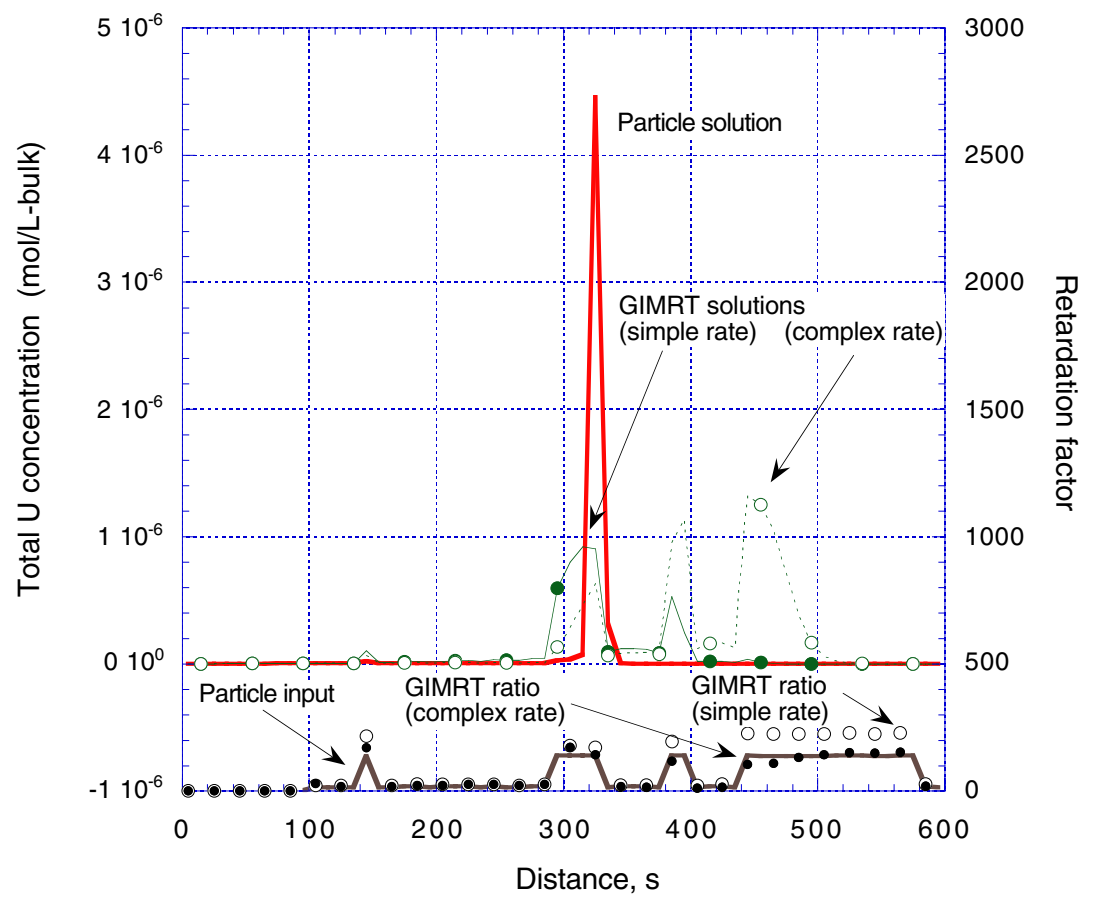

Figure E.6(a) Predicted distribution of total $U$ (mol/L-bulk) released from melt glass in the simple 1-D model after $100 \mathrm{yr}$ (left axis), as predicted by the GIMRT and particle models with no specified dispersion or diffusion. Retardation factors (right axis) as specified in the particle model input (solid curve) and as computed from the GIMRT model solution (open circles).

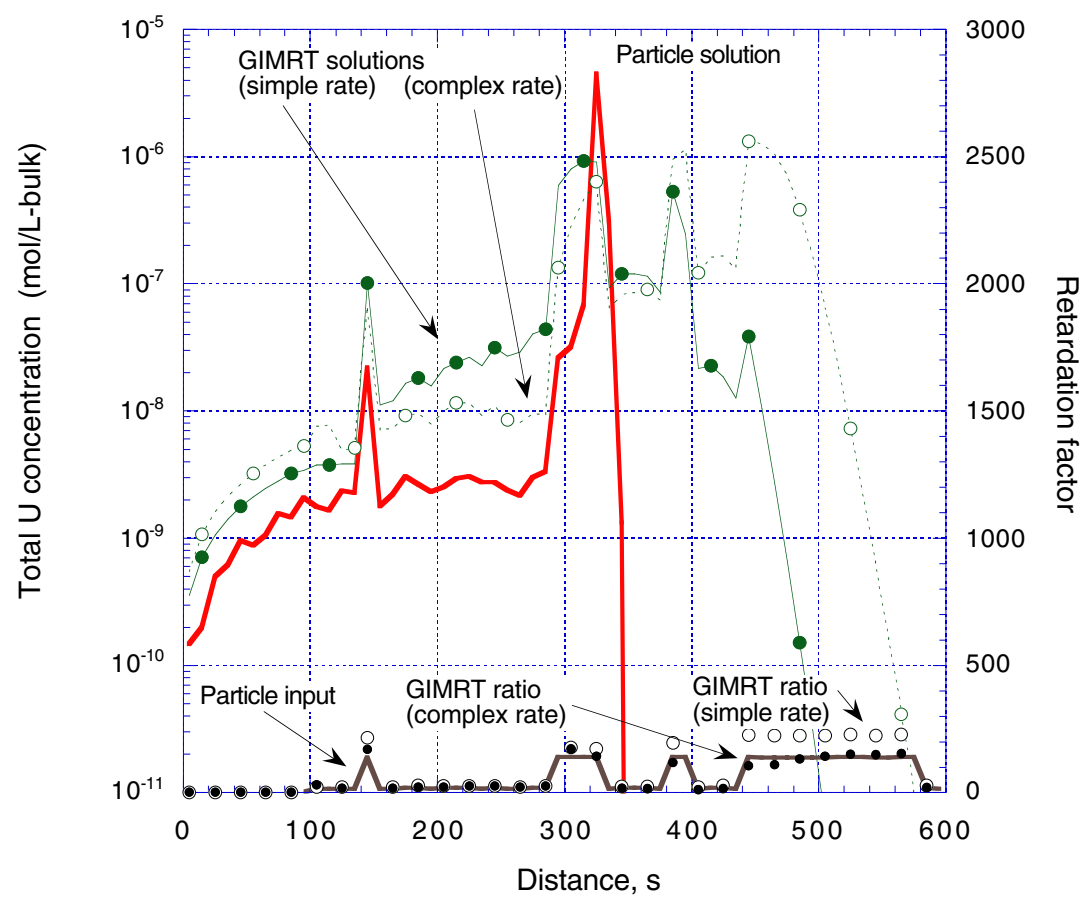

Figure E.6(b) Same as Figure E.6(a), but with concentrations shown on a log scale. 


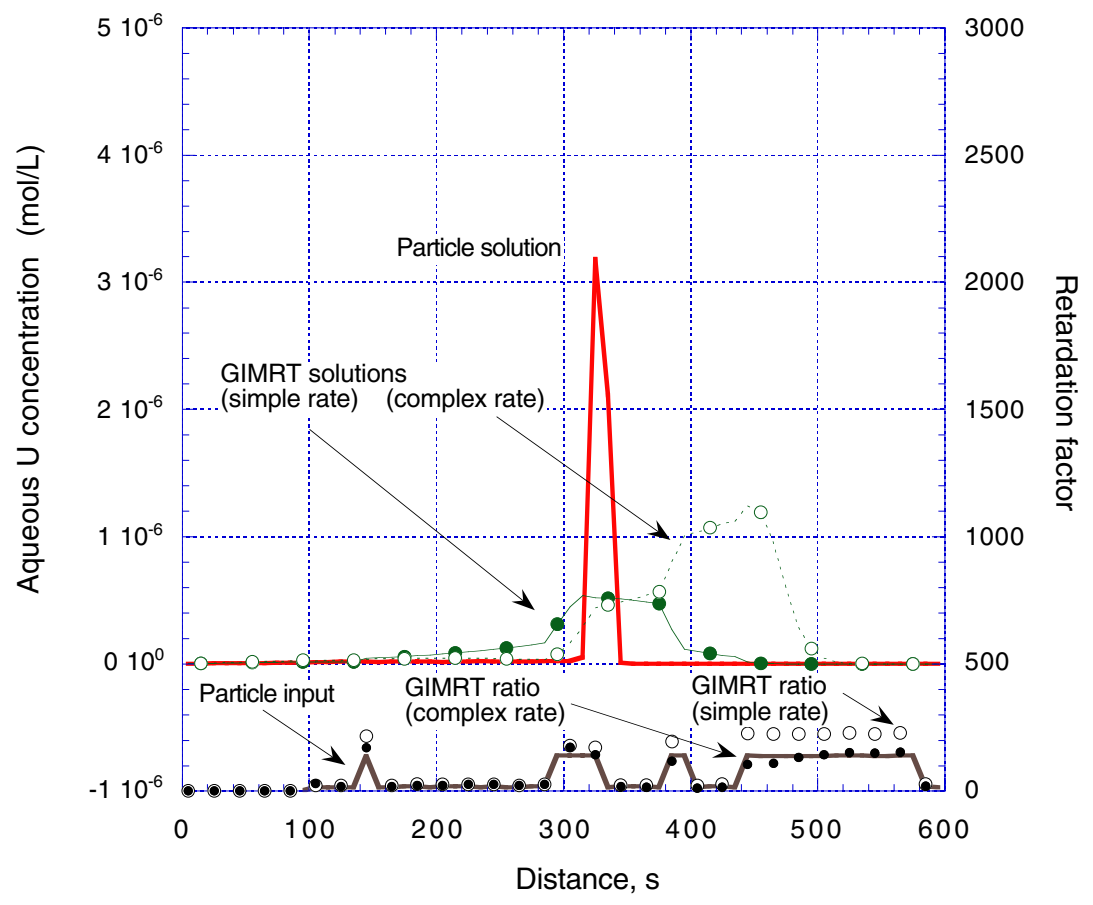

Figure E.7(a) Predicted distribution of aqueous $U(\mathrm{~mol} / \mathrm{L})$ released from melt glass in the simple 1-D model after $100 \mathrm{yr}$ (left axis), as predicted by the GIMRT and particle models with no specified dispersion or diffusion. Retardation factors (right axis) as specified in the particle model input (solid curve) and as computed from the GIMRT model solution (open circles).

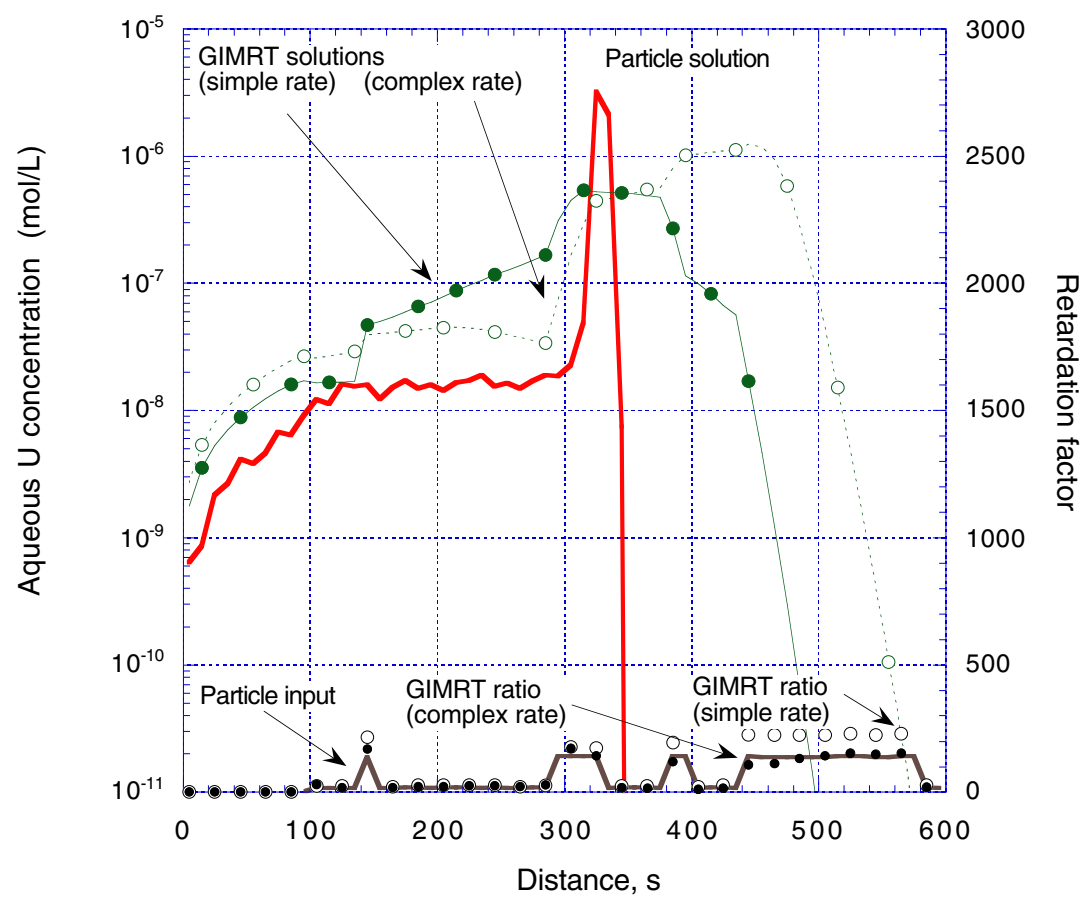

Figure E.7(b) Same as Figure E.7(a), but with concentrations shown on a log scale. 
The total and aqueous concentration profiles shown in Figures E.6 and E.7 are in mediocre agreement. Here, and especially in the log plots of Figures E.6(b) and E.7(b), we see a pronounced pulse or front of $U$ moving in advance of a more subdued profile behind it. This is consistent with a greater release early on when temperatures (and dissolution rates) were higher. In all figures, the GIMRT profiles are diffused and slightly damped relative to the particle model results, owing again to numerical dispersion errors and differences in the advection scheme of the two models. The computed GIMRT retardation factors agree only approximately with the pre-computed retardation factor used in the particle model. The differences are attributable to chemical changes down-gradient of the glass that affect the sorption (and retardation) behavior in GIMRT. ${ }^{1}$

A comparison of the two GIMRT-based solutions reveals that the slightly larger complex rate leads to a larger release of $U$, and, accordingly, a greater amount of $\mathrm{U}$ in the system. Interestingly, the computed GIMRT retardation factors associated with the complex rate are in better agreement with the particle model values. Note, however, that the retardations presented here are only instantaneous retardations derived from a ratio of sorbed to aqueous $\mathrm{U}$ at $100 \mathrm{yr}$. The retardation factors were found to change with time in this simulation; the retardation factors in the particle model do not change with time. This, in part, explains why the retardation factor in the simple rate GIMRT simulation is higher than in the particle model at $100 \mathrm{yr}$ but the migration of $\mathrm{U}$ is comparable in the two models. See Appendix I for a discussion of the chemical changes affecting retardation that are induced by glass dissolution.

\footnotetext{
${ }^{1}$ Unlike the particle model, GIMRT simulations allowed retardation coefficients to change with time as a result of changing water chemistry and mineralogy.
} 


\section{APPENDIX F:}

Analysis of Hydraulic Data 


\section{F.1 Introduction}

The scope of hydraulic testing in the CHESHIRE emplacement hole, U-20n, was minimal. Two injection tests were conducted near the working point of the CHESHIRE test at a depth range of 1166 to $1215 \mathrm{~m}$. However, more extensive hydraulic testing was performed in U-20a \#2 Water Well located $91 \mathrm{~m}$ to the west of U-20n (Blankennagel et al., 1964; Blankennagel and Weir, 1965). U-20a \#2 Water Well was drilled to a depth of $1371.6 \mathrm{~m}(4500 \mathrm{ft})$, which is $70.4 \mathrm{~m}(231 \mathrm{ft})$ deeper than $\mathrm{U}-20 \mathrm{n}$. Two types of hydraulic tests were performed on U-20a \#2 Water Well-pumping and injection. One $30 \mathrm{hr}$ pumping test was performed to estimate the overall transmissivity of the saturated zone. Thirteen injection tests were sited or packed-off on intervals ranging from 44 to $103 \mathrm{~m}$ (145 to $337 \mathrm{ft}$ ) in length and spanned $98 \%$ of the saturated zone.

The injection tests were designed to investigate permeability variations, with emphasis on the low-permeability rocks. Importantly, the injection tests were originally evaluated with respect to a semi-quantitative measure called relative specific capacity (RSC) because the mathematical formulation needed for accurate interpretation of the injection test was not yet developed. To address this problem, we have derived a procedure for converting the relative specific capacity values to permeability. Consequently, the U-20a \#2 Water Well hydraulic data provide the most direct and detailed estimates of permeability variation relevant to in situ (undisturbed) rocks surrounding CHESHIRE.

The injection test data support characterization of spatial variation of permeability for native rocks within the scale of our flow and transport modeling domain, but not within the $10 \mathrm{~m}$ resolution of the grid blocks. We identify four hydrofacies based on permeability, with the highest permeability hydrofacies akin to lava flow aquifer materials described in Prothro and Drellack (1997). Interpretations of hydraulic testing and tracer data from the BULLION Forced Gradient Experiment (IT Corporation, 1998a), which was sited in similar geologic setting, support our interpretations of the U-20a \#2 Water Well hydraulic data. Further insights to permeability variation and anisotropy are obtained from examination of fracture data (Hoover et al., 1964; Drellack et al., 1997).

\section{F.2 Hydraulic Testing}

\section{F.2.1 Pumping Test}

Pumping tests were conducted at Pahute Mesa to determine the overall water yielding potential in the volcanic rock strata (Blankennagel, 1967). A 30-hour pumping test was conducted at U-20a \#2 Water Well on February 10-11, 1965 (Blankennagel and Weir, 1965). The test was conducted by pumping water from U-20a \#2 Water Well at a constant rate averaging $11.7 \mathrm{~L} / \mathrm{s}(186 \mathrm{gal} / \mathrm{min}$ ) and monitoring decline in the water level of U-20a \#2 Water Well. Blankennagel and Weir (1973) analyzed the drawdown curve by the Cooper-Jacob (straight-line) method to obtain a transmissivity estimate of 
$224 \mathrm{~m}^{2} / \mathrm{d}(18,000 \mathrm{gal} / \mathrm{d} / \mathrm{ft})$. Figure F.1 shows the drawdown data and a straight-line fit to the data between 10-1000 min. The Cooper-Jacob method of analysis (Cooper and Jacob, 1946) yields a transmissivity, $T$, estimate of $18,000 \mathrm{gal} / \mathrm{d} / \mathrm{ft}$ as follows:

$$
T=\frac{2.3 Q}{4 \pi \Delta s}=\frac{2.3(186 \mathrm{gpm}=267840 \mathrm{gpd})}{4 \pi(2.72 \mathrm{ft})}=18,000 \text { gallons } / \mathrm{day} / \mathrm{ft}
$$

where:

$$
Q=\text { pumping rate }
$$

$\Delta \mathrm{s}=$ change in drawdown for one log10 cycle of time

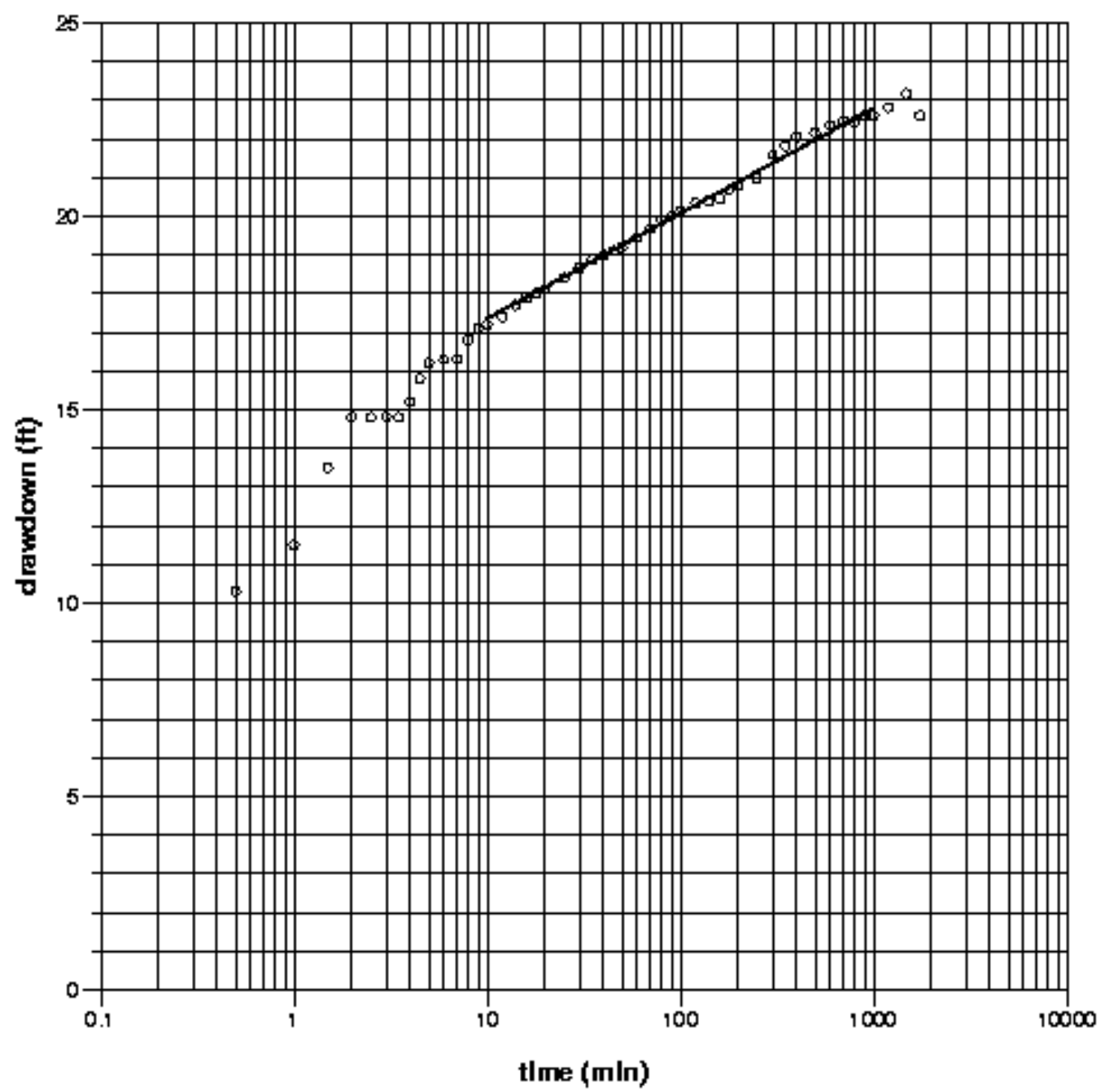

Figure F.1 Drawdown data from pumping test at U-20a \#2 Water Well. Straight-line fit between $10-1000$ min results in Cooper-Jacob transmissivity estimate of $18,000 \mathrm{gal} / \mathrm{d} / \mathrm{ft}$. 
At the initial time of the test, the water level was at $635.97 \mathrm{~m}(2086.5 \mathrm{ft})$ depth. For the $735.6 \mathrm{~m}(2413.5 \mathrm{ft})$ thick saturated zone, this pumping test indicates an average permeability of $2.4 \times 10^{-13} \mathrm{~m}^{2}$ or an average hydraulic conductivity of $0.30 \mathrm{~m} / \mathrm{d}$ assuming a water temperature of $37.8^{\circ} \mathrm{C}\left(100^{\circ} \mathrm{F}\right)$ as indicated in the pump test record. The quality of this pumping test is considered good by the U.S. Geological Survey, ${ }^{1}$ particularly in comparison with other pumping tests conducted at Pahute Mesa.

According to Blankennagel and Weir (1973), some of the pumping-test data for 16 holes on Pahute Mesa (including U-20a\#2 Water Well) were inadequate because of heterogeneous aquifer systems, time limitations, and erratic measurements caused by foaming of detergents used during drilling. Transmissivity estimates were questionable for four holes, but not for U-20a\#2. In fact, Blankennagel and Weir (1973) used the drawdown data for U-20a\#2 as an example to show a classical Cooper-Jacob straightline model fit for estimation of transmissivity. Importantly, these transmissivity estimates at Pahute Mesa were obtained exclusively from single well tests, which may be affected by local permeability heterogeneity (e.g. deviation from laterally continuous permeable zones) or disturbance of sidewalls by drilling.

\section{F.2.2 Injection Tests}

Injection tests are designed to estimate the transmissivity over an isolated interval of rock rather than over the entire saturated zone, as obtained from a pumping test. The injection tests at Pahute Mesa are useful for examining variations in permeability within the volcanic strata of the saturated zone. The original motivation for performing the injection tests at Pahute Mesa was to identify zones of low permeability suitable for siting chambers for underground nuclear tests (Blankennagel et al., 1964). Low permeability rock would minimize infiltration of water into a subsurface excavation.

The injection tests were conducted by using inflatable packers to isolate the intervals of interest, usually about $61 \mathrm{~m}(200 \mathrm{ft})$ long. A tube running from the surface down the well to the packed interval was filled with water after closing a valve at the tube-packer connection. The test was initiated by opening the valve, which then allows the pressure head of the water-filled column to force water into the formation. The drop in water level in the tube was monitored to obtain a curve of pressure head in the packed interval as a function of time. Locations of the packed intervals for the injection tests varied because of considerations for the hydrogeology (e.g., spatial distribution of high and low permeability zones), smoothness of the borehole, and operational constraints. In U-20a \#2 Water Well, the injection tests spanned $98 \%$ of the saturated zone.

The original analyses of the injection test data did not directly yield estimates of permeability or transmissivity. Rather, a semi-quantitative empirical measure called "relative specific capacity" was devised (Blankennagel et al., 1964; Blankennagel, 1967; Blankennagel and Weir, 1973). Assuming a $61 \mathrm{~m}$ (200 ft) packed interval, the relative specific capacity (RSC) was defined by

\footnotetext{
${ }^{1}$ A. L. Geldon, oral communication, 1999.
} 


$$
r s c=\frac{Q}{d_{w}-d}
$$

where:

$Q=$ quantity of water injected into the formation during a 1 min time interval

$d_{w}=$ depth of static water level

$d^{\prime}=$ average depth of water level during the 1 min time interval of injection

For the Pahute Mesa injection tests, the 1 min time interval was chosen between 3.0 and 4.0 min after initiation of a test, and $d^{\prime}$ was chosen as the depth of the water level at $3.5 \mathrm{~min}$ after initiation of a test. $Q$ was estimated by

$$
Q=\pi r_{c}^{2} \Delta h
$$

where:

$r_{c}=$ radius (in feet) of the tubing containing the water column

$\Delta h=$ difference in height of the water column during the $1 \mathrm{~min}$ time interval

At U-20a \#2 Water Well, 3 in. diameter tubing was used, so that $r_{c}=0.125$. If the packed-off intervals deviated from $200 \mathrm{ft}$, the RSC value was adjusted by multiplication by a factor of $200 \mathrm{ft}$ / (interval length in feet). At U-20a \#2 Water Well, the RSC values ranged from 0.00 to 0.17 . According to Blankennagel et al. (1964), the RSC values could be converted to hydraulic conductivity in units of gallons per day per square feet (gal/d/ft ${ }^{2}$ ) by multiplying the RSC value by a factor of 10 . Therefore, a RSC value of 0.1 would indicate a hydraulic conductivity of $1.0 \mathrm{gal} / \mathrm{d} / \mathrm{ft}^{2}$ over an interval of $200 \mathrm{ft}$, or a transmissivity of $200 \mathrm{gal} / \mathrm{d} / \mathrm{ft}$.

The RSC analysis, rather than a more quantitative injection test analysis, was used at NTS because (a) hydraulic testing methods were in their infancy in the 1960s, (b) accurate mathematical solutions for injection tests in wells had not yet been derived (e.g., Cooper et al., 1967), and (c) the RSC analysis adequately served the purpose of locating low permeability zones suitable for siting chambers for underground nuclear tests. Unfortunately, RSC analysis of injection tests breaks down for the characterization of high-permeability zones, which are of particular interest to flow and transport modeling at CHESHIRE.

\section{F.2.3 Spatial Variation of Permeability}

Blankennagel and Weir (1973) suggested that transmissivity in the lava flow aquifers is dominated by narrow zones occupying about $3-10 \%$ of the saturated section. Importantly, the spatial distribution of high permeability zones will strongly influence flow and transport behavior. One important objective of our current work is to determine whether the injection tests in U-20a \#2 Water Well could be reevaluated with 
respect to permeability instead of relative specific capacity. We found two major difficulties in evaluating the injection tests: (1) although a conversion from RSC to permeability can be derived, it breaks down for high permeability values, and (2) injection tests conducted in high-permeability zones at U-20a \#2 Water Well suffer from head losses because of rapid flow velocities in the narrow tubing, rendering the head data useless for interpretation. Nonetheless, we can convert the RSC values to permeability for low- and moderate-permeability zones with reasonable confidence. In conjunction with the transmissivity from the pumping test, we can estimate the permeability of high permeability zones.

\section{F.2.4 Interpretation of RSC Values with Respect to Permeability}

One indication of a problem with converting RSC to permeability is that integrating the product of the RSC values and the 10.0 multiplication factor given by Blankennagel et al. (1964) over the saturated thickness yields a transmissivity of 1600 $\mathrm{gal} / \mathrm{d} / \mathrm{ft}$ - more than an order of magnitude less than the transmissivity of 18,000 $\mathrm{gal} / \mathrm{d} / \mathrm{ft}$ estimated from the pumping test. Blankennagel (1967) and Blankennagel and Weir (1973) noted that hydraulic conductivity values inferred from RSC values from high-permeability zones are too low; however, no quantitative explanation was given.

We need a more quantitative relationship between RSC and hydraulic conductivity to understand how permeability varies as a function of RSC. Accordingly, we use an injection test type curve to numerically derive the transmissivity-RSC relationship given the parameters of the Pahute Mesa tests. Accurate type curves for injection test analysis were derived by Cooper et al. (1967). Each type curve depends on the storativity of the aquifer. Storativity is defined as the volume of water released per unit area of the transmissive zone per unit decline in pressure head. Storativity is relatively difficult to infer from injection test data because the shape of the type curves for different storativities are very similar at intermediate times. Type curves converge at very small storativities. Fortunately, a large error in the estimate of storativity results in a relatively small error in the estimate of transmissivity. The lava flow aquifers will have very small storativity because of the low effective porosity and low compressibility of the lava flows. A low storativity type curve is a reasonable assumption for relating RSC to transmissivity in the lava flow aquifers.

To estimate RSC for different values of transmissivity, we use the type curve values for $\alpha=10^{-5}$ corresponding to the smallest storativity values used by Cooper et al. (1967), where:

$$
\alpha=S r_{s}^{2} / r_{c}^{2}
$$

$S=$ storativity (storage coefficient)

$r_{s}=$ radius of the well below the water table

$r_{c}=$ radius of the tubing (casing) of the water column axis, where:

The type curves are normalized to $T t / r_{c}^{2}$ on the $x$ axis and $h(t) / h_{0}$ on the $y$ 
$T=$ transmissivity

$t=$ time

$h(t)=$ height of the water column at time $t$

$h_{0}=$ initial height of the water column above the static water level

Recognizing that

$$
h(t)=d(t)-d_{w}
$$

where:

$d(t)=$ depth of water column at time $t$

$d_{w}=$ depth of water table at time zero

and that flow, $q$, in the water column is governed by

$$
q=-\pi r_{c}^{2} \frac{\partial h(t)}{\partial t}
$$

Assuming laminar flow, Equation F2 can be expressed in differential form as

$$
r s c=-\frac{\pi r_{c}^{2}}{h(t)} \frac{\partial h(t)}{\partial t}
$$

Recognizing that $T, h_{0}$, and $r_{c}$ are constants in the RSC analysis, Equation (F7) can be expressed with respect to the type curve variables $\left[h(t) / h_{0}\right]$ and $\left[T t / r_{c}^{2}\right]$ by

$$
r s c=-\frac{\pi r_{c}^{2}}{h\left(\bar{t}_{k}\right)}\left(\frac{T \bar{t}_{k} / r_{c}^{2}}{3.5 \mathrm{~min}}\right) \frac{\left[h\left(t_{k+1}\right) / h_{0}\right]-\left[h\left(t_{k}\right) / h_{0}\right]}{\left(T t_{k+1} / r_{c}^{2}\right)-\left(T t_{k} / r_{c}^{2}\right)}
$$

To numerically approximate RSC from values of the type curve variables $\left[h(t) / h_{0}\right]$ and $\left[T t / r_{c}^{2}\right.$ ] for discrete times $t_{k}, t_{k+1}, \ldots$ given by Cooper et al. (1967), we assume the following approximations:

$$
T \bar{t}_{k} / r_{c}^{2} \approx \frac{1}{2}\left(T t_{k} / r_{c}^{2}+T t_{k+1} / r_{c}^{2}\right)
$$

and

$$
h\left(\bar{t}_{k}\right) / h_{0} \approx \frac{1}{2}\left[h\left(t_{k}\right) / h_{0}+h\left(t_{k+1}\right) / h_{0}\right]
$$

where 


$$
\bar{t}_{k}=\frac{1}{2}\left(t_{k}+t_{k+1}\right)
$$

We numerically approximate Equation (F8) at a time interval centered at

$$
\begin{gathered}
\bar{t}_{k}=3.5 \mathrm{~min} \\
\text { by } \\
r s c=-\frac{\pi r_{c}^{2}}{h\left(\bar{t}_{k}\right)}\left(\frac{T \bar{t}_{k} / r_{c}^{2}}{3.5 \mathrm{~min}}\right) \frac{\left[h\left(t_{k+1}\right) / h_{0}\right]-\left[h\left(t_{k}\right) / h_{0}\right]}{\left(T t_{k+1} / r_{c}^{2}\right)-\left(T t_{k} / r_{c}^{2}\right)}
\end{gathered}
$$

The transmissivity $T$ for the given RSC value is then inferred from

$$
T=\frac{r_{c}^{2}}{\bar{t}_{k}}\left(T \bar{t}_{k} / r_{c}^{2}\right)
$$

For the Pahute Mesa tests

$$
r_{c}=0.125 \mathrm{ft}
$$

and

$$
\bar{t}_{k}=3.5 \mathrm{~min}
$$

so that

$$
T=\frac{(0.125 \mathrm{ft})^{2}}{3.5 \mathrm{ft}}\left(T \bar{t}_{k} / r_{c}^{2}\right)
$$

Hydraulic conductivity, $K$, corresponding to the RSC value is obtained by dividing $T$ by $200 \mathrm{ft}$. 


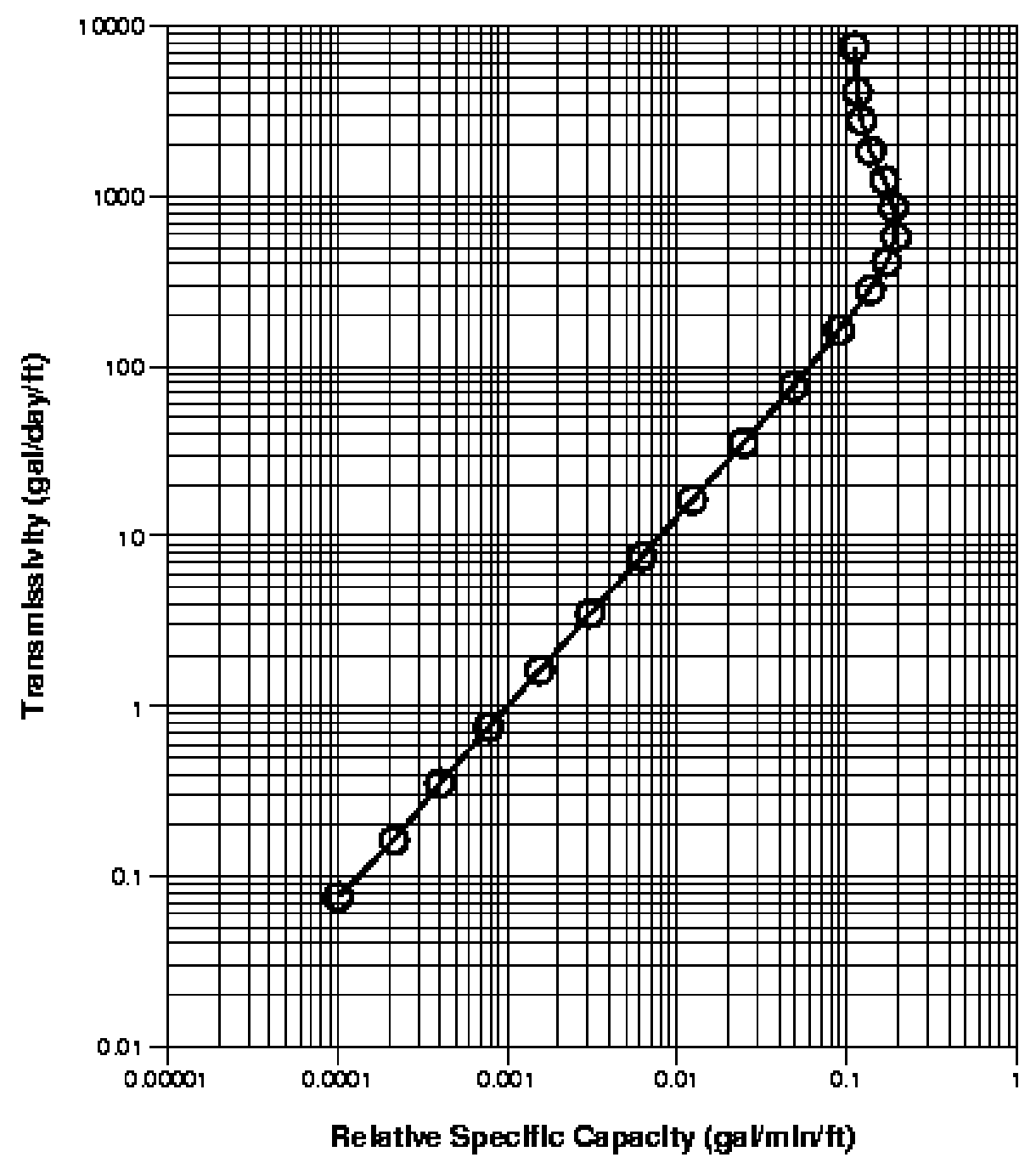

Figure F.2 Relationship between transmissivity and RSC, which was used to evaluate variations in permeability at Pahute Mesa (Blankennagel and Weir, 1973)

tests with

Figure F.2 shows the resulting relationship between RSC and T for injection

$$
r_{c}=0.125 \mathrm{ft}
$$

and

$$
\bar{t}_{k}=3.5 \mathrm{~min}
$$

as conducted in well U-20a \#2 Water Well. For RSC less than 0.1, the conversion to $T$ is direct and nearly linear. For RSC greater than 0.1 , the conversion to $T$ is non-unique because $T$ values above $200 \mathrm{gal} / \mathrm{d}$ / ft could have the same RSC value. Therefore, RSC estimates above 0.1 would indicate hydraulic conductivity values much greater than estimates obtained from the 10.0 multiplication factor given by Blankennagel et al. (1964). We are pleased that our derivation yields a result that is consistent with an 
example given by Blankennagel et al. (1964), who indicate that RSC $=0.1$ converts to $K=$ $1.0 \mathrm{gal} / \mathrm{d} / \mathrm{ft}^{2}$. According to our calibration curve in Figure F.2, an RSC value of 0.1 converts to $T=200 \mathrm{gal} / \mathrm{d} / \mathrm{ft}$, which converts to $K=1.0 \mathrm{gal} / \mathrm{d} / \mathrm{ft}^{2}$ assuming the standard packed interval length of $200 \mathrm{ft}$.

Another problem with converting the RSC values to transmissivity derives from the manner in which the injection tests were conducted. The tests were initiated by connecting the packed-off interval to a $0.25 \mathrm{ft}$ diameter water column of height greater than $2000 \mathrm{ft}$. Based on the pumping test, the average hydraulic conductivity in U-20a \#2 Water Well is about $0.3 \mathrm{~m} / \mathrm{d}$. As shown later, the average hydraulic conductivity in the high permeability zones is about $0.85 \mathrm{~m} / \mathrm{d}$. For a packed interval of $60 \mathrm{~m}$ thickness, the transmissivity of a high-permeability zone would be about $50 \mathrm{~m}^{2} / \mathrm{d}$. To maintain the ideality of frictionless flow in the tube at $1 \mathrm{sec}$ after commencing the test, the water column would drop at a rate of about $200 \mathrm{ft} / \mathrm{s}$. Considerable head losses will result for such high-velocity flow. The U.S.G.S. (see footnote 1) has conducted a careful type curve analysis of the injection test data to obtain better $T$ estimates. Their analysis also indicates that the data do not fit type curves for RSC values greater than 0.06 . The poor fits at higher RSC values are attributed to head losses.

Table F.1 gives the RSC values and estimated $T$ and values of mean interval hydraulic conductivity obtained from combining the pumping test and injection tests in U-20a \#2 Water Well.

Considering that the injection test ranges overlap and high-permeability zones are adjacent for several depth intervals in U-20a \#2 Water Well, we simplify Table F.1 as shown in Table F.2.

Two injection tests were performed in U-20n within the intrusive dike (Jenkins, 1969). Table F.3 shows the RSC data and estimated transmissivities and hydraulic conductivities. 
Table F.1 Transmissivity and hydraulic conductivity estimates from interpretation of RSC data for U-20a \#2 Water Well.

\begin{tabular}{|l|l|l|l|}
\hline $\begin{array}{c}\text { Interval, } \\
\text { ft b.g.s. }\end{array}$ & RSC & \multicolumn{1}{|c|}{$\begin{array}{c}\text { T, } \\
\text { m2/d }\end{array}$} & $\begin{array}{c}\text { K, } \\
\text { m/d }\end{array}$ \\
\hline \hline $2067-2404$ & 0.05 & 0.97 & 0.0094 \\
\hline $2404-2608$ & 0.13 & High & High \\
\hline $2492-2682$ & 0.13 & High & High \\
\hline $2693-2883$ & 0.06 & 1.31 & 0.019 \\
\hline $2895-3085$ & 0.12 & High & High \\
\hline $3090-3280$ & 0.09 & High & High \\
\hline $3265-3455$ & 0.02 & 0.18 & 0.0031 \\
\hline $3460-3650$ & 0.06 & 1.16 & 0.017 \\
\hline $3648-3838$ & 0.17 & High & High \\
\hline $3848-4038$ & 0.05 & 1.04 & 0.015 \\
\hline $4048-4238$ & 0.04 & 0.70 & 0.010 \\
\hline $4161-4351$ & 0.00 & Very low & Very low \\
\hline $4355-4500$ & 0.01 & 0.15 & 0.0034 \\
\hline
\end{tabular}

b.g.s. = below ground surface.

Table F.2 Transmissivity and hydraulic conductivity estimates from interpretation of RSC data for U-20a \#2 Water Well, adjusted for overlapping intervals

\begin{tabular}{|l|l|l|}
\hline $\begin{array}{c}\text { Interval, } \\
\text { ft b.g.s. }\end{array}$ & \multicolumn{1}{|c|}{$\begin{array}{c}\boldsymbol{T}, \\
\mathbf{m}^{\mathbf{2}} / \mathbf{d}\end{array}$} & \multicolumn{1}{|c|}{$\begin{array}{c}\boldsymbol{K}, \\
\mathbf{m} / \mathbf{d}\end{array}$} \\
\hline \hline $2067-2404$ & 0.97 & 0.0094 \\
\hline $2404-2682$ & High & High \\
\hline $2693-2883$ & 1.31 & 0.023 \\
\hline $2895-3265$ & High & High \\
\hline $3265-3455$ & 0.18 & 0.0031 \\
\hline $3460-3650$ & 1.16 & 0.020 \\
\hline $3650-3838$ & High & High \\
\hline $3848-4038$ & 1.04 & 0.018 \\
\hline $4048-4161$ & 0.70 & 0.020 \\
\hline $4161-4351$ & Very low & Very low \\
\hline $4355-4500$ & 0.15 & 0.0034 \\
\hline
\end{tabular}

b.g.s. = below ground surface. 
Table F.3 Transmissivity and hydraulic conductivity estimates from interpretation of RSC data for well U-20n.

\begin{tabular}{|l|l|l|l|}
\hline \multicolumn{1}{|c|}{ Depth interval, ft } & \multicolumn{1}{|c|}{ RSC } & \multicolumn{1}{|c|}{$\boldsymbol{T}, \mathbf{~ m}^{2} / \mathbf{d}$} & \multicolumn{1}{c|}{$\boldsymbol{K}, \mathbf{~ m} / \mathbf{d}$} \\
\hline \hline $3824-3896$ & 0.003 & 0.040 & 0.0018 \\
\hline $3885-3985$ & 0.0005 & 0.0053 & 0.00018 \\
\hline
\end{tabular}

\section{F.3 Hydrofacies}

Based on the hydraulic conductivity values given in Tables F.2 and F.3, we identify four hydrofacies within the lava flows - high, moderate, low, and very low permeability. We define these hydrofacies by the ranges of hydraulic conductivity shown in Table F.4. The distribution of permeabilities inferred from the injection tests, shown in Figure F.3, also shows how we distinguish the moderate, low, and very low permeability hydrofacies. The total transmissivity values for the moderate, low, and very low permeability hydrofacies are obtained by summing the $T$ values given in Table F.2 for the given range of $K$. These sums were multiplied by a factor of 1.02 to account for the fact that the packer tests sampled $2396 \mathrm{ft}$ of the $2433 \mathrm{ft}$, or $98 \%$ of the thickness of the saturated zone in U-20a \#2 Water Well. An average hydraulic conductivity of $0.0020 \mathrm{~m} / \mathrm{d}$ for the dike is estimated by combining the transmissivity estimates from the RSC data in the 4355-4500 ft depth interval in U-20a \#2 Water Well with the two measurements in U-20n.

The sum of the transmissivities for the dike and the moderate, low, and very low permeability hydrofacies in U-20a \#2 Water Well was subtracted from $224 \mathrm{~m}^{2} / \mathrm{d}$ estimate of total transmissivity to obtain the estimated transmissivity of $218.7 \mathrm{~m}^{2} / \mathrm{d}$ for the high permeability hydrofacies. The resulting hydraulic conductivity estimate of $0.83 \mathrm{~m} / \mathrm{d}$ for the high permeability hydrofacies falls within a range of hydraulic conductivity of $0.5-2.4 \mathrm{~m} / \mathrm{d}$ obtained from U.S.G.S. analysis of pumping tests at ER-206 \#1, ER-20-6 \#2, and ER-20-6 \#3 well cluster located about $1.5 \mathrm{~km}$ northwest of hole U20n and screened in lava flow aquifers of the mafic-poor Calico Hills Formation. ${ }^{2}$ Therefore, we ascribe our high permeability hydrofacies to previous hydrofacies descriptions of lava flow aquifers (Drellack et al., 1997; Prothro and Drellack, 1997; IT Corporation, 1998a).

\footnotetext{
${ }^{2}$ A.L. Geldon, written communication, 1999.
} 
Table F.4 Hydrofacies defined by hydraulic conductivity ranges inferred from hydraulic testing data in U-20a \#2 Water Well and well U-20n.

\begin{tabular}{|l|l|l|l|l|}
\hline Hydrofacies & \multicolumn{1}{|c|}{$\begin{array}{c}\text { Range of } \boldsymbol{K}, \\
\mathbf{m} / \mathbf{d}\end{array}$} & \multicolumn{1}{|c|}{$\begin{array}{c}\boldsymbol{\Sigma} \boldsymbol{T}, \\
\mathbf{m}^{2} / \mathbf{d}\end{array}$} & $\begin{array}{c}\text { Average } \boldsymbol{K}, \\
\mathbf{m} / \mathbf{d}\end{array}$ & $\begin{array}{c}\text { \% of section in } \\
\text { U-20a\#2 Water Well }\end{array}$ \\
\hline \hline High & $0.5-2.4$ & 218 & 0.83 & 38 \\
\hline Moderate & $0.0094-0.0226$ & 5.26 & 0.016 & 45 \\
\hline Low & 0.0031 & 0.18 & 0.0031 & 8.5 \\
\hline Very low & 0.0003 & 0.02 & 0.0003 & 8.5 \\
\hline Dike & $0.00018-0.0034$ & 0.194 & 0.0020 & $\sim 10 \mathrm{~m}$ thick \\
\hline
\end{tabular}

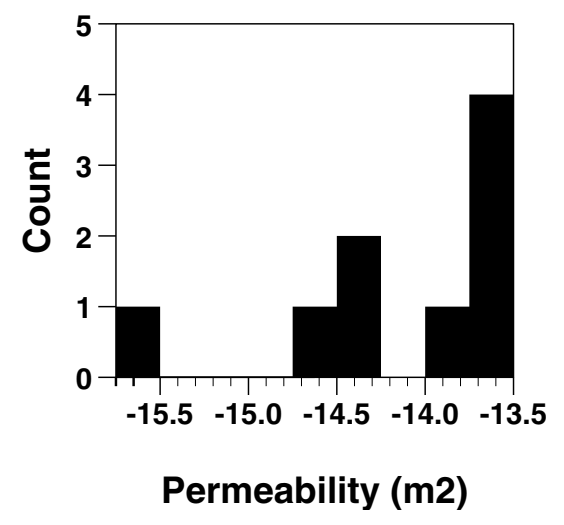

Figure F.3 Permeability distribution inferred from injection tests in U-20a \#2 Water Well and well U20n. The three clusters define the very low, low, and moderate permeability hydrofacies.

Interestingly, the hydraulic conductivity estimates obtained from the ER-20-6 well cluster ranged from 0.5 to $0.7 \mathrm{~m} / \mathrm{d}$ from analysis of the pumping well data and from 1.1 to $2.4 \mathrm{~m} / \mathrm{d}$ from analysis of the observation well data. These results indicate that the ER-20-6 cluster was aligned along a major axis of anisotropy. For example, if we assume that the effective lateral hydraulic conductivity, $K_{e}$, interpreted from drawdown at the pumping well is $0.6 \mathrm{~m} / \mathrm{d}$, and the hydraulic conductivity in the major direction, $K_{y}$, is $1.2 \mathrm{~m} / \mathrm{d}$, the anisotropy ratio is $4: 1$ considering that

$$
K_{e}=\sqrt{K_{x} K_{y}}
$$

The two ER-20-6 pumping test analyses yield two important implications for CHESHIRE. First, $0.83 \mathrm{~m} / \mathrm{d}$ is a reasonable estimate of the effective hydraulic conductivity of the high-permeability hydrofacies. Second, the preferential alignment of fracture systems in the lava flows may cause anisotropy of at least 4:1 between the major-to-minor lateral flow directions. 


\section{F.3.1 Fractures}

Fractures are considered the dominant contributor to permeability in the lava flows aquifers at Pahute Mesa (Blankennagel and Weir, 1973). Fractures at Pahute Mesa have been characterized by examination of core and geophysical logs (Drellack et. al, 1997). However, the character of the fractures, including spatial variation of location, aperture, and secondary mineralization remains highly uncertain at CHESHIRE. Both sparseness of data and spatial variability of fracture characteristics in the lava flow aquifers cause this uncertainty.

The frequency and dip of fractures was examined in about $14.7 \mathrm{~m}(48.1 \mathrm{ft})$ of core obtained from lava flows of the mafic-poor Calico Hills Formation in U-20a \#2 Water Well (Hoover et al., 1964). Fracture frequencies are 0.64, 0.09, 0.09, 0.64, 0.67, 1.28, and 1.31 fractures per meter in each core, averaging 5.5 fractures per meter (Table F.5). Dips are fairly uniformly distributed between 0 and 90 degrees. These cores span about $2 \%$ of the saturated zone, representing a small sample of the spatial characteristics of fractures in U-20a \#2 Water Well. No information was given on aperture or whether fractures were open or closed.

Table F.5 Fracture data for core obtained from rhyolite lava flows of the mafic-poor Calico Hills Formation in U-20a \#2 Water Well, categorized by range of dip angle.

\begin{tabular}{|l|c|c|c|c|c|c|c|c|c|c|}
\hline $\begin{array}{l}\text { Depth, } \\
\mathbf{m}\end{array}$ & $\begin{array}{c}\text { Fractures } \\
\text { per meter }\end{array}$ & $\begin{array}{c}\mathbf{0}- \\
\mathbf{1 0}\end{array}$ & $\begin{array}{c}\mathbf{1 0 -} \\
\mathbf{2 0}\end{array}$ & $\begin{array}{c}\mathbf{2 0}- \\
\mathbf{3 0}\end{array}$ & $\begin{array}{c}\mathbf{3 0 -} \\
\mathbf{4 0}\end{array}$ & $\begin{array}{c}\mathbf{4 0 -} \\
\mathbf{5 0}\end{array}$ & $\begin{array}{c}\mathbf{5 0 -} \\
\mathbf{6 0}\end{array}$ & $\begin{array}{c}\mathbf{6 0 -} \\
\mathbf{7 0}\end{array}$ & $\begin{array}{c}\mathbf{7 0 -} \\
\mathbf{8 0}\end{array}$ & $\begin{array}{c}\mathbf{8 0 -} \\
\mathbf{9 0}\end{array}$ \\
\hline $\begin{array}{l}718.7- \\
721.5\end{array}$ & 6.9 & 0 & 0 & 2 & 3 & 5 & 2 & 0 & 3 & 4 \\
\hline $\begin{array}{l}784.9- \\
787.3\end{array}$ & 1.0 & 0 & 0 & 1 & 0 & 0 & 0 & 0 & 0 & 1 \\
\hline $\begin{array}{l}882.1- \\
884.5\end{array}$ & 7.2 & 1 & 3 & 1 & 1 & 2 & 1 & 2 & 0 & 1 \\
\hline $\begin{array}{l}1115.6- \\
1185.0\end{array}$ & 1.0 & 0 & 0 & 0 & 0 & 0 & 0 & 1 & 1 & 0 \\
\hline $\begin{array}{l}1214.0- \\
1216.8\end{array}$ & 14.1 & 3 & 6 & 6 & 3 & 0 & 4 & 2 & 3 & 1 \\
\hline $\begin{array}{l}1341.0- \\
1343.0\end{array}$ & 13.8 & 0 & 0 & 1 & 4 & 1 & 1 & 2 & 4 & 5 \\
\hline Total & 5.5 & 4 & 9 & 11 & 11 & 8 & 8 & 7 & 11 & 12 \\
\hline
\end{tabular}

Drellack et al. (1997) analyzed fracture characteristics in more detail at wells UE-20e \#1, UE-20f, UE-20bh \#1, UE-20c, UE-19x, ER-20-5 \#1, and ER-20-2 \#1 on Pahute Mesa. In addition to fracture frequency and dip, these analyses include data on direction, aperture, and mineralization. Important for hydrogeologic considerations, open fractures were distinguished from closed fractures.

Each well shows unique fracture orientation characteristics. The spatial distribution of fracture orientations is affected by a variety of factors including variation in the tectonic and volcanic stress fields, the cooling history, and proximity to faults. 
Notably, fracture data from the same well could show marked variations in orientation with depth. Well UE-20bh \#1, located about $1 \mathrm{~km}$ east of U-20n, is situated in a similar lithologic and tectonic setting to CHESHIRE. Directional data for UE-20bh \#1 (Figures F.5 and F.5), derived from acoustic (BHTV) and microresistivity (FMS) geophysical logs, characterize variation in open fracture orientations (Drellack et al., 1997; Lefeuvre et al, 1993; Paillet and Goldberg, 1991), which is particularly important for understanding the fractured flow system. The open fracture distributions in UE-20bh \#1 show a major tendency in the NNE direction and a minor tendency in the ESE direction. These directions are aligned or slightly oblique with major faults and tectonic boundaries in Pahute Mesa. The main distribution of fracture orientations is steeply dipping and centered between strikes of $\mathrm{N} 20^{\circ} \mathrm{E}$ and $\mathrm{N} 30^{\circ} \mathrm{E}$. This orientation is similar to the $\mathrm{N} 30^{\circ}$ E alignment of the hydraulic gradient in our flow model. The West Greeley Fault, which passes between CHESHIRE and UE-20bh \#1, strikes to the NNE. The distribution of fractures near CHESHIRE is certainly influenced by tectonic conditions and faulting.

Drellack et. al (1997) subdivided aperture data according to hydrogeologic units. From examination of core from lava flow aquifers, closed fracture occurrences average $1.8 / \mathrm{m}$ and open fracture occurrences average $0.39 / \mathrm{m}$ with an average aperture of $0.91 \mathrm{~mm}$. This average aperture estimate is believed skewed to a higher value by data from well UE-18r. The average of open fracture apertures throughout Pahute Mesa is $0.5 \mathrm{~mm}$.

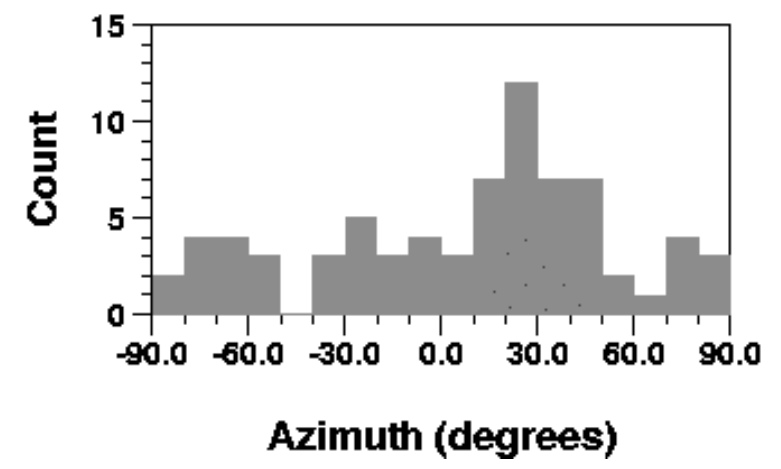

Figure F.4 Distribution of open fracture azimuths in mafic-poor Calico Hills Formation inferred from sonic (BHTV) log of well UE20bh \#1 (modified from Drellack et al., 1997). 


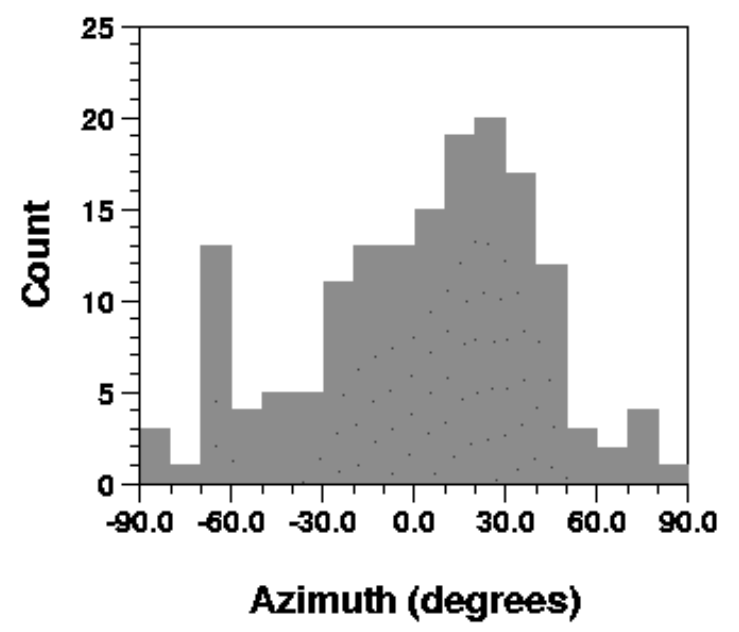

Figure F.5 Distribution of open fracture azimuths in mafic-poor Calico Hills Formation inferred from microresistivity (FMS) log of well UE-20bh \#1 1 (modified from Drellack et al., 1997).

If fractures dominate the permeability of the lava flow aquifers, the question arises: Can observed fracture densities and apertures account for the transmissivities measured in pumping tests? By applying the cubic law, the permeability, $k$, of a fracture zone is approximated by

$$
k=\frac{N b^{3}}{12}
$$

where $N$ is the fracture density, and $b$ is the aperture. Setting $N=0.39 / \mathrm{m}$ and $b=0.0005$ $\mathrm{m}(0.5 \mathrm{~mm})$ yields

$$
k=4.0 \times 10^{-12} \mathrm{~m}^{2}
$$

which corresponds to a hydraulic conductivity of $5.0 \mathrm{~m} / \mathrm{d}$ at a temperature of $37.8^{\circ} \mathrm{C}$ $\left(100^{\circ} \mathrm{F}\right)$ The transmissivity for the pumping test at U-20a \#2 Water Well corresponds to an average hydraulic conductivity of $0.3 \mathrm{~m} / \mathrm{d}$. Therefore, fractures certainly could account for the permeability in the lava flows at CHESHIRE.

Of course, natural fracture zones will be less permeable than an idealized parallel plate model, as assumed for the cubic law, because of surface roughness, tortuosity, and degree of interconnectivity. We must also consider that a cubic power law dependency on fracture aperture indicates that a distribution of fracture aperture sizes will yield a permeability estimate that is higher than the permeability estimate obtained by using the average aperture. A few fractures with relatively large aperture could create a very high permeability zone. Zimmerman and Bodvarsson (1994) give a detailed discussion on the effects of surface roughness, aperture variations, and proportions of contact area on hydraulic conductivity of fractures, which is beyond the scope of this report. Nonetheless, simple calculations from the available fracture data at Pahute Mesa certainly indicate that fractures could produce permeabilities of the magnitude estimated from pumping tests. 


\section{F.3.2 Effective Porosity}

The flow simulations require specification of a porosity value at each grid block to determine simulated flow velocities. We must keep in mind that at the $10 \mathrm{~m}$ scale of our grid blocks, these simulated flow velocities represent volume averaged or effective flow velocities. Thus, the porosity values represent the effective porosity values used to obtain realistic effective flow velocities. Therefore, a porosity value assigned to a grid block of the model represents effective porosity relevant to fluid flow at the grid block scale, which is $10 \mathrm{~m}$ in our flow simulations. Although matrix porosity in the rhyolite lavas is typically $15 \%$, the effective porosity is much less because fluid flow occurs primarily in fractures. Assuming an average fracture density of $N=0.39 / \mathrm{m}$ and an average fracture aperture of $b=0.0005 \mathrm{~m}$ yields a porosity of $0.02 \%$. However, the effective porosity used for the grid block scale in the flow model will be greater than fracture porosity. This difference is because the effective fluid velocity is less than what would be obtained from an ideal parallel plate model, considering tortuosity, surface roughness, interconnectivity, etc.

Effective porosity remains one of the most difficult transport parameters to estimate for a fracture-dominated flow system. Analysis of field tracer tests could provide a useful effective porosity estimation approach. Analyses of tracer tests conducted for the BULLION Forced Gradient Experiment yielded effective porosity estimates ranging from 0.008 to 0.023 . In our transport simulations, we have assumed an effective porosity of 0.01 for high and moderate permeability hydrofacies, where fracture flow is assumed dominant over matrix flow.

\section{F.4 Conclusions}

We have conducted a detailed review of data relevant to hydraulic properties of mafic-poor Calico Hills Formation rhyolitic lava flows within the saturated zone near the CHESHIRE site. These data primarily consist of a pumping test in U-20a \#2 Water Well, injection tests in U-20a \#2 Water Well and U-20n, interpretations of the BULLION Forced Gradient Experiment, and fracture data from wells on Pahute Mesa including U20a \#2 Water Well and UE-20bh \#1.

Our interpretations of hydraulic data indicate that the rhyolitic lava flows exhibit a range of bulk permeabilities between $2.5 \times 10^{-16}$ and $7.0 \times 10^{-13} \mathrm{~m}^{2}$, which corresponds to a range of hydraulic conductivities of 0.0003 to $0.83 \mathrm{~m} / \mathrm{d}$ at $35^{\circ} \mathrm{C}$. Given this wide distribution of permeability, we conclude that intermediate-scale permeability variations in the undisturbed rhyolitic lava flows can be accounted for by defining four hydrofacies - high, moderate, low, and very low permeability - that provide a basis for generating realizations of in situ lava flow permeability heterogeneity at CHESHIRE. The resolution of our interpretations of permeability heterogeneity are limited to the finest scale of hydraulic testing, the injection tests, which typically sample a 50 to $60 \mathrm{~m}$ interval. Finer scale heterogeneities, such as narrow fracture zones, would certainly lead to more complex flow and transport behavior. Further study and research on finer scale heterogeneity, particularly spatial characteristics of interconnected fracture networks, would be useful. 
Fracture data on aperture and spacing indicate that fractures can account for the permeabilities inferred from hydraulic testing data in well U-20a \#2 Water Well. Geophysical logs indicate that fractures near CHESHIRE tend to be steeply dipping and have a primary azimuthal distribution centered at about $\mathrm{N} 25^{\circ} \mathrm{E}$ and a secondary distribution centered at about $\mathrm{N} 65^{\circ} \mathrm{W}$, which are consistent with orientations of faults and tectonic blocks in the area. Therefore, we expect that enhanced permeability will occur in the vertical direction and toward the NNE.

Given that we are using a continuum-based model to simulate flow, effective porosity becomes an important parameter for transport simulation because it directly scales effective flow velocities. Interpretations of tracer data from the BULLION ForcedGradient Experiment indicate values ranging between 0.008 and 0.023 for effective porosity of the high permeability hydrofacies (lava flow aquifers), which brackets the 0.01 value that we assume for most of our flow simulations. 


\section{APPENDIX G:}

Geostatistical Modeling 


\section{G.1 Introduction}

In this appendix, we describe our approach to generating geostatistical realizations of heterogeneous in situ or native rock permeability at our $10 \mathrm{~m}$ grid block resolution. Our goal in generating the geostatistical realizations of subsurface permeability is to examine how heterogeneity affects the flow field. In turn, the multiple permeability realizations yield multiple realizations of flow and transport behavior (see Chapters 5 and 7). The transport simulations produced from multiple permeability realizations enables evaluation and quantification of uncertainty in transport predictions resulting from uncertainty in the characterization of subsurface permeability structure.

We use a categorical geostatistical approach to quantify, model, and simulate spatial variability of lava flow heterogeneity. The categories are defined as hydrofacies — rock units with distinctive hydraulic characteristics - within the maficpoor Calico Hills Formation. The more prevalent indicator geostatistical techniques (Deutsch and Journel, 1998) employ indicator variograms as the measure of spatial variability and rely on intensive data sets to fit empirical models of spatial variability. Alternatively, we employ a transition probability/Markov approach (Carle and Fogg, 1996; Carle and Fogg, 1997; Carle et al., 1998) to improve interpretability (and lessen reliance on intensive data sets), to ensure reproduction of specified volumetric proportions, and to include consideration for spatial auto- and cross-correlations. Spatial cross-correlations control juxtapositional tendencies, which govern how different rock categories tend to occur adjacent to each other in space. The stochastic simulation algorithm uses a Markov chain model of spatial variability for automatic generation of geologically plausible realizations of hydrofacies architecture. This process is called conditional simulation to emphasize that the simulation algorithm honors or is conditioned to prescribed data, such as hydrofacies inferred from injection tests in well U-20a \#2 Water Well.

\section{G.1 Modeling Spatial Variability}

We begin by using the transition probability/Markov approach to quantify spatial variability of hydrofacies occurrences by use of a transition probability matrix. The transition probability simply measures the conditional probability that one hydrofacies occurs at one observation point given that another (or the same) hydrofacies occurs at another observation point (Carle and Fogg, 1996). To impart the spatial dependence, the transition probability matrix is formulated as a function of lag, the separation vector (or distance in a particular direction) between two observation points. The geostatistical analysis was applied to hydrofacies interpretations of the injection test data for well U-20a \#2 Water Well (Appendix F). A vertical ( $z$ ) direction transition probability matrix $\mathbf{T}\left(h_{z}\right)$ was measured from these data as a function of a vertical lag vector $h_{z}$ at spacings of $10 \mathrm{~m}$, the grid block spacing of the flow model (Figure G.1). Each entry $t_{j k}\left(h_{z}\right)$ in the matrix $\mathbf{T}\left(h_{z}\right)$ is defined in terms of a conditional probability by 


$$
t_{j k}\left(h_{z}\right)=\operatorname{Pr}\left\{k \text { occurs at } \mathbf{x}+\mathbf{u}_{z} h_{z} \mid j \text { occurs at } \mathbf{x}\right\}
$$

where $\mathbf{x}$ is a spatial location, $\mathbf{u}_{z}$ is the unit vector in the $z$ direction, and $j$ and $k$ denote facies $j$ and facies $k$, respectively.

In Figure G.1, the solid line indicates a continuous-lag Markov chain or matrix exponential model of facies spatial variability in the vertical direction defined by

$$
\mathbf{T}\left(h_{z}\right)=\exp \left[\mathbf{R}_{z} h_{z}\right]
$$

where $\mathbf{R}_{z}$ represents a transition rate matrix for the vertical direction (Carle and Fogg, 1997). We choose a Markov chain model to fit the data primarily because it is, in theory, the simplest stochastic model, and it has been shown to be an excellent model for many earth science applications. Clearly, the transition probability data do not exhibit a close fit to the model, mainly because the data are sparse, such that the transition probability measurements are inaccurate. The most accurate transition probability data are obtained for the high and moderate hydrofacies because these categories constitute most $(85 \%)$ of the section. The transition probability data for the low and very low permeability hydrofacies are very noisy and do not support much interpretation. We see that the transition probability data for the high and moderate permeability hydrofacies exhibit some apparent cyclicity, which is related to the fact that occurrences of high permeability hydrofacies in U-20a \#2 Water Well tend to be spaced about $200 \mathrm{~m}$ apart. With more data and irregular spacings of the high permeability hydrofacies, cyclicity would disappear in the transition probability measurements. We do not impart cyclicity into the Markov chain model because we do not expect the high permeability zones to have spatial cyclicity. Accordingly, we fit the Markov chain model through the middle of the transition probability data, emphasizing fit to the shortest lags.

For CHESHIRE, our modeled vertical transition rate matrix, $\mathbf{R}_{z}$, is given by

$$
\mathbf{R}_{z}=\left[\begin{array}{cccc}
-0.01667 & 0.01583 & 0.00083 & 0.00000 \\
0.01274 & -0.02315 & 0.00333 & 0.00708 \\
0.00363 & 0.01804 & -0.03333 & 0.01167 \\
0.00000 & 0.03833 & 0.01167 & -0.05000
\end{array}\right] \mathrm{m}^{-1}
$$

where categories 1 through 4 are high, moderate, low, and very low permeability, respectively. The entries $r_{j k, z}$ correspond to slopes of $t_{j k}\left(h_{z}\right)$ at the lag origin where $h_{z}=0$. The diagonal entries $r_{j j, z}$ are related to mean length in the $z$ direction (mean thickness) by

$$
r_{j j, z}=-\frac{1}{\bar{L}_{j, z}}
$$



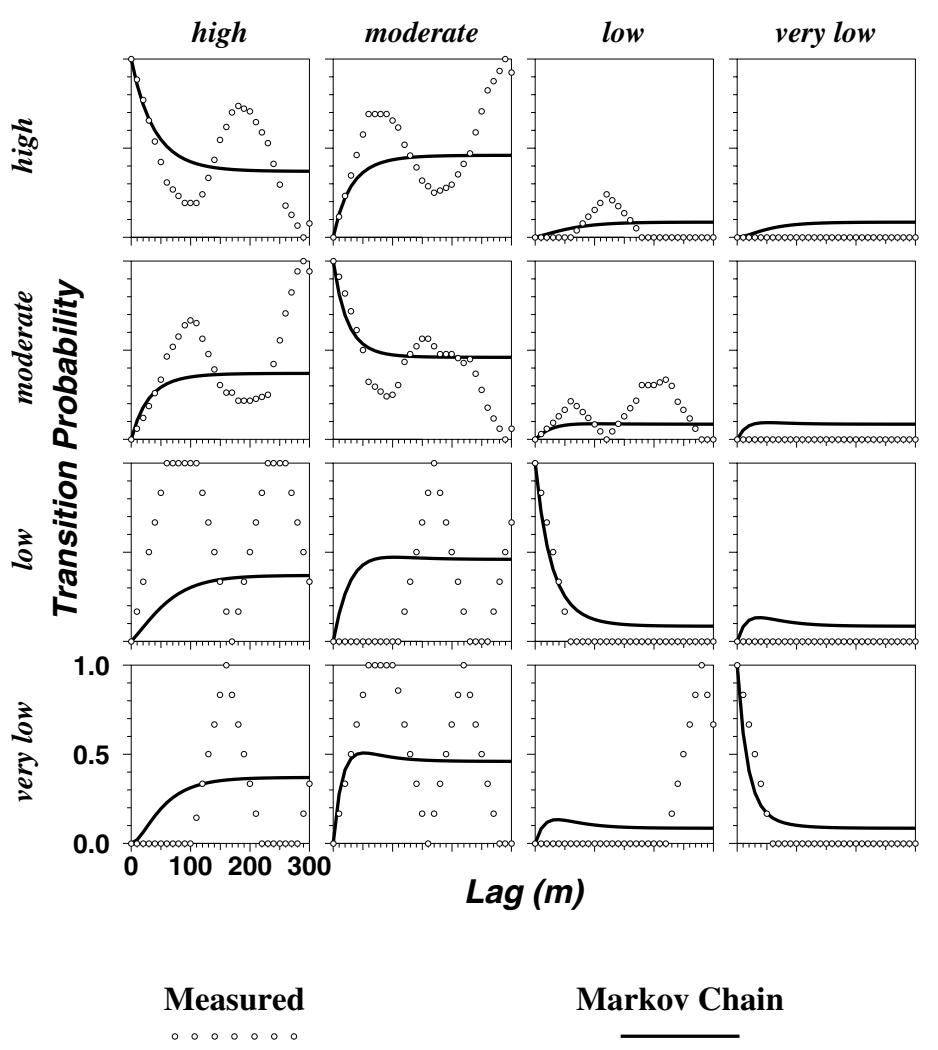

Figure G.1 Vertical transition probability measurements and Markov chain model. Data are based on hydrofacies interpretations of hydraulic data from U-20a \#2 Water Well.

For example, the entry $r_{11, z}=-0.01667$ indicates by Equation (G4) that the high permeability zones have a mean thickness of $60 \mathrm{~m}$. In the practice of developing the stochastic model, we established $r_{11, z}$ from the estimate of the mean thickness of high permeability zones. The off-diagonal entries, $r_{j k, z}$ for $j$ not equal to $k$, are related to the juxtapositional tendencies between one facies and another (Carle and Fogg, 1997; Carle et al., 1998). An off-diagonal transition rate of zero indicates that the facies do not occur adjacent to each other. The row sums of the transition rates equal zero. As the magnitude of an off-diagonal transition rate approaches the magnitude of the diagonal transition rate, the more likely those two facies occur adjacent to each other. The "sills" of $t_{j k}\left(h_{z}\right)$ approach the column category proportions $p_{k}$ as the lag becomes large so that

$$
\lim _{h_{z} \rightarrow \infty} t_{j k}\left(h_{z}\right) \rightarrow p_{k}
$$

The entries $t_{j k}\left(h_{z}\right)$ in $\mathbf{T}\left(h_{z}\right)$ for the matrix exponential model of Equation (G2) are not calculated by

$$
t_{j k}\left(h_{z}\right)=\exp \left(r_{j k, z} h_{z}\right)
$$

Rather, a eigenvalue decomposition of the transition rate matrix is performed such that each entry $t_{j k}\left(h_{z}\right)$ consists of a linear combination of proportions and $K-1$ exponential functions, where $K$ is the number of categories (Agterberg, 1974; Carle and Fogg, 1997). 
Importantly, the Markov chain provides an extremely simple model of the spatial variability; the 16 model curves shown in Figure G.1 are developed from nine parameters - six transition rates with an assumption of symmetry and three facies proportions - in conjunction with the conditions of probability law (Carle and Fogg, 1997).

In most earth science applications, borehole spacing is inadequate for direct measurement of lateral spatial variability. The CHESHIRE site is no exception. However, considering that parameters of the Markov chain can be defined in terms of geologically interpretable concepts of proportions, mean length, and juxtapositional tendencies, the transition probability/Markov geostatistical approach provides a framework for developing geologically plausible models of lateral spatial variability (Carle, 1996; Carle et al., 1998). To develop models of lateral spatial variability of the hydrofacies, we made the following three assumptions: (1) lateral juxtapositional tendencies are similar to those of the vertical, (2) spatial correlation in the $x y$ plane is isotropic, and (3) lateral:vertical anisotropy ratios for the high, low, and very low hydrofacies are 5:1, 4:1, and $4: 1$, respectively.

The most important anisotropy ratio is the 5:1 value used for the high permeability zones because it dictates the lateral continuity of the major conduits of flow and transport downgradient from the CHESHIRE test. We arrived at the 5:1 value because it reflects a mean length of $300 \mathrm{~m}$ in the lateral direction, which is nearly the distance between wells U-20n and UE-20n \#1. The hydrogeologic information obtained from these two wells suggests some but not perfect lateral correlation of high permeability zones between these two wells (Erikson, 1991). Accordingly, the $300 \mathrm{~m}$ value yields an intermediate correlation of high permeability zones between U-20n and UE-20n \#1. The three-dimensional Markov chain model needed for the conditional simulation algorithm was generated by spatial interpolation of the $x, y$, and $z$ direction transition rates (Carle and Fogg, 1997).

\section{G.3 Conditional Simulation}

The conditional simulation algorithm used in this study contains two steps: (1) cokriging-based sequential indicator simulation (SIS), and (2) simulated quenching as described in detail by Carle (1996), Carle et al. (1998), and Deutsch and Journel (1998) and summarized below.

The SIS process cycles through every grid cell in the realization along a random path, using cokriging to estimate conditional probabilities that a facies occurs at a grid cell given the conditioning information, which are facies occurrences located at nearby grid cells. Initially, data are the only conditioning information. Based on the cokriging estimates of the conditional probability that a facies occurs at a particular grid cell, a random number generator selects the facies that occurs at a grid cell in the realization. As the SIS process continues to other grid cell locations along random path, the conditioning information is sequentially updated by the simulated values. This process continues one grid cell at a time until all cells are visited by the random path. 
Understand that the cokriging estimate only approximates the conditional probability that a facies $k$ occurs at a location $\mathbf{x}_{0}$ given nearby data. The cokriging estimate is formulated as a weighted sum by

$$
\operatorname{Pr}\left[k \text { occurs at } \mathbf{x}_{0} \mid I_{j}\left(\mathbf{x}_{a}\right) ; \alpha=1, \ldots, N ; j=1, \ldots, K\right] \approx \sum_{\alpha=1}^{N} \sum_{j=1}^{K} I_{j}\left(\mathbf{x}_{\alpha}\right) w_{j k, \alpha}
$$

where $N$ is the number of data, $K$ is the number of categories, $w_{j k, \alpha}$ represents a weighting coefficient, and $I_{j}\left(\mathbf{x}_{\alpha}\right)$ represents an indicator variable defined by

$$
I_{j}\left(\mathbf{x}_{\alpha}\right)=\left\{\begin{array}{c}
1, \text { if category } j \text { occurs at location } \mathbf{x}_{\alpha} \\
0, \text { otherwise }
\end{array}\right.
$$

The weighting coefficients $w_{j k, \alpha}$ are computed by solving the transition probability-based cokriging system of equations (Carle, 1996; Carle and Fogg, 1996),

$$
\left[\begin{array}{ccc}
\mathbf{T}\left(\mathbf{x}_{1}-\mathbf{x}_{1}\right) & \cdots & \mathbf{T}\left(\mathbf{x}_{N}-\mathbf{x}_{1}\right) \\
\vdots & \ddots & \vdots \\
\mathbf{T}\left(\mathbf{x}_{1}-\mathbf{x}_{N}\right) & \cdots & \mathbf{T}\left(\mathbf{x}_{N}-\mathbf{x}_{N}\right)
\end{array}\right]\left[\begin{array}{c}
\mathbf{W}_{1} \\
\vdots \\
\mathbf{W}_{N}
\end{array}\right]=\left[\begin{array}{c}
\mathbf{T}\left(\mathbf{x}_{0}-\mathbf{x}_{1}\right) \\
\vdots \\
\mathbf{T}\left(\mathbf{x}_{0}-\mathbf{x}_{N}\right)
\end{array}\right]
$$

where

$$
\mathbf{W}_{a}=\left[\begin{array}{ccc}
w_{11, a} & \cdots & w_{1 K, a} \\
\vdots & \ddots & \vdots \\
w_{K 1, a} & \cdots & w_{K K, a}
\end{array}\right]
$$

The SIS step alone does not ensure that the realization will honor the model of spatial variability including all spatial auto- and cross-correlations. The simulated quenching step is used to improve the match between modeled and simulated spatial variability by minimizing a global objective function

$$
\mathbf{O}=\sum_{i=1}^{M} \sum_{j=1}^{K} \sum_{k=1}^{K}\left[t_{j k}\left(\mathbf{h}_{t}\right)_{S I M}-t_{j k}\left(\mathbf{h}_{t}\right)_{M O D}\right]^{2}
$$

where $\mathbf{h}_{1}$ denote lag vectors with specific locations, and SIM and MOD distinguish simulated (as measured from the realization) and modeled transition probabilities, respectively (Aarts and Korst, 1989; Deutsch and Cockerham, 1994; Carle, 1997; Deutsch and Journel, 1998). The simulated quenching is implemented by cycling through every grid cell of the realization several times along a random path and querying whether a change in facies will decrease $\mathbf{O}$; if yes, the facies is changed. 


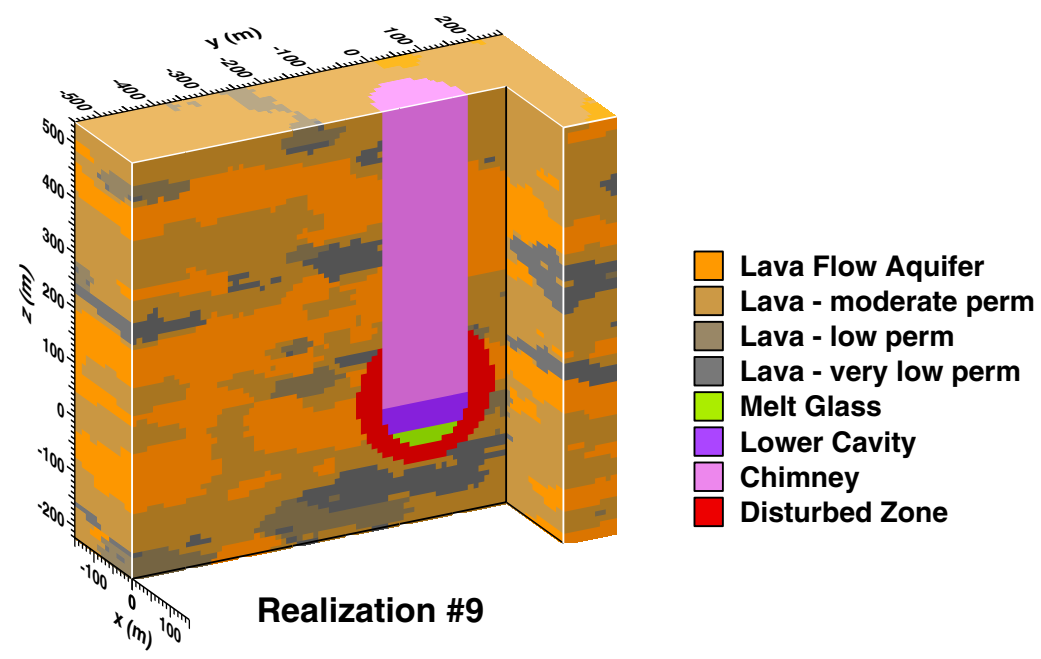

Figure G.2 Realization \#9 out of 10 geostatistical realizations generated for flow and transport simulation at CHESHIRE.

Figure G.2 shows a geostatistical realization of lava flow hydrofacies architecture around CHESHIRE. The image also includes the post-test units of melt glass, lower cavity, chimney, and disturbed zone as deterministic zones for the flow and transport simulations. Each realization will display a different spatial distribution of the lava flow hydrofacies, each having similar spatial statistics (proportions, mean lengths, juxtapositional tendencies).

\section{G.4 Conclusions and Recommendations}

We used the transition probability/Markov geostatistical methods described above to generate stochastic simulations or realizations of the spatial distribution of permeable zones near the CHESHIRE test. Our goal was to create realistic simulations of subsurface permeability to examine how heterogeneity affects the flow field. The generation of multiple realizations for multiple flow and transport simulations enables evaluation and quantification of uncertainty in transport predictions resulting from uncertainty in the characterization of the subsurface heterogeneity. Granted, considerable uncertainty remains in the determination of the geostatistical parameters, which could introduce several more dimensions of sensitivity analyses. Importantly, the geostatistical approach offers a realistic alternative to more simplistic conceptual models such as homogeneous or layer cake geology, which are both extreme-case scenarios.

Further improvement of the geostatistical approach could be obtained by integrating more interpretations of soft or indirect data such as geophysical data (e.g., temperature logs), geochemical data (e.g., radionuclide concentrations), and geologic interpretations (e.g., fracture geometries). Certainly, the flow and transport behavior is affected by scales of heterogeneity finer than the resolution of our $10 \mathrm{~m}$ grid blocks. Unfortunately, our characterization data and computing capabilities did not support a finer resolution. Nonetheless, we have learned that the nonisothermal flow and transport behavior is profoundly affected by the intermediate scale of heterogeneity we have considered. 


\section{APPENDIX H: \\ Spatial Variation of Mineralization}




\section{H.1 Introduction}

We learned from our simulations of reactive transport for the CAMBRIC test that the presence and location or spatial distribution of reactive minerals, such as hematite, calcite, zeolite, and clay, will greatly affect migration of radionuclides (Tompson et al., 1999). Therefore, uncertainties in the spatial distribution of minerals cause uncertainty in estimating the effect of reactive minerals on retardation of radionuclide transport at CHESHIRE. Given the heterogeneous permeability structure of the subsurface and the strongly transient nonisothermal flow field created by the CHESHIRE test, a wide variety of transport pathways occur. The varied transport pathways are bound to experience spatial variation in mineral distributions. Because the exact spatial distributions of minerals in the subsurface are unknown and are expected to vary, we adopt a stochastic approach to evaluate the effect of spatially variable mineral distributions. Our approach is to develop multiple plausible geostatistical realizations - stochastic simulations having a realistic degree of spatial variability — of the spatial distribution of key reactive minerals. We develop the model of spatial variability of minerals from core sample data collected for the Yucca Mountain Project.

We know that where minerals are present, mineral concentrations vary considerably in space within the scale of meters, as observed in core samples. Yet our flow and transport simulations are limited to a resolution of $10 \mathrm{~m}$. Thus, we must resort to averaged properties at this $10 \mathrm{~m}$ scale. Although clay minerals may be relatively ubiquitous in fractures, minerals such as hematite, calcite, and zeolites are not always present. Thus, a zonal approach based on consideration of the presence and absence of minerals is worthy of consideration. Accordingly we will focus on characterization of the spatial distribution of average mineral concentrations in high and low mineralization zones. Low mineralization may refer to zero concentration for minerals that are not ubiquitous. We focus on analysis of spatial variation of presence and absence of minerals rather than absolute mineral concentrations because (a) the spatial variation of mineral concentrations occurs at a scale much smaller than the $10 \mathrm{~m}$ grid block size of our transport model, and (b) the possibility for extensive transport for certain radionuclides may largely depend on the spatial distribution of nonmineralized zones.

We use two data sets based on core samples obtained from boreholes for the Yucca Mountain Project (Carlos et al., 1995) to analyze the spatial variation of mineralization: (1) x-ray diffraction data obtained exclusively from devitrified tuff (DVT) below the water table, and (2) x-ray diffraction data obtained from a variety of tuffs from above and below the water table (ALL). Chapter 6 describes these data in more detail. We use these data sets to conduct a geostatistical analysis of the spatial variability of the minerals of interest. Both the DVT and ALL data sets are relatively sparse to embark on a purely empirical geostatistical approach to characterizing spatial variation of mineralization. We use a transition probability approach to maximize the interpretability of the spatial variability in the data, as well as to benefit from infusion of geologic insight and interpretation (Appendix $\mathrm{G}$ ) to develop the models of spatial variability. We assume that the mineralization characteristics of the DVT data set are 
more relevant to the rhyolitic lava flows at CHESHIRE. However, the ALL data are more numerous, providing better means for characterizing spatial variation.

Our approach is to analyze both data sets separately and use interpretations of spatial transition probabilities to develop a plausible model of spatial variability of mineralization at CHESHIRE. In turn, we used the DVT data set primarily to establish the proportions of mineralized zones and proportions of fractures for which the fracturelining minerals are present, and we used the ALL data set to establish the spatial variation of the mineralized zones. We focus on developing a model of spatial variability at a scale relevant to the $10 \mathrm{~m}$ grid block size of our flow and transport models.

\section{H.2 Preliminary Analysis}

In analyzing the data, we first focus on presence or absence of each mineral lining the fractures of the core samples. We define an occurrence as meaning that a mineral is present in the fractures of a core sample. Therefore, we first sort the data for each mineral into two categories: (1) occurrences, and (2) nonoccurrences. We will later use block averaging of concentration estimates from core samples to estimate average concentrations and spatial variation of high and low mineralization zones at a $10 \mathrm{~m}$ resolution.

\section{H.2.1 ALL Data}

The ALL data set contains 307 x-ray diffraction analyses of samples obtained from fracture linings in core from five boreholes. The data are irregularly spaced. Table H.1 shows the proportion of fractures in which hematite, calcite, zeolite, and clay are present according to the ALL data set.

Table H.1 Proportions of fractures in which hematite, calcite, zeolite, and clay fracture-lining minerals are present in core samples from the ALL data set.

\begin{tabular}{|c|c|c|c|}
\hline Hematite & Calcite & Zeolite & Clay \\
\hline \hline 0.179 & 0.104 & 0.635 & 0.684 \\
\hline
\end{tabular}

\section{H.2.1.1 Lag Spacing of $1 \mathrm{~m}$}

Figure H.1 shows a matrix of transition probabilities of mineral occurrences plotted as a function of vertical separation or lag. Each entry in the matrix represents the transition probability, $t_{j k}\left(h_{z}\right)$, defined as

$$
t_{j k}\left(h_{z}\right)=\operatorname{Pr}\left\{\text { mineral } k \text { occurs at } x+h_{z} \mid \text { mineral } j \text { occurs at } x\right\}
$$

where $x$ is a location of a core sample, and $h_{z}$ is the lag in the $z$ (vertical) direction (Agterberg, 1974; Carle and Fogg, 1996). In words, $t_{j k}\left(h_{z}\right)$, represents the probability that mineral $k$ occurs at a vertical distance $h_{z}$ away from an occurrence of mineral $j$. The 
diagonal entries represent the transition probabilities for one mineral to itself, and the off-diagonal entries represent the transition probabilities from one mineral to another mineral. Therefore, the diagonal transition probabilities characterize the spatial variability (or continuity) of an individual mineral, whereas the off-diagonal transition probabilities characterize the variability of spatial juxtapositioning of different minerals. In Figure H.1, the transition probabilities are computed for a $1 \mathrm{~m}$ lag spacing. These transition probabilities are relevant to the analysis of vertical spatial variability of mineral occurrences within a $10 \mathrm{~m}$ grid block.

Transition probabilities for the diagonal entries at lag zero, $t_{j j}(0)$, tend to approach 1.0. This should not be surprising because for $j=k$ and $h_{z}=0$, Equation (H1) reduces to

$$
t_{j k}\left(h_{z}\right)=\operatorname{Pr}\{\text { mineral } j \text { occurs at } x \mid \text { mineral } j \text { occurs at } x\}
$$

In practice, gathering mineral data at widely scattered locations will lead to a calculation of $t_{j j}(0)=1.0$. However, if multiple data occur at the same or nearby locations and small-scale variability is present, $t_{j j}(0)$ can be calculated as less than 1.0. Each transition probability measurement was averaged over a $0.5 \mathrm{~m}$ lag tolerance (because the data are not regularly spaced). Therefore, the zero-lag transition probability measurements were averaged over data spaced less than $0.5 \mathrm{~m}$ apart. If considerable spatial variability exists within a scale of $0.5 \mathrm{~m}$, we can expect $t_{j j}(0)<1.0$. Off-diagonal transition probabilities for lag zero, $t_{j k}(0)$ for $j$ not equal to $k$, are generally nonzero because more than one mineral can occur at each data location as a result of small-scale spatial variability.

The transition probability measurements shown in Figure H.1 are computed for two sets of categories: mineralized (circles) and not mineralized (crosses). "Not mineralized" refers to a category defined by the situation of a location where the mineral of interest does not occur. In this way, the spatial variability of both mineralized and not-mineralized zones is analyzed. The solid and dashed lines indicate the transition probabilities for a random distribution of mineralization according to the proportions (see Table H.1) of mineralized and not-mineralized occurrences, respectively. If the minerals were randomly distributed in space without any spatial correlation, the circles will fall near the solid line, and the crosses will fall near the dashed line. For example, if the circles fall above the solid line, this represents a transition probability that is higher than random. Higher-than-random transition probability measurements may result from: (1) spatial continuity of mineralized zones for the diagonal entries, (2) a propensity of one mineral to occur with or near another mineral for the off-diagonal entries, or (3) scatter caused by insufficient data. 

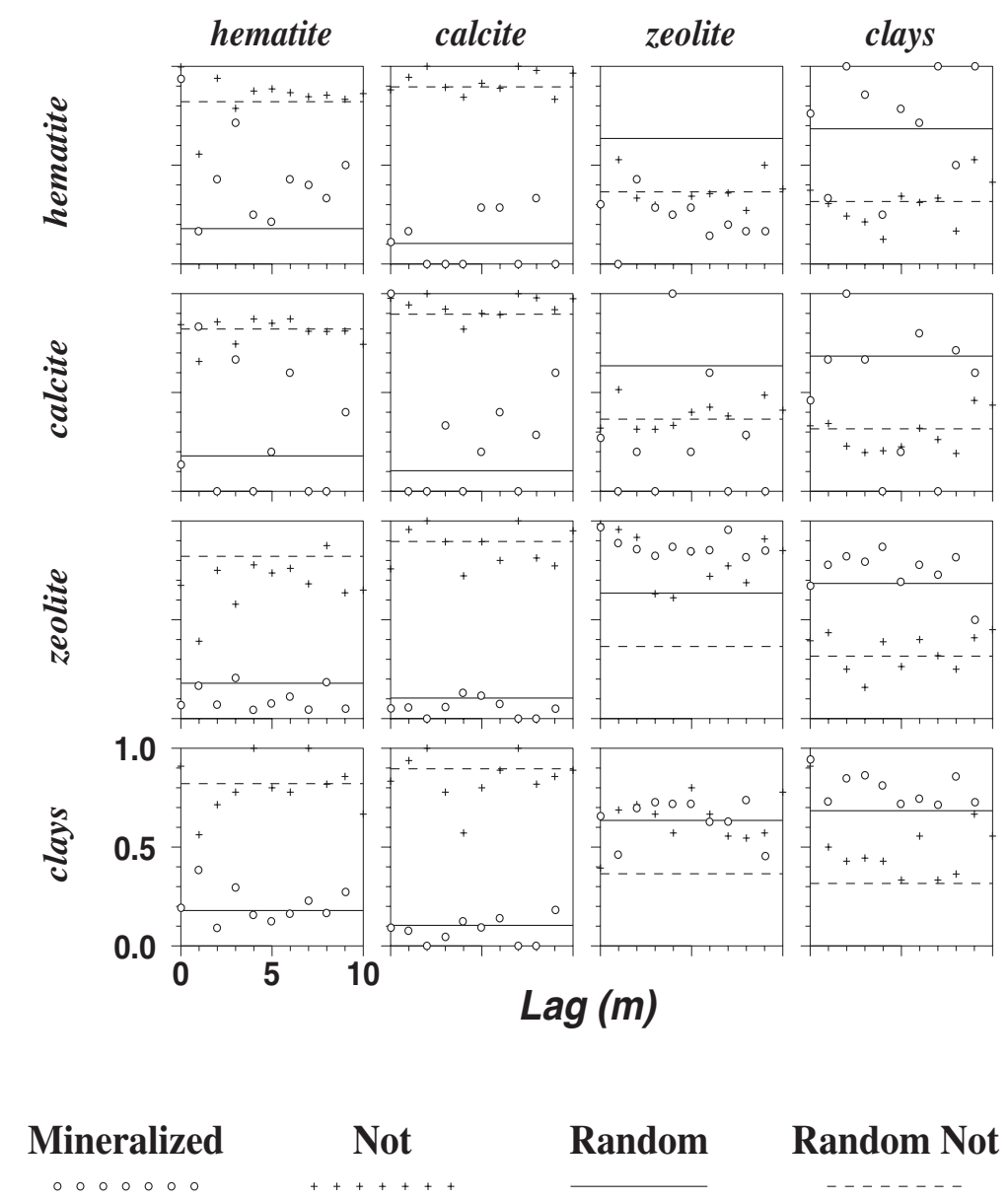

Figure H.1 Vertical transition probability matrix with $1 \mathrm{~m}$ lag spacing for mineralized and not-mineralized fractures for the ALL data set.

For the diagonal entries, the circles generally fall above the solid line except for calcite, indicating that if hematite, zeolite, or clay occur at a location, these minerals tend to occur more abundantly than average within a $10 \mathrm{~m}$ distance. The crosses for the off-diagonal entries reinforce this interpretation, indicating that if hematite, zeolite, or clay do not occur at a location, these minerals occur less frequently than average within a $10 \mathrm{~m}$ distance. Interestingly, comparison of the circles with respect to the solid lines for off-diagonal entries appears to indicate some spatial cross-correlation within $10 \mathrm{~m}$ zones. The $t_{13}\left(h_{z}\right)$ and $t_{23}\left(h_{z}\right)$ data (circles) mostly fall below random, indicating that zeolites tend not to occur where hematite and calcite are present. In complementary fashion, the $t_{31}\left(h_{z}\right)$ and $t_{32}\left(h_{z}\right)$ data (circles) also mostly fall below random, indicating that hematite and calcite, respectively, tend not occur given that zeolite occurs within a $10 \mathrm{~m}$ zone. The other off-diagonal data exhibit too much scatter to interpret as nonrandom. Caution should be exercised to not over-interpret this sparse data; the appearance of nonrandom tendencies may result from insufficient sampling to capture the true spatial variation. 


\section{H.2.1.2 Lag Spacing of $10 \mathrm{~m}$}

Figure H.2 shows a transition probability matrix for the ALL data set at a 10 $\mathrm{m}$ lag spacing. Compared to the $1 \mathrm{~m}$ lag spacing scale of spatial variability shown in Figure H.1, the $10 \mathrm{~m}$ lag spacing scale of spatial variability of mineralization shown in Figure H.2 is more relevant to our flow and transport models.

For the diagonal entries, the circles generally indicate larger, above-random transition probabilities near lag zero and decreasing toward random with increasing lag, which indicates that the mineralized zones do exhibit some spatial continuity at scales greater than $10 \mathrm{~m}$. Again, the data are relatively sparse, so one should take caution to not over-interpret the data. Nonetheless, the $t_{11}\left(h_{z}\right), t_{22}\left(h_{z}\right)$ and $t_{33}\left(h_{z}\right)$ data indicate that hematite, calcite, and clay have less spatial continuity than zeolites. Similar to the transition probabilities analyzed for $1 \mathrm{~m}$ lag, the $t_{13}\left(h_{z}\right)$ and $t_{23}\left(h_{z}\right)$ data (circles) mostly fall below random, indicating that zeolites tend not to occur where hematite and calcite are present in $100 \mathrm{~m}$ scale zones. Otherwise, the spatial cross-correlations do not exhibit any obviously nonrandom tendencies. We point out that, given sufficient data, examination of the spatial cross-correlations should be useful for determining whether certain minerals exhibit preferential patterns of spatial distribution relative to the locations of other minerals.

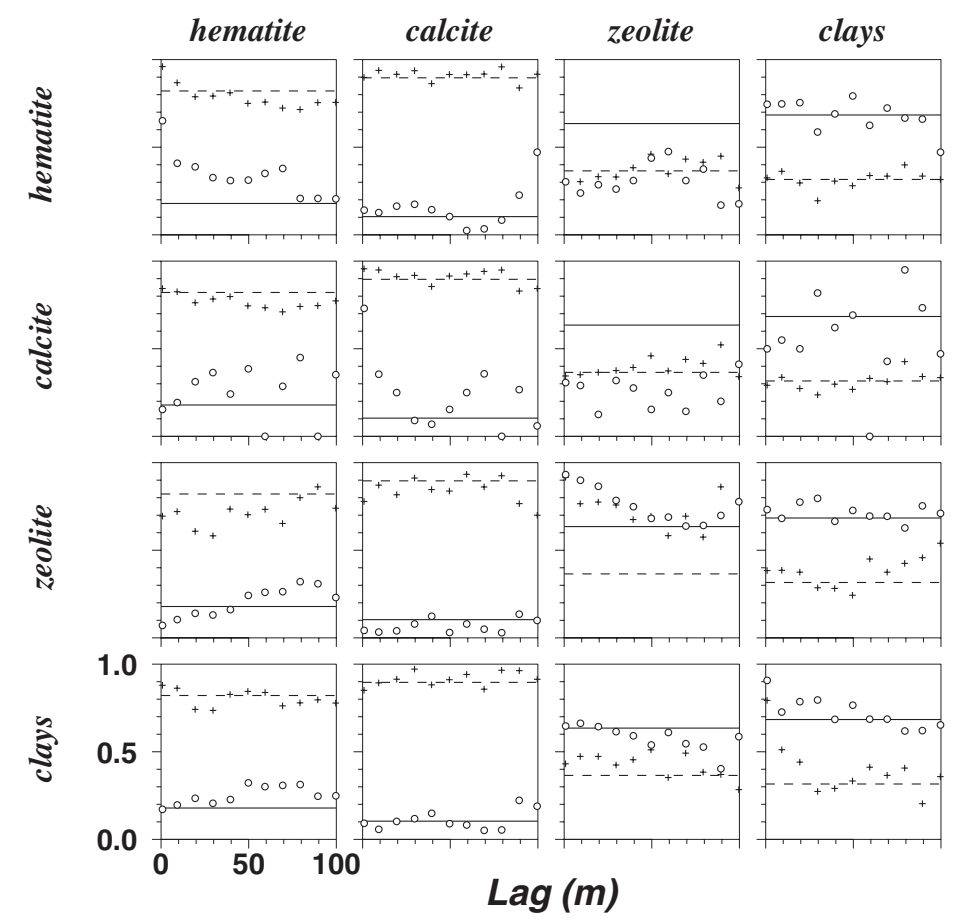

Mineralized Not Random Random Not

Figure H.2 Vertical transition probability matrix with $10 \mathrm{~m}$ lag spacing for mineralized and not-mineralized fractures for the ALL data set 


\section{H.2.2 DVT Data Set}

The DVT data set consists of 68 x-ray diffraction analyses of samples obtained from fracture linings in core obtained from five boreholes. The data are irregularly spaced. Table H.2 shows the proportion of fractures in which hematite, calcite, zeolite, and clay are present according to the ALL data set. We analyzed spatial variability for the DVT data set in a similar manner to the ALL data set. Because the DVT data were less numerous, much more scatter is present in the $t_{j k}\left(h_{z}\right)$ measurements.

Table H.2 Proportions of fractures in which hematite, calcite, zeolite, and clay minerals are present in core samples from the DVT data set.

\begin{tabular}{|l|l|l|l|}
\hline Hematite & \multicolumn{1}{|c|}{ Calcite } & Zeolite & Clay \\
\hline \hline 0.221 & 0.191 & 0.250 & 0.676 \\
\hline
\end{tabular}

\section{H.2.2.1 Lag Spacing of $2 \mathrm{~m}$}

To analyze the smaller-scale spatial variability, we used a $2 \mathrm{~m}$ lag spacing with a $1 \mathrm{~m}$ lag tolerance because data were insufficient to support transition probability analyses at a $1 \mathrm{~m}$ lag spacing. Even at the $2 \mathrm{~m}$ spacing, the $t_{j k}\left(h_{z}\right)$ measurements (Figure H.3) exhibit too much scatter to permit a substantive interpretation. The transition probability measurements do not exhibit strong spatial (cross-) correlation except for possibly $t_{33}\left(h_{z}\right)$, representing spatial variability of zeolites. The $t_{33}\left(h_{z}\right)$ measurements indicate that zeolitic zones exhibit greater spatial continuity than the other mineralized zones, which was also evident in the ALL data set.
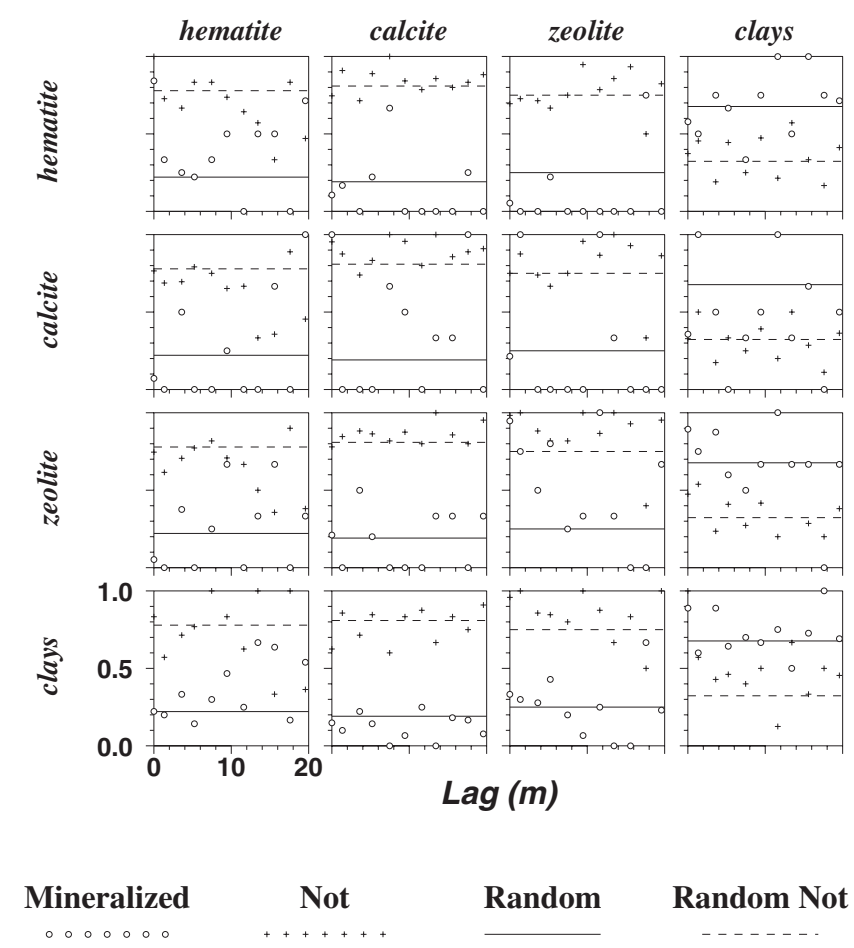

Figure H.3 Vertical transition probability matrix at $2 \mathrm{~m}$ lag for mineralized and notmineralized fracture categories of DVT data set. 


\section{H.2.2.2 Lag Spacing of $10 \mathrm{~m}$}

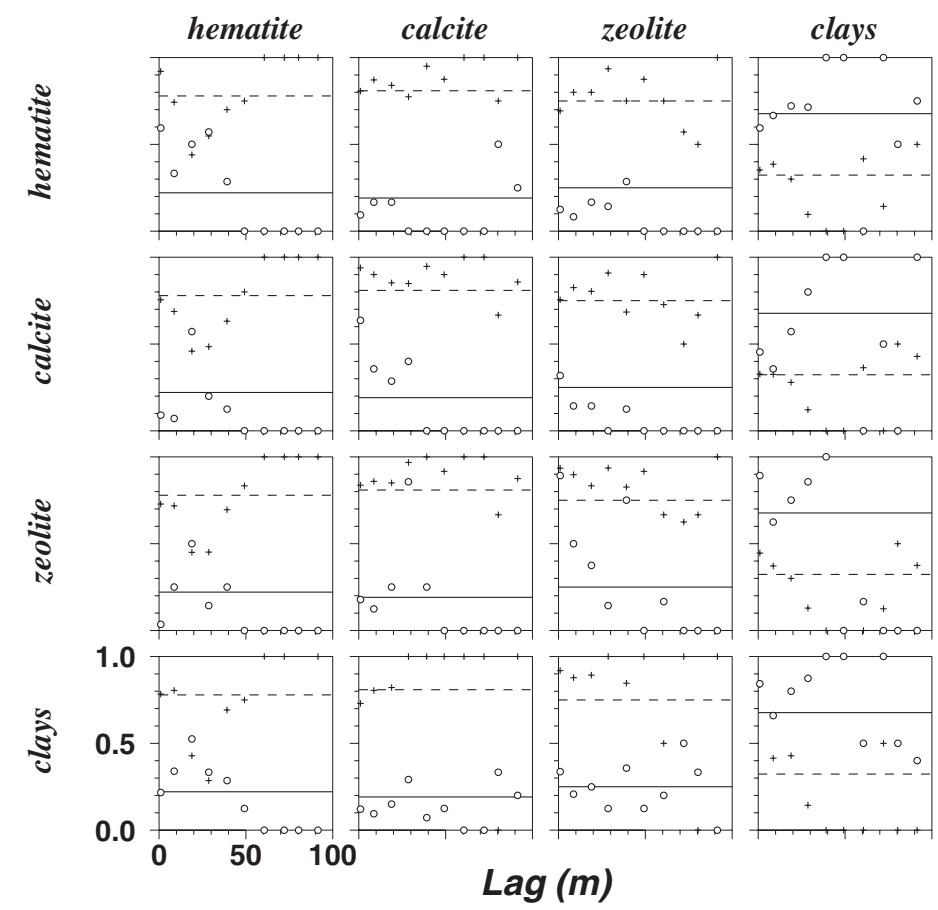

Mineralized Not Random Random Not

Figure H.4 Vertical transition probability matrix at $10 \mathrm{~m}$ lag for mineralized and notmineralized fracture categories of DVT data set.

At $10 \mathrm{~m}$ lag spacing, the $t_{j k}\left(h_{z}\right)$ measurements (Figure H.4) from the DVT data also exhibit considerable scatter. For $h_{z}=50 \mathrm{~m}$, the data are very poor and should be ignored. There is some hint of large-scale spatial continuity for mineralized zones containing hematite, calcite, or zeolites. Similar to the ALL data set, occurrences of clays exhibit high frequency, but exhibit randomness without any noticeable spatial continuity.

\section{H.3 Analysis of High and Low Mineralization Zones}

Based largely on the combined transition probability analyses of the ALL and DVT data sets, we conclude that the hematite, calcite, and zeolites tend to occur in spatially continuous zones. Beyond the $10 \mathrm{~m}$ grid block scale, clays appear to be ubiquitous. Within the $10 \mathrm{~m}$ grid block scale, clays exhibit small-scale spatial variability approaching a random spatial distribution. Considering these interpretations and our need for a simple means for distributing a heterogeneous spatial distribution of mineralization at a $10 \mathrm{~m}$ grid block resolution, we will reanalyze the spatial variability of mineralization by a simple categorical approach. We will define two categories of mineralized zones for each mineral: (1) high mineralization and (2) low mineralization. 

data, we can:

By categorizing the data into zones using moving averages of the original

- Perform the data analysis at the relevant $10 \mathrm{~m}$ scale.

- Smooth out scatter in the transition probability model.

- Provide a simple framework for developing three-dimensional stochastic simulations or realizations of mineralization spatial distributions needed for the three-dimensional transport model.

To accomplish the categorization, we compute moving averages over a $10 \mathrm{~m}$ window (our flow model grid block size) to compute the local (within $\pm 5 \mathrm{~m}$ ) proportions or fractures containing each mineral. If the local proportions exceed the global proportions, given earlier in Tables H.1 and H.2, the location is considered to have high mineralization. Conversely, if the local proportions are less than the global proportions, the location is considered to have low mineralization. Figure H.5 illustrates this conceptualization. In a high mineralization zone, a high proportion of the fracture surfaces are lined with a mineral; in a low mineralization zone, a low proportion of the fracture surfaces are lined with a mineral.

With the data now reanalyzed according to high and low mineralization zones, we define a transition probability $t_{j k}\left(h_{z}\right)$ to examine the spatial variability of high mineralization zones as

$t_{j k}\left(h_{z}\right)=\operatorname{Pr}\left\{\right.$ high mineralization of $k$ occurs at $x+h_{z} \mid$ high mineralization of $j$ occurs at $\left.x\right\}$

In words, Equation $(\mathrm{H} 3)$ defines $t_{j k}\left(h_{z}\right)$ as the probability that high mineralization of $k$ occurs at a distance $h_{z}$ above an occurrence of high mineralization of $j$. By incorporating a moving average, we expect that $t_{j j}(0)=1$ for all $j$, which indicates that any data location is either in a high mineralization zone or a low mineralization zone (not both). This approach assumes that the fractures in high mineralization zones are not completely filled with minerals, and that fractures in low-mineralization zones are not necessarily completely devoid of minerals. We will see that the moving average approach cleans up our interpretation of the spatial variability of mineralization and provides a means for scaling the data to our transport model. Taking moving averages of the raw data helps remove spatial bias or data clustering, which could bias estimates of transition probabilities and proportions. 


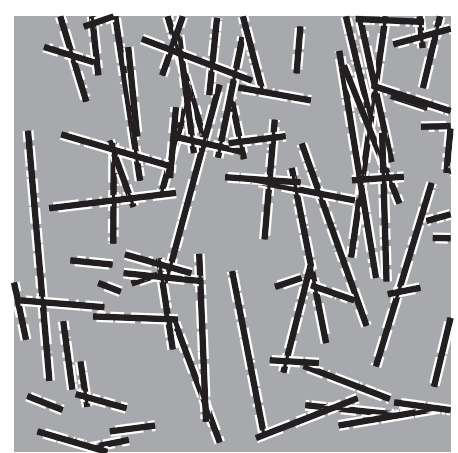

High Mineralization Zone

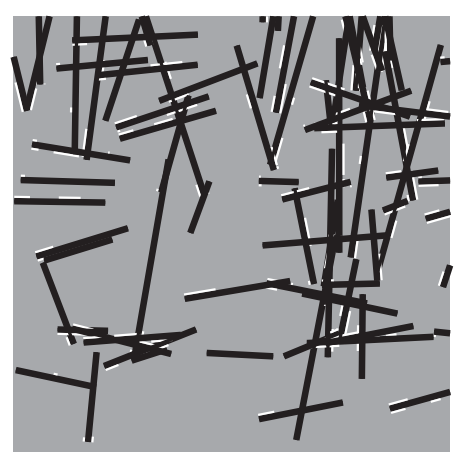

Low Mineralization Zone

Figure H.5 Conceptualization of high and low mineralizations zones. In a high mineralization zone (at left), a high proportion of the fractures (black) are lined with a mineral (white). In a low mineralization zone (at right), a low proportion of the fractures are lined with a mineral.

\section{H.3.1 ALL Data}

The ALL data set was reanalyzed by categorizing the data into high and low mineralization zones. Within the high and low mineralization zones, the average proportion of fractures that are mineralized (contain occurrences of the minerals) was determined. Table H.3 shows the proportion of high and low mineralization zones and the proportion of mineralized fractures in both zones for the ALL data set.

Table H.3 Proportion of high and low mineralization zones and proportion of fractures that are mineralized within those zones for ALL data set.

\begin{tabular}{|l|l|l|l|l|}
\hline \multicolumn{1}{|c|}{ Mineral } & \multicolumn{1}{c|}{ Hematite } & \multicolumn{1}{c|}{ Calcite } & \multicolumn{1}{c|}{ Zeolites } & \multicolumn{1}{c|}{ Clays } \\
\hline \hline $\begin{array}{l}\text { \% high } \\
\text { mineralization }\end{array}$ & 0.37 & 0.30 & 0.60 & 0.57 \\
\hline $\begin{array}{l}\text { \% mineralized } \\
\text { fractures in high }\end{array}$ & 0.48 & 0.35 & 0.97 & 0.94 \\
\hline $\begin{array}{l}\text { \% low } \\
\text { mineralization }\end{array}$ & 0.63 & 0.70 & 0.40 & 0.43 \\
\hline $\begin{array}{l}\text { \% mineralized } \\
\text { fractures in low }\end{array}$ & 0.002 & 0.0 & 0.14 & 0.34 \\
\hline
\end{tabular}

The moving average analysis of the ALL data set indicates several interesting features. These features are all geologically plausible:

- Hematite and calcite tend to occur sporadically in narrow zones.

- Zeolites occur in extensive high mineralization zones with zeolites present in almost all fractures.

- Clays are ubiquitous, in high mineralization zones with clays present in almost all fractures and in low mineralization zones with clays present in about one-third of the fractures. 


\section{H.3.1.1 Lag Spacing of $1 \mathrm{~m}$}

Figure H.6 shows the $t_{j k}\left(h_{z}\right)$ for high mineralization zones at $1 \mathrm{~m}$ lag spacing. These $t_{j k}\left(h_{z}\right)$ data are useful for examining spatial variation within the $10 \mathrm{~m}$ grid block. The diagonal terms, $t_{i j}\left(h_{z}\right)$, all indicate very strong spatial continuity within 3 to $5 \mathrm{~m}$. Notably, the trends in spatial cross-correlation are more distinct than in the raw data analysis. The $t_{13}\left(h_{z}\right), t_{23}\left(h_{z}\right), t_{31}\left(h_{z}\right)$, and $t_{32}\left(h_{z}\right)$ data more clearly indicate a tendency for zeolites to not occur where hematite and calcite occur. Moreover, the $t_{12}\left(h_{z}\right)$ and $t_{21}\left(h_{z}\right)$ data indicate that calcite and hematite tend to occur in conjunction with each other. The remaining off-diagonal transition probabilities appear random.

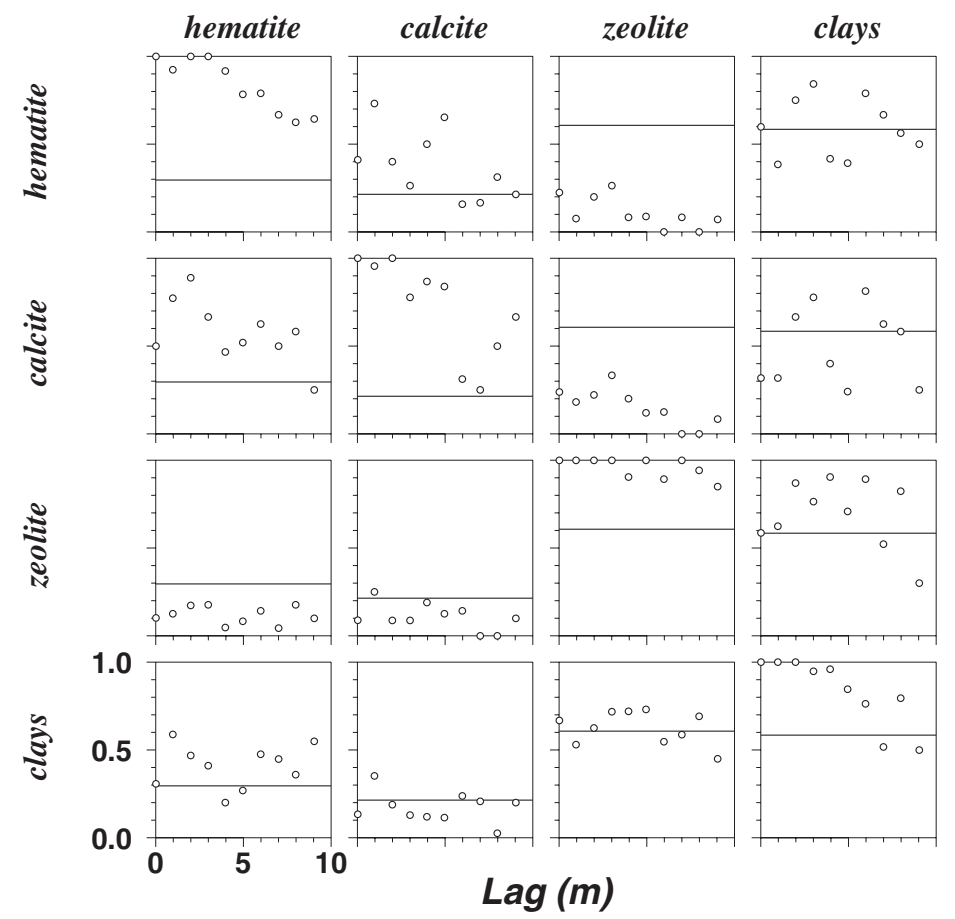

Figure H.6 Vertical transition probability matrix at $1 \mathrm{~m}$ lag for high mineralization zones of ALL data set.

\section{H.3.1.2 Lag Spacing of $10 \mathrm{~m}$}

Figure H.7 shows the $t_{j k}\left(h_{z}\right)$ for high mineralization zones at $10 \mathrm{~m}$ lag spacing. The $t_{j k}\left(h_{z}\right)$ measurements at $10 \mathrm{~m}$ lag spacing are most useful for establishing the spatial variability of high-mineralization zones at the scale relevant to our transport model.

Because of the $5 \mathrm{~m}$ lag tolerance used, it is possible to have $t_{i j}(0)<1$. We see that for all minerals, $t_{i j}(0)$ is approximately 1 , which was not necessarily the case for $t_{i j}(0)$ analyzed from the raw data. The high mineralization categorization in Equation (H3) provides a less stringent condition than Equation $(\mathrm{H} 1)$. The $t_{11}\left(h_{z}\right)$ and $t_{22}\left(h_{z}\right)$ for hematite and calcite, respectively, indicate some spatial continuity. The $t_{33}\left(h_{z}\right)$ for zeolites indicates pronounced spatial continuity. High clay mineralization zones lack spatial continuity because $t_{44}\left(h_{z}\right)$ nears the global proportions for all $h_{z}>0$. Again, the transition probability matrix indicates that zeolites tend not to occur within $100 \mathrm{~m}$ of high 
hematite and calcite zones. Hematite and calcite tend to occur adjacent to each other. All other mineralization spatial cross-correlations are near random. As indicated by $t_{31}\left(h_{z}\right)$, hematite zones occurring vertically adjacent to zeolite zones may be random to aboverandom in frequency. Again, the sparseness of data precludes more detailed interpretation.

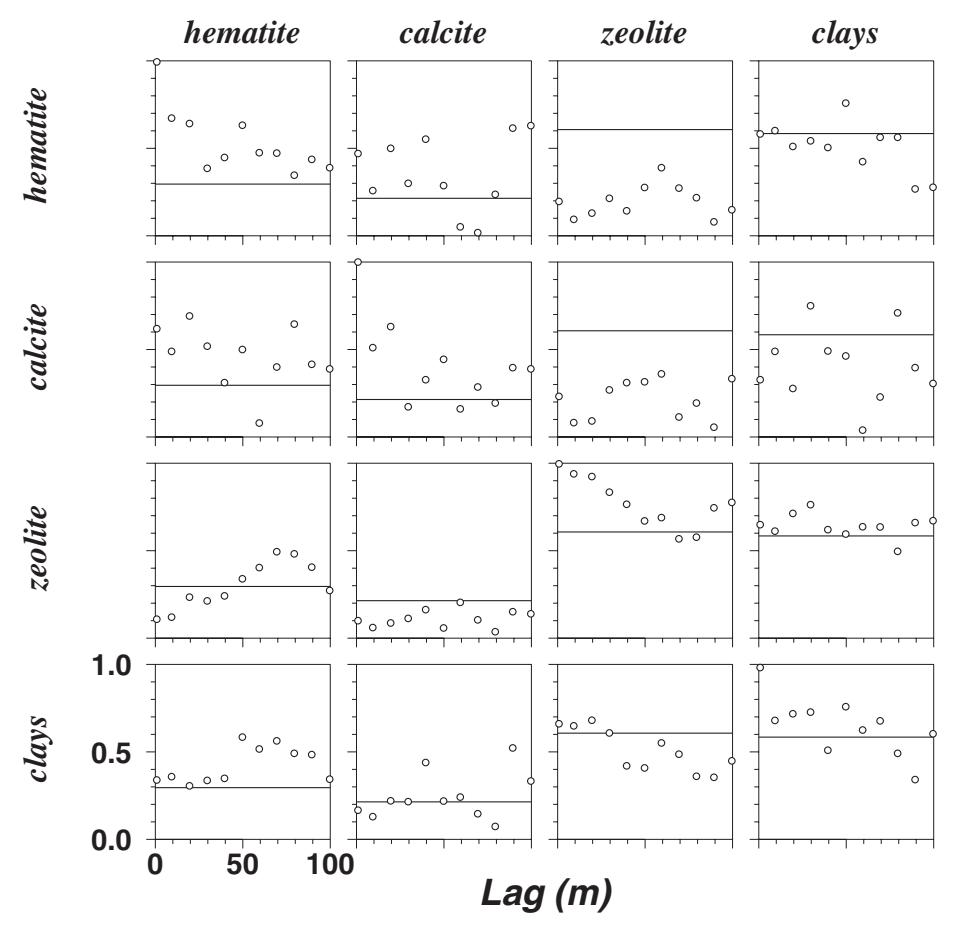

Figure H.7 Vertical transition probability matrix at $10 \mathrm{~m}$ lag for high mineralization zones of ALL data set.

\section{H.3.2 DVT Data}

Table H.4 shows the proportion of high and low mineralization zones and the proportion of mineralized fractures in both zones obtained from the moving average analysis of the DVT data set. features:

The moving average analysis of the DVT data set reveals several interesting

- Hematite, calcite, and zeolites occur almost exclusively within the high mineralization zones.

- In high mineralization zones, zeolites, and clays are present in almost all fractures.

- Clays are ubiquitous, occurring in nearly half of all fractures in low mineralization zones. 
These features support an interpretation that hematite, calcite, and zeolites tend to occur in discrete zones, whereas clay tends occur ubiquitously at the $10 \mathrm{~m}$ scale.

Table H.4 Proportion of high and low mineralization zones and proportion of fractures that are mineralized within those zones for DVT data set.

\begin{tabular}{|l|l|l|l|l|}
\hline \multicolumn{1}{|c|}{ Mineral } & \multicolumn{1}{c|}{ Hematite } & \multicolumn{1}{c|}{ Calcite } & \multicolumn{1}{c|}{ Zeolites } & \multicolumn{1}{c|}{ Clays } \\
\hline \hline $\begin{array}{l}\text { \% high } \\
\text { mineralization }\end{array}$ & 0.43 & 0.28 & 0.23 & 0.52 \\
\hline $\begin{array}{l}\text { \% mineralized } \\
\text { fractures in high }\end{array}$ & 0.41 & 0.43 & 0.95 & 0.96 \\
\hline $\begin{array}{l}\text { \% low } \\
\text { mineralization }\end{array}$ & 0.57 & 0.72 & 0.76 & 0.48 \\
\hline $\begin{array}{l}\% \text { mineralized } \\
\text { fractures in low }\end{array}$ & 0.00 & 0.08 & 0.08 & 0.43 \\
\hline
\end{tabular}

\section{H.3.2.1 Lag Spacing of $2 \mathrm{~m}$}

Figure H.8 shows the transition probability matrix at $2 \mathrm{~m}$ lag spacing for high-mineralization zones defined from $10 \mathrm{~m}$ moving averages of the DVT data set. The transition probability measurements remain highly scattered, and interpretation of it alone would be highly speculative.

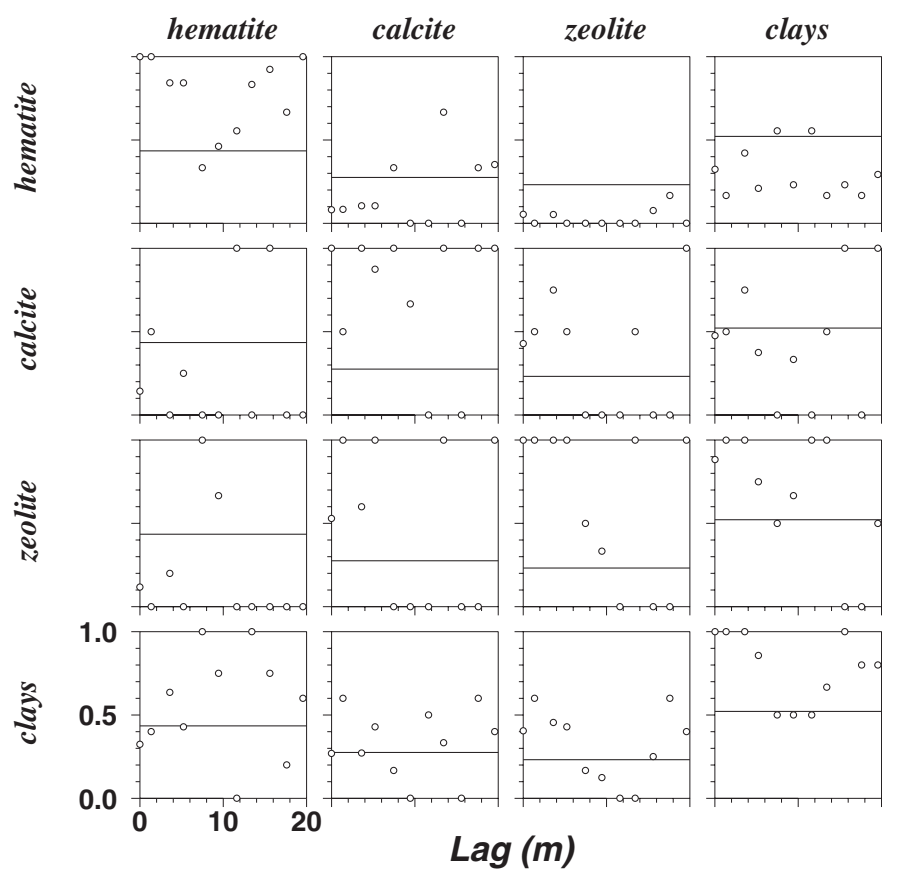

Figure H.8 Vertical transition probability matrix at $2 \mathrm{~m}$ lag for high mineralization zones of DVT data set. 


\section{H.3.2.2 Lag Spacing of $10 \mathrm{~m}$}

Figure H.9 shows the transition probability matrix at $10 \mathrm{~m}$ lag spacing for high mineralization zones defined from $10 \mathrm{~m}$ moving averages of the DVT data set. The transition probability measurements remain highly scattered, and interpretation of it alone would be highly speculative. Measurements of $t_{j k}\left(h_{z}\right)$ for $h_{z}>50 \mathrm{~m}$ are particularly unreliable.

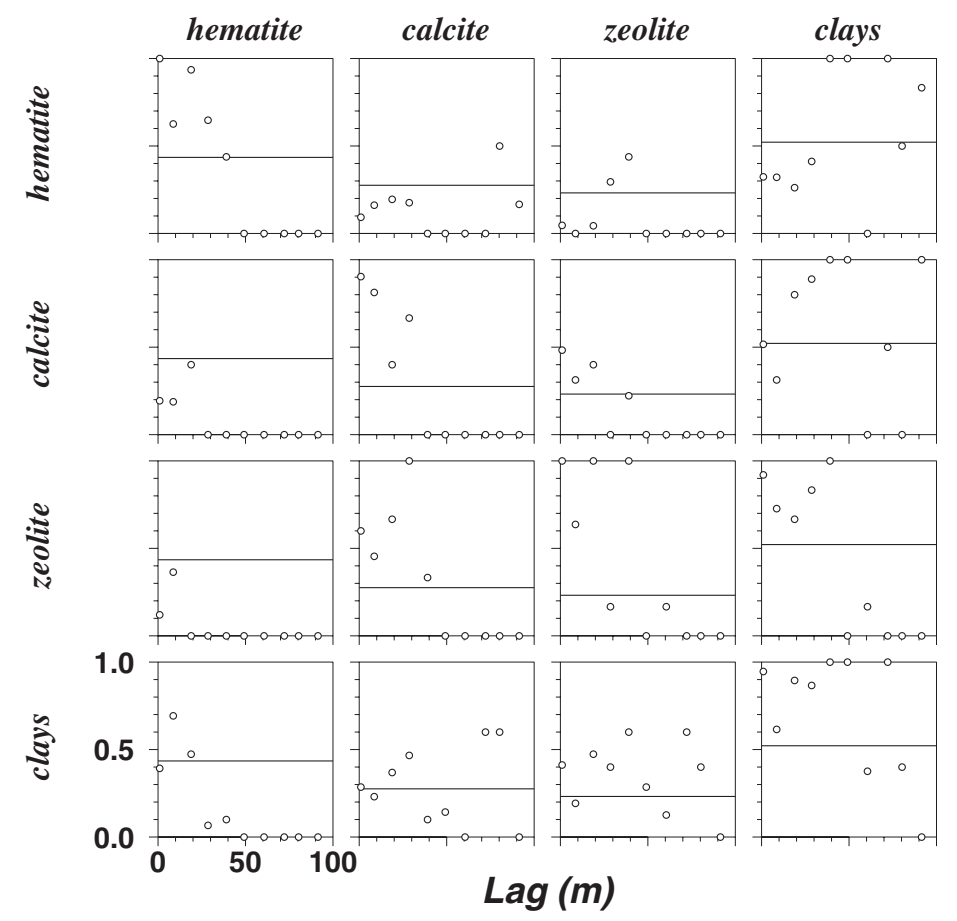

Figure H.9 Vertical transition probability matrix at $10 \mathrm{~m}$ lag for high mineralization zones of DVT data set.

\section{H.4 Spatial Variability Modeling}

Analysis of the mineralization data with transition probability and moving average analyses has been useful for developing both quantitative and conceptual models of the spatial distribution of hematite, calcite, zeolites, and clays at scales relevant to the $10 \mathrm{~m}$ grid spacing of our reactive transport model. We use the DVT data set to guide proportions of the low and high mineralization zones and the more numerous ALL data set to guide development of the spatial (cross-) correlation parameters.

\section{H.4.1 Proportions}

Because the DVT data set was obtained from rocks that are more similar to those at CHESHIRE as compared with the ALL data set, our model of spatial variability for the high and low mineralization zones assumes the proportions given in Table H.4 for the DVT data. 


\section{H.4.2 Range of Spatial Correlation}

The DVT data were inadequate to develop a model of spatial variability. We use the ALL data set to establish the range of correlation for each mineral. We fit a Markov chain (an exponentially decaying function for this two-category case) to the transition probability measurements of each diagonal entry-the auto transition probabilities (Carle and Fogg, 1997). The Markov chain model for $t_{j j}\left(h_{z}\right)$ is formulated by

$$
t_{j j}\left(h_{z}\right)=p_{j}+\left(1-p_{j}\right) \exp \left(\frac{h_{z}}{a_{j}}\right)
$$

where $p_{i}$ is the global proportion of high mineralization zone $j$, and $a_{j}$ is the distance at which the spatial correlation has decayed by $1 /$ e. Markov chain models fit to the $t_{j j}\left(h_{z}\right)$ measurements from the ALL data set are shown in the top row of Figure H.10.

To adapt the Markov chain models developed for the ALL data set to the DVT data set, we simply assume the same $a_{j}$ values, which determine the range of spatial correlation, and substitute the $p_{j}$ values for the DVT data set. The resulting models are shown in the bottom row of Figure H.9 relating to the $t_{j j}\left(h_{z}\right)$ measurements. The models are formulated as follows:

$$
\begin{array}{ll}
\text { hematite: } & t_{11}\left(h_{z}\right)=0.43+0.57 \exp \left(-\frac{h_{z}}{24.3 \mathrm{~m}}\right) \\
\text { calcite: } & t_{22}\left(h_{z}\right)=0.28+0.72 \exp \left(-\frac{h_{z}}{15.6 \mathrm{~m}}\right) \\
\text { zeolite: } & t_{33}\left(h_{z}\right)=0.23+0.77 \exp \left(-\frac{h_{z}}{39.4 \mathrm{~m}}\right) \\
\text { clay : } & t_{44}\left(h_{z}\right)=0.52+0.48 \exp \left(-\frac{h_{z}}{6.2 \mathrm{~m}}\right)
\end{array}
$$

Based on the $a_{j}$ values of the fitted models, we see that zeolitic highmineralization zones exhibit the largest range of correlation, $39.4 \mathrm{~m}$, followed by hematite $(24.3 \mathrm{~m})$, calcite $(15.6 \mathrm{~m})$, and clays $(6.3 \mathrm{~m})$. The estimated $a_{4}$ for clays of $6.2 \mathrm{~m}$ indicates a range of spatial correlation that is comparable to the $10 \mathrm{~m}$ grid block size. These ranges of correlation values appear geologically plausible for each mineral. 

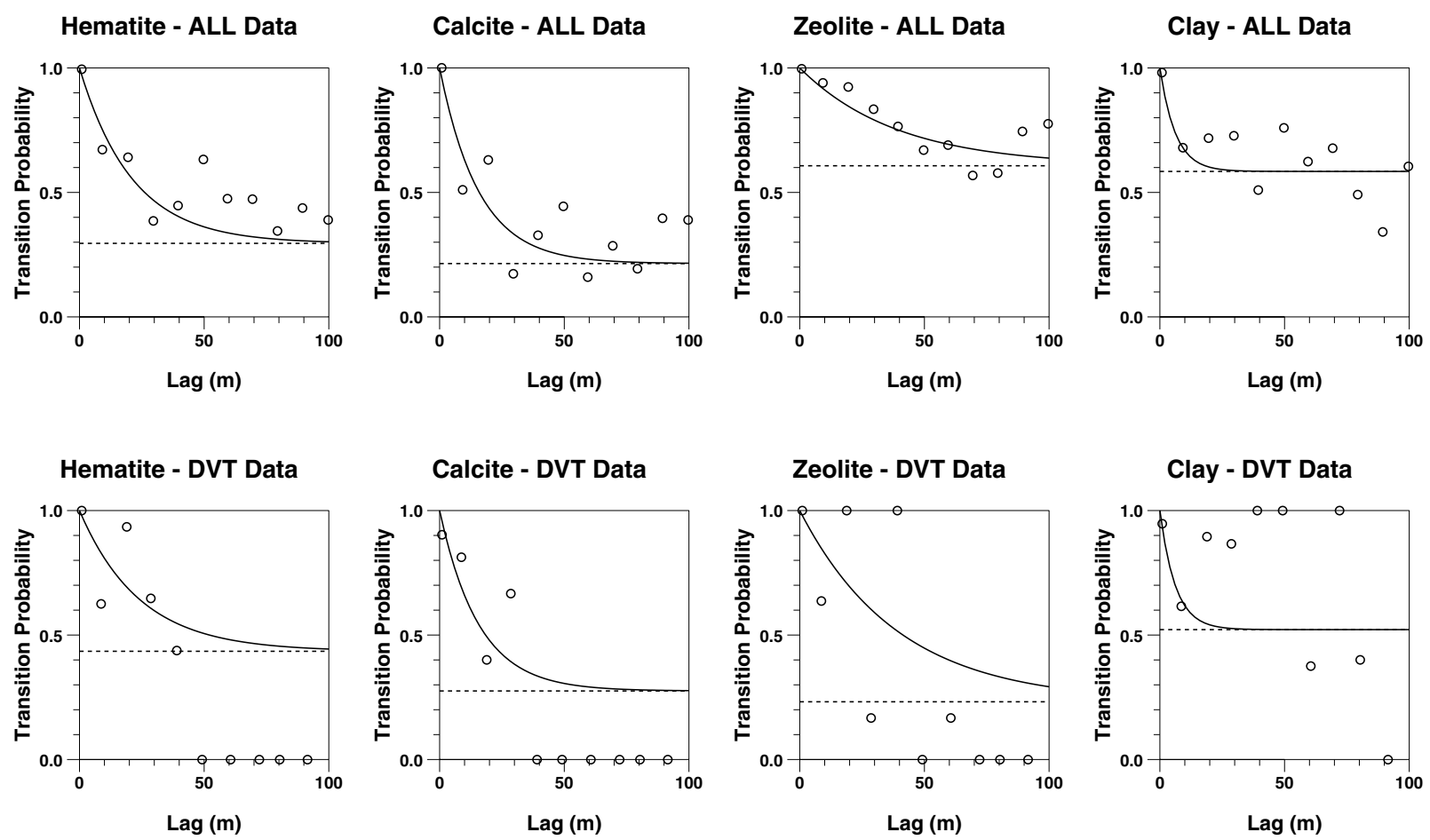

Figure H.10 Transition probability measurements (circles) and Markov chain models (lines) for high mineralization zones for ALL data set (top row) and DVT data set (bottom row). Dashed lines indicate proportions of high mineralization zones in each data set.

\section{H.4.3 Spatial Cross-Correlation}

To fully consider the spatial variability of the mineralization zones, we would need to develop models of spatial cross-correlation to fully account for the juxtapositional tendencies of the different minerals. Although a tendency for hematite and calcite to occur together but not with zeolites was evident in the transition probability analyses of the ALL data set, the DVT data set did not reveal similar tendencies. There is no obvious explanation why these minerals would preferentially or nonpreferentially occur in association, or why the spatial distributions of minerals would exhibit nonrandom spatial cross-correlations. This is clearly a subject for further research.

For this study, we will assume random spatial cross-correlations. This will allow us to generate realizations of mineralization zones independently for each mineral, then combine those realizations to obtain a realization of the spatial distribution of the 16 possible combinations of mineralization zones.

\section{H.5 Realizations of Mineralization Zones}

We define a realization as a stochastic simulation of the spatial distribution of an attribute. In generating a realization, the goal is to generate realistic, not smoothed, spatial variability of the attribute. 
Geostatistical methods of conditional simulation have been developed to generate realizations of continuous variables such as permeability and categorical variables such as rock facies. The mineralization zones are categorical variables. We will use a categorical geostatistical simulation technique to generate separate realizations of hematite, calcite, zeolite, and clays. Assuming independence in spatial cross-correlation, we combine each of these realizations to produce realizations of the combined spatial distribution of mineralized zones. These realizations will be used in the reactive transport model to define the three-dimensional spatial distribution of the reactive minerals.

To generate three-dimensional realizations, geostatistical conditional simulation methods require a three-dimensional model of spatial variability. Unfortunately, the ALL and DVT data sets were only sufficient in spatial sampling density to characterize the vertical-direction spatial variability, as presented in the previous sections. Presumably, the mineralized zones will exhibit complex patterns of spatial variability that may or may not be isotropic. However, we are not aware of any studies on this subject, so we will assume isotropy in the spatial distribution of mineralization zones. Therefore, our model of three-dimensional spatial variability assumes that mineralized zones exhibit a pattern of spatial variability similar in all directions to the $z$-direction model that we have developed from the ALL and DVT data sets.

We use the same geostatistical conditional simulation algorithm used to generate realizations of hydrofacies (see Appendix G). The categories for each cell are initialized by data, and remaining categories are selected by the sequential indicator simulation algorithm (Deutsch and Journel, 1998). A simulated quenching (zerotemperature annealing) step is added to improve match between the modeled and measured transition probabilities (Carle, 1996; Carle, 1997; Carle et al., 1998).

\section{H.6 Final Conceptual Model}

Now we reexamine our results from a conceptual perspective. We have defined high and low mineralization zones. For low mineralization zones of hematite, calcite, and zeolites, the proportion of fractures containing minerals ranges from 0.0 to 0.08 in the DVT data set (Table H.4). Given that typical open fracture densities are $0.35 / \mathrm{m}$ in lava flow aquifers at Pahute Mesa (Drellack et. al, 1997), a typical cross section through a $10 \mathrm{~m}$ grid block of a low mineralization zone for hematite, calcite, and zeolites would not contain any mineralized open fractures. Also, many of the radionuclides will have the potential to travel significant distances only if significant proportions of their flowpaths are not lined by sorbing minerals. If our low mineralization zones have a finite amount of mineralization, our reactive transport simulations not be able to consider the impact of flowpaths with nonreactive segments. Considering the low fracture density and the low proportion of mineralized fractures for low mineralization zones of hematite, calcite, and zeolite, we set the mineralization concentration to zero for low mineralization zones of hematite, calcite, and zeolite. The ALL and DVT data sets strongly support a ubiquitous presence for clay. 
Figure H.11 shows perspective views of the stochastic simulations of highand low-mineralization distributions for hematite, calcite, zeolite, and clay that are combined to construct a single mineralization realization (lower right in Figure H.11). Notice that zeolite exhibits the largest spatial continuity, followed by hematite, calcite, and clay. There are some large, lense-shaped nonmineralized zones related to the presence of low and very low permeability hydrofacies, where we assume matrix flow is prevalent (Chapter 5 and Appendix F). In producing the mineralization realizations, we assign low mineralization to cells in which the low and very low permeability hydrofacies are present. The combination of four binary categories leads to sixteen different combinations of mineralization states that could occur at a grid block. The 16category realization shown in Figure H.11 illustrates an isotropic pattern of heterogeneity consistent with the models of mineralization zone spatial variability shown on the bottom row of Figure H.10. As described above, these models are based on proportions inferred from the DVT data set and spatial correlation inferred from the ALL data set.
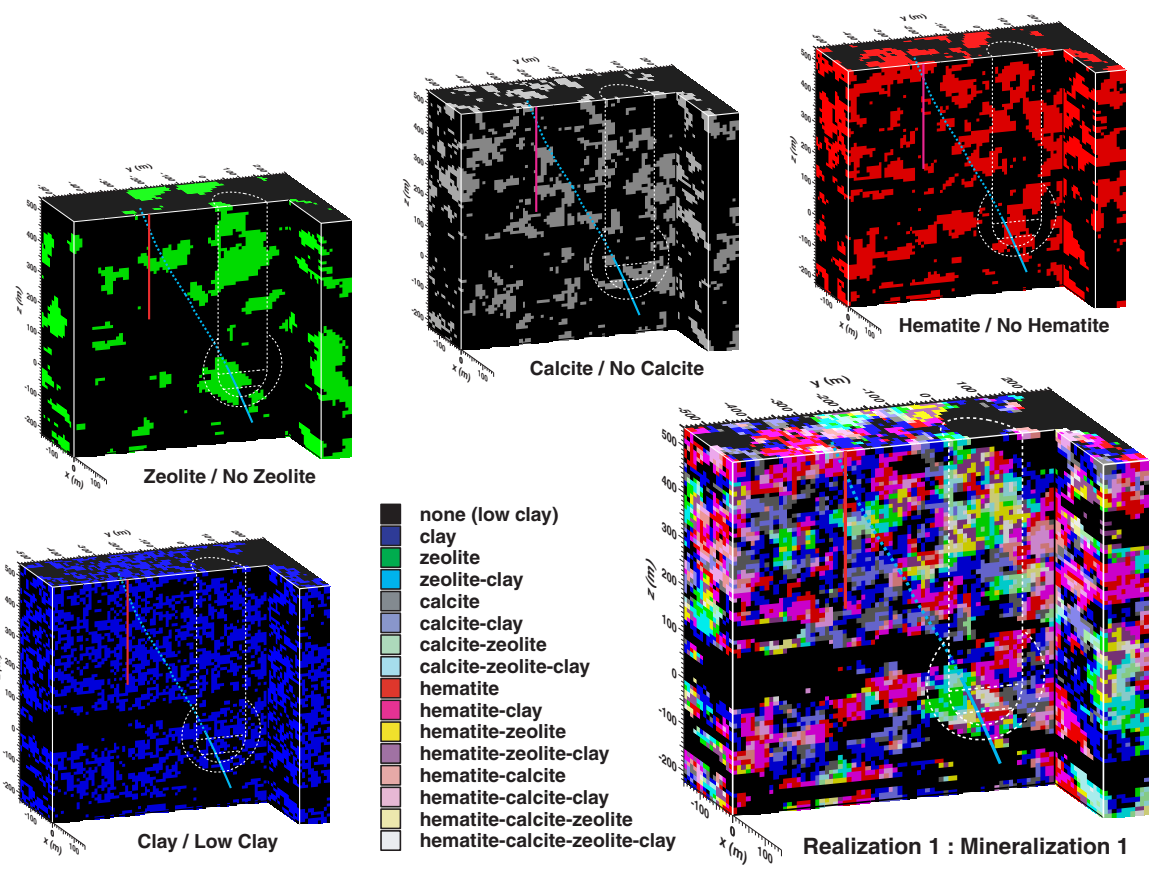

Figure H.11 Realization of spatial distribution of high mineralization zones. The low clay category represents absence of high mineralization for all minerals.

\section{H.7 Conclusions}

We have described our approach for generating realizations of mineral distributions at the $10 \mathrm{~m}$ grid block resolution of our flow and transport simulations. Because the mineral data are sparse and indirect, we rely very much on interpretation to guide the development of the models of spatial variability. This effort was facilitated by the transition probability/Markov geostatistical approach. Given that the mineral 
data obtained from core samples represent a scale far smaller than our $10 \mathrm{~m}$ grid blocks, we focus not on the spatial variability of concentration, but rather the spatial variability of the presence or absence of minerals in the fractures. We find that spatial variability of the minerals can be quantified in a systematic way by simply sorting the data into zones of high and low mineralization. The aim is to distinguish between zones having low or high proportions of fractures with minerals present. The sorting is improved and made consistent to the $10 \mathrm{~m}$ grid block scale by averaging the mineral data over $10 \mathrm{~m}$ intervals. The resulting models of spatial variability appear geologically plausible, as do the realizations of the spatial distribution of mineralization zones. Use of multiple realizations of the mineralization zones enable us to examine the effect of uncertainties in transport behavior resulting from uncertainties in the spatial distribution of reactive fracture-lining minerals at CHESHIRE. 


\section{APPENDIX I: \\ Summary of Reactive Transport Simulations Using GIMRT Code}




\section{I.1 Introduction}

used to

This appendix presents a summary of GIMRT reactive transport simulations

- Test the effects of decay and ingrowth on reactive transport.

- Examine matrix diffusion.

- Examine the effects of mineral heterogeneity.

- Examine the role of our simplified colloid model.

- Examine the uncertainty in our sorption model.

- Examine the effect of glass dissolution on reactive transport.

These simulations are much simpler in their geometry than the threedimensional simulation described in the main text. Thus, it is much easier to observe the effects of the near-field chemistry on radionuclide reactive transport.

\section{I.2 Radionuclide Decay and Ingrowth in the GIMRT Code}

In previous near-field reactive transport simulations performed at LLNL (Tompson et al., 1999), radionuclide decay was calculated by post-processing GIMRT results. ${ }^{1}$ In at least two instances, accounting for decay post-process may result in radionuclide transport errors:

- Radionuclide decay affects radionuclide retardation (e.g., nonlinear sorption).

- The parent and daughter radionuclides are retarded to varrying degrees (and both radionuclides are of concern).

For example, if radionuclides are found at high enough concentrations such that sorption sites become saturated or a precipitate forms, reactive transport simulations will be affected by the method of decay correction. In the first case, decay correction post-process will result in a more conservative measure of radionuclide transport. In the second case, decay correction post-process will result in a less conservative measure of radionuclide transport. If the parent radionuclide is more mobile than the daughter radionuclide, there is no realistic way to account for decay and ingrowth post-process. In this case, a very immobile radionuclide may be found far downstream because its

1 Rather than calculating radionuclide decay explicitly during the GIMRT simulations, we mean that the reduced concentration at the downstream boundary as a result of radionuclide decay was calculated as a correction factor after the transport simulations were completed. This method is accurate in the case of simple linear retardation in the absence of daughter ingrowth. 
parent radionuclide is more mobile. An example of this will be shown in the following section.

In our reactive transport model, ${ }^{41} \mathrm{Ca},{ }^{90} \mathrm{Sr},{ }^{135,137} \mathrm{Cs},{ }^{151} \mathrm{Sm},{ }^{150,152,154} \mathrm{Eu}$, ${ }^{232,233,234,235,236,238} \mathrm{U},{ }^{237} \mathrm{~Np},{ }^{238,239,240,241} \mathrm{Pu}$, and ${ }^{241} \mathrm{Am}$ retardation is accounted for, ${ }^{166 \mathrm{~m}} \mathrm{Ho}$ and ${ }^{244} \mathrm{Cm}$ retardation is assumed to equal that of $\mathrm{Eu}$, and all other radionuclides are treated as tracers. Because tracers are assumed to be nonsorptive, accounting for their decay post-process does not affect the accuracy of the simulations. Of the reactive radionuclides, the following have half-lives short enough to significantly affect their concentrations over the $1000 \mathrm{yr}$ simulation time: ${ }^{90} \mathrm{Sr},{ }^{137} \mathrm{Cs},{ }^{151} \mathrm{Sm}, 150,152,154 \mathrm{Eu},{ }^{166 \mathrm{~m}} \mathrm{Ho},{ }^{232} \mathrm{U}$, ${ }^{238,241} \mathrm{Pu},{ }^{241} \mathrm{Am}$, and ${ }^{244} \mathrm{Cm}$. Of this set, only ${ }^{90} \mathrm{Sr},{ }^{151} \mathrm{Sm},{ }^{241} \mathrm{Pu}$, and ${ }^{241} \mathrm{Am}$ are explicitly decay-corrected in the GIMRT simulations. The other radionuclides were decay corrected post-process because the radionuclide inventory contained multiple isotopes of the same element; at present, GIMRT cannot proportionally decay radionuclides as a function of the isotope ratio of an element. ${ }^{2}$

Figure I.1 compares the decay and ingrowth behavior of ${ }^{241} \mathrm{Pu},{ }^{241} \mathrm{Am}$, and ${ }^{237} \mathrm{~Np}$ calculated by the GIMRT code with analytical calculations based on the Bateman equations. The results are nearly identical; the only deviation in the GIMRT code is for ${ }^{241} \mathrm{Pu}$ at long times. The inaccuracy is a result of the linear interpolation of the smooth decay curve and is dependent on the maximum time step size chosen in the GIMRT code. The decay in Figure I.1 was modeled with a 1-yr maximum time step. If the maximum time step is reduced to $0.1 \mathrm{yr}$, the accuracy is significantly improved at long times but at the expense of computational time. In effect, the inaccuracy of the decay in the GIMRT code is inconsequential because significant deviation from the Bateman equation result occurs only when the ${ }^{241} \mathrm{Pu}$ mass has decreased by 10 orders of magnitude relative to its original mass.

\footnotetext{
${ }^{2}$ In the $1 \mathrm{D}$ reactive transport simulations described later, $\mathrm{Sr}, \mathrm{Sm}$, and the tritium tracer were not decayed to simplify the interpretation of the geochemistry. In our three-dimensional streamline simulations, $\mathrm{Sr}$ and $\mathrm{Sm}$ are decayed during the simulations while tritium is decayed via postprocessing.
} 


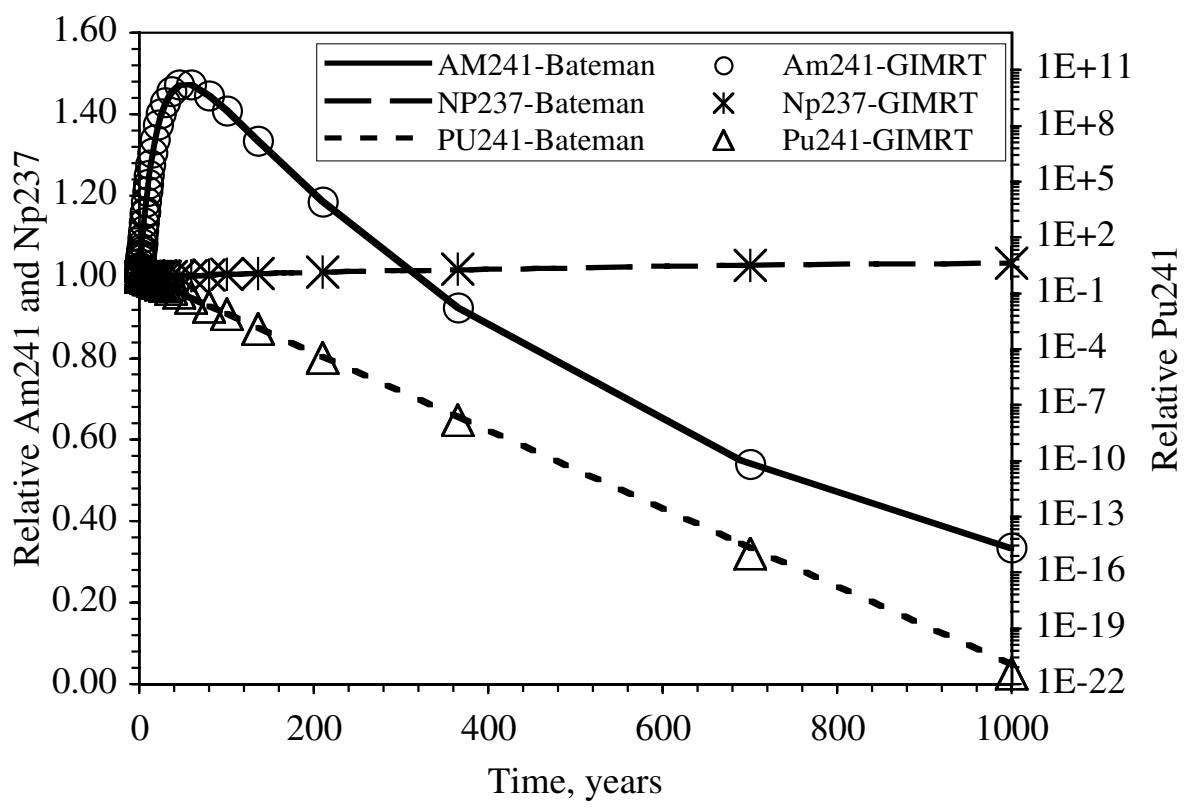

Figure I.1 Relative ${ }^{241} \mathrm{Pu},{ }^{241} \mathrm{Am}$, and ${ }^{247} \mathrm{~Np}$ decay and ingrowth as modeled by the GIMRT code and as calculated by Bateman equations.

\section{I.3 Matrix Diffusion Effects on Radionuclide Retardation}

The effects of matrix diffusion on radionuclide retardation were examined using the same fracture flow conceptualization as defined in Chapter 6. Fluid flow was limited to a $0.5 \mathrm{~mm}$ aperture fracture, a $0.1 \mathrm{~mm}$ fracture lining and $2.5 \mathrm{~mm}$ of adjoining matrix. $60 \mathrm{~mm}$ of adjoining matrix was available for diffusion. The amount of matrix available for diffusion is based on the fracture density defined in Chapter 6 (eight fractures per meter in the high fracture zones). This fracture conceptual model results in an effective flow porosity of $1 \%$, equivalent to the conceptualization in Chapter 6. Fracture flow was assumed to be fully mixed, and colloids (Chapter 6 and Appendix K) were excluded from the matrix. Fluid velocities in the fracture were set to $100 \mathrm{~m} / \mathrm{yr}$ with a total fracture length of $200 \mathrm{~m}$. In all cases, radionuclides were introduced into the fractured system for $100 \mathrm{yr}$ at a concentration of $10^{-10} \mathrm{~mol} / \mathrm{L}$ and subsequently flushed out with groundwater. Average fracture lining and matrix mineralogies were assumed. Mineralogy data can be found in Chapter 6. Surface complexation/ion exchange data can be found in Appendix K.

The effective diffusion coefficient $\left(D_{e}\right)$ was assumed to equal $10^{-6} \mathrm{~cm}^{2} / \mathrm{s}$ for all radionuclides. Reimus et al. (2000) measured the $\mathrm{D}_{\mathrm{e}}$ of several radionuclides in tuffs from Pahute Mesa and found that the average $\mathrm{D}_{\mathrm{e}}$ for ${ }^{3} \mathrm{H},{ }^{14} \mathrm{C}$, and ${ }^{99} \mathrm{Tc}$ equaled $10^{-6.0 \pm 0.3}$, $10^{-5.6 \pm 0.5}$, and $10^{-6.1 \pm 0.3} \mathrm{~cm}^{2} / \mathrm{s}$, respectively. These three values are consistent with our model $\mathrm{D}_{\mathrm{e}}$ of $10^{-6} \mathrm{~cm}^{2} / \mathrm{s}$. Though the diffusivity of ${ }^{3} \mathrm{H},{ }^{14} \mathrm{C}$, and ${ }^{99} \mathrm{Tc}$ should be somewhat different (given their size, charge, etc.), the uncertainty in the $\mathrm{D}_{\mathrm{e}}$ for these elements far outweighs their diffusivity differences. In their analysis of tracer responses in the BULLION forced-gradient experiment on Pahute Mesa, Reimus and Haga (1999) estimated a $D_{e}$ for iodide of $10^{-8}$ to $10^{-7.1} \mathrm{~cm}^{2} / \mathrm{s}$, significantly lower than the values used 
here. This lower $D_{e}$ will reduce the impact of matrix diffusion at early times while increasing the tailing at long times (i.e., while radionuclides will diffuse from the fracture flow zones into the matrix more slowly, and they will also diffuse back into fracture flow zones from the matrix more slowly).

Breakthrough at the downstream boundary for ${ }^{3} \mathrm{H}$ is plotted in Figure I.2. Breakthrough was measured using 1,5 and 10 nodes in the matrix and a $D_{e}$ of $10^{-6}$ $\mathrm{cm}^{2} / \mathrm{s}$. The results indicate that, under these model conditions, one node in the matrix can adequately simulate matrix diffusion. Initial breakthrough of tritium is fast for both the diffusion and no-diffusion cases. In the diffusion case, a slow increase in tritium concentration at the breakthrough plane at early times and significant tailing at later times results. In the no-diffusion case, the tritium front at the breakthrough plane is very sharp. Thus, the initial arrival time of tritium is not significantly affected by matrix diffusion but the concentration profile differs greatly. If the $\mathrm{D}_{\mathrm{e}}$ were reduced to $\sim 10^{-8}$ $\mathrm{cm}^{2} / \mathrm{s}$, the impact of matrix diffusion at early times would be reduced while the tailing effect would be more pronounced (Figure I.2). Breakthroughs for retarded radionuclides (Figures I.3 and I.4) yield a similar result in that matrix diffusion increases the initial breakthrough time of most radionuclides only by a factor of $\sim 4$ but the breakthrough concentration as a function of time differs by orders of magnitude. For $\mathrm{Eu}$, the breakthrough time and concentration are not affected greatly by matrix diffusion. This results from the strong sorption of $\mathrm{Eu}$ on fracture-lining minerals and sorbing colloids which minimize Eu diffusion into the matrix. Cs, on the other hand, is very strongly influenced by matrix diffusion because micas located in the matrix have a high affinity for Cs and provide a nearly continuous Cs sink.

Figure I.5 illustrates the influence of sorbing mineralogy and diffusion on $\mathrm{Np}$ breakthrough. The curve labeled "Np-complete" represents $\mathrm{Np}$ breakthrough when diffusion and sorption to fracture-lining, matrix, and colloid minerals are considered. The initial breakthrough time decreases from 45 to 15 years when diffusion into the matrix, and thus sorption to matrix minerals ("Np-no diffusion") is neglected. Accounting for diffusion but ignoring sorption to matrix minerals ("Np-no matrix retardation") decreases the initial breakthrough time from 45 to 20 years, similar to the "Np-no diffusion" case. If only sorption to fracture-lining minerals is ignored (Np-no fracture), the initial breakthrough time decreases to from 45 to 25 years. Thus, Np retardation is affected by the combined retardation effects of sorption to fracture lining minerals, diffusion, and sorption to matrix minerals.

The greater effect of sorption compared to diffusion in controlling initial breakthrough is best illustrated by comparing tracer diffusion data (Figure I.2) with data in Figure I.5. The nonsorptive tracer initial breakthrough is very quick ( 2 years, Figure I.2). Consideration of sorption to fracture lining minerals alone (Np-no diffusion) increases the initial breakthrough time to 15 years (a factor of $\sim 7.5$ increase). Consideration of sorption to fracture lining minerals and matrix diffusion (Np-no matrix retardation) increases the initial breakthrough time only slightly. However, the consideration of sorption to fracture lining minerals, diffusion, and sorption to matrix minerals ( $\mathrm{Np}$-complete) increases the initial breakthrough time to 45 years. Regardless, the breakthrough times for $\mathrm{Np}$ are controlled by sorption to fracture linings, sorption to matrix minerals, diffusion into the matrix, and sorption to colloids. All of these factors must be taken into account to accurately represent the migration of $\mathrm{Np}$ and other 
radionuclides. Matrix diffusion is only one of several factors that will control downstream radionuclide concentrations.

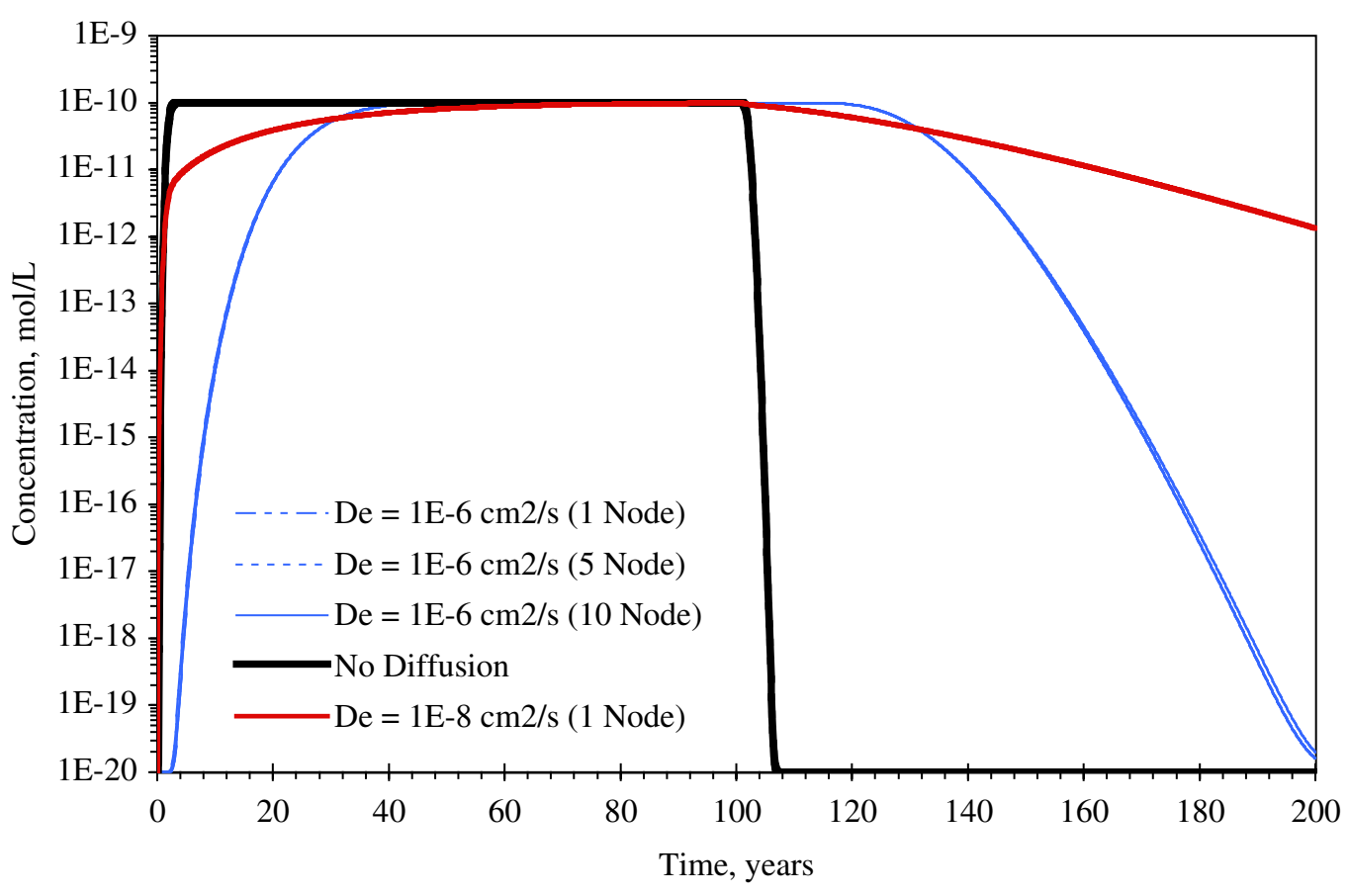

Figure 1.2 Breakthrough of $10^{-10} \mathrm{~mol} / \mathrm{L}$ tritium under conditions of no diffusion, diffusion with 1,5 , and 10 nodes in the matrix and $D_{e}=10^{-6} \mathrm{~cm}^{2} / \mathrm{s}$, and diffusion with 1 node in the matrix and $D_{e}=10^{-8} \mathrm{~cm}^{2} / \mathrm{s}$. 


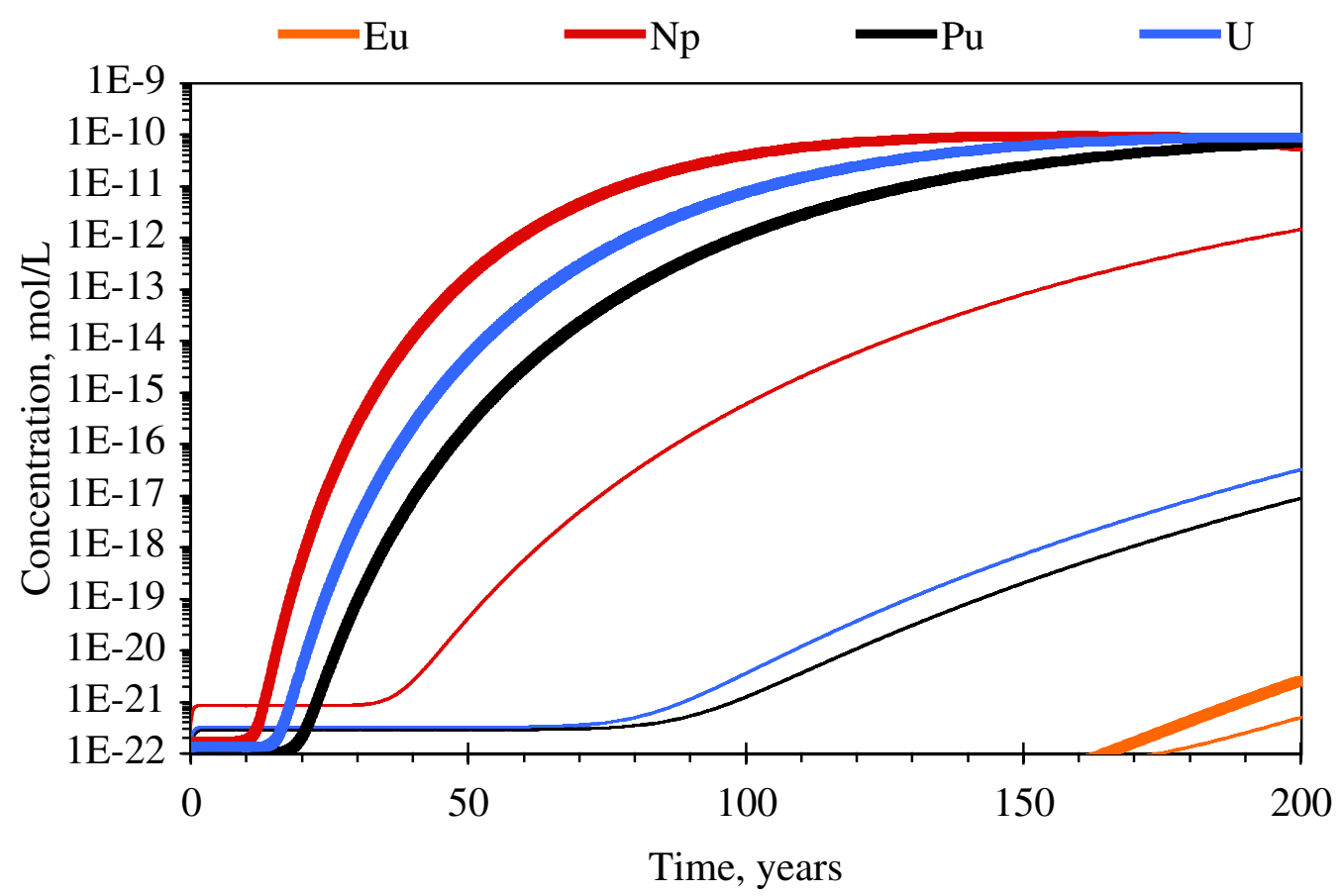

Figure I.3 Breakthrough of $\mathrm{Eu}, \mathrm{Np}, \mathrm{Pu}$, and $\mathrm{U}$ with (thin line) and without (thick line) matrix diffusion. Note that background aqueous radionuclide concentrations vary between $10^{-20}$ to $10^{-23} \mathrm{~mol} / \mathrm{L}$, depending on the sorption strength of the various radionuclides.

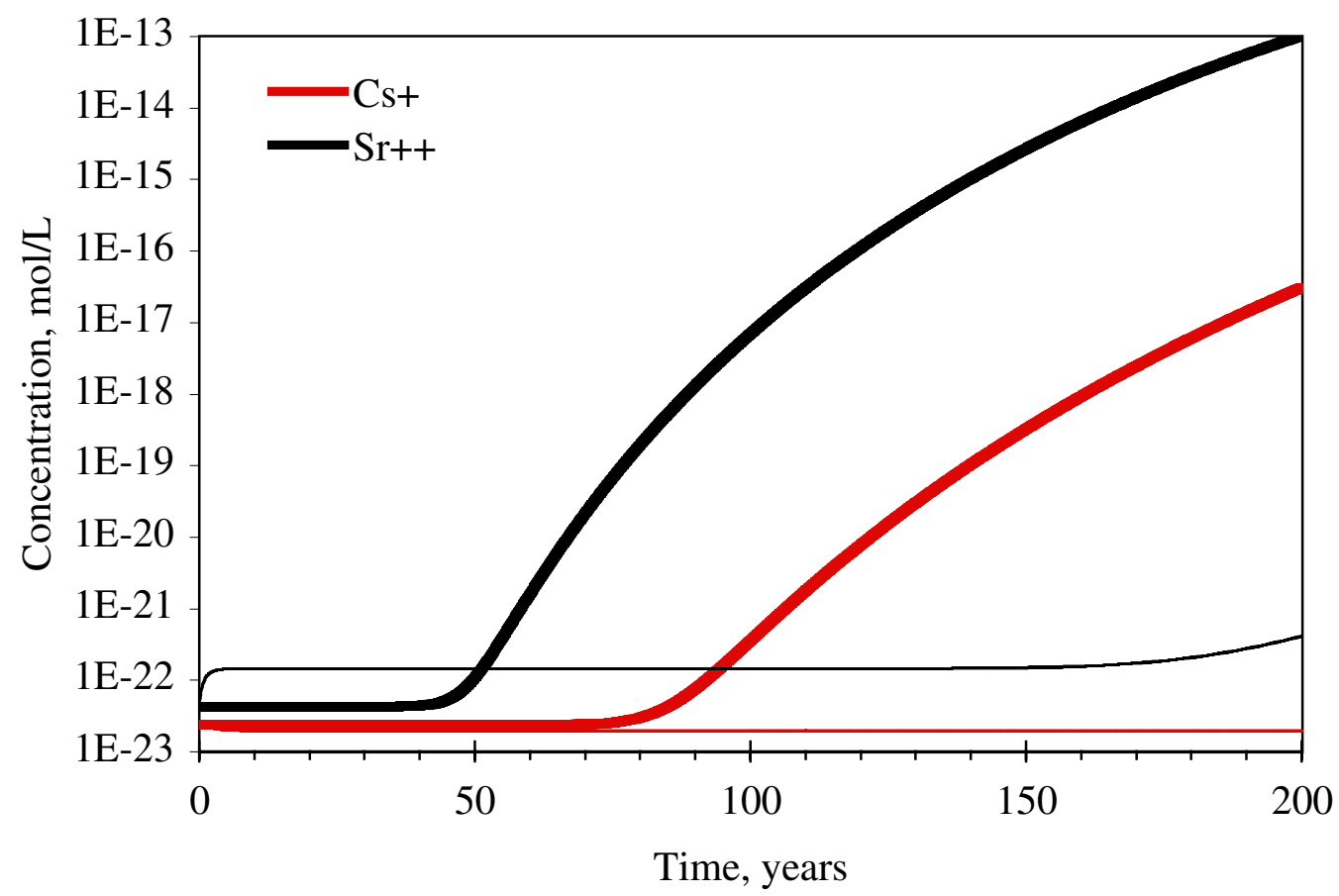

Figure I.4 Breakthrough of Sr and Cs with (thin line) and without (thick line) matrix diffusion. Note that background aqueous radionuclide concentrations vary between $10^{-20}$ to $10^{-23} \mathrm{~mol} / \mathrm{L}$, depending on the sorption strength of the various radionuclides. 


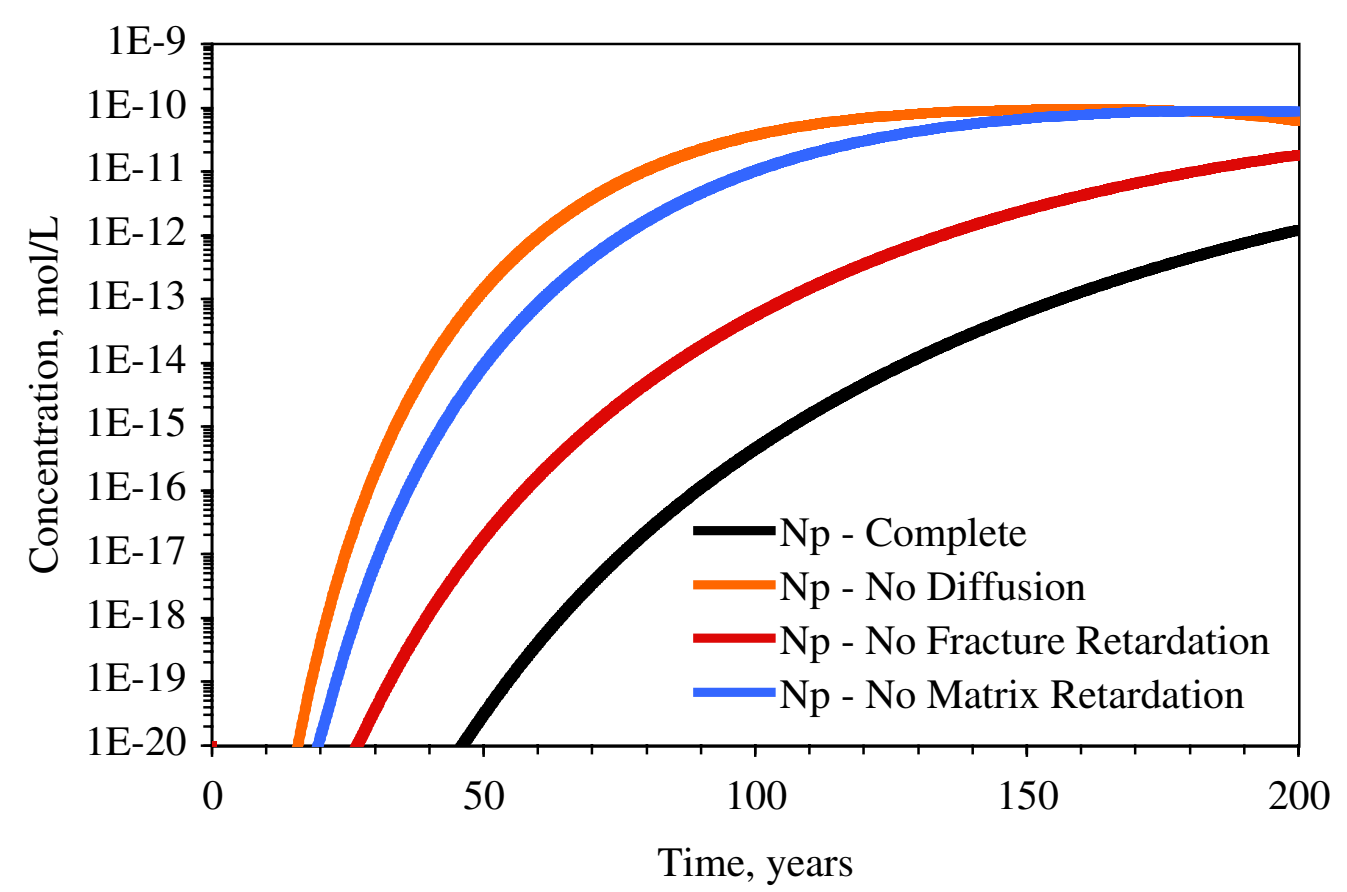

Figure I.5 Breakthrough of Np under various model conditions.

\section{I.4 Mineral Heterogeneity Effects on Radionuclide Migration}

In Chapters 5 and 6, the heterogeneous distribution of sorbing minerals in the near field was discussed. Here, simple 1D reactive transport simulations are presented to illustrate the effect of 10 different heterogeneous sorbing mineral distributions on radionuclide transport.

Figure I.6 shows a conceptualization of these simulations. Simulations with the same mineralogic distributions were also used to compare GIMRT reactive transport simulations with the particle simulations, as discussed in Appendix E. Here, we discuss the geochemical interactions that control radionuclide migration in these simulations. 


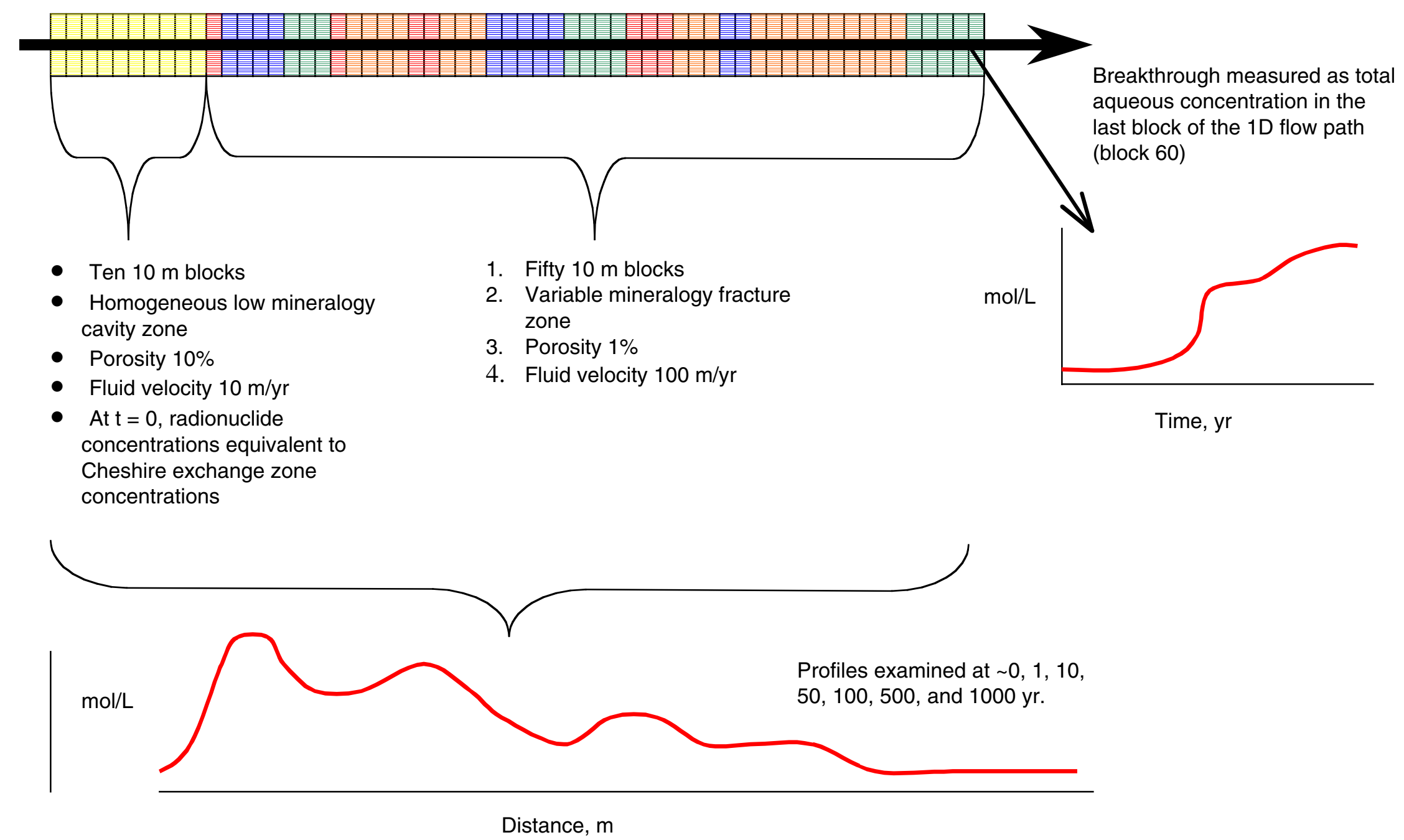

Figure I.6 Schematic of 1D fracture flow simulations used to test the particle and GIMRT codes here and in Appendix E. 
Figure I.7 contains breakthrough plots for reactive radionuclides examined in the CHESHIRE near-field model. For all reactive radionuclides, the homogeneous mineralogy case results in the greatest radionuclide retardation. For example, ${ }^{241} \mathrm{Am}$ initial breakthrough occurs at $\sim 225$ years in the homogeneous case; in the heterogeneous case, initial breakthroughs range from 125 to 200 years. ${ }^{241} \mathrm{Am}$ migration is complicated by the fact that ${ }^{241} \mathrm{Pu}$ decays to ${ }^{241} \mathrm{Am}$. Because Pu migration is much less retarded than the trivalent radionuclides (see Eu and $\mathrm{Sm}$ plots and compare with $\mathrm{Pu}$ ), the leading edge of ${ }^{241} \mathrm{Am}$ breakthrough is, in fact, developed largely from decayed ${ }^{241} \mathrm{Pu}$. The tailing in the ${ }^{237} \mathrm{~Np}$ breakthrough, on the other hand, results from the slow decay of retarded ${ }^{241} \mathrm{Am}$ to relatively mobile ${ }^{237} \mathrm{~Np}$.

Cs migration is less affected by heterogeneous mineral distribution than $\mathrm{Sr}$, even though both radionuclides are retarded principally by ion exchange. This difference results from the sorbing mineral distribution patterns and the preferential sorption to particular minerals. For Cs, sorption is dominated by ion exchange in micas. In our model, micas are homogeneously distributed in the matrix and near the fracture surface. For Sr, sorption is dominated by either clays or zeolites. Because zeolite distribution is heterogeneous, Sr breakthrough is dependent on the mineral distribution patterns in the one-dimensional simulations. This also ensures that in the homogeneous case, $\mathrm{Sr}$ is much more retarded than in the heterogeneous case. Eu and Sm migration is greatly affected by the distribution of sorbing minerals. The elution of Eu and Sm from the source term in this simulation ${ }^{3}$ begins at $\sim 500 \mathrm{yr}$ for Eu and $\sim 700 \mathrm{yr}$ for $\mathrm{Sm}$. In the homogeneous case, Sm never reaches the downstream boundary by $1000 \mathrm{yr}$ while Eu only begins to elute at $\sim 1000 \mathrm{yr}$.

\footnotetext{
${ }^{3}$ In Figure I.7, the breakthrough of Eu and Sm at early time occurs because the heterogeneously distributed background concentrations of the radionuclides slowly elute. Model background radionuclide concentrations were set at $10^{-20} \mathrm{~mol} / \mathrm{L}$. Any radionuclide concentration below $10^{-20} \mathrm{~mol} / \mathrm{L}$ should, therefore, not be considered part of the source term.
} 


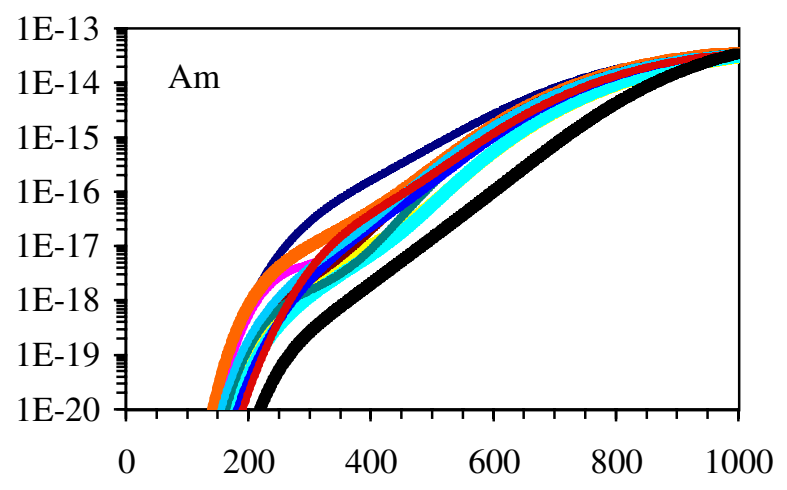

Time, years
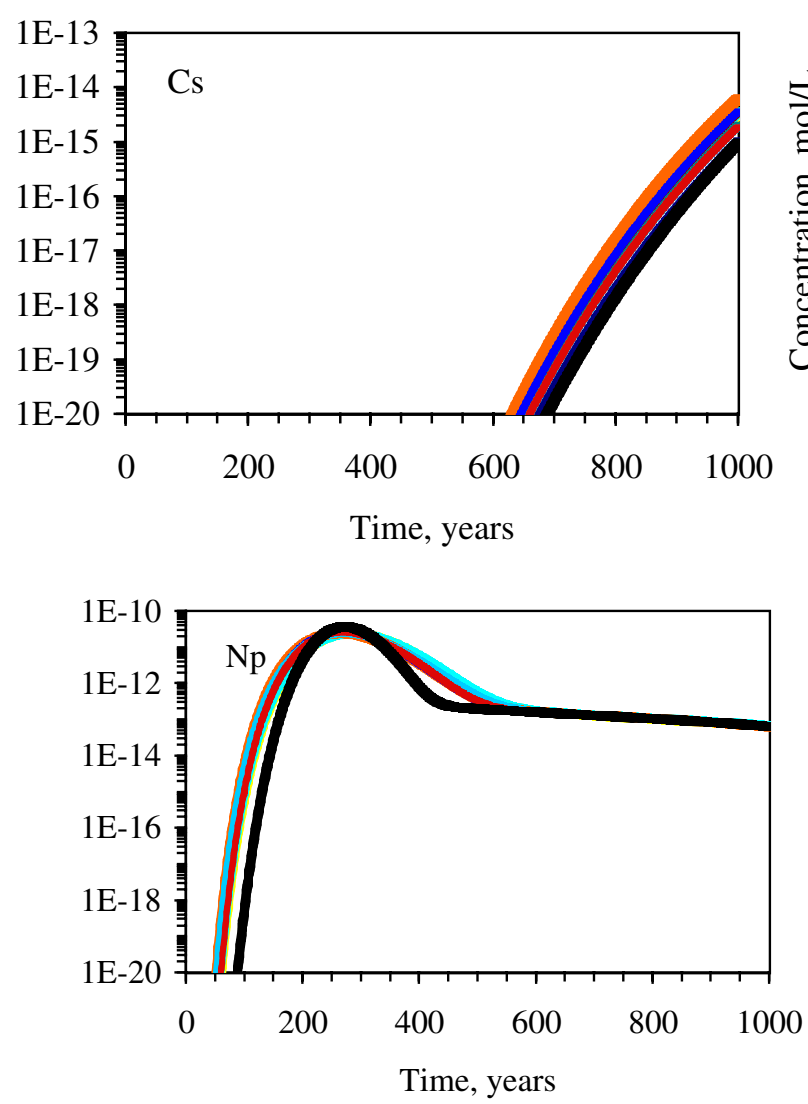
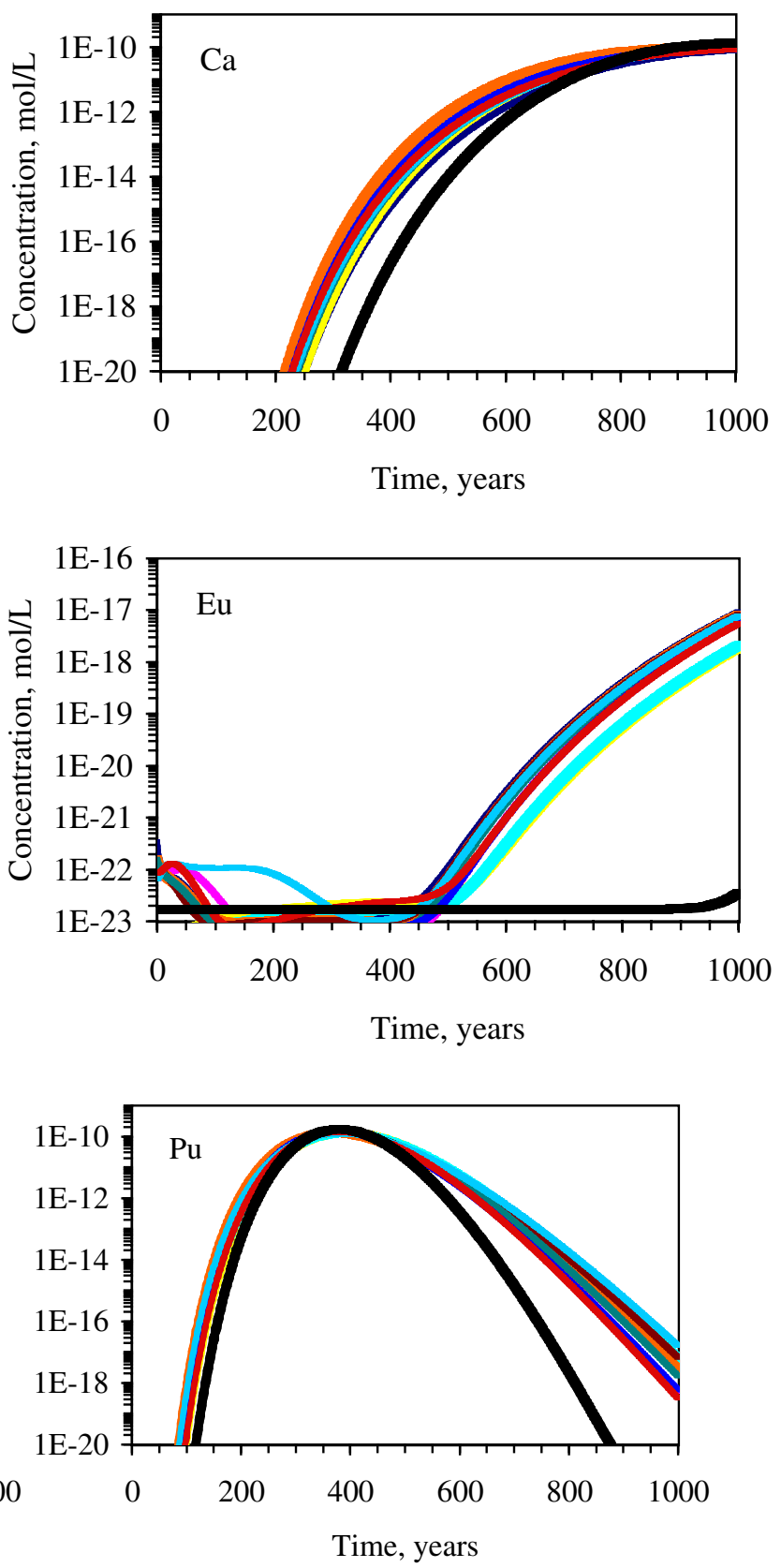

Figure I.7 Breakthrough of radionuclides for simple one-dimensional reactive transport simulations in which sorbing minerals are heterogeneously distributed using the method defined in Chapter 6. Colored curves represent 10 simulations with different mineral distributions; black line is the homogeneous mineralogy case for comparison. 

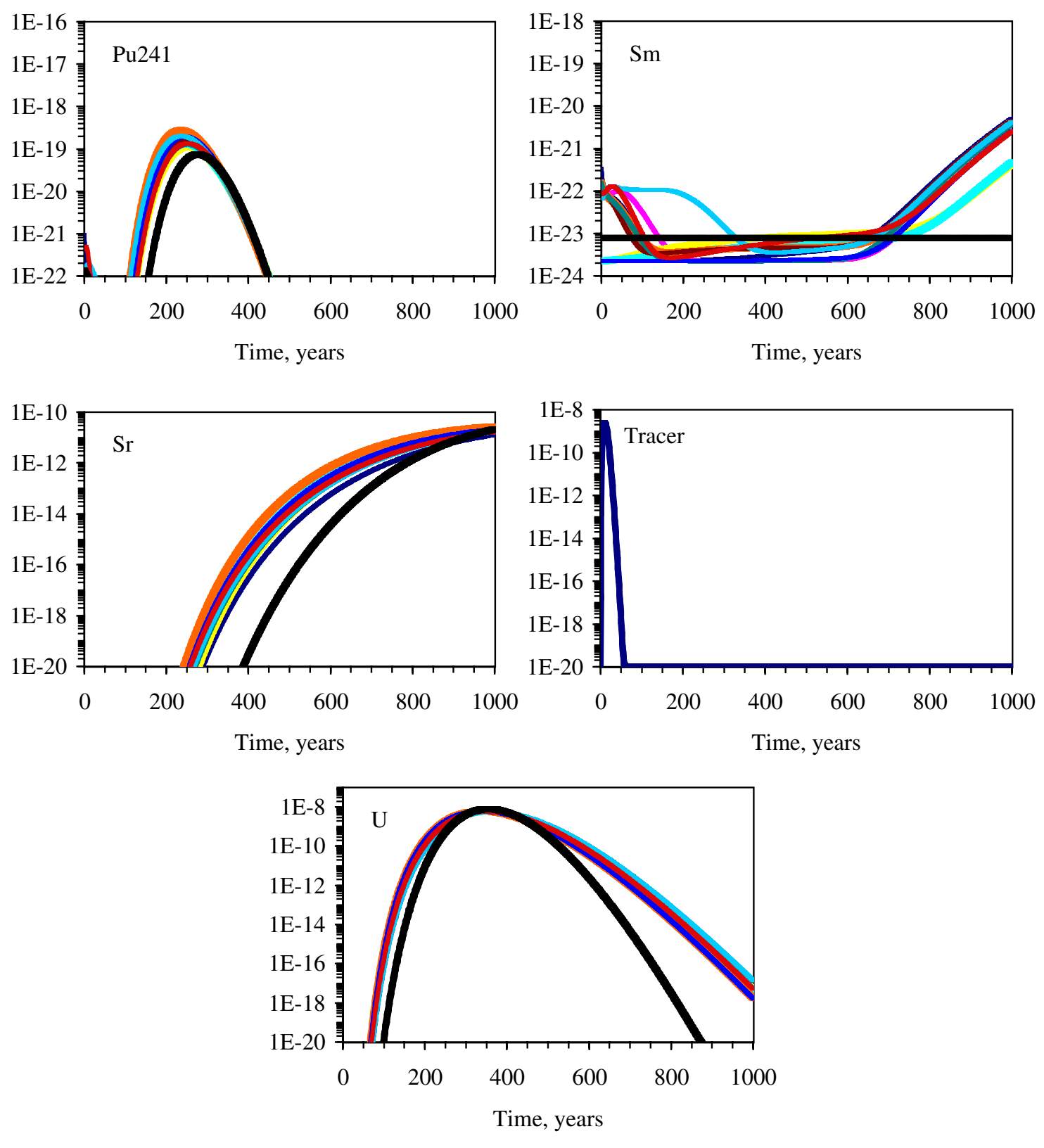

Figure 1.7 (Continued).

\section{I.5 Effect of Colloids on Radionuclide Migration}

The implementation of a simplified colloid model in our near-field reactive transport simulations is described in Chapter 6 and Appendix K. Here, we present some examples of the colloid effects on radionuclide migration and compare these results to observations reported by Kersting et al. (1999) and Buddemeier and Hunt (1988). The conceptual model used in these 1D simulations is identical to the model used in the previous section with a heterogeneous distribution of fracture-lining minerals. Figure I.8 compares the breakthrough predicted for the colloid and colloid-free simulations. The presence of aluminosilicate colloids greatly affects the breakthrough of $\mathrm{Am}, \mathrm{Eu}$, and 
$\mathrm{Sm}$. For these three radionuclides, breakthrough above background concentrations $\left(10^{-20} \mathrm{~mol} / \mathrm{L}\right)$ does not occur in the simulations without colloids. When colloids are present, $\mathrm{Am}, \mathrm{Eu}$, and $\mathrm{Sm}$ concentrations at the breakthrough plane exceed $10^{-20} \mathrm{~mol} / \mathrm{L}$ at 140,620 , and $1000 \mathrm{yr}$, respectively. Colloids affect the breakthrough of other radionuclides only slightly.

The influence of colloids on radionuclide transport correlates directly with the proportion of radionuclide associated with the aluminosilicate colloids. In our model, the percentages of mobile radionuclide associated with the aluminosilicate colloids, relative to aqueous radionuclides, are $\mathrm{Am}(99 \%), \mathrm{Sm}(97 \%), \mathrm{Eu}(96 \%), \mathrm{Pu} /{ }^{241} \mathrm{Pu}$ (12\%), U (4\%) and Np (2\%). Our Eu prediction agrees well with observations of Buddemeier and Hunt (1988) and Kersting et al. (1999). However, Kersting et al. (1999) found that $>90 \%$ of $\mathrm{Pu}$ was associated with colloids (study conducted at the TYBO-BENHAM site). The inconsistency between our result and that of Kersting comes, most likely, from an incomplete description of Pu redox states in NTS waters. Because $\mathrm{Pu}(\mathrm{IV})$ sorbs much more strongly to aluminosilicates than $\mathrm{Pu}(\mathrm{V})$, the redox state of $\mathrm{Pu}$ plays a dominant role in controlling the Pu retardation and colloid association. Further study of the redox state of Pu in NTS waters and a more thorough investigation of the effect of Pu redox state on reactive transport is warranted.

Cs, $\mathrm{Sr}$, and ${ }^{41} \mathrm{Ca}$ are not affected by colloids in our model because sorption to aluminosilicate colloids was defined in terms of surface complexation and Cs, Sr, and ${ }^{41} \mathrm{Ca}$ interact with aluminosilicates primarily via ion exchange (see Appendix K). Observations of Buddemeier and Hunt (1988) suggest that some colloids may be micaceous and sorb a significant fraction of Cs. In that case, colloids may affect the transport of $\mathrm{Cs}$ in the near field. The maximum observed $\mathrm{Cs}$ association with colloids $(\sim 50 \%)$ would yield a 50\% decrease in Cs retardation in our model. The average breakthrough shown in Figure I.7 for Cs would decrease from $\sim 600$ to 300 yr. Kersting et al. (1999) found that $\sim 90 \%$ of ${ }^{137} \mathrm{Cs}$ was associated with colloids at the TYBO-BENHAM site. In our equilibrium model, this would require that the majority of colloids be micaceous. Nevertheless, Cs-colloid associations at this level would result in a dramatic decrease in Cs retardation ( 1 order of magnitude). $\mathrm{Sr}$ and ${ }^{41} \mathrm{Ca}$ were not reported by Buddemeier and Hunt (1988), and simulations indicate that their association with any aluminosilicate colloids via surface complexation or ion exchange would be insignificant. 


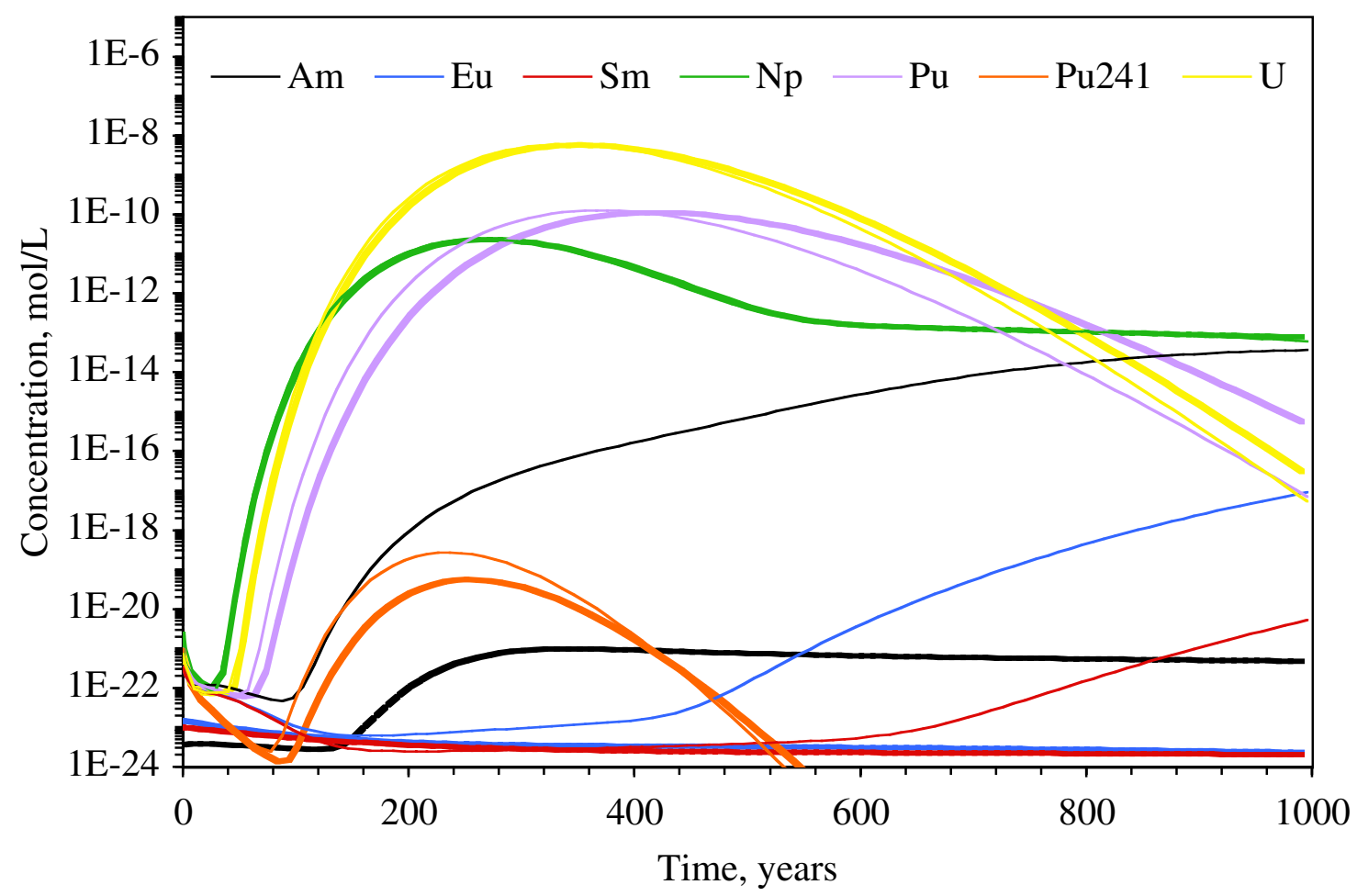

Figure I.8 Radionuclide breakthrough in a heterogeneous fracture-lining mineralogy, 1-D reactive transport simulation in which colloids are present (thin line) and absent (thick line).

\section{I.6 Effect of Sorption Uncertainty on Radionuclide Migration}

The uncertainty in surface complexation constants derived from published and laboratory sorption data is described in Appendix K. Uncertainty in ion exchange constants is not known because these constants were taken directly from published sources that did not identify the uncertainty of those values. Some nominal uncertainty was used in Appendix $\mathrm{K}$ to emphasize the implication of possible uncertainties in radionuclide ion exchange. In this section, only surface complexation constant uncertainty is discussed. As in earlier sections, we use our simplified one-dimensional heterogeneous mineral distribution model in these simulations (Figure I.6). Uncertainties in the surface complexation constants are listed and described in Appendix K.

Figure I.9 contains several plots of radionuclide breakthrough from our 1D transport simulations and illustrates the effect of sorption constant uncertainty on breakthrough. Radionuclide breakthroughs when surface complexation constants are reduced by 2 standard deviations ${ }^{4}$ are significantly different from breakthroughs based on average surface complexation constants. Nevertheless, the uncertainty effect varies among radionuclides. For example, a 2 standard deviation decrease in Eu surface complexation constants will decrease the initial breakthrough time from 640 to 480

\footnotetext{
${ }^{4}$ Reducing surface complexation constants decreases the strength of radionuclide-mineral interactions.
} 
years (a 25\% decrease in breakthrough time), but results in a decrease in initial breakthrough time from 80 to 2 years (a 98\% decrease in breakthrough time) for $\mathrm{Pu}$. While some of this has to do with differences in surface complexation constant standard deviations, the interplay between several geochemical processes affects these results. The breakthrough of Am is radically affected by our uncertainty estimate in part because Am breakthrough is affected not only by the uncertainty in Am surface complexation constants but also by the ${ }^{241} \mathrm{Pu}$ surface complexation constants (its parent radionuclide). The breakthrough uncertainties presented in Figure I.9 emphasize that uncertainties other than the hydrologic and mineralogic ones presented in detail with the particle model (Chapter 7) can significantly affect the confidence in our downstream boundary radionuclide flux. Additional improvements to our surface complexation model (e.g., addition of electrostatic effects, multiple sites on mineral surfaces) may reduce uncertainty. However, additional uncertainties not discussed here (e.g., mineral concentrations, reactive surface areas, effects of temperature, glass dissolution rates and resulting changes in groundwater composition) must also be accounted to achieve a more robust analysis of near-field source term uncertainties.
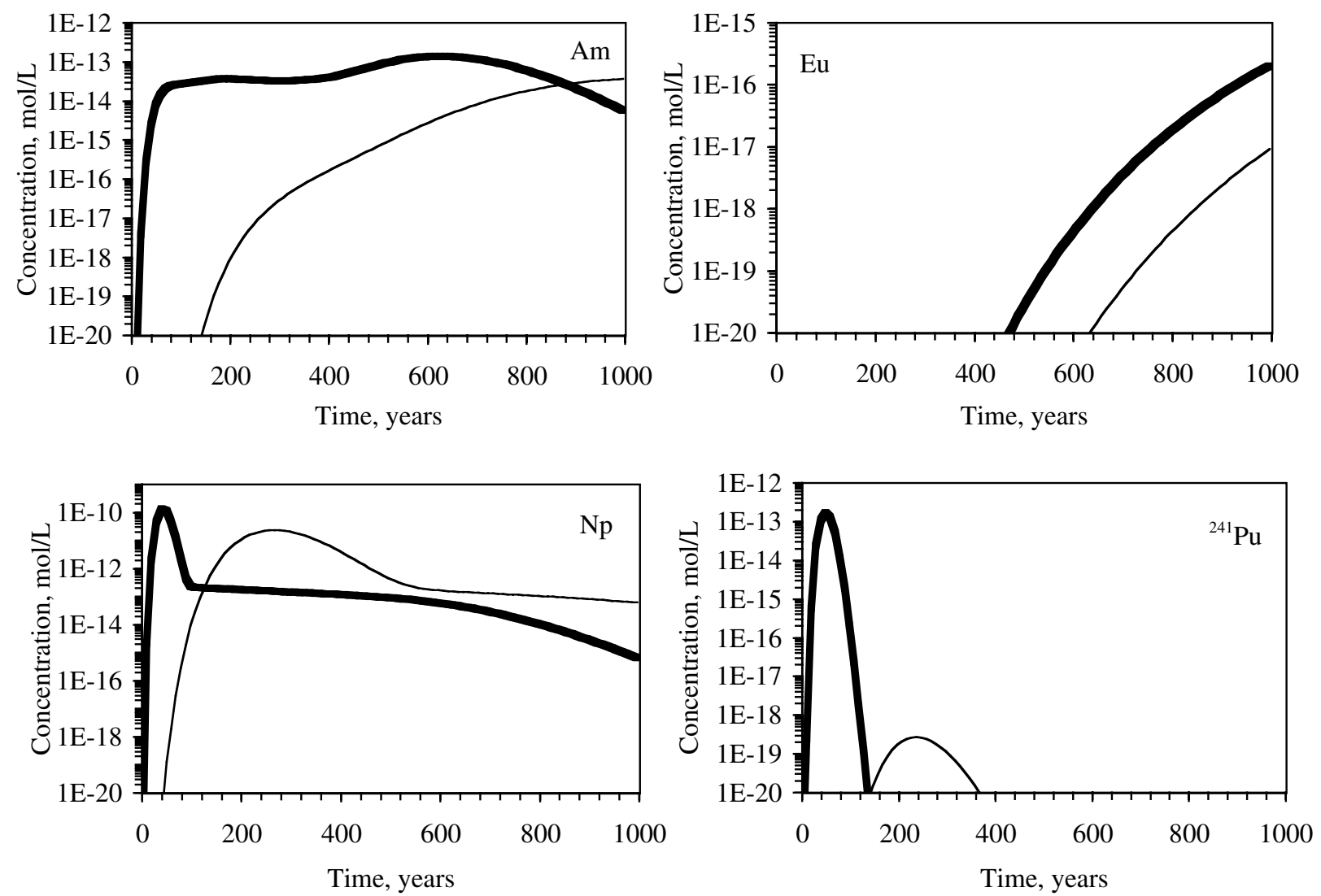

Figure I.9 Breakthrough of sorbing radionuclides in a heterogeneous fracture-lining mineralogy, 1-D reactive transport simulation. Thick line is the breakthrough when surface complexation constants are adjusted to two standard deviations from the average (thin line). 

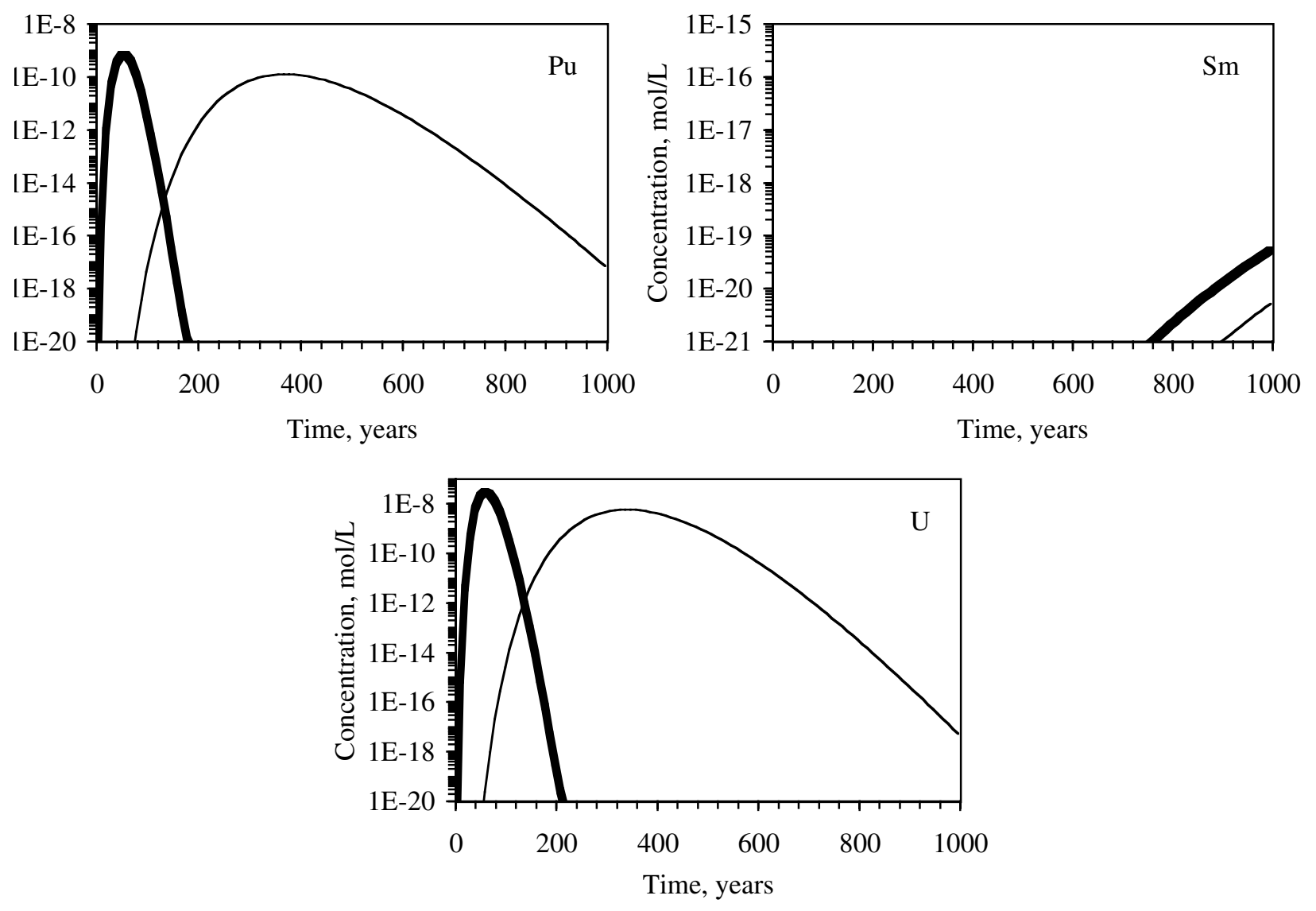

Figure I.9 (Continued).

\section{I.7 Glass Dissolution Model Effects}

In this section, radionuclide migration is calculated along illustrative 1D streamlines intersecting the glass zone to compare the impact on radionuclide release and migration using the complex glass dissolution model (Appendix E), the simple glass model (Appendix E) and the moderate-rate glass dissolution model used in the particle code (section 6.4.5). The results of these comparisons are used to:

- Verify the geochemical description of glass dissolution and sorption in the particle model by comparison with the simple glass model.

- Illustrate the consequences of using different techniques to solve the equations describing fluid flow and chemical reactions (discussed previously in Appendix E).

- Highlight the complex phenomena affecting radionuclide migration that might not be captured using simple models for glass dissolution and chemical reactions. 
- Evaluate the performance of the complex glass model during the thermal pulse, which was not otherwise addressed in the HST streamlines in this report.

- Verify that the chemical reactions and processes along streamlines used to define the HST are behaving as expected for both the particle and GIMRT models.

Additional calculations in this section demonstrate the extreme sensitivity of glass durability to the reactive surface area as temperature increases. Based on the behavior of natural analogues, this sensitivity may be used to place probable limits on the reactive surface area of melt glass to be used in modeling.

Simple 1D reactive transport simulations were carried out according to the system conceptualization discussed in Appendix E and shown in Figure I.6, except that the $100 \mathrm{~m}$ at the beginning of the streamline is composed of melt glass with $20 \%$ porosity. This glass zone was subject to the thermal pulse shown in Appendix E, Figure E.5, whereas the temperature of the fractured lava was fixed at $35^{\circ} \mathrm{C}$.

Effects of the choice of glass dissolution model are evidenced in the glass dissolution rate, fluid chemistry, retardation coefficients, the dominant surface complexation and ion exchange reactions, breakthrough concentrations and timing, and mineral dissolution/precipitation reactions along the flow path. Selected simulations that illustrate these effects will be discussed later. For purposes of simplification, GIMRT simulations using the complex and simple glass dissolution models will be described as the complex and simple GIMRT lines, respectively.

\section{I.7.1 Simple vs. Complex Glass Models}

Breakthroughs from the simple and complex GIMRT glass lines are shown in Figure I.10. U breaks through slightly faster and at significantly higher concentrations in the complex model. As shown in Figure E.5, the glass dissolution rate using the complex model is about 1.5 times faster than the simple glass rate. The faster rate arises largely from the difference in saturation term caused by the use of $\alpha$-cristobalite rather than $\beta$-cristobalite to control aqueous silica concentration (section 6.4.5). The arrivals of $\mathrm{Cs}, \mathrm{Sr}$ and ${ }^{41} \mathrm{Ca}$ are delayed in the complex model, but the arrivals of Eu and Am are roughly the same.

The differences between the simple and complex models are more apparent when plotted on a linear scale, as shown for $\mathrm{U}, \mathrm{Np}$ and $\mathrm{Pu}$ in the bottom two graphs in Figure I.10. The difference in breakthrough between the two models is related to the change in retardation ratios with time that occur in the complex model. Figure I.11 shows the change in the retardation ratios for $\mathrm{Pu}$ and $\mathrm{U}$ along the complex streamline as a function of time. Whereas the retardation ratio of $\mathrm{Pu}$ increases with time, that for $\mathrm{U}$ decreases. The constant retardation ratio for Pu assumed in the particle model is shown for reference. Accounting for changes in fluid chemistry alters the retardation ratio of $U$ and $\mathrm{Pu}$ by a factor of 2, although in opposite directions. 
Variations in the retardation ratio (ratio of total sorbed to total aqueous concentration) are related to changes in groundwater composition and $\mathrm{pH}$ generated by glass dissolution and secondary mineral precipitation (see e.g. section 6.4.5). Changes in the major element chemistry of groundwater (e.g. $\mathrm{Na}, \mathrm{K}, \mathrm{Ca}, \mathrm{Mg}$ ) affect radionuclide sorption to ion exchange sites, and changes in $\mathrm{pH}$ affect surface complexation. Figures I.12 and I.13 illustrate the changes in water composition and $\mathrm{pH}$ that can occur due to glass dissolution in the complex glass model. In contrast, $\mathrm{pH}$ was maintained at about 8 downstream of the glass in the simple glass GIMRT run (Figure I.14), and the Na and Ca concentrations varied little (Figure I.15), as expected owing to the neglect of cations released from the glass (see Appendix E). 

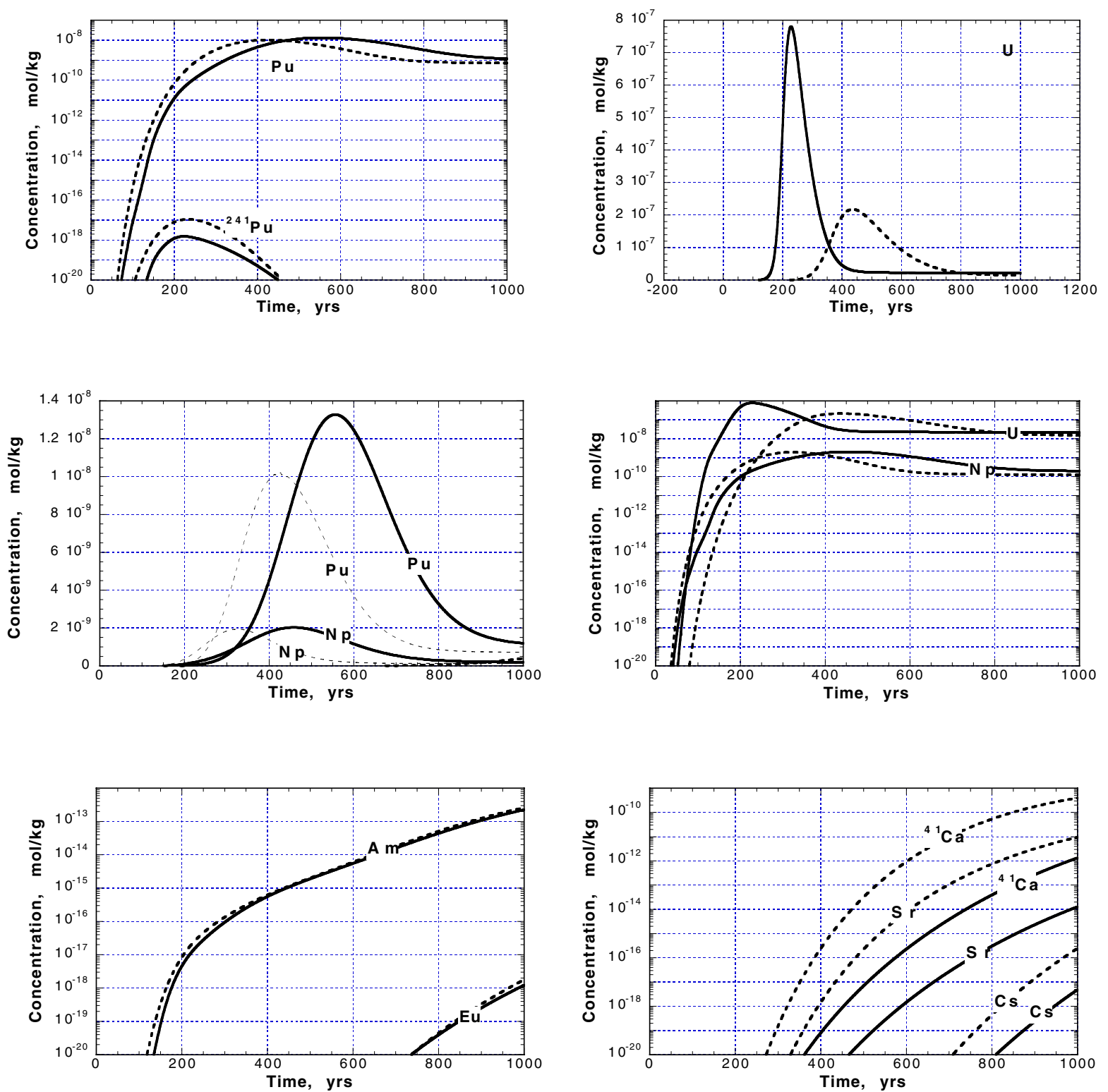

Figure I.10 Comparison of radionuclide breakthrough from the 1-D simple glass streamline (dashed lines) and complex glass streamline (solid lines). Radionuclides are not decay corrected except for $\mathrm{Am}, \mathrm{Np}$ and ${ }^{241} \mathrm{Pu}$. 

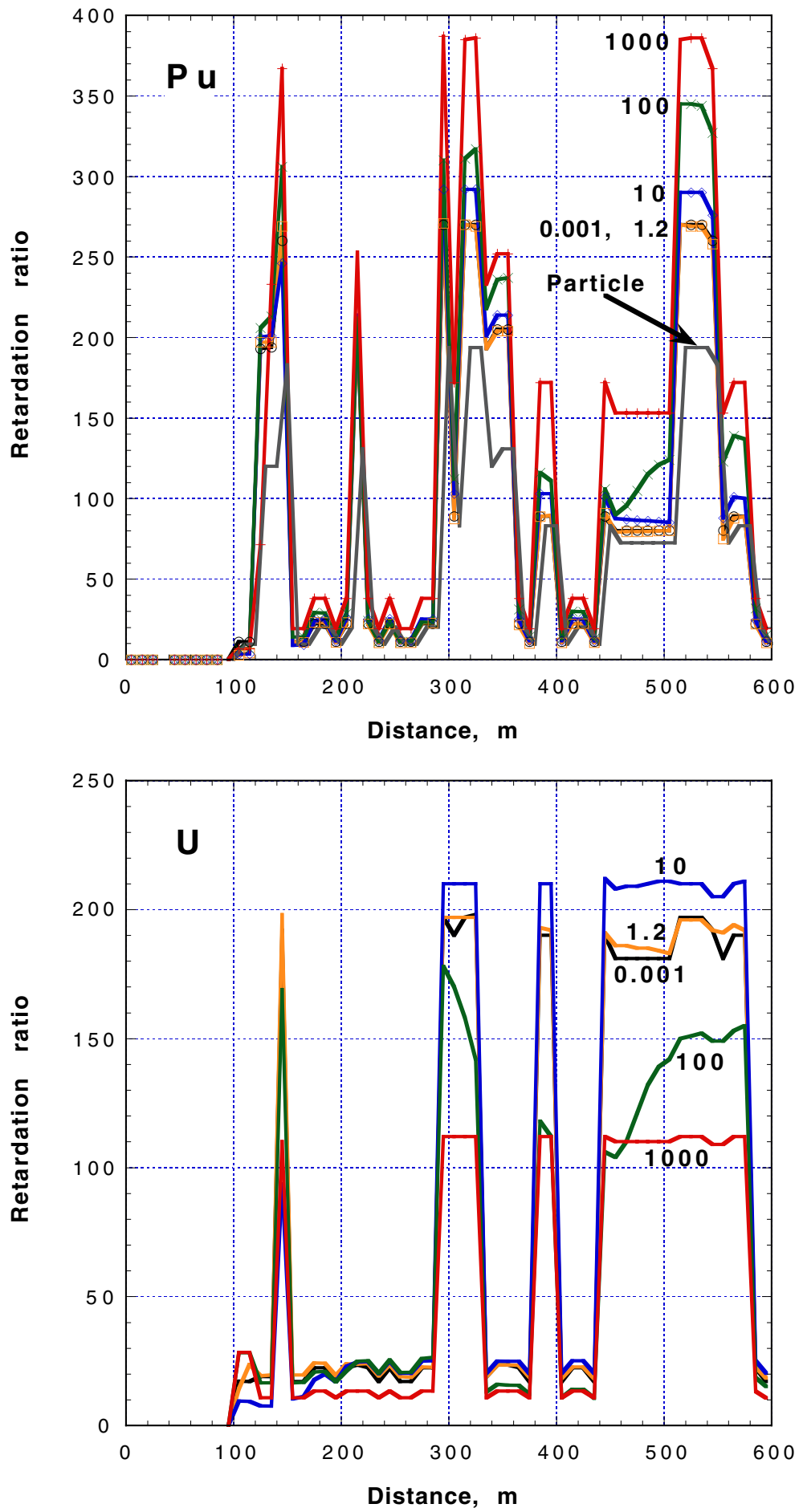

Figure I.11 Comparison of retardation ratios of $\mathrm{U}$ and $\mathrm{Pu}$ as a function of time, labelled in years, in the 1D streamline model for the complex glass GIMRT model. Retardation ratio for Pu used in the particle model, assumed invariant with time, shown for reference. 


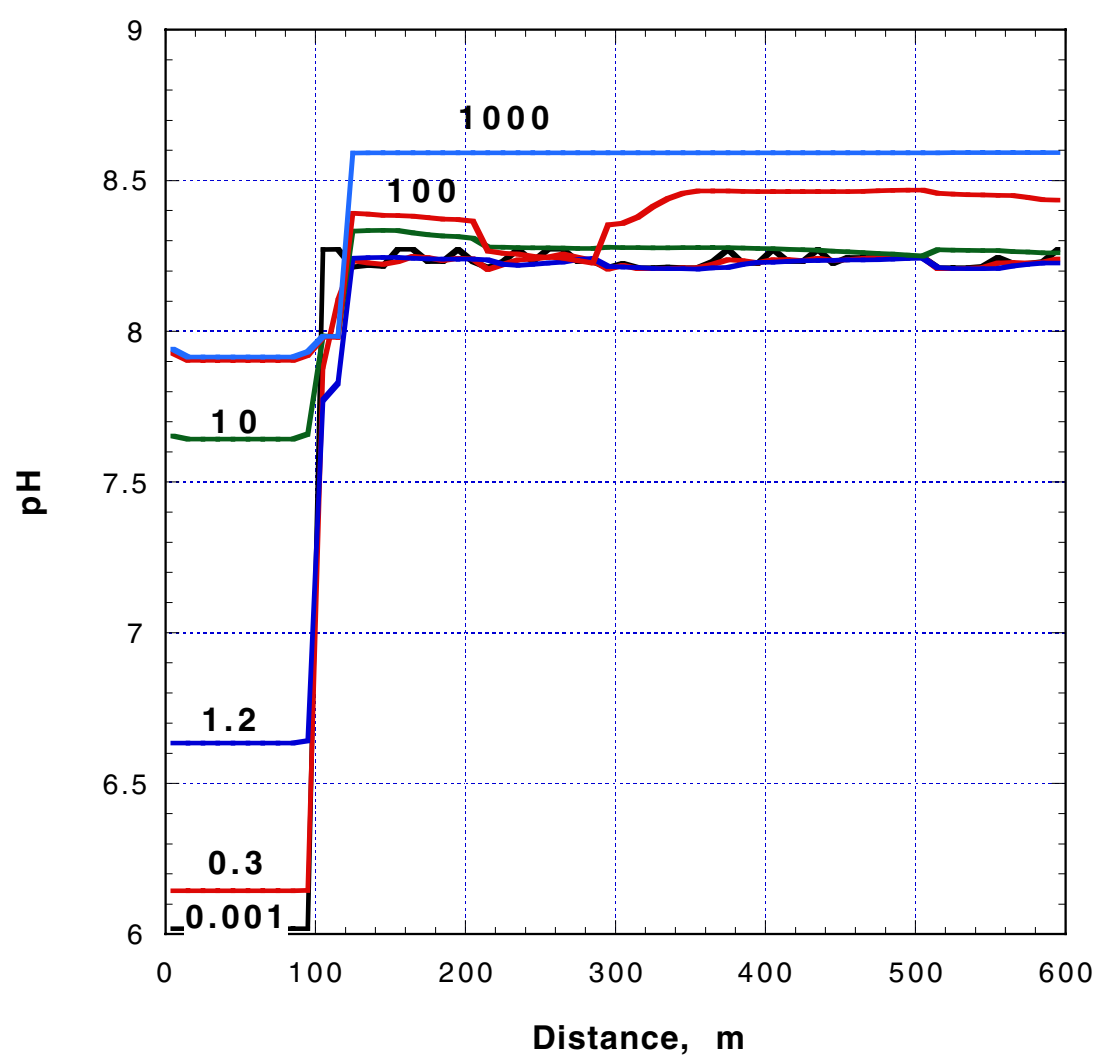

Figure I.12 The $\mathrm{pH}$ along complex glass streamline as a function of distance and time, as labeled on the curves in years. 

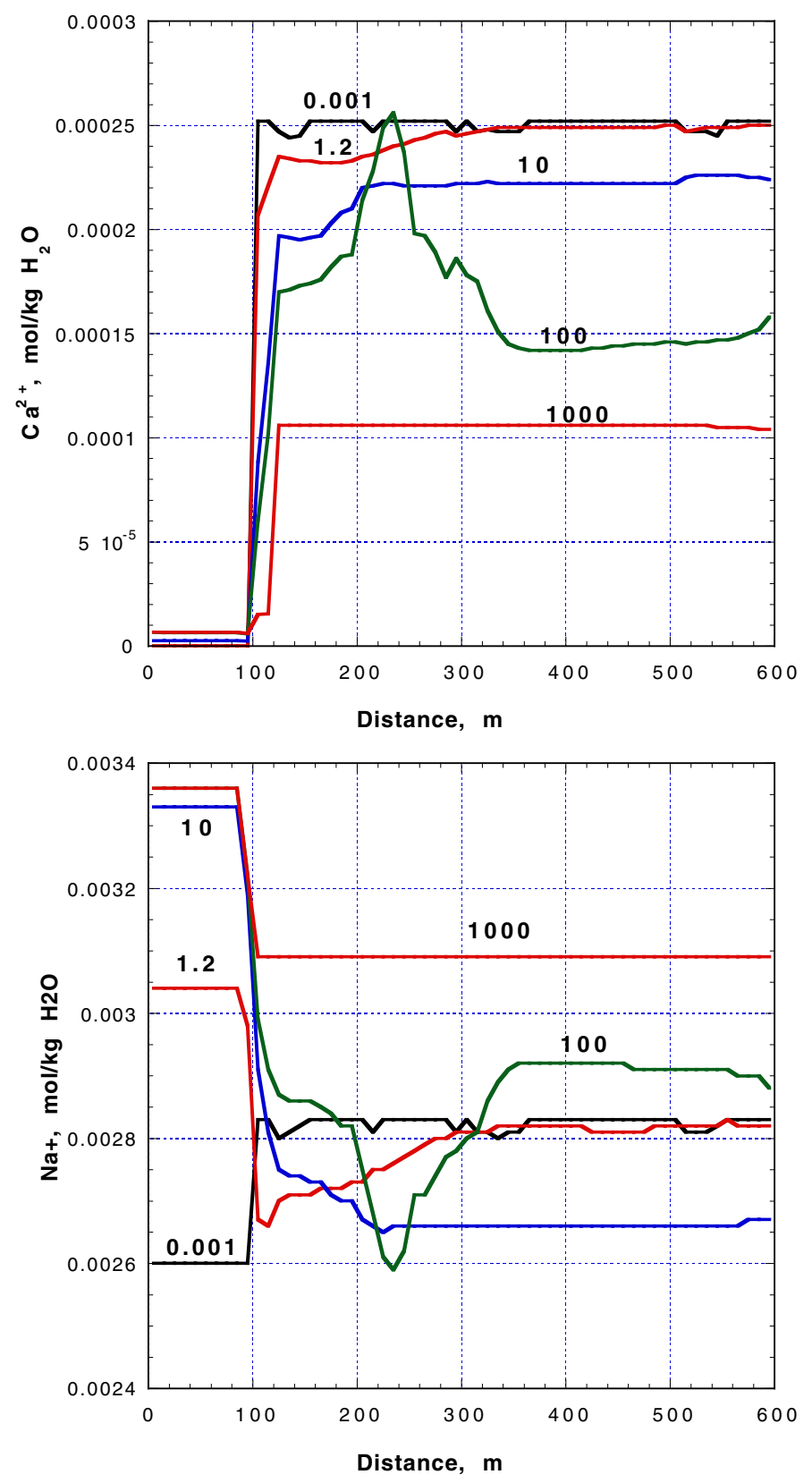

Figure I.13 Variations in $\mathrm{Na}$ and $\mathrm{Ca}$ concentration during dissolution of complex glass in GIMRT along an illustrative 1D streamline. The fluid composition at $0.001 \mathrm{yr}$ differs from the ambient fluid chemistry owing to re-equilibration of $35^{\circ} \mathrm{C}$ ambient fluid with $160^{\circ} \mathrm{C}$ conditions in glass melt during the initial time steps. Small amounts of alteration mineral precipitation caused the change in fluid chemistry. 


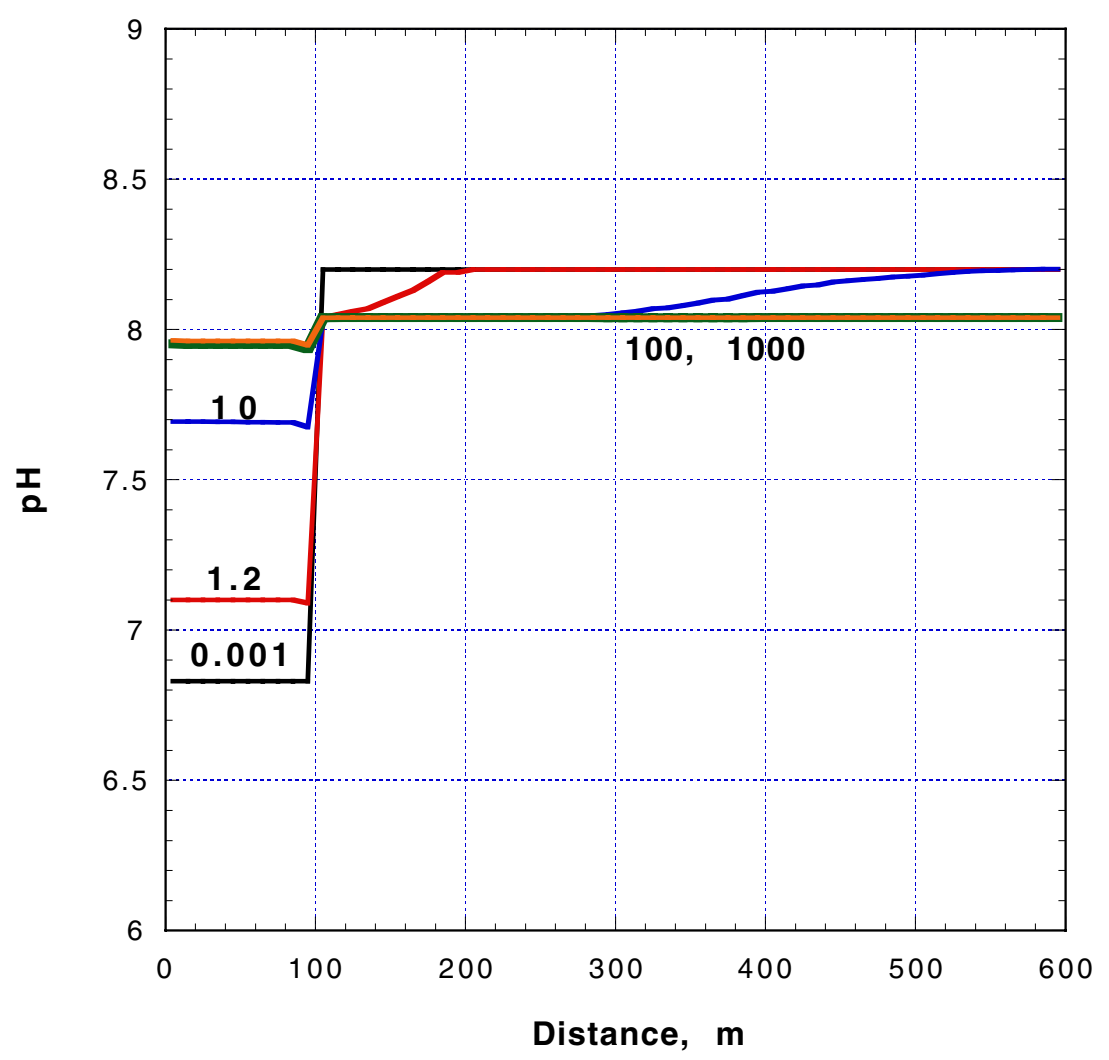

Figure I.14 The $\mathrm{pH}$ along "simple glass" streamline as a function of distance and time, as labeled on the curves in years. 

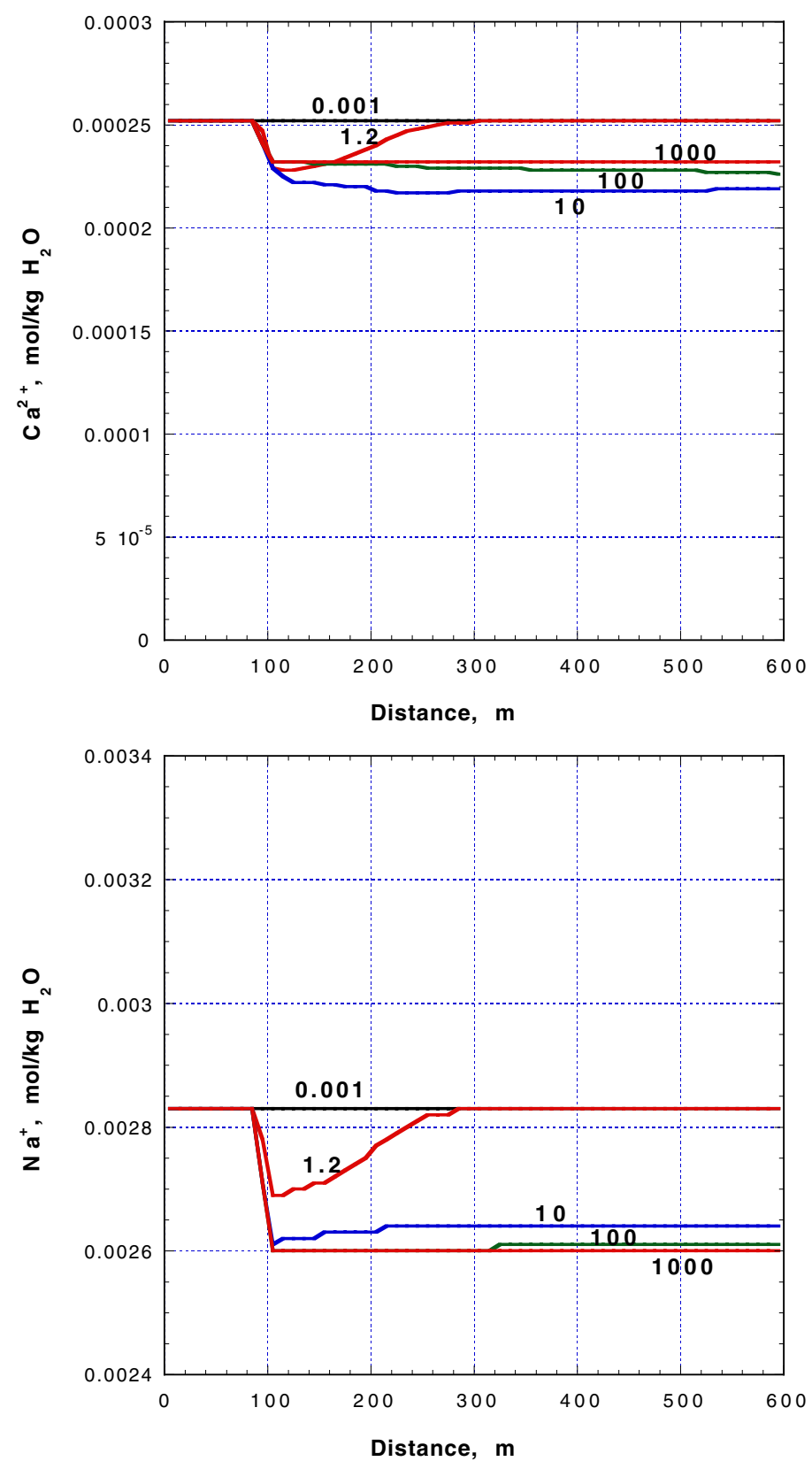

Figure I.15 Variations in $\mathrm{Na}$ and $\mathrm{Ca}$ concentrations during dissolution of simple glass in GIMRT along an illustrative 1-D streamline. 
The variation in $\mathrm{pH}$ in the glass zone in Figures I.12 is related both to elevated temperature and precipitation of alteration minerals. As temperature increases, the neutrality point of water decreases, such that in shifting from 35 to $160^{\circ} \mathrm{C}$, there is a tendency for the $\mathrm{pH}$ to decrease by about one log unit if not buffered by chemical reactions (as illustrated in the simple glass run in Figure I.14). The precipitation of aluminosilicate alteration minerals in the glass zone at elevated temperature in the complex model (discussed later) tends to decrease the $\mathrm{pH}$ still further, whereas no aluminosilicate alteration minerals form in the simple glass model. The $\mathrm{pH}$ gradually increases to about 8.5 when the groundwater enters the $35^{\circ} \mathrm{C}$ fractured lavas downstream and calcite is dissolved. This increase of $\mathrm{pH}$ owing to dissolution of fracture-lining calcite was a prominent feature of the HST streamlines intersecting the glass, as well.

Figure I.16 shows the minerals that precipitated in the glass zone as alteration minerals during the complex GIMRT run. Calcite dissolution and other very minor mineral precipitation/dissolution reactions also occurred downstream in the fractured lavas. Though the absolute amounts were minor, they had a significant effect on fluid chemistry. Dissolution of calcite not only increased the $\mathrm{pH}$ (Figure I.12) but also increased the Ca content of the Ca-poor fluids exiting the glass zone. Ca competes with radionuclides for ion exchange sites, so if the Ca concentration changes, radionuclide migration will be affected. Comparatively little calcite dissolution was required to buffer the $\mathrm{pH}$ over the $1000 \mathrm{yr}$ span of the simulation, so that calcite throughout most of the fracture was unaffected. For example, in a $20 \mathrm{~m}$ zone containing $0.042 \mathrm{vol} \%$ calcite, only the calcite in the first $10 \mathrm{~m}$ dissolved completely over $1000 \mathrm{yr}$ to affect the observed $\mathrm{pH}$ change, given a darcy flux of $100 \mathrm{~m} / \mathrm{yr}$.

Very small quantities of Ca-clinoptilolite precipitated sporadically in the fractured lavas in the simulation. Very small quantities of K-feldspar and Ca-nontronite precipitated downstream of the glass zone. The precipitation of K-feldspar was intimately related with an event shown in the $100 \mathrm{yr} \mathrm{Na}$, Ca and pH curves between 200 and $300 \mathrm{~m}$. K-feldspar precipitation caused the $\mathrm{pH}$ to decrease, calcite to dissolve and Ca concentrations to increase. K-feldspar precipitation simultaneously caused $\mathrm{K}$ in solution to decrease, which caused exchange of $\mathrm{Na}$ for $\mathrm{K}$ on exchange sites of clinoptilolite, and a decrease in Na in solution. Such nonlinearities in behavior and their effects on radionuclide sorption cannot be captured in a simplistic glass dissolution/ constant partition coefficient transport model. 


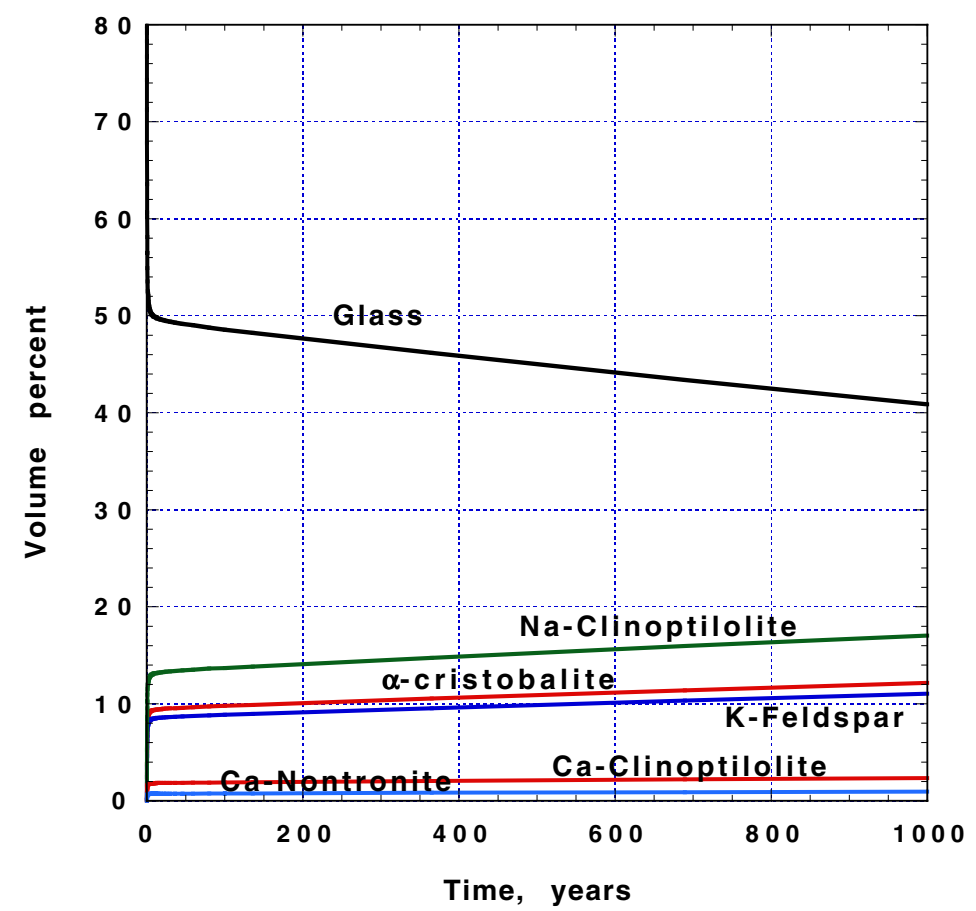

Figure I.16 Precipitation of alteration minerals in the glass zone at a point $95 \mathrm{~m}$ along complex glass streamline in the glass zone. Trace quantities of kaolinite, $\mathrm{Na}$ - and $\mathrm{Ca}-$ montmorillonite precipitates are not shown owing to their small volumes (less than $0.4,0.1$ and $0.1 \mathrm{vol} \%$, respectively, at $1000 \mathrm{yr}$ ). Note that there was no feedback assumed in GIMRT between porosity and the flow field. Thus, although the volume of alteration minerals resulting was calculated along with the lost volume of glass, the porosity of the glass zone was fixed at $20 \%$.

\section{I.7.2 Testing Complex Glass Model Implementation}

To check that the GIMRT streamline calculations used to define the HST in this report are performing as expected, we selected a streamline (1554) running through the glass zone from the NUFT flow field at $135 \mathrm{yr}$ and calculated transport along this streamline from 135 to $1000 \mathrm{yr}$. Sorbing mineralogy was distributed along the streamline as described in Appendix K. Note that, unlike the HST transient streamline calculations, a single streamline was followed for 1000 yr. Also, an arbitrary $x$ distance axis is assigned to the results illustrated in Figures I.17 through I.19 rather than converting the time-of-flight parameter to distance. This approach is adequate for checking whether the geochemical process models are correctly implemented in the transient streamlines. The purpose of this comparison is not to compute the HST but to assure ourselves that the chemistry of the system and its processes fall within expected bounds, in which case the value of the $x$ axis does not affect our analysis.

Figures I.17 through I.19 show that the changes in solution chemistry ( $\mathrm{pH}$ in Figure I.17; Na and Ca in Figure I.18), and alteration minerals that precipitate in the glass zone (Figure I.19) are similar to those in the complex glass GIMRT model after the thermal pulse has passed (compare with Figures I.12, I.13, and I.16 at times greater than $10 \mathrm{yr}$ ). This suggests that our streamlines are behaving as expected. Figure I.20 shows the breakthrough of radionuclides along this streamline. 


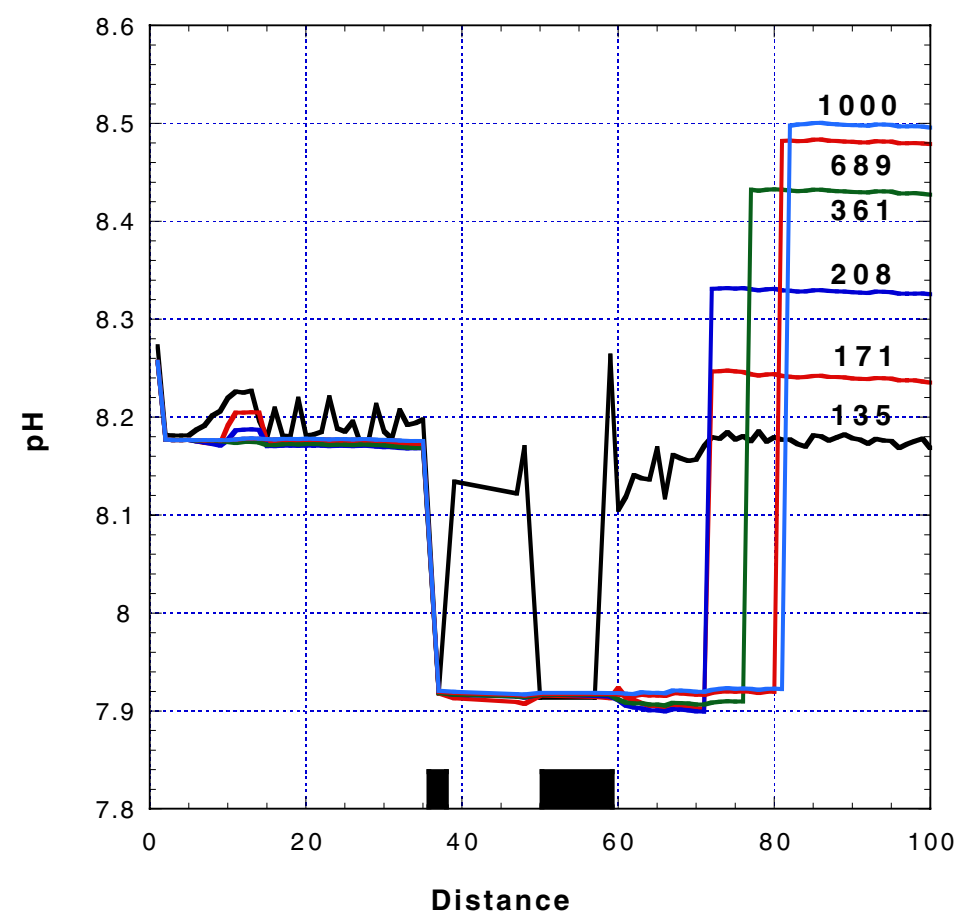

Figure I.17 The $\mathrm{pH}$ as a function of distance along streamline 1554 from135 to $1000 \mathrm{yr}$. Black blocks on top of $x$ axis show position of glass zones. 

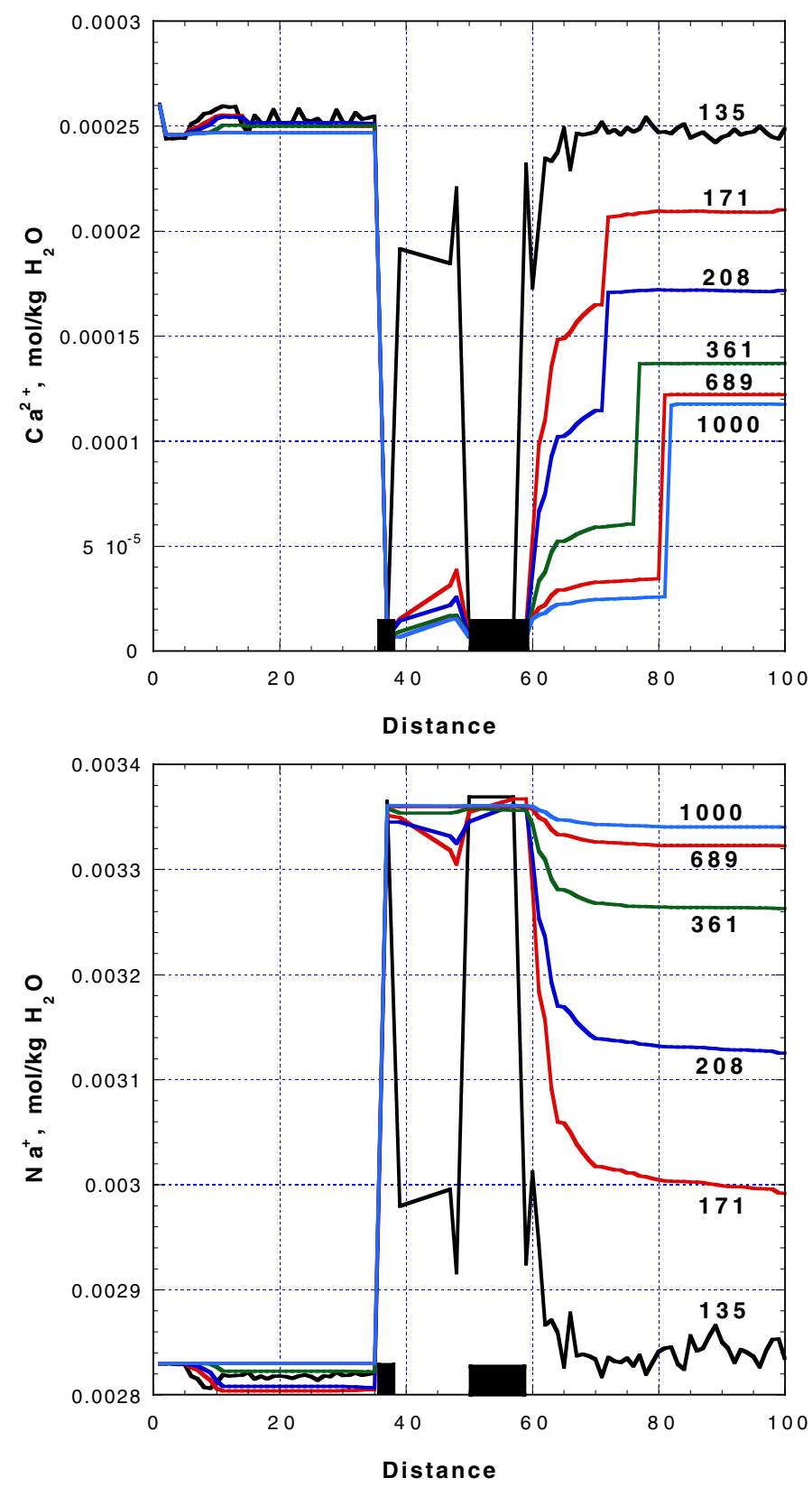

Figure I.18 $\mathrm{Ca}$ and $\mathrm{Na}$ concentrations as a function of distance along streamline 1554 from 135 to $1000 \mathrm{yr}$. Black blocks on top of $\mathrm{x}$ axis show position of glass zones. 


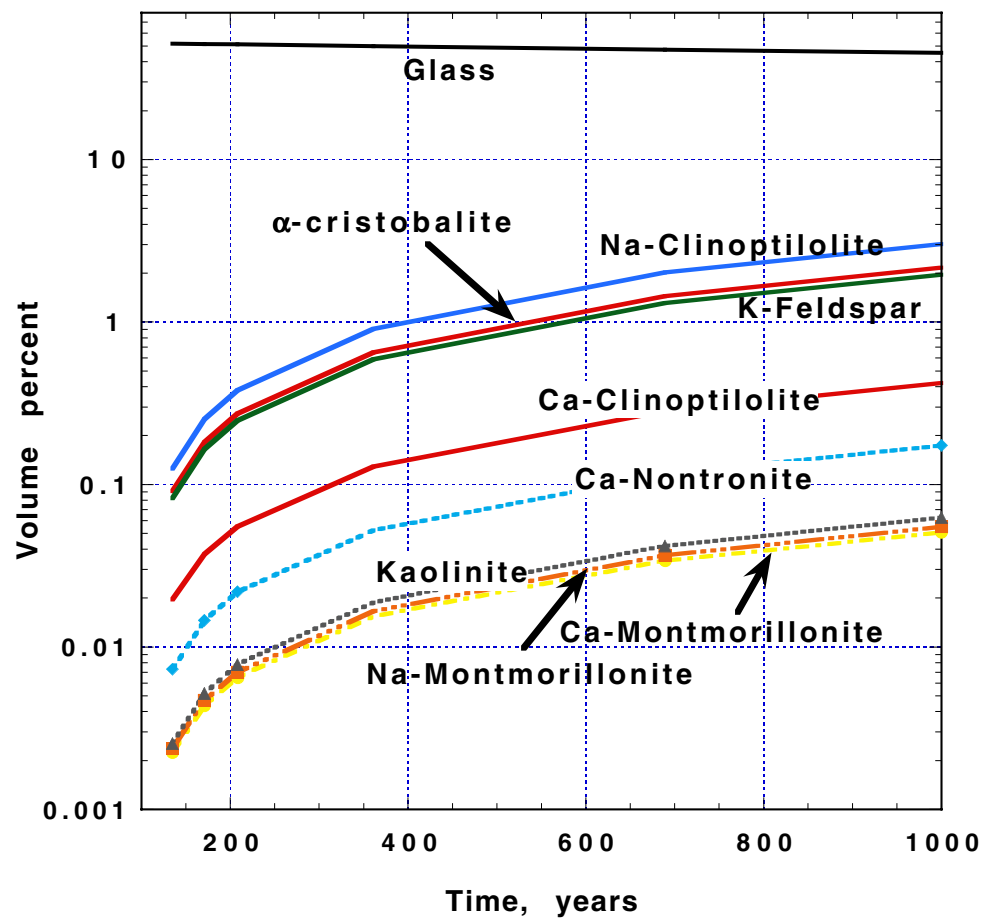

Figure I.19 Alteration minerals predicted by GIMRT to precipitate in glass zone along streamline 1554 from 135 to 1000 yr. Volume percent glass also shown. Note similarity to alteration minerals shown in Figure 7, although in smaller volumes because this simulation begins at $135 \mathrm{yr}$ when thermal pulse has dissipated.

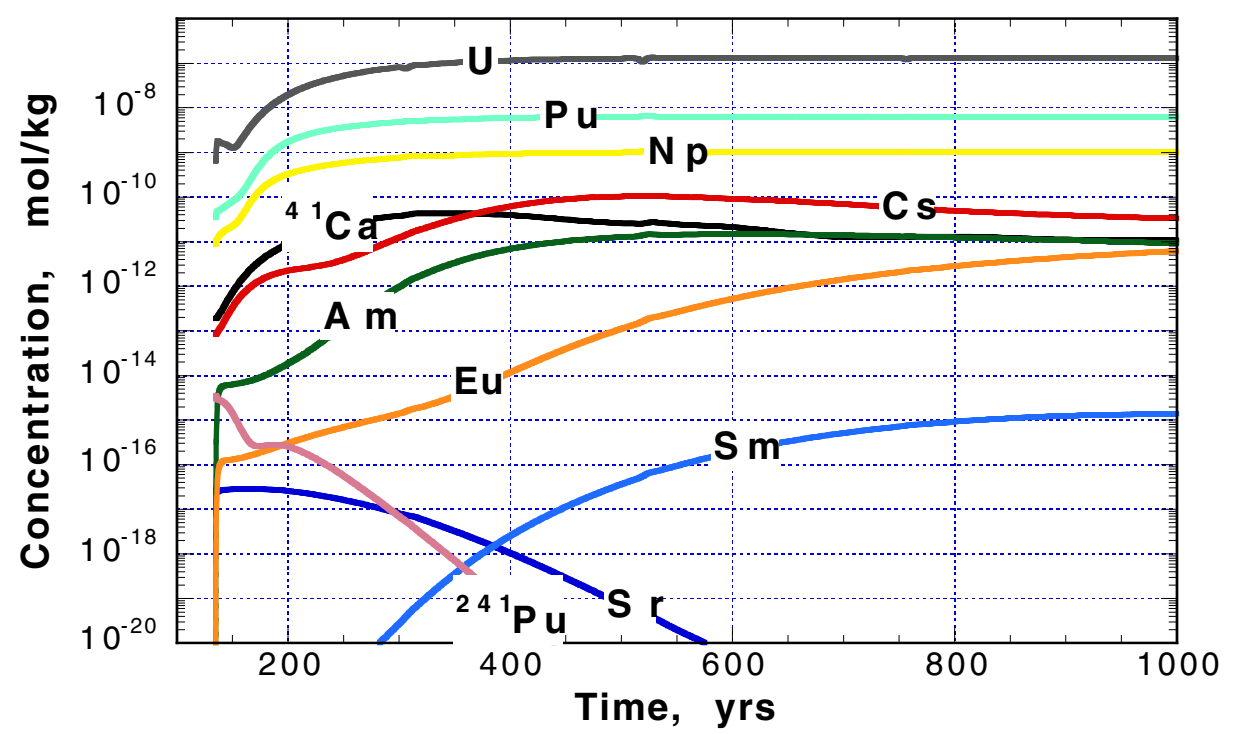

Figure I.20 Breakthrough calculated by GIMRT for streamline 1554 from 135 to $1000 \mathrm{yr}$. 


\section{I.7.3 Reactive Surface Area of Melt Glass and Glass Durability}

The reactive surface area of melt glass chosen for this report, $0.001 \mathrm{~m}^{2} / \mathrm{g}$, results in dissolution of about $30 \%$ of the glass over the $1000 \mathrm{yr}$ span of the simulations. For example, given $80 \%$ glass initially, $56 \%$ of the glass remains after $1000 \mathrm{yr}$. It is argued in section 6.4.4 that the use of reactive surface area determined from flowthrough tests of intact glass cores is an appropriate measure of reactive surface area to use in reactive transport modeling. At the present time, a single mass-normalized reactive surface area is used for the entire glass melt, regardless of its physical characteristics. There is little data with which to derive a statistical distribution of glass properties, and in any case, Bourcier ${ }^{5}$ found surprisingly little correlation between glass texture in intact glass blocks and reactive surface area.

The use of different surface areas to compute the extent of glass dissolution with time and comparison of the results with our knowledge of the durability of natural glasses may give us more confidence in the reactive surface area used in the calculations in this report. It may also be used to generate a reasonable upper bound to reactive surface area. The temperature dependent particle glass dissolution model was used to calculate glass loss with time as a function of surface area given the time-temperature relationship in Figure E.5 (Figure I.21). If the glass surface area is assumed to be an order of magnitude greater than the surface area used in this report (0.01 vs. $0.001 \mathrm{~m}^{2} / \mathrm{g}$ ), $100 \%$ of the melt glass dissolves after only $68 \mathrm{~d}$. $100 \%$ of the glass dissolves in $355 \mathrm{~d}$ assuming $0.005 \mathrm{~m}^{2} / \mathrm{g}$. Note that the particle glass model used a fixed saturation term equaling 0.48 , and did not provide for a long-term, near-saturation glass dissolution rate (see sections 6.4.4 and 6.4.5). Near-saturation dissolution rates were not activated in the GIMRT simulations owing to the assumption that silica released from glass precipitates quickly (section 6.4.5).

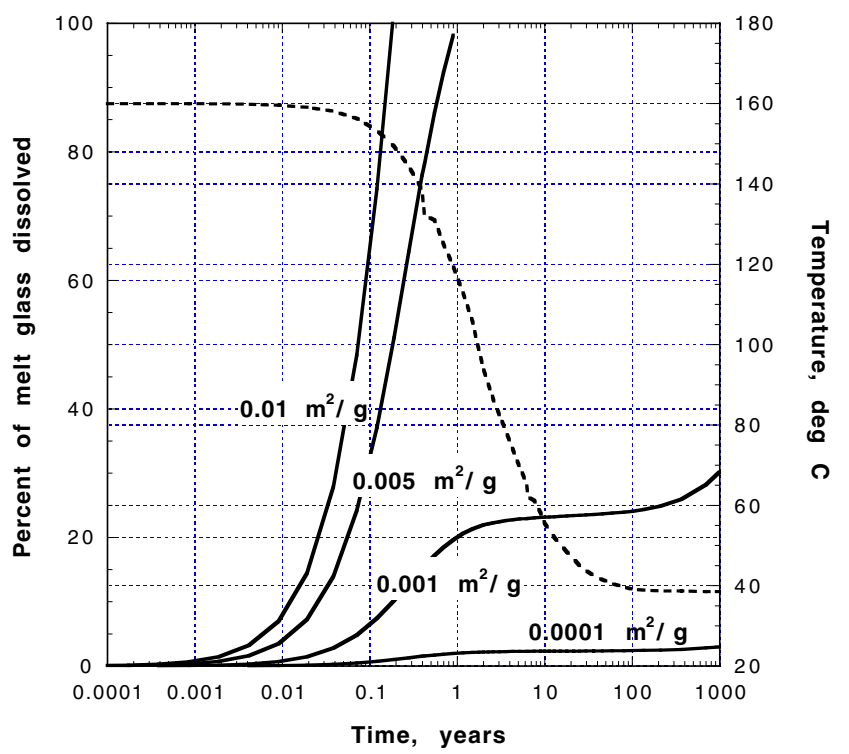

Figure I.21 Extent of glass dissolution predicted using the particle glass dissolution model as a function of time, temperature and reactive surface area given glass temperature-time relationship in Figure E.5.

\footnotetext{
${ }^{5}$ Bourcier, personal communication, 2001.
} 
Previous simulations of melt glass dissolution (Pohll et al., 1998; Tompson et al., 1999) were conducted at low temperature $\left(25^{\circ} \mathrm{C}\right)$. Glass dissolution rates were sufficiently slow at this temperature that the choice in surface area did cause complete glass dissolution. For example, SHOAL was modeled using a comparatively high surface area of $0.05 \mathrm{~m}^{2} / \mathrm{g}$. At $25^{\circ} \mathrm{C}, 100 \%$ of the glass dissolved in $6000 \mathrm{yr}$. However, glass dissolution rates are much faster at elevated temperature, so the consequences of using relatively high surface areas are magnified (Figure I.21).

The occurrence and durability of volcanic glasses in natural settings, and especially NTS, can be used to guide our selection of the reactive surface area. Volcanic glasses at NTS were probably subjected to conditions not unlike the post-event conditions to which melt glass was subjected in terms of cooling and fluid flow (although without the influence of in-fallen chimney blocks). The cooling rates of melt glass are expected to be fairly slow and comparable with the cooling rates of shallow intrusive rocks and the interiors of extrusive flows. The NTS itself can be used as a natural analogue for the durability of rhyolitic glasses. Natural volcanic glasses (e.g., vitric tuffs) still exist at NTS up to millions of years. Natural glass dissolution rates at NTS might even have been higher than those of melt glasses because of the elevated geothermal gradients in the past due to volcanic activity, and the progressive burial of the glasses. Many glasses are below the water table, and have been for extended periods of time. For example, the mafic-poor Calico Hills Formation at well UE-20n \#1 and several other nearby wells are composed, in part, by a vitric component, indicating that initially deposited glasses of the mafic-poor Calico Hills Formation still remain (Warren et al., 2000).

Given the observed durability of natural silicic volcanic glasses, it is unreasonable to think that melt glass will completely disappear on the order of hundreds of days. This puts upper limits on our choice of reactive surface area in our reactive transport modeling given the current form of our glass dissolution model. Factors must be at work in the field to limit the extent of glass dissolution in situ. These factors, whether some combination of effective porosity, saturation-limited rates, or others, are not clearly defined. Thus, the sum of these factors is accounted for in the reactive surface area term in our current glass dissolution model. The effect of these heterogeneities, such as highly variable textures and types and distributions of porosity, is represented in the measurements of reactive surface area and in the recommended reactive surface area of $0.001 \mathrm{~m}^{2} / \mathrm{g}$.

It can be argued that the reactive surface areas can be larger if another parameter in the kinetic rate law for glass dissolution is decreased, or if we are using an inappropriate form of the rate law. At this time we have good confidence in the rate constant $k$. If glass saturation is attained and the long-term rate law is achieved, the glass dissolution rate becomes independent of reactive surface area. However, the long term dissolution rate for melt glass has not been measured, and the rates of chemical reactions in the post-test environment that control the approach to glass saturation (for example, precipitation of silica polymorphs; see section 6.4.5) are poorly known. Attainment of the long-term saturation rate produces the slowest rate of glass dissolution, and the least conservative estimate of radionuclide release from glass. Because little is known about this term for melt glasses, it is best to err on the side of conservatism. On the other hand, natural and man-made glasses persist for longer than 
hundreds of days, so we should use a glass reactive surface area much less than $0.01 \mathrm{~m}^{2} / \mathrm{g}$.

The decrease in surface area with time is also a concern, although its impact is extremely minor compared to the effects of temperature. Decreases in surface area are often related to the change in the diameter of spherical or cubic particles, as exemplified by equation (6.4). This may be reasonable for granular aggregates, but not for massive glass and most other textures of the melt glass. In our models, we use reactive surface areas measured in bulk cores. This surface area should more properly have a linear dependence on the mass of bulk glass remaining. This linear relationship was assumed for the particle model, but not in GIMRT, which had an area term related to the cubic law. The linear relationship should be provided for in future versions of GIMRT. However, its effect on radionuclide migration is very small.

\section{I.8 Summary}

- The treatment of radionuclide decay and ingrowth in GIMRT has been tested and validated against the Bateman equations. Time steps of one year and less in GIMRT maintain good agreement with the analytic solutions.

- Preliminary results suggest that a very limited number of nodes extending into the matrix may adequately model matrix diffusion in GIMRT. This would minimize the computational requirements associated with explicitly modeling mass flux from fractures to the matrix.

- Radionuclide retardation is governed by a combination of sorption to fracture-lining minerals, diffusion into the matrix, and sorption to minerals within the matrix. No single mechanism surpasses others in importance.

- For all reactive radionuclides studied, a homogeneous distribution of sorbing minerals in the near field results in the greatest degree of radionuclide retardation. Heterogeneous distribution of sorbing minerals results in increased radionuclide migration.

- The response of individual radionuclides to sorbing mineral distribution heterogeneity is highly dependent on the affinity of the radionuclide for particular minerals and the distribution of those minerals.

- Colloids can control the migration of radionuclides depending on the mineralogy of the colloid and the affinity of radionuclides for the colloids.

- The redox chemistry of Pu and groundwater at NTS must be better defined to explain observed colloidal transport of $\mathrm{Pu}$ and to more accurately simulate the sorption of $\mathrm{Pu}$ to sorbing minerals, and thus $\mathrm{Pu}$ migration. 
- Uncertainties in surface complexation and ion exchange constants can potentially have as large an effect on radionuclide migration as uncertainties in hydrologic and mineralogic parameters evaluated in section 7.3.

- Glass dissolution results in precipitation of alteration minerals and changes in fluid chemistry that can significantly impact radionuclide sorption to minerals, and thus radionuclide migration.

- The occurrence and durability of natural volcanic glasses at the NTS can be used to bound the upper limit for the reactive surface area of melt glass. 


\section{APPENDIX J: \\ Thermodynamic and Kinetic Data}




\section{J.1 Thermodynamic Data}

Thermodynamic data for aqueous species, solids and gases were taken from version com.V8.R6 of the GEMBOCHS thermodynamic database (Johnson and Lundeen, 1997) with revised and updated thermodynamic data as given in Tompson et al. (1999) and noted later in this appendix. Tables J.1 through J.4 list the thermodynamic data used in the simulations. The choice of aqueous species, minerals, and gases used in the simulations is discussed in sections 6.3 and 6.4 of Chapter 6. Appendix K contains a summary of the surface complexation and ion exchange data used in the model.

Table J.1 Basis species used in GIMRT thermodynamic database.

\begin{tabular}{|l|c|c|}
\hline & $\begin{array}{c}\text { Ion size, } \\
\text { Åt }\end{array}$ & $\begin{array}{c}\text { Mol. wt., } \\
\text { g/mol }\end{array}$ \\
\hline \hline $\mathrm{H}_{2} \mathrm{O}$ & 3 & 18.0 \\
\hline $\mathrm{Al}^{3+}$ & 9 & 27.0 \\
\hline $\mathrm{Am}^{3+}$ & 5 & 243.0 \\
\hline $\mathrm{Ca}^{2+}$ & 6 & 40.1 \\
\hline $\mathrm{Cl}^{-}$ & 3 & 35.5 \\
\hline $\mathrm{Cs}^{+}$ & 2.5 & 132.9 \\
\hline $\mathrm{Eu}^{3+}$ & 5 & 152.0 \\
\hline $\mathrm{Fe}^{2+}$ & 6 & 55.8 \\
\hline $\mathrm{H}^{+}$ & 9 & 1.0 \\
\hline $\mathrm{HCO}_{3}{ }^{-}$ & 4 & 61.0 \\
\hline $\mathrm{K}^{+}$ & 3 & 39.1 \\
\hline $\mathrm{Mg}^{2+}$ & 8 & 24.3 \\
\hline $\mathrm{Na}^{+}$ & 4 & 23.0 \\
\hline $\mathrm{Np}^{4+}$ & 5.5 & 237.0 \\
\hline $\mathrm{Pu}^{4+}$ & 5.5 & 244.0 \\
\hline $\mathrm{SO}_{4}{ }^{2-}$ & 4 & 96.1 \\
\hline $\mathrm{SiO}_{2}(\mathrm{aq})$ & 3 & 60.1 \\
\hline $\mathrm{Sm}^{3+}$ & 9 & 150.4 \\
\hline $\mathrm{Sr}^{2+}$ & 5 & 87.6 \\
\hline $\mathrm{UO}_{2}{ }^{2+}$ & 4.5 & 270.0 \\
\hline $\mathrm{O}_{2}(\mathrm{aq})$ & 3 & 32.0 \\
\hline $\mathrm{Fin}^{2+}$ & 5 & \\
\hline
\end{tabular}

† Ion size parameter used in Debye-Hückel activity coefficient model. 
Table J.2 Parameters in extended Debye-Hückel activity coefficient model as a function of temperature.

\begin{tabular}{|l|r|r|l|l|l|l|l|l|}
\hline \multicolumn{1}{|c|}{ Constants } & $\mathbf{0}^{\circ} \mathbf{C}$ & $\mathbf{2 5}^{\circ} \mathbf{C}$ & $\mathbf{6 0}^{\circ} \mathbf{C}$ & $\mathbf{1 0 0}^{\circ} \mathbf{C}$ & $\mathbf{1 5 0}^{\circ} \mathbf{C}$ & $\mathbf{2 0 0}^{\circ} \mathbf{C}$ & $\mathbf{2 5 0}^{\circ} \mathbf{C}$ & $\mathbf{3 0 0}^{\circ} \mathbf{C}$ \\
\hline \hline$A$ & 0.4939 & 0.5114 & 0.5465 & 0.5995 & 0.6855 & 0.7994 & 0.9593 & 1.218 \\
\hline$B$ & 0.3253 & 0.3288 & 0.3346 & 0.3421 & 0.3525 & 0.3639 & 0.3766 & 0.3925 \\
\hline$B^{\circ}$ & 0.0374 & 0.041 & 0.044 & 0.046 & 0.047 & 0.047 & 0.034 & - \\
\hline
\end{tabular}


Table J.3 Logarithm of equilibrium constants $(\mathrm{K})$ of aqueous reactions as a function of temperature $\left({ }^{\circ} \mathrm{C}\right)$ used in GIMRT thermodynamic database. When only one $\log \mathrm{K}$ value is shown, $\log \mathrm{K}$ is assumed to be invariant with temperature. Data for Pu are not shown, pending Nuclear Energy Agency approval for publication.

\begin{tabular}{|c|c|c|c|c|c|c|c|c|c|}
\hline \multirow[t]{2}{*}{ Reaction } & 0 & 25 & 60 & 100 & 150 & 200 & 250 & 300 & \multirow{2}{*}{$\begin{array}{c}\text { lon } \\
\text { size† } \\
a^{*}\end{array}$} \\
\hline & \multicolumn{8}{|c|}{$\log K$} & \\
\hline $\mathrm{H}_{2} \mathrm{O}=\mathrm{OH}^{-}+\mathrm{H}^{+}$ & 14.9 & 14.0 & 13.0 & 12.3 & 11.6 & 11.3 & 11.2 & 11.3 & 3.5 \\
\hline $\mathrm{Al}^{3+}+2 \mathrm{H}_{2} \mathrm{O}=\mathrm{AlO}_{2}^{-}+4 \mathrm{H}^{+}$ & 25.0 & 22.2 & 19.0 & 16.2 & 13.5 & 11.3 & 9.7 & 8.3 & 4 \\
\hline $\mathrm{HCO}_{3}^{-}=\mathrm{CO}_{3}^{2-}+\mathrm{H}^{+}$ & 10.6 & 10.3 & 10.1 & 10.1 & 10.2 & 10.5 & 10.9 & 11.5 & 4.5 \\
\hline $\mathrm{Fe}^{2+}+0.25 \mathrm{O}_{2}(\mathrm{~g})+\mathrm{H}^{+}=\mathrm{Fe}^{3+}+0.5 \mathrm{H}_{2} \mathrm{O}$ & -9.4 & -7.8 & -5.9 & -4.2 & -2.5 & -1.2 & 0.0 & 1.0 & 9 \\
\hline $\mathrm{Fe}^{3+}+2 \mathrm{H}_{2} \mathrm{O}=\mathrm{FeO}_{2}^{-}+4 \mathrm{H}^{+}$ & 24.5 & 21.6 & 18.4 & 15.7 & 13.2 & 11.3 & 10.0 & 8.9 & 4 \\
\hline $\mathrm{Fe}^{3+}+2 \mathrm{H}_{2} \mathrm{O}=\mathrm{HFeO}_{2}^{0}+3 \mathrm{H}^{+}$ & 14.3 & 12.0 & 9.6 & 7.6 & 5.8 & 4.5 & 3.5 & 2.7 & 3 \\
\hline $\mathrm{SiO}_{2}\left(\mathrm{aq}^{\prime}+\mathrm{H}_{2} \mathrm{O}=\mathrm{HSiO}_{3}^{-}+\mathrm{H}^{+}\right.$ & 9.8 & 9.6 & 9.2 & 9.0 & 8.8 & 8.8 & 9.0 & 9.4 & 4 \\
\hline $\mathrm{Ca}^{2+}+\mathrm{HCO}_{3}^{-}=\mathrm{CaCO}_{3}^{0}+\mathrm{H}^{+}$ & 7.5 & 7.0 & 6.5 & 6.0 & 5.5 & 5.1 & 4.6 & 4.0 & 3 \\
\hline $\mathrm{O}_{2}(\mathrm{aq})=\mathrm{O}_{2}(\mathrm{~g})$ & 2.7 & 2.9 & 3.1 & 3.1 & 3.0 & 2.9 & 2.6 & 2.4 & - \\
\hline $\mathrm{Np}^{4+}+0.25 \mathrm{O}_{2}(\mathrm{~g})+1.5 \mathrm{H}_{2} \mathrm{O}=\mathrm{NpO}_{2}^{+}+3 \mathrm{H}^{+}$ & \multicolumn{8}{|c|}{9.9} & 4 \\
\hline $\mathrm{NpO}_{2}^{+}+\mathrm{HCO}_{3}^{-}=\mathrm{NpO}_{2} \mathrm{CO}_{3}^{-}+\mathrm{H}^{+}$ & \multicolumn{8}{|c|}{5.7} & 4 \\
\hline $\mathrm{NpO}_{2}^{+}+\mathrm{H}_{2} \mathrm{O}=\mathrm{NpO}_{2} \mathrm{OH}^{0}+\mathrm{H}^{+}$ & \multicolumn{8}{|c|}{8.9} & 3 \\
\hline $\mathrm{Np}^{4+}+4 \mathrm{H}_{2} \mathrm{O}=\mathrm{Np}(\mathrm{OH})_{4}{ }^{0}+4 \mathrm{H}^{+}$ & \multicolumn{8}{|c|}{9.6} & 3 \\
\hline $\mathrm{Am}^{3+}+2 \mathrm{HCO}_{3}^{-}=\mathrm{Am}\left(\mathrm{CO}_{3}\right)_{2}^{-}+2 \mathrm{H}^{+}$ & \multicolumn{8}{|c|}{8.4} & 4 \\
\hline $\mathrm{Am}^{3+}+2 \mathrm{H}_{2} \mathrm{O}=\mathrm{Am}(\mathrm{OH})_{2}^{+}+2 \mathrm{H}^{+}$ & \multicolumn{8}{|c|}{14.1} & 4 \\
\hline $\mathrm{Am}^{3+}+\mathrm{HCO}_{3}^{-}=\mathrm{AmCO}_{3}^{+}+\mathrm{H}^{+}$ & \multicolumn{8}{|c|}{2.5} & 4 \\
\hline $\mathrm{Am}^{3+}+\mathrm{H}_{2} \mathrm{O}=\mathrm{AmOH}^{2+}+\mathrm{H}^{+}$ & \multicolumn{8}{|c|}{6.4} & 4.5 \\
\hline $\mathrm{Eu}^{3+}+2 \mathrm{HCO}_{3}^{-}=\mathrm{Eu}\left(\mathrm{CO}_{3}\right)_{2}^{-}+2 \mathrm{H}^{+}$ & \multicolumn{8}{|c|}{7.7} & 4 \\
\hline $\mathrm{Eu}^{3+}+2 \mathrm{H}_{2} \mathrm{O}=\mathrm{Eu}(\mathrm{OH})_{2}^{+}+2 \mathrm{H}^{+}$ & \multicolumn{8}{|c|}{14.9} & 4 \\
\hline $\mathrm{Eu}^{3+}+\mathrm{HCO}_{3}^{-}=\mathrm{EuCO}_{3}^{+}+\mathrm{H}^{+}$ & \multicolumn{8}{|c|}{2.4} & 4 \\
\hline $\mathrm{Sm}^{3+}+2 \mathrm{HCO}_{3}^{-}=\mathrm{Sm}\left(\mathrm{CO}_{3}\right)_{2}^{-}+2 \mathrm{H}^{+}$ & \multicolumn{8}{|c|}{7.9} & 4 \\
\hline $\mathrm{Sm}^{3+}+\mathrm{HCO}_{3}^{-}=\mathrm{SmCO}_{3}^{+}+\mathrm{H}^{+}$ & \multicolumn{8}{|c|}{2.5} & 4 \\
\hline $\mathrm{UO}_{2}^{2+}+2 \mathrm{HCO}_{3}^{-}=\mathrm{UO}_{2}\left(\mathrm{CO}_{3}\right)_{2}^{2-}+2 \mathrm{H}^{+}$ & \multicolumn{8}{|c|}{3.8} & 4 \\
\hline $\mathrm{UO}_{2}^{2+}+3 \mathrm{HCO}_{3}^{-}=\mathrm{UO}_{2}\left(\mathrm{CO}_{3}\right)_{3}{ }^{4-}+3 \mathrm{H}^{+}$ & \multicolumn{8}{|c|}{9.4} & 4 \\
\hline $\mathrm{UO}_{2}^{2+}+\mathrm{H}_{2} \mathrm{O}=\mathrm{UO}_{3}^{0}+2 \mathrm{H}^{+}$ & \multicolumn{8}{|c|}{10.3} & 3 \\
\hline $\mathrm{UO}_{2}^{2+}+2 \mathrm{H}^{+}=\mathrm{U}^{4+}+0.5 \mathrm{O}_{2}(\mathrm{~g})+\mathrm{H}_{2} \mathrm{O}$ & \multicolumn{8}{|c|}{32.5} & 5.5 \\
\hline $\mathrm{U}^{4+}+2 \mathrm{H}_{2} \mathrm{O}=\mathrm{UO}_{2}^{0}+4 \mathrm{H}^{+}$ & \multicolumn{8}{|c|}{4.6} & 3 \\
\hline $\mathrm{Pu}^{4+}+2 \mathrm{HCO}_{3}^{-}+2 \mathrm{H}_{2} \mathrm{O}=\mathrm{Pu}(\mathrm{OH})_{2}\left(\mathrm{CO}_{3}\right)_{2}^{2-}+4 \mathrm{H}^{+}$ & \multicolumn{8}{|c|}{$2.8 \S$} & 3 \\
\hline
\end{tabular}

$\dagger$ Ion size parameter, used in Debye-Huckel activity coefficient model, for the aqueous complex formed by the basis species.

$\S$ Speciation constant derived from Rai et al. (1999). Other Pu speciation data will be released in a forthcoming comprehensive NEA publication. 
Table J.4 Logarithm of equilibrium constants $(\mathrm{K})$ of mineral solubility as a function of temperature $\left({ }^{\circ} \mathrm{C}\right)$ used in GIMRT thermodynamic data base. When only one $\log \mathrm{K}$ value is shown, $\log \mathrm{K}$ is assumed invariant with temperature (see text).

\begin{tabular}{|c|c|c|c|c|c|c|c|c|}
\hline \multirow[b]{2}{*}{ Reaction } & 0 & 25 & 60 & 100 & 150 & 200 & 250 & 300 \\
\hline & \multicolumn{8}{|c|}{$\log K$} \\
\hline Goethite $=-3 \mathrm{H}^{+}+\mathrm{Fe}^{3+}+2 \mathrm{H}_{2} \mathrm{O}$ & 1.54 & 0.53 & -0.58 & -1.55 & -2.45 & -3.15 & - & - \\
\hline Kaolinite $=-6 \mathrm{H}^{+}+2 \mathrm{Al}^{3+}+2 \mathrm{SiO}_{2}(\mathrm{aq})+5 \mathrm{H}_{2} \mathrm{O}$ & 7.40 & 5.44 & 2.77 & 0.14 & -2.55 & -4.80 & -6.81 & -8.74 \\
\hline Montmor- $\mathrm{Ca}=-6 \mathrm{H}^{+}+0.165 \mathrm{Ca}^{2+}+0.33 \mathrm{Mg}^{2+}+1.67 \mathrm{Al}^{3+}+4 \mathrm{H}_{2} \mathrm{O}+4 \mathrm{SiO}_{2}(\mathrm{aq})$ & 2.32 & 1.35 & -0.59 & -2.72 & -4.98 & -6.86 & -8.49 & -10.04 \\
\hline Montmor- $\mathrm{Na}=-6 \mathrm{H}^{+}+0.33 \mathrm{Mg}^{2+}+0.33 \mathrm{Na}^{+}+1.67 \mathrm{Al}^{3+}+4 \mathrm{H}_{2} \mathrm{O}+4 \mathrm{SiO}_{2}(\mathrm{aq})$ & 2.20 & 1.34 & -0.47 & -2.47 & -4.58 & -6.34 & -7.86 & -9.29 \\
\hline Nontronite- $\mathrm{Ca}=-7.32 \mathrm{H}^{+}+0.165 \mathrm{Ca}^{2+}+0.33 \mathrm{Al}^{3+}+2 \mathrm{Fe}^{3+}+3.67 \mathrm{SiO}_{2}(\mathrm{aq})+4.66 \mathrm{H}_{2} \mathrm{O}$ & -11.63 & -11.81 & -12.77 & -13.95 & -15.26 & -16.43 & -17.56 & -18.80 \\
\hline $\mathrm{SiO}_{2}(\mathrm{am})=\mathrm{SiO}_{2}(\mathrm{aq})$ & -3.12 & -2.71 & -2.41 & -2.18 & -1.98 & -1.82 & -1.69 & -1.60 \\
\hline Cristobalite(alpha) $=\mathrm{SiO}_{2}(\mathrm{aq})$ & -4.02 & -3.45 & -2.99 & -2.66 & -2.36 & -2.13 & -1.94 & -1.78 \\
\hline Clinoptilolite- $\mathrm{Ca}=-13.868 \mathrm{H}^{+}+1.7335 \mathrm{Ca}^{2+}+3.467 \mathrm{Al}^{3+}+14.533 \mathrm{SiO}_{2}(\mathrm{aq})+17.856 \mathrm{H}_{2} \mathrm{O}$ & -9.97 & -9.23 & -11.32 & -14.48 & -18.20 & -21.53 & -24.71 & -28.12 \\
\hline Clinoptilolite- $\mathrm{Na}=-13.868 \mathrm{H}^{+}+3.467 \mathrm{Al}^{3+}+3.467 \mathrm{Na}^{+}+14.533 \mathrm{SiO}_{2}(\mathrm{aq})+17.856 \mathrm{H}_{2} \mathrm{O}$ & -11.30 & -9.36 & -9.98 & -11.70 & -13.85 & -15.80 & -17.74 & -20.00 \\
\hline Calcite $=-\mathrm{H}^{+}+\mathrm{Ca}^{2+}+\mathrm{HCO}_{3}^{-}$ & 2.23 & 1.85 & 1.33 & 0.77 & 0.10 & -0.58 & -1.33 & -2.22 \\
\hline $\mathrm{K}-$ Feldspar $=-4 \mathrm{H}^{+}+\mathrm{Al}^{3+}+\mathrm{K}^{+}+2 \mathrm{H}_{2} \mathrm{O}+3 \mathrm{SiO}_{2}(\mathrm{aq})$ & -1.03 & -0.96 & -1.50 & -2.26 & -3.13 & -3.90 & -4.63 & -5.38 \\
\hline $\mathrm{PuO}_{2}(\mathrm{OH})_{2} \cdot \mathrm{H}_{2} \mathrm{O}=-2 \mathrm{H}^{+}+\mathrm{PuO}_{2}^{2+}+3 \mathrm{H}_{2} \mathrm{O}$ & \multicolumn{8}{|c|}{5.5} \\
\hline $\mathrm{EuOHCO}_{3}=-2 \mathrm{H}^{+}+\mathrm{Eu}^{3+}+\mathrm{H}_{2} \mathrm{O}+\mathrm{HCO}_{3}^{-}$ & \multicolumn{8}{|c|}{2.98} \\
\hline $\mathrm{AmOHCO}_{3}=-2 \mathrm{H}^{+}+\mathrm{Am}^{3+}+\mathrm{H}_{2} \mathrm{O}+\mathrm{HCO}_{3}^{-}$ & \multicolumn{8}{|c|}{3.15} \\
\hline $\mathrm{Sm}(\mathrm{OH})_{3}(\mathrm{am})=-3 \mathrm{H}^{+}+\mathrm{Sm}^{3+}+3 \mathrm{H}_{2} \mathrm{O}$ & \multicolumn{8}{|c|}{18.59} \\
\hline $\mathrm{NpO}_{2} \mathrm{OH}(\mathrm{am})=-\mathrm{H}^{+}+\mathrm{H}_{2} \mathrm{O}+\mathrm{NpO}_{2}^{+}$ & \multicolumn{8}{|c|}{4.24} \\
\hline Schoepite $=-2 \mathrm{H}^{+}+\mathrm{UO}_{2}^{2+}+3 \mathrm{H}_{2} \mathrm{O}$ & \multicolumn{8}{|c|}{4.84} \\
\hline Celestite $=\mathrm{SO}_{4}^{2-}+\mathrm{Sr}^{2+}$ & \multicolumn{8}{|c|}{-6.61} \\
\hline
\end{tabular}

Montmor $=$ Montmorillonite 
The extended Debye-Hückel formulation (also known as the B-dot model) was used for activity coefficients of aqueous species (Bethke, 1996; Helgeson, 1969). This formulation is well suited to describe the groundwaters at Pahute Mesa, which possess ionic strengths significantly less than 0.1. Values of the ion size parameter (Bethke, 1996; Helgeson, 1969) for aqueous species added to the database were estimated by analogy to aqueous species of similar valence and ligand. Tables J.1 and J.2 list the parameters used in the Debye-Hückel activity coefficient model.

Thermodynamic properties as a function of temperature are largely unavailable for radionuclide-bearing aqueous species and solids, and for their surface complexation and ion exchange reactions. It was necessary, therefore, to assume that the equilibrium constants for reactions involving radionuclides were invariant with temperature, and equal to the equilibrium constant at $25^{\circ} \mathrm{C}$. For a discussion on the effect of temperature on sorption, see Appendices I and K. Data were available to provide explicitly for the effects of temperature on all nonradionuclide reactions and on the rate constant for glass dissolution.

The impact of temperature on radionuclide reactions will be most important in the particle simulations, which span the main thermal pulse associated with the test. Temperatures have decreased to about $40^{\circ} \mathrm{C}$ at the time GIMRT simulations begin at $100 \mathrm{yr}$, which minimizes the error introduced in GIMRT by neglecting the effects of temperature on radionuclide reactions. However, the Kds used in the particle model were calculated at temperatures of $25^{\circ} \mathrm{C}$ and are used as constants despite the presence of a significant thermal pulse. Sparse data from the literature suggests that this assumption would tend to result in a conservative measure of sorption, as discussed in Appendix K. However, assessing the implications of such an assumption is difficult because of variability in the temperature dependence of equilibrium constants among multi-component aqueous and sorbed species and solids. Errors are also introduced by considering the temperature dependence of some species and not others in a given reaction. Additional work is recommended to estimate the temperature dependence of radionuclide reactions and to evaluate its impact on radionuclide release and migration.

Although the assumption of invariance with temperature is far from ideal, several factors reduce the impact of this assumption on the calculations described in this report. Elevated temperatures are largely restricted to the glass zone, so reactions outside the glass zone will not be subjected to major changes in temperature. Because no surface complexation or ion exchange reactions are assumed to occur in the glass zone (in the interest of calculating a conservative HST), their temperature dependencies are not of concern in the glass zone. However, the temperature dependence of radionuclide behavior in waters in the glass zone cannot be provided for, nor can the temperature dependence of the solubility of radionuclide-bearing solids, which can limit released radionuclide concentrations. 


\section{J.2 Kinetic Rate Equation and Parameters of Solids}

\section{J.2.1 Rate Equation}

Minerals were allowed to precipitate and dissolve during the GIMRT simulations according to the kinetic rate equation

$$
r_{m}=\operatorname{sgn}\left(\log \left[\frac{Q_{m}}{K_{m}}\right]\right) A_{m} k_{m}\left(\prod_{i=1}^{N c+N x} a_{i}^{p}\right)\left(\frac{Q_{m}}{K_{m}}\right)^{M}-\left.1\right|^{n}
$$

where $r$ is the rate of dissolution of the $m$ th mineral in $\mathrm{mol} / \mathrm{sec}, k$ is the rate constant in $\mathrm{mol} / \mathrm{m}^{2}$-sec, and $A$ is the surface area in square meters. $Q$ and $K$ are the ion activity product and equilibrium constant of the mineral, respectively, and $a$ is the activity of a species $i\left(\mathrm{H}^{+}\right.$in this paper) to the $p$ th power, which is determined experimentally (Steefel and Yabusaki, 1996). The values $M$ and $n$ are also determined experimentally but are assumed to equal one in this report. Dissolution can be expressed as the sum of $\mathrm{pH}$ dependent, $\mathrm{pH}$-independent and $\mathrm{pOH}$ dependent reactions by specifying multiple parallel reactions with different dependencies on the $a_{i}^{p}$ term. The multiple parallel reactions are summed to obtain the total rate. The equation is the same for both precipitation and dissolution except that the $\operatorname{sign}\left(\operatorname{sgn}\left(\log \left[Q_{m} / K_{m}\right]\right)\right)$ of the equation changes.

\section{J.2.2 Rate Constant and pH Dependence}

Table J.5 gives kinetic parameters for the minerals considered in GIMRT. Minerals were allowed to precipitate or dissolve in the lava, but changes in their mass were not related to the ion exchange or surface complexation capacity of the rock. This maintains the spatial distribution of masses of sorptive minerals in the lava. The rate constants for clays and zeolites were based on published data, whereas those for calcite, goethite and the radionuclide-bearing solids were chosen to limit kinetic inhibitions to their precipitation and dissolution. Calcite and goethite are known to precipitate relatively quickly from solution. Little is known about the reaction kinetics of radionuclide-bearing solids, so relatively fast reaction kinetics were assumed for these minerals as well.

Note that nucleation kinetics, the energetic barrier to precipitation that must be overcome before precipitation can begin, were not accounted for in our simulations. Data on nucleation kinetics for the minerals considered in this study, and for most rockforming minerals, are generally not available. 
Table J.5 Kinetic parameters for minerals and solids used in the GIMRT simulations consistent with rate equation (J1). Rate constant $k$ in units of $\mathrm{mol} / \mathrm{m}^{2}$-sec.

\begin{tabular}{|l|c|l|}
\hline \multicolumn{1}{|c|}{ Phase } & $\begin{array}{c}\text { Neutral region } \\
\log ^{10} \mathbf{k}\end{array}$ & \multicolumn{1}{|c|}{$\begin{array}{c}\text { Alkaline region } \\
\log ^{10} \mathbf{k}, \mathbf{i}, \mathbf{p}^{\mathbf{i}}\end{array}$} \\
\hline \hline Glass & -11.59 & $-8.01, \mathrm{OH}-, 0.5155$ \\
\hline$\alpha$-cristobalite & -8 & -8 \\
\hline K-Feldspar & -12.15 & $-9.75, \mathrm{OH}-, 0.67$ \\
\hline $\begin{array}{l}\text { Ca-Clinoptilolite } \\
\text { Na-Clinoptilolite }\end{array}$ & -12 & $-9.2, \mathrm{OH}-, 0.4$ \\
\hline $\begin{array}{l}\text { Ca-Montmorillonite } \\
\text { Na-Montmorillonite } \\
\text { Ca-Nontronite } \\
\text { Kaolinite }\end{array}$ & -13 & $-11.25, \mathrm{OH}-, 0.25$ \\
\hline $\begin{array}{l}\text { Goethite, Calcite, } \\
\text { AmOHCO3, EuOHCO3 } \\
\text { Sm(OH)3(am), Schoepite, } \\
\text { Celestite, NpO2OH(am) }\end{array}$ & & -10 \\
PuO2(OH)2•H2O & -10 & \\
\hline
\end{tabular}

${ }^{1}$ Independent of $\mathrm{pH}$, so $\mathrm{p}=0$.

Table J.6 Activation energy (Ea), in $\mathrm{kcal} / \mathrm{mol}$, for minerals and solids used in the GIMRT simulations.

\begin{tabular}{|l|c|}
\hline \multicolumn{1}{|c|}{ Phase } & \multicolumn{1}{|c|}{$\begin{array}{c}\text { Ea } \\
\text { kcal/mol }\end{array}$} \\
\hline \hline Glass, $\alpha$-cristobalite & $20^{\mathrm{a}}$ \\
\hline K-Feldspar & $13.82^{\mathrm{b}}$ \\
\hline Na-Clinoptilolite, Ca-Clinoptilolite & $13.86^{\mathrm{c}}$ \\
\hline $\begin{array}{l}\text { Ca-Montmorillonite,Na-Montmorillonite } \\
\text { Ca-Nontronite, Kaolinite }\end{array}$ & $2.39^{\mathrm{d}}$ \\
\hline $\begin{array}{l}\text { Goethite, Calcite, } \\
\text { AmOHCO }\end{array}$ & \\
$\begin{array}{l}\mathrm{Schoepite}, \mathrm{EuOHClestite,} \mathrm{NpO}_{2} \mathrm{OH}(\mathrm{Sm}), \\
\mathrm{PuO}_{2}(\mathrm{OH})_{2} \bullet \mathrm{H}_{2} \mathrm{O}\end{array}$ & $20^{\mathrm{e}}$ \\
\hline
\end{tabular}

${ }^{a}$ Ea of $\alpha$-cristobalite assumed equal to that of glass to ensure that silica precipitation can keep pace with silica released by glass; this avoids silica buildup, which can slow glass dissolution rates, thereby helping to ensure that conservative estimates are made of radionuclide release. Measured values of Ea are roughly the same for the two phases.

${ }^{\mathrm{b}}$ Blum and Stillings (1995).

${ }^{\mathrm{c}}$ Ragnarsdottir (1993).

${ }^{\mathrm{d}}$ Nagy (1995).

${ }^{\mathrm{e}} \alpha$-cristobalite assumed equal to glass. 


\section{J.2.3 Temperature Dependence of the Rate Constant}

Rate constants vary with temperature according to the Arrhenius equation (eq. 6.7). Activation energies for the minerals of interest are listed in Table J.6. Activation energies are unknown for minerals such as the radionuclide-bearing precipitates. In these cases, the activation energy is assumed equal to that of glass.

\section{J.2.4 Reactive Surface Area}

The reactive surface area for all minerals in the glass zones was assumed to equal $2000 \mathrm{~m}^{2} / \mathrm{m}^{3}$-medium. This value was based on the reactive surface area of a zone with $20 \%$ porosity and $80 \%$ glass, in which the glass possessed a reactive surface area of $0.001 \mathrm{~m}^{2} / \mathrm{g}$ and a density of $2.5 \mathrm{~g} / \mathrm{cm}^{3}$. For a discussion of the reactive surface area of melt glass used in the simulations, see section 6.4.4.3, "Glass Surface Area," in Chapter 6 . The glass is assumed to act as the substrate for secondary mineral precipitation. In actuality, the $80 \%$ glass in a glass grid block had to be reduced in the particle and GIMRT simulations by a factor of 0.858 to account for the mismatch between total number of grid blocks and the total mass of glass (see Chapter 6). However, in-fallen chimney blocks or other host rocks make up the remainder of the mass, which can also serve as a substrate for secondary mineral precipitation. Thus the value of $2000 \mathrm{~m}^{2} / \mathrm{m}^{3}$-medium was retained.

The reactive surface areas for all minerals in the native lava were assumed to equal $2000 \mathrm{~m}^{2} / \mathrm{m}^{3}$-medium. Mineral reactions, other than calcite reactions, were extremely limited and inconsequential in the simulations, so this value does not affect simulation results.

The reactive surface areas (A) of secondary minerals (minerals whose initial volume fraction equalled zero) were updated according to the following expressions from Steefel and Yabusaki (1996):

$$
\begin{gathered}
A_{m}=A_{m}^{0}\left[\left(\frac{\phi}{\phi^{0}}\right) \phi_{m}\right]^{\frac{2}{3}} \text { for dissolution } \\
\mathrm{A}_{\mathrm{m}}=\mathrm{A}_{\mathrm{m}}^{0}\left(\frac{\phi}{\phi_{0}}\right)^{\frac{2}{3}} \text { for precipitation }
\end{gathered}
$$

where $\mathrm{A}_{\mathrm{m}}^{0}$ denotes the initial surface area of the mth mineral, $\phi^{\circ}$ stands for the initial porosity of the medium, and $\phi_{\mathrm{m}}$ represents the volume fraction of the $\mathrm{mth}$ mineral.

Calcite was the only alteration mineral in the native rock at the start of the simulations that was allowed to react with groundwater. Its reactive surface area evolved with time during dissolution according to the same expression as glass (equation (6.3)), and during precipitation according to equation (J3). 
In the course of simulations with GIMRT, it was discovered that for secondary minerals, the affinity term tended to compensate for the value of the reactive surface area. If the surface area was decreased, the rate of precipitation decreased, and the mineral's degree of saturation increased. The increase in the saturation term effectively negated the decrease in the surface area to maintain a nearly constant dissolution rate. The affinity term is dependent on surface area, rather than being an independent variable. As emphasized in Pawloski et al. (2000), the rate of glass dissolution is not linearly related to surface area when the affinity term is explicitly accounted for because of the dependence of the affinity term on the surface area. 


\section{APPENDIX K: \\ Surface Complexation and lon Exchange}




\section{K.1 Introduction}

Minerals that exhibit surface charge (e.g., goethite, calcite, and aluminosilicates) can significantly reduce radionuclide mobility in the environment. The reduced mobility is a result of surface complexation and ion exchange reactions. Surface complexation and ion exchange reactions provide a mechanistic approach to modeling sorption and can account for the effect of changing environmental conditions on sorption.

Radionuclide retardation in the CHESHIRE near-field environment was modeled using our non-electrostatic surface complexation and ion exchange database. This database was developed to model the interaction of radionuclides with the surfaces of iron oxides, carbonates, and aluminosilicates (Zavarin and Bruton, 2000a; $2000 \mathrm{~b}$ ). Below, we present a short summary of these data and their use in our near-field model.

\section{K.2 Reactions Included in the Near Field Simulations}

Table K.1 lists the radionuclide-mineral surface complexation reactions accounted for in our reactive transport model. ${ }^{1}$ Table K.2 lists the ion exchange reactions accounted for in our model. ${ }^{2}$ In all cases, isotopes of the same element were treated identically. The reactions were used both in the GIMRT reactive transport calculations and in the particle code simulations. In the case of GIMRT, surface complexation and ion exchange reactions were used directly. For the particle code, these reactions were converted to linear retardation ratios; a description of this conversion is given later in this appendix.

While the radionuclide-mineral reactions used in our CHESHIRE near-field model represent a large proportion of reactions expected to control radionuclide migration in the near field, several notable reactions are missing. In particular, manganese oxide minerals may play an important role in decreasing radionuclide migration but published sorption data are scarce. Data from Keeney-Kennicutt and Morse (1985) suggest that Pu sorbs more strongly to goethite (an iron oxide) and calcite than $\delta-\mathrm{MnO}_{2}$ (a manganese oxide). Vaniman et al. (1995) found that Pu was most strongly associated with smectite in fracture linings while Pu sorbed strongly to disordered Mn-oxides in the bulk tuff (Duff et al., 1999). Data from Keeney-Kennicutt and Morse (1984) suggest that calcite and goethite sorb Np much more strongly than $\delta-\mathrm{MnO}_{2}$ or Na-montmorillonite (a smectite). Although these data suggest that manganese oxides may not be the dominant sorbers in the CHESHIRE near field, the sorptive capacity of the many different manganese oxide minerals found on Pahute

\footnotetext{
1 In the surface complexation reactive transport model, iron oxide surface complexation is based on hematite and aluminosilicate surface complexation is based on montmorillonite (a smectite group mineral).

2 In the ion exchange reactive transport model, smectite ion exchange is based on montmorillonite (a smectite group mineral), illite and mica reactivity is considered equivalent, and zeolite ion exchange is based on clinoptilolite.
} 
Mesa still needs to be examined. ${ }^{3}$ Additional data regarding the interaction of radionuclides with manganese oxide minerals would likely result in a more accurate description of radionuclide migration; the absence of such data results in a more conservative measure of radionuclide migration.

Besides acknowledging the absence of manganese oxide reactions, we approximate the sorptive properties of several radionuclides. For Sm(III), data regarding sorption to iron oxides and aluminosilicates was not available in the literature. Thus, its behavior was assumed to be equivalent to that of $\mathrm{Eu}(\mathrm{III})$. This is not altogether unreasonable; rare earth elements are often assumed to behave similarly, with Kd's decreasing slightly with increased rare earth elements atomic number (see calcite data of Zhong and Mucci (1995) and goethite data of Koeppenkastrop and Decarlo (1992)). Trivalent cations Cm(III) and Ho(III) were assumed to behave identically to $\mathrm{Eu}(\mathrm{III})$ because a survey of published data was not made in time for implementation in CHESHIRE near-field simulations.

Many elements (Tritium, C, Cl, Ar, Kr, Tc, I, Ni, Zr, Nb, Pd, and Sn) were assumed to behave as nonsorbing tracers with no retardation. Tritium, $\mathrm{Cl}, \mathrm{Ar}, \mathrm{Kr}, \mathrm{Tc}, \mathrm{I}$ were treated as tracers because their retardation is likely to be small or negligible. For $\mathrm{C}$, $\mathrm{Ni}, \mathrm{Zr}, \mathrm{Nb}, \mathrm{Pd}$, and $\mathrm{Sn}$, a survey of published data was not made in time for these simulations. ${ }^{4}$ Though we expect some retardation of these elements, they were treated as tracers. Their predicted migration, therefore, does not represent a likely transport behavior but, instead, represents the most conservative estimate of transport.

\footnotetext{
3 Carlos et al. (1995) reported the existence of four manganese oxide minerals (ranceite, lithiophorite, cryptomelane group, and pyrolysite in fractures from Yucca Mountain. Each of these minerals will have significantly different sorptive properties. For example, the cryptomelane group minerals have a tunnel structure and are believed to be potentially strong radionuclide getters. Lithiophorite is a 1:1 sheet structured mineral with alternating Al and Mn octahedral sheet. Presumably, this mineral would have significantly different radionuclide sorption properties. Little published data is available regarding the sorptive properties of these minerals. The most heavily studied manganese oxide mineral with respect to sorption is most likely birnessite (a layered manganese oxide often found in soils). However, the properties of birnessite may be significantly different from the predominant manganese oxide minerals observed at NTS. Regardless of the diffuculties, sorption data on manganese oxides is necessary. However, UGTA has not yet funded LLNL to develop sorption parameters for Mn-oxides.

${ }^{4}$ If $\mathrm{C}$ retardation was modeled solely as isotopic exchange on the calcite surface, the retardation factor would be 2.1 in the calcic zones of the fractured tuff and $\sim 1$ at all other locations.
} 
Table K.1 Radionuclide-mineral interactions described by nonelectrostatic surface complexation in the near-field model.

\begin{tabular}{|c|c|c|c|}
\hline Element & Iron oxide & Calcite & Aluminosilicate \\
\hline Am(III) & $\sqrt{ }$ & $\sqrt{ }$ & $\sqrt{ }$ \\
\hline $\mathrm{Ca}(\mathrm{II})$ & - & $\sqrt{ }$ & $-^{\ddagger}$ \\
\hline $\mathrm{Cs}(\mathrm{I})$ & П & П & $\mathcal{-}^{\ddagger}$ \\
\hline $\mathrm{Eu}(\mathrm{III})$ & $\sqrt{ }$ & $\sqrt{ }$ & $\sqrt{ }$ \\
\hline $\mathrm{Np}(\mathrm{V})$ & $\sqrt{ }$ & $\sqrt{ }$ & $\sqrt{ }$ \\
\hline $\mathrm{Pu}(\mathrm{IV})$ & $\sqrt{ }$ & $\sqrt{ }$ & $\sqrt{ }$ \\
\hline $\mathrm{Pu}(\mathrm{V})$ & $\sqrt{ }$ & $\sqrt{ }$ & $\sqrt{ }$ \\
\hline Sm(III) & $\S$ & $\sqrt{ }$ & $\S$ \\
\hline $\operatorname{Sr}(I I)$ & $\sqrt{ }$ & $\sqrt{ }$ & $\mathcal{L}^{\ddagger}$ \\
\hline $\mathrm{U}(\mathrm{VI})$ & $\sqrt{ }$ & $\sqrt{ }$ & $\sqrt{ }$ \\
\hline
\end{tabular}

† Surface complexation to aluminosilicates modeled assuming smectite to be the dominant sorbing aluminosilicate.

¥ Sorption to aluminosilicates via ion exchange.

I This radionuclide-mineral interaction was not taken into account but is known to be relatively insignificant.

$\S \mathrm{Sm}$ (III)-iron oxide and Sm-aluminosilicate interactions were estimated using the reaction constants of $\mathrm{Eu}(\mathrm{III})$ because data were not available.

Table K.2 Radionuclide-mineral interactions described by Vanselow ion exchange in the near-field model.

\begin{tabular}{|c|c|c|c|}
\hline Element & Smectite & Illite/micał & Zeolite (clino) \\
\hline $\mathrm{Na}^{+}$ & $\sqrt{ }$ & $\sqrt{ }$ & $\sqrt{ }$ \\
\hline $\mathrm{K}^{+}$ & $\sqrt{ }$ & $\sqrt{ }$ & $\sqrt{ }$ \\
\hline $\mathrm{Ca}^{2+} \mathrm{q}$ & $\sqrt{ }$ & $\sqrt{ }$ & $\sqrt{ }$ \\
\hline $\mathrm{Mg}^{2+}$ & $\sqrt{ }$ & $\sqrt{ }$ & $\S$ \\
\hline $\mathrm{Cs}^{+}$ & $\sqrt{ }$ & $\sqrt{ }$ & $\sqrt{ }$ \\
\hline $\mathrm{Sr}^{2+}$ & $\sqrt{ }$ & $\sqrt{ }$ & $\sqrt{ }$ \\
\hline $\mathrm{UO}_{2}{ }^{2+}$ & - $^{\ddagger}$ & - $^{\ddagger}$ & - $^{\ddagger}$ \\
\hline
\end{tabular}

Clino = clinoptilolite.

† Sorption of actinides and REEs to aluminosilicates dominated by surface complexation in most cases.

$\ddagger$ Three site types on illite/mica with varying affinities (Tompson et al., 1999).

$\S \mathrm{Mg}^{2+}$ does not exchange readily into the inner channels of clinoptilolite (clino).

ๆ Both background (stable) and test-related $\left({ }^{41} \mathrm{Ca}\right)$ isotopes were considered explicitly, but their reactivity was assumed to be equal. 


\section{K.3 Surface Complexation}

Surface complexation reactions involve mineral surface functional groups and aqueous species. A typical surface complexation reaction and associated equilibrium constant can be written in the following manner:

$$
\begin{gathered}
>\mathrm{SiOH}+\mathrm{Pu}^{4+} \Leftrightarrow>\mathrm{SiOPu}^{3+}+\mathrm{H}^{+} \\
K=\frac{\left(>\mathrm{SiOPu}{ }^{3+}\right)\left(\mathrm{H}^{+}\right)}{(>\mathrm{SiOH})\left(\mathrm{Pu}^{4+}\right)}
\end{gathered}
$$

where $>\mathrm{SiOH}$ is a surface functional group (on a silicate mineral), $\mathrm{Pu}^{4+}$ is an aqueous plutonium species that reacts with the surface (to form $>\mathrm{SiOPu}^{3+}$ ), and $\mathrm{H}^{+}$is released as a result of the reaction. Just as for simple aqueous complexation reactions, the above surface complexation reaction has an equilibrium reaction constant, $K$, that describes the relative activity of all species at equilibrium.

Factors that influence surface complexation on a particular mineral include

- Surface area

- $\mathrm{pH}$

- Aqueous complexation

- Ionic strength

- Surface charge

Because sorption reactions occur at the mineral-water interface, sorption will be dependent on the mineral surface area available for reaction. The $\mathrm{pH}$ can significantly affect sorption as well. For example, in equation (K1), as the concentration of $\mathrm{H}^{+}$ increases, a larger fraction of $\mathrm{Pu}^{4+}$ will remain in solution. Surface functional groups (e.g., $>\mathrm{SiOH}$ ) may also become protonated/deprotonated as a function of $\mathrm{pH}$ and affect sorption. Aqueous complexation will influence the concentration of aqueous species in solution; this may increase or decrease sorption depending on the species involved in the reactions. For example, uranium sorption decreases as a function of carbonate concentration in solution due to the formation of uranyl carbonate complexes (Duff and Amrhein, 1996). Ionic strength may influence sorption by reducing the activity of aqueous species and affect the charging behavior of the surface. Surface complexes as well as surface protonation and deprotonation can also affect the charging of the surface, which will, in turn, influence sorption. Unlike $\mathrm{K}_{\mathrm{d}}$ values, surface complexation reactions can, ideally, account for all factors that influence the ratio of sorbed to aqueous radionuclide concentrations. Because surface complexation reactions account for changes in environmental conditions, they provide a much more robust basis for simulating radionuclide sorption. 
Here, we use the non-electrostatic surface complexation model (NEM). The NEM (Kurbatov et al., 1951) assumes that surface electrical charge does not affect equilibrium surface complexation reactions. Although the NEM oversimplifies the factors affecting surface complexation, several investigators have used this model approach to describe sorption reactions (Bradbury and Baeyens, 1997; Davis et al., 1998; Zachara et al., 1994). Davis et al. (1998) argued that the NEM approach may be the most appropriate for complex environmental applications because the surface charging behavior of nonideal natural mineral phases is not well known. For additional information regarding the nonelectrostatic model and data, see Zavarin and Bruton (2000a; 2000b).

\section{K.4 Ion Exchange}

The permanent charge on some clay minerals is the result of non-chargebalanced ion substitution. For example, the substitution of $\mathrm{Al}^{3+}$ for $\mathrm{Si}^{4+}$ in a clay will result in a permanent negative charge. A permanent negative charge is typically balanced by cations in solution that are attracted to the mineral surface. For example, the aluminosilicate montmorillonite will typically have a permanent negative charge equal to $\sim 850 \mathrm{meq} / \mathrm{kg}$. In soils, the majority of this charge is balanced by the major cations in the waters $\left(\mathrm{Na}^{+}, \mathrm{K}^{+}, \mathrm{Ca}^{2+}\right.$, and $\left.\mathrm{Mg}^{2+}\right)$. When other cations such as $\mathrm{Cs}^{+}$are present, they may also become associated with the negatively charged surface via ion exchange. The distribution of cations on surfaces as a result of permanent charge can be described by ion exchange reactions of the following form:

$$
\mathrm{Na}-\mathrm{X}+\mathrm{Cs}^{+}<==>\mathrm{Cs}-\mathrm{X}+\mathrm{Na}^{+}
$$

with an associated equilibrium constant

$$
K=\frac{(C s-X)\left(N a^{+}\right)}{(N a-X)\left(C s^{+}\right)}
$$

where $X$ designates a surface association and the four terms in parentheses are the activities of the respective species. The constant, $\mathrm{K}$, describes the relative activity of the various species at equilibrium. For homovalent exchange such as the reaction shown in equation (K3), the activity of surface-associated species is often assumed to be defined by the relative concentration of each species on the surface $\left(\frac{[C s-X]}{[C s-X]+[N a-X]}\right.$ and $\frac{[N a-X]}{[C s-X]+[N a-X]}$ ). Because the denominators for $\mathrm{Cs}-\mathrm{X}$ and $\mathrm{Na}-\mathrm{X}$ activity are identical, the activity ratio of surface species can be simplified to the total mole ratio of $\mathrm{Cs}$ and $\mathrm{Na}$ associated with the mineral surface. The activities of species in solution are determined from speciation and ionic strength activity corrections.

For heterovalent ion exchange, the equilibrium reactions are complicated by the fact that the two exchanging ions balance different amounts of charge on the surface. Heterovalent ion exchange reactions can be written in several forms. By the 
Vanselow convention, a heterovalent exchange reaction is written in a form that relates to the relative mole concentration of surface species:

$$
\mathrm{Na}-\mathrm{X}+0.5 \mathrm{Ca}^{2+}<==>0.5 \mathrm{Ca}-\mathrm{X}_{2}+\mathrm{Na}^{+}
$$

with an associated equilibrium constant of the form:

$$
K=\frac{\left(\mathrm{Ca}-\mathrm{X}_{2}\right)^{0.5}\left(\mathrm{Na} a^{+}\right)}{\left.(\mathrm{Na}-\mathrm{X})(\mathrm{Ca})^{2+}\right)^{0.5}}
$$

The two terms in the above equation that relate to surface species activity are determined by

$$
\left(\frac{\left[\mathrm{Ca}-\mathrm{X}_{2}\right]}{\left(\left[\mathrm{Ca}-\mathrm{X}_{2}\right]+[\mathrm{Na}-\mathrm{X}]\right)}\right)^{0.5} \text { and }\left(\frac{[\mathrm{Na}-\mathrm{X}]}{\left(\left[\mathrm{Ca}-\mathrm{X}_{2}\right]+[\mathrm{Na}-\mathrm{X}]\right)}\right)
$$

where the terms in the brackets relate to $\mathrm{mol} / \mathrm{L}$ concentrations. For more information regarding the Vanselow and other ion exchange conventions, see Zavarin and Bruton (2000a).

\section{K.5 Reaction Constants}

Tables K.3 to K.6 list all surface complexation and ion exchange reactions used in our near-field model. The reaction constants were calculated by fitting published and unpublished sorption data to the NEM and Vanselow models, by using published reaction constants directly. ${ }^{5}$ References to the large set of sorption data used are in Zavarin and Bruton (2000a; 2000b). When multiple sets of data were evaluated, a standard deviation was calculated for each reaction constant. These values are used to evaluate the uncertainty in reaction constants and, in turn, radionuclide retardation. Uncertainty results will be discussed in Appendix I. The values in parentheses in Table K.4 refer to sorption constants determined using sorption data collected in FY 2000 but not yet published. These data were used instead of the fits to published data. Published $\mathrm{Eu}, \mathrm{Np}, \mathrm{Pu}$, and $\mathrm{Sm}$ data were collected at a single $\mathrm{pH}$ and in relatively uncontrolled laboratory conditions. See Zavarin and Bruton (2000a) for additional information.

\footnotetext{
${ }^{5}$ Calcite sorption data collected by Lawrence Livermore National Laboratory in FY 2000 for the UGTA Program.
} 
Table K.3 Surface complexation reactions for iron oxides using the nonelectrostatic model.

\begin{tabular}{|c|c|c|}
\hline Reaction & No. of curves evaluated & $\log K$ \\
\hline$>\mathrm{FeOH} \Leftrightarrow \mathrm{FeO}^{-}+\mathrm{H}^{+}$ & & -8.93 \\
\hline$>\mathrm{FeOH}+\mathrm{H}^{+} \Leftrightarrow \mathrm{FeOH}_{2}^{+}$ & & 7.29 \\
\hline$>\mathrm{FeOH}+\mathrm{Am}^{3+} \Leftrightarrow>\mathrm{FeOAm}^{2+}+\mathrm{H}^{+}$ & 11 & $1.24 \pm 0.43$ \\
\hline$>\mathrm{FeOH}+\mathrm{Am}^{3+}+2 \mathrm{H}_{2} \mathrm{O} \Leftrightarrow>\mathrm{FeOAm}(\mathrm{OH})_{2}+3 \mathrm{H}^{+}$ & & $-15.29 \pm 0.37$ \\
\hline$>\mathrm{FeOH}+\mathrm{Eu}^{3+} \Leftrightarrow>\mathrm{FeOEu}^{2+}+\mathrm{H}^{+}$ & 11 & $1.85 \pm 0.58$ \\
\hline$>\mathrm{FeOH}+\mathrm{NpO}_{2}^{+} \Leftrightarrow>\mathrm{FeOHNpO}_{2}^{+}$ & 10 & $4.32 \pm 0.11$ \\
\hline$>\mathrm{FeOH}+\mathrm{NpO}_{2}^{+}+\mathrm{H}_{2} \mathrm{O} \Leftrightarrow>\mathrm{FeOHNpO}_{3}^{-}+2 \mathrm{H}^{+}$ & & -11.26 \\
\hline$>\mathrm{FeOH}+\mathrm{Pu}^{4+}+\mathrm{H}_{2} \mathrm{O} \Leftrightarrow>\mathrm{FeOHPuO}^{2+}+2 \mathrm{H}^{+}$ & 2 & 6.93 \\
\hline$>\mathrm{FeOH}+\mathrm{Pu}^{4+}+2 \mathrm{H}_{2} \mathrm{O} \Leftrightarrow>\mathrm{FeOHPuO}_{2}+4 \mathrm{H}^{+}$ & & -1.29 \\
\hline$>\mathrm{FeOH}+\mathrm{PuO}_{2}^{+} \Leftrightarrow>\mathrm{FeOHPuO}_{2}^{+}$ & 2 & 4.79 \\
\hline$>\mathrm{FeOH}+\mathrm{PuO}_{2}^{+}+\mathrm{H}_{2} \mathrm{O} \Leftrightarrow>\mathrm{FeOHPuO}_{3}^{-}+2 \mathrm{H}^{+}$ & & -10.66 \\
\hline$>\mathrm{FeOH}+\mathrm{Sr}^{2+} \Leftrightarrow>\mathrm{FeOHSr}^{2+}$ & 12 & $2.22 \pm 0.13$ \\
\hline$>\mathrm{FeOH}+\mathrm{Sr}^{2+} \Leftrightarrow>\mathrm{FeOSr}^{+}+\mathrm{H}^{+}$ & & $-5.30 \pm 0.31$ \\
\hline$>\mathrm{FeOH}+\mathrm{Sr}^{2+}+\mathrm{H}_{2} \mathrm{O} \Leftrightarrow>\mathrm{FeOSrOH}+2 \mathrm{H}^{+}$ & & $-14.14 \pm 0.40$ \\
\hline$>\mathrm{FeOH}+\mathrm{UO}_{2}^{2+}+\mathrm{H}_{2} \mathrm{O} \Leftrightarrow>\mathrm{FeOHUO}_{3}+2 \mathrm{H}^{+}$ & 17 & $-3.05 \pm 0.43$ \\
\hline$>\mathrm{FeOH}+\mathrm{UO}_{2}{ }^{2+} \Leftrightarrow>\mathrm{FeOHUO}_{2}{ }^{2+}$ & & $6.63 \pm 0.54$ \\
\hline
\end{tabular}

Table K.4 Surface complexation reactions for calcite using the nonelectrostatic model.

\begin{tabular}{|c|c|c|}
\hline Reaction & No. of curves evaluated & $\log K$ \\
\hline$>\mathrm{Ca}^{2+}+\mathrm{AmCO}_{3}^{+} \Leftrightarrow>\mathrm{AmCO}_{3}^{+}+\mathrm{Ca}^{2+}$ & $10^{\mathrm{a}}$ & $4.13 \pm 0.06$ \\
\hline$>\mathrm{Ca}^{2+}+\mathrm{EuCO}_{3}{ }^{+} \Leftrightarrow>\mathrm{EuCO}_{3}{ }^{+}+\mathrm{Ca}^{2+}$ & $2^{a}$ & $\begin{array}{l}2.57 \\
(4.14) \dagger\end{array}$ \\
\hline$>\mathrm{Ca}^{2+}+\mathrm{LaCO}_{3}^{+} \Leftrightarrow>\mathrm{LaCO}_{3}{ }^{+}+\mathrm{Ca}^{2+}$ & $2^{\mathrm{a}}$ & 3.24 \\
\hline$>\mathrm{Ca}^{2+}+\mathrm{NpO}_{2}^{+} \Leftrightarrow>\mathrm{NpO}_{2}^{+}+\mathrm{Ca}^{2+}$ & $8^{a}$ & $\begin{array}{l}2.35 \pm 0.19 \\
(1.46)\end{array}$ \\
\hline$>\mathrm{Ca}^{2+}+\mathrm{PuO}_{2}^{+} \Leftrightarrow>\mathrm{PuO}_{2}^{+}+\mathrm{Ca}^{2+}$ & $7^{\mathrm{a}}$ & $\begin{array}{l}1.85 \pm 0.35 \\
(1.63)\end{array}$ \\
\hline$>\mathrm{Ca}^{2+}+\mathrm{Pu}(\mathrm{OH})_{3}{ }^{+} \Leftrightarrow>\mathrm{Pu}(\mathrm{OH})_{3}{ }^{+}+\mathrm{Ca}^{2+}$ & 1 & $(7.23)$ \\
\hline$>\mathrm{Ca}^{2+}+\mathrm{SmCO}_{3}^{+} \Leftrightarrow>\mathrm{SmCO}_{3}^{+}+\mathrm{Ca}^{2+}$ & $2^{a}$ & $\begin{array}{l}2.68 \\
(4.62)\end{array}$ \\
\hline$>\mathrm{Ca}^{2+}+\mathrm{Sr}^{2+} \Leftrightarrow>\mathrm{Sr}^{2+}+\mathrm{Ca}^{2+}$ & 1 & -1.75 \\
\hline$>\mathrm{Ca}^{2+}+\mathrm{UO}_{2}^{2+} \Leftrightarrow>\mathrm{UO}_{2}^{2+}+\mathrm{Ca}^{2+}$ & $17^{\mathrm{a}}$ & 5.12 \\
\hline$>\mathrm{Ca}^{2+}+\mathrm{YbCO}_{3}^{+} \Leftrightarrow>\mathrm{YbCO}_{3}^{+}+\mathrm{Ca}^{2+}$ & $2^{\mathrm{a}}$ & 1.50 \\
\hline
\end{tabular}

a Single point data.

† The log $\mathrm{K}$ constants in parentheses were determined from unpublished sorption experiments performed with support from UGTA project funds at LLNL and were used in the model. 
Table K.5 Surface complexation reactions for aluminosilicates using the nonelectrostatic model.

\begin{tabular}{|c|c|c|}
\hline Reaction & No. of curves evaluated & $\log K$ \\
\hline$>\mathrm{AlOH}+\mathrm{Am}^{3+} \Leftrightarrow>\mathrm{AlOAm}^{2+}+\mathrm{H}^{+}$ & 11 & $2.49 \pm 0.26$ \\
\hline$>\mathrm{SiOH}+\mathrm{Am}^{3+} \Leftrightarrow>\mathrm{SiOAm}^{2+}+\mathrm{H}^{+}$ & 4 & $0.7 \pm 0.1$ \\
\hline$>\mathrm{SiOH}+\mathrm{Am}^{3+}+\mathrm{H}_{2} \mathrm{O} \Leftrightarrow>\mathrm{SiOAmO}+3 \mathrm{H}^{+}$ & & $-14.2 \pm 0.8$ \\
\hline$>\mathrm{AlOH}+\mathrm{Eu}^{3+} \Leftrightarrow>\mathrm{AlOEu}^{2+}+\mathrm{H}^{+}$ & 5 & $2.21 \pm 0.54$ \\
\hline$>\mathrm{SiOH}+\mathrm{Eu}^{3+} \Leftrightarrow>\mathrm{SiOEu}^{2+}+\mathrm{H}^{+}$ & 4 & -0.62 \\
\hline$>\mathrm{SiOH}+\mathrm{Eu}^{3+}+\mathrm{H}_{2} \mathrm{O} \Leftrightarrow>\mathrm{SiOEuO}+3 \mathrm{H}^{+}$ & & -15.30 \\
\hline$>\mathrm{AlOH}+\mathrm{NpO}_{2}^{+} \Leftrightarrow>\mathrm{AlONpO}_{2}+\mathrm{H}^{+}$ & 9 & $-4.67 \pm 0.27$ \\
\hline$>\mathrm{AlOH}+\mathrm{NpO}_{2}^{+}+\mathrm{H}_{2} \mathrm{O} \Leftrightarrow>\mathrm{AlONpO}_{3} \mathrm{H}^{-}+2 \mathrm{H}^{+}$ & & $-14.26 \pm 0.04$ \\
\hline$>\mathrm{SiOH}+\mathrm{NpO}_{2}^{+} \Leftrightarrow>\mathrm{SiONpO}_{2}+\mathrm{H}^{+}$ & 6 & $-3.72 \pm 0.15$ \\
\hline$>\mathrm{SiOH}+\mathrm{NpO}_{2}{ }^{+}+\mathrm{H}_{2} \mathrm{O} \Leftrightarrow>\mathrm{SiONpO}_{3} \mathrm{H}^{-}+2 \mathrm{H}^{+}$ & & -12.16 \\
\hline$>\mathrm{AlOH}+\mathrm{Pu}^{4+}+\mathrm{H}_{2} \mathrm{O} \Leftrightarrow>\mathrm{AlOPuO}^{+}+3 \mathrm{H}^{+}$ & 4 & $5.95 \pm 0.47$ \\
\hline$>\mathrm{AlOH}+\mathrm{Pu}^{4+}+2 \mathrm{H}_{2} \mathrm{O} \Leftrightarrow>\mathrm{AlOPuO}_{2}^{-}+5 \mathrm{H}^{+}$ & & -11.93 \\
\hline$>\mathrm{SiOH}+\mathrm{Pu}^{4+}+\mathrm{H}_{2} \mathrm{O} \Leftrightarrow>\mathrm{SiOPuO}^{+}+\mathrm{H}^{+}$ & & $2.32 \pm 0.89$ \\
\hline$>\mathrm{AlOH}+\mathrm{PuO}_{2}^{+} \Leftrightarrow>\mathrm{AlOPuO}_{2}+\mathrm{H}+$ & 2 & -3.09 \\
\hline$>\mathrm{SiOH}+\mathrm{PuO}_{2}^{+} \Leftrightarrow>\mathrm{SiOPuO}_{2}+\mathrm{H}+$ & 2 & -6.43 \\
\hline$>\mathrm{SiOH}+\mathrm{PuO}_{2}^{+}+\mathrm{H}_{2} \mathrm{O} \Leftrightarrow>\mathrm{SiOPuO}_{3} \mathrm{H}^{-}+2 \mathrm{H}^{+}$ & & -14.80 \\
\hline$>\mathrm{AlOH}+\mathrm{UO}_{2}^{2+} \Leftrightarrow>\mathrm{AlOUO}_{2}^{+}+\mathrm{H}^{+}$ & 5 & $3.13 \pm 0.15$ \\
\hline$>\mathrm{SiOH}+\mathrm{UO}_{2}^{2+}+\mathrm{H}_{2} \mathrm{O} \Leftrightarrow>\mathrm{SiOUO}_{3} \mathrm{H}+2 \mathrm{H}^{+}$ & 15 & $-5.18 \pm 0.31$ \\
\hline$>\mathrm{SiOH}+\mathrm{UO}_{2}^{2+}+\mathrm{H}_{2} \mathrm{O} \Leftrightarrow>\mathrm{SiOUO}_{3}^{-}+3 \mathrm{H}^{+}$ & & -12.35 \\
\hline
\end{tabular}


Table K.6 Vanselow ion exchange reactions for smectite, illte/mica, and clinoptilolite.

\begin{tabular}{|c|c|c|}
\hline Exchange reaction & $\log K$ & Site type \\
\hline \multicolumn{3}{|l|}{ Smectite $†$} \\
\hline $\mathrm{Na}^{+} \longrightarrow 0.5 \mathrm{Ca}^{2+}, 0.5 \mathrm{Mg}^{2+}, 0.5 \mathrm{Sr}^{2+}$ & 0.085 & \\
\hline $\mathrm{Na}^{+} \longrightarrow \mathrm{K}^{+}$ & 0.255 & \\
\hline $\mathrm{Na}^{+} \longrightarrow \mathrm{Cs}^{+}$ & 0.792 & \\
\hline $0.5 \mathrm{Ca}^{2+} \longrightarrow 0.5 \mathrm{UO}_{2}{ }^{2+}$ & -0.125 & \\
\hline $\mathrm{Na}^{+} \longrightarrow 0.5 \mathrm{UO}_{2}^{2+}$ & -0.040 & \\
\hline \multicolumn{3}{|l|}{ Illite/mica $\ddagger$} \\
\hline \multirow[t]{3}{*}{$\mathrm{Na}^{+} \longrightarrow 0.5 \mathrm{Ca}^{2+}, 0.5 \mathrm{Mg}^{2+}, 0.5 \mathrm{Sr}^{2+}$} & -1.026 & I \\
\hline & -0.147 & II \\
\hline & 0.000 & III \\
\hline \multirow[t]{3}{*}{$\mathrm{Na}^{+} \longrightarrow \mathrm{K}^{+}$} & 1.613 & I \\
\hline & 1.686 & II \\
\hline & 0.894 & III \\
\hline \multirow[t]{3}{*}{$\mathrm{Na}^{+} \longrightarrow \mathrm{Cs}^{+}$} & 5.718 & 1 \\
\hline & 3.079 & II \\
\hline & 1.539 & III \\
\hline \multicolumn{3}{|l|}{ Zeolite (clinoptilolite) ๆ } \\
\hline $\mathrm{Na}^{+} \longrightarrow \mathrm{K}^{+}$ & 1.100 & \\
\hline $\mathrm{Na}^{+} \rightarrow \mathrm{Cs}^{+}$ & 1.708 & \\
\hline $\mathrm{Na}^{+} \longrightarrow 0.5 \mathrm{Ca}^{2+}$ & -0.037 & \\
\hline $\mathrm{Na}^{+} \longrightarrow 0.5 \mathrm{Sr}^{2+}$ & 0.037 & \\
\hline
\end{tabular}




\section{K.6 Comparison of Model to Sorption Experiments}

The surface complexation and ion exchange constants listed above are based on single mineral batch sorption experiments with simple fluid chemistry. In Figure K.1, sorption of several radionuclides to mineralogically complex tuff samples from Yucca Mountain is compared with our surface complexation/ion exchange model results. The attributes of the mineral surfaces used in our model are defined in the next section. The batch sorption data and mineralogy of samples were taken from Thomas (1987) and Chipera and Bish (1989), respectively. Because the water chemistry associated with each sorption sample was not available, it was assumed that the solution composition of all sorption samples was identical and equivalent to that used in our CHESHIRE near-field model. This solution composition is nearly the same as the composition of J-13 water listed by Thomas (1987).

The Sr sorption modeling results correlate well with the sorption data while the Cs correlation result is rather poor. These results are consistent with the modeling results of Viani and Bruton (1992). While Sr sorption is controlled largely by ion exchange to zeolites ( $0-71 \%$ found in samples), Cs sorption is affected strongly by illite/mica in samples ( $0-4 \%$ found in samples). Because the Cs sorption is strongly affected by a mineral typically found in trace quantities, significant scatter in the data would be expected. The conservative sorption modeling result is consistent with the underestimation of trace illite/mica concentrations in samples. The rather weak correlation between modeled and batch sorption data for the other radionuclides (Am, $\mathrm{Eu}, \mathrm{Np}, \mathrm{Pu}$, and $\mathrm{U}$ ) results from both the poor quantification of strong sorbers at trace quantities and also as a result of missing radionuclide-mineral interactions in our model (particularly for the very strong sorbers $\mathrm{Am}$ and $\mathrm{Eu}$ ). For example, $\mathrm{U}, \mathrm{Np}$, and $\mathrm{Pu}$ sorption is strongly affected by iron oxide in the tuff. However, quantification of amorphous iron oxide content in samples is difficult by XRD, especially when iron oxide concentrations are low (0-1\% in tuff samples). The underestimation of Eu sorption and the poor correlation with sorption data suggest that sorbers other than those used in our modeling may effectively sorb Eu.

While the correlation between predicted sorption and batch sorption data is weak for most radionuclides shown in Figure K.1, the range of sorption values derived from our model is consistent with the sorption strengths of the various radionuclides. For example, both the modeled and batch sorption results indicate that Np sorption is very weak, not exceeding a $\mathrm{Kd}$ of 10 . $\mathrm{U}$ sorption is also rather weak, with only a few samples exhibiting Kds greater than 10. The Pu sorption is weak both in the predicted and batch sorption data, but the predicted $\mathrm{Kd}$ is typically 1 order of magnitude lower than the sorption data. This is likely to be a result of our conservative modeling of the redox state of $\mathrm{Pu}$ in groundwater. Our model predicts a $\mathrm{Pu}(\mathrm{IV})$ concentration that is $<1 \%$ of the total $\mathrm{Pu}$ in solution (dominated by $\mathrm{Pu}(\mathrm{V})$ at an $\mathrm{O}_{2}(\mathrm{~g})$ fugacity of $10^{-7}$ bars). At $25^{\circ} \mathrm{C}$ and $\mathrm{pH} 8.5$, Nitsche et al. (1994) reported the $\mathrm{Pu}(\mathrm{IV})$ fraction in solution to be $31 \%$ in high carbonate Yucca Mountain waters and 6\% in the lower carbonate J-13 waters (Nitsche et al., 1993). Because Pu(IV) is a significantly stronger sorber than $\mathrm{Pu}(\mathrm{V})$, it is likely that the underestimation of Pu sorption results from the underestimation of $\mathrm{Pu}(\mathrm{IV})$ content in solutions. For a more thorough comparison 
between predicted and batch sorption data, sorption of radionuclides to samples with more detailed mineralogic and water chemistry analysis would be necessary.

Nevertheless, these data indicate that our surface complexation/ion exchange model is consistent with batch sorption experiments.

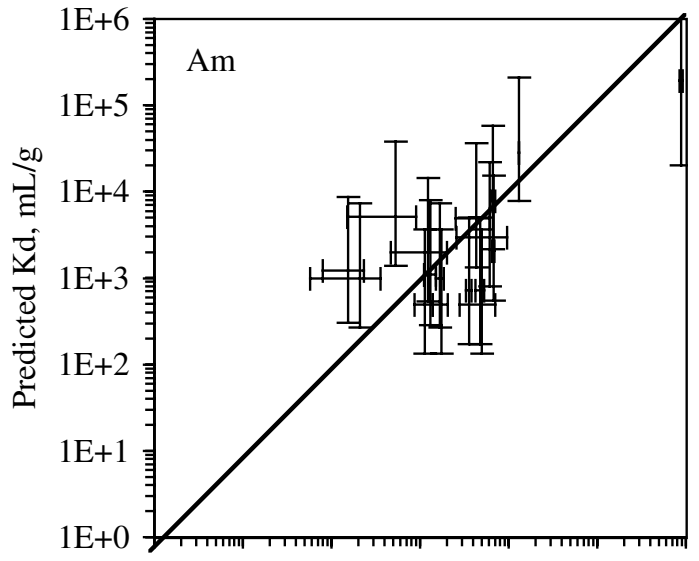

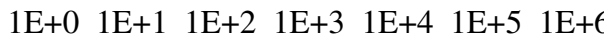

Measured Kd, mL/g

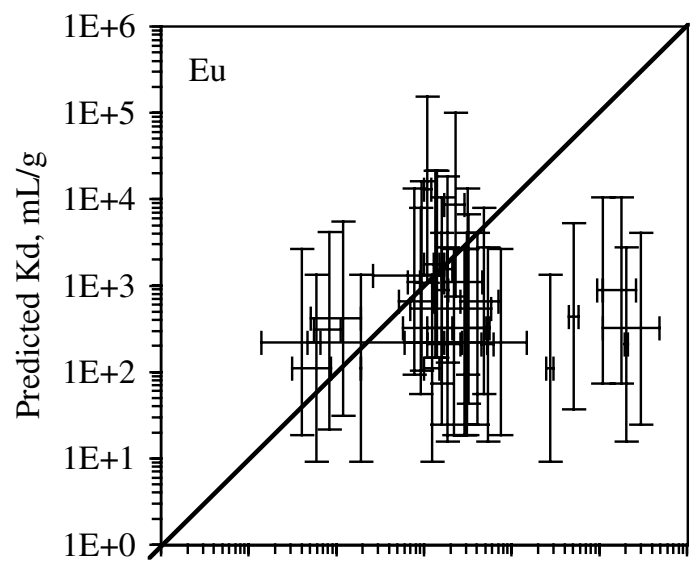

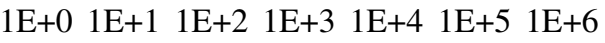

Measured Kd, mL/g

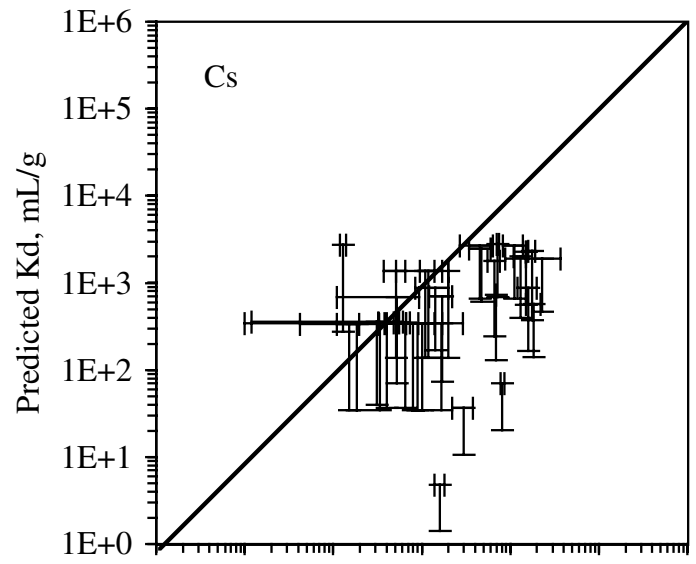

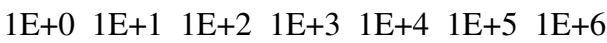
Measured Kd, mL/g

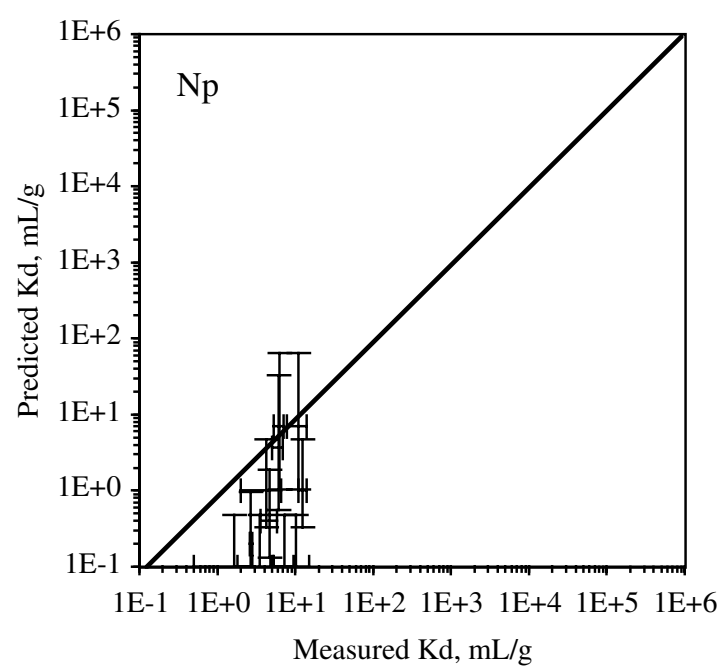

Figure K.1 Correlation between measured and predicted sorption of Am, Cs, Eu, Np, Pu, Sr, and $\mathrm{U}$ to Yucca Mountain tuffs. X-axis shows range of $\mathrm{Kd}$ values determined for each sample. $Y$-axis shows modeled $\mathrm{Kd}$ and uncertainty. 


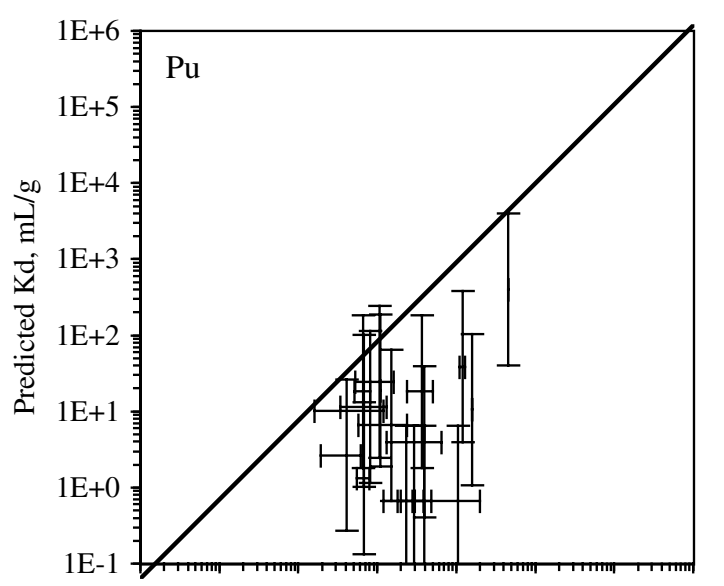

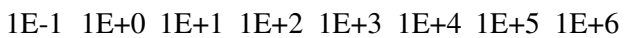

Measured Kd, mL/g
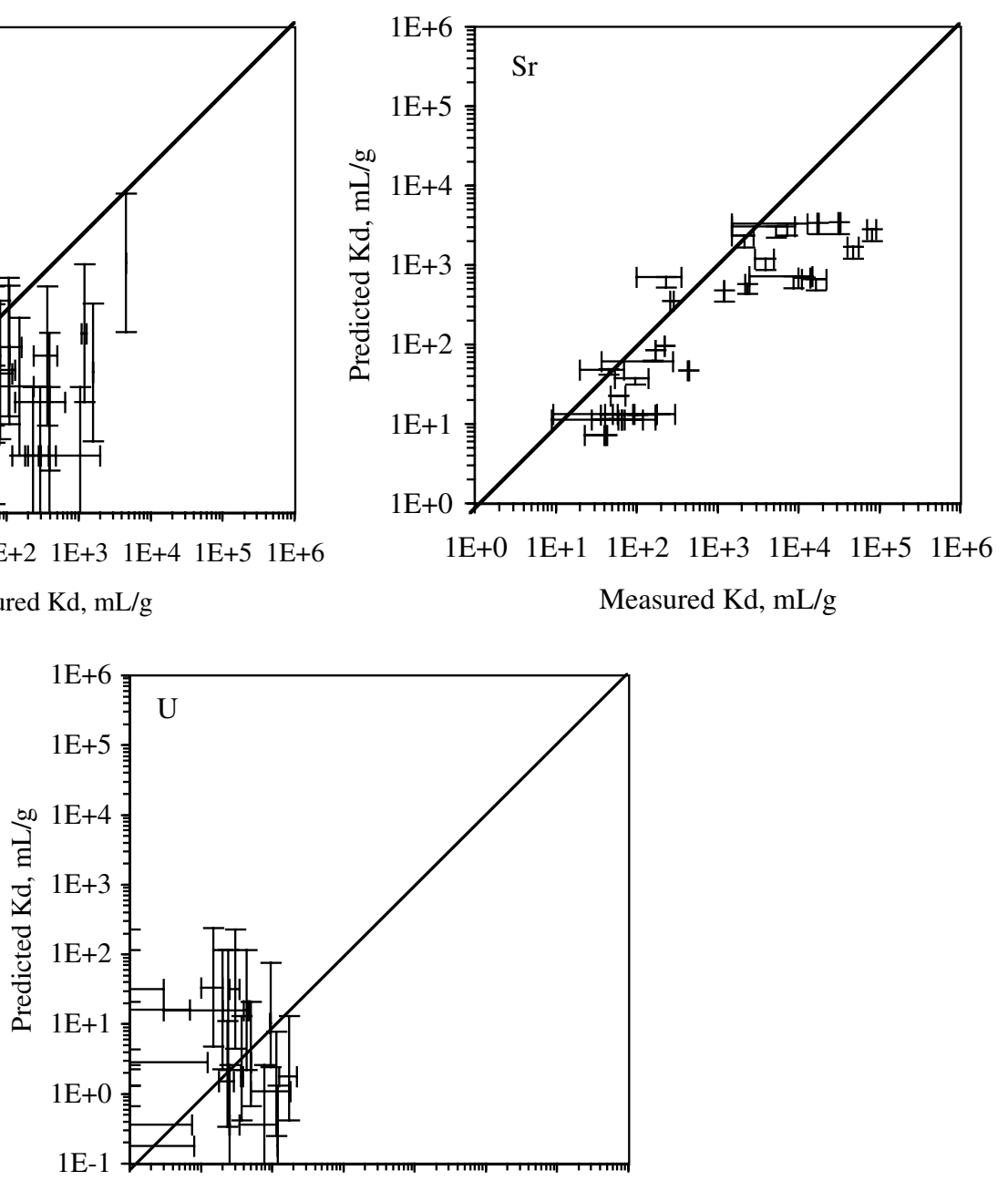

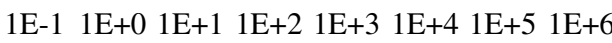

Measured $\mathrm{Kd}, \mathrm{mL} / \mathrm{g}$

Figure K.1 Continued. 


\section{K.7 Implementation in the GIMRT Transport Model}

To use the surface complexation and ion exchange data listed earlier, several additional parameters need to be established. These are: surface area, reactive site type, reactive site density, and cation exchange capacity for each mineral. The CHESHIRE nearfield model contains iron oxide, calcite, smectite, illite/mica, and clinoptilolite sorbents. The parameters used for each of these minerals is listed in Table K.7. For iron oxide, a surface area consistent with that of natural hematite (Hsi and Langmuir, 1985) was chosen. Hematite is the iron oxide mineral with the lowest surface area thus leading to a conservative estimate of the sorptive capacity of iron oxides at CHESHIRE. The site density was taken from Dzombak and Morel's (1990) estimate of site density on hydrous ferric oxide. Unlike Dzombak and Morel (1990), only one site was used in our model (see Zavarin and Bruton (2000a; 2000b) for further discussion). The calcite surface area and site density was taken from Zachara et al. (1993). As in the case of iron oxide, only one site was used in our model. Smectite surface area was taken from McKinley et al. (1995). The site density was determined by estimating that $10 \%$ of the smectite surface accounts for edge sites and that the site density at those edge sites is 2.31 sites per $\mathrm{nm}^{2}$. The fraction of $>\mathrm{SiOH}$ and $>\mathrm{AlOH}$ sites on the smectite is consistent with values proposed by McKinley et al. (1995) and Turner et al. (1996). The cation exchange capacities of smectite, clinoptilolite, and illite were taken from Viani and Bruton (1992; 1996). Surface complexation on illite/mica and clinoptilolite was not included in our model. Our surface complexation model is based on the assumption that $>\mathrm{AlOH}$ and $>\mathrm{SiOH}$ sites on any aluminosilicate will behave identically. This is an expansion of the modeling approach used by Turner et al. (1996). In this case, surface complexation reactions on $>\mathrm{AlOH}$ and $>\mathrm{SiOH}$ sites in clinoptilolite and illite/mica are equivalent to those on smectite. Because smectite is the most homogeneously distributed, the most abundant, and has a high surface area, we expect that smectite will be the dominant radionuclide sorbing (via surface complexation) aluminosilicate mineral. Clinoptilolite and illite/mica will, nevertheless, contribute significantly to radionuclide retardation via ion exchange.

Sorption of radionuclides to aluminosilicate colloids was modeled assuming that the composition of the colloids is dominated by aluminosilicates with a 1:1 ratio of $>\mathrm{SiOH}$ and $>\mathrm{AlOH}$ sites. Kersting and Brachman (1998) found zeolite, clay (illite, smectite), and silica colloids in groundwater from the ER-20-5 well cluster. Data regarding colloid particle concentrations and average size (Chapter 6) were used to evaluate the surface area of the colloids. Assuming a site density of $2.31 \mathrm{sites} / \mathrm{nm}^{2}$ and colloidal loads of 0.06 and $0.1 \mathrm{~g} / \mathrm{L}$, the concentration of surface complexation sites on colloids is $5.75 \times 10^{-6}$ and $1.18 \times 10^{-5} \mathrm{~mol}$ sites $/ \mathrm{L}$. These values are consistent with particle mass concentrations reported by Buddemeier and Hunt (1988) but significantly higher than colloid loads typically reported in the literature (McCarthy and Degueldre, 1993; Moulin and Ouzounian, 1992). The cation exchange capacity of colloids was assumed to be negligible. If one assumes that the CEC of the colloids is equivalent to that of smectite, equilibrium modeling results suggest that ion exchange on colloids would not be a significant radionuclide sink. 
In the CHESHIRE near-field model, all surface complexation and ion exchange reactions were based on an equilibrium model. Irreversible sorption and sorption/desorption kinetics were not employed in our model. Published information regarding the reversibility of sorption vary. For example, Sanchez et al. (1981) showed that $\mathrm{K}_{\mathrm{d}} \mathrm{s}$ measured from desorption experiments are consistently higher than those measured during sorption experiments for both $\mathrm{Pu}$ and $\mathrm{Am}$. This would indicate that some fraction of the sorbed radionuclide may not desorb or desorbs very slowly. Krishnaswami et al. (1982) examined the sorption/desorption kinetics of Ra and Th in the field using $U$ and $T h$ series radionuclides and found that sorption occurred on the scale of minutes while desorption occurred on the scale of a week or less. This would tend to indicate that sorption and desorption are relatively fast, albeit not instantaneous. Moore and Hunter (1985) found that Th is reversibly sorbed onto suspended sediment particles in the ocean with sorption/desorption rates on the scale of hours, consistent with the observations of Krishnaswami et al. (1982).

For the case of radionuclide sorption to fracture-lining minerals or tuff matrix, the equilibrium model yields a more conservative estimate of radionuclide migration. For the case of radionuclide sorption to colloids, the equilibrium model is less conservative. The effect of colloids will be further discussed in Appendix I. The invocation of the equilibrium model for the case of colloid transport allows us to approach colloid-mediated radionuclide transport in a simple way. In the CHESHIRE near-field model, we assume that the migration of colloids in the near field has reached steady state. ${ }^{6}$ Thus, at all points in space and time, the colloid concentration in flowing waters is uniform and constant, and colloid filtration does not need to be implemented. If we assume that radionuclide sorption to colloids is instantaneous, then the colloid model can be simplified to an aqueous model in which colloids are defined as aqueous species. The limitations of our colloid approach and the effects of colloid-mediated transport are also discussed in Appendix I and elsewhere in this report.

Table K.7 Parameters used to define reactions on mineral surfaces.

\begin{tabular}{|l|c|l|c|c|c|}
\hline \multicolumn{1}{|c|}{ Mineral } & $\begin{array}{c}\text { Iron oxide } \\
\text { (hematite) }\end{array}$ & Calcite & $\begin{array}{c}\text { Smectite } \\
\text { (montmorillonite) }\end{array}$ & $\begin{array}{c}\text { Zeolite } \\
\text { (clinoptilolite) }\end{array}$ & $\begin{array}{c}\text { Illite/mica } \\
\text { (illite) }\end{array}$ \\
\hline $\begin{array}{l}\text { Surface Area, } \\
\mathrm{m}^{2} / \mathrm{g}\end{array}$ & 2.0 & 2.2 & 30.0 & -- & -- \\
\hline $\begin{array}{l}\text { Site Density, } \\
\mathrm{Nm}^{-2}\end{array}$ & 2.31 & 5.0 & 0.231 & -- & -- \\
\hline Site Type & $>\mathrm{FeOH}$ & $>\mathrm{Ca}^{2+}$ & $\begin{array}{l}>\mathrm{SiOH}(0.5) \\
>\mathrm{AIOH}(0.5) \\
(\mathrm{IE})\end{array}$ & $(\mathrm{IE})$ & $\begin{array}{l}\mathrm{I}(0.005) \\
\text { II }(0.03) \\
\text { III (0.965) }\end{array}$ \\
\hline $\begin{array}{l}\mathrm{CEC}, \\
\text { meq/g }\end{array}$ & -- & -- & 0.85 & 2.12 & 0.2 \\
\hline
\end{tabular}

\footnotetext{
${ }^{6}$ We also assume that effects such as electrostatic exclusion will not significantly alter radionuclide transport.
} 


\section{K.8 Implementation in the Particle Model}

In the CHESHIRE near-field simulations, two codes are being used to model radionuclide transport: GIMRT and the particle code. While GIMRT can explicitly use the surface complexation and ion exchange data presented above (in conjunction with the mineralogic data presented in Chapter 6), the particle code is presently limited to a simple $\mathrm{K}_{\mathrm{d}}$ approach. GIMRT is able to account for nonlinear retardation as a function of $\mathrm{pH}$, reactive site saturation, aqueous speciation, competition for reactive sites, and other effects, which makes the code much more robust in its handling of geochemistry. The robustness of the geochemical model comes at the cost of computational complexity. While the particle code is not able to account for nonlinear sorption effects, its simplicity allows us to more effectively run sensitivity analyses. For discussions regarding the two transport codes, see Appendices C to E.

While this simplified radionuclide retardation approach is expected to accurately forecast radionuclide retardation at ambient CHESHIRE near field conditions, changes in water chemistry due to glass dissolution and the high temperatures near the glass zone at short times are likely to affect retardation. Water chemistry changes due to glass dissolution could, for example, increase or decrease $\mathrm{Na}^{+} / \mathrm{K}^{+} / \mathrm{Ca}^{2+} / \mathrm{Mg}^{2+}$ concentrations, which would affect radionuclide sorption to ion exchange sites. Glass dissolution could also affect the $\mathrm{pH}$, which would affect both the aqueous complexation and the protonation on surface complexation sites. Changes in the redox state of nearfield groundwater as a result of glass dissolution could severely alter the transport behavior of redox sensitive elements such as Pu and U. In Appendix I, we compare the GIMRT transport simulations with the particle code to examine these nonlinear effects and their importance to our simulations. The effect of temperature will be discussed in the following section.

While the GIMRT and particle codes are different in their treatment of geochemistry, radionuclide retardation must be consistent between the two models. In the particle model, surface complexation and ion exchange reactions are represented by simplified chemical retardation factors that modify the advective and dispersive motion of each particle. For each radionuclide class, a single "composite" retardation factor, $K_{j}(\mathbf{x})$, is defined as a function of spatial location. The composite retardation factor has the following features:

- The composite retardation factor is a function of radionuclide class ( $\mathrm{j}$ ) because each radionuclide will interact differently with a given sorbing mineral (i).

- The composite retardation factor is a function of position ( $\mathbf{x})$ because the spatial distribution of sorbing minerals (i) is not uniform in our model and because local porosity $(\phi)$, which also affects $R_{j}(\mathbf{x})$ is spatially variable.

- The composite retardation factor is considered a "composite" quantity because the overall retardation effect for radionuclide class (j) at a given location ( $\mathbf{x}$ ) may be a function of more than one sorbing mineral (i) that 
exists at that location. In this sense, the definition in Appendix D (Equation D1) can be decomposed into the following form

$$
R_{j}(\mathbf{x})=1+\frac{u_{j}^{i m}}{u_{j}}=1+\sum_{i} R_{j}^{i}(\mathbf{x})
$$

where the sum over the mineral index (i) represents the individual (and independent) contributions of different sorbing minerals to the total immobile mole fraction of radionuclide $\mathrm{j}$ at location $\mathbf{x}$. In this equation, $R_{j}^{i}(x)$ is defined as the retardation ratio. ${ }^{7}$

The composite retardation factor for a particular radionuclide class ( $\mathrm{j}$ ) at a particular position ( $\mathbf{x}$ ) will be a function of a number of radionuclide-mineral retardation ratios, as defined in Equation (K1). These retardation ratios can be determined from GIMRT model calculations using the surface complexation/ion exchange model and evaluating the mole ratio of sorbed to aqueous radionuclide under specified conditions. The conditions that need to be specified include:

- mineral characteristics,

- surface complexation/ion exchange reaction constants,

- effective porosity,

- groundwater composition,

- radionuclide concentration,

- temperature, and

- mineral abundance.

Mineral characteristics are defined in Table K.7 and are constant. Surface complexation/ion exchange constants are defined in Tables K.3 to K.6 and are constant. The effective porosity in the near field has four possibilities: $1 \%$ in fracture zones, $15 \%$ in matrix zones, $10 \%$ in cavity and chimney zones, and $20 \%$ in glass zones (Table 6.8). For the particle model, we assume that the groundwater chemistry is constant and equivalent to ambient conditions (Table 6.10). We also assume that radionuclide concentrations are low enough for sorption to be linear and that temperatures are ambient $\left(25^{\circ} \mathrm{C}\right)$. Finally, based on our statistical analysis of spatial variation of mineralization (Appendix $\mathrm{H}$ and Chapter 6), smectite, calcite, iron oxide, and/or zeolite is present or absent from fractures while illite/mica is distributed homogeneously in the matrix (along with a small quantity of smectite and iron oxide). Based on these specifications, for each radionuclide, 16 composite retardation factors are possible in fracture zones, 16 composite retardation factors are possible in the cavity and chimney

\footnotetext{
${ }^{7}$ A retardation ratio is determined by the ratio of moles $\mathrm{RN}$ sorbed to moles $\mathrm{RN}$ aqueous. This is not equivalent to a retardation factor which is determined by the ratio of moles $\mathrm{RN}$ sorbed to moles $\mathrm{RN}$ aqueous plus 1 (Retardation Factor $=$ Retardation Ratio +1 ).
} 
zones (since some fractures can be found in this zone), 1 possible composite retardation factor is possible in the matrix zone (since matrix is homogeneous), and the composite retardation factor for the glass zone is 1 (since reactive minerals are absent from the glass zone). ${ }^{8}$ The retardation ratios, $R_{j}^{i}(x)$, necessary to define the composite retardation factors, $R_{j}(\mathbf{x})$, are listed in Table K.8. They are listed as "average log retardation ratios." The high and low log retardation ratio data are an identical matrix of retardation ratios based on the upper and lower range of retardation ratio uncertainty defined by the uncertainty in surface complexation/ion exchange constants. Only the average log retardation ratios were used in particle simulations.

Table K.8 lists the retardation ratios for the suite of mineralogic conditions used to define the near-field model. As in the case of mineralogic distribution, the fracture, cavity, chimney, and exchange zones have heterogeneous sorbing mineral combinations distributed over space using the statistical distribution discussed in Appendix F. Thus, for each heterogeneously distributed sorbing mineral-radionuclide pair in each distinctive zone, two retardation ratios are listed. One value is a positive occurrence retardation ratio and the other is a negative occurrence retardation ratio. The distribution of four minerals (hematite, calcite, zeolite, and smectite) in the mineralogically heterogeneous zones results in a total of 16 different mineralogic conditions, each with its respective retardation ratio. ${ }^{9}$ Table K.9 lists the retardation ratios for the suite of geochemical conditions used to define the near-field model in the homogeneous mineral distribution case. These values can be used to compare the heterogeneous mineral distribution case to the homogeneous mineral distribution case.

Tables K.8 and K.9 include retardation ratios calculated at \pm 2 standard deviations of the surface complexation constants (high log retardation ration and low $\log$ retardation ratio) listed in Tables K.5 and K.6. For those surface complexation reactions that do not have standard deviations listed, a standard deviation of 0.5 was assumed. The uncertainty in the ion exchange reaction constants could not be readily estimated. Thus, in most cases, a standard deviation of 0 was assumed. However, for $\mathrm{Cs}$, the lower limit ion exchange constants were assumed to be equivalent to $\mathrm{K}$ (potassium) for zeolite, smectite, and basal plane illite/mica ion exchange. The logarithm of the lower limit ion exchange constant was reduced by 1.0 for the two illite/mica edge sites. The lower limit ion exchange constant for Sr on zeolite (clinoptilolite) was adjusted to be equivalent to that of $\mathrm{Ca}$ on zeolite. Other $\mathrm{Sr}$ ion exchange constants and all $\mathrm{Ca}$ ion exchange constants were unchanged. The changes in ion exchange constants are not based on measured uncertainties and are, thus, only useful to demonstrate the potential effects of ion exchange affinities on radionuclide transport.

The composite retardation ratios based on the retardation ratios listed in Tables K.8 and K.9 are plotted in Figures K.2 to K.4. Only five (heterogeneous mineralogy) or three (homogeneous mineralogy) composite retardation ratios are

\footnotetext{
${ }^{8} 16$ composite retardation factors are possible in the fracture and cavity and chimney zones because four mineral may be present or absent at any one location; the total number of possible combinations for these four minerals is 16 .

${ }_{9}^{9}$ Illite is distributed homogenously in the matrix. Therefore, it does not contribute to the 16 mineralogic conditions.
} 
shown for each radionuclide. For the heterogeneously distributed mineral zones case (Table K.8), maximum (all heterogeneously distributed minerals present) and minimum (all heterogeneously distributed minerals absent) composite retardation ratios are presented. This represents the range of radionuclide retardations present in our heterogeneous mineral distribution particle model. For example, the composite log retardation ratio of Sm under fracture flow conditions ranges from 3.6 to 1.5, depending on fracture-lining mineralogy. In the cavity/chimney zones, the log retardation ratio ranges from 2.6 to -0.5 , depending on fracture-lining mineralogy. In the matrix zone (i.e., the unfractured tuff), the retardation ratio is always 3.2 because heterogeneously distributed fracture linings are not present. The heterogeneous retardation ratios, as compared to the homogeneous values (Figure K.4) result in greater radionuclide migration because a fraction of the radionuclide inventory is able to bypass zones of high retardation.

The error bars in Figures K.2 to K.4 results from the the uncertainty in our surface complexation/ion exchange constants. The uncertainty in the composite retardation ratios for the various radionuclides is quite variable. For example, the uncertainty in composite retardation ratio for $\mathrm{Sm}, \mathrm{Eu}$, and $\mathrm{Am}$ is quite small in the fracture flow and cavity/chimney conditions but is quite large in matrix flow. Although this may seem to be counterintuitive, it is a result of the interplay between dominant mineralogy, water chemistry, and colloid mineralogy and colloid load. Because $\mathrm{Sm}, \mathrm{Eu}$, and Am all sorb strongly to aluminosilicate colloids and aluminosilicate fracture lining minerals, the uncertainty in the retardation is dampened by the interplay of colloid and fracture-lining mineral sorption. Thus, for these radionuclides, uncertainty in retardation is controlled more by the uncertainty in colloid or fracture lining concentrations (which are not discussed here). For radionuclides that do not sorb strongly to aluminosilicate fracture-lining minerals or colloids (e.g., $\mathrm{Np}$ and $\mathrm{U}$ ), the uncertainty in retardation ratios is significantly greater.

As discussed earlier, uncertainty in the ion exchange reaction constants was not determined explicitly. Thus, for Ca, no uncertainty is plotted in Figures K.3 and K.4. In the case of $\mathrm{Sr}$, the decrease of $\mathrm{Sr}$ affinity for zeolites to that of Ca results in a slight decrease in retardation ratio. For $\mathrm{Cs}$, the lower limit for retardation was qualitatively estimated by assuming that ion exchange coefficients decrease by either one Log unit or are equivalent to that of $\mathrm{K}^{+}$(see earlier discussion). The Cs retardation ratios (Table K.8) clearly show that migration is controlled largely by illite/mica. The strong sorption of Cs to micaceous minerals has been well documented in the literature. Given the above discussion regarding the retardation of radionuclides that sorb strongly to aluminosilicate colloids, one may speculate that if colloids were primarily micaceous, the retardation of Cs might look quite different. This is, in fact, the case. Thus, while the effect of smectite colloids on Cs migration is small, illite/mica colloids could significantly affect the migration of Cs in the near field. For example, if the total colloid mass was comprised of illite/mica, the retardation ratios for Cs would decrease by a factor of 10. In fact, the presence of some quantity of illite/mica colloids is likely given the observation of Buddemeier and Hunt (1988) that approximately $2 \%$ to $45 \%$ of Cs may be associated with colloids. Our illite/mica colloid calculations result in $89 \%$ of aqueous Cs sorbed to colloids. To result in $45 \%$ of Cs associated with colloids, the illite/mica colloid concentration would have to account for only $10 \%$ of the total colloid mass. The resulting retardation ratio would decrease by a factor of 2 compared with the 
smectite-only colloid model. For the case of Sr, an even smaller colloid effect is observed regardless of the aluminosilicate mineralogy of the colloid.

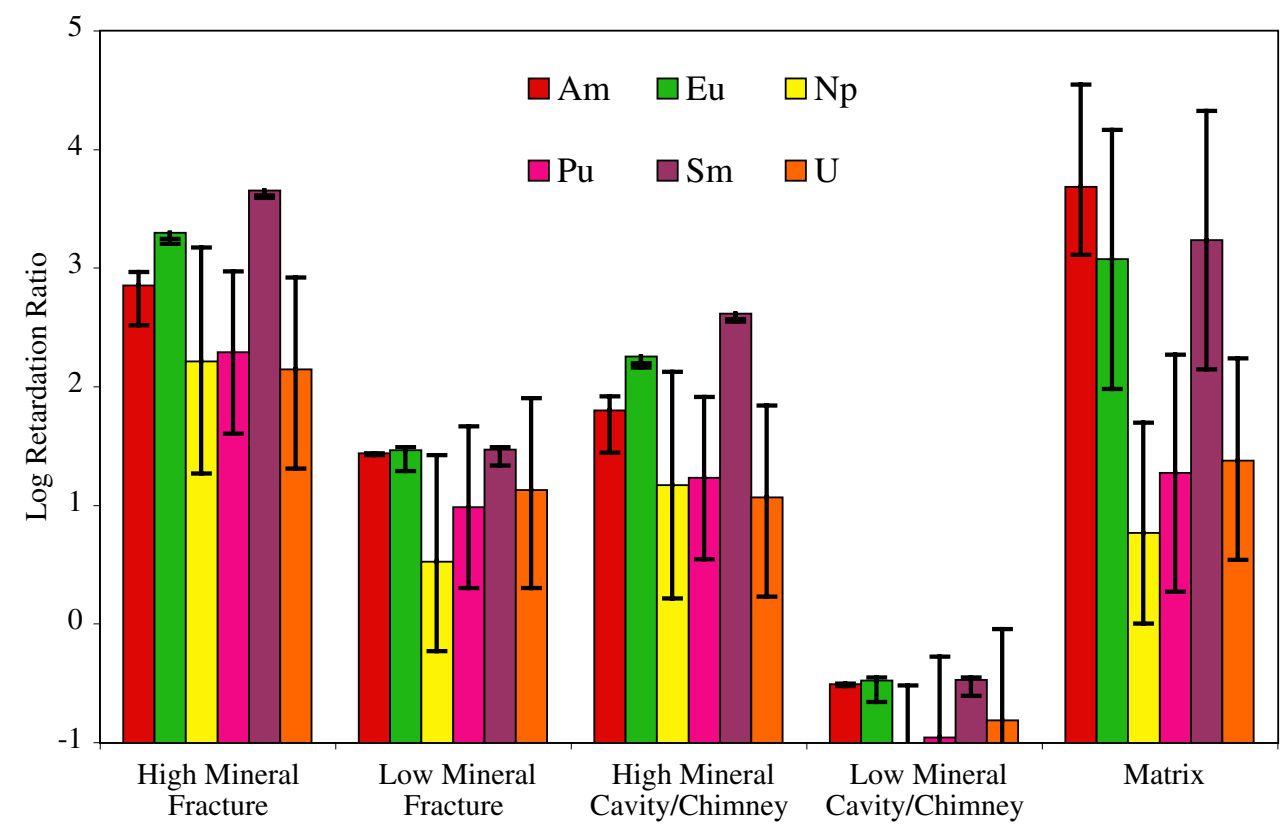

Figure K.2 Retardation ratios for surface complexation dominated radionuclide sorption in heterogeneously distributed mineral particle model.

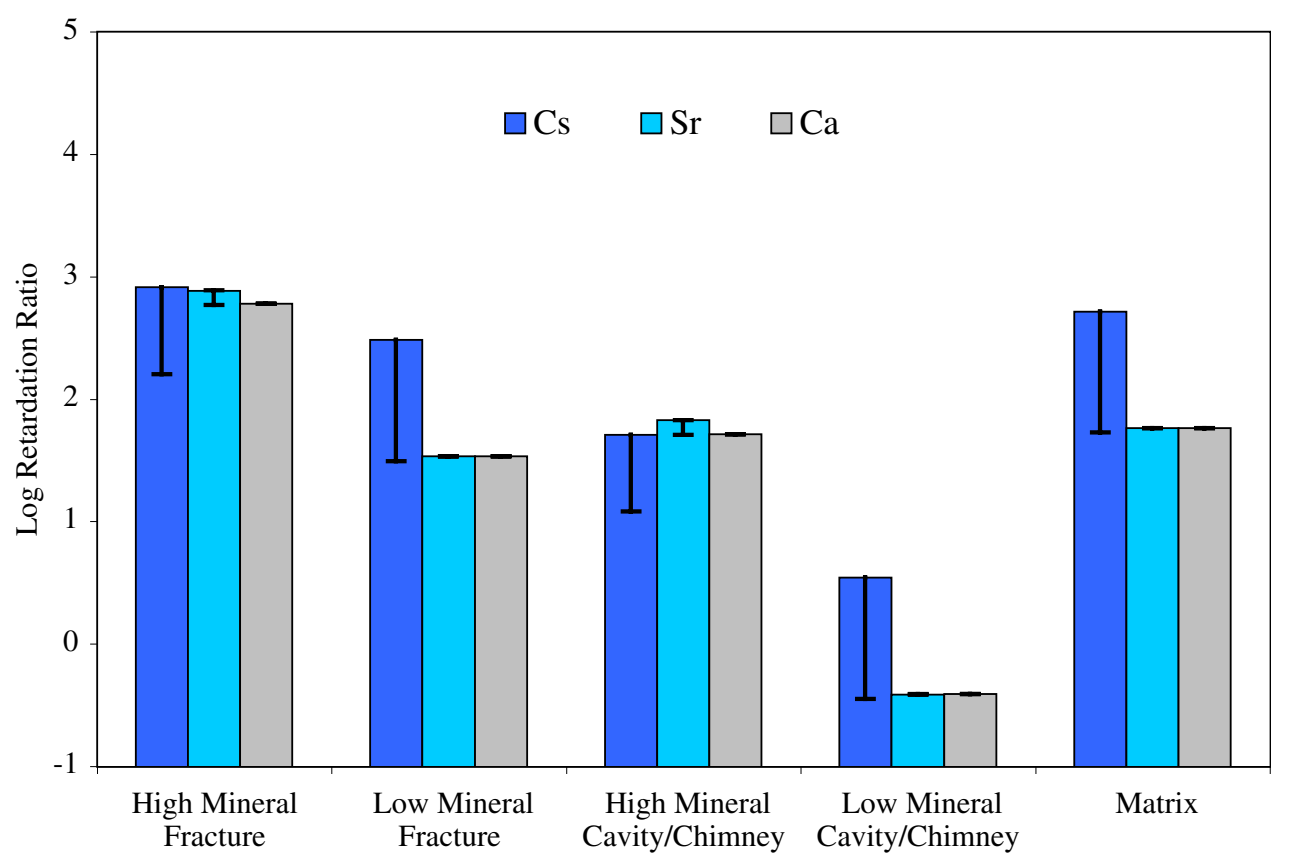

Figure K.3 Retardation ratios for ion exchange dominated radionuclide sorption in heterogeneously distributed mineral particle model. 


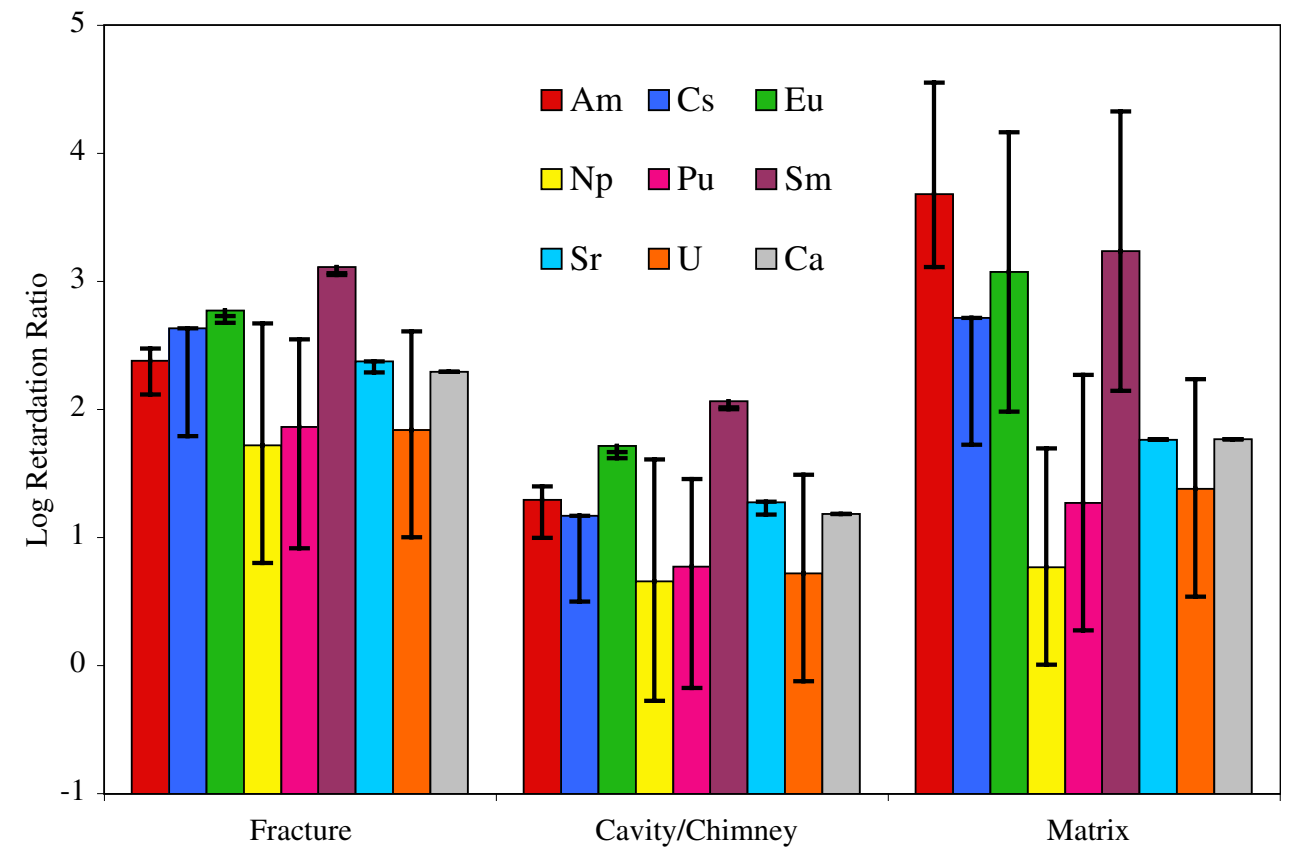

Figure K.4 Retardation ratios for radionuclide sorption in homogeneous mineral particle model. 
Table K.8 Logarithm of the retardation ratios for the heterogeneous mineral distribution near-field model. Refer to Tables 5.2 and 5.3 to correlate flow condition with permeability and porosity values.

\begin{tabular}{|c|c|c|c|c|c|c|c|c|c|c|c|c|c|c|c|}
\hline \multirow{3}{*}{ On/off } & \multicolumn{5}{|c|}{ Average log retardation ratio } & \multicolumn{5}{|c|}{ High log retardation ratio } & \multicolumn{5}{|c|}{ Low log retardation ratio } \\
\hline & \multicolumn{2}{|c|}{$\begin{array}{c}\text { Fractured Flow } \\
\text { Condition }\end{array}$} & \multicolumn{2}{|c|}{$\begin{array}{l}\text { Cavity/chimney } \\
\text { Condition }\end{array}$} & \multirow[t]{2}{*}{$\begin{array}{l}\text { Matrix } \\
\text { Cond. }\end{array}$} & \multicolumn{2}{|c|}{$\begin{array}{l}\text { Fracture Flow } \\
\text { Condition }\end{array}$} & \multicolumn{2}{|c|}{$\begin{array}{c}\text { Cavity/chimney } \\
\text { Condition }\end{array}$} & \multirow[t]{2}{*}{$\begin{array}{l}\text { Matrix } \\
\text { Cond. }\end{array}$} & \multicolumn{2}{|c|}{$\begin{array}{c}\text { Fracture Flow } \\
\text { Condition }\end{array}$} & \multicolumn{2}{|c|}{$\begin{array}{l}\text { Cavity/chimney } \\
\text { Condition }\end{array}$} & \multirow[t]{2}{*}{$\begin{array}{l}\text { Matrix } \\
\text { Cond. }\end{array}$} \\
\hline & 1 & 0 & 1 & 0 & & 1 & 0 & 1 & 0 & & 1 & 0 & 1 & 0 & \\
\hline & \multicolumn{15}{|l|}{ Am } \\
\hline Smectite & 2.06 & 1.42 & 0.92 & -0.52 & 3.67 & 2.06 & 1.43 & 0.92 & -0.52 & 4.54 & 2.05 & 1.41 & 0.91 & -0.53 & 3.10 \\
\hline Calcite & 2.77 & -3.84 & 1.73 & -4.84 & -3.00 & 2.91 & -3.71 & 1.87 & -4.70 & -2.00 & 2.32 & -4.29 & 1.29 & -5.28 & -4.00 \\
\hline Iron oxide & 0.99 & -0.05 & -0.08 & -1.99 & 2.20 & 0.93 & -0.11 & -0.15 & -2.05 & 3.00 & 0.75 & -0.28 & -0.32 & -2.22 & 1.41 \\
\hline Zeolite & - & - & - & - & - & - & - & - & - & - & - & - & - & - & - \\
\hline \multirow[t]{2}{*}{ Illite/mica } & - & - & - & - & - & - & - & - & - & - & - & - & - & - & - \\
\hline & \multicolumn{15}{|l|}{$\mathrm{Ca}$} \\
\hline Smectite & 2.15 & 1.52 & 1.01 & -0.43 & 1.75 & 2.15 & 1.52 & 1.01 & -0.43 & 1.75 & 2.15 & 1.52 & 1.01 & -0.43 & 1.75 \\
\hline Calcite & 0.85 & -5.77 & -0.19 & -6.76 & -6.93 & 0.85 & -5.77 & -0.19 & -6.76 & -6.93 & 0.85 & -5.77 & -0.19 & -6.76 & -6.93 \\
\hline Iron oxide & - & - & - & - & - & - & - & - & - & - & - & - & - & - & - \\
\hline Zeolite & 2.65 & -26.81 & 1.61 & -26.81 & -26.81 & 2.65 & -26.81 & 1.61 & -26.81 & -26.81 & 2.65 & -26.81 & 1.61 & -26.81 & -26.81 \\
\hline \multirow[t]{2}{*}{ Illite/mica } & 0.07 & 0.07 & -1.87 & -1.87 & 0.31 & 0.07 & 0.07 & -1.87 & -1.87 & 0.31 & 0.07 & 0.07 & -1.87 & -1.87 & 0.31 \\
\hline & \multicolumn{15}{|l|}{ Cs } \\
\hline Smectite & 1.16 & 0.52 & 0.02 & -1.42 & 0.76 & 1.16 & 0.52 & 0.02 & -1.42 & 0.76 & 0.62 & -0.01 & -0.52 & -1.96 & 0.22 \\
\hline Calcite & - & - & - & - & - & - & - & - & - & - & - & - & - & - & - \\
\hline Iron oxide & - & - & - & - & - & - & - & - & - & - & - & - & - & - & - \\
\hline Zeolite & 2.71 & -26.76 & 1.67 & -26.76 & -26.76 & 2.71 & -26.76 & 1.67 & -26.76 & -26.76 & 2.10 & -27.37 & 1.06 & -27.37 & -27.37 \\
\hline \multirow[t]{2}{*}{ Illite/mica } & 2.48 & 2.48 & 0.53 & 0.53 & 2.71 & 2.48 & 2.48 & 0.53 & 0.53 & 2.71 & 1.48 & 1.48 & -0.46 & -0.46 & 1.71 \\
\hline & \multicolumn{15}{|l|}{ Eu } \\
\hline Smectite & 2.04 & 1.41 & 0.90 & -0.54 & 3.02 & 2.06 & 1.42 & 0.92 & -0.52 & 4.10 & 1.88 & 1.24 & 0.74 & -0.70 & 1.94 \\
\hline Calcite & 3.26 & -3.35 & 2.23 & -4.34 & -3.14 & 3.20 & -3.41 & 2.16 & -4.41 & -2.14 & 3.18 & -3.44 & 2.14 & -4.43 & -4.14 \\
\hline Iron oxide & 1.57 & 0.54 & 0.50 & -1.41 & 2.15 & 1.67 & 0.64 & 0.60 & -1.31 & 3.31 & 1.29 & 0.25 & 0.21 & -1.69 & 0.95 \\
\hline Zeolite & - & - & - & - & - & - & - & - & - & - & - & - & - & - & - \\
\hline Illite/mica & - & - & - & - & - & - & - & - & - & - & - & - & - & - & - \\
\hline
\end{tabular}


Table K.8 Continued.

\begin{tabular}{|c|c|c|c|c|c|c|c|c|c|c|c|c|c|c|c|}
\hline \multirow{3}{*}{ On/off } & \multicolumn{5}{|c|}{ Average log retardation ratio } & \multicolumn{5}{|c|}{ High log retardation ratio } & \multicolumn{5}{|c|}{ Low log retardation ratio } \\
\hline & \multicolumn{2}{|c|}{$\begin{array}{l}\text { Fractured Flow } \\
\text { Condition }\end{array}$} & \multicolumn{2}{|c|}{$\begin{array}{l}\text { Cavity/chimney } \\
\text { Condition }\end{array}$} & \multirow[t]{2}{*}{$\begin{array}{l}\text { Matrix } \\
\text { Cond. }\end{array}$} & \multicolumn{2}{|c|}{$\begin{array}{l}\text { Fracture Flow } \\
\text { Condition }\end{array}$} & \multicolumn{2}{|c|}{$\begin{array}{l}\text { Cavity/chimney } \\
\text { Condition }\end{array}$} & \multirow[t]{2}{*}{$\begin{array}{l}\text { Matrix } \\
\text { Cond. }\end{array}$} & \multicolumn{2}{|c|}{$\begin{array}{l}\text { Fracture Flow } \\
\text { Condition }\end{array}$} & \multicolumn{2}{|c|}{$\begin{array}{l}\text { Cavity/chimney } \\
\text { Condition }\end{array}$} & \multirow[t]{2}{*}{$\begin{array}{l}\text { Matrix } \\
\text { Cond }\end{array}$} \\
\hline & 1 & 0 & 1 & 0 & & 1 & 0 & 1 & 0 & & 1 & 0 & 1 & 0 & \\
\hline & \multicolumn{15}{|l|}{$\mathrm{Np}$} \\
\hline Smectite & 0.37 & -0.27 & -0.77 & -2.21 & -0.02 & 1.01 & 0.38 & -0.12 & -1.56 & 0.65 & -0.11 & -0.74 & -1.25 & -2.69 & -0.51 \\
\hline Calcite & 2.12 & -4.50 & 1.08 & -5.49 & -5.66 & 3.08 & -3.53 & 2.05 & -4.52 & -4.66 & 1.12 & -5.49 & 0.08 & -6.49 & -6.66 \\
\hline Iron oxide & 1.48 & 0.45 & 0.41 & -1.50 & 0.69 & 2.42 & 1.38 & 1.34 & -0.56 & 1.65 & 0.65 & -0.39 & -0.43 & -2.33 & -0.16 \\
\hline Zeolite & - & - & - & - & - & - & - & - & - & - & - & - & - & - & - \\
\hline \multirow[t]{2}{*}{ Illite/mica } & - & - & - & - & - & - & - & - & - & - & - & - & - & - & - \\
\hline & \multicolumn{15}{|l|}{$\mathrm{Pu}$} \\
\hline Smectite & 1.14 & 0.51 & 0.00 & -1.44 & 0.80 & 1.82 & 1.19 & 0.68 & -0.76 & 1.79 & 0.20 & -0.44 & -0.94 & -2.38 & -0.20 \\
\hline Calcite & 2.04 & -4.57 & 1.00 & -5.56 & -5.68 & 2.73 & -3.89 & 1.69 & -4.88 & -4.68 & 1.09 & -5.52 & 0.05 & -6.51 & -6.68 \\
\hline Iron oxide & 1.84 & 0.80 & 0.76 & -1.14 & 1.09 & 2.52 & 1.49 & 1.45 & -0.45 & 2.09 & 0.89 & -0.15 & -0.19 & -2.09 & 0.09 \\
\hline Zeolite & - & - & - & - & - & - & - & - & - & - & - & - & - & - & - \\
\hline \multirow[t]{2}{*}{ Illite/mica } & - & - & - & - & - & - & - & - & - & - & - & - & - & - & - \\
\hline & \multicolumn{15}{|l|}{ Sm } \\
\hline Smectite & 2.05 & 1.41 & 0.91 & -0.53 & 3.18 & 2.06 & 1.42 & 0.92 & -0.52 & 4.26 & 1.93 & 1.29 & 0.79 & -0.65 & 2.10 \\
\hline Calcite & 3.64 & -2.97 & 2.60 & -3.97 & -2.60 & 3.57 & -3.04 & 2.53 & -4.04 & -1.60 & 3.60 & -3.02 & 2.56 & -4.01 & -3.60 \\
\hline Iron oxide & 1.58 & 0.54 & 0.50 & -1.40 & 2.31 & 1.67 & 0.64 & 0.60 & -1.31 & 3.47 & 1.34 & 0.30 & 0.26 & -1.64 & 1.11 \\
\hline Zeolite & - & - & - & - & - & - & - & - & - & - & - & - & - & - & - \\
\hline \multirow[t]{2}{*}{ Illite/mica } & - & - & - & - & - & - & - & - & - & - & - & - & - & - & - \\
\hline & \multicolumn{15}{|l|}{$\mathrm{Sr}$} \\
\hline Smectite & 2.15 & 1.52 & 1.01 & -0.43 & 1.75 & 2.15 & 1.52 & 1.01 & -0.43 & 1.75 & 2.15 & 1.52 & 1.01 & -0.43 & 1.75 \\
\hline Calcite & -0.90 & -7.52 & -1.94 & -8.51 & -8.68 & 0.10 & -6.52 & -0.94 & -7.51 & -7.68 & -1.90 & -8.52 & -2.94 & -9.51 & -9.68 \\
\hline Iron oxide & -0.55 & -1.58 & -1.62 & -3.52 & -1.35 & 0.09 & -0.95 & -0.98 & -2.89 & -0.71 & -1.13 & -2.17 & -2.21 & -4.11 & -1.94 \\
\hline Zeolite & 2.80 & -26.67 & 1.76 & -26.67 & -26.67 & 2.80 & -26.67 & 1.76 & -26.67 & -26.67 & 2.65 & -26.82 & 1.61 & -26.82 & -26.82 \\
\hline Illite/mica & 0.07 & 0.07 & -1.87 & -1.87 & 0.30 & 0.07 & 0.07 & -1.87 & -1.87 & 0.30 & 0.07 & 0.07 & -1.87 & -1.87 & 0.30 \\
\hline
\end{tabular}


Table K.8 Concluded.

\begin{tabular}{|c|c|c|c|c|c|c|c|c|c|c|c|c|c|c|c|}
\hline \multirow{3}{*}{ On/off } & \multicolumn{5}{|c|}{ Average log retardation ratio } & \multicolumn{5}{|c|}{ High log retardation ratio } & \multicolumn{5}{|c|}{ Low log retardation ratio } \\
\hline & \multicolumn{2}{|c|}{$\begin{array}{l}\text { Fractured Flow } \\
\text { Condition }\end{array}$} & \multicolumn{2}{|c|}{$\begin{array}{c}\text { Cavity/chimney } \\
\text { Condition }\end{array}$} & \multirow[t]{2}{*}{$\begin{array}{l}\text { Matrix } \\
\text { Cond. }\end{array}$} & \multicolumn{2}{|c|}{$\begin{array}{c}\text { Fracture Flow } \\
\text { Condition }\end{array}$} & \multicolumn{2}{|c|}{$\begin{array}{c}\text { Cavity/chimney } \\
\text { Condition }\end{array}$} & \multirow[t]{2}{*}{$\begin{array}{l}\text { Matrix } \\
\text { Cond. }\end{array}$} & \multicolumn{2}{|c|}{$\begin{array}{l}\text { Fracture Flow } \\
\text { Condition }\end{array}$} & \multicolumn{2}{|c|}{$\begin{array}{c}\text { Cavity/chimney } \\
\text { Condition }\end{array}$} & \multirow[t]{2}{*}{$\begin{array}{l}\text { Matri } \\
\text { Cond }\end{array}$} \\
\hline & 1 & 0 & 1 & 0 & & 1 & 0 & 1 & 0 & & 1 & 0 & 1 & 0 & \\
\hline & $\mathbf{u}$ & & & & & & & & & & & & & & \\
\hline Smectite & 0.62 & -0.02 & -0.52 & -1.96 & 0.23 & 1.39 & 0.75 & 0.25 & -1.19 & 1.09 & 0.00 & -0.64 & -1.14 & -2.58 & -0.40 \\
\hline Calcite & -1.74 & -8.36 & -2.78 & -9.35 & -9.51 & -0.83 & -7.45 & -1.87 & -8.44 & -8.51 & -2.73 & -9.35 & -3.77 & -10.34 & -10.51 \\
\hline Iron oxide & 2.13 & 1.10 & 1.06 & -0.85 & 1.34 & 2.90 & 1.87 & 1.83 & -0.07 & 2.20 & 1.28 & 0.25 & 0.21 & -1.69 & 0.48 \\
\hline Zeolite & - & - & - & - & - & - & - & - & - & - & - & - & - & - & - \\
\hline Illite/mica & - & - & - & - & - & - & - & - & - & - & - & - & - & - & - \\
\hline
\end{tabular}


Table K.9 Logarithm of the retardation ratios for homogeneous mineral distribution near-field model. Refer to Tables 5.2 and 5.3 to correlate flow condition with permeability and porosity values.

\begin{tabular}{|c|c|c|c|c|c|c|c|c|c|}
\hline & \multicolumn{3}{|c|}{ Average log retardation ratio } & \multicolumn{3}{|c|}{ High log retardation ratio } & \multicolumn{3}{|c|}{ Low log retardation ratio } \\
\hline & $\begin{array}{l}\text { Fracture Flow } \\
\text { Condition }\end{array}$ & $\begin{array}{c}\text { Cavity/chimney } \\
\text { Condition }\end{array}$ & $\begin{array}{l}\text { Matrix } \\
\text { Cond. }\end{array}$ & $\begin{array}{c}\text { Fracture Flow } \\
\text { Condition }\end{array}$ & $\begin{array}{l}\text { Cavity/chimney } \\
\text { Condition }\end{array}$ & $\begin{array}{l}\text { Matrix } \\
\text { Cond. }\end{array}$ & $\begin{array}{l}\text { Fracture Flow } \\
\text { Condition }\end{array}$ & $\begin{array}{l}\text { Cavity/chimney } \\
\text { Condition }\end{array}$ & $\begin{array}{l}\text { Matrix } \\
\text { Cond. }\end{array}$ \\
\hline & \multicolumn{9}{|l|}{ Am } \\
\hline Smectite & 1.86 & 0.65 & 3.67 & 1.86 & 0.65 & 4.54 & 1.85 & 0.64 & 3.10 \\
\hline Calcite & 2.21 & 1.17 & -3.00 & 2.34 & 1.31 & -2.00 & 1.76 & 0.72 & -4.00 \\
\hline Iron oxide & 0.68 & -0.44 & 2.20 & 0.61 & -0.50 & 3.00 & 0.44 & -0.67 & 1.41 \\
\hline Zeolite & - & - & - & - & - & - & - & - & - \\
\hline \multirow[t]{2}{*}{ Illite/mica } & - & - & - & - & - & - & - & - & - \\
\hline & \multicolumn{9}{|l|}{$\mathrm{Ca}$} \\
\hline Smectite & 1.95 & 0.75 & 1.75 & 1.95 & 0.75 & 1.75 & 1.95 & 0.75 & 1.75 \\
\hline Calcite & 0.29 & -0.75 & -6.93 & 0.29 & -0.75 & -6.93 & 0.29 & -0.75 & -6.93 \\
\hline Iron oxide & - & - & - & - & - & - & - & - & - \\
\hline Zeolite & 2.02 & 0.98 & -16.81 & 2.02 & 0.98 & -16.81 & 2.02 & 0.98 & -16.81 \\
\hline \multirow[t]{2}{*}{ Illite/mica } & 0.07 & -1.87 & 0.31 & 0.07 & -1.87 & 0.31 & 0.07 & -1.87 & 0.31 \\
\hline & \multicolumn{9}{|l|}{ Cs } \\
\hline Smectite & 0.96 & -0.25 & 0.76 & 0.96 & -0.25 & 0.76 & 0.42 & -0.78 & 0.22 \\
\hline Calcite & - & - & - & - & - & - & - & - & - \\
\hline Iron oxide & - & - & - & - & - & - & - & - & - \\
\hline Zeolite & 2.07 & 1.03 & -16.76 & 2.07 & 1.03 & -16.7 & 1.46 & 0.42 & -17.37 \\
\hline \multirow[t]{2}{*}{ Illite/mica } & 2.48 & 0.53 & 2.71 & 2.48 & 0.53 & 2.71 & 1.48 & -0.46 & 1.71 \\
\hline & \multicolumn{9}{|l|}{ Eu } \\
\hline Smectite & 1.84 & 0.64 & 3.02 & 1.86 & 0.65 & 4.10 & 1.68 & 0.47 & 1.94 \\
\hline Calcite & 2.70 & 1.66 & -3.14 & 2.64 & 1.60 & -2.14 & 2.62 & 1.58 & -4.14 \\
\hline Iron oxide & 1.26 & 0.14 & 2.15 & 1.36 & 0.24 & 3.31 & 0.98 & -0.14 & 0.95 \\
\hline Zeolite & - & - & - & - & - & - & - & - & - \\
\hline Illite/mica & - & - & - & - & - & - & - & - & - \\
\hline
\end{tabular}


Table K.9 Concluded.

\begin{tabular}{|c|c|c|c|c|c|c|c|c|c|}
\hline & \multicolumn{3}{|c|}{ Average log retardation ratio } & \multicolumn{3}{|c|}{ High log retardation ratio } & \multicolumn{3}{|c|}{ Low log retardation ratio } \\
\hline & $\begin{array}{c}\text { Fracture Flow } \\
\text { Condition }\end{array}$ & $\begin{array}{c}\text { Cavity/chimney } \\
\text { Condition }\end{array}$ & $\begin{array}{l}\text { Matrix } \\
\text { Cond. }\end{array}$ & $\begin{array}{c}\text { Fracture Flow } \\
\text { Condition }\end{array}$ & $\begin{array}{c}\text { Cavity/chimney } \\
\text { Condition }\end{array}$ & $\begin{array}{l}\text { Matrix } \\
\text { Cond. }\end{array}$ & $\begin{array}{c}\text { Fracture Flow } \\
\text { Condition }\end{array}$ & $\begin{array}{c}\text { Cavity/chimney } \\
\text { Condition }\end{array}$ & $\begin{array}{l}\text { Matrix } \\
\text { Cond. }\end{array}$ \\
\hline & \multicolumn{9}{|l|}{$\mathrm{Np}$} \\
\hline Smectite & 0.17 & -1.04 & -0.02 & 0.82 & -0.39 & 0.65 & -0.31 & -1.52 & -0.51 \\
\hline Calcite & 1.55 & 0.52 & -5.66 & 2.52 & 1.48 & -4.66 & 0.56 & -0.48 & -6.66 \\
\hline Iron oxide & 1.17 & 0.05 & 0.69 & 2.11 & 0.99 & 1.65 & 0.33 & -0.78 & -0.16 \\
\hline Zeolite & - & - & - & - & - & - & - & - & - \\
\hline \multirow[t]{2}{*}{ Illite/mica } & - & - & - & - & - & - & - & - & - \\
\hline & \multicolumn{9}{|l|}{$\mathrm{Pu}$} \\
\hline Smectite & 0.94 & -0.26 & 0.80 & 1.62 & 0.41 & 1.79 & 0.00 & -1.21 & -0.20 \\
\hline Calcite & 1.48 & 0.44 & -5.68 & 2.17 & 1.13 & -4.68 & 0.53 & -0.51 & -6.68 \\
\hline Iron oxide & 1.53 & 0.41 & 1.09 & 2.21 & 1.10 & 2.09 & 0.58 & -0.54 & 0.09 \\
\hline Zeolite & - & - & - & - & - & - & - & - & - \\
\hline \multirow[t]{2}{*}{ Illite/mica } & - & - & - & - & - & - & - & - & - \\
\hline & \multicolumn{9}{|l|}{ Sm } \\
\hline Smectite & 1.85 & 0.64 & 3.18 & 1.86 & 0.65 & 4.26 & 1.73 & 0.52 & 2.10 \\
\hline Calcite & 3.08 & 2.04 & -2.60 & 3.01 & 1.97 & -1.60 & 3.04 & 2.00 & -3.60 \\
\hline Iron oxide & 1.27 & 0.15 & 2.31 & 1.36 & 0.24 & 3.47 & 1.02 & -0.09 & 1.11 \\
\hline Zeolite & - & - & - & - & - & - & - & - & - \\
\hline \multirow[t]{2}{*}{ Illite/mica } & - & - & - & - & - & - & - & - & - \\
\hline & \multicolumn{9}{|l|}{$\mathrm{Sr}$} \\
\hline Smectite & 1.95 & 0.74 & 1.75 & 1.95 & 0.74 & 1.75 & 1.95 & 0.74 & 1.75 \\
\hline Calcite & -1.47 & -2.50 & -8.68 & -0.47 & -1.50 & -7.68 & -2.47 & -3.50 & -9.68 \\
\hline Iron oxide & -0.86 & -1.97 & -1.35 & -0.22 & -1.34 & -0.71 & -1.44 & -2.56 & -1.94 \\
\hline Zeolite & 2.16 & 1.12 & -16.67 & 2.16 & 1.12 & -16.67 & 2.01 & 0.97 & -16.82 \\
\hline \multirow[t]{2}{*}{ Illite/mica } & 0.07 & -1.87 & 0.30 & 0.07 & -1.87 & 0.30 & 0.07 & -1.87 & 0.30 \\
\hline & \multicolumn{9}{|l|}{$\mathbf{U}$} \\
\hline Smectite & 0.42 & -0.79 & 0.23 & 1.19 & -0.02 & 1.09 & -0.20 & -1.41 & -0.40 \\
\hline Calcite & -2.31 & -3.34 & -9.51 & -1.39 & -2.43 & -8.51 & -3.29 & -4.33 & -10.51 \\
\hline Iron oxide & 1.82 & 0.70 & 1.34 & 2.59 & 1.47 & 2.20 & 0.97 & -0.15 & 0.48 \\
\hline Zeolite & - & - & - & - & - & - & - & - & - \\
\hline Illite/mica & - & - & - & - & - & - & - & - & - \\
\hline
\end{tabular}




\section{K.9 Temperature Effects}

The effect of temperature on radionuclide retardation has not been widely studied. However, the available information suggests that sorption typically increases with temperature. Leckie and Ela (1992) examined the effects of temperature on the goethite (iron oxide) surface. They found that the point of zero charge (pzc) decreased with increasing temperature. This is consistent with pzc calculations of Schoonen (1994), which indicated that oxide pzc would decrease with temperature up to temperatures of $200^{\circ} \mathrm{C}$ (temperatures in our CHESHIRE model are always $<200^{\circ} \mathrm{C}$ ). A decreasing pzc should result in an increased negative charge on the surface that will, in turn, result in increased cation sorption to mineral surfaces at a particular $\mathrm{pH}$. The sorption data of Leckie and Ela (1992), in fact suggested that uranyl sorption increased with temperature (experiments only up to $70^{\circ} \mathrm{C}$ ) when $\mathrm{pH}$ was held constant. Brady $(1992,1994)$ examined the surface chemistry on silica and alumina and found that sorption constants for $\mathrm{Pb}$ and $\mathrm{Cd}$ increased by up to two orders of magnitude between 25 and $60^{\circ} \mathrm{C}$.

While the above data suggests that radionuclide sorption to mineral surfaces will increase with temperature, the available information is insufficient to allow a realistic and defensible description of radionuclide sorption as a function of temperature. Because the effect of temperature on sorption cannot be realistically included in our reactive transport model at this time, the following steps were taken to result in a conservative estimate of radionuclide transport:

- Sorbing minerals were excluded from the glass zone (the zone that experiences the highest temperatures) at all times.

- Surface complexation and ion exchange constants were held constant as a function of temperature in GIMRT runs

- Aqueous complexation constants of radionuclides were held constant as a function of temperature in GIMRT runs

- Aqueous complexation constants of nonradionuclides (e.g., major cation/anion solution species, including $\mathrm{pH}$ ) were allowed to vary as a function of temperature in GIMRT runs

- Retardation ratios used in the particle model were constant and based on retardation at $25^{\circ} \mathrm{C}$.

Several other points should be made with regards to temperature effects on sorption, exclusive of effects caused by glass dissolution. Because the high temperatures in our near-field model are isolated mainly in the glass zone and are high only at very early times, we expect that temperature effects on radionuclide sorption in the near field should be relatively small. Although the temperature dependence of radionuclide speciation and sorption were removed to a large extent, some temperature effects are still manifested in our GIMRT model as a result of the temperature dependence of $\mathrm{pH}$ and the aqueous speciation of the major elements. Regarding the mineralogic cases 
plotted in Figures K.2 and K.3, the impact of these reactions with temperature on the relative radionuclide retardation ratio as a function of temperature is limited to $0.2 \log$ units and, in most cases, less that 0.1 Log units. 


\section{APPENDIX L: \\ Model Parameter Roadmap}




\section{L.1 Introduction}

The purpose of this appendix is to briefly reiterate the model parameters employed in the groundwater flow and reactive transport simulations described in this report and provide a "roadmap" to where pertinent parametric data may be found.

\section{L.2 Hydrothermal Flow Model}

The hydrothermal groundwater flow model of was developed to drive simulations of radionuclide transport away from the CHESHIRE test. The modeling domain involved an $800 \times 300 \times 800 \mathrm{~m}$ prismatic volume of saturated rock surrounding the CHESHIRE cavity, melt glass, and chimney system. The geologic media within the domain was considered either in its native form - as undisturbed rhyolitic lavas - or material disturbed or altered by the test. Disturbed materials included collapsed rubble in the cavity and chimney, melt glass at the bottom of the cavity, and a zone of rock surrounding the cavity wall that was fractured by the test.

The geologic media was conceptualized as a series of distinct hydrofacies with specific flow properties, as described in Section 5.2.1 and Table 5.1. These properties include

- Permeability, $\mathbf{k}$,

- Effective porosity, $\phi$,

- Thermal conductivity, $K_{H}$, and

- Specific heat of the solid, $C_{p}$.

\section{L.2.1 Geostatistical Distribution of Permeability}

The permeability of the undisturbed lavas and their degree of fracturing is known to be spatially variable. In the principal flow simulations, an indicator-based geostatistical model was developed to represent the observed spatial structure of four classes of fractured rock (hydrofacies) to which specific permeability values (high, moderate, low, and very low) and effective porosities were assigned. The values used in the model are listed in Table 5.2, along with the interpreted degrees of anisotropy. Flow was considered to be either fracture-dominated (in the high and moderate permeability hydrofacies) or matrix-dominated (in the low and very low permeability hydrofacies). Ten equally likely realizations of the hydrofacies were developed (Figure 5.4) as a basis to develop ten flow simulations.

The permeability and effective porosity values used in the altered zones of the model (melt glass, lower chimney, cavity, and disturbed zone around the cavity) 
were the same in all ten of the geostatistical realizations and are listed in Table 5.3. Flow in the disturbed zone was considered fracture-dominated, while that in the other three altered zones was assumed matrix-dominated.

The bulk (wet rock) thermal conductivity and specific heat capacity were considered constant in all parts of the system and for all of the ten realizations, as described in Section 5.5.

\section{L.2.2 Alternative Hydrogeologic Models}

Two alternative conceptualizations of the hydrofacies architecture in the undisturbed lavas were used to develop two additional flow simulations (Figure 5.3). In the first, a layer cake model using high and moderate permeability values in the undisturbed zones was used, with all other specifications remaining the same. In the second, a homogeneous model was used to specify a single, moderate-to-high permeability in all parts of the undisturbed system, again, with all other specifications remaining the same. These data are listed in Table 5.2.

\section{L.2.3 Flow Model Sensitivity Simulations}

Several sensitivity simulations were conducted with the geostatistical and alternative hydrogeologic models, as part of the process that led to the data in Tables 5.2 and 5.3. These simulations are described in Sections 5.6.6 and 5.6.7 and were used, in general, to assess calibration of, and variation in the flow, tracer transport, and temperature results as a function of

- Hydrogeologic model,

- Hydrofacies permeability and porosity,

- Melt glass permeability and porosity, and

- Anisotropy in permeability.

\section{L.3 Reactive Transport Models}

Reactive transport simulations were used to forecast the release and migration of an averaged unclassified radiologic inventory within the modeled hydrologic regime for a period of 1,000 years. Two transport models were used to develop these simulations - a particle-based model and a streamline model - as initially introduced in Section 2.3 and described in detail in Appendices C and D.

\section{L.3.1 Radionuclide Inventory}

Although the averaged unclassified radiologic inventory applied at the CHESHIRE site is composed of 37 radionuclides (Table 4.1), the list was reduced to a set of 
13 radionuclide "classes" (Table 4.5) to simplify the computational expense. The members of each class were perceived or known to have similar chemical reactivity, decay, and initial partitioning characteristics, unique from those of other classes. The initial inventory of each class was determined by adding the inventories of radionuclides in each class. Initial mass distributions of each class $(j)$ were specified in the exchange volume and melt glass, either as individual particle distributions (in the particle model) or as initial concentrations (in the streamline model).

\section{L.3.2 Radionuclide Release and Migration}

The idealized radionuclide inventories were subjected to the release and migration mechanisms outlined in Appendices B, C and D. These include, or are influenced by

- Advection with the groundwater velocity field, $\mathbf{v}(\mathbf{x}, t)$,

- Hydrodynamic dispersion, as described by the dispersivities $\alpha_{L}$ and $\alpha_{T}$, and an effective molecular diffusivity, $D_{e}$,

- Release from the melt glass via dissolution, according to the rate $R_{j}^{\text {glass }}$,

- Surface complexation and ion exchange with sorbing minerals in the fracture- or matrix-dominated flow regimes,

- Aqueous complexation reactions,

- Radioactive decay and ingrowth, as described by rates $\lambda_{j}$, and

- Diffusion between the fractures and matrix in the fracture-dominated flow regimes, as described by a matrix diffusion coefficient $D_{m}$.

Ultimately, the release and migration behavior simulated for each radionuclide class was deconstructed to reveal individual results for each of the 37 radionuclides in the inventory.

\section{L.3.3 Geostatistical Distribution of Sorbing Minerals}

Five sorbing minerals were considered in the current transport models: smectite (or clay); calcite; iron oxide (or hematite); zeolite, and illite/mica. Based on field data, the first four were considered spatially variable within the fracture and matrix-dominated flow regimes, while the latter was assumed to be uniformly present throughout the domain. In the transport models, the spatial distribution of the first four minerals was represented in a geostatistical fashion, as described in Appendix $\mathrm{H}$.

The geostatistical model of the sorbing minerals was used to define the presence or absence of a particular mineral at particular locations, but not quantify its actual abundance in terms of mass, volume, or specific surface area (see Figure H-11 for an 
example image). The particular reactivity of a radionuclide at a location is later specified separately (and differently) for use in the particle and streamline models. The reactivity will reflect both the influence of mineral mass, volume, and specific surface area at a location, and it will be based on the geochemical conceptualizations of Chapter 6, the surface complexation and ion exchange constants defined in Appendix $\mathrm{K}$, and the aqueous thermodynamic constants defined in Appendix J.

Altogether, ten mineralogic realizations were developed with this geostatistical model, which, if combined with the ten flow realizations, provide the basis for completing 100 unique reactive transport simulations.

\section{L.3.4 Particle Transport Model}

As described in Chapter 2 and Appendix D, the particle model is based on several simplifications of the geochemical processes pertinent to release and migration behavior. Because of its computational efficiency, the particle model was used to carry out 100 Monte Carlo reactive transport simulations. The transient velocity fields obtained in the ten primary flow simulations (Chapter 5) were used to define particle advection behavior in these simulations.

Hydrodynamic dispersion within the fracture- or matrix-dominated flow regimes, as described by $\alpha_{L}, \alpha_{T}$, and $D_{e}$, was not included in the 100 Monte Carlo particle simulations, but was addressed in particle model sensitivity calculations (described below and in Section 7.4.6). Similarly, matrix diffusion between fracturedominated flow regimes and adjacent matrix, as controlled by $D_{m}$, was also not considered in the 100 Monte Carlo particle simulations, but was considered in sensitivity calculations (see below and Section 7.4.3,).

Radionuclide release from dissolving melt glass was defined by freeing particles assigned to the melt glass volume according to a simplified version of the rate law in Equations (6.2) or (6.3). The simplified rate was defined as the product of a simplified moderate-rate function (Section 6.4.5.1, Figure 6-20, and Section D.6), a fixed melt glass specific surface area $\left(A_{s}^{m}=0.001 \mathrm{~m}^{2} / \mathrm{g}\right)$, and the particular stoichiometry of each radionuclide class in the glass $\left(v_{j}\right.$, as determined from Table 4.5). This overall rate was controlled by the melt glass temperature history obtained in each flow simulation, but was otherwise independent of changing chemistry in the glass.

\section{L.3.4.1 Particle Model Retardation Effects}

In the particle model, the effects of surface complexation and ion exchange reactions are specified through the retardation factor introduced in Appendices B, D., and $\mathrm{K}$. The retardation factor for a given radionuclide $(\mathrm{j})$ is a function of the location and the minerals present at that location, as descibed in Appendix K. According to Equation (K1), the retardation factor is computed in terms of a linear combination of independent contributions - labeled here as "retardation ratios" - from each mineral (i) present at a given location. This approach was based on the geochemical conceptualizations of Chapter 6 and the particle model approximations in Appendix D. The ratios themselves were evaluated as a function of the ambient CHESHIRE 
groundwater composition, the surface complexation/ion exchange constants defined in Appendix K, and the aqueous thermodynamic constants defined in Appendix J.

Computed values of the retardation ratios are given in Tables K-8 and K-9. They are distinguished by radionuclide class (j), mineral (i), and location (fracture or matrixdominated flow; disturbed or undisturbed geology). Average, high, and low values are provided to reflect uncertainty in the retardation ratios which was based on the uncertainty in surface complexation and ion exchange reaction constants reported in Appendix K.

In the particle simulations, all ten mineralogic realizations - with the average partitioning ratio values - were combined with the permeability flow realizations to yield 100 Monte Carlo transport simulations.

\section{L.3.4.2 Particle Model Sensitivity Simulations}

A limited series of sensitivity simulations were conducted to assess the variation in transport results as a function of

- The presence or lack of test-related heat (see Section 7.4.1),

- The influence of two alternative conceptual models of the hydrogeologic system (see Section 7.4.2 and above),

- The presence or lack of matrix diffusion (see Section 7.4.3),

- A lower long term glass dissolution rate (see Section 7.4.4 and above),

- Low partitioning ratios in the retardation relationship (see Section 7.4.5 and above), and

- Nonzero longitudinal and transverse dispersivities (see Section 7.4.6).

These simulations were limited in the sense that they were either focused on a reduced set of radionuclides (such as tritium), or they only considered one transport simulation (based on, for example, one hydrofacies realization and one mineralogic realization) as a basis for sensitivity studies.

\section{L.3.5 Streamline Transport Model}

As described in Chapter 2 and Appendix C, the streamline model is capable of handling complex geochemical behavior, especially at earlier times when the interactions associated with high temperature are important. However, since the viability of the method is limited when flows are highly transient, it could only be run after the first 100 years of the simulation. Because of this limitation and because the computational costs associated with the approach limit its use in a Monte Carlo framework, only one transport simulation was developed using this method, based upon one flow realization and one mineralogic realization. 
The flow simulation was used to define five sets of streamlines that corresponded to each of the five flow field time steps between $t=100$ and 1000 years. The initial distribution of radionuclides along the first set of streamlines (at $t=100$ years) was developed from the corresponding particle model results at $t=100$ years for one hydrofacies realization and one mineralogic realization. The streamline model also includes a number of other (non-radionuclide) aqueous species, as described in Table 6.11, which were initialized using the ambient groundwater chemistry in Table 6.10.

Matrix diffusion between fracture-dominated flow regimes and adjacent matrix, as controlled by $D_{m}$, could not be considered in the streamline calculations, nor could transverse dispersion and diffusion, as controlled by $\alpha_{T}$, and $D_{e}$. Longitudinal dispersion and diffusion, as controlled by $\alpha_{L}$, and $D_{e}$, could be handled, but were not considered in the streamline simulation.

\section{L.3.5.1 Geochemical Processes in the Streamline Model}

Geochemical processes considered in the streamline model include aqueous complexation, surface complexation, ion exchange, mineral dissolution and precipitation (which includes melt glass dissolution), and radionuclide decay/ingrowth (Section 6.4.2). Specifically,

- Aqueous complexation is computed using thermodynamic data in Appendix J assuming homogeneous equilibrium in the fluid phase.

- Surface complexation and ion exchange processes onto sorbing minerals were addressed using the fundamental mechanistic models described in Appendix K. The calculations were based on the geochemical conceptualizations of Chapter 6, the surface complexation and ion exchange constants defined in Appendix $\mathrm{K}$, the aqueous thermodynamic constants defined in Appendix J, and the specific mass, volume, and surface area features of the system described in these appendices.

- The non-electrostatic surface complexation model is used to model pHdependent sorption of radionuclides to iron oxide, calcite, and aluminosilicates. The Vanselow ion exchange formalism is used to describe ion exchange reactions among radionuclides and $\mathrm{Na}, \mathrm{Ca}, \mathrm{K}$, and $\mathrm{Mg}$ on smectite, illite/mica, and zeolite. The surface complexation and ion exchange models and model parameters are discussed in detail in Appendix K.

- The stability of minerals and the kinetics of mineral dissolution and precipitation are described using the thermodynamic data in Table J.4, and the kinetic rate law and parameters in Appendix J. Modeling of the kinetics of glass dissolution is discussed in Section 6.4.4. The treatment of radionuclide decay and ingrowth is discussed in Appendix I.

In particular, radionuclide release from dissolving melt glass was defined by a more complete version of the glass dissolution model in Equations (6.2) or (6.3), as described in Section 6.4.5.2. Release utilized the same initial melt glass specific surface 
area $\left(A_{S}^{m}=0.001 \mathrm{~m}^{2} / \mathrm{g}\right.$ ), and a slightly modified radionuclide stoichiometry in the glass to account for release that occurred over the first 100 years. 